\title{
Stilistische und verbalsyntaktische Untersuchungen zum Moskovitischen Prunkstil des 16. Jahrhunderts
}

\author{
Die Erzählung über die Belagerung Pleskaus \\ durch den polnischen König Stephan Báthory 1581/82 \\ im Vergleich mit der Erzählung über die Eroberung \\ Konstantinopels durch die Türken 1453.
}

Verlag Otto Sagner München - Berlin - Washington D.C.

Digitalisiert im Rahmen der Kooperation mit dem DFG-Projekt „Digi20“

der Bayerischen Staatsbibliothek, München. OCR-Bearbeitung und Erstellung des eBooks durch den Verlag Otto Sagner:

http://verlag.kubon-sagner.de

( bei Verlag Otto Sagner. Eine Verwertung oder Weitergabe der Texte und Abbildungen, insbesondere durch Vervielfältigung, ist ohne vorherige schriftliche Genehmigung des Verlages unzulässig. 


\section{SLAVISTISCHE BEITRÄGE}

BEGRÜNDET VON

ALOIS SCHMAUS

HERAUSGEGEBEN VON

JOHANNES HOLTHUSEN · HEINRICH KUNSTMANN · JOSEF SCHRENK

REDAKTION

PETER REHDER

Band 127

\section{Bayerlecro}

Staatsbibliothek

Münction

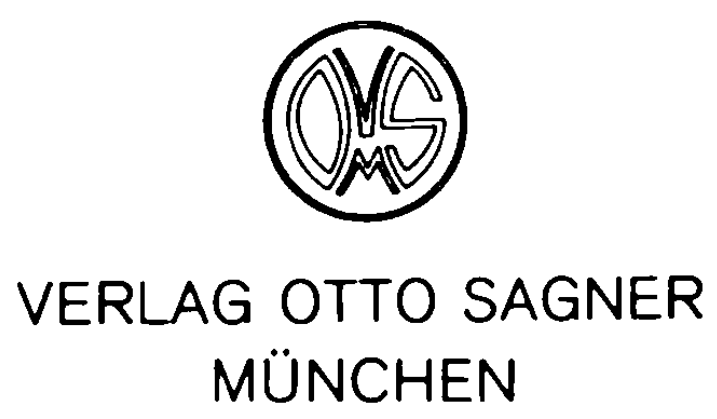




\section{GERD STRICKER}

STILISTISCHE UND VERBALSYNTAKTISCHE UNTERSUCHUNGEN ZUM MOSKOVITISCHEN PRUNKSTIL DES 16. JAHRHUNDERTS

Die Erzählung über die Belagerung Pleskaus

durch den polnischen König Stephan Báthory 1581/82

im Vergleich mit der

Erzählung über die Eroberung Konstantinopels

durch die Türken 1453

VERLAG OTTO SAGNER · MÜNCHEN

1979 
Gedruckt mit Hilfe von Mitteln des

Rektorats der Westfälischen Wilhelms-Universität Münster

D 6

ISBN 3-87690-160-X

Copyright by Verlag Otto Sagner, München 1979

Abteilung der Firma Kubon \& Sagner, München

Druck: Alexander Grossmann

Fäustlestr. 1, D-8000 München 2 
Die vorliegende Arbeit wurde im Sommersemester 1978 von der Philosophischen Fakultät der Westfälischen Wilhelms-Universität zu Minster als Dissertation angenommen.

Sie geht auf eine Anregung von Herrn Prof. Dr. Hubert $R$ ö $s$ e $l$ zurück, dem $1 \mathrm{ch}$ für viele Anregungen und vor allem für seine geduldige Betreuung der Arbeit herzlich danke.

Herrn Prof. Dr. Friedrich $S \mathrm{c} h \circ \mathrm{l} z$ bin ich für sein wohlwollendes Interesse und wertvolle Hinweise verpflichtet.

Beiden Herren danke ich für die einzigartigen Arbeitsmöglichkeiten, die sie mir in der Bibliothek des Slavisch-Baltischen Seminars an der Westfälischen Wilhelms-Universität geboten haben.

Die Fertigstellung dieser Untersuchung wurde durch ein zweijähriges Promotionsstipendium aus wtteln des Landes Nordrhein-Westfalen gefördert.

Schlieblich habe $1 \mathrm{ch}$ den Herausgebern der

Slavistischen Be1träge

und vor allem Herrn Priv.-Doz. Dr. Peter $R$ e $h d e r$ fur die Aupnahme meiner Arbeit in diese Reihe zu danken.

Müster, im Dezember 1978.

Gerd Stricker 
I $n h$ a 1 t $s$ ve r z e ichnis

Vorwort

Inhal tsverzeichnis

VI

Literaturverzeichnis

Wörterbucher und Nachschlagewerke

Textausgaben

Gelegentlich herangezogene Quellen

Verzeichnis der Abkürzungen

Vorbemerkungen

A. Einleitung

1. Ivan Grozny $j$ und Metropolit Makarij 34

1.1 Ivan Groznyj im Urteil der Geschichte 34

1.2 Metropolit Makarij und das ideologische Konzept Ivan Groznyjs

1.3 Die offizielle Literatur

1.4 Der moskovitische Monumentalstil

2. Werdegang und Zielsetzungen der Arbeit 48

2.1 Motivation 48

2.2 Der Untersuchungsgegenstand: das Verb 53

2.3 Zur Methode der Untersuchung 54

B. Textgeschichte - Konzeption - Komposition 56

1. Die Erzählung über die Einnahme Konstantinopels durch die Türken 1453

1.1 Textgeschichte

1.1.1 Bestehen Beziehungen zwischen der kurzen und der langen Erzählung?

1.2 Konzeption und Komposition der Erzählung uber die Eroberung Konstantinopels 1.2.1 Zusammenfassung

1.3 Rezeption der Erzählung in Rußland 
2. Die Erzählung über die Belagerung Plęskaus durch den polnischen König Stephan Bathory

2.1 Textgeschichte

2.1.1 Die Handschriften

87

2.1.2 Die Edierungen

89

2.1.3 Literatur uber die Erzählung 90

2.1.4 Mögliche Vorlagen

2.2 Konzeption und Komposition der Erzählung uber die Belagerung Pleskaus

2.2.1 Die Einleitung

\subsubsection{Der Iivländische Krieg}

104

2.2.1.2 Die Wiedergabe des Realgeschehens in der Exposition 109

2.2.2 Der Hauptte1l

2.2.3 Der Schluß; das Nachwort

2.2.4 Zusammenfassung

2.3 Der Autor und die Entstehungszeit der Erzählung uber die Belagerung Pleskaus

C. Anmerkungen zu Phonetik, Morphologie und Lexik unserer Texte

1. Zur Phonetik

1.1 Vokalismus

1.2 Konsonantismus

2. Zur Morphologie

2.1 Adjektiv

2.2 Substantiv

3. Zur Lexik

3.1 Die Erzählung von der Eroberung $K-$ pels ${ }^{1}$

3.2 Die Erzählung über die Belagerung Pleskaus

4. Zusammenfassung

1) $\mathrm{K}$-pel = Konstantinopel; K-pler Text = Konstantinopler Text. 
D. Anmerkungen zum Stil unserer Texte

1. Satzbau

198

2. Informationsgehalt der Texte

202

3. Figurae per ordinem

4. Figurae sententiae

5. Wortwahl

6. Bildersprache

6.1 Metapher

224

6.2 Vergleich

230

7. Zusammenfassung

E. Das Verb

I. Zur Literatur uber den Gebrauch

des Verbs im 16. Jh.

II. Uberblick über das Auftreten

der verbalen Kategorien in unseren Texten 252

1. Die Tabelle $1 \quad 254$

2. Die verbalen Kategorien im Vergleich 257

Das Präsens 257

Das Imperfekt 259

Der Aorist 261

Das 1-Partizip 262

Die nominalen Partizipien 265

III. Vorbemerkungen $z u$ den Einzeluntersuchungen 269

IV. Präsens - Futur - Konditional 271

1. Praesens historicum 271

2. Unabhängige Aufforderungssätze 274

3. Abhängige Final- und Heischesätze 275

3.1 Abhängige Finalsätze 279

3.1 .1 K-pler Text 279

3.1 .2 Pleskauer Text 280

3.2 Abhängige Heischesätze und
abhängige Sätze nach Verben des Schickens 283

$3.2 .1 \mathrm{~K}$-pler Text 283

3.2.2 Pleskauer Text 284

3.3 Unausgedrücktes finales oder Wunsch-
verhältnis (= Parataxe) 
4. Der Konditional im Konditionalsatz

5. Das periphrastische Futur

6. Zusammenfassung

1.1 Ipf.-Formen bei Nichtdurativa und präfigierten Durativa (Primärableitungen)

1.1.1.1 K-pel: Nichtdurativa (Simplicia und Komposita)

1.1.1.2 K-pel: Präfiglerte nichouffigierte Durativa (mit belegter sekundärer Ableitung)

1.1.1.3 K-pel: Präfigierte nichtsuff1gierte Durativa (ohne belegte sekundäre Ableitung)

1.1.1.4 Pleskau: Nichtdurativa sowie prärigierte nichtsuffigierte Durativa

1.1 .2 3.ps.pl. -achu

1.1.2.1 K-pel: Nichtdurativa (Simplicia und Komposita)

1.1.2.2 K-pel: Präfigierte nichtsuffigierte Durativa (mit belegter sekundärer Ableitung)

1.1.2.3 K-pel: Präfigierte nichtsuffiglerte Durativa (ohne belegte sekundäre Ableitung)

1.1.2.4 Pleskau: Präfigierte nichtsuffigierte Durativa (ohne belegte sekundäre Ableitung)

1.1.3 Zusammenfassung: Ipf.-Formen von Nichtdurativa und präfigierten nichtsuffigier- 331

1.2 -ä́e beim Plural

K-pel: Präfiglerte nichtsuffigierte Durativa (mit belegter sekundärer Ableitung)

1.2.1.2 K-pel: Präfigierte nichtsuffigierte Durativa (ohne belegte sekundäre Ableitung)

1.2.1.3 K-pel: Dehnstufige/suffigierte Ableitungen 
$\begin{array}{ll}1.2 .1 .4 \mathrm{~K} \text {-pel: Simplicia } & 339 \\ 1.2 .2 \text {-aše beim Plural im Pleskauer Text } & 341\end{array}$

1.2.3 Zusammenfassung: -aše beim Plural 352

1.3 Die Funktion des Ipf. in unseren Texten 353

1.3.1 Das Ipf. als Ausdruck eines Zustandes 356

1.3.1.1 K-pler Text 356

1.3.1.2 Pleskauer Text 358

1.3.2 Das Ipf. als Ausdruck durat. Handlungen 361

1.3.2.1 K-pler Text 361

1.3.2.2 Pleskauer Text 363

1.3.3 Das Ipf. als Ausdruck

sich wiederholender Handlungen $\quad 367$

1.3.3.1 K-pler Text 367

1.3.3.2 Pleskauer Text 371

1.4 Zusammenfassung: Das Ipf. in unseren Texten 375

2. Der Aorist

379

2.1 Aor.-Formen bei durativen Simplicia 385

$2.1 .1 \mathrm{~K}$-pler Text 385

2.1.2 Pleskauer Text 386

2.2 Aor.-Formen bei determinierten Verben 396

2.3 Aor.-Formen bei Simplicia der
4. Leskien'schen Klasse

2.3.1 K-pler Text 401

2.3.2 Pleskauer Text 411

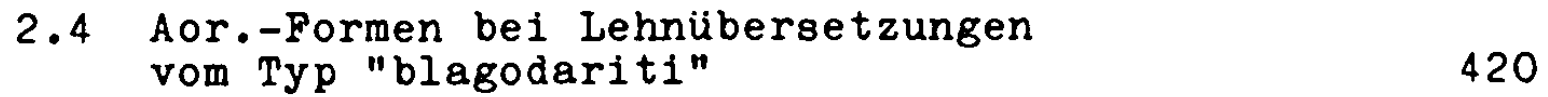

2.5 Aor. -Formen bei
nichtdeterminierten Verben der Bewegung

2.6 Aor.-Formen bei dehnstufigen und/oder
suffigierten Ableitungen

2.7 Zusammenfassung: Die Verwendung des Aorist
in unseren Texten

2.8 Die Funktion des Aorist in unseren Texten 435

2.8.1 Der Aorist in der
aktualisierenden Situationsbeschreibung 439

2.8.1.1 K-pler Text 440

2.8.1.2 Pleskauer Text 443 
2.8.2 Der Aorist in berichtenden Passagen

2.9 Der Ersatz des Aorlst durch das Part.praet.

2.10 Zusammenfassung: Der Aor1st

in unseren Texten

$3.1 \mathrm{~K}$-pel: Belege für die Perfekt-Periphrase und das 1-Part.

3.2 Pleskau: Belege für die Perfekt-Periphrase und das l-Part.

484

3.2.1 Das 1-Part. in der Rede und nach Verben des Sagens und Erfahrens

485

3.2.2 Das 1-Part. bei punktuellen Ze1tangaben

3.2.3 Sonstiges Auftreten des 1-Part.8

505

3.2.4 Exkurs: Das Schreiben

des Hans Möller

508

3.2.5 Zusammenfassung: Das 1-Part.

im Pleskauer Text

510

3.3 Zusammenfassung: Das 1-Part.

in unseren beiden Texten

512

4. Das Plusquamperfekt - Vorvergangenheit

4.1 Vorvergangenheit im K-pler Text

4.2 Vorvergangenheit im Pleskauer Text

4.3 Zusammenfassung: Die Vorvergangenhe1t in unseren Texten

5. Zusammenfassung: Die finiten Präteritalformen in unseren Texten 
1. Das nominale Partizip (aktiv) der Nominativform 541 in der sprachlichen Entwicklung

2. Erscheinungsformen des nominalen Partizips

2.1 Der Formenbestand der nominalen

Partizipien in unseren Texten

2.2 Die Numerus-Kongruenz

zwischen Subjekt und nominalem Partizip

3. Die Funktion der nominalen Partizipien (Nominat.) im Rahmen unserer Texte

3.1 Partizipiale Syntagmen mit eigenem Subjekt

('Nominativus absolutus')

3.1.1 K-pler Text

3.1.2 Pleskauer Text

3.2 Koordinierende Konjunktion zwischen

Verbal- und Partizipial-Syntagma

3.2.1 K-pler Text

3.2.2 Pleskauer Text

3.3 Eigenständige partizipiale Syntagmen $\quad 585$

3.3.1 K-pler Text

587

3.3.2 Pleskauer Text

594

3.4 Das untergeordnete Partizipial-Syntagma 602

3.4.1 K-pler Text 604

3.4 .2 Pleskauer Text 610

3.5 Zusammenfassung: Die Funktion des nominalen
Partizips in unseren Texten

4. Partizip und Aspekt 618

4.1 Part.praes.-Formen perfektiver Verben 618

4.1.1 K-pler Text 618

4.1.2 Pleskauer Text 619

4.2 Part.praet.-Formen imperfektiver Verben 622

4.2.1 K-pler Text 624

4.2.2 Pleskauer Text 626

4.2.3 Anzelchen für die Aussonderung von Part.praet.-Formen, die von imperf. (durativen) Simplicia gebildet sind 
5. Der Dativus absolutus

5.1 Die B1ldungsweise des Dat.abs. (Kongruenz zwischen (Pro-) Nomen und Partizip)

5.2 Die Funktion des Dat.abs. in unseren Texten

5.3 Der Dativus absolutus - Zusammenfassung

6. Akkusativ mit Partizip

7. Das nominale Partizip als Prädikativum

8. Zusammenfassung: Das nominale Partizip in unseren Texten

F. Zusammenfassung

661

\section{Zur Transliteration}

Hinsichtlich der Transliteration des kyrillischen Alphabets wurde in folgender We1se verfahren:

1. Bei der Transliterierung neurussischer Texte und meist auch der Namen verfuhr ich nach Mabgabe der wissenschaftlichen Norm DIN 1460 (vom Oktober 1962).

2. Bei der Transliterierung altrussischer Texte wurde diese Bibliotheksnorm im Prinzip ebenfalls angewandt, jedoch mit der Einschränkung, daß die beiden "Jer" ("mjagkij" und "tverdyj znakn - b, b) belbehalten werden. 
Gerd Stricker - 9783954792900

Downloaded from PubFactory at 01/10/2019 05:43:48AM

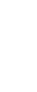

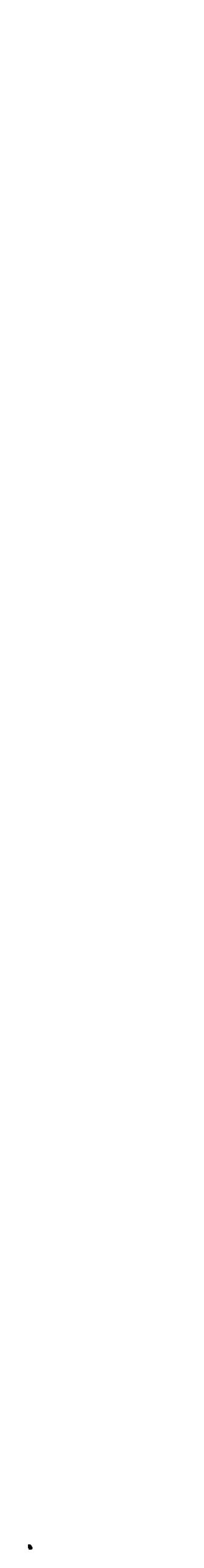


L i t e r a t u r v e r z e ich n 1 s

Adrianova-Peretc, V. P.: Očerki poetičeskogo stilja drevnej Rus1. M. - I. 1947.

(zitiert: Adrianova-Peretc, Očerki).

Adrianova-Peretc, V. P. (Hrsg.): Voinskie povesti Drevnej Rusi. M. - I. 1949.

(zitiert: Adrianova-Peretc, Voinskie povesti).

Adrianova-Peretc, V. P.: Drevnerusskaja Iiteratura 1 fol'klor. I. 1974.

Angelowa, G.: Die Partizipialkonstruktionen in den altbulgarischen Sprachdenkmälern. Sofia 1929.

Angermann, N.: Studien zur Iivlandpolitik Ivan Groznyjs. Marburg/Lahn 1972. (Marburger Ostforschungen. 32 ).

Anpilogov, G. N.: Novye dokumenty o Rossil konca 16 načala 17 v. M. 1967.

Arnold, H. L. - Sinemus, V. (Hrsg.): Grundzüge der I1teraturund Sprachwissenschaft. Bd. 1: Iiteraturwissenschaft. wunchen ${ }^{4} 1976$. (dtv: Wissenschaftliche Reihe. 4226).

Auerbach, I.: Nomina abstracta im Russischen des 16. Jahrhunderts. Ein Beitrag zur Geschichte der Abstraktasuffixe im Slavischen. München 1973. (Slavistische Beiträge. 68).

Azbelev, S. N.: K datirovke russkoj Povesti o vzjatil Caŕgrada turkami. In: TODRL 17 (1961). S. $334-37$.

Azbelev, S. N.: K sravnitel'nomu izučeniju povesti o zavoevanil Konstantinopolja turkami. In: Sravnitel'noe izučenie literatura. Sbornik stat'ej k 80-letiju ak.

M. P. Alekseeva. I. 1976. S. $18-22$.

(zitiert: Azbelev, Pestschrift Alekseev).

Barnet, V.: $K$ vývoj1 slovanských konstrukcl s participil aktivnlmi. In: Acta Univ. Carolinae - Slavica Pragensia $2(1961)$. S. $151-63$.

Barnet, V.: Vývoj systému participil aktivnlch v ruštině. Praha 1965. (Acta Univ. Carolinae - Philologica, Monographia 9). (zitiert: Barnet, vývoj). 
Bielfeldt, H. H.: Altslawische Grammatik. Einfuhrung in die slawischen Sprachen. Halle/Saale 1961. (Slawistische Bibliothek. 7).

(zitiert: Bielefeldt, Altslaw. Grammatik).

Birnbaum, H.: Untersuchungen $z u$ den Zukunftsumschreibungen mit dem Infinitiv im Altkirchenslavischen. Ein Beitrag zur historischen Verbalsyntax des Slavischen.

Stockholm 1958. (Acta Univ. Stockholmensis. Etudes de Philologie Slave. 6).

(zitiert: Birnbaum, Zukunftsumschreibungen).

Boretzky, N.: Der Tempusgebrauch in Kurbskijs "Istorija velikago knjazja moskovskago". Diss. Bonn 1964. (zitiert: Boretzky, Tempusgebrauch).

Borisova, E. N.: 0 sposobach obrazovanija imen suščestvitel'nych $\mathrm{v}$ pamjatnikach delovoj pismennosti $16-18 \mathrm{vv}$. In: Materialy 1 nabljudenija po russkomu jazyku. Ufa 1961.

Borkovsk1f, V. I. - Kuznecov, P. S.: Istoričeskaja grammatika russkogo jazyka. M. 1963.

(zitiert: Borkovskij, Istor. grammatika).

Borkovskij, V. I.: Sintaksis drevnerusskich gramot.

Prostoe predloženie. I'vov 1949.

(zitiert: Borkovskif, Sintaksis drevnerusskich gramot I).

Borkovskij, V. I.: Sintaksis drevnerusskich gramot.

Složnoe predložente. M. 1958.

(z1tiert: Borkovskij, Sintaksis drevnerusskich gramot II).

Borkovskif, V. I. (Hrsg.): Sravnitel'no-1storlčeskij sintaksis vostočnoslavjanskich jazykov. Cleny predloženija. M. 1968 .

Borkovsk1f, V. I. (Hrsg.): Sravnitel'no-istoričeskij sintaksis vostočnoslavjanskich jazykov. Složnopodčinennye predloženija. M. 1973.

Bräuer, H.: Untersuchungen zum Konjunktiv im Altk1rchenslavischen und im Altrussischen. Teil I: Final- und abhängige He1schesätze. Wiesbaden 1957. (Veröffentlichungen 
der Abteilung für slavische Sprachen und Literaturen des Osteuropa-Instituts (Slavisches Seminar) an der FU Berlin. 11). (zitiert: Bräuer, Konjunktiv).

Bräuer, H.: Slavische Sprachwissenschaft. I: Einleltung, Lautlehre. Berlin 1961. (Sammlung Göschen. 1191/1191a).

Bräuer, H.: Slavische Sprachwissenschaft. II: Formenlehre.

1. Te1l. Berlin 1969. (Sammlung Göschen. 1192/1192a) $1192 b)$.

Bräuer, H.: Slavische Sprachwissenschaft. III: Formenlehre.

2. Te1l. Berlin 1969. (Sammlung Göschen. 1236/1236a).

Braun, M. - Schneider, A. M.: Bericht uber die Eroberung Konstantinopels. Nach der Nikon-Chronik ubersetzt und erläutert von M. Braun und A. M. Schneider. (Le1pzig 1941). (zitiert: Braun-Schnelder, Bericht über die Eroberung). Budich, W.: Aspekt und verbale Zeitlichke1t in der I. Novgoroder Chronik. Graz 1969. (Editiones monumentorum elavicorum veteris dialecti).

(zitiert: Budich, Aspekt).

Bulachovskij, L. A.: Istoričeskif kommentarif k russkomu literaturnomu fazyku. Kiev '1958.

Cernov, V. I.: $K$ voprosu o strukture novogo russkogo pl juskvamperfekta (tipa 1 - byl). In: Slavia 30 (1961), S. $432-42$.

Cernych, P. Ja.: Istoričeskaja grammatika russkogo jazyka. M. ${ }^{3} 1962$.

(zitiert: Cernych, Istor. grammatika).

Tschernych, P. J. = Xernych, P. Ja.: Historische Grammatik der russischen sprache. Deutsche Bearbeltung unter Redaktion von H. H. Bielfeldt. Halle/Saale 1957. (Slawistische Bibliothek. 6). ND Berlin 1977.

(zitiert: Cernych, Histor. Grammatik).

Cocron, F.: La langue russe dans la seconde molt1é du XVII siocle (Morphologie). Paris 1962. (B1bliothèque russe de l'Institut d'études slaves. 33). (zitiert: Cocron, La langue). 
Cyževśkyj, D. - s. Tschižewskij, D.

Damerau, N.: Russisches und Westrussisches bei Kurbskij. Wlesbaden 1963.

(zitiert: Damerau, Russisches).

Diels, P.: Altkirchenslavische Grammatik. Mit elner Auswahl von Texten und einem Förterbuch. Heldelberg ${ }^{2}$ 1963. (Sammlung slavischer Lehr- und Handbucher. I. Reihe: Grammatiken. 6). (zitiert: Diels, Aksl. Grammatik).

Donnert, E.: Der livländische Ordensritterstaat und RuBland. Der livländische Krieg und die baltische Prage in der europälschen Polltik 1558 - 83. Berlin 1963.

Donnert, E.: RuBland an der Schwelle der Neuzeit. Der Moskauer Staat im 16. Jahrhundert. Berlin 1972.

Dostál, A.: Staroslověnaká praeterita, jejich čas a vid.

In: Ceský časopis fllologický 3 (1945). S. 65 - 70;

$111-116 ; 219-225$.

Dostél, A.: V1d pomocných sloves $v$ staroslovènštiné.

In: Byzantinoslavica $8(1937 / 38)$. S. $174-183$.

Dostál, A.: Studie o vidovém systému v staroslovènštinè.

Praha 1954.

(zitiert: Dostál, Studie).

Durnovo, N. N.: Očerk istoril russkogo jazyka.

M. - L. 1924. ND 's Gravenhage 1959.

Durnovo, N. N.: Vvedenie $v$ 1storiju russkogo jazyka.

Brno 1927; M. 1969.

Efimov, A. I.: Istorija russkogo literaturnogo jazyka. M. 21967 .

(21tiert: Ef1mov, Istorija russk. I1t. jazyka).

Elmermacher, K.: Studien zu den Verba der II. Leskien'schen Klasse im Russischen. Diss. Berlin 1966.

Fennell, J. L. I.: The Correspondence Between Prince

A. M. Kurbsky and Tsar Ivan IV of Russia 1564 - 1579. 
Edited with translation and notes by J. L. I. Fennell. Cambridge 1955.

Pennell, J. L. I.: Ivan the Great of Moscow. London 1963.

Pennell, J. L. I.: Prince A. M. Kurbsky's History of Ivan IV. Edited with a translation by J. L. I. Pennell.

Cambridge 1965.

Preidhof, G.: Vergleichende sprachliche studien zur GennadiusBibel (1499) und Ostroger Bibel (1580/81). Die Bücher Paralipomenon, Esra, Tobias, Judith, Sapientia und Makkabäer. Frankfurt 1972. (Osteuropastudien der Hochschulen des Landes Hessen. Reihe III. Frankfurter Abhandlungen zur slavistik. 21).

Galton, H.: Aorist und Aspekt im Slavischen. Eine Studie zur funktionellen und historischen Syntax. Wiesbaden 1962.

Goehrke, C.: Die Moskauer Periode. In: RuBland. Hrsg. und verf. von C. Goehrke, M. Hellmann, R. Lorenz, P. Sche1bert. Prankfurt/Main 1972. (Fischer Weltgeschichte. 31 ). Gorškova, K. V.: Očerki 1storičeskoj dialektologil severnoj Rusi (po dannym 1storičeskof filologil). M. 1968.

Grammatika sovremennogo russkogo literaturnogo jazyka.

4. 1970. (= Akademie-Grammatik 1970).

Grebe, P. (Hrsg.): Grammatik der deutschen Gegenwartssprache. Mannheim - Zürich ${ }^{2} 1966$. (Der GroBe Duden. 4).

Gudz1j, N. K.: Chrestomatija po drevnej russkoj literature $11-17$ vv. M. 71962 .

(zitiert: Gudzij, Chrestomatija). Gudzid, N. R.: Istorija drevnej russkoj literatury. M. ${ }^{6}{ }_{1956 .}$ (zitiert: Gudzij, Istorija).

Haleck1, 0.: Geschichte Polens. Frankfurt/Main 1963.

Hellmann, M.: Moskau und Byzanz. In: JbbfGo (NF) 17 (1969). S. $321-344$.

Hellmann, H.: Ivan IV. der Schreckliche. Moskau an der Schwelle der Neuzelt. Göttingen 1966. (Persönlichkeit und Geschichte. 35).

(zitiert: Hellmann, Ivan IV.). 
Henśorśkyd, A. I.: Značennja form mynuloho času $v$ HalyćkoVolynśkomu litopysu. Kyiv 1957.

Hermelin, E.: Uber den Gebrauch der Präsenspartizipien von perfektiven Verben im Altkirchenslavischen.

Diss. Uppsala 1935.

Hösch, E.: Byzanz und die Byzanzidee in der russischen Geschichte. In: Saeculum 20 (1969). S. $6-17$.

Hrushevsky, M.: A History of Ukraine. Hrsg. O. J. Frederiksen. New Haven ${ }^{3} 1948$.

Istorija russkof literatury. (10 Bde.). M. - L. 1941 - 1956. Bd. 2.1: L1teratura 1220-ch - 1580 gg. M. - L. 1946.

Istorifa russkof literatury $v$ trech tomach. T. 1: Iiteratura 10 - 18 vv. M. - L. 1958.

Istorifa SSSR. T. 1: S drevnejšich vremen do 1861 g. M. 1956.

Istrina, E. S.: Sintaksičeskie javlenija Sinodal'nago spiska I Novgorodskoj lětopisi. In: Izv. ORJaS 24 (1919; gedruckt 1923), kn. 2. S. 1-172. Izv. ORJaS 26 (1921; gedruckt 1923). S. 207 - 239. ND Graz 1967 (beide Bände). (zitiert: Istrina, Sint. javlenija).

Jakubinskij, L. P.: Istor1ja drevnerusskogo jazyka. M. 1953. Karinskij, N. M.: Jazyk Pskova 1 ego oblasti v 15 v. $\mathrm{SPb}$. 1909. (Zapiski 1storiko-filologičeskago fakul'teta Imperatorakago S.-Peterburgskago universiteta. 93). (zitiert: Karinskif, Jazyk Pskova).

Kiparsky, V.: Russische historische Grammatik. Bd. II: Die Entwicklung des Formensystems. Heidelberg 1967. (zitiert: Kiparsky, Russ. hist. Grammatik).

Kitch, F. C.: The Literary Style of Epifanif Premudryj. "Pletenie sloves". München 1976. (Slavistische Beiträge. 96).

Kølln, H.: Zum Aorist im Altrussischen. In: Scando-slavica 5 (1959). S. $64-77$.

Kravcov, N. I. (Hrsg.): Russkoe narodnoe trorčestvo. Chrestomatija. M. 1971. 
Ǩrfžková, H.: Vývoj opisného futura v jazyclch slovanských zvláště v ruštinè. Praha 1960.

Krull, E.: Zur Bildsprache des altrussischen Josephus Plavius. Dis8. Bonn 1959.

Krumbacher, K.: Geschichte der byzantinischen Litteratur. Von Justinian bis zum Ende des oströmischen Reiches (527 - 1453). Munchen 1891. (Handbuch der klassischen Altertumswissenschaft. 9. Bd., 1. Abtlg.).

Kudrfavak1f, D. N.: K statist1ké glagol'nych form $v$ Lavrent'evskoj lětopisi. In: Izv. ORJaS 14 (1909), kn 2 . S. 48 - 54. ND Graz 1967.

Lägre1d, A.: Der rhetorische St1l im Sestodnev des Exarchen Johannes. Wlesbaden 1965. (Monumenta Linguae Slavicae dialecti veteris, Fontes et Dissertationes. 5). Lämmert, E.: Bauformen des Erzählens. Stuttgart ${ }^{6} 1975$. Lausberg, H.: Elemente der literarischen Rhetorik. wunchen ${ }^{3} 1967$.

(zitiert: Lausberg, Elemente).

Lausberg, H.: Handbuch der literarischen Rhetorik. Elne Grundlegung der Literaturwissenschaft. 2 Bde. München 1960.

(zitiert: Handbuch I/ Handbuch II; HB I / HB II).

Leontovitsch, V.: Die Rechtoumwälzungen unter Iwan dem Schrecklichen und die Ideologie der russischen Selbstherrachaft. Stuttgart (1948).

Leskien, A.: Handbuch der altbulgarischen (altkirchenslavisehen) Sprache. Grammatik - Texte - Glossar. Heldelberg ${ }^{9}$ 1969. (Indogermanische Bibliothek. Erste Reihe: Lehr- und Hand bucher). (zitiert: Leskien, Hand buch).

Lettenbauer, $W_{.:}$Russische Literaturgeschichte. Tiesbaden ${ }^{2} 1958$.

Lettenbauer, W.: Moskau das Dritte Rom. Zur Geschichte einer politischen Theorie. Munchen 1966. 
Lichačev, D. S.: Vozniknovenie russkoj literatury. M. - I. 1952.

Lichačev, D. S.: Nekotorye zadači 1zučenija vtorogo južnoslavjanskogo vlijan1ja $v$ Rossi1. In: IV Meždunarodny $j$ 8-ezd slavistov. Doklady. M. 1958. S. 95 - 150.

Lichačev, D. S.: Predvozroždenie na Rus1 v konce XIV - pervoj polovine XV veka. In: Literatura épochi vozroźdenija 1 problemy vemirnoj literatury. M. 1967. S. $136-182$.

Lichatschow, D. S. = L1chačev, D. S.: Die Kultur Russlands während der osteuropälschen Frührenalssance. Aus dem russischen Manuskript ubersetzt von Ingeborg und Horst Bretschneider. Dresden 1962.

( = Ubersetzung nach dem Manuskript zum vorigen Titel).

Lichačev, D. S.: Poétika drevnerusskoj literatury. L. 1967. Lichaćev, D. S.: Celovek v literature drevnej Rusi. M. 1970. Lichačev, D. S.: Razvitie russkof literatury X - XVII vv. Epoch1 1 stil1. L. 1973.

Ilchatschow, D. S. = Lichačev, D. S.: Russ1sche Literatur und europälsche Kultur des 10. - 17. Jahrhunderts. Berlin 1977. (Slawistische Studien und Texte). (= Ubersetzung des vorigen Titels von Renate Franke).

Lichačev, D. S. - Pančenko, A. M.: 'Smechovoj mir' drevnej Rusi. L. 1976. (Serija 'Iz istoril mirovoj kul'tury').

Lomtev, T. P.: Očerki po 1storičeskomu sintaksisu russkogo jazyka. M. 1956.

Lomtev, T. P.: $\mathrm{K}$ charakteristike vidovoj differenciacil preterital'nych form glagola $v$ drevnem russkom jazyke. In: Učenye zapiski MGO. Trudy kafedra russkogo jazyka. $\mathrm{Kn}$. 2. M. 1948 . S. $70-88$.

Lomtev, T. P.: Ob upotreblenil glagola otnositel'no kategorl1 vrement $v$ drevnerusskom jazyke. In: Učenye zaplsk1 MGU. Trudy kafedra russkogo jazyka. M. 1952. S. $219-253$. 
Lure, Ja. S.: Novye spiski 'Careva gosudareva poslanija vo vse ego Rossijskoe carstro'. In: TODRL 10 (1954). S. $305-309$.

Lứe, Ja. S.: Ideologičeskaja boŕba v russkoj publicistike konca 15 - načala 16 v. M. - L. 1960.

Maslennikova, N. N.: Prisodinenie Pskova k Russkomu centralizovannomu gosudarstvu. L. 1955.

Maslennikova, N. N.: Ideologičeskaja boŕba v pskovskoj literature $v$ period obrazovanija Russkogo centralizovannogo gosudarstva. In: TODRL 8 (1952). S. $187-217$.

Maslov, Ju. S.: Imperfekt glagolov soveršennogo vida $v$ slavjanskich jazykach. In: Voprosy slavjanskogo jazykoznanifa 1 (1954). S. $68-138$. (zitiert: Maslov, Imperfekt).

Maslov, Ju. S.: Zur Entstehungsgeschichte des slavischen Verbalaspekts. In: ZsfSl. 4 (1959). S. $560-568$. muller, G.: Erzählze1t und erzählte Ze1t. In: Festschrift für P. Kluckhohn und H. Schnelder. 1948. S. $195-212$. N1k1forov, S. D.: Glagol, ego kategori1 1 formy v russkof piśmennost1 vtorof poloviny 16 veka. M. 1952. (zitiert: Nikfforov, Glagol).

Obnorsk1j, S. P.: Očerki po 1storil russkogo l1teraturnogo jazyka. H. 1946.

Očerki 1storif SSSR. Period feodal1zma konec 15 v. - načalo 17 v. M. 1955.

Onasch, K.: Einführung in die Konfessionskunde der orthodoxen Xirchen. Berlin 1962. (Sammlung Göschen. 1197/1197a).

Onasch, K.: Grundzuge der Russischen Kirchengeschichte. Gottingen 1967. (Die Kirche in ihrer Geschichte. Ein Handbuch herausgegeben von Kurt Dietrich und Ernst Wolf. Band 3, Lieferung $x / 1$. Teil).

Orlov, A. S.: O nékotorych osobennostjach stilja velikorusskoj istoričeskoj belletristik1 $16-17 \mathrm{rv}$. In: 
Izv. ORJaS 13(1908), km. 4. S. 344 - 379. ND Graz 1967. Orlov, A. S.: Ob osobennostjach formy russkich volnskich pověstey (končaja $17 \mathrm{v}$. ). In: Ctenija $v$ Imperatorskom obščstvě 1storil 1 drevnostej rossijskich pri Moskovskom universiteté. 1902, kn. 6. S. $1-50$.

Orlov, A. S.: Drevnjaja russkaja l1teratura 11 - 16 vv. M. - L. 21939 .

Orlov, A. S.: Gerolčeskie temy drevnej russkoj 11teratury. M. - L. 1945.

Otten, F.: Die finiten Verbalformen und ihr Gebrauch in der Stepennaja kniga carskogo rodoslovija. Berlin 1973. (Veröffentlichungen der Abtellung für slavische Sprachen und Iiteraturen des Osteuropa-Instituts (Slavisches Seminar) an der FU Berlin. 42). (zitiert: Otten, Pin. Verbalformen). Rezension hierzu von H. Keㄹert In: ZsfSlPh 38 (1975). S. $394-397$.

Otten, F.: Zum Infinitiv auf $-t_{b}$ in der Stepennaja kniga carskogo rodoslovija. In: ZsfSlPh 38 (1975). S. $361-367$.

Panzer, B.: Der slavische Konditional. Form - Gebrauch Punktion. Munchen 1967. (Forum Slavicum. 14). (zitlert: Panzer, Der slavische Konditional).

Panzer, B.: Der Verbalaspekt im Konditional des Slavischen. In: Slavistiache Studien zum VI. Internationalen SlavistenkongreB in Prag 1968. München 1968.

S. $90-111$.

Pollok, K.-H.: Studien zur Poetik und Komposition des balkanslawischen lyrischen Volksliedes. I. Das Llebeslied. Göttingen 1964. (Forum Slavicum. 5).

Potebnja, A. A.: Iz zapisok po russkoj grammatike. t. I - II. M. 21968 .

(zitiert: Potebnja, Iz zapisok).

Potebnja, A. A.: Iz zapisok po russkoj grammatike. t. III: 
Ob Izmenenil značenija 1 zamenach suščestritel'nogo. M. 21968 .

Potebnja, A. A.: Iz zapisok po russkoj grammatike. t. IV:

Glagol. Mestoimenie. Cislitel'noe. Predlog. M. - L. 1941. Rhode, G.: Geschichte Polens. Ein Uberblick. Darmstadt ${ }^{2} 1966$. Rogova, V. N.: Slovoobrazovatel'naja sistema russkogo jazyka v 16 v. (po materialam publicističeskich proizvedenif). Krasnojarsk 1972 .

Runciman, S.: The Fall of Constantinopel 1453. Cambridge 1965. Runciman, S.: Die Eroberung von Konstantinopel 1453. Munchen ${ }^{2}$ 1977. (dtv. W18senschaftliche Re1he. 4286).

Ruzicka, R.: Der Verbalaspekt in der altrussischen Nestorchronik. Berlin 1957. (Veroffentlichungen des Instituts fur Slawiotik. 14).

(zitiert: Ruzicka, Verbalaspekt).

Rư̌ička, R.: Das syntakt1sche system der altslavischen Part1ziplen und sein Verhiltnis zum Griechischen. Berlin 1963. (Veroffentlichungen des Instituts für Slawistik. 27). (zitiert: Ruzicka, Das eynt. System).

Ř́lga, V.: Kto perevel kratkuju povest' o vzjat11 Konstant1nopolja turkam1? In: Slavia 13 (1934). S. 105 - 108.

Sachmatov, A. A.: K voprosu o proischoždenil Chronografa. In: Sbornik ORJas 66 (1899). S. 21 ff.

Sachmatov, A. A.: Istoričeskaja morfologija russkogo jasyka. น. ${ }^{2} 1957$.

Sachnatov, A. A.: Sintaksis russkogo jazyka. Učenie o predlošen11 1 o slovoeočetanifach. I. 1925.

Seroonov, K. G.: Drevnerusek1J Jazyk. M. 1973.

gedn1k, I.: Das slavische Imperfekt. In: WdSl 5 (1960). s. $19-30$.

Sadnik, I.: Die Masalpräsentia und das fruhurslevisohe Verbaløystem. In: D1e Spraohe 8 (1962). S. $238-249$. Badnik, I.: Aksl. 'rekg: rool'. In: Orbis Scriptus. 
Dmitrij Tachižewskij zum 70. Geburtstag. Munchen 1966. S. 659 - 662 .

Sadnik, L.: Der Ergatz von Aorlot und Imperfekt durch die 1-Periphrase, namentlich im Russischen. In: AzfSIPh 1 (1966). S. $16-30$.

Schaeder, H.: Moskau - das Dritte Rom. Darmstadt ${ }^{2} 1957$.

Schelesniker, H.: Entstehung und Entwicklung des slavischen Aspektgystems. In: TdSI 4 (1959). S. $390-409$.

Schmidt, W. H.: Gattungstheoretische Untersuchungen zur altrussischen Kriegserzählung (Zur Soziologie mittelalterlicher Gattungen). Berlin 1975. (Veröffentlichungen der Abtellung für slavische Sprachen und Ilteraturen des Osteuropa-Instituts (Slavisches Seminar) an der PU Berlin. 44 ). (zitiert: Schmidt, Untersuchungen).

Schneider, R.: Die Sprache Posoğkovs (Phonetik und Morphologie). Diss. Münster 1973.

(zitiert: Schneider, Die Sprache Posoškovo).

Scholz, P.: Studien zur Geschichte des umschriebenen Perfekts In den slavischen Sprachen. Masch.-Diss. Hamburg 1952.

Scholz, F.: Ergtarrung und Entwicklung in der altslavischen Kirchensprache RuBlands. In: Orbis 6 (1957). S. $427-436$. van Schooneveld, C. H.: A Semantic Analysis of the Old Russian Pinite Preterite System. 's-Gravenhage 1959. (Slavistic Printings and Reprintings. 7 ). (zitiert: van Schooneveld, A Semantic Analysis.

Sel1vanov, G. A.: K charakteristike 'delovogo stilja' $\nabla$ drevnerusskom literaturnom jazyke. Krasnojarsk 1963.

Sevčenko, I.: Byzantine Cultural Influences. In: C. E. Black (Hrsg.): Rewriting Russian History. Soviet Interpretations of Russia's Past. New York 1956. S. 138 - 154.

Skr1p1l', M. 0.: 'Istorija' o vzjat11 Cárgrada turkami Neatora Iskandera. In: TODRL 10 (1954). S. $166-184$. (zitiert: Skripil', 'Istorija'). 
Słońak1, S.: Tak zwane perfektum w jegykach slowlańakich. In: Prace f1lologiczne 10 (1926). S. 1 - 33.

Smirnov, I. I.: Očerk1 političeskoj lstor11 russkogo gosudaratva 30 - 50 godor 16 v. M. - L. 1958.

Smirnor, N. A.: Istoričeskoe značenie russkoj 'Povesti'

Nestora Iskandera o vati1 turkami Konstantinopolja $v$

1453 g. In: Viz.Vr. 7 (1953). S. $55-56$.

Sob1k, M. E.: Polnisch-russische Bezlehungen in Spiegel des russischen Wortschatzes des 17. und der ersten Hilfte des 18. Jahrhunderts. Meisenheim am Glan 1969. (Slavisch-Baltiaches Seminar der Westfilischen WilhelmsUniversitat Münster/Festf., Veröffentlichung Nr. 13). (zitiert: Sobik, Beziehungen).

Rezension hierzu von S. Ur bańçzyk

In: AzfSIPh 5 (1971). S. $120-124$.

Sobolevgk11, A. I.: Lekc11 po 18tori1 russkago jazyka. M. 41907. ND 's-Gravenhage 1962.

(21tiert: Sobolevakij, Lekc11).

Sokolova, M. A.: Očerk1 po jazyku delovych pamjatnikov 16 v. L. 1957.

Sokolova, M. A.: Očerk1 po 18toričeskoj grammatike russkogo jazyka. L. 1962.

Sorokoletov, F. P.: Istorifa voennoj leksiki v russkon fazyke. L. 1970 .

Speransk11, M. N.: Povest1 1 skazan1ja o vzjat11 Cá́grada turkani (1453) v russkof p1śmennost1 $16-17$ vo. In: TODRL 10 (1954). S. $136-165$. TODRL $12(1956)$. S. $188-225$. (21tiert: Speranskif, Povest1 10 / Povest1 12).

Stahl1n, K.: Geschichte Russlands. Von den Anfängen bis zur Gegenwart. 4 Bde. 1. Bd. Stuttgart 1923. ND Graz 1961.

Stang, C.: Die westrussische Kanzleisprache des Grossfurstentums Litauen. 0810 1935.

Stang, C.: Die altrussische Urkundensprache der Stadt Polock. 08101939. 
Stang, C.: Das slavische und baltische Verbum. 0slo 1942. Stang, C.: La langue du livre 'Učenie 1 chitrost' ratnago stroenija pěchotnychz ljudej - 1647'. Une monographie linguistique. Oslo 1952.

Stender-Petersen, A.: Anthology of 0ld Russian Iiterature. New York 1954 .

Stender-Petersen, A.: Geschichte der russischen Iiteratur. Erster Band. München 1957.

(zitiert: Stender-Petersen, Geschichte).

Stender-Petersen, A. - Jordal, K.: Das griechisch-byzantinische Erbe im Russischen. In: Travaux du cercle Iinguistique de Copenhague 11 (1957). S. $163-218$.

Stecenko, A. N.: Istoričeskif sintaksis russkogo jazyka. M. 1972 .

Stökl, G.: Rubland von 1462 bis 1689. In: Handbuch der europäischen Geschichte. Herausgegeben von Th. Schieder. Band 3: Die Entstehung des neuzeitlichen Europa. Stuttgart 1971. S. 1135 - 1169 .

Stökl, G.: Russische Geschichte. Von den Anfängen bis zur Gegenwart. Stuttgart ${ }^{3} 1973$. (zitiert: Stökl, Russ. Geschichte).

Stökl, G.: Testament und Siegel Ivans IV. Opladen 1972. (Abhandlungen der Rheinisch-Westfälischen Akademie der Wissenschaften. 48 ).

Stola, R.: Zum Gebrauch der unbestimmten Formen von aktiven Partizipien in der Punktion von zweitrangigen Prädikaten im Lavrent'evskij spisok. In: WSlJb 5 (1956). S. $14-27$. Stola, R.: Zur Prage der Entwicklung des deepričastie im Altrussischen. In: Slavjanskaja filologija. Sbornik Statej I. M. 1958.

Talev, I.: Some Problems of the Second South Slavic Influence in Russia. München 1973. (Slavistische Beiträge. 67). Tauscher, E. - Kirschbaum, E.-G.: Grammatik der russischen Sprache. Düsseldorf ${ }^{8} 1968$. 
Thorndahl, W.: Genetivens og lokativens -u/-ju-endelser 1 russiske middelaldertekster. Med tysk resumé. Kobenhavn 1974 .

Tichomirov, M. N.: "Povest' o prichoženil Stefana Batorija na grad Pskor". Recenzija. In: Tichomirov, M. N.:

Russka ja kul'tura $10-18$ vv. M. 1968. S. $346-353$. (zitiert: Tichomirov, Recenzija).

Trost, K.: Die aktiven Präsenspart1z1pia perfektiver Verben im Altkirchenslavischen.

In: AzfSIPh 1 (1966). S. $31-51$. AzfSIPh 2 (1967). S. $27-41$.

(zitiert: Trost, Die aktiven Präsenspartizipia 1/2).

Trost, K.: Die Perfektperiphrase im Altkirchenslavischen und Altarmenischen. Ein Beltrag zur verglelchenden Syntax. In: Indogermanische Porschungen 73 (1968).

S. 87 - 109 .

Trost, K.: D1e Adverbialpartizipia auf -'a von perfektiven Verben 1m Russischen. In: AzfSIPh 3 (1969). S. $26-58$.

Trost, K.: Perfekt und Konditional im Altkirchenslavischen. Wiesbaden 1972. (Bibliotheca Slavica).

(zitiert: Trost, Perfekt).

Trost, K.: Untersuchungen zur Ubersetzungstheorie und -praxis des späteren Kirchenslavischen. Die Abstrakta in der Hexaemeronubersetzung des Zagreber Zbornik von 1469. Munchen 1978. (Forum Slavicum. 43).

Tschižewskij, D.: Geschichte der altrussischen Ilteratur. Prankfurt/M. 1948.

Ciževskij, D. = Tschižewskij, D.: History of Russian

Literature. Prom the $11^{\text {th }}$ Century to the End of the

Baroque. 's-Gravenhage 1960. (Slavistic Printings and Reprintings. 12).

Tsch1źemsk11, D.: AbriB der altrussischen Literaturgeschichte. München 1968. (Forum Slavicum. 9).

Tschtžewskif, D.: Vergleichende Geschichte der slavischen Ilteraturen. Bd. I: Einfürung. Anfänge des slavischen 
Schrifttums bis zum Klassizismus. Berlin 1968. (Sammlung Göschen. 1222/1222a).

Tschižewskif, D.: Russische Geistesgeschichte. München ${ }^{2} 1974$. (Kritische Information. 18).

Unbegaun, B.: La langue russe au XVI siècle (1500 - 1550). I: La flexion des noms. Paris 1935. (Bibliothèque de l'Institut français de Leningrad. 16).

Unbegaun, B.: Les relations vieux-russes de la prise de Constantinople. In: RES 9 (1929). S. $13-38$.

(zitiert: Unbegaun, RES).

Vaillant, A.: Grammaire comparěe des langues slaves.

Tome 1: Phonétique. Lyon - Paris 1950.

Tome 2: Morphologie. Lyon - Paris 1958.

Tome 3: Le verbe. Paris 1966.

Tome 4: La formation des noms. Paris 1974.

Tome 5: La syntaxe. Paris 1977.

Vinogradov, V. V.: Izslędovanifa $v$ oblasti fonetiki sévernorusskago narěčija. Očerki iz istoril zvuka 'ě' v sěvernorusskom narěčil. In: Izv. ORJaS 24 (1919, gedruckt 1923), kn. 2. S. $188-348$.

Wipper, R. J. = Vipper, R. Ju.: Iwan Grosny. M. 1947. (= aus dem Russischen übertragen nach der 3. Auflage M. ${ }^{3} 1947$ ).

Vondrák, W.: Altkirchenslavische Grammatik. Berlin ${ }^{2} 1912$. Vondrák, W.: Vergleichende Slavische Grammatik. 2. Band: Formenlehre und Syntax. Göttingen ${ }^{2} 1928$. van Wijk, N.: Die sog. Verba iterativa und die Bezeichnung wiederholter Handlungen im Aksl. In: Indogermanische Porschungen 45 (1927). S. $100-104$.

Weinauer, G.: Die Anwendung des Konditionalis im Altkirchen-slavischen. Masch.-Diss. Göttingen 1951.

Winter, E.: Byzanz und Rom im Kampf um die Ukraine 955 1939. Leipzig 1942.

Winter, E.: RuBland und das Papsttum. Teil 1: Von der 
Christianislerung bis zu den Anfängen der Aufklärung. Berlin 1960. (Quellen und Studien zur Geschichte Osteuropas. Band VI, Te1l I).

Wittram, R.: Baltische Geschichte. Die Ostseelande Livland, Estland, Kurland 1180 - 1918. München 1954.

Zenkovsky, S. A. (Hrsg.): Aus dem alten RuBland. Epen, Chroniken und Geschichten. München 1968.

Zimin, A. A.: I. S. Peresvetov $i$ ego sovremenniki. Očerki po istoril russkoj obščestvenno-političeskoj mysli serediny 16 v. M. 1958.

Zimin, A. A.: Reformy Ivana Groznogo. M. 1960.

Zimin, A. A.: Opričnina Ivana Groznogo. M. 1964.

Zlatanova, R.: Die Struktur des zusammengesetzten Nominalprädikats im Altbulgarischen. München 1976. (Slavistische Beiträge. 103).

(zitiert: Zlatanova, Die Struktur). 
W ö $r$ t e $r$ b ü $c h e r$ und $N$ a $c h s c h l$ a $g$ e we $r k e$

Belorussko-russkij slovaŕ. M. 1962.

Brückner, A.: Encyklopedia staropolska. (2 Bde.)

Narszawa 1939.

Brückner, A.: Slownik etymologiczny języka polskiego. Kraków 1927. ND Warszawa 1970.

Dal', V.: Tolkovyj slovár živogo velikorusskago jazyka.

(4 Bde.). SPb. - M. ${ }^{4} 1912$. ND M. 1956.

Daum, E. - Schenk, W.: Die russischen Verben. Grundformen.

Aspekte. Rektion. Betonung. Deutsche Bedeutung.

Mit einem Aufsatz ... von Prof. Dr. Rudolf Rúžička.

Lizenzausgabe München 1963 nach: Leipzig ${ }^{2} 1963$.

(zitiert: Daum-Schenk, Die russischen Verben).

Gloger, Z.: Encyklopedja staropolska illustrowana. (4Bde.).

Harszawa 1900 - 1903.

Gruzberg, A. A.: Castotnyj slovár russkogo jazyka vtoroj poloviny 16 - načala 17 v. Perm 1974.

Pavlovskif, I. Ja.: Russko-nèmeckij slovaŕ. Riga - Leipzig ${ }^{3} 1911$. ND Leipzig 1960.

Polnyj pravoslavnyj bogoslavskij ènciklopedičeskij slovár.

(2 Bde.). SPb. (1913). ND London 1971.

Preobraženskij, A. G.: Etimologičeskij slovaŕ russkago jazyka/ Preobrazhensky, A. G.: Etymological Dictionary of the Russian Language. New York 1951.

Pskovskij oblastnoj slovaŕ s istoričeskimi dannymi.

vyp. 1 - 3 (= von A bis "vzjatbsja"). L. 1967 - 1976.

Sadnik, L. - A1tzetmuller, R.: Handwörterbuch zu den alt-

kirchenslavischen Texten. 's-Gravenhage - Heidelberg 1955.

(Slavistic Printings and Reprintings. 6).

(zitiert: Sadnik-Aitzetmüller, Handwörterbuch bzw. HWB).

Sadnik, L. - Aitzetmüller, R.: Vergleichendes wörterbuch der slavischen Sprachen. Bd. 1 (A/B). Wiesbaden 1975. 
Sławski, F.: Slownik etymologiczny jegzyka polskiego. Bd. 1 Bd. 5, Heft 2 (= von A bis "Xom"). Kraków 1952 - 1976.

Slovaŕ russkogo jazyka 11 - 17 vv. Vyp. $1-4$ (= von $A$ bis "djafinz"). M. 1975 - 1977.

Slovnfk jazyka staroslověnského. Lexicon linguae palaeoslovenicae. Bd. 1 - Bd. 3, Heft 32 (= von A bis "poustynbnz"). Praha 1966 - 1977.

słownik polszczyzny XVI wieku. Bd. 1 - Bd. 10 (= von A bis "korzyśćn). WrocXaw - Warszawa - Kraków 1966 - 1976.

słownik staropolski. Bd. 1 - Bd. 7 (= von A bis "rozproszyćn"). Wroclaw - Warszawa - Kraków - Gdańsk 1953 - 1977.

Sreznevskij, I. I.: Materialy dlja slovarja drevne-russkago jazyka po piśmennym pamjatnikam. ( 3 Bde).

$\mathrm{SPb} .1893$ - 1903. ND M. 1958.

(zitiert: Srezn. I / II / III).

Vasmer, M.: Russisches etymologisches Wörterbuch. ( 3 Bde.). Heldelberg 1953 - 1958.

(zitiert: Vasmer, REW I / II / III).

Pasmer, M. = Vasmer, M.: Étimologičeskij slovaŕ russkogo jazyka. (4 Bde.). M. 1964 - 1973.

T e $x$ t a us g a b e $n$

Povestb o prichoženii Stefana Batorija na grad Pskov. Hrsg. V. I. Malyšev. M. - L. 1952.

Povestb o vzjatif Caŕgrada turkami.

In: Russkie povesti 15 - 16 vv. Hrsg. M. O. Skripil'. M. - L. 1958. S. $55-78$. 
G e l e ge nt l $1 \mathrm{ch}$ herangezogene $Q$ u e l l e $\mathrm{n}$

Aleksandrija. Roman ob Aleksandre Makedonskom po russkoj rukopisi 15 v. Hrsg. M. N. Botvinnik, Ja. S. Lure und O. V. Trorogov. M. - L. 1965.

Chronograf 1512 g. PSRL 22, $1+2$. SPb 1911.

Heidenstein, R.: Rerum Polonicarum ab excessu Sigismundi Augusti libri XII. Frankfurt 1672.

(Die darin enthaltenen detaillierten Beschreibungen der Feldzüge Stephan Báthorys waren bereits gesondert 1584/85 in Krakau erschienen unter dem Titel: Commentarium de bello Moscovitico. Diese Beschreibung wurde ins Russische übersetzt: Rejngol'da Gejdenštejna Zapiski o Moskovskoj vojně 1578 - 1582. Perevod s latinskago. SPb 1889).

Josephus Flavius: Istorija iudejskoj vojny Iosifa Flavija $\mathrm{v}$ drevnerusskom perevode.

Hrsg. N. A. Meščerskij. M. - I. 1958.

Kazanskaja Istorija. Hrsg. G. N. Moiseeva. M. - L. 1954 .

Kurbskij, A. M.: Briefwechsel mit Ivan Groznyj.

Istorija velikago knjazja moskovskago.

s. im Literaturverzeichnis unter: Fennell, J. I. I.

Iitauische Chronik = Chronika litovskaja i žmojtskaja. PSRL 32. M. 1975.

Nestor-Chronik = Povest ' vremennych let. Cast ' pervaja:

Tekst i perevod. Textbearbeitung: D. S. Lichačev. Ubersetzung: D. S. Lichačev und B. A. Romanov. M. - I. 1950. Nikon-Chronik = Patriaršaja ili Nikonovskaja letopiś. PSRL 9 - 13. SPb. 1862 - 1906. ND M. 1965.

Herangezogen wurde vor allem PSRL 12.

Pskovskie letopisi. Hrsg. A. N. Nasonov.

Vypusk pervyj: M. - L. 1941. ND Diisseldorf-The Hague 1967

Vypusk vtoroj: M. 1955.

Skazanie O Mamaevom poboišče.

In: Russkie povesti $15-16$ vv. Hrsg. M. O. Skripil'. M. - L. 1958. S. $16-38$. 
Staden, H. von: Aufzeichnungen uber den Moskauer Staat. Nach der Handschrift des Preubischen Staatsarchivs in

Hannover hrsg. von Fritz_Epste1n. Hamburg 1930.

(Abhandlungen aus dem Gebiet der Auslandskunde. 34 .

Reihe A. Rechts- und Staatswissenschaften. Bd. 5).

Stefanit 1 Ichnilat. Srednevekovaja kniga basen po russkim rukopis jam 15 - 17 vv. Hrsg. 0. P. Lichačeva und Ja. S. Lứe. L. 1969.

Stepennaja kniga = Kniga stepennaja carskogo rodoslovija. PSRL 21, $1+2$. SPb. 1908 und 1913.

(zitiert: Step.kniga).

Voinskie povesti drevnef Rusi.

Hrsg. V. P. Adrianova-Peretc. M. - L. 1949.

Inhalt: Povest: o razorenil Rjazani,

Zadonscina,

Povest1 ob azovskom vzjatil 1 osadnom sideni1 v 163711642 gg.

(zitiert: Adrianova-Peretc, Voinskie povesti).

Le topiś po Voskresenskomu spisku.

PSRL 7. SPb. 1856. Prodolženie: PSRL 8. SPb. 1859.

Verze 1 chnis der A b k ürzungen

1. Periodica, Zeitschriften, Reihen

ArfSlPh Anzeiger für slavische Philologie. Wiesbaden 1966 - 1972. Graz 1974 ff.

AfSiPh Archiv für slavische Philologie.

Berlin 1876 - 1929.

JbbfGO NF Jahrbücher für Geschichte 0steuropas. Neue Folge. München 1953 - 1960.

Wiesbaden 1961 ff.

Orbis

Orbis. Bulletin international de documentation linguistique. Gembloux, Louvian 1952 ff. 
Izv.

Sborn1k

ORJaS

RES

Scando-Slavica

Slavia

Die Sprache

TODRL

WdSI

WSIJb

ZsfSI

ZgfSIPh
Izvěstija bzw. Sbornik

Otdělenija russkago jazyka 1 sloveenost1 Rossifakof Imperatorskof Akademil Nauk. Izvest1ja otdĕlenıja ... SPb. $1896 \mathrm{ff}$. Sbornik ... SPb. $1872 \mathrm{ff}$.

Polnoe sobranie rueskich lètopioef. SPb. 1841 ff. (Bd. $6=1841$; Bd. $1=1872$ ). Révue des Etudes slaves. Par1s 1921 ff. Scando-Slavica. Kopenhagen 1955 ff.

Slavia. Casopis pro slovanskou f1lologi1. Praha 1922 ff.

Die Sprache. Ze1tachrift für Sprachwissenschaft. Wien 1949 ff.

Trudy otdela drevne-russkoj literatury. Institut russkof literatury. L. $1934 \mathrm{ff}$. Die Welt der Slaven. Fiesbaden 1956 - 1971. Köln - Wien 1972 - 1976. Munchen 1977 ff. Wiener Slavistisches Jahrbuch. Wien $1950 \mathrm{ff}$. Ze1tschrift für slawistik. Berlin $1956 \mathrm{ff}$. Ze1tschrift fur slavische Philologie. Le1pz1g 1924 - 1950. Heldelberg 1952 ff.

2. Ortgnamen

M. = Moskva L. = Leningrad

$\mathrm{SPb} .=$ Sankt Peterburg

Rongtantinopel wird im laufenden Text $\underline{\mathrm{K} \text {-pel }}$ abgekirgt. Die Herkunft von Wort- und Textbelopielen wird (in Verbindung mit Selten- und Zellenangaben) durch folgende Sigla verdeut11cht: $\quad K P=$ Erzählung uber d1e Elnnahne Konetantinopels PS = Ergählung uber die Belagerung Plegkaug

z.B. KP 77/12 he1Bt: K-pler Text S. 77, Ze1le 12; PS 41/15 helBt: Pleskauer Text S. 41, Ze1le 15. 


\section{Sonstige Abkürzungen}

Neben allgemein üblichen Kürzeln (z.B. Kasus- oder Genusbezeichnungen) verwende $1 \mathrm{ch}$ noch folgende Sigla, die zum großen Teil bekannt oder aber sofort verständlich sind:

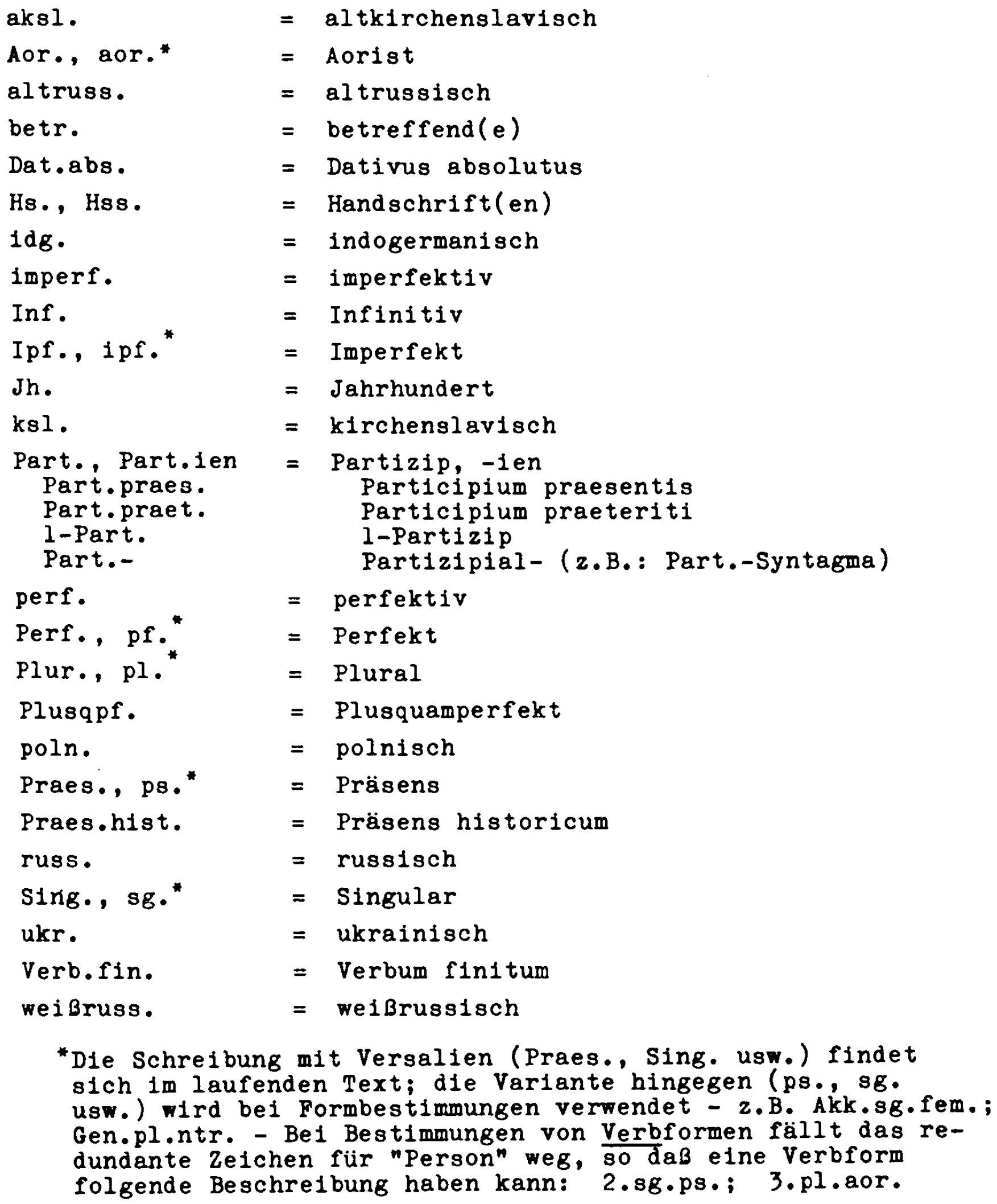


Was hat man sich unter dem Begriff 'Moskovitischer Prunkstil des 16. Jahrhunderts' vorzustellen? Als etablierter Terminus erscheint er in keiner Literaturgeschichte; aber dem Kenner der russischen Literatur im 16. Jahrhundert ist sicher klar, daß dieser Begriff jene Stilrichtung umschreiben soll, die für Werke der offiziösen Literatur z.Z. Ivans des Schrecklichen charakteristisch ist und die ihre Prägung dem Wirken des Metropoliten Makarij verdankt.

Dieser hatte, 1542 als Metropolit berufen, sogleich den Schutz des jungen, verwaisten Großfüsten übernommen, der als Werkzeug in den Händen slch befehdender Bojarencliquen eine schlimme Zeit hinter sich hatte. Glelchzeltig übte er als Erzieher Ivans den entscheidenden EInfluß auf dessen gelstige Entwicklung, aus. Der Metropolit machte Vorstellungen zu selbstverständlichen Maximen Im Denken Ivans, die seit spätestens Iosif von Volokolamsk, vor allem seit den Formulierungen des Pleskauer ${ }^{1}$ Moncho Filofej in den führenden kirchlichen Krelsen beheimatet waren, die aber in die praktische Politik bisher noch keinen Eingang gefunden hatten: Es war dies die Idee von der Beerbung Kon-

1) Russ. ON "Pskov" wurde von den Kaufleuten der Hanse, von den Rittern des (Livländischen) Schwertbrüderordens, später des Deutschen Ordens als 'Pleskau' wiedergegeben. So nannte auch die deutsch-baltische Bevölkerung muss. "Pskov". 'Pleskau' reflektiert die altruss. Lautung "Plbskorb", wie wir sie z.B. in der Laurentius-und in der 1. Novgoroder Chronik vorfinden - in den Pleskauer Chroniken begegnet meist die Schreibung "Pskovs", da die erhaltenen Hss. durchweg jungeren Datums sind (die älteste Hs. stammt vom Ende des 15. Jh.s - s. Pskovskie letopisi. Vyp. 1. Hrsg. A. Nasonov. M. - L. 1941. ND Disseldorf - The Hague 1967. S. LXIII). Wenn wir die Bezelchnung 'Pleskau' verwenden, so geschieht dies in Analogie zu anderen Ortsbezeichnungen, wo ausländ1sche und deutsche Namensformen nebenelnander existieren: Wir sagen 'Moskau' statt "Moskva", "Warschau' statt "Marszawa", 'Prag' statt "Praha", "Mailand' statt "Milano", 'Neapel' statt "Napolin usw. - Hiervon ist Jene Problematik zu trennen, die zum Ausdruck kommt, wenn 'Breslau' statt "Wroclaw" gesagt, 'straßburg' statt "Strasbourg" geschrieben wird. 
stantinopels (translatio imperi1) nach dessen Eroberung durch die Tüken 1453, als deren tiefere Ursache man die Union mit den römischen Häretikern (8. Synode von Perrara und Florenz 1438/39) sah - die Idee von Moskau dem Dritten Rom.

Es bedurfte eines machtvollen Herrschers, der dem hochmuligen Anspruch, Moskau sel in die Nachfolge Roms und Konstantinopels getreten und bilde nun das einzige wirklich christliche, d.h. rechtgläubige Staatswesen auf Erden (= das Hellige RuBland), hätte allgemelne Geltung verschaffen können. Die K1rche war es nun, die durch Metropolit Makarijs Erzlehungswerk an dem jungen Grofürsten Ivan IV. dieser religiös-politischen Ideologie auch die notwendige politische Relevanz verschaffe ${ }^{2}$ die Krönung Ivans zum helligen, von Gott gekrönten ("bogoven-

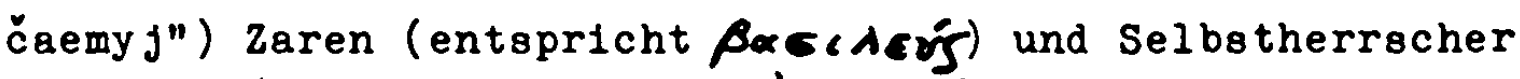

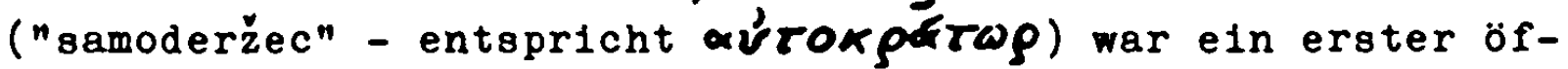
fentlicher Schritt in diese Richtung; die spektakuläre Eroberung Kazańs paßte ebenso in dieses Konzept wie die spatere Einnahme Astrachańs. 3

Besonders gut 1st das Wirken Metropolit Makarijs auf literarischem Gebiet oder besser: im Bereich des rellgiös-politischen Schrifttums zu verfolgen. Hier sind jene Zentralisierungsbestrebungen auf gelstiger Ebene vorgezelchnet, die Ivan IV. später mit schrecklicher Konsequenz in der realen (Macht-) Politik nachvollzieht. So läbt Makarij, um eine repräsentative Acta sanctorum $z u$ schaffen, die überall kursierenden Helligenlegenden zusammentragen, überprüfen und - wenn sle der Tradierung für würdig befunden wurden - uberarbeiten. AuBerdem läBt er zahlreiche wundertäter kanonisieren und auch für sie Viten an-

2) Entgegen fruherer Auffassung besaB die Lehre von Moskau dem Dritten Rom' weder für Ivan III. noch für Vasilif III. irgendwelche politische Relevanz - hierzu ausfuhrlicher 8.u., S. 42 f., Anm. 15 .

3) Diese Ideologie von Moskau dem Dritten Rom und vom Selbstherrschertum bewirkte in RuBland die unauflösliche Verbindung von rel1giösem und polit1schen Sendungsberußtsein, bewirkte das schnelle Zusammenwachsen von Selbstherrschaft und Orthodoxle, was wiederum recht bald zur Ausbildung jener spezifisch russischen, jener oft so demutigenden Porm des Startskirchentums fürte. 
legen - so entstand die groBe Menkien-Sammlung ("Velikie Cet'1 Mine1"). Auch die Chroniken werden entsprechend der neuen Staats- und Herrscherideologie umgestaltet - territoriale und nicht-moskaufreundliche Tendenzen werden eliminiert, hag1ographlsche Passagen eingefügt; die russische, ja sogar die Weltgeschichte erscheint als auf Moskau hinfuihrend dargestellt (z.B. "Voskresenskij" und "Nikonovskij svod"). Das gleiche gilt für das 'Stufenbuch' ("Stepennaja kniga carskogo rodoslovija"), worin die panegyrische Darstellung der bedeutendsten Fürstengestalten der Ruś, die durch Auslassungen und Zusätze gleichsam zu Heiligengestalten emporstilisiert werden, in der Schilderung Ivans des Schrecklichen ihren absoluten Höhe punkt findet.

Diese Kombination von Historlographie, Propagierung einer stolzen Idee und haglographischer Beschrelbung von russischen Fürsten erfordert naturgemäß einen sehr gespannten, emotionalisierenden St1l - denn es geht in diesen Werken nicht so sehr um sachliche Information als darum, den Leser in eine erhabene Stimmung zu versetzen, die ihn zur Aufnahme jener stolzen Ideologie bereitmacht.

Der Stil dieger Werke wird denn auch in folgender Welse charakterisiert: es handele sich um einen "pomphaften und preziösen, mit Bildern stark uberladenen Stiln $;^{4}$ wir hätten es zu tun mit elnem "fast zum Selbstzweck ubersteigerten schwer geschmückten Stil, der den Gehalt völlig zurückdrängt und gar absichtlich verdeckt".$^{5}$ An anderer Stelle wieder 1ot die Rede vom 'St1l panegyrischer Rhetorik', 6 vom 'erhaben-felerlichen.7 oder auch vom 'hochtrabend-schwulstigen stil', 8 für den die

4) A. Stender-Petersen: Geschichte der russischen Literatur. 1. Bd. Yúnchen 1957. S. 191.

5) D. Tschižewskif: Vergleichende Geschichte der slavischen ifteraturen. Bd. 1: Einfuhrung. Anflinge des slavischen Schrifttums bis zum Klasgieismus. Berlin 1968. (Sammlung Göschen. 1222/12228). S. 91.

6) N. K. Gudz1 : Istorija dremej russkof 11teratury. ${ }^{7} 1966$. S. 338: "atil panegeričeskogo vitijstra".

7) ebda., S. 338: "paneg1ričesk1-toržestrenny st1l'n.

8) ebda., S. 340: "vysprennyj st1l'n. 
- allerdings epigonenhaft vergröbernde - Anknupfung an den emotionalislerenden St1l Eplfanif Premudryjs ("pletenie sloves") kennselchnend so1.9 GröBe der elnem Ferk zugrundeliegenden Idee werde nun durch GröBe des Umfangs, Schönhe1t des St1ls werde durch hohle Rhetorik ersetzt. ${ }^{10}$ Den Autoren der Makar1jSchule se1 elne Vorliebe fur uppig-hochtrabende Wendungen e1gen. ${ }^{11}$ 'Alles wirkt prunkhaft und uberladen, zuglelch aber auch sehr hölsern und otarr. 12 Das Epltheton "pysinyj" scheint mir einen, wenn nicht gar den wichtigsten Stilzug der von Metropolit Makarif infilierten Viten- und Chronik-Kompilationen $z u$ benennen. W1r fanden "pyǒny j" durch 'prunkhaft und uberladen' wedergegeben (8. Anm. 12), an anderer stelle wurde "pyšnaja frazeologija" als 'glanzvolle Redekunst, die allerdings ubertrieben wirkt' (s. Anm. 11) interpretlert; w1r selbst ubersetzten hier: 'üppig-hochtrabende Wendungen'. Pür "pyšnaja ritorika" fanden wir die Wledergabe 'üppig-prunkvolle rhetorische Gestaltung' angemessen.

Dieses Epitheton "pyšnyj" hatten wir im Sinn, als wir uns - und damit kommen wir auf unsere elnle1tende Frage zurück - beim Versuch, die fragliche stilrichtung zu benennen, fü den Terminus 'Prunkst1l' entschieden, denn 'Prunk-' scheint mir am

9) Gudz11, a.a.0., S. 346. D. S. Lichačev: Razvitie russkof 11teratury $10-17$ vv. Epochi 1 sti11. L. 1973. S. 135. Ilchačev spricht von "ètiketny $J$ man'erlam" und meint damit die manieristische Anwendung eines bestimmten literarischen Klischees - nämlich elnes Kanons von Stilmitteln, Kunstgriffen, die einen literarischen Stil charakterisieren - er nennt die Ze1t: Ende 14./Anfang 15. Jh. = dee Schaffenszeit Epifanijs. - Die Ubersetzung 'etikettenhafter Manier1smus' oder 'literarische Etikette' fur "literaturnyj étiket" geht an der Sache vorbe1 - D. S. L1chatschow: Russ1sche Ifteratur und europälsche Kultur des 10. - 17. Jh.s. Aus dem Russ1schen ubersetzt von Renate Pranke. Berlin 1977. S. 116. - Vgl. hierzu: D. S. Lichaćev: Poetika drevnerusskoj i1teratury. I. 1967. Kapitel "L1teraturnyj etiket" - S. $84-108$.

10) L1chaciev, a.a.0., s. 135.

11) ebda., S. 135: "I Jubov' $k$ pyónof frazeolog11". R. Pranke Ubersetrt (L1chatschow, a.a.0., S. 116): 'ausgeprigte Le1denschaft für glanzvolie Redekunst, die allerdings ubertrieben wirkt, An anderer Stelle verwendet Lichacev (a.a.0., S. 137) auch das Ep1theton "pompezny j".

12) Ubersetzung von R. Pranke in: Lichatschow, a.a.0., S. 116; 
deutlichsten und knoppsten jene Bedeutung zu umgreifen, die "pyšny jn"13 im ubertragenen Sinne hat: 'prächt1g, prunkvoll, prangend; uppig'; ${ }^{14}$ 'uppig, vornehm, prunkvoll'; ${ }^{15}$ 'Uppig; hochmüthig, aufgeblasen; prachtvoll, prächtig, glänzend, prangend '. 16

Die vorliegende Arbeit nun ist aus dem Versuch hervorgegangen, an einem bestimmten Text systematisch zu uberprüfen, ob jene Beschrelbungen des Moskovitischen Prunkstils der MakarijSchule wie z.B. Jene von Stender-Petersen, Tschižewskij, Gudzij oder Lichačev zutreffen - bzw. wir wollten einmal untersuchen, was man sich konkret unter solchen Charakterisierungen vorzustellen hat. Bel den in den Literaturgeschichten zur Illustration vorgefuhrten Textstellen handelt es sich ja stets um sorgfältig ausgewählte Belspiele, die auBerdem in den melsten Literaturgeschichten und Abhandlungen immer wiederkehren - wie beispielsweise der endlose, hochtrabende Titel der "Stepennaja kniga". Man kann sich kaum vorstellen, wie eine solche 'pompöse' Sprache, ein solcher 'pompöser' St1l (vgl. Llchačev - 8.0., Anm. 11) uber einen längeren Text hin durchgehalten werden kann.

vgl. L1chačev, a.a.0., S. 135: "Vse očeń pyšno 1 vse oćeń sucho 1 mertvo."

13) vgl. Slovar sovremennogo russkogo literaturnogo jazyka. 17 Bde. M. - L. 1950 - 1965. Bd. 11, Kol. 1805 f. "pyśnost'" - Bedeutung 3: "velikoleple, roskos', toržestvennost', napyścennost'".

"pyšny j" - Bedeutung 3: "vellkolepny $j$, roskošny $j$, napyscenny $j$, vysokoparny $j "$.

14) H. H. Bielfeldt: Russisch-deutsches Wörterbuch.

Berlin 71970. (Veröffentlichungen des Inst1 tuts fur Slawistik. Sonderrethe Wörterbücher). S. 777 - Bedeutung 2.

15) M. Vasmer: Russisches etymologisches Wörterbuch. 3 Bde. Heidelberg 1953 - 1958. Bd. 2, S. 476.

16) I. Ja. Pavlovsk1ji Russko-německij slovaŕ. Riga - Leipzig 1911. ND Leipzig 1960. S. 1346 Bedeutung 1,2 und 3 . 
Als Grundlage fur die geplante systematische Analyse schien mir ein eigenständiger, von einer Hand geschriebener Text ${ }^{17}$ mittleren Umfangs am besten geeignet. Es bot sich die Erzählung lber die Belagerung Pleskaus durch den polnischen König Stephan Báthory (1581/82) an, die allgemein als Musterbelspiel fur den manierierten Stil der Makarij-Schule gilt. ${ }^{18}$ Um die charakteristischen Elemente dieses Stils besser herausarbelten und demonstrieren zu können, $z \circ g$ ich einen Vergleichstext heran, dessen Entstehung in einen anderen zeitabschnitt fält - in das letzte Drittel des 15. Jahrhunderts. Die Erzählung über die Eroberung Konstantinopels durch die Türken (1453), um die es sich handelt, elgnet sich besonders deshalb für elnen (kontrastiven) Verglelch, well auch sie eine Kriegserzkhlung ist und auch sie aus der Perspektive der Verteldiger heraus die Bedrohung einer christlichen Stadt durch Heerscharen des Glaubensfeindes (dort der katholische König von Polen, hier der mohammedanische sultan) schildert.

Infolge der vergleichenden Untersuchungen wurde ganz besonders deutlich, wie sehr die verschledenen Beschrelbungen des Makarij'schen Prunkat1ls auch auf die Erzkhlung uber die Belagerung Pleskaus zutreffen: elne groBe Rolle spielen bildsprachliche Elemente - allerdings werden selten neue Vorstellungen evoziert, vielmehr varilert der Autor ganz bestimmte Bllder, die den Text leltmotivertig durchziehen: der vielflüglige, giftspelende, alles verschlingende Drache, der die Inkarnation des Bösen darstellt (= Stephan Báthory); die

17) Die bekannten, z.T. auch bereits genannten Monumentalwerke scheiden aus, weil sie gerade nicht von einer Hand geschrieben sind. Einzelteile dieser Kompilationen wurden z.T. unverändert aus den Chroniken ubernommen, z.T. st1l1stisch uberarbeltet. Von Interesse für uns wären eingeschobene Reflexionen, Lobprelsungen, Anrufungen, Gebete usw. die von der Hand der Redaktoren stammen, sowie $z$. B. die 16. und 17. Stufe der "Stepennaja kniga", die zum groBen Teil in Makarijs Schreibstuben entstanden sind.

18) $\mathrm{Vgl}$. Stender-Petersen, Geschichte der russischen L1teratur, S. 199-202; Gudzil, Istorija drevnej russkoj literatury, S. $347 \mathrm{f}$; Istorlja russkoj Iiteratury. ( $10 \mathrm{Bde}$ ). M. - L. 1941-1956. Bd.2.T, S. 523 - 527 (Be1trag von A.S. Orlov, s. auch dessen im Literaturverzeichnis genannten Arbeiten); b.w.! 
helligmäbige, beinahe vergöttlichte Gestalt des Zaren an der Spltze des Heeres christlicher Märtyrer. Bezelchnend lat auch fur den Pleskauer Text seine hohe sprachliche Redundanz: Synonyme, Tautologien, Leerformeln (insbesondere in der Titulatur), Häufungsfiguren, wiederholungen usw. Auffallend sind die fast unglaublichen Wortzusammensetzungen. Häufig 1st starke Rhythmislerung der Sprache spurbar: Parallele Konstruktionen erhalten oft durch verbalen Endreim strophische Gestalt, die vielfach noch durch Anapher gestrafft wird. Typisch ist auch, daB in der Pleskauer Erzählung logische Gegensätze nur selten zur Antithese zugespitzt werden, sondern im Wortschwall oder in vager Formulierung untergehen.

Die Erzählung über die Eroberung Konstantinopels stellt in vieler Hinsicht einen krassen Gegensatz zum Pleskauer Text dar und zwar in zweierlei Hinsicht: 1. die dominierenden berichtenden Passagen zeichnen sich durch eine nüchterne, straffe Erzählwelse aus; 2. reflektierende Abschnltte, Wiedergaben von Prophezelungen, Gebete usw. sind of rhetorisch sehr kunstvoll gestaltet.

Je mehr ich mich jedoch in die Verglelchstexte vertiefte, desto klarer wurde mir, daB jene markanten stilistischen Unterschiede eher vordergründig sind und nicht den Hauptgegensatz der Texte bilden. Dieser liegt tiefer.

Beide Autoren verwenden das kirchenslavische Idiom und wollen dadurch thren Werken die Zuordnung zur höchsten stilistischen Ebene sichern. Jedoch die Art und Welse, wie sie kirchenslavische Elemente und Elemente der lebenden russischen Sprache vermengen, und vor allem, wie unterschledlich sie die verbalen Kategorien des Kirchenslavischen anwenden - darin tst der eigentliche Gegensatz zwischen den Vergleichstexten zu sehen. Wollten wir unserer zielsetzung, nämlich den Stil der Erzählung uber die Belagerung Pleskaus zu analysieren, in vollstem Umfange gerecht werden, dann durften wir die Untersuchung der verbalen Kategorien und die Uberprüfung ihrer Funktion nicht unterlas-

D. Xiževski1: History of Russian Literature. From the $11^{\text {th }}$ Century to the End of the Baroque. 's-Gravenhage 1960.

S. $253-255$. 
sen - ja, diese mußte immer stärker in den Vordergrund treten, je deutlicher sich herauskristallisierte, dab in diesem Bereich nicht nur der elgentliche stilistisch-sprachliche Gegensatz zweler individueller Texte liegt, sondern dab dieser Gegensatz ganz generell den unterschiedilchen Gebrauch der verbalen Kategorien im 15. und 16. Jahrhundert charakterisiert - dab sich also in diesen Unterschieden eine bestimmte Phase der Entwicklung der russischen Schriftsprache vom Kirchenslavischen hin zur schriftlichen Wiedergabe der lebenden musischen Sprache manifestiert.

Natürlich sind die allgemeinen Entwicklungslinien der Sprachgeschichte auch für diesen Zeitraum (15. und 16. Jahrhundert) bekannt und werden in den historischen Grammatiken nachgezogen. Insofern war nicht zu erwarten, daB diese Untersuchungen etwas grundsätzlich Neues bringen wïden. Uns ging es vielmehr darum, durch Gegenuberstellung zweier Werke gleichen Inhalts und gleicher stilistischer Intention (höchste Stilebene durch Anstreben der kirchenslavischen Sprachnorm) vorzuführen, wie unterschiedlich sich doch trotz der sprachlich so konservativen Grundhaltung beider Autoren in Ihren Werken, die in ihrer Entstehung ein Jahrhundert auseinanderliegen, die Auflösung der kirchenslavischen Normen (z.B. nivellierender Gebrauch der PräteritalTempora) und das Eindringen der lebenden Sprache (der Aspekt; das 1-Partizip als Universal-Präteritum) niederschlagen. Weder der AbriB in einer historischen Grammatik noch Spezialarbeiten zum Gebrauch der verbalen Kategorien in einem bestimmten Zeitraum können elne solche Beschreibung leisten, weil sie vorwärtswelsende Entwicklungsinien suchen, während systematische Analysen wie diese hier alle Verbalformen eines bestimmten Textcorpus berücksichtigen und daher progressive und konservative Erscheinungen in die Folgerungen einbeziehen können.

In Ke1perts Rezension der Arbeit Ottens uber den Gebrauch der finiten Verbalformen in der "Stepennaja kniga"19 lesen wir:

19) F. Otten: Die finiten Verbalformen und inr Gebrauch in der Stepennaja kniga carskogo rodoglovija. Berlin 1973. (Veroffentlichungen der Abtellung für slavische Sprachen und Literaturen des Osteuropa-Instituts (Slavisches Seminar) 
"Inwleweit man die 'Stepennaja kniga' als charakteristisch fur die buchsprachliche Norm im RuBland des 16. Jh. ansehen darf (...), werden 1m Detall erst spätere Porscher belegen können. Vorläufig fehlen dazu fast ganz die notigen Vergle1chsmbglichke1ten durch ünlich ins Einzelne gehende Ontersuchungen zum Tempusgebrauch in anderen Denknalern dieger Ze1t."

Elne solche Verglelchsmöglichkeit wollten wir bieten. Darüber hinaus haben wir immer wieder auf Ottens Ergebnisse verwiesen, Verbindungsilnien hergestellt. Auch die Sprache Purst Kurbskijs, die von Boretzky 20 untersucht worden war, haben wir in unsere Betrachtungen einbezlehen können. Wenn otten festatellt, das die "Stepennaja kniga in bemerkenswerter Weise der buchsprachlichen Norm verbunden" bleibe, 21 go stellen wir anknüpend fest, dab die Erzählung uber den Fall Konstantinopels (Ende 15. Jh.) dieser Norm, dem Kirchenslavischen, noch viel besser entspricht, wohingegen in Kurbskijs "Istorija" und in der Erzählung uber die Belagerung Pleskaus das Kirchenslavische allein St1lislerungszwecken dient, wobel von einem korrekten Gebrauch dieses Idioms längst nicht mehr die Rede sein kann: Falsche Anwendung der verbalen Kategorien in formaler und in funktionaler Hinsicht fallen vor dem Hintergrund des vielfach noch korrekten Gebrauchs im Konstantinopler Text besonders ins Auge.

Die Gliederung splegelt den Werdegang der Arbeit: den ersten Teil bilden die literarischen Analysen, im zweiten Teil steht das Verb im Mittelpunkt. Dieser Te1l ist wesentlich umfangre1cher als der erste, da ich mich nicht auf die Behandlung der finiten Verbalformen beschränkt habe wie otten. Be1 einem Antell von Partiziplen, der in manchen Bereichen der Pleskauer Erzählung fast die Hälfte aller Verbalformen ausmacht, konnte ich gar nicht umhin, das Partizip mit in die Untersuchung einzubeziehen, wollte $1 \mathrm{ch}$ dem Anspruch, elne umfagsende Stilanalyse vorzulegen, gerecht werden. Hicht so sehr im hohen Anteil partiziplaler Formen liegt aber eine stileigentumlichke1t der Erzahlung uber die Belagerung Pleskaus (quantitativ

an der FU Berlin, 42). - Rezension: H. Kelpert in: ZsfSIPh 38 (1975). S. 394 - 397. Z1tat S. 396.

20) N. Boretzky: Der Tempusgebrauch in Kurbsk1 js "Istorija velikago knjazja moskovgkagon. D188. Bonn 1964.

21) otten, a.a.0., s. 472 . 
eteht ihr insgesamt die Erzahlung Uber den Fall Konstantinopels nur wentg nach), sondern darin, welche Punktion die Partizipien im Pleskauer Text melstens haben: Sle dienen nicht der hypotaktischen Fugung, sondern sie ersetzen das Verbum finitum auch in der Parataxe. Diese Elgentümlichke1t erweist sich nicht als eine Besonderhelt der Pleskauer Erzählung, vielmehr stellt sie ein Charakteristikum des Moskovitischen Prunkst1ls dar, das man durchaus als Stileigentüllchke1t ansprechen kann. Das Partizip in der Funktion eines Verbum finftum demonstriert aber auch in sinnfälliger Weise, daB im Hinblick auf den Gebrauch verbaler Formen im 16. Jahrhundert eine allgemeine Unsicherheit herrscht - selbst bel den Autoren, die sich an den kirchenslavischen Normen orientieren: Diese Verunsicherung trifft nicht nur die spezif1sch k1rchenslavischen Kategorien (Imperfekt, Aorist, Perfekt als die wichtigsten), sondern das gesamte Verbalsystem.

Um meine Argumentationen und Schlubfolgerungen glaubhaft zu machen, habe ich stets relchliches Belegmaterial vorgelegt; in manchen Bereichen wurde auch das gesamte Material dargeboten. Ganz bewubt habe ich nicht - wie es häufig geschieht - Satzfragmente vorgestellt, die eine Uberprufung der dadurch zu stutzenden Argumentation sehr erschweren bzw. Oft uberhaupt unmöglich machen, sondern 1ch biete ganze Sinneinheiten. Ich verzichte auch weitgehend - wiederum aus Grüden der besseren Uberprufbarke1t - auf Auslassungen; melstens beschränke ich mich auf die Auslassung irrelevanter Aufzählungsglieder.

Die Belegstellen werden in der Regel mit Ubersetzung geboten. Dieses Vorgehen zwingt elnerseits zur Selbstkontrolle, andererseits erleichtert es dem Leser das Durcharbeiten der Untersuchung und gibt inm glelchzeitig die Möglichkeit, die gegebene Interpretation und die Schlubfolgerungen schärfer zu kontrollieren. Es ging mir nicht um eine wortwötliche Ubersetzung, sondern um sinngerechte Deutung.

Be1 der Ubertragung der Textbelsplele habe 1ch grbBte Sorgfalt walten lassen. Merkwirdige oder auch inkonsequente Schrelbungen sogar 1m engeren Kontext gehen auf die Textvorlagen zurúck. 
A. EINLEITUNG

\section{Ivan Groznyj und Metropolit Makarid}

\subsection{Ivan Groznyj im Urteil der Geschichte}

In der "Erzählung über die Belagerung Pleskaus durch den polnischen König Stephan Báthory"l, der das Hauptinteresse unserer Untersuchung gelten wird, ist Ivan der Schreckliche ${ }^{2}$ als helligmäBige zentrale Gestalt in die Darstellung verwoben, ohne daß er selbst, außer in der Exposition, persönlich in Pleskau erscheint. Dies Bild widerspricht so vollkommen der gewohnten Vorstellung vom schrecklichen Zaren, daB es mir nötig erscheint, der Untersuchung einige allgemeine Bemerkungen zur Regierung Ivan Groznyjs und zur geistesgeschichtlichen Situation seiner Zeit voranzustellen, zumal gerade letztere für die Umdeutung der Persönlichkelt des Zaren in groBen Bereichen der zeitgenössischen Literatur verantwortlich ist.

Ivan Groznyj hat seine Zeit wie kaum ein anderer Herrscher geprägt. Die Bewertung seiner Fersönlichke1t und insbesondere seiner Regierung durch die Geschichte war stets kontrovers. In unserer Zeit bildet die Grenze zwischen Ost und West, wie so oft, die Scheidelinie der Standpunkte. So ist im Westen

1) Die Belagerung dauerte vom 18.8. 1581 - 4.2. 1582

2) Ivan IV. der Schreckliche, russ. Ivan Groznyj $1531-84$. Nach seines Vaters, Vasilif III. Tod 1533 offizieller Herrscher. Krönung zum Zaren 1547. - Im folgenden schre1ben wir aus rein schreibtechnischen Gründen "Ivan Groznyj". Keineswegs wollen wir uns damit einer Stellungnahme zwischen russ. "groznyj" - 'der Gestrenge' und europäischem ider Schreckliche', 'Le/The Terrible' entziehen. $2 \frac{D \text {. Tschi- }}{1974}$ SKritische Information. 18) (weiterhin zitiert als: Tsch1zewskij, Geistesgeschichte), S. 99 Anm. I kritisiert die Tendenz, vom Epitheton "der Schreckliche" abzugehen und stattdessen "groznyf" übersetzen zu wollen - 'der Gestrenge, der Dräuende'. Die Kritik ist berechtigt, denn wir haben es hier ja nicht mit einem philologischen (Ubersetzungs-) Problem zu tun. Das europäische Beiwort gibt das Urteil wieder, das eich 1n wostlichen Ausland auf Grund zeitgenषssischer Berichte (Furst Kurbskif, H.v.Staden, A. Schlichtung u.a.) gebildet hatte, beror die Frage der Ubersetzung oines "Ivan Grozny1" Uberhaupt entstand. 
die pauschale Be-, besser: Verurteilung Ivans im Sinne des Schrecklichen einer differenzierteren Betrachtungsweise gewichen, die die komplexe Persönlichkeit des Zaren sowie Ansätze bzw. durchgeführte MaBnahmen mit erkennbarer rationaler Perspektive 3 mit in die Bewertung einzubeziehen versucht und nicht allein die Exzesse und die grauenhaften Verbrechen zur Richtschnur nimmt.

Die moskauorientierte Geschichtsschreibung sieht Ivan Groznyf zwar auch zunehmend kritischer, ihre Grundhaltung ist aber doch positiv. Er hat der zentralistischen Ausrichtung des Staatswesens den Weg bereitet, eine sehr 'progressive' Le1stung. Er ersetzte das reglonale Bestrebungen begünstgende Namestniksystem durch staatliche Administration, die den Pomešciki (Dienstadligen) unterstellt wurde. 4 Damit war die Gefahr gebannt, die sich aus der Möglichkeit ergab, daß der Namestnik Besitz (seine "votčina") und Amt verquicken und dadurch eine regionale Machtkonzentration schaffen konnte, die außerhalb der Kontrolle Moskaus lag. - Die berüch-

3) "1zbrannaja rada" - Kollegium von Wïrdenträgern und Bojaren, das den Jungen Zaren berlet. - "prikazy" - Kanzleien, die bestimmte Bereiche reichsweit, also zentral verwalteten, z.B. der bekannte "Posolbskij prikaz" = Außenamt, Außenministerium;"Kazanskif $p . "=$ Amt für Angelegenheiten, die Kazah betrafen. "Sudebnik 1550" - Rechtskodifizierung, Neubearbeltung und Anpassung an dIe gegenwärtigen Verhältnisse elnes "Sudebnik 1497", von Ivan III. Initilert. "Uloženie o službe" a) Neuregelung der Landvertellung zur verstärkten Ausstattung des Dienstadels mit Dienstgütern. Das hierzu benötigte Land wurde durch Einziehung von BoJarenland beschafft; b) Heeresreform.

4) "namestn1k" - ungefähr: 'Statthalter'. Gewöhnlich erhlelt ein Mitglied der Hocharistokratie dieses Amt, das den betr. Bojaren oder Puraten zum Vertreter des Zaren in oiner bestimmten Region machte. Diese Machtposition murde noch dadurch verstärkt, daB der Namestnik außer der allgeme1nen Verwaltung und Rechtsprechung aus seinem Geblet auch noch seine Pfrüde bezog, sein Einkommen also gewissermaßen selbst regeln konnte ("kormlenie"). War ein Würdentriger sum Namestnik uber sein eigenes, Vatererbe ("votdina") bestelit, so konnte hier ein Machtfaktor entsteheng mit dem man in Moskau rechnen mußte.

"pomesçik" - Angehöriger des unteren Adelo, der sich durch (Heeres-, Verwaltungs- u.a.) Dienst belm Zaren ein Anrecht auf ein Dienstgut erworben hatte. 
tigte "opričnına" 5 wird in der östlichen Geschichtsschre1bung als im Grunde demokratioche Organisation bezeichnet, da sie ihre kitglieder aus belnahe allen Schichten der Bevölkerung rekrutierte, sogar Ausländer zulieB (z.B. H. v. Staden). Blinde Unterwerfung unter den willen des Zaren war die einzige Bedingung für die Aufnahme. Sovjetische Historiker sind bemüht, das Terror-Regime Ivan Groznyjs, das er vor allem mit Hilfe der Opričnina betrieb, zu relativieren, indem sle behaupten, Ivan se1 tatsächlich überall von Verrätern umgeben gewesen, so daB viele seiner MaBnahmen ihre Berecht1gung gehabt hätten. An manchen Tatsachen kommen aber auch ole nicht vorbe1: an der Ermordung vieler Onschuldiger (z.B. Blutbad von Novgorod), am Mord an seinem Sohn usw. Das olch der zar von den Auswüchsen der Opričnina, nicht vom System distanzierte, zeige die Tatsache, daB er das Frinzip der Opričnina nach deren Auflösung im "dvor" bzw. "dvorjanstvo" weiterleben ließ. Dabel übersieht man aber geflissentlich, daß die Terrorakte der Opričnina vom Zaren z.T. angeordnet, z.T.

5) "opričnina" - bestimmte zentrale Geblete der Rus (und auch Moskaus), die der allgemeinen Verwaltung und der Oprićnina untersteilt waren. Dies Land wurde an die Opricniki vergeben. Zur Requirierung dieses Landes muRten die dort ansäss1gen Bojarenfamilien umgesledelt werden bzw. wurden ausgerot tet. Dam1t errelchte der Zar, daB die verhaBten alten Adelsgeschlechter, von denen er nur Verrat ausgehen sah, entweder für immer oder aber aus der unmittelbaren Nähe verschwanden, sodann gewann er auf diese Weise riesige Territorien, die seinem direkten Zugriff offenstanden, zudem zog er sich auf diese We1se in den Opricniki blindergebene Partelgänger heran. Die wichtigsten Quellen fün das Terrorregime der Opricnina sind: Heinrich von Staden: Auf zeichnungen über den Moskauer Staat. Nach der Hs. des preuB. Staatsarch1vs in Hannover. Hrsg. Fritz Epstein. Hamburg 1930 (Hamburgische Oniversität. Abhandlungen aus dem Gebiet der Auslandskunde 34. Re1he A. Rechts- und Staatsw1ssenschaften, 5), S. 20 - 81. - Andref Rurbsk1j: History of Ivan IV (Istorija o velikom knjaze Uoskovskom, ...). Edt. w1th a Translation and Notes by J. L. I. Feneil, Cambridge 1965. Neben vielen anderen kaum zugänglichen Quellen schelnt viel Material zu bieten A. Schlichting, der sechs Jahre in der RuBIvan Groznyjs lebte - s. Ju. R. Vipper, Ivan GroenyJ - J. R. Tipper, Iwan Grosny, 4. i 947 - dtsche Ausgabe nach der $3_{j}$ russ. Auflage) (weiterhin zitiert: Vipper, Ivan Groznyj)

$S$. $128 \mathrm{ff}$. Innerhalb der Literaturangaben finden wh 
gedeckt und z.T. geduldet wurden und daß erst vermuteter oder tatsächlicher Verrat zur Auflösung derselben führten. Außenpolitisch ist das Wirken Ivan Groznyjs durch die "Liquidierung" 6 Kazahs und Astrachahs gekennzeichnet. Stärker als der Triumph darüber wird aber die Last des fast 25 Jahre währenden Livländischen Krieges, der der Rus den Zugang zur Ostsee bringen solite, im Lande empfunden worden sein. Der Frieden von 1582 ( 10 Jahre daffenstillstand mit Folen) und von 1583 (mit Schweden) zeigt, daß der Krieg umsonst geführt worden war - Ivan war seinem Ziel nicht nähergerückt, er hatte nur unendliches Leid über die betroffene Bevölkerung Livlands gebracht und die Rus in einen desolaten Zustand geführt.?

S. 240 die russ. C'bersetzung einer latein. Vorlage angefürt: Schlichting, Albert: Aufzeichnungen. "Eîn neuer Bericht über das RuBland der Zeit von Iwan Grosny" (übersetzt aus dem latein., hrsg. und kommentiert von A. J. Nalejin) A.N. SSSR, 1934 (russ.).

6) Istorija SSSR (2 Bde.), Bd. 1, M. 1956, S. 240: "Likvidacija Kazanskogo i Astrachanskogo chanstv." (A. A. Zimin).

7) Pur die nestl. Literatur seien exemplarisch zwei deutsche Historiker genannt: G. Stökl: Russische Geschichte. Von den infängen bis zur Gegenwart. Stuttgart 1965 (weiterhin zitiert: Stökl, Russ. Geschichte), hier vor allem das Kapitel "Das Moskauer Zartum unter Ivan IV."3 ders.: RuBland von 1462 - 1689, in: Handbuch der europäischen Geschichte, Hrsg. T. Schieder, Bd. 3: Die Entstehung des neuzeitlichen iuropa, Stuttgart 1971, S. $1135-69$ (dort: das Noskauer Zartum Ivans IV.). M. Helimann: Ivan IV. der Schreckliche. Lioskau an der Schwelie der Neuzeit, Göttingen 1966 (Fersönlichkeit und Geschichte 35 ). (weiter zitiert: Helimann, Ivan IV.). tber die gesamte Literatur informiert der schon etwas ältere Bericht G. Stökl: Russ. Geschichte von der Entatehung des Kiever Reichs bis zum Ende der Nirren ( 862 1613). Ein Literaturbericht. in: JbbfGO NF 6 (1958). S. $201-54,468-88$.

Für die sovjetische Literatur seien exemplarisch genannt: Istorifa SistR (2Bde.), Bd. I, M. 1956; Kap. $9.3-9.6$ (Verf.A. A. Zimin) Iizma konec 15 - nacalo 17v., M. 1955; Kap. 2.8 - 2.10, $2.12,2.13$ (Verf. A. A. Zimin, V. D. Koroljuk) A. A. Zimin: Reformy Ivana Groznogo, M. 1960. ders.: Opricnina Ivana groznogo, $M$. 1964. ders.: Peresvetov i ego sovremenniki, M. 1958. Vipper, Ivan Groznyj, besonders zur Opričnina Kap. 5: Der Kampf gegen den Verrat, S. $122-157$ 
Trotz verschiedener Reform-Ansätze und trotz der für das Selbstbewußtsein der Russen so.wichtigen Eroberung Kazahs und Astrachahs kann man nicht umhin, die geradezu epigrammatische Formulierung G. Stökls in Bezug auf Ivan Groznyjs Regiment $z u$ bekräftigen:

"Der 'gestrenge' Zar, das war die erhabene Theorie, der 'schreckliche' Zar, und $z$ war nicht nur für die Bösen unter seinen Untertanen schrecklich, das war die "lirklichkeit. Und 'schrecklich' war am Ende das Ergebnis für alle - für den Tyrannen selbst ebenso wie für die Tyrannisierten und für den Staat, der beide vereint." 8

\subsection{Metropolit Makarij und das ideologische Konzept Ivan Groznyjs}

Wie konnte es dazu kommen, daß Zar Ivan der Beiname 'der Schreckliche' mit so vieler Berechtigung zugelegt wurde? Hie waren solche Auswüchse überhaupt möglich? Gewiß lag bei Ivan eine pathologische Veranlagung vor, die als Triebfeder für all die bekannten Verbrechen und Exzesse zu gelten hat. Beinahe ebenso wichtig ist aber, daß Ivan keine moralische Barriere, keine psychologische Sperre, keine geistige Kontrolle über sich selbst kannte, die ihn an seinen Untaten hätten hindern können. Das gelegentliche nachträgliche Bereuen, von dem berichtet wird, gehört sicher zu einem anderen Problemkreis.

Ivan war noch nicht drei Jahre alt, als sein Vater, Vasilij III. 1533 starb. Nach dem Tod der Mutter, Elena ${ }^{9}, 1538$ wurde der junge Herrscher zum Spielball intrigierender Bojaren-

8) Stökl, Russ. Geschichte, S. $247 \cdot$

9) Hellmann, Ivan IV., S. 23: Entgegen der oft geäußerten Meinung, mit der Regentschaft Elenas habe das Chaos in der Rus begonnen, meint Hellmann, daB diese durchaus in der Lage gewesen sei, das Abgleiten des Landes ins Chaos einigermaßen zu verhindern. Daruber hinaus habe sle auch die außenpolitischen Ansprüche der Rus gegen Litauen und Tataren durchsetzen können. 
cliquen (Sujskij, Glinskij, Bel'skij, Obolenskij u.a.). Sie versuchten, durch Schockmethoden den Knaben unter Druck zu setzen, durch Erzeugen von Angstzuständen in Ivan diesen jeweils für sich - und gegen die konkurrierende Partei - einzunehmen. ${ }^{10}$ Es ist ganz klar, daB die schrecklichen Erlebnisse dieser Jahre eine weitere Deformation der Psyche Ivans bewirkt haben.

In dieser Situation, die sich bereits fünf Jahre hingezogen hatte, muß die energische Zuwendung des aus Novgorod berufenen Netropoliten Nakarij $(1542$ - 63) ein tief empfundenes Glück für den junơen Herrscher gewesen sein, aus dem eine Dankbarkeit und Zuneigung erwuchs, die bis zum Tode des Metropoliten andauerte. ${ }^{11}$ Dieser verteidigte Ivan gegen die Bojarencliquen und konnte ihn allmählich aus den Intrigen herauslösen; er stützte Ivan in allem durch seine Autorität - weitreichender noch war aber Makarijs Erziehungswerk an Ivan: das ubersteigerte Selbstbemubtoein, das er in inm aufbaute. Makarij fuhrte Ivan in seine Gedankenwelt ein, mehr noch: er formte den jungen Herrscher nach dem Bild, das er sich vom Herrscher der Rus gebildet hatte. Die dankbare Zuwendung Ivans und dessen natürliche Veranlagungen erleichterten dem Metropoliten gewiß seine Aufgabe.

10) Uber die Methoden der intrigierenden Parteien - $s$. Hellmann, Ivan IV., S. 26; Vipper, Ivan Groznyj, S. 55; Karl Stählin: Geschichte Rusiands. Von den Anfängen bis zur Gegenwart (4 Bde.), Bd. I, Stuttgart 1923, ND Graz 1961 (weiter zitiert als: Stählin, Geschichte RuBlands), S. 255 - 56.

11) Das Verhältnis eines geistigen Schülers, das Ivan zum Metropoliten gehabt haben mochte, äußert sich nicht so sehr in den pomphaft-unterwürfigen Sendschreiben, die wir in den Chroniken finden (deren Authentizität bestä-

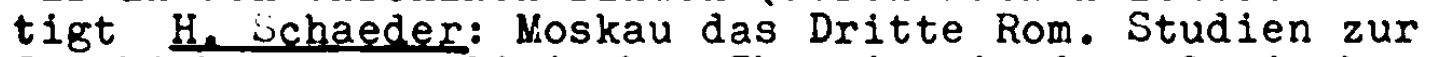
Geschichte der pqlitischen Theorien in der slawischen Welt. Darmstadt 1957 (weiter zitiert als : Schaeder, Moskau das Dritte Rom), S. $34 \mathrm{Anm}$. 2). - Vielmehr ist aus der Tatsache, daB nach des Metropoliten Tod die eigentliche 'schreckliche' Phase begann, zu schließen, daB der Netropolit in gewissem $\mathrm{NaBe}$ noch als moralisches Regulativ bei Ivan fungiert hat, welches die schlimmsten Exzesse noch verhinderte. Anzeichen für das Kommende sind aber schon zu Makarijs Lebzeiten erkennbar. 
Metropolit Makarif war in besonderem MaBe josifljanischem Gedankengut verhaftet, und in diesem Sinne erzog er auch Ivan. Der Begriff "josifljanisch" (< "1081fljanin") leitet sich ab von Josif von Volokolamsk (1440 - 1515), der sich unter Ivan III. um 1500 als Exponent machtkirchlicher Bestrebungen gegen N11 Sorskij (1433 - 1509) durchgesetzt hatte. Letzterer forderte Armut der Kirche und der Klöster (kein Landbesitz!), St1lle und Verinnerlichung des Klosterlebens, sinngemäBe (also nicht äuBerliche) Erfullung der Regeln und Gebote. Uber das Innere Gebet soll der Mensch zur geistigen Vervollkommnung gelangen. Hesychast1sche Einflusse kuBern sich in N118 Anle1tungen zu bestimmten Gebetsubungen und -haltungen. Josif von Volokolamsk trat solchen Vorstellungen entschleden entgegen. Er forderte die gewissenhafte, gleichsam rituelle Befolgung Jener Vorschriften, die die äußere Lebensfuhrung regeln. Die Kirche solle relch sein, die Klöster mübten Landbesitz haben - we sonst könnte sie ihren karitativen Verpflichtungen nachkommen, wie sonst wirden Glieder angesehener Pamilien einen Anreiz finden, in ein Kloster einzutreten? Diese allein seien doch befäh1gt, die höchsten k1rchlichen wurden zu bekleiden - umgekehrt gewinne die Kirche doch erst durch Glieder vornehnoter Familien Ansehen und werde daher vom Herrscher respektiert. 12 Josif und - inm folgend - die offizielle Xirche sahen den weltlichen Herrscher, ahnlich dem byzantinischen Vorbild, uber die (orthodoxe) Christenhe1t gestellt. Er allein könne den Glauben wirksam nach innen (Häretiker) und nach außen (Heiden) verte1digen. Der Herracher sel von Gott eingesetzt ("bogovenčaemy j") und habe daher alle Macht uber die Menschen. Inm zu widerhandeln komme also einem Sakrileg gleich und mulsse entsprechende Bestrafung nach olch ziehen; das gelte auch fur die Xirche und thre Wurdenträger. 13

12) Vgl. Tschižewakif, Gelotesgeschichte, S. 82 - 93.

13) Wie sehr sich Ivan IV. diese Maximen zueigen gemacht hat, zelgt die Absetzung des Metropoliten German 1566, weil er die Abschaffung der Opricnina gefordert hatte, und die Absetzung, Verbannung und 1569 die Frmordung des Metropoliten Pilipp, weil dieser den Zaren bffentlich zur Umkehr aufgerufen hatte. 
Dieses Dogma vom Gottesgnadentum des Herrschers, das inn über alle Nelt stellte und das die Verantwortung für alles Tun allein seinem Gewlssen überlieB, war für einen Menschen mit der Persönlichkeitsstruktur Ivans - mit seiner Labilität, seinem Ehrgeiz, seinem Mißtrauen usw. - die Lizenz, seinen Neigungen und Trieben freien Lauf $z$ u lassen, was ja nach dem Tod des Metropoliten (s.o. Anm. 1l) geschah. Die maBlose Selbstüberschätzung und die absolute Skrupellosigkeit (vor einer Tat), auf die man letztlich die 'schreckliche' Periode Ivans zurückführen könnte, sind also gewiß in ganz besonderem liaße den liaximen anzulasten, nach denen der Metropolit den jungen Herrscher erzogen und geformt hat.

Diese Vorstellungen - Gottesgnadentum des Herrscheramts, dienende Funktion sogar der Kirche - floß zusammen mit dem Gedankengut, das wir unter die Idee von lioskau als dem Dritten Ror subsummieren: Translatio imperii, Beerbung K-pele. Das Erste Rom hatte sich rom rechten Glauben entfernt; das Zweite Ron, K-pel, hatte sich 1438/39 mit den katholischen Häretikern von Rom verbunden und war deshalb von Gott mit der Eroberung durch die Turken bestraft worden. Die Rú war nun das einzige frele rechtgläubige Land - das Hellige RuBland; Moskau wurde zum 'Dritten Rom'. So trat der Herracher der Ruś auch in die Nachfolge des Basileus und war somit dem westlichen Kaiser ranggleich, im Grunde aber diesem weit überlegen, da der Kaiser Häretiker war. Legitimistische Legenden ${ }^{14}$ kur-

14) Rjurik stammt von Frus ab, der im Fruzzenlande geherrscht hat - Prus aber war ein Bruder des Kaisers Augustus, "Skazanie o knjazěch vladimirskich".

Kaiser Konstantin Monomachos hat die Regalien an Vladimir Monomach gesandt, als Anerkennung seiner "iirde: die kaiserliche Krone, ein Pelzkragen ("barmy"), ein Karneol- (Sardonyx-) Kästchen, ein VieihrauchfaB und sogar ein Kreuz, in das ein Stückchen Holz vom Kreuz Christi eingearbeltet sei. - Beide Legenden finden sich erstmals in einem Brief des ehemaligen Metropoliten SpiridonSarva, abgefaßt zwischen $1513-23$.

Den babylonischen Legenden nach habe Kaiser Leon befohlen, dab man ihm die Regalien aus Babylon hole, das seit Nebukadnezars Tod verödet und von Schlangen beherrscht war. Ein Russe habe sich unter den Beauftragten befunden. Schaeder, Moskau das Dritte Rom, S. 93 - 117 . 
sierten, wonach die Herrscher der Rus von Kaiser Augustus abstammen sollen, daß die Krönungsregalien aus $K$-pel stammten, bel deren gefahrvollem'Raub aus dem schlangenbewehrten BabyIon auch ein Russe beteiligt gewesen sei. Damit hat die Rus also alle bekannten Weltreiche beerbt.

Nach diesen Grundsätzen hat Metropolit Makarij Ivan erzogen, und daR seine Belehrungen auf den denkbar fruchtbarsten Boden fielen, lehrte die Zukunft.Hinter der prunkvollen Krönung Ivans zum Zaren 1547 ist natürlich die Regie Makarijs zu sehen, der damit sein Erziehungswerk effektvoll und seiner hochfahrenden Belehrungen gemäß abschloß - erstmals fanden hiermit die in der offiziellen Kirche schon lange propagierten Gedanken der Josifljane offiziellen Ausdruck, wurden von welticher Seite, also vom Herrscher, öffentlich bestätigt. 15

15) Daß dieldee von Moskau als Drittem Rom ausschließlich in kirchlichen Kreisen zu Haus war und nicht zu einer Staatsideologie geworden war, bovor Ivan IV. zum Zaren gekrönt wurde, deutete Hellmann, Ivan IV., S. 13 bereits 1966 an. Diese These, die allen bisherigen, wohlvertrauten Gedankengängen widersprach, führte er en détail aus in seinem Aufsatz: Moskau und Byzanz. In: JbbfGo KF 17 (1969). S. $321-44$. Bisher war gängige Meinung, daß die Idee von Moskau als Drittem Rom, die Idee der Beerbung K-pels als offizielle Staatsideologie der moskovitischen Rus zu gelten habe, seit/Ivan III. 1472 die Palaiologen-Erbin Zoè geheiratet hatte. Er habe den byzantinischen Doppeladler als Staatssymbol übernommen, byzantinisches Zeremoniell in Moskau eingeführt und sich schlierlich auch titularmäBig bewußt in die Nachfolge des Basileus gestellt, indem er den Titel "carb" annahm, zwar noch nicht konsequent, aber Schwächeren gegenüber.

Hellmann widerlegt dieses eingängige und wohlvertraute Gedankengebäude vollkommen. Nur elnige Funkte können genannt werden: Zoë war z.Z. ihrer Heirat gar nicht Erbin des byzantinischen Throns - sie besaB noch zwei Brüder, die z.T. erfolgreich versuchten, ihre Erbanspruiche auf den Basileus-Titel an europäische Potentaten zu verkaufen, sogar in Moskau soll einer der beiden sich darum bemüht haben. - An reichem faktischen und Photomaterial kann Hellmann nachweisen, daB der Doppeladler in Byzanz weder auf Münzen noch als Herrschaftszeichen erscheint. Uberhaupt taucht er in Byzanz erst vom 14. Jh. gelegentlich auf, vorwiegend in der Kunst. Im Westen dagegen ist der Adlér lange als Wappentier bekannt. Friedrich II. fürte den Doppeladler auf Münzen, und überhaupt scheint er $z . Z$. der Staufer kaiserliches Wappen gewesen zu sein. - 


\subsection{Die offizielle Literatur}

Die bald nach der Krönung Ivans zum Zaren eingele1teten liaßnahmen verraten ebenfalls die Regie Nakarijs. Man wird hier aber von "Beeinflussung" des Zaren durch den Metropoliten gar nicht mehr sprechen können: Er hatte den jungen Zaren so gut auf seine Mission in der ijelt vorbereitet, daß er vermutlich nur einen Gedanken zu äußern brauchte und der begeisterten Aufnahme durch Ivan gewißsein konnte. Erst recht aber bei solchen monumentalen Plänen, die der Metropolit hatte: Um die Heiligkeit und würde der Heiligen Rus zu demonstrieren, sollten die Viten aller russischen Heiligen zusammengefabt werden. Kanonisierungssynoden ( 1547 und 1549) sonderten aus, was in die neue Acta Sanctorum aus theologischen oder politischen Grüden nicht hineinpaßte. Das trgebnis war eine 27000 Folioblätter umfassende Vitensammlung, die in drei Exemplaren angefertigt wurde: die "veli-

Byzantinisches Protokoll und Krönungszeremoniell kann Zö̈ nicht kennen, denn bei der Flucht aus $K$-pel war sie noch ein Kind; und im itelienischen Exil lebte sie in zu birmlichen Verhiltnissen, als dab sie byzantinischen Pomp hatte kennenlernen können. - Dies sind nur einige der von Hellmann - reich belegt - vorgetragenen Punkte, die dazu zwingen, vertraute Gedankengange zu revidieren. - Ansätze zu dieser Revision bereits bei J.L. I. Fennell: Ivan the Great of Moscow. Lond on - New York 1961; dab der russische Doppeladler nicht von Byzanz, sondern vom deutsch-römischen Kaiser ubernommen ist, legte dar G. Alef: The Adaption ot the Muscovite Two-headed Eagle: A Discordant View. In: Speculum 41 (1966). S. 1 - 21. In einem Aufsatz greift diese Gedanken auf $\mathrm{E}$. Hösch: Byzanz und die Byzanzidee in der russ1schen Geschichte. In: Saeculum 20 (1969). S. $6-17$. Sich schon auf Hellmann stutzend C. Goehrke: Die Moskauer Perlode. In: RuBland. Frankfurt 1972. (Flscher Feltgeschichte. 31). Sehr wichtig G. Stökl: Testament und Siegel Ivans IV. Opladen 1972. (Abhdlgen der Rhein.-Westfäl. Akademie der Fissenschaften. 48). - Moch heute wichtig wegen des reichen Quellenmaterials H. Schaeder: Moskau das Dritte Rom. Den geietesgeschichtlichen Aspekt beleuchtend W. Lettenbauer: Moskau das Dritte Rom. Zur Geschichte einer politischen Theorie. Munchen 1966.

P. Otten: Die finten Verbalformen und $1 \mathrm{hr}$ Gebrauch in der Stepennaja kniga carskogo rodoslovija. Berlin 1973. (Veroffentlichungen der Abtig. für slav. Sprachen und literaturen des 0steuropa-Instituts (Slavisches Seminar) an der PU Berlin. 42). (weiter zitiert: Otten, Pin. Verbalformen) gibt die alte Auffassung (S. 28) unreflektiert wieder. 
kie Cetbi-Hinei".

Die sogenannte Fundertkapitelsynode schuf die Grundlage für den "Stoglav" - 'das Hundert-Kapitel-Buch': es umschreibt den geistlichen Freiheitsraum des lesekundigen Laien. Außerdem sollte dieses Werk offensichtlich den Laien mit einem gewissen geistlichen Grundwissen ausstatten, damit er nicht so leicht für Häresien und Aberglauben anfällig wurde. ${ }^{16}$

Der "Domostroj" regelte das häusliche Leben. iir finden darin altruss. Verhaltensnormen fixiert, Lebensgewohnheiten, vor allem tritt die Form der Religiosität deutlich zutage, die Iosif von Volokolamsk propagiert hatte: Formalismus alles, selbst das Gebet, erstarrt zum Ritus.

Im "Azbukovnik" schließlich ist das Wissen zusammengefaßt, das dem lesekundigen kussen zugemutet wurde.

Die genannten ierke, die wir einmal vorsichtig als didaktische bezeichnen wollen, reflektieren in ihren Anweisungen indirekt die Ideologie. Die Vorstellung vom Zaren, der direkt von Gott erwählt und gekrönt ist, ging in Verbindung mit der Idee 'Moskau das Dritte Rom' als ideologisches Grundmuster in eine andere Gattung ein, die jetzt zu neuer Blüte gelangte: die Historiographie. Der ketropolit l.akarij initiierte eine beispiellose kompilationstätigkeit: Die Chroniken der Rus wirden umgeschrieben, der neuen ideolokischen Ausrichtung angepaßt. 1 Es entstehen der Voskresen-

16) A. Stender-Petersen: Geschichte der russischen Literatur. Erster Band. Iunchen 1957. (weiter sitiert: StenderPetersen, Gesch1chte).

17) Khnl1che Erscheinungen gab es schon friher - so kennt beispielsweise eine Trerer Chronik diesen Anspruch: 'Trer - das Dritte Rom'. Im Gegensats zur sjotematischen 1deologischen Neuorientierung der gesamten Chronikschre1bung unter Iran Grozny handelte es sich jedoch in Trer um ein vereinzeltes Auftreten dieser Idee. 
skij-, der Nikon-, der $L^{\prime}$ vovskij-, vor allem der alle an Umfang und an Fracht übertreffende Illustrierte Codex ("Licevoj letopisnyj svod") 2.a. Sie künden von Moskaus und des Zaren Größe und Herrlichkeit. Die "Stepennaja kniga", kurz vor dem Tod des Metropoliten $1563^{18}$ abgeschlossen, zeigt einen noch stärkeren Hang zur haglographischen Schilderung als die genannten Codices. Bel 0l'ga beginnend, gruppiert der Redaktor die wichtigsten Ereignisse der russisohen Geschichte um weitere 16 Grobfursten, wobei er Chronikberichte panegyrisch umgestaltet. Die Darstellung 1st auf Ivan Gr. als letzte Stufe, als triumphales Endzlel der russischen Geschichte auggerichtet. Wie der Höhepunkt in einer vom Netropoliten eingerichteten Inszenierung wirkt die Eroberung Kazanis durch Ivan Groznyj, die gleichsam konsequent der Zarenkrönung folgte. Damit konnten die Chroniken einen Zielpunkt der Geschichte darstellen, der von größter “irksamkeit gewesen sein muß: Es war dem Zaren gelungen, die heidnischen Unterdrücker, die die Rus so lange geknechtet hatten, zu besiegen und der Taufe zuzufuhren. Die iroberung Astrachahs wirkt daneben nur noch wie ein Epilog.

\subsection{Der moskovitische Nonumental-Stil}

Es war festgestellt worden, daßs das Auffallendste an jenen Nerken, die die Staatsideologie der Ivan-Groznyj-Zeit direkt propagieren, ihr hagiographischer Grundzug ist. Aber auch über panegyrische Aussagen hinaus setzt sich die schwülstige Ausdrucksweise durch, und es ist diese, die Kurbskij an Ivan Groznyjs Briefen verspottet. ${ }^{19}$ Dieser hagiographische Grundzug war bereits für die durch den

18) Zur Datierung: Otten, Fin, Verbalformen, S. 43-45: Makar1j starb am 31.'12. 1563, die "Step.kniga" vermerkt seinen Tod nicht.

19) Sendschreiben A. Kurbskij an Ivan Gr. 1564 in: N.K. Gud21.1: Chrestomatija po drevnej russkoj literature IItija). S. 296. 
2. Südslavischen EinfluB so veränderte Vitenliteratur charakteristisch gewesen, (Epifanij Premudryj, Pachomij Serb) und er hatte sich seitdem in dieser Gattung als lierkmal erhalten. Die durch den Metropolit Makarij initiierte Sammeltätigkeit wurde eingeleitet mit den "Velikie Cetbi-Minei", deren Stil den anderen Kompendien als Vorbild gedient haben wird :

"Dieses Monumentalwerk brachte dem spätbyzantinischen Stil die offizielle Anerkennung und war Ausdruck für dessen endlichen Sieg. Hier zogen die zahlreichen Heiligen der orthodoxen Kirche am Leser vorüber, in festliche Gewänder gekleidet, geschildert und gepriesen mit wohlgeschliffenen, glatten, wohlverflochtenen lorten, zu den Wolken erhoben durch rhetorische Fragen und Antworten, geschmückt mit langen ausgeklügelten Attributlisten und durch wohlziselierte Vergleiche und wohlerdachte lietaphern vergöttlicht. Der Stil war hier zu seiner höchsten quantitativen Entfaltung gelangt. Die Ideologle schritt auf majestätischen Kothurnen einher. Die Vorstellung vom gotterwühlten, glaubensreinen, begnadeten heiligen Rußland war geschaffen." 20

Die stilistische Verwandtschaft, die $z$ wischen den Lesemenäen und dem Stufenbuch besteht, dürfte wokl darin begründet sein, daß so mancher Autor, an den Lesemenäen geübt, vielleicht auch an der Step. kniga mitgewirkt haben wird. Bei Stender-Petersen, der, wie uns scheint, am ausführlichsten auf diese Epoche der russischen Literatur eingeht, lesen wir über den Stil speziell der Step. kniga folgendes:

20) Stender-Petersen, Geschichte, S. 186 f. Hervorhebung bei Stender-Petersen.

Für die didaktischen Nerke - "Domostroj", "Stoglav", "Azbukovnik" - war dieser Stil nicht so geeignet, vielmehr sind diese Worke uber weite strecken in recht einfacher Sprache geschrleben. 
"Die Geschichte des russischen Reiches war also geschaut als die Geschichte der Herrlichkeit Gottes, als Triumphzug des rechten Glaubens durch alle Zeiten, mit dem Strahlenglanz göttlichen Ruhms umgeben. Zugleich aber wurde das Stufenbuch zu einem neuen offiziellen Sieg des pomphaften und preziösen, mit Bildern stark überladenen Stils. Er ließ lange, zusammengesetzte Nörter in kunstvoll gebauten Sätzen und Ferioden einherziehen, jenen feierlichen Prozessionen vergleichbar, in denen sich der Zar selbst in seiner fernen Majestät zuweilen dem Volke zeigte.... Nur in gemessenem Rhythmus, nur in würdig steigendem und fallendem Vortrag konnte dieser Stil ganz zu seinem Recht kommen."2l

Ob diese Charakterisierung so richtig ist, wollen wir vorerst dahingestellt sein lassen. ${ }^{22}$ Zumindest für bestimmte Bereiche - und dies sind die charakteristischen, nämlich die hagiographischen - trifft dies $2 u$.

Alle Codices enthalten Briefe in extenso, wobei die panegyrisch gefärbten Sendschreiben an den Zaren riesigen Umfang haben, hingegen die ebenso manlerierten Schreiben des Zaren aber reckt kurz sind. 23

21) Stender-Petersen, Geschichte, S. 191.

22) F. Otten ist leider nicht über die oben zitierte Charakterisierung durch Stender-Petersen hinausgegangen, sondern hat lediglich, wie jener, zur Demonstration den in der Tat sehr bombastischen Titel der "Stepennaja kniga" in Original und tbersetzung vorgestellt. - Otten, Fin. Verbalformen, S. 33; Stender-Petersen, Geschichte,S.190.

23) Vorwiegend sind es Briefwechsel mit geistlichen Nürdenträgern, in erster Linie mit lietropolit Nakarij selbst, die wir in den Chroniken vorfinden, z.B. Nikon-Codex S. 192 - 97: fünf Druckseiten (PSRL 13); L' vov-Codex S. 507 - 511: fünf Druckseiten; Step.kniga S. 666 - 71: sechs Druckseiten (Briefwechsel 2 wischen Ivan $\mathrm{Gr}$. und dem $\mathrm{Pa}-$ triarchen von Alexandria). - Vgl. hierzu Schaeder, Moskau das Dritte Rom, S. 34 Anm. 2. Dort betont sie, daB es ausdrückliche Weisungen gab, bestimmte Schreiben in den Chroniken festzubalten. So zitiert sie eine Anweisung aus der $2 t$. Ivan Gr.s: "jaścik ... a v nem spiski cto pisati v lètopisec lèta novye pribrany ot 1.7068 do 1.7074 i do 1.76$\}=1560-66$ bzw. 68)." 


\section{Nerdegang und Zielsetzung dieser Arbeit}

\subsection{Motivation}

Die Charakterisierung dieses "fast zum Selbstzweck übersteigerten schwer geschmückten Stil(s), der den Gehalt völlig zurückdrängt und gar absichtlich verdeckt ..."24 ist bei Stender-Petersen (s.o.) ausführlich dargestellt worden und berüht viele Aspekte desselben.

Aber was sagen uns solche Beschreibungen, die in den besten Fällen noch mit einigen - selbstverständlich den markantesten - Beispielen belegt werden? Es sind letztlich Impressionen, die mit Hilfe entsprechender Epitheta die notwendige Klassifizierung vollziehen ("bombastisch", "ornamental", "dekorativ", "prunkend", "pompös", "monumental" usw.).

Bei der Suche nach Analysen jenes Stils, die über die genannten Definitionen hinausgehen, war $z u$ beobachten, daß dieses Feld von der Forschung sorgsam gemieden wird. Es scheint das Byzantinische 25 zein, dieses in vieler Beziehung Liaßlose, das vor einer näheren Beschäftigung mit dieser spröden, unzugänglichen Materie zurückschrecken läBt.

24) D. Tschižewskijj: Vergleichende Geschichte der slavischen Literaturen I. Einführung. Anfänge des slavischen Schrifttums bis zum Klassizismus. Berlin 1968. (Sammlung Göschen Bd. 1222/1222a) S. 91. (weiterhin zitiert als: Tschižewskij, Vergl. Geschichte.)

25) K. Firumbacker: Geschichte der byzantinischen Litteratur. Von Justinian bis zum Ende des oströmiscren Reiches (527 - 1453). München 1891. (Handbuch der klassischen Altertums-Nissenschaft, 9.Bd., 1. Abtlg.). In seinem Vorwort beklagt er, es seien in der Philologie die "Feinschmecker die Regel, die es unter ihrer würde finden, ihre kostbare Kraft anderem als dem majestätischen Königsadler und der duftigen Rose zu weihen ..." (S. V), die sich nicht "mit widerwärtigen oder hässlichen Gegenständen" (ebda.) beschäftigen wollen. Nun liegen in der Slavistik die Dinge etwas anders als in der klassischen Philologie, namentlich, was die "Königsadler", die hier selten sind (Igorlied), anbetrifft. Aber die Einstufung als "häBlich" oder "dekadent" liegt ganz sicher dem allgemeinen Desinteresse an diesem Monumental-Stil zugrunde. 
Wir wollten versuchen, diese sehr ausdrucksvolle Beschreibung - wie die von Stender-Petersen o. zitierte - durch Untersuchungen am konkreten Material zu verifizieren oder zu korrigieren. Wir wollten wissen: Was verbirgt sich hinter solchen Definitionen? Ist es möglich, diesen Stil fundierter, faktischer zu erklären, als es selbst sehr blumige Beschreibungen in Verbindung mit ausgewählten extremen Beispielen tun?

Um eine Antwort auf diese Fragen zu finden, wählten wir eine Erzählung mittleren Umfangs, die allgemein als ein Musterbeispiel dieses Stils hingestellt wird. Wir hofften, an einem weniger umfangreichen Text durch umfassende Untersuchungen Kriterien $z u$ einer exakten Beschreibung dieses Stils gewinnen zu können, die dann später an breiterem Niaterial (z.B. "Stepennaja kniga") überprüft werden könnten. Die "Erzählung über die Belagerung Pleskaus durch Stephan Báthory" erwies sich als den Beschreibungen, wie wir sie in den Literaturgeschichten vorfinden, entsprechend. 26

26) Stender-Fetersen (Geschichte, S. 199) leitet seinen Artikel über diese Erzählung folgendermaßen ein:

"Pskov war jetzt eine moskovitische Stadt geworden wie alle anderen. Der sprachliche Stil hatte sich verändert. Man befand sich in der Blütezeit des MAKARIOS-Stils, in der gezierten Sprache des Stufenbuchs. ... Jetzt aber waren ganze Schwärme künstlich zusammengesetzter, zuweilen ganz neu erfundener, feiner und gezierter Nörter in die Sprache gekommen und hatten die alten, allzu gegenständlichen und rohen Wörter verdrängt. Die Zeit suchte nach einer ausdrucksvollen Frosa, und man kann behaupten, daB hinter diesem Suchen eine Tendenz zur Poetisierung der "irkl1chkeit lag, obgleich die liittel, die gewählt wurden, nicht zum gewünschten Ziel führten." Tschižewskij (D. Xiževskij: History of Russian Literature. From the Eleventh Century to the End of the $\mathrm{Ba}-$ roque. S'Gravenhage 1960. (Slavistic Printings and Reprintings. 12). ) konstatiert nach einer kurzen Besprechung der Erzählung: S. 253 - 255; hier S. 255:

"The spoken language, so typical of the Fskovian Chronicles, is evident on rare occasions only; on the whole, the Muscovite style of splendour predominates."

Für die sovjetische Literaturgeschichte ist immer noch maßgebend ein Aufsatz A. S. Orlovs von 1908, in dem er 
Mit dem Anwachsen der Materialsammlung wurde aber immer klarer, daB eine solche Stilanalyse in ihrer Aussagekraft beschränkt bliebe, selbst wenn sie später beim Vergleich mit anderen typischen, hierher gehörigen Werken auf eine breitere Basis gestellt werden könnte. Es schien uns notwendig, die besagte Erzählung einem anderen Text gegenüberzustellen, der die Merkmale des moskovitischen Prunkstils nicht aufweist. Einen solchen Text fanden wir in der thematisch sehr verwandten "Erzählung über die Belagerung und Einnahme Konstantinopels durch die Türken".

einige Kriegserzählungen untersucht. (A. S. Orlov: O někotorych osobennostjach stilja velikorusskoj istoričskoj belletristiki 16 - $17 \mathrm{v}$. In: Izvéstija otdelenija russkago jazyka i slovesnosti imperatorskoj Akademii Nauk. 13 (1908). kn. 4. S. 344 - 79, insbesondere S. 362 - 68). Seine aligemeine Charakteristik der Erzählung lautet:

"Esli Istorija o vzjatii Kazani nosit na sebĕ jarkija certy volnskoj poèil 1 tol'ko meźdu pročim podcinjalas vlijaniju agiografii, esli Istorija lis méstami ukrasena kniznym ritorstrom 16 v., to Povest' ob osade Pskova voobsce plod vysokoparnych cerkovnych tvorenij v stile Makarevskoj epochi. V nej zvucit 1 propovéd'i pochval'noe slovo i blagočstivoe poslanie." (ebda. S. 363).

Orlov führt verschiedene bildsprachliche Wendungen vor, die besonders charakteristisch für die Erzählung sind, und geht auf andere typische Stilzüge ein: besondere Wortzusammensetzungen und paronomatische wendungen. Sodann befaBt er sich mit möglichen Quellen bzw. Vorlagen, die der Autor benutzt haben könnte.

Von diesem Aufsatz unterscheidet sich Orlovs Beitrag in der groben Literatur-Geschichte der Akademie nur dadurch, daB er stärker - wie bel Orlov uiblich - auf den Inhalt eingeht und die für die Zeit (1946) charakteristischen patriotischen Einlassungen enthält: ( $A, S$, Orlov: Povest o prichozenil Stefana Batorija na Pskov. In: Istorija russkoj literatury. Bd. 2.1 (L1teratura 1220 - 1580 88.) AN SSSR M.-I. 1946. S. $523^{-27 .)}$

Wenn die Erzählung über die Belagerung Pleskaus in der Sovjet-Union erwähnt wird, dann wird sio mit Orlovs Worten und Beispielen chararterisiert, entweder mit direkter Bezugnahme oder in allgomolner inlohnung an $1 \mathrm{hn}$.

So ${ }^{2} \mathrm{~B}$. $\mathrm{N}, \mathrm{K}$, Gudzif: Istorija drevnej russkoj literatury.

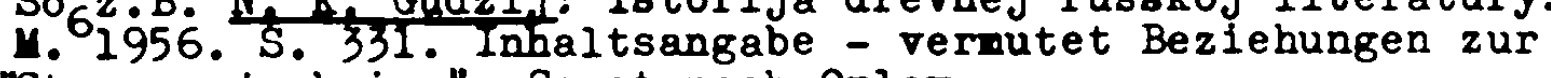
"Stepennaja kniga" . Sonst nach Orlov.

Istorifa russkoj iiteratury $\nabla$ 3-ch tomach. Bd.1: Literatura 10-18 vv. AN SSSR 1958. S. 253 f. Nach Orlov. 
Diese Erzählung schildert die der Eroberung Konstantinopels 1453 vorausgehenden Wochen und die Einnahme der Stadt selbst. Sie ist, wie ein neuerer Fund beweist, im letzten Viertel des 15. Jh.s entstanden, also 100 Jahre älter als die Pleskauer Erzählung. 27 Sie ist als Kriegserzählung bekannt, die auBer tradierten Bildern auch viele sehr realistische Szenenbeschreibungen gibt. 28

Diese Erzählung bietet viele Möglichkeiten zu hagiographischer Apostrophe, Periphrase oder zu preisendem Exkurs, doch bleiben alle diese Möglichkeiten bis auf ganz wenige Wendungen in Monolog und Gebet vollkommen ungenutzt.

Diese Eigenschaft empfiehlt die "Erzählung über die Eroberung K-pels durch die Türken" für eine vergleichende Untersuchung mit der "Erzählung über die Belagerung Pleskaus durch Stephan Bethory".

Der kontrastive Vergleich beider Texte lieB so richtig deutlich werden, wie feinsinnig, treffend und umfassend die oben angefuhrten Beobachtungen Stender-Petersens - aber nur in Bezug auf die hagiographischen Passagen! - sind. In unserem Kapitel D. Annerkungen zum St1l unserer Terte geben die Abschnitte 2. Informationsgehalt, 3. Figurae per ordinem und 5. Wortwahl einen ungeflahren Begriff von dem, was StenderPetersen meinte. Das Material, das die Pleskauer Erä̈hlung bietet, gewinnt seine Anschaulichke1t erst vor dem entspre-

27) Ausführlich dazu s.u.:B Textgeschichte - Konzeption Komposition. 1.1 Textgeschichte der K-pler Erzählung.

28) Stender-Petersen, Geschichte, S. 194 :

"Ganz besonders zeichnete sich die Darstellung durch zahllose farbenreiche Kampfschilderungen aus, ... Der Verfasser mühte sich auch, sich nicht mit dem schematischen Grundakkord des traditionelien Martialstils: Und die Schlacht war blutig und fürchterlich zu begnügen, sondern wirklichkeitserfulite und inhaltsreiche szenen zu geben: ..." (Hervorhbg. Stender-Petersen). Ahnlich: W, Lettenbauer: Russische Literaturgeschichte.

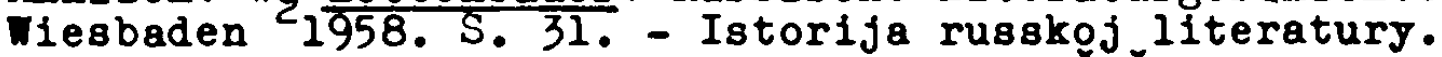
Bd. 2.1. AN SSSR. M.-L. 1946. S. 223. - Cižev8ki.j, History, $S .198$. Im weiteren legt dieser aber die Betonung auf die tradierte Kriegsterminologie. 
chenden Material des $\mathrm{K}$-pler Textes.

Es wäre möglich gewesen, die durch Gegenüberstellung stilistisch so gegensätzlicher Texte gewonnenen Ergebnisse noch stärker zu systematisieren und zu klassifizieren, als dies in unseren 'Anmerkungen zum Stil unserer Texte' geschehen ist. Mit einer gröBeren Anzahl von Belegen versehen, hätten wir eine solche Untersuchung als eigenständige Arbeit vorlegen können. Im Rahmen einer umfangreicheren Arbeit hatte man die gewonnen Erkenntnisse dann an den GroBwerken der Makarij-Ära uberprufen können. Hierbei würden sich wahrscheinlich keine wesentlich neuen Gesichtspunkte ergeben, allerdings würde das vielschichtige Material manche Differenzierung zwischen den einzelnen Denkmälern erzwingen und so eine wesentlich genauere Kenntnis uber jene Großwerke der Makarij-Ze1t vermitteln, als wir sie z.z. besitzen.

Wir haben dies nicht getan. Bei der Gegenüberstellung der Texte und im Laufe der kursorischen Lektüre anderer Texte trat eine an sich selbstverständliche Tatsache deutlich in Erscheinung, die aber, liest man etwas über die literarischen Produkte der Makarij- (und Nach-Makarij-) Zeit, nie erwähnt wird: die Tatsache nämlich, daß die typischen hagiographischen Passagen eben nur einen Teil, und zwar den geringeren Teil des jeweiligen Textes bzw. des Kompendiums ausmachen; daß sie innerhalb von Texten, die historische Ereignisse oder Vorgänge beschreiben, quantitativ weit hinter den rein erzählenden Abschnitten zurücktreten. Wie verfahren die Autoren, d.h. meist die professionellen Kompilatoren der zweiten Hälfte des 16. Jh.s innerhalb der erzählenden Abschnitte, in denen nur hin und wieder - bei Nennung z.B. von Heiligen oder des Zaren - das hagiographische Element durchbricht? Wird hier der hochgespante panegyrische Ton beibehalten oder kehren die Autoren/Kompilatoren zum faktischen Erzählton zurück oder aber beschreiten sie einen Weg, der 2wischen beidem liegt?

Die Beantwortung dieser Frage schien uns genauso wichtig zu sein wie die Antwort auf die Frage, wie die in panegyrischem Stil gehaltenen Passagen exakt charakterisiert werden könn- 
ten. Eine Einbeziehung der quantitativ überwiegenden berichtenden Abschnitte in eine Beschreibung des durch Makarij geprägten Stils würde dadurch ermöglicht.

2.2 Der Untersuchungsgegenstand: das Verb

Im Rahmen der vergleichenden Untersuchung an der Èrzählung über die Eroberung $\mathrm{K}$-pels und an der Erzählung über die Belagerung Pleskaus fiel uns neben den stilistischen Merkmalen eine weitere Besonderheit auf, die beide Texte scheidet, und $z$ war nicht nur die hagiographischen bzw. nicht nur die erzählenden Passagen, sondern beide Texte insgesamt durchzieht. Es handelt sich um den unterschiedlichen Gebrauch der verbalen Kategorien.

Damit wird die Untersuchung auf einen überaus komplexen, aber doch überschaubaren Bereich gelenkt. Und vor allem - es handelt sich hier nicht um einen einzelnen Aspekt, der vielleicht in irgendeiner Hinsicht Bedeutung gewinnen könnte. Vielmehr scheint uns, daß es gerade der Gebrauch der verbalen Formen ist, auf welchem Gebiet sich die Werke der Makarij-Ära (die, nimmt man diese Bezeichnung einmal als Stilbegriff, weit über dessen Tod 1563 hinausreicht) von ihrem literarischen Kontext abheben.

Sieht man einmal von den hagiographischen Fassagen ab, wo andere Stilmittel von Bedeutung sind, kann man sagen, daß sich der Stilunterschied unserer beiden Texte insgesamt auf den unterschiedlichen Gebrauch der verbalen Kategorien in jedem der Texte zurückführen läßt.

Es ist sicber nicht verwunderlich zu erfahren, daß das Hauptaugenmerk auf die präteritalen Tempora einerseits und auf die Part. act. andererseits gerichtet werden wird. Kennern jener Epocbe ist bekannt, daß in der zweiten Hälfte des 16. Jh.s gerade das Partizip eine wichtige Rolle im verbalen System spielte. Die Gegenüberstellung der K-pler Erzählung ermöglicht uns wiederum, die Tendenz und den Grad der Tendenz abzumessen und $z u$ bewerten. Selbstverständlich haben wir damit 
noch keine verbindliche Norm für den gesamten Stil der Kakarij-Ära gewonnen, aber wir dirfen sicher sein, ein wichtiges Kriterium für die Charakterisierung der zu jener Epoche gehörigen Werke in der Tendenz erfaBt zu haben, die in mehr oder weniger starkem Maße auch in den anderen hierher gehörigen Werken, vor allem z.B. in der "Kazanskaja Istorija", in der "Stepennaja kniga", in der "Istorija" Kurbskijs usw., beobachtet werden kann. Einzeluntersuchungen müssen hier klärung bringen.

AuBer Unterschieden in der Funktion der verbalen Kategorien fiel eine geradezu gegensätzliche Satzgliedfolge innerhalb der Vergleichstexte auf, die auf der Position des Prädikats im Satz beruht. Sehr weitgehende Untersuchungen in dieser Richtung, die keinen Platz in dieser Arbeit finden können, machten deutlich, dab man den Pleskauer Text in der Tendenz als repräsentativ betrachten kann: In ca. $75 \%$ aller Sätze zeigt das Prädikat Endstellung, wohingegen sich in der K-pler Erzählung die Verbform in ca. $80 \%$ aller Sätze vor dem objekt bzw. vor anderen Ergänzungen befand (s. S. 63/Anm. 23; S. 663 ff.). Bei dieser Erschelnung handelt es sich offensichtlich um ein Merkmal hagiographischer, also emotionalisierender Diktion.

\subsection{Zur Methode der Untersuchung}

Im Gegensatz zu anderen Untersuchungen über das Verb an älteren Texten wollen wir die heutige Aspektkategorie nicht in den Vordergrund stellen. Natürlich ist im ausgehenden 16. Jh. das Aspektsystem berelts weltgehend ausgebildet, dennoch ist es methodisch sicherlich falsch, von vornherein von einer Aspektkorrelation: Imperfekt = imperfektiver Aspekt - Aorist = perfektiver Aspekt auszugehen (wobel der Aorist imperfektiver Verben nicht in dem MaBe als Ausnahme angesehen wird wie das Imperfekt von perfektiven Verben). Welches Verb perfektiv, welches imperfektiv 
ist - das bestimmt der heutige Sprachgebrauch. ${ }^{29}$ Hierdurch werden heutige Verhältnisse in unzulässiger Welse auf einen älteren Zustand projiziert.

Deshalb wollen wir vom älteren, aktionsartlichen Zustand ausgehen. 30 Wir unterscheiden grundsätzlich zwischen Momentan-Verben, Durativa (mit allen Varianten - Kursiva, Iterativa, usw.); als formale Kategorie ist besonders wichtig die der suffigiert und/oder dehnstufigen Ableitungen.

Die Scheidung 2 wischen momentanen und durativen Verben wird grundsätzlich auch auf die Komposita übertragen. Die wenigen Fälle von Aktionsartänderung durch Präfigierung sind so selten, daB sie das allgemeine Bild nicht stören. Es wird uns natürlich nicht möglich sein, alle Verbformen vorzuführen. 31 Doch wollen wir alle Belege für Ipf. und Part. präs., von víomentan-Verben gebildet, sowie viele Belege für Aorist und Part. prät., gebildet von durativen und suffigierten und/ oder dehnstufigen Stämmen, vorstellen.

29) Tendenzen zu dieser Vergröberung bei $\mathrm{H}$, Ja, Cernych: Istgriceskaja grammatika russkogo jazyka. Kratkij ocerk. M. 1962. (weiterhin zitiert als: Cernych, Ist. grammatika). S. 252 und S. 256.

N. Boretzky: Der Tempusgebrauch in Kurbskijs "Istorija velikago knjazja moskovskago". Diss. Bonn 1964. (weiterhin zitiert als: Boretzky, Tempusgebrauch). S. $40 \mathrm{f.,}$ S. $52 \mathrm{f}$.

30) Die Vorarbeiten zu dieser stärker aktionsartlichen Betrachtungsweise des Verbalsystems von L. Sadnik-Aitzetmüller, R. Aitzetmüller, $H$. Schelesniker finden sich gedankiich und bibliographisch zusammengefaBt bei $\mathrm{H}$. Budich: Aspekt und verbale Zeitlichkeit in der 1. $\overline{\text { Nov- }}$ goroder Chronik. Graz 1969. (weiterhin zitiert als: Budich, Aspekt). Für uns wichtig (mit weiteren Literaturangaben) S. $10-22$.

K, Trost: Perfekt und Konditional im Aksl. Wiesbaden 1972 (BIbliotheca Slavica). S. 1 - 11. (weiterhin zitiert als: Trost, Perfekt).

31) Budich, Aspekt, S. 23, fordert vollständige Vorstellung des untersuchten Materials, da nur dieses tberzeugungskraft besitze. Diese Vollständigkeit wird sich aber in der Praxis nicht immer verwirklichen lassen. 


\section{B. TEXTGESCHICHTE - KONZEPTION - KOMPOSITION}

Unserem Prinzip folgend, über die speziellen Untersuchungen hinaus möglichst viel über die vorliegenden Texte mitzuteilen, wollen wir im folgenden auf die Textgeschichte, auf die ideologische Konzeption und die Komposition der Texte eingehen. Die beiden letztgenannten Aspekte sollen aus Raumgründen zusammengefaßt werden; dies bietet sich auch an, da zwischen Komposition und der zugrundeliegenden ideologischen Konzeption gewisse Zusammenhänge bestehen.

Leider ist in diesem Abschnitt eine getrennte Behandlung der Texte nicht zu umgehen. Allerdings wollen wir uns bemühen, bei Besprechung des jüngeren - Pleskauer - Textes auf den älteren Text Bezug zu nehmen.

Der Gegenstand erfordert es, dab wir in den einzelnen Erzählungen die Schwerpunkte anders setzen. So ist im $\mathrm{K}$-pler Text die Textgeschichte recht kompliziert. Wir müssen aber darauf eingehen, weil die Literaturgeschichten die Entstehungsgeschichte der Erzählung über die Eroberung K-pels in einer Weise darstellen, wie sie einer genauen Textanalyse nicht entspricht. Dafür ist aber der historische Kontext, in den die K-pler Erzählung zu stellen ist, so bekannt, daB wir uns ganz kurz fassen können. 1

Umgekehrt wird es nötig sein, die Entwicklung des Livländischen Krieges zu skizzieren, an dessen Ende die Belagerung Pleskaus steht.

Wie die beiden Texte das historische Material verarbeiten wie sie selektieren, hinzufügen und dehnen - dies hängt wesentlich von der (ideologischen) Konzeption des Autors ab und gehört insofern in den Rahmen der Komposition.

1) In diesem Zusammenhang verweise ich auf die Monographie von S. Runciman: The Fall of Constantinopel 1453. Camb idge 1965: neuerdings auch in deutscher tbersetzung S. Runciman: Die Eroberung von Konstantinopel 1453. Aus dem Englischen übertragen von Peter de Mendelssohn. München 21977. (dtv. Wissenschaftliche Reihe. 4286). 
1. Die Erzählung über die Einnahme Konstantinopels durch die Türken 1453

\subsection{Textgeschíchte}

Die Literatur über die Textgeschichte dieser Erzählung ist mittlerweile fast unübersehbar geworden. Wir müssen uns innerhalb dieses kurzen Abrisses damit begnügen, nur einige wesentliche Pakten und Meinungen vorzustellen, um ein wenigstens ungefähres Bild von Quellenlage und Forschungsstand zu vermitteln.

Wir unterscheiden $z$ wischen einer kurzen und einer ausführlichen Erzählurig; unserer Untersuchung liegt die letztere zugrunde. Wir kommen hier auf die kurze Erzählung zu sprechen, weil verschiedentlich ein genetischer Zusammenhang zwischen beiden gesehen wird.

Statt einer dieser beiden Erzählungen finden wir in manchen Codices nur eine ganz kurze Notiz uber den Pall Konstantinopels. Vielleicht hat der Kompilator der betr. Chroniken keine der Erzählungen gekannt - z.B. 3. und 4. Novgoroder Chr., PSRL 3, S. 240 ; PSRL 4, S. 464, 2. Soph.Chr. PSRL 6, S. 180 u.a.

Eine knappe Mitteilung über den Untergang der Stadt und eine sich hieran knüpfende Klage mit vielen Apostrophen, Ausrufen, Anaphern und auch Reimen hat der Chronograph 1512 PSRI 22.1, S. 437 - 38 (Kap. 208).

Die für uns interessante kurze Erzählung über die Eroberung $\mathrm{K}$-pels befindet sich z.B. im Nikon-Codex, PSRL 12, S. 97 ff., im Chronograph 1512, PSRI 20.2, S. 204 ff.

Im Nikon-Codex, PSRL 12, S. $78 \mathrm{ff}$. 1st auch die ausführliche Redaktion anzutreffen (die kurze ebda, S. 97 ff.). Da die längere Passung häufig in (jüngeren) Chronograph-Redaktionen begegnet, wird sie in der sovjetischen Porschung als "chronografičeskaja redakcija" bezeichnet. Eine Variante derselben ist auch die uns vorliegende Erzählung, die der 
Archimandrit Leonid entdeckt und 1886 veröffentlicht hat. ${ }^{1}$

Die kurze Erzählung beschreibt die Ereignisse nicht nur stilistisch in ganz anderer Weise als die ausfürlichen Varianten, sondern sie berichtet $z . T$. auch ganz andere Vorfälle. oft sind auch Unterschiede in der Darstellung des gleichen Ereignisses erkennbar. Das zeigt sich besonders deutlich bei der Schilderung des Todes von Johannes Giustiniani, eines Genuesers, der - der ausfürlichen Fassung zufolge - der bedrohten Stadt als einziger aus dem lateinischen Westen zu Hilfe geeilt war. Beide Erzählungen heben seine groBe Tapserkeit und seine Verdienste um die Verteidigung der stadt hervor. In der chnronograph-Fassung wird er zwei Mal am Oberkörper verletzt. Der Kaiser eilt jedes Mal an sein Lager. Da er nach der zweiten Verletzung nicht mehr genannt wird, ist der Leser der Meinung, daß Giustiniani gestorben ist. In der kúrzen Erzählung flieht dieser nach einer Beinverletzung aus der stadt und stirbt in Schmach und Schande: "sb bezslaviemb žiznb razrěšilb. Voistinu blaženz by bylb, ašč by

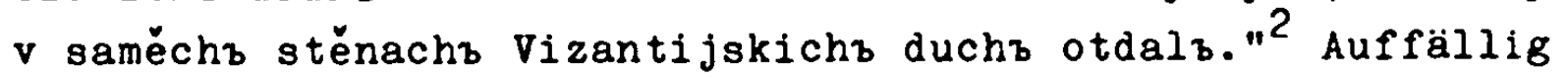
ist auch die unterschiedliche Schreibung des Namens: "Ioans že Ioustinijanı, vъ Genue gradé ... roženъ" ${ }^{3}$ in der kurzen Fassung, in der längeren dagegen heiBt er einfach "Zustuneja". Letztere Namensform reflektiert die griechische Volkssprache, während "Ioanъ že Ioustinijanъ" entweder auf die griechische Hochsprache oder aber auf das Lateinische verweist. 4

1) Es handelt sich um eine einzelne Hs., während alle übrigen Textvarianten in die Codices eingearbeitet sind. Povest $b$ o Carbgrade (ego osnovanii i vajatii Turkami v 1453 godu) Nestora-Iskandera 15 veka (Po rukopisi TroiceSergievoj Lavry nac. 16 veka, No. 773). Soobšcil Archimandrit Leonid, SPb. 1886 (Pamjatniki drevnej pissmennosti i iskusstva, 62 . (weiterhin zitiert: Leonid, Povest $t_{b}$ )

2) Chronograph 1512, PSRI 22.2, S. 206

3) ebda.

4) Bericht über die Eroberung Konstantinopels. Nach der Nikon-Chronik übersetzt und erläutert von M. Braun und A. M. Schneider. Leipzig 1941 (weiter zitiert: Braun-Schneider, Bericht uber die Eroberung), S. 34: "Zustuneja" sei volksgriechisch. 
Die ausführliche Fassung enthält auBer einer viel breiteren Schilderung der Kampfhandlungen noch den Bericht über die Gründung K-pels (mit der Erzählung über den Kampf des Adlers mit der Schlange) und als großen SchluBteil die Prophezeiungen über die Errettung der Stadt, in denen der Hinweis auf "rusii že rodz" enthalten ist. In verschiedenen Codices fehlt den ausfürlichen Berichten (= Chronograph-Redaktion) der Anfangsteil, der die Gründung der Stadt behandelt. Die Prophezeiungen am SchluB unterscheiden sich meist stark im Umfang. Jedoch der Hinweis auf "rusii že rodz" ist allen gemeinsam. Schlieblich sind in den Berichten nach der Chronograph-Redaktion, die wir in über 200 Codices $^{5}$ finden, gelegentlich Auslassungen und zusätze innerhalb der eigentlichen Kampfberichte festzustellen. Im Ganzen gesehen, stellen sich die ausführlichen Fassungen, die ungefähr ab 1530 in den Codices erscheinen, als zu einer Redaktion gehörig dar, gehen also auf eine Hs. zurück. 6

Die von Archimandrit Leonid entdeckte einzelne Hs. unterscheidet sich von den ausführlichen Berichten in den Codices dadurch, dab sie das berühmte Nachwort - die autobiographische Notiz des Nestor-Iskander ${ }^{7}$ - enthält. Dieser sei als Jüngling vor den Türken gefangengenommen und beschnitten worden, habe an der Eroberung $K$-pels mitwirken müssen, habe sich aber seinen Verpflichtungen auf verschiedenste Heise entzogen. Währenddessen habe er einen Bericht über die Kampfhandlungen angefertigt und diesen nach dem Fall $\mathrm{K}$-pels durch Darstellungen ergänzt, die ihm hochgestellte Bürger der

5) S. N. Azbelev, K sravnitel'nomu izučeniju povesti o zavoevani1 Konstantinopol ja turkami. In: Sravnitel'noe izucenie literatura. Sborn. stat'ej k 80-letiju ak. M. P. Alekseeva, I. 1976 (weiter zitiert: Azbelev, Festschrift Alekseev),S.23.

6) M.N. Speranskij, Povesti i skazanija o vzjatii Cárgrada turkami (1453) v russkoj piśmennosti $15-17$ vekov. In: TODRL 10 (1954) (weiter zitiert als: Speranskij, Povesti 10), S. $147 \mathrm{ff}$.

7) Schaeder, Moskau das Dritte Rom, S. 47, Anm. 4, liest nach einer der Edition des Archimandrit Leonid beigegebenen Photographie des letzten Blattes "Iskinder". 
Stadt gegeben hätten. Diese Fassung stellt eine eigene Redaktion dar, die als Variante zu der Hs, anzusehen ist, die der Chronograph-Redaktion zugrundeliegt. Diese (unbekannte) Hs. und die von Archimandrit Leonid gefundene Hs. gehen auf einen gemeinsamen Archetypus zurück. ${ }^{8}$

Die Hs. des Archimandrit Leonid gilt allgemein als die älteste Redaktion und wird auf den Anfang des 16. Jh.s datiert, während die ausführlichen Berichte in den Codices erst ab 1530 einsetzen $($ s.0.).9

Während über die referierten Fakten Einmütigkeit besteht, entzündet sich die Diskussion an zwei Pragen, wovon für uns die letztere Bedeutung hat:

1. Bestehen Beziehungen zwischen der kurzen und der ausfuhrlichen Erzählung über den Fall K-pels? Welche?

2. Wie ist die umfangreiche Chronograph-Redaktion eigentlich entstanden und wie verhält sich dazu das Nestor-Iskander Nachwort der Leonid-Hs.?

1.1.1 Bestehen Beziehungen zwischen der kurzen und der ausführlichen Erzählung?

Bereits Sachmatov hatte die kurze crzählung über die Eroberung $\mathrm{K}$-pels als Ubersetzung angesehen, ${ }^{10}$ und $\mathrm{zwar}$ aus dem Griechischen. Speranskij schließt sich dem an und hält den

8) Speranskij, Povesti 10, S. $147 \mathrm{ff}$.

9) Leonid, Povest', S. IV: die von inm entdeckte Hs. wurde Anfang des 16. Jh.s geschrieben. Ebenso Speranskij, Povesti 10, S. 151. Allein Skripil', M. O., "Istorija" o vzjatii Caŕrgrada turkami Nestora Iskandera. In: TODRL 10 (1954) (weiterhin zitiert als: Skripil', Istorija), S. 177, meint, daß die Erzählung bereits Ende des 15. Jh.s entstanden sei. Allerdings stützt er sich dabei nur auf das Nestor-Iskander-Nachwort: dort wird die Augenzeugenschaft des Verfassers hervorgehoben. Wenn also der Verfasser Augenzeuge der Ereignisse gewesen sei, könne die Erzählung nicht erst im 16.Jh. entstanden sein.

10) A. A. Sachmatov, $K$ voprosu o proischoždenii Chronografa, in: Sbornik ORJaS 66 (1899), S. 21 f. 
Bericht des Leonhard von Chios ${ }^{11}$, den dieser Papst Nikolaus II. gesandt hatte, für die Vorlage ${ }^{12}$; ebenso sreznev$\operatorname{skij.} 13$

Dagegen machte V. Ržiga 1934 bereits Mitteilung von einem Pund, den er im Zusammenhang mit seinen Maksim Grek-Forschungen gemacht hatte: Eine fbersetzung des 7. Kapitels der geographischen und historischen Studien des nachmaligen Papstes Pius II., in dem über die Eroberung $K-$ pels berichtet wird. Die entdeckte Hs. Maksim Greks trägt die tberschrift "O vajatil Carjagrada, perevedeno $s$ latinskogo Maksimom, inokom grekom svjatyja goryn. 14 Diese Entdeckung blieb lange Zeit unbeachtet und wurde, während man weiter nach einer griechischen Vorlage suchte, kürzlich wiederholt. 15

Die Ubersetzung Maksim Greks gibt das lateinische Original viel besser wieder als die kurzen Erzählungen in den Codices. Terminus ante quem ist hier 1518, da in diesem Jahr

11) Leonhard von Chios: Epistula. Migne, Gr. 159. Leonhard hat den Brief mit dem 16. Aug. 1453 datiert die Eroberung K-pels fand aber am 29. Mai 1453 statt.

12) M. N. Speranskij, Povesti i skazanija o vzjatii Caŕgrada turkami (1453) v russkoj pismennosti $16-17$ vekov, in: TODRL 12 (1956) (weiter zitiert als: Speranskij, Povesti 12), S. $192-98$

13) I. I. Sreznevakì, Povest' o Caŕgrade, in: Učenye zapiski II otd. imp. Akad. Nauk kn. I, otd. III, SPb. 1854, S. $61-68$, vor allem S. 66 - bei Speranskij, Povesti 12 , S. 196. - auch Schaeder, Moskau das Dritte Rom, S. 45

14) V. Ržiga, Kto perevel kratkuju povest' o vzjatil K-polja turkami? in: Slavia 13, Praha 1934, S. $105-08$. Original: Aeneae Silvii Piccolominei, postea Pii II papae opera geographica i historica. Helmstadii 1690, pp. 243247. A. I. Sobolevskij, tnej Sil'vij i Kurbskij, in: Serta Borysthenica, Sborn. v cest' zaslužennogo prof.a Ju. Kulakovskogo, Kiev 1911, S. 1 - 17, vermutete, daB A. Kurbskij die kurze Chronikerzählung nach Aeneas Silvius Piccolomini übersetzt habe.

15) B. M. Kloss teilte seinen "neuen" Pund mit in: Pamjatniki kultury: Novye otkrytyja. (Predsedatel' redkollegija D. S. Iichacev), M. 1975, S. 55 - 61. bei Azbelev, Pestschrift Alekseev, S. 19 Anm. 9. 
Maksim Grek nach Moskau kam. Ržiga meint vorsichtig, daB Maksim die Ubersetzung vor 1543 angefertigt habe. ${ }^{16}$ Das aber schliebt aus, daB sie der kurzen Erzählung über den Untergang K-pels zugrundeliegen kann, da diese bereits im Chronographen 1512 in der Redaktion von 1520 erscheint. ${ }^{17}$ Auch stellt die Erzählung in den Chroniken eine so schlechte Ubertragung des lateinischen Originals dar, dab man auch von daher die Ubersetzung Maksim Greks als viel jünger einschätzen muB.

Speranskij hielt die ausführliche Erzählung für jünger als die kurze, die er ja für eine Ubersetzung aus dem Griechischen ansah. Und er meinte, daB die letztere der ausführlichen Passung als Quelle gedient habe. ${ }^{18} \mathrm{Er}$ begründet dies damit, daß die ausführliche Erzählung erst in den 30-er Jahren im Chronographen erscheint, also fast 15 Jahre später als die kurze Erzählung. AuBerdem finden sich in manchen ausführlichen Passungen der Codices ganz klare Ubernahmen aus der kurzen, aus dem Lateinischen übertragenen Erzählung, worauf schon Unbegaun hingewiesen hat. ${ }^{19}$

Nun hat allerdings Azbelev 1961 mitgeteilt, daB er ein Bruchstück der "chronografičeskaja redakcija", also der ausführlichen Fassung in den Codices, entdeckt hat, das er als wesentlich älter einschätzt als sogar die Hs., die Archimandrit Leonid veröffentlicht hat. Azbelev datiert sein Fragment auf etwa 1480.20 Wenn auch Speranskijs Begründung für das höhere Alter der kurzen Fassung z.T. (früheres Erscheinen derselben in den Chroniken) durch Azbelevs Fund hinfällig geworden ist, so hält Azbelev Speranskijs These, daB sich die ausfuhrlichere Erzählung wesentlich auf die kurze Fassung stützt, doch für durchaus gerechtfertigt ("vpolne obosnovanno" ${ }^{21}$ ), ohne aber

16) Ržiga, K to perevel kratkuju povest', S. 106.

17) Speranskij, Povesti 12, S. 193 f.

18) ebda.

19) ebda.

20) S. N. Azbelev: $K$ datirovke russkoj Povesti o vzjatii Cafgrada turkami, in: TODRL $17(1961)$, S. $334-37$.

21) Azbelev, Festschrift Alekseev, S. 19. 
diese seine Annahme näher zu begründen.

M. E. sind beide Erzählungen - die kurze und die ausführlichere - unabhängig voneinander entstenden. Gelegentliche Ubernahme von Angaben der kurzen Fassung in die längere und umgekehrt lassen sich dadurch erklären, daB der Kopist beide Texte kannte. So kommen in manchen Codices beide Fassungen vor, vgl. 2.B. in der Nikon-Chr. PSRL 12, S. $97 \mathrm{ff.:}$ die kurze Fassung; PSRL 12, S. 78: die ausfuhrliche Fassung. Bezeichnenderweise sind in der von Archimandrit Leonid aufgefundenen Hs. keine Ubernahmen aus der kurzen Erzählung festzustellen. 22

Mir scheint, daB die Grundkonzeption in beiden Texten grundverschieden ist. Während die lange Erzählung die Griechen in ihrem Kampf idealisiert (s.u.: Konzeption und Komposition), muß man in der kurzen Erzählung nach positiver Darstellung der Griechen suchen - sie sind habgierig, kleinlichegoistisch; statt zu beten, feiern sie Gelage; statt ihr Vermögen der Verteidigung der Stadt zu opfern, vergraben sie es; doch ihre Diener stehlen es oder verraten es den Türken. DaB der Autor ein Lateiner ist, wird hieran recht deutlich. Ein russischer Autor, dem es hätte darum gehen müssen, den Fall $\mathrm{K}$-pels als durch die Sunden und Laster, als durch den Abfall der Stadt von Gott (= die Union von Perrara-Florenz 1438/39) verursacht darzustellen, hätte jenes Material, das die kurze Erzählung bietet, in ganz anderer Heise verwertet, als die ausfühliche Erzählung uns den Lauf der Ereignisse darbietet. Die kurze Erzählung ist sprachlich recht unbeholfen, ungelenk, wohingegen die längere Version von beispielhafter Klarheit ist, eine logische Satzgliederung hat, die für das Altrussische ungewöhnlich ist. In der langen Erzählung steht das Prädikat meist vor, in der kurzen Erzählung meist nach dem Objekt, also am Satzende. ${ }^{23}$

22) Speranskif, Povesti 10, S. 147 f.; Povesti 12, s. 197 f.

23) Chronograph 1512, PSRI 22.2, S. 205-07: Von 151 Sätzen steht in 112 Sätzen das Prädikat hinter der Ergänzung $=$ $74 \%$, in 31 Sätzen davor $=31 \%$. - In der langen Erzählung

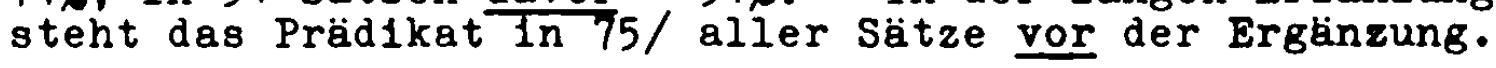


$\mathrm{Zu}$ den eben angemerkten stilistischen Unterschieden zwischen beiden Erzählungen ist allerdings zu sagen, daB ein souveräner Stilist, wie wir ihn im Autor der ausführlicheren Erzählung vermuten müssen, sich durch die Stileigentümlichkeiten der kurzen Erzählung kaum hätte beeinflussen lassen.

Die ausführliche Erzählung über die Einnahme K-pels liegt, wie erwähnt, in 2 wei Variantengruppen vor uns: die eine wird repräsentiert durch die einzelne, von Archimandrit Leonid aufgefundene Hs., die zweite Gruppe bilden die Versionen, die wir seit etwa 1530 in den verschiedenen Codices vor finden. Beide Gruppen gehen, wie bereits gesagt, auf einen Archetypus zurück.

Wie nun hat man sich die Entstehungsgeschichte der uns vorliegenden ausführlichen Erzählung in der Leonidschen Hs., also mit dem Nestor-Iskander-Nachwort, vorzustellen? Diese Frage berürt nicht die soeben mehr oder weniger offengelassene Frage nach dem Einfluß der kurzen Erzählung auf die längere: Denn die hier gestellte Frage zielt mehr oder weniger deutlich darauf $a b$, ob wir es mit einer originalen russischen Erzählung zu tun haben - oder aber mit einer Ubersetzung aus dem Griechischen. Die Fraige nach der Beziehung zwischen der kurzen und langen Erzählung würde dann nur in dem Falle Interesse gewinnen, wenn man schlüssig sagen könnte, daß die ausfuhrliche Version unserer Erzählung eine auf russischem Boden entstandene Schöpfung ist. Die Frage wäre auch von gewisser Relevanz im sekundären Stadium - nämlich dann, wenn man feststellen sollte, daß die lange Erzählung eine tbersetzung darstellt: dann könnte man fragen, ob die kurze Erzählung bei der Ubersetzung der längeren Fassung in irgendeiner Weise EinfluB gehabt hat.

Die heute noch gängige Version über die Entstehung der ausführlichen Erzählung über den Fall K-pels hat schon Archimandrid Leonid anläßlich der Edition seiner Hs. vorgezeichnet: ${ }^{24}$ ) ein irgendwie in türkische Gefangenschaft geratener

24) Leonid, Povest', S. III - IV 
Russe habe die Ereignisse, wie im Nachwort beschrieben, festgehalten, seine Informationen nach der Eroberung der Stadt durch Befragen vertrauenswürdiger Leute ergänzt und dann, in die Heimat zurückgekehrt, niedergeschrieben; es wird dabei nicht ausgeschlossen, $d a b$ eine erfahrene Hand die originalen Aufzeichnungen bearbeitet hat. ${ }^{25}$

Beim genauen Lesen muß man erkennen, daB der Standpunkt des Erzählers sich - im Gegensatz zur Aussage im Nestor-Iskander-Nachwort - innerhalb der Stadt befindet. Offenbar ist er an den Kämpfen beteiligt, und zwar unter dem Kommando Giustinianis, den der Autor vergöttert. 26 Von wichtigen Ereignissen an anderen Frontabschnitten weiB er so gut wie gar nichts zu berichten. Von der idealisierenden Verzeichnung Giustinianis in der längeren Erzählung war ja bereits die Rede.

Speranskij zählt eine Reihe ron Informationen auf, die der Autor - Speranskijs Meinung nach - nur erhalten konnte, wenn er sich, wie Nestor-Iskander erklärt, im türkischen Lager befunden hat. ${ }^{27} \mathrm{E}_{\mathrm{g}}$ ist hier leider nicht der Platz, auf die bei Speranskij genannten Punkte einzugehen. Zusammenfassend kann man jedoch sagen, dab es sich dabei um Nachrichten handelt, die entweder in $K$-pel ohnehin bekannt gewesen sein dürften oder aber die als dramatisierende Zusätze des Autors $z u$ werten sind, z.B. wenn es heiBt, Mehmed habe nicht schla-

25) 80 Z.B. N. K. Gudzij: Istorija drevnej russkoj literatury, M. 9956, S. 244-48, (weiterhin zitiert: Gudzij, Istorija); Stender-Petersen, Gesch.der russ. Literatur, S. 193 - 195; Istorija russkoj literatury, AN SSSR M.-L. 1946, S. $222-25$; D. Cizevskij, History of Russian Literature. Prom the 11 th Cent. to the End of the Baroque, Den Haag 1960 (Slavistic Printings and Reprintings. 12) (weiterhin zitiert: Tschižewskij, History), S. 198, zweifelt an Nestor-Iskander als Autor. Wr Lettenbauer, Russische Literaturgeschichte, Wiesbaden $\frac{1}{1958,5.31}$, spricht sich als einziger für griech. Original aus. Nachwort: späte Erfindg.

26) Braun-Schneider, Bericht uber die Eroberung K-pels, S. 35Giustiniani: Vermutlich Kommandeur des Autors, der zu den Griechen gehörte, die dem Genueser zugeteilt waren.

27) Speranskij, Povesti 10, S. 140. 
fen können, weil er an die vielen Gefallenen und auch an die Tapferkeit des Zaren habe denken mussen (unsere Textvorlage 73/15); zwei Mal habe der Sultan bereits abziehen wollen, weil er meinte, er werde die stadt nicht einnehmen können (60/36 und 73/18); als der Sultan die Zeichen über der Stadt sah, rief er seine Zeichendeuter, und die sagten $2 u$ ihm: "Znamenie veliko estb i gradu paguba." 73/36 usw. 28

Verneint man die Autorschaft eines Christen im Türkenlager, dann erhebt sich sogleich die Prage nach dem nun anzunehmenden griechischen Original der Erzählung. Ein Vergleich mit den wichtigsten Quellen - Georgios Phrantzes und Michael Dukas $^{29}$ - führt zu dem SchluB, daB diese als Vorlage nicht gedient haben können, denn unsere Erzählung enthält Mitteilungen, die beide nicht kennen. Demnach wäre eine griechische Vorlage anzusetzen, die wohl - falls je vorhanden nicht mehr aufgefunden wird.

So kann nur sachliche Textanalyse eine Lösung der Prage herbeiführen. Diese aber scheint solange nicht gewährleistet, als nationales Prestigedenken die Antwort mitbestimmt - so scheint für die sovjetische Forschung die Annahme eines griechischen Originals a priori unmöglich. Da das Problem noch der lösung harrt, da es an gründlichen Arbeiten vor allem am Text selbst fehlt, können wir nur einige Meinungen vorstellen, die den einen oder anderen Punkt charakterisieren. Es ist dabei bezeichnend, $d u B$ die (wenigen) westlichen Arbeiten, die sich der Prage zuwenden, stärker zur Annahme eines griechischen Originals tendieren, während die sovjetischen Arbeiten auf einem russischen Autor bestehen.

H. Schaeder hatte schon 1929 auf die "Benutzung von griechischem Gut" innerhalb der ausführlichen Erzählung über den

28) Auf den Erzähler innerhalb der Stadt weisen hin Schaeder, Moskau das Dritte Rom, S. 48; Braun-Schneider, Bericht uber die Eroberung K-pels, S. 35; Lettenbauer, Russ. Literaturgeschichte, S. 31; Speranskij, Povesti 10, S. 139.

29) (Michael?) Ducas: Istoria turco-bizantină (1341-1462). Hrsg.: Vasile Grecu. Bucuregti 1958. (Scriptores Byzantini. 1). - Georgius Sphrantzes: Chronicon (1401-1477). Hrsg.: Vasile Grecu. Bucuresti 1966. (Scriptores Byzantini. 5 ). 
Gerd Stricker - 9783954792900

Downloaded from PubFactory at 01/10/2019 05:43:48AM

via free access 
ratur bereits bekannt waren - er fand Entlehnungen aus der serbischen Passung des 'Trojanischen Krieges' - der "Trojanskaja pritčan-und aus der russischen Ubersetzung der latelnischen Bearbeitung dieses Stoffes durch Guido de Columna 'De proeliis'. ${ }^{4}$ Beide, die serbische und die altruss. Ubersetzung, finden sich gelegentlich im gleichen Codex. Viele für Kriegserzählungen so typische Bilder und Tendungen in der K-pler Erzählung kommen aber auch in anderen altruss. Kriegserzählungen schon vor. ${ }^{45}$ wir werden an anderer stelle Gelegenheit haben, auf viele Ähnlichkeiten mit dem 'Jüdischen Krieg" ("Padenie" oder "Razorenie Ierusalima") hinzuweisen ${ }^{46}$ (s.u. S.230ff.: 6.2 Vergleiche. Im Rahmen der 'Anmerkungen zum Stil unserer Textel.

Mir scheint aber zweifelhaft, ob man derartige Entlehnungen, d.h. den Gebrauch tradierter Wendungen und Bilder (Topoi) als Beweis für eine originale altruss. Schöpfung betrachten darf, dies umso mehr, als ja diese Wendungen zumeist wiederum aus ubersetzten Werken stammen. DaB der Autor oder tbersetzer der K-pler Erzählung ein für die altruss. Iiterarischen Verhältnisse der zweiten Hälfte des 15 . Jh.s ${ }^{47}$ unge-

44) Vorlage: 'Roman de Troie' des Benolt de Sainte-Maure.

45) A. S. Orlov: Ob osobennostjach formy russkich voinskich povéstej (konçaja 17 v.). In: Ctenija v obscestvé istoril 1 drevnostej rossijskich pri Moskovskom universiteté. 1902, kn.6. S. 1-50. - ders,: Povest o vajatii Cafgrada turkami 1453 g. i ee 1stocniki. In: Drevnjaja russkaja literatura $11^{-}-17$ vv. M. - L. 1945. S. 226 - 37. hier S. 226 . S. 237 betont er aber: "grekofil'skoe... sočinenie".

46) Speranskij, Povesti 10, S. 151 Anm.2: auch er betont die Parallelen zum 'Jüdischen Krieg'.

47) S. N. Azbelevs Pund eines Bruchstückes unserer, der ausführlichen Fassung der Erzählung, das er als um 1480 herum geschrieben datiert, verlegt die Entstehung unserer Erzählung ziemlich nahe an die berichteten Ereignisse: Das Fragment gehört - 8.0. S.62 Anm. 20 - zu den Chronikerzählungen, die "chronografičeskaja redakcija" bilden. Die Hs., auf die jene Redaktion zurückgeht, und die Leonid-Hs.bilden aber selbst nur Varianten eines Archetypus, der demnach in seiner Entstehung mehr oder weniger weit vor 1480 angesetzt werden muB. vgl.: S. N. Azbelev: $K$ datirovke russkoj Povesti o vzjatii Cargrada turkami. in: TODRL $17(1961)$. S. 334 - 37 . 
mein talentierter und gewandter Schreiber war, wird nirgends bestritten. ${ }^{48}$ Ein so begabter "knižnik" wird in jedem Pall ob er eine Ubersetzung anfertigt oder aber selbst einen Stoff gestaltet - auf vorhandene Werke des entsprechenden Genres zuriuckgreifen und Wendungen oder Bilder adaptieren, wenn diese das, was er selbst sagen oder aber ubersetzen möchte, treffend und stilgerecht auszudrücken vermögen. So sind also m. E. Parallelen zwischen der K-pler Erzählung und bereits früher im altruss. Schrifttum vorhandenen Texten weder ein Beweis für eine originale altruss. Schöpfung noch ein Beweis für oder gegen Annahme einer Ubersetzung - solche Parallelen beweisen nur, daB der Autor oder Ubersetzer in der altruss. Literatur Bescheid wubte und die entsprechenden Werke, die bereits vorhanden waren, als Formulierungshilfe heranziehen konnte.

Trotzdem stützen sich Skripil' und Speranskij, die die umfassendsten Forschungen hierzu während der letzten Zeit vorgelegt haben, in ihrer Betonung des russischen Originals wesentlich auf Orlovs Beweisfürung. ${ }^{49}$ Beide Thesen sollen hier kurz umrissen werden, well die eine - Skripil's - den dogmatisch-russischen Standpunkt vertritt, während die andere - Speranskijs -, obwohl bereits vor nunmehr vier Jahrzehnten formuliert, eine in den wichtigsten Zügen akzeptable Lösung anbietet.

Wir wollen uns zunächst Speranskij zuwenden, weil Skripil' sich in seinen Ausführungen gerade gegen dessen und ähnliche Auffassungen wendet.

48) z.B. Skripdi', "Istorija", S. 183: "Istorija' byla napisana Celovekom bol'sogo li teraturnogo talanta". Speransk1j, Povest1 10, S. 143: "Vpolne verojatno, čto povest napisana ... opy tnym $v$ literaturnom dele russkim kniźn1kom ..."

49) Bs handelt sich um die bereits mehrfach genannten Arbeiten 0 . Skriplil: "Iatorija" o vzjati1 Cargrada turkami Nestora Iskandera. In: TODRL 10 (1954). S. 166 184. - N. N. Speranak1f: Povesti 1 skazanija o vajatil Cargrada turkami (1453) v russkoj pismennost1 $16-17 \mathrm{vv}$. in: TODRL 10 (1954). S. $136-165$. und in: TODRL 12 (1956). S.188 - 225. Speranskij hatte die Arbeit schon 1937 abgeschlossen. 
Speranskij unterscheidet zweierlei Berichte, die der Erzählung das faktische Material liefern: ein Bericht wurde im türkischen Lager niedergeschrieben. Das beweisen die Nachrichten innerhalb der Erzählung, die nur jemand erfahren konnte, der sich auf türkischer Seite befand: ${ }^{50}$ eben jener im Nachwort erwähnte Nestor-Iskander. Nach der Eroberung der Stadt habe dieser in K-pel Erkundigungen uber die Ereignisse während der Kampfhandlungen innerhalb der Stadt eingeholt und niedergeschrieben und diese Notizen einem Christen gegeben. Das Nachwort, das also vom eigentlichen Verfasser stammt, nenne zwar den Namen Nestor-Iskander. Doch sei damit nichts für die Bestimmung der Nationalität desselben gewonnen. ${ }^{51}$ Diese Notizen seien dann mit sicherlich griechischen Plüchtlingen in die Rus gelangt, wo sie von einem ungewöhnlich talentierten "knižnik" (s.o.) miteinander verarbeitet worden seien. Dieser habe sich dabei auch die in der Rus bereits kursierende Weissagungsliteratur, die sich auf $\mathrm{K}$-pel bezog, zunutze gemacht und diese Erzählung geschaffen, die voll in der Tradition der altruss. Kriegserzählung des ausgehenden 15., beginnenden 16. Jh.s stehe. Aus stilistischen Gruinden habe der russische Autor das Nachwort des Verfassers der originalen Aufzeichnungen beibehalten. Der Kopist der Hs., die den Fassungen der Codices zugrundeliegt, habe das Nachwort aus verschiedenen Gründen fortgelassen, so dab es nur in der Hs. zu finden ist, die Archimandrit Leonid entdeckt hat.

Skripil' wendet sich ganz entschieden gegen alle Standpunkte, ${ }^{52}$ die - wie Speranskijs These - davon ausgehen, daB der ausführlichen Erzählung über den Pall K-pels (vermutlich griechische) Aufzeichnungen zugrundeliegen, die auf dem Boden der Ruś nachträglich ihre heutige Gestalt erhalten haben.

50) s.0. S.65: die von Speranskij angefürten Nachrichten überzeugen nicht. Speranskij, Povesti 10, S. 140.

51) ebda., S. 142.

52) z.B.: N. A. Smirnov: Istoričeskoe značenie russkoj 'Povesti Festora Iskandera o vajatil turkami Konstantinopolja v 1453 g. in: Viz.vr. 7 (1953). S. $55-56$. 
Seiner Meinung nach ist die Erzählung durch und durch russisch. Und zwar sei Nestor-Iskander ein Russe (Ukrainer?) gewesen, der von den Tataren gefangen, an die Tüken verkauft und dort womöglich den Janičaren eingereiht worden sei. Bei den Türken habe er in einer russischen Kolonie gelebt und "konečno" in einer russischen Abteilung gedient. Deshalb habe er auch bei Preunden ("ovogda skryvaniem, ovogda že soveščaniem prijatelej svoichn) untertauchen können, diese 'Freunde' seien Landsleute gewesen. In der russischen Kolonie und in jenem russischen Regiment habe er auch seine Muttersprache bewahrt. Daß er ein professioneller Kriegsmann gewesen sei, beweise die detaillierte, kenntnisreiche Beschreibung einzelner Szenen. Sein groBes literarisches Talent und seine intime Kenntnis der internationalen Verhältnisse hätten es ihm nach seiner Heimkehr ermöglicht, diese Erzählung niederzuschreiben. 53

Dieser phantasievolien Interpretation ist natürlich die speranskijs vorzuziehen. Tenn dieser nicht so bemüht wäre, unbedingt die Authentizität des Nestor-Iskander-Nachworts zu retten und aus dem Grunde den Autor der Aufzeichnungen im türkischen Lager finden muß, könnte man seine Version übernehmen. Sie bietet einen vernüftigen KompromiB $2 w i s c h e n$ den dogmatischen Standpunkten, deren einer ein russisches Original onne Zuhilfenahme einer fremden Quelle postuliert, während der andere die Ubernahme und Ubersetzung einer in der vorliegenden Form voll ausgebildeten (griechischen) Erzählung voraussetzt.

Wenn wir auch z.B. Speranskijs Standpunkt als einen möglichen akzeptieren, so steht eine solche Aussage nur in Bezug zu Äußerungen, die als zu konstruiert erscheinen müssen. Es bleibt uns daher keineswegs erspart, auch weiter nach Möglichkeiten $z u$ suchen, die uns dem tatsächlichen Ablauf der Dinge, der tatsächlichen Geschichte des Textes näher bringen - nicht nur einer akzeptablen Version.

53) Skripil', "Istorija", S. 182 - 184. 
1.2 Konzzeption_und Ko﹎ompositínon der Erzählung über die Eroberung Konstantinopels durch die Turken

Um einer Antwort auf die Prage nach der tatsächlichen Geschichte des uns vorliegenden Textes etwas näherzukommen, wollen wir versuchen, den ideologischen Standpunkt des Erzählers zu ergründen: was will der Erzähler mit seiner Geschichte bewirken, an wen wendet er sich? ${ }^{54}$ Wir wollen versuchen, die Beantwortung dieser Frage mit der Erläuterung der Komposition unseres Textes zu verbinden.

Die Erzählung besteht aus vier ungleich langen $T_{e} i l e n$ :

1. Legenden über die Gründung K-pels (55 - 58/18);

2. Belagerung und Eroberung K-pels durch die Türken - dazwischengeschal tet: Gebete, Klagen, Sündenbekenntnisse, Wunderzeichen.

$(58 / 19-77 / 15)$;

3. Weissagungen: nach Wethodius von Pathara, Leo sapiens, Visio Danielis.

$(77 / 16-78 / 14)$;

4. Nachwort: biographische Notiz Nestor Iskanders,

$$
(78 / 15-77 / 30) \text {. }
$$

Die Erzählungen über die Gründung K-pels gipfeln in dem Bericht uber den Kampf des Adlers mit der Schlange: der Adler schleppt die Schlange hinweg, diese umschlingt ihn aber, so daB der Adler kraftlos zu Boden sinkt. Menschen, die diesen Vorgang beobachten, töten die Schlange und retten den Adler. Die Deutung des Vorgangs wird expressis verbis angefügt $(56 / 21-56 / 26)$. Der Kernsatz ist folgender:

56/23 "A poneže krestbjane zmija ubiša, a orla izymaša, javljaet, jako naposledok paky chrestbjanstro odoleet besermanstva i sedmocholmago pritmut i $v$ nem vocarjatsja."

Damit ist das eschatologische Schema unserer Erzählung vorgegeben: es wird ein Kampf mit den Mohammedanern stattfinden, in dem diese die Christen besiegen. Aber die Stadt wird be-

54) Die folgenden Ausführungen weisen gewisse Parallelen zum entsprechenden Abschnitt in W.-H. Schmidts gattungstheor. Untersuchungen auf. Doch gehen wir in unseren Auffassungen stellenweise - insbesondere bei der Bewertung der Analysen - auseinander. Schmidt, Untersuchungen, S.101-14. 
freit werden und wieder auferstehen. Dem Kampf mit der Schlange/Islam ist der zweite, der Hauptteil der Erzählung gewidmet; von der Errettung $\mathrm{K}$-pels berichtet $8 \mathrm{chlie} B l i c h$ der dritte reil.

Dies Bild des Kampfes des Adlers mit der Schlange stellt nicht den gesamten ersten $T_{e i l}$ dar, vielmehr ist es in die Gründungsgeschichte $(n) \mathrm{K}$-pels verwoben. Der erste Teil liefert nicht allein das Grundmotiv der erzählung, sondern bildet kompositionell gesehen die Exposition: Aufbau und Aufstieg K-pels dank des Schutzes und der Gnade der Gottesmutter stehen im Mittelpunkt. Und plötzlich erhebt der Autor seine Stimme: in einem fast predigthaften Monolog schlägt er ein anderes Grundmotiv an, das als allgemein christlich bezeichnet werden kann: gesündigt haben wir, haben uns von Gottes Gnade abgewandt. Hier wird das formelhafte "grech radi našich", wie wir es sonst, auch in der Erzählung über die Belagerung Pleskaus antreffen, aktualisiert, es wird zum zentralen Thema; immer wieder unterbricht der Autor das Geschehen mit Sündenbekenntnissen, die oft, wie auch in der Einleitung, in folgender Weise beginnen:

58/4 "... na nas milostb božbju i ščedrot otvraščaemsja i na zlodejanija i bezzakonija obraščmesja, imi že boga $i$ prečistuju ego materb razgnevaem $i$ slavy ovoeja $i \check{c}_{b} t i$ otpadaem, ... n55

So ähnlich: $59 / 5,69 / 6,75 / 37$.

Die Stadt hat sich der Zucht- und Gottlosigkeit ergeben, und deshalb wird sie von Gott gestraft. Aber die Strafen werden - zunächst - nur kurz aufgezählt: Ansturm der Ungläubigen, Hunger, Seuchen, Fehden untereinander ...56 (58/13 - 18).

55) Die Monologe heben sich, wie dargestellt werden wird, durch ihre straff, meist parallel gestalteten Sätze vom ubrigen Kontext ab: daher wurde vom 'predigthaften Ton' gesprochen (s.u.: C Anmerkungen zur Stilistik: 3. Figurae per ordinem).

56) Diese Aufzählung gehört eigentlich zu einem Versatzotück, das wohl zur Verbindung der Teile $1+2$ eingefügt ist. Der 1. Teil schliebt: K-pel litt unter unsagbaren Qualen: "tbmocislennymi bedami 1 ... napastbmi ... postrada." KP 58/11. 
Die Strafen Gottes werden nur summarisch genannt, weil sie kompositionell im ersten $\mathrm{T}_{\mathrm{e}} \mathrm{il}$ nichts zu suchen haben, und leiten zum zweiten, zum Hauptteil über.

Dieser hat dreierlei Punktion:

1. Der Kampf der Christen mit den Türken wird zur Beschreibung der schlimmsten Strafe Gottes: Belagerung, Not, Kampf und schlieblich Eroberung der Stadt durch die Ungläubigen.

2. Durch die in die Kampfhandlungen eingeschobenen Monologe des Autors und die Gebete von Klerus und Volk ergibt sich ein ständiger Wechsel von Sündenbekenntnis/Selbstanklage und Kampfhandlung: Die Bezlehung von Sünde als Ursache und Strafe Gottes als Folge wird ständig aktualisiert.

3. Die Darstellung des Kampfes durch den Autor gibt dieser Beziehung allmählich eine ganz andere Qualität: Aus der antithetischen Stellung von 'Sunde und Strafe' (antithetisch, weil das eine die Folge vom anderen ist) entwikkelt sich eine einheitliche, eine synthetische Position. Das Volk von K-pel er- und bekennt seine Sünden - vom Kaiser bis zum Bürger hinab. Die Bevölkerung wandelt die Strafe, sozusagen vor den Augen des Lesers, um, indem sie diese willig auf sich nimmt als Möglichkeit, für die Sünden zu büßen. So kann aus dem Krieg als GeiBel Gottes ein Kampf für den rechten Glauben im Sinne von BuBe, von tätiger Reue werden: Aus dem Gegensatz: 'Sünde - Strafe'wird eine Gleichung 'Sündenbekenntnis - BuBe, tätige Reue'.

Das Kampfgeschehen ist so dargestellt, daß der Leser fast ständig daran glaubt, daß die gläubige Haltung der Burger, ihr heroischer Kampf, ihre Einmütigkeit belohnt werden durch den ersehnten Sieg. Zwei Mal denkt der Sultan daran, die Belagerung der stadt aufzugeben. Immer wieder wird der Leser Zeuge von unvorstellbaren Abwehrle1stungen der Büger, Einzelleistungen griechischer Ritter. Aber noch bevor der Leser rechten Mut, rechte Hoffnung auf ein gutes Bnde schbpfen kann, bringt der Autor den dusteren Grundakkord der Erzah- 
lung in Erinnerung: er erzählt von Wunderzeichen, die die Weissagung vom Anfang bekräftigen - Wunder, die auf den angekündigten Sieg der Ismaeliten hindeuten: einmal, als der Sultan, bekümmert wegen der unmöglich erscheinenden Einnahme der Stadt, seinem Kriegsrat eine neue Taktik vorgeschlagen hatte - in einem Augenblick also, da der Leser Grund hat, sich über den Ärger und die Niedergeschlagenheit des Sultans zu freuen - da berichtet der Autor, daB der Heilige Geist die Hagia Sophia als Lichterscheinung verlassen habe. Das Entsetzen bei den Griechen ist allgemein; der Kaiser bricht ohnmächtig zusammen $(67 / 37-68 / 20=21$. Mai). Bald wird der Erzählton aber wieder optimistischer: Nach einem schweren Kampftag waren die Türken wieder vertrieben, der Kaiser hatte sich, wie üblich, vor allen ausgezeichnet:

$73 / 11$ "I pochvaljachu cesarja i tako necil skazasa, jako i sam cesarb $v$ serdci svoem voznesesja, no $i$ otšestrie pogan čajachu, ..."

'... und einige berichteten auch, daB der Kaiser sogar ein bibchen stolz wurde in seinem Herzen, und sie erhofften (nach den neuen MiBerfolgen der Türken) nun auch den Abzug der Türken, ..."

Und tatsächlich, so berichtet der Autor, denkt der Gottlose an Aufhebung der Belagerung, als ein neues Wunderzeichen den Sultan wieder von seinem Vorhaben abbringt: Regentropfen fallen vom Himmel - groB wie stieraugen und rot - und bleiben lange auf der Erde liegen. Die Weisen und Mullahs deuten dem Sultan die Erscheinung:

$73 / 36$ "Znamenie veliko estb 1 gradu paguba."

Der Autor arbeitet also mit zwei Spannungsfeldern:

1. mit der dem Kampfgeschehen immanenten Spannung, die er durch Schuren der Hoffnung immer wieder erhöht;

2. mit der Spannung, die zwischen dem meist Hof fnung weckenden Rampfbericht und $2 w i s c h e n$ dem dusteren Leitmotiv (Schlange besiegt Adler), das oft anklingt, entsteht. H. W. Schmidt spricht in diesem Zusammenhang 57 von der

57) Schmidt, Untersuchungen, S. 111. 
"für die Erzählung konstitutive(n) Spannung zwischen der Statik des heilsgeschichtlichen Determinationsund Ablaufschemas und einem Höchstar an zugelassener Realdynamik ...n

Im dritten Teil endlich wird der Bogen zum ersten Tell geschlagen: Die Stadt ist von den Ungläubigen genommen, und Mehmed bestelgt den edelsten Thron unter der Sonne. Nun greift der Autor auf das Glelchnis vom Kampf des Adlers mit der Schlange zuruck. Zwar hat die Schlange des "besermanstvon gesiegt, aber:

$77 / 22$ "No ubo da razumeěsl, okajanne, ăčce vsja prežerečennaja Mefodiem Pataromskym 1 Lbvom Premudrym 1 znamenija o grade sem soverğišasja, to 1 poslednjaja ne prejdut, no takože soveršitisja 1mut. Pib̆et bo: 'Rugil že rod s preźde sozdatelbnyml vaego 1zma1lbta pobedjat 1 Sedmocholmago priłmut a prežde zakonnymi ego 1 v nem vocarjatsja 1 suderžat Sedmocholmago rusy. jazyk šestyj 1 pjatyj ...'n

.... wenn alles der stadt zuvor .... Gewelssagte sich bewahrheitet hat, dann wird sich auch dies letzte erfuillen. ... Denn es steht geschrleben: 'Ein blondes Volk wird die Ismaeliten besiegen .....'

Damlt 1st erklärt, wie man sich die Rettung des Adlers, die im Gleichnis ja durch Menschen (= Christen) erfolgte, konkret vorzustellen habe: eben jenes 'blonde Volk' werde $\mathrm{K}-\mathrm{pel}$ von der Herrschaft der Mohammedaner befreien. - Damit sind Anfang und Ende der Erzählung strukturell miteinander verbunden, der eschatologische Rahmen um die Erzahlung ist gespannt.

Auch das christliche Motiv wird im Sinne der He1lolehre zu Ende gefuhrt: Bisher war von sufstieg - Sünde/Abfall von Gott - Strafe - Sühne/Bube berichtet worden. Die in der Prophezelung angekündgte Rettung der stadt erweist olch nun als Gnadenbewe1s Gottes: Gott hat die Bube der reulgen sunder angenommen, sie sind der Ne1ssagung (Rettung) gowurdigt worden. Letzteres scheint mir besonders wichtig zu sein. Die Gnade, die Gott den Bürgern von K-pel gewährt, indem or sie der 
prophezeiten Rettung fur wirdig hält, soll die Rechtfertigungsabsicht ${ }^{58}$ des Autors stutzen: Gott hat den Byzantinern verziehen - möge die Welt, d.h. der Leser - dies auch tun. Für den Aufbau der Erzählung hat die Schllderung des Kampfes als herolsch, selbstlos, nur auf Verteidigung des Glaubens ausgerichtet, die Funktion der BuBe, der tätigen Reue im Hinblick auf die Begnadigung. In bezug auf den Leser hat die Stilisierung des Belagerungskrieges zu einem Glaubenskampf die Funktion, die Griechen möglichst gut dastehen zu lassen, als wollte der Autor sagen: Seht, so haben wir gekämpft, mehr konnten wir nicht tun; sogar Gott hat uns verziehen, indem er uns Befreiung versprach!

DaB diese Rechtfertigungsabsicht die Motivation für das Niederschreiben der Erzählung uberhaupt darstellt, ergibt sich ganz deutlich an Veränderungen der Fakten, Umdeutungen und Auslassungen des Autors. ${ }^{59} \mathrm{E}_{\mathrm{g}}$ lst hier nicht der Platz, um die gesamte Erzählung auf Verzelchnungen des Geschehens, wie es sonst die Autoren zeitgenössischer Berichte schildern, zu untersuchen. Wir wollen nur kurz daran erinnern, wie z.B. die kurze Erzählung uber den Fall K-pels, wie sie uns in einigen russischen Chroniken begegnet, 60 die Griechen schildert: zwar gibt es Vorbilder an Tapferkeit, wie z.B. der Kalser und Giustiniani. Doch von der Gemeinsamke1t des Wollens, vom Durchdrungensein aller, für den Glauben gegen die Heiden einzustehen, ist in der kurzen Erzählung nichts zu spüren: Peigheit, MiBgunst, Habgier, Egoismus sind die hervorstechenden Merkmale der Menschen. Von Gelagen, Festlichkeiten in der gröBten Not ist die Rede, der typischen Totentanzstimmung also, von Verrat, von sozialen Spannungen.

Die Zahl der Toten erscheint immer maBlos ubertrieben:

So lesen wir S. $60 / 21$ ff.: 2440 auf griechischer, fast 18000 auf turkischer Se1te, auf S. 62/ 24 ff.: 5700 auf

58) Schmidt, Untersuchungen, S. 114, "Rehabilitierungsbestreben"

59) Runclpan, St.: The Pall of Constantinople 1453. Cambridge 1965. S. 203 (Dat1erung).

60) Chronograf zapadno-russkoj redakc11. PSRL 22.2. S. 204 unten bis 207 . 
griechischer Seite stehen 35000 Gefallene auf turkischer Seite gegenuber usw. - Die Belagerung $\mathrm{K}$-pels dauerte $59 \mathrm{Ta}-$ ge, in unserer Erzählung werden daraus sechs Monate. Hier lesen wir auch, daB nach der Erstürmung der Stadt am 29. Mai die Straßenkämpfe noch elf Tage angedauert hätten, während welcher der Sultan nicht gewagt habe, die Stadt zu betreten. Erst, als er Schonung zusagte und versprach, dab er keine Ausschreltungen und keine Plünderungen zulassen werde, legten die Burger die Waffen aus der Hand. Der Sultan bedenkt den gefallenen Kaiser und die Bevölkerung $\mathrm{K}$-pels mit ehrenden Worten, tritt dem Patriarchen respektvoll gegenuber. In Wirklichkeit fand nach der Eroberung $\mathrm{K}$-pels ein tagelanges Morden und Plundern statt. An die Idealisierung Giustinianis in unserer Erzählung se1 noch einmal erinnert.

Auf die Frage, welcher Sunden der Autor die Griechen anklagt, wurde bereits eingegangen: Gott- und Sittenlosigkeit, Eigensucht, Zwietracht, Korruption ...61 Diesen reuevollen, selbst kritischen, wenn auch allgemein gehaltenen Selbstanklagen, die weit uber das gewohnte Pormelhafte hinausgehen, steht die beschönigende Schilderung des Kampfgeschehens gegenuber. An wen wendet sich der Autor damit? Ist die Erzählung nicht als Versuch zu werten, allen an den Kämpfen beteiligten Bürgern, aber auch der ferneren Um- und der Nachwelt durch das Verschweigen alles HäBlichen die GewiBheit zu geben: wir, die Griechen, haben alles Menschenmögliche getan, wir haben heroisch gekämpft; darüberhinaus den Griechen durch die Weissagungen Hoffnung auf Rettung zu wecken, damit ihnen das Schicksal leichter wird? Wenn ein Werk solcher Tendenz dem gedemütigten,

61) Schmidt, Untersuchungen, S. $108 \mathrm{f}$. meint, der Autor habe als Hauptsünde $K$-pels die Unionsbestrebungen mit Rom hinstellen wollen. Well $\mathrm{K}$-pel rom rechten Glauben abgewichen sei und mit Rom Kontakt aufgenommen habe, sel diese Strafe uber die Stadt gekommen. $11 \mathrm{~s}$ Beleg fur diege Annahme fuhrt Schmidt an, daB bei Phrantres u.a. byzantinischen Chronisten gelegentlich ein solcher Berug hergestellt werde. In unserem Text findet er als Beweis hierfur nur die hämische Antwort der Lateiner auf das Hilfegesuch K-pels: "ne dejte, no da vorbmut i turki, a u nich my vozbmem Carbgrad" $60 / 45=$ sollen doch die Türken $\mathrm{K}$-pel erobern - denen jagen wir es dann ab!' Sonst kann Schmidt 
Le1matlos gewordenen Leser Irgendeine Hoffnung auf Restitution des alten Zustandes geben kann, dann wird es sich noch gröBerer Beliebtheit erfreuen. ${ }^{62}$

Wenn wir also annehmen, daB der Autor mit seiner Schrift den Leidensgenossen einen Trost bieten wollte, dann kommt als Autor nur ein Grieche in Prage. Das gleiche gilt, wenn wir den Begriff "Rechtfertigung" ausdehnen auf die Nachwelt. Hier kommt natülich das Tröstungsmotiv nicht mehr in Prage, sondern der hellsgeschichtliche Grundzug: zwar haben wir gesíndigt, aber in diesem Kampf haben wir uns geläutert.

Gerade der letztere Zug gibt uns das Recht, den Autor in kirchlichen Xreisen zu suchen. ${ }^{63}$ Wer sonst sollte dies verschiedenartige Material in einen so dichten und durchgäng1gen Spannungebogen verwandeln, zu einem solchen Motivbündel verknupfen können? ${ }^{64}$ Es $18 t$ bemerkenswert, wie der Autor

nur noch solche Wendungen anfuhren wie: 'wir haben uns von dir abgewandt, Herr!', was er als auf Unionsbestrebungen in $\mathrm{K}$-pel bezogen deutet. M.E. geht er damit zu weit. Fenn es 80 wäre, daB der Autor alle Strafe wegen der Annkiherung an Rom auf $K$-pel gekomen sleht und daB der Autor - sich und $\mathrm{K}$-pel rechtfertigend - eine bewuBt und streng orthodoxe, antirömische Haltung einnimmt, dann bliebe unverständlich, warum der Autor eine so gute Gelegenheit ausgelassen hat, indem er das Be1opiel von Peigheit, Schmach und Schande des Iateiners Giustinea (vgl. Runciman, The Pall of C-pel, S. 144) nicht ausgeschlachtet, sondern ihn vielmehr idealisiert hat.

62) $\nabla g 1$. Schmidt, Untersuchungen, S. 110: "Die besondere Bedeutung der in ferner zukunft $z u$ erwartenden Befreiung und Wiedergeburt in diesem Schema weist den Autor als Repräsentanten einer bestimmten feudalen Gruppe aus, die sich mit dem Untergang des Reiches, konkret: mit dem Verlust der eigenen Herrschaft, noch längst nicht abgefunden hat." - erstens gibt der Text keine Rechtfertigung fur solchen SchluB, zweitens liegt diesem SchluB völlige Pehleinschätzung der menschlichen Natur zugrunde: nicht nur Peudale, jeder leidet unter einem solchen Schicksalsschlag.

63) 80 auch Schmidt, Untersuchungen, S. 109.

$64)$ Uber die Prophezeiungen und ihre Herkunft 8 . Schaeder, Moskau das Dritte Rom, S. 40 - 42, vor allem die Herkunft des "rusil ze rod" aus Pehlúbersetzung von hebr. 'ros' - Haupt' in Septuag. zu gr. 'Rhos' = vulgärgr. 'rotblond'. - Offenbarung d.Methodios: Kampf des Adlers mit der Schlange, a.a.0., S. 46. 
trotz des quantitativen Ubergewichts der reinen Kriegserzählung die beiden Hauptmotive ständig bewubt zu halten weiB:

1. Schlange besiegt Adler $\leftrightarrow$ spätere Rettung durch Christen;

2. Sünde - Strafe - Reue/BuBe - Begnadigung.

Umgekehrt wird aber auch der reine Kriegsbericht, der sicher als Rohmaterial vorlag 65 , durch den eschatologischen Rahmen, in den er hineingestellt ist, nicht gestört oder gar in seiner Wirkung beeinträchtigt. Vielmehr gewinnt er an innerer Spannung, wenn gelegentlich das Motiv der Unvermeidlichkeit des Untergangs $K$-pels anklingt.

Vor diesem Hintergrund wird noch deutlicher, was bereits ver schiedentlich angemerkt worden war-daB das Nestor-Iskander Nachwort eine spätere Anfügung sein muB; zumal dann, wenn man sich unter Nestor einen Russen vorstellen soll. Auch die Vorstellung, daß der Kriegsbericht oder gar die ganze Erzählung von einem Griechen niedergeschrieben worden sei, der sich vielleicht Jahrzehnte lang in türkischer Gefangenschaft befunden habe, ist unwahrscheinlich. Zwar wäre die Motivation, die dieser Erzählung zugrundeliegt, auch auf jenen übertragbar, aber es fällt schwer, diese geschickte und gelehrte Kompilation jemandem zuzuschreiben, der längere Zeit als Gefangener bei den Türken gelebt hat. Schlieblich ist, bezüglich des Nachworts, daran zu erinnern, dab sich der Erzähler, von der Erzählperspektive her zu urteilen, innerhalb der stadt befunden haben muß. 66

65) Die Annahme eines gelehrten geistlichen Kompilators schliebt nicht aus, dab der eigentliche Kriegsbericht in Volksgriech. abgefabt ist: Braun-Schneider, Bericht uber die Eroberung $\mathrm{K}-$ pels, S. 3 und 8. 35 .

66) Schaeder, Moskau das Dritte Rom, S. 45 ff.; Speranskij, Povesti 10, S. 142 f.; Schmidt, Untersuchungen, S. 104, Anm. 2; B. Unbegaun: Les relations vieux-russes de la prise de C-ple. In:RES 9 (1929). S. 13 - 38. Hier S.žf.: Nachwort sicher angefügt. Verfasser war in der Stadt. Dennoch ist Autor Russe, weil er z.B. dem Patriarchen Anastasius eine wichtige Rolle im Gefüge der Erzählung zuweist - K-pel hatte seit 1450 keinen Patriarchen mehr. Ein Grieche hätte das gewust. - Vermutlich hat der Autor im Bestreben, $\mathrm{K}$-pel als intakten Organismus hinzustellen, den Patriarchen eingefürt, wie auch der Kaiser (Witwer) in der Erzählung eine Gattin erhält. 


\subsubsection{Zusammenfassung}

Der unserer Erzählung zugrundeliegende Kriegsbericht ist in einen bestimmten eschatologischen Rahmen gestellt, der ihm aber nichts von seiner auf der geschickten Darstellung eines weltgeschichtlich ungeheuren Vorganges beruhenden Qualität nimmt. Durch den heilsgeschichtlichen Rahmen wird die Erzählung über die Wiedergabe des rein Faktischen hịausgehoben.

Dieser Rahmen hat eine zweifache Komponente:

1. Das Gleichnis von der Schlange, die den Adler besiegt, dann aber selbst von Christen erschlagen wird.

Der erste Teil der Weissageung bildet den Grundakkord des Kriegsberichtes: der Untergang der Stadt ist unvermeidlich - durch Wunderzeichen wird dies Motiv immer wieder in Erinnerung gebracht. Da der Kampfbericht aber bis zum letzten Augenblick Hoffnung auf einen christlichen Sieg suggeriert, uberkreuzen sich hier zwei Motive: Unvermeidlichkeit des Untergangs - Hoffnung auf Sieg. Aus diesem Kontrast entsteht ein Spannungsfeld, das die durch die eigentlichen Kampfhandlungen erzeugte Spannung überlagern kann.

2. Der allgemein christliche Aspekt, der umschrieben sei mit den für die Erzählung zentralen Begriffen: Sünde - Strafe Gottes - Reue/BuBe - Begnadigung.

Die schwerste Strafe Gottes wird von den Bürgern $\mathrm{K}$-pels freiwillig angenommen, sie verwandeln die Strafe, in Verbindung mit reuigen Sündenbekenntnissen und Selbstanklagen, in ihr BuBopfer und reinigen sich so von ihren Sünden. Dadurch werden sie der Prophezeiungen, die eine Errettung der Stadt ankündigen, würdig.

Die Errettung der Stadt wird also nicht allein durch die Deutung des Adler-Schlange-Gleichnisses motiviert: Christen werden die Schlange des Islam erschlagen, sondern die Rettung der stadt wird auch abhängig gemacht von der Reue und der BuBe der sünder.

Eine solche Konzeption macht eine stilisierung der Kampfhandlungen notwendig. Der Kampf um das nackte tberleben wird umgeformt $2 u$ einem Krieg für den rechten Glauben, die Orthodoxie. Gebete und Sindenbekenntnisse gewinnen daher ihre zentrale Bedeutung. Heroisierung und Glorifizierung der 
griechischen Streiter sind auch dadurch motiviert. Vor allem ist dem Autor daran gelegen, alles, was den Eindruck des nur auf Verteidigung der Orthodoxie konzentrierten Rriegers stören könnte, zu eliminieren. Daher finden wir keine Spuren des moralischen Verfalls, den andere Quellen so hervorheben. Der Autor düfte demnach einen Adressatenkreis von zwei Personengruppen beim Abfaseen der Erzählung im Auge gehabt haben:

1. Landsleute, die die Kämpfe miterlebt, den Untergang der Stadt durchlitten haben und nun entweder unter turkischer Herrschaft oder als Plüchtlinge in der Premde leben.

2. Menschen, die die Vorgänge nicht erlebt haben - also fern dem Geschehen Lebende oder die Nachwelt.

Denjenigen, die all das Beschriebene, dann Türkenjoch oder Plucht erlebt haben bzw. noch durchleben, will der Autor Trost bieten. Die Erzählung verklärt die Verhältnisse, wie sie früher waren, die Erinnerung wird idealisiert. Vor allem besteht der Trost darin, daB der Autor im Leser die Hoffnung auf Ruckkehr in die Heimat bzw. Restitution der alten Verhältnisse weckt bzw. wach erhält.

Dem fernen Leser bzw. der Nachwelt gegenüber will der Autor K-pel und seinen letzten Kampf in möglichst günstigem Licht darstellen. Dabel nimmt er eine Verteidigungsstellung ein. In den Selbstanklagen, die aus kompositionellen Grunden die gesamte Erzählung durchziehen, splegeln sich ganz sicher all die Vorwürfe, die man der byzantinischen Lebensweise gemacht hat. In den Ausdrücken "zlodejanija, bezzakonija, oogrešenija" muB man wohl, abstrakt formuliert, all.das vermuten, was der Autor verschweigt, wovon die anderen Quellen aber ein so schlimmes Bild zelchnen. Er bekennt sich zu dlesen Sünden, läbt die Bürger von $x$-pel die Súnden bereuen. Durch den Glaubenskampf werden die Griechen gelautert und durch die Prophezelungen begnadigt. Die Rechtfertigung des Autors besteht nun darin, das er durch das Zugeben der Suinden die Vorwurfe der Ummelt pariert und in seiner Darstellung der Kriegshandlungen und des Stadtlebens demonstriert: 
Im entscheidenden Augenblick, in der Zeit der Not hat $81 \mathrm{ch}$ das sündige Volk der Griechen auf selne Aufgabe, die Verteidigung des rechten Glaubens, besonnen, das alte Leben abgeworfen und nur noch als Streiter für Christus gelebt. Es steht also keinem zu, die Sünden der Griechen als Ursache fur den Untergang der Stadt hinzustellen. 'Tir, die Griechen, sind in uns gegangen und haben das Menschenmögliche zur Rettung der Stadt getan - aber keiner lot uns zu Hilfe gekommen. Deshalb wurde $\mathrm{K}$-pel erobert!'

Sieht man diese Aussagen als Motive für die Entstehung der uns vorliegenden Erzählung an, wird man von elnem russischen Autor nicht mehr sprechen können.

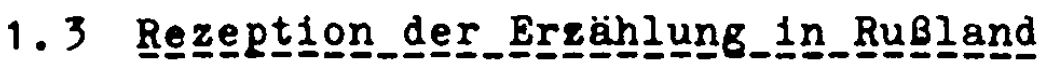

Die ausfühliche Erzählung uber den Fall K-pels, liegt, wie erwähnt, in mehr als 200 Passungen vor, die sich - bis auf die einzelne, von Leonid entdeckte Ho. mit dom HestorIskander-Nachwort - in historlographischen Werken finden. Der Grund fur diese grobe Verbreitung kann schwerlich in der Motivation der Erzählung, wie sie dargelegt wurde (Sympathiewerbung für die Verteidiger von $\mathrm{K}$-pel, Rechtfertigung, Trost), zu suchen sein. Eine solche mubte mit der in RuBland sich gegen Byzanz - wegen der Union von Plorenz - ausbreitenden Stimmung kollidieren.

Die Verbreitung der Erzählung in RuBland hat nicht deren Gesamtkonzeption und Gesamtaussage zum Grund, sondern beruht auf der Betonung bestimmter Aussagen und Aspekte der Brzählung: In einer Ze1t, da in RuBland ant1-unionistische= antibyzantinische Tendenzen die geistliche Atmosphäre weeentlich pragten, konnte man die in der Brzählung reichlich vorhandenen Selbetanklagen und Sundenbekenntnisge gerade auf die Union beriehen und so deuten, als hktten die Griechen gerade diese in thren Klagen angeoprochen und berout. Also konnte die Ereählung als Boweis dafur dienen, daB K-pel der Union nit Rom wegen untergegangen ist. 
Natülich mußte die Prophezeiung, daB $\mathrm{K}$-pel durch ein "rusil že rod" erlöst werde, in RuBland auf allerhöchstes Interesse stoßen. Die Deutung, die diese Wendung erfuhr - sie dokumentiert sich darin, daß die meisten (jüngeren) Hss. aus "rusiin" ein "rus(s)kiin" gemacht haben - war dazu angetan, ein Uberlegenheltsgefühl der Russen gegenuber allem Byzantinischen zu stärken.

Schließlich darf man nicht übersehen, daB die Erzählung ausfuhrlich über ein Ereignis berichtet, das seinerzeit sicher die gesamte Christenheit erschuttert und dessen Beschreibung dementsprechend jeden interessiert hat.

Die Rezeptionsgeschichte der uns vorliegenden ausführlichen Erzählung über den Pall K-pels zelgt, daß diese an der Ausformung der Idee von Moskau als dem Dritten Rom nicht beteiligt gewesen sein konnte. 67 Von den mehr als $200 \mathrm{Ab}-$ schriften der Erzählung ist es allein die einzelne Hs. des Archimandriten Leonid, die auf Anfang 16. Jh. datiert wird alle anderen Abschriften bzw. Varianten der Erzählung erscheinen erst ab 1533 in den Codices.

Wenn man sich vor Augen hält, daß die Theorle von der Beerbung K-pels durch Moskau gegen Ende des 15. Jh.s entstanden sein muß, jedenfalls im ersten viertel des 16 . Jh.s formuliert wurde (Chronograph 1512, Pilofej von Pleskau etwa ab 1520, Legitimiatische Legenden Ende 15. Jh., Spiridon-Savva ab 1513) 68 , dann wird man nicht umhin können, unsere Erzählung lediglich als die bereits ausgeformte Idee otutzend anzusehen. Azbelevs Fund, ein auf ungefähr $1480 \mathrm{zu}$ datieren-

67) Vgl. dagegen: Stender-Petersen, Geschichte, S. 193: "Der Roman bildet den literarischen Auftakt zu dem Aufatieg Moskaus zu Glanz und Macht." - Istorije russkoj Iiteratury, Bd. 1.2 (Akademie), S. 222: ... podgotovljaet ... ideju preemstva Moskvoj roll vtorogo Rina - Konstantinonopolja ..." u.v.a.

68) Sehr ausfuhrlich hierzu: Schaeder, Moskau das Dritte Rom, S. $65-81$, S. $82-117$; Detenbauer, Moskau das dritte Rom, München 1961, S. 51 - 58. 
des Bruchstück der "chronografičeskaja redakcija", bestärkt uns in dieser Meinung, denn er bewe1st, dab die Erzählung im letzten Viertel des 15. Jh.s in RuBland zwar bekannt war, aber kaum Verbreitung fand.

Bereits A. S. Orlov hatte auf die graecophile Tendenz der Erzählung hingewiesen. ${ }^{69}$ In einer Zeit, da Gedankengebäude heranrelften, die alles andere als graecophil waren - Moskau das Dritte Rom, konnte also unsere Erzählung keine groBe Verbreitung finden. Als sich jedoch diese Idee durchgesetzt hatte, schien man übor die graecophile Grundtendenz der Erzählung hinwegzusehen und die für den eigenen antibyzantinlschen Standpunkt relevanten Inhalte (Sündenbekenṇtnisse = beziehen sich auf Union von Plorenz 1438/39) hervorzuheben bzw. der eigenen Position entsprechend umzudeuten ("rusi1" zu "rus(s)kii že rod"). So diente sie ab 1533 in Hunderten von Abschriften der Theorie von Moskau dem Dritten Rom als Bestätigung.

\subsection{Díe_- Textaug}

Unseren Untersuchungen diente die von M. O. Skripil' besorgte Ausgabe der ausführlichen Fassung nach der Hs. des Archimandriten Leonid als Grundlage:

"Povest' o vzjatii Cargrada turkamin. In: Russkie povest1 15 - 16 vekov. Hrsg. M. 0. Skripil'. M. 1958. S. $55-78$.

Leider lst die 1886 von Archimandrit Leonid selbst besorgte Ausgabe seiner Hs. nicht wieder aufgelegt worden, so daB sie auBerhalb (und sicher auch innerhalb) der Sovjet-Union eine Rarität darstellt. Eine Untersuchung auf Grund der Ausgabe der Erzählung von 1886 hätte zur Folge, daB sie beinahe unkontrolllerbar wäre. Aus diesem Grunde entschloB $1 \mathrm{ch}$ mich dazu, die Skripll'sche Ausgabe heranzuziehen, die in jedem seminar resp. Institut für slavistik vorhanden sein durfte.

69) Orlov, Drevnjaja russkaja literatura, S. 237. - D1eses "grekofil'stvo" oder, wie wir oben festgestellt hatten, die griech. Grundhaltung der Erzbhlung durfte einen russiochen Autor ausschlieBen. 
Die Texte sind dort in jener in der Sovjet-Union ublich gewordenen vereinfachten Wiedergabe altruss. Hss. abgedruckt, die sich auch im Westen allmählich durchzusetzen scheint. 70 so erscheinen altruss. - $e-$ und $-q-$ als $-(j) a-$ und $-(j) u-$. -3 am SchluB wird nicht wiedergegeben, -e-. Das in altruss. Hss. nur gelegentlich erscheinende -j- (sog. "i-kratkoen) wird heutigen Gepflogenheiten gemäB geschrieben - also finden wir "kratkyin in der Hs. als "kratky $i^{n}$ in unserer Ausgabe. Die Interpunktion bildet in jedem Fall eine Interpretation des Hrsg.s.

Für bestimmte Untersuchungen ist eine solche Edition ungeeignet. 2.B. stößt man auf gewisse Schwierigkeiten, wenn man an ihr morphologische oder phonetische Besonderheiten eines Textes erarbeiten will - so sehen in unserem Text nbogorodi$\mathrm{cg}^{\mathrm{n}}=$ Nom.sg. und "bogorodicę" = Gen.8g. gleich aus: "bogorodican usw. Pür unsere Untersuchungen vorwiegend am Verb in Verbindung mit stilistischen Kriterien stellt eine Ausgabe mit vereinfachter Wiedergabe der originalen Orthographie der Hs. kein Hindernis dar.

\section{Die Erzählung über die Belagerung Pleskaus durch den polnischen König Stephan Báthory}

Die Erzählung über die Belagerung Pleskaus hat keine so bewegte Textgeschichte und dementsprechend kein solches Interesse in der Porschung gefunden wie die Erzählung über die Eroberung $\mathrm{K}$-pels. Das ist verständlich, denn der Pleskauer Text hat nur eine zögernde Verbreitung erlebt; die Prage nach dem Autor, im Grunde recht unwichtig, stellt das gröBte Problem dar, das mit der Entstehung der Pleskauer Erzählung zusammenhängt.

70) Ich erinnere nur an Fennells Kurbskij-Editionen: The Correspondence between Prince A. M. Kurbskij and Tsar Ivan IV of Russia. Edt. with a Translation and Notes by J. L. I. Fennell. Cambridge 1955. Prince A. M. Kurbsky's History of Ivan IV. Edt. with a Translation and Notes by J. L. I. Fennell. Cambridge 1965. 
2.1 Textge日gchichthte

\subsubsection{Die Handschriften}

Während die Erzählung über die Eroberung $\mathrm{K}$-pels durch die Türken ("chronografičeskaja redakcija") in mehr als $200 \mathrm{Ab}-$ schriften erhalten ist, fand V. I. Malyšev nur 38 Abschriften der Erzählung über die Belagerung Pleskaus. 71

Malyšev besorgte die Textausgabe, die unserer Untersuchung zugrundeliegt. Er hat die einzelnen Hss. sorgfältig uberpruft und sie in Redaktionen und Gruppen aufgeteilt. Die eingehende Beschreibung der Hss. finden wir auf S. $114-127$ unserer Textausgabe, so daB wir uns mit einer knappen Charakterisierung der Hss. begnügen können.

Malyšev unterscheidet zwei Redaktionen: die "redakcija osnovnaja" steht der - verschollenen - Urfassung nahe, während die "redakcija pozdnejšaja", wie der Name schon sagt, jünger ist als die andere Redaktion und sich auBerdem stark an die Aufzelchnungen des Pleskauer Höhlenklosters anlehnt, wie uberhaupt ihre ganze Tendenz die Kopisten bzw. Bearbeiter in kirchlichen Kreisen vermuten läBt. Letztere Redaktion besteht nur aus sieben Hss. ( $a b$ 18. Jh.). Die restlichen 31 Handschriften vertelien sich auf vier Gruppen, in die Malyšev die der Urfassung näherstehende Redaktion aufgeteilt hat.

Die älteste Hs., die Malyšev finden konnte, legte er seiner Ausgabe zugrunde (Anfang 16. Jh. ${ }^{72}$ ) - sie bildet, zusammen mit acht anderen Hss., die erste Gruppe der ursprünglichen Redartion. - Die zweite Gruppe ist in manchen Punkten etwas ausführlicher als die erste, die Ergänzungen sollen nach einer polnischen Quelle hinzugefügt worden sein. 73 -

71) V. I. Malyšev in: Povest' o prịchoženil Stefana Batorija na grad Pokov. Hrsg. V. I. Malysev. AN SSSR M.-L. 1952. (weiter zitiert als: Textausgabe Pleskau). S. $114 \mathrm{ff}$.

72) M. N. Tichomirov: "Povest' o prichoženii Stefana Batorija na grad Pskov". Recenzija. In: Ders.: Russkaja kul'tura 10 - 18 Vv. M. 1968. S. 349: Erzählung entstand Ende 15. Ih.

73) Malys̆ev in: Textausgabe Pleskau, S. 116. - Zeitlich wäre 
Die dritte Gruppe der zur "osnovnaja redakcija" gehörigen Hss. enthält, im Unterschied zu den beiden ersten Gruppen, die Vision eines Schmiedes, namens Dorofej. ${ }^{74}$ Diese Vision wird in der dritten Hss.-Gruppe in knappen, einfachen Worten dargelegt. - Die vierte Gruppe enthält ebenfalls die Vision des Dorofej, sie zeigt stilistische Annäherung an die "Kazanskaja Istorija" sowie an das "Skazanie" des Avramij Palycin - mit diesen beiden Texten ist die vierte Hss.-Gruppe oft zusammen eingebunden.

Von den 38 dem Hrsg. de visu bekannten Hss. stammen nur 13 aus dem 17. Jh., höchstens die der Textausgabe zugrundeliegende Hs. könnte - s. Anm. 72 - Ende des 16. Jh.s entstanden sein. Diese 13 ältesten Hss. entfallen zum großen Teil auf die erste und dritte Gruppe der ersten Redaktion. Nur zwei Hss. der zweiten Gruppe stammen aus der zweiten Hälfte des 17. Jh.s. Das zeigt, daB diese beiden Gruppen, die erste (uns in einer Hs. als Text vorliegende) und die dritte (mit einfacher Darstellung der Vision des Dorofej), die Hss. bilden, die dem Archetypus am nächsten kommen.

Die zweite Redaktion ist, we berelts erwännt, nur mit Hss. vom 18. Jh. $a b$ vertreten. Die Betonung des religiösen Elements, die fur diese Redaktion charakteristisch ist, ëuBert sich auch darin, dab die Vision des Dorofej hier nicht in der knappen, schlichten Version der dritten Gruppe/erste Redaktion dargelegt, sondern in der wortreichen Passung der Aufzeichnungen des Pleskauer Höhlenklosters geschildert ist.

das möglich. 2.B. ein Tell von R. Heldensteine Rerum polonicarum ab excessu S1gismundi Augusti I1bri XII, nämlich: Commentarium de bello Moscovitico erschien bereits 1584/85 in Krakau, Vgl. Rejngol'da Gejdenstejna Zapisko o Moskovskoj vojne 1578-1582. Perevod s latinskago. SPb. 1889. S. VII. (weiter zitiert: Heidenetein, Rerum polonicarum). Wenn Malysev, a.a./., S. 116, meint, der Autor bzw. der Redaktor der'zweiten Gruppe habe selbst an der Verteidigung Pleskaus teilgenommen und habe polnische Quellen gekannt, so ist dies doch sehr in zweifel zu ziehen.

74) 8. Textausgabe Pleskau S. 112 f. und 117 Anm.: Dem Schmied erschien die Gottesmutter zusammen mit Pleskauer Heiligen. Auf deren Bitten hin zeigte die Gottesmutter Dorofej, wo die Voevoden die Kanonen aufstellen und wohin sie zielen soliten; sie zelgte auch das zelt des Königs. 


\subsubsection{Edierungen}

Zuerst erschienen Auszüge der Pleskauer Erzählung in Karamzins groBer Geschichte des Russischen Reiches:

N. M. Karamzin: Istorija Gosudarstva Rossijskago. Bd. 9. SPb. 1821. S. 325 - 40 sowie Anm. 567, 574 - 84, 599, 602 .

Karamzin legte seinen Auszügen eine Hs. aus dem dritten Viertel des 17. Jh.s zugrunde. Bei Malyšev: 1. Redaktion, 3. Gruppe - Hs. 17 (S. 123 f.). 75

Die erste vollständige Ausgabe legte Bodjanskij vor: Pověst' o prichoženil litovakago korolja Stepana na velikij 1 olavnyj grad Pskov ... In: Ctentja v Obscestré 1storii $i$ drevnostej rossijokich pri Moskovokom universiteté.

$1847 \mathrm{Ir}$. 7. S. II und S. $1-47$.

Sonderdruck: M. 1847 .

Bodjanskij benutzte für seine Ausgabe elne Hs. aus dem zweiten Viertel des 17. Jh.8. Malyšev: 1. Redaktion, 3. Gruppe Hs. 15 (S. 122).

Schlieblich wurde die Erzählung noch zwei Mal in Pleskauer Organen abgedruckt, nach jungeren Hs8.:

Povèst' ob osadé goroda Pskova pol'skim korolem Stefanom Batorlem. In: Pokovakle gubernskie védomosti. 1876 Br. 44 47 und 51. $1877 \mathrm{Nr} .1,2,6$ und 9.

Sonderdruck: Pskov 1878.

Ende 18. Jh. Malyšev: 2. Redaktion-Hs. 26 (S. 124 ).

Pověst' o prichoždenii litovakago korolja stefana s velikim 1 gordym voinstrom na velikij 1 slavnyj grad Pakov. in: Trudy Pskovgkogo archeologičeskogo obscestva za 1903-04 g. Pskov 1905. S. 1 - 69.

Ende 18. Jh. Malyšev: 2. Redaktion-Hs. 29 (S. 125).

Ein halbes Jahrhundert später erfolgte eine neue Edierung die unserer Untersuchung zugrundeliegende:

Povest' o prichoženii Stefana Batorija na grad Pakov. Hrog. V. I. Malysev. AN SSSR M.-L. 1952.

Malyŏev benutzte die älteste lhm zugängliche Hs. - Ende 16.Anfang 17. Jh. Malyšev: 1. Redaktion, 1. Gruppe - Hs. 1 (S.119)

75) Die am Schluß der bibliographischen Angaben angegebene Seitenzahl bezieht sich auf die Hs8.-Beschreibung bei Yalyser in: Textausgabe Pleskau. 
Danach hat M. 0. Skripil' unsere Erzählung auch in seinem Sammelband russischer Erzählungen des 15. und 16. Jh.s abgedruckt:

Povest ob osade Pskova Stefanom Batoriem. in: Russkie Povesti 15 - 16vv. Hrog. M. 0. Skripil'. M.-L. 1958. S. 124 166. Neuruss. Ubersetzung S. $296-330$.

Diese Ausgabe beruht auf einer Hs. des zweiten Viertels des 17. Jh.8. Malyšev: 1. Redaktion, 1. Gruppe - Hs. 3 (S. 120). Diese Hs. gleicht der von Malyšev benutzten in solchem MaBe, da $B$ unsere Versuche, an unklaren Stellen hier eine andere Lesart vorzufinden, die uns hätte weiterhelfen können, in der Regel keinen Erfolg hatten. ${ }^{76}$

\subsubsection{Literatur uber die Erzählung}

Spezialliteratur zur Pleskauer Erzählung gibt es nicht. Die wichtigsten Abschnitte, die in allgemeinen Darstellungen (Literaturgeschichten) und in Aufsitzen (2.B. Orlov) uber die Erzählung von der Belagerung Pleskaus zu finden sind, murden bereits in der Einleltung (S. $49 \mathrm{Anm} .26$ ) vorgestellt:

A. S. Orlov mit seinen sich meist wörtlich wiederholenden Charakterisierungen der Erzählung, die auf seinen Aufsatz zurückgehen "O někotorych osobennostjach stilja velikorusskoj latoričeskoj belletristiki $16-17$ vv." in: Izvěstija otdělenija russkago jazyka 1 slovesnost1 imperatorskoj Akademil Nauk. 8 (1908). kn. 4. S. 344 - 79, besonders S. $362-$ 368. Dieser Aufsatz dient auch weiterhin bei Chararterisierungen der Erzählung als Vorlage.

In westlichen Iiteraturgeschichten waren die Besprechungen der Pleskauer Erzählung von Stender-Petersen (Geschichte der russischen Literatur, Bd. 1, S. 199 - 202) und von Tschižewskif (Ciževskij, History of Russian Literature, S. 253 - 55) hervorzuheben.

76) Auszüge der Erzählung - nach Bodjanskifs Ausgabe be1: A. Stender-Petersen: Anthology of Old Bussian Literature. New York 1954. 5. 282 - 97. - Auszugowe1se übersetzt in: Aus dem alten RuBland. Epen, Chroniken und Gedichte. Hrsg. Serge A. Zenkovsky. München 1968. S. 357 - 372. 
Die Rezension der Textausgabe Malyševs durch $M$. N. Tichomirov wurde bereits erwähnt. 77 Wir brauchen hier nicht weiter darauf einzugehen, weil wir in anderem Zusammenhang (Charakterisierung unserer Textausgabe, Frage des Autors) ohnehin darauf zurückkommen werden.

\subsubsection{Mögliche Vorlagen}

Beschreibt der Autor der Erzählung über die Belagerung Pleskaus durch Stephan Báthory auch einen Vorgang, den er vermutlich selbst erlebt hat, so stützer sich doch auch auf literarische Vorlagen, die ihm bestimmte Wendungen, Bilder und sonstige Schreibmuster lieferten.

A. S. Orlov nennt als wichtigste Vorlagen des Pleskauer Autors die "Kazanskaja Istorija" und das "Skazanie o Mamaevom poboiščen, er erwähnt auch mögliche Entlehnungen aus dem Pabelzyklus über Stefanit und Ichnilat (offensichtlich nur, weil 91/29 dem päpstlichen Legaten Antonio Possevino "Ichnilatovo lukavetvo" zugesprochen wird), die Alexandreis u.a. ${ }^{78}$ So glaubt er, daB das Bild der Schlange, das-auf Stephan Báthory bezogen - in unserer Erzählung eine dominierende Rolle spielt, auf die "Kazanskaja Istorija" zurückgeht - der Chan Ulu Machmet sei dargestellt als Chan des Schlangennestes Kazañ. 79 - Stender-Petersen erwähnt als Vorlage Josephus Flavius' "Jüdischen Krieg". 80 - Tschižewskij vermutet darüberhinaus noch Einfluß der Manasses-Chronik. 81

77) M. N. Tichomirov: "Povest" o prichoženii Stefana Batorija na Grad Pskov". Recenzija. In: Ders.: Russkaja kul'tura 10 18 vv. M. 1968. S. 346 - 53. (weiter zitiert als: Tichomirov, Recenzija)

78) Orlov, 0 někotorych osobennostjach, S. 365 f.; Istorija russkoj literatury (Akademie), S. $526 \mathrm{f}$. (= Orlov).

79) Kazanskaja Istorija. Hrsg. G. N. Moiseeva. AN SSSR M.-L. 1954. (weiter zitiert: Kazanskaja Istorija). Dort besonders S. 47 "... o zmilskom žilisce. Glava 1 ".

80) Stender-Petersen, Geschichte, S. 200.

81) Ciževakij, History, S. 254. 
Der EinfluB der "Kazanskaja Istorija" wird von allen Gelehrten immer wieder an ersterstelle angefuhrt, aber es scheint sich dabei nicht um Ergebnisse konkreter Untersuchungen $z u$ handeln. Es wäre jedenfalls von Interesse, das AusmaB dieses Einflusses genauer zu erfahren - was nicht heiBen soll, daB Ich den EinfluB überhaupt anzweifelte. So ist z.B. Orlovs Bemerkung in Bezug auf das "gnezdo zmievo" = Kazań zutreffend, zumal die Schilderung im Ersten Kapitel der "Kazanskaja Istorija" in der Tat sehr beeindruckend ist. Andererseits findet sich das Bild der Schlange auch in der altruss. Iiteratur häufig (s. ausfuhrlicher hierzu in: Anmerkungen zum Stil unserer Texte, besonders im Abschnitt: Bildersprache S. 225 f.). Vor allem sei daran erinnert, daB wir es im Pleskauer Text mit fliegenden Schlangen = Drachen zu tun haben, die auch Feuer speien. Mythische, im Volksdenken wurzelnde Vorstellungen düften hier auch Pate gestanden haben, Stender-Petersen vermutet Entlehnung aus hagiographischen Vorlagen. 82 Allerdings wird man die Schaffung dieses den polnischen König und seine Umgebung 80 wirkungsvoll darstellenden systematisch-geschlossenen Bild-Komplexes als eigene Leistung des Pleskauer Autors betrachten durfen. Die intlehnungen aus dem "Skazanie o Mamaevom poboišče" scheinen mir nicht so gravierend zu sein, wie Orlov u.a. das meinen.

Ich möchte an dieser stelle nur ganz kurz auf Entlehnungen hinweisen, die m.E. die Prioritäten bei der EinfluBnahme älterer Werke auf die Pleskauer Erzählung, wie sie Orlov u.a. gesetzt haben, zumindest auf die Erzählung über die Mamaj-Schlacht, in Prage stellen. Dies gilt vor allem für die Alexandreis. Mir scheint, daB diese eine viel gröbere Anzahl von Redewendungen, Bildern und Formeln bei der Schaffung der Pleskauer Erzählung geliefert hat, als man bisher angenommen hat. Ich sehe mich nicht in der Lage (aus Raumgruinden), das von mir aufgefundene Material im Ganzen vor-

82) Stender-Petersen, Geschichte der russ. Iiteratur, S. 201. 
zustellen. Einige wenige Beispiele mögen für die vielen Parallelstellen stehen:

Der polnische König und seine Würdenträger benutzen in Briefen folgende Eingangsformel: Empfänger im Dativ + "radovatisjan.

49/21 "Bližnim moim susedam, po imeni načalsnomu koegoždo, na svoem deržavstve radovatisja! "

51/17 nØesnejšemu i vysokostolsnejšemu korolju polbskomu

i velikomu knjazju litovskomu stepanu radovatisja.

Mudrosložnaja ... troja k nam pos lanb_ja l jubeznno_priem i_pročtóch $i$ razumechom pisanija, ..."

Vgl. hierzu aus der Alexandreis ${ }^{83}$ s. 16 ( 1.42 ob.):

"Aleksandr vitjazb, carb makidonskij, carb, syn pilippa carja, ... perskomu Dariju carju radovatisja."

S. 17 (1. 45 ob.)

"Moemu l jubimomu bratu ko Archidonu, silurijskomu

carju, Aleksandr, carb makidonsky, radovatisja. Pogs ní

In der Pleskauer Erzählung lesen wir:

92/24 "Ole gluposti, ole nerazuma, glava nogam beseduet, gospodin rabu svoju čests otdaet!"

In der Alexandreis heibt es entsprechend S. 16 ( 1.42 ob.):

".'Ne podobaet carju Darbju, glavu ostavlbse, k nogam besedovat1, ..."

83) Aleksandrija. Roman ob Aleksandre Makedonskom po russkoj rukopisi 15.v. Hrsg. M. N. Botvinnik, Ja. S. Lure, 0. V. Trorogov, M.-L. 1965. - Die Angaben in Klammern hinter der Seitenangabe geben die am Rande vermerkte $\mathrm{Pa-}$ ginierung der Hs, an, damit das Auffinden des 21 tats erleichtert werde ( $1.42 \mathrm{ob} .=11 \mathrm{st} 42 \mathrm{ob}$.$) .$

84) Aleksandrija, S. 229 Anm. 45: die Anrede 'Empfänger im Dativ + "radovatisjan" (vgl. noch S. $17 / 1.43$ ob/, s. 25 /l. $70 \mathrm{ob} / /$ ) sei eine traditionelle antike Briefformel. Die Pormel "poslanie troe l juberno/userdno/... priem 1 proctoch" war vielleicht weiter verbreitet - vgl. Gudzij, Chrestomatija, S. 296, Kurbskij an Ivan Gr.: "Birokovescatelsnoe $i$ mogosumjascee tvoe p1sanie prijach, 1 vrazumech 1 poznach, ...n 
Pleskauer Text:

70/2 "I be videti chrestbjanskie glavy, jako pšeničnye klasy ot zemlja vosterzajusč́lsja 1 tako za christovu veru skončevašesja."

Alexandreis S. $19(1.51)$ :

"Aleksandra videch na Ive jazdjašča vo grad našem Afinstem po širokym ulicam, videch aky klas pšeničnoe izras tajušča 1 makidonjane serpy ak1 žnušče zreloe 1 zelenoe."

Das in der Erzählung über die Belagerung Pleskaus so wichtige Bild von Schlange/Drache ist dem tbersetzer der Alexandreis nicht fremd - S. 15 (1.39):

"..., 1 na ščltech belestro pisatí povele 1 voluja glavy, 1 na selomech vasiliskovy rogy so aspidovymi krily 1 o mersinovym periem."

S. 68 ( 1.186 ob. $)$

'Ne mošči žiti vo gradu tom (= Alexandria) nikomu že, zane že zmlfvelik, iz reki Eglpetskyja 1schodja, mnogi ljudi pogubljaet." "

Weitere Beispiele für offenkundige Entlehnungen aus der Alexandreis finden sich im Kapitel 'Anmerkungen zum $S$ til unserer Texte' im Abschnitt 6. Bildersprache (S. 235).

Möglicherwelse hat der Pleskauer Autor auch den Pabel-zyklus uber Stefanit und Ichnilat stärker benutzt, als bisher vermutet. Allerdings besteht hier auch $A$ la $a$ zur Vermutung, daB die Wendungen, deren Ursprung in jenem Pabelzyklus zu sehen 1st, als 'geflügelte Worte' durch die spätere altruss. Ilteratur wandern. Dennoch bleibt es erstaunlich, daB wir eine so beträchtliche Zahl derartiger Ubernahmen aus dem Pabelzyklus gerade in der Pleskauer Erzählung vorfinden. Vgl.:

$63 / 28$ "I bogomudrene o gradoukreplenb1 smÿ̆ljachu, koego koim obrazom $v$ sovete bog vrazmuit, poneše ne možestrom vladelec izpravljajutca načinanija, no dobryz sovetom, ..." 
Past wörtlich finden wir diese Stelle bereits in Fabelzyklus uber Stefantt und Ichnilat - S. 12 (1. 499 ob.): $84 a$

"Ie možsatrom bo vladalc1 lopravl jajutb načinanba gvon, no 1zrjadnym sovetom."

Im folgenden wird der 21tatcharakter deutlich hervorgehoben: 50/2 "Ha vysokom že otepen1 atoju, na vysočajs̆1e že 1 pre-

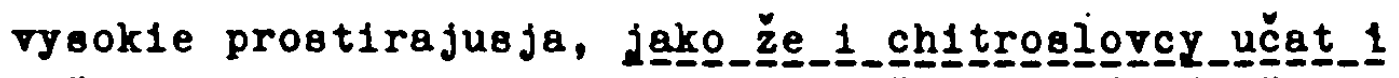

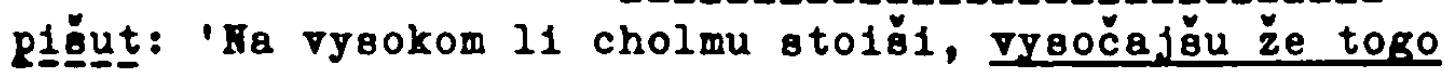

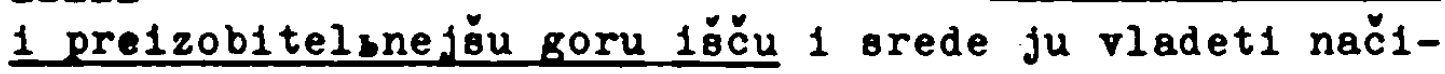
naju. Jako že 1 lev, aŏče 1 deržit zajca 1 vidit verbluda, ostavljaet zajca 1 gonlt verbluda." n

In 'Stefanit und Ichnilat' lautet die entoprechende Stelle: S. $10(1.496)$ :

"Vysokoumnych že muž ne do n1žnich oto1t 1 chudych, no Bornjar 1̊̈čet 1 dostojnar 1m gontt. Jako že 1 lev, ašce raeca drž́lt 1 vidit velobljuda, ostavljaet zaeca 1 vlsbljude ${ }^{84 b}$ gon1t."

Ich bin an dieser Stelle etwas ausuhrlicher auf die Alexandre1s und den Stefanit-und-Ichnilat-zyklus eingegangen, weil diese belden Texte als Vorlage fur die Pleskauer Erzählung viel zu wenlg beachtet werden. Diese werden zwar manchmal als mögliche Quellen für die Pleskauer Erzählung genannt, aber fur die Alexandreis wird kein Belsplel vorgefuhrt, bezuglich des Pabelzyklus um Stefanit und Ichnilat muB man o1ch, wie erwähnt, mit "Ichnilatovo lukavatvo" (Pleskau 91/29) als Belspiel für Entlehnung zufrledengeben.

84a) Stefan1t 1 Ichnilat. Srednevekovaja kniga basen po russk1m rukopis jam $15-17$ vv. Hrsg. 0. P. I1chaceva und Ja. S. Lure. L. 1969. (weiterhin zitiert als "Stefanit 1 Ichnilat").

84b) 80 1m Fext: "velobljuda" - "vlbbljuda". 


\subsection{Konzeption und Komposition der Erzählung} über die Belagerung Pleskaus durch Stephan Báthory

Die Erzählung über die Einnahme $\mathbb{R}$-pels durch die Türken (nach der Hs. des Archimandrit Leonid) zerfiel in vier Teile. Das Nachwort (biographische Notiz des Nestor-Iskander) hatten wir ausgesondert, da es sachlich nicht stimmt (Erzählerperspektive: innerhalb der Stadt, nicht im türkischen Lager) und da es kompositorisch keine erkennbare Punktion besitzt. So zeigt die K-pler Erzählung die klassische Dreiteilung: Einleitung - Hauptteil - SchluB, wobei Einleitung und SchluB einen eschatologischen Rahmen um den bedeutend umfangreicheren Hauptteil (die Schilderung der Kämpfe und der Untergang der Stadt) spannen. Der Kampf wịd so einerseits zu einem Ringen mit dem Unvermeidlichen, andererseits zu einem Läuterungsproze $B$ für die Bevölkerung K-pels.

In der Pleskauer Erzählung sind fünf Teile zu erkennen, von denen nur der letzte (biographische Notiz des Autors/Kopi$\operatorname{sten}^{85}$ und eine Captatio benevolentiae) klar vom vorausgehenden 'Teil abgesetzt ist. Schon die Frage, wo die Exposition endet, ist eine Interpretationsfrage - soll man den Hauptteil als dort beginnend ansehen, wo Stephan Báthory sein Heer aufstellt, um nach Pleskau zu ziehen, oder aber dort, wo er vor Pleskau erscheint 'wie dunkler Rauch vor Pleskaus hellen Mauern' (59/4)? Deutlich ist auch der Schlub erkennbar - dies aber nur auf Grund des Inhalts: FriedensschluB und Abzug der polnischen Truppen.

Dem nur locker gefugten Stoff wollen wir folgendes lockere Gliederungs-Schema unterlegen:

1. Exposition: Schilderung des Livländischen Krieges ab 1577 als Vorgeschichte der Belagerung Pleskaus.

Der Darstellung liegt zugrunde die ideologische Konzeption - rechtgläubiges RuBland : heidnische, satanische Feinde.

$35 / 9-52 / 2=16$ seiten.

85) Nachwort stammt von einem Kopisten: Tichomirov, Recenzija, S. 350. 
2. Hauptteil I:

a) Stephan Bäthory sammelt sein Heer zum Zug nach Pleskau. $52 / 3-59 / 2=7$ Seiten.

b) Erscheinen der köntglichen Truppen vor Pleskau. Bau des Feldlagers. Vorbereitungen zum Sturm.

$$
59 / 2-64 / 9=5 \text { seiten. }
$$

c) Beschießung der Stadt. Hauptangriff.

$$
64 / 10-80 / 9=16 \text { seiten. }
$$

3. Houptteil II:

Belagerung der Stadt vom 9.9. 1581 - 17. 1. 1582. Episodenhafte Anreihung aller Aktionen, die die gegnerische Seite unternahm, um in den Besitz der Stadt zu gelangen.

4. SchluB:

$80 / 10-97 / 16=17$ Seiten.

Nachricht vom FriedensschluB am 17. 1. 1582. Abzug der polnischen Truppen und Offnen der Tore am 4.2. 1582.

$$
97 / 17-98 / 28=11 / 3 \text { seiten. }
$$

5. Nachwort:

Biographische Notiz. Captatio benevolentiae.

$$
98 / 29-88 / 8=1 / 3 \text { Seite. }
$$

Bereits diese grobe Wiedergabe des Inhalts der Pleskauer Erzählung zeigt, daß diese - im Gegensatz zum K-pler Text einlinige Handlungsführung hat. Die in der Exposition vorgegebene Konstellation ( $\mathrm{Zar}=$ Schützer der Orthodoxie/RuBland = identisch mit (hristlichem Reich) wird von Anfang bis Ende beibehalten und findet im SchluB (Aufhebung der Belagerung $=$ Sieg der Orthodoxie) ihre Entsprechung. Diese Geradlinigkeit der Erzahlung geht so weit, daß der Autor keinerlei Spannung aufkommen läßt, die dadurch entstünde, daß die Gegner die echte Chance hätten, die Stadt zu erobern. Diese ist de facto im Verlauf des Hauptansturms zwar gegeben, doch räumt der Autor im kritischen Augenblick alle Zweifel aus dem Wege, indem er in einem Monolog den endgulltgen S1eg der Christen verkundet. Während im $\mathrm{K}$-pler Text solche Vorausdeutungen (wunder) die frisch geschürten Hoffnungen auf Rettung wieder zerstören und an den Untergang gemahnen, haben solche Voraussagen im Pleskauer Text die Funktion, die Situation im Sinne der vorgegebenen Konzeption zu klären. 
Der Autor ist bemüht, die Geschehnisse um Pleskau zu einem Glaubenskrieg emporzustilisieren, aber es gelingt ihm nicht. Zwar ist das Vokabular dem offiziellen moskovitischen Sprachgebrauch und der Absicht des Autors entsprechend gewählt: Russen = Synonym für Christenheit; Polen/Iitauer = Heiden, Satansbrut - doch bleiben diese Wendungen, zumindest was die russische Seite anbelangt, leere Etikettierungen. Obwohl die der polnisch-litauischen Seite beigegebenen Epitheta und Bildfelder wesentlich bunter sind und affektischer wirken, zeigt sich doch, dab es dem Autor letztlich nur um die Glorifizierung der Pleskauer und die Diffamierung der Polen und Litauer geht. Zwar fehlt es nicht an Gebeten, Ansprachen, Segnungen, Prozessionen usw., doch ist der Autor zu stark dem äuBeren Detail verhaftet, der Freude an der Schilderung lebendiger Vorgänge, als dab die Vorgänge hier symbolisch verstanden werden könnten. Der berechtigte stolz des Autors auf seine Pleskauer Mitbürger und ihre Leistung wird oft verdrängt durch jene Borniertheit und Schadenfreude, die durch großtönende Worte aus geistlichem Vokabular nur wenig kaschiert werden.

Differenzierung ist dem Autor fremd, er verwendet nur den Kontrast. Von dem schwarzen Rauch (= polnisches Heer) vor Pleskaus weiBen Mauern war schon die Rede. Die Bevölkerung von Pleskau wird - ähnlich wie die K-pels - als Einheit geschildert. Auf polnischer Seite sehen wir HaB und 2wietracht, Konkurrenzdenken der hohen Chargen, Neid der einzelnen im Heer vertretenen Nationen auf die Erfolge der anderen, die Rottmeister treiben die Heiducken mit der blanken Klinge in den Kampf - in der Erfindung negativer Eigenschaften der gegnerischen Selte ist der Pleskauer Autor sehr einfallsreich und geschickt. Erst durch diese zwar einseitige, aber doch bunte und vielfältige Schilderung des königlichen Heeres und nicht zuletzt des Bönigs gewinnt die Erzählung Leben, wohingegen die Pleskauer seite farblos bleibt. Als Ausnahme kann man vielleicht das Mitwirken der Prauen an der Kampftätigkeit ansprechen $(76 / 22$ - 77/8) - diese Einzelstudie ist wirklich gelungen. Die ubrigen Kampfszenen wirken meist stereotyp, doch kommt dieser Eindruck kaum auf, da 
Ihnen der Autor ständig kontrastierende Szenen entgegensetzt. So folgt dem ersten Ansturm auf die Stadt, dem der Autor durch konventionelle Verglelche ("jako voda mnoga lbjuščesja" 66/28, ähnlich 66/5) Macht, Wucht und Gefährlichkeit zu geben versucht, ein Blick ins königliche Lager, wo sich der König im Gespräch mit seinen würdenträgern und Höflingen befindet $(67 / 25 \mathrm{ff}$.$) . Neben dem 80$ gewonnenen Kontrasteffekt nutzt der Autor diese Szene, um das Negativbild des Gegners zu vervollständigen: im Gespräch des Königs mit seinen Würdenträgern offenbart sich der Konkurrenzneid der letzteren, ${ }^{86}$ inre Uberheblichkeit und Prahlsucht, indem sie den Einzug des Königs nach der (selbstverständlich als sicher vorausgesetzten) Einnahme Pleskaus mit dem Einzug Alexanders d.Gr. in Rom vergleichen. ${ }^{87}$ In den GroBangriff sind verschiedentlich Bilder elngeblendet, die die Gelstlichkeit oder die Prauen im Gebet zeigen $(66 / 8,77 / 10,75 /$ 21). Auf dem Höhepunkt des Kampfes, als Polen und Ungarn je einen Turm eingenommen haben und der Leser für einen Augenblick einen $S_{i e g}$ der Angreifer fürchten müBte, setzt der Autor dem Kampfgeschehen einen eigenen Konolog entgegen er bildet gleichsam eine Antiklimax (71/8 - 72/21): Darin dankt der Autor, vorausgreifend, Gott für die Errettung der Stadt. - Eine so kontrastreiche und bunte Folge von Szenen 1st uns in der $\mathrm{K}$-pler Erzählung nicht begegnet.

Die Geradinigke1t des Erzählstrangs und die fehlende Uberhöhung des Geschehens fängt der Autor nicht nur durch die genannte Polarisierung und Kontrastierung in der Szenenfolge auf, sondern versteht es auch, durch pseudo-authentische Angaben den Leser zu interessieren (Briefwechsel zwischen König Stephan und seinen Feldherren - 46/11, 49/19, 51/17; zahlreiche Dialoge zwischen König und Wüdenträgern u.a.) und gleichzeitig von der Richtigkeit seiner Darstellung zu uber-

86) $68 / 3$ "Molím že ..., da otpustiŏı ... nas napred $v$ zamok Pskova 1 da ne pochvaljatca pred toboju rochmisty, jako ediny z gajduki Pskov vosprijali esmjan".

87) 68/16 " (v Pskov) vnidešl, jako že velikij carb Aleksandre Makodonskij $i$ vaeja vaelennye vladelec $v$ Rim velikij slavnoe svoe viestrie pokaza." 
zeugen - durch das Mittel der Selbstdarstellung des Gegners. Die Darstellung der Gestalten, die das christliche und das heidnische Lager symbolisieren - Zar und König, ist eine völlig andere als in der K-pler Erzählung. Das liegt an der anderen und viel differenzierteren Struktur der K-pler Erzählung: der Sultan ist naturlich Todfeind und Inkarnation des Heidnischen, aber das wird nicht demonstriert - es wird als selbstverständlich vorausgesetzt. Vor allem fehlt dem Sultan das Odium der Infamie, der Falschheit, das Stephan Báthory (allein schon durch die Schlangen-Symbolik) charakterisiert. Der Sultan erscheint als falrer Gegner. 88 Nur als solcher kann er gegen SchluB der Erzählung den Bürgern $\mathrm{K}$-pels großmüig gegenubertreten, dem gefallenen Kaiser respektvolle Worte zollen und beinahe ehrfürchtige Worte an den Patriarchen richten: durch den auf diese Weise bekundeten Respekt eines berümten, gefurchteten und in der Erzählung als fair dargestellten Gegners findet die Heroisierung des Kampfes der Bürger von $\mathrm{K}$-pel ihren Höhepunkt und gleichzeitig die Bestätigung. - Anders im Pleskauer Text, wo die Bestätigung der Tapferkeit im Abziehen der Polen und Litauer (= Sieg) liegt, also im realen Geschehen.

Da also der Pleskauer Autor der Bestätigung der eigenen Tapferkeit nicht bedarf, kann er den Gegner diffamieren und dadurch die Pleskauer Seite besonders in moralischer Hinsicht über die Polen und Litauer erheben. Dies geschieht einerseits durch schilderung besonders gemeiner und hinterhältiger Handlungen ${ }^{89}$ der Soldaten des Königs, andererseits durch die Beschreibung des Königs selbst, Wledergabe seiner

88) Manchmal wird er sogar als ängstlich hingestellt (wenn er Angst vor dem Kaiser hat 75/3, wenn er wegen der 11tägigen Straßenkämpfe nicht wagt, die Stadt zu betreten 76/8): Damit will der Autor nicht den Sultan erniedrigen, sondern Kaiser und K-pler Bürger aufwerten, deren Heldenmut durch die Ängstlichkeit des berühmten Mehmed II. besonders klar vor Augen tritt.

89) Der gesamte Hauptteil II stellt einen Katalog solcher gemeiner Handlungen dar, wobei die Gemeinheit meist in der Bewertung durch den Autor liegt: Das Sprengen der Stadtmauer von Kazań ("Kazansk. Istorija" S. 148 - 50) wird mit Gebeten begleitet; derselbe Versuch der Litauer aber $(84 / 15 \mathrm{ff.})$ 1st eine "bezzakonnych derzostb" $(86 / 8)$. 
Worte, seiner Briefe und seiner Handlungen. Der König tritt ständig in Erscheinung, und dies fast nie ohne abwertende Epitheta (prahlerisch, übermäBig stolz; Schlangensymbolik). Er plant all jene hinterhältigen Handlungen, die seine Söldner ausführen; und umgekehrt geht alles, was an Bösem geschieht, auf ihn zurück.

Zar und König werden nicht miteinander konfrontiert, denn der Zar befindet sich während der Belagerung auBerhalb Pleskaus. Während dieser Zeit tritt er nur einmal kurz handelnd in Erscheinung, und zwar wird berichtet, daB er dem belagerten Pleskau eine Strelitzen-Abteilung zu Hilfe schickt $(89 / 26)$. Sonst erscheint der Zar nur in der Einleitung. Dort wird er vor allem im Gebet geschildert, das stets von Tränenströmen begleitet ist $(37 / 1,-/ 7,39 / 16,-/ 24)$. Damit dokumentiert der Autor jene Epitheta ornantia, die er dem Zaren beizulegen pflegt: "blagovernyj", "christoljubivyj", "pravoslavnyj" usw. Von seinen siegreichen Feldzügen nach Livland wird ruhmend berichtet, von seiner Großmut den Deutschen gegenüber, die sich ihm unterwerfen; erwähnt wird aber auch seine Strenge denen gegenüber, die ihm in ihren Festungen Widerstand leisten. 90 Er erscheint als weiser und umsichtiger Hüter seiner Votcina, wenn er Voevoden nach Pleskau entsendet und von Ferne die Verteidigung organisiert.

Erscheint er also in der Einleitung personlich als idealer Herrscher, so gewinnt er während seiner Abwesenheit von Pleskau den Schein der Heiligkeit: Ständig wird seiner ge-

90) $38 / 18$ "Elịcy že ich na mnogoljudie ili na tverdostb grada nadejuscesja krepce vooruzisasja sideti, u sich steny daze do osnovanija razrusati povele, samech že raznymi gorbkimi gmertbmi, $i$ ich zeny $i$ deti, umertviti povele, da $i$ protčii strach priimutb." - 39/7 "..., mnogija grady vosprija, zivuscaja $v$ nich $v$ plin otvede, bogatestvo .... zlato i srebro ... vo Moskvu prikati." Solche Andeutungen finden ihre volie Gestaltung in den Livländischen Chroniken, die jene Schrecknisse schildern. Die Deportation, "vyvod", wurde auch in Livland praktiziert. Vgl. Bal thasar Russow; Chronica der Prouintz Lyfflandt (1584). Scriptores rerum Livonicarum II. Riga und Leipzig 1848. R. Wittram: Baltische Geschinte. Die Ostseelande Livland, Estland, Kurland 1180 - 1918. S. 72. S. 271 Anm. 25. 
dacht, entweder im Gebet oder - und dies besonders häufig in Ausrufen wie diesen:

75/26 "Dnesb o, druzi, umrem vkupe za christovu veru i za pravoslavnago gosudarja našego i carja i velikogo knjazja Ivana Vasilbeviča vsea Rusi ot litovskich ruk, ...."

Der christliche, d.h. orthodoxe Glaube wird praktisch gleichgesetzt mit dem Zaren. Schon in Byzanz, das Moskau ja beerbt hatte, war das höchste geistliche Amt, das Patriarchat, dem weltlichen Herrscher, dem Basileus, untergeordnet. DaB aber der Zar dem Menschlichen entrückt und Heiligkeit erlangt, ist eine russische Veiterentwicklung der Idee des Gottesgnadentums. Deutlich zeigt der Vergleich mit der K-pler Erzählung den Unterschied: Klar ist die Unterordnung des Patriarchen unter den Kaiser erkennbar. Aber dieser bleibt Mensch. Zwar ist auch er stark idealisiert, aber eher als Vorbild des geistlichen Ritters. Er tritt auch weinend im Gebet auf, aber dies nur nebenbei - in erster linie beeindruckt er mit dem Schwert in der Hand. Außerdem stellt der Autor sein VerantwortungsbewuBtsein und Pflichtgefül heraus: trotz vielen Anmahnens verläBt er $K$-pel nicht. - Man kann nicht argumentieren, daB dem Pleskauer Autor gar nichts anderes ubrig blieb, als den Zar als fast uberirdisches Wesen darzustellen, er sei fa nicht in der stadt gewesen. Darauf ist zu antworten, daß der Autor den zaren gar nicht hätte zu erwähnen brauchen und statt dessen die stadkommandanten klarer herausstellen können.

Dies ist ein weiteres Merkmal der Schilderungstechnik des Pleskauer Autors: Obgleich wir aus beiden Lagern viele Namen von Heerführern kennenlernen, so sind es doch gesichtslose Gestalten - weder die Voevoden von Pleskau, die Pürsten V. P. Sujskij-Skopin und I. P. Sujskij, noch z.B. der Kanzler und Kronhetman Jan Zamoyski, der ja den längsten Teil der Belagerung Pleskaus geleitet hat, treten aus dem Schatten von Zar bzw. König heraus. Dies geschieht offensichtlich, um die Wirkung der Darstellung zu verstärken: den Zaren edler, heiliger und den König böser und gemeiner erscheinen zu lasen. 
In der K-pler Erzählung ist fraglos der Kaiser die dominierende Gestalt. Neben ihn treten aber als durchaus profilierte Gestalten der Genueser Giustiniani und der Patriarch Anastasios (der, wie erwähnt, in Wirklichkeit nicht existierte). Uber das türkische Lager können wir nichts sagen, da die Nachrichten darüber zu dürtig sind. Nicht einmal Sultan Mehmed II. wird mit bestimmten Zügen ausgestattet (über Sultan Mehmed als fairen, gelegentlich ängstlichen Gegner als Mittel zur Aufwertung K-pels - s.0. S. 100, Anm. 88).

Nach diesen allgemeinen Bemerkungen zu wichtigen Mitteln der Erzähltechnik des Pleskauer Autors wollen wir verfolgen, wie sich das Motivationssystem der Erzählung in Einleitung und Hauptteil äußert.

\subsubsection{Die Einleitung}

An Hand der Gegenüberstellung von tatsächlichem Geschehen und dessen Darbietung in der Pleskauer Erzählung wollen wir versuchen darzulegen, wie der Autor durch Selektion und Umdeutung von Pakten dem Leser seinen Standpunkt geradezu propagandistisch aufzwingt. Seine Motive, die infolge der Geradlinigkeit der Erzählung zu erkennen kein Problem darstellt Lobpreis des Herrschers, Glorifizierung der Pleskauer, Sieg des wahren Glaubens über "Heidentum" - sollen durch diese Gegenüberstellung besonders deutlich werden.

Es ist hier nicht der Platz, den Gang des sich 24 Jahre hinziehenden Livländischen Krieges $(1558$ - 82$)$ in extenso dar zustellen. Andererseits sind selbst die wichtigsten Motive und Fakten darüber weithin unbekannt (im Gegensatz zur K-pler Erzählung, wo die Ausgangsituation jedem klar ist). So meinen wir, hier wenigstens einen knappen Uberblick geben $z u$ müssen, da sonst die Technik der Auslassung und Umstellung von Pakten, welcher sich der Autor bedient, gar nicht verständlich wird. Es genügt im folgenden AbriB, wenn wir stärker auf Hintergründe als auf einzelne Kriegsgeschehnisse eingehen, wenn sie nicht gerade unmittelbar mit unserer Erzählung zu tun haben. 


\subsubsection{Der livländische Krieg}

Ohne im einzelnen darauf hinzuweisen, halte ich mich bei dem allzu knappen tberblick an folgende Darstellungen:

C. Goehrke: Die Moskauer Periode. in: RuBland. Prankfurt 1973 (Fischer Weltgeschichte 31). S. $139-41$.

M. Hellmann: Ivan IV. der Schreckliche. Moskau an der Schwelle der Neuzeit. Göttingen 1966 (Persönlichkeit und Geschichte 35).

K. Stählin: Geschichte RuBlands (4 Bde.). Von den Anfängen bis zur Gegenwart. 1. Bd. Stuttgart 1923

ND Graz 1961. S. $266+283 f$.

G. Stökl: Russische Geschichte. Von 3 den Anfängen bis zur Gegenwart. Stuttgart 31973. S. $241-43$.

R. J. Wipper: Iwan Grosny. Moskau 1947. S. 179 - 216.

R. Wittram: Baltische Geschichte. Die Ostseelande Livland, Estland, Kurland 1180 - 1918. München 1954. S. $64-77$.

G. Rhode: Geschichte Polens. Ein tberblick. Darmstadt ${ }^{2} 1966$. S. $211-13$ und $250-253$.

Die blühenden Städte des Deutschen Ordenslandes, d.h. des L1vländischen Zweiges des Deutschen Ordens, wickelten fast den gesamten (ebenfalls anwachsenden) russischen AuBenhandel $a b$ - Riga, Reval und Narva mit ihren Häfen hatten die gröbte Bedeutung. tber das Ordensland kamen - vor allem seit Ivan III. - Fachleute aller möglichen Gewerbe nach RuBland, die die Großfüsten im Westen anwarben, um AnschluB an den dortigen Stand der Technik und der Wirtschaft zu finden. Die deutschen Städe verdienten nicht nur an dem RuBland-Handel, sie kontrollierten auch bis zum gewissen Maße den Menschenstrom, der immer stärker nach Osten $f l O B$. Vor allem für das Kriegswesen wichtige Leute - Festungsbaumeister, Waffenschmiede, Heeresorganisatoren und Söldner - versuchte man, nicht nach RuBland zu lassen - sah man doch zu Recht in jedem vom Grobfursten neu angeworbenen militärischen Spezialisten einen Paktor, der das Ubergewicht RuBlands im Heerwesen gegenüber dem Ordensland vergrößerte.

Mit der vorsichtigen offnung nach Westen seit Ivan III. Diplomatie, Wirtschaft und Handel - muBte die Abhängigkeit von den deutschen Ostseestädten immer deutlicher werden. So war es vereits Ivan III., der 1492 die Festung Ivangorod anlegen lieB - gegenuber Narva (vgl. den Bau des strategischen Stützpunktes Svjazsk in unmittelbarer Nähe Kazańs 1551) und die Schließung des Novgoroder Kontors der Hanse 1494.

Nach der Eroberung Kazańs glaubte Ivan Groznyj, militärisch in der Lage zu sein, das wirtschaftlich hochentwickelte, bevölkerungsreiche Livland mit seinen Hafenstädten RuBland einverleiben zu können. Der Orden stellte kein militärisches Potential mehr dar. Infolge der Paralysierung der politischen Kräfte im Ordensland durch innere Streitigkeiten war kein gemeinsamer Wille, daher auch kein Geld, zumindesten eine 
gemeinsame Politik RuBland gegenüber zu betreiben: Der Orden lag mit den Bischöfen (vor allem Erzbischof von Riga) in ständiger Fehde, die Ritterschaften mit den Städten; im Orden selbst gab es Spannungen zwischen deutsch- und polnisch(Gotthard Kettler) orientierten Gruppierungen, der Konfessionsstreit hatte im Orden fruh schon Wellen geschlagen. Das Fehlen eines gemeinsamen Willens fürte dazu, daß man nicht in der Lage war-da die eigene Kampfkraft schon längst nichts mehr zählte -, Gelder für Söldnerheere aufzubringen.

Das war allgemein bekannt, doch war niemand von den am livländischen Territorium Interessierten (Polen, Schweden) skrupellos genug, grundlos mit Militärmacht ins Ordensland einzufallen. Ivan Groznyj nahm den Vertrag von Pozvol 1557 als einen Vorwand zum Losschlagen: unter polnischem Druck hatte der Ordensmeister Wilhelm von Plettenberg jenen Vertrag (=Verteidigungsbundnis mit Polen gegen RuBland) schließen muissen - dies aber stand im Widerspruch zu einer 1554 von Ivan Groznyj aufgezwungenen Vereinbarung, kein Bündnis mit Polen einzugehen. Der zweite"Kriegsgrund" Ivans war die Unfähigkeit des Ordens, einen bestimmten Tribut an RuBland abzufuhren: Mit Verweis auf einen Vertrag des Hochmeisters Wolther von Plettenberg mit Ivan III., aus dem Ivan Grozny die Anerkennung eines Lehnsverhältnisses des Stifts Dorpat herauszulesen beliebte und Nachzahlung der aus dem Lehnsverhältnis (seit 1503!) resultierenden Tribute forderte, begann er, als der Orden die summe nicht schnell genug aufbringen konnte, den Krieg (91). Die stereotype Formel von Livland als der Votcina, also alten russischen Erblandes, fehlte natürich auch nicht (92).

Zwar brach der Orden unter Ivan Groznyjs militärischen Vorstößen zusammen, doch hielten sich Ivans territoriale Gewinne in Grenzen, da sich die Ritterschaften in Estland Schwoden unterwarfen, das "Uberdüische Land" und Erzstift Riga unmittelbar an Polen kamen, während Gotthard Kettler die südlich der Düna gelegenen Ordensgebiete vom polnischen König als "Herzogtum Kurland und Semgallen" zu Lehen bekam. Die Inseln gingen durch Verkauf an Dänemark. Ivan behielt Wierland (mit dem wichtigen Hafen Narva) und Stift Dorpat in der Hand. Doch waren die Abgrenzungen keineswegs festgeschrieben, vielmehr wurde aus dem so erfolgreich begonnen Krieg Ivans mit dem Orden ein sich zäh dahinschleppender, menschen- und geldverzehrender Krieg mit Schweden, Litauen und Polen. Alte Unionsbestrebungen awischen Polen und Litauen (von Polen bereits seit längerem betrieben), fanden in

91) In der Sovjet-Union begrundet man den Einfall Ivan Gr.s nach Livland so: 1. RuBland benötigte zu seiner wirtschaftlichen Entwicklung, zur Wahrung seiner Interessen einen Zugang zur Ostsee. 2. Livland ist altes russisches Territorium. 3. Esten, Liven und Letten mußten vom deutschen Joch befreit werden. $z_{\text {. B. Istorija SSSR ( } 2 \text { Bde.) }}$ ) Bd. 1. M. 1956. S. 251 (Verf.d. Kapitels: A. A. Zimin).

92) Es wird sovjetischerseits gern darauf verwiesen, daB in der PVL (Nestorchronik) Jurev erwähnt wird. Dazu erklärt 
Litauen schlieblich Zustimmung, als - Zeichen für den russischen Druck auch auf die litauische Grenze - 1563 Polock von russischen Truppen eingenommen wurde: 1569 wurde die Union von Lublin besiegelt - die Staaten, Polen und Litauen, schlossen sich, unter Wahrung relativer Autonomie der beiden Teile, zusammen. Der polnische König hatte in Personalunion auch das Amt und die würde des Litauischen Großfürsten inne. Doch auf den Livländischen Krieg sollte sich diese Union erst ein Jahrzehnt später auswirken.

Ab 1575 führte der Zar - durch Herzog Magnus von Dänemark, den er zum König über die russischen Besitzungen in Livland gemacht hatte (nach dem Vorbild Herzog Gotthard Kettlers in Kurland und Semgallen) - den Krieg wieder mit konzentrierten Kräften fort. 1577 rüstet der Zar selbst zu einem großen Feldzug. Es gelingt inm, innerhalb kürzester Zeit das gesamte alte Ordensland bis hinunter zur Dün zu besetzen. Nur Reval, Riga, Treiden und Dünamünde bleiben unerobert. $D_{a}$ für kann er sich aber auch der Inseln- nach einem Marsch einiger Abteilungen über die zugefrorene See - bemächtigen (Dago, Ösel, Moon). Um jeden Widerstand zu brechen, bedient er sich des Prinzips der "verbrannten Erde", der Zerstörung, Massenhinrichtung und Deportation. - Diese militärischen Erfolge beruhten jedoch darauf, dab Schweden zu der Zeit in Estland militärisch gar nicht präsent war und Polen-Litauen durch das Interregnum (1572 - 76, incl. der "Regierungszeit" von Henri de Valois) vollkommen paralysiert war. Immerhin wagte der Zar aber nicht, die Dunalinie zu überschreiten. Nachdem er das neu gewonnene Gebiet durch Besatzungen und Voevoden gesichert zu haben meint, führt Ivan sein Heer wieder nach RuBland zurück und löst es auf. Hierauf erheben sich viele deutsche Städ te und können sich, z.T. durch Unterstützung aus dem Herzogtum Kurland, wieder befreien.

1576 wird in Polen und Litauen der Fürst von Siebenbürgen

Hellmann, Ivan IV. S. 42, daß es sich bei diesem "Juŕev" nicht um Dorpat handele, sondern um eine alte Siedlung, die sich in der Nähe von Dorpat befunden hat und längst vor der Gründung des deutschen Dorpat von den Esten zerstört worden war. - Bei Tipper (Vipper), Iwan Grosny, S. 67, findet sich eine Aufzeichnung der Rede des Kämmerers und damaligen Günstlings Ivan Groznyj8, A. P. Adasev, die dieser den um Verlängerung des Friedens bittenden Gesandten des Ordens (1554) gehalten haben soll: "Erstaunlich ist es, wieso Ihr nicht wissen wollt, daB Eure Vorfahren nach Livland über das Meer gekommen und in die Erblande der russischen Grobfürsten eingefallen sind, was großes BlutvergieBen nach sich gezogen hat; nicht gewillt, weiteres Christenblut zu vergießen, haben die Vorfahren des Zaren den Deutschen gestattet, das von ihnen besetzte Land $z$ besiedeln, aber unter der Bedingung, da $B$ sie den GroBfürsten dafür zahlen; sie aber haben ihr wort gebrochen und die Abgaben nicht gezahlt, so mübt ihr also jetzt alle AuBenstände begleichen." = jene ungeheuren Tributforderungen des Zaren. 
Stephan Báthory zum König gewählt. Dieser, als Feldherr schon weithin bekannt, muBte erst Danzig zur BotmäBigkeit zwingen ( 1577), das seinem Gegenkandidaten, Kaiser Maximilian II., die Treue hielt (93). Erst danach konnte sich der König dem Livländischen Krieg zuwenden.

Er erkannte, dab es nicht sinnvoll sei, die Selbstbefreiung der städte im einzelnen zu unterstützen, weil sich auf diese Weise ein zäher Festungskrieg entwickeln müBte - Eroberung jedes einzelnen befestigten Platzes, Schlosses, jeder Stadt. vielmehr stieß er direkt auf russisches Territorium vor, um so den Zaren zu zwingen, seine Truppen aus Liviand abzuziehen. 1579 eroberte er Polock zurick, 1580 gewann er Velikie Luki (diese Namen bezeichnen nur immer das Zentrum eines bestimmten Gebietes), und 1581 wollte er in Richtung Novgorod vorstoßen, um so Livland von RuBland abzuschnüren.

Völlig hoffnungslos wurde die Lage der entkräfteten, in Iivland verbliebenen russischen Truppen, als von Estland her der schwedische Peldherr de la Gardie eine weitere Kriegsfront aufrollte.

Ivan Groznyj kam auf den Einfall, Papst und Kaiser zu bitten, Stephan Bathory zur Beendigung des Krieges zu veranlassen. Er habe schon lange vor, sich an einer antitürkischen Liga zu beteiligen, das könne er aber nicht, solange ihn stephan in seinen Krieg verstricke. Auch könnte man nun uber eine Kirchen-Union verhandeln. Derartige offerten verfingen in Rom immer - am 6. Sept. 1580 hatte Ivan Groznyj Istroma Sevregin nach Rom abgefertigt, bereits am 5. Mai 1581 verhandelte der päpstliche Legat Antonio Possevino, der in Zusammenarbeit mit König Stephan bereits vorher die Gegenreformation vorangetrieben hatte, mit diesem wegen eines Priedens mit Ivan Groznyj. Dem König paßten solche Bemuihungen gar nicht, da er hoffte, den Krieg noch eine Zeitlang erfolgreich weiterführen zu können - so verzögerte er die Verhandlungen, während Possevino dauernd von Moskau bzw. vom Lager des Zaren zum Lager des Königs hin- und herreiste (94). Auf die Dauer konnte der König dem Papst keinen Widerstand leisten, deshalb wollte er vor dem zu erwartenden Friedensschlub möglichst viele Faustpfänder in Form von besetzten städten und ländereien auf russischem Territorium gewinnen, um eine gute Ausgangsposition zu haben, wenn die Friedensbedingungen ausgehandelt wïden.

Der Feldzug, den er im Sommer 1581, also Monate nach dem Beginn der Vermittlungsbemühungen Possevinos, in Angriff nahm, war beinahe improvisiert: der sejm hatte nicht genügend Gelder für die Fortfürung des Krieges genehmigt; die Soldatenwerbungen waren nicht so erfolgreich, wie sich der König das erhofft hatte - das Heer hatte nicht die Stärke, die es für die geplanten Unternehmungen brauchte; zudem waren einzelne

93) Der Krieg wurde von Seiten Danzigs "weniger für den Habsburger, als für die weitgehende Selbständigkeit der Stadt geführt." Rhode, Geschichte Polens, S. $250 \mathrm{f}$.

94 ) Uber Possevinos Mission - tendenziös, aber materialreich: E. Winter: RuBland und das Papsttum. Teil 1. Berlin 1960. S. $231-40$. 
Truppenteile noch völlig oder kaum kampferfahren. Ein Teil der polnischen Truppen (unter Hetman Christoph Radziwi $(\mathcal{X}$ ) zwang Ivan Groznyj, der an der oberen Tolga einige Truppen zusammengezogen hatte, zum Rückzug, während der König selbst gegen Pleskau 2og. Wenn man Heidensteins Bericht (Rerum Polonicarum) liest, gewinnt man den Eindruck, daß der ganze Zug eher eine halbherzige Verlegenheitslösung darstellte. Man wuBte nicht recht - sollte man nach Novgorod weiterziehen, sollte man das flache Land besetzen. Die Uberzeugung, da $B$ man Pleskau werde nehmen können, war umso geringer, als der König kaum Pulver hatte, um eine richtige BeschieBung durchführen zu können - kurz zuvor war sein großes Pulverlager in die Luft geflogen. Die Truppen waren z.T. auch unwillig und meuterten, weil sie nur unregelmäbig oder gar keinen sold bekamen (95).

Die Eroberung Pleskaus gelang unter diesen Umständen nicht. Der König sah das auch bald ein. Zwar versuchte er, auf verschiedenste Weise, in die Stadt zu gelangen, aber Anfang November erst konnte er noch einmal einen richtigen Sturmangriff wagen, als er endlich eine groBe Ladung Pulver bekommen hatte (96). Danach verlegte er sich darauf, die Stadt nur zu belagern und womöglich auszuhungern. Doch lesen wir in den Berichten mehr davon, wie die königlichen Heere unter der Kälte litten als die Pleskauer unter Hunger. Anfang Dezember überließ Stephan Báthory dem Kanzler Jan Zamoyski die belagerung und begab sich zuruick nach Polen: es ging nur noch darum, Faustpfänder zu behalten für die Friedensverhandlungen. Báthorys Heere waren auch erschöpft, dazu drohten neue Auseinandersetzungen - diesmal mit Pontus de la Gardie, der für die schwedische Krone Teile Altlivlands $2 u$ erobern suchte - daher blockierte er die Friedensverhandlungen nicht mehr. Zwar brachte der Friede von Jam Zapol'skij (genauer: Kiverova Gorka) bei Velikie Luki kaum Geländegewinne für die polnische Krone, aber Ivan muBte alle besetzten livländischen Gebiete an Polen abtreten. Im folgenden Jahr trat er Estland und Ingermanland an Schweden ab, also auch Narva, das sich in den 25 Jahren bis zum Friedensschlub zum russischen Handelsplatz entwickelt hatte.

95) Reinhold Heidenstein, Rerum Polonicarum ... S. 227 ff. 96) ebda., S.229. 
2.2.1.2 Die Wledergabe des Realgeschehens in der Exposition

Es konnte dem Autor unserer Erzählung, der lediglich ein Schlußkapitel des Livländischen Krieges beschreiben wollte, natürlich nicht darum gehen, diese eben dargestellten komplexen Verhältnisse in ihrer Gänze darzustellen. Er konnte es schon deshalb nicht, weil er die Zusammenhänge und die Kausaltiät der Vorgänge gar nicht kannte. Hier stellt sich grundsätzlich die Frage, wie wir die Darstellung der letzten Phase des Krieges (ab 1577) in der Exposition bewerten sollen: gibt der Autor die allgemeine - manipulierte - Meinung wieder, oder aber findet dort eine elgenmächtige Umdeutung der Vorgänge durch den Autor statt? Es wird wohl beides zutreffen. Zumindest wird man in einigen Fällen bemate Aussonderung allgemein bekannter Tatsachen, die nicht ins Konzept des Autors passen, annehmen dürfen. Deshalb wollen wir im Folgenden den Autor nicht so sehr in den Vordergrund stellen, sondern allgemeiner von der Konzeption der Erzählung sprechen, die, falls sie der damals allgemeinen Meinung entspricht, die offizielle Manipulierung derselben belegt. 97

Die Erzählung setzt ein mit der Jahresangabe ("Be že sie $v$ leta 7085-go, ..." = 1577) und der Nennung des Zaren sowie seiner Söhne Fedor und Ivan. 1582 hat Ivan Groznyj seinen älteren Sohn Ivan in einem Wutanfall erschlagen. 2war ist die frühe Abfassung der Erzählung, sicher nach tagebuchartigen Notizen wahrscheinlich. Aber es ist doch zu bezweifeln, da $B$ die endgültige Ausformung der Erzählung noch im Jahr der zuletzt berichteten Ereignisse (Abzug des polnischen Heeres und Offnen der Stadtore am 4.2. 1582) stattgefunden hat. Es 1st also zu vermuten, daß der Autor unserer Erzählung, der eigenen oder sonstigen Notizen die uns vorliegende Gestalt gegeben hat, den Tod des designierten Nachfolgers und die ihn verursacht habenden Umstände bewuBt verschweigt, um

97) Es führte zu weit, wollten wir hier verfolgen, in welcher We1se die sovjetische Literaturgeschichte bei Besprechungen unserer Erzählung die darin gegebene Deutung der Geschehnisse unkorrigiert läßt. 
das Bild Ivan Groznyjs nicht zu verdunkeln. Hierher können wir den gesamten Komplex der Idealisierung Ivan Groznyjs stellen. Wenn auch das Andenken des Volkes Ivan Groznyj idealisiert hat, 98 wenn auch das gemeine Volk den Zaren anders sah als die Bojaren, die ihn zumeist persönlich haBten und um ihr Leben fürchten mußten, so bedeutet dies nicht, daß man im Volk nicht auch um die Untaten Ivans wuBte. 99 Es ist in diesem Zusammenhang besonders darauf hinzuweisen, daß die Pleskauer Chroniken ein ganz anderes Bild von Ivan zeichnen, was wegen der "Strafgerichte" gegen Novgorod, Pleskau und Tvér 1570, die von der Opričnina durchgeführt, geradezu Feldzugs-Charakter hatten, nur natülich ist. 100

98) Stählin, Geschichte RuBlands, S. 288

99) Beim Volk genoß Ivan Grozny mischte Verehrung, vielleicht, weil es meist nicht so direkt von den Maßnahmen des Zaren betroffen war - Ausnahmen $2 . B$. die gleich erwähnten Strafaktionen gegen Novgorod und Pleskau. Von dieser eigenartigen Verehrung zeugen Bylinen und Lieder. Von besonderem Interesse ist ein Lied "Ivan Groznyj 1 syn". Darin rühmt sich Ivan Gr., in Pleskau und Novgorod den Verrat ausgerottet zu haben, das wolle er nun auch in Moskau tun. Da antwortet ihm sein Sohn Ivan, der Verrat lebe weiter, sogar in seiner engsten Umgebung. Und völlig grundlos bezichtigt er seinen Bruder Fedor des Verrats, woraufhin Ivan Gr. befiehlt, diesen töten zu lassen. Doch ein Knjaz Nikita Romanovic (offensichtlich ein Tribut an die z.Z. der Entstehung des Liedes bereits regierenden Romanovs?) rettet Fedor im letzten Augenblick. Als der Zar seinen toten Sohn betrauert und bereut, daB er ihm nicht verziehen hat, stellt Fürst Nikita den tot geglaubten Sohn vor den $2 a-$ ren hin. - Die Verheerung Pleskaus und Novgorods ist also allgemein bekannt. Vor allem aher bildet das Lied einen Kommentar des Volkes zur Ermordung Ivans durch den Zaren: Es stellt den Sohn Ivan als Schurken dar, der den Vater zur Ermordung des Bruders, also zum Kindesbzw. Sohnesmord verleitet. Damit wird eine gewisse Rechtfertigung für den Mord des Zaren an Ivan geliefert. Die Reue des Zaren über den totgeglaubten Sohn wird sicher eine Parallele zu Ivan Gr.s Schmerz darstellen, der diesen nicht mehr verlassen hat, nachdem er erkannte, was er getan hatte. - Text in: Rusproe narodnoe posticeskoe tvorcestro. Chrestomatija. Hrsg. N. I. Kravcov. M. 1971. S. $239-42$.

100) Die erste und die dritte Pleskauer Chronik berichten von diesem Strafgericht. 1. Chronik: Nach Aufzählung aller Grausamkeiten des Zaren in Novgorod heiBt es: "prilde carb... vo Pskov, ....; prilde s velikoju jarostiju, 
Von der stetigen Sorge des Zaren um das Wohl Pleskaus während der Belagerung und seiner Antellnahme am Schicksal der Stadt, wie sie der Autor unserer Erzählung ständig herausstellt, lesen wir in den Chroniken nichts. Vielmehr heiBt es in der 3. Pleskauer Chronik: ${ }^{101}$

"A u velikogo knjazja carja Ivana bylo $v$ sobranif togda $300000 \mathrm{v}$ Staricy, a na vyručku bojar svolch ne posylal podo Pskov, ni sam pošol, no strachom uderžimz bě. Glagoljut něcyi, jako syna svoego careviča Ivana togo radi ostnem pokolol, čto emu učal govoriti o vyručenil grada Pskova." 102

'Aber der ... Zar ... hatte damals 300000 Mann bei sich, aber er schickte keinen seiner Bojaren zum Entsatz nach Pleskau, kam auch nicht selbst, sondern war von Entsetzen/Furcht gelähmt. Auch erzählt $\operatorname{man} s i c h$, daß er seinen Sohn deshalb mit einem spitzen Stab erschlagen habe, weil dieser begonnen hätte, inm zum Entsatz Pleskaus zuzureden zu raten."

Aus diesen Zeilen spricht die ganze Enttäuschung über die Tatenlosigkeit und die Angst des Zaren. Man muB allerdings hier einräumen, daB der Schreiber dieser Zeilen vermutlich falsche Vorstellungen, von der Stärke des bei Ivan Groznyj

jako levъ rykaja, chotja rasterzati nepovinnyja kjudy 1 krovb mnoguju proliti." Pskovskie letopisi. Vyp. I. Hrsg. A. Nasonov. AN SSSR M.-L. 1941. ND Duisseldorf-The Hague 1967. S. 115. - Die 3. Plsk. Chronik schildert die Grausamkeiten und die Bedrückung Novgorods und Pleskaus womöglich noch drastischer. Der Autor kann sich als Ursache dessen nur einen deutschen Zauberer vorstellen: "Elisej" mit Namen - dieser "i konečne byl otvel carja ot véry : na ruskich vérnych ljudej carju (sic) voszlozil sverépstvo, a k Némcamb na l jubovb preloźi." Pskovskie letopisi. Vyp. II. Hrsg. A. N. Nasonov. AN SSSR M.-L. 1955. S. 262. Vgl. die gesamten Angaben 8.8. 7083 (ebda. S. 262) und s.a. 7078 (ebda. S. 261).

101) Die 1. Plsk. Chronik nennt nur die wichtigsten Daten sich auf unsere Erzählung stützend. Die 2. Plsk. Chronik reicht nur bis 1486 .

102) Pskovskie letopisi II, S. 263. 
in Starica stehenden Heeres hatte. ${ }^{103}$ Eigenartig ist es auch, wie die Gerüchte, denen der Schreiber der Chronik hier bestimmt folgt, die Ermordung des Carević mit dem Schicksal Pleskaus verbinden.

Die der umständlichen Nennung des Zaren und seiner Söhne 104 folgendenden Charakterisierungen als Verteidiger des rechten, wahren Glaubens, vor allem die wortreichen Wendungen und Wiederholungen sowie die Bezeichnung der umliegenden (= nordwestlichen) Reiche als ungläubig ( $35 / 14 \mathrm{ff.}$, zeigen die typischen Kennzeichen des Makarij-Stils und der ihm zugrundeliegenden Ideologie, die auf der Theorie von Moskau als dem Dritten Rom basiert. Hier zeigt sich, wie Gottesgnadentum und HeiligmäBigkeit des Zaren an die Stelle des Weltkaisertums des Basileus getreten sind.

Nachdem durch diese hagiographischen Wendungen, deren Inhalt - wie gezeigt - auch in der konkreten Situation Pleskaus nicht zutreffen, der allgemeine Ton der Erzählung angeschlagen ist, wendet sich der Autor den $z u$ berichtenden Vor gängen zu: Im Jahre 1577 brachen die livländischen Deutschen in russisches Land ein und verwüsteten es. Selbst vor geheiligtem Boden - Pleskauer (?) Höhlenkloster - machten sie nicht halt $(36 / 6)$. - Wie oben dargelegt, hatte König Magnus, Herr über die russischen Eroberungen von Ivan Groznyjs Gnaden, mit seinen Söldnerheeren und russischen Truppen seit 1575 konzentrierte Vorstöße gegen die polnischen und schwedischen Teile Livlands unternommen und verschiedentlich Riga berannt. Noch 1575 wurde auf diese Weise Stift Pernau erobert. $E_{3}$ war gesagt worden, daB Ivan Groznyj 1577 einen riesigen Feldzug vorbereitete, den er auch im Spätsommer begann und im Verlauf dessen er sich das gesamte alte Iivland - bis auf die südlich der Dina gelegenen Gebiete (vorwlegend Herzogtum Kurland und Semgallen) - unterwarf. Auf diesen Feldzug kommt der Autor im folgenden zu sprechen.

103) Ein Zehntel ( 30 000) durfte eher zutreffen. - Heidenstein, Rerum polonicarum, s. 242, berichtet, daB Christoph Radziwi $\not \not \not$, der ja bel Starica operierte, den Zaren einmal beinahe gefangengenommen hatte. Radziwi $\not \chi \not$ selbst hatte nur eine kleinere Abteilung bei sich. 
Und diesem Feldzug dienen die ruchlosen Einfälle der Deutschen, von denen der Autor berichtet, als Begrindung. Vor dem historischen Hintergrund wird deutlich, daß solche Einfälle, die einen riesigen Feldzug wie denjenigen Ivans von 1577 gerechtfertigt hätten, ${ }^{104}$ nicht stattgefunden haben können. Der 'Rachefeldzug' oder 'Gegenschlag', als der der Feldzug 1577 in unserer Erzählung erscheint, ist also eine Erfindung des Pleskauer Autors, die darauf zurückzuführen ist, daß die Fiktion des Glaubenskrieges einerseits und die Fiktion von Ivan Groznyjs Heiligmäbigkeit andererseits einen grundlosen, unprovozierten Angriffskrieg durch den Zaren nicht verträgt.

Es ist auch daran zu denken, daß der Autor das Kriegsleid, das dieser Feldzug in der Folge auch über die russischen Heere und die russische Bevölkerung gebracht hat, nicht als durch Ivan Groznyj verursacht hinstellen, sondern dies alles den Deutschen anlasten möchte. Für den mit den wirklichen Zusammenhängen nicht vertrauten Leser ist die Ursache des Feldzuges 1577 durchaus plausibel - in den Pleskauer Chroniken begegnet man auf Schritt und Tritt Beschreibungen ähnlicher Ubergriffe auf russisches, speziell Pleskauer Gebiet von Iivland aus. 105

Die folgenden Beschreibungen - Ivan Groznyj, wie und was er betet - folgen wohl nicht nur der Fiktion von der HeiligmäBigkeit des Zaren, vielmehr ist wohl Exhibitionismus besonders in religiösen Dingen Ivan Groznyj zur zweiten Natur geworden. Sein Vorgehen in Iivland, wie es der Autor unserer Erzählung andeutet (38/13 ff., $39 / 6 \mathrm{ff.}-$ s.0. S.101, Anm.90), bestätigen in schrecklicher Weise livländische Chroniken.

104) Das muß nicht heißen, daß der Behauptung, daß ein Uberfall auf Pleskauer Gebiet mit evt. Angriff auf das Höhlenkloster stattgefunden habe, keine wahre Begebenheit zugrundeliegen muß. $\mathrm{Zu}$ jener Zeit war offenbar alles möglich: "Die Entwurzelten aus allen Ständen, besonders aus dem waffenfähigen Adel, sammelten sich in abenteuemden Banden, die übel hausten und sich an den Meistbietenden verkauften." Wittram, Baltische Geschichte, S. 75.

105) z.B. Pskovskie letopisi I, S. $63-72$. 
Wenn der Autor im AnschluB daran ( $38 / 24 \mathrm{ff.}$ ) davon berichtet, daB die Deutschen in Kurland ("kurlanskie nemcy") in Purcht und Schrecken gerieten, als sie von den groben siegen des Zaren erfuhren, und sich daher schnell dem Zaren unterworfen haben, so ist das einfach falsch. Ivan Groznyj hat die Diina-Linie nicht überschritten, kurländische Unterwerfungen unter den Zaren gab es nicht. 106

UnermeBlicheSchätze werden aus den eroberten Gebieten nach Moskau gebracht, Massendeportationen finden statt. Der Zar wird wieder ausgiebig im tränenreichen Gebet geschildert. Kaum ist er nach Moskau zurückgekehrt und hat sein Heer aufgelöst, als sich auch in den unterworfenen livländischen Gebieten gleich der Widerstand regt (40/4 ff.). Viele Städte können sich selbst befreien, und auch von Litauen und Polen aus werden Versuche gemacht, die nördlich der Düna gelegenen Gebiete ("Uberdünsches Land") zurückzugewinnen. - In diesen Abschnitten stimmen Darstellung und Realität etwa uberein.

Die nun folgenden schilderungen ( $40 / 32 \mathrm{ff}$.) gehören aber ins Reich der Legende: Als der Zar vom Verrat der Deutschen erfährt, rüstet er zu eines neuen Feldzug. Dies wird den Deutschen bekannt, und wieder verfallen sle in Angst und Schrekken und suchen (da sie wissen, daB sie dem Zaren gegenüber machtlos sind) einen Ausweg: Sie senden den Verräter $A$. Kurbskij zum polnischen König; Kurbskij solle ihnen die Waffenhilfe des Königs vermitteln. Der König nimmt diesen hinterhältigen Vorschlag der Deutschen freudig auf und lädt seine Peldherren zum Feldzug gegen Ivan Groznyj ein.

Die Flucht Kurbskijs (30.4. 1564 von Dorpat aus, wo er Voevode war) muB ein ungeheures Aufsehen erregt haben. Nicht umsonst machte sich der Zar die Muhe, inm so lang und breit auf seine Briefe zu antworten und inn zum Verräter abzustem-

106) Ob hier bewuBte Pälschung vorliegt oder Unkenntnis des Autors, bleibt unklar. Es ist denkbar, daB der Autor mit "kurlanskie nemcy" auch die Bewohner des "Uberdunschen Landes"meinte, das ja (wie Kurland) dem polnischen König (allerdings unmittelbar) sowie Litauen (Rhode, Geschichte Polens, S. 211) unterstellt war und das, nördilch der Dün gelegen, auch von Ivan Gr. $1577 / 78$ erobert wurde. 
peln. Ivans Briefe finden weite Verbreitung, ${ }^{107}$ und so ist es auch kein Wunder, daB "Kurbskij - der Verräter" gleichsam als Topos in die offiziöse, besonders historiographische Literatur einging. ${ }^{108}$ Der Verrat bleibt unvergessen: Noch 1577 schrelbt der Zar Kurbskij aus dem soeben eingenommenen Wollmar (dem ersten Zielpunkt Kurbskijs nach seiner Flucht aus Dorpat und Absendeort von Kurbskifs erster Epistel an den Zaren) ein triumphierend-1ronisches Pamphlet. ${ }^{109}$ - Der Autor unserer Pleskauer Erzählung verknupft nun geschickt den "Verrat" Kurbakijs, den Ort seiner Flucht (von Dorpat nach Wollmar = Livland) und das 21 el seiner Flucht (der polnische König), bringt Livländer und polnischen König durch die Person Kurbskijs als Vermittler in einen direkten Zusammenhang, wodurch alle drei Faktoren in ein gleichermaßen uibles Licht geraten sollen.

Eine derartige Vermittlung durch Andrej Kurbskij war in Wirklichkeit gar nicht nötig - die polnischen Interessen in Livland waren ohnehin handfest genug. Und daB man in Livland polnische Politik machte und kelne deutsche, ist verstänlich: Mit möglichst geringem Aufwand den gröbtmöglichen politischen Effekt und gröBten territorialen Gewinn zu erzielen, so zumindest z.zt. Sigismund II. August $(1548-72) \cdot{ }^{110}$ Wenn wir also beobachten, wie in unserer Erzählung der polnische König - nunmehr Stephan Báthory - mit Hilfe von Purst

107) Ja. S, Lure: Novye spiski 'Careva gosudareva poslanifa vo vae ego Rossijskoe carstvo'. In: TODRL 10 (1954). S. 305 - 309. Lure meint, daB zumindest der erste Brief des Zaren in besonderem Maße zur Veröffentlichung bestimmt war.

108) Vgl. z.B. Nikon-Chronik, PSRL 13, S. 383 s.8. 7072.

109) Pennell, Prince Kurbsky and Tsar Ivan IV, S. 186-97. Nach 1hm son der Brief - trotz der Datierung "7068 g.a" - an 12. 9. 1577 ausgefertigt sein - ebda. 8. 197 Anm.2.

110) So hatte z.B. die Tatsache, dab sich das nUberdunische Land" (also Ritterschaften usw. nördlich der Duna gelegen) der polnischen Rrone unterstellt hatte (8.0. Anm. 106), für die Bevölkerung kaum positive Folgen, da durch die Besetzung der als Pfand für den Schutz gegebenen Schlösser lediglich die Duna-Linie gesichert wurde. Schutz erwuchs der Bevölkerung hieraus nicht, im Gegenteil: die undisziplinierten polnischen Truppen (Völkergemisch, z.T. Tataren) wurden zur Plage. Pittram, Baltische Geschichte, S. 69. Rhode, Geschichte Polens, S. 211 f. 
Kurbskij zum Werkzeug der Deutschen in Livland und Kurland wird, so düfen wir darin sicher eine von unserem Autor selbst hergestellte Verbindung (= Erfindung, Fiktion) sehen. Auf den ersten Seiten wird also, allein schon durch den Vergleich von Angaben der Erzählung mit anderen Quellen, die Tendenz des Textes klar. Der Autor übernimmt aus den Chroniken einen der häufigen Vorwürfe gegen die Deutschen - den Vorwurf unberechtigter, vertragsbrechender und hinterhäliger Angriffe der Deutschen (speziell des Dorpater Gebiets) auf Pleskauer Land. In den Chroniken führen diese Kleinkriege zu Verhandlungen zwischen Pleskau und Dorpat und besonderen, beide Vertragspartner betreffenden Regelungen. In unserer Erzählung geben diese Geplänkel den Grund für Ivan Groznyjs großen Feldzug von 1577 ab. Es geht darum, den Zaren nicht als Angreifer dastehen zu lassen. Ebenso entspricht es nicht der Tendenz der Erzählung, die Feldzüge Stephan Báthorys als Reaktion auf Ivans Angriffe hinzustellen - dies wäre ja eine verständiche Reaktion, die nur dem Zaren zugebilligt wird. Um auch aus diesem Gegenzug des polnischen Königs einen infamen Akt zu machen, läßt der Autor unserer Erzählung jenen als Werkzeug der hinterhältigen, vertragsbrüchigen deutschen Städte erscheinen. Charakteristisch ist, daß Stephan Báthory diese Judas-pläne ("iud(e)jskim sovetom" 41/7) mit Freuden ("radostno") aufnimmt. - Weiter war zu bemerken, daB die Ermordung des Carevič durch Ivan Groznyj verschwiegen wird. Die Idealisierung des Zaren bis zum Grade der HeiligmäBigkeit wird beinahe systematisch vom ersten Satz an betrieben, obgleich wir an Hand anderer Quellen nachweisen konnten, daB diese Idealisierung gerade im Hinblick auf die Pleskauer Verteidigung absolut nicht angebracht war.

Durch das Hilfeersuchen der Deutschen wird Stephan Báthory eingefürt. Wie der erste Teil der Einleitung der Beschützerrolle Ivan Groznyjs, die er dem rechten Glauben, hier speziell den Livländischen Deutschen gegenüber, innehat, gewidmet ist, gilt der zweite Teil der Einleitung der Vorstellung 8 tephan Báthorys als Inkarnation des Antichrist.

Den ersten Schritt hierzu hat der Autor bereits durch die 
Einführung des polnischen Königs als Werkzeug der Deutschen getan. Durch den allgemein bekannten Gang der Geschehnisse des Krieges ist dem Leser Stephan Báthory als Erzfeind vertraut.

Der Autor hätte die Möglichkeit, die der K-pler Autor realisiert, den polnischen König als Heiden, Ungläubigen, Verdammten usw. hinzustellen. Das würde sich umso eher anbieten, als der Zar ja als allem Menschlichen enthoben stilisiert wird. Dadurch wäre bereits eine schärfere antithetische Zeichnung ermöglicht als im K-pler Text, weil der Kaiser eher das Ideal des christlichen Ritters und nicht so sehr der Heiligkeit ver körpert und umgekehrt der Sultan nicht als der Bösewicht schlechthin erscheinen darf, well er aus Gründen der Rechtfer tigungsmotivation in der K-pler Erzahlung die Tapferke1t des Kaisers und der Bürger loben muB (Lob durch den Gegner ist das hochete Lob).

Aber der Pleskauer Autor gibt sich mit dieser effektvollen Gegenüberstellung von Zar und König nicht zufrieden: sie scheint ihm die Bösartigkeit und Infamie des Königs noch nicht genuigend herauszustellen.

Dies dokumentiert bereits die durch den Autor erfundene Mittlerrolle Kurbskijs, der die Deutschen und Báthory 'miteinander ins Geschäft bringt'. So erscheint der Verräter Kurbskij als Vertrauter der Deutschen und des Königs, d.h. schon dadurch wird der König in MiBkredit gebracht.

Der polnische König wird in unserer Erzählung generell als 'Iitauischer König' bezeichnet (Ausnahmen: Anreden seiner Untertanen, ironische Apostrophierungen u. ä.). Das ist nichts Ungewöhnliches. Auch im 16. Jh. begegnet außer im diplomatischen Verkehr statt 'polnisch' im allgemeinen 'litauisch'. 111 Liest man in Chroniken, vor allem in nordrussischen, dann fallen haufige Streitigkeiten mit dem litauischen Nachbarn auf. Diese oind dadurch bedingt, dab die Moskauer Grobfursten immer versucht haben, im litauischen Staatsgebiet lebende we1B-

111) Wenn wir z.B. in der Nikon-Chronik, PSRL 13, S. 340, lesen: "korolb polbskij", so steht dem S. 340 "korolju 11tovskomu" gegenüber, dazu auf diesen Seiten ca. 15 Mal $11-$ tovskij" statt "polbskij". Plesk. Text: 151x"litovokijn, dagegen $16 x^{n}$ polsokij". 
russische und ukrainische (oft gemeinsam als "ruthenisch" bezeichnet) Fürsten (mit ihrem Land natürlich!) auf ihre Seite zu ziehen. Fälle von religiöser Repression oder von Bestrebungen, in Litauen eine katholisch-orthodoxe Union in die Wege zu leiten, ${ }^{112}$ wurden von den Moskauer GroBfürsten gern zum AnlaB genommen, sich in litauische Angelegenheiten einzumischen. Andererseits war A. Kurbskij nicht der erste russische Pürst, der in Litauen oder Polen Zuflucht suchte. Trotz alledem hat der Terminus "litovskij" incl. der Nebenbedeutung "polbskij" keinen negativen Sinn, verbindet sich nicht unbedingt mit einem Feindbild. Die Beziehungen zwischen Litauen und der Rus und dem moskovitischen RuBland kann man zwar als gegnerschaftlich, aber doch relativ emotionsfrei betrachten - so stellen sie sich in den schriftlichen Zeugnissen, Chroniken vor allem dar.

Anders das Bild der (livländischen) Deutschen in der Pleskaner Chronik! Die Kämpfe mit dem Orden sind ein General thema dort. Und in der Regel sind diese Kleinkriege als Vertragsbrüche der Deutschen deklariert. Zwar schildern die Chroniken nach solchen Auseinandersetzungen auch den Friedensschlub, die Handreichung als Symbol - aber manchmal ist man erstaunt, daß nach den vorausgehenden Schilderungen und Paraphrasierungen der Deutschen überhaupt noch ein Friedensschluß möglich ist. ${ }^{113}$ Das Verhältnis zwischen Pleskau und dem nördlichen Nachbarn erscheint als grundsätzlich feindlich. Hab und Wut führen den Chronisten oft die Feder - der Krieg geht offenbar ständig hin und her. Friedensverträge wirken oft wie Zwangspausen. Diese Vorstellung nun grelft der Ples-

112) Diese kam 1595 zustande. Näheres: M. Hrushevsky; A Hi3 story of Ukraine. Hrsg. 0. J. Frederiksen. New Haven 31948. S. 205 - 10. Rhode, Geschichte Polens, S. 265-67.

113) "Togo że lěta, v velikoe gov̌nie, oni poganii Latyni, Nêmcy, izgonivse izgonoju, i ne věruja vo krestnoe celovanie, na to obidnoe mesto, ...., na zeml ju Svjatyja Troica, devjatb človékb sozgosa i cerkovb archistratiga bozija Michaila. Togo ze leta knjazb pskovskij... sedsi

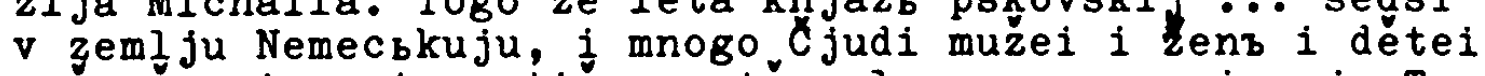
pozgosa, i mestb mstisa za té golovy za nepovinny ja. Togo ze leta, ne na dolze vremeni, Nemcy échavse ... vo Paskov skuju zemlju, ..." Pskovskie letopisi I, S. 56 s.a.1459. 
kauer Autor auf, läBt sie lebendig werden. Sie dient ihm als Anlab für die Feldzüge von $1577 / 78$ - dies Bild des verräterischen, hinterhältigen, kriegssüchtigen Doutschen dient dem Autor auch zur ersten Charakterisierung Stephan Báthorys. Durch Kurbskij, den Vermittler, gehen diese Elgenschaften alle auf den König über. Er wird also zunächst indirekt cha rakterisiert: 1 . er hat den Verräter Kurbskif zum Freund; 2. er erscheint als Werkzeug der ublen Deutschen, 3. deren judashaften Vorschlag er freudig aufnimmt.

Nach diesen Vorbereitungen kommt der Autor endlich zur direkten Charakterisierung des Königs: "be bo 1 sam toj litovskij

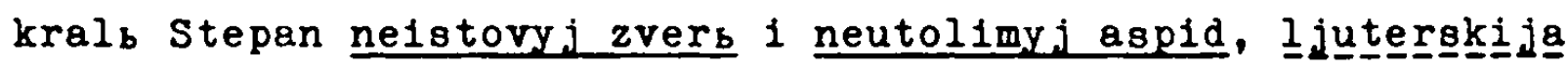
svoeja very voin, 1 rad be vsegda krovoprolitbju 1 naćinanija branem. NA POLOCKO. Ljutyj že 1 sver1pyj zmeinyj jad ot svoeja nesytyja utroby otrygnuv, ..." 41/11. An dieser stelle setzt die Schlangensymbolik ein, die bis zum Beginn der Kampfhandlungen geradezu systematisch der Iitauischen Seite beigegeben wird (1m Einzelnen hierzu - s. Anmerkungen

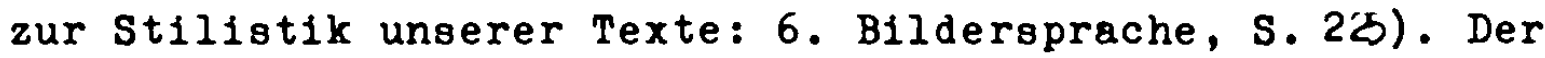
Autor versucht mit allen Mitteln - mit denen der direkten Chararterisierung, wie z.B. dem direkten Epitheton (das zum Epltheton ornans wird), mit allen möglichen Varianten des Schlangenbildes - die Gegenseite zu verunglimpfen, zum charakterlich-menschlichen Abfall zu stempeln. Dies geschieht b1s zum Einsetzen der Kamphhandlungen in so konsequenter und so konzentrierter Weise, daB dann, wenn der Autor bzw. der Leser durch die sich überstürzenden. Handlungen gefesselt sind, nur ein Epitheton genügt, um das gewünschte B1Id, die gewinschte Vorstellung $z u$ evozieren.

Vor diesem Hintergrund werden die "Christen", das sind Pleskauer und Russen uberhaupt, zum Inbegriff für Tugend, Glaube und Reinheit. Hier bleibt das Vokabular stereotyp.

114) Zur Einle1tung noch eine abschlieBende allgemeine Bemerkung: Entgegen dem allgemeinen Sprachgebrauch verwendet unser Autor "votcina" nie in Verbindung mit Livland: $36 / 9$ "vifljanskija zemli nemec", $37 / 31$ "Dostigsu emu ... vifl janskija zemija", $39 / 6$ "Vifi janskuju ze zemlju ... povoeva,.... vo svoju votćinu na Ruskuju zemlju vozvratisja." "votćina" = RuBld. od. Pleskau. Vgl. dagegen die 'Geschichte Livlands' in "Stepen.kniga" PSRI $21, \mathrm{~S} .655$. 


\subsubsection{Der Hauptteil}

Ähnlich wie in der Einleitung könnten wir jetzt die Darbietung des Realgeschehens im Hauptteil auf ihren Wahrheitsgehalt prifen. Doch mir scheint, die durch die Tendenz der Erzählung bedingte Praxis der Umdeutung, Aussparung, Umstellung von Pakten ist im Rahmen der Betrachtung der Einleitung bereits ausführlich genug dargestellt worden. Fur eine systematische Untersuchung der Nachrichten waren mir darüberhinaus nicht alle Quellen zugänglich. ${ }^{115}$ Im Wesentlichen stimmen die Fakten mit denen bei Heidenstein, De rerum Polonicarum ... überein. Jeder Autor - Heidenstein und der unserer Pleskauer Erzählung - setzt die Akzente anders, wobei die Glorifizierungstendenz des letzteren beim Vergleich besonders hervorsticht. Heidenstein betrachtet den gesamten Feldzug ziemlich kritisch, sachlich, distanziert - wie Jemand, der dem ganzen Unternehmen keine großen Chancen eingeräumt hat und sich nun bestätigt sieht. Lob der Pleskauer und Tadel an den Truppen des Königs sind häufig anzutreffen. Uberhaupt kommen kritische Anmerkungen viel häufiger vor als lobende. Auf Grund dieser Beobachtungen ist man geneigt, Heidenstein eher zu glauben als dem Pleskauer Autor in seiner tendenziösen Darstellung.

Dies Kriterium der Glaubwüdigkeit reicht aber nicht, ersetzt keine weiteren Quellen - 30 muB man im folgenden Beispiel doch fragen, ob Heidenstein da nicht bagatellisiert: Er berichtet, daß man begonnen hatte, unterirdische Gänge zur Stadtmauer zu graben, um diese von dorther zu sprengen zwei Gräben gab man auf, weil der Grund zu steinig war. Einer konnte fast bis an die Mauer gefüht werden, als er von den Pleskauern entdeckt und gesprengt wurde. ${ }^{116}$ - Der Pleskauer Autor erwähnt neun Gänge, die man an der Mauer entdeckt habe. Die "Litauische Chronik, knapp hierauf eingehend, nennt gar kei-

115) Besonders Jan Piotrowaki: Dnernik poslednego pochoda Stefana Batorija na Rossiju (Osada Pskova). Perevod 8 pol'skogo 0. N. Milevskago. Pskov 1882. (Polnischer Originaltitel ist mir unbekannt).

116) Heidenstein, Rerum polonicarum, s. 213. 
ne Zahl. 117 - Wenn der Pleskauer Autor die Entdeckung der unter1rdischen Gänge als eine besondere Strafe Gottes an den Iitauern darstellt, weil diese eine Prozession beschossen und dabel auch eine Ikone getroffen hatten, dann ist das eine Deutung, die im belagerten Pleskau slcher sehr populär war, stärkte sie doch das Vertrauen der Pleskauer in Gottes Hilfe. Eine elgene Leistung unseres Autors liegt hier sicher nicht vor (S. $84-86) \cdot 118$

Den Gipfel der litauischen Infamie bildet die Ubersendung der Schatztruhe eines gewissen Hans völler, die aber eine Sprengladung enthält und beim Offnen die Stadtkommandanten Pleskaus töten soll ( 3.95 - 97). Stellen wir die uns vorliegenden Quellen daneben, wird klar, daB der Pleskauer Autor nicht den Grund für diese Maßnahme genannt hat: Es war zwischen Polen und Pleskauern ein Tag Waffenruhe vereinbart worden, damit man die Toten einsammeln könne. An diesem Tag tummelte sich viel Kriegsvolk aus den königlichen Lagern vor der Stadt - nichts Böses ahnend, als plötzlich von der Stadt her starkes Peuer, sogar aus Kanonen, eröffnet wurde. Die Höllenmaschine sel ein Racheakt für Jenen Vertragsbruch gewesen. Ubrigens soll die Maschine, im Gegensatz zur Aussage der Pleskauer Erzählung, einige Voevoden getötet und anscheinend auch Ivan P. Sujakif verletzt haben. 119

In beiden Texten ist davon die kede, daB es einer russischen Strelitzenabteilung gelungen war, durch den polnischen Belagerungaring nach Pleskau vorzustoBen - für den Pleskauer Autor Grund zur Freude und zu spott und Hohn den "IItauern" (s. 90). In den anderen Quellen erscheint dieser kleine

117) Chronika litorakaja 1 žmojtskaja. In: PSRL 32. M. 1975. (weiter zitiert als: Litauische Chronik). S. 123

118) Diese Seltanangaben in den Klammern beriehen sich auf die unserer Untersuchung zugrundeliegende Textausgage der Erzählung über die Belagerung Pleskaus von Malyser.

119) Heidenstein, 'Rerum polonicarum, S. 249 I., S. 252. IItauische Chronik S. 125. Belde berlchten von einer Duellforderung sujskijs an den Kanzler Zamoyski wegen des Attentats. Zwar sel letzterer zur vereinbarten stunde dort gewesen, nicht aber Sujokif. Daraul habe der Kansler an Sujakijj eine Maus geschickt, "naryvajučl ego takom, Jako mys v jamé, ricerom" - Lit. Chronik, S. 125. 
Trupp als nicht der Rede wert (Varianten der Pleskauer Erzählung - S. 105 Anm. 44 sprechen von 500 Mann; Heidenstein nennt 300, die nach Pleskau gelangten, 150 Gefangene und 60 , die getötet wurden ${ }^{120}$ ). He1denstein berichtet von Tausenden, die bei dem Versuch, nach Pleskau hineinzukommen, abgefangen wurden - einmal seien 7000 auf einen Schlag in polnische Gefangenschaft geraten. 121 Fur den Pleskauer Autor und die Bürger zählte aber nicht die kleine Zahl, für sie alle war die Tatsache, daß es doch einmal gelungen war, den Gegner zu überlisten, ein Triumph sondergleichen.' 122

Der Pleskauer Autor erwännt natürlich auch nicht, daB der litauische Hetman Chr. Radziwill $\not$ bei Starica beinahe den Zaren gefangengenommen hätte ${ }^{123}$ - diese Nachricht hätte dem Bild des Zaren, wie es der Autor zeichnet, allzu sehr geschadet. - Andererseits erzählt er aber auch nicht, daB der König den Heerfuhrer Fahrensbek mit seinen Deutschen 124 zum Pleskauer Höhlenkloster geschickt hatte, damit der es eroberte. Die Tatsache, daB es Pahrensbek selbst nach Eintreffen von Verstärkung nicht gelang, das stark befestigte Kloster einzunehmen, hätte dem Autor weiteren Stoff $z u$ Triumph einerseits, $z u$ Hohn und spott andererseits geliefert. Der Autor konzentriert sich ganz auf das Geschehen in und um Pleskau - doch ist es auch denkbar, daß er von den Dingen, die sich außerhalb der stadt zutrugen, nichts weiB.

Zunächst verwundert liest man, was der Pleskauer über den päpstlichen Legaten Antonio Possevino schreibt. Ivan Groznyj hatte bekanntlich, als keine Hoffnung mehr bestand, das Kriegsglück zu wenden, zu Kaiser und Papst gesandt mit der Bitte, einen Frieden zwischen Stephan Báthory und dem Zaren

\footnotetext{
120) Heidenstein, Rerum polonicarum, S. 216.

121) Heidenstein, ebda. S. 215

122) Zur Gefangennahme von Hilfstruppen für Pleskau: Litauische Chronik S. 123.

123) Heidenstein, a.a.0., S. 242. Lit. Chronik, S. 123 f. 124) Heidenstein, ebda. S. 204 ; Litauische Chronik S. 124.
} 
zu vermitteln, und dabel Betelligung an einer antiturkiochen Liga in Aussicht gestellt und Unions-Gespriche angedeutet. Der Pleskauer Autor stellt die Dinge völlig auf den Kopf:

91/21 "Ole premudrosti 1 milosti božija, jako gordyja smirjaet, a smirennyja voznosit! Inogda bo litovakij korolb glagolaše, jako 's ruskim o mire nikako ni $v$ pomysle, reče, prijmu', nyne že sam sovetuet 2 gosudarem našlm carem $1 \ldots$,

Es entsteht der Eindruck, alo sel es Stephan Báthory, der hier um Prieden bittet. Man muß wohl annehmen, daB dies die allgemeine Meinung war - denn die wirklichen Vorgänge um die Mission Antonio Possevinos dürften in RuBland kaum bekannt geworden sein. Die Charakterisierung Possevinos "Ichnilatovo lukavatvo 1 vae jako zbojlivyja lisicy lestb" (91/29) muB auch weit verbreitet gewesen sein. Diese Paraphrasierung lot olcher nicht allein als automatische Reaktion auf dio katholische Konfession Possevinos zu sehen. Vielmehr beruht sie wohl darauf, daB Ivan Grozny f belm Prledensechlus 1582/83 die gesamten Eroberungen in Livland, selbst die Hafenstadt Narva, herauggeben muBto und man dies in RuBland allgemein als Polge eines Xomplotte zwischen Stephan Báthory und Possevino sah. ${ }^{125}$

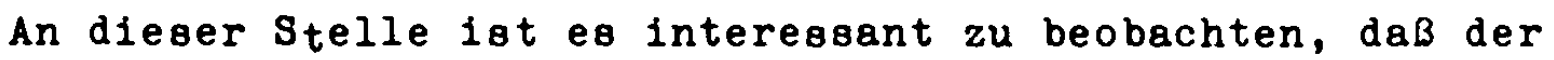
Autor nun doch Informationen in die Erzählung hineinnimmt, die inm erst opler zugegangen sein können.

Diese wenigen Beispiele für unterschiedliche Berichterstattung in den einzelnen Quellen mögen genügen; es sind die auffälligsten. Auch diese wenigen Belege zeigen, daB wir im Hauptteil, der vom realen Geschehen bestimmt 1st, zwar viele Umdeutungen, Aussparungen in der Pleskauer Erzählung feststellen können, daB es olch aber im Wesentlichen um Wiedergabe der allgemeinen Meinung handeln durfte, die naturlich der Intention des Autore entgegenkam: Neben der Glorifizierung des Zaren, die sich gelegentlich in Auslassungen (evt. Aussparung seiner nahon Gefangenname) und im allgemeinen in abotrakter Idealisierung und in Anrufungen und Schwiren kuBert, kommt es im Haupt-

125) vgl. hierzu: Pakovakie Letopiai II, S. 263 (3. Chronik): ni omanisa ego I1tva, zaslasa k nemu (carju) protopopa 
teil vor allem auf die Heroisterung der Pleskauer selbst an. Da der Kampf zweifellos - trotz aller Abstriche, die man bei der Berichterstattung des Pleskauer Erzählers machen muB heldenhaft war, dá man außerdem in Rechnung stellen muß, daß dem Autor viele Pakten nicht bekannt gewesen sein mochten, er also nur die gültige Meinung gekannt hat, kann man festhalten, daB Umdeutungen in dem AusmaB, wie wir sie in der Einleitung beobachtet haben, im Hauptteil nicht vorkommen. Wie sehr die Glorifizierung der Pleskauer Bevölkerung im Vordergrund steht, zeigt ein Vergleich von Erzählzeit und erzählter Zeit ${ }^{126}$ im ersten und im zweiten Abschnitt des Hauptte1ls: Hauptteil Ic schildert BeschieBung der Stadt. und Hauptansturm der "Litauer" = zwei Tage; die Erzählzeit, die sich im Umfang des Geschilderten äuBert, beträgt 16 Seiten. Klammern wir noch die Beschießung vom 7. September aus, die in der Erzählung etwas mehr als eine Seite einnimmt (S. 64/10 - 65/18), dann bleibt für den Tag des Hauptangriffs eine Erzählzeit von knapp 15 Seiten. - Die restliche Zeit der Belagerung bis zur Nachricht vom FriedensschluB (der noch weitere zwei Wochen Belagerung folgten), also vier Monate und e1ne Woche werden in Hauptteil II auf 17 Seiten abgehandelt die verschiedenen Hauptaktionen werden episodenhaft dem Sturmangriff angefügt.

Natürlich geht es dem Autor darum, die Hauptkampfhandlungen zu schildern, also eine Kriegserzählung zu schreiben. Dies und der Wunsch, die Pleskauer zu herolsieren, gehen fast untrennbar ineinander über. BewuBt oder unbewuBt suggeriert der Autor bei dieser Verteilung des Erzählstoffes dem Leser, daB der heldenhafte Nahkampf mit dem Feind, Auge in Auge mit diesem, den Hauptteil der Belagerungszeit ausgemacht hat.

Antonija rimskago ot papy mirovati; $i$ povědaša carju, jako vzjat Pskov, vzjat bystb, 1 carb Ivan poslal o miré ch korolju ko Pskovu, 1 vdasts emu na Pskov 15 gorodov Iivonskich jurbevskich."

126) G. Müller: Erzählzeit und erzkihlte zeit. in: Festachrift für P. Kluckhohn und H. Schneider. 1948. S. $1956^{-2} 212$. E. Lämmert: Bauformen des Erzbihlens. Stuttgart 61975 . S. 89 f., S. 91 f. 
Die in Hauptteil II den eigentlichen Kampfhandlungen angehängten Aktionen der Litauer dienen dem Autor dazu, die Niedertracht der "Litauer" zu dokumentieren. Jede Episode ist der edlen Haltung der Pleskauer in Kampf und Gebet, im Handeln und im Denken gegenübergestellt zu betrachten. Damit dies auch deutlich genug wird, sind die meisten $S_{z e n e n}$ mit spöttischen Kommentaren, Dankgebeten oder Erläuterungen versehen, auBerdem wird in der Beschreibung der litauischen Handlungen nie versäumt, auf die Niedertracht und Hinterhältigkeit dieses Beginnens hinzuweisen.

An handlungsmäßig wichtigen Punkten finden wir mehr oder weniger lange Gebete, Monologe, Ansprachen u.d. in den Lauf des Geschehens eingeschoben. Diese resümmieren das soeben Berichtete und stellen es in den ideologischen Kontext hinein: die selbständige Einordnung durch den.Leser wird von Anfang an verhindert. So bilden diese Einlassungen an sich keine gliedernden Elemente, sondern richten sich nach dem Realgeschehen, das sie kommentieren.

\subsubsection{Der SchluB; das Nachwort}

Der Schluß der Erzählung ist kompositionell nicht herausgearbeitet und ist - wie ja auch die übrige Gliederung der Erzählung - nach handlungsorientierten Kriterien von uns nachträglich unterlegt. So bezeichnen wir als Schlub die Nachricht vom FriedensschluB (15. 1. 1582), die am 17. Januar nach Pleskau gelangte, und die Mitteilung vom Abzug des polnischen Heeres (4. 2.), der das Offnen der Stadttore ermöglichte. Zwischen beide Nachrichten ist noch ein Lobpreis bam. eine Danksagung gestellt, die im Grunde, wie wir das im Pleskauer Text so häufig beobachten, lediglich aus z.T. ungemein verschachtelten Aufzählungen all derer besteht, die an der Rettung Pleskaus beteiligt waren: Dreifaltigkeit, Muttergottes, die Heiligen (mit vielen namentlichen Nennungen und diese wieder mit vielen Epitheta) und Gott.

Das Nachwort - Kryptogramm mit 'Berufs'-Angabe des Autors/ Kopisten, und Entschuldigungsformel - hängt strukturell mit der eigentlichen Erzählung noch weniger zusammen als in der 
K-pler Erzählung das Nachwort. Während letzteres Bezug nimmt auf die geschilderten Ereignisse, befaßt sich die Schlubnotiz im Pleskauer Text ausschlieblich mit der Person des Autors.

Zum äuBeren Aufbau der Erzählung ist noch zu bemerken, daß die ersten zwei Drittel des Pleskauer Textes durch viele $\mathrm{Zwischen-Uberschriften} \mathrm{zergliedert} \mathrm{sind.} \mathrm{In} \mathrm{der} \mathrm{K-pler} \mathrm{Er-}$ zählung erfolgt die Aufteilung des eigentlichen Kriegsberichtes nach Kampftagen, wobei nur einige wenige, besonders wichtige herausgestellt sind. Dasselbe trifft auch auf die Pleskauer Erzählung $z u$, doch äuBert sich dies chronologische Prinzip nicht in den tberschriften. Diese sind z.T. auf den.Inhalt bezogen - "Iz narjadu p(e)rvoe str(e)ljati" 60/4; "Načal(o) brani s kurla(ny)" 40/4 usw.; z.T. enthalten sie nur das allgemeine "Suščeen = $24 \mathrm{Mal}$ ! Dabei leitet letzteres meist längere Abschnitte ein; die Uberschriften mit konkretem Bezug auf den Inhalt aber stehen oft Abschnitten vor, die nur aus ein-zwei sätzen bestehen.

Erstaunlich ist, daB - in unserer Ausgabe S. 78 - diese Zergliederung des Textes aufhört. Die letzte Uberschift lautet "Soveršenie pervomu bolsšomu pristupu." - dieser Abschnitt konstatiert am Schlub den Sieg des christlichen Heeres uber die niederträchtigen Iltauer. Von nun an läuft der Text ohne Uberschrift bis zum SchluB durch. Ein Vergleich mit den Varianten zeigt das gleiche Bild: Wenn auch nicht genau an der gleichen Stelle, so doch ungefähr mit AbschluB des Hauptangriffs hören die Uberschriften auf. ${ }^{127}$ Gerade jener Hauptteil II, wie wir ihn nannten, jener Teil, in welchem episodenhaft die einzelnen Versuche der "Litauer" erzählt werden, die Stadt in die Hand $z u$ bekommen, hätte reichlich Anlab $z u$ tberschriften gegeben.

127) Näheres hierzu s. In diesem Kapitel 2.3 Autor und Entstehungszelt der Pleskauer Erzählung. 


\subsubsection{Zusammenfassung}

Die X-pler Erzählung fanden wir in einen eschatologischen Rahmen hineingestellt, der auch für die Komposition bestimmend wurde. Im Gleichnis vom Kampf des Adlers mit der Schlange, in dem die Schlange den Adler besiegt und dieser durch Menschen gerettet wird, ist der Gang der Erzählung vorgegeben. Der Sieg der Schlange über den Adler bildet das Grundmotiv des Hauptteils - des eigentlichen Kriegsberichts. Dies Grundmotiv (Unvermeidlichkeit des Untergangs von $\mathrm{K}$-pel), durch dustere Wunderzeichen, Selbstanklagen und reuige Gebete immer wieder in Erinnerung gebracht, steht im Gegensatz zur Tendenz des Kriegsberichts, der in seiner schilderung griechischer Heldentaten auf das Wecken von Hoffnung angelegt ist: So kommt es zu einer Uberlagerung und Durchdringung der Spannungsfelder. Die Heroisierung der Bürger K-pels dient nicht allein dem Rechtfertigungsmotiv (der Beweisführung, daB die Bürger bis zum letzten gekämpft haben), sondern sie hat auch kompositionelle Punktion: Wegen ihrer Sunden und ihres Abfalls von Gott wurde die Stadt mit der GeiBel des Türkenkampfes und der mit der Eroberung $X-p e l s$ beginnenden Türkenherrschaft bestraft. In diesem Strafgericht Gottes bewährten sich aber die Bewohner K-pels als echte Christen, sie besannen sich, bereuten ihre Verfehlungen und nahmen die Strafe als BuBe auf sich. Auf diese Welse wurden sie der im Gleichnis vorgedeuteten und in den Prophezeiungen angekündigten Rettung durch das "blonde Volk" würdig.

Vor diesem komplizierten Gebilde tritt die schlichte Komposition der Pleskauer Erzählung besonders deutlich hervor. Eine bestimmte Position wird im Einleitungsteil festgelegt, und die gesamte Erzählung hat im Grunde keine andere Punktion, als jene Prämisse zu belegen. Eine Entwicklung ist in diesem Rahmen nicht möglich: alle Welt und alles Geschehen werden auf die Kategorien "Gut" und "Böse" reduziert, wobei natürlich gut $=$ christlich (orthodox) und böse $=$ heidnisch (nicht orthodox) zu setzen sind. "Wir" = Erzähler und seine Volksgenossen gehören zur christlichen Seite, die anderen sind die Heiden und daher entsprechend böse. 
Man vergleiche wiederum mit der ganz anders gearteten Ausgangssituation der K-pler Erzählung, wo die Sündhaftigkeit der Menschen von K-pel, also ihr Böse-Sein das gesamte Geschehen erst in Gang bringt.

Im Pleskauer Text siegt der rechte Glaube in Verbindung mit allem Guten über das Heidnisch-Böse. Die Gleichsetzung von Rechtgläubigkeit und Russentum ("Heiliges RuBland") ist nicht der einzige Ausdruck der Idee von Moskau als dem Dritten Rom, vielmehr kommt sie auch in der Stellung des Zaren zum Ausdruck - war der byzantinische Kaiser nicht nur Repräsentant der weltilchen Macht, sondern auch höchste geistliche Autorität (Ernennung des Patriarchen), so erfuhr diese Ștellung auf russischem Boden, jedenfalls in Makarijs Ideologie, noch eine Aufwertung, indem der Zar als eine Art Institution zwischen Gott, Gottesmutter und die Heiligen einerseits und die Menschen andererseits tritt.

Im Rahmen dieser festgelegten Positionen kann das Realgeschehen kein Eigenleben entwickeln (vgl. K-pler Text: Kampfbericht erweckt Hoffnung - Grundmotiv aber ist Untergang), da ja am Ende der Erzählung der Sieg des Christentums (= Abzug des polnischen Heeres) steht.

Daß man die Pleskauer Erzählung trotz dieses starren, einfachen Schemas nicht als fad und konventionell bezeichnen kann, hat seinen Grund darin, daB der Autor dies Schema wenigstens zum Teil mit Leben füllen kann. Die Schilderung der russischen Seite ist blaß, bleibt ganz im Rahmen des Gewohnten, weder die Bildersprache noch die Handlung selbst geht über das aus anderen Werken der Makarij-Schule Bekannte (insbesondere aus den historiographischen Werken) hinaus, die einzelnen Wendungen und die beschriebenen Handlungen sind $z . B$. mit solchen der "Kazanskaja Istorija" austauschbar. Dagegen entwickelt der Autor bei der Schilderung der gegnerischen Seite eine Vielfalt von Techniken, die den Leser unbedingt von der Richtigkeit der vorgegebenen Position überzeugen muBte. Sehr ausdrucksstark ist die bereits mehrfach angesprochene Schlangensymbolik, die dem polnischen König und seinem Heer in immer neuen Varianten beigegeben wird, bis sie so fest ver- 
ankert ist, $d a B$ in den Hauptteilen nur noch Andeutungen genügen, um die entsprechenden Bilder zu evozieren.

Vor allem aber ist es ein stark fiktionaler Zug der Erzählung, der inr Lebendigkeit verleint: Immer wieder wendet der Erzähler den Blick ins polnische Lager, schildert Szenen, die sich dort abspielen, gibt Dialoge wieder, führt Briefe des Königs und seiner Würdenträger im Wortlaut an, wobei die Verwendung polnischer Titel, auch gelegentlicher Polonismen und We1Brussismen ( = Litauen) den Eindruck von Authent1zität erwecken. Diese Blicke hinuber auf die polnisch-litau1sche Selte fuhren die Schlechtigke1t, die Niedertracht und die Bösartigkeit des Gegners besonders anschaulich vor Augen, weil dieser scheinbar selbst handelt. Doch haben wir es hier ganz sicher mit Erfindungen des Autors zu tun. Weder bei He1denstein noch in der L1taulschen Chronik finden wir Berichte über jene Beratungen, Gespräche und auch über manche Schreiben, die oft im Wortlaut in der Pleskauer Erzählung nachzulesen sind; und da Heidenstein genügend Negatives uber Vorgänge im polnischen Lager $z u$ berichten we1B, wäre es verwunderlich, weswegen er ausgerechnet jene Begebenheiten, Jene Schriftstucke usw. verschweigen sollte, von denen der pleskauer Autor erzählt. Bel den Schilderungen des polnischen Lagerlehens im Pleskauer Text, be1 den schelnbar im Wortlaut wiedergegebenen Gesprächen und Schrelben handelt es sich in den allermelsten Fällen ganz sicher um Piktion, die der systematischen Herabsetzung, ja Verteufelung des Gegners dient. Und gerade diese fiktionalen Passagen sind es, die der Erzählung Parbe und Leben verleihen - trotz des schlichten Konzepts und der einlinigen Komposition. 


\subsection{Der_Autor

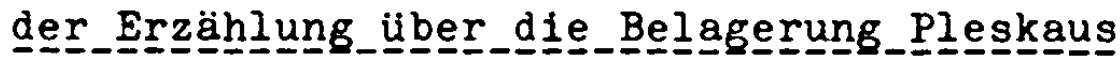

Scheinbar erübrigt sich die Prage nach dem Autor der Erzählung: Im Nachwort ist zu lesen, daB die Erzählung von einem Bürger der Stadt, dem Ikonenmaler Vasilij niedergeschrieben worden sei (98/29). Die Frage nach dem Autor erregte nie großes Interesse, und so übernahm man gern die Feststellung A. S. Orlovs von 1908, die Schilderungstechnik in der Pleskauer Erzählung sei typisch für einen Ikonenmaler, für den gerade die symbolhafte Zeichnung chrakteristisch sei. ${ }^{128}$

M. N. Tichomirov hat erstmals die Frage gestellt, ob diese Interpretation (Ikonenmaler Vasilij als Autor) richtig sein könne. Er weist $z u$ Recht auf die moskovitische Grundtendenz der Erzählung hin, die wir oben aufgezeigt haben. Ferner erinnert er daran, daß die Pleskauer Chroniken z.T. ausgesprochen antimoskovitische Tendenzen aufweisen, was - wegen der Annexion Pleskaus durch Moskau 1510 - historisch bedingt ist; vor allem hat aber ein in pleskau zu vermutender HaB auf Moskau und auf Ivan Groznyj insbesondere seinen Grund in den Ausschreitungen der Opričnina unter persönlicher Führung des Zaren gegen Pleskau und Novgorod von 1570, die geradezu Feldzug-Charakter hatten. Wir haben Beispiele aus der 3. Pleskauer Chronik vorgestellt, die vermuten lassen, daB die allgemeine Stimmung in Pleskau gegen Ivan Groznyj war, zumal man es für Feigheit des Zaren hielt, dab er innen von seinen angeblichen 300000 Mann keine Hilfe schickte. ${ }^{129}$

Ferner weist Tichomirov auf einen interessanten Umstand hin, der V. I. Malyšev entgangen war: Die Codices, in denen sich die Pleskauer Erzählung findet, haben inhaltlich alle mit Ivan Groznyj zu tun - wie z.B. die "Kazanskaja Istorija",

128) Orloy, O nékotorych ogobennostjach stilja, S. 365: "Takoj simvoliceskoj zivopieju izobrazil Pskovskij inok, po nekotoroj zapisi 'zograf', pochval'nyja slova Stefana Batorija ...". Malysev, Povest', S. 26, übernimmt und erweitert diesen Standpunkt Orlovs.

129) s.0., S. 110, Anm. 100. 
das "Skazanie o knjazech vladimirakich"u.a. moskaufreundliche, Insbesondere Ivan Groznyj im Sinne der staatlichen Ideologie in den Vordergrund stellende Textel. Mit diesen ist die Pleskauer Erskiblung sehr oft susammengebunden. In kelnem der Codices, die die Pleskauer Erzählung enthalten, scheinen weitere Texte, die sich auf Pleskau beziehen, vorhanden zu sein. ${ }^{130}$ Das trifft, so Tichomirov, allem Anschein nach auf die gesante erste Redartion zu. Andererseits ist die zweite Redartion, die wesentlich jüger ist ("pozdnejsaja red.") und sich durch ihre klerikale Ausrichtung und starke Anlehnung an Aufzelchnungen des Pleskauer Höhlenklosters anlehnt, nur in Pleskauer Hss. enthalten.

Aus diesen beiden Tatsachen (Ivan-freundliche Grundhaltung und Erscheinen der älteren Redaktion ausschlieblich in nicht-pleskauischen Codices) zieht Tichomirov den SchluB, daB die Erzahlung nicht in Pleskau entstanden 1st, wo die allgemeine Haltung, den Chroniken nach zu urteilen, gegen Ivan war, sondern in offiziellen Kreisen in der Nähe des Zaren, also vermutlich in Moskau. 131

Wenn Tichomirov allerdings meint, die genaue Kenntnis der internationalen Beziehungen 132 und der politischen Situation 133 spreche dagegen, daB ein "zograf" die Erzählung geschrieben habe, dann stellt er seinen eigenen Kenntnissen der internationelen Beziehungen $2.2 t$. des endenden Livländ1schen Krieges eine sehr schlechte Note aus. Für seine These spricht m.E. viel eher die Tatsache, daß die Erzahlung in Bezug auf die Topographie Pleskaus sehr vage ist. Hin und wieder fallen ein par Namen, doch wird nicht weiter gesagt, wo sich - z.B. die eroberten Türme - genau befunden haben $u . \ddot{a}$.

130) Me Tichomirov, Recenzija, S. 353, Er zieht seine Schlusse aus.den Angaben $V$. I. Malysevs, die dieser im Rahmen eeiner Hs8.-Beschreibungen gemacht hat (Yalyó. Povest', S. 120 f.).

131) Tichomirov, a.a.0., s. $350 \mathrm{f}$.

132) Tichomirov, ebda., S. 350: "0staetsja neponjatnym, počemu avtor ... s takoj tecatel'nost'ju 1 s tak1m chorosim znaniem rasikazyvaet o mezdunarodnych otnosent jach, ...n

133) Tichomirov, ebda., S. 351: "osvedomlennost'v političeBkich delach togo vremeni." 
Bei Heidenstein gewinnt man eine viel klarere Vorstellung von den topographischen Verhältnissen, von den Rampfstätten und den strategischen Zügen. 134

Tichomirov meint, Ivan Groznyj habe die Erzählung von der Belagerung Pleskaus in Auftrag gegeben: damit habe er von dem katastrophalen MiBerfolg des Livländischen Krieges ablenken wollen. Bereits die "Kazanskaja Istorija" verdanke einem ähnlichen Motiv ihre Entstehung: Ivan Groznyj habe sie anfertigen lassen, damit sich in der Offentlichkeit die Wellen der Empörung über seine Opričnina-Politik beruhigten. 135 Dieser Hypothese entsprechend hält Tichomirov das Nachwort der Pleskauer Erzählung mit der biographischen Notiz für den Zusatz eines Kopisten.

V. I. Malyšev dagegen meint, der Ikonenmaler Vasilij sei tatsächlich der Autor unserer Erzählung. Die vielen Argumente, die einer solchen Annahme entgegenstehen, glaubt er, dadurch zu entkräften, indem er erklärt, daß dieser Ikonenmaler vermutlich in der Kommandantur, also in unmittelbarer Nähe der Voevoden als Schreiber tätig war, dort alle Informationen bekommen, sich die militärische Terminologie zueignen konnte und natürlich auch dort mit der moskovitischen Ideolorie in Beruihrung gekommen sei. 136

Im Grunde muB diese Diskussion im Bereich des Hypothetischen bleiben, weil wir kaum konkrete Anhaltspunkte über die Erzählung hinaus besitzen. Tichomirovs Standpunkt scheint mir über-

134) Allerdings sei in diesem Zusammenhang daran erinnert, dai3 konkrete Beschreibungen lokaler Verhältnisse auch noch im 16. Jh. kaum das Interesse der Autoren gefesselt haben. So sind z.B. in der "Kazanskaja Istorija" auch nur wenige konkrete, umfassende topographische Angaben $z u$ finden.

135) Tichomirov Recenzija, S. 351 . Er scheint hier allzu sehr von der sovjetischen Medienpolitik auszugehen. Diese dirigiert durch entsprechend frisierte Berichte die öffentliche Meinung gerielt und ochnell. Zur Manipulierung der bffentlichen Meinung konnte die Literatur in 16. Jh. nur auf lange sicht eingesetzt werden - die Verbreitung dauerte zu lange. Der propagandistischen Verwendung der Pleskauer Erzbhlung steht zudem entgegen, daB aus dem 16. Jh. höchstens 1 He. erhalten ist.

136) Nalyšev, Povest', S. 26 f. 
dies nicht den eigentlichen Text, sondern nur seine ideologische Ausrichtung $z u$ berücksichtigen. Umgekehrt kennt Malyšev zwar den Text, dafür ist aber seine Erklärung, daß jener Ikonenmaler Vasilij als Autor der Erzählung angesehen werden müßte, ganz und gar nicht überzeugend. Daß er vielmehr, wie auch Tichomirov meint, als Kopist zu gelten habe, dafür spricht m.E. die Tatsache, daß von den fünf Hss. der zweiten Gruppe/erste Redaktion drei Hss. das Nachwort mit der biographischen Notiz nicht enthalten. 137 Andererseits mübte sich dies Nachwort aber in einer der ersten Kopien unserer Erzählung befunden haben, da wir es in den meisten der bis heute bekannten Hss, antreffen.

Tichomirov hat recht, wenn er daran erinnert, dab die allgemeine Stimmung in Pleskau sicher nicht besonders moskaufreund$11 \mathrm{ch}$, und schon gar nicht besonders freundlich Ivan Groznyj gegenüber war - offenbar glaubten sich die Pleskauer während der Belagerung von Ivan im Stich gelassen, ${ }^{138}$ außerdem lag der Feldzug der Opričnina unter persönlicher Leitung des Zaren gegen Pleskau und Novgorod 1570 noch nicht so lange zurück, als daß er hätte vergessen sein können. 139 Andererseits ist doch als sicher anzunehmen, daB es auch in Pleskau und entsprechend in Novgorod Ivan Groznyj wohlgesonnene Kreise gegeben haben muß - Dienstadlige, Verwaltungsbeamte, vielleicht im Klerus. Es sei nur daran erinnert, daB gerade die ersten konkreten Formulierungen der Idee von Moskau als dem Dritten Rom von einem Pleskauer Mönch, Filofej, stammen niedergelegt kurz nach der Annexion der Republik Pleskau durch Vasilij III. 1510. ${ }^{140}$ Damit soll nur gesagt werden, daß die Entstehung unserer Erzählung in Pleskau durchaus vorstellbar erscheint, vor allem, wenn man bedenkt, wie gerade in Pleskau Richtungskämpfe und Parteienstreit (Iitauen- und Moskau-freundliche Gruppierungen) an der Tagesordnung waren. 141

137) Malyšev, Povest', S. 106 = Varianten, S. 121 Hss. $11-13$. 138) s.0.S. 111 , Anm. 101.

139) 8.0. S. 110, Anm. 100.

140) Schreder, Moskau das Dritte Rom, S. 188-215: Abdruck der Schreiben Pilofejs (in deutscher Ubersetzung).

141) N. N. Maslennikova: Prisoedinenie Pskovu k Russkomu 
Beim kurzen Vergleich der Schilderungen Heidensteins und unseres unbekannten Autors war aufgefallen, dab die Erzählperspektive des Autors die innere stadt ist. Was draußen vor sich geht, wird nicht erwähnt - selbst der so schmachvoll gescheiterte Versuch, das Pleskauer Höhlenkloster einzunehmen, bleibt unkommentiert, obwohl sich hier doch reichlich Anlab zu Spott und Hohn durch den Autor geboten hätte. Nachträglichkeitsperspektive ist nur erkennbar dort, wo der Autor über Possevino berichtet - diese dort erzählten Dinge konnte er erst nachträglich erfahren haben. Das widerspricht auch der Auffassung von der Auftragsarbeit, die womöglich in Moskau entstanden sei. Auch die erwähnte konsequent fehlende Bezeichnung Livlands als "votčina" des Zaren läßt nicht an die Entstehung in offiziellen moskovitischen Kreisen glauben.

Das schließt aber nicht aus, daß die Erzählung zwar in Pleskau - in moskaufreundlichen Kreisen - für Ivan Groznyj bzw. sonstige Moskauer Auftraggeber geschrieben worden ist. Denn wir kommen an Tichomirovs Beobachtung nicht vorbei, dab die meisten und vor allem die ältesten Hss. in der Regel mit promoskovitischen, Ivan-freundlichen Texten zusammengebunden erscheinen.

Die erwähnten Uberschriften, die nach den ersten zwei Dritteln der Erzählung, nach Vertreibung der "Litauer" nach dem größten Sturmangriff, aufhören, markieren vermutlich eine ursprüngliche Fassung, der dann später erst, von einem anderen Autor, jene Episoden (Hauptteil II), die die Maßnahmen der "Litauer" nach dem Hauptangriff beschreiben, angefügt worden sind. Doch bereits die erste, also etwa um ein Drittel kürzere Fassung muB, den Uberschriften nach, die in der uns vorliegenden Fassung dominierende Ideologie enthalten haben, denn die besonders wichtige Einleitung gehört ja auch dazu. Es könnte z.B. die erweiterte Version ( = unser Text) dann in Moskau entstanden sein, also die Schilderung des Hauptkampfes am 8. Sept. 1581 durch Beschreibung der wichtigsten

centralizovannomu gosudarstvu. L. 1955. S. 84 - 105 . Dies.: Ideologičeskaja boŕba v pskovskoj iiterature v period obrazovani ja Russk. central.gosudarstva. In: TODRL 8(1952). 
Maßnahmen des Feindes während der übrigen knapp fünfmonatigen Belagerung angefügt worden sein. Gerade die Charakterisierung der Mission Possevinos ( $91 / 12-92 / 2)$, die in ihrer Ausfühlichkeit (nicht Objektivität!) Chronikmitteilungen über die Tätigkeit Possevinos bei weitem übertrifft, ${ }^{142}$ würde für einen informierteren Autor, den man sich in der näheren Umgebung des Zaren vorstellen könnte, sprechen.

Gegen eine Annahme, daB die ersten zwei Drittel der Erzählung in Pleskau unmittelbar nach dem groBen Hauptangriff vom 8. Sept. 1581 entstanden seien, das letzte Drittel in moskovitischen Kreisen angefügt und dort auch die gesamte Erzählung überarbeitet und stilistisch eingeebnet sei, also ihre letzte, jetzige Ausformung erhalten habe, könnten die vielen Nordwest-Russismen sprechen, die wir in unserem Text vorfinden. Die beiden anderen von mir eingesehen Varianten zeigen sie in nicht so starkem Maße. ${ }^{143} \mathrm{Um}$ in dieser Frage eine Klärung zu erzielen, wäre es wohl nötig, alle wichtigen älteren Hss, auf Spuren der Pleskauer - oder Moskauer - Mundart $z$ untersuchen. Aber selbst wenn eine solche Untersuchung ein deutliches Uberwiegen von Eigenheiten der Moskauer Sprache ergeben würde, könnte das nur bewelsen, dab unsere Erzählung in offiziellen moskovitischen Kreisen Verbreitung fand. Ein solches Untersuchungsergebnis macht die endguiltige Ausformung der Erzählung in Ivan Groznyj nahestehenden Kreisen wahrscheinlicher, aber keineswegs sicher.

Die Textanalyse hilft uns auch nicht viel weiter. Wie erwahnt, wurden die ersten zwei Drittel (bis zum Ende des großen Hauptangriffs) vermutlich noch während der Zeit der Belagerung abgefaBt: Einleitung und Hauptteil I. Die promoskovitische Grundhaltung im Sinne der Uberhöhung des Zaren und des allein rechtgläubigen RuBland waren bereits in der Einleitung angelegt, ebenso die auf den polnischen König und die gesamte gegnerische Seite angewandte Schlangen-/Drachensymbolik - eine nachträgliche Einarbeitung derselben durch den

142) Vgl. S. 123, Anm. 125.

143) Hs. 3 (nach Malyšev, Povest' S. 120) bei Skripil', Russkie Povesti $16-17 v v$., S. $124-166$; Hs. 15 (nach Malysev Povest' S. 122) - Bodjanskijs Edjerung von 1847 . 
letzten Redaktor ist vollkommen ausgeschlossen, da die dieser Symbolik gewidmeten Abschnitte einen wesentlichen Bestand teil der Einleitung ausmachen. AuBerdem findet diese Symbolik im letzten Drittel keine Verwendung mehr, wie über haupt bildsprachliche Elemente hier selten sind.

Uber den Zeitpunkt der Erstellung der endgültigen Version, wie sie heute vorliegt, kann man auch nur Vermutungen anstellen. Als Terminus ante quem dirfte der Tod Ivan Groznyjs - 18. 3. 1584 - anzusetzen sein. Selbst ein nachträglicher Bearbeiter der Erzählung hätte sicher nicht versäumt, einige Worte des Gedenkens, ein Gebet für den verstorbenenen Zaren einzufügen - vermutlich hätte er den ganzen Grundton der Erzählung und damit ihren ganzen Charakter verändert: ein von Trauer beherrschter Panegyrikos.

Die Ermordung des Carevič durch Ivan Groznyj, obwohl sich die Kunde davon schnell verbreitet haben muBte, ${ }^{144}$ bleibt unerwähnt. Es dürfte sich hierbei aber eher um ein Verschweigen handeln, damit durch diese Nachricht das von Ivan Grozny $j$ entworfene Bild nicht verdunkelt werde. Lehnt man diese Deutung $a b$, mübte man sich die endgültige Fassung unserer Erzählung bereits zwischen Februar und November (Ermordung Ivans) 1582 entstanden denken. Dagegen spricht aber, daB die stilistische, lexikalische und stoffliche Verarbeitung der beiden angenommenen Textteile so grüdlich ist, daß vermutlich wenige Monate für eine solche Aufgabe nicht ausgereicht hätten.

144) Iitauische Chronik, S. 125. Die Nachrichten dort über die Zeit St. Báthorys entstammen der "Kronika Marcina Bielskiego", t.III. Sanok 1856. S. 1487-97. (PSRL 32/1975, S. 5): 1495-1575 - wegen Todesdatums wohl eher Joachim Bielskis gest. 1599: "Kronika wszystkiego świata"4. Auf1. 1597. 


\subsection{Die}

Die uns vorliegende Textausgabe hat V. I. Malyšev nach der seiner Meinung nach ältesten vorhandenen und gleichzeitig der dem Original vermutlich am nächsten stehenden Hs. besorgt: sie gehört zur ersten Gruppe der ersten Redaktion (Hs. 1 in seiner Hss.-Beschreibung, S. 119). Die Hs. ist auf den Anfang des 17. Jh.s zu datieren. 145

Die Editionsgrundsätze sind die gleichen wie die im Zusammenhang mit der K-pler Erzählung (Skripil's Edition) beschriebenen: Es handelt sich um eine Ubertragung des originalen Textes in die moderne Schreibung - heute nicht mehr übliche Zeichen werden durch die modernen Entsprechungen er setzt. In Fällen, wo ein nicht mehr vorhandener und ein heute noch gebräuchlicher Buchstabe in einem modernen zusammenfallen (altes -a- und altes -ę- in heutigem -a-), ist die ursprüngliche Schreibung nicht erkennbar. Im Rahmen unserer Untersuchungen, innerhalb welcher morphologische und phonetische Fragen kaum eine Rolle spielen, stört die vereinfachte Orthographie nicht.

Auf kleinere Mängel der Edition hat bereits Tichomirov in 146 seiner Rezension hingewiesen. So ersetzt llalyšev Lesarten, die ihm nicht korrekt vorkommen, durch eigene "Verbesserungen" - z.B. 92/7 korrigiert er ursprüngliches "mnju že", das in der älteren Literatur als Einwurf auf Schritt und Tritt begegnet, durch "mnja že" - diese Veränderung nimmt der Wendung den Charakter des Einwurfs, den der Autor macht, und der Leser bezieht das Partizip auf das Subjekt des Satzes. (in diesem Falle auf den Kanzler Jan Zamoyski). Ähnliches begegnet häufig - aber dadurch, dab Malyšev solche Einlassungen deutlich und unter Hinzufügung der originalen Schreibweise markiert, wieg.t dieser Mangel nicht schwer.

145) Tichomirov, Recenzija, S. 349 f.: Ende 16. Jh.

146) Tichomirov, ebda., S. 352. 
Problematisch ist immer die Interpunktion: "punktuacija ... - sovremennoe."147 In der Regel wird dadurch das Verständnis des Inhalts erleichtert. Aber wir haben es doch immer mit einer Interpretation durch den Hrsg. zu tun. Bei unserer Ausgabe gewinnt man den Eindruck, daB die Interpunktion oft flüchtig und manchmal entstellend gehandhabt wird. Wir werden im Laufe der Untersuchungen verschiedentlich auf diesen Umstand hinzuweisen haben. Das folgende Beispiel soll daher im Augenblick genügen:

38/24 "Slyšav že sie ... kurlanskie nemcy, jako ot rosijskago gosudarja ni kaja že tverdostb ustojati možet, a prichodjaščii k nemu ... z darmi ...velikoju oslabu priemljušče, sobravše že sja načalınicy strany toja, kurlanskich nemec, sovet_sotvorše. Da pošljut $k$ našemu gosudarju so mnogimi darmi svoja posly, i da milostb ruskago gosudarja da pokažet nad nimi ..."

'Als die ... Deutschen erfuhren, daß dem Herrscher keine Festung zu trotzen vermag und daB alle, die mit Geschenken und ... zu ihm kommen, groBe Gnade/Vergebung/Milde (von ihm) erfahren - da versammelten sich die Häupter der Deutschen von Kurland und faßten den Plan, daß man zum Zaren Gesand te mit vielen Geschenken schicken solle, auf daB der 2 ar ihnen seine Gnade erzeige.'

Derartige Objektsätze, die nach Verben des Bittens, Wollens, Wünschens, Befehlens, Planens usw. Finalsätzen sehr nahe kommen, ${ }^{148}$ werden sowohl im $\mathrm{K}$-pler als auch im Pleskauer Text fast ausschlieblich mit "da + Präs. mit futur. Bedeutung" gebildet. Die durch den Hrsg. mittels der Interpunktion vorgeschlagene Übersetzung müßte vollkommen inadäquat lauten: '... versammelten sich die Häupter der ... Deutschen und faßten einen Plan. Und sie schicken zum Zaren ...' Diese Ubersetzung wird auch der Form "pošljut" nicht gerecht. Sehr flüchtig und inkonsequent verfährt der Hrsg. bei der Setzung von Anführungszeichen - gelegentlich fehlen sie am Ende des als wörtliche Rede oder litat gekennzeichneten Abschnitts;

147) Malyšev, Povest', S. 30.

148) H. Bräuer: Untersuchungen zum Konjunktiv im Altkirchenslavischen und im Altrussischen. Wiesbaden 1957. S. 30 nennt diese Objektsätze "abhängige Heischesätzen. 
z.B. 89/6. Manchmal fehlen notwendige Anführungszeichen ganz - z.B. $81 / 12$ - 81/17. Zitate innerhalb der Monologe und Reden werden wie Zitate im erzählenden Kontext behandelt - sie bekommen auch das zweigestrichene Anführungszeichen ="-, so daß man nach jedem $Z$ itatende fragen muß, ob nun eigentlich z.B. nur das Bibelzitat zu Ende ist oder aber der gesamte Monolog - z.B. 78/32 - 79/27, 92/13 - 94/5. Im letzten Beispiel etwa enden in $94 / 5$ sowohl ein eingeschobenes 2 itat als auch der gesamte Monolog mit dem gleichen Zeichen: $94 / 5$ "..., eže naslediti zemlju". Nastojaščee glagoletca. Das Zeichen hinter "zemlju" markiert das Ende eines Zitats (Psalm 37.34), aber zugleich das Ende des knapp zwei Seiten langen Monologs.

Schließlich fällt die Inkonsequenz auf, mit der Malyšev das häufig die wörtliche Rede einleitende "jako" behandelt mal nimmt er es in das 2 itat hinein in der Art: 68/35 Sie že im prirek: "Jako vemyi druze, ..." $43 / 5$... mnogogordelivaja izreče. "Jako ne možet, reće,..." Manchmal stellt er es auBerhalb des Zitats, z.B. $47 / 28$ priglašaet gosudarb, jako "na tebe mi, reče, ..." -/30 On že sie slyšav, jako "na tebe mi, reče, i mimo ..." Die letztere Wiedergabe bzw. Verdeutlichung der Rede bzw. des $Z$ itats dürte die angemessene sein, denn dieses "jako" fungierte ja im Altruss, als eine Art Anführungszeichen.

Einen echten Mangel der Edition bildet Malyševs Variantenapparat - er gibt nur andere Lesarten wieder, wenn sie textlich-inhaltlicher Natur sind: Auslassungen in anderen Hss. fehlen, morphologische Varianten, Variationen der Wortfolge werden nicht erwähnt - wir können mit diesem Apparat so gut wie gar nichts anfangen. Fast das gesamte Vorwort, das den Inhalt im Tone des Stalinschen Patriotismus wiedergibt, hätte zugunsten eines brauchbaren Variantenapparates eingespart werden können. Darüberhinaus befinden sich die Varianten unübersichtlich am SchluB zusammengestellt. 


\section{ANMERKUNGEN ZU}

\section{PHONETIK, MORPHOLOGIE UND LEXIK UNSERER TEXTE}

Es ist im Rahmen dieser Arbeit nicht möglich, auf alle Erscheinungen aus den Gebieten der Phonet1k, der Morphologie und der Lexik innerhalb unserer Texte, die eine detaillierte Untersuchung verdienten, in der gebotenen Ausfuhrlichkeit einzugehen. In diesem Abschnitt soll nur versucht werden, einige bestimmende Züge der beiden Texte herauszuheben, damit eine Einordnung unserer Erzählungen auch in bezug auf Phonetik, Morphologie und Lexik möglich wird. Solche Erscheinungen, die auf Grund ihres eher zufälligen Auftretens nicht so charakteristisch für den einzelnen Text sind, bleiben hier unberüksichtigt.

\section{Zur Phonetik}

Das Bemühen beider Autoren um ksl. Lautung ist ganz deutlich. Der grundsätzliche Unterschied zwischen beiden Erzählungen ist der, daß der $\mathrm{K}$-pler Autor dieses Bestreben ganz konsequent durchsetzt, während der Verfasser des Pleskauer Textes wohl eher intuitiv vorgeht, so daß wir in seiner Erzählung neben archaischen Formen auch stark umgangssprachliche Elemente antreffen.

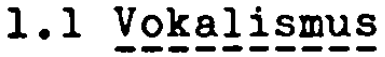

Zum Vokalismus sind vorwiegend Bemerkungen zu machen, die auf regionale Züge der Texte, $d . h$. auf regionale Züge der Pleskauer Erzählung, verweisen.

Allgemeinerer Natur ist die grundsätzliche Beibehaltung von anlautendem e-.Diese äußert sich allerdings fast ausschließlich in "edin" und Ableitungen hiervon ("edinica" usw.). Während die $\mathrm{B}$-pler Erzählung hiervon keine Ausnahme macht, hat der Pleskauer Text neben 34 Belegen mit "edin" zwei Mal "odin":

62/11 "odny" = die einen, die ersten(es folgt: die zweiten, anderen - "vtorye", die dritten - "tretie"); $95 / 17$ "tridcatb odin". 
Einen weiteren Beleg für anlautendes e- haben wir in "elenb" $(41 / 5)$.

Die graphische Vertretung von ursprünglichem i nach lautlich geschmundenem $-b$ ist in beiden Texten nicht grundsätzlich verschieden. Im Pleskauer Text finden wir durchgehend die Schreibung - $y$ - statt -bi-, z.B. "otỹde", "obymaše", während in der $\mathrm{K}$-pler Erzählung ungefähr $1 / 3$ aller Belege noch die aksl. Lautung reflektiert: "oţ̧ide", "obßimaše". Diese Schreibung ist in beiden Texten vor Präpositionen die Regel, also z.B. "s(b) inymi", aber im Pleskauer Text finden wir auch 57/22 "s ב̇nimi mnogimi svjatynjami" neben 49/16 "vo inyja strany". Während wir für die K-pler Erzählung keinen Beleg für Reflexe des umgangssprachlich allgemein verbreiteten ${ }^{l}$ Nandels von -e- zu -'o- (unter dem Ton nach $\mathrm{Zischlauten)} \mathrm{beibringen} \mathrm{kön-}$ nen, finden wir deren im Pleskauer Text eine ganze Anzahl, was auch vom Eindringen der Umgangssprache in die Erzählung zeugt, z.B. "pošol" 54/20 (gegenüber "pošell" 95/24), "prišoll" 56/25; hierzu gehören auch jene Genitive (P1.) auf "-cov" statt urspr. "-cev", z.B. regelmäBig "strelbcov" (3 Mal), "čosnok" (81/32 und $-/ 33)$. $^{2}$

Die folgenden lautlichen Besonderheiten der Texte deuten eher auf regionale Eigenheiten. Allerdings manifestiert sich in der Zulassung solcher Eigenheiten auch ein mehr (= K-pel) oder weniger ( = Pleskau) enges Verhältnis zur ksl. Norm.

So ist z.B. die Auffüllung von altem $-b$ in Präpositionen auch in schwacher Stellung weit verbreitet. ${ }^{3}$

1) Cernych, Ist. grammatika, S. $129 \mathrm{ff}$.

2) "čosnok" = Palisadenzaun - gegen sonstiges "česnok" = Knoblauch. Die Bedeutung Palisadenzaun ist nur belegt bei I. Ja. Pavlovski,j: Russisch-deutsches Wörterbuch. Riga 1911. ND Leipzig 1960. (weiter zitiert als Pavlovskij) S. 1726: -cesnok' Bedeutung 2: Staketen-, Stangen-, Pfahlzaun. S. u.: Zur Lexik.

3) R. Schneider: Die Sprache Posoškovs (Phonetik und Morphologie). Diss. Münster 1973. (weiterhin zitiert als: Schneider, Sprache Pososkovs.) S. $66 \mathrm{f}$. findet diese Erscheinungen noch mehr als 100 Jahre später. Allerdings glaubt sie, daß Präpositionen mit ungesetzmäBiger Auffül- 
Im Pleskauer Text ist die entsprechende Auffüllung des alten reduzierten Vokals häufig und begegnet uns etwa in $1 / 3$ entsprechender Fälle; z.B. "12o Pskova", "vo osade" 44/31, "so okrestnymi grady" $45 / 5$ (sogar Hiatus in den beiden letzten Fällen). In der $\mathrm{B}$-pler Erzählung sind uns solche Fälle nicht aufgefallen.

Das häufige und - wie die Hiatūs ("vo osade" - regelmäBig) zeigen - auch extreme Vorkommen von nicht lautgesetzlichen Auffüllungen reduzierter Vokale bei Präpositionen deutet auf eine Eigenhe1t der Pleskauer Sprache hin. 4

Hierzu gehören auch jene Fälle von nicht lautgesetzlicher Auffüllung im Innern eines Wortes ${ }^{5}$ - diese Fälle sind weniger häufig als jene an Präpositionen und betreffen das alte $-\mathrm{b}$.

So finden wir neben "mužskij" 76/27 auch "mužeskij"6 $77 / 2$ und 57/27 - hier mochte der eingeschobene Vokal die Funktion haben, Assimilation (vielleicht zu "mušskij" oder "mušškij") zu verhindern. Eine äbnliche Begründung gilt auch für die 12 Belege für "bogatestvo" (etwa zu "bogatstvo"). Allerdings ist die Auffüllung von -bst- und -bsk- zu -est- und -eskkeineswegs konsequent durchgeführt, wie "mužskij" bereits zeigte. So treffen wir nur noch auf "voinstvo" und "voinskij".?

lung in Textstellen mit expressiver bzw. besonders literarischer Färbung, vorkommen, s. Verqeis auf Cernzchs Untersuchungen am "Uloženie": Jazjk Ulozenija 1649 goda. $\mathbf{~ . ~}$ 1953. S. 200, wo er diese Erscheinung auch beobachtet.

4) N. Karinskij: Jazjk Pskova 1 ego oblasti v 15 v. SPb 1909. (Zapiski istoriko-filologičeskago fakul' teta Imperatorskago S.-Peterburgskago universiteta. 93). (weiter zitiert als: Karinskij, Jazyk Pskova). S. 170, besonders Punkt $3 a$.

5) Erscheinungen wie die Auffüllung von Reduzierten 2 wischen Präfix und Stamm ("rozoslav" 51\%11) bleiben hier unberücksichtigt, da sie anscheinend uberall in gleicher Häufigkeit aufreten.

6) "mužeskif" - die heutige Sprache hat diese Auffüllung z.T. schriftsprachlich fixiert: "muźskof", "muźnif" - aber "muzestrennyj", "mužestvo".

7) 33 Bêlege für "voinst守o", 2 Mal die historische Schrelbung "volnbstvo" 40/13, 74/10; 14 Mal "volnskij". 
Auch ein Beleg "pristupleše" ist an dieser Stelle zu nennen (statt altem "pristuplıše"). 8 Absolut gesehen stellen die hierher gehörigen Belege, die wir im Pleskauer Text vorfinden, nur einen geringen Prozentsatz aller entsprechender Formen dar, aber dennoch sind sie sehr auffällig und dürfen ganz sicher als Zeichen regionaler Lautung betrachtet werden. Schlieblich scheidet die Vertretung von historischem -è- beide Texte voneinander. Weil wir wegen der Modernisierung der Schreibweise in unseren Textausgaben kein -e- vom -è- mehr unterscheiden können, wissen wir auch nicht, wie die einzelnen Autoren oder Kopisten -e- und -ě- verwenden.

In der K-pler Erzählung ist der anzusetzende Laut -ě- in Hunderten von Belegen als -e- wiedergegeben. 9

Im Pleskauer Text finden wir altes -ě- wiederholt durch -iwiedergegeben: "neuvedinbe" (90/15), "vediv" (86/32), "izminikov" (4l/3), "povelí" (= Aor. 89/13), "stríleckij golova" (90/2, gegen sonstiges "strelec"), "plinn" (39/7, gegen sonstiges "plen"), u.a. In dieser Lautung schlägt sich die nordgroBrussische Artikulation nieder. ${ }^{10}$

Einige Beispiele für Verwechslung von -u- und -v- finden wir im Pleskauer, möglicherweise auch im K-pler Text:

"nouggorodckif" (52/22, 54/13), " Svingch vorot, u togo

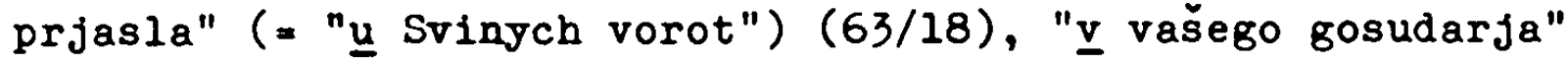
( = "ú vašego gosudarja") (82/28) u.a.

In der K-pler Erzählung haben wir drei Mal "zunk" für "zvuk". Sobolevskij ${ }^{11}$ konstatiert ausdrücklich, daB in den Pleskauer Denkmälern diese Erscheinungen nicht auftreten; auch Karinskij belegt sie nicht. Immerhin weist letzterer aber darauf

8) Karinskij, Jazyk Pskova, S. 170/3c. 9) Einmal begegnet "razsjadesja" für "razsèdesja" (63/44)

10) Xernych, Ist. grammatika, S. 128. Sobolevskij, A. I.: Lekcii po istorii russkago jazyka. M. 1907. (weiterhin zitiert als: Sobolevskij, Lekcii.) S. 71 ff. Karinskij, Jazyk Pskova, S. 172 u.a.

11) Sobolevskij, Lekcii, S. 122. 
hin, $d a B$ auf Grund der weibrussischen Siedlungsbewegung nach Nordosten im 13. und 14. Jh. einige WeiBrussismen, wie die 0. g. Verwechslung von $-u-$ und $-v-$, Eingang in die Pleskauer Sprache gefunden haben sollen, womit sich derartige Erscheinungen in den schriftlichen Denkmälern Pleskaus erklären lassen. 12

A- sowie Ja-kanje erscheinen in beiden Texten selten.

So begegnet im Pleskauer Text drel Kal "esmja" für l.sg. präs. "esme". 13 Unter sleben Belegen für "mesjac" findet sich einer mit "mesec" (62/6). Ähnlich ist "vremjana" (36/6) zu bewerten. Umgekehrt finden wir für "tysjašča" keinen Reflex für diese Erscheinung. 14 Auch die ca. 20 Belege mit "devjatb", "desjatb" zeigen keinen Reflex des Ja-kanje. 15

Der K-pler Text hat ein vereinzeltes "skăčiša" (72/17) und regelmäBig "navadiša" ( $61 / 25$ "navadiša pušku bolbšuju" also 'ausrichten, zielen', vgl. 66/4 u.a. Stellen). Die Belege im $\mathrm{K}$-pler Text sind nicht besonders aussagekräftig. Vor allem genügen sie nicht, um den Autor irgenwie einzuordnen, da wir sonst gar nichts besitzen, was uns bei diesem Versuch von Nutzen sein könnte. Beim Pleskauer Autor verwundern diese Erscheinungen nicht - zwar sind die genannten Erschei-

12) Karinski,j, Jazyk Pskova, S.206. cernych weist in früheren Ausgaben, vgl.: $P$, J, Tscherprch: Historische Grammatk der russ. Sprache. Halle 1957 (Slawistische Bibliothek 6).S. 296, auf die Verwechslung von " $u$ " und "v" in westmuss. und weiBmiss. Chroniken bin. Chr. S. Stang: Die altruss. Urkundensprache der Stadt Polozk. Oslo 1939. S. 32, weist u.a. darauf hin, daB diese Erscheinung zwar lebendige Form der Smolensker Kundart sei, den Polocker Urkunden sowie dem Lit.-Russ. unbekannt sei.

13) Stang, Altruss. Urkundensprache, $S .32$, bezeichnet gerade "esme" als besonders typisch für die Pleskauer Sprache; Damerau, N.: Russisches und Westrussisches bei Kurbskij. Wiesbaden 1963. S. 23 hält "esmja" für eine Ja-kanje-Variante zu "esme".

14) s. Schneider, Sprache Posoškoys, S. 30, we1st in den Schriften Peters I. oft "tysęca" nach.

15) Schneider, ebda. S. 30, führt Belege für "desêts" und devetb" aus Pososkovs Schriften an. 
nungen im SüdgroBrussischen beheimatet, haben sich dann aber auch im Moskauer Gebiet durchgesetzt. Karinskij erwähnte den zunehmenden EinfluB des WeiB- und Westrussischen, dem die Pleskauer Mundart ausgesetzt war, und so fügt es sich in das Bild, wenn Kuznecov für die schriftlichen Pleskauer Zeugnisse ab der 2. Hälfte des 14 . Jh.s A-kanje registriert. ${ }^{16}$

In der Pleskauer Erzählung fällt die regelmäBige Schreibung "tovaryšci"l7 auf (der K-pler Autor verwendet korrekt "tovaríšči").

Die konservative Haltung des K-pler Erzählers (bzw. Kompilators oder Ubersetzers) äuBert sich besonders auffällig darin, daB er der auf russischem Boden erfolgten Veränderung der Artikulationsstelle der Velare ${ }^{18}$ graphisch nicht folgt, also -8y-, -ky- schreibt, wenn es nach den morphologischen GesetzmäBigkeiten des Aksl. erforderlich ist (und noch darüber hinaus). So lesen wir vorwiegend "turky", "greky" 1m Akk.pl., allerdings auch in Nom. pl. (z.B. 61/17 "turky", 65/19 "greky" - hier aber auch häufig palatalisiert: "turcí", "grecil", "frjazi", auch "frjagovi"). Wir finden Akk. pl. "is pušky" 71/35, regelmäBig Instr. Pl. "turky", aber auch andererseits Bildungen, die die Änderung der Artikulation der Velare reflektieren, z.B. Akk. pl. "v vragi" 64/11. Fast immer schreibt er "aky", "paky", "do oblaky" (64/7), "so mnogymi polky" (74/30), "izo mnogych pušek".19

16) V. I. Borkovskij, P, S. Kuznecov: Istoričeskaja grammatika russkogo jazyka. M. 1963. (weiterhin zitiert als: Borkovskij, Istor. grammatika.) S. 141.

17) s. R. Schneider, Sprache Posoškovs, S. 43 : es scheint hier so etwas wie Volksetymologie hineinzuspielen Sachmator dachte an Angleichung an "tovars - tovary", Cernych an Einfluß des Suffixes - Jš.

18) Die Artikulationsstelle der Velare $g, k$, ch mit folgendem Vokal der mittleren Reihe $I$ verlagerte sich (etwa ab 12. Jh.) durch Entlabialisierung nach vorn, so daB aus dem Vokal der mittleren Reihe ein Vorderzungenvokal murde: $i$, der seinerseits eine Palatalisierung der Velare be Wirkte : $-g^{\prime} 1-,-k^{\prime} 1-,-c^{\prime} 1-V_{B l}$. Borkovskij, Istor. grammatika, S. 53 § 2 ; Zernjch, Istor. grammatika, S.142 f.

19) Dies gilt nicht für Fremdwörter, z.B. "stratigi". 
In der Pleskauer Erzählung sind derartige Schreibungen ziemlich selten anzutreffen, etwa "otroky" Vok. (45/17), die beutige Schreibweise ist die Norm.

Die bisher behandelten Erscheinungen im Bereich des Vokalismus stellen zwar Besonderheiten der einzelnen Texte dar, aber die die Texte wirklich auffallend prägenden bzw. die Texte von einander absetzenden Unterschiede sind die folgenden: Am deutlichsten ist die unterschiedliche Behandlung der *ort, *olt, *ert, *elt - Gruppe: der K-pler Text verwendet beinahe auschlieBlich die aksl. Lautung, wohingegen der Pleskauer Text den ostslav. Vollaut in $50-60 \mathrm{v}$. Hd. hat. 20

Hierher ist auch die anlautende Gruppe "ro- zu stellen (für * lo- finden wir in unseren Texten keine Belege). Diese Gruppe reflektiert im Aksl. (und im Südslav.) als ra-, während sie im 0st- und Festslav. ro- lautet ("rabb - robb", "rasti - rostb, poroslb", "ravnyj - rovnyj", "raz- - roz-"). Unser K-pler Text läBt keine Anfälligkeit gegen umgangssprachliches ro- erkennen; so begegnen wir nur der Vorsilbe "raz-", nur "rab", "rasti" usw., wohingegen in der Pleskauer Erzäblung der Antell der russischen Variante des aksl. Präfixes "raz-", nämlich "roz-" immerhin bei $15-20$ v.Hd. liegt.

Auch in bezug auf die Vertretung von aksl. -ie unterscheiden sich beide Texte in ähnlicher fieise. Es handelt sich dabei um die Lautgruppe: $b+j+$ Vokal. 21 Während die aksl. Denkmäler diese Lautfolge im gegebenen Fall als -ie wiedergeben, fand diese Lautgruppe auf ostslav. Boden die graphische Form -be, die sich in den Texten verschieden stark durchsetzt.

20) Bei dieser Angabe sind die zahllosen Benennungen Pleskaus als "grad Pskov" nicht berücksichtigt.

21) $b+j+$ Vokal: "gespannte Stellung des -b-": H, Bräuer: Slavische Sprachwissenschaft. Is Einleitung, Lautlehre. Berlin 1961. (Sammlung Göschen 1191/1191a). S. 124; (we1terhin zitiert als: Bräuer, Sprachwissenschaft I). P. Diels: Altkirghenslavische Gramatik. I. Teil: Grammatik. Heidelbers 1963. (weiterhin zitiert als: Diels, Aksl. Grammatik). S. 64 ff. 
Dieser Reflex ist auch in der K-pler Erzählung erkennbar, aber doch nur in schwachem MaBe. Die Abweichungen von der ksl. Norm dürften hier etwa bei 5 - $10 \mathrm{v}$. Hd. liegen. Wir treffen also "vzjatie", "plenenie", "molenie", "smertiju", "znamenija",aber auch "swertbju".

Anders im Pleskauer Text: hier findet sich die mussische Vertretung in 40 - $50 \mathrm{v}$. Hd. aller Belegstellen. NaturgemäB sind es besonders profane Wörter, die für die russische Lautung anfällig sind: "vzjatbe", "vodolitbe" 88/15, "ponuženbe" $88 / 32$, "otstojanse" 89/30, "želanbe" 68/8, "opolčenbja" 69/8, "zamyšlenbi" (Instr. pl.) 90/18 - sonst "zamyšlenii" (Instr.pl., falls nicht wie meist "-enbmi") 92/21. Aber auch wörter des geistlichen Bereichs finden wir auf "-be": "prošenbja" 82/29, "milostbju" 75/17 (gegen acht Kal "milostiju"). Dabei haben die entsprechenden Formen keine erkennbare stilistische Funktion. So kommen in Passagen mit stärker religiöser Orientierung wenige Belege vor, die auf "-be" lauten, - das liegt aber am speziell kirchlich geprägten Wortschatz, der dort gebraucht wird. Umgekehrt sind in den rein erzählenden und auch in den Kriegsereignisse schildernden Abschnitten beide Varianten nebeneinander und ohne erkennbare Funktionsteilung anzutreffen.

\subsection{Konsongantiㅗ픈}

Der Konsonantismus zeigt in beiden Texten weitgehende tbereinstimmung. Allerdings unterscheiden sich beide Texte darin, in welchem Umfang sie die Ergebnisse der drei Palatalisierungen bewahren oder aber rückgängig machen. Zur Verdeutlichung seien einige typische Erscheinungen kommentarlos aufgezählt: "ženy mnozil" 61/44, "turçi" 65/21, "krepcee" 61/44, "krepçae" 65/43, "v frjazech" 63/35, "v tuze veliçej" 73/25, "ruçe" Nom. Akk. dual. 70/37, "v sile tjažçe" 71/6. Daß dabei Verwechslungen $z$ wischen "turći"= Nom. pl. und gelegent$11 \mathrm{ch}$ "turçi" = Akk.pl. oder zwischen "turk y" = Akk.pl. und "turky ${ }^{n}=$ Nom.pl. auftreten, ist unwesentlich-Beispiele: K-pel. Die Pleskauer Erzählung folgt der Tendenz der auf russischem 
Boden erfolgten Rückbildung der Palatalisationsergebnisse per analogiam. Gelegentlich auftauchende Reste der Palatalisationen haben z.T. stilistische Funktion, meistenteils aber dienen sie wohl allein dem Ziel, den Text der ksl. Lautung anzunähern. Die Verwendungen palataler Formen kann man nicht anders als sporadisch bezeichnen. Ziemlich regelmäBig finden wir den Akk. dual. "v ruçe" oder Nom. dual. "ruçe", aber auch "v rukach" 64/8, "na rukik" 47/17, "gajduçi" Voc. pl. 89/9 - "otrokyy" 45/17 Voc. pl., "po boze" 49/4. Neben üblichem "pskovskoj" finden wir plötzlich "pskovstii narodi" Nom. pl. 57/23 vor, als der Autor eine Prozession beschreibt. Der Grund für die Falatalisierung "v morstej pučine" $92 / 16$ ist ähnlich - der Autor hält einen sehr hochgestimmten Monolog, in dem er sich in immer neuen Apostrophen und mit rhetorischen Fragen an den polnischen König wendet; Ironie und reiche Metaphorik sollen die Sinnlosigkeit seines Vorhabens unterstreichen. Derartige Archaismen werden ganz gezielt eingesetzt.

Die Verbindung folgender Laute führte zu efnem gemeinsamen Palatalisationsergebnis:

st-j / sk-j / skb wurden zu aksl. -št-, dem im Altruss. die Lautung -štš-entsprach. Diese wurde aber ziemlich früh zu -ť́s- $(=-\check{c}-)$ vereinfacht.

Ob nun durch den Zweiten Südslavischen EinfluB oder durch die Makarij-Ära bedingt - jedenfalls konnte sich die offensichtlich als Kirchenslavismus gehaltene Lautung -štı́- in allen Schriftdenkmälern, die in irgendeinem Sinne als Literatur, als über den Hausgebrauch hinausgehend konzipiert waren, gut erhalten. Die Verwendung der einen oder der anderen Schreibweise gibt ziemlich sichere Auskunft darüber, wo ein Verfasser sein Opus eingeordnet wissen wollte: beide Autoren benutzten fast ausschlieblich (d.h. in über 95 v. Hd. aller Fälle) die an das Ksl. angelehnte lautung -štš-. Die gesprochene Sprache komnt in manchen häufigen Wendungen zum Durchbruch: beide Autoren gebrauchen gelegentlich "noči" oder "noçb". Dagegen im beliebten Dat. abs.: "nošči že prispevši" (K-pel 60/29). 
Im K-pler Text finden wir einmal "tysjać" 60/25 neben sonstigem "tysjašč". Auffällig ist,wie der Pleskauer Autor, der sonst ausschließlich "chošču, gebraucht, zwei Mal stilisierend "chočju" verwendet $(96 / 1$, -/2): er fügt in die Erzählung einen Brief ein, den ein Ausländer (Hans Möller) an den Stadtkommandanten Fürst $I . P$. Sujskij geschrieben haben soll - die Schreibung mit -č- statt literarischem - šč 22

Neben "gorjašçoju vodoju" PS $77 / 18^{23}$ finden wir in der gleichen Bedeutung "smolu gorjaçjuju" PS 88/5. "mećjušče" PS 77/ 19 ist sicher durch "meč" 'Schwert' in der Schreibweise beeinflußt, außerdem mochte das folgende nochmalige -šč- den Autor irritiert haben. Bekanntlich bilden hyperkorrekte Bildungen einen besonders sicheren Beweis dafür, daß 2 wischen Schriftbild und umgangssprachlichem Gebrauch eine Differenz besteht, und der Autor die Kategorien nicht sicher beherrscht:

"istošči" PS 90/35 - zu "istočiti" - 'ausschütten'.

"..., mnogaja svoja imenija istošči,..."

'.... so viele deiner Güter hast du vergeudet,...'

Die stimmhafte Entsprechung der soeben dargestellten Lautgruppe bilden: $z d-j / z g-j / z g-b$, die $z u$ aksl. den, der im Altruss. die Lautung zždž- entsprach; diese wurde in der Umgangssprache früh $z u=\underline{z}-$ vereinfacht.

Auch bezüglich dieser Lautvariante verhalten sich beide Texte in der gleichen Weise - nur: sie benutzen beinahe ausschlieblich die auf russischen Boden ungangssprachlich verbreitete Variante -̌̃-. Die Ursache dafür, wieso es hier zur

22) Auf diesen Brief wird noch im Rahmen der Besprechung des 1-Part.s einzugehen sein - aus demselben Grunde: im Gegensatz zur gesamten Pleskauer Erzählung verwendet der Autor dort - um Primitivität des Stils zu symbolisieren als Präteritum ausschlieBlich das 1-Part. 95/30 - 96/8.

23) Um Klarheit und tbersichtlichkeit zu gewährleisten, verwenden wir weiterhin, wenn es erforderlich ist, folgende Abkürzungen: 
graphischen Beibehaltung eines archaischen Zustandes ( -řtš-

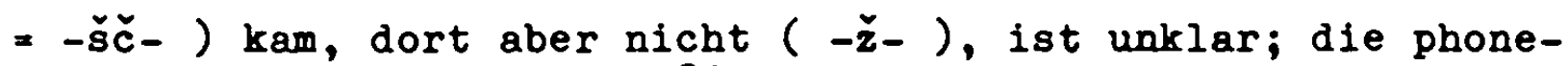
tischen Erklärungsversuche ${ }^{24}$ reichen m.E. nicht aus, um dieses graphische Phänomen zu erklären, denn es stellt die Norm im russischen Schrifttum jener Zeit dar. Allerdings gibt es auch hier einige wenige Ausnahmen. So finden wir in der Pleskauer Erzählung von "rožestvo", das doch nur im geistlich gefärbten Kontext (mit Heiligennamen) gebraucht wird, fünf Mal diese Schreibung und nur einmal "roždestro" (PS 65/20).

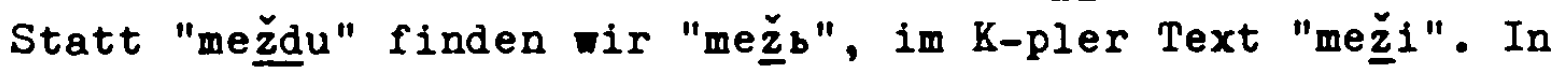
beiden Texten ist so viel von "nadeža" die Rede, aber nur im K-pler Text stoBen wir einmal auf "nadežda" (KF 61/12, desgleichen "osuždenie" KP 75/24); ebenso in dieser Form das leitmotvartig erscheinende "nuža". Die K-pler Erzählung kennt weder ein "voinstvo" noch "voiny" - Termini, die in anderen Kriegserzählungen dominieren - , neben "greci" ist immer von "gražane" die Rede, "graždanom" (KP 69/40) gehört zu den Ausnahmen. Sonst treffen wir noch an: KP 59/20 "obъeždaše" - neben sonstigem "obrežaše" (z.B. KP 59/41) ; "daždub" KP 66/3 neben sonstigem "daj" ; "raždenet" KP 59/41 zu "razgrnati, raždenu".

Assimilationserscheinungen ${ }^{25}$ begegnen in der Pleskauer Erzählung auf Schritt und Tritt, kommen aber auch im K-pler Text vor. So wird in beiden Texten häufig "voz-" an den folgenden Konsonanten angeglichen: "voskolebatisja" PS 37/35 (aber "vozskočiti" PS 87/1), "vosplakasja" KP 63/33.

"raz-" dagegen hat größere Resistenz und erscheint meist nicht

24) z.B. Borkovskij, Istor granatika, S. $89 \mathrm{ff.,} \$ 56$. S. 91: "Opredelit" fonetičskoe značnie vsech privedennych vyse oboznacenij ne tak prosto." (Hervorbbg. G.Str.) - Borkovskij meint hier die vertretung der 2d-j/2g-j/2g-b - Gruppe und ibre Entwicklung.

25) $V_{\text {Bl }}$. Sobolevskij, Lekci1, S. $146 \mathrm{ff}$. 
assimiliert: "rozsylaše" PS 48/34; "razseče" KP 74/7. "1ㄹ-" und "ㅇ-" werden meistens assimiliert: "ispravil esi" PS 92/31, "1stjazaniem" PS 84/11, "istajaše" XP 74/21; "zbiša" KP 59/37 aber "sbiša" KP 61/29.

Die spontane Schreibweise fällt in der Pleskauer Erzählung bei dem Epitheton ornans "bezçislen(n)yj" auf - etwa ein Drittel der Belege (sieben von zwanzig) hat "besčislen(n)yj". Beide Autoren sind bemüht, zusammentreffendes -ž̃- zu trennen, aber auch hier gibt es Anzeichen in beiden Texten, daB die Aussprache sicher ein langes -žž- war. "roz(b)ežžzajtesja" PS 45/19, "obъežžaja" PS 48/21. Das gleiche Verb im $\mathrm{K}$-pler Text war bereits oben erwähnt: "obъežaše" KP 59/41 und "obъeždaše" KP 59/20 (unter Beibehaltung des archaischen "-žd-" s.0.). - Dagegen aber in der Regel Trennung -ž́- : "sъezžajasja" PS 63/23, "rozžigaja" PS 47/8 (bei diesem Verb sind Präfix und Stamm, trotz zahlreicher Belege im Sinne von 'brennend in beiden Texten, nie verschmolzen).

Fälle von Verschmelzung "-sč-" oder "-sšč-" treten nicht auf das wäre denkbar z.B. bei "bezçestno" - "besčestno" zu "beščestno", ebenso wie bei "bezçislen(n)yj", "sçastbe" usw. Ein deutlicher Unterschied 2 ischen beiden Texten besteht darin, daB in der Pleskauer Erzählung die regressive Assimilation in besonders starkem Maße auch uber die Tortgrenze, insbesondere auf Präpositionen ausgedehnt wird. Die $\mathbb{R}$-pler Erzählung folgt dieser Tendenz nur selten (vgl. gelegentliches "ig pušky"), meist finden wir auch in dieser Position etymologische Schreibung ("1z pušky"). Polgende Kombinationen begegnen häufig im Pleskauer Text:

"brat z bratom" (trotz vorausgehendem - $\underline{t}$ !) $80 / 31$, "z bezčislennymi" 77/34, "z goncy" 48/33, "is polja" 97/20, "z_gramoty" 94/16, -/22, "is-pod steny" 94/16, "is toe ukraing" $41 / 30$

Ist diese Erscheinung noch als Wiedergabe der Artikulation verständlich, so muB man bei den folgenden Belegen, die bei weitem nicht die einzigen sind, vermuten, $d a B$ die obigen Schreibungen dem Pleskauer Autor so in Fleisch und Blut über- 
gegangen sind, daß er solche unaussprechlichen lautgebilde wie die folgenden herstellt: "z svoimi...", "z čjudotvornymi..." (62/25).

Die letztgenannten Erscheinungen (regressive Assimilation, nicht lautgesetzliche Auffüllungen und Veränderungen) dürfen wir als besonders charakteristisch für den Pleskauer Text ansehen.

Dissimilation (Lösung des doppelten Verschlusses) finden wir ausschlieBlich in der Pleskauer Erzählung. Auch dieser Vorgang scheint nicht so sehr an eine Region gebunden zu sein, ebensowenig wie die Assimilationsvorgänge. Bei Kurbskij kann Damerau ${ }^{26}$ die gleiche Erscheinung feststellen. Für das 18. Jh. bringt Schneider 27 eine Anzahl Belege bei. In der Pleskauer Erzählung handelt es sich vorwiegend um die Erleichterung der Aussprache zusammenstoBender "k", dementsprechend finden wir acht Mal "ch korolju" (z.B. 60/8), sodann auch "nechto" 86/13, "ch korolju k Stepanu" 52/16, "ch krestnomu celovanbju" 48/27 - im Ganzen sind im Pleskauer Text etwa 15 solcher Belege. Stang ${ }^{28}$ erwähnt nur die regelmäBige Vertretung von "kъto" durch "chto".

In der Pleskauer Erzählung werden verschiedentlich die Konsonantenfolgen -zdn- und $-\underline{s t n}$ - in der Weise vereinfacht, daB der Dental ausfällt. So begegnen uns von den 13 Belegstellen mit "čestnyj" sechs in der Gestalt von "česnyj". Stets regelmäBig gebildet finden wir "krestnyj" vor, ebenso häufiges "okrestnyj"; "vesnicy" 74/29. Aber auch im K-pler Text haben wir einen Beleg für dieses Phänomen: "lesnica" 67/35 neben sonstigem "lestnica".

26) N. Damerau: Russisches und Westrussisches bei Kurbskif. Wiesbaden 1963. S. 25.

27) Schneider, Sprache Pososkovs, S. $49 \mathrm{f}$.

28) Stang, Altruss. Urkundensprache, S. 66. 
"-zdn-" ist nur in 'Feiertag' zu erwarten - die regelmäBige Schreibung ist aber "praznik" (vier Belege); vgl. KP 55/9 "praznovati".

DaB die ehemalige Palatalität sich zur Zeit der Entstehung unserer Texte noch stark im Schriftbild niederschlägt, ist nichts AuBergewöhliches - dies ist z.T. heute noch der Fall ("žits", "šits" usw.). Als Zeichen seiner noch existierenden Palatalität findet man in beiden Texten nach -č- noch häufig jotierten Vokal - also "čjudo". Auch folgende Belege verweisen auf ungesicherte morphologische Verhältnisse: "v serdcych" PS 57/29, -/31, 79/17, "v serdcy" PS 89/8 - dagegen "v serdcech" PS 75/33, "vychodeç" PS 86/13. Es hat den Anschein, als sei der Ubergang ehemaliger jo-Stämme (z.B. "vychodecs", "serdce") zu den o-Stämmen" 29 noch nicht gänzlich vollzogen. In der K-pler Erzählung reflektiert ausnahmslos ein noch älterer Zustand: "v serdcí" 64/32, "v serdcích" "vladyčicjü" KP 63/1.

Auslautendes -t der $3.8 \mathrm{~g} \cdot / \mathrm{pl}$. findet sich beinahe ausnahmslos verhärtet. Möglicherweise haben die Herausgeber die Orthographie unifiziert. Allerdings finden wir im

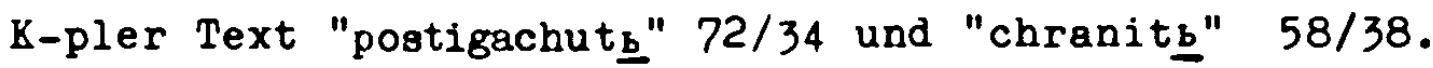
Meist haben wir jedoch - $t b$, wenn der Endung ein -s- vorangeht - also: "bystb", "dastb", "estb", "vestb".

Im Fleskauer Text fällt die Schreibung "tca" 30 in der 3. sg./pl. präs. und der 3. pl. ipf. der Reflexiva auf. Die Lösung findet sich auf S. 30 der Vorbemerkungen des Hrsg.s: der Autor hat alle Reflexivformen in der Weise vereinheitlicht bzw. die hochgestellten Sigla in dieser Weise aufge-

29) A. Leskien: Handbuch der altbulgarisghen Sprache. Grammatik - Texte - Glossar. Heidelberg 91969. S. $81 \mathrm{f}$. (weiterhin zitiert als: Leskien, Handbuch).

30) vgl. Sobolevskij, Lekcii, S. 108, seinen Belegen nach ist diese Lautung für den nordwestrussischen und weiBrussischen Raum chrakteristisch - z.B. Novgorod, Smolensk. 
gelöst. Dies aber vermutlich darum, weil die Belege seiner Hs., die er ausgeschrieben fand, diese Form gehabt haben mochten. Wir sehen darin bereits die Verhärtung der Silbe, wie sie heute auch die sprachliche Norm darstellt.

Der K-pler Text hat historisches "-sja", hin und wieder begegnet man einem verkürzten " $-8 b$ " nach auslautendem Vokal: "zatvorišasb" 68/3, "podvizašesb" 57/32, "sovokupitisb 1 kolebatisb" ( = Inf.) 60/5. In beiden Texten findet man das Pronomen auch gelegentlich vom Verb getrennt: "bojase bo sja" KP 74/23 ("bojašebosja" 75/4), "nadejaše že sja" PS 90/28 und wenige andere.

Es fällt auf, daB der Pleskauer Autor die reflexiven Formen viel häufiger verwendet als der $\mathrm{K}$-pler: dieser Text enthält $7 v$. Hd. reflexive Verbformen, jener fast drei Mal so viel: 19 v.Hd. Man kann sich des Eindrucks nicht erwehren, daB der Fleskauer Autor das reflexive Verb verwendet, um dadurch eine besonders hochtönende Sprache zu erreichen. Bei genauem Hinschauen stellt man fest, daB ein groBer Teil dieser Reflexivpronomina entweder gar nicht nötig oder durch geringfügige Veränderung des Satzes vermeidbar wäre, manche Reflexivpronomina sind auch einfach falsch gesetzt:

69/5 "Tako že ottobravsja ich, izbrannych gradoemec i pribliznych korolevskich dvorjan, dve tysjasci ..."

'So wählte er 2000 seiner besten Leute aus ...'

Für die vielen Belege, wo man nach dem Sinn des "-sja" fragen muB, ohne daB man das Demonstrativ-Pronomen direkt als falsch gesetzt bezeichnen könnte, mag dieser Satz stehen: 86/29 "I tako božieju millostiju i sie ich umyšlenie vsjaceski razmusisasja ..."

Auch diese Konstruktion wäre, wenn man in "unyšlenie" nicht evt. ein Kollektivum vermuten könnte, als grammatisch falsch anzusehen. Und es ist wohl auch gemeint: 'so durchkreuzten sie durch Gottes Güte diesen ihren Plan vollkommen.'

SchlieBlich ist noch eine Erscheinung zu erwähnen, die für den nordwestlichen und westlichen Bereich des GroBrussischen charakteristisch" ist: das "Co-kanje". Die Belege hierfür

31) Borkovskij, Istor grammatika, S. 93, § 58; Sobolevskij, Lekcil, S. I07. Einige Beispiele, die auf Nord- und Westruss. deuten, bei Cernych, Istor. grammatika, S. $146 \mathrm{f}$ Co-kanje begegnet im Raune Novgorod, Pleskau, Polock bis Smolensk hinunter und hat sich zeitweise noch weiter ausgebreitet. 
sind Jedoch wider Erwarten nicht nennenswert. Die Pleskauer Erzählung hat ein klares Beispiel für diese Erscheinung: 67/29 "ko vzjatbju grada putb očlščajušče" so auch in 69/15, 70/16 "schodu svoego putb oçščajut".

Im K-pler Text finden wir sogar drei Belege. Einer davon ist mehrfach vertreten: "pesca" 67/7 (m1t kommentierendem "sic" von Seiten des Hrsg.s dort),73/41, 71/5; in 67/2 finden wir "turkom mnogym všedšlm grad, konnym 1 pešcem" wobel hier das fragliche Wort attributiv zu "turkom" gebraucht ist. $74 / 33$ "v sile tjažğe", in 71/6 "v sile tjažsce" - in genau der gleichen Funktion die typlsche Schreibweise für Co-kanje. 74/16 "ašče ... ne gospodb sożǐdet chram, vsue tružaemosja 吕1žduščel."

'wenn ... nicht Gott erbaut das Haus, dann mühen wir uns vergebens, die wir es erbauen.'

Eine Besonderheit des Pleskauer Textes sei hier angefügt, obgleich diese mit phonetischen Erscheinungen nichts zu tun hat - genausowenig aber mit den anderen Abschnitten, deshalb sei sie an dieser Stelle erwähnt: es finden sich in der Pleskauer Erzählung fast zwanzig Fälle von Präpositionsverdoppelung - d.h., ein präpositionales Objekt mit einem Attribut (Pronomen, Adjektiv, Partizip) erhält sowohl für das Attribut als auch für das Objekt eine eigene Präposition. Es handelt sich hierbei um eine sehr volkstümliche Ausdrucksweise. Einige Beispiele:

88/12 "z dolgimi s samopaly"

$65 / 25$ "12 stanov iz korolevskich"

$65 / 35$ "12 narjadu 1zo mnogago"

$63 / 18$ " tom ze $v$ Pokrovskom ugle $1 \mathrm{v}$ Svinjch vorot"

Für den auch sonst sehr ausglebigen, für die Pleskauer Erzählung so typischen Gebrauch der Präpositionen nur ein Beispiel:

61/20"k Velikim vorotam, k čeloveku božiju Alekseju 1 vorodu, k Velikim i $1 \underline{k}$ Svinym $1 \underline{k}$ Pokrovskim

Eine Stelle aus der K-pler Erzählung lieBe sich hier anfügen, doch sie war das Ergebnis einer langen Suche, während solche Konstruktionen in der Pleskauer Erzählung einen Stilzug darstellen.

63/38 "...; takože na stenach ugotovljachu mnogJe sosudy, napolnjajuoce smolbja 1 sery gorjucee so smoloju 1 B poskaniju 1 s zeliem $\underline{\underline{a}}$ pusećnym.

Ohne auf alle phonetischen Einzelhelten unserer Texte ein- 
gehen zu können, läBt sich aus dem vorgestellten Material und den beschriebenen Beobachtungen ersehen, daß der K-pler Text - bis auf den zu jener Zeit literarischen Reflex der alten Lautfolge "-zd-j-" usw. zu "-̌̌-" (statt zu "-žd-") - konsequent die historische Schreibung gebraucht, was Fehlbildungen nicht ausschlieBt, die aber kaum auffallen.

Dagegen bietet die Pleskauer Erzählung ein geradezu chaotisches Nebeneinander umgangssprachlicher Formen und ksl. Schreibungen. Allein gelegentliche hocharchaische Formen haben stilistische Funktion. Man gewinnt den Eindruck, daß für den Pleskauer Autor jene literarischen Normen, die den K-pler Autor geleitet haben, nicht mehr galten. Die russ. Lautung scheint für ihn weitgehend gleichberechtigt neben der ksl. zu stehen. Der ksl. Reflex der alten Lautfolge "-sk-j" usw. zu "-štš-" = "-šč-" weist auf eine bestimmte schriftsprachliche Norm •

2war finden wir im Pleskauer Text viele Anzeichen des Eindringens der gesprochenen Sprache ("gorod", "roz-", "z svoimi", "ch korolju" u.a.), doch ausgesprochene Regionalismen spielen hier kaum eine größere Rolle als in der K-pler Erzählung. In beiden Texten begegnen schwache Reflexe des A-kanje, des Cokanje stärker im K-pler Text; die Pleskauer Erzählung zeigt stärkere Vertauschung von " $u$ " und "v" als der B-pler Text. Letzteres weist auf weiBrussische sprachliche Einflüsse (heute auch in den ostruss. Dialekten verbreitet ${ }^{32}$ ), während das Co-kanje für Teile der Novgoroder/Pleskauer Gebiete charakteristisch ist. Auf den Nordwesten weisen auch die häufigen Genitiv-Endungen der Adjektive auf -evolovo und der Gen. von "onb": "evo" statt "ego". Die Vertretung alten -è- durch -i-, wie wir sie in der Pleskauer Erzählung häufig antreffen, ist auch charakteristisch für den nordwestrussischen Raum um Novgorod-Pleskau.

Andererseits darf man auch nicht übersehen, daB dem Pleskauer ${ }^{3:}$

32) Cernych, Istor. grammatika, S. 46.

33) zum folgenden vgl.: Borkovskij, Istor. grammatika S. 90 und S. 95; Cernych, Istor. Brammatika S. 154. 
Text so typische Erscheinungen wie Ersatz von "-zdj-", "-zgj-" und "-zg'-" durch "-žg-" (statt großruss. "-ž(d)-n) fehlen, z.B. für "dzžde" liest man im Novgorod-Pleskauer Gebiet oft "dъžge", für "vozželavši" findet man "vъzgelavšin" usw.

Des weiteren fehlt der ebenso für die Pleskauer Mundart typische Einschub eines "-k-" oder "-g-" vor "-l-" beim 1-Part., z.B. das im Pleskauer Text häufige "po-", "priveli" reflektiert im Nordwesten verschiedentlich als "po-", "privegli". Hier handelt es sich darum, daB sich die ursprüngliche Lautung "povedii nach Ersatz des "-d-" durch "-g-" erhalten hat vgl. die entsprechende Erscheinung: nordwestruss. "soustrĕkli" (1. Pleskauer Chronik) anstatt "sustréli" (aus * sosrětli). Da der Pleskauer Text nur wenige 1-Part. aufweist, ist das Fehlen dieser Erscheinungen nicht so verwunderlich, obwohl andererseits gerade das 1-Part. von "-vesti", z.B. "poveli", "priveli" stark vertreten ist. Das Fehlen dieser für Pleskau typischen sprachlichen Erscheinungen stützt aber nicht die These, der Verfasser der Pleskauer Erzählung sei in Moskauer Kreisen zu suchen. 35

Beide uns vorliegende Texte stellen Kopien dar, die ihrerseits auch von Kopien angefertigt worden sind. Uns scheint, daB sich hier bestimmte sprachliche bzw. dialektologische Schichten überlagern, wobei deutlich stärker westruss. Züge in der K-pler Erzählung, nordwestruss. Züge, vermischt mit weiBruss. Einsprengseln, die Pleskauer Erzählung beherrschen.

34) Borkovskij, Istor. grammatika, S. 94 ; Karinskij, Jazyk

$35)$ s.o. B. Textgeschichte, Konzeption, Komposition, S.130 ff. Tichomirov, Recenzija, S. 350 f. kam jedoch nicht auf Grund sprachlicher Analysen $z u$ seiner Vermutung, daB der Autor in unmittelbarer Umgebung des Zaren zu suchen sei, sondern auf Grund des ideologischen Grundzugs der Erzählung. 


\section{Zur Morphologie}

Die eben umrissenen Züge spiegeln sich auch in der Morphologie: Der Pleskauer Text zeigt ein Nebeneinander von Formen, das vom Aksl. bis zum heutigen Russisch reicht, wohingegen der K-pler Autor ganz selten neuere Formen zuläßt. Wir wollen hier nur kurz einige aufällige Unterschiede in der Morphologie des Nomens vorstellen und einige Bemerkungen zum Pronomen machen. Der Bereich des Verbs kann hier ausgeklammert werden, da dort auch der Pleskauer Autor den älteren Zustand gut wiedergibt; außerdem werden die aufälligsten Erscheinungen im Rahmen der Besprechung des Verbs erläutert.

\subsection{Adjektivi}

Auf die nominalen Formen gehen wir hier nicht ein. Diese spielen eine vollkommen untergeordnete Rolle und bieten vom Formenbestand her das alte Bild, wie wir es von den aksl. und frühen altruss. Texten kennen.

Nom.sg.: Während der K-pler Text im Mask. ausschließlich die Endung -yi (in unseren Texten $=-y j$ ) verwendet, schreibt der Pleskauer Autor entweder $-y j$ oder $-0 j$, nach $-g-,-k-,-c h-$ aber $-\underline{i} i(=-i j)$ und $-o j$. Fem.: keine Besonderheiten: -aja/ -jaja.

Gen.sg.: KP: mask.,ntr. -ago,-jago

PS: " " -ago ( 40 v.Hd.), -ogo (60 v.Hd.)

(manchmal -ovo)

KP: fem. -yja (als Reflex von altem -yje)

PS: " -yja (55 v.Hd.), -yje ( 33 v.Hd.; tbergangslautung zum heutigen $\mathrm{Zu}-$ stand)

$$
\text { -oj/-ej (12 v.Hd.; heutiges Bild) }
$$

Dat.sg.: heutiges mask.,ntr. -omu und fem. (weich) -ej haben bereits im Aksl. im Wesentlichen diese Lautung.

Akk.sg.: keine Besonderheiten - mask.,ntr. s. Nom.sg., fem. -uju/-juju. 
(Akk.sg.) Die Kategorie der Beseeltheit hat im Sing. Ilingat die Form des Gen.sg.

Instr.sg.: mask.,ntr. -ym/-im (Behandlung von -y- und -i-s. Nom.sg.)

fem. -ojufeju

Lok.sg. : mask.sg -em, PS gelegentlich schon heutiges -om.

Nom.pl. : KP -yja und die Kurzform -i mit Palatalisation in Akk.pl. entsprechender Stellung: mnozi

PS -ye, دie

KP fem. - yja

PS " -yja (60 v.Hd.), -ye,-ie (40 v.Hd.)

Die Kategorie der Beseeltheit bildet den Akk.pl. im KP beinahe ausschlieBlich mit Nom.pl., aber auch im PS ist der Gen. noch nicht häufig - ca. 20 v.Hd. aller entsprechenden Fälle.

Gen.pl. : -ych/ich (über -y und -i s. Nom.sg.mask.)

Dat.pl. : $-\operatorname{ym} /-i m("$ " " " " )

Instr.pl.: $-\operatorname{ymi} /-i m i("$ " " " "

Lok.pl. : $\operatorname{ych} /-i c h("$ " " " )

Der Dual begegnet nur gelegentlich innerhalb eines Dat.abs. als -šema.

Da die meisten Flexionsformen vom Aksl. bis heute recht stabil geblieben sind, zeigt sich die Entwicklung nur im Gen.sg. und im Nom./Akk.pl.fem., wo der Pleskauer Autor das für eine Ubergangszeit so typische Nebeneinander aller Formen bietet, wobei sich in diesem Nebeneinander eine gewisse Gleichberechtigung der Umgangssprache äuBert.

\subsection{Substantiv}

Bezüglich des Substantivs bemerkt Unbegaun, daß auch im 16. Jh. noch (bel ihm: erste Hälfte) das morphologische Formans nicht nur Kasus und Numerus, sondern auch das Genus zu mar- 
kieren in der Lage sei, zumindest was mask. und fem. Stämme anbelange. 36

Die i-Stämme flektieren im Sing. nach dem bekannten Muster, das sich vom Aksl. bis heute nicht geändert hat. Im Instr. fem. begegnen wir häufig, im $K$-pler Text fast regelmäBig der $z u$-iju (statt -bju) erweiterten Endung. Der Plural ist belegt mit häufigem "napastej","blagodatej", im Pleskauer Text zusätzlich mit "krepostbmi" ( $43 / 19,=$ Festungen), Dat.pl. "moščem" (47/12), Akk.pl. "mošči" (73/30), Instr.pl. "moščbmi" $(85 / 5)$.

Die a-Stämme und die ja-Stämme zeigen noch heute große Xhnlichkeit mit dem aksl. Paradigma. Der Instr.sg. auf -oju braucht wohl kaum erwähnt $z u$ werden. Auffällig ist die gelegentliche Ubernahme mask.ntr. Instr.pl.-Endungen der a-Stämme und auch der ja-Stämme - vgl.:

PS 58/31 "Vsju stenu vooružiša ljudbmi i narjady, puški i piščali i ručniç̨ 1 vsjakimi ukreplenbmi ..."

Darüberhinaus finden sich noch 2 wei Belege für Instr.pl. von "gramota auf -y: PS $94 / 16$ und $-/ 22$ "s simi že gramoty".

Bei den ja-Stämmen fällt auf, daß der Gen.sg. und Nom./Akk. pl. noch das alte -je reflektieren - allerdings ist es wahrscheinlich, daß an dieser Stelle in den Originalen noch -A/A $z u$ finden ist. In unseren Textausgaben besteht jedenfalls keine Opposition zwischen Nom.sg. "bogorodica" und Gen.sg., Akk./Nom.pl. "bogorodiça", vgl. "nuža", "duša"; "ot vseja duša" (KP 68/37), "ot vseja duša i serdca" (FS 44/8). Neben diesen vorherrschenden Formen finden wir aber im Pleskauer Text verschiedentlich die neue Form des Gen.sg: "bogorodicy" (48/9, 74/32), "ot žažy" (77/7).

Den Dat. finden wir in der Pleskauer Erzählung vertreten:

36) B. Unbegaun: La langue russe au XVI giècle $(1500-1550)$. 1. La flexion des noms. Paris 1935. (Bibliotheque de 1 Institut français de Leningrad. 16). (weiter zitiert: Unbegaun, La langue). S. $37 \mathrm{ff}$. 
er reflektiert die ksl. Lautung: "bogorodicy" (47/7, 62/31, $70 / 24,-128$ ) - diese Form list nun also nicht mehr von den jüngeren Gen.-Bildungen auf $-\mathrm{y}$ zu unterscheiden.

Zum Akk. ist nur zu bemerken, daB noch Reflexe der einstigen Palatalität des "c" erkennbar sind: "caricju" (KP 75/42), "vladyčicju" (KP 63/1), "bogorodicju" (PS 75/23), 8.0., S. 153.

Für den Instr. finden wir in beiden Texten Belege, z.B. "žažeju" (PS 77/7), im K-pler Text regelmäBig "nužeju" und "nadežeju" (insgesamt neun Mal), "cariceju" (KP 62/42), aber: "nadežoju" (PS 46/20).

Für den Lok. finden wir einen zweifelhaften Beleg in K-pler Text - zweifelhaft, weil es sich vermutlich um ein Maskulinum handelt: "na zlatnice" (55/12) - auf der Münze, auf dem Goldstück'. 37

Für den Plural können wir folgende Belege beibringen: "lesnica" - Akk.pl. (KP 67/31), "lestvicami" (KP 59/39); "lesnici"

- Akk.pl. (KP 67/35).

Der Vok. 1st repräsentiert durch "gospože bogorodice" (PS $37 / 8)$.

Bei jenen ja-Stämmen, die auf Vokal oder palatalen Konsonanten ausgeben, liegen die Verhältnisse ähnlich - im K-pler Text fehlt es an Belegen, vom Pleskauer Text können wir durch das reichlich belegte "zemlja" den Zustand ermitteln:

Gen.8g. : "zemlja" und "zemli" (im Verhältnis 1 : 3)

Dat.sg. : "zemli"

Akk.8g. : "zemlju"

Instr.sg.: "zemleju"

Lok.sg. : "zemli"

37) In Sadnik B. Altretmüller: Handwörterbuch zu den altkirchenslavischen Texten.'s-Gravenhage 1955. (weiterhin zitiert ale: Sadnik-Aitzetmüller, HWB S. 167: "zlatica". Srezn., I, 981: "zlatica". ebenda, 984: "zlatbnikz", "zlatinica" -'numus'. 


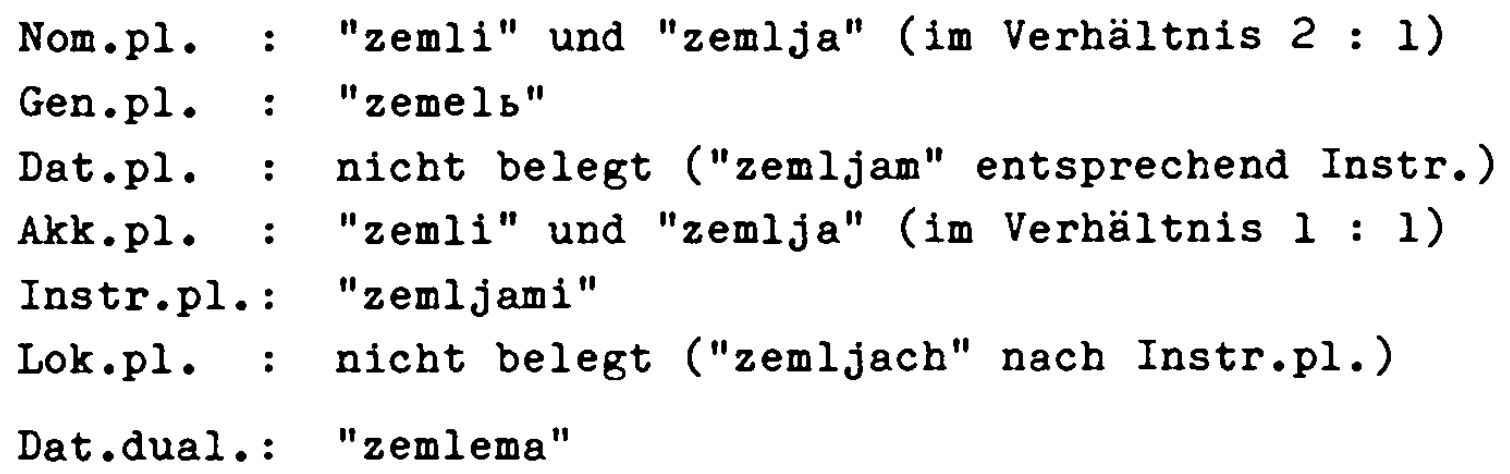

In den fraglichen Kasus - Gen.sg. sowie Nom.Akk.pl. ist die auf dem Aksl. basierende Endung $-j p /-q>-j a /-a$ noch nicht ganz zugunsten der heutigen Endung -i zurückgedrängt, die - in Palatalitätskorrelation zu den Endungen der a-Stämme eine neue Opposition zwischen Nom. und Gen.sg.:-ja/-a statt heutigem $-i$ bildet.

Ergänzend seien hier noch einige Beispiele für die Falatalisation bzw. deren Unterlassung bei den a-Stämmen angefügt: KP 77/40 "na desnoj noze", KP 73/24 "vo tuze velicej"; PS 60/26 "na moskovskoj doroge", PS 61/19 "po dorogi".

Bei den o-Stämmen fallen im Gen.sg. die Bildungen auf -u auf, eine Erscheinung, die mit der allmählichen Eingliederung alter $\breve{u}$-Stämme in die o-Flexion zusammenhängt. Auch im Lok.sg. ist diese Erscheinung bemerkbar, doch längst nicht in diesem Ausmaß. So finden wir im K-pler Text:

"do torgü" 56/46, "ždachu pristupü" 59/33, "ot stukü, ot zukú"60/1, "do verchụ" $62 / 19$ u.a. Für den Iok.sg.: "v Rimü" $55 / 1,-125$, "o mirü" $64 / 30,-/ 35,-/ 36$, "na otseku grada" $66 / 33$.

Belere in der Fleskauer Erzählung sind:

"vsjakie kreposti gradü" 46/12, "sego sverepstvă" 46/4, 56/21, "pervago svoego chodū" 40/20, "vremja že svoego pochodü" 49/12, "iz narjadú" 58/17 (im Ganzen 13 Mal mit Gen. $-u$ ), "Polockú gradụ" 4l/28 u.a. Für den Lok.sg.: "vo pskovskom rvul" 77/30, "v koem polkü" 54/l (im Ganzen 4 kal mit Lok. -u), "o mirú" 42/26, 43/13 (vgl. "o mire" 43/8).

Im Ganzen gesehen machen die Gen.-Formen auf -u im Pleskauer Text 15 - 20 v.Hd. der Genitiv-Belege aus, die hierher zu 
zählen sind; im K-pler Text sind es 7 v.Hd. DaB es sich hierbei nicht allein um alte $\ddot{u}$-Stämme handelt, sollten die obigen Beispiele zeigen. So finden wir das alte ü-stämmige "syn" nur einmal im Pleskauer Text im Gen.sg. belegt: "u syna svoego" 37/9. Es handelt sich in den meisten Fällen auch nicht um den Gen.part., auch nach Attributen tritt - im Pleskauer Text dieser Gen. auf, ebenso wie nach Präpositionen. Die meisten Belege finden wir bereits in Unbegauns Listen. 38

DaB 2wischen den Gen.- und den Lok.-Bildungen auf -u insofern ein Zusammenhang besteht, als die Bildungen von Lok. auf -u in der Regel auch im Gen. auf -u vorkommen, dokumentieren schon die Listen Unbegauns. Für den K-pler Autor dürfte auch jener Gedanke die Entscheidung zugunsten des Lok. auf $-u$ beeinfluBt haben, den Sachmatov geäuBert hat ${ }^{39}$ : In einer Zeit, da keine Palatalisationen mehr stattfanden, entstanden zunehmende Unsicherheiten bei der Bildung des Lok. velar ausklingender o-Stämme, da die alte Lok.-Endung -ě ja ursprünglich palatalisierende Wirkung hatte, welche sich in den der literarischen Tradition verbundenen schriftlichen Zeugnissen niederschlug. Die tbernahme der Lok.-Endung der ü-Stämme auf $-u$ auch auf die o-Stämme enthob einen Autor der Schwierigkeit, von sich aus eine ksl. Endung bilden zu müssen - also statt "v pescé" - "v pesku", statt "v polcě" "v polku" usw. Diese Lok.-Endung -u mit Beibehaltung des auslautenden Velars bewirkte auch eine Vereinheitlichung des Paradigmas.

Das Vordringen der Gen.- und Lok.-Endungen auf $-u$ in den schriftlichen Denkmälern ist ein deutliches Zeichen für das

38) Unbegaun, La langue, S. $83 \mathrm{ff}$, wo die Ausbreitung der Kategorie anschaulich dargestellt ist. Schneider, Sprache Pososkovs, $S .77$, registiert in ihren Texten des beginnenden 18.Jh.s gar fast 50 v.Hd. Gen., die auf $-u$ enden. 8. auch die Monographie von Whorndahl: Genitivens og lokativens - $u /$-ju endelser. Kobbenhavn 1974.

39) A.A. Sachratov: Istoričeskaja morfologija russkogo jazyka. M. $\frac{1957 .}{19 .} 249-253$. 
Eindringen volkssprachlicher Elemente in die Schriftsprache. ${ }^{40}$ Diese Beobachtung konnten wir bezüglich der Sprache des Pleskauer Autors bereits verschiedentlich machen. $D a B$ in der $K-$ pler Erzählung Gen.sg. auf -u lediglich 7 v.Hd. aller mask $f$ ntr. Gen. Belege ausmacht, d.h. nur knapp die Hälfte in Bezug auf den Pleskauer Text, weist wieder auf das Bemühen dieses Autors (Kompilators, ibersetzers), sich möglichst streng an die tradierte Literatursprache $z u$ halten.

Der Akk.sg. von Beseelten wird durchgehend mit Gen.sg. -a gebildet.

Auch der Instr.sg. wird ausnahmslos auf -om gebildet.

In Lok.sg. finden wir neben den erwähnten Endungen auf $-u$ den üblichen Lokativ auf -e (aus altem -è - unsere Texte unterscheiden ja nicht 2 wischen $-e$ und $-\check{\text { ) }}$. Wie bereits angedeutet, umgehen beide Autoren mit den Endungen der ü-Stämme die durch -è bedingten Palatalisationsergebnisse $g>2$, $\mathrm{k}>\mathrm{c}, \mathrm{ch}>\mathrm{s}$.

Der Vokativ der o-Stämme ist im Pleskauer Text durch "kralju Stepane" vertreten (z.B. 52/24). Im K-pler Text finden wir "zastupniče našgospodi, prizri ..." (64/43); "gospodi bože naš" (68/43); "grade božii" (78/10); "pobedonosçe 1 velikomučeniče" (PS 85/26).

Im Nom.pl. sind nur aufällig die vielen Belege mit Palatalisatiosreflexen im K-pler Text wie "greci, frjazi,turci, vrazi" u.a., während wir in der Pleskauer krzählung z.B. "polki" $5 \mathrm{Mal}$, "vragi" sechs Mal vorfinden.

Zum Gen.pl. ist $2 u$ bemerken, daB im K-pler Text kaum die Endung -ov (z.B. "domov" $57 / 37$ = korrekt, da alter ü-Stamm) $z u$ beobachten ist. Es überwiegen die Endungen -ej oder Zero ("stratig i nakazatelej" 57/26, doch stets "vragov, turkov"). Im Pleskauer Text ist der alte Zustand noch z.T. gut erkennbar 2.B. "mučenik" 59/20, "gradoemec" 53/4 - aber "čjudotvorcov" 78/8, "tovariščov" 47/30, "pervosovetnikov" 53/11, "izminni-

40) Efimov, Ist. russk. lit. jazyka, S. 40. 
kov" 41/3, "koncov" 94/17 - die heutige Endung -ov der alten u-Stäme lot ganz deutlich is Vordringen begriffen.

1. Dat.pl. sind uns keine Ausnahmen von der alten Bildung -om/-em aufgefallen.

Der Akk.pl. entspricht im Pleskauer Text dem Nom.pl., be1 Belebten häufiger dem Gen.pl. Der K-pler Text dagegen unterscheidet oft noch zwischen Nom.-Ausgang auf -1. (mit Palatalisation) und Akk.-Ausgang auf -J. - So begegnen uns "potoci" 60/35 im Akk.(!), also mit Palatalisierung des Velaren, wie sie nur im Nom.pl. durch -1 hervorgerufen werden kann.

Im Instr.pl. kennt der K-pler Text ausnahmslos die Endung -y (gelegentlich -1). In der Pleskauer Erzählung kommen bereits viele Formen auf -ami vor: "znamenam1" $65 / 24$, "zmejnymi jazykam1" 54/4, "polkam1" 59/22, "krylami" 57/3, "nestam1" 64/18, "žalam1" 57/5 u.a.

Der alte Lok.pl. auf - ๕ch ist in Pleskauer Text noch gut erhalten: "vo svoeich streleckich prikazech" 89/33, "na krylech" 57/2 - es sind keine Endungen auf - ach festzustellen, ebenso kelne palatalisierten Velare, wie es z.B. die folgenden Beispiele des $\mathrm{K}$-pler Textes zeigen: "v potecech $1 \mathrm{v}$ brezech" 60/25, "v potecech" 63/11 - aber "v oknach" 76/1. Zu den jo-Stämmen läBt sich - in Anknüpfung an die o-Stämme folgendes feststellen:

Der Sing. zeigt in Vergleich zum aksl. Paradigma in beiden Texten kaum Abreichungen.

Reichlich ist der Vokativ belegt:

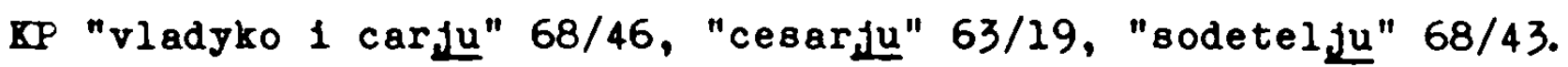
PS "kralju Stepane" (sehr häuf1g, z.B. 52/31), "gosudar 迆" $52 / 31$.

In Plural der jo-Stäne fällt die Anglelchung des Iok. an die Endung der o-Stämne auf:

PS "na konech" 67/4, 74/29, 89/20.

Be1 "serdce" zelgt sich der tbergang noch: 
"v serdcech" PS 75/33, aber drei Mal noch finden wir den alten Zustand reflektierendes "v serdcych" PS 57/29, -131 , 79/17. - vgl.: "v propastech" KP 76/3, "v choženilich" KP $78 / 17$.

Der Akk.pl. hat me1stens - auch bei Lebewesen - die Gestalt des Nom.pl.

Im Dat.pl. erscheint ausschlieblich die Endung -em.

Der Instr.pl. läBt noch keine Hinweise auf die Entwicklung zur Endung - jami/-ami erkennen - uns begegnet nur $-1 /-y$ ("s ... voln, "s ... mladency" usw.). Allerdings hat sich bei den Neutra auf -nie die Endung -nbmi (heute -nijami) durchgesetzt; in jedem Text verzeichnen wir von dieser Regel je eine Ausnahme: "neizrečennymi blagodejanii" KP 75/34,

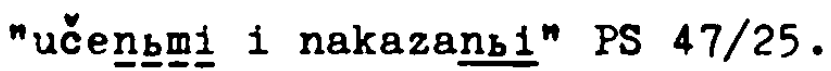

Konsonantische Stämme sind mit Resten ihrer alten Flexion in beiden Texten noch recht gut belegt. So finden wir in der Ple $\underline{\text { gka }}$ aue Erzählung viele Formen von "telon, vor allem Instr. pl. "telesy" 76/28,73/2; daneben "telesamin 73/7, "s telom". Weiter begegnen flektierte Formen von "slovon, "1mjan und

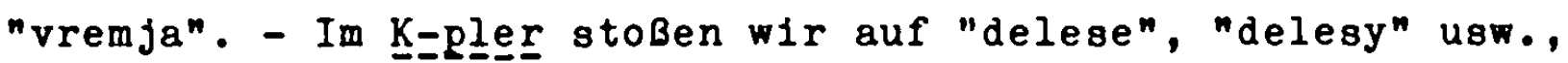
auf verschiedene Formen von "čjudon ("po čjudesem" 69/23 z.B.) u.v.a.

Die Kategorie des Dual ist in beiden Texten weitgehend erstarrt. Häufiger treffen wir "rucen (für alle drei Kasus) an, gleichzeitig finden wir - auch in beiden Texten - die Entsprechungen im Plural, z.B. "V rukach" KP 65/40, "ruci 1 oći" KP 68/27, "ruky" KP 69/34, "na ruki" (Akk.pl.) PS 47/17, "12

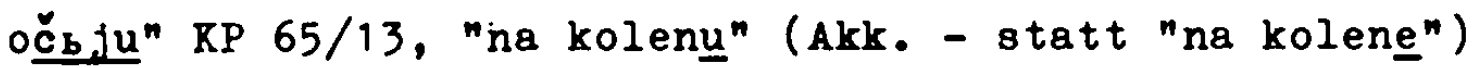
PS $70 / 22$.

Schlieblich findet sich in jedem Text noch eine mit Dual gebildete partizipiale Konstruktion:

KP $72 / 16$ "Videvŏa .... tri brateniki ..."

'Als die drei Blutsbruder sahen/gesehen hatten ...'

Der Pleskauer Text enthält sogar einen Dat.abs. mit Dual: PS 52/15 "Sobravšema že sja sima mogima zemlema v Iitvu ch korolju k stepanu." 
'Es hatten sich all diese Völker ( $=$ Länder) in L1tauen beim König Stephan versamelt.'

Hier ist zwar der Dual formal eindeutig, doch ist nicht ersichtlich, weshalb er hier steht: es handelt sich ja um viele Länder - sicher soll der Dual als exotische Form die Aussage unterstreichen.

Auf die Pronomen kann an dieser Stelle nicht eingegangen werden. Die vielfalt ist $z u$ groB, als daB man, ohne weiter auszuholen, einen Uberblick vermitteln könnte.

Es sei noch auf die enklitischen Pronomina sowie die im Russ. außer Gebrauch kommenden alten Akk.-Formen hingewlesen: Im Pleskauer Text treten sie selten, in der K-pler Erzählung aber so häufig auf, daß sie beinahe wie eine lebendige Kategorie wirken: "mi, ti, si, ny, vy" und " $1, j e, j u, j a, n_{b}, m j a, t j a n$. Wenn wir nun diesen kleinen Uberblick abschließen, so sei noch einmal darauf hingewiesen, daß es sich hierbei um keine systematische Untersuchung handeln konnte, sondern lediglich darum, eine ungefähre Vorstellung von dem Formenbestand $z u$ vermitteln und den Unterschied der Texte herauszustellen. Nie nicht anders zu erwarten, ist der K-pler Text der angestrebten ksl. Norm viel näher als der Pleskauer. Für letzteren scheint eine ganz andere Vorstellung von"literarischer Norm" zugrunde zu liegen. DaB der Autor im "hohen Stil" schreiben will, daB er sein Opus als hochliterarisch konzipiert, zeigt seine konsequente Verdrängung des 1-Part. Demnach scheinen umgangssprachliche Elemente in Phonetik und Morphologie zumindesten für den Pleskauer Autor das N1veau eines Werkes nicht mehr herabzudrücken. Ihm genügt es, 2war häufig, aber durchaus nicht konsequent, durch Ksl.men hohen Stil anzudeuten. Das aber zeugt von einer beachtlichen Eanzipation der Umgangssprache an die tradierte Literatursprache. Im übrigen mag hier auch eine Sonderentwicklung vorliegen. Die Novgoroder und die Pleskauer schriftlichen Zeugnisse unterschieden sich schon immer von den Denkmälern aus den anderen Gebieten der Rús durch groBe Blarheit und Nähe zur gesprochenen Sprache.

Es zeigt sich, daß die Untersuchungsergebnisse Unbegauns, 
die er am Material der ersten Hälfte des 16. Jh.s gewonnen hatte, auch für die zweite Hälfte, zumindest für den Pleskauer Text, Gültigkeit haben. ${ }^{41}$ So ist die Annäherung der maskulinen und neutralen o- und jo-Stämme ansatzweise zu erkennen: Lok:pl. der jo-Stämme -ich verschwindet zugunsten von -ech (= -ěch) der o-Stämme - dieser Zusammenfall bildet u.a. die Voraussetzung zur späteren gemeinsamen Aufgabe des "Themavokals" - è- zugunsten der Palatalitätskorrelation, wie sie die a- und ja-Stämme schon immer hatten: -am, -ami, $-a c h /-j a m,-j a m i,-j a c h$.

41) Unbegaun, La langue, S. $193 \mathrm{ff}$.

Allerdings zeigt sich, daB sich der Pleskauer Text die $\mathrm{K}$-pler Erzählung brauchen wir erst gar nicht zum Vergleich heranzuziehen - in Beziehung auf die Entwicklung von Dat., Instr. und Lok.pl. hin zur Universalendung auf der Basis von $-a /-j a$ doch konservativer darstellt als die breite Masse des von Unbegaun untersuchten Materials.

Der ProzeB der Generalisierung dieser Endung war auch in der Petrinischen Zeit noch nicht abeeschlossen:

V $\mathrm{gl}$. Schneider, Die Sprache Posoškovs, S. $107 \mathrm{ff}$. 


\section{Zur Lexik}

Ein systematischer Vergleich des lexikalischen Bestandes beider untersuchter Texte würde sich lohnen. Allein schon die Gegenüberstellung der Benennung technischen, vor allem kriegstechnischen Geräts und der damit in Verbindung stehenden Handlungen eröffnet ein weites Feld. Aus Raumgründen müssen wir uns aber darauf beschränken, die für den einzelnen Text charakteristischen lexikalischen Erscheinungen vorzustellen. Wir wollen zeigen, mit Hilfe welcher lexikalischer Mittel die Autoren versuchen, dem Leser Lokalkolorit zu vermitteln der K-pler Autor muß die griechische und die türkische Seite schildern, der Pleskauer Autor braucht dem Leser nur die gegnerische polnische Seite nahezubringen.

Weiterhin muß es uns darum gehen, Wörter vorzustellen, in denen wir Neologismen ${ }^{42}$ einerseits und Regionalismen andererseits vermuten.

\subsection{Die_Erzzählung}

Der Autor ${ }^{43}$ der Erzählung versetzt den Leser mit Hilfe vieler Graecismen in das belagerte K-pel. Byzantinische Titel 44 bleiben fast ausschließlich unübersetzt, dasselbe gilt für topographische Bezeichnungen, die in groBer Zahl anzutreffen sind. Letztere aufzuzählen, führt uns nicht weiter, wir wollen nur kurz die wenigen vorstellen, die übersetzt sind: "zlatoe mesto" (69/43) - wahrscheinlich 'Goldenes Horn',

42) Hier soll allerdings nicht von jenen Neologismen die Rede sein, von denen wir im Zusammenhang mit den Anmerkungen zum Stil sprachen - jene kühnen stilistisch bedingten Wortzusammensetzungen, die so charakteristisch für den Pleskauer Text sind.

43) Wenn wir hier und im weiteren von "Autor" sprechen, dann geschieht dies der Einfachheit halber. Es soll damit keineswegs früher Gesagtes - s.o. B Anmerkungen zur Textgeschichte, S.60 f.- In Frage gestellt werden: Wenn wir also ferner von "Autor" sprechen, schlieBen wir die Mögl1chke1t eines "tbersetzers" bzw. "Redaktors" mit ein.

44) Braun-Schnoider, Bericht über die Eroberung, S. 34 - 35. 
mit "derevjanye vraty" (69/42) könnte dem Kontext nach das 'Blachernentor' gemeint sein, unter "tesnoe ustie" (77/34) muß man sich vermutlich die Dardanellen vorstellen, "u zlatych vrat" (77/9) meint das 'Goldene Tor'.45 Die übrigen topographischen Bezeichnungen bleiben unübersetzt. Zwar wird der gebildete moskovitische Leser manche Bezeichnung bereits kennen, ${ }^{46}$ aber im allgemeinen wird der Leser recht hilflos dieser Menge von Benennungen gegenübergestanden haben.

Folgende Titel sind auf Schritt und Tritt anzutreffen: "cesarb" (ganz selten "carb"), "kesarb" (im Sinne von 'kaisar' - Mitkaiser), "magistr", "megistan", "stratig", "eparch", "archiduks", "velikij domestik", "velikij logofet", "protostrator", "velikij dukas", "anaktos" u.a. Dazu kommen die im Russischen bekannten Titel "velbmoža" und aus dem geistlichen Bereich "patriarch", "sinklit" und "klirik", beide im Sinne von 'Klerus', 'höhere Geistlichkeit'.

Andererseits sind Graecismen im Bereich des Gegenständlichen, Dinglichen selten - Giustiniani kommt "na dvu korabljach i na dvu katargach" (69/2) nach K-pel. Letzterem dürfe griech. "xátepror" zugrundeliegen. Vasmer verweist auch (eine Verbindung aber ablebnend) auf osman. "kadyrya" - Galeere'. 47

Schneider weist darauf hin, daß der Autor eine ausgezeichnete Kenntnis der byzantinischen Beamtentitulatur verrät,"die einem Russen kaum zugemutet werden kann."

45) Braun-Schneider, Bericht über die Eroberung, S. 30 Anm. 64 und $\hat{s} .34$. - Schneider weist darauf hin, daB hier offentar falsche lbersetzung vorliegt: der $K-p l e r$ Autor berichtet, daB der Kaiser am Goldenen Tor gefallen sei, die byzant. Quellen aber bezeichnen einmüig das Charsiostor als den Platz, wo der Kaiser den Tod fand: der Ubersetzer hätte in diesem Falle "Charsé pýle" und "Chrysè pýle" verwechselt.

46) Drevnerusskaja povestb o vzjatii Carbgrada frjagami $v$ 1204 godu. Hrsg. N.A. Meščerskij in: TODRL X (1954), S. 120-135. In der Novgoroder Chronik finden sich noch drei weitere Reiseberichte von Pilgern und wohl auch Kaufleuten - s. D.S. Lichačev, Die Kultur RuBlands,S.43 fi:

47) Vasmer, REW I,541. - In diesem Abschnitt werden wir fernerhin solche Verweise in den Text hineinnehmen, da sonst der FuBnoten-Apparat zu umfangreich und die tbersichtichkeit leiden würde. 
Als die Türken $\mathrm{X}$-pel erobert haben, leisten die Griechen ihnen - so unsere Erzählung - noch elf Tage heldenmütigen Widerstand, u.a. bewerfen sie die Türken mit "keramidy i plity" $(76 / 5)$. Zwar sind beide Wörter schon früh in der altruss. Literatur belegt (Srezn.: keramidy I 1206, plity II 965), aber sie scheinen vorwiegend in der Ubersetzungsliteratur aufzutauchen (vgl. griech. kéfxpog - 'aus Ton Gebrann-

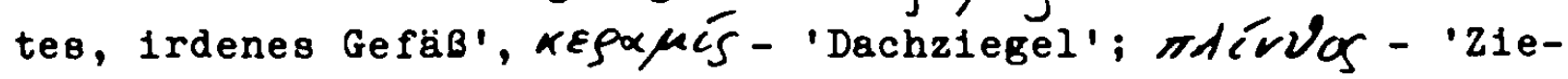
gel') und ihren Premdwort-Charakter bewahrt zu haben. Turkische Instrumente werden vorwiegend mit griech. Namen bezeichnet: "zaigrav vo vse igry 1 v tumbany" (70/15) - "tumbany" geht zuruck auf $T 5{ }^{2}$ rraror - 'Handtrommel, Tamburin', das Srezn. III 1037 zwar bereits im 13. Jh. (Simonovskaja psaltyrs do $1286 \mathrm{g.}$ ) nachweist, doch wird auch "tumbanz/tumpanz" als Fremdwort empfunden worden sein.

"načaša surny igrati i v vargany i nakry biti ..." (59/29) "surny" geht sicher zurück auf $\tilde{\mathcal{v} \rho y \xi}-$ 'Syrinx, (Pan-) Flöte'. "vargan" - Maultrommel, Brummeisen' (Vasmer REW I, 170) geht zwar indirekt auf ópperor zurück, doch ist der v-Vorschlag nur im Ukrain. "virhány" und im Cech. "varhany" bekannt. Srezn. I 227 findet "vargan" erstmals in der Erzählung über die Mamaj-Schlacht. "nakry" dürfte ein Turcismus $\operatorname{sein}(s . u$.$) .$

Ein sonst nirgends belegtes Wort bezeichnet Schneider 48 als Graecismus: "sklop" - 'Geschoß, Geschoßsplitter oder herabfallender Gegenstand' und stellt es zu Gkónoy-'Dorn, Splitter, Nagel', auch 'Balken':

72/27 "...: priletevšu ubo sklopu i udari Zustuneja 1 srazi emu desnoe plečo, ..."

'eine Kugel/Splitter/GeschoB/Stein traf Giustiniani und zerfetzte ihm die rechte Schulter'.

48) Braun-Schneider, Bericht über die Eroberung, S. 26 Anm. 54, S. 34 . 
Eine ähnliche Wendung finden wir eine Seite vorher:

$71 / 35$ "..., no priletev is pušky jadro kamennoe na izlete, i udariv Zustuneja po persem,..."

Bedeutungsmäßig in die gleiche Richtung weist "sklëp, sklëpka" - 'eine zusammengénietete Stelle, Stück; das Zusammennieten'. ${ }^{49}$ Für dieses Wort ist nirgendwo ein Nachweis zu finden. Allerdings finden sich bei Dal' (Tolk. Slovaŕ Bd. 4) und bei Pavlovskij Hinweise auf "sklëpb, sklëpka" - 'eine zusammengenietete Stelle, Stück; das Zusammennieten'. Das geht auf "klepatb, kleplju" -'klopfe, läute, niete, verleumde' zurück (s. Vasmer REN I, 568), das in dieser Form bereits im Aksl. als 'stoßen' belegt ist. - Eine vage Verbindung wäre möglich $z w i s c h e n$ 'Nietung, genietetes Stück' und 'Stein-oder Kugelsplitter, Kugelstück'.

Abgesehen von diesen vereinzelten Beispielen für mögliche Graecismen im dinglich-materiellen Bereich ist der Hortbestand dieses - insbesondere des kriegstechnischen - Bereichs in der altruss. Literatur gut belegt.

Es fehlt auch nicht an türkischen Titeln, aber sie treten quantitativ weit hinter den griechischen zurück, ihr Erscheinen beschränkt sich fast ausschlieBlich auf die Kampfhandlungen: "saltan"; "begilarbej" - Beglerbey'; "sančak-bej" 'Sandschakbey'; außerdem wird "-bej" zur Würdenbezeichnung auch an Namen angehängt, "mulla", "paša"; "stol morskij" 'Befchlshaber der Flotte'; andererseits wird ein Sandschakbey auch "flaburar" (z.B. 65/32, 72/11) genannt, nach griech.

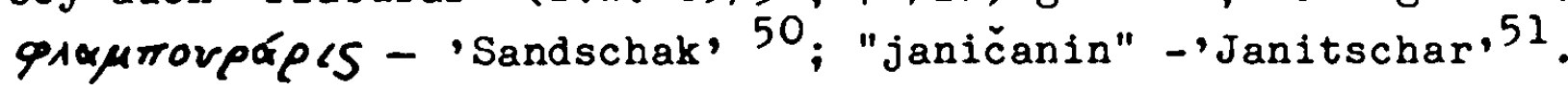

49) Pavlovskij, Wörterbuch 1480 ; V, Ral': Tolkovyj slovaŕ veliko-russkogo jazyka. Bd. 4. H. T956. S. 198. (weiterhin zitiert als: Dal’, Tolkovyj slovaŕ).

50) Braun-Schneider, Bericht über die Eroberung, S. 17, Anm. 33.

51) Janitscharen - Elitetruppe des Sultans, die sich aus gefangenen Christenkindern rekrutierte, die am Hof des Sultans erzogen und ausgebildet wurden; setzte sich zum groBen Teil aus Serben zusammen - vgl.: "i tu srete ego nekyj serbin, prinese emu cesarevu glavu". (76/45). 
Gelegentlich werden die Würdenträger des Sultans auch "magistry" genannt (60/37 u.a.). Die Christen werden einmal als "gaurove" (67/27) bezeichnet: 'Giauren' - Bezeichnung der Mohammedaner für Andersgläubige. An einer Stelle rufen die Türken: "Jagma, jagma!", und der Autor fährt fort: "jagma, jagma, sirečb - na razgrablenie grada" (61/40), also 'Auf, laBt uns die Stadt stürmen und plündern!" Mehrmals heiBt es: "(Magumet) so vsemi činy vrat svoich" (70/14, 76/21 u.a.).- '... mit den Würdenträgern der Hohen Pforted. Von den aufgezählten Instrumenten "surny, vargany" und "nakry" wurden die beiden ersten als Lehnwörter aus dem Griech. identifiziert. Bis zu einem gewissen Grade gilt dies auch für "nakra" - 'Schelle, Tamburin;

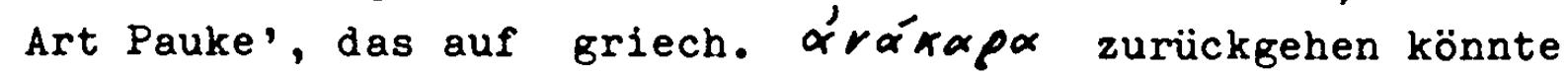
(Srezn. II 294), dies aber gibt osman. "nakara" - Pauke, Trommel" wieder (Vasmer REW II, 195). Henn wir also "nakra" als Turcismus bezeichnen, dann mit der ausdrücklichen Einschränkung, daB vermutlich das Wort bereits im Griech. als Lehnwort existierte.

Diese Gegenüberstellung griech. und türkischer Lehnwörter sowie von Titeln bestätigt, daß der Autor der K-pler Erzählung in $\mathrm{K}$-pel geweilt haben muB und nicht im türkischen Lager. Im letzteren Fall würde man einen viel stärkeren Anteil von Turcismen in unserem Text erwarten.

Nach diesen allgemeinen Bemerkungen über Wörter griech. und türkischer Herkunft, die der Leser in Rußland als Fremdwörter empfunden haben muB, seien noch einige Betrachtungen angestellt über Wörter, die einen Hinweis auf den Verfasser oder Ubersetzer der Erzählung geben könnten. Bereits der Archimandrit Leonid, der die erste Ausgabe der Erzählung, auf welcher die uns vorliegende Textausgabe fuBt, besorgt hat, wies auf das Wort "izrada" : "breči izrady" - Verrat verhindern, vor Verrat sichern' als einem westslavischem hin. 52 Skripil" erwähnt noch $z$ wei weitere Wörter, die westlicher Provenienz

52) s. Skripil', Povesti, S. 396. 
sind: "pučma" - 'Bündel, Büschel' als westruss. und

"guf" - 'Abteilung, Heerhaufe' (in unsrem Text eigentlich "gufa") als poln. Ursprungs. Uns sind noch einige weitere Belege aufgefallen, die in diese Richtung deuten, und die wir kurz vorstellen möchten; zunächst jedoch die soeben genannten:

"izrada" - 'Verrat'

$76 / 20$ "... posla sančak-beev po vsem ulicam s mnogimi ljudbmi breči izradz."

'Er schickte seine Sandschak-Beys aus ... damit sie Verrat verhinderten.'

Srezn. I, 1076: frühester Beleg im Sofijskij vrem. 15.-16.Jh. I, 997 : "zradca" - Verräter", Belege aus den Jahren 1493 und 1496.

I, 997 : "zraditi" - 'Verrat üben', Beleg aus dem Jahre 1496.

Vasmer REW I, 475: findet für "izradca" - 'Verräter' einen Beleg im 17. Jh., sonst "zradca".

I, 463: "zraditb, zdraditb" - 'verraten' oft in westruss. Urkunden des 15. Jh.s. (Hinweis auf Srezn. über poln. "zdradzić, "zdradzca", čech. "zraditi").

Sobik ${ }^{53}$, 228: führt nur "zdradecko" - verräterisch, an; belegt bei Ivan IV., sonst Azbukovnik 16.17.Jh.

Unbegaun $54,30:$ "izrada" - westruss., aber auch großmuss. belegt.

53) M. E. Sobik: Polnisch-russische Beziehungen in Spiegel des russischen Wortschatzes des 17. und der ersten Hälfte des 18. Jahrhunderts. Meisenheim/Glan 1969. (weiterhin zitiert als: Sobik, Beziehungen). In diesem Abschnitt über lexikologische Besonderheiten wollen wir die Verweise auf den Fundort in den Text hineinnehmen (s.0. Anm. 47). Wir begnügen uns dann damit, hinter dem Namen der Verf. Soblik die Seitenzahl der Fundstelle anzugeben.

54) B. Unbegaun: Les relations vieux-russes de la prise de Constantinople. In: RES 9 (1929). S. 13 - 38. (weiterhin zitiert als: Unbegaun, RES + Seite). Zur Zitierweise in diesem Abschnitt über lexikologische Besonderheiten unserer Texte - s.0. Anm. 47 und Anm. 53. 
Es dürften hier wohl am überzeugendsten die Belege Srezn.s aus dem 15. Jh. für "zradca" und "zraditi" aus den Jahren 1493 und 1496 sein: Gesandtschaftsschreiben des litauischen GroBfürsten Alexander an den Moskauer Grobfürsten Ivan Vasilbevič, die ganz klar für eine Entlehnung aus dem Nest-bzw. Weibrussischen sprechen: iz-rada - poln. "rada" - 'Rat'. Wenn wir die Entstehung der K-pler Erzählung in das letzte Drittel des 15. Jh.s verlegen, dann haben wir hier den bisher ältesten Beleg für "izrada" - 'Verrat'.

"pučma" - 'Bündel, Büschel'

71/15 "... metachu na turky ... smolja pụcmy velikyj zažigajušče." 55

'Sie warfen den Türken große Bündel brennenden Teers entgegen.'

"pučma" konnten wir nirgends auffinden. "pučok" ist als 'Bündel, Büschel, im HeiBruss. bekannt. 56

Vasmer REW II, 471: verweist auf "puk".

462: "puk" ist nur westslav., weiBruss. und ukr. belogt:

ukr., weiBr. "puk", čech., slk. "puk" 'Keim, Knospe', poin. "pek" - 'Bündel' und "pak" - 'Knospe', ähnlich oberund niedersorb.

Vasmer stellt die Verbindung zu "pukatb" - 'platzen' und zu "pučitb" - 'aufblasen' her, das von aksl. "poknoti" - 'plat-

55) "zažigajušče" taucht im Zusammenhang mit "smola" häufig auf und ist wohl weniger als partizipial 'entzündend', sondern attributiv, fast adverbial aufzufassen: 'brennend'. $\mathrm{Vgl}$. im Pleskauer Text 82/1 "smolbe zazigaja, na nich metati gotovljachu", 87/29 "povelevajut, smolbe zazigaja, na nich ... metati" $88 / 6$ "tako ze 1 , len osmoliv zazigaja, na nich metasa".

56) Vgl. Belorussko-russkij slovar. H. 1952. S. 768. 
zen' herkommend, in fast allen Slavinen Niederschlag gefunden hat. Doch ist für uns die Bedeutung 'Bündel, Büschel' relevant, und die findet sich nur im Westslav. sowie WeiBr. und Ukr. Daher ist der Weg der Entlehnung aus dieser Richtung der wahrscheinliche. Belege für "pučok" im Großr., von dem "pučma" eine Variante sein dürfte, finden wir nicht.

"gufa" - 'Heerhaufe, Abteilung (Heer)'

$74 / 10$ "..., sobravšu množestvo vojska, pride gufoju $i$ gordostiju velikoju na poloe mesto, ..."

'zog, nachdem er einen großen Teil der Krieger versammelt hatte, mit dieser seiner Truppe überaus stolz gegen die Breschenstelle ...'

Hier liegt die polnische Entlehnung ${ }^{57}$ klar auf der Hand:

Brückner ${ }^{58}$ SE, 173: über atsch. 'haufe'

Słaquski 59 SE I, 1432: dto.

Unbegaun RES, 19: dto.

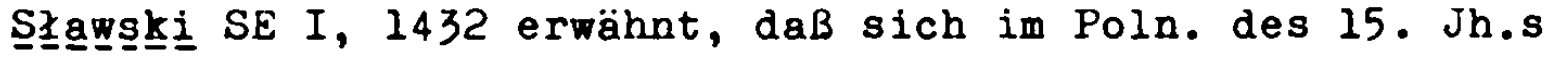
bereits "uf" (z zanikiem h- ...) im Umlauf befand; im Słㅡㅁník stạropolski II, 546 ist "uf" bereits im Jahre 1466, 1490 und 1497 belegt. Der Gebrauch in der K-pler Erzäblung

57) Allerdings ist hierbei eines erstaunlich: Słownik polszczyzny XVI $w$. Bd. 8, 371 findet den ersten Beleg für "guf" im Foln. erst im Jahre 1586: In der tbersetzung eines Lutherliedes: S. Krofej, Duchowne piesnie z niemieckiego w sławi ski jধzyk wylozone, Gdahsk 1586:

"bo slostnich huffa sie mnozy"

' Der Gottloß hauff sich umbher find'

M. Luther, Gesangbüchlin, Nürmberg 1558.

Demnach hätten wir einen Beleg für eine Entlehnung aus dem Poln. - 100 Jahre bevor die erste schriftliche Vertretung auftaucht.

58) A. Brückner: Slownik etymologiczny jezyka polskiego. Krakow 1927. ND Warszawa 1970. (zitiert als: Brückner SE)

59) F. Slawski: Slownik etymologiczny jezyka polskiego. T. I. Krakow 1952 - 56. (2itiert als: SLawski SE I). 
mit anlautendem " $g$ " für " $h$ " deutet darauf hin, daB im Poln. das als "uf" fixierte Wort "huf" gesprochen wurde.

In heutigen Russ. ist dies Wort völlig unbekannt, und auch im WeiBr. und im Ukr. hat evt. zeitweise Verwendung desselben keine Spur hinterlassen.

Immerhin verwandte es Kurbskij mehrmals in seiner "Istorija".60

Im übrigen ist die Form "gufoju" verwunderlich; denn das Wort "huf, uf" ist ja im Altpoln. mask. Möglicherweise liegt hier Verschreibung von irgendeiner Seite vor für "gufom".

"meži" - 'zwischen, unter'

Damergau ${ }^{61}, 76$ sieht in dieser Form eine Variante von "meždu", die von der altruss. Norm abweicht und auf westruss., evt. weiBruss. EinfluB hinweist. Im 16. Jh. sel im Weißruss. und Ukr. die Lautung auch "meži" gewesen. Dazu altpoln. miedzy, 16.Jh. schon wieder miedzy. (Brückner SE 332) Damerau bezeichnet "meži" als eine westruss. Form.

56/8 "..., tako bo be mesto to meži dvu morb 62 - Cernago 1 Belago."

'...,so befand sich diese Stelle (der Errichtung K-pels) zwischen zwe1 Meeren, dem Schwarzen und dem WeiBen.'

"bašta" - Turm, Wehrturm"

72/6 "Zustuneja že paky povele sebja nesti tamo 1 načat delati baštu s userdiem velikim, no dnju eže prespevšu, egda videša turky baštu delajuščich, vskore pustiša na nich 120 mnogych pušek..."

60) Damerau, Russisches, S. 70.

61) Damerau, Russisches - über Zitierweise hier B. Anm.47, 53.

62) 3.0. S.166: der Dual exigtiert nur noch in bestimmten Wendungen, hier wäre "meži dvema morema" zu erwarten. 
'... begann mit großer Energie, den Turm zu bauen,

..., als die Türken sahen, daß sie den Turm errichteten, befeuerten sie diese aus vielen Geschützen ...'

Wir finden im Text 17 Belege für "bašta".

Srezn. $\quad$ : kein Beleg für diese Wortform.

Damerau : dto.

Vasmer REW I, 66: erwähnt "bašta" im Zusammenhang mit "bašnja" als dessen ältere Form. Hierbei nennt er ausdrücklich unsere Erzählung.

Sobik 182 : übernimmt die Etymologie: "bašnja" aus älterem "bašta", dies über poln. "baszta" aus mhd. "Bastei" bzw. ital. "bastia".

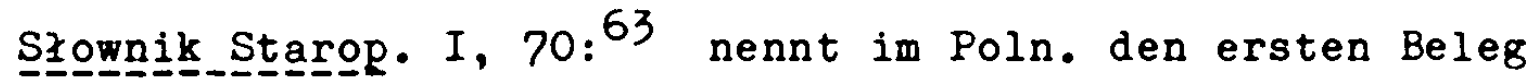
1448 .

Unbeggaung RES, 30: dto.

"delo" - 'Geschütz, Schußwaffe'

$60 / 5$ "..., i ne be slyšati drug druga čto glagolet: sovokupiša bo sja vopli i kryčanija i plač i rydanija ljudej 1 stuk delbnyj i zvon klakolbnyj $v$ edin zuk, $i$ bystb jako grom velij."

'... und es vereinigten sich Rufe und Schreien und Heulen und Nehklagen der Menschen mit dem Krachen der Geschütze/Waffen und dem Dröhnen der Glocken zu einem einzigen Getöse - und es war wie mächtiger Donner.'

Da sonst "delo" nur im Sinne von 'Sache' ganz allgemein gebraucht wird, bekommt die folgende Belegstelle,insbesondere "delo" im Sinne von obigem "stuk delbnyj" großes Gewicht:

63) Słownik staropolski. Tom I. Warszawa 1953 - 55. tber die Zitierweise s.o. Anm. 47, 53 u.a. 
61/40 "Abie vskriča voinstvo vse, pristupiša k gradu vsemi silami, po zemlje že 1 po morju vsjakimi dely 1 chitrostbmi na vzjatie grada; ..."

'... griffen sie die Stadt mit allen verfügbaren Kräften an - zu Lande und zu Wasser - mit aflen Waffen und Eroberungswerkzeugen/-maschinen ${ }^{64}$...',

Srezn. I, 789

: verweist auf Kurbskij als erster Fundstelle.("delo" = "puška", also Geschütz).

Unbegaun RES, 19 : verweist auf poln. "działo" und čech. "dèlo" - Geschütz.

Vasmer REW I, 338 : vermutet gerade jene Stelle mit "stuk delbngj" als erste Belegstelle für "delo" im Sinne des poln. "dziazo" Geschütz .

Słaamski SE I, 190: gibt für "działo" keineswegs jene spezielle Bedeutung an, sondern allgemeiner in einem Sinne, der gut zu beiden Textstellen, insbesondere der letzten paBt:

64) "chitrostb" - in unseren Texten bedeutet dies Wort nicht 'Schlauheit, List', sondern ist in Bezug auf Städtebelagerung stets eine 'listenreiche Erfindung', gemeint sind also mit "chitrostb" jene erwähnten "tury" - die Schanzkörbe/bewegliche Eroberungstürme, es dürften auch Leitern gemeint sein - alles das, was man an technischem Gerät zur Erstürmung eines Festungswerkes gebraucht. "delo" dürten dann, mit Bezug auf den "stuk delbnyj" die SchuBwaffen sein an bewegliche Geschütze, die im obigen Satz als beim Angriff mitgefürt erwähnt werden, kann man sicher um diese Zeit noch nicht denken - daher die vorgeschlagene Ubersetzung: 'Waffen, SchuBwaffen').

Vgl. PS 51/31 "... nikaja že tverdostb (= Festung) ostojatisja možet i vojakimi chitrostbmi 1 mudrymi umyslenbmi sego mozem vzjat1." nicht 'Kriegslisten', sondern

'mit allem Kriegsgerät und fein ersonnenen Maschinen'. 
Damerau, 67 : kann allerdings bei Kurbskif (vgl. Srezn. I, 789) "delo" zweifelsfrel als 'Geschütz' nachweisen.

"oboz" - 'Wagenburg, Troß'

$75 / 3$ "..., a (saltan) sam sja osta tokmo s janičany, obryvsja vo oboze i puški i piščali ugotoviv, bojašebosja cesarja."

'..., und Mehmed blieb mit den Janitscharen zusammen, verschanzte sich im TroB und bereitete die verschiedenen Waffen vor, denn er fürchtete den Kaiser.'

Srezn. II, 532 : erster Beleg in der Nikon-Chronik (1558). Vasmer REW II, 242: ksl. "obozb", čech. "oboz" -Gepäck, ohne zeitliche Angabe.

Sobik und Damergau führen "oboz" nicht an.

"piščalb" - '(tragbare?) Schußwaffe, Feldschlange' (offenbar im Gegensatz zur größeren "puška").

60/37 "..., I (Magumet) povele magistrom vskore pribaviti puški i pišçali mnozi na bienie grada $i$ ing stenobitnjja kozni gotoviti, ..."

'.... und Mehmed befahl seinen Wirdenträgern, schleunigst noch mehr Geschütze und Feldschlangen zur BeschieBung der Stadt herbeizuschaffen und weitere Listen zur BeschieBung der Mauer zu ersinnen, ...'

Srezn. II, 946

: Erstbeleg - 1. Plesk. Chr. s.a. 1471.

Vasmer REW II, 363 : Erstbeleg - Avrakum.

Vasmer ESRJa III, 271: Erstbeleg - Ende 15. Jh. im Yoskovskij letopisnyj srod, S. 247.65

65) M. Fasmer (=M, Vasmer): Etimologičeskij slovaf russkogo jazyka. Bd. 1-4.M. 1964 - 73. Die Vordatierung des Erstbelegs in der russ. tbersetzung des REW erfolgte nach E. Dickenmann in: Rocznik Slawlstyczny 21 (1960), S. 136. 
Sobik, 296 : Erstbeleg 1472 (mit Verweis auf Srezn. II, 946). Sie hält Entlehnung aus poln. "piszczel, piszczałka" - 'Feuermaffe, Flinte, für möglich. Die Grundbedeutung ist "piscalb" - Rohrpfeife, Schalmei'.

"inafty" - ? ,

$72 / 20$ "..., onem že obranjajuščesja ot nich, ujdoša $\nabla$ grad, bjachu že trie ty inaftyi: odin grečin, drugyj ugrin, a tretij arbonas."

'..., (die drei Blutsbrüder) aber zogen sich von diesen zurück und gelangten in die Stadt - es waren dies aber drei "inaftyi": ein Grieche, ein Ungar und ein Albaneser.'

Skripil", Povesti 396 - sieht hinter "inaftyi" eine verballhornte Schreibung eines lat. "Infans" im Sinne etwa von 'Jüngling'. Natürlich ist es denkbar, daß verschiedene Termini während des lateinischen Kaiserreichs (1204 - 61) ins byzantinische Griech. gedrungen waren und sich bis ins 15. Jh. haben halten können. Sehr überzeugend ist diese Annahme aber nicht.

Unbegaun RES, 20: "inaftyi" sei Verschreibung für weiBruss. "inaksyj" - 'ein anderer'. Zwar kann man seiner Bemerkung, "inaksyj" "convient bien ici pour le sens", sicher nicht ganz beipflichten, doch ist sein Versuch, das merkwürdige Wort zu klären wahrscheinlicher als Skripil's Vorschlag, da er nicht so weit hergeholt wie die Annahme eines lat. "infans" ist.

"zbruja" - 'Rüstung, Nehrzeug; Pferdegeschirr'

$72 / 43$ "...- padachu pod nim, 1 ne uderževaše bo meč ego ni zbrui, ni konskija sila."

'...- (die Krieger) stürzten unter ihm zu Boden, und keine Rüstung, kein Pferd hielt seinem Schwert stand (keine Rüstung, kein Pferd war stark genug, seinem Schwertstreich zu widerstehen).'

Srezzn. : kein Beleg für "zbruja".

Vasmer REW II, 585: deutet Entlehnung aus dem Poln. ("vielleicht") an: poln. "zbroja" - Bewaff- 
nung, Rulstung'. Er findet "zbruja", allerdings in der heutigen Bedeutung 'Geschirr (bei Pferden), Gerät, Werkzeug' bei G. Kotos̆ichín in: "O Rossil v caratvovanie Alekseja Michajlovičan, S. $52(1666-67)$.

Sobik, 223 : findet "zbruja" 1m Russ. erstmals 1600 belegt; auch sie nimmt poln. Vermittlung an; im Poln. lat "zbroja" als 'Rüstung, Bewaffnung' geit 1455 bezeugt.

Dameraa, 92 : kann "zbroja" - 'Bewaffnung, Ausruistung' be1 Kurbskif mehrfach nachweisen.

Das vorgelegte lexikalische Material aus der K-pler Erzählung (abgesehen einmal von Graecismen und Turcismen) deutet stark auf einen Autor/Redaktor/Ubersetzer, der im Westen des russ. Sprachraums beheimatet war. Unbegaun ${ }^{66}$ siedelt ihn im Norden des heutigen weibruss. Sprachgebiets an. Der gröbte Teil des vorgeatellten Materiala (aechs wörter von zehn) gehört zur militärischen Terminologie; vier Wörter sind anderen sprachlichen Bereichen zuzurechnen: "1zrada" - "Verrat', "pučma" 'Bündel', "mežin - für großruss. "meždun, schlieblich auch das unklare "inafty1" als möglicherweise verschriebenes weißruss. "Inakšyj" - 'ein anderer'.67 Diese Belege reichen nicht aus als Beweis dafur, daB der Autor/Redaktor/tbersetzer aus dem west- bis weiBruss. Sprachraum kommt, als deutlichen Hinweis können wir sie aber doch gelten lassen.

Die sechs kriegaterminologischen Lexeme, die wir soeben vorgestellt haben, gehören zu den ersten bekannten Belegstellen im russ. Schrifttum uberhaupt - entweder sie waren bereits als im $\mathrm{X}$-pler Text erstmals verwendet ausgewiegen (z.B. "delo" bei Vasmer, REW I, 338, Bedeutg. 2) oder eracheinen hier gleichzeitig mit den anderen bisher be-

66) Unbegaun, RES, S. 20 - er hält die uns vorliegende Fassung ( $\mathrm{Hs}$. des Archimandrit Leonid) fur eine ausgeschmickte Abachrift des Originals, dem die Chronograph-Redaktionen sehr nahestüden. An den Ausschmulckungen erkenne man den "copiste originaire du nord de la Russie Blanche."

67) Unbegaun zählt hierzu noch "nepriemnyj" - beeinflubt durch poln. "nieprzyjemny" uber weibruss. "njapryemny". 
zeugten Erstbelegen ("piščalb" -'Feuerwaffe, Flinte', "zbruja" - 'Rüstung, Bewaffnung'), in der K-pler Erzählung erstmals belegt zu sein scheinen "guf/a" - 'Heerhaufe', "bašta" - 'Wehrturm', "oboz" - 'Wagenburg, TroB'.

Aus diesen Lexemen, die aus dem Poln. übernommen oder durch poln. Vermittlung ins Russ. gelangt sind, kann man nur schlieBen, daB sich der Autor in der militärischen Terminologie auskannte - das aber verwundert nicht, da auch die eigentlichen Szenenschilderungen für einen Autor sprechen, der sich auf dem Schlachtfeld auskennt. 


\subsection{D1e Er_zählung_von_der_Belagerung_Pleskgaus}

In dieser Erzählung liegen die Dinge etwas anders als im $\mathrm{K}$-pler Text: der Pleskauer Autor schrelbt für eine Leserschaft, die an dem geschilderten Geschehen aktiv betelligte Partei war und den Kriegsschauplatz z.T. kannte. Der Autor brauchte dem Leser nur die polnische Seite sprachlich nahezubringen, brauchte nur einer Selte Lokalkolorit zu verleihen.

In einer langen kriegerischen Auseinandersetzung werden oft Begriffe, die für das gegnerische Heer charakteristisch sind - Rangbezeichnungen, Truppengattungen - übernommen und zur Bezelchnung des Gegners benutzt. In der Pleskauer Erzählung finden wir solche poln. Benennungen in reichem Maße: "korolb/ kralb", "getman", "kancler", "rochmist", "pan/panbi", "gajduk" u.a. Eine Verfolgung solcher Begriffe ist insofern von keinem großen Interesse, als es sich hier in keinem einzigen Falle um Entlehnungen handelt, sondern um ein stilistisches Mittel, die polnische Seite zu charakterisieren, ein wenig polnische Atmosphäre zu schaffen. Es geht also bei Verwendung dieser Begriffe nicht um Ubernahme einer Bezeichnung in den allgemeinen Sprachgebrauch, sondern es geht bei Verwendung dieser Begriffe gerade darum, das Fremde herauszustellen, es gerade als Fremdes zu charakterisieren. 68

68) Den Nachweis für die einzelnen Begriffe, Bezelchnungen usw. In den einschlägigen Wörterbúchern und in Spezialarbeiten, was soeben versucht wurde, können wir uns hierbei ersparen. Wir finden sie ausschlieblich in Schriften, die die poln./Iitauisch-russ. Beziehungen zum Gegenstand haben. Wir dürfen damit rechnen, daB diese Bezeichnungen in unserer Erzählung im russ. Schrifttum zu den ältesten Belegen gehören. So führt z.B. Srezn. I, 508 "gajduk" als in unserer Erzählung erstmals bezeugt an (1582), Sobik, setzt den Erstbeleg mit 1592/93 an. "getman" findet Srezn. I, 513 bei Karamzin, Ist.Gos.Ross. Anm. 321 (aus "Rostovsk1f Letop1sec" s.a. 1533), Sob1k, 203 nennt dies Wort 1584 erstmals bezeugt ("Istorija Vkratce o Bocheme". "rochmist" (= dissimilative Verschleifung für "rotmistr") aus frühnhd. 'rottmeister' - Srezn. - kein Beleg, Sobik, 328 - Erstbeleg 1584 ("Ist. vkratce o Bocheme"). Damerau kann "getman" 69 und "rotmistr" 84 in Kurbsk1js IstoriJa nachweisen. 
Der Pleskauer Autor bedient sich beim Gebrauch polnischer Würden- und Rangbezelchnungen einer Technik, die dem Leser der K-pler Erzähler seinerzelt sicher groBe Erleichterung bereitet hätte: bei Nennung solcher Titel oder auch Truppengattungen verwendet er "glossierende Synonymie", 69 d.h. er benutzt diese Figur nur ungefähr - er stellt nicht die russische Ubersetzung neben den polnischen Titel, sondern setzt ein Synonym im engeren oder weiteren Sinne daneben - so finden wir häufig "getmany" mit "pervosovetniki" zusammengestellt, der Kanzler Jan Zamoyski, Krongroßhetman, wird eingeführt mit den Worten "ustroit pana kanclera, velikogo getmana polbskogo" 54/18, "rochmisty" finden wir oft neben "voinskie ljudi", womit wohl das freiwillige Kriegsvolk gemeint ist ('Volontäre,70), das wohl - ähnlich wie die Rottmeister - eine freiere Position innehatten, als z.B. die "gajduki", die oft in einer Reihe stehen mit den "gradoemcy". Dies ist wohl im Sinne einer Tätigkeitsbeschreibung der "gajduki"gemeint - die Pleskauer erlebten diese FuBtruppe ja nur als Hauptpotential zur Erstürmung ihrer Stadt. Folgende Textstelle soll die beschriebene Technik des Pleskauer Autors demonstrieren:

64/25 "Togda že litovskij korolb Stepan sed na svoem gordel1vom korolevskom meste, getmang že svoja 1 velikikja_pany 1 vsja svoja pervosovetniki, 1 vse rochmisty 1 vse

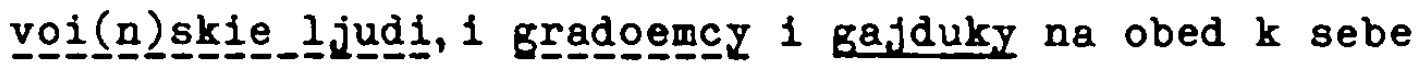
paki vsech sozva."

'...., und er rief seine Hetmane und groBe Herren und seine Ratgeber, alle Rottmeister und Volontäre, seine Sturmtruppen und die Heiducken zu sich zum Essen zusammen.'

69) Lausberg, Handbuch II, S. 823, ders, Elemente, $\$ 284$ : "Die 'glossierende Synonymie' ist die (...) Erläuterung (...) eines 'dunklen' (...) Ausdrucks durch einen 'klareren' Ausdruck. Der zu erläuternde Ausdruck kann sein 1. ein Tropus, ...., 2. ein Fremdwort (...), das durch das verbum proprium ... erläutert wird."

70) In der russ. Ubersetzung von R. Heidensteins "Rerum poIonicarum ..." (s.o. Textgeschichte - Konzeption - Konstruktion, Anm. 73) wird oft von 'volonterJ' gesprochen. 
Im Gegensatz zum Verfasser der K-pler Erzählung läBt der Pleskauer Autor nur wenige polnische Titel unübersetzt. Diese tauchen nur einmal (S. 54) auf, wenn der Autor berichtet, welcher Würdenträger welchen Truppenteil erhält. Für das russische Ohr sind dies sicher exotisch klingende Titel, der Leser weiB ohnehin, daß hier nur die höchsten polnischen und litauischen Würdenträger genannt werden: "kuchmist", "moršçalok velikij litovskij", "starosta" 71 .

Von viel größerem Interesse sind für uns solche Begriffe, die vom Autor nicht aus Stilisierungsgrüden verwandt werden, sonders die unbeabsichtigt in den Text eingeflossen zu sein scheinen, also Lehnwörter darstellen.

"bašnją" - 'Turm, Wehrturm"

$72 / 22$ "S Pochvalbskogo roskatu, iz velikie piščali iz Barsa udariša po Svinskoj bašni i ne pogrešiša; togda množestvo voinskich ljudej litovskija sily v bašni pribiša."

'Vom Pochval'skij-Bollwerk/Wall schossen sie auf den Schweineturm, und zwar mit dem "Bars" ( = Schneeleopard), und sie trafen - viele Litauer fanden damals dort ihren Tod.'

71) "kuchmist" - poln. "kuchmistrz", einer der höchsten Hofbeamten am poln. (bzw. auch am litauischen) Hof. Vertrauenssteliung wie etwa die des Mundschenks an deutschen Höfen. s. $Z$. Gloger: Encyklopedja Staropolska. Tom 3. Warszawa 1902, S. 110 - III. Słownik III, I 960 - 62, S. 435.

"morščalok velikij litovskij" - poln. "marszałek", einer der höchsten Hofbeamten - vielleicht dem Haus hofmeister an deutschen Höfen vergleichbar. s. Słownik staropolski. Tom 4. Wrocław - Harszawa - Krakow 19631965 . S. 163.

"starosta" - poln. "starosta", höchster Verwaltungsbeamter zunächst in GroB-, Kleinpolen und im Pomorze, später der Starosteien. Als höchster Militär stand inm ursprünglich der iojewoda gegenüber bzw. zur Seite. s. Z. Gloger: Encyklopedja staropolska lllustrowana. Tom 4. Warszawa 1903. S. 271 - 273. 
Srez… : erwähnt es nicht

Vasmer REW I, 66: benennt die 1. Plesk. Chronik. (Wir konnten dort allerdings - auf den S. 107 bis Schluß - nur einige Belege von "tjurm" finden.) Uber "bašnja" aus "bašta" aus poln. "baszta" aus dt. "Bastei" bzw. ital. "bast1a" - s.o.

Solbik, 187 : findet es erstmals $1592-93$.

Damerau, 65 : findet "bašnja" bel Kurbskij bezeugt.

Wie "bašta" im K-pler, so ist "bă̌nja" im Pleskauer Text mit 27 Belegen einer der am häufigsten gebrauchten kriegsterminologischen Begriffe.

"de10" - '(schwere) Waffen; Geschütz, Kanone'

wie in der K-pler Erzählung ist auch hier "delo" in der Regel allgemein als 'Sache' gebraucht. Doch der rolgende Satz deutet auf polnisch beeinfluBten Gebrauch im Sinne von '(schwerere) Waffen', 'Geschütz', 'Kanone':

95/6 "..., gradoemnym že delom ni s koim ko gradu ne smejaše i približitisja, ..."

'.... mit den Geschützen, die bel der Eroberung von Festungen/Städten eingesetzt wurden, wagte er nicht, näher an die Stadt heranzurücken, ...'

"roskat" - 'Umwallung, Bollwerk'

$72 / 22$ "S Pochvalbskogo roskatu, iz velikie piščali iz Barsa udariša ..."

' Vom Pochval'skij-Bollwerk/Wall schossen sie ...., und zwar aus der groBen Feldschlange, dem 'Schneeleopard...'

"roskat/raskat" ist in keinem altruss. Wörterbuch zu finden. In dieser Bedeutung erwähnt es Dal' (Tolkovyj slovaf III, 1593), bel Pavlovskij finden wir es in dieser Bedeutung, aber er vermerkt bereits "Kriegswesen, veraltet"(Russkonèmeckij slovaf 1387). Die Vorsilbe "ros-" könnte polnische 
Entlehnung vermuten lassen, aber 1) begegnen wir dieser Variante von "raz-" im Pleskauer Text auch sonst häufig genug, 2) ist in polnischen einschlägigen Wörterbüchern keine Spur eines solchen Wortes zu finden. Die speziellen altpolnischen Wörterbücher sind noch nicht bis zum Buchstaben " $r$ " geführt. In einem jüngeren Häufigkeitswörterbuch zur russischen Sprache der zweiten Hälfte des 16. Jh.s 72 finden wir"roskat" ein Mal verzeichnet (unsere Belegstelle), die Variante "raskat" erscheint auch nur ein Mal (in: "Dokumenty iz istorii gorodov El'caiVoroneža"73) - vgl. "bašnja" ist 88 Mal bezeugt. 74

"zamok" - 'Festung, Burg'

$65 / 12$ "..., zamok Fskov za ščitom vozmeve $75, \ldots$..."

'.... die Festung Fleskau wollen wir erobern/in unsere Gewalt bringen,...'

$65 / 1$ "..., sego že dni, gosudarju, v zamce Pskove večerovati u tebe trebueve 75 i zdravuem tebe ..."

'...., noch heute, Herr, werden wir in der Festung pleskau bei dir ein (abendliches) Festmahl halten und dich beglückwïschen...'

šrezn. I, 929 : geht nicht auf "zamok" ein, verweist nur kurz auf "zambknuti".

Vasmer REy I, 440 : setzt es für das 17. Jh. an: entlehnt aus poln. "zamek" - 'Schloß, Feste'.

72) A. A. Gruzberg: Castotnyj slovar russkogo jazyka vtoroj poloviny 16 - načala 17 veka. Perm 1974 .

73) Dokumenty iz istorii gorodov El'ca i Voroneža. In: Ge $N_{\text {s }}$ Anpilogov. Novye dokumenty o Rossii konca 16 - nacala 17. v. 1967 .

74 ) "roskat" _- s. Gruzberg, S. 371, "raskat" s. Gruzberg S. 364, "bašnja" - s. Gruzberg S. 81 .

$75)$ "vozmeve" und "trebueve" - wir werden immer wieder Gelegenheit haben, auf solche Dualformen innerhalb wörtlicher Rede und in Briefen hinzuweisen. Nicht immer ist der Dual so berechtigt wie in diesen Zitaten - 'wir und du wollen ... erobern', 'wir und du wollen ein Festmahl halten' - aber: "zdravuem tebe" - 'wir beglückwünschen dich'. 
Sobik, $220 \mathrm{f}$. : findet das Wort in dieser Bedeutung bereits in Gesandtschaftsberichten der Jahre 1567 - 69.

Wir finden aber "zamok" noch in einer Spezialbedeutung, die in dem Sinne an dieser Stelle sicher erstmals auf mussischen Boden schriftlich fixiert wird, nämlich in dem Sinne von 'Zünd-Gewehrschlob': An der entsprechenden Stelle geht es um die Höllenmaschine, die dem Pleskauer Stadtkommandanten aus dem litauischen Lager geschickt wird: ein Gefangener wird nach Pleskau entlassen und bekommt eine Schatulle mit, die er I. P. Sujskij übergeben soll - es handele sich um die Wertsachen eines deutschen Offiziers - Hans Möller, die er zur Verwahrung schicke, da er bald in den Dienst des Zaren treten werde. Sujskij solle unbedingt allein das Kästchen öffnen, damit niemand sehe, was darin sei. Beim Offnen der Schatulle wird ein Mechanismus ausgelöst, der Funken schlägt, die entweder über Lunten oder aber direkt in das Schießpulver fallen, mit dem das Kästchen angefüllt ist (ca. ein Pud - mehr als 30 Pfund). 76

$96 / 18$ "..., zavodnenye že zamki remenem privedeny k ličinbki larca, za nego že tokmo prinjatisja, zavedenym že samopalbnym zamkom ognenym vsem otpad, ognem zapaliti."

'... die gespannten (Zünd-) Schlösser waren am VerschluB der Schatulle befestigt, man brauchte diese nur zu öffnen, dann würden die gespannten Gewehrschlösser (-hähne) gelöst und alles würde in die Luft fliegen.'

76) In unserer Erzählung merken die Pleskauer die Absicht und können ohne Schaden diese mittelalterliche Bombe entschärfen. Polnischen Berichten nach ist die Bombe aber explodiert und hat einige Tote gefordert, auch Fürst Sujskij sei schwer verletzt gewesen und daraufhin nicht wieder auf den Verteidigungswerken gesehen

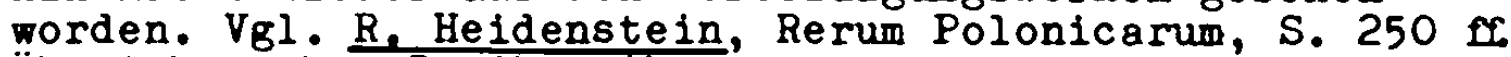
Ähnlich auch z.B. Chronika litovskaja, S. 125. 
"samopal" - 'Art Gewehr'

$96 / 15$ "...(on) v nem že vidit .... dvadcatb četyre samopala zanarjažena na vse četyre storony,..."

'..., er erblickte 24 Gewehre, nach allen vier Seiten hin ausgerichtet,...'

Diese Textstelle rechtfertigt auch die für "samopalbnyj zamok" vorgeschlagene lbersetzung 'Gewehr-/zündschloß'.

Srezn. III, 251 : "samopal" - 'piščalb s zamkom i ognivom'. Srezn.s frühester Beleg datiert aus dem Jahre 1589 aus einer Beschreibung der Kriege Boris Godunovs mit den Schweden.

Sobik, 331

: bezieht sich auf den Beleg Srezn.s, also 1589 und übernimmt die tbersetzung aus Poln., in dem "samopał" seit 1584 belegt ist: "samo" und "pał" zu "palić" - 'brennen, losbrennen, sckießen.'

Unsere Belege in Verbindung mit dem (einzigen) bei Srezn. aufgeführten, der sich ja auch auf den Nil bezieht, lassen auf eine regional und zeitlich begrenzte Verwendung dieses Begriffs schließen, der ganz bestimmt polnischen Ursprungs ist.

" ručnica" - 'Feuerrohr, Büchse'

88/4 "Umysliša iz ručnic po nich streljati"

'Sie wollten mit ihren Büchsen/Flinten auf sie schießen'.

(noch weitere fünf Belege und zwei mit "ručničnyj" vorhanden)

Srezn. III, 200 : findet "ručnica" 1579 belegt (quelle unklar, ist nicht aufgeschlüsselt).

Dạmeraㅡㅁㅡ, 85

: bringt eine Anzahl Belege aus der "Istorija" herbei. Auch hier dürfte poln. 


\section{"rucznica/rusznica" der Ausgangspunkt sein.}

"pulbka" - 'Gewehrkugel'

69/10 "streljati ručnymi pulbkami" (einziger Beleg)

Sobik, 317 : Sie als elnzige erwähnt "pulbka" - Im Zusammenhang mit "pulja". "pulbka" sei von "puška" abgeleitet, dieses von poln. "ǩulja"; in Anlehnung an "palitb" und "puška" sei auf russ. Boden aus "kulja" "pulja" entstanden. - Allerdings: ihr erster Beleg für "pulja" datiert 1710. Das würde bedeuten, daB die Ableitung ein Jahrhundert früher belegt ist als das Ableitungswort. Doch wird man sich bei solchen kriegsbedingten Wörtern das Eindringen in schriftliche Zeugnisse als von vielen Zufällen abhängig, nicht immer in der Chronologie ihres Eindringens oder Entstehens denken müssen.

\section{"šanec" -'Schanze'}

89/10 ":.. jako ne vozbmem (Pskova), na vašej vole sotvorju vam $i$ iz šancev $i$ ot zamka otvedu'."

'... wenn wir Pleskau nicht erobern, dann werde ich euren Willen erfüllen und euch aus den Schanzen und von der Festung zurückziehen.'

Srezzn. : nicht belegt.

Vasmer REW III, 372 : findet es zuerst in "Azovskoe vajatbe" aus poln. "szaniec", dies aus spätmhd. 'schanze' - 'Reisigbündel, Faschine, Schanze'.

Sobㅡㄴ, 362 : Erstbeleg - 1609.

Damerau, 88 : Erstbeleg - Kurbskijs Istorija. 
"čosnok"77 - Pallisadenzaun,

81/30 "Promeži že obejuch kamennyja i drevjanyja steny vo grade poveleša rov vykopati i postaviša $v$ nem dubovyj ostryj čosnok, tako že i po vsemu prolomu i $v$ bašnjach mnogočislenyj $i$ ostryj čosnok izstaviv, ukrepiša, ..."

' Zwischen der steinernen und der hölzernen Mauer befahlen sie, einen Graben auszuheben. Dahinein setzten sie einen angespitzten eichenen Pallisadenzaun. Auch an der gesamten Bresche und in den Türmen bauten sie solche angespitzten Pallisadenzäune und sicherten (so) die Stadt.

In der Schreibung "česnok" heiBt es heute 'Knoblauch' (endbetont). Pavlovskij (Nemecko-russkij slovaf, 1726) und Dal' (Tolkovyj slovar IV, 599) nennen als Nebenbedeutung zu "česnok" auch 'Pfahl-, Pallisadenzaun'. Ebenfalls

Vasmer REW III, 330: nimmt etymologische Verwandtschaft zwischen "česnok" - 'Knoblauch' und "česnok" - 'Pallisadenzaun' an, indem er es - nach Brückner - zu "česati" 'kämmen, pflücken, spalten' stellt. Die Bedeutung 'Pallisadenzaun' ist sicher Entlehnung aus dem Poln.: "czosnek", vgl. auch ukr. "časnýk, čosnf́k".

Die Schreibung in unserem Text weist darauf, daB unser "čosnok" sicher anfangsbetont war, das macht die Entlehnung aus dem Poln., jedenfalls in der speziellen Bedeutung des 'Pfahlzauns', noch wahrscheinlicher.

Słáwski SE I, 125 : nennt nur 'Knoblauch'.

Ś_ownik XVI_w. 78 : Bedeutung 2: ostrokóx, palisada, zasieka, allerdings mit einer Belegstelle aus 1597.

Brücknner SE, 80 : Nebenbedeutung: ostrok8x.

77) Die Variante: S. 154 - "česnok"

78) Słownik polszczyzny XVI wieku. Tom 4. Wrocław - Warszawa-Krakbw. 1969. S. 236. 
"koždyj" - 'jeder'

Damerâu, 72 bezeichnet "koždyj" als Westrussismus. Bei uns dürften die Belege eher als Archaismus gelten. Denn während die von Damerau aus Kurbskijs Istorija zusammengestellten Belege bereits die jüngere Flexion haben ("koždoe, koždomu, koždom" usw.), zeigen unsere Belege ausnahmslos die Flexionsformen von "kъ-" ("kiiždo, koegoždo, koemuždo" usw.).

\section{"1znailepšij" - 'der allerbeste'}

52/22 "Tako že 1 približnye ego iznallepšle getmany sicevaja že emu glagolachu: ..."

'So sprachen denn seine nächsten und allerliebsten Hetmane folgendes zu ihm: ...'

poln. "najlepszy".

Allerdings dürften wir es hier nicht mit einer Entlehnung, sondern mtt einem Polonismus zur Stilisierung, zur Erzeugung von Lokalkolorit zu tun haben.

Be1 den Entlehnungen im Pleskauer Text handelt es sich fast ausschlieBlich um Begriffe der Kriegsterminologie. Die lange Auseinandersetzung mit Polen im Rahmen des Livländischen Krieges hatte zur Ubernahme vieler Termini technici aus dem Poln. geführt - diese Tatsache spiegelt unser Text ganz besonders deutlich. Allerdings begegnen fast alle Lehnwörter unseres Textes in Kurbskijs" "Istorija knjazja velikago moskovskago", die elnige Jahre vor der Pleskauer Erzählung abgeschlossen murde (um $1580^{79}$ ). Die in der Pleskauer Erzählung erscheinenden Lehnwörter sind zum groBen Teil wieder gesunken bzw. murden von russ. Bezeichnungen verdrängt. 80

79) Damerau, Russisches, S. 10: 1576 - 78; Boretzky, Tempusgebrauch, S. 12: 1577 - 83.

80) "guf" des K-pler Textes verschwand bald wieder aus dem Russ., "delo" als 'Geschütz' splelte neben "puska" und "narfad" immer eine Nebenrolle; "sanec" hat sich vielleicht wegen seiner speziellen technischen Bedeutung halten können. 
Das Wortmaterial der Pleskauer Erzählung erlaubt keine weiterreichenden Schlüsse bezüglich des Autors, des Entstehungsortes (Pleskau oder Moskau). Die vorgestellten Lexeme sind zwar beinahe ausnahmslos aus dem oder über das Polnische in unseren Text gelangt, doch da es sich meist um militärische Spezlalbegriffe handelt, weist diese groBe Zahl polnischer Entlehnungen nicht so sehr auf einen in Grenzgebiet, etwa auf weiBruss. Boden, lebenden Autor, sondern awe einen Kriegsmann, der diese Terminologie beherrschte wie sie wohl jeder Kriegsmann, wo er auch immer herkam, kannte. Eindeutige lexikalische Hinweise auf das benachbarte WeiBruss. IieBen sich nicht nachweisen. 81

81) Die nordgroßruss. und die Ubergangsmundarten sind lexikalisch viel schwerer nachzuweisen als die sügroBruss. Mundart - daher wären weiBruss. lexikalische Einflüsse von besonderer Hichtigkeit für uns - im K-pler Text fanden wir ja einige recht sichere Hinweise.

vgl. Cernych, Istor. grammatika, S. 45 . 


\section{Zusammenfassung}

Das vorgelegte Material uber verschiedene Erscheinungen auf den Gebieten der Phonetik und der Morphologie im Rahmen unserer beiden Texte hat erkennen lassen, wie sich die der Literatur verpflichtete russische Schriftsprache im Laufe eines Jh.s - vom Ende des 15. bis zum Ende des 16. Jh.s der Umgangsaprache angenähert hat. Wir dürfen natülich beide Texte nicht als reprasentatio fur ihre zeit betrachten. Dennoch scheint mir, daB wir die Texte einander gegenuberstellen durfen. Denn belde Autoren sind nachweislich bemulht, ihre Erzählungen in die (altruss.) literarische Tradition zu stellen, indem sie umgangsoprachliche Elemente zu eliminieren versuchen - dies 1st am deutlichsten (weil für den Autor am besten kontrollierbar) im Bereich der Präterital tempora: belde Autoren verwenden fast ausschlieblich (uber 95 v.Hd.) Imperfekt und Aorist. Dieser archaisierende Grundzug ist charakteristisch fur den K-pler Text im Ganzen. Im Pleskauer Text allerdings stehen der bewuBten Wahl archa1scher Verbformen viele umgangsoprachliche Erscheinungen gegenuber, die der Autor sicher unbewubt hat in den Text einfließen lassen. Diese sind aber so häufig, daB man geneigt 1st anzunehmen, daB für den Pleskauer Autor nicht konsequente ksl. Schrelbung bzw. Formenbildung die angestrebte Archaisierung ausmacht, sondern dazu relativ häufiges Auftreten ksl. Lautungen und Formen (mehr als die Hälfte aller Fälle) genügt. $\mathrm{Zu}$ den häufigsten umgangssprachlichen Erscheinungen Im Pleskauer Text gehören Polnoglasie, häufige Aufgabe der Palatalisation auf Grund der Flexionsendungen (-é, -ěch, -1 usw.), fast ausschlieblich Schreibung von -g1-, -k1-, -ch1statt ksl. -gy-, -ky-, -chy- (so im K-pler Text), "roz-" neben "raz-", starke Assimilation der Präpositionen ("brat $\underline{z}$ bratomn), Dissimilation ("ch koroljun), Wiederholung der Präposition ("ㅌk korolem g Stepanom"). Auf dem Geblet der Morphologie sind die Unterschiede 2 wischen beiden Texten nicht oo auffälig. Bei sorgfältigem Vergleich zelgt sich, daB sich die pronominale Adjektiv-Flexion im Pleskauer Text bereits stark der heutigen Plexion genähert hat - Gen.8g.mask. 
ntr. hat bereits in $60 \mathrm{v} . \mathrm{Hd}$. aller Belege die Endung -ogo (manchmal sogar -ovo) anstelle von ksl. -ago (so ausnahmslos in der K-pler Erzählungh Im Gen.8g.Nom.Akk.pl. fem. finden wlr in fast $50 \mathrm{v}$. Hd. aller Fälle Formen, die auf den heutigen Lautstand hindeuten oder diesen sogar schon zeigen: Sing. -ye oder heutiges -oj/-ej, im Plur. heutiges -ye; der K-pler kennt auch hier ausschlieblich die ksl. Lautung -yja. Im Rahmen der Substantiv-Flexion fällt im Pleskauer Text das Vordringen der Endung -u (besonders Gen.sg., aber auch Lok.sg.) innerhalb der o-Stämme auf.

In beicen Texten waren west-, nordwest- bis weiBruss. Einflüsse feststellbar: der Pleskauer Text hatte stärker Schreibung -1- für altes -è-, stärker auch Verwechslung von -o- und -uvor Konsonant ("nouggorodckij", "ㅁ Svinych vorot" statt "uㅡ Svinych vorot" u.a.); häufiger ist im $K$-pler Text Verwechelung von -ś- und -s- zu beobachten ("pešca" - "pesca").

Auf lexikalischem Gebiet finden wir eine Reihe westlicher Entlehnungen und Einflüse. Während sich diese in der Pleskauer Erzählung auf Kriegsgerät beschränkten, stießen wir in der K-pler Erzählung auch auf Wörter, die weiBruss. Einfluß signalisieren ("izrada" - Verrat', "pućma" - 'Büschel', evt. "inakšy" statt "inafty", möglicherweise "nepriemny", "meži" fưr "meždu").

Unsere Beobachtungen an der $\mathrm{K}$-pler Erzählung bringen uns in der Prage nach Autorschaft oder Ubersetzer nicht weiter.

Aber auch bezikglich des Pleskauer Textes sind unsere Beobachtungen nicht besonders aussagekräfig - zwar sind einige spezielle Zuge der Pleskauer Sprache unverkennbar, andere typische Erscheinungen fehlen völlig. Bel der Toleranz des Autors der Umgangssprache gegenuiber würde man auch mehr Pleskauer Regionalismen erwarten. Da wir es mit einer Abschrift zu tun haben und nicht mit dem Original, könnte man auch mit sprachlicher Glättung durch einen Moskauer Kopisten rechnen. 82

82) Vgl. Tichomirovs Vermutung (in: Recenzija, S. 350 f.), daB wegen der promoskovitischen Grundhaltung der Erzählung der Autor vielleicht in Moskauer Kreisen zu suchen sei obige Untersuchungen lassen die Vermutung $2 u$, daB die Erzählung wohl doch in Pleskau entstanden ist. 
D. ANMERKUNGEN ZUM STIL UNSERER TEXTE

Be1 der Untersuchung der st1listischen Charakteristika unserer beiden Texte stellte sich heraus, daB eine systematische Darstellung ihrer stilistischen Eigenheiten zu umfangreich und in den Ergebnissen zu detailliert und zu weitführend 1st, so daß selbst der Versuch einer äußerst komprimierten Darstellung den Rahmen unserer Arbeit sprengen würde. Daher sollen die folgenden Anmerkungen nur dem Zweck dienen, eine annähernde Vorstellung von den Eigenheiten der Texte zu geben und vielleicht, durch Belspiele gestützt, dem Lesenden Verglelche mit Texten zu ermögl1chen, die ihm selbst bekannt sind.

Belde Texte unterscheiden deutlich 2 wischen berichtenden Passagen und Abschnitten monologisch-reflektierender Rede vorwlegend geistlichen Inhalts (Monolog, Predigt, Prophezelung, belehrende Briefe).

Im Pleskauer Text scheiden wir in anderem Zusammenhang (Verb) noch $z$ wischen allgemein berlchtenden und kampfschildernden Tellen; da der Unterschied aber im wesentl1chen im Gebrauch der verbalen Formen liegt, können wir uns diese Unterscheidung hier ersparen. Das glelche gilt für eine Scheidung 2 wischen profanen (z.B. Briefwechsel zwischen Stephan Bhthory und seinen Würdenträgern) und belehrenden Briefen (Brief der Pleskauer an den polnischen König S.) sowle Abschnitten geistlicher Ausrichtung. Wir können die profanen Briefe den berichtenden Passagen zuordnen, weil sie sich von diesen allein dadurch unterscheiden, daB der Autor - um Authentizitat zu suggerleren statt der überall wuchernden partizipialen Konstruktionen in den Briefen dem Verb.fin. den Vorzug gibt. ${ }^{l}$

1) In welch vielfkltiger Weise der Pleskauer Autor die verschiedenen verbalon Kategorien stilistisch differenziort, wird olch seigen, wenn wir uns naher ait dem Verb beschuftigen. 
Im folgenden wollen wir versuchen, ohne große formale Scheidung $z$ wischen den berichtenden und stärker geistlich orientierten Passagen die Verhältnisse zu schildern. Es sei ganz allgemein vorausgeschickt, daß Abschnitte sakralen Inhalts rhetorisch viel stärker geformt sind als der übrige Text. Für den K-pler Text bedeutet dies, daß Figuren der Nortfolge ${ }^{2}$ im Vordergrund stehen, wohingegen in der Pleskauer Erzählung die Konzentration besonders affektischer Mittel ${ }^{3}$ die "figurae per ordinem" zurückdrängt, wenngleich die Anapher auch dort eine unübersehbare Rolle spielt.

\section{Satzbau}

Die allgemein berichtenden und die kampfschildernden Abschnitte der K-pler Erzählung sind auf Informationsvermittlung ausgerichtet. Die Sätze gliedern sich in der Regel in einen oder $z$ wei partizipiale Teile und einen Hauptteil mit Verb.fin. Dabei ist die Rangordnung, die Wertigkeit der Handlungen durch die Verbform - Part. = Nebenhandlung, Verb. fin. = Haupthandlung - ausged rückt. Das Part. prät. erscheint. fast immer vor, das Fart. präs. fast immer hinter dem Verb. fin. Oft sind die Partizipien ohne Ergänzung, dann haben sie rein adverbiale Funktion. Meist stehen sie aber mit Erweiterungen; sie behalten dann immer eine enge Bindung an die Haupthandlung, der sie logisch untergeordnet sind, so daB wir sie, auch wenn sie einmal etwas umfangreicher sind, stets als Partizipien in Funktion von erweiterten Adv.-

2) "figurae per ordinem": Lausberg, Handbuch I, S. $355-74$. Insbesondere Isokolon/Parallelismus, seltener Chiasmus; darüberhinaus auch Anastrophe und Exclamatio, die sich jedoch meist in das formale Gerüst des Kontextes fügen.

3) "figurae sententiae": Lausberg, Handbuch I, 375 - 81. Insbesondere rhetorische und Ironische Frage, Apostrophe, Exclamatio sowie häufiger Gebrauch von Zitaten. 
Partizipien ansprechen können. Hier die drei wichtigsten Satztypen:

1) Einfacher Satz:

$65 / 26$ "I be straśno videti oboich derzosti 1 kreposti."

2a) Erwe1t. ${ }^{4}$ Part.praet. (in Funktion einer adv. Bestimmung) + Hauptsatz (mit Verb,fin.):

64/18 "Greki že, vy ġed iz grada, pobivachu vo rvech turky, ..."

2b) Hauptsatz (mit Verb.fin.)

+ erweit. Part.praes.

(iñ Fựktioñ ênér adv. Bestimmung)

$65 / 17$ "..., turky načaša streljatí iz mnogych pušek $v$ to že mesto, tako 1 črez vaju nošč ne

3) Erwe1t. Part.praet. (in Funktion einer adv. Bestimmung) + Hauptsatz (mit Verb.fin.)

+ erweit. Part.praes.

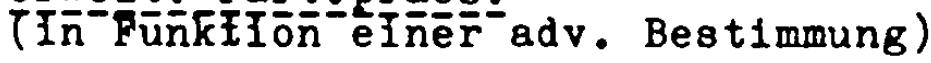

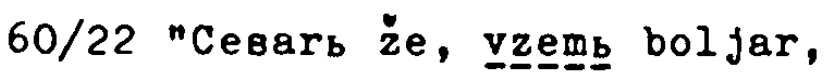
poide po stenam grada, chotjạg če_videti ratnych, ..."

An diese drel häufigsten Satzvarianten des $\mathrm{K}$-pler Textes gewöhnt man sich in einem solchen Maße, dieser Satzrhythmus geht einem 80 in Fleisch und Blut über, daB man ganz verwundert aufmerkt, wenn man einmal auf eine ganz andere Kombination der Syntagmen stöBt. Da die partizipialen Konstruktionen gesondert behandelt werden, sei eine der wenigen Abweichungen von obigen Schemata nur exemplarisch vorgestellt:

64/41 "Sija vsja gly abie vgtengengse ot sredy serdca 1 ruce na nebo voz še, glagolachu: ..."

4) Erweit. = erweitertes. 
Die drei einander gleichgeordneten, dem Hauptverb untergeordneten (da vorzeitige Handlungen) Partizipien erschweren in keiner Neise das Verständnis des Satzes bzw. des Satzgefüges.

Im Pleskauer Text ist ein so klares und durchgängiges System von Satztypen nicht erkennbar. Zwar gibt es auch dort die obigen Typen, doch spielen sle eine untergeordnete Rolle.Dem Pleskauer Text fehlt ein einheitliches Satzbild. Während die obige Anordnung der Satzabschnitte als Hypotaxe bezeichnet werden kann - wobei die partizipialen Konstruktionen dem Hauptsatz mit dem Verb.fin. untergeordnet sind -, ist im Pleskauer Text uberwiegend Farataxe zu registrieren. Dadurch verwischen sich die inneren Beziehungen der Handlungen zueinander, das Verstehen wird stellenweise behindert, eine exakte Analyse der Konstruktion ist manchmal unmöglich. Außerdem ist verschiedentlich die tortstellung so willkürlich, daß der lbersetzungsversuch zur bloßen Interpretation wird.

$59 / 3$ "Ot poludennyja strany bogochranimago grada I'skova dym temen: litovskaja sila na černostb pskovskija belye kamennye tverdija steny predposlasja, eja že ni vsja litovskaja zemlja očerniti vozmože,..."

- Südlich der Stadt erhob sich schwarzer Rauch: das litauische Heer erschien wie ein schwarzer Schatten vor den weiBen Mauern Pleskaus, die ganz litauen nicht imstande wäre zu schwärzen.'

47/4 "Po semu že razsmotritelbne bojarina svoego bogonadežnoe o otstojanil ot koroloja grada Pskova slovo slyšit." 5

- Danach vernahm er die Rede seines Voevoden, die von Gottvertrauen zeugte - nämlich, daß Fleskau dem König sicher erfolgreich Niderstand leisten werde.'

5) In diesem Satz ist Hyperbaton zu beobachten - Lausberg, Handbuch I, §§ $716-18$. Normale Wortfolge: "Po semu Ze razsmotritelbne svoego bojarina slovo o otstojanii Pskova ... slysit." 
Das folgende Beispiel zeigt eine parataktische Satzfolge, wie sle für den Pleskauer Text so typisch ist:

$62 / 19$ "Gosudarevy že bojare i voevody sija vsja litovskaja umyšlenie nad gorodom videvše, tako že boga na pomoščs prizvav, 1 bogorodicu zastupnicu imušče 1 vsja svjatyja k bogu molebniki, tako že protivu ich v tom že meste, po boze, utverženbe tvorjašče."

- Die herrscherlichen Bojaren ... hatten den Plan der Litauer erkannt und flehten Gott um seine Hilfe an. Auch hatten sie in der Gottesmutter einen Beistand und in allen Heiligen einen Fürsprech bei Gott. Gegenüber jener Stelle (wo die Litauer ihre Schanzkörbe aufgezogen hatten) errichteten sie mit Gottes Hilfe - (weitere) Befestigungen.'

Der Ubersetzungsversuch macht deutlich, wie sehr man an solchen Stellen auf eine Interpretation des so vage Ausgedrückten ausweichen muß. Hierzu noch eine ähnliche Textstelle, bei der wir auf eine tbersetzung verzlchten wollen:

$75 / 21$ "Tako že vo edino serdce vse bogorodicy milostb priemše, i seja pomoščiju vooruživšesja, jako edinimy usty bogoródicju na pomošč prizyvajušce 1 vo edin glas kriknuvše, gosudarevy bojare 1 voevody, s nimi že 1 predpomjanutye černecy 1 vse voinstvo rekušče: ..."

Die gegensätzliche Satzstruktur beider Texte wollen wir abschließend noch mit einer Satzfolge aus der K-pler brzählung demonstrieren, wobei eine lbersetzung überflüssig 1st. Der Abschnitt ist wahllos aus dem Textcorpus herausgegriffen:

60/31 "On že, bezvernyj, ne tako pomyšljaše. No vo vtoroj denb posla videti mertvyja svoja, 1 jako gkazaša emu mnogo mertvych, vskore posla mnozi polki vzjati truplja svoja. Cesarb že zapoveda, da ne dajut 1ch n1 kotoroju branbju, jako da očlstjat rvy 1 potoci. I tako vzjaša svoja trupy bezbranno 1 požgoša 1." 


\section{Informationsgehalt der Texte}

Eine gewisse Vorstellung vom unterschiedlichen Informationsgehalt der Texte vermittelt die Tatsache, daß der Pleskauer Text bei fast doppeltem Umfang im Vergleich zur K-pler Erzählung etwa die gleiche Anzahl verbaler Formen aufweist (sogar etwas weniger als dieser). Geht man vom Verb als Kern einer Aussage aus, dann zeigt allein schon diese Gegenüberstellung, wieviel stärker die K-pler Erzählung aussageorientiert ist als der Pleskauer Text. Redundanz gehört zum liesen eines jeden literarischen Textes, doch mir scheint, daß im Pleskauer Text die Grenze, innerhalb welcher man noch von "ästhetischer Redundanz" 6 sprechen kann, häufig überschritten ist.

In beiden Texten treffen wir verschiedentlich auf vielgliedrige Aufzählungen. Diese haben in der K-pler Erzählung zweifelsohne den Zweck, dem Leser die Komplexität des Geschehens eindrucksvoll vor Augen zu führen.

59/43 "Turki ż paki, uslyšavše zvon velij, pustiša surnyja i trubnyja glasy i tumban tomočislennych, 1 bystb seča velija preužasna: ot pušečnago bo 1 piščalbnago stuku $i$ ot zuku zvonnago i ot glasa

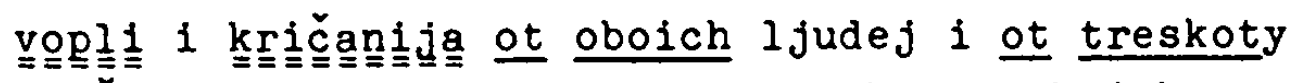
oruzija: jako molnija bo blistachu ot oboich oružija, takže $i$ ot plača $i$ rydanija gradckich ljudej 1 žen $i$ detej ... sovokupiša bo sta vopli $i$ kryčanija i plać i rydanija ljudej i stuk delbnyj $i$ zvon klakolbnyj vo edin zuk, 1 bystb jako grom velij."

6) Arnold, H. L. - Sinemus, V. (Hrsg.): Grundzüge der Literatur- und Sprachyissenschaft. Bd. 1: Literaturmissenschaft. Munchen 1976. (dtv: Wissenschaftliche Reihe. 4226). S. 487. - Die Subjektivität einer derartigen Wertung ist mir durchaus bewuBt, doch hoffe $1 \mathrm{ch}$, das die we1teren Ausfuhrungen 2 weifel an der Gultigkeit dieser Feststellung ausräumen werden. 
Diese Schilderung gibt den Schlachtenlärm in eindrucksvoller Heise wieder. Fast glaubt man zu spüren, daß der Autor vor allem vom ungewohnten Krachen der Schußwaffen besonders beeindruckt ist und dies dem Leser mitteilen möchte.

Auch im Pleskauer Text finden wir solche Schilderungen, innerhalb welcher die vielgliedrige Aufzählung dem Beschriebenen korrespondiert, dieses gleichsam dokumentiert. Aber viel öfter begegnen uns dort Aufzählungen, wo diese suggestive Nirkung überhaupt nicht beabsichtigt gewesen sein kann.

46/34 "I vsjakim tščaniem tščaščichsja za boga $i \underline{\text { za }}$ svoego gosudarja, i za ego gosudarevy deti, i za pravoslavnuju veru, $i$ za svoja domy $i$ ženy $i$

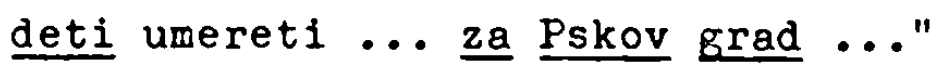

58/26 "...; tako že koždo u sobja bojarskich golov 1 detej bojarskich, 1 golov streleckich i strelbcov potomu že i vsech posadckich pskovskich, narovckich strelbcov $i$ vsech psković, po činu vsech rozčetav, postaviša."

Es handelt sich hierbei weder um kontextuell notwendige noch das Gesagte in irgendeiner Form dokumentierende Aufzählungen: es sind nämlich formelhafte liendungen, wie sie in kürzerer oder längerer Form überall in Text auftauchen. Dem sutor geht es nicht darum, durch die vielzahl der aufgezählten Glieder dem Leser etwas Extremes anschaulich vorzuführen, sondern Aufzählungen dieser Art im Pleskauer Text sollen, indem sie sich so oft wiederholen, den Leser von der konkreten Aussage des Textes weg- und auf die klanglichen und rhythmischen Eigenschaften des Textes hinlenken.

Das Gesagte wird besonders deutlich, wenn wir als Beispiel zweigliedrige Aufzählungen heranziehen. Sondern wir einmal die Substantive für unseren Vergleich aus: Im Pleskauer Text gibt es deren 164, in der K-pler Erzëhlung 67. Stellen wir einmal den doppelten Umfang der 
Pleskauer Erzählung in Rechnung (was angesichts der gle1chen Anzahl von Verbalformen in beiden Texten sicher nur bedingt gerechtfertigt ist), dann sind solche Aufzählungen im Pleskauer Text immer noch häufiger. Der Unterschied $z$ wischen den Texten liegt in der Qualität dieser Aufzählungen. Der Pleskauer Autor benutzt $64 \mathrm{Mal}$ die Formel: "gosudarevy bojare $i$ voevody; weitere $15 \mathrm{Mal}$ verwendet er die gleiche, lediglich etwas verkurzte Formel: "bojare 1 voevody". $38 \mathrm{Mal}$ finden sich entsprechende Wendungen wie "getmany $i$ pervosovetniky", "gajduiki i gradoemcy", "vsemu činu 1 pričtu" u.a. - völlig automatisierte Formeln also.

Natürlich gibt es ähnliche Aufzählungen auch im $\mathrm{K}$-pler Text, es soll nicht behauptet werden, daB derartige $\mathrm{Be}-$ nennungen jedes einzelne Mal dem Leser die Zusammensetzung der jeweiligen Gruppe ausdrücklich mitteilen sollen - so finden wir häufig "megistany $i$ magistry", seltener "boljary i stratigy", selten auch "pas̆i i mulli". Besonders bei der häufigen doppelten Benennung liegt die Vermutung nahe, daß hier auch klangliche Effekte bei der iortwahl mitgewirkt haben können. Derartige $z$ weigliedrige formelhafte Aufzählungen finden sich im K-pler Text $19 \mathrm{Nal}$, d.h. weniger als ein Drittel; im Pleskauer Text machen diese dagegen weit mehr als $z$ wei Drittel aus. Die verbleibenden zweigliedrigen Setzungen sind in beiden Texten von ähnlicher qualität - selten wird wirklich Verschiedenes aufgezählt, meist handelt es sich um synonymische Setzungen, wodurch der so bezeichnete Gegenstand eine besondere Bewertung erhält. Dies umso mehr, wenn jene Kombination selten oder einmalig ist.

So finden wir in der K-pler Erzählung z.B. "vladyko $i$ carju" 68/46, "obyšedšich ny zol i napastej" 69/22, "vedjachu chrabrosti i silu ego" 66/27, oružija bo vsja $i$ strely suetno padachu" $67 / 13$, "bez vreda i bez pečali" $64 / 41$.

Beispiele aus der Pleskauer Erzählung: 
"so studom mnogim 1 sramom" $80 / 12$ (noch zwei Mial), "strachom že 1 trepetom" 40/24, "radostb $i$ blagovestie" 76/23, zaščiščnija že 1 zatuly nikoeja" 67/4, "železy i bronjami" 67/19.

Es wird deutlich, wie auch zwei ursprünglich nicht synonyme Begriffe durch thre Koordination zu einem Begriff zusammenwachsen - sei es, daß sie semantisch Ahnliches benennen, 7 sel es, daß die Glieder der Aufzählung Teilaspekte eines Ganzen darstellen. ${ }^{8}$ Es scheint uns bezeichnend $z u$ sein, daß diese kunstvollere Form der zweigliedrigen Setzung - im Gegensatz zu der formelhaft-schematischen doppelten Benennung von Personengruppen - in der K-pler Erzählung einen so wichtigen Platz einnimmt, in der Pleskauer Erzählung insgesamt gesehen aber nur eine unwesentliche Rolle spielt.

Das gleiche gilt für die anderen Formen der Worthäufung (Aufzählung von Verben, Adverbien, Epitheta, von drei-, vier- und mehrgliedrigen Aufzählungen) beinahe noch in verstärktem Maße: Formelhaftigkeit, die sich durch ständige Niederholung und Varilerung der gleichen Wortgruppen ausdrückt in der Pleskauer Erzählung, starker Ante1l der individuelien, neu geschaffenen Aufzählungen im K-pler Text.

Redundanz durch Formelhaftigkeit als Grundzug des Pleskauer Textes zeigt sich besonders deutlich bel Betrach-

7) Synonymie - Lausberg, Handbuch I, § 650 ff. "so studom 1 sramom" - der Ubergang von vollkommener semantlscher Deckung über die nur lockere Synonymle (semantische Unterschiede der koordinierten Begriffe) bis hin zur "Enumeratio" (s.u.) ist fließend. Vgl. Lausberg, Handbuch I, $\S 651$.

8) "Enumeratig" - Lausberg, Handbuch I, §§ 669-674. "denb 1 noscb boga molili" PS 65/8': "die Glieder der Aurzahlung sind die koordinierenden Telle eines Ganzen", wobei die polare Ausdrucksweise (ElnzelwortAntithese - vgl. "sodetelju vseja tvar1, vidimyja 1 nevidimyja" KP 68/43) den - alles umfassenden - Extremfall darstellt: "Reduktion der Aufzählungsglieder auf zwel gegensätzliche Glieder" - Lausberg,

Handbuch I, $\$ 672$. 
tung der Epltheta. Das individuelle, aussagekräftige Epltheton ist selten. 9 Aufzählungen von Epltheta können wir im Pleskauer Text, wo diese beinahe fünf Mal so häufig sind wie im K-pler Text, vorwiegend als Epitheta ornantia ansprechen, die also für den Kontext keine relevante semantische Neuigkeits-Aussage enthalten. ${ }^{10}$ So erhält "Pskov" meist ein Epitheton. Es erscheint in der Regel als "slavnyj (naš) grad Pskov", häufig treten hinzu "velikij", "bogochranimyj", "bogospasaemyj" und/oder "(pre)imenityj". Moskau ist bis auf eine Ausnahme "carstvujuščij (slavnyj) grad Moskva". Der Zar wird 41 Mal genannt, davon $17 \mathrm{Mal}$ einfach "carb" oder "gosudarb (naš)" - $24 \mathrm{Mal}$ aber "christoljubivyj/pravoslavnyj/blagovernyj gosudarb naš, carb 1 velikij knjazb, Ivan Vasilbevič vsea Rus11 (samoderžec)".ll Dabel 1st zu betonen, daß derartig breitgefächerte Bezeichnungen nicht in speziell hagiographischen Abschnitten erscheinen - vielmehr markiert das Auftreten dieser Apostrophierungen in allen Bereichen des Textes, daB das panegyrische Element im Fleskauer Text ein bestimmendes 1st. Die Pleskauer Krieger werden melstens als "chrestbjanskoe/christol jubivoe/ pravoslavnoe voinstvo" bezeichnet. Für Formulierungen innerhalb der geistlich ausgerichteten Passagen werden wir weiter unten ein Beispiel vorführen.

Die Apostrophierung der feindlichen Seite ist viel mannigfaltiger. Aber in diesem Zusammenhang wird eines deutlich, was oben; in bezug auf den Zaren, auf Pleskau und die Pleskauer schon unausgesprochen anklang: Den Begriff

9) So finden wir in unseren Texten z.B. kaum Farbangaben - Im Pleskauer Text sind die Mauern Pleskaus we1B, vor welchen die litauischen Truppen schwarz erscheinen (59/4), schwarz sind die Kleldung und Waffen(?) der "Streiter Christ1" (74/27), vergoldet das Gewand auf einer Ikone ("zlačenyj dospech" - 85/20). - Im K-pler Text: über K-pol geht ein Regen nieder, die Troplen "aki slezy, kapli velicy ... cerleny" $(75 / 22)$.

10) Lausberg, Elemente, $\$ 310 / 2$.

11) s. $35 / 9$ - erste Textse1te - wo als adjektivische Epitheta "blagovernyj 1 christoljubivyj" fungieren. 
"Epitheton ornans" müssen wir hier weiter fassen - das stehende Belwort ist nicht dem Wortkörper nach dasselbe, sondern sinngemäB dasselbe, also Synonymon im weitesten Sinne: die individuelle Bedeutung des Attributs, das beispielsweise zu "carb" tritt, schwindet und wird so auf eine allgemein glorifizierende Bedeutung hin verschoben. Das gleiche beobachten wir bei der Benennung Stephan Bathorys: "gordyj/vsegordelivyj/vysokogordelivyj/mnogogordelivyj/ velechvalbnyj/bezbožnyj litovskij korolb". "Litovskij" erscheint dabei beinahe regelmäBig und wird somit zur Inkarnation all der anderen genannten Epitheta, zu deren Synonym, so daB "litovskij" nicht mehr als geographischer Begriff zu verstehen ist, sondern semantisch alle Schattierungen von "gordyj" einbezieht. Darüber hinaus inhäriert "litovskij" noch ein weiteres Wortfeld, das mit "ljutyj, lukavyj" und auch"ljuterskij"12 zu beschreiben ist. Diese Epitheta finden sich seltener bei "korolb" selbst, sondern vielmehr bei Zuständen und Handlungen, die sich auf ihn beziehen: "simi že slovesy lukavymi" 45/35, aber auch "lukavyj 11tovskij korolb" 61/12, "zloumyšleno že i ljute lukavo k

12) "ljuterskif" - Damerau, Russ1sches, S. 74, weist "ljutorskij" in Kurbskijs "Istorija" nach, er hält es für eine Ableitung von "ljutor" - Anhänger von Luthers Lehre', ähnlich Sobik, Beziehungen, S. 265 , Wir haben hier die Lautung "ljuterskij", was buchstäblich der polnischen Lautung "luterski" entspricht. Ich halte die Ableitung von "ljutor" - 'Lutheraner' für irrelevant. Nie gerade aus dem Pleskauer Text klar wird, konnte wohl "ljutor" und die Ableitungen nur so populär werden, weil es sich lautlich so eng an "ljutyj" anlehnte - vgl. Vasmer, REW II, S. 79. DaB hier das Religiöse nicht im Vordergrund steht, zeigt sich auch daran, daB gerade Stephan Bathory als Katholik sowie der Vertreter des Papstes, der "protopop Antonej" (Possevino) 91/13 als "ljuterskij" bezeichnet werden. Ein paar Zeilen später hoikt es: "Antonej ze Ichnilatovo lukavstro 1 vee jako zbojlivyja lisicy lestb v sebe vospriemlet ..." $91 / 29$. 
gorodu približšesja" 61/33, "ljutyi toj varvar, l1tovskij kralb ${ }^{13}$ Stepan" $42 / 11$.

Für die Litauer allgemein - vor allem "litovskie", "-oe vojsko" und "getmany" - finden sich neben den Epitheta mit dem Stamm "gord-" ebenfalls oft "lukavyj", "ljutyj", "vele-/mnogopochvalbnyj", "gordonapornyj", "sverepyj" und "zlouserdyj"; auch"bezumnyj", "glupyj".

Abschließend soll ein kurzer Abschnitt aus der Pleskauer Erzählung demonstrieren, wie sehr der Autor stellenweise die Vermittlung von Information zugunsten rational kaum noch faBbarer Aneinanderreihungen und ihrer suggestiven *irkung vernachlässigt. Es handelt sich um die angekündigte Belegstelle aus einem geistlich orientierten Abschnitt, wo das Element der Emotionalisierung immer besonders stark hervortritt. Es muß aber betont werden, daB wir es bei diesem abschnitt keineswegs mit dem extremsten Fall zu tun haben (vgl. z.B. die viel umfangreichere, noch viel weniger durchschaubare Fassage 98/2 - 23).

PS "Sie že vididiva, gosudarevy bojare $i$ voevody $i$ vesb $78 / 12$ jaže o christe osvjaščennyj sobor i vse pravoslavnye chrestbjane, muži $i$ ženy $i$ svoimi čady, neizrečennoe 1 neskazannoe miloserdie presvjatyja $i$ prebožestvennyja, živonačalbnyja i nerazdelimyja troica $i$ molitvami $i$ moleniem nadežnyja našeja chrestbjanskija zastupnicy, vozbrannoj voevode, istinnyja bogorodicy i prisnodevy Marija i svjatych velikich ćjudotvorcov, vsea svjatyja ruskija zemlja zastupnikov, naipače velikogo svetilbnika i nastojaščee imenitomu gradu Pskovu istinnago

13) "kralb - korolb" - sie erscheinen im Verhältnis 21 : 93 . Eine semantische oder stilistische Differenzierung ist nicht erkennbar - nur sechs Belege für "kralb" befinden sich in schmeichelnden Anreden seiner Würdenträger. Für die freie Variabilität vgl.: "Takoze i getmany ne mogoša svoemu kralju javitisja, za nastojasciju $k \mathrm{nim}$ sramotu iza mnogoe ich $k$ kerolju pochvalenbe." $80 / 15$. 
zastupnika, blagovernago, velikago knjazja Gavrila Vsevoloda, s nim že 1 knjazja Domanta 1 Mikulu, iže Christa radi urodivago, 1 vsech svjatych miloserdie, neizrečennyja radosti í darenbe vsech bogu vozdașa."

Die Konstruktion ist ganz einfach, wird nur durch die Aufzählungen und Verschachtelungen undurchschaubar:

'Als die herrscherlichen Bojaren und ... die Barmherzigkeit der ... unteilbaren Dreifaltigkeit (erkannten), sowie die aus Gebeten ... (bestehende) Barmberzigkeit der ... Jungfrau Maria und aller Nundertäter der Rus sowie der ...., insbesondere des Fürsten Gabriel Vsevolod und ...., da wurden sie von unaussprechlicher Freude erfuilt, und alle dankten Gott von ganzem Herzen.'

Hatten wir also in bezug auf die Aufzählungen (und damit verbundener vielgliedriger Benennung von Personengruppen) feststellen können, daß sich der Pleskauer Text durch seine Formelhaftigkeit vom K-pler abhebt, so verstärkt sich dieser Eindruck noch, wenn wir uns dem Epitheton im K-pler Text zuwenden.

Ist das Epitheton im Pleskauer Text unbedingt als pleonastisch einzustufen, so sind die Epitheta in der K-pler Erzählung in den meisten Fällen "für die semantisch-syntaktische Vollständigkeit der Aussage strikte notwendig" 14 Es seien nur einige Beispiele wahllos herausgegriffen: "pogybelb konečnaja uže be postigla grad" 72/35, "srazi emo desnoe plečo" 72/28, "poloe mesto" $72 / 10$, "v velikuju cerkovb" (= Hagia Sophia) 73/10, "tjažkim 1 zveroobraznym rveniem" $74 / 1$. Ohne eine genaue Zählung durchgeführt zu haben, glauben wir nach sorgfältiger Prüfung sagen zu dürfen, daß in der Pleskauer Erzählung ungefähr $15 \mathrm{Mal}$ so viele Adjektive/Epitheta vorkommen wie im K-pler Text. Ein Teil derselben ist auch im $\underline{\mathrm{K} \text {-pler }}$ Text zur semanti-

14) Lausberg, Elemente, $\S 310 / 1$ 
schen Vollständigkeit nicht notwendig - so etwa sind die Epitheta "velikyj" und "mnogyj" als emphatisierend anzusehen; damit baben sie aber eine gewisse semantische Funktion behalten; so 1st es sicher ein Unterschied, ob wir lesen:

$74 / 19$

"ot mnogogo truda iznemogachu" oder "ot truda iznemogachu",

$72 / 6$ "načat delati baštu s userdiem velikim" oder "načat delati baštu s userdiem".

Betrachten wir uns die wichtigsten Personengruppen in der K-pler Erzählung, so wird der hier immer wieder hervorgehobene Kontrast $z$ wischen den Texten noch deutlicher: es sind dies "grec1", "frjaz1/frjagove", turc1/turkove", sowie "cesarb" und "saltan/Magumet".

Die beiden ersten Personengruppen treten stets ohne Epitheton auf, ebenso die Türken; diese werden allerdings manchmal antonomast1sch als "bezbožnyf" und ähnlich bezeichnet. Der Kaiser erhält einmal, in einer Rede des Patriarchen, das Epitheton "svetlejŏif cesarju" (73/26) - sonst lesen wir nur "cesarb". Allein dem Sultan Mehmed ist häufiger, bei weitem nicht immer, ein Epitheton beigegeben - entweder "bezbožnyj", "beznravny j", "zloverny j", "oka jannyj" oder "lukavyj". Häufig bleibt der Eigenname bzw. Titel einfach fort, und wir finden Mehmed nur als "bezvernyj" oder gelegentlich als "okajannyj" bezeichnet - also in Gestalt der Antonomasie. 15

Während die Antonomasie charakteristisch für einen konzisen Stil ist, gilt die "Setzung mehrerer Epitheta zu einem Hauptwort als schwerfäll1g"(s.0. Anm. 14). Damit 1st m.E. der Unterschied $z$ wischen beiden Texten treffend beschrieben, wennglelch man hier bezüglich des Pleskauer

15) Lausberg, Handbuch, $\S 677$ und zum folgenden $\S 678$. 
Textes ja hervorheben muß, daB es sich dort nicht um eine ungewollte Schwerfälligkelt, sondern um eine bewußt gepflegte Manier handelt.

Es wäre möglich - und in vieler Hinsicht auch notwendig -, verschiedene Erscheinungen zu kommentieren, die den m.E. auffälligsten Stilzug der Pleskauer Erzählung - die redundante oder pleonastische Ausdrucksweise - bzw. umgekehrt die informationsorientierte Erzählweise des K-pler Autors weiter belegen. Doch scheint mir, daß die kommentierten Erscheinungen (Aufzählung und Epitheton) einen umfassenden Eindruck vom unterschiedlichen Informationsgehalt beider Texte vermitteln.

\section{Figurae per ordinem}

Figuren, die auf der Wortstellung beruhen, sind in beiden Texten zwar (wenn auch in unterschiedlichem MaBe) quantitativ gut vertreten, doch handelt es sich im Grunde um eine einzige Figur, die in verschiedenen Variationen auftritt: das Isokolon. 16

In den erzählenden und namentlich in den kampfschildernden Bereichen finden wir das Isokolon besonders häufig, und $z$ war werden Handlungsketten bevorzugt parallel gestaltet; da es sich zumeist um kurze Kola handelt, bekommen die entsprechenden Passagen unwillkürlich rhythmische Qualität. Im K-pler Text ist diese Rhythmisierung der Sprache nur spürbar, jedenfalls nicht besonders hervorgeboben. Im Pleskauer Text dagegen wird diese in jeder Hinsicht verstärkt - sei es durch Endreim (verbalen Reim) oder/und durch anaphorische Einleitung der Kola.

16) Lausberg, Handbuch I, \$§ 719-54. In unseren Texten haben wir es vorwiegend mit.gelokkertem Isokolon zu tun. ('Klein-Parallelismus' Elemente, $\$ 337 / 2$ : mehr oder minder genaue Entsprechung der Reihenfolge.) 
KP 76/24 "(Mehmed) prišed na pole u velik1ja cerkvi,/ sleze s konja/ i pad na zemlju licem/ - vzjat perstb/ i posypa glavu,/ blagodarjašče boga,/ i počjudivsja onomu velikomu zdanieju,/ tako reče: ..."

65/14 "..., bbjachut izo mnogych pušek po tri dn1/ i, jako utrudiša stenu,/ 1 udariša iz bolbšie pušky,/ i spade kamenie mnogo./ $V$ drugie udariša,/ $i$ raspadesja steny velikoe mesto,/ no uže večeru nastavšu,/ turky načăa streljati iz mnogych pušek $v$ to že mesto,/ tako $i$ črez vsju noščb,/ ne dajušče gražanom zadelyvati togo vsego mesta."

iir möchten hier anmerken, daß für die Beurteilung solcher Textstellen, wie sie im K-pler Text allerdings nicht allzu häufig sind, stets das persönliche Empfinden ausschlaggebend ist. Diese Tatsache bestätigt nur das zuvor Gesagte, daß nämlich die Rhythmisierung der Sprache nur angedeutet ist.

Beispiele aus dem Fleskauer Text:

62/30 "Nolebnaja že mnogaja k bogu i bogorodicy peša,

i tako to mesto krestom ogradiša

i svjatoju vodoju okropiša.

Tako že 1 gosudarevy bojare $i$ voevody krestom blagosloviša

i svjatoju vodoju okropiša

i na podvig vooružiša,..."

$77 / 15$ "Mužie s nimi že 1 ženg $i$ na dostalınuju litvu v Fokrovskuju bašnju ustremišasja koegoždo s čim $i$ kak bog vrazumit: ovil že iz ručnic strelja,jušče, inii že kameniem litvu pobivajušče, ovii že ich gorjaščeju vodoju polivajušče, inii že ogni zažigajušče, na nich mečjušče, i vsjačeski i promyšlja.jušče." 
Weitere Belegstellen können wir uns in diesem Zusammenhag ersparen, da im Rahmen anderer Teiluntersuchungen gerade dieser Aspekt - "der gleichtönende Ausklang aufeinanderfolgender Kola" 17 - im Pleskauer Text immer wieder eine Rolle spielen wird und wir daher an anderer Stelle hierher gehörige Beispiele vorführen werden, z.B. $82 / 1,77 / 4,49 / 24,52 / 27,92 / 13,38 / 13$ u.a.

Im $z$ weiten Beispiel tritt die Verwendung der Anapher klar in Erscheinung. Gerade diese Gegenüberstellung "ovii - inii", auch "elicy - elicy", gibt dem Pleskauer Autor immer wieder Anlaß zu reimenden Kolon-Folgen. Wie erkennbar ist, sind die Kola im Fleskauer Text z.T. von unterschiedlicher Länge. Es stellt sich die Frage, ob man dann noch von "Isokolon" sprechen kann. Zumindest ist die Abfolge der syntaktischen Glieder gleich: (Subjekt) - Ergänzung(en) - Prädikat. Solcherart gelokkerter Parallelismus ist in der Fleskauer Erzählung eine der häufigsteh Erscheinungen:

a) die Gleichheit der irortzahl der Kola ist nicht immer gewährleistet,

b) die Gleichheit des syntaktischen Auf baus ist stets in jedem Kolon vorhanden,

c) die Kola haben oft gleichtönenden Ausklang durch verbalen Reim.

Durch. die beiden letzten Faktoren wird der Nangel, der im häufigen Fehlen der Gleichheit der Wortzahl besteht, ausgewogen. Die vom Autor gern benutzte Anapher verleiht dem Isokolon noch zusätzliche Stringenz.

Wenden wir uns den Abschnitten geistlichen Inhalts zu,so stehen wir einer vollkommen anderen Situation gegenüber. Die Figuren, die auf einer bestimmten Hortfolge beruhen

17) Lausberg, Handbuch I, $\$ \S 725-729$ - das Homoeoteleuton. 
und im Pleskauer Text innerhalb der erzählenden Abschnitte ganze Partien dominieren, treten im geistlichen Bereich ganz zurück, während sie in den religiös ausgerichteten Passagen des $\mathrm{K}$-pler Textes zum beherrschenden Aufbauprinzip werden. Auch hier ist es die parallele Konstruktion, die die Aussagen strafft, aber oft nur den äußeren Rahmen für andere rhetorische Figuren (figurae sententiae) bildet.

N1cht im Pleskauer, jedoch im K-pler Text beobachten wir gelegentlich "Iteratio", $18 \mathrm{~d} . \mathrm{h}$. die Wiederholung eines

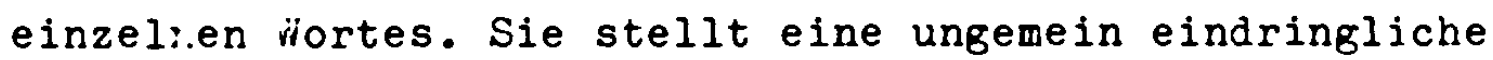
Form der Anrufung bzw. des Ausrufs dar.

$69 / 3$ "Sogrešichom bo, gospodi, sogrešichom na nebo ..." 69/19 "Poščadi, gospodi, poščadi,...." 68/36 "Derzajte ubo, čada, derzajte,... Die Anrufungen sind meist in kurze, aus Imperativ und $\mathrm{Cb}$ jekt bestehende Ausrufesätze gegliedert, etwa:

$69 / 1$ "..., i prịmi grešnoe naše molenie,/ i prikloni ucho troe/ 1 uslyši glagoly naša,..."

$69 / 6$ "..., ozlobichom bo tvoju blagodatb

$i$ razgnevachom troe božestvo, prestupajušce i popirajušči tvoich zapovedej

i ne posluščajušči tvoich povelenii."

$69 / 20$ "..., ne predaj že nas vragom i supernikom vladyčestvija tvoego, 1 izbavi nas ot obstojanija dnešnjago $i$ obyšedšich ny $z 01$ i napastej;

18) Die Iteratio kann als Sonderform der Geminatio zugezählt werden; letztere bezeichnet speziell die Niederholung eines einzelnen Hortes, während erstere auch die wiederholung von Nortgruppen beinhaltet. Zwischen die $z u$ wiederholenden Worter/rortgruppen kann ein trennendes Satzglied treten - diese Form finden wir in der K-pler Erzählung ausschließlich vor. Lausberg, Handbuch I, $\S$ 616-618. 
svobodi po množestru milost1 troeja,

1 1zm1 nas po čjudesem troim,

$1 \underline{d a z ̌ d}$ blavu imeni tvoemu,

da posramjatsja vrazi tro1 1

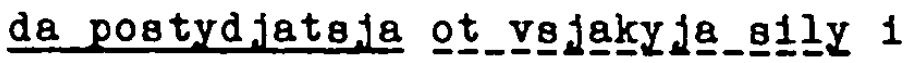

krépogetb_isch da sokrusitsja,

da razumejut, jako ty esi bog naš, ..."

In der zweit- und drittletzten Zeile erkennen wir Anklänge an Chiagmus, der im Pleskauer Text so gut wie nie begegnet. Allerdings ist er auch in der $\mathrm{K}$-pler Erzahlung selten anzutreffen. In der folgenden Periode jedoch scheint Chiasmus ganz bewußt zur Auflockerung der parallel gebauten Folgen verwendet zu sein ( $\underline{\text {-pler }}$ Text):

$75 / 26$ "0, velika sila ..., o, koliko zla ...! 0, gore tobe,..., ovogda proslavljaja 1 velićaja pače inych gradov, ovogda mnogoobrazne 1 mnogokratne nakazaja

1 nastavljaja blagymi dely 1

ćjudesy preslavnymi,

ovogda że na vragy pobedami proslavljaja,

ne prestaše bo poụçâda

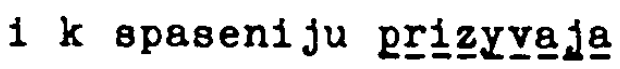

1 žitejskim lzobiliem utešaja,

no ukrašaja vajačesky;

takože 1 preneporočnaja mat1 Christa...

neizčetnymi darovanbmi pomilovaše

1 chranfaše vo voja vremena." 19

Es 1st hier nicht der Platz, um diesen Abschnitt auf stilistiache wittel hin zu untersuchen - Anapher, Wort- und Endreim (= verbal), Parallelismus, Chiasmus aind nur die auffälligsten Erscheinungen. In khnlicher Telse kann man fast alle Prophezelungen auf S. 77, fast alle Gebete und Anrufungen aufgliedern. Man hat das Gefühl, als habe der Autor in all diesen gebetihnlichen Monologen intuitiv oder bemiBt liturgische

19) durchgezogener Strich: Anklänge an Chiasmus, unterbrochener " : Anklänge an Parallelismus. 
Hymnen nachgestaltet. Es ist gewiß nicht übertrieben, im Zusammenhang mit den Monologen im $\mathrm{K}$-pler Text von einer kunstvollen Gestaltung zu sprechen.

\section{Figurae sententiae}

Neben den bereits angesprochenen Apostrophen sowie den angedeuteten Ausrufen ${ }^{20}$, die sich weitgehend in die formale Gestaltung der Monologe einfügen, finden wir im K-pler Text besonders häufig die Antithese ${ }^{21}$ vertreten: 69/11 " '... choteniem ne chošču smerti grešniku, no jako eže obratitisja i živu byti':

1 paky: 'ne prildoch pravednych prizvati, no grešnych na pokajanie'; ne choščesi bo, vladyko, sozdanie ruk troich pogubiti, nizze blagovoliši o pogibeli čelovečestej, no choščeši vsem spastisja ..."

69/30 "No ubo elikko preže blagodatej 1 darov božilch 1 prečlstyja bogomateri blagodejanij spodobleni_bychom, tololikoㅛ nyne, grech radi našich, pomilovanija 1 šcedrot božiich lis šeny_bychom."

Die Antithese ist auch im Fleskauer Text, namentlich in Monologen und Abschnitten geistlichen Inhalts eine häufige Erscheinung.

72/7 "Obotura, v bezzakonnoj svoej eresi ne znaeši ego (Gott), no prevoznesesja na Pskov gorod do nebesi,..."

20) s.o. $75 / 26$ "O, velika sila grechovnago žala, o, koliko zla tvorit prestuplenie!

0 , gore tobe, sedmocholmi1,..." "Sedmocholmyj" = die Siebenhügelige = Konstantinopel Ausruf = "Exclamatio", s. Lausberg, Handbuch I, 8809.

21) Lausberg, Handbuch I, - Antitheton - $\$$ 787-807. 
Allerdings finden wir im Pleskauer Text antithetische Gedanken in der Regel nicht so pointiert formuliert, meist ist der Gegensatz verwässert, so daB er nicht zur Wirkung gelangt, $z . B$.

79/14 "Izvolim že za svjatuju veru 1 umereti 1 za pravoslavnago gosudarja našego, carja 1 knjazja ..., 1 za ego deti, naši gosudari.

A ne pomyslim $v$ serdcych našich koeju mysiliju ili bojaznestvom v rozmyšlenie sja dati ili otčajati,..."

-Wir wollen für unseren hlg. Glauben und für unseren ... Herrscher und für seine ... Kinder sterben und nicht in Zweifel geraten oder gar verzwelfeln.'

Eine große Rolle spielen im Pleskauer Text Sätze antithetischen Inhalts, der sich besonders darin äußert, daß sich in jedem Glied des Satzpaares das Glied einer Einzelwort: antiththese befindet. Nicht immer geschieht das in solch prägnanter Neise wie im folgenden Beispiel:

\section{$58 / 7$ "... ; led ted tajanija otčajaniem nadeži ni edinomu vo Pskove kosnutisja, ognb že blagodati christovy vsem serdca na podvig vozvari,..." \\ - Das Eis - das Sinkenlassen aller Hoffnung - berührte keinen (bedrohte keinen) in $\mathrm{P}$., das Feuer aber - die Gnade Christ1 - bewirkte, daß alle auf heldenhaften Kampf brannten.'}

Neben dem durch die Metaphern "led" und "ognb" pointierten gedanklichen Gegensatz finden wir im ersten Glied des Satzpaares eine Einzelwortantithese vor, die wohl eher aus Gründen der effektvollen Formulierung Anwendung fand: "otčajaniem nadeži" -'Verzwelflung an der Hoffnung'. In dieser Funktion - der effektvoll-plastischen Formulierung begegnet uns die Einzelwortantithese im Pleskauer Text fast hundertfach: "vkupe ubog 1 bogat" 71/44, "vižu 1 slyšu" 60/19, "laskoju 1 grozuju" $81 / 9$ und $81 / 13$, "nemošč - krepostb" 76/24 (ähnlich 75/18), "silbnil - nemoščnil" 79/4, "život - smertb" 90/6 u.v.a. 
Im $\mathrm{K}$-pler Text ist diese effektvolle Ausdrucksweise selten anzutreffen: "soditelju vseja tvari, vidimyja i nevidimyja" 68/43 (s.o.), "vse obogatejut i nikto že nišč budet"78/2, "oružija ratnaja sotvorjajut serpove" $78 / 4 \mathrm{u}$.a. Die hier vorgestellten Belege sind alle den stark geistlich ausgerichteten Monologen entnommen, insbesondere dem letzten, der die Prophezeiungen enthält (Visio Danielis, Leo Sapiens, Methodios von Patara). Da es sich bei diesen um direkte oder indirekte 22 thersetzung handelt, ist davon auszugehen, daß der Autor unseres Textes die Einzelwortantithesen in der - griechischen oder altrussischen - Vorlage vorgefunden und übernommen hat.

Die Antithese, in Gestalt der Satz- als auch der Einzelwortantithese, wird also in unseren beiden Texten vollkommen verschieden gehandhabt.

Die Satzantithese findet in der K-pler Erzählung beinahe ausschließlich in den Konologen Anwendung, wo sie scharf pointiert ist und in oft paralleler Setzung nicht übersehen werden kann, die effektvoll-plastische Einzelwortantithese hingegen kommt nur gelegentlich im Monolog vor. Daraus erhellt, daß der K-pler Autor zwar einen intellektuelien Gegensatz gern zugespitzt formuliert, daß er aber auf die emotionalisierende, der reinen Information nicht besonders dienliche Einzelwortantithese fast vollkommen verzichtet, wohingegen der Pleskauer Autor

22) Entweder ist die gesamte K-pler Erzählung die direkte tbersetzung eines griechischen Textes, dessen Autor an diesen Stellen andere Quellen ausgeschrieben hat, oder aber wir haben es mit einer original altrussischen Erzählung zu tun, deren Autor die Prophezeiungen bereits in altrussischer Ubersetzung vorgefunden und in seine Erzählung übernommen hat, auf welchem Wege die Einzelwortantithese Eingang in unseren Text gefunden hat. Ausführlicher zu dieser Problematik s. Kapitel B 1.1 (Textgeschichte). 
auf die Herausarbeltung gedanklicher Gegensätze oft verzlchtet, dafür aber die auf Emotion gerichtete Einzelwortantithese forciert.

Elne große Rolle spielen in der Pleskauer Erzählung rhetorische bzw. 1ronische Fragen. Wir treffen diese auch gelegentlich im K-pler Text an, wo sie gemeinhin in den Gang der Ereignisse eingestreut sind - gleichsam als ein retardierendes Element, als wollte der Autor einen Augenblick innehalten, sich besinnen und in einem Stoßseufzer sich von den schrecklichen Erinnerungen befrelen:

$61 / 30$ "...; no čto močno be učiniti protiv takie sily?"

62/12 "I jakože pred1 p1sachom: kyj jazyk možet ispovedati ili izrešč toja bedy 1 strasti : ..."

71/27 "Padenie že obolch stran, a naipače rannych - kto možet 1sčest1."

Im Rahmen eines Monologes finden wir einmal eine rhetorische Frage, und zwar am Schluß jenes Monologs, der sich an die Nachricht vom Tode Konstantins anschlieBt:

$75 / 39$ "..., 1 kto o sem ne vosplačetsja 111 ne vozrydaet?" Auch diese Frage 1st eher als ein StoBseufzer, denn ein Zeichen der Resignation und der Trauer zu verstehen. Keineswegs trifft auf diese Fragen $z u$, was $H$. Lausberg über die rhetorische Frage schreibt: "Dle 'rhetorische Frage' (...) peitscht die Affekte (...) durch die Evidenz (...) der Unnötigkeit der fragenden Formulierung auf." 23 Viel eher trifft diese Definition auf rhetorische und ironische Pragen zu, die uns im Plegkauer Text häufig entgegentreten:

PS "Kto vozglagolet sily gospodnja, i(11)

$71 / 9$ kto slyšany sotvorit chraly ego?"

23) Lausberg, Elemente, $\S 445 / 2$. 


\section{PS} $92 / 13$

"Xto že troego uma,

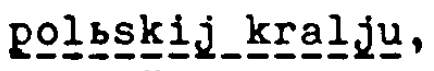

bezbožnage sovetu,

čto že tvoego domyslu, Stepane,

knjazb_velikijj_litovskij,

jako vetra goniši

ili $\mathrm{v}$ morstej pučine putna choženija

videti choščeši,

ilí vysokoparna orla stezi ščitaeši?"

Diese Fragen 'peitschen die Affekte', um mit Lausberg zu sprechen: im ersten Block, gebildet durch drei Isokola, finden wir dreifache Anapher, den Schluß bildet - nach jeweils einem in allen drei Gliedern des Isokolons synonymen Begriff ("um", "sovet", "domysl") - stets ein Vokativ. Im folgenden Block, bestehend aus ebenfalls drei - allerdings locker gefügten Isokola, beobachten wir Endreim; fnapher in den beiden letzten beiden Gliedern. Vor allem gewinnt diese Satzfolge ihre ungeheure Wirkung durch die Klimax der drei letzten Sätze: 1. jagst du den iind? 2. oder suchst du dir auf dem Meeresgrund einen Weg? 3. oder glaubst du, dich auf den Bahnen des hochfliegenden Adlers zu bewegen? Eine jede lendung drückt - stärker als die vorausgehende - die Unmöglichkeit des Unterfangens aus. Gelegentlich stoßen wir auf Anklänge von Ironie, hier aber ist sie ganz bewußt eingesetzt, zur Verhc̈hnung Báthorys. Linige Zeilen später lesen wir:

92/24 "Ole gluposti, ole nerazuma, glava nogam beseduet, gospodin rabu svoju čestb otdaet!" 92/31 "No čto že sja chvališi vo zlobe silbne bezzakonija?" Aus diesem Monolog des Autors könnten wir noch viele solcher "aufpeitschender" rhetorischer Fragen anführen, doch wollen wir es mit der folgenden bewenden lassen:

93/5 "Kako umel esi svoim derzostnym jazykom takoe pochvalenie izrešči, - chrestbjenskoe carstvo razoriti, 111 predoteča esi onogo pred javljaemago otstupnika?" Der Triumph über Báthory legt so emotionale Ausdrucksweise nahe, doch entspricht sie auch der Diktion des Autors. Dagegen: das tragische Geschehen im K-pler Text zwingt zu distanzierter Diktion. 


\section{Nortwahl}

In diesem Abschnitt behandeln wir Paronomasie ("figura etymologica") sowie die Bildung von Neologismen durch den Pleskauer Autor. Da wir diese weder den Ordnungs- noch den Sinnfiguren zurechnen können, seien sie in einem eigenen Abschnitt erörtert.

Es handelt sich bei unseren Belegen für Paronomasie ${ }^{24}$ fast ausschließlich um "figura etymologica". Auch die wenigen Ausnahmen sind im Grunde dazu zu zählen, da man annehmen kann, daß sie der Autor als semantisch verwandt empfand. vir können daher von "pseudo-etymologischen" Figuren sprechen.

Die pseudo-etymologische Faronomasie kommt in verschiedenen Belegen in stets der gleichen Kombination nur im Pleskauer Text vor, z.B.:

$84 / 2$ "O tom troem bezumnym umyšleni1";

stets werden also in solchen Fällen wörter mit der Wurzel "-um-" zusammengestellt mit Formen des Kompositums von "mysliti" : "u-mysliti/ u-myšljati".

Uns scheint, die Definition der Faronomasie, wie sie lausberg gibt, trifft auf unsere Texte nicht $z u$.

Vom K-pler Text können wir beinahe absehen. Zwar begegnen uns hin und wieder Faronomasien, aber sie sind so selten, daß sie keine auf den gesamten Text $z u$ beziehende Funktion erfüllen. Sie konzentrieren sich, wie alle Figuren, die irgendwie affektisch wirken, auf die kionologe, z.B.:

69/27 "molebnymi glagoly po vsja dni moljaščesja" $69 / 38$ "molbby $i$ molenija"

24) Lqusberg, Handbuch I, $\S \S 637-39$. "Die annominat1o 'Paronomasie' ist ein (pseudo-) etymologisches Splel mit der Geringfügigkeit der lautlichen Anderung einerseits und.der interessanten Bedeutungsspanne, die durch die lautliche Anderung hergestelit wird, andererseits." $(=\S 637)$. 
$77 / 18$ "1zobladaše vladejuščich"

$77 / 19$ "odole odolevšich".

Ein Beispiel für das seltene Vorkommen in erzählenden Fassagen:

64/6 "vozgreme zemlja, aky grom velij".

Bereits diese Beispiele aus dem $K$-pler Text zeigen, daß es hier nicht so sehr um ein "etymologisches Spiel mit der Geringfügigkeit der lautlichen änderung einerseits und der interessanten Bedeutungsspanne ... andererseits" 24 geht, sondern ganz eindeutig um den lautlichen Effekt.

Die Beispiele für Paronomasie in unseren Texten unterscheiden sich nicht in ihrer qualität, sondern in ihrer Quantität. Zum Vergleich sollen nur einige wenige Beispiele auch aus dem Pleskauer Text zitiert werden:

a) $44 / 13$ "obety carskimi obeščavsja im" (fünf Mal)

$81 / 12$ "na strelach streljati"

$88 / 10$ "skorozel snym begstvom ... bežachu"

b) $76 / 34$ "mnogo množestvo"

$78 / 6$ "moleniem 1 molitvami"

c) $86 / 25$ "zlozamys̆lenoe ich umyšlenie"

d) $81 / 20$ "blagochval bne razum ich pochvali"

Die Buchstaben bezeichnen die verschiedenen Varianten der Figur, wobei a) den Haupttypus darstellt.

Wie sehr oder wie wenig unsere beiden Autoren den durch diese Figur erzeugten klanglichen Effekt schätzen, zeigen die folgenden Zahlen: Die Paronomasie in obiger Form kommt in der K-pler Erzählung $17 \mathrm{Mal}$, in der Pleskauer Erzählung 103 kial vor. Diese Angaben sagen mehr über die Intention der Autoren und über ihre Motivation bel Verwendung der verschiedenen rhetorischen Mittel aus als lange, wortreiche Erklärungen.

Als Effekthascherei in soeben beschriebenen Sinne dürfen wir auch die Vorllebe des Pleskauer Autors zur Bildung von Neologismen betrachten. Hierbei handelt es sich um 
ungewöhnliche, erstaunliche Wortzusammensetzungen, meist von $z$ wei, manchmal auch drei verschiedenen Wurzeln. Nur am Rande seien die affektischen Bildungen mit "mnogo-", "pre-", "vele-", "vysoko-" erwähnt, während die Bildungen mit "blago-" eher als habitualisiert betrachtet werden können. Um eine Vorstellung zu geben, seien ein par Beispiele genannt:

mnogo- -boguchulbnyj, -gordelivyj, -zelbnyj, -molebnoe, -naloženyj, -nepravdivyj, -potrebnyj, -pochvalbnyj, -radostno, -slavnyj, -ukreplenyj, -čislenyj, u.a. (Insgesamt 28 Belege)

pre- -beznačalbnyj, -božestvennyj, -velikij, -vysokij, -gordelivyj, -izobilovanbe, -imenityj, -mnogij, -mudrostb, -neporočnyj, -terpelivyj, -udobrenyj, -umnožennyj. (Dies sind nur die auffälligsten, daneben stehen noch viele mehr oder weniger habitualisierte Zusammensetzungen, z.B. "prečistyj", "prevoznošenie" u.a., insgesamt 84 Belege!)

vele- -ohvalbnyj ( 3 Mal)

vse- -gordelivyj, -deržitelb, -duševne, -zakrytyj,-kamennyj, -lukavyj, -mudro, -serdečne, -silbnyj. (13 Belege)

vysoko- gordyj, -gordellvyj, -stolbnejšij (auf höchstem Throne).

Viel auffälliger sind Zusammensetzungen der folgenden Art, von denen man unterstellen darf, daß der Autor sie aus dem Grunde gebildet hat, um Erstaunen und Verwunderung des Lesers noch zu vergrößern, den Leser also weiter zu emotionalisieren:

"molebnosoveščatel bnyj" 49/17, "smirennomudrostiju umudarjasesja" 57/29, "skorozel bnym begstvom" 88/10, okradoobraznym obrazom" 87/1, mertvotrupogl jadetel bnyj" 45/32, "kamennoogradnym krepostbmi" 43/19, "vsezakrytyj 1 zlojadovityj ... 1ad" 42/28, "tverdoukrepleny ja ich steny protivu ruskich otenobitnych sosud" 38/5, "pervoprestolbnyj chrestbjanskif cars" 36/1, "mudrodrugoljubnyja sovety" 50/12, "gradoste- 
novnaja tverdostb" 52/28, "mudromyšlenyj un" 53/1, "kolenopokolenie" 56/16, "mudroučitel sne" 78/30, "bezbogonadežnoe umyšlenie" 81/18, "blagochvalbne" 81/20.

Es sind dies bei weitem nicht alle seltenen und neuen Bildungen, aber die auffälligsten.

Im $\mathrm{K}$-pler Text kommen derartige fortbildungen nicht vor.

6. Bildersprache

6.1 Nietapher

Wie schon im Zusammenhang mit der Benennung von Fersonen und Fersonengruppen erwähnt wurde, wird im $\underline{K}$-pler Text der Sultan manchmal antonomastisch als "bezvernyj", "okajannyj", "bezbožnyj" bezeichnet. Gelegentlich werden auch die Türken als Gruppe "bezbožnyj" ( = Singular!) genannt. 25

Hin und wieder begegnet uns auch eine adjektivische Metapher, z.B. "zveroobraznym rveniem" $74 / 1$, wo der metaphorische Charakter durch die Zusammensetzung mit "-obraznyj" ( = 'ähnlich') verdeutlicht wird. Die ab und zu vorkommende Bezeichnung Konstantinopels als "Sedmocholmyj" wird man als lietapher bezeichnen dürfen, genauer gesapt, als Antonomasie, da dem russischen ieser diese leriphrase sicher nicht sehr bekannt war.

25) Es handelt sich hier um die tbertragung einer antonomastischen Benennung ("bezbožnyj" = Mehmed) für eine einzelne Ferson auf das Volk, dem diese vorsteht - eine Synekdoche.

Lausberg, Handbuch I, \& 573/3, ders, Elemente, \& 201/1: "Die Synekdoche der Nationalitätsbezeichrung ist bis heute in allen europëischen Sprachen geläufig." Man denke an die im Krieg verbreiteten Bezeichnungen: 'der Ivan', 'der Tommy'. Nllerdings sind uns synekdochische Cbertragungen von Antonomasien nicht bekannt. Vielleicht im Wittelalter im Dt.: Türke = der Heide, der Ungläubige. 
Im Ganzen gesehen ist in der K-pler Erzählung die Metapher eine beinahe unbekannte Erscheinung - selbst im abschlieBenden Teil, der die Weissagungen enthält.

Die gegenteilige Beobachtung machen wir im Pleskauer Text. Selbstverständlich ist der polnische 26 König mit seinem Heer ziel tropischer Bezeichnungen. Aus der Fülle der Beispiele sollen nur die wichtigsten Erscheinungen eine Vorstellung vom überschwenglichen Gebrauch bildsprachlicher Elemente im Pleskauer Text vermitteln.

Wie nicht anders $z u$ erwarten, treten die metaphorischen Bezeichnungen thematisch neben die reichlich vorhandenen Epitheta (ornantia). So wird der polnische König "krepkij varvar" 41/33, "ljutyj toj varvar" 42/11, "agarjanin" 45/4, "ljuterskija svoeja very voin" $41 / 13$ genannt.

Für Stephan Bathory und überhaupt für die gegnerische Seite ist charakteristisch als bildspendendes Feld "zmijal zmij" - 'Schlange/Drache'. Hinzu gesellt sich "aspid" 'Natter'. Zum liortfeld 'Schlange/Drache' gehc̈ren natürlich auch Gift und Feuer: "zmeinyj jad" und "iskry ogneny". Das Gift pflegt die Schlange aus ihrem Unterleib "utroba"- auszuspeien. Feuer und Gift sind aber die Symbole des Satans und der Hölle, deshalb wird Sttephan Bathory auch mit diesem in Verbindung gebracht: "sotonskij" und "ad".

41/15 "Ijutyj že 1 overipyj zmelnyj jad ot svoeja nesytyja utroby otrygnuv".

26) S.0., S. 117 f. und Anm. 111.- "polsokif" erscheint in der altruss, I1teratur selten - zw1ochen Polen und der Rus erotreckte olch I1tauen, zu dem die Beztehungen immer intensiv waren entweder freundschaftilch (gerade pleskau und Novgorod) oder (beonders eit der 'Sammlung rus818cher Lande' durch Moskau) immer felndilcher. Mar also "litorarif" bereita otark negativ aufgeladen, so entwickelte oloh die entsprechende semantische Verengung (oder Erweiterung) erot während der "omuta". zu nlitovokif - l jutyj - lukavyj - ljuterskifn 8.0., S. 207, Anm. 12 . 
42/28 "K semu že i vsezakrytyj i zlojadovityj, jako ot adovy utroby, jad otrygnuv, jako ne tokmo na Luki Velikie sverepstvo svoe ... pokazovaše, no sotonskim svoim voznošeniem prevoznesesja ..."

Wie erkennbar, erhalten auch diese tropischen Wendungen die stehenden Epitheta beigelegt: "ljutyj","nesytyj", "sverepyj".Diese werden oft verbal und substantivisch verwand:

42/10 "razsverepisja i razgordisja ljututyj toj varvar.

$52 / 18$ "bolbmi razgordesja vo svoem vysokon bez boㅡnom pomysle" u.v.a.

Um das zentrale iortfeld 'Schlange/Drache, Natter - Gift, Unterleib - Feuer - Satan/Hölle' gruppieren sich noch weitere, meist erniedrigende Tierbezeichnungen: vor allem "zverb" - 'Tier', sowohl als Substantiv als auch als Epitheton; sodann "veprb" - Wildschwein,27.

Da der König und sein Heer untrennbar zusammengehören, so gelten für ihn natürlich auch die Benennungen, die der Pleskauer Nutor den litauischen dürdenträgern und dem Heer gibt: Da finden wir neben selbstverständlichem "zmii", "aspidy" auch "skorpii", die bereits erwähnten "mertvotrupogljadetelbnye psy" und auch sonst häufig "psy".

Der folgende kleine Ausschnitt möge zur Illustration des eben Gesagten dienen:

56/26 "Približenbe že svoe (=St. Báthory) do Fskova uvidevše, jako ne sytyj ad propas(t)nyja svoja čeljusti raskidaše

27) Vgl. die Belege bei I, I, Sreznevskij: Materialy dlja slovarja drevnerusskogo jazyka, 3 Bde. SPb $1893-1903$. ND M. 1958. Bd. I, 243: r rüh belegt, oft mit Epitheton: "divil veprb". (weiterhin zitiert als: Srezn., I bzw. II bzw. III plus Zahl der Kolumne). 
1 ottole Pskova poglat1t1 chotjaše.

Spešne 1 radostne ko Pskovu, jako 12 velikich peščer lutyj velikij zm1j let,jaše,

strašilišča že svol, jako 1skry ogneny 1 dym temen na Pskov metaše;

ne doletev, vo utrobe u sobja togo Pskova slyšati skazovaše.

Aspldy že svol 1 približnye zme1 1 skorpe1 velikif toj zmej, litovskij korolb, blevanlem nasyt1ti chvaljašesja.

I tako vse, jako zmej, na krylech na Pskov letjaše

i sego gordelivstrom svoim, jako krilami,

zmelnym1 svolmi jazykam1 voja živuščaja povaliti chotjaše, vo grade, jako žalam1 umoriti mnjašesja.

Vsja že $v$ nem blagaja vo svolch adovych utrobach vo svoju Litru otnesti chvaljašesja ..."26

- Des Könlgs Ankunft sah aus, als ob die unersättliche Hölle ihre abgrundtlefen Schlünde aufrisse und so Pleskau verschlingen wollte.

Schnell und freudig flog der groBe Drache gleichsam aus selner rlesigen Höhle,

selne Ungeheuer warf er wie Feuerfunken und schwarzen Rauch auf Pleskau.

Er war noch nicht angelangt, da behauptete er schon, Pleskau in seinem Wianst zu hören.

26) Es se1 auch an die Schlangen-Symbolik in der "Kazanskaja Istorija" erinnert. Das "gnezdo zmlevo" wird z.B. In Kap. 1 allegorisch von der Schlangenbrut gereinigt Schlangenbrut - hier: Heidentum. s. Kazanskaja lstor1ja, Hrsg. G. N. Mo1seeva. M-L 1954 (z1t1ert weiterhin: "Kazanskaja Istorija"), S. 47.

Häufig findet sich diese Symbolik auch bel Ivan Gr. vil. $\mathbb{N}, \mathrm{K}_{2}$ Gudz11, Chrestomat1ja russkof literature 11 - If vv., '1962 (z1tiert weiter als: Gudzij, Chrestomatija), S. 290: "tvoj zlobnyj jad" = dein verräter1scher Geist; S. 29I: "polozil es1 jad aspiden pod ustnami svoimi" z deine falschen Worte; S. 292 "jako ze besovskim obyčem jad otrygaesi?" " Gift dos hęidnischen Verrats. - Vgl. Ke P. Adrienoya-Peretc: Ocerk1 poétičeskogo ot1lja Drevnej Rus1, M-I 1947, S.92 und S. 94: Die allegorische Bedeutung von 'Schlange' als 'Lug, Trug, Hinterlist' 1st gew1B von der bibl1schen Erzählung vom Sündenfall abzule1ten. 
Seine Nattern aber, seine ihn umgebenden Schlangen und Skorpione wollte dieser große Drache, der polnische König, mit seinem Erbrochenen speisen, wie er sich rühmte.

Und so flog er* wie ein Drache mit seinen Plügeln auf Pleskau zu, und er wollte es durch seinen stolz - wie mit Flügeln - niederstrecken.

Er hatte vor, mit seinen Schlangen-/ Drachenzungen alles Leben in Pleskau (wie mit/giftigen/ Stacheln) zu vernichten/zu töten.

Alle Güter dort wollte er dann in seinem höllischen Leib nach Litauen schleppen -

so prahlte er.'

* Möglich ist auch eine etwas andere Deutung der folgenden Sätze: Anstatt 'Und so flog er wie ein Drache ...

Plural 'Und so flogen sie wie ...27

Wenn in obigem Textausschnitt - wie auch in der gesamten Erzählung - Metapher und Vergleich ineinander ubergehen, 80 liegt dies einerseits in der Natur dieser Piguren, ${ }^{28}$ andererseits ist diese mangelnde Abgrenzung auch charakteristisch für die ältere Literatur auf russischem Boden, wo man so feine Scheldungen nicht vornahm.

Wir finden das litauische Heer bzw. die Heerfuhrer als

27) Hierzu s. die Ausfuhrungen über die Verwendung des Imperfekt im Pleskauer Text: in mehr als 50 v.Hd. aller Fälle erscheint bel einem Subjekt im Plural das Prädikat (Imperfekt) nicht korrekt als - $(j)$ achu, sondern in Gestalt der 2./3.8g.1pf. - ( j)ase. Der Singular "zmej", den wir Im Zitat ilinden, stellt die Interpretation des Hrag.s dar - Im Original ateht alcher "zmein - vgl. die Bemerkungen des Hrag.s unserer Textauggabe (S. 30 ) zur Schreibung von "1" und "1-kratkoe" (= "jn): "upotreblenie ' $j$ ' - sovremennoe".

28) Lausberg, Handbuch I, $\S 846 / 1 \mathrm{c}$, d: der Ubergang vom Vergleich minimalen Umfangs zur Metapher lst flieBend: "Als Unterschreitung des minimalen Umfangs der similitudo wird die Metapher aufgefaßt." Hervorhbg. - Lausberg. 
"stras̆ilišča" - 'fürchterliche Ungeheuer' bezeichnet; "blevanie" - 'das Erbrochene' kann entweder Bezug nehmen auf eine Ernährungsweise, die be1 Raubvögeln üblich 1st, vermutlich handelt es sich aber auch um einen sehr pejorativen Vergleich. Als sehr kühn, weil mit geringem Bekanntheitsgrad, darf man die Nendung 'wollte mit seinem Stolz wie mit Flügeln (= des Drachen) Pleskau niederwerfen' bezeichnen. Schließlich geht der Autor so weit, die Metapher 'will mit seinen Schlangen-/Drachenzungen alles Lebende in Pleskau töten' noch durch einen welteren Vergleich aus diesem Nortfeld zu erläutern: 'wie mit (Gift-) Stacheln'.

Der Vergleich des litauischen Heeres mit 'dunklen Rauchschwaden' begegnet uns später noch einmal, wo er noch ausgeweitet wird: litauisches Heer = schwarz, Pleskau = we1B.

59/3 "Ot poludennyja strany ... dym temen: litovskaja sila na černostb pskovskija belye kamennye tverdyja steny predposlasja, eja že ni vsja litovskaja sila očernit1 vozmože, semu že dymu, litovskim voinom prišedšu,..."

(Ubersetzung s.0., S.200)

Die sich auf die christliche Seite beziehende Metaphorik ist in beiden Texten traditionell: das Kreuz Christi = "oružie" - "Waffe', die Gottesmutter und die Helligen erscheinen als "stena, pokrov, molebnik, zastupnik" - Wauer, Schutz/Schirm, Fürsprech, Be1stand' u.ä., die Bibel - "svjatye usty", Christus - "pastyrb 1 nastavnik", Gott (speziell im K-pler Text) "sodetelb vseja tvari, vidimgja 1 nevidimyja; vladyka, pomoščnik v skorbech, pribežišče". 29 Die Streiter für den rechten Glauben werden lediglich mit Vergleichen bedacht.

29) Zur Ubertragung der Kriegsterminologie auf geistliche 


\subsection{Vergleich}

Nas im Rahmen der Betrachtung der Metaphorik unserer Texte mangels Material nur zu vermuten war, of fenbart sich im $\mathrm{Zu}-$ sammenhang mit den Vergleichen in voller Klarheit: der K-pler Text bedient sich fast nur des tradierten Vergleichsmaterials. Ohne hier in diesem knappen iberblick Parallelstellen anführen zu wollen, möchten wir doch einige derke nennen, wo diese Vergleiche erscheinen: Josephus Flavius, "Istorija Judejskoj vojny"; Slav. Manasses-Chronik; Alexandreis usw. Es handelt sich um Bilder, wie sie schon der ältesten antiken Kriegsliteratur bekannt waren. Vor allem darf man das von den Vergleichen sagen, die vollkommen wertneutral einen Vorgang auf dem Kriegsschauplatz Vorgängen aus dem Ieben der Natur oder aber aus anderen Lebenssituationen gegenüberstellen. Ein hyperbolischer Zug ist vielen Vergleichen eigen und ist nicht gattungsspezifisch zu bewerten.

Der Kaiser: "vozrykav jako lev" $3064 / 6,71 / 11$, der Lärm, den die Türken mit ihren Instrumenten vollführen (70/15) und eine Serie von Explosionen (64/7) erscheinen wie " burja silbnaja", die Türken "sovachu na nich, aki

Inhalte - s. V.F. Adrianova-Feretc: Očerki poètičeskogo stilja Drevnej Rusi. M-I 1947 (weiterhin zitiert als: Adrianova-Feretc, Očerki), S. 102 - 109.

In der Pleskauer Erzählung wird Gott kaum genannt. Alles geschieht vor allem durch die Gottesmutter und die Heiligen, seltener durch Christus. In der K-pler Erzählung ist das Verhältnis des Autors bzw. der Menochen zu Gott viel inniger, viel direkter. - Hier wäre an einen Religionsgeschichtler die Frage zu richten, $o b$ in diesem klaren Unterschied des Gottesverständnisses und Verhältnisses zu Gott ein Hinweis auf die $\mathrm{K}$-pler Erzählung zu sehen ist - ob vielleicht die byzantinische Orthodoxie den direkten Zugang zu Gott nicht in dem Maße durch Heilike und die Gottesmutter verbaut hat, wie sich dies im Pleskauer Text äuBert.

30) "lev" - vgl. Adrianova-feretc, Očerk1, S. 87 f. Abgesehen davon, $d a \bar{B}$ die Löwenmetapher bereits in der ant1ken Literatur eine große Rolle spielt und daher auch in den entsprechenden bersetzungen ins Altruss. erscheint, finden wir dies Bild bereits in der Hyp.-Chr.(s.8. 1202). 
div11 zver1" $(67 / 4)$. (Hier kann man von Hertneutralität allerdings nicht sprechen. 31 ) In $74 / 46$ ist dieser Vergleich noch ausgeweitet:

$74 / 46$ "(turci) sovachusja na vse strany, aki divi1 zveri, Išča sebe lovu cesarja."

Der Vergleich des vergossenen menschlichen Blutes ist schon ein Topos in der ältesten Kriegsliteratur: "krovb ich tečaše, jako reky po stenam" $62 / 15$; im folgenden Vergleich hat, so scheint es, der Autor (d.h. hier ganz sicher der tbersetzer - es handelt sich um die Vislo Danie118) dieses Bild ganz automatisch angewand, obgleich es an dieser Stelle gar nicht paßt, offensichtlich inspiriert durch das einleitende "potekut" :

$77 / 32$ "potekut (jazyc1)... po ... ul1cam Sedmocholmago jako reki krovi čelovečeskyja, 1 vozmutitsja more ot krovi ..."

- Die Heiden werden durch die Straßen der Slebenhügeligen strömen wie Ströme menschlichen Blutes, und das leer wird aufwallen vor lauter Blut ...'

Geradezu klassischen Charakter trügt die folgende $\mathrm{Be}-$ schreibung, die allein aus tradierten Bildern besteht:

$62 / 18$ "...; 1 napolnišasja rvy trupija čeloveča do verchu, jako črez nich chodlt 1 turkom, aky po stepenem, 1 bitiss: mertvyja bo im bjachu most 1 lestnica $k$ gradu. Tako 1 potoci vsi napolnišasja 1 bregy vkrug grada trupija, 1 krovi $1 \mathrm{ch}$ aky potokom silsnym tešči,..., 1 voblizu rvov po dolijam napolnitisb krovi: ..."

31) "divi1 zver1" s.0. Anm. 30 - bereits in der ins Altruss. übersetzten Literatur, aber auch in originalen altruss. Texten. Sehr hëufig benutzt von Ivan Gr. Vgl. Adrianova-Peretc, Ocerki, S. 87 und 93. 
'...; und es füllten sich die Gräben mit Gefallenen bis an den Rand, so daß die Türken auf ihnen gehen und kämpfen konnten wie auf Stufen: die Toten dienten ihnen als Brücke und als Leiter zur Stadt. Auch die Bäche und die Ufer um die Stadt füllten sich mit Toten an, und ihr Blut floB wie ein starker Strom dahin, und die Niederungen in der Nähe der Gräben füllten sich ebenfalls mit Blut.'

Die vorige Schilderung erinnert an viele tiendungen bei Josephus Flavius: 32

"Krovb so zabral tečaše, jako rěka. I moglb by kto po trupija vlèzti vb grad, jako po stepenem."

ius der. Juidischen $\mathrm{Krieg}$ ist auch der folgende Vergleich bekannt :

62/14 "padachu bo trupija oboich stran, jako snopy s zabral"

- Die Gefallenen beider jeiten fielen von den Zinnen wie Garben.'

Eei Josephus Flavius lesen wir:

"I bystb viděti padajušči židy, aky snopy, so zabral." 33

Vergleiche, welche man daraufhin überprïfen müßte, ob sie vom Autor oder lbersetzer selbst geschaffen oder aber ibernommen wurden, sind die folgenden, die uns in der altruss. Ubersetzungsliteratur nicht begegnet sind:

74/4 "pobiša ich gražane bezčisleno, zakalachu bo ich aki svinej" - 'stachen sie ab wie Schweine'.

Hier muß man weiter fragen, ob der Autor den Vorgang des 'Abstechens' veranschaulichen will oder aber eine evt. bereits vorhandene pejorative Bedeutung von 'Schwein'

32) Istorija iudejskoj vojny Iosifa Flavija v drevnerusskom perevode. Hrsg. N. A. Mescersk1 J. M. - L. 1958. S. $304 / 31$. VGl. auch $343 / 28$ "I chodjachu po nich (= po trupija), akj po mostu."

33) Vgl. auch idrianova-Peretc, Očerki, $S .70$, die diese Formel in der tbersetzung des "Trojanischen Krieges" vorfindet. 
auf die Türken übertragen $\$ 111$.

Eine der Tundererscheinungen, die den Untergang der Stadt vorauedeuton, ist ein merkwirdiger Regen - es fallen rie8ig grobe rote Tropfen, die lange nicht wegflieben, sondern liegenbleiben. Der Autor vergleicht sie erst einmal mit dem toposhaften "ak1 slezy", erläutert dann aber:

73/22 "aki Blezy; kapli velicy, podobnye veličestrom 1 vroron bujivalbnomu oku, čerlenu ..."

' In GröBe und Aussehen Büffelaugen ähnlich - rot ...'

In jüngeren Texten finden wir gelegentlich den Vergleich "jako pijani1". 34

74/19 "1znemogachu i padachu, aki pijani "

'marden schwach (sicher: schwankten) und stürzten wie trunken'.

Diesen zumeist also in der traditionellen Kriegserzählung wrzelnden Vergleichen stehen auch einige entsprechende in der Pleskauer Erzählung gegenüber:

66/4 "Oni že naporne 1 deržostne 1 nadežne $k$ gorodu idjaše, Jako nogaja voda k gorodu Ibjašesja;

strašlliščami že svoimi, jako volbnami morskimi ustră̌ajušč ;

sabljami že svolmi, jako molnijami besčislenymi na gorod svekčjušče."

- Wie vieles Wasser strömten sie der Stadt entgegen, mit icren Ungeheuern entsetzten sie, wie (durch) Meereswogen die (Stadt),

34) VGl. z.B. auch Pleskauer Erzählung 37/35; "Povests o razorenil Rjazani Batyem" in: Voinskie povesti Drevnej Rus1, Hrsg, V. P. Adrianove-Peretc, $M_{-}-\mathrm{L}$. 1949 (we1terhin $21-$ tiert als: Rarianova-Peretc Voinsicie povest1) $S_{1} 13$ und S. 27; "Kn1ga stepennaja carskogo rodoBlovifa". ‥ Bd.. PSRL $\}_{1 / 1}$, SPb 1908 (we1terbin zitiert als "Stepennaja kniga") S. 530 (viertletzte Zeile). 
mit ihren Säbeln funkelten sie wie (mit)

zahllose (n) Blitze (n) zur Stadt.'

Sinngemäß finden wir eine ähnliche Wendung im "Skazanie o liamaevom poboiščen :

"Ot mečnago sverkanija jako solnce protivu zari

bl1stajasja, ..."35

"Dospechi že ruskie aki voda morskaja ot vetra kolybašesja, a šelomy na golovach - jako zlatom utrennjaja zarja vo vremja vedra svetjaščesja. Elovcy že šelomov ich ak1 plamenb ognen." 36

Das letzte Beispiel aus der 'Mamaj-Schlacht' zeigt noch einmal deutlich, wie habitualisiert bestimmte Vergleiche sind.

Sehr beliebt ist das Bild von den Pfeilen, die so dicht geflogen kommen, daß sie (manchmal zusätzlich:'wie eine Nolke') das Licht verdunkeln. Im folgenden ist dieser Vergleich kombiniert mit einem anderen: die Vielzahl der Pfeile ähnelt einem dichten Regen.

69/7 "načaša streljat1 iz okon po chrestbjanskomu narodu, ... jako ot vel1ka doždevna oblaka ručbnymi pulbkami, jako besčislenymi krapljami narod polivajušči i jako zmlinymi žalami chrestbjan umorjajušče."

Das'Zeitalter der Feuerwaffen zeigt sich im Ersatz der Ffeile durch die Gewehrkugeln (vgl.dtsch. 'Kugelregen'). - Neben den $\mathbf{z w e i}$ in der Kriegsliteratur längst beheimateten Vergleichen steht als dritter das die feindliche, die litauische Seite begleitende B1ld von der Schlange/Drachen: 'wie mit Schlangenstacheln' - gemeint sind wohl die geteliten Zungen der Schlangen oder die Giftzähne.

Vgl. hierzu aus dem 'Jüdischen Krieg' des Josephus Flavius:

35) "Skazanie o Mamaevom pobolšce" in: Russkie povesti 15- 16 vekov, Hrsg. M. O. Skripil' M. -L. 1958, S. $16-38$ (weiterhin zitiert als: "Skazanie o Mamaevom poboisče"), S. 33 (Mitte).

36) ebda. S. 29 (letztes Drittel). 
301/15 ".... strély pomračlša světz."

$343 / 24$ "I strèly na nich lětachu, jako doždb."

Und in der Alexandreis lesen wir: (S. 181.49$)^{37}$

"Togda videt1 strely, letjaščaja vo grad, jako oblak."

Die hyperbolische Aussage, daB s1ch Gräben, Flüsse u.a. m1t Leichen füllten, gehört auch zum klassischen Instrumentarium der Krlegserzählung:

73/7 "... 1 telesami svoimi pskovskij velikij rov napolniša." 343/27 "I pomoščenb bystb Iordan truplemb." (Jüdischer Krieg)

Wenn gesagt wird, daß die Leiber der Toten den Hunden zum Fraß dienten, so wird damit darauf angesplelt, daB es zur alten kriegerischen Tradition gehört, seinen gefallenen Mitstreiter $z u$ bergen und ihm eine würdige letzte Ruhestätte zu geben, zumindest inn würdig (mit Gebet bzw. anderem religiösen Ritual) zu bestatten. Dienen also die Leiber der Gefallenen den Hunden (Schakalen) zum Fraß, dann ist deren Zahl so groß, daB sie nicht geborgen werden können:

$81 / 1$ "..., no telesa lch na snedenie psom vdašasja." $337 / 22$ "I nynè poverženi sutb naz1 na snĕdenie psom 1 zvĕremb."

SchlieBlich sei noch an einen direkten Verweis auf Alexander d. Gr. erinnert:

68/18 "uy že, gosudarju, tvoja raby, Jako že Aleksandra carja 12 Rima, $s$ troego velikago grada Pskova slavno že stretim $i$ pobednye, mnogochvalbnye pesni prinesem ..."

Bereits in der Alexandreis treffen wir das Bild von den herausgerissenen Weizenähren, mit denen der Tod, das Töten in mancherle1 We1se verglichen wird; Pleskauer Text:

70/2 "I be videt1 chrestbjanskie glavy, fako pšenlčnye klas. ot zemlja vosterza.jušcis la 1 tako $2 a$ christovu veru skončevašesja."

37) "Aleksandr1ja". Roman ob Aleksandre Makedonskom po maskoj letop1si 15 v. Hrsg. M. K. Botvinnik, Ja. S. Lurie, und 0. V. Trorogov (weiter zitlert: "Aleksandrija). 
Und in der Alexandreis heiBt es: (S. 19 1. 51)

"..., videch aky klas pšeničnoe izrastajušča 1 maktdonjane serpy aki žnušče zreloe 1 zelenoe."

'.... ich sah (Alexander) gleichsam die Heizenähren herausreißen (vermutlich: "klasy pšeničnyja") und die Makedonier mähen wie das Reife und Grüne mit Sicheln.'

Der folgende Vergleich, erweitert und wieder aufgenommen, erinnert etwas an eine Stelle der 'Mamaj-Schlacht':

$88 / 23$ "..., pugami že temi 1 ostrymi krjukami, jako jastrebimi nosy is-pod kustovbja i na zavodjach utjata izvlačachu, ...; strelbcy že, jako belye krečaty sladkij lov, iz ručnic telesa ich klevaše ..."

'...., mit Hilfe ihrer mit spitzen Haken versehenen Peitschen holten sie diese (= Litauer) unter der Mauer hervor wie junge Enten unter dem Gebüsch oder am Ufer, ...; die Schützen aber zerpickten/zerhackten ihre Körper mit ihren Flinten wie weiBe Jagdfalken ihre Lieblingsbeute...'

Die entsprechende Stelle in der 'Mamaj-Schlacht' ahnelt nur sinngemäß dem im Pleskauer Text evozierten bild:

"I poskočiša iz dubravy zelenyja, aki jasnyja sokoly ot zlatych kolodiic na žaravlinoe stado, ..."38

Einige Vergleiche scheinen aber auch entweder vom sutor selbst ersonnen oder aber aus der volkstümlichen sprache in den Text eingebracht zu sein, so z. B.:

$43 / 2$ "... grad vaš Pskov, jako kamenem žernovym obratiti sego imam ..."

'... werde ich wie einen Mühlstein wenden (gemeint sicher: auf den Kopf stellen)'

40/25 "voskolebašesja, bezsilbni že sebja, jako mravie znajušče " - ... wie Ameisen ...'

$61 / 33$ "...k gorodu približšesja, kopljušče že 1 rojušče zemlju, jako kroty; ..." - '... wie Maulwüfe ...'

38) "Skazanie $\circ$ Mamaemom poboišče", S. 34 (Anfang des zweiten Drittels). 
$66 / 21$ "..., šc̆1tam1 že 1 .... kopbjami, jako krovlełu, zakryvajuščesja."

Die meisten Vergleiche varileren die bereits bekannten Metaphern und Epitheta wie:

Stolz und Prahlerei,

Schlange/Drache - Gift - Hölle usw., Tierwelt.

Antonius Possevino, dessen Bezeichnung als Lutheraner bereits erwähnt wurde, wird folgendermaßen charakterisiert:

91/29 "Protopop ze tof Antonej Ichnilatovo lukavstvo $i$ vse jako zbojlivgla lisicy lestb v sebe vozpriemlet,..."

Das Fabelwesen Ichnilat ist eine höchst zweifelhafte, intrigante Gestalt, die mit dem Beiwort "lukavyl" recht treffend charakterisiert ist, und auch die Hinterlist der Füchsin scheint bereits sprichwörtlich $z$ u sein.

Die livländischen Deutschen wenden sich an Fürst Andrej Kurbskij, er möge sich beim polnischen König für sie einsetzen. Kurbskij ("s tovarı̌čil") und Genossen versprechen, "jako želatelbni eleni" (wie die brunftigen Hirsche) mit ihrem Flan ("ijud(e)jskom sovetom") an den König heranzutreten $(41 / 5,-/ 7)$.

Hatten die litauischen lürdenträger den König mit Alexander d. Großen verglichen - womit der Autor die Großsprecherei, Prahlsucht der Litauer und inren Hochmut demonstrieren will,. so ist seine historische Bewertung des Feldzuges Stephan Báthorys natürlich anders: In einem weitausholenden Vergleich erinnert er an den assyrischen König Sanherib, der Jerusalem erobern wollte und dabei zuerst sein Heer und dann sein Leben verlor: die göttlichen Heerscharen hatten eingegriffen $(53 / 12 \mathrm{ff.}) .39$

39) Vgl.Jesaja 37/36-38. Diese Erzählung erfreut sich in der altruss. Literatur groBer Beliebtheit. Vgl. "Povestb o Temire Aksake", in: Russkie povest1 $115-16$ vv., S. 49-54, S. 53. Nikonovikaja letopisb, PSRL 13, S. 193 unten. 
Schließlich finden wir noch einen groB angelegten Vergleich der Situation Pleskaus mit derjenigen Moskaus, als Moskau von'Temir Aksak (= Tamerlan) 1395 bedroht wurde und die Translatio der Muttergottes-Ikone von Vladimir nach Moskau die Rettung brachte. Der Uberführung der Mariae-Himmelfahrts-Ikone vom Pleskauer Höhlenkloster in die Stadt wird nun eine ähnliche Wirkung zugeschrieben:

73/33 "Jako že čjudotvornuju svjatuju 1konu prečistuju bogorodicu,

1 . Volodimera v carstrujuščij grad Moskvu, rachožzenijła radi Temiru-Aksaka carja. Zde že $v$ bogom spasaemom grade Pskove nachónžñija radi polbskago kralja. Tamo, jako imjanitago Koltyri, zde že proimennago Obotury; tamo že po vladimerskuju ikonu, zde po pečerskuju 1konu;

tamo, jako ponesena presvjataja ikona iz Vladimera na Moskvu v samyj bogorodicyn praznik Uspenbja, togo_że_dni 1 Temir-Aksak carb usramisja, ot precistago obraza nevidimo ubojasja $i$ so vsem voinbstvom ot Moskvy 1 so vsea Kusii pobeža;

zde že $v$ preimenitom $i$ slavnom grade Pskove $v$ samyj eja že bogorodicyn praznik, čestnago i slavnago eja rožestva, egda ponesena bystb čjudotvornaja ikona uspenbja ...,

togo으르돈 1 otrada Pskova nevidimo javisja na prolome."

Dieser Vergleich ist durch Antithesen, antithetische Anaphern und 1sokolonartigen Aufbau gestrafft. Wir haben es an dieser Stelle mit einem der dichtesten, expressivsten Abschnitte der Pleskauer Erzählung zu tun. ${ }^{40}$

40) Die beiden angeführten Beispiele aus der Geschichte (Sanherib und Temir-Aksak) würde Lausberg, Handbuch $I$, $\$ \S 410-26$, als "Exemplum" bezeichnen. 
Die christliche Seite ist nur mit bekannten, tradierten Vergleichen bedacht, wie wir das auch schon bei der Metaphorik konstatiert hatten: so sind die Fleskauer hingemetzelt worden "Jakože drevnie mučeniki ... ot mučitelbskich litovskich ruk" -'wie früher die Märtyrer von den Händen ihrer litauischen Peiniger' (80/2). An einer Stelle wird noch ein Bezug $z u$ Alexander Nevskij hergestellt $(85 / 32)$. In einem Kampfbericht wird das christliche Heer mit "zvezdy nebesnye" verglichen (66/29). Hier handelt es sich sicher um einen Terminus aus der Vitenliteratur.

Stellen wir abschließend die Bildersprache unserer beiden Texte nebeneinander, so dürfen wir festhalten, daR sich die Vergleiche in der K-pler Erzählung fast aussch:ießlich in den Bahnen bewegen, welche die traditionellen Kriegsberichte und -erzählungen bereits gewiesen hatten. Auch in der Fleskauer Erzählung ist das traditionelle Vokabular bzw. Vergleichsmaterial nicht zu übersehen. Jedoch dominieren hier bildsprachliche Elemente, deren ivurzeln vermutlich in der hagiographischen Literatur ${ }^{4}$, möglicherweise auch in mythischen quellen zu suchen sind. wenn auch nicht besonders zahlreich, so aber doch mit einer Anzahl von Beispielen vertreten, sind in der fleskauer Erzählung Vergleiche vorhanden, die offensichtlich der Umgangssprache entstammen.

Da also der Pleskauer Autor aus so verschiedenen Quellen seine Bilder bezieht und diese eigenständig weiterentwickelt, herrscht in der Pleskauer Erzählung eine Vielfalt und Buntheit der bildsprachlichen Elemente, neben welchen die meist wohlbekannten, z.T. toposhaften Hendungen im K-pler Text oft abgegriffen wirken.

41) Stender-Petersen, Geschichte, S. 201, vermutet, daB das Bild vom Drachen aus der hagiographischen Literatur stammen könnte. 


\section{Zusammenfassung}

Unsere belden Texte kontrastieren einander in jeder Hinsicht. Während der K-pler Text elne Fülle von Informationen auf engstem Raum bletet und beim Leser/Hörer durch das reine Geschehen innerliche Anteilnahme erwecken will, versucht der Pleskauer Autor darüber hinaus, durch eine Vielzahl st1listisch-rhetorischer Mittel die emotionale Bete1ligung des Lesers/Hörers zu steigern.

Der K-pler Autor bevorzugt eine knappe Ausdrucksweise, die allerdings eine Vielzahl synonymer Formulierungen zuläft, die sich kaum wiederholen, stets also den Reiz des Neuen haben und geradezu von einer virtuosen Beherrschung der Sprache zeugen. Auch bezeichnet er verschiedentlich handelnde Personengruppen durch 2 wei (manchmal auch dre1) byzantinische Nürden ( "megistany 1 magistry", "stratigy $i$ velbmožı" usw.).

Ist für den K-pler Text die Informationofulle charakteristisch, so ist Redundanz in der Darstellung bezeichnend für die Fleskauer Erzühlung. Der Autor verwendet einen bestimmten Kodex von Leerformeln: formelhafte Bezeichnungen der handelnden Personengruppen in einem solchen lbermaB, das keinen Vergleich mit den entsprechenden Benennungen im K-pler Text zuläßt; vielgliedrige Epitheta ornantia vor der Nennung Moskaus, Pleskaus, vor allem des Zaren, der Bojaren und der Pleskauer - ebenso wie vor Namen oder Titel des polnischen Königs, des litaulschen Heeres usw. Im K-pler Text 1st das Epltheton ornans so gut wie unbekannt. In der K-pler Erzählung spüren $⿴ 囗 1)$ an elnigen Stellen die Andeutung rhythmisierter Sprache: an Stellen mit sich überstürzender auch für dle Gosamterzählung besonders relevanter Handlung (Kampfszenen, aber auch das Betreten der Stadt durch den Sultan; ebenso, wenn dlesem das Haupt des Ka1sors gebracht wird). Die Rhythmisierung erfolgt in der Neise, daB die Sätze parallel gebaut (Prädikat plus Ergänzungen) und zlemlich kurz sind, wobel sich die Zahl der 
Ergänzungen in den zur Periode gehörigen Kola nicht allzu sebr unterscheidet.

Ist in der K-pler Erzählung rhythmisierte Sprache gerade als Andeutung spürbar, so wird im Pleskauer Text dem Leser, vielmehr noch dem Hörer, der Rhythmus der Sprache geradezu aufgezwungen. Dazu bedient sich der Autor zwar ebenfalls parallelen Satzbaus, aber mit dem Unterschied, daß er verbalen Reim gebraucht, also das Verb an den Schluß des Kolons stellt. Die ohnehin schon $z$ wingende Kraft des verbalen Reims wird häufig noch verstärkt durch Anapher bzw. als Anapher fungierende Nortpaare ("ovii - inii"). Die Fülle beteutungsentleerter Vendungen (Formeln, Epitheta) im Verein mit rhythmisierter Sprache lenken sehr oft vom Geschehen ab und führen dazu, daf sich der leser dem Klang der Sprache zuwendet und emotionaler Beeinflussung zugänglich wird.

Deutliche formale Gestaltung der iprache ist im $K-p l e r$ Text in den konologen zu konstatieren; es ist möglich, sie fast in ihrer Gänze in parallel oder chiastisch gefügte Kola aufzugliedern. Diese strenge Form gibt den Rahmen für Ausrufe, Apostrophen (zumeist an Gott) oder pointierte Antithesen. Letztere finden wir auch im Fleskauer Text in groBer Zahl, doch neben einigen beispielhaft aufgebauten, straf $f$ formulierten Antithesen sind die gedanklichen Gegensätze in der hiehrzahl der Fälle formal nicht gestaltet. Dafür stoßen wir in der Fleskauer Erzählung ständig auf Einzeliort-Antithesen, die durch den semantischen Gegensatz auf engstem Raum sehr effektvoll sind und sicher den Zweck haben, den Leser emotional anzusprechen. Diesem $Z$ weck dienen auch bestimmte Auswahlkriterien für den ̈̈ortgebrauch im engeren kontext: hundertfach Paronomasie ("fig. etym." vom Typus "nakazanbmi nakazati") sowie kaum vorstellbare, durch Zusammensetzumg entstandene Neologismen ("mertvotrupogljadetelbny"). - Im K-pler Text fehlt diese affektische Figur fast vollkommen.

Die Monolge im Fleskauer Text haben ein ganz anderes Aussehen als die in der K-pler Erzählung. Von formaler Gestaltung ist bis auf einige (allerdings wirkungsvolle) Stellen 
nicht viel zu spüren - im Gegenteil: der Autor appelliert dort fast ausschlieblich an die Emotionen des Lesers - die rhetorische Frage "peitscht die Affekte ... auf".

Darüber hinaus finden wir in den Monologen nicht nur inrufungen der Gottesmutter und der Helligen - viel effektvoller sind die Apostrophen an den polnischen König, in die der Autor Spott, Ironie und Triumph legt - der Autor gebraucht eine pathetische Sprache, vermischt aber auch mit volkstümlichen iendungen ("Elava nogam beseduet, gospodin rabu svoju čestb otdaet" $92 / 25 \mathrm{z.B.}$ ) und vor allem einer Vielzal.l von Bibelzitatea, die dem Gesagten Authentizität und iutorität der biblischen Aussage verleihen soll. 42 Bis zum gewissen Grade äußert sich in der gecensätzlichen Diktion, die wir an unseren Texten beobachten, auch die Eecensätzliche Grundstimmung: Trauer, Resignation, schwache Ioffnung (= Frophezeiungen) hier - dort Triumph, Freude, Dankbarkeit.

Die Zurückhaltung, die wir beim K-pler Autor gegenüber allen lleuerungen beobachten (z.B. umganessprachliche Formen), zeict sich auch in seinem Verhältnis zur Bildersprache, die sich fast ausschließlich aus bereits zu Topoi cyewordenen Bildern der traditionellen kriegserzählung zusammensetzt. Dieses ilement fehlt auch im ileskauer iext nicht, doch tritt es weit zuruck hinter einer ungemein wirkungsvolien, Im Wesentlichen auf dem Wortfeld "Schlange/Drache" beruhenden

42) D. S. Lichačev: Poét1ka drevnerusskof l1teratury. L. 1967. S. 95: "Avtory stremjatsja vae vvest1 vizvestnye normy, vae klassifizirovat', sopostavit's izvestnymi glucajami iz svjašcennoj 1storil, snabdit' sootvetstrujusćimi citatami iz svjascennogo pisanija 1 t.d. Srednevekovyj piastel' ïcet precedentov $v$ prošlom, ozabocen obrazcami, formulami, analogijami, podbiraet citaty, ..."

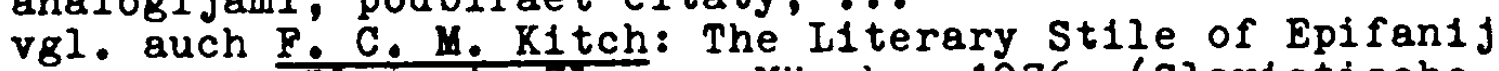
Premudryj. Pletenie Sloves. Munchen 1976. (Slavistische Be1träge. 96). S. $131-142$. I. Talev: Some Problems of the Second South Slavic Influence fluence in Russia. Munchen 1973. (Slavistische Beiträgo. $67)$. S. $32-59$. 
Bildersprache sowie verschiedenen Vergleichen und Metaphern, die sicher aus der Volks- bzw. Umgangssprache übernommen worden sind.

Der K-pler Autor versucht auf folgende Teise, seine Absichten zu verwirklichen: 1) den Leser durch detaillierten Bericht innerlich anzurühren, zu erschüttern; 2) durch feierlichstrenge Sprache und straff gegliederten Satzbau zu belehren und mit Hoffnung auf das Wiedererstehen der Stadt zu erfüllen.

Der Fleskauer Autor dagegen bringt dem Leser sein ideologisches Konzept - die Glorifizierung des Zaren - dadurch nahe, daß er neben einer sich an den tradierten literarischen Vorstellungen orientierenden allgemeinen Ausrichtung des Textes eine grobe Zahl volks- und umgangssprachljcher Elemente in die krzählung hineinnimmt, die den Leser/Hörer direkt angesprochen haben dürften. Dazu kommt die Bevorzugung solcher rhetorischer Mittel, die auf ieckung von Emotionen abstellen. So finden wir oft ein wirres Nebeneinander von traditionellen und ungangssprachiichen Elementen als littel rhetorisch-affektischer ausdrucksweise.

Stellen wir abschließend die beiden Erzählungen in ihren literarischen kontext - wir können leider nicht näher darauf eingehen -, so ist $z u$ bemerken, $d a B$ beide Texte $z$ war nicht typisch für ihre Zeit sind, diese aber dennoch in gewisser Weise charakterisieren.

Das sprachliche und stilistische Niveau der K-pler Erzählung liegt weit über demjenigen der meisten zeitgenössischen (Ende 15. Jh.) ilerke. Dennoch kann man die K-pler Erzählung als dem sprachlichen Ideal inrer Zeit - dem Kirchenslavischen - entsprechend ansehen. Andererseits widerspricht die konzentrierte Darstellung (weitgehend ohne offektische Ausschmückung) der Tradition des Zwe1ten Südslavischen Einflusses, dessen emotionaler Vitenstil um diese Ze1t sehr lebendig war. (Pachomif Serb starb erst um 1480.) Die Frage, ob wir|ln der K-pler Erzählung eine Ubersetzung vor uns haben oder nicht, könnte beisplelsweise an diesem 
Funkt ansetzen.

Die.Fleskauer Erzählung ist in diesem Sinne charakteristisch für ihre Zeit, als sie wie in einem Zerrspiegel, wie eine harikatur, viele zeitgenössische sprachliche und auch literarische irscheinungen in sich vereinigt. "ir finden jenen omotionalen Stil, der für die lleskauer irzählung so charakteristisch ist, nicht allein $\vdots n$ den Viten, sondern auch in den hagiographischen lassagen aller Genres, besonders der Chronik-hompilationen (Stepennaja kniga, iikon-Chronik, nicht so sehr im I'vovskij Codex). Das Eindringen der Umgangssprache ist ebenfalls ein Zeichen der Zeit und kann selbst in den konservativsten Schriftzeugnissen verfolgt werden. In welchem iral:e dies in der Fleskauer irzählung stattfindet, konnten wir an vielen Erscheinungen auf den Gebieten der Phonetik und der Morphologle beobachten (Polnoglasie, häufiges "roz-" fur ksl. "raz-", weitgehende Aufgabe der Palatalisationen im Bereich der Deklination;

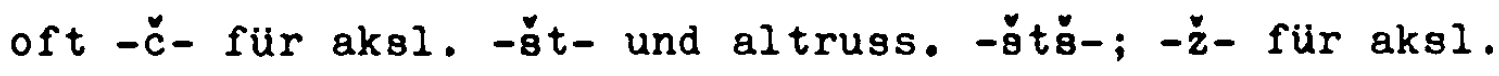
und altruss. $-\check{z} d-$, Assimilationserscheinungen usw.; insbesondere bei der Flexion des pronominalen Adjektivs starker Anteil von solchen Formen, die auf die modernen Endungen weisen u.a.). Vor diesem Hintergrund fällt der intakte ksl. Formenbestand in der Erzählung über die Eroberung $\mathrm{K}$-pels ganz besonders ins Auge. 
E. DAS VERB

\section{Zur Literatur über den Gebrauch des Verbs im 16. Jahrhundert}

In der Entwicklung des russischen Verbalsystems bildet das 16. Jahrhundert einen Zeitraum des Umbruchs. Zwar war das alte, aktionsartorientierte Verbalsystem nicht mehr lebendig, zwar sind überall die Anzeichen der Aspektualisierung erkennbar, aber das alte Formensystem, wie wir es in den aksl. und den frühen altrussischen Texten antreffen, lebt in verschiedenen Gattungen fort.

Wie die Normen der gesprochenen Sprache waren, wissen wir ungefähr aus einer Gruppe von Quellen, die wir einmal 'profan' ("delovoj") nennen wollen - Akten, Urkunden, Privatbriefe ("gramoty" und "gramotki"); in diesem Zusammenhang sei z.B. nur an die Birkenrindenurkunden erinnert. Eine gehobene oder sogar literarische Form dieser an der gesprochenen Sprache orientierten "delovaja pismennost" repräsentieren die Novgoroder und die Pleskauer Chroniken.

Den 'profanen' schriftlichen Zeugnissen stehen diejenigen gegenüber, die der literarischen Tradition verpflichtet sind: die geistliche Literatur, $d . h$. Predigt, Vita (von Heiligen und Fürsten), offizielle und offiziöse Sendschreiben, z.B. jene des Mönches Filofej von Pleskau, in denen er seine Vorstellungen von Moskau als Drittem Rom entwickelt; schließlich das weite Feld der offiziellen und offiziösen Literatur, vor allem der Makarij-Ära : Lesemenäen, historiographische Kompendien, die gesamte sich in die moskovitische Ideologie einfügende Literatur - sei es historische Erzählung, sei es jener Bereich, der meist mit "publizistischen Tendenzen"l umschrieben wird.

1) Stender-Petersen, Geschichte, S. 202 f.; Gudzij, Ist. dr. russ. lit., S. 332 ff.; Efimov, Ist. russk. lit. jazyka, S. $64 \mathrm{f}$. 
Jener sich an der literarischen Tradition orientierende sprachliche Stil wird in der Sovjet-Union generell "knižnyj" oder als der "knižnaja tradicija" verbunden bezeichnet. Wir wollen hier von 'literarisch' oder, an "knižnyj" anknüpfend, von 'buchsprachlich-archaisierend' sprechen. 2 Selbstverständlich ist immer mit Beeinflussungen zu rechnen, vor allem mit dem EinfluB der gesprochenen Sprache auf die Schriftzeugnisse, die sich sprachlich an der literarischen Tradition orientierten.

Lange Zeit hat man die Iiteratur des 16. Jahrhunderts nur allgemein charakterisiert, indem man auf den Ubergangscharakter der Epoche hinwies und an Hand von einigen Beispielen das Nebeneinander kirchenslavischer und umgangssprachlicher Normen belegte. SchlieBlich erschien 1952 S. D. Nikiforovs Monographie uber das Verb, seine Kategorien und Formen in der 2. Hälfte des 16. Jahrhunderts. ${ }^{3}$ Es handelte sich hierbei um einen besonders glücklichen Umstand, der darin bestand, daß

S. 65. - Dieser Terminus, der sich durchgesetzt hat, umfaßt z.B. die Nerke Peresvetovs, Ermolaj-Erazm a, aber auch die Sendschreiben Ivan Groznyjs, sein Briefwechsel mit Kurbskij, wobei aber darauf hinzuweisen ist, daß gerade die Schriften Ivan Groznyjs viele umgangssprachliche Elemente enthalten (vor allem die Schreiben an das Kloster am NeiBen See oder an den Opričnik Vasilij Grjaznoj, der in tatarische Gefangenschaft geraten war).

Vom sovjetischen Interesse an der Sprache Ivan Groznyjs zeugen die vielen lexikologischen Arbeiten darüber - vgl. V. N. Rogova: Slovo-obrazovatel naja sistema russkogo jazyka v 16. v. Krasnojarsk 1972. (diese Arbeit befaBt sich nur mit der Sprache Ivan Groznyjs.) S. 9 Anm. 2l: verweist auBer auf sechs eigene noch auf sieben weitere Arbeiten z.T. Monographien - zu diesem Gegenstand.

2) Kiparsky, Russ. hist. Gram., S. 22l z.B. spricht von "Buchform", wenn er diese traditionalistische Buchsprache bzw. Literatursprache meint; Xernych und seine tbersetzer ungehen diesen Terminus und unterscheiden zwischen 'altruss. Literatur- und altruss. Umgangssprache', Hist. Gram. russ. Spr., S. 221. Fred Otten, Die fin. Verbalformen, gebraucht ständig, erstmals auf $S$. 4, 'buchsprachlich'.

3) S. D. Nikiforov: Glagol, ego kategorii i formy v russkoj pismennosti vtoroj poloviny 16. veka. AN SSSR M. 1952. (weiterhin zitiert als: Nikiforov, Glagol). 
Nikiforov allen Tendenzen in der Sovjet-Union zum Trotz, Sprachbetrachtung allein vom Standpunkt des Eindringens der russischen Volkssprache in die Literatursprache zu betreiben und dementsprechend auch das Material, das man betrachtet, auszuwählen ${ }^{4}$, beide Aspekte des russischen Schrifttums im 16. Jh. berücksichtigt hat. Er bezieht nicht nur Urkunden, Chroniken oder Akten in seine Untersuchungen ein, sondern ebenso, wenn nicht in noch stärkerem viaße, werke der traditionalistischen Richtung, vor allem die Kazanskaja Istorija, den Briefwechsel Ivan Groznyj - Kurbskij, Povests o Fetre i Fevronii, u.a. Die Fleskauer Erzählung gehört nicht zu seinen quellen. In seinen Betrachtungen berüchsichtigt er - verständlicherweise - keine neuen Chronik-Kompendien der Makarij-Ara. In seinem Bestreben, den Zustand der Sprache eines bestimmten Zeitraumes, also synchron zu beschreiben, mußte ihm daran gelegen sein, eine Vielfalt von werken der verschiedenen Gattungen und Stilrichtungen zu untersuchen. Das Ergebnis ist eine - sieht man einmal über die schematische Behandlung des Verbalaspekts ab - vor allem auch durch ihren Beispielreichtum überzeugende Arbeit.

Andererseits ist nicht $z u$ übersehen, daB die Arbeit eher Katalogcharakter hat: Alle Kategorien werden abgehandelt, es finden sich auch gelegentlich Hinweise über den Gebrauch bestimmter Formen - etwa den vielsagenden Hinweis darauf, daB das Ipf. vorwiegend in "ierken angewandt wird, deren Autor sich der schriftsprachlichen Tradition verpflichtet wei $B^{5}$; die Part. präs.-Form -če, -ča, -ču (im Gegensatz zu -šče, -šča,-ščju) bezeichnet er als typisch für den geschäftliohen und sonstigen profanen Sprachgebrauch. Diese Formen deuteten auf ein EinflieRen umgangssprachlicher Elemente. ${ }^{6}$

4) E. N. Borisova: O sposobach obrazovanija imen suščstvitel nych $v$ pamjatnikach delovoj piśmennosti $16-18 \mathrm{vv}$. In: Materialy $i$ nabljudenija po russkomu jazyku. Ufa 1961. M. A. Selivanov : $K$ charakteristike 'delevogo stilja' $v$ drevneruskom Iiteraturnom jazyke. Krasnojarsk 1963. M. A. Sokolova: Očerki po jazyku delovych pamjatnikov $16 \mathrm{v}$. L. 1957.

5) Nikiforov, Glagol, S. $148 \mathrm{f}$.

6) ebda.S. $262 \mathrm{f}$. 
Solche allgemeinen Aussagen gewinnen natürlich auch nicht sehr viel dadurch, daß sie mit zahlreichen beispielen belegt werden. Dadurch, daB Nikiforov alle in einem bestimmten Zeitraum gebrauchten Verbalkategorien aufzunehmen sucht, verliert seine Monographie die Fähigkeit, einzelne Tendenzen zu bezeichnen, ganz bestimmte Entwicklungen zu beschreiben.

In eine ganz andere Richtung zielen zwei Arbeiten, die in letzter Zeit auf deutschem Boden entstanden sind. Sie untersuchen die verbalen Kategorien an einzelnen Werken und kommen auf diese Weise zu Ergebnissen, die $z$ war nicht verallgemeinsrt werden können, die aber den Vorteil haben, daB sie - im Gegensatz zu den vagen "allgemeingültigen" Aussagen, zu denen Nikiforov kommt - klar formulieren können, wie jede Kategorie angewandt wird.

Die erste Arbeit ist von N. Boretzky: Der Tempusgebrauch in Kurbskijs "Istorija velikago knjazja moskovskago". Diss. Bonn 1964. Der Autor stellt darin die Verwendungsmöglichkeiten der einzelnen Kategorien und ihrer Varianten beinahe thesenmäBig vor und belegt diese dann mit wenigen Beispielen. ${ }^{7}$ Er stellt fest, daB das 1-Part. die Hälfte aller Fräteritalformen in Kurbskijs "Istorija" bildet. Eine funktionale Scheidung 2 wischen ksl. Präteritalformen und dem l-Part. kann er nicht erkennen, vielmehr scheine es, als habe Kurbskij in Bereichen (Kriegsberichte), in denen er sich auf literarische Vorlagen stützen konnte, Aor. und Ipf. bevorzugt, dort aber, wo er über die Grausamkeiten Ivan Grozryjs berichtet, für deren Beschreibung er natürlich keine Vorbilder finden konnte - also eigenständig schrieb -, das 1-Part. benutzt. Ansonsten stellt Boretzky häufig falsche

7) Bereits Budich, Aspekt, S. 23, hat den Mangel an Beispielen speziell an dieser Arbeit kritisiert. Hieraus resultiert seine Forderung nach Vorstellung allen untersuchten Materials. Er bat zumindestens insofern recht, als die meist $z$ wei Beispiele für einen Thesenpunkt bei Boretzky kaum zur Demonstration ausreichen, geschweige denn Beweis- oder Uberzeugungskraft besitzen. 
formale Bildungen sowie häufig inadäquate Verwendung der Tempora - etwa das Ipf. an Stelle von Aor. - fest. An der Sprache Kurbskijs in der "Istorija" ist also deutlich zu erkennen, $d a B$ die alten Tempora verwandt werden, um dem betreffenden Werk ein bestimmtes stilistisches Niveau zu sichern - daB aber sogar Kurbskij, ein Mann von hoher Bildung, die alten Tempora formal und funktional nicht mehr sicher beherrscht.

Die zweite, jüngere Arbeit, befaßt sich mit den finiten Verbalformen in der "Stepennaja kniga": F. Otten: Die finiten 8 Verbalformen und ihr Gebrauch in der Stepennaja kniga carskogo rodoslovija. Berlin 1973.

Die Arbeit zeichnet sich durch große Materialfülle aus; der Autor scheut sich auch nicht, einmal einen größeren Abschnitt seines Textes in die Arbeit zu übernehmen, um eine bestimmte Verwendungsart einer Kategorie deutlich zu machen (Boretzkys Beispiele überschreiten selten die Länge von 1 1/2 Zeilen). Sehr häufig verweist der Verfasser auf Vorlagen, die der kompilator der "Stepennaja kniga" ausgeschrieben hat, oder aber auf jüngere Abschriften: auf diese weise gelingen hin und wieder diachronische Einblicke in bestimmte intwicklungen, z.B., wenn der Autor verschiedentlich beobachtet, wie der Kompilator bzw. Redaktor ein l-Fart. der Vorlage durch Aor. oder Ipf. ersetzt. Er stellt fest, daß der Gebrauch der finiten Verbalformen weitgehend der ksl. Tradition entspricht. Zwar ist stellenweise $z u$ beobachten, wie das BewuBtsein für die Funktion von Perf., Aor. und Ipf. schwindet - sie werden austauschbar - , doch ist ganz deutlich, daß der Redaktor sich bemüht, umgangssprachliche Formen (1-Part. als Er-

8) Auf Deckblatt und Buchrücken he1Bt es kurioserwelse: "Die finitiven Verbalformen ...". Auf dem Titelblatt helBt es dann aber korrekt: "Die fintten Verbalformen und ...". - Vgl. auch die Rezension dieser Arbeit von H. Keipert in: ZofSIPh 38 (1975). S. $394-397$. 
satz für Ipf.) zu meiden. 9

Angesichts der ungeheuren Materialfulle, die Otten zu bearbeiten hatte, ist es verständlich, daB er sich auf die Behandlung des Verb.fin. beschränkte und die Partizipien nicht in seine Untersuchungen einbezog. Doch hätte er unbedingt von vornherein deutlich darauf hinweisen müssen, dab in der "Stepennaja kniga" die aktiven Partizipien eine ganz bedeutende Rolle spielen (m.E. machen sie mindestens 25 v.Hd. aller verbaler Formen aus) und offensichtlich sehr oft in die Funktion eines Verb.fin. eingerückt sind, was als zusätzlicher Hinweis auf Unsicherheiten im Gebrauch der bevorzugten ksl. Verbalformen zu werten ist.

Otten fuhrt die finiten Verbalkategorien (nebst Beobachtungen zum Aspekt) an Hand rechen Belegmaterials (korrekte und abwelchende Bildungen) vor Augen und kommentiert ihre Funktion. Es wäre vielleicht darüber hinaus noch sinnvoll gewesen, hätte Otten seine Bewertung der einzelnen Erscheinungen öfter als geschehen durch statistische Angaben gestützt - der Leser würde thm in seinen Schlüssen noch bereltwilliger folgen.

Beide genannten Arbeiten verraten wenig über den untersuchten Text selbst, was über den engeren verbalen Bereich hinaus-

9) Nenn Otten, Fin. Verbalformen, $S .152,232,250$ und 273 betont, daß die hohe Prequenz ksl. Formen auf den 2 we1ten Südslavischen Einfluß zurückzuführen sei, so müssen wir dem entschieden widersprechen.

Dieser Einfluß war lebendig Ende des 14. und in der ersten Hälfte des 15 . Jh.s - der Autor mit dem breitesten Nirkungsfeld, Pachomij Logofet (bzw. Serb), starb um 1480. Natürlich brachte der Zweite Südslavische EinfluB eine Renaissance der ksl. Formen, eine bestimmte Stilrichtung, insbesondere in der altruss. Vitenliteratur. wenn diese archaisierende Tendenz und jene spezielle hagiographische itilrichtung in der 2. Hälfte des 16. Jh.s eine Belebung erfahren, dann liegt das nur indirekt am Zweiten Südslavischen Einfluß; der eigentliche Grund ist eher darin zu sehen, daB - wie wir zu zeigen versuchten - die durch den Metropolit Nakarij angeregte Kompilationstätigkeit, die mit der Sammlung und Neubearbeitung der Viten begann, sich dieses Stils bediente und so den typischsten Erscheinungen des Zweiten Südslavischen Einflusses ou einer Renaissance verhalf. 
ginge. Bei Otten geben die gelegentlich vorgestellten größeren Textpassagen einen gewissen Eindruck vom Stil der "Stepennaja kniga", obgleich die Einblicke ganz zufälliger Natur sind, weil sie sich ja aus verbalen, nicht stilistischen, Untersuchungen ergeben.

Wenn wir uns nun verstärkt dem Verb zuwenden, dann aus der Erkenntnis heraus, daB zumindest für die Zeit des Verfalls der alten verbalen Kategorien die nähere Betrachtung eines Textes um eine Untersuchung derselben nicht herumkommt. Der ursprüngliche Ansatz unserer Arbeit, eine allgemeine Stiluntersuchung zur Bestimmung des moskovitischen Frunkstils durchzuführen, zeigte, daß der wesentliche stilistische Unterschied $z$ wischen den beiden Texten - trotz vieler gravierender Gegensätze im Gebrauch der "rhetorischen Elemente" - in der Verwendung der Verbalkategorien liegt. Und diesen wesentlichen Unterschied wollen wir herausarbeiten und deutlich machen. Die Gegenüberstellung der beiden Texte wird uns helfen, die Besonderheit der lleskauer Erzählung klar hervortreten zu lassen. 
II. Uberblick über das Auftreten

der verbalen Kategorien in unseren Texten

Die Veränderungen, die wir im altruss. Verbalsystem beobachten, betreffen den Ubergang vom aktionsartorientierten Tempussystem zum aspektorientierten, paarigen Verbalsystem mit imperfektiver (= imperf.) und perfektiver (= perf.) Vertretung der meisten Verben.

Für eine grobe Bestimmung des Entwicklungsstandes ist das Präteritum signifikant: Inwieweit werden in einem gegebenen Text die ksl. Tempora Imperfekt (= Ipf.) und Aorist (= Aor.) durch das umgangssprachlich längst etablierte l-Partizip $(=1 \text {-Part. })^{1}$ ersetzt? Wir gingen von der Erwartung aus, daB in einer Kriegserzählung des 16. Jh.s, wie sie die Erzählung über die Belagerung Pleskaus darstellt, innerhalb bewegter Kampfezenen mit sich überstürzender Handlung das umgangssprachliche ${ }^{2}$ 1-Yart. leicht Eingang finden könnte.

Um eventuelle Unterschiede im Gebrauch der Verbalformen

1) Ich werde im folgenden bei der Bezeichnung "l-Fart." bleiben; sehr treffend wäre auch die Bezeichning "l-Präteritum". Auf keinen Fall scheint mir aber der Begriff "Perfekt" für dies durch 1-Part. ausgedruickte universale Präteritum angebracht zu sein. Das alte Perfekt bestand aus flektiertem Hilfsverb "byti + l-Part.". "Perfekt ist der aus einer vergangenen nichtdurativen Handlung resultierende Zustand $\ldots *=K$. Trost: Perfekt und Konditional im Altkirchenslavischen. Wiesbaden 1972 (Bibliotheca Slavica). S. 13. (weiterhin zitiert: Trost, Perfekt). Von "Perfekt" spricht z.B. Efimov, Ist.russk.lit. jazyka, S. 44; Nikiforov, Glagol, S. 155 benutzt es mit Einschränkungen; ähnlich otten, Pin. Verbalformen, S. 331 "liit derartigen formalen Veränderungen tritt das Perfekt, auch semantisch umgestaltet, als einfaches Vergangenheitstempus neben den Aorist."

2) In nichtliterarischen schriftlichen Zeugnissen ("delovaja pismennost' ) ist das l-Part. das am stärksten vertretene Vergangenheitstempus - vgl. Nikiforov, Glagol, S. 155; Efimov, Ist.russk.Iit.jazyka, S. 44: "Perfekt byl vesma rasprostranen $v$ razgovornom jazyke drevnejøej pory, ...." Ders., ebda., S. 44, Anm. 3: In 83 Birkenrinden-Urkunden erscheint als Präteritum ausschlieblich das Perfekt (= I-Part.) - Ausnahme: ein einziger Aorist in all diesen Urkunden. 
auch innerhalb der einzelnen Texte aufzuspüren, teilten wir ungere Erzählung in inhaltlich verschiedene Bereiche auf. Zunächst einmal trennten wir Passagen persönlicher Diktion von den rein erzählenden Bereichen ab: Wörtliche Rede (Dialoge, Monologe, Ansprachen z.B. der Voevoden an die Pleskaner, Gebete) und Briefe. Hierbei unterschieden wir wieder zwischen allgemeiner Rede bzw. Brief und Rede/Brief geistlichen Inhalts. Während wir im Pleskauer Text eine Keihe von Sendschreiben vorfinden, spielen schriftliche Mitteilungen in der K-pler Erzählung keine Rolle - selbst die Prophezeiungen im SchluBteil, die auf schriftlichen Vorlagen beruhen, werden meist frei wiedergegeben und ordnen sich im Duktus dem monologischen Charakter dieses SchluBteils unter. Aus gelegentlichen $Z$ itaten (Leo sapiens, Visio Danielis) lassen sich keine weitgehenden Schlüsse ziehen.

Die umfangmäBig bei weitem dominierenden erzählenden Abschnitte der Texte haben wir in

1. allgemein berichtende Passagen,

2. geistlich orientierte ${ }^{3}$ ",

3. Kampf-/Kriegsberichte

aufgeteilt.

Für unsere statistischen Untersuchungen haben wir als zusätzlichen Vergleich eine dritte, wenn auch kürzere ErzähI ung hinzugezogen: Die Erzählung über die Annexion Pleskaus durch Vasilij III. 1510 aus der 3. Pleskauer Chronik. ${ }^{4} \mathrm{Da}$, wie schon verschiedentlich hervorgehoben, die Novgoroder und die Pleskauer Chroniken den Stand der gesprochenen

3) Unter "geistlich orientierte Passagen" sind Beschreibungen geistlicher Handlungen $z u$ verstehen - z.B. von Prozessionen, Vorgängen in der Kirche, von Handlungen geistlicher Würdenträger.

4) Wir haben die ausführliche Variante der Erzählung nach der Archivhs. herangezogen - Pskovskie letopisi 2, S. 253 - 59. Sie entstammt der litte des 16. Jh.s. - In der Erzählung wird in überaus scharfer Form das erpresserische und betrügerische Vorgehen des lioskauer Grobfürsten angeprangert und der "vyvod" = die Deportation von 300 der angesehensten Pleskauer Familien ins tioskauer Gebiet angeklagt. Eine die Annexionspolitik Moskaus bloBlegende Einleitung und eine lyrische Klage uber den Verlust der Veče-Glocken ( = Freiheit Pleskaus) heben sich in ihrer Diktion scharf vom übrigen Text ab. 
Sprache besser als andere literarische Zeugnisse spiegeln, hoffen wir, die Einordnung unserer beiden Kriegserzählungen durch Vergleich mit der Pleskauer Chronikerzählung erleichtern zu können.

\section{Die Tabelle 1}

Auf der Schautafel sind die drei Bereiche der erzählenden Abschnitte und die zwei Bereiche der persönlichen Diktion deutlich zu erkennen.

Grundsätzlich besteht jede Angabe aus drei Zahlen. Nehmen wir einmal als Beispiel den Aorist im erzählenden Bereich (allgemein berichtend) des $\mathrm{K}$-pler Textes. Dort finden wir folgende Angaben: $211 / 8-21,3-48,8 \%$. Die erste Angabe 211/8 nennt die Zahl der Aorist-Belege (von 219 Formen $=8$ "rečen), die letzte Angabe $(48,8 \%$ ) besagt, daB diese 219 Aoristformen 48,8 v.Hd. aller im allgemein berichtenden Bereich vorkommenden Verbalformen (siehe unterste Spalte: "Gesamt" - 449 Verbalformen) darstellen.

Während diese Prozentangabe auf den jeweiligen Bereich (allgemein berichtend, geistlich orientiert usw.) bezogen ist, bezeichnet die mittlere Angabe die absolute Häufigkeit der vorkommenden Verbalformen, und zwar durchgehend gültig für alle drei in der Graphik erfabten Texte. Diese Angabe soll helfen, sich eine konkrete Vorstellung von der Frequenz der einzelnen Verbformen $z u$ machen. Die Zahl gibt an, wie of $t$ die bestimmte Kategorie in einem umfangmäBig klar begrenzten, für alle Bereiche und für alle drei Texte gleich groBen Textabschnitt vorkommt - z.B. lesen wir in der Tabelle unter der Kategorie "Imperfekt" (allgemein berichtende Abschnitte) folgendes:

K-pel: $59 / 9 / 3^{5}-6,6-15,1$

Plsk.: $88 / 7 / 11-3,4-16,2$

5) Die dreifache Untergliederung der Angabe der Ipf.-Belege soll die Formen von Vollverben und die Ipf.-Belege von "byti" trennen: die erste Zahl nennt Ipf.-Belege von Vollverben, die zweite $Z$ ahl das Vorkommen von "be" (7), die dritte Zahl Belege von "bjase" (11) - Pleskauer Text. 
Aus dieser Zahlenkombination ist zu ersehen, daB die 71 Ipf.Belege im $\mathrm{K}$-pler Text ( 59 von Vollverben, 9 von "be", 3 von "bjaše) 15,1 v. Hd. der gesamten Verbalformen des allgemein berichtenden Bereichs ausmachen und daB die 106 Ipf.-Belege im Pleskauer Text ( 88 von Vollverben, 7 von "be", 11 von "bjaše") mit 16,2 v.Hd. ungefähr den gleichen Anteil in diesem Bereich haben. Ein Blick auf die mittlere Zahl zeigt aber, daß im K-pler Text das Ipf. - absolut gesehen - doppelt so häufig ist wie im Pleskauer Text. Die Erklärung für diese Diskrepanz, der wir bei jeder Angabe begegnen, finden wir bereits beim Vergleich von Umfang der Texte und Zahl der Verbalformen: Die Pleskauer Erzählung 1581 ist beinahe doppelt so umfangreich wie die K-pler Erzählung, dennoch hat letztere noch mehr Verbformen als der Pleskauer Text 1581: K-pel 1550 Formen, Pleskau 1490 Formen. Wir erinnern in diesem Zusammenhang an das, was im Kapitel: Anmerkungen zum Stil unserer Texte - 2. Informationsgehalt der Texte S. $202-11$ festgestellt worden war - Aufzählungen, Synonymien, Epitheta ornatia, vielgliedrige formelhafte Benennungen von Personen und Personengruppen $u . a$. lassen sehr oft den Informationsgehalt im Pleskauer Text fast auf Null herabsinken. Redundante Wendungen dieser Art waren dagegen im $K$-pler Text ziemlich selten. Die gröBere Konzentration auf die Vermittlung von Fakten, auf die Mitteilung von Vorgängen usw. im K-pler Text findet auch in der hohen Frequenz verbaler Formen ihren Niederschlag.

Um diesen absoluten Vergleich zu ermöglichen, wurden die drei in der Tabelle aufgeführten Texte auf ein gemeinsames Format projiziert. Zur Veranschaulichung wählten wir als MaBstab eine Textseite der Ausgabe der Pleskáuer Erzähung 1581 - auf diese also beziehen sich alle Angaben über die Frequenz einer Verbalform (= mittlere Zahl). Um diese Vereinheitlichung zu erreichen, wurde folgendermaßen verfahren:

Die Pleskauer Textseite zählt 35 Zeilen. Oft sind es aber weniger wegen der Fußnoten am unteren Seitenende. AuBerdem wird die Zeilenzahl faktisch durch Absätze (Teile der Zeilen bleiben textfrei) und durch Uberschriften (die wir nicht in die Untersuchungen einbezogen haben) verringert. Der so entstandene Zeilenausfall wurde genau berechnet 
und auf den gesamten Text umgelegt. Dabei ergab sich, dab die Textseite des Pleskauer Textes im Durchschnitt 33,7 Seiten beträgt. Da eine Zeile der Edition durchschnittlich 53 Drucktypenstellen enthält, ergibt sich für die Pleskauer "Norm"-Seite eine Zahl von $33,7 \times 53=1786$ Drucktypenstellen.

Die einzelnen Bereiche, wie sie in der Tabelle erscheinen, wurden zunächst im Pleskauer Text zeilenmäBig ausgezählt und durch Division durch die Zeilenzahl der Norm-Seite $(33,7)$ auf dieses Format gebracht.

Entsprechend wurde bei den anderen beiden Texten verfahren: die einzelnen Bereiche wurden auf die Zahl der Zeilen - unter Berucksichtigung textfreier Zeilenteile durchgezählt. Da der Pleskauer Chroniktext 1510 im Durchschnitt 60 Drucktypenstellen, der K-pler Text 59 Drucktypenstellen hat, multiplizierten wir die Zeilenzahl eines bestimmten Bereichs mit 59/60, erhielten so die Zahl der Drucktypenstellen des betr. Bereichs, die wir dann durch 1786 ( = Zahl der Drucktypenstellen auf der Pleskauer Normseite) dividierten - damit ist der Vorgang der Transponierung beendet: das so erzielte Ergebnis gibt uns den Umfang des entsprechenden Bereichs der Erzählung über den Fall K-pels und der Pleskauer Chronikerzahlung 1510 im Format der ileskauer "Norm"-Seite an. (6)

Durch diese Operation gelangten wir zu folgenden Relationen:

\begin{tabular}{|c|c|c|c|c|c|c|c|}
\hline & alleem. & jgeistl. & Kampf & $\begin{array}{l}\text { wrt. Kede } \\
\text { allgem. }\end{array}$ & $\begin{array}{c}\text { wrt.kede } \\
\text { geistl. }\end{array}$ & lgesamt & $\begin{array}{l}\text { Plesk. } \\
\text { Seiten }\end{array}$ \\
\hline 10 & 6,5 & --- & -- & 1,6 & 0,7 & 8,8 & $"$ \\
\hline -pel & 10,3 & 3,4 & 13,3 & 2,7 & 5,1 & 34,8 & $"$ \\
\hline 1581 & 28,1 & 7,7 & 11,2 & 6,8 & 6,5 & 60,3 & $"$ \\
\hline
\end{tabular}

Wir beziehen uns im folgenden nicht weiter auf diese absoluten Frequenz-Angaben. Sie sollen, wie gesagt, nur eine konkrete Vorstellung von der Häufigkeit der einzelnen Verbformen vermitteln und absolute Vergleiche ermöglichen. So ist es beispielsweise interessant zu sehen, daß das Part.präs. im Kampfbericht des Pleskauer Textes 1581 nicht nur prozentual häufig höher liegt als im K-pler Text (Pleskau 23,1 v.Hid.,

6) Beispiel: im K-pler Text finden sich bei genauster Zählung für den geistlich orientierten Bereich (erzählend) 103 Zeilen. Die Druckzeile hat hier durchschnittlich 59 stellen, wir kommen also für diesen Bereich $(103 \times 59)$ auf 6077 Drucktypenstellen. Diese dividieren wir durch 1786 (Zahl der Drucktypenstellen der Pleskauer "Norm"-Seite) und erhalten so 3,4 Pleskauer "Norm"-Seiten. 
K-pel 8,4 v.Hd.), sondern auch absolut gesehen - auf unserer Normseite - viel häufiger ist als in der K-pler Erzählung: Pleskau - fast 7 Belege, K-pel 4 Belege pro Normseite. Wenn wir an das zuvor über die doppelte Dichte an Verbformen im K-pler Text Gesagte erinnern, dann wird klar, daB das starke Ubergewicht des Part.praes. im Pleskauer Text (Kampfbericht) - nicht nur im prozentualen, sondern auch im absoluten Maßstab - einen signifikanten Unterschied im Gebrauch dieser Kategorie innerhalb dieser beiden Texte anzeigen muß.

\section{Die verbalen Kategorien im Vergleich}

Das Präsens ist im Pleskauer Text 1581 mit durchschnittlich 20 v.Hd. vertreten, im Kampfbericht erreicht es allerdings nur 6 v.Hd. 20 v.Hd. an Praes.-Pormen innerhalb eines Bereiches nicht-persönlicher Diktion erweisen sich als sehr hoher Prozentsatz, wenn man sich vergegenwärtigt, dab das Präsens in den beiden anderen Texten im erzählenden Bereich jeweils nur bei 5 v.Hd. liegt. ${ }^{7}$ Das große Ubergewicht an Praes.-Formen im Pleskauer Text rüht daher, daB wir dort häufig auf Abschnitte stoßen, die als Erzähltempus durchgehend das Praesens historicum (= Praes.hist.) haben. Das fällt besonders im ersten Drittel der Erzählung auf (bis zum Einsetzen der Kampfhandlungen), wo der Autor die Vorgeschichte beleuchtende Vorgänge darstellt. Im aktuellen Bericht stoBen wir - wie auch in den anderen Texten - nur vereinzelt auf Praes.hist.

Praes. Formen sind in der K-pler Erzählung nicht nur viel seltener als in der Erzählung über die Belagerung Pleskaus, sondern haben dort auch eine ganz andere Qualität - in der Tabelle finden wir die Angaben zum Praes. fur die beiden Kriegserzählungen aufgeteilt; eine der beiden Spalten ist mit "da" bezeichnet: Diese Angabe nennt solche Praes.-Pormen, die in abhängigen Heische-, Final- und seltener in Konsekutivätzen auftreten, die durch "da" eingeleltet werden; $z$. B.

7) Im allgemein berichtenden Bereich des K-pler Textes finden sich 10 v.Hd. Praes.-Belege - aber kein Praes.hint. Uber die andere Qualität dieses Präs. - siehe im folgenden. 
KP 69/23 "..., i daždb slavu imeni tvoemu, da posramjatsja vrazi tvoi ..."

'...., und Iaß Deinen Namen im Glanz des Ruhmes erstrablen, damit Deine Feinde erniedrigt/beschämt werden...'

Praes.-Formen innerhalb solcher Konstruktionen machen im K-pler Text $\mathrm{zwei}$ Drittel aller Belege aus: von 71 Praes.Pormen können wir nur 25 als Praes.hist. bezeichnen, die übrigen 46 Praes.-Belege befinden sich in abhängigen Heischeund in Finalsätzen.

Betrachten wir daraufhin die Angaben zum Pleskauer Text 1581 , so bemerken wir einen grundsätzlichen Unterschied zur K-pler Erzählung: Dort stehen 180 Belegen, die wir als Praes.hist. bezeichnen können, nur fünf ${ }^{8}$ Praes.-Belege in abhängigen Heische- und Finalsätzen gegenüber. Ein Blick auf die Vertretung des Konditionals, der im Russ. die indikativische Konstruktion des Aksl. ("da + Praes. mit Futur-Bedeutung") ablöste, 9 zeigt uns, daB der Konditional in beiden Texten nur eine minimale Vertretung hat. ${ }^{10}$ Final-, Heische- und die seltenen Konsekutivsätze haben also in der K-pler Erzählung ein erdrückendes Ubergewicht gegenuber entsprechenden Satzkonstruktionen im Pleskauer Text. 11

Diese Schlubfolgerung düfen wir verallgemeinern und auf einen bezeichnenden Gegensatz (von "Unterschied" kann hier keine Rede mehr sein) zwischen den beiden Kriegserzählungen hinweisen, auf den wir im Rahmen dieser Arbeit leider nur am Rande eingehen können: Im $K$-pler Text dominiert die hypotaktische Fügung von Sätzen, wohingegen der Pleskauer Autor Parataxe bevorzugt. Letztere ist nicht im-

8) Bräuer, Konjunktiv, S. 243, nennt 4 derartige Belege. Er ïbersah den durch Malysevs Interpunktion verdeckten abhängigen Heigchesatz, auf den wir S. 138 hingewiesen haben: $38 / 28$ "naćalbnicy ... sovet sotvorse. Da pośljut $k$..." 'die Oberen faßten den Plan, zum Zaren zu schicken'.

9) Bräuer, Konjunktiv, S. 237: Der Konditional in Final- und Heischesätzen ist häufiger als die indikativische Konstruktion in Denkmälern des 16. Jh.s "mit geringerem ksl. EinfluB, so daB also hier die Zunahme des Konditionalgebrauchs als Merkmal der russischen Sprache zu werten ist."

10) Der Kondit. wird in unseren Texten durch "daby + 1-Part." gebildet.

11) $\begin{aligned} & \text { K-pel: } 25 \\ & \text { Plsk.: Praes.hist. : }\end{aligned}$ 
stande, Innere Beziehungen geschilderter Vorgänge zueinander und Abhängigkeiten voneinander so klar herauszustellen, wie dies die Hypotaxe vermag. (12). Eine detaillierte Untersuchung der $\mathrm{K}$-pler Erzählung auf ihre Satzkonstruktionen, Batzgefüge und konjunktionale Nebensätze hin, sodann ein Vergleich mit einer repräsentativen Auswahl altrussischer Texte könnte einen Ansatz liefern zur Beantwortung der eingangs erörterten Frage, ob die $\mathrm{K}$-pler Erzählung eine Ubersetzung (aus dem Griechischen?) darstelle.

$\mathrm{DaB}$ in den Abschnitten persönlicher Diktion - wörtliche Rede, Monologe, Sendechreiben usw. - das Präsens dominfert, braucht nicht hervorgehoben $z u$ werden und bedarf keiner weiteren Erläuterungen. 13

Das Imperfekt kommt in der Pleskauer Chronikerzählung 1510 im Vergleich zu den beiden anderen Texten besonders selten vor - 7 v.Hd. aller Verbformen bilden es im berichtenden Bereich. Diese Angabe deckt sich mit elner Zählung P. Ja. Cernychs an der 1. Novgoroder Chronik (Synodal-Hs.): Der Hauptanteil aller Verbformen fällt auf den Aorist (83,3 v.Hd.), auf das Imperfekt nur 5 v.Hd. ${ }^{14}$ Xernych meint, daB das Ipf. umgangssprachlich vielleicht schon im 13. Jh. außer Gebrauch gekommen se1. 15 In Akten, Urkunden, auch in der "Russkaja Pravda" begegnet es selten. Insofern bestätigt also der Pleskauer Chroniktext 1510 die Vorstellung, daB die Pleskauer Chroniken besser die gesprochene sprache reflektieren als andere Schriftdenkmäler.

Im K-pler Text und in der Pleskauer Erzählung 1581 macht das Ipf. in den allgemein berlchtenden Passagen ungefähr $15 \mathrm{v} . \mathrm{Hd}$. aus. Im geistlich orientierten Bereich des K-pler Textes bleibt der Anteil des Ipf.s mit 17 v.Hd. etwa gleich stark.

12) Im Rahmen der Untersuchung an den partizipialen Bonotruktionen kommen wir auf Para- und Hypotaxe nochmals zu epre chen, und dort wollen wir auch konkrotes Material hierou vorlegen, das die hier gemachten Beobachtungen voll be tktigt.

13) Den Prese. - Angaben sind die wenigen Bolege fur periphrast. Putur zugezählt: 11 - Pleskau 1510, 2 K-pol, 11 Pleskau 1581.

14) P, J, Tachernych (Cernych): Historische Grannatik der noolschen Sprache. Halle 1957. S. 221 - diese ingaben inden oich nur in der deutschen Ausgabe.

15) Tschernych (Cernych), ebda. 
Im Pleskauer Text 1581 sinkt es dagegen auf 9,7 v.Hd. herab. Der Begründung für diese Erscheinung werden wir im Rahmen der Auswertung unserer Statistik noch öfter begegnen: Die Abnahme der Ipf.-Formen im geistlichen Bereich des Pleskauer Textes 1581 ist eng verbunden mit einer Zunahme der Part. praes.-Belege; im Hinblick auf den $\mathrm{K}$-pler Text ist wohl auch eine Abnahme finiter Verbalformen zugunsten des Part.praet. zu konstatieren (Ipf. K-pel: 17 v.Hd. - Pleskau: 9,7 v.Hd.; Part.praet.: K-pel 7,5 v.Hd. - Pleskau: 16,8 v.Hd.).

Innerhalb des Kampfberichtes steigt in beiden Kriegserzählungen jer Anteil an Ipf.-Formen an, aber während im Pleskauer Text der Ipf.-Anteil hier nur knapp um 3 v.Hd. über demjenigen des Ipf. im allgemeinen Bericht liegt, beträgt diese Steigerung im K-pler Text mehr als $10 \mathrm{v} . \mathrm{Hd}$. auf fast $28 \mathrm{v} . \mathrm{Hd}$. (Pleskau 1581 hat nur $19 \mathrm{v} . \mathrm{Hd}$. ). Obwohl sich im Pleskauer Text auch innerhalb des Kampfberichts der Anteil der Partizipien erhöht, erfährt gegenüber dem geistlichen Bereich das Ipf. auch im Kampfbericht eine 10-prozentige $2 u-$ nahme, die darauf zuruickzufüren ist, daß in diesem Bereich das Praes.hist. auf knapp 6 v.Hd. absinkt.

Der allgemeine Anstieg des Ipf. in den Kampfszenen, den wir mit 10-prozentiger Erhöhung ja in beiden Texten (gegenüber dem geistlichen Bereich) konstatieren, hängt mit den dort geschilderten Vorgängen zusammen: Entweder werden sich ständig wiederholende oder iterative genannt (hauen, schlagen, schießen), oder der Autor schildert mächtige Vorgänge, die aber durchaus gezielt und begrenzt sein können; während im ersteren Fall das Ipf. das natürliche Tempus ist, kommt im letzteren Fall eine Funktion des Ipf.s zum Tragen, die gerade für Massenszenen typisch ist - die sog. distributive Funktion $^{16}$ des Ipf. Ein einheitlicher Vorgang, der von einer Vielzahl von Menschen bewirkt wird, wird durch das Ipf. gleichsam atomisiert - durch das Ipf. hebt der Autor die Vielzahl der Menschen hervor, die an der Handlung beteiligt ist: angreifen, sturmen, schreien usw.

16) Boretzky, Tempusgebrauch, S. 44; sinngemäB: Nikiforov, 
In den Abschnitten persönlicher Diktion kommt das Ipf. kaum vor - nicht einmal in den umfangreichen Briefen der Pleskauer Kriegserzählung. Erstaunlich ist, daB in den Monologen das Ipf. so selten anzutreffen ist - sie sind doch vorwiegend geistlichen Inhalts. Man gewinnt den Eindruck, daB das Ipf. als so gelehrt oder so gespreizt empfunden wird, daB man es sogar im Monolog oder auch im Brief meidet.

Der Aorist bildet in unseren Kriegserzählungen das Haupterzähl tempus, und mit $40 \mathrm{v} . \mathrm{Hd}$. ist er in der Pleskauer Chronikerzählung 1510 noch stärker vertreten als in der Erzählung über die Belagerung Pleskaus (um $30 \mathrm{v} . \mathrm{Hd}$, in allen Bereichen). Die Schwankungen im Gebrauch des Aorist in der $K$-pler Erzählung sind groB: im allgemeinen Bericht hat er einen Anteil von fast $49 \mathrm{v} . \mathrm{Hd}$. aller Verbformen dieses Bereichs, im Kampfbericht fast $43 \mathrm{v} . \mathrm{Hd}$. und im geistlich orientierten Bericht nur 33 vHd. Letzteres steht in engstem $\mathrm{Zu}-$ sammenhang damit, daB im geistlichen Bereich des K-pler Textes das Part.präs. mit 38 v.hd. die stärkste Verbalkategorie darstellt (in allgemeinem und Kampfbericht jeweils um $10 \mathrm{v} . \mathrm{Hd}$. !). Wenn wir beobachten, daB in der Erzählung über den Fall K-pels im Kampfbericht der Anteil des Aorist $(42,6$ v.Hd.) gegenüber dem allgemeinen Bericht $(48,8$ v. Hd.) um immerhin $6 \mathrm{v} . \mathrm{Hd}$. sinkt, dann ist dies eine Folge der erwähnten Erhöhung des Anteils der Imperfekt-Formen im Kriegsbericht.

DaB der Aorist im Pleskauer Text mit durchgehend etwa $30 \mathrm{val}$. zwar das am häufigsten gebrauchte Tempus, im Vergleich eu den beiden anderen Texten jedoch relativ schwach vertreten ist, liegt daran, daB im Pleskauer Text 1581 die Streuung der Verbalformen über die einzelnen Kategorien gleichmäBiger ist als in den beiden anderen Texten - man könnte es auch so formulieren: Die semantische Indifferenz bezüglich des Ipf., des Part.praes. und des Part.praet. führt im Pleskauer Text zu einer gewissen Angleichung ihrer Frequenz ebenso wie zu deren Erhöhung. Die Schwankungen sind nicht so stark wie in der K-pler Erzählung. Innerhalb der semantisch indifferenten Kategorien stellt der Aorist anscheinend das Tempus dar, dessen Funktion dem Autor noch am klarsten ist. 
Die Angaben in der Tabelle über die Verwendung des Aorist in Abschnitten persönlicher Diktion sagen nicht viel aus. Da in den Reden, Gebeten, Briefen etc. das Haupterzähltempus das Präsens ist, hängt es vom Gegenstand des Gesagten oder im Brief Geschriebenen $a b$, ob überhaupt oder in welchem Maße ein Vergangenheitstempus benötigt wird. Präsens und Aorist machen innerhalb der Bereiche persönlicher Diktion der beiden Kriegserzählungen jeweils ca. $80 \mathrm{v.Hd}$. aller Verbformen aus, Partizipien bilden den größten Teil der verbleibenden 20 v. Hd.

Das 1-Partizip als Präteritaltempus verdeutlicht den großen Unterschied zwischen der Pleskauer Chronikerzählung 1510 und den beiden Kriegserzählungen: Im $K-p l e r$ Text sind Belege für l-Part. kaum anzutreffen - fast in allen Bereichen liegt es unter 1 v.Hd. Im Pleskauer Text 1581 ist es ebenfalls selten und erreicht durchschnittlich $3 \mathrm{v} . \mathrm{Hd}$. Dagegen übersteigt in der Pleskauer Chronikerzählung das 1-Part. mit 42 v.Hd. sogar noch den Aorist ( $40 \mathrm{v} . \mathrm{Hd}$.). Hierin nun zeigt sich auch ein gewaltiger Unterschied zu oben erwähnter Zählung P. Ja. Cernychs an der 1. Novgoroder Chronik (Synodal-Hs.): Dort bildete der Aorist mit 83,3 v.Hd. eindeutig das Haupterzähl tempus - in der Pleskauer Chronikerzählung $1510 \mathrm{ma-}$ chen Aorist und 1-Part. zusammen diesen Anteil aus. Die Tatsache, $d a B$ in der Novgoroder Chronik Aorist und Imperfekt zusammen fast $90 \mathrm{v} . \mathrm{Hd}$. des gesamten Verbalbestandes bilden, läßt das hohe Alter derselben ahnen. ${ }^{17}$ Unsere Pleskauer Chronikerzählung dagegen zeigt deutlich die sprachlichen Veränderungen an, die seit dem 11. oder 12. Jh. gerade in bezug auf den Gebrauch der verbalen Kategorien in Verbindung mit dem Vordringen des Aspektsystems vor sich gegangen sind, wenn in ihr das 1-Part. vollkommen gleichberechtigt neben den Aorist tritt (ihn sogar um 2 v.Hd. überflügelt).

17) A. A. Sachmatov meinte, dab die (von Cernych untersuchte) Synodal-Hs. auf Vorlagen beruhe, die in die erste Hälfte des 11. Jh.s zurückreichen könnten. - s. Budich, Aspekt, S. 6 und Anm. 5 . 
Die eindeutige Tendenz ungerer beiden Kriegserzählungen, die umgangsoprachliche Präteritalbildung (= l-Part.) zu meiden, beweist, daB die Autoren (bzw. Redaktoren) diese Erä̈hlungen ganz bewuBt in die altrussische literarische Tradition hineingestellt haben, indem sie die "klassischen" Vergangenheitstempora Imperfekt und Aorist verwendeten. Der Autor (oder Ubersetzer) der K-pler Erzählung mochte dazu vom Zweiten Südslavischen EinfluB motiviert gowesen sein, unser Pleskauer Autor folgt hierin der durch den Metropoliten Makarij begruindeten Stilrichtung, die in bestimmten Bereichen (Verb) eine Renaissance des Zweiten Südslavischen Einflusses mit sich brachte.

Betrachten wir einmal den Anteil der finiten Verbalformen ${ }^{18}$ in unseren drei Texten, so ergibt sich - für die erzählenden Bereiche - folgendes Bild:

Im Pleskauer Chroniktext machen finite Verbalformen 92 v.Hd. aus. Die beiden Kriegserzählungen betrachten wir wieder getrennt nach Bereichen:

\begin{tabular}{l|r|r|c} 
& allgemein & geistlich & Kampf \\
\hline K-pel & 74 v.Hd. & 55 v.Hd. & 75 v.Hd. \\
Pleskau & 70 v.Hd. & 63 v.Hd. & 59 v.Hd.
\end{tabular}

Die Jeweils fehlenden Prozentpunkte zu 100 ergeben den Anteil des jeweiligen Bereichs an Partizipien.

Wenn wir davon ausgehen, daB die Verwendung von partizipialen Konstruktionen ein Anzeichen für hohen stil ist, ${ }^{19}$ dann bestätigen die obigen Angaben für die K-pler Erzählung diese Festatellung: die finiten Verbalformen gehen auf 55 v.Hd. zurück, d.h. fast die Hälfte aller Verbformen besteht aus Partizipien; der Unterschied zu den allgemeinen und den Kampfberichten beträgt jeweils ca. $20 \mathrm{v} . \mathrm{Hd}$. In der Pleskauer

18) Der schwach vertretene Konditional ist mit eingeschlosien. 19) Nikiforov, Glagol, S. 261 ff., S. 286, Punkt 8 b. 
Erzählung 1581 ist im Vergleich zwischen allgemein berichtendem und geistlich ausgerichteten Bereich auch eine Abnahme der finiten Verbformen zugunsten der Partizipien zu beobachten - aber diese nimmt sich mit 7 v.Hd. gegenüber dem Absinken finiter Verbformen um $20 \mathrm{v}$. Hd. im geistlichen Bereich des $\mathrm{K}$-pler Textes recht bescheiden aus.

Es war gesagt worden (s.0., S. 261), daB im Pleskauer Text 1581 vielleicht auf Grund einer semantischen Nivellierung der Verbalkategorien die Verben gleichmäßiger über die Tempora und Partizipien verteilt sind und daB daher vielleicht auch die Schwankungen des Anteils einzelner Kategorien von Bereich $z u$ Bereich nicht so stark sind wie im K-pler Text. Von daher ist das bescheidenere Ansteigen der Partizipien im geistlichen Bereich des Pleskauer Textes nicht verwunderlich. Verwunderlich ist aber, daB in den Kriegsberichten in der Pleskauer Erzählung 1581 der Anteil der Partizipien noch um vier Prozentpunkte höher liegt als deren Anteil im geistlich orientierten Bereich - während doch im K-pler Text die finiten Verbalformen innerhalb des Kriegsberichtes den gleichen Stand erreichen wie innerhalb des allgemeinen Berichts: 75 v.Hd. Im Pleskauer Text (Kampfbericht) liegt der Anteil der Partizipien fast genau so hoch wie deren Anteil im geistlich ausgerichteten Bereich des K-pler Textes - $41 \mathrm{v} . \mathrm{Hd}$.

Im Rahmen der persönlichen Diktion nimmt in allen Texten der Gebrauch der finiten Verbalformen $z u$, im $k-p l e r$ Text nur wenig: der Anteil steigt von 75 auf ca. 80 v.Hd. Beim Lesen ist dieser Unterschied gar nicht $z$ spüren. Ganz anders sieht es dagegen im Pleskauer Text 1581 aus: Finite Verbalformen beherrschen alle Bereiche der persönlichen Diktion - sie steigen auf mehr als 93 v.Hd.! Wenn man auch in Rede, Dialog, Gebet, Sendschreiben in anderer Hins1cht keine Annäherung an die Umgangssprache feststellen kann, so ist doch dieses fast gänzliche Verschwinden partizipialer Konstruktionen unbedingt als Stilisierung gesprochener Rede aufzufassen. 
Die Partizipien spielen, wie aus allem zuvor Gesagten hervorging, in den beiden Kriegserzählungen eine bedeutende Rolle, in der Pleskauer Chronikerzählung 1510 bleiben sie unter $10 \mathrm{v} . \mathrm{Hd}$. , denen wir keine Bedeutung beizumessen haben. 20 Wenn wir hier vom Partizip sprechen, dann ist damit im Grunde genommen das nominale Partizip gemeint. Da aber im Pleskauer Text Vermischungen nominaler mit pronominalen Partizipialformen um sich greifen, ${ }^{21}$ wollen wir die in unserer Graphik registrierten uns interessierenden Partizipien durch ihre Funktion beschreiben: wir untersuchen verbal und adverbial gebrauchte Partizipien. Da wir uns hauptsächlich mit dem Verb beschäftigen wollen, erhebt sich die Frage, warum auch adverbial gebrauchte Partizipien zur Untersuchung herangezogen werden: $D a$ beide Funktionen in unseren Texten formal noch nicht geschieden werden, darüberhinaus 'verbale und adverbiale Funktion' nur die Extrempunkte einer ganzen Skala von $\mathrm{Zwischenstufen} \mathrm{darstellen,} \mathrm{werden} \mathrm{sich} \mathrm{unsere} \mathrm{Einzelun-}$ tersuchungen gerade mit der Prage befassen, wo unsere Texte in bezug auf die Entwicklung des nominalen Partizips hin zum Adverbialpartizip ("deepričastie") stehen. Das bedeutet also, daB wir attributiv und substantivisch gebrauchte Partizipien weder in unsere Tabelle aufgenommen haben noch in unsere Betrachtungen einbeziehen werden.

Ebenso lassen wir auBer acht passive Partizipien. Die Veränderungen, die diese vom Aksl. hin zum Neuruss. erfahren haben, sind weniger syntaktischer als vielmehr formaler Natur, und auch diese Veränderungen sind gering. Eine Behandlung der passiven Partizipien wuirde sich auf ein statistisches Erfassen beschränken.

Während das Part.praet. in den berichtenden Bereichen des Pleskauer Textes 1581 etwa gleich häufig ist - zwischen 17 und 21 v.Hd. -, sinkt im geistlichen Bereich des K-pler Tex-

20) Der hohe Anteil in geistlich-persönlicher Diktion beruht auf der Kürze des Abschnitts $(27$ Verbformen = Verzerrung).

21) z.B.beim Dat.abs. finden wir ausschlieblich statt nomin. - émb pronom. - 
tes der Anteil des Part.praet. auf 7,5 v. Hd., also auf die Hälfte herab. Dieser Rückgang kommt dem Part.praes. zugute, das u.a. dadurch auf $38 \mathrm{v}$.Hd. aller Verbformen im geistlichberichtenden Bereich des K-pler Textes ansteigt und $z u$ der am stärksten vertretenen Verbalkategorie wird - im allgemeinen und im Kampfbericht hat das Part.praes. nur einen Anteil von $10 \mathrm{v} . \mathrm{Hd}$. Dieser Anstieg zeigt ganz deutlich (Beispiele folgen im Rahmen der Einzeluntersuchungen), daß der $\mathrm{K}$-pler Autor (Utbersetzer?) den Gebrauch des Partizips, insbesondere des Part.praes., mit erhabener - in erster Linie geistlicher Thematik verbindet. Für inn ist offensichtlich das Part.praes. das bevorzugte Mittel, mit dem er dem Dargelegten sprachlich die größte Würde verleiht.

In diesem Zusammenhang erhebt sich die Frage, warum wir dann im Rahmen der Monologe geistlichen Inhalts, der Gebete usw. des $K$-pler Textes nur einen unwesentlichen Anstieg des Part. praes. feststellen: 8 - 10 v.Hd. innerhalb der erzählenden Bereiche - 12,3 v.Hd. innerhalb der Gebete, geistlich ausgerichteten Monologe. Das Part.praet. erreicht hier sogar - wie auch im geistlich orientierten Bericht - seinen Tiefststand von 7,5 v.Hd. Diese Angaben widersprechen scheinbar obiger Feststellung, daB das Part.praes. der Aussage Erhabenheit ver leihe. Hier nun dürfen wir auf unsere Ausführungen in den 'Anmerkungen zum Stil unserer Texte', insbesondere 3. Figurae per ordinem und 4. Figurae sententiae zurückkommen (S. 211 ff.): Dort stellten wir fest, daB sich Gebete und Monologe im K-pler Text in ihrer Diktion klar vom übrigen Text durch kunstvolle Gestaltung der Sätze abheben (Parallelismus, Chiasmus gelegentlich, Anapher; als Gedankenfigur vor allem die Antithese, die - parallel gefügt - besonders wirksam ist u.a.). Wenn aber der Autor beim Abfassen eines Textes auf formale Gestaltung und damit verbunden gedankliche Zuspitzung des Darzulegenden den größten Wert legt, dann muß notwendigerweise das sonst bevorzugte (auf seiner spezifischen, dem Part.praes. eigenen Semantik beruhende) Mittel zurücktreten. Zwar kann es dann auch zu Häufungen von Part.praes. kommen (vgl. Monolog S. 75/29 - 33), öfter sind aber solche Konzentrationen bestimmter verbaler, vor allem finiter Kategorien 
zu beobachten - was wohl mit der Situation der "Rede", zu der wir Monolog, Gebet usw. zählen können, zusammenhängt.

Wie bereits erwähnt, ist auch im Pleskauer Text ein Ansteigen des Part.praes. innerhalb der geistlich orientierten Berichte festzustellen, im allgemeinen Bericht haben sie einen Anteil von $11,5 \mathrm{v} . \mathrm{Hd}$., in den geistlich ausgerichteten Passagen einen Anteil von 21,2 v.Hd. - es handelt sich also fast um eine Verdoppelung. Der Anstieg ist zwar nicht so spektakulär wie im K-pler Text (von 10 auf fast 40 v.Hd.), aber für die Verhältnisse im Pleskauer Text bedeutet eine solche Verdoppelung sehr viel. - Das eigentlich Verwunderliche liegt aber, wie wir schon betont haben, darin, daB im Pleskauer Text nicht - wie zu erwarten wäre und wie es in der K-pler Erzählung auch geschieht - der Anteil an Part.praes. im Kampfbericht wieder auf den Anteil in den erzählenden Abschnitten zurückgeht, sondern noch einmal um 2 v.Hd. steigt, im Vergleich zu den geistlich ausgerichteten erzählenden Passagen.

In den Abschnitten persönlicher Diktion (Monolog, Dialog, Rede; Gebet, geistlich ausgerichtete Reden usw.) tritt im Pleskauer Text das yart. fast ganz zurück - beide Partizipien zusammen bleiben zumeist weit unter $10 \mathrm{v} . \mathrm{Hd}$. Hierin hatten wir die Absicht des Autors erblickt, seine wörtlichen Reden ein wenig der gesprochenen Sprache anzunkihern.

Der Vergleich des statistischen Materials, das sich aus den Verbformen dreier Texte zusammensetzt, ließ die archaisierende Tendenz als bestimmenden Grundzug der beiden Kriegserzählungen hervortreten. Während in der Pleskauer Chronikerabihlung das umgangssprachlich als universales Präteritaltempus längst etablierte 1-Part. mit 42 v.Hd. die am stärksten vertretene Verbalkategorie darstellte, spielte diese Kategorie in den Kriegserzählungen eine ganz unbedeutende Rolle (Frequenz: zwischen 1 und 4 v.Hd.). Die archaisierende Tendenz der Kriegserzählung bzw. die gröBere Nähe der Chronikerzählung zur Umgangssprache bezeugt auch das hohe Vorkommen von Imperfekt-Belegen und von Partizipien in den Kriegserzählungen und deren Fehlen im Pleskauer Chroniktext. 
Abgesehen von diesen allgemeinen Beobachtungen stie $B$ uns die Auswertung des statistischen Materials auf ein Problem, dem auf den Grund $z u$ gehen wichtig zu sein scheint, wenn wir unserer Aufgabe, die beiden Kriegserzählungen zu charakterisieren und voneinander abzugrenzen, gerecht werden wollen: Offensichtlich unterscheiden sich die beiden Texte - der K-pler und Pleskau 1581 - in der Verwendung der Partizipien. Hatten wir anfangs die Vermutung geäubert, dab vielleicht im Pleskauer Text, der ja immerhin etwa ein Jahrhundert jünger ist als die K-pler Erzählung, gerade im Kampfbericht Elemente der Umbangssprache einfließen könnten - besonders l-Partizipien, so mußten wir feststellen, dab das Gegenteil der Fall ist - daß nämlich das buchsprachliche Partizip (insbesondere Part.praes.) im Kampfbericht seine höchste Frequenz erreicht: beide Partizipien kommen zusammen auf 41 v.Hd. Ob es sich hier um syntaktische, semantische oder stilistische Unterschiede handelt, werden die Einzeluntersuchungen erweisen. - Unterschiedlicher Gebrauch des Verb.fin. ist natürlich auch in Rechnung zu stellen. Daruber gibt uns die Statistik kaum Auskunft. Wir konnten beispielsweise auf häufige Verwendung des Praes.hist. im Pleskauer Text hinweisen - aber konkrete Ergebnisse werden uns erst die Einzeluntersuchungen bringen. 
III. Vorbemerkungen zu den Einzeluntersuchungen

Wenn wir uns nun der Behandlung der verbalen Kategorien ia einzelnen zuwenden, dann sei vorausgeschickt, daB der Schwerpunt der Untersuchung auf den Präteritaltempora und auf den Partizipien liegen wird. Die übrigen Kategorien Prösens, Putur, Konditional; aber auch Plusquamperfekt werden vorgestellt, damit man einen vollständigen Uberblick uber das verbale system der untersuchten Texte gewinnt und evt. selbst Vergleiche zu anderen Texten ziehen kann.

Die Pleskauer Chronikerzählung über die Annexion der Republik Pleskau 1510 durch Vasilif III. diente uns lediglich dazu, die archaisierende Tendenz der beiden Kriegserzählungen mit statistischem Material zu erhärten. In den folgenden Untersuchungen blelbt daher die Chronikerzählung unberücksichtigt.

Von einer Behandlung des Infinitivo haben wir abgesehen. Die Problematik des Infinitiva $18 t$ eine andere als die der von uns untersuchten Rategorien - Im Zusammenhang mit dem Infinitiv stehen syntaktische Pragen im Vordergrund ( $z . B$. der Infinftiv als objekt, unpersönliche Infinftiv-Konstruktionen usw.). Semantisch bietet der Infinitiv keine Schwierigkelten. Man könnte vielleicht dem Zusammenfall von Infinitiv und Supinum nachgehen - aber dieser Vorgang ist z.z. des Entstehens unserer Texte längst abgeschlossen. Man könnte nach der Porm des Infinttive (nach seiner Endung) fragen aber os lat nicht möglich, diese Prage zu beantworten, weil Malyšev in seiner Edition der Pleskauer Erzählung die Inf1nitiv-Endungen ( $-t_{1}$ und $-t_{b}$ ) normiert $q u$ haben scheint. Er erwahnt die rermutete Normierung nicht, da aber nicht eine eineige Endung auf $-t_{b}$ lautet, liegt diese Vermutung nahe. Er verfihrt so ähnlich mit dem Reflexivpronomen: ${ }^{22}$ Der Kopist hat es immer als Kurzel hochgestellt, und Malysev gibt es regelabig als -sja bzw. ca wieder. Vermutlich lot

22) Maly̌ev, Povest', S. 30. 
in der Hs. die Infinitiv-Endung durch ein hochgestelltes Kürzel bezeichnet, das Malyšev regelmäßig als -ti aufgelöst hat. - Im K-pler Text begegnen vier oder füf Infinitive, die auf $-t_{b}$ ausgehen, aber das sind solche Ausnahmen, daB man an ein zufälliges Auftreten denken möchte.

Die Kategorien, die wir in den Tabellen vorfinden, wollen wir zu drei größeren Komplexen zusammenfassen:

1. Präsens, Futur, Konditional

Diese drei Kategorien greifen so ineinander, daß eine volikommen getrennte Behandlung ständige Wiederholungen, viele Hin- und Herverweise erforderlich machte. Das Futur wird normalerweise durch Präsensformen sog. perfektiver Verben ausgedrückt - die seltene periphrastische Futurbildung interessiert uns nur wegen des Hilfsverbs, mit dessen Hilfe es gebildet ist. - Der Konditional tritt aus ähnlichen Gründen zu dieser Gruppe: Abhängige lleische- und Finalsätze, die heute mit Konditional gebildet werden, kommen in unseren Texten zwar gelegentlich auch in dieser Form vor, gewöhnlich aber finden wir die indikativische Konstruktion vor, wie wir sie aus dem Aksl. kennen: "da + futurisches Präsens".

2. Imperfekt, Aorist, 1-Partizip, (Plusquamperfekt) Wir wollen versuchen, den semantischen Wert vor allem der archaischen Kategorien $z u$ bestimmen, was ständige Gegenüberstellungen von Imperfekt und Aorist erforderlich macht. Auch wollen wir beobachten, wie sich die Aspektualisierung des Verbalsystems, die ja im 16. Jh. schon weit fortgeschritten war, auf den Gebrauch der alten Tempora auswirkt.

\section{Part.praes. und Part.praet.}

Hier interessiert uns a) die Frage nach deren Funktion(-en) uberhaupt in unseren Texten, b) die Frage, worin sich der Gebrauch der Partizipien in unseren Texten unterscheidet - damit in Zusammenhang stehend die Frage, ob der Pleskauer Text in seinem Gebrauch der Partizipien exemplarisch für den Makarij-stil oder das 16. Jh. ist. 
IV. Präsens - Konditional - Futur

Auf die Behandlung von Präsens-Formen imperf. Verben zur Bezeichnung der Gegenwart, wie sie uns etwa in wörtlicher Rede entgegentreten, können wir verzichten. An dieser Art, Gegenwart auszudrücken, hat sich vom Aksl. her bis hin zum Neuruss. so gut wie nichts geändert. Morphologische Besonderheiten scheinen in keinem der Texte auf. Unsere Texte reflektieren durchgehend den alten Zustand, wo eine Entwicklung stattgefunden hat - z.B. 2.sg. kommt nur auf -si endend vor, wobei allerdings auch gleichmäßige Auflösung hochgestellter Sigeln durch die Hrsg. unserer Texte in Rechnung zu stellen ist. Die 3.sg. und die 3.pl. erscheinen nur ganz selten und wohl eher zufällig mit der für das Altruss. charakteristischen Erweichung des Schlußkonsonanten - $t_{b}$; fast ausschließlich finden wir die ksl./südslav. Variante -tb, die sich in unseren Texten darin äußert, daß die entsprechenden Praes.-Formen auf $-t$ ausgehen.

\section{Praesens historicum}

Die hohe Frequenz der Präsens-Kategorie im Pleskauer Text beruht, wie bereits hervorgehoben, auf dem häufigen Vorkommen des Praes.h1st. Hauptsächlich begegnet es im ersten Drittel der Erzählung, wo Hintergrund und Vorgeschichte der in den Hauptteilen geschilderten Ereignisse, der Belagerung Pleskaus durch Stephan Báthory, dargelegt werden; wir hatten dies erste Drittel als Einleitung bezeichnet. In den Haupteilen, in denen der Autor aktuelles Geschehen darstellt, bevorzugt er das Präteritum und Partizipien.

Offensichtlich bedient sich der Pleskauer Autor zur Aufarbeitung der Vorgeschichte des Praes.h1st., um der einen oder anderen Schilderung, die zur. Beleuchtung des Hintergrunds aus der Vergangenheit nachgetragen werden muB, Aktualität $z u$ verleihen. In der Pleskauer Erzählung beherrscht das einmal gewählte Tempus oft einen ganzen Sinnabschnitt - das gilt auch für des Praes.hist.

Wir zählen 16 mehr oder weniger lange Abschnitte, in denen 
das Praes.hist. dominiert. ${ }^{23}$ Der Autor scheint, sich von den Praes.-Formen auch einen emotionalisierenden Effekt versprochen zu haben, denn von den genannten 16 Abschnitten mit vorherrschendem Praes.hist. beschreiben allein neun Abschnitte Handlungen des Zaren. Vielleicht hängt diese ständige 24 Aktualisierung der Handlungen des Zaren durch Praes.hist. mit der ideologischen Uberhöhung seiner Gestalt zusammen, wobei das Präsens Allgegenwart des Zaren suggerieren soll, wie diese ja auch Gott, der Gottesmuter und den Heiligen eigen ist:

$36 / 34$ "MOLEBNOE CARSKOE. ${ }^{25}$ Prichodit že blagovernyj gosudarb $v$ sobornuju cerkovb Zivonačalbnye Troica i pripadaet so slezami pred svjatym obrazom živonačalbnye troica $i$ molit $v$ troicy slavimago edinago boga, daby emu, gosudarju, bog podal milostb svoju svyše i ... PLACEVNOE. Tako že prichodit pred čjudotvornuju ikonu prečistyja bogorodica, slezy že mnogi prolivaet pred svjatym eja obrazom: ' ...'"

Als Beispiel für Praes.hist., das eine nicht auf den Zaren bezogene Beschreibung gibt, soll die anschlieBende Satzfolge gelten:

$52 / 3$ "SOBIRANbE MNOGICH ORD. Vkupe že i sami mnogočislenyja zemli v litvu ch korolju k Stepanu sobirajutca, na slavnyj Pskov grad bezčislenoju ratbju

Mnogija že ordy i mnogija zemli s litovskim vooružajutca. korolem Stepanom podymajutca na slavnyj $i$ velikij grad Pskov. Slavy radi grada sobirajutca jazycy mnozy, im že imena sutb sija: ...n

23) Gegenstand der Beschreibung - der Zar: 36/22 ff., $-/ 34$ ff., $37 / 6$ ff. $39 / 12$ ff. $-/ 22$ ff., $42 / 17$ ff., $43 / 25$ ff. $46 / 6$ ff., 47/21 ff.; im Mittel punkt steht andere Personengruppe: $55 / 18$ ff., $44 / 12$ ff., $-/ 27$ ff., $42 / 9$ ff., $49 /$ 10 ff., $54 / 2$ ff., $91 / 16$ ff.

24) Präteritum im Zusammenhang mit Handlungen des Zaren ist selten, z.B. $35 / 21,36 / 1$ ff.

25) Mit Großbuchstaben werden Uberschriften im Text wiedergegeben. 
Die emotionalisierende Firkung, die der Autor sicher erreichen möchte, wird in obigem Abschnitt noch durch Rhythmisierung der Sprache und verbalen Reim ${ }^{26}$ verstärkt. Dies ist die einzige Textstelle, an der wir diesen Reim, der von anderen verbalen Kategorien gebildet, uberall anzutreffen ist, mit Praes.-Formen vorfinden.

Im Gegensatz zum Pleskauer Text kommt das Praes.h1st. in der K-pler Erzählung nur gelegentlich vor, und zwar als Einzelerscheinung, z.B.:

58/19 "Sija ubo vsja uvedev togda vlastrujuščei turky, bezbožnyj Magumet Amuratov syn, $v$ miru $i v$ dokončanbe syi $s$ carem Konstjantinom, abie zbiraet voja mnoga zemleju $i$ morem 1, prišed vnezaapu, grad obstupi so mnogoju siloju.n

Hier handelt es sich um eine Kernstelle der Erzählung: Mehmed II. samelt ein Heer, um $\mathrm{K}$-pel anzugreifen; vgl.:Auch der Pleskauer Autor schildert den entsprechenden Tatbestand im Praes.hist.(52/3 ff.). Jedoch begnügt sich der $\mathrm{K}$-pler Autor damit, den entscheidenden Vorgang präsentisch auszudrücken, die Nebenhandlungen aber im Prikteritum zu belasen.

Die Beispiele, die Otten aus der "Stepennaja kniga" für Proes.hist. vorfuhrt, entsprechen genau dem vereinzelten Auftreten von Präsens-Formen im K-pler Text. ${ }^{27}$ Auch die von Nikiforov ${ }^{28}$ vorgestellten Beispiele für Prass.hist. erwecken den Eindruck, als handele es sich um vereinzelte Erscheinungen im präterital bestimmten Kontext.

26) Lausberg, Handbuch I, $\$ \S 725$ f.: gleichtönender Ausklang aufelnander folgender Kola - Homoeoteleuton = Reim. Gleicher Ausklang zweier Worte im Satzinneren bzw. an beliebiger Stelle - Homoeoptoton, Lausbers. Elemente $88361 \mathrm{f}$ - etwas anders in: ders, Handbuch I, $88929 \mathrm{ff}$.

27) otten, Pin. Verbalformen, S. $97 \mathrm{f}$.

28) Wikiforov, Glagol, S. $174 \mathrm{f}$. 


\section{Unabhängige Aufforderungssätze}

In beiden Erzählungen kommen - in wörtlicher Rede - Aufforderungssätze vor, die durch "da + perf. Präsens" gebildet werden. Dem futurischen Präsens entspricht auch die Bedeutung der Sätze: Der Beginn einer Handlung wird entweder sogleich in Angriff genommen oder aber (flehentlich) erhofft:

'so wollen wir ...',' 'so laßt uns denn ...'; 'soll er doch ...', 'möge er doch ...' usw.

Beispiele aus der $\underline{K}=\underline{p l} \underline{\text { er }}$ Erzählung:

$60 / 45$ "'ne dejte, no da vozbmut i turki, a u nich my vozbmem Carbgrad'."

- 'labt nur, sollen doch die Türken K-pel erobern wir werden es ihnen schon abnehmen'.'

$64 / 31$ "...., no da pošlem k nemu o miru, ..."

64/36 "'...; no da izydet cesarb iz grada v Ammoreju, takože i patriarch $i$ vsi ljudie, iže voschotjat, ..."

$62 / 12$ "'dnesb da umrem za veru christbjanskuju ..."

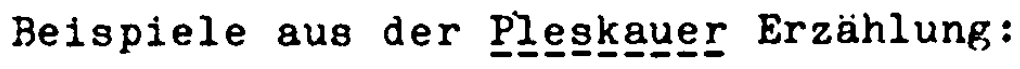

42/6 "'Volja gospodnja da budet, ..." (so auch 43/24).

$44 / 21$ "'Bog, reče, i bogorodica $i$ svjatii vsi s vami da budut'."

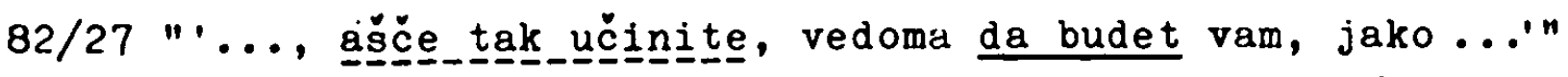
...., wenn ihr dies tut, dann sollt ihr wissen/dann seid dessen versichert, daB...'

83/4 "Aśče_ne_pokoritesgja, ni edin milostb uzrit, no gorbkimi smertbmi vse da umrut'."29

Die Beispiele zeigen deutlich, daß dieser Satztypus in der $\mathrm{K}$-pler Erzählung - der häufigen und individuellen Verwendung nach zu urteilen - noch lebendig ist. Im Pleskauer Text dagegen wird diese Form des unabhängigen Aufforderungssatzes

29) A. P. Jakubinskij: Istori ja drevnerusskogo jazyka. I. 1953. S. 298: "asce + perf.Praes., da + perf.Praes." $=$ ksl. Konstruktion, z.B. in der PVL. - "oze + perf.Praes., to + Inf. ${ }^{n}=$ altruss. Konstruktion, z.B. in "Russk. Pravda". 
nur noch schablonenhaft gebraucht - entweder in tradierten Formeln ("Volja gospodnja da budet") oder in konditionalen Satzgefügen, wo diese Wendung dem Hauptsatz (= der Folge der geäuBerten Bedingung) Nachdruck verleiht.

\section{Abhängige Final- und Heischesätze}

Es war bereits davon die Rede gewesen, daB sich die Praes.Formen unserer Texte in ihrer großen Mehrzahl grundsätzlich voneinander unterscheiden. Wir hatten festgestellt, daB das Praes.hist. im Pleskauer Text ein sicherlich bewuBt angewandtes Stilmittel darstellt, das dazu dient, bestimmte Vorgänge der Vergangenheit zu aktualisieren. Im K-pler Text aber, so hatte uns ein Blick auf die Tabelle der Verbalformen gezeigt, dient nur ein Drittel der Praes.-Belege zur Bildung des Praes. hist. Die anderen zwei Drittel stehen in abhängigen Wunschund in Finalsätzen, die mit "da" eingeleitet werden. ${ }^{30}$ Meist handelt es sich in diesen Konstruktionen um Praes.-Formen mit Zukunftsbedeutung - also perfektiver Verben. 31 Das gelegentliche Vorkommen durativer, iterativer u.a. imperfektiver Praes.-Formen zeigt vielleicht, dab im Rahmen dieser etwas Zukünftiges - ein Wollen, Wünschen, Planen oder Hoffen - aus drückenden Konstruktion noch ein Rest der alten Futurbedeutung, die ja in älterer Zeit auch Durativa besaßen, lebendig wurde. 32

Bei dieser Konstruktion von abhängigen Wunsch- und von Finalsätzen ("da + (im-) perfektives Präsens") handelt es sich offenbar um eine südslavische Konstruktion, die mit den aksl. Denkmälern die altruss. Schriftsprache von ihren ersten An-

30) Bei folgenden Zahlenangaben kann es zu kleinen Differenzen zu früheren Angaben in der allgemeinen Ubersicht kommen - jene bezogen sich meist allein auf die berichtenden Bereiche, während wir uns hier auch auf die persönliche Diktion beziehen.

31) Bräuer, Konjunktiv, S. 25: In den aksl. Evange lien-Ubersetzungen sind 176 griech. Konstruktionen mit lre wieder gegeben durch 111 "da + perf. Präsens" 51 mit Kondit.

$$
51 \text { nda + imperf. " " } 6 \text { mit Konklar. }
$$

32) Bräuer, Konjunktiv, S. 48. A. A. Potebnja: Iz zapisok po russkoj grammatike. Bd. 4. M.-L. 1941. S. 129. 
fängen an begleitet und natürlich stark beeinfluBt hat. Auf ost- (und auch west-)slavischem Boden mögen aber Final- und abhängige Heischesätze mit Konditional konstruiert worden sein. Nur so ist das vergleichsweise häufige Auftreten des Konditional innerhalb abhängiger Wunsch- und Finalsätze in Werken altruss. Provenienz bereits in den ältesten Denkmälern zu erklären. Die gesamte altrussische Literatur zeigt die allmähliche Verdrängung der Indikativischen Konstruktion ("da + (perf.) Präsens") durch den Konditional, wie Bräuer in seiner Monographie "Untersuchungen zum Konjunktiv im Altkirchenslavischen und im Altrussischen" dargestellt hat. Innerhalb der erzählenden, der literarischen Tradition verpflichteten Genres hält sich - wie gerade die K-pler Erzählung zeigt - die indikativische Konstruktionsweise noch lange, zumal der Zweite Südslavische Einfluß sicher auch ihr zu neuer Ausbreitung verholfen hat. Die altrussischen Briefe und Urkunden zeigen ein ganz anderes Bild. Bezüglich des 13. bis Mitte des 14. Jh.s sind Bräuers Aussagen 33 noch vage, Finalsätze werden teils mit Indikativ, teils mit Konditional konstruiert. Für die nächsten anderthalb Jahrhunderte (bis 1500) ist das Haterial reicher, Bräuers ${ }^{34}$ Aussage konkreter: In Final-sowie in abhängigen Wunschsätzen findet sich fast ausschlieblich die Konstruktion mit Konditional, als Konjunktion wird "čtoby" gebraucht, ganz selten "daby" bzw. seltenes "aby" in Heischesätzen. Für das 16. Jh. kann Bräuer 35 schlieblich feststellen:

"Die konditionale Konstruktionsweise ist also in den Urkunden dieser Zeit mit einer solchen Häufigkeit anzutreffen, daß sie als Norm gelten muß. Die indikativische Konstruktion bildet daneben gleichsam nur eine Ausnahmeerscheinung, wovon manches durch das Kirchenslavische zu erklären ist."

Im folgenden wollen wir eine Tabelle vorstellen, die die Konstruktionsweise von Final- und abhängigen Wunschsätzen in

33) Bräuer, Konjunktiv, S. $178 \mathrm{f}$.

$34)$ Bräuer, ebda., S. 181 ff.

35) Bräuer, ebda., S. 185 ff., Zitat: S. 189. 
unseren Texten in ihrer Häufigkeit vorfuhrt. Bräuer ${ }^{36}$ folgend, sondern wir einen Satztypus aus, der in besonderem MaBe die gedankliche Nähe zwischen Pinal- und zwischen abhängigem Wunschsatz demonstriert und gleichzeitig eine besonders intensive Variante des Wunschsatzes darstellt - nämlich jene Satzkombination, die ein 'Losschicken mit einem Auftrag' ausdrückt: "A schickt zu B (C), damit C etwas tue.", z.B. KP 77/5 "I posla em (= ju - G.Str.) k patriarchu, da oblożit ju zlatom $i$ srebrom i sochranit ju, ..." - Und (der Sultan) schickte es (das Haupt des Kaisers) dem Patriarchen, damit dieser es mit Gold und Silber schmuicke und es bewahre ...'

Konstruktionen, die hier unter "da" aufgeführt sind, sind gelegentlich durch "jako" noch akzentuiert" - "jako da".

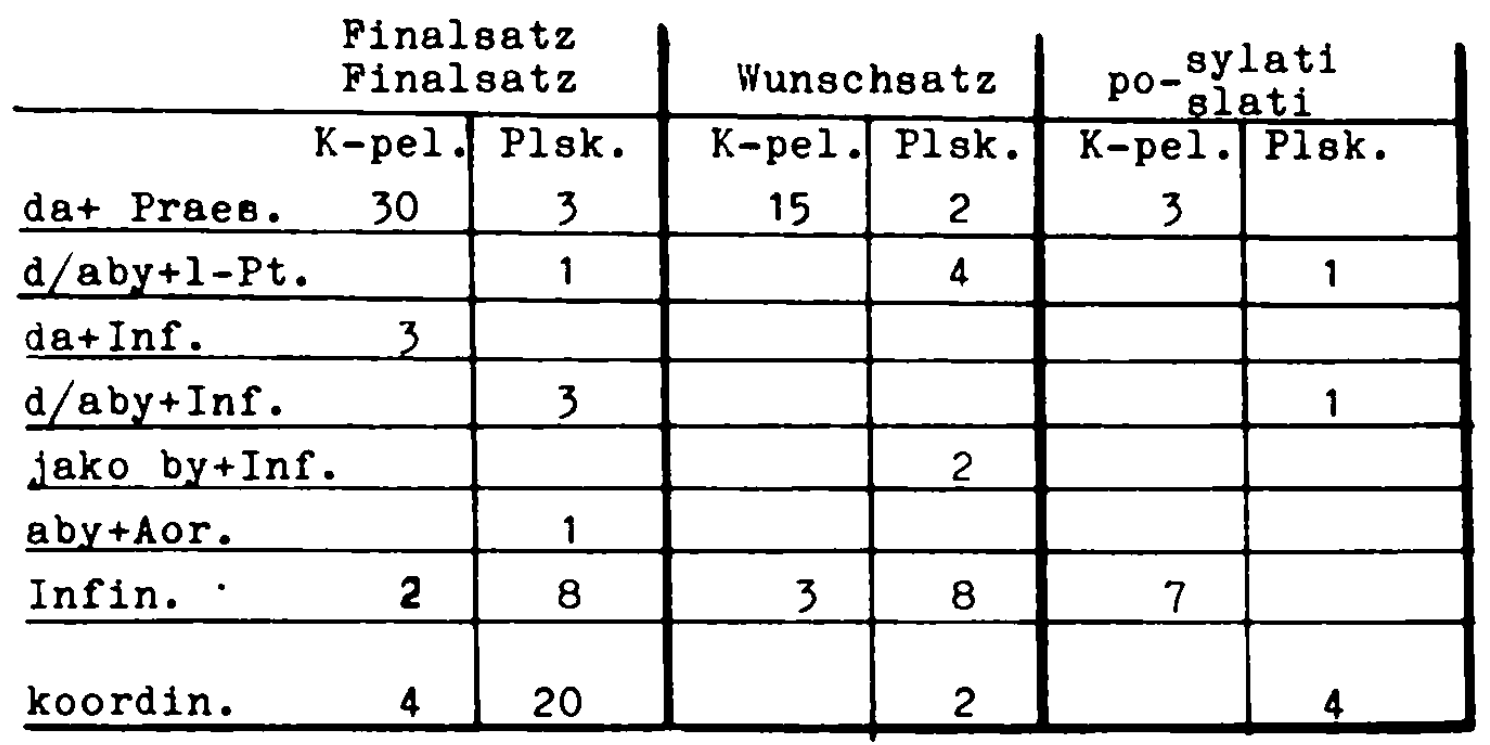

Wir brauchen diese Zahlen nicht im einzelnen zu interpretieren. Uns geht es hier um einige allgemeine Beobachtungen. Die Aufstellung zeigt ganz deutlich, daB die K-pler Erzählung abhängige Heische- und Finalsätze vorwiegend indikativisch ("da + (perf.) Präsens") konstruiert, daB auch infinitivische Konstruktionen (mit und ohne "dan) einen gewissen Anteil stellen.

36) Bräuer, Konjunktiv, S. 16.

37) Bräuer, ebda., S. $80 \mathrm{f} . ; \mathrm{vgl}$, auch A, Vafllant: Manuel du vieux slave. Bd. 1: Grammaire. Paris 1948 (Collection de manuels publiée par l'Institut d'Etudes slaves.6). "jako da" deutete ursprünglich eine konsekutive Nuance des Pinalsatzes an, dann als Verstärkung verallgemeinert. 
Am Pleskauer Text fällt die Vielfalt der Konstruktionsweisen auf. Die sudslavisch ${ }^{38}$-kirchenslavische indikativische Konstruktion macht einerseits im Vergleich mit der entsprechenden Bildungsweise in der K-pler Erzählung nur einen geringen Prozentsatz aus und stellt andererseits auch im Pleskauer Text innerhalb der Final- und abhängigen Heischesätze nur einen kleinen Anteil. Konditionale Bildungen dominieren auch im Pleskauer Text nicht, doch immerhin sind sie etwas stärker vertreten ( 6 Mal) als die Bildungen mit "da + (perf.) Praes." ( $5 \mathrm{Mal}$ ). Abgesehen von einer Bildung "aby + Aor." (s.u.) finden wir im Pleskauer Text vorwiegend reine Infinitiv-Konstruktionen, gelegentlich mit einleitendem "daby" oder "aby" 39 oder "jako by".

Final- und abhängige Heischesätze, konstruiert mit Infinitiv (oft durch "aby" bzw. "daby" eingeleitet), sind sicher als Kussismen oder Ostslavismen zu werten. Während Bräuer ${ }^{40}$ an den aksl. Evangelien-Übersetzungen aufzeigen konnte, da $B$ griech. Infinitiv-Konstruktionen (nach ǘre, rov, cis ró, Érí,

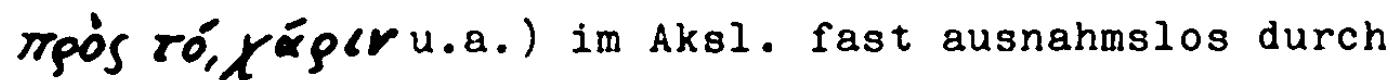
"da + (perf.) Praes." wiedergegeben wurden, erscheinen Infinitiv-Konstruktionen innerhalb von Final- und abhängigen Wunschsätzen bereits früh in den altruss. Denkmälern. ${ }^{41}$

38) Bekanntlich haben die südslavischen Sprachen fast durchgängig die indikativische Konstruktionsweise "da + perf. Präs." beibehalten, vor allem nach Verben, die "semantisch den iillen eines Subjekts bezeichnen" - B, Panzer: Der Slavische Konditional. Porm-Gebrauch-Funktion. München 1967 (Porum Slavicum 14). S. 50; vgl. ebda. S. $63 \mathrm{ff}$. und S. 69 f.=Panzers Beispiele für Final-und Wunschsätze aus dem südslavischen Bereich.

39) Zwischen "daby" (<"da by") und "aby" (<"a by") besteht genetisch kein Zusammenhang. Borkovskij, Istor. grammatika, S. 502 und ders.: Sintaksis drevnerusskich gramot. II. Sloźnoe predloženie. AN SSSR M. 1958. S. 163 f. hält "aby" für westruss. Variante - sie erscheint in Plesk., Novgor., Laurent.- und Hypat.-Chronik; auBerdem in ukrainischen, weiBruss., polnischen und cechischen Denkmälern.

40) Bräuer, Konjunktiv, S. 33 f., S. 75 f., S. 83 ff.

41) Bach Bräuers Aufstellungen wächst mit der Zeit der Anteil an Inf.-Xonstruktionen im Altruss.: Suzdaler Chr. (Laur.Hs J - Bräuer, S. 106; Hyp.-Chr. - Bräuer S. 117; Soph.-Chr, - Bräuer S. $137+142 ; 20+3$. Plesk. Chr. - Bräuer S. 146 $+153 \mathrm{f}$. 
In der Vielfalt der Formen, wie sie uns im Pleskauer Text begegnen, manifestiert sich das Eindringen der Umgangssprache in diesen Text. Dies wird umso deutlicher, wenn man daran denkt, daB der Pleskauer Autor um das Einbringen ksl. Formen bemüht ist - so verwendet er nie das russ. "čtoby", sondern stets ksl. "daby" bzw. "aby", das er vermutlich wegen der klanglichen Ähnlichkeit ebenfalls für ksl. hält. ${ }^{42}$

Auf die unterste spalte der Tabelle, die mit "koordiniert" bezeichnet ist, kommen wir etwas später zu sprechen.

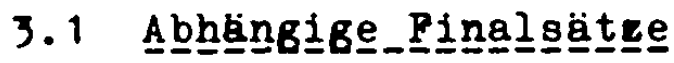

3.1.1 K-pler Text: Abhängige Finalsätze

62/4 "'...: mužajtesja i krepitesja.... jako da i nas proslavit vseščedryj bog'."

63/6 "Bezvernyj že trupija svoich ljudej ... pomyšljaše metati ich poroky $v$ grad, da sognijut i usmerdjat grad; ..."

$73 / 18$ "... no da sbudetsja božie izvolenie, sovet toj ne sveršisja."n 43

So ähnlich: $65 / 10$ und $76 / 38$.

$74 / 34$ ".... (stratigi) otvedoša cesarja, da ne vsue umret;..."

Die drei Belege für "da + Infinitiv", die wir in der Tabelle verzeichnet finden, bilden alle den Finalsatz mit "jako da", und den Nebensatz selbst bildet ein Debitiv - ein Infinitiv mit Dativ der Person (Dcl):

$56 / 38$ "... dast im žiti v grade 80 ... cesarskymi činy, jako i svoja domy 1 otečestva im zabyti." .... er ließ sie in der stadt ... wohnen, damit sie ihre Hauser und ihre Heimat vergäßen.'

42) Nikiforov, Glagol, S. 207, Borkovgidy, Istor. grammatika, S. 501, Otten, Pin. Verbalformen, S. 473.

43) "se že vse bysţ da sbqdet sę rečenoje ot bogan ut. 1,22 (Suprasl.?) - zitiert bei G. Weinauer: Die Anmendung des Konditionalis im Aksl. Masch.Diss. Göttingen 1951. S. 19. 
70/41 ".... i izmi nas, obzemše desnoju ti rukoju, ... jako da $i$ voem proslavitbsja i vozblagodaritb vsesvjatoe i velikolepnoe imja troe'."44

.... reibe uns heraus, ..., damit alle deinen ... Namen preisen ...'.'

vgl. weiter $55 / 6$.

Der reine Infinitiv in Finalsätzen steht im K-pler Text nur in solchen Sätzen wie dem folgenden, der viele finale Teilglieder hat. Zum SchluB scheint sich der Autor der Konstruktion nicht mehr ganz sicher zu sein und bedient sich des Infinitiv:

$58 / 35$ "... (cesarb povele) vsich 1 judej $i$ klakoly ratnye na vsech stranach izstaviti, da kojżdo ich vestb i chranitb svoju stranu, i vsja jaže na brannuju potrebu ustrajaet, $i \frac{d a}{4}$ betsja s turki so steny, $i$ iz grada ne vyezžati. "

'... (der Kaiser befahl,) alle Leute und die Sturmglokken auf allen Seiten aufzustellen, damit jeder seinen Platz kennt und verteidigt, alles den Notwendigkeiten des Kumpfes entsprechend richtet, von den Mauern herab

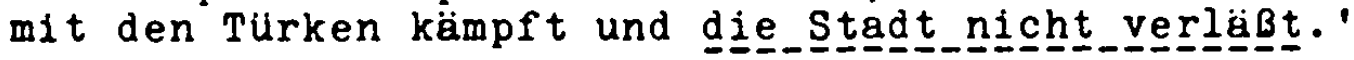

\subsubsection{Pleskauer Text A Ahängige Finalsätze}

$37 / 10$ "Pomolisja, bogorodice, ... o rabe svoem i da ispolnit bog žalanie serdca moego, jako da vozvysit desnicu grešnago raba tvoego na vragi i nasilujuščich na chrestbjany, ..."

'Bete um deines Knechtes Willen,.... daß Gott meinen Herzenswunsch erfüllt, damit er meine Rechte (Variante Skripil': "desnicu moju"), (die Hand) deines Knechtes, gegen die Feinde erhebt, die das Christenvolk bedrängen, ...'

$38 / 22$ ".... i ich żeny $i$ deti, umertviti povele, da $i$ protćii strach prilmutb. 45

'.... befahl er, ihre Prauen und Kinder zu töten, damit auch die anderen von Angst und Schrecken ergriffen würden.'

44) Seltene Fälle von Infinitiv auf ts endend.

45) Seltene Fälle von 3.8g.ps. und 3.pl.ps. auf -tb endend. 
47/18 ".... (vam) grada Pskova predaju, jako da ... eliko koego bog vrazumit da utveržajutca vo grade Pskove'." ' .... ich übergebe (euch) Pleskau, damit ... ihr euch - wie es Gott einem jeden eingibt - in der stadt verschanzt'.'

Durch "utveržajutca" 3.pl. ist die Konstruktion etwas verdunkelt: die 3.pl. lehnt sich an "koego" - 'einen jeden' als logisches Subjekt ('ein jeder' = alle).

Nur ein Pinalsatz wird durch Konditional gebildet:

$87 / 19$ "..., poćali kamennuju stenu podsekati kirkami i ..., aby vsja ot toe storony stena podsečensja ich radi na Velikuju reku povalilasja."

'.... und sie begannen, die Stadtmauer mit ihren Hacken zu untergraben, damit diese schlieBlich ... zum GroBen PluB hin einstürzen sollte.'

Die Finalsätze, die durch "d/aby + Inf." gebildet sind, haben entweder kein subjekt $(61 / 35)$ oder das logische subjekt als Dativ der Person ( = Debitiv/DcI) (82/19).

$61 / 35 " . .$. , velikija gory $v$ zemIi sogradiša, daby ne videti chodu ich so gradny ja steny." ......... damit man nicht sehen konnte, wenn sie (in den Gängen) herumliefen.'

$82 / 19$ "'... ne na to esmi priidoch pod grad vaš Pskov, aby ne vzem mne ego ottyti."n ' ... ich bin nicht deshalb nach Pleskau gezogen, um wieder abzuziehen, ohne die Stadt erobert zu haben."

Im folgenden Beispiel wird ein Finalsatz durch "aby + Aor." gebildet:

87/29 "... : povelevajut, smolbe ... na nich ... metati, aby rospaleniem ognja ščity ich zagorešasja,

i gorbkotoju radi dyma i samem im iz-pod steny vybegati (1) li tamo zgarati."

¿... damit sich ihre schilde entzündeten und sie selbst des Rauches und der Hitze wegen fliehen oder verbrennen mübten.'

Bräuer meint, vielleicht sei der Satz "aby ... zagorešasja" ursprünglich ein Konsekutivsatz (mit der Konjunktion "jako") gewesen, der dann durch Auswechselung der Konjunktion in einen Finalsatz umgewandelt werden sollte, "da die'Polge' hier 
zugleich eine finale Nebenbedeutung hatte. Nur ist die Umwandlung unvollständig geblieben. ${ }^{46}$ Mir scheint aber eher unkorrekte Verwendung des Aorist vorzuliegen, wie er für das 16. Jh. ublich ist. 47

Wenn wir im Pleskauer Text eine Anzahl reiner Infinitiv-Konstruktionen vorfinden, die im Grunde als Finalsätze anzusprochen sind, dann äuBert sich hierin eine Erscheinung, die in der K-pler Erzählung (s.0.) bereits angelegt war - wir fanden eine Infinitiv-Konstruktion als letztes Glied einer Aufzählung von Finalsätzen (etwas Ähnliches gibt es auch bei den Heischesätzen, und bei den Finalsätzen nach posylati, poslati" haben sich die reinen Infinitiv-Konstruktionen bereits durchgesetzt - s. Tabelle). Heute ist die Infinitiv-Konstruktion der Bildung mit "čtoby + 1-Part." gleichwertig, ja, der Akademiegrammatik nach, knapper und die Aussage treffender wiedergebend als die Konstruktion nčtoby + 1-Part.". ${ }^{48}$

76/27 "Mladyja že i sverstnyja, krepkija telesy, dostalb s pristupa litvu pribivati oružie nošachu." '... schleppten Waffen (herbei), um den vom Angriff 49

$82 / 4$ "..., ovo że suchuju sejanuju izvestb prigotoviša, litovskomu že voinstru bezs-tudngye_ich '... um den Litauern die Augen (mit dem Kalk) zuzuschütten ( $=$ zu verbrennen).'

$97 / 6$ "'Se daju vam vlastb nastupati nązzmiju ..."n (Lk. 10,19)

46) Bräuer, Konjunktiv, S. 244.

47) S. L. Baženova: Pridatočnye predloženija celi $v$ drevnerusskom jazyke. Po pamjatniki 16-17 vv. Avtoreferat kandid. dissertacii. M. 1954. S. 10 - Pinalsätze mit Aorist (nach "da" und "cton") waren bis ins 17. Jh. anzutreffen. Bei Borkovskij, Sintaksis, S. 163, Anm. 136.

48) Grammatika sovremennogo rysskogo literaturnogo jazyka. AN SSSR M. 1970. S. 706, \& 1559: Voraussetzung für die Inf. - Ronstruktionen - a) Subjekt in Haupt - und Kebensatz ist gleich, b) Subjekt des Nebensatres ist (dort unausged rückt) objekt ("adressat") in Hauptsatz - a) $76 / 27$ $+82 / 4$, b) $97 / 6$ unserer obigen Beispiele.

49) "dostalb" - Srezn. I, 712: 1. "sovsem", 2. "ostalbnoe". vgl.: $76 / 20$ "vam ... veleno ... ostatok litvy pobivati." 
3.2 Abhänglge Helschesätze und

abhängige Sätze nach Verben des Schickens

Unsere Graphik zeigt, daB die Verhältnisse bei diesen Sätzen ähnlich liegen wie bei den Finalsätzen: klare Dominanz indikativischer Konstruktionen im $\mathrm{K}$-pler Text, Ansätze von Infinitiv-Konstruktionen, deren Dominanz nach Verben des Schikkens. Im Pleskauer Text erstaunt dagegen die Vielfalt der Konstruktionsweisen. Da letztere sich aber in beiden Texten nicht grundsätzlich ändern, mag im folgenden je ein Beispiel für die wichtigsten Erscheinungen genügen:

3.2.1 K-pler Text: Abhäng1ge Heischesätze ...

$76 / 33$ "I, obrativsja, reče bašam i sančak-beem, da zapretjat vaemu vojsku i vsjakomu činu moich vrat, da ne dejut vesb narod gradckij $i$ žen $i$ detej...n .... sagte/befahl er seinen Paschas .... daB sie dem ganzen Heer und allen Wurdenträgern verbieten sollten, die Stadtbevölkerung zu drangsalieren ...' $60 / 33$ "Cesarb že zapoveda, da ne dejut ich ni kotoroju
branbju, ..." 50 .

$63 / 45$ "... (bezvernyj) vskore zapoveda tury prikatiti $k$ gradu vaemi silami, ...n

Die belden letzten Belege zeigen die Tondenz auch des $\mathrm{K}$-pler Autors zur Infinitiv-Konstruktion.

$60 / 17$ ".... i posila cesarb $k$ patriarchu, da povelit svjaščennikom $i$ ds jakonom sobrati mertvyja ..."

$76 / 20$ "... (Magumet) pogsla sanćak-beev po vsem ulicam s mnogimi ljudbmi breči izrady."

'... und er schickte seine sandschak-Beys aus, damit sie Verrat verhindern sollten.'

Der letzte Beleg mit Infinitiv-Konstruktion entspricht nicht ganz dem Bräuerschen Typus "A schickt B (zu C), damit C etwas tue." - Hier handelt es sich um den Typus "A schickt B,

50) Die Indikativ-Konstruktion ist nicht etwa von der Verneinung abhängig - $\nabla$ gl.: RP $62 / 45$ "... (patriarch) zapovedaja voem ljudem, .... de poidut $\dot{k}$ svoemu prichodü, ..." 
damit B etwas tue." Diesen Typus können wir eher als Variante des abhängigen Heischesatzes bezeichnen, ungefähr entsprechend folgendem Typus: "A befiehlt B, etwas zu tun." Wir haben diese Variante, die im $\mathrm{K}$-pler Text verbreitet ist (s. Tabelle 5.277 - 7 Belege), deshalb vorgestellt, um $z u$ demonstrieren, dab Infinitiv-Konstruktionen auch im K-pler Text eine gewisse Rolle spielen.

\subsubsection{Pleskauer Text: Abhängige Heischesätze ...}

68/3 "Molim že tvoju preumnožennuju lasku, da otpustísi $i$ poslĕsi nas napred $v$ zamok Pskova $i$ da ne pochvaljatca pred toboju rochmisty, ..."

- Wir erbitten von dir die... Gnade, dab du uns nach vorn zur Pestung Pleskau ... schickst, damit sich die Rottmeister vor dir nicht bristen...

Der zweite Teil des abhängigen Satzes ("da ne pochvaljatca ..." ) ist - s. Ubersetzung - final aufzufassen, und zwar abhängig von "posleši nas napred ...n51

$37 / 2$ n... (gosudarb) molit $v$ troicy slavimago edinago boga, daby emu, gosudarju, bog podal milostb svoju svyše

$i$ pobedu na nevernye svoja vragi ..."

$56 / 6$ "... archiepiskop pišet,

aby besprestani $v$ sobore neoslabno molebny peli, tako že i po domam denb i nošç boga molili za..., daby gospodb otvratil pravednyj svoj ... gnev ... $i$ prizrel by gospodb ... na Pskov grad,

$i$ ne predal by ego $v$ ruce vrag, ...n

- ... der Erzbischof schreibt, daB sie in den Kirchen ständig Bittgesänge abhalten sowie Tag und Nacht Gott zu Haus darum bitten sollten, daB er seinen berechtigten Zorn abwenden und auf Pleskau herabblicken und es nicht in die Hand der Peinde geben möge.' Hier sind zwei Heischesätze ineinander verschachtelt der eine ist sbhängig von "pišet", der andere von "(aby) molili". An diesem Abschnitt ist die bereits

51) Bräuer, Konjunktiv, S. 244, führt in seiner kurzen Darstellung der Final- und Heischesätze im Pleskauer Text dies Beispiel auch vor, jedoch zur Gänze als Heischesatz. 
einige Male erwähnte Vorliebe des Pleskauer Autors zu erkennen, in einem bestimmten Sinnabschnitt eine verbale Rategorie in den Vordergrund zu rücken, wodurch verbaler Reim innerhalb des Satzes oder, bei entsprechender Wortstellung, sogar am Satzende erzielt wird.

$91 / 24$ "..., nyne (korolb) že sam sovetuet

2 gosudarem našim carem ... mir vosprijati."

Fast die gleiche Konstruktion begegnet einige zeilen über dieser Belegstellte:

$91 / 19$ "...; vkupe že sovetútjut,

jako by choti z gosudarem našim, ... mir vosprijati."

Der Unterschied $z$ wischen beiden Konstruktionen - einmal mit reinem Infinitiv, einmal mit "jako by + Inf." bleibt unklar. Der letzte Satz hebt wohl stärker die Absicht hervor, mit dem zar in Verhandlungen treten zu wollen, während der erste Satz ( $91 / 24$ mit reinem Infinitiv) ausdrücken mag, dab die Verhandlungen bereits im Gange sind.

Wie aus der Tabelle - 5.277 - zu ersehen ist, dominiert im Pleskauer Text die Bildung der Heischesätze durch reinen Infinitiv. So sei abschließend hierzu noch ein Kontrastbeispiel zum oben zitierten Beleg 56/6 angefüht:

$55 / 14 ":$. (gosudarb) svoi carskie gramoty pišete: neoslabno že $i$ mužestvenno vo osade byti $i$..."

Für die Variante der Heische- und Finalsätze nach Verben des Schickens haben wir zwei Belege:

48/35 "Po okolbnim že selom $i$ volostem tako že posyla ąsée, daby koždo v svoi približnye gorody echali ..."

$91 / 27$ "... (koroIb) k gosudarju goncov svoich posylaet, aby poslom u nich sъezd učiniti."

Die Debitiv-Konstruktion (DcI) ist durch das einleitende "aby" noch unterstrichen ('... schickte zum Zaren, /damit dieser veranlasse/, dab die Gesandten zusammenträfen/zusammentreffen sollten. '). 
Der Vergleich beider Texte daraufhin, wie sie Pinal- und abhängige Wunschsätze bilden, zeigte abermals, daß der K-pler Autor die ksl. Normen auf's Beste beherrscht - in der $K-p l e r$ Erzählung dominieren die indikativischen Konstruktionen "da + (perf.)Praes." in beeindruckender Weise (48 indikat. Bildungen stehen 15 Inf.- Konstruktionen gegenüber). Der Pleskauer Autor ist dagegen stark von den Sprachnormen seiner Zeit geprägt: Indikativische Konstruktionen begegnen selten (5 Mal); die Bildungsweise mit Infinitiv ist vorherrschend (22 Mal) und reflektiert sicher auch die gesprochene Sprache wip die Konditional-Konstruktion, die etwas stärker vertreten ist als die indikativische Bildung ( $6 \mathrm{Mal})$.

Darüber hinaus fällt überhaupt auf, daß Satzgefüge, die wir als final oder einen Wunsch ausdrückend bezeichnen können, im $\mathrm{K}$-pler Text mit insgesamt 63 Belegen (indikativische und Infinitiv-Konstruktionen zusammen) beinahe doppelt so häufig vertreten sind wie in der Pleskauer Erzählung (alle Bildungsweisen zusammen: 33 Sätze).

\subsection{Unausgedruuktes_finales}

Das heibt aber nicht, daB der $K$-pler Text vom Inhalt her mehr finale oder Wunschverhältnisse anbietet als die Pleskauer Erzählung. Hierin äußert sich vielmehr die bereits angesprochene Neigung des Pleskauer Autors zur Parataxe. Wir haben versucht, in beiden Texten Satzpaare aufzufinden, die unausgedrückt ein finales oder Wunschverhältnis beinhalten das Ergebnis dieser Suche schlägt sich in der letzten Spalte unserer Tabelle auf S.277: "koordiniert" nieder. Selbstverständlich ist die Beurteilung, ob zwei in Parataxe stehende Sätze innerlich durch ein z.B. finales Verhältnis verbunden sind, subjektiv. 2weifel in dieser Richtung können nur die Zahlen selbst beseitigen - eine vollkommene Vorführung der entsprechend beurteilten Satzpaare ist in diesem Rahmen leider nicht möglich. $Z u$ den Beispielen allgemein sei gesagt, daB die Belege für unausgedrückte z.B. finale Verhältnisse aus der K-pler Erzählung viel schwerer aufzufinden und m.E. auch weniger überzeugend sind als die Beispiele hierfür aus dem Pleskauer Text, im Rahmen dessen es nicht schwer gewesen 
wäre, noch weitere hierher gehörige Satzpaare aufzuspüren. Die in der Graphik in der Rubrik "koordiniert"angefuhrten Zahlen bezeichnen also im $\mathrm{K}$-pler Text die obere, im Pleskauer Text die untere Grenze aller hierher zu rechnenden Belege.

KP 72/6 "Zuetuneja že paki povele eebja nestí tamo

$i$ načat delati baštu s userdiem velikim, ..."

'Giustiniani befahl, daB man ihn dorthin trage, damit er beginnen könne, mit großer Energie den Bau des Turmes zu betreiben, ...'

Diese tbersetzung ergibt sich beinahe zwingend aus dem Kontext, denn zuvor war gesagt, daB seine Abteilung, die er kommandierte, bereits den Bau des Turmes begonnen hatte - dieses "načat" setzt also ke1nen objektiven Beginn, sondern das persönliche Wollen Giustinianis: er lieb sich (verletzt, wie er war) dorthin bringen, um die Aufsicht über den Bau des Turmes zu ubernehmen (der bereits begonnen war).

KP 65/27 "Zustuneja že pak1 sobra mnogye ljudi, voskryčav napade na turky ...."

Giustiniani sammelte viele Leute um sich, damit or - mit Geschre1 - uber die Tüken herfallen könne/um über die Türken herzufallen ...'

Es war darauf hingewiesen worden, daB die Beispiele aus dem K-pler Text nicht immer sehr überzeugend sind.

PS $77 / 4$ "...: ovil že kamenbe voinom grinnoğachu

1 temi litvu z goroda 1 za gorodom pobivachu: ..."

'...: sie schleppten den Xriegern steine herbei, damit diese mit denselben die Litauer aus der stadt vertrieben.'

vgl. $76 / 28$ "dostalb o pristupa litvu pribivati oružie noěachu"

'um den Reet der Iitauer zu vernichten, ochleppten ole waffen herbei/damit der Rest der Litauer vernichtet werde, ...'

PS 85/10 "kameniem mnogim na to mesto vo grad getachu 1 eiml chrestsjan uraźachu."

'viele Steintugeln schossen ole in die stadt, um die Rusien damit zu erschlagen/töten." 
PS $69 / 32$ "... gosudarevy bojare $i$ voevody svoemu voinstru s ljuboviju i so slezami na_booj_ponužáajuščce, chrestbjanskomu voinstru serdečne ...s nimi

bbjuščesja."

'... die Voevoden drängten ihr Heer mit Tränen und mit (aller) Liebe zum Kampf, damit es von ganzem Herzen (= mit aller Energie) mit ihnen zusammen kämpfe.'

PS 68/30 "...; oboich že (Sujskich) ... ízvedẹ,

slavnyah Sujskich svjazannych pred toboju postavim." 'Die Fürsten Sujskij (=Stadtkommandanten) werden wir (aus Pleskau) herausholen, um sie dir (dem polnischen König) vorzuführen.' (So rühmen sich die polnisch-litauischen Würdenträger).

So ließe sich die Reihe der Beispiele aus der Pleskauer Erzählung beinahe beliebig fortsetzen.

An zwei Textstellen wollen wir darlegen, daB es sich bei der unterschiedlichen Konstruktionsweise (K-pel: meist Hypotaxe, Pleskau: meist Parataxe) um eine grundsätzlich verschiedene Erzählweise handelt, die den Autoren unserer Texte eigen ist. In beiden Sätzen wird etwas geschildert, was in die tat umgesetzt wird:

PS 77/20 "Tako že i pod tuju bašnju zelbja podne-sosoša

$$
\text { i z zažzoša, }
$$

i božiim posobiem tako i dostalb s Pokrovskie bašni vsech zbiša ..."

'So brachten sie unter dem ... Turm Pulver an und entzündeten es, und mit Gottes Hilfe erschlugen, sie den Rest (der Litauer) aus dem ... Turm ...'

KP 60/33 "Cesarb že zapoveda, da_ne_dejut ich ní kotorojú brang $\underline{j} \underline{j}$, jako da očistjat rvy i potoci. I tako vzjaša svoja trupy bezbranno i požgoša i." ' Der Kaiser untersagte, daB man (den Türken) Gefechte lieferte, damit sie die Gräben und Plüsse (von Leichen) säuberten.

Und so holten sie ihre Gefallenen und verbrannten sie:

Der Pleskauer Autor bietet eine faktische Berichterstattung: 'legten Pulver unter, entzündeten es, erschlugen sie/vertrie- 
ben sie'; wir können diese Erzählweise mit Lämmert ${ }^{52}$ als additiv bezeichnen. Der gleiche Vorgang hätte auch anders dargeboten werden können: 'sie legten Pulver an den Turm und entzündeten es, um die verbliebenen Litauer zu töten/vertreiben'. Diese Erzählweise - wir wollen sie mit Lämmert ${ }^{53}$ kausativ nennen - deckt die inneren Beziehungen, die Abhängigkeiten der Handlungen - Ursache + Polge/Ziel - in der Konstruktion auf: die hypotaktische Verknüpfung in Verbindung mit Konjunktionen signalisiert sofort die Haupthandlung und das - finale, kausale, temporale, konsekutive ... - Verhältnis, welches zwischen Neben- und Haupthandlung besteht. Und genau diese Erzählweise beobachten wir ständig in der K-pler Erzählung, nicht allein am Final- und abhängigen iunschsatz. Obige Textstelle berichtet von einer bestimmten Ordre des Kaisers - die Begründung für den Befehl wird in Form eines Finalsatzes nachgeliefert: '...damit die Türken die Gräben (wegen der Seuchengefahr) von den Leichen säuberten'. DaB der Vollzug der im finalen Nebensatz als Ziel genannten Handlung gleich im AnschluB festgestellt wird, kommt im $\mathrm{K}$-pler Text kaum vor - wir haben dieses Beispiel nur deshalb gewählt, um zu zeigen, dab hier tatsächlich die erwünschte Folge eintritt. Im Normalfall bleibt die Bestätigung aus, und erst der weitere Verlauf der Erzählung offenbart, ob sich die im Finalsatz geäußerte Hoffnung oder der im Heischesatz geäuBerte Wunsch erfüllt oder nicht, z.B.:

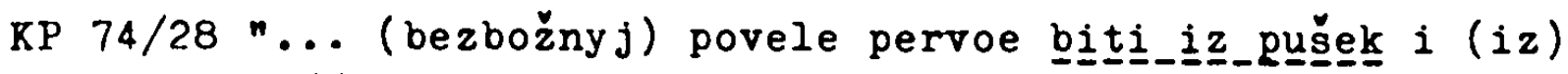
piščalej, da otstupjat gražane, ..."

'.... damit sich die Griechen zurückzögen, ...'

$O b$ dieses $2 i e l$ der Beschiebung erreicht wird, erfährt der Leser erst $74 / 41$ n..., no ne vozmogoša uderžati ego (= türkischer Feldherr), $i$ vnide $\checkmark$ grad rsemi polki i napade na gražan, ..." - die Türken hatten also die Griechen zurückgeworfen und drangen in die Stadt ein. Diese Erzählweise, die wir kausativ nannten, legt nicht allein die inneren Beziehungen

52) Lämmert, Bauformen des Erzählens, S. $45 \mathrm{ff}$.

53) Lämmert, ebda., S. 56 ff.: "Konsekutive (kausative) Form der Verknüpfung" - wir entschieden uns für "kausativ". 
der geschilderten Vorgänge zueinander bloB, sondern bringt gerade hinsichtlich der Final- und abhängigen Heischesätze ein zusätzliches Element der Spannung in die Erzählung, indem (als Begründung für eine Handlung) ein bestimmtes Ziel, eine Hoffnung, ein Wunsch genannt wird, der Leser aber erst im Lauf des Geschehens erfährt, ob denn der Zweck einer Handlung auch erreicht worden ist. 54

Es sei noch angemerkt, daB es die additive Erzählweise dem Pleskauer Autor erleichtert, über größere Abschnitte hinweg bei gleichem Subjekt die gleiche Verbalkategorie mit gleichbleibender Personalendung zu erhalten, so da $B$ verbaler (oder bei Endstellung des Verbs End-) Reim entsteht - wie wir es in unserem Beispielsatz PS 60/33 sehen können: "podnesoša zažgos̆a - bi $\underline{\dot{s} a} . "$

\section{Der Konditional in Konditionalsätzen}

Bedingungssätze werden in beiden Texten in der Regel ohne Konditional gebildet. Sie werden durch "ašče" eingeleitet, das Prädikat ist meist ein perf. Verb im Präsens, das gleiche gilt für den Hauptsatz:

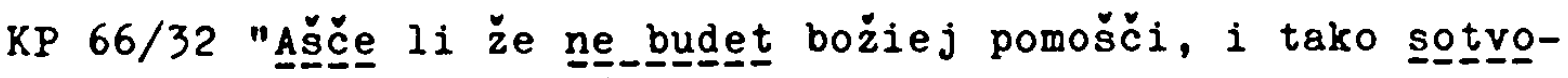
rím - edinom ćasom vsi pogibnem i grad pogubim."

- Wenn wir dies alles tun, Gott uns aber nicht hilft - dann werden wir in einer Stunde untergehen und $\mathrm{K}$-pel verlieren/werden wir alle gleichzeitig untergehen ...'

PS $82 / 33 "$ "... mnogie grady $v$ votčinu dam vam, ašče s mirom zdadite mi grad." .... viele Städte werde ich euch zum Erbe geben, wenn ihr mir kampflos Pleskau übergebt.'

Eine andere Konstruktionsweise ist die folgende:

"Part.praet., perf.Praes."

KP $66 / 38$ "..., da uslyšav christbjane, zberutsja k nemu

54) Die parataktische Satzfügung ist charakteristisch für die frühen altrussischen Denkmäler: Efimov, Istorija russk. lit.jazyka, S. 55, Eernych, Istor.grammatika, S. $327 \mathrm{f}$. Potebnja, Iz zapisok I-II, S. $400 \mathrm{ff}$., Borkovskij, Istor. grammatika, S. 466 uv.a. 
mnogie ljudi."

'..., und wenn davon die Christenheit erfährt (erfahren haben wird), dann werden ihm auch viele Menschen zu Hilfe eilen.'

PS $81 / 14$ "... koždo svoj podkop zạys

pod gradovnuju stenu podvedem

i zelbja podkkatî́ i ząžeg ego,

krovi ne prolivav litovskago svoego vojska, skoro $i$ spešne možem vzjati Pskov."

'... wenn jeder seinen (unterirdischen) Gang ersonnen hat (haben wird), dann werden wir ihn bis zur Stad tmauer heranführen.

Und wenn wir Pulver (an die Stadtmauer) gelegt und es entzündet haben (werden), dann werden wir auch ohne litauisches Blut zu vergieBen - Pleskau einnehmen können. (55)

Der Konditional kommt nur im K-pler Text im irrealen Bedingungssatz vor. Er begegnet uns in der bis Ende des 16. Jh.s üblichen Konstruktionsweise:

"ašče + Kondit., perf. Präsens"

Die irreale (oder auch potentiale) Bedingung steht also mit Konditional, die Folge im Indikativ. Noch Ivan Groznyj z.B.

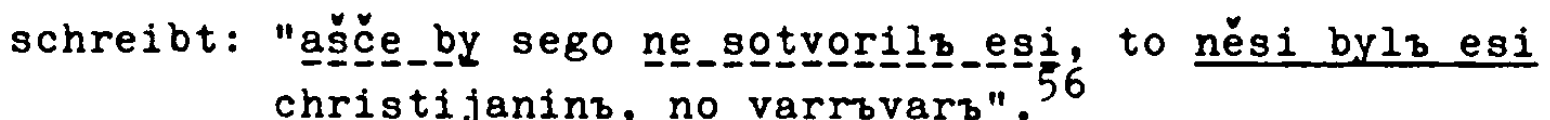

Der Konditional im bedingenden Nebensatz mit "ašče" und im Hauptsatz scheint erstmals bei westlich gebildeten bzw. mit dem Latein in Berührung gekommenen Autoren aufzutauchen:

Fürst A. Kurbskij und auch schon Peresvetov.

"I ašče byy sego ne bylı, oni by vozmogli protivu naş izvéţ postaviti" (Kurbskij). 56

"ạs̆če boy ne té tvoja serdečnyja slezy, kajuščis - gréséchъ svoich predo Mnoju, - vse by to na tebè vzyskalos" (Peresvetov). 56

Diese Konstruktionsweise setzt sich aber erst im 17. Jh.

55) Näheres hierüber s.'Vorzeitigkeit durch Part.praet. S. $526 \mathrm{ff}$.

56) Alle Beispiele bei (V. I. Borkorskij u,a, ): Sravnitel'noistoriceskij sintaksis vostocnoslavjanskich jazykov. Sloznopodčinennye predloženija. M. 1973. S. 165. 
durch. 57 So finden wir die irrealen Bedingungssätze im $\mathrm{K}$-pler Text in der für das frühere Altmss. charakteristischen Weise gebildet: Konditional nur im "aščen-Satz, der die irreale Bedingung nennt:

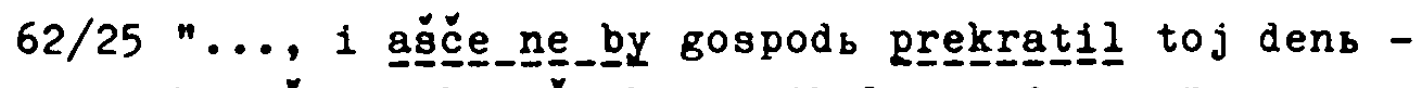
konečnaja bo uže be pogibels gradu ...."

'Wenn der Herr diesem Tag nicht ein Ende gemacht hätte, dann war der Untergang der Stadt ein endguiliger.'

fast identisch: $67 / 4$.

$72 / 35$ "..., i pogybels konečnaja uže be postigla grad,

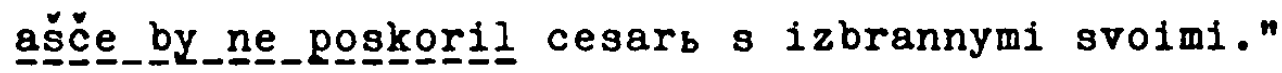
'Die Stadt mar schon verloren/der Untergang mar sicher, wenn nicht der Kaiser mit seiner Garde herbelgeeilt wäre.'

Ähnlich konstruiert: $74 / 15$.

$71 / 44 "$..., chotjachu bo

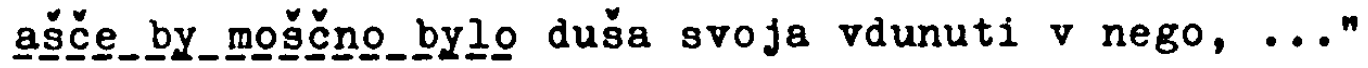

'Sie wollten - wenn dies möglich wäre - ihm ihre Seele einhauchen.'

Wie an den Beispielen zu erkennen war, ist in unseren Texten "by" zur Konditionalpartikel erstarrt, vgl. z.B.

$74 / 15$ "ašče by gorami podvizall, ..." (K-pel), was auch die kontaminierten Pormen im Pleskauer Text ("daby", "aby") bezeugen (vgl. PS $56 / 6$ "aby peli $\ldots$...".$^{58}$

57) A. N. Stecenko: Istoričeskij sintaksis russkogo jazyka. I. 1972 . S. 238 f.

Es scheint noch ungeklärt, warum der irreale Bedingungssatz mit "asce" + Kondit. und dem die irreale Folge ausdrückenden Hauptsatz, ebenfalls mit Konditional, im Altruss. geschwundeq ist. Im Aksl: jedenfalls war dieger Typus lebendig: "aste bo biste vẹrrg imali moséovi, vérg biste jęli 1 mbnén Mt. 24,43; "aste bi sbde byls, ne bl bratro mol umrols" Joh. 11.21. - Beispiele bei: Panzer, Der slavische Konditional, S. $122 \mathrm{f}$.

58) etten, Fin. Verbalformen, S. 395, kann in der "Step. kniga" das gesamte Paradigwa bychs, by, by, bychonb, byste, bysa beim Konditional nachweisen, was aber nicht verwunderlich ist, da die ersten 14 Stufen praktisch nur Kompilationen darstellen. Immerhin findet er in Stufen 15 - 17 (Ivan III. - Ivan IV.) Konditionalb1ldungen mit bychs, bychoms und byste (auBer vorherrschendem 


\section{Periphrastisches Futur}

In unseren Texten wird das Futur generell durch das Präsens perfektiver Verben gebildet. Andere Bildungen stellen Ausnahmen dar. Sie sind so selten, dab wir sie nicht einmal als gesonderte Kategorie in unsere Tabelle der verbalen Kategorien aufgenommen haben. So sei nur am Rande erwähnt, daB die gesamten Prophezeiungen in der $\mathbb{R}$-pler Erzählung, die die Zukunft der Stadt betreffen ( $S .77-78$ ) bis auf eine Ausnahme mit dem Präsens perfektiver Verben ausgedrückt werden. Die Ausnahme ist folgende Textstelle:

$77 / 22$ "No ubo da razumeeši, okajanne, ašče vsja prežerečennaja Mefodiem Pataromskym i Lbvom Premudrym i znamenija - grade sem soveršišasja, to i poslednjaja ne_pregldut no takože soveršitisja imut."

'..., wenn (an sich wohl: weil, da) sich alle Prophezeiungen des Methodios von Pathara und Leos des Feisen und alle sonstigen Vorzeichen (z.B. Kampf des Adlers mit der Schlange) über dieser Stadt erfüllt haben, dann wird auch dies letzte nicht unerfullt vorubergehen, sondern auch Wirklichkeit werden.'

Ganz offensichtlich will der Autor durch die Periphrase eine Intensivierung der Aussage erzielen, denn an sich läge Parallelbildung zum vorausgehenden "ne prejdut", dem es ja synonym ist; nahe. Es genügt ihm nicht die antithetische Formulierung seiner Schlubfolgerung - er setzt die positive Aussage vom negierten Glied der Antithese noch dadurch $a b$, daB er für das Prädikat das periphrastische Putur wählt: das einzige wirklich eindeutig umschriebene Futur. Dadurch erhält die Aussage eine besondere Akzentuierung - sicher mit Recht, denn mit diesen Worten wird von der Katastrophe zur Prophezeiung über die Rettung der Stadt übergeleitet.

Zwei Belegen "choteti + Infinitiv" kann man die Puturbedeutung nicht gänzlich absprechen, doch überwiegt das voluntative Element:

68/12 "....: i se znamenuet, jako milostb božija i ščedroty ego oţidoša ot nas $i$ choščet bog predati grad vragom našim'."

'... und daB Gott $K-$ pel den Feinden überlassen will.' 
69/13 "'...; ne choščesi bo, vladyko, sozdanie tvoich ruk pogubiti, niže blagovoliši o pogibeli čelovečestej, no choščeši vsem spastisja i $v$ razum istinnyj priiti." " .'...; du willst doch, o Herr, nicht das Werk Deiner Hände vernichten, und auch der Untergang der Menschheit bereitet Dir doch keine Freude, sondern Du willst alle erretten und zu geistiger Klarheit führen. $(=$ daB alle gerettet werden und.. gelangen)." (59)

Im zweiten Beleg ist die futurische Nuance vielleicht etwas stärker zu spüren, aber doch überwiegt die voluntative Bedeutung, denn alles ist zunkichst vom Willen Gottes abhängig - und wie sich ja zeigt, wollte Gott eben nicht, dab die Stadt gerettet würde.

Im Pleskauer Text kommt Puturbildung mit "imeti, imam" sowie nimati, imaju" vor. Bei einigen Bildungen mit "choteti" steht das Wollen ebenso im Vordergrund wie im K-pler Text.

$45 / 29$ "... po vremeni šestbvija puti listy vozveščatelbnyja k vam imaju prislati'."

'...' wenn die Zeit für den (geplanten) Feldzug gekommen ist, werde ich euch das schriftlich mitteilen'.'

$42 / 33$ "'Jako ne tokmo ... Luki Velikie vospríi杰 .... no $i$ slavnyj $i$ velikij grad vaś Pskov ... obratiti gego imam i gosudarb semu imenovatisja'." " Nicht nur Velikie Luki werde ich erobern, sondern auch ... Pleskau auf den Kopf stellen und mich Herr dieser Stadt nennen'."

82/30 "'Ašče za seju laskoju uvideti lice moe imaete,

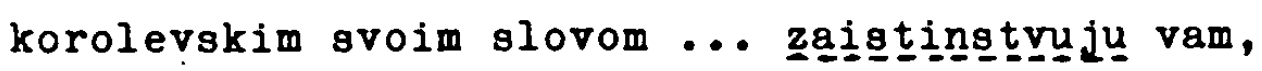
jako ne tokmo ... namestniki ot mene budete,...'n - Wenn ihr dann nach dem Offnen der Stadtore (za seju laskoju) vor mir erscheinen werdet, dann werdet ihr - ich gebe euch mein königliches Wort darauf - nicht nur meine Statthalter werden, ..."

59) "blagovoliši" kann ung bei der zeitlichen Bestimmung keine Hilfe sein, die Gruppe der Lehnübersetzungen aus dem Griech. mit nblago-n konnte sowohl für das Prïs. als auch für das Putur verwand die slav. Sprachen, als die Aspektbildung bereits im Gang war - daher ist sie im Aspekt indifferent - $\nabla g l$. A. Dostal: Studie o vidovém systému $\checkmark$ staroslovenstiné. Praha 1954. S. $476 \mathrm{f}$. 
$82 / 34$ "'Vsego vo grade naroda pomilluuu i paki na svoich zakonech žiti imate, ...."

- Dem ganzen Volk von Pleskau werde ich mich gnädig erweisen, und ihr sollt/werdet wieder nach euren (eigenen) Gesetzen leben, ..."

Wir haben ganz bewuBt die zwei Belege für "imati, -aju + Inf." $(45 / 29,82 / 30)$ mit Beispielen der gleichen Person von "imeti, imam" zusammengestellt, um zu zeigen, daB zwischen beiden Varianten der Puturbildung im Pleskauer Text kein Unterschied erkennbar ist. Allerdings fällt auf, daB bei "imati, -aju" klare perf. Infinitive stehen (uvideti, prislati), während bei "imeti, imam" der Anteil imperf. Infinitive stark ist: "imenovatisja" (s.0.), "stojati" (52/26),

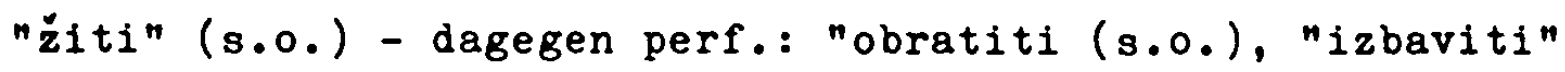
(47/13). - Um hieraus irgendwelche Schlüsse zu ziehen, ist unser Material nicht reichhaltig genug. 60

Es fält auf, daB periphrastische Futurbildungen immer in wörtlicher Rede vorkommen. Dies füht uns auf unsere Beobachtung an der K-pler Erzählung zurück, wo wir glaubten, feststellen zu können, daB das zusammengesetzte Futur einen starken Nachdruck auf die Aussage lege. Im Rahmen der wörtlichen Rede (oder des Briefes) dürfte dies auch zutreffen.

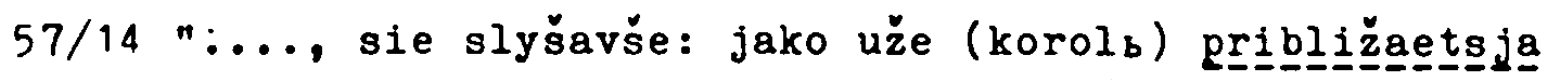
ko Pskovu, vtoroe, jako lev revyj, živyja poglotiti choščt."

'..., daß er sich nähert und ... alles Lebende verschlingen will.'

68/6 "Korolb že, sie slyšav ot svoich dvorjan i pervosovetnik, jako $i$ te radostno $i z$ svoimi promysli sami ego želanbe ispolniti chotjat, togda bolbmi radosti na-

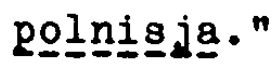

$83 / 23$ "'Ili ložnoju laskoju i dščju lestiju, ili suetnym bogatestrom prelbstiti choščescí (sic!) nas?""

60) Beim periphr. Futur uberwiegen Inf. perf. Verben: H. Birnbaum: Untersuchungen zu den Zukunftsumschreibungen mit dem Infinjtiv im Aksl. Stockholm 1958. S. 267 (weiter zitiert: Birnbaum, Zukunftsumschreibungen); Borkovski Istor.grammatika, S. 261 f., Nikiforov, Glagol S. 180 u.a. 
An der primär voluntativen Bedeutung dieser Bildungen "choteti + Inf." gibt es keinen Zweifel.

Zukunftsumschreibungen mit "budu + Inf." kommen in unseren Texten nicht vor. "budu" usw. erscheint nur in Verbindung mit nominalem Prädikativum (s.0.82/30 "namestniki ot mene budete"). Das entspricht allen bisherigen Untersuchungen, die die Verbreitung der Futur-Periphrase "budu + Inf." ins 17. Jh. verweisen. 61

Die alleinige Vertretung der Putur-Periphrase durch "imam + Inf." (bzw. "imaju + Inf.") sowie u.U. durch "chošču + Inf." belegt die literarischen Ambitionen der Autoren unserer Texte - beide Bildungsweisen haben stark archaisierenden Charakter. ${ }^{62}$ Das wird besonders deutlich, wenn man die entsprechenden Bildungen in der Pleskauer Chronikerzählung danebenhält: neben acht Umschreibungen mit "chošč + Inf."63 zwei Mal "učbnu + Inf.", ein Mal "stanu + Inf." (vgl. hier zu Anm. 62 über die Zugehörigkeit der beiden letzteren zur "delovaja pismennost'n). In der Chronikerzählung fehlt die literatursprachlich-archaisierende Zukunftsumschreibung "imam/imaju + Inf." ganz.

Die 'Volllendete_zukunft' (Futur II), gebildet durch "budu + 1-Part." lot in unseren Texten nicht anzutreffen. Es dien-

61) F. Cocron: La langue russe dans la seconde moitié du XंIIe siécle. Morphologie. Paris 1962. (weiter zitiert als: Cocron, La langue). S. 240 ff.; Birnbaum, Zukunftsumschreibungen, S. 268, spricht nur von "jüngere Bildungsweisen; Hikiforov, Glagol, S. 179 - nur bei Peresvetov findet sich "budu + Inf." (aber: Hs. des 17.Jh.s), in einer Orkunde 1588 und im Domostroj (zweifelhafter Beleg).

62) Cocron, La langue, S. $246 \mathrm{ff}$; Hikiforov, Glagol, S. 178f., S. 184 - 86; Otten, Fin. Verbalformen, S. 127 f.: "Wie bei der Periphrase mit imam ist auch für diese Kanstruktionsweise (= "chosču + Inf." - G.Str.) eine sekundäre Aktivierung, im 3. südslavischen Einflub zu beobachten." $i$ H. Kríkovei Vyvoj opisnéno futura $v$ jazycleh slovanskych, zvilest v rustine. Praha 1960. S. $116 \mathrm{f} . ; \mathrm{S}$. $142-44,146$ - Bildungen mit "nacnu", "ucnu" und jüngerem "stanu" gehören der "delovaja pismennost" an.

63) Allerdings: "chotim" - PS 1581 "choščem" 83/24, "chosceten $50 / 13$. 6972 . 
te vorwiegend ${ }^{64}$ als Prädikat in Bedingungssätzen. In dieser Funktion haben wir im Laufe unserer Betrachtungen perf. Präsens, Part.praet. und auch periphrastisches Futur (s.0. - PS $82 / 30$ "ăšce ... uvideti lice moe imaete") angetroffen. Im Pleskauer Text stoBen wir auf folgende merkwürdige Pormenkombination, die offenbar den Versuch darstellt, Vorvergangenheit auszudrücken:

$50 / 12$ "..., da ăšce choščete vkupe soveščav̌̆esją, da podymetesja so mnoju koždo so vsesilbnym svoim rojskom ..."

'...., und wenn ihr euch miteinander beraten habt (=wenn/nachdem ihr eine tbereinkunft getroffen haben werdet), dann macht euch auf mit mir, jeder mit seinem mächtigen Heer ...'

Das Fehlen dieser Kategorie, des Futurum exactum, in unseren Texten und solche falschen Bildungen bezeugen, daB es eine überkommene Formel darstellt, "die zwar bis ins 16. Jh. tradiert wird, aber nicht mehr als Ausdruck einer lebenden Verbalkategorie aufgefabt werden kann. "65 Diese Konstruktion verschwindet beinahe spurlos aus dem russischen Schrifttum. Die im 17. und 18. Jh. gebräuchliche konditionale Konjunktion "bude" dürfte als ein letztes tberbleibsel anzusehen sein. 66

64) Nikiforov, Glagol, S. 181 - von 5 von ihm überhaupt gefundenen Belegstellen (mit 12 Beispielen für Fut. II) befinden sich 4 Textstellen (mit 11 Beispielen) in Konditionalsätzen, z.B. "Asće tak budet pomyslil, to kaznb priimet o dele sem." (Kaz. let.); Borkovskij, Istor. grammatika, S. 277,304 f., Sobolevskij, Iekcii, S. 245 f.; Potebnja, Iz zapisok I-II, s. $288-92$ - wendet sich gegen den von Buslaev und Vogtokov geäuBerten Standpunkt, daB das Fut. II als "buduscee uslovnoe" zu betrachten sei. Es sei auch modaler Nuancierungen (Möglichkeit, Wahrscheinlichkeit) fähig.

$65)$ otten, Pin. Verbalformen, S. 374.

66) cocron, La langue, S. 237 - findet in seinen Texten aus dem 17. Jh. keine Spur des Put. II mehr - "mais at testent souvent le mot budets, dans la fonction de esli, emploi disparu au courg du siècle suivant." Potebnja, Iz zapisok I-II, S. 293; Kŕlíková, Vývoj, S. 167 1.; otten, Fin. Verbalformen, S. 376 . 


\section{Zusammenfassung}

Wir haben festgestellt, daB im Gebrauch von Präsens, Konditional und (periphrastischem) Putur zwischen beiden Texten erhebliche Unterschiede bestehen, obgleich doch Konditional und periphrastisches Futur in beiden Texten nur schwach vertreten sind.

Bezulglich des Präsens ist daran zu erinnern, daß die Pleskauer Erzählung, im Unterschied zum K-pler Text, in Erzählbereichen, die der Zusammenfassung und der Raffung von Vorausgegangenem (=Exposition) dienen, über größere Abschnitte hinweg das Praesens historicum verwendet, wodurch der sonst vielleicht stereotype Bericht an Aktualität und Leben gewinnt.

Präsensformen (meistens perf.) begegnen in der $\mathrm{K}$-pler Erzählung vorwiegend in Final- und abhängigen Wunsch-bzw. Heischesätzen, die nach ksl. Muster gebildet werden "da + (perf.) Präsens". Innerhalb solcher Konstruktionen befinden sich zwei Drittel aller Präsensformen des K-pler Textes.

Im Pleskauer Text ist diese Konstruktion uberaus selten. Doch verwendet der Pleskauer Autor stattdessen nicht den für Pinal- und abhängige Wunschsätze in Urkunden, Akten usw. längst üblichen Konditional (immerhin begegnet dieser häufiger als die ksl. "da"-Konstruktionen), sondern er bevorzugt die stilistisch vielleicht neutraleren InfinitivKonstruktionen (die auch in der $\mathrm{K}$-pler Erzählung eine gewisse Rolle spielen). Neben häufigen reinen Infinitiv treffen wir oft Infinitiv-Konstruktionen, die durch "aby", "daby", "jako by" eingeleitet werden, wodurch offensichtlich ein archaisierender Effekt bezweckt ist - umgangssprachliches und in der profanen Iiteratur verbreitetes "čtoby" (oder gar "atb", "ato" oder "ože") wird konsequent gemieden. 67

67) Otten, Fin. Verbalformen, S. 425 - macht die gleiche Beobachtung an der "Stepennaja kniga", die auf Grund ihrer Zielsetzung (Verherrlichung des zarischen Goschlechts und insbesondere Ivan Grosnyjs) a priori dem traditionalistisch-archaisierenden Stil verpflichtet ist, da dieser der Schilderung Erhabenheit verleint. 
Der grobe Unterschied 2 ischen beiden Texten besteht aber nicht darin, daB der $\mathrm{K}$-pler Autor die ksl. Konstruktionsweise "da + (perf.) Präsens" und der Pleskauer Autor vorwiegend Infinitiv-Konstruktionen verwendet, um finale und Tunschverhältnisse auszudrücken; vielmehr besteht der Unterschied zwischen den beiden Texten darin, das der Pleskauer Autor solche Verhältnisse meist gar nicht ausdrückt. Dieser bevorzugt die parataktische satzfügung, die eine faktische, sozusagen von Resultat zu Resultat schreitende Erzählweise bewirkt (Lämmert: "additiv"). Im $\mathrm{K}$-pler Text dagegen gewinnen die Sätze, weil hypotaktisch gefügt, an innerer Spannung (Lämmert: "kausative Erzählweisen), an Dynamik. Durch bestimmte Konjunktionen (hier: "dan) werden bestimmte Beziehungen zwischen einzelnen Vorgängen (hier: finale Beziehungen bzw. Wunsch-Vorstellung) verdeutlicht, die innere Struktur des Geschehens tritt klarer hervor. 


\section{Das Präteritum}

"In der zweiten Hälfte des 16. Jh.s unterliegt das System der russischen Präteritaltempora (im Vergleich zum frühen Altruss) wesentlichen Veränderungen. ${ }^{1}$ Bekanntermaßen sind diese Veränderungen dadurch bedingt, daß die gesprochene russ. Sprache immer stärker in den schriftlichen Zeugnissen ihren Niederschlag findet. Neben phonetischen, morphologischen, syntaktischen und auch lexikalischen Erscheinungen ist es vor allem das Verbalsystem, das die Zeit des Umbruchs reflektiert. Imperfekt und Aorist stehen symbolisch für die kirchenslavischaltrussische Tradition, das 1-Partizip als alleinige Vertretung des Präteritums symbolisiert die gesprochene Sprache. Zwischen beiden Extremen breitet sich das ganze Spektrum der im 16. Jh. schon breit gefächerten literarischen Produktion aus. Einen ungefähren Anhaltspunkt über die Orientierung eines Textes gibt die Uberprüfung des Pormenbestandes, insbesondere der Präteritaltempora, wie wir es in der Tabelle zu den Verbul-Kategorien versucht haben. Eine solche Bestandsaufnahme sagt uns etwas über die Intention des Autors - im Falle unserer beiden Texte gibt es gar keinen Zweifel, daB beide Autoren/Redaktoren ihre Erzählungen in die literarische Tradition hineinstellen wollten und aus diesem Grunde fast ausschlieblich die archaischen Tempora verwandten. Eine tabellarische Aufstellung der verbalen Kategorien sagt uns aber nichts daruber, wie diese gebraucht werden - ob korrekt, ob eher stilisierend. Die tabellarische tbersicht sagt uns nichts über Fehler, Unsicherheiten usw. im Gebrauch der ksl. Tempora. Diesen Fragen wollen wir uns in den weiteren Ausführungen zuwenden und bei der Gelegenheit verschiedene Aspekte, de zur Charakterisierung eines der Texte besonders wichtig scheinen, besonders herausarbeiten.

Otten in seiner Monographie über die finiten Verbalformen in

1) Nikiforov, Glagol, S. 143 (Hervorhbg. dort); "po sravneniju s drevnerusskoj sistemoj" - "im Vergleich zum frühen Altruss. (System)': die sovjet. Forschung unterscheidet m.E. zu Recht zwischen "drevnerusskij" und "starorusskij jazyk". Ersteres umschließt die ersten schriftlichen Zeugnisse russischer Provenienz bis zum Beginn der Differen- 
der "Stepennaja kniga" stellte fest, dab darin fast ausschlieblich die alten Tempora und diese daruberhinaus weitgehend korrekt verwendet werden, ${ }^{2}$ wohingegen Boretzky in Kurbskijs "Istorija velikago knjazja moskovskago" einen Anteil des 1-Part.s am Präteritum von ca. 50 v.Hd. feststellte und auBerdem beobachtete, dab im Gebrauch der ksl. Tempora z.T. erhebliche Unsicherheiten sowohl im formalen (häufig 3. 8g.aor. auf -i $\underline{\text { ša }, ~-a ̆ g a ~ u s w .) ~ a l s ~ a u c h ~ i m ~ f u n k t i o n a l e n ~}$ (Austauschbarkeit von Ipf. und Aor.) Bereich auftreten. 3

Speziell über den Gebrauch von Ipf. und Aor. In der zweiten Hälfte des 16. Jh.s bemerkte Nikiforov, daß ersteres fast ausschlieblich von imperf. Verben, der Aor. aber entweder von perf. Verben gebildet werde oder aber sich aspektuell neutral verhalte. ${ }^{4}$ Boretzky spricht von der "Affinität" des Ipf. zum imperf. Aspekt und des Aor. zum perf. Aspekt. 5

Von dieser "Norm" wollen wir ausgehen. Ich halte es für unnötig, diese an unserem Material nochmals darzulegen. Ich halte es für sinnvoller, die "Ausnahmen" von dieser Norm genauer ins Auge zu fassen. Bei diesem Versuch will ich mich von Budichs herber, wenn auch sehr berechtigter Kritik an Boretzkys Arbeit leiten lassen: "Es genügt ... nicht, seinen Zettelkasten an eine Reihe von Musterbeispielen kommentarlos anzufügen, ...", oder wie er sich der Arbeit Ruzickas über den Verbalaspekt in der Nestorchronik gegenüber äuBert: "Es genügt nicht, aus einem oder mehreren bestimmten Texten Musterbeispiele vorzulegen, ...". Für Budich gilt: "Bei einem

zierung des Schrifttums in 'altrussisch, altukrainisch und altweibrussisch'. "drevnerusskij" können wir also in diesem Sinne gut mit 'gemein-ostslavisch' übersetzen, abgegrenzt gegen "starorusskij, staroukrainskij, starobelorugskijn, vgl. z.B. (Borkovskjju.g.), Sravnitel'noistoriceskij sintaktsis vostocnoslavjanskich jazykov, I, 1 , S. 44 - dort wird für. "starorusskij" als Zeitangabe 15." 17. Jh. genannt. - BSE Bd. 22. M.31975. S. 410: unter

2) otten, Pin. Verbalformen, S. 472.

"Russkij jazyk".

3) Boretzky, Tempusgebrauch, S. $65-67$.

4) Bikiforov, Glagol, S. 144 und 150.

5) Boretzky, Tempusgebrauch, S. 66 - diese Affinität sei alIordings im Verhältnis von Aor. zum perf. Aspekt nicht 80 ausgeprägt wie im Verhältnis von Ipf. zum imperf. Aspekt. 
so komplizierten Gebilde wie dem russischen Verbalsystem kann nur die Vollständigkeit, die jedes Für und wider abwägt, Beweiskraft erlangen. ${ }^{6}$ Natürlich können wir nicht das gesamte Material vorführen, aber wir wollen doch versuchen, dem Prinzip der Vollständigkeit in Bezug auf die Ausnahmen von oben genannter Norm weitgehendst zu entsprechen. Sehr starke Norm-Konformität wäre als Aspektualisierung des alten Tempussystems zu werten.

Die eigentliche Kritik Budichs an allen früheren Arbeiten zum altruss. Verb gilt aber nur am Rande der mangelnden Vollstiandigkeit des vorgefuhrten Belegmaterials. Seine Kritik ist viel grundsätzlicherer Natur: "Die Mehrzahl der Forscher versucht, den 'Aspekt' im Altrussischen bzw. Altkirchenslavischen nach den heutigen Aspektverhältnissen zu bestimmen. Daraus erklärt sich das Bestreben, schon für den ältesten schriftlich belegten Sprachzustand ein 'vollständiges Aspektsystem' zu rekonstruieren." 7

Nun liegen im 16. Jh. die Verhältnisse bezüglich des Verbalsystems etwas anders als etwa im 11. Jh., in das Budich (mit A. A. Sachmatov) die Urfassung der 1. Novgoroder Chronik verlegt. Immerhin zeigt aber beispielsweise folgende hilflose Bemerkung Ottens, daB man in Schmierigkeiten kommt, sogar wenn man ans 16 . Jh. mit heutigen Aspektbegriffen herantritt. Otten hat ständig Schwierigkeiten, Ipf.-Pormen heute perf. Verben zu erklären - zunächst sucht er nach Iterativität, past diese beim besten Willen nicht, sucht und findet er modale Schattierungen (konative Bedeutung $u_{\circ} a_{.}$), oder wir stoBen auf hilflose Bemerkungen wie folgende, anläBlich einer Belegstelle mit "predglagolašen:

"Diesem Beleg ist die angesprochene Bedeutung nicht abzusprechen (sic), obgleich in Rechnung zu stellen ist, daB das Verb glagolati durch die vorliegende Präfigierung mit pred- nicht notwendigerweise perfektiv werden nubte." 8

6) Budich, Aspekt, S. 26 (alle drei zitate).

7) Budich, ebda., S. 55 f.

8) Otten, Pin. Verbalformen, S. 208, zu "perf. Ipf.-Formen" S. S. $200-215$. 
Wir wollen nicht in unzulässiger Weise heutige Aspekt-Verhältnisse auf das 15. und 16. Jh. ubertragen, obgleich natürlich unbestritten bleibt, daB zu diesem Zeitpunkt die Aspektualisierung des Verbalsystems weit fortgeschritten war.

Als Ausgangspunkt unserer Untersuchungen soll uns die der im Verb ausgedrückten Handlung innewohnende Axtionsart dienen. Die Entwicklung vom aktionsartlich orientierten Verbalsystem zum heutigen Aspektsystem haben Ju. S. Maslov, H. Schelesniker, L. Sadnik und R. Aitzetmuller herausgearbeitet, zusammenhängend formuliert wurde der Entwicklungsgang von w. Budich und K. Trost. 9 Daher können wir uns hier auf die Darstellung der uns interessierenden Punkte beschränken.

Aktionsart bedeutet Einheit von Art und objektiver Zeitlichkeit einer Handlung. Als Gegensatzpaar bezuglich ihrer Aktionsart sind Durativa und Nichtdurativa anzusehen. $\mathrm{Zu}$ den Durativa gehören Kursiva (laufen, tragen), Iterativa (schlagen, zittern) und Zustandsverben (sitzen, liegen). Nichtdurativa sind Momentanverben (sterben, finden). Hierher gehört aber auch eine Gruppe von Verben, die bereits insofern "XompromiBformen" darstellen, als sie den "Anfangs- oder Endpunkt einer Handlung' markieren, die Handlung selbst jedoch als dauernd voraussetzen. ${ }^{10}$ Dies sind die Ingressiva (erblühen, entzünden) und die Terminativa (verblühen, verlöschen).

In unseren Betrachtungen gehen wir vom Simplex aus, von der diesem innewohnenden objektiven Zeitlichkeit - Durativum : Momentanverb (zur besseren Charakterisierung stellen wir Durativa und Momentanverben gegenüber). In unserer Tabelle 2, die die Ipf.- und Aor.-Belege inrer Aktionsart nach aufgliedert, werden von den durativen Simplicia Determinierte (itti) und Nicht-Determinierte abgetrennt (choditi), während alle anderen Durativa (Zustandsverben und Iterativa) zusammen-

9) Budich, Aspekt, S. 10 - 22; Trost, Perfekt, S. $1-11$. Bei beiden dort die ins einzelne gehenden Literaturangaben zu Maslov, Schelesniker, Sadnik und Aitzetmüller.

10) Trost, Perfekt, S. 2. - vgl. Budich, Aspekt, S. 11. 
bleiben. Bei der Aufteilung der Komposita sondern wir von vornherein solche mit suffigierter und/oder dehnstufiger Wurzelsilbe aus - diese sind zweifelsfrei imperfektiv: "Das slavische Aspektsystem entstand nicht durch Präfigierung, sondern durch Verwendung von Dehnstufe und Suffix. " 11 Des weitern trennen wir die Verben der 4. Leskien'schen Klasse zusammen mit den dazugehörigen (-'a-Suffix-haltigen) Imperfektivoildungen ab (prigotoviti - prigotovljati). Deren Simplicia stellen aktionsartich und formal eine geschlossene Gruppe dar, die uns keine Probleme aufgibt.

Allerdings ist hier formal nicht zu unterscheiden zwischen Ipf. des grundstufigen und dem Ipf. des suffigierten Kompositums:

otbvratiti: Ipf.: otbvrat'-a-aše > oţvrašçaaše kontrahiert > otsvrascase otbvraščati: Ipf.: otbvrašča - aše ${ }^{12}>$ otovraşçaše kontrahiert > otıvrascase

Solche Ipf.-Formen haben wir grundsätzlich zu den suffigierten Ableitungen gestellt. Damit kehren wir Untersuchungsergebnisse Kollns gewissermaßen um: Dieser hat herausgefunden, daB von suffigierten Ableitungen obigen Typs keine Aoristformen anzutreffen seien. (13). Wir ziehen daraus den SchluB, daB umgekehrt von Komposita der 4. Leskien'schen Klasse auch kein Ipf. gebildet wird, sondern daB die auftauchenden Ipf.-Formen den suffigierten Ableitungen zuzuordnen seien. Es scheint dies ganz natürlich, da Ipf. und imperfektive (weil suffigierte) Variante formal und bedeutungsmäBig so ineinanderfließen.

Gesondert stellen wir auch hier die Ableitungen (d.h. nicht suffigiert/dehnstufige Komposita) determinierter und nichtdeterminierter simplicia.

Von der verbleibenden größten Gruppe teilen wir nun jene Komposita $a b$, die von nichtdurativen Simplicia, also von Momentanverben gebildet sind - diese blieben auch als Komposita nichtdurativ.

11) Budich, Aspekt, S. 10 - Hervorhebg. G. Str. ebda. Anm. 15: "Dehnstufe in nari Q $_{2}$. Dehnstufe und Suffix

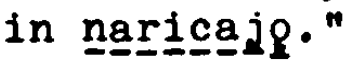

12) Leskien, Handbuch, S. 161: Das Ipf. der 4. Klasse (4.II abgele1tete Verben) wird vom zweiten Stamm gebildet.

13) H. Kolln: Zum Aorist im Altrussischen. In: Scando-slavica 5 (1959). S. 67 (Untersuchungen an der PVL); vgl. Boretzky Tempusgebrauch, S. 40 . 
Die Gruppe, die nach diesen Abtrennungen zuruickbleibt, läBt sich folgendermaBen charakterisieren: Komposita durativer Simplicia mit nichtdehnstufiger und/oder nichtsuffigierter Turzelsilbe (ohne Komposita von Determinierten und Fichtdeterminierten ${ }^{14}$ sowie ohne Komposita von 1ti-Verben). In dieser großen Gruppe präfigierter Durativa vollzog sich der Wandel vom Durativum zum Perfektivum. In der Regel bewirkte Präfigierung lediglich Aktionsartweiterbildung, d.h. "das Präfix gab dem Kompositum eine eigene Bedeutung dem Simplex gegenuber", ${ }^{15}$ doch war von dieser (meist nicht sehr weitgehenden) Bedeutungsänderung (oft lediglich Nuancierung) die Aktionsart selbst nicht betroffen, also trotz der Präfigierung blieb das Verb meist durativ. Es gab aber auch Fälle, da das Durativum durch die Präfigierung zu einem Momentanverb wurde - es trat eine Aktionsartveränderung ein ${ }^{16}$ - eine solche Gruppe wurde schon erwähnt: die Ingressiva und Terminativa; durch die Präfigierung wird aus der durativen Grundhandlung entweder der Anfangs- oder der Endpunkt herausgenommen. Auf dem gleichen Prinzip beruhen auch die anderen Aktionsartveränderungen: Herausheben eines bestimmten Punktes aus einer durativen Handlung, wobei diese aber, etwa im Vergleich zu Terminativa oder Ingressiva, stärker zurücktritt. Bekanntestes Beispiel hierfur ist "ubiti" - 'erschlagen, töten'. Durch die Präfigierung wird aus der iterativen Handlung - "biti" - 'schlagen' ein einziger, ganz bestimmter Schlag herausgenommen: der Hieb, der jemanden tötet.

Wir kennen viele solcher Verben: "zažešči" - 'entzünden', "nalesti" - 'auffinden; erreichen' usw. Sie sind natürlich im Aspektsystem genauso unter den perfektiven Verben anzusiedeln wie Momentanverben, da sie ja auch einen Moment, einen Hieb usw. bezeichnen. Dennoch haben wir diese Gruppe

14) Auch Determinierte und Nichtdeterminierte verdienen unser Interesse, da ihre aspektuelle Zuordnung durchaus nicht immer (in unseren Texten) gesichert zu sein scheint.

15) Budich, Aspekt, S. 76, $\$ 180$.

16) Budich, ebda., S. 16, \& 27 : "Akt1onsartänderung (= Xnderung der Bedeutung und dadurch der Akt1onsartze1tlichkeit) und Aktionsartweiterbildung (= Anderung der Bedeutung bei gleichbleibender Aktionsartzeitlichke1t)". 
bei den von Durativa abgeleiteten Verben stehengelassen, weil wir in unseren Texten nur wenige vorfinden, von denen wir sicher wissen, dab durch die Präfigierung eine Aktionsartänderung eingetreten ist. Bei anderen Komposita sind wir aber dessen nicht sicher, und in unseren Texten fehlt das notwendige Vergleichsmaterial, um die Aktionsart des fraglichen präfigierten Durativums endgültig abzusichern. Um Pehlbeurteilungen hinsichtlich der Aktionsart präfigierter Durativa aus dem Nege zu gehen, haben wir die Aktionsart nicht zum Kriterium für weitere Aufgliederungen des Materials erhoben.

Als Grundlage einer solchen diente uns vielmehr das Kriterium, inwieweit von einem präfigierten Durativum eine dehnstufige/suffigierte Ableitung - z.z. der Abfassung unserer Texte - belegt ist oder nicht. Momentanverben, die durch Präfigierung aus Durativa (= Aktionsartänderung) entstanden sind, haben sehr früh dehnstufige/suffigierte Ableitungen gebildet. Komposita, die derartige sekundäre Ableitungen besitzen, bezeichnen wir als perfektiv; die Ableitungen selbst, die ja eine subjektiv-logische Dehnung der nichtdurativen (momentanen) Handlung ${ }^{17}$ ausdrücken, nennen wir imperfektiv. Präfigierte Durativa ohne dehnstufige/suffigierte Ableitung geben zu der Vermutung AnlaB, daB sie aspektuell noch indifferent sind.

Allerdings ist auch in Rechnung zu stellen, daB im 15. und 16. Jh. die Entwicklung hin zur aspektuell ausgerichteten 2 weiverbigkeit bereits so schematisiert war, $\mathrm{daB}$ auf dem Wege der Analogiebildung Verbpare entstanden, von denen das nichtdehnstufige/nichtsuffigierte Kompositum erst allmählich in die Funktion des perf. Aspektpartners hineinwuchs; d.h. der heute perf. Aspektpartner kann durchaus auch noch z.Z. der Nachweisbarkeit des dehnstufigen/suffigierten imperf. Verbs gelegentlich in Positionen auftreten, die zwar der ursprünglich durativen Aktionsart des Kompositums, nicht aber einem perfektiven Verb entsprechen.

Schlieblich ist auch die Prage, ob - 2.B. im 15. oder 16. Jh. - eine sekundäre Ableitung zu einem Kompositum bereits belegt ist, nicht immer klar zu beantworten.

17) Budich, Aspekt, S. 15, $\$ 23$ : "Verbalaspekt bedeutet subjektive Begrenzung oder Dehnung der objektiv gleichbleibenden verbalen $Z$ eitlichkeit." (bei Budich hervorgehoben). s. auch $\S 24$. 
Das erste Auftreten einer dehnetufigen/suffigierten Ableitung von einem präfigierten Durativum lot oft unalcher datiert. Hierzu kommt noch die Problematik, wie ein solcher Erstbeleg zu werten se1 - 1st er von einem Autor ad hoc gebildet, let er nur regional verbreitet oder aber 1st er als aligemein ublich zu betrachten?

Wenn wir trotz dieser Bedenken die Existenz dehnetufiger/ suffiglerter Ableitungen als Kriterium bel der Auftellung der präfigierten Durativa benutzen, dann aus der Uberlegung heraus, $d a B$ die $A b l e 1 t u n g e n$ in unseren Texten meist so gut belegt sind, daß weiträumige Verbreitung anzunehmen 1st.

Oben war von einer im 16. Jh. (und natürlich auch schon früher) zu beobachtenden 'Norm' die Rede, von einer Aspektkorrelation: das Imperfekt werde fast ausschlieblich von imperfektiven Verben, der Aorist meist von perfektiven Verben gebildet. Doch scheint auch im 16. Jh. das Aspektsystem noch nicht voll ausgeformt zu sein. Wir wollen in den folgenden Ausfuhrungen unser Augenmerk nicht auf solche Verbformen lenken, die der obigen Norm entsprechen, sondern uns auf solche Bildungen konzentrieren, die in bezug auf die Aspektkorrelation als Ausnahmen erscheinen können. Möglicherwelse können wir an solchen Verbformen Spuren des alten aktionsartlich ausgerichteten Verbalsystems wahrnehmen.

Be1 unseren Untersuchungen werden wir von der dem jeweiligen Verb innewohnenden Aktionsart ausgehen - bei den Simplicia gibt es in dieser Hinsicht kaum Probleme. Bel der Bestimmung der Komposita sind wir in der Regel von der Aktionsart des Simplex ausgegangen, wobel allerdings so klare AktionsartÄnderungen wie von iterativem "biti" zu momentanem "ubiti" bericksichtigt wurden. - Unser Hauptinteresse galt ohnehin nicht solchen Fällen, sondern jenen Komposita, deren Aktionsart durch die Präfigierung nicht verändert wurde, die durch das Präfix lediglich eine spezifizierte, modifizierte Bedeutung erhielten und die heute fast ausnahmslos perfektiv sind. Im Gebrauch dieser Verben lassen sich noch am ehesten aspektuelle Schwankungen nachweisen. 


\section{Das Imperfekt}

Mit der morphologischen Seite des Imperfekts (= Ipf.) brauchen wir uns nicht weiter zu befassen, da nicht viel Auffallendes begegnet.

Wie zur Entstehungszeit unserer Texte üblich, begegnet uns fast ausnahmslos die kontrahierte Form des Ipf: statt -aase - -aše; statt łaaše - -jaše, statt -éaše - -jaše. Auch in der "Stepennaja kniga" und in Kurbokijs "Istorija velikago knjazja moskovskago" begegnen nur diese Formen. ${ }^{\top}$

Verben vom Typus "čajati", "tajati" usw. kontrahieren z.B. "čajaaše" zu "čajašen. Das gilt auch prinzipiell für dehnstufige/suffigierte Bildungen vom Typus "dajati", "stajati" usw. Letztere kommen jedoch vorwiegend präfigiert vor, vielleicht geht deshalb der ProzeB der Verschleifung bei diesen noch weiter: neben "dajachs", "daachb" begegnen in steigendem Maße Bildungen wie "vъzdachb" und "predagsen" (so in unseren Texten) - zur Unterscheidung sei die Ipf.-Porm des nichtdurativen "dati, damb" genannt: "dadjašen" ${ }^{3}$. Das Simplex begegnet aber meist nicht mit totaler Kontraktion: "dajatin: Ipf. "dajaśe". - Ähnlich steht es mit dem häufigen "-stajati", das z.B. besonders oft als "prestajatin erscheint - hier wird das Ipf. zu "prestaše" kontrahiert - gegen das Ipf. von nichtdurativem "prestati - prestanjaše". ${ }^{4}$

Das gleiche gilt für das Ipf. von padati, -ajun: "padaše < "padajaaše" gegen Ipf. von "pasti, padu" : "padjaše < paděašen."

1) Otten, Fin. Verbalformen, S. 153; Boretzky, Tempusgebrauch, S. 41 .

2) Diels, Aksl. Grammatik, S. 237.

3) "dadjaše" aus "daděaše" - Diełs, ebda., S. 277; Ju. S, Maslov: Imperfekt glagolov soversennogo vida $v$ slavjanskich jazykach. In: Voprosy slavjanskogo jazykoznanija. 1 (1954). S. $68-138$. (weiter zitiert als: Maslov, Imperfekt). - aksl. "dadeasen, S. 83, 86 aruss. Belege für "dadjase".

4) "prestanjaše" aus "prestaněašen - Dielg, Aksl. Grammatik, S. 278,281 , Anm. 21; Masler, Imperfekt, S.114-aksl. "ostaneachp", "prestanéese" (sic!), S. 83 und 86 - altruss. Belege für "stanjase".

5) Diels, Aksl.Grammatik, S. 244 ; Maslov, Imperfekt, S. 83, 85. 
Pormen wie "skazaše", "pokazachu" usw. könnten von "po-, skazati, - kažun" oder von "po-, skazati, -kazaju" gebildet sein. Da bereits - sicher wegen der Unmöglichkeit, bei den Präteritaltempora $z$ wischen dem suffigierten und dem nichtsuffigierten Verb zu unterscheiden - früh Ableitungen mit eindeutigeren Suffixen erscheinen (aksl. "skazovati", altruss. "skazyvati"), ist man geneigt, Formen wie "skazaše", "pokazachu" usw. als Ipf.-Belege von "po-, skazati, -kažün anzusehen, in moderner Terminologie: als Ipf.-Formen perf. Verben. Dieser SchluB scheint mir aber nicht gerechtfertigt. Hinsichtlich der "Stepennaja kniga" erklärt 0tten: "Da jedoch in der St.kn. noch keine konsequent gehandhabte Aspektkorrelation -kazati : kazovati/-kazyvati zu erkennen ist, können Belege von -kazati durchaus als imperfektiv gelten,....n 6

Hinzu kommt, daß man m.E. bei so hochfrequentierten Verbformen wie denjenigen von "kazati, kažu/kazaju" in Rechnung stellen muB, daB bestimmte Formen (vor allem 3.8g. und 3.p1.) formelhaften Charakter bekommen. So ist es vermutlich bei "kazaše" und "kazachu" der Fall, die - von "kazati, -kazaju" gebildet - die Zurückdrängung der übrigen Formen dieser suffigierten Ableitung durch "-kazovati/-kazyvati" uberdauert haben und als habitualisierte Formeln weiterlebten. So war es ja auch bei "rku(š)če, rekše, rečen oder "glagolju(๕) će, glagolachu, glagola", die als Formeln noch in Gebrauch waren, lange nachdem die Verben "reči" und "glagolati" auBer Gebrauch gekommen waren.

Wir schicken dies jetzt voraus, weil ein Bingehen auf diese Fragen innerhalb der Untersuchungen diese belasten würde. Es sei in diesem Zusammenhang darauf verwiesen, dab otten "prestašen?, "predašen" "vostašen" als "perf." ansieht und an der Bedeutung dieser Ipf.-Formen herumrätselt.

6) Otten, Fin. Verbalformen, S. 212.

7) Otten, ebda., S. 207; 8.0. Anm. 4).

8) Otten, ebda., S. 208; 8.0. Anm. 3).

9) Utten, ebda., S. 208; s.0. Anm. 4). 
Wie wir in den Anmerkungen zur Phonetik (s.0., S. 149) darlegten, fällt beim Palatalisationsergebnis der Lautgruppen-zg-j-, $-z g-b-,-z d-j-$, das im Aksl. -źd-war, in unseren Texten der Dental fast durchgehend aus, so dab obige Gruppen als - ž- in unseren Texten reflektieren. Dies zeigt sich auch verschiedentlich im Ipf., z.B. bei Simplicia der 4. Leskien'schen Klasse "nuditi - nužachu" und beim Ipf. der dehnstufigen Ableitungen von Komposita dieser Klasse: "prečužati - prečužachu". Manchmal unterbleibt die lautgesetzliche Palatalisierung ganz: "chodjaše" neben "chožaše"; auch "myşljaše". Häufig fehlt das l-Epentheticum: "ljubjaše", "blagoslovjaše" u.a.

Schlieblich sei auf die Verdeutlichung der Ipf. Endung im $\mathrm{K}$-pler Text hingewiesen, wie sie in der 3.pl. (nicht 3.sg.) anzutreffen ist: "dajachutb" (63/25), "soźigachut" (65/15) z.B. ein "tvorjašet(b/z)" begegnet aber nicht. ${ }^{1 \delta}$

Die Bedeutung des Ipf. hat bereits Vondrák beispielhaft formuliert: "Das Imperfektum drückt eine in der Vergangenheit dauernde oder wiederholte Handlung aus. Es wird dadurch mehr der Verlauf der Handlung veranschaulicht (bei der Schilderung), während der Aor. konstatiert, was geschah oder eingetreten ist; ... Das Impf. kommt also in der Erzählung meist den Nebenhandlungen zu, es schildert Gewohnheiten, Sitten u.dgl." 11

Während dies für das Ipf. imperf. Verben uneingeschränkt zutrifft, kann das Ipf. perf. Verben scheinbar eine solche Bedeutung nicht haben, da perf. Verben ja "vollendet" sind. Schon früh wurde diese Prage ins Auge gefabt, und man fand auch bald eine Sonderbedeutung des Ipf. perf. Verben, die

10) V, Riparsky: Russische historische Grammatik. Bd. II. Die Entwicklung des Formensystems. Heidelberg 1967. (weiterhin zitiert als: Riparsky, Russ. hist. GrammatikII). S. $221 \mathrm{f}$ :

11) П. Vondrák: Vergleichende Slavisché Grammatik. II. Bd. Formenlehre und Syntax. Göttingen 21928. (weiterhin zitiert als: Vondrak, Vergl. Slav. Grammatik II).

- S. 387 . 
ebenfalls Vondrák in einer We1se dargelegt, die der heutigen allgemeinen Auffassung voll entspricht: "Das Impf. wird melst

nur von impf. Verben gebildet, nicht selten kommt es aber auch bei pf. vor und drückt dann häufig eine in der Vergangenheit wiederholte oder verallgemeinernde Handlung aus, ... Mitunter bekommt das Impf. derartiger Verba eine modale Bed., die allerdings sekundär ist; ..."12 Chnlich finden wir diesen Tatbestand nicht nur bel Gebauer, Sarauw, van Wijk u.a., sondern auch in jüngeren Arbeiten Mikiforovs, Ruzickas, Lomtevs, Maslovs, van Schoonefelds, Kiparskys u.a. - dargestellt. 13

Besonders ausführich hat sich Maslov in jenem oben genannten Aufsatz (8.0., S. 308, Anm. 3) mit dem Ipf. perf. Verben beschäftigt. Aber auch diese Arbeit stellt im weoentlichen nur eine Typisierung der verschiedenen Möglichkeiten dar, die das Ipf. perf. Verben in seiner Punktion als Ausdruck sich wiederholender Handlungen hat. Im Grunde stellen seine drel Gruppen Varianten realer Bedingungsiätze dar nach dem Muster "Jedes Mal, wenn das geschah, dann tat er jenes."

1. 'Jeģes Mal, wenn .... dann ...' Asce/egda/kto + peff. Ipf., to + perf. Ipf."
Kratno-parnyj tip.

12) Vondrák, Vergl. Slav. Grammatik, S. 388; dazu auch S. 389.

13) Je Gebauer: Die Bedeutung des altböhmischen Imperfects. In: AfslPh 25 (1903). S. 341 - 54 ; C. Sarauw: Syntakt1sches. Das perfektive Imperfekt im Altslavischen. In: 28.f.idg. Porschungen 45 (1927). S. 100 - 04 . N. Van Wijk: Die sog. Verba iterativa und die Bezeichnung wederholter Handlungen im Aksl. In: Idg. Forschungen 45 (1927). S. 100 - 04 ; Nikiforov, Glagol, S. $148 \mathrm{f}$; R. Ruzicka: Der Verbalaspekt in der altruss. Nestorchronik. Berlin 1957. S. 92 ff.; T. P. Lomtev: K charakteristike vidovof differenciacil preterital'nych form glagola $v$ drevnem russkom jazyke. In: Učenye zapisk1 MGU. Trudy kafedra russkogo jazyka. Kn. 2. M. 1948. S. 70 - 88 (Insbesondere S. 72); ders,: Ob upotreblenii glagola otnositel'no kategoril vremeni v drevnerusskom jazyke. In: Ucenye zapisk1 MGU. Trudy kafedra russkogog jazyka. M. 1952. S. $219-53, \mathrm{C}_{2} \mathrm{H}_{2}$ van Schoonefeld: A Semantic Analysis of the Old Russian Pinite Preterite System. 's-Gravenhage 1959. S. 55 f.; Kiparsky, Rus8. hist. Gramnatik, S. 221.

14) Maslov, Imperfekt, S. 82. 
2. 'Gelegentlich geschah dies - in dem Palle tat er das.' "perf. Ipf. - imperf. Ipf." (die auslösende Handlung steht im perf. Ipf.).

Die parataktisch gefügten Sätze haben eine lockerere Beziehung zueinander als die des ersten Typus. Auch ist Typus 2) nicht auf 2weigliedrigkeit angelegt ('wenn .... dann ....), sopdern kann erweitert sein daher: Kratno-cepnoj tip. 15

3. 'Er pflegte dies zu tun, bis (jedes Mal) jenes geschah (bis jenes zu geschehen pflegte).' "imperf./perf. Ipf., donsdeze + perf. Ipf." Kratno-predel nyj tip. 16

Unter den modalen Bedeutungen nimmt die deg Imperfectum de conatu den wichtigsten Platz ein.17

Die m.E. interessantesten Bemerkungen finden wir aber in einem wohl als Schlubabschnitt gemeinten Kapitel: "Mnimye slućai", Typ a)18. Er verweist darauf, daB es im heutigen Bulgarischen und Russischen Verben gibt, die sich der aspektuellen Zuordnung entziehen ("rodit', kaznit', zenit', ranit'n u.a.). Wenn es noch heute solche Verben gebe - zu einer Zeit, da das Aspektsystem voll ausgebildet ist - dann mussen solche aspektuell indifferente Verben zu einer Zeit, da das Aspektsystem noch nicht voll entwickelt war, noch viel häufiger gewesen sein, Als Beispiele (mit Belegen) fuhrt er an ma-, zazbrèti, poslusati, proiti, porazumetinu.a.

Dazu erklärt er: "nazbréachq' fm Marien-Evangelium kann man nur als Uberbleibsel ('perezitok') jener Zeit verstehen, da es noch keine Ableitung 'nazirati' gab und auch keine Notwendigkeit für eine solche Ableitung bestand, weil 'nazbèti' noch kein perf. Verb geworden war, sondern im Zustand aspektueller Indifferenz verharrte ('byl 'bezvidovy' nedifferengirovannym $v$ smysle soversennosti $i$ nesoversennosti')."19

Mit diesen Bemerkungen berührt Maslov den Schlüssel zur Lösung des Problems 'perf. Ipf.', doch das Verharren in aspektuellen Denkkategorien versperrt ihm (zunächst noch ${ }^{20}$ ) die Möglichkeit, alle Erscheinungen in einen groBen Gesamtzusammenhang zu stellen.

15) Maslov, Inperfekt, S. 89. 16) Maslov, ebda., S. 90.

17) Maslov, ebda., S. 112.

18) Maslov, ebda., S. $124 \mathrm{ff}$.

19) Maslov, ebda., S. 127.

20) Ju. S. Maslov: Zur Entstehungsgeschichte des slavischen Verbalaspekts. In: ZsfS1 4 (1959). S. 560 - 68. Dort arbeitet er heraus, daB das slavische Aspektsystem nicht durch Präfigierung, sondern durch Suffigierung entstanden ist. Allerdings arbeitet er diese seine Erkenntnisse nicht zum geschlossenen System aus. 
Betrachten wir die Verben, die Maslov als Beispiele für aspektuell indifferente Verben anführt (s.o.), so fällt auf, daB diese gerade jener Verbgruppe angehören, auf die wir unsere besondere Aufmerksamkeit richten wollen, weil sie von dem Wechsel vom aktionsartlich ausgerichteten zum aspektuell orientierten Verbalsystem am stärksten betroffen ist: die präfigierten Durativa (sofern sie nicht durch die Präfigierung ihre durative Aktionsart geändert haben und Momentanverben geworden waren).

Die traditionelle Forschung betrachtet die Gruppe der perf. Verben als Einheit. Zum Charakter perf. Verben will das Ipf. gar nicht passen; die Vorstellung, daß es die Wiederholung oder Verallgemeinerung einer Handlung ausdrückt, paßt gerade noch ins Bild - kann die geradezu beschworene Wiederholung der durch perf. Ipf. ausgedrückten Handlung beim besten Willen nicht nachgewiesen werden, muß man das betr. Verb als aspektuell indifferent erklären und stellt es so in die Position einer Ausnahme. Dabei deutet sich uberall an, dab diese "Ausnahme" gerade die GesetzmäBigkeit darstellt - es sind nämlich immer wieder die präfigierten Durativa, die als solche "Ausnahmen" erscheinen. Allerdings wird das Bild etwas verdunkelt dadurch, daB man - wie Maslov in oben besprochenem Aufsatz - zum Beweis, daB perf. Ipf. die Wiederholung der so ausgedrückten Handlung meint, immer auf konditionale Satzgefüge vom Typus "jedes Mal, wenn ..." zurückgreift in solchen Sätzen muB ja jede Verbform zwangsläufig Wiederholung bedeuten, was aber mit der Semantik des Verbs selbst gar nichts zu tun hat. In dieser Position werden keine Unterschiede $2 w i s c h e n$ perf. und imperf. Ipf. erkennbar. Unterschiede treten erst dann auf (und hier beginnt die Problematik für die traditionelle Forschung), wenn perf. Ipf.-Formen auBerhalb derartiger Wiederholung der Handlung inhaltlich voraussetzender Satzgefüge ("jedes Mal, wenn ..." ) auftreten. In solchem nicht auf Wiederholung programmierten Kontext treten plötzlich die "aspektuell indifferenten" (im Sinne von: in der Entwicklung zum aspektuell ausgerichteten Verbalsystem zurückgebliebenen) Verben auf. 
Die aspektuell indifferenten (heute meist perf.) Verben verlieren ihren Ausnahmecharakter, wenn wir die perf. Verben nicht als geschlossene Gruppe betrachten, sondern bei der Betrachtung stets die ursprüngliche Aktionsart des jeweiligen Verbs zugrundelegen.

Trost hat in seinen Arbeiten - z.B. über Perfekt und Konditional im Aksl. oder über die aktiven Präsenspartizipien perfektiver Verber im Aksl. 21 - stets die ursprüngliche Aktionsart der heute perf. Verben als wichtigstes Kriterium seiner Untersuchungen betrachtet: "Denn die dem Aspekt nach perfektiven Verben sind der Aktionsart nach entweder nichtdurativ (z.B. jetí 'ergreifen') oder durativ (z.B. gonesti 'tragen' mit Hervorhebung des Handlungsabschlusses) $\cdot n^{22}$

Durch diese Scheidung wird es ihm möglich, grundsätzliche semantische Unterschiede im Rahmen der von ihm untersuchten verbalen Kategorien $z w i s c h e n$ perf. Verben durativer Provenienz und perf. Verben nichtdurativer Provenienz herauszuarbeiten.

Wenn wir im folgenden die Ipf.-Belege unserer Texte in den Mittelpunkt unserer Betrachtung stellen, dann wollen wir bei der Bewertung der Ipf.-Formen von heute perf. Verben ebenfalls die ursprüngliche Aktionsart zum Ausgangspunkt nehmen. Vielleicht gelingt es uns, nach Durchsicht des uns vorliegenden Materials einige konkrete Aussagen bezüglich perf. Ipf.-Formen zu formulieren. Wir übersehen hierbei keineswegs, daß unsere Texte des 15. und 16. Jh.s die Entwicklung zum aspektuell ausgerichteten Verbalsystem viel stärker reflektieren als die aksl. Texte, an denen Trost gearbeitet hat. Mir scheint, daB aber die Existenz zahlreicher "aspektuell Indifferenter" Verben im 15. und 16. Jh. zumindesten einen Versuch in der angedeuteten Richtung rechtfertigt.

21) Trost, Perfekt und Konditional im Altkirchenslavischen; K. Trost: Die aktiven Präsenspartizipien perfektiver Ver ben im Altkirchenslavischen. In: AnzfslPh 1 (1966). S. 31 - 51 und Anzfslph 2 (1967). S. 27 - 47.

22) Trost, Die aktiven Präsenspartizipien, AnzfalPh 2 , S. 38. 
Die Ausfuhrungen über das Imperfekt innerhalb unserer Texte wollen wir in zwei Abschnitte aufgliedern. Der erste soll jene Belege beleuchten, die von nichtdurativen sowie von präfigierten (nichtsuffigierten/nichtdehnstufigen) durativen Verben gebildet sind. Diese beiden Verbgruppen sind heute fast ausschlieblich perfektiv. Da im ausgehenden 15. und erst recht im 16. Jh. das Aspektsystem weitgehend ausgebildet war, ist es wichtig zu erfahren, was es mit den betr. Ipf.-Pormen auf sich hat.

Wenn wir in vielen Fällen Verschreibung bzw. Verwechslung der Endung annehmen können, wollen wir immer die Möglichkeit prüfen, ob nicht vielleicht doch ein bestimmter Sinn im Gebrauch der Ipf.-Porm liegen könnte.

Formal nicht zu unterscheiden sind Ipf. und Aor. in der 1.ps.sg. vor allem auf -a- auslautender Verbalstämme ("délachz", außerdem vom Typus "slyšach" oder "tečachъ"), da wir nur die kontrahierte Ipf.-Endung antreffen: -aachb > ach. Wir haben die wenigen Belege zum Aorist gestellt - dort werden sie gesondert überpruft.

In einem gesonderten Abschnitt (1.1.2) betrachten wir alle Ipf.-Belege auf -aše, die von einem Subjekt im plural abhängig sind. Dies ist, so scheint es, notwendig, da diese Gruppe im Pleskauer Text nicht als Ausnahmeerscheinung zu werten ist: Mehr Ipf.-Belege auf -aše stehen beim Plural als beim Singular. In diesem Abschnitt müssen wir selbstverständlich alle Verbgruppen betrachten - nicht nur Momentanverben, Primärableitungen (= präfigierte Simplicia), sondern auch durative Simplicia und sekundärableitungen (= präfigierte simplicia mit Dehnstufe und/oder Suffix), um dies Phänomen beurteilen zu können.

Nach dieser Durchsicht solcher Erscheinungen, die man als Abweichungen ansprechen kann, wollen wir im zweiten Teil der Behandlung des Imperfekts die Funktion desselben im Satz darlegen. Gleichzeitig nutzen wir diesen zweiten Teil, um das Imperfekt vorzustellen, wie es in der Masse der Belege vorkommt: von Verben, die heute imperfektiv sind. 


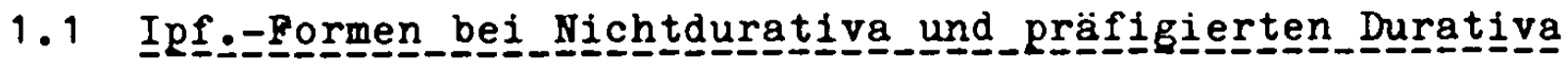

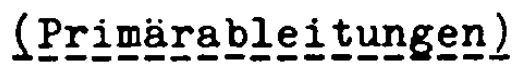

1.1 .1 -aše beim Singular

-aše ist an sich die Endung der 2. und 3.ps.sg. des Ipf. In unseren Texten, aber auch sonst in der aksl. und der altruss. Literatur, wird diese Form für die 2.ps.sg. selten gebraucht. Das liegt in der Natur der erzählenden Genres (im Gegensatz etwa zum Drama, wo der Dialog im Vordergrund steht). Das gleiche gilt ja auch für die 2.ps.pl. und auch bis zum gewissen Grade für die 1.ps.sg./pl. - in allen Tempora. Bei Ipf. und Aor. kommt hinzu, daB die 2./3.ps.sg. formal identisch sind, so dab hier bereits früh für die 2./3.sg. auf periphrastisches Perfekt (1-Part. + esi) oder später auf einfaches 1Part. ausgewichen wurde.

1.1.1.1 K-pel: Nichtdurativa (Simplicia und Komposita)

68/3 "Patriarch ne sobrav boljar i sovetnikov vsech, poide k cesarju 1 načaše uveščevati ego, da izydet iz grada ..."

- Der Patriarch ging - ohne Begleitung - zum Kaiser und begann, ihn zu überreden ... (und wollte ihn uberzeugen)'

Bei "načaše" handelt es sich um eine hybride Bildung. Der Aor. "nača-" wurde mit der Ipf.-Endung "-aše" zu "načaše" kontrahiert. Als korrektes Ipf. wäre "načnjašen < načnèašen zu erwarten. 23

Versehentliche Schreibung, ob vom Autor/Redaktor/Ubersetzer oder Kopisten - für Aor. "nača" - ist nicht auszuschlieBen. Das Erscheinen einer solchen Form fast direkt neben einem korrekt gebildeten und korrekt gebrauchten Aor. bleibt aber merkwuirdig. "načati" und "počati" "geben nicht den Anfang einer bestimmten Handlung an, sondern den Anfang schlechthin, da die Handlung selbst durch ein anderes Verb ausgedruickt wird. ${ }^{24}$ Von einer sich wiederholenden Handlung kann hier

23) Diels, Aksl. Grammatik, S. 235, Anm. 2 .

24) Budich, Aspekt, S. 58, \& 143. 
nicht die Rede sein - man müBte sich in diesem Falle vorstellen, daB der Patriarch den Anfangspunkt seiner Handlung wiederholen, d.h. mehrmals mit seiner Rede neu einsetzen muBte. Diese Deutung paBt aber vom Sinn her nicht.

will man dieser Ipf.-Form "načaše uveščevati ego" unbedingt eine Bedeutung zumessen, müBte man an Imperfectum de conatu denken: ${ }^{25}$ 'er wollte anfangen ...' Vielleicht könnte man die Porm auch als Ausdruck von Expressivität werten.

Da diese Erklärungsversuche aber nicht recht überzeugend sind, scheint mir, trotz der geäußerten Bedenken, absichtslose Schreibung für Aor. "nača" anzusetzen zu sein.

$\mathrm{Zu}$ "načati" ist anzumerken, daB es in den Tabellen unter 'nichtdurative Simplicia' eingetragen ist. Natürlich handelt es sigh bei diesem Verb um ein Kompositum. Aber das Simplex cati < cęti ist weder im Aksl. noch im Altruss. belegt6 Mit Sicherheit war altes "cęti ein Momentanverb. 2

Der eigentliche Grund aber, "načati" zu den momentanen Simplicia zu stellen, war ein praktischer: Vor allem Aor.-Belege kommen von diesem Verb in solcher Zahl vor, daB sie im Rahmen der statistischen Angaben in den Tabellen die Relationen verzerren würden - man bekäme eine falsche Vorstellung von der Gruppe präfigierter Nichtdurativa. Umgekehrt stört "naçati" in der Gruppe nichtdurativer Simplicia nicht, da hier ohnehin einige wenige Verben eine besonders hohe Frequenz haben ( $2 . B .3$. Tabelle II - Aorist (außer 3.pl.): 50 Belege, gebildet von nur fünf Stämmen (die Zahl in der Klammer benennt die Anzahl der Stämne, aus welchen sich die Belege zusammensetzen). "pasti", "byti" sind zusammen mit "nacati" die Formen, die die Gruppe nichtdurativer Simplicia dominieren (im Aorist).

67/5 "...; dostigšu že cesarju vopijaše na svoich, ukrepljaja $i c h, i$, vozrykav jako lev, napade na turky so izbrannymi svoimi pesca (sic) 27 i konniky i sećase ich krepko: ich že bo dostižaše, razsekage ich na dvoe $i$ inych presekaja na-poly, ne uderríavaše bo sja meč ego ni o čem."

25) Maslov, Imperfekt, S. 112; 0tten, Fin. Verbalformen, S.204.

26) Budich, Aspekt, S. 58, § 143.

27) (sic) befindet sich in unserer Textvorlage - es soll auf das Cokanje aufmerksam machen - 3.0. D.1 Zur Phonetik, S. $154 \mathrm{f}$. 
'... und er hieb kräftig auf sie ein: Und auf wen auch immer er traf, den (= jeden einzelnen) schlug/spaltete er mittendurch ...., kein Hindernis konnte sein Schwert aufhalten.'

Wie "načaše" ist auch "dostižaše" eine hybride Form, die Aor.- und Ipf.- Endung kombiniert: "dostižen und -aše. Die korrekte Ipf.-Form müBte lauten: "dostignjašen < nostigněašen ${ }^{28}$ als Inf. ist "dostignutin" oder jüngeres "dostiščin arzisetzen.

Versehentliche Schreibung für sekundäres imperf. "dostigašen liegt nahe, da wir folgende Parallelstelle finden: $71 / 0$ "... i jako že kogo dostigaše mečem po ramu ili po

'... und wen er auch immer mit seinem Schwert auf die Schulter oder den Oberkörper traf - den hieb er nie$\operatorname{der}(=$ hieb er durch); ...'

Andererseits gibt auch die Ipf.-Form eines punktuellen 29 Verbs in diesem Kontext einen guten Sinn: Es werden ja Handlungen aufgezählt, deren ständige Wiederholung erst ihren Sinn (im Krieg) ausmacht. "dostižašen drückt die Bedingung aus, unter der die anderen sich wiederholenden Handlungen einsetzen - man könnte auch ubersetzen:

'...jedes Mal, wenn er einen/jemanden traf, schlug er ihn (jedes Mal) mittendurch.'

Allerdings muB man in diesem Palle fragen, warum dann nicht auch die anderen zum Konditionalgefüge gehörigen Verben "razsekašen und "uderževaše" - wenn schon nicht von einem punktuellen Verb, dann wenigstens von einem sicher bereits Ende des 15. Jh.s als perf. empfundenen Verb gebildet worden sind, also "presečašen und "uderžašen. In Wirklichkeit haben wir statt derer eindeutige Imperfektivbildungen (durch Suffigierung) vor uns, was uns annehmen läBt, daß wir statt "dostižašen als hybride Ipf.-Bildung Verschreibung für Ipf. des imperf. "dostigatin ("dostigašen) ansetzen sollten.

28) Diels, Aksl. Grammatik, S. 236, Anm. 2; Maslov, Imperfekt, S. 90 - zitiert aus PVI, dort Ipf.: "dvizase" in einer H, die übrigen Hss. zeigen dort "dvignjasen; ebda. S. 114: "podvignease" aus dem Cod. Supr.

29) K. Eimermacher: Studien zu den Verba der II. Leskien'schen Klasse im kussischen. Diss. Berlin 1966. S. 73. 


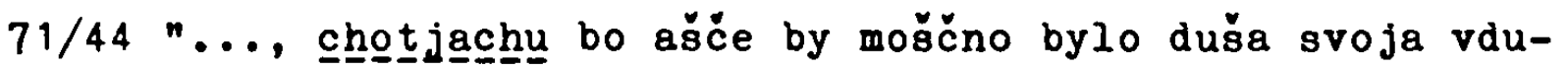
nuti $v$ nego, obbjaše bo ich skorbb 1 pečalb velija o nem, zaneže ..."

'...., sie wollten ihm ... ihre Seele einhauchen, denn es hatten sie großer Kummer und Schmerz ergriffen ..."

Ausgangspunkt für die hybride Bildung "obrjaše" dürfte auch hier der Aor. "obъja" sein. 30 Das richtige Ipf. von "obsjati" müBte lauten "obъměašen > "obъmjašen - Maslov" findet in der PVI (Laur.-Chr.) einen Beleg "vъzmjašen, der hierher zu stellen ist. Diese Bildung war dem $\mathrm{K}$-pler Autor sicher nicht mehr nachvollziehbar, das würde die falsche Bildung "obzjaǧen erklären.

Eine Parallelstelle spricht aber deutlich für Verschreibung für Aor. "obъ jašą":

$74 / 21$ "..., razpadoša krepostjłju i istajaša mysliju, obbjasga ich skorbb i pecalb velija."

Es wäre auch schwierig, eine plausible Begründung für diesen Ipf.-Beleg zu geben - man müBte wieder Expressivität im Ausdruck oder Ähnliches vermuten.

1.1.1.2 K-pel: Präfigierte nichtsuffigierte Durativa (mit belegter sekundärer Ableitung) 32

$75 / 15$ "Vsech že voin sobrašesją s nim do treju tysjašč, 1 obrete ..."

'Er sammelte um sich/es sammelten sich um ihn an die 3000 Mann, und er fand ...'

"Bb-bbrati" > "sobrati, -beru" - "sobirati, -biraju"

Wie der Ubersetzungsversuch andeutet, ist die Konstruktion nicht klar. Betrachtet man den Kaiser als Subjekt, stört die reflexive Endung: "(севаrb) sobraše vsech že voin do

30) Im K-pler Text oft: "vzjat", "obъjat" usw. = Aor. Vgl. Leskien, Handbuch, S. 145.

31) Maslov, Imperfekt, S. 89.

32) Primäre Ableitung: "so-brati" (= nichtsuffigiert/nichtdehnstufig); sekundäre Ableitung: "so-birati" (suffigiert) dehnstufig). 
treju tysjašc̆" - 'von allen Kriegern sammelte er um sich an $3000^{\prime}$.

"brati 'sammeln, ...' ist auf Grund seiner Bedeutung durativ.n33 Das Gleiche gilt für "sobrati/sjan. 34

Wenn wir annehmen, daß "sobrašen ursprünglich statt "sobrašesja" gestanden hat, dann wäre dieser Ipf.-Beleg in dem Sinne $z u$ interpretieren, daB der Autor/Ubersetzer nicht allein die Tatsache (knapp 3000 Krieger) mitteilen, sondern durch das Ipf. die Langwierigkeit des Prozesses - diese 3000 Krieger überhaupt zusammenzubekommen - mit ausdrücken wollte.

Wir können aber auch 'Krieger, Soldaten' als Subjekt hinstellen: "Vsech že voin sobrašasja/sobrachusja s nim do treju tysjašc̆" - "von allen Kriegern versammelten sich etwa 3000 um ihn'. In diesem Palle wäre Verschreibung ("sobrašesja" für "sobrašasja") anzusetzen - oder aber Verschreibung: "sobrašssja" für "sobrachusja". Das erstere ist wahrscheinlicher, stellt das Resultat in den Vordergrund; die Annahme eines ursprünglichen "sobrachusja" würde - s.o. - die Schwierigkeit und Langwierigkeit des Sich-Sammelns in den Vordergrund stellen.

Trotz der Wahrscheinlichkeit der Verschreibung für Aor. ist es nicht ganz ausgeschlossen, dab "sobrašesja" auch ursprünlich eine Ipf.-Form darstellte - sie würde aber keine wie auch immer geartete wiederholte Handlung ausdrücken, sondern im Gegensatz zum Aorist, der das Ergebnis referiert, gerade die Durativität (Schwierigkeit, Mühseligkeit, Langwierigkeit des (S1ch-) Sammelns) betonen. 35

33) Budich, Aspekt, S. $88, \S 196$.

34 ) Budich, ebda., S. 89, § 198.

35) Die ubrigen Belege von "sobrati sja" stehen alle im Aor.: $55 / 3,60 / 19,62 / 33,65 / 27,67 / 25$. Diese Beobachtung verstärkt die Vermutung, daB statt "sobrasesja" zu lesen sei: "sobrašsja". 
65/6 "... gkkaząğą okajannomu turku, jako puška ona velija

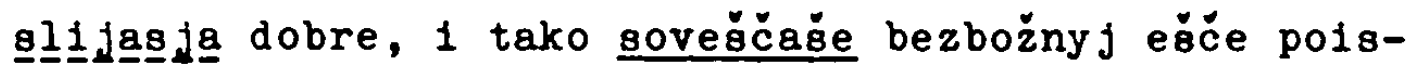
kusiti ju i povele paki ... pojti k gradu ..."

'... man berichtete dem Sultan, daß die groBe Kanone gut ausgegossen sei; und so empfahl er, diese noch einmal auszuprobieren, und er ordnete an, dab die Stadt wieder angegriffen werden solle ...'

"sověščati" - "sovéščevati" < *vèt-

Die suffigierte Ableitung ist auBer Gebrauch gekommen; heute begegnet nur noch das Parr "uveščat' - uveščevat'n, belde imperf. 36 Die Komposita von "věšcati" sind heute imperf. ("otvečat'" mit jünger Perfektiv-Bildung "otvetit'n in Analogie zu "narjaźat' - narjadit'n) oder aspektuell neutral ("ob-, zavešcat'n 37 ). Im $K$-pler Text begegnen uns noch viele suffigierte Ableitungen vom Typus "sověščevati", wohingegen im Pleskauer Text nur noch ein Mal "otveščraše" 38 vorkommt.

Unser Beleg zeugt davon, daB "sověščati" trotz der suffigierten Ableitung nicht perf. war. "sovešçase" bezeichnet eine einmalige Handlung, deren Zeitlichkeit unklar ist. Semantisch ist es mit "povele" fast gleichzusetzen, dem es koordiniert 1st. Entsprechend wuirden wir auch "sovešca" erwarten - vgl. "soveščachu, u-": S. 327.

1.1.1.3 K-pel: Präfigierte nichtsuffigierte Durativa (ohne belegte sekundäre Ableitung)

55/22 "On že bolbma priležaše mysliju na Trojadu, ideźe vsemirnaja pobeda byst - (Als Platz für die zu gründende Stadt) lag inm Troja besonders am Herzen, wo die Griechen die Phryger besiegt hatten.'

36) Daum-Schenk, Die russischen Verben, S. 644 .

37) ebd., S. 122 und S. 277.

38) PS $65 / 11$ "oni że protivu emu otveăčavasen; vom Typus "-vêgcevat1" finden wir im K-pler Text: $68 / 5,-/ 21,-/ 25$, $-/ 31 ; 73 / 33$ u.a. 
Wie "ležati" bezeichnet "priležati" einen Zustand, hier 'anliegen' ("priležaše mysliju" - 'am Herzen liegen'). Dem heutigen Leser wird das Verständnis dieses Ipf.-Belegs dadurch erleichtert, dab dies verb auch heute imperf. ist. 39

$73 / 30$ "..., i povedaša emu mnogo dejanij prě̌nich cesarej sim podobna, takože $i$ klirik vesb i sunklit mnogo glagolaše emu, da izydet iz grada, i ne poslušắe ich, no

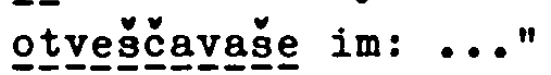

'... der gesamte Klerus redete auf ihn ein, daB er die Stadt verlassen solle, er aber war dagegen (= gehorcht.e ihnen nicht), vielmehr antwortete er : ...'

Imperf. Aspekt, also Durativität, bescheinigen "poslusatin" Dostál, 40 Maslov ${ }^{41}$ u.a. für die aksl. und die altruss. Zeit, ebenso perf. Aspekt. Das Gehorchen oder Nicht-Gehorchen ist ja in dem Sinne keine aktive Handlung, sondern eher ein $\mathrm{Zu}-$ stand (s. Ubersetzungsversuch: 'war dagegen'). Dieser Ipf.Beleg reiht sich in den Kontext: "glagolaše" und "otveščavašen. Die durative Aktionsart von "poslušatin bezeugen auch die tbersetzungsvorschläge, die L. Sadnik und R. Aitzetmilller in ihrem Handwörterbuch ${ }^{42}$ machen: 'angehören, gehorchen'.

71/42 "Egda že skazaše cesarju, abie raspadese krepostiju i iatajaše mysliju i skoro poide k nemu ...n

-Als man dem Kaiser gesagt hatte, (daB Giustiniani verletzt ist), brach er (physisch) zusammen und es schwand ihm jegliche Hoffnung .../es schwanden inm die Sinne...'

$E_{3}$ ist nicht daran zu zweifeln, daB der Autor an dieser Stelle zwei Vorgänge gegeneinanderstellen wollte - das punktuelle "raspadese" - 'brach zusammen' und das durative "istajasen 'schmelzen', durch welches das allmbiliche Erfassen der Situation, d.h. das Fahrenlassen aller Hoffnung ausgedruckt ist. Die durative Grundbedeutung von "tajati" - 'schmelzen' ist

39) Daum-Schenk, Die russischen Verben, S. 563.

40) Dostál, Studie, S. 454 f. Dort auch A. Meillet.

41) Maslov, Imperfekt, s. $127 \mathrm{f}$.

42) Sadnik-Aitzetmuiller, HWB, S. 95 . 
in "istajati" nur insofern varilert, als der Endpunkt durch "1z- (1s-)" in die Aussage mit einbezogen ist, möglicherwelse bewirkt das Präfix auch die Abstrahierung der Grundbedeutung 'schmelzen'.

Allerdings ist nicht zu übersehen, daB die Verbformen um "istajaše" herum auf diese Porm eingerirkt haben, vgl. $74 / 20$ "..... (oni) razpadoša krepostiju 1 1stajaša mysliju,

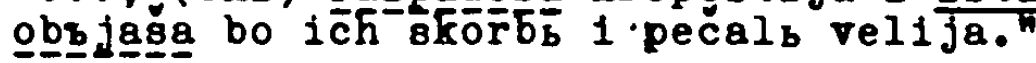

$71 / 38$ "..., (oni) rastajachu i ne vedachu, čto sotvoriti." In unserem Hauptbeleg wäre ein Aor. "1staja" neben "skazašen und "poide" und "raspadese" (für "raspadesja", das lautlich auch nicht paBt) ein zu starker Kontrast zu den ubrigen Endungen, die alle kurz auf -e auslauten (zu dem Ipf. "skazašen s. u. im Abschnitt '-aše beim Plural' s. 336). DaB die Ableltungen von "-tajatin generell noch imperfektfähig waren, zeigt Beleg 71/38 "rastajachu", wo nicht so sehr die lautliche Beeinflussung von "vedachu" in Rechnung zu setzen ist, sondern vielmehr der Blickwinkel des Autors, der zwei durative Handlungen durch das Ipf. In inrer Zeitlichkeit ausdrucken woll te. ${ }^{43}$

1.1.1.4 Pleskau: Nichtdurativa sowie präfigierte nichtsuffigierte Durativa auf - aše (8ing.)

Hierfür können wir aus dem Pleskauer Text keinerlei Beispiele herbelbringen. Die Endung -ase (Sing.) kommt im Pleskauer Text nur bel Verben vor, die auch heute imperf. sind. In diesem Tellbereich zeigt sich der Pleskauer Text also vollkommen ae pektkonform.

43) "Der Unterschied 2 ischen Imperfekt und komplexivem Aodst ist oubjektiv, von der Anschauung des Sprechers abhängig, ein Aspektunterschied." = Budich, 4 spekt, S. 14, 817 , der ganze Satz ist im Original hervorgehoben; 'komplexir' lot der forist durativer Verben. Ipf. und Aor. eines durativen $V_{\text {orbs }}$ geben keine verschiedenen Handiungen wieder, Bondern sie geben dieselbe Handlung verschieden wieder." Budich, Aspekt, s. 13, \$ 17; Hervorhbg. Im OrIginal. 
1.1.2 3.pl. Imperfekt -achu

Wie be1 der 2./3.8g.1pf. auf -abe, wovon wir aus der K-pler Erzählung sowohl für Momentanverben als auch für präfigierte Durativa elnige Textbeispiele, im Pleskauer Text jedoch nicht einen einzigen Beleg finden konnten, so enthält der $\mathrm{K}$-pler Text auch fúr die 3.pl.1pf. auf -achu einige aussagekräftige Beloplele, wohlngegen wir aus dem Pleskauer Text nur zwe1 Belege mit geringer Ausgagekraft vorstellen können.

Allerdings treffen wir in beiden Erzählungen auf Verbformen, die wie Ipf.-Pormen von Momentanverben und von präfigierten Durativa aussehen: "na-/padachu" im $\mathrm{K}$-pler und "skazachu" im Pleskauer Text. Be1 "padachu" handelt es alch aber der Form nach um Ipf. von der ouffigierten Varlante "padat1, padaju"; die entsprechende Ipf.-Form von "past1, padu" lautet "padjaše" < "paděaše" (8.0., S. 308, Anm. 5). - "skazachu" kann formal Ipf. sein von "skazat1, skažu" und auch von "skazat1, skazaju"; die Annahme, daB es sich bel "skazachu" um Ipf.-Pormen von "skazat1, skažu" handeln könnte, findet elne gewisse stutzung in der Tatasche, daB im Pleskauer Text sechs Belege fur "okazovat1/akazyvat1" begegnen. Ea se1 aber an das oben, $\mathrm{s} .308 \mathrm{f}$. Gesagte erinnert: bei einem so hochfrequentierten Verb wie "skazat1" 18t otets daran zu denken, daB die wicht1gsten Pormen (In der Regel die 3.p8.8g. und die 3.ps.pl.) bald zu hab1tualialert-formelhaften Wendungen wurden, olch lange der Aspektualisierung entzogen, ja sogar das Aussterben des Verbs selbst lange úberdauern konnten, was beldes an den Aor.-Pormen "reče, rekoša" und "glagola, glagolab̆a", belde von Durat1va gebildet, die auBer Gebrauch kamen, demongtriert werden kann. So mag es auch mit den Ipf.-Formen von "okazat1, skazaju" gewesen gein - das Verb selbst kam zwar auBer Gebrauch und wurde von "ekazovet1" allmkillch verdringt, aber die Formen einzelner Kategorien blieben, unter anlohnung an "skazat1, skažu", noch lange in Gebrauch, z.B. "skazachu": ale formelhafte Wendungen, nicht aber lebendige Verbalformen.

Einige wenige Belopiele fur die genannten Formen wollen wir hier anfuhren: K-pel - "padachu", Pleskau - "skazachu": 
KP "...: padachu bo trup1ja obolch stran, jako snopy 62/14 zabral, 1 krovb $1 \mathrm{ch}$ tẹẹeée, Jako reky po stenam; ..." '...: wie Garben flelen die Toten belder Selten von den Zinnen; und ihr Blut floB in Strömen die Mauern herab.'

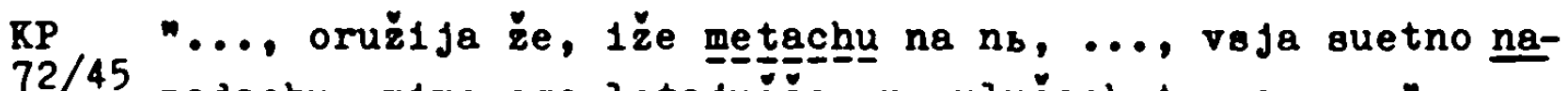
$72 / 45$ padachu, m1mo ego letajuǿče, ne ulu učcachut ego, ..." '.... die Geschosse, mit denen sle thn bewarfen, flogen alle an $1 \mathrm{hm}$ vorbe1, ohne thr zlel zu erre1chen, ...'

D1e Ubrigen Belegstellen entsprechen diesen in ihrem Charakter. D1e Ipf.-Form unterstre1cht den distributiven Charakter der 44 Handlung - die Menge, die Vlelzahl der Handlungsträger (hier: Gefallene, Pfelle) wird aktualisiert; 45 "na-/padosa" wüde den glelchen Sachverhalt - aber anders - wledergeben: referterend, 1m Nachhinein konstatierend. - Wir haben die Belege für "na-/ padachu" n1cht zu Ipf.-Formen von Momentanverben gestellt, sondern sie den dehnstufigen Ipf.-Formen zugeordnet (Tabelle 2).

PS $81 / 8$

"Ovo że pak1 pristupami vejat1 gkazachu,

in11 že pervoeovetnik1 laskoju 1 grozoju govelevacha u gosudarevych bojar 1 u voevod grada prosit1 ..." - Die einen schlugen vor, die Stadt mit Hilfe weiterer Sturmangriffe zu erobern, die anderen meinten, man eolle den Bojaren und Voevoden die Ubergabe der Stadt vorschlagen ...'

"skazachu" und "povelevachu" sind gleichgeordnet. Gerade diese Zusammenstellung unterstrelcht m.E. uberzeugend, daB "skazachu" als Ipf. von "skazat1, skazaju" empfunden wird. D1e Ipf.-Formen haben in diesem Satz - wie die Textbelopiele aus der X-pler Erzahlung oben - distributive Punktion: die Vielzahl der Hetmane und Befehlshaber, die jene Vorschlage machen, wird unterstrichen.

44) distributive Handlung: e1ne Handlung, die von vielen getragen wird - hier: viele Pfelle kommen geflogen, viele Gefallene sturzen herab, unten: viele Hetmane schlagen vor... vgl. Dostal, Studie, z.B. S. 534 "dej d1str1but1vnl"; Boretzky, Tempusgebrauch, S. $44 ; 8.0 ., \mathrm{s}$.

45) Vgl. d1e me1teren Ipf.-Belege "na-/padachu" XP 62/14, $67 / 1,72 / 43$. 
PS "Tako že 1 vajakich gradoemcov u Pakova pobitych, $80 / 24$ jako že 1 one same gkazachu, bole pjat1 tysjašč,...." 'Sie selbst gaben an/erzählten, daB ole vor Pleskau uber 5000 Mann verloren hätten, ...'

"skazachu" hat hier die glelche Bedeutung wie sonst "skazyvachu" - 'es wird gesagt, man hört', s.u., s. 412 f.. Wir haben es hier also mit einem besonderen Fall von Iterativität $z u$ tun. - "skazachu" haben wir in Tabelle 2 zwar unter Ipf.formen durativer ${ }^{46}$ Komposita (mit belegter Dehnstufe) belassen, aber diese mit einem Fragezeichen versehen. 47

\subsubsection{K-pel: N1chtdurativa (Simplicia und Komposita)}

$70 / 8$ "... 1 naçachu b1t1 grad otvajudu 1 mosty na rvech

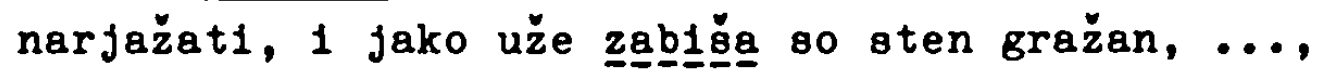
núžachútgi ja siloju vzojti na stenu, ..." -... und sie begannen, die stadt von allen Selten zu beschießen und Bricken uber den Gräben zu errichten; und als sie die Griechen (durch den BeschuB) von der Mauer vertrieben hatten, 48 da versuchten ole mit aller Gewalt, die Mauer zu erklimmen.'

Auch diesen Beleg finden wir in unserer Tabelie mit einem Pragezelchen versehen - deshalb, weil "načachu" (wie wir auch schon In bezug auf "načašen feststellten) elne hybride Form 18t. Ipf. von "načat1, načnu" lautet "načnjaše" < načněašen (8.0., S. 316, Anm. 23). Sicher konnte der Autor diese uberaus selten ${ }^{49}$ auftretende Porm nicht bilden, so dab er in Analogle zu "skazat1, skažu" - "skazat1, skazaju" oder zu "past1, padu" - "padat1, padaju" eln Ipf. von fikt1vem "načat1, načaju" b1ldete und sie "načat1, načnu" gedanklich zuordnete. Eine Verwechslung mit dehnstufigem und ouffigiertem "načinati - načlnachu" 18t kaum denkbar.

Im Gegensatz zu allen sonstigen Textstellen lot der Anfang

46) Dootál, Stud1e, S. 180: "kazat1, kažq" = 1mperf. S. 317: "sokazat1, ozkažq" = perf.

47) Be1spiele mit "okazyvachu" - 8.u., S. 412.

48) Aorlst druckt Vorze1tigke1t aus: N1k1forov, Glagol, S. 152.

49) Diels, Aksl. Grammat1k, S. 235, \$113, Anm. 2. 
der BeschleBung nicht als Punkt gesehen, 50 vielmehr fabt er den Beginn gewissermaßen als eine Welle, wie eine Salve erster Kanonenschüsie. Das Ipf. evoziert die einzelnen ersten Schüsse jeder Kanone - "načachu" 18t also 1terative Bedeutung zuzusprechen.

1.1.2.2 K-pel: Präfigierte nichtsuffigierte Durativa (mit belegter sekundärer Ableitung)

$66 / 34$ "... 1 In1 mnoz1 velbmož1 soveščchu, da 1zydet cesarb 12 grada, vzem s soboju 1zbrannych koliko močno ..." ¿... und viele andere wurdenträger redeten auf ihn ein (= versuchten, ihn zu uberreden), dab er die stadt verlasse, ...'

$74 / 37$ "I vzem otvedóğa ego ot naroda 1 mogo uveščchu ego, da 1zydet iz grada ...."

'Und sie (ergriffen ihn und) fuhrten ihn weg vom Volk und redeten auf inn ein (= verouchten, thn zu uberreden), dab er die stadt verlasee...'

Uber "-véğčatin" sowie die ouffiglerten Ableitungen "-véščvati" B.0.. S. 321. Bel dem dort besprochenen Sing.-Beleg "soveščàe" war nicht recht klar geworden, warum der Autor diese Ipf.-Form gewihlt hatte - die belden obigen Textstellen dagegen lassen kelnen Zweifel: wir haben es mit längerwahrenden Handlungen (fast: Verhandlungen) zu tun; die tbersetzung versucht, dies herauszustellen. Auch unterstrelcht das Ipf. die Vielzahl derer, die es unternehmen, den Kalser zu überreden: einmal heibt es "mnozl velbmoži" und einmal steht "mnogo" adverbial bel der fraglichen Form und unterstreicht indirekt die vielzahl derer, die dem Kalser raten.

Den dre1 Ipf.-Formen stehen dre1 Aor.-Belege gegenuber. 51 Daraus können wir schließen, daß "věšcatin seine aspektuelle Neutralitkt, die es ja z.T. heute noch hat ("ob-, zaveščt'n), bewahren konnte, dab aber andererselts dieser stamm trote háufigen Auftretens ouffigierter Ableitungen nicht als perf.

50) 2.B. 59/30 "načăa b1t1 grad", vgl, we1ter $66 / 2,-/ 4$, $65 / 17,63 / 18,61 / 31 \mathrm{u} .8$.

51) "soveв̌ca/в̈a" - 64/29, -/35; "otveв̌ón" - 64/34. 
empfunden worden sein kann, dafur zeugen die drei vorgestellten Ipf.-Belege.

1.1.2.3 K-pel: Präfigierte nichtsuffigierte Durativa (ohne belegte sekundäre Ableitung)

59/36 "Egda že turk1 načajachu - uže vsich ljudil s sten

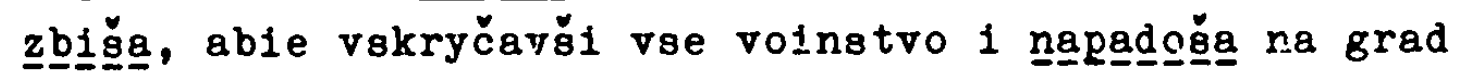
vkupe so vsech stran, ..."

'Als die Türken glaubten, dab sie durch ihr SchieBen die Griechen von der Mauer vertrieben hätten, stürzten sie sich, nachdem sie ihr Kampfgeschrei erhoben hatten, ...., der Stadt entgegen, ...'

Duratives "čajati" - 'erwarten, in Hoffnung sein' (Zustandsverb) bekommt zwar durch das Präfix "na-" eine bestimmte Zielrichtung ('etwas Bestimmtes hoffen, hoffen auf'), verändert durch die Präfigierung natülich auch nicht seine durative Aktionsart - so 1st dieser Ipf.-Beleg uberhaupt nicht erstaunlich.

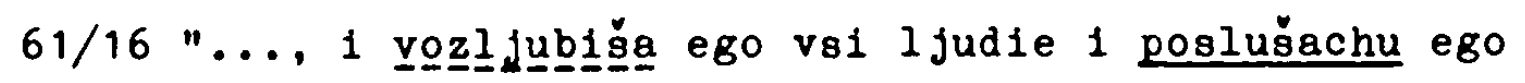
vo vsem, ..."

'..., alle Griechen gewannen Giustiniani lieb und gehorchten ihm in jeder Beziehung/

waren inm in jeder Beziehung gehorsam, ...'

Die Durativität von heute perf. "poslusati" hatten wir bereits in anderem Zusammenhang demonstrieren können (s.0., S. 322). Auch in diesem Satz kommt sie deutlich zum Ausdruck, das fast Zuständliche hebt sich plastisch ab gegen aoristisch ausgedrlicktes 'gewannen inn lieb'.

$65 / 3$ "Sija v8ja izreksim, paki ugotovl jachusja na branb, kajuščesja o poslan11 k Moametju, zane tem uderžachu ego."

'... berelteten sle sich wieder zum Kampf, und sie bereuten die Botschaft ( $=$ Bitte um Prieden) an Mehmed sehr, weil sie 1 hn dadurch veranlaBt, hatten, vor $K-p e l$ $z u$ bieiben = zuruckgehalten hatten. ${ }^{52}$

52) Ipf. zum Ausdruck der Vorzeitigke1t im abhängigen Satz 8. Hikiforov, Glagol, S. 147 . 8.0., S. 519. 
2war 1st "uderžat1" heute perf., dennoch ble1bt es durativ; das Prafix modifizlert, verengt die Bedeutung ein wenig: von allgemeinem 'halten' zu 'zuruckhalten'; wir haben es also nur mit einer bestimmten Art von Halten zu tun. Dieser Sachverhalt wird dadurch, daß "uderžachu" Vorzelt1gke1tabedeutung hat, etwas verdunkelt. Vorze1tig lot aber nicht das Zuruckhalten an $81 \mathrm{ch}$, sondern nur der Anfang, der mit der griechischen Bitte um Frieden an Mehmed markiert wird: mit dleser wurde Mehmed veranlaBt, selne Ruckzugsplane aufzugeben, damit hielten die Griechen inn zuruck - aus dem Zuruckhalten, gesehen von den Griechen, wurde ein Zuruckbleiben, von Mehmed aus gesehen - und das währt ja noch heute.

66/15 "...; Feodor že tisjačnik sovokupivaja s Zustunesm,

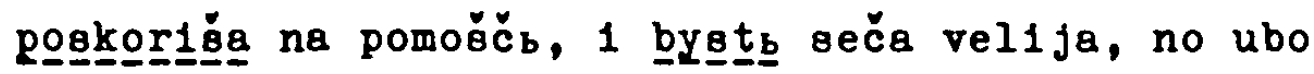
turky osilovachut $t_{b} 1 \mathrm{ch}$."

'...; (diese) ... ellten zu Hilfe, und es ward ein mkchtiger Kampf, aber die Turken waren ihnen uberlegen.'

2war 1st ein simplex "silovat1" nicht belegt, aber verschledene Komposita sind Im Altruss. bekannt - z.B. heutiges "nasilovat'" - 'zwingen; vergewaltigen' (Srezn. II, 330). Das Textbeispiel zeigt deutlich, dab dor Autor nicht 'Oberhand gewinnen' (höchstens eln allmähliches Oberhand Gewinnen) meint, sondern eher zuständliches 'Uberlegen Sein', 'Oberhand Haben'. Auch in diesem Beleg tritt der Gegensatz zwischen den Handlungen durch das schroffe Nebenelnander von Aor. und Ipf. klar hervor, unterstrichen noch durch die Ant1these: "bystb seča velija, no ubo turky osilovachuts $1 \mathrm{ch}^{\prime \prime}$ - 'zwar kam es zu einer máchtigen Schlacht, aber es hatte alles keinen 2 weck, well die Turken (80) Uberlegen waren.

$71 / 37$ "... 1 v81 ljudie 1 frjagove, 12̌e beša a nim, rastajachu 1 ne vedachu, čto sotvoriti."

'... und alle, die bel thm waren, waren mutlos und muBten nicht, was zu tun se1.'

"rastajat'" lot heute perf., dabel handelt es $81 \mathrm{ch}$ bel der Prafiglerung um eine Spezialisierung des simplex "tajati", um elne Abstrahierung - wie wir auch schon bel "1stajasen, 
"načajachu", "uderžachu" u.a. beobachten konnten. Bel "rastajati" tritt der Anfangspunkt des Vorgangs etwas in den Vordergrund ('Mut verlieren'), davon bleibt aber die Durativ1tät der Handlung unberuhrt.

\subsubsection{Pleskau: Präfigierte nichtsuffigierte Durativa} (ohne belegte sekundüre Able1tung)

81/1 "Pak1 że korolb sed na svoem vysokogordom meste, emu że predstojachu velikija ego getmany ..." '... vor thm aber standen seine Hetmane ...'

Das Präfix gibt lediglich eine lokale Präzisierung 'stehen vor', was nichts an der Zuständlichkelt des Vorgangs ändert. Auch heute 1st "predstojat'n 1mperf., allerdings hat es nicht mehr die konkrete Bedeutung wie im Beispiel oben, sondern hat abstrakteren Sinn bekommen: 'bevorstehen', hat also eine zeitliche Dimension gewonnen.

85/6 "Litovskija že gajduki, egda uslyšachu po prolomu ot chrestbjanskich svjašćennikov molebnaja pevaema, .... kameniem mnogim na to mesto vo grad metachu 1 chrestbjan uražachu."

- (Jedes Mal), wenn die litauischen Heiducken ... die Bittgesänge der Pleskauer Gelstlichke1t hörten, beschossen sie diese Stelle mit Steinen und töteten (so) viele Pleskauer.'

Die Ubersetzung: 'jedes Mal, wenn ...' ergibt sich aus dem Kontext, denn $85 / 3$ ff. helBt es: "takože po triždy na nedell na prolom so kresty ... prichožachu ..." - 'dre1 Mal wöchentlich fanden diese Prozessionen statt', im Verlaufe welcher die Litauer die Bresche beschossen. Heute perf. "uslysati" druckt in diesem Kontext also Iterativitat aus - we jede Verbform in einem Konditionalsatz, der als 'jedes Mal, wenn ...'-Typus interpretiert werden muB.

Auch ohne diese kontextabhägige Interpretation ('jedes Mal, wenn ...') ergäbe der Satz einen schönen Sinn: 'Als die litauischen Helducken ... hörten, beschossen sle ...' Die Bittgesänge zogen sich hin, lange waren sie zu vernehmen: "uslyšachu" drückt dies aus, wobel "u-n den Beginn des Vernehmens noch miterfabt. 
1.1.3 Zusammenfassung: Imperfekt-Formen von H1chtdurativa und prälgierten nichtdehnstufigen und nichtsuffigierten Durativa

Soeben stellten wir fest, daB die Pleskauer Erzählung kaum hierher gehorige Textbeispiele aufwe1st, wenn wir einmal von den zweifelhaften Belegen mit "skazachu" absehen. Die angefuhrten Textstellen waren von geringerem Interesse, we1l der eine Beleg ("predstojachu") von elnem prafiglerten Zustandsverb, das auch heute imperf. 1st, geblldet murde. D1e zwe1te Form ("uslysachu") bezelchnet Iterativität - doch nicht als Punkt1on der Verbalform, sondern infolge des Kontextes und des Satztypus, dem "uslyšachu" als Prädikat dient: elnem bedingenden Rebensatz 1m Kond1tionalsatrgefuge rom Typus 'Jedes Mal, wenn ...., denn ...'.

Das Material, das wir im $\mathrm{K}$-pler Text vorfanden, lat unglelch relchhaltiger und vielfaltiger - allein diese Tatsache zelgt schon, daB in dem Jahrhundert, das zwischen der Abfassung unserer beiden Texte liegt, die Aspektualisierung des Verbalsystems we1t forgeschritten 1st: Während der K-pler Text noch eine gewlsse Anzahl von Ipf.-Formen solcher Verben enthilt, die heute perf. oind, entsprechen die Ipf.-Belege in der Pleskauer Erzählung fast vollkommen der Aspekt-Korrelation:

Imperfekt - imperfektiver Aspekt.

Bezuglich der Ipf.-Formen von Momentanverben in der K-pler Erzahlung vermuteten $\mathbf{w l}$ in den me1sten Pällen Verschrelbung, etwa statt anzusetzendem "obъjaša" lasen wir "obъjašen, statt anzusetzendem "načan (oder "načaša") lasen wir "načašen. In zwe1 Pällen war aber - trotz falscher Bildung 53 - 1terative Bedeutung der Ipf.-Form erkennbar. D1ese 1terat1ve Qualitit hat aber auch das Ipf. der suffiglerten (heute 1mperf.) Variante. 54 dahier aind wir nicht alcher, wie wir die fraglichen Pormen zu douton haben.

53) "načachu" für "načnjachu" < "načsněachu"; "dost1zagen fur "dost1gnjasen < ndost1gnésen.

54 ) M1k1forov, Glagol, S. 144 "... 1mperfekt vyražaet dejetvija 111 javlenija, obycno 111 neodnokratno soversavaleofa." (Hervorhebg.: Hikliorov). 
Auch das Ipf. präfiglerter (nichtdehnstufiger und nichtsuffiglerter) Durativa kann Iterativität ausdrucken. Scheinbar ist dies selbstverständlich, denn bel diesen Verben handelt es sich in den melsten Fällen um perf. Verben - und die Grundbedeutung der Ipf.-Formen perf. Verben se1, so lat die herrschende Me1nung, gerade die Iterativitat.

Das Material, das uns die K-pler Erzählung an die Hand gab, let naturlich nicht ausreichend für grundsätzliche Untersuchungen zum Imperfekt perfekt1ver Verben. Immerhin reicht es aber aus, um Vermutungen anzustellen. Wir sind ja bei unseren Untersuchungen nicht von aspektuellen Kategorien ausgegangen, sondern von der den Verben innewohnenden Aktionsart. Den Momentenverben stellten wir die nichtmomentanen gegenuber, die wir allgemein als 'durativ' bezeichneten. Die Gruppe präfigierter Durativa (gemeint: nichtmomentane Verben) setzt sich ja aus Verben zusammen, die houte meist perf. sind - wir konnten aber zwischen Ipf.-Pormen dieser und Ipf.-Formen präfigierter (nichtdehnstufiger/nichtsuffiglerter) Durativa, die heute imperf. oind, nicht den geringsten semantischen Unterschied feststellen: Das Ipf. dieser Verben bezelchnete (auBer in Konditionalsätzen vom Typus 'Jedes Yal, wenn .... dann ...') nfemalo Iterativität, sondern benannte die jeweilige Handlung in ihrer ursprünglichen zeltlichke1t, wie dies auch die ubrigen Tempora dieser Verben tun. Selbst die modale Bedeutung, die so gern ins Feld gefuhrt wird, wenn sich bei entsprechenden Belegen Iterativitat beim besten Fillen nicht festotellen läBt, konnten wir nur selten beobachten.

Unsere Beobachtungen berechtigen zu der Vermutung, daB Iterativitat nicht die Grundbedeutung von Ipf.-Formen perf. Verben sein kann - zwar trifft dles auf Momentanverben su, doch Verben, die durch Präfiglerung zwar perf. gewordon sind, inre durative Aktionsart jedoch dadurch nicht verloren haben, 55 bezeichnen auch im Ipf. die Handlung in ihrem ursprunglichen verlauf, wobel naturlich die durch die Präfiglerung bewirkte

55) Durative Verben, die perf. aind, werden auch 'komplexiv' genannt: "Als komplexiv wird hier jede durative verbform 
Differenzierung der Semantik erhalten bleibt (z.B. Begrenzung der Handlung zum Anfang oder Ende hin).

Iterativität drückt das Ipf. durativ-perfektiver (= komplexiver) Verben - meiner Beobachtung nach - nur in bestimmten Konditionalsätzen aus; daher durfte Iterativ-Bedeutung beim Ipf. dieser Verben als Ausnahme, nicht aber als die Regel zu betrachten sein.

Da das Ipf. von Verben, die eine dehnstufige und/oder suffigierte Ableitung besitzen, ziemlich selten gebildet wird, scheint es mir, daß diese Formen dazu dienen, dem Ausdruck in erster Linie Expressivität, sicher aber auch modale Schattierungen (Imperfectum de conatu; konditionale oder kausale, auch voluntative Nuance) zu verleihen.

Vor uber 100 Jahren machte Potebnja ${ }^{56}$ bereits einen Unterschied zwischen präfigierten perf. Verben, die durch die Präfigierung eine ursprüngliche durative Bedeutung nicht verloren haben, und solchen, die durch die Präfigierung eine in sich abgeschlossene, einmalige Handlung bezeichnen. Das Ipf. der ersteren drucke die jeweilige Handlung in ihrer Ausdehnung aus, in ihrer Durativität also; das Ipf. der zweiten Gruppe aber bezelchne die Wiederholung der in sich abgeschlossenen Handlung.

Die Textbeispiele in van Schoonevelds Monographie: A Semantic Analysis of the Old Russian finite Preterite System enthalten auch einige Ipf.-Belege perf. Verben. 57 Wenn er auch an einer Stelle schreibt "Here we have one of the few places where the connotation of repeated action is absent in the perfective imperfect. ${ }^{58}$ - so zeigen die Belege, dab umgekehrt 1terative Bedeutung die Ausnahme darstellt.

Verbform verstanden, die eine Begrenzung der Handlung zum Ausdruck bringt, sei es durch das gewählte Tempus (Aorist) oder durch den verwendeten Aspekt (pf.):" Budich, Aspekt, S. 13 , Anm. 23.

56) Potebnja, Iz zapisok po russkoj grammatike IV (erst 1941 erschienen), S. 148.

57) van Schooneveld, A Semantic Analysis, S. 39 (Beleg 7).

58) ebd., S. 39, Beleg 9; S. 43 Beleg 13; S. 44, Belege $15+$ b.w.1 
Bud1ch 59 meint, daß das Ipf. perf. Verben ein Relikt aus ältester 2e1t se1, es komme bel Verben von 'durativer Aktionsartzeltlichke1t' vor und bezelchne auch in Gestalt des Ipf. Durativität. Iterativität dagegen drucke das Ipf. von Hichtdurativa, von Momentanverben also, aus - von Verben, die erst in der jüngeren Entwicklung Ipf.-Formen bilden konnten.

16: Innerhalb dieser Belege bezelchnen Ipf.-Formen perf. Verben einmalige, (meist) nichtmomentane Handlungen.

59) Bud1ch, Aspekt, S. 20, Anm. 36. 


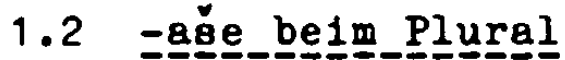

Ein Blick auf Tabelle 2 zelgt lns, daB sich hingichtlich der Ipf.-Pormen auf -aše, deren Subjekt im Plural steht, beide Texte sehr unterscheiden: im $\mathrm{K}$-pler Text machen die 11 Belege 13 v.Hd. aller Pormen auf -aše aus, die 51 Ipf.-Belege auf -aše beim Plural im Pleskauer Text stellen 54 v.Hd. aller Pormen auf -ase dar. Innerhalb aller Ipf.-Belege im $\mathrm{K}$-pler Text 222) machen die 11 Pormen auf -aše beim Plural 5 v.Hd., die 51 Belege im Pleskauer Text (von 161) aber 32 v.Hd. aus. Schon diese Diskrepanz rechtfertigt eine genauere Betrachtung des Phänomens. Vergleichen wir die elnzelnen Angaben in dieser Rubrik (-aše belm Plural), so fällt auf, daB sich, abgesehen von der quantitativen Diskrepanz, die Texte auch darin unterschelden, dab sich die entsprechenden Belege unserer beiden Texte aus ganz anderen Bereichen rekrutieren: Von den 11 Belegen des $\mathrm{K}$-pler Textes sind 5 (6) nach heutigen Begriffen perf. Von den 51 -ase-Formen beim Plur. im Pleskauer Text sind nur 6 nach heutigen Begriffen perf. - dort also ungefähr 50 v.Hd., im Pleskauer Text nur etwa 10 v.Hd.

1.2.1.1 K-pel: Präfigierte nichtsuffigierte Durativa (mit belegter sekundärer Ableitung)

68/16 "(cesarb) pade na zemlju, jako mertv, 1 bystb bezglasen na mnog čas, edva otolbjaše ego aramatnymi vodami." '.... und es gelang ihnen nur mit Mühe, ihn durch Besprengen mit ... Tassern ins Leben zurückzurufen.'

"otolbjati" ist - trotz des -a-Suffixes - kein Aspektpartner zu perf. "otzliti". Vielmehr sind beide perf. In Bezug auf notslivati". 60

vg1.: 71/36 "..., pade na zeml ju: edva ego otolbjaša 1 otnesesosa $i$ v dom ego."

Die Parallelstelle läbt sofort an Verschreibung denken, also

60) Budich Aspekt, S. $96, \S 212$ stellt dies fest bezüglich "prolit1/prolbjat1 - prolivati". 
Ipf. "otolbjašen statt Aor. "otolbjaša". Das ist auch die wahrscheinlichste Klärung dieser Form.

Trotz der Parallelstelle wäre auch Verschreibung für "otolbjachu" denkbar: das BegieBen/Besprengen wurde so lange fortgesetzt, bis der Kaiser schlieblich wieder zu sich kam.

62/34 "...; Zustuneja že i vsi velbmoži poídoša po stenam grada, smotrjajušče sten $i$ trupija nevernych, 1 tako $3 k a-$ zaše cesarju $i$ patriarchu do 35000 ubbenych." '... und sie meldeten dem Kaiser und dem Patriarchen, daß ca. 35000 (Türken) gefallen seien.'

71/42 "Egda že i skazaše cesarju, abie raspadese krepostiju

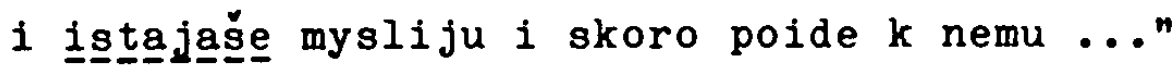

-Als sie dies dem Kaiser meldeten/gemeldet hatten, ver lieb ihn seine Kraft, seine Hof fnung sank, und gleich eilte er zu ihm...'

vgl.: 65/6 "Dnem že trie minuvšim skazaša okajannomu turku, jako puška ona velija slijasja dobre, ..." '... meldeten sie dem Sultan, dab ...'

In den beiden ersten Beispielsätzen dürfen wir wohl mit Verschreibung für Aor. "skazaša" rechnen, wie er im Beleg 65/6 begegnet. In beiden Pällen ( $62 / 34$ und $71 / 42)$ haben wir es mit einer bestimmten Nachricht $z u$ tun, die dem Kaiser uberbracht wird; daher unsere Ubersetzung 'meldeten'; vgl. die Belegstellen im Pleskauer Text mit "skazachu" (s.o., S. 326), die eine oft wiederholte Nachricht bezeichnen: 'es wurde gesagt'.

76/1 "...; takože i v oknach suščei voini, ne predaše okny (sic), no bjąachusją s dvoimi turky, i ... v denb odole-

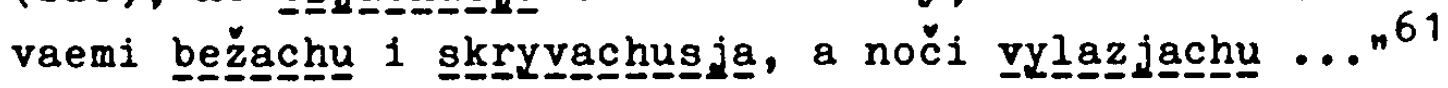
'.... sie gaben die Penster/SchieBscharten nicht auf, sondern kämpften mit den ... Türken, und tagsüber ... verbargen sie sich in den Verliesen/Katakomben, aber nachts kamen sie wieder hervor ...'

61) s.0.S. 308: die korrekte Ipf.-Bildung von "dati, dam" ist "dadéaśe" > "dadjase": Maslov, Imperfekt, S. $86+100 ; 0 t-$ ten, Pin. Verbalformen, S. 205 ; L. Sadnik: Das slavische Imperfekt. In: WdSI 5 (1960). S. $19-30$. Zu "daděaše" s. S. 308, Anm. 3 . 
"predaše" steht sicher für "predaša". Das Nicht-Aufgehen der Fenster/Schießscharten stellt gewissermaßen die Konstante dar, der die anderen Handlungen untergeordnet sind: sie verbargen sich, sie kamen wieder hervor - aber ihre Schiebscharten gaben sie nicht auf. Diesen Sachverhalt wüde eine perfektische Konstruktion noch verdeutlichen: "ne su predali ...". Eine derartige Interpretation drängt sich auf, da sich im Rahmen dieser Handlungskette, ausgedrückt durch Ipf.-Formen auf -achu, auch ein Ipf. "predajachu" oder "predachu" anbieten würde.

1.2.1.2 K-pel: Präfigierte nichtsuffigierte Durativa (ohne belegte sekundäre Ableitung)

$68 / 33$ "Vo vtoroj že denb, egda uslyšš̌e ljudie otšestvie svjatago ducha, abie rastajasasja vsi, i napade na nich strach 1 trepet."

'.... als sie erfahren hatten, daß der Heilige Geist gen Himmel gefahren war, verzweifelten alle, und es befiel sie Furcht und zittern.'

Grammatisch liegt hier gar keine Unkorrektheit vor, doch in beiden unserer Texte steht bei Kollektiva - "ljudien, "voingtvo" usw. - gewöhnlich noch der Plural. 62 Aus diesem Grunde haben wir "ljudie uslyšaše" hierher zu -as̆e beim Plural gestellt. - Auf jeden Fall düfte es sich be1 "uslyšše" um den Versuch handeln, Vorzeitigke1t (im abhängigen Satz) auszudrücken. 63 parallelstellen sprechen dafür, daß diese Vorzeitigkeit hier durch Aor. bezeichnet werden sollte, wir also mit "uslyššn" zu rechnen haben: $68 / 15$ "..., 1 jako uslys̆a cesarb glagoly 1ch, pade ..." $70 / 29$ "Egda že uslys̆a zvonu, ... izyde pred cerkvoju ..."

62) Vgl. z.B. Borkovskij-Kuznecov, Istor. grammatika, S. 324 ff.; Potebnta, A. A.: Iz zapisok po russkoj grammatike. Tom III: ${ }^{0 b}$ izmenenii znacenija 1 zamenach suscestvitel'nogo. M. ${ }^{2} 1968$. (weiterhin zitiert als: Potebnja, Iz zapisok po russkoj grammatike III). S. 25 if.

63) Nikiforov, Glagol, S. 147 - Ipf. Im abhängigen Satz als Plusqpi.; S. 152 - Aor. Im abhänglgen Satz als Plusqp .; s.u., S. $515-529$. 
$72 / 38$ "..., 1 (on1) naçaša vozvraščati frjag s moleniem 1 rydaniem, 1 ne poslušaše ego, ...n

'und sie begannen, die Pranken zurückzudrängen ....' aber sie gehorchten ihm nicht, ...' (= dem Kaiser) vg1. $73 / 32$ "... glagolağe emu, da izydet iz grada,

Es war (8.0., S. 322) bereits vom durativen Charakter von "poslušati" - 'gehorsam sein' die Rede. Unsere Textstelle $72 / 38$ entspricht sinngemäB der zweiten $73 / 32$ genau. So ist in 72/38 statt "ne poslušše ego" sicher "ne poslušchu ego" zu lesen, nicht aber "ne poslušaša ego".

1.2.1.3 K-pel: Dehnstufige/suffigierte Ableitungen auf -aše beim Plural

56/15 "Ljudie že tekše zmija u彑bịğa, a orla 1zymaše, ..." 'Die Leute aber liefen (herbel), töteten die Schlange (Nom.sg. "zmij" s. 56/10), und den Adler befreiten sie.'

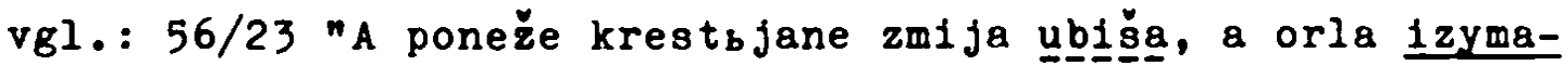
离, javljaet, jako naposledok ..."

Die Vergleichsstelle zeigt zweifellos die bessere Lesart. Da wir auch hier das Momentanverb "ubiti" neben dem Imperfektivum "izymati" vorfinden, müssen wir darin eine bestimmte Absicht des Autors/Ubersetzers sehen: Der Vorgang des Tötens wird als momentane Handlung gesehen, der der Befreiung aus den Umschlingungen der Schlange aber als langwierige, von vielen Händen durchgeführte Handlung. So betrachtet, sind vermutlich belde Lesarten nicht der Intention des Autors entsprechend - adäquat wäre hier nur "izymachu".

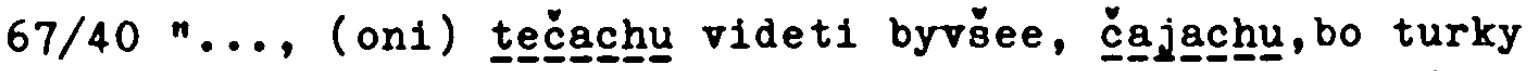
zažgoša grad, 1 vsklikaše veliim glasom; sobravšimže sja ljudem mnozem videğa ... plamenju ognennu veliju..." '.... sie liefen herbei, um zu sehen, was vorgefallen war, glaubten sie doch, die Türken hätten die Stadt angezundet, und sie schrien mit lauter Stimme ...'

"vsklikaše" 1st "vsklikati" zuzuordnen, denn das Ipf. von 
"vskliknutı" müßte "vsklikněaše" > "vskliknjaše" lauten. 64 Im Rontext ist "vsklikaše" den ubrigen Ipf.-Belegen auf -achu beigeordnet. Es handelt sich hier nicht um einen einzelnen Aufschrei, sondern um das Schreien der vielen Menschen, die herbeilaufen, die da glauben, daß die Türken die stadt angesteckt hätten: es wäre hier also "vaklikachun" zu erwarten.

\section{2 .1 .4 K-pel: Simplicia}

$61 / 17$ nTurky že bbjašesja po vsem mestom, jakože predi rekochom, bez opočivanija premenjajuščsja, zaneže množestvo tem bjach hu $1 \mathrm{ch} . "$

'Die Türken kämpften überall und wechselten sich pausenlos ab, weil ihrer so viele waren.'

Auch hier muB man sicher "bbjachusja" lesen, wie wir es im $k$-pler Text elf Mal vorfinden. Der Sing. ist vier Mal als "bbjaše/sja" vertreten - der Aorist "-bi, -biša" erscheint in der K-pler Erzählung nur bei Komposita. 65

$73 / 29$ "..., i povedąag emu mnogo dejanij prě̌nich cesarej sim podobna, takože $i$ klirik vesb 1 sunklit mnogo glagoląse emu, da izydet iz grada, ..." 'und sie erzählten ihm, wie sich frühere Kaiser in ähnlichen Situationen verhalten hatten, auch der gesamte Klerus redete inm $z$, er solle doch die Stadt verlassen, ...'

Es ist kaum anzunehmen, daB "klirik vess i sunklit", zwei Kollektiva also, beim Sing. stehen. Tenn wir "glagolaše" lesen, dann ist Verschreibung, möglicherweise unter Einflub von vorherigem "povedaš" zu vermuten; da in unseren Texten "glagolaša" nie erscheint, ist an dieser stelle mit einem ursprünglichen (oder beabsichtigten) "glagolachu" zu rechnen. (vgl. "glagolachu" 60/43, 64/43).

64) vgl. Eimermacher, Studien, S, 72 ; Diels, Aksl. Grammatik, S. 236, Anm. 2: "outzknège" 'geriet', S. 261, Anm. 4: dasselbe, dazu "sbchnéasen.

65) Im Pleskauer Text dagegen: drei Mal unpräfigiert "b1 šn", nie nbbjachu/sja"; nie nbbjase/sjan - Sing. stets präfigiert "sbi", "pobi" usw. 
64/21 "Cesarb že s patriarchom 1 vesb ... klirik bjąchu po

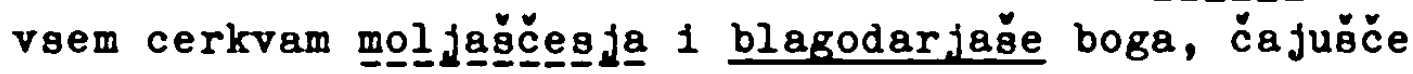
uže konec branem."

'... (sie) beteten in allen Kirchen und dankten Gott, meinten sie doch, die Kämpfe hätten ein Ende gefunden.'

"bjachu" und "blagodarjaše" sind koordiniert, demnach könnte man, in der Annahme, daB auch die Danksagungen an Gott in allen Kirchen vollzogen werden, an Verwechslung mit "blagodarjachu" denken - doch scheint mir hier eine andere Verschreibung vorzuliegen: "bjjachu mol faščes ja 1 blagodar jašče boga", demnach gehörte "blagodarjaše" zu dem aus einer flektierten Form von "bytin (meist Ipf.) und Part.praes. bestehenden 'Tempus intensivum' (s.0., S. 652 ff.).

Ipf.-Pormen auf -ase bel einem Subjekt im Plural stellen im K-pler Text eine gehr heterogene Gruppe dar. Der Vergleich mit Parallelstellen ließ die Tendenz erkennen, daß bei präfigierten Durativa, die ihrerseits dehnstufige Ableitungen zur Selte haben, die Endung - ase offenbar Verschreibung für die Aor.-Form -aša darstellt. Präfigierte Durativa ohne bekannte dehnstufige/suffiglerte Ableitung lieBen keine Tendenz erkennen - die fragliche Endung schien einmal die 3.pl.aor., einmal die 3.pl.1pf. zu ersetzen. Mit groBer Wahrscheinlichkeit vertrat bei durativen Simplicia und bel dehnstufigen/suffigierten Ableitungen -aše die 3.pl.1pf. -achu. - Pür fundierte Aussagen reicht das geringe Material allerdings nicht aus. Ersetzt -aše die 3.pl.aor. -aša , dann dürfen wir ganz sicher irgendeine Art von Verschreibung annehmen - zufällige Bildungen also. Diese Erklärung trifft auf die Verwechslung der Formen -aše und -achu sicher nicht zu - dazu ist die 3.pl.ipf. -achu zu markant. Wie gesagt, ist unser Material für grundsätzliche Erklärungen oder auch nur Vermutungen quantitativ zu gering, als dab man in der Vertauschung von -aše und markantem -achu bereits Ansätze für eine Schwächung des alten Pormensystems erblicken durfte. Trotzdem wollen wir diese Erscheinung im Gedächtnis behalten; im Zusammenhang mit den Untersuchungen am Pleskauer Text werden wir daran erinnern, darauf zurückkommen. - Die Zusammenstellung aller ent- 
sprechender Belege von -aše mit Plural erweckt möglicherweise den Eindruck größerer Unsicherheit hinsichtlich der Numerus-Kongruenz zwischen Subjekt und Prädikat in der K-pler Erzählung. Deshalb sei daran erinnert, dab die vorgefürten elf Belege mit gestörter Kongruenz im Numerus nur knapp 5 v.Hd. aller Ipf.-Formen ausmachen - gegenüber 32 v. Hd. Belegen von -aše beim Plural im Pleskauer Text.

1.2.2 -aše beim Plural im Pleskauer Text

Von den elf Ipf.-Pormen auf -aše beim Plural im K-pler Text waren es fün, die heute perf. sind. Ein Blick auf Tabelle 2 belehrt uns, dab diese Gruppe (-aše beim Plural) im Pleskauer Text viel homogener zusammengesetzt ist: bis auf einen Beleg sind alle ubrigen - 50 - heute imperf. Bei letzteren handelt es sich um Simplicia und um sekundäre (= suffigierte/dehnstufige Ableitungen von Komposita) Imperfektivbildungen.

76/34 "Zbežavšesja mnogoe množestvo žen k prolomnomu mestu $i$ tu velikoe posobie $i$ ugodie voinskim, chrestbjanskm ljudem pokazase. Ovii že ot nich ... nad litroju odolenie poksazasa: " 66

- Viele Frauen eilten zur Bresche in der Mauer und leisteten hier den kämpfenden Männern wertvolle Hilfe. Sie haben ... den Sieg iuber die Li tauer errungen:' (= waren mit am Sieg beteiligt)

Die Variante 67 zeigt hier sicher die ursprungliche lesart: "... ugodie voinskim, chrestbjanskim l judem pokazağa." Es handelt sich bei diesen beiden Sätzen nicht um aktuelle Schilderung, vielmehr wird etwas konstatiert, worauf die auf Veranschaulichung von Geschehen und Handlungen ausgerichtete

66) In beiden Fällen ersetzt "pokazati + Verbalsubstantiv" ein rein verbales Prädikat - Nikiforov, Glagol, S. $108 \mathrm{ff}$. hält diese Ausdrucksweise für einen. typischen Zug des "knižnij" bzw. "vysokij stil'". Hier also: "posobie 1 ugodie pokazati" = "posobiti i ugoditi", "odolenie pokazati" = "odolet1".

67) Skripil', Povesti, S. 124 - 66. Hier: S. 151. Es handelt 
Darstellung erst folgt - diese mit Hilfe der 3.8g.1pf. "pokazaše" In ob1gem Belsplelsatz 1st also als Verschreibung, vermutlich eines Koplsten, anzusehen.

Da der Hrsg. des Pleskauer Textes, V. I. Malyšev, darauf verzichtet hat, morphologische Varianten seinem Apparat beizufügen, lst es fur uns oft schwlerig oder unmöglich, die originalen Verbformen zu rekonstruleren. Es lassen sich zwar einlge Grundzüge, die sicher den Original elgen waren, erkennen (besonders die Relmabsicht des Autors), viele Erscheinunmüssen wir aber als allgemein für das auggehende 16.Jh. ansehen - es bleibt oft unklar, ob wir im Einzelfall UnregelmäBigke1ten bzw. Unkorrektheiten im Gebrauch der Kategorien dem Autor oder elnem Koplsten zuzuschreiben haben.

Es 1st uns nicht möglich, die ubrigen 50 Belegstellen mit -aše belm Plural aus der Pleskauer Erzählung vorzustellen. Da diese 50 Belege nach heutigen Begriffen alle imperf. sind, wir also die fast vollständige aspektuelle Ausrichtung der Imperfekt-Kategorle konstatieren, ist auch eine vollständige Vorfuhrung der Belegstellen unnötig. Wir wollen vielmehr ver suchen, anhand einer größeren Anzahl von Beispielen zu zeigen, wie in der Pleskauer Erzählung Ipf.-Formen auf -aše beim Plural verwendet werden. Die Vielzahl der vorzufuhrenden Textstellen soll dem Vorwurf entgegenwirken, daB hier nur Paradebelspiele vorgestellt werden.

Eine Auftellung der hierher gehörigen Belege in verschledene Gruppen (Determinierte, N1chtdeterminierte, 1t1-Verben, sekundäre Ableltungen $u_{0} a_{.}$) erwelst sich als unnötig. Eine derartige Auftellung würde kelne Ergebnlsge bringen, die wir durch Hinzuziehung des welteren Kontextes nicht auch gewinnen werden. Umgekehrt kommen wir durch die Einbezlehung größerer Textpassagen zu Elnsichten, zu denen wir bel systematischer Aufgliederung des Belegmaterials wahrscheinlich nicht gelangen könnten.

glch hierbel um Ho. 3 bel Malyšev (Textausgabe, Anhang S. 120), sie gehört, wie unser Text zur 1. Red./1. Gruppe uber Einzelheiten - 8.0. S. 87 ff., B. Textgeschichte ... 
$65 / 19$ n... sentjabrja $>8$ denb, ... $>5-m$ času dni,

- togda toj sedmičnyj denb pjatok bjaše, -

litovskie že voevody ...68 speśne $i$ radostne

i nadežne vzjati grad idjaše.

... voevody, $i$ vse voinskie $l$ judi $i$ pskoviči, uvidergše 69

iz stanov iz korolevskich velikie mnogie polki

i znamenami k gorodu idjaše

$i$ vse $v$ borozdy utesnene napolnjašesja

litovskich gajdukov, 70

urazazumevše že,

jako gradoemstvom na prolomnye mesta ídus $\underline{\text { šce, }}, 71$

vo osadnyj že kolokol zvoniti veljaše

$v$ Serednem gorode, ...n

'... am 8. September, an einem Freitag, zur fünten Stunde, griffen die Litauer an - voller Hoffnung, die Stadt zu erobern.

... die Voevoden ... und die Pleskauer sahen, wie aus dem polnischen Lager viele Heerhaufen mit ihren Bannern gegen die stadt vorrückten und wie sich die litauischen Heiducken in den Laufgräben drängten.

Und es war ihnen klar, daß sie den Breschen zustrebten, um die Stadt (von dort aus) zu erobern.

Sie ordneten an, da $B$ in der ... Stadt die Sturmglocke geläutet werde, ...'

Auf die mit "bjašen 7 ausklingende Zeitangabe folgt ein Reihe von syntaktischen Einheiten, die mit ähnlich auslautenden Verbformen enden. $D a B$ es in der Absicht des Autors lag, die

68) Bei Auslassungen wollen wir uns weitgehend auf Aufzählungen beschränken, damit der Eindruck, den das Original er weckt, möglichst erhalten bleibt. Diese Stelle heiBt: "Iitovskije ze voevody $i$ rochmisty, i vse gradoemcy i gajduki.spesne i ..." - Danach dreigliedrige Synonymie: "speśne $i$ radostne $i$ nadežne"

69) Ein typisches Beispiel für die willtkürliche Zeichensetzung des Hrsg.s: das Komma vor "uvidevse" ist unbedingt durch Doppelpunkt dahinter zu ersetzen, denn danach folgt, was sie sehen.

70) Variante: S. 144 "... litovskich gajdukov napolnjašesja", also Endstellung des Verbs.

71) Variante: S. 144 "idjaše"

72) Es sei daran erinnert, daß in Tabelle 2 Ipf.-Formen von "byti" - "be, bjase, bjachu" zahlenmäBig nicht erfaBt sind, sondern nur Vollverben. 
Glieder der Satzfolge reimend bzw. ähnlichklingend abzuschlieBen, zeigt obiger Textausschnitt deutlich. Der Pleskauer Autor verwendet - wenn er Reimeffekt erzielen will verbalen Reim. Hierbei kennt er drei Varianten:

1.: 3.pl.aor. - -aša, -1ša, -oša, -eša;

2.: 3.pl.ipf. - -achu;

3.: in dieser größten Gruppe alternieren jene Endungen, die wir im obigen Textausschnitt sehen:

a) Part.präs. auf -ğče;

b) Part.prät. auf $-(\nabla)$ se ;

c) Ipf.-Endung -ase für Sing. und Plur.

Außer "bjaše" haben alle auf -jaše endenden Verbformen ein Subjekt im Plural - eine Tatsache, die sich an den Part.Endungen ablesen läBt (mit der Einschränkung allerdings, dab oben genannte Endungen oft auch beim Sing. stehen). Die Prage, welches Tempus die Ipf.-Endungen -aše vertreten, läbt sich nicht ohne weiteres einfach mit dem Hinweis auf das Ipf. beantworten - der Autor habe lediglich den Numerus verwechselt, statt -ăse müsse man -achu lesen.

Diese Erklärung trifft bereits auf das erste "idjaše" nicht zu: Es folgt nämlich einer punktuellen Zeitangabe, nach der das Verb regelmäBig im Aorist steht, z.B.

$64 / 10$ "na pervom ćasu dni načaša biti ..." $62 / 6$ "v 4 denb $\nabla$ noči ... postavisa tury." $74 / 27$ "Egda że, jako rekoch, 1doša k prolomnomu mestu ..."

Weitere 19 ähnliche Textstellen - punktuelle Zeltangabe mit Aorist - zeigen, daB dem Autor der richtige Gebrauch bekannt 1st. Aber an dieser Stelle setzt er, um den Gleichklang nicht zu stören, sein Wissen vom korrekten Gebrauch zuruck. DaB inm das nichts ausmacht, zeugt davon, dab das Gefuhl für die alten Tempora bereits ziemlich erloschen war. Die Stutze, die Ipf. und Aor. Im Aspektsystem fanden, indem das Ipf. fast ausschlieblich den imperf. Verben, der Aor. Vorwiegend perf. Verben vorbehalten war, versagt im Falle von "idjasen, weil "1t1" ein Durativum, also imperf. ist. DaB es einen Aorist bilden kann, hat seine Ursache darin, daB es ein determiniertes Verb ist, deren Romposita bekanntlich 
perfektiv, die Komposita der entsprechenden Nichtdeterminierten imperfektiv wurden. Beim ersten "1djaše" wirde man umsomehr einen Aorist erwarten, als es ja eine Feststellung beinhaltet, die die folgenden Ausführungen einleitet - gleichsam elnen Doppelpunkt für das folgende darstellend.

Die folgenden Verbformen (auch die Partizipien) darf man als Ipf.-Formen deuten - also "idjachu", "napolnjachusja", denn in der dem ersten "1djaše" folgenden Beschrelbung läßt der Autor das Geschehen vor unseren Augen abrollen - er versetzt uns in die Handlungen hinein, auch wenn das zweite "idjaše" durch "k gorodu" gleich mit dem 21 elpunkt versehen ist.

"veljaše" am Schluß muß man wohl als Substitut für einen Aorist werten, denn ein Befehl ist in der Regel etwas Einmaliges. Jedoch der Pleskauer Autor gebraucht niemals "vele" oder "veleša", stattdessen verwendet er "povele, poveleša" - oder er schreibt "veljašen (sechs Mal für Plur., zwei Mal fur sing.). "velěti" ist schon so stark imperf. geprägt, daß ein Aorist davon nicht mehr bildbar ist (im Gegensatz zum determinierten "iti").

Der Ersatz des hier angezelgten "po-/velešn" = 3.pl.aor. durch "vel jašen = 3.8g.1pf. wird erst dadurch möglich, daß letzteres nicht mehr Singular-signifikant ist. Diese Entwicklung, die sich in der Pleskauer Erzählung als abgeschlossen darstellt, fanden wir in der K-pler Erzählung noch in den Anfingen - ein Teil jener im vorigen Tellabschnitt besprochenen elf Belege (-aše beim Plural) wäre hierher zu stellen. - Mir dürfen einmal vorgreifen, um das Phänomen im Ganzen darzustellen: Zwar lot die Ipf.-Endung - $(j)$ aše für die 2.3.8g. und die 3.pl. glelchermaßen verwendbar, doch gilt das gleiche nicht fur die Endung - $(j)$ achu: diese begegnet niemals beim Sing. Auch konnte bei Verbformen, auf -achu endend, nie eindeutig nachgewiesen werden, dab sie fur einen Aor. stehen. Ungekehrt konnten - und können - wir Belspiele voratellen, wo eine Ipf.-Form auf -ase ganz klar die 3.pl.aor. ersetzte. 
$65 / 35$ "... (voevody 1 ...)

iz narjadu izo mnogago po polkom streljati veljaše.

Iz narjadu že po polkom bezprestanno strreljajušč́ím, 73

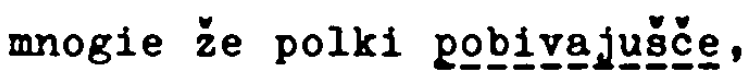

bezčislenyja že mnogie litorskie ljudi

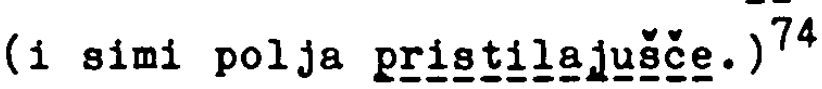

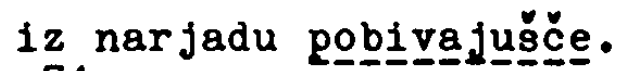

Oni že naporne 1 derzostne 1 nadežne $k$ gorodu idjaše, jako mnogaja voda $k$ gorodu lbjašesja;

strašiliščami že svoimi, jako volnami morskimi

sabljami že svoimi, jako molnijami besčislenymi,

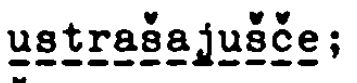

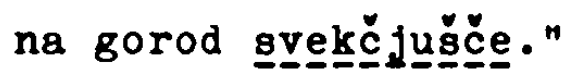

'... (die Voevoden ...) gaben Befehl, aus vielen Geschützen die polnischen Abteilungen zu beschießen. Unaufhörlich beschossen sie die Heerhaufen, viele Abteilungen töteten sie, unzählige Litauer töteten sie mit ihrem Geschütz. (und mit diesen ( $=$ den Toten) bedeckten sie das Schlachtfeld.)

Sie aber besturmten machtvoll ... die stadt, so, wie große Wassermengen strömten sie der Stadt zu; mit ihren Ungeheuern verbreiteten sie - wie mit Meereswogen - Entsetzen;

mit ihren Säbeln funkelten sie zur Stadt herüber wie mit Hilfe zahlloser Blitze.'

Auch in diesem Abschnitt steht das Subjekt im Plural - im ersten Teil handeln die Pleskauer, im zweiten Teil die Litauer. Der Endreim tritt in diesem Abschnitt noch deutlicher hervor als im vorigen Textauszug. Auch in diesem Absatz dominieren die Partizipial-Endungen, denen sich die finiten Verbalformen wegen des satzschließenden Gleichklangs anpassen - die Endung - jaše steht wieder für den Plural. "veljaše" steht wieder für "po-/veleša" - nicht nur wegen der Einmaligkeit und Endgultigkeit des Befehls an sich, sondern weil es die Punktion einer Feststellung innehat, die eine rein handlungsbezogene aktuelle schilderung einleitet

73) Variante: S. 144 - "streljajušče".

74) Diese Zeile befindet sich nur in der Variante (S. 144). 
(im Zusammenhang mit der zuvor zitierten Textstelle sprachen wir von der Doppelpunkt-Funktion des ersten "idjaše", das ebenfalls für einen Aor. "idoša" steht).

Die beiden anderen Belege - "idjaše" und "lbjašesja" - stehen sicher für 3.pl. ipf. auf -achu, 75 denn der Autor versucht hier, eine möglichst lebendige Darstellung der Vorgänge zu geben.

48/33 "... (oni) že neprestanno z goncy gramoty rozsylaše - ukreplenii gradov (, $)^{76}$ vsjakomu utverženiju veljaše. Po okolbnim že selom $i$ volostem tako že posylaše, daby koždo ... echali ...

I sicevymi obrazy $v$ bogospasaemom grade Pskove $i$... vsjako utverženie po boze tvorjašesja.". '... (die Voevoden) schickten ständig ... Botschaften aus (;)

zur Sicherung/Stärkung der Städte ordneten sie alle möglichen Befestigungen an.

Auch in die Dörfer und Ortschaften in der Umgebung schickten sie, damit jeder ...

Und auf diese Weise versah man Pleskau mit allen nur denkbaren Befestigungen/traf man alle Sicherhei tsmaßnahmen.'

Die ersten drei Verbalformen auf $-(j)$ aše dürften für 3.pl. ipf. -achu stehen (auch "veljaše", da hier distributive Punktion anzunehmen ist: in jedem Schreiben stand der entsprechende Befehl). Fragen muB man sich allerdings, warum dann der Autor nicht durchgängig die Endung -(j)achu gewählt hat - der Effekt des Gleichklangs am jeweiligen Satzende wäre so auch erreicht worden.

"tvorjašesja" ist von den drei anderen Belegen durch einen hier nur angedeuteten Satz getrennt. Ob der Autor durch den Reim einen Bogen über den ausgelassenen Satz spannen wollte, muB dahingestellt bleiben. "tvorjašesja" steht hier in der Funktion eines Aor.: "tvorišasja", es drückt eine abschlie-

75) "lьjašesja" könnte vom Autor auf "voda" bezogen sein.

76) vgl. Anm. 69: wieder ein Beispiel für die inadäquate Interpunktion des Hrsg.s - das Komma muB, will man der Intention des Autors entgegenkommen, hinter "rozsylase" stehen. 
Bende Feststellung aus (sprachen wir zuvor von Verbalformen, die gleichsam für einen Doppelpunkt stehen, so dürfen wir "tvorjašesja" als einen Schlußpunkt bezeichnen).

59/25 "Sii (= litovskie) že načalo svoim boleznem begotvornym obrazom vsjačeski načinaše, $k$ gorodu že ni pristupiti smejaše.

'Sie deuteten den Anfang inrer (späteren) Nöte voraus, jedenfalls haben sie mit Flucht/Rückzug (die Belagerung) begonnen, (vorerst) wagten sie nicht, die Stadt anzugreifen.'

Für die Verwendung der Sing.-Endung -aše anstelle der Plur.Endung -achu (oder anstelle des Aor.) liegt kein zwingender Grund vor - die Sätze würden in jedem Falle reimend ausklingen. Diese Satzfolge stellt ein Resümee dar (kaum vor Pleskau angekommen, wurden sie durch einen Ausfall der Pleskauer gezwungen, sich ein Stück von der Stadt zurückzuziehen). Aorist ("predpokazaša", "načašan, "posmejašan) würde man hier erwarten.

$76 / 23$ ".... (ženy) malo nekako radosti $i$ blagovestie príemše 1 ostâvívǧe nemošči ženskie

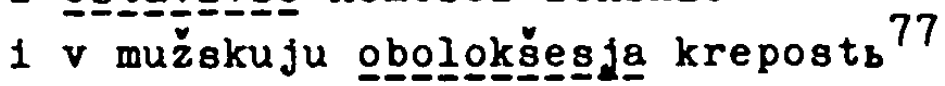

1 vse vskore, koźdo iz svoich dvorov $i$ kajaždo protiv svoeja sily, oružie nošaše. Mladyja že 1 .... dostalb s pristupa litu pribivati oružie nošachu, 78 staryja že ženy 1 ... malyja 1 kratkie vervi nošaše 1 temi litovskij narjad ... v gorod vvesti pomys̆

'.... (die Prauen) hatten die gute Nachricht gehört, hatten ihre weibliche Schwäche ab- und männliche Stärke angelegt:

Und gleich brachten sie ... Waffen herbei, die älteren Prauen aber trugen kurze Stricke herbei, mit denen sie die litauischen SchuBwaffen in die Stadt bringen wollten.'

77) Variante: S. 15 ! - Nachstellung der Verbform "v mužskuju krepostb oboloksesja".

78) Variante: S. 151 - statt "nošachu" dort "nošašen". 
Die Lesarten der Variante geben sicher den ursprünglichen Text besser wieder als unsere Hs.: ähnliche Satzausklänge beherrschen den Abschnitt. D1e Ipf.-Formen auf -aše beim Plural sind daher sicher durch die Partizipien auf $-(v)$ še und -jušče bedingt. Erstaunlich ist an diesem Satz die (wie wir annehmen) Verschreibung durch einen Kopisten "nošachu". Mir scheint, diese Verschreibung zeugt von einer totalen Indifferenz den Verbalformen gegenüber, denn hätte der Kopist korrigieren wollen, dann hätte er auch die anderen Verb.fin., d.h. die übrigen Formen "nošaše" mit der Endung -achu versehen.

$88 / 21$ "I simi knuty, egda $1 z$ grada za stenu protivu litovskich podsekatelej udarjachu, pugami že temi i ..., jako jastrebimi nosy ... (ich) izvlačachu;

knutjanymi že temi železnymi krjukami, egda litovskich ... za rizy ich 1 s telom zachvataše, $i$ temi ich iz-pod steny vytergaše; strelbcy že, jako belye krečaty sladkij lov, iz ručnic telesa ich klevaše

i nikoimi obrazy litvy utekati ne dajachu.

' Wenn sie mit diesen Knuten ... über die Mauer schlugen, dann zogen sie mit den Haken die Litauer ... heraus wie mit Palkenschnäbeln. Wenn sie die Litauer an Körper und Kleidern erwischt und sie daran unter der Mauer hervorgezogen hatten, dann feuerten (pickten) die Schützen aus ihren Gewehren auf ihre Leiber, so wie die weiben Jagdfalken auf inre süBe Beute picken.

Und sie ließen ihnen keine Möglichkelt zu entkommen.

Wir haben hier zwei parallel aufgebaute Satzgefüge vor uns es handelt sich nicht, wie die Konjunktionen vermuten lassen, um Temporal-, sondern um Konditionalsätze, und zwar vom Typus "Jedes Mal wenn ...., dann ..." Das zweite Satzgefüge weist zwei bedingende Glieder auf - sonst ist die Parallelität vollkommen - der Konjunktion ist jeweils ein Instr.pl. vorangestellt, beide Satzgefüge enthalten einen Vogelvergleich, 
wobei das Hacken, Picken das Tertium comparationis darstellt. Der letzte Satz kann als Schlußsentenz gelten.

Trotz der vom Autor offensichtlich ganz bewuBt herausgearbeiteten Parallelität der Sätze versieht er die beiden Satzgefüge mit verschiedenen Verbalformen: Die erste Kombination enthält Prädikate mit der 3.pl.ipf. auf -achu, die zweite Kombination hat Prädikate mit 3.sg.ipf. auf -aše. Die Schlußsentenz erscheint nicht, wie erwartet, mit Aorist, sondern gleichsam den gesamten Komplex verklammernd, mit der $3 . \mathrm{pl}$. ipf. auf -achu wie das erste Satzgefüge.

Hier zelgt sich ganz deutlich, daß es sich bei -aše mit plural nur noch um eine stilistische Variante von -achu handelt.

$36 / 9$ "...: (nemcy) ne tokmo že mnogim ... gradom ... mnoga zla sotvorjajut i nasiliujut,

no $i$ svjatoe mesto ... Pećerakogo monastyrja

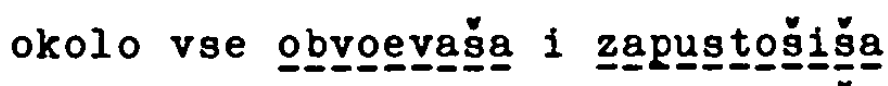

i mnogozel bnaja zlaja monatyrju tvorjaše. 79

'...: die Deutschen fügen nicht nur den Städten großen Schaden zu, sondern haben auch das Höhlenkloster und alles drum herum mit Krieg uberzogen und verheert und dem Kloster selbst mancherlei Ubles zugefüt.'

Bei dieser Satzfolge interessieren uns die letzten drei Verbformen - sie enthalten zweifelsfrei eine Feststellung, die Polge dessen, was eingangs durch die Präsens-Pormen auggedrückt worden war. Die drei präteritalen Verbformen haben genau die gleiche Punktion, sind vollkommen gleichberechtigt; und dennoch finden wir im ergten Satz zwei Aor.-Formen, im zweiten Satz einen Ipf.-Beleg vor ( $\mathrm{daB}$ wir in der Variante "tvorjachu" lesen, berührt diese Prage nicht). Ein Aorist "tvoriša" würde die zwei letzten Sätze reimend abschließen. Aber "tvoritin 1st für den Autor so eindeutig imperf., daB selbst seine Liebe zum Reim keine Ausnahme ermöglicht.

79) Variante: S. 124 - "tvorjachun". 
Die Prage, warum der Autor anstelle des "tvorjaše" oder "tvorjachu" nicht die sonst benutzte Aorist-Vertretung: "sotvori/-ša" gebraucht, muB allerdings unbeantwortet bleiben.

Auf diese Weise könnten wir sämtliche Belegstellen von -aše mit plural vorführen und interpretieren - von den 51 entsprechenden Formen wurden in diesem Abschnitt 21 besprochen. Weitere Beispiele werden wir auch im folgenden $\mathrm{Ab}-$ schnitt finden, wo es um die Punktion des Ipf. in unseren Texten geht.

Noch weitere Belege mit -aše beim Plural vorzustellen, erscheint als nicht sehr sinnvoll, da sich keine neuen Gesichtspunkte mehr ergeben und wir daher stets auf bereits Dargelegtes verweisen müßten. So wollen wir nur zusammenfassen, wie es dazu kommt, daß uns im Pleskauer Text so viele Ipf.-Formen mit einem Subjekt im Plural begegnen:

1. Die Endung -aśe hat ihre Funktion, die 2.3.sg.ipf. zu bezeichnen, eingebüßt. Sie ist, zumindest im Berelch der 3.sg./pl.ipf., zur Universalendung des Ipf. geworden. Beide Endungen - -aše und -achu - bilden rein stilistische Varianten für die 3.pl.ipf.

2. Die Endung -achu bleibt auf die 3.pl.ipf. beschränkt, kann also nicht an die Stelle von ase treten.

3. Satzausklänge mit verbalem Reim bzw. ähnlichklingendem Satzschluß sind ein charakteristischer Stilzug der Pleskauer Erzählung - am häufigsten bildet der Pleskauer Autor ähnlichklingende Satzenden mit Hilfe der Endungen -šče (Part.präs.), -(v)še (Part.prät.) und -ă̌e - alle drei Endungen al ternieren.

4. Die Endung -aše erfreut sich beim Pleskauer Autor solcher Beliebtheit, da $B$ wir sie auch ohne zwingenden Grund an Textstellen vorfinden, wo wir einen Aorist erwarten würden. Der Aspektualisierung des alten Temporalsystems entsprechend befindet sich die Endung -aše stets an der imperf. Verbvariante. 
5. Die Aspektualisierung des alten Temporalsystem, insbesondere die Korrealtion "Imperfekt - imperfektiver Aspekt" ist so ausgeprägt, daß nicht einmal die Liebe des Pleskauer Autors zum verbalen Reim den Aorist eines Verbs ermöglicht, das als eindeutig imperf. empfunden wird - z.B. "tvoriti", "veleti" u.a.

\subsubsection{Zusammenfassung: -aše beim Plural}

In der K-pler Erzählung fanden wir 11 Beispiele für -aše beim Plural. Es handelte sich dabei um Verschreibungen, die - vielleicht Kopisten zuzuschreiben - an sich gar nicht ins Gewicht fallen. Fehlende Kongruenz des Numerus ist zwar in der K-pler Erzählung auch beim Aorist zu beobachten, allerdings nur in drei-vier Fällen. Betrachten wir den Pleskauer Text bezüglich der -aše-Endungen beim Plural, erkennen wir, daß sich in der K-pler Erzählung mit jenen 11 Belegen eine Entwicklung andeutete, die zwar in der Pleskauer Erzählung noch längst nicht abgeschlossen, aber doch deutlich sichtbar ist: Die alten Tempora werden noch gern aus stilistischen Gründen benutzt, aber die Formen der einzelnen Personen und der Numeri geraten zunehmend in Vergessenheit - es kommt zu Verwechselungen. Schlieblich beginnt eine bestimmte Form - beim Ipf.z.B. -aše - zur Universalendung für ein bestimmtes Tempus $z u$ werden, so daB diese universale Tempus-Endung in Verbindung mit dem dazugehörigen Aspekt zur Bezeichnung für das Präteritum - entweder eines imperf. oder eines perf. Verbs - wurde, ein Zustand, den (mit Unterscheidung der Numeri und der Genera) das 1-Part. als alleinige Präteritalform symbolisiert.

Am Pleskauer Text konnten wir beobachten, wie eine bestimmte Ipf.-Endung sich bereits weitgehend als Universalendung des Ipf. durchgesetzt hat. 


\subsection{Die}

Bisher haben wir Ipf.-Belege vorgestellt, die entweder den aspektuellen Normen, wie sie sich im 15. und 16. Jh. schon weitestgehend stabilisiert hatten, nicht entsprachen, oder die im Numerus keine Kongruenz zum Subjekt des Satzes aufwiesen.

Im folgenden werden/wir Beisplele für korrekten - "normalen" Gebrauch der Ipf.-Kategorie vorführen. Dabei wollen wir weiterhin Gelegenheit nehmen, auf stilistische und sonstige Eigenheiten der Texte hinzuweisen.

Eine Beschreibung der Funktionen des Ipf. speziell für die zweite Hälfte des 16 . Jh.s gibt 8ikiforov in seiner Monographie über das Verb im russischen Schrifttum eben jenes Zeitraums. ${ }^{80}$ Die wesentlich eingehenderen Untersuchungen van Schoonevelds ${ }^{81}$ zu den finiten Präteritalformen im Altruss. lassen sich im Grunde auf Nikiforovs Funktionsbeschreibung des Ipf. zurückführen, da diese nicht allein für die zweite Hälfte des 16 . Jh.s gilt.

Nach Nikiforov drückt das Ipf. aus:

1. eine sich gewohnheitsmäßig oder anderweitig in der Vergangenheit wiederholende Handlung (bzw. Geschehen) "dejstvija ili javlenija, obyčno ili neodnokratno soveršašiesja." (Hervorhbg. - Nikiforov) - dies sei die wichtigste Punktion des Ipf.

2. einen ununterbrochenen Prozess, Vorgang, der sich in der Vergangenheit vollzogen hat - "nepreryvnyj process $v$ prošlom"; dieser kann sich aus vielen einzelnen Handlungen zusammensetzen.

3. eine durative Handlung in der Vergangenheit, deren Ab-

80) Nikiforov, Glagol, S. $144-46$, wo auch die nachfolgenden Definitionen zu finden sind.

81) C. H. van Sohooneveld: A Semantic Analysis of the 0ld Russian Finite Preterite System. 's-Gravenhage 1959. (weiter zitiert: van Schooneveld, A Semantic Analysis). S. $34-58$. 
schluB oder Begrenzung nicht genannt sind - "dlitel'noe $v$ prošlom dejstvie bez ukazanija na ego granicun (bei Nikiforov ist alles hervorgehoben).

4. eine Handlung (Vorgang), die in der Vergangenheit parallel/gleichzeitig einer anderen, ebenfalls präterital durch ein imperf. Verb bezeichneten Handlung verlaufen ist - "dejstvie, sovers̆av̌̌eesja v prošlom parallel'no (odnovremennc) s drugim dejotviem (javleniem), vyražennym imperfektom, 111 aoristom, 111 deepričastiem prošedšego vremeni nesoveršennogo vidan (Hervorhebg. - Nikiforov).

5. Das Ipf. kann auch Bedeutung eines Aorist erlangen "Imperfekt ... mog prosto otnosit' dejstvie vlub' prošlogo, t.e. imet' aoristnoe značenie." (Hervorhebg. Nikiforov).

Hierher könnte man auch noch van Schoonevelds Hinweis stellen, 82 daß das Ipf. zur Schilderung des Hintergrundes verwendet wird, vor dem sich die (aoristisch ausgedruckte) aktuelle Handlung abspielt.

Das Imperfekt zum Ausdruck distributiver Handlungen ${ }^{83}$ ist nicht nur auf Nikiforovs Definitionen 1. und 2. beschränkt, sondern kann auch $z u$ den anderen drei Definitionen hinzutreten, so daß bei einem Subjekt im Plural in einer durch Ipf. ausgedruckten Handlung/Vorgang stets die distributive Funktion - neben einer der von 1. bis 5. genannten - mitschwingt. Auf das Ipf. im abhängigen Satz gehen wir nicht gesondert ein - es kommt so selten vor. Es druckt in dieser Position entweder Gleichzeitigkeit oder Vorzeitigkeit aus. Wenn solche Fälle auftreten, weisen wir darauf hin. Uber die Bedeutung der Vorzeitigkeit des Ipf. im abhängigen Satz - s.u. S. $51 y$ (Plusquamperfekt).

82) van Schooneveld, A Semantic Analysis, S. 55: "general "framing situation".

83) Boretzky, Tempusgebrauch, S. 44 . 
Als Gliederungsprinzip wollen wir die Nikiforov'sche Aufteilung nicht übernehmen, denn die Definitionen 2. und 3. sind in der Praxis schwer zu scheiden. Definition 4. ist eher formaler Natur und kann zusätzlich zu den Definitionen 1., 2. und 3. (womöglich auch 5.) hinzutreten. Was den Ersatz des Aor. durch Ipf.-Formen anbelangt, so ist Nikiforovs Erklärung $z u$ vage, als dab man damit operieren könnte ('das Ipf. ... kann eine Handlung in die Tiefe der Vergangenheit übertragen'). Wir wollen lieber bei unserer bisher geübten Praxis bleiben und von Fall zu Fall auf eine mögliche Aor.Bedeutung, ausgedrückt durch Ipf., hinweisen. Die Beurteilung solcher Fälle ist notwendig subjektiv - genauso subjektiv, wie ein Autor die Tempora verwendete: das Ipf.z.B. zur aktuellen, das Geschehen, die Handlung als solche in den Vordergrund stellenden Schilderung; den Aor. eher zum referierenden Bericht, zur Feststellung.

Unser Gliederungsscheme ist einfacher und entspricht vollauf unserer Intention, das korrekt gebildete und richtig gebrauchte Ipf., wie es uns in der älteren Literatur allenthalben begegnet, an einigen Textauszügen $z u$ demonstrieren. Wir unterscheiden zwischen Ipf.

1. als Ausdruck eines 2ustandes,
2."
einer durativen Handlung,
3. "
einer iterativen oder sich anderweitig wie- derholenden Handlung.

Diese einfache Gliederung garantiert uns eine gewisse Flexibilität und erlaubt uns, auch größere Textauszüge vorzustellen, an denen wir mehr beobachten können, als an kleinen Satzfetzen, die nur eine ganz spezielle Bedeutung demonstrieren. 2wischen den ersten beiden Kategorien gibt es therschneidungen, auch herrscht nicht immer Einhelligkeit darüber, was als Zustandsverb zu bezeichnen sei - da wir die Gliederung aber nur als ein lockeres Ordnungsprinzip brauchen, messen wir solchen Einwänden kein Gewicht bei. Im Zweifelsfalle haben wir Verben mit Aor.-Formen nicht den Zustandsverben, sondern den Durat1va zugeordnet. 
1.3.1 Das Imperfekt als Ausdruck eines Zustandes

1.3.1.1 K-pel: Das Imperfekt als Ausdruck eines Zustandes

$66 / 25$ "Tako ubo sovetujušče, mnozi na to ukklanjachus nadejachubosja na cesarja, zane vedjachu ${ }^{4}$ chrabrosti i silu ego, ...."

-Während sie so berieten, neigten viele dem Standpunkt des Kaisers (= na to) zu. Ihre Hoffnung lag auf dem Kaiser, weil sie seine Tapferkeit und Kraft kannten.'

Die beiden Zustandsverben - eines im unabhängigen, eines im abhängigen Satz - stehen im Verhältnis der Gleichzeitigkeit. "uklanjachubosja" hat nicht (oder nur zum geringen Teil) die Form des Ipf., weil es viele Leute sind, die zu einer Meinung neigen, sondern weil der ProzeB der Meinungsbildung, des zu einem Standpunkt Tendierens ein allmählicher ist, der durch das Part.präs. "govetujušče" seinen Ausdruck findet 'während, indem sie berieten ...'.

$73 / 11$ "I pochvaljạchú cesarja i tako necii gkazašă, jako $i$ sam cesarb $v$ serdcem svoem voznesesją, no $i$ otšestvie pogan čajachu, ne vedachu ${ }^{84}$ bo boźie izvolenie." 'Und sie rünmten den Kaiser, und einige sagten (dann), daB der Kaiser selbst (= auf das Lob hin) ein wenig von Stolz ergriffen wurde in seinem Herzen. Sie erhofften den Abzug der Heiden, aber niemand kennt die Wege/die Absicht Gottes.'

Die beiden Zustandsverben stehen antithetisch, daher gleichberechtigt nebeneinander. - "pochvaljachu" ist als Situationsschilderung - Hintergrund - aufufassen, in die die Hauptaussage "skazaša" hineingestellt ist. Schon diese Interpretation der Formen als Neben- und Haupthandlung erklärt hinreichend die verschiedenen Tempora. Es kommt hinzu, dab "skazati" im K-pler Text nie im Ipf. anzutreffen ist (im Gegensatz zum Pleskauer Text, wo die Aussage vieler gelegentlich imperfek-

84) "vedjachu" < "vĕdětí" "vedachun < "vědati" - letzteres ersetzt allmählich "védéti", ein semantischer oder sonstiger Unterschied zwischen beiden ist nicht festzustellen; beide sind zwei Mal verneint. - Im Pleskauer Text treffen wir "vèdéti" nicht mehr an. Formen wie "vedjachu" gehören dort su "vesti". 
tisch ausgedrückt wird - s.0., S. 326, zu "skazachu"). Pür den $\mathrm{K}$-pler Autor steht offensichtlich die konkrete Aussage 'Der Kaiser wurde sogar ein wenig stolz in seinem Herzen' im Vordergrund, nicht aber die Anzahl Menschen ("neciin), die diesen Ausspruch tut. Gerade an diesem Nebeneinander von Ipf. und Aor. wird deutlich, daB "skazati" im Empfinden des $\mathrm{K}$-pler Autors bereits fest im perf. Aspekt verhaftet ist. Der zweite Aor. in diesem Satz "voznesesja" bringt in feinsinniger Weise zum Ausdruck, daB es sich hier nur um eine augenblickliche Aufwallung handelt, bedingt durch das Lob, das die Bürger thm wegen seiner Tapferkeit zollen. Ein Ipf. an dieser Stelle (z.B. "voznošašesja") müBte so gedeutet werden, $d a b$ hier beinahe ein Zustand des Stolzseins einsetzte - das aber würde aber der Darstellung des Kaisers, der Konzeption der Erzählung widersprechen.

$74 / 24$ "..., i (Magumet) vozъjarivsja poidde sam svoimi vraty i so vsemi silami, a na cesarja povele navaditi puški $i$ piščali, bojaše bo sja ego, da ne izydet ..."

'..., und voller Zorn $20 g$ Mehmed mit seinen Würdenträgern los, und er gab Befehl, auf den Kaiser Geschütze und Feldschlangen zu richten, fürchtete er doch, der Kaiser könnte die Stadt verlassen ...'

Gegenüber den beiden aoristisch ausgedrückten Handlungen kommt die Zuständlichkeit von "bojati sja" besonders klar zum Ausdruck.

$77 / 16$ "..., bezzakonnyj Magumet sede na prestole carstvija blagodarnejša sušča vsech iže pod solncem i izobladaše vladejuščich dvema časti vselennyja i odole ..."

'.... und .... Mehmed bestieg den edelsten Thron unter der Sonne, herrschte über die, die Herr sind über beide Teile der Welt, und er besiegte ...'

"izobladati" kommt in seiner Bedeutung einem Zustandsverb sehr nahe. Wie im vorigen Beispiel tritt der Gegensatz zwischen 'herrschen' einerseits und 'sich setzen, besteigen' sowie 'Sieg erringen' deutlich hervor. 
1.3.1.2 Pleskau: Das Imperfekt als Ausdruck eines Zustandes

56/26 "Približenbe že svoe do Pskova uvidevše, jako ne sytyj ad propas(t)nyja svoja čeljusti raskidaše $i$ ottole Pskova poglatiti chotjase.

Spešne že 1 rađostne ko Pskovu, jako iz velikich peščer ljutyj velikij zmij letjaše, strašilišča že svol, jako iskry ogneny

1 dym temen na Pskov metăgo ;

ne doletev, vo utrobe u sobja togo Pskova

slyšati skazazovaše.

Aspidy že svol 1 ...korolb, blevaniem

nasytiti chvalaljäsesja.

I tako vse, jako zmej, na krylech na Pskov letjaše

1 sego gordelivstrom svoim,

jako krilami, povaliti chotjase,

zmeinymi svoimi jazykami vsja živuščaja

vo grade, jako żalami, umoriti mnjašesja. "

Die Ubersetzung dieses Abschnitts findet sich auf $S$. 227, wo diese Stelle im Rahmen der Behandlung der bildsprachlichen Elemente bereits zitiert wurde.

Zwar ist zu fragen, ob "letjaše" hier als Zustandsverb aufzufassen sei oder nicht eher als ein aktives pliegen (Durativum), dafür erubrigt sich diese Prage bei "chotjašen und bei "mnjašesjan". Es handelt sich hier um jene stelle, wo der Zug Stephan Báthorys gegen Pleskau in den Mittelpunkt der Erzählung tritt. Der Autor begnïgt sich an dieser Stelle nicht damit, die wesentlichen bildsprachlichen Elemente, die uns in der Pleskauer Erzählung begegnen, konzentriert vorzustellen, sondern er versieht den gesamten Abschnitt auch mit (verbalem) Endreim. Die Durativa und die Zustandsverben dominieren den Absatz; die allein auf die Vorgänge gerichtete Schilderung ohne jegliche zeitliche Dimension rechtfertigt das Imperfekt der Durativa. Die Pormen "skazovašen und "chvaI jašesja" wären auch als Aorist denkbar, doch wählte der Autor um des Reimes willen das suffigierte Imperfektivum, das ihm die Bildung des Ipf. ermöglichte. 
$50 / 21$ "Crez sego vel1kogo grada ... rece tekuščej, ${ }^{85}$ skroze kamennye steny, po rece že toj vo grade mnogopotrebny ja vešćl stojachu."

'Durch diese groBe Stadt flieBt - mitten durch die steinernen Mauern - ein FluB, und an diesem PluB entlang lagern uberaus wertvolle (= brauchbare) Waren.'

"stojachu" erscheint im Pleskauer Text neun Mal, als Part. praes. und als Praes. ("stojašče"; "stojat") insgesamt acht Mal. Die Textstelle ist einem Brief entnommen, den der polnische König an seine Würdenträger schrelbt und in dem er Pleskau in den verlockendsten Farben schildert, um diese für den geplanten Feldzug nach Pleskau zu gewinnen. In solchem Zusammenhang würde man statt "stojachu" Präsens "stojat" erwarten, doch steht jene Form in offensichtlicher Anlehnung an die vorhergehenden Verbalformen "skazyvachu" und "povedachu".

87/22 "Podle toja že drevjanaja stena, ukreplenija radi, u kamenny ja poddelana, - s1ju ognem zažešči chotjachu. $V$ te pory 1z-za Velikija reki, iz narjadu, vo grade u

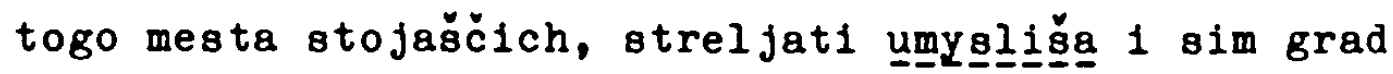
soveršenne vajat1 čajachu."

' Zur zusätzlichen Befestigung war entlang der steinernen Mauer noch eine hölzerne errichtet - diese wollten sie anzünden. Gleichze1tig (d.h. wenn diese Paliisa äebrannte) wollten sie hinter dem Großen FluB hervor diese SteIIe- beschießen, um die zu treffen, die sich dort versammeln würden. Auf diese Weise hofften sie, die Stadt endgulltig zu erobern.'

Wir haben hier drei fast synonyme halbkopulahafte 85 a verbformen vor uns "chotjachu", "umysliša", "čajachu" - jeweils mit Inf. Obgleich also alle drei Verben fast genau das gleiche bedeuten - 'etwas wollen, etwas planen, etwas hoffen' - und obglelch sle alle koordiniert sind, konstatieren wir neben den adaquaten Ipf.-Formen einen Aorist "umyslisa". Es scheint mir bezeichnend zu sein, dab wir Verben im gleichen Kontext

85) Dies ist einer der wenigen Dat.abs. femin. in unseren Texten (man beachte: pronominales Part.praes.)

85a) Vgl. R. Rlžička: Das syntaktische System der altslavischen Partizipien und sein Verhiltnis zum Griechischen. Berlin 1963. S. 168 f.: dort 1st rom "potentiellen halbkopulativen Charakter" dieser Verben die Rede. 
in absolut identischer Punktion - jedoch in unterschiedlichem Tempus (damit verbunden: unterschiedlichem Aspekt) antreffen; es bezeugt, $\mathrm{da} B$ am Ende des 16. Jh.s das alte Tempussystem trotz der Stütze durch das Aspektsystem (Imperfekt - imperfektives Verb, Aorist - perfektives Verb) selbst von professionellen Schreibern nicht mehr beherrscht wird. ${ }^{86}$ Solche Fälle beweisen beträchtliche Unsicherheit in der Handhabung der alten Formen.

Auf ein Beispiel für die für den Pleskauer Text so charakteristischen pleonastischen Wendungen sei nur am Rande hingewiesen: "siju ognem zažešči chotjachu" - 'diese wollten sie mit Feuer entzünden'.

$87 / 33$ "Litva že vaja sija ot ponužajuščich 1 nevoleju terpjachu,

1 vsprotivne stojachu,

1 krepkonaporne stenu podsekajušče.

- Die Litauer erduldeten dies alles ... gezwungenermaBen/ungern, hielten aber wacker stand und hackten ungemein kraftvoll unter der Mauer (weiter).'

Die Ipf.-Formen der Zustandsverben bezeichnen den Hintergrund zu dem vorher Gesagten - zuvor wurde berichtet, was die Pleskauer versucht hatten, um die Litauer, die die Stadtmauer von unten aufhackten, zu vertreiben - obiger Satz ist die resignierende Schlubbemerkung 'Die Litauer aber ... hielten wacker stand ...' Das Part.praes. ersetzt hier ebenfalls ein Ipf. (1terative Handlung).

86) Die Variante: S. 158 - hat statt "chotjachu" "chot fa", also Part.präs., "umysliša" und "cajachu" finden wir auch dort. 
1.3.2 Das Imperfekt als Ausdruck durativer Handlungen

1.3.2.1 K-pel: Das Imperfekt als Ausdruck durativer Handlungen

58/41 "... i množestvo žen $i$ detej chožachu po cerkvam božiim i molbby $i$ molenija dejušče, ..."

'... und viele Frauen und Kinder zogen von Kirche $z u$ Kirche und beteten und baten, ...'

"chožachu" verweist, neben seiner Bedeutung als durative Handlung, auf die Vielzahl derer, die diese Handlung begeht (distributive Funktion); auch für das an sich ziellose 'von Kirche zu Kirche Ziehen' ("chožachu po cerkvam"), also ein nichtdeterminiertes Gehen, ist das Ipf. das angemessene Tempus.

59/24 "Turki že po vsja mesta bbjachusja bez opočivanija denb $i$ noščb premenjajuščesja, ..., poneže ugotovljachusja k pristupu, i tako tvorjachu otboi do 13 dne."

- Die Türken kämpften ununterbrochen Tag und Nacht, indem sie sich ablösten, (um die Griechen zu schwächen), denn sie bereiteten sich auf den Angriff vor - (die Griechen aber) schlugen sie zurück/leisteten Widerstand bis zum 13. Tage.'

Es ist hier von den kleineren Scharmuitzeln die Rede, die den GroBangriffen auf $\mathrm{K}$-pel vorangingen und die die Griechen entnerven und schwächen sollten. Die Angabe 'bis zum 13. Tag' hebt die lange Dauer der genannten Handlungen hervor, gibt aber gleichzeitig die Begrenzung der durativen Handlung an. Es stünde dem Autor gerade im Hinblick auf den Endpunkt der Handlungen frei, diese aoristisch auszudrucken. In Verbindung mit dem Ipf. gewinnt der 13. Tag aber nioht den Charakter des Endpunkts einer x-beliebigen Handlungen, sondern zeigt an, wie lange die Griechen diesen Kleinkrieg pausenlos ertragen mußten.

"ugotovljachusja" signalisiert, daß diese 13-tägigen ununterbrochenen Scharmuitzel Teil der Vorbereitungen zu den Sturmangriffen waren. Die Handlungen im unabhängigen Satz "bbjachusja", dann "tvorjachu" verlaufen parallel der Handlung im Nebensatz "ugotovljachusja". 
67/5 "...; dostigšu že cesarju vopijaše na svoich, ukrepl jaja ich, 1 , vozrykav jako lev, napade na turky ..."

'...; als der Kaiser angekommen war, redete er schreiend auf die Griechen ein und stärkte sie auf diese Weise. (Dann aber) schrie er auf wie ein Löwe und warf sich auf die Türken ..."

In diesem Beispielsati wird der Gebrauch der Tempora und Partizipien geradezu schulbuchmäBig-korrekt demonstriert. Unter dem "vopijaše" hat man sich ermunternde, ermutigende Worte - jedenfalls viele Worte - vorzustellen, denn die Griechen wurden durch sie gestärkt und gefestigt. Das Schreien ist durch das Kampfgetümmel bedingt. Scharf abgesetzt der Aor. des Momentanverbs: "napade". Bevor er sich in den Kampf stürzt, bricht der Kaiser in ein löwenähnliches Gebrüll aus (kein einzelner Kriegsschrei "vozryknuv"), das mit dem Augenblick endet, da der Kaiser sich auf den Gegner wirft.

74/22 "Magmet že okajannyj, slyšav vostočnago begilar-beja ubijstvo, plakaše mnogo: ljubjaše bo ego, mužestva radi ego 1 razuma, ..."

'Mehmed, der Verruchte aber, als er vom Tod des BeglerBeg des Ostens erfahren hatte, weinte bitterlich denn er hatte ihn wegen seiner Tapferkeit und seiner Klugheit sehr geliebt, ...'

/denn er liebte inn wegen seiner ...'

"plakaše" entspricht als Tempus genau dem erläuternden "mnogo" - es handelt sich offenbar um ein langanhal tendes und sicher auch oft wiederholtes Weinen. "ljubjaše" wird vom K-pler Autor anscheinend zuständlich aufgefabt - ein Zustand, der durch den Tod nicht beendet wird; oder der Autor meint diesen Zustand, der bis zum Moment des Todes zwischen Mehmed und dem Begler-Beg, seinem Berater und Heerfuhrer, geherrecht hatte. Immer wieder fällt auf, wie gekonnt und feinfülig der K-pler Autor das Instrumentarium der alten Tempora zu benutzen versteht. 
1.3.2.2 Pleskau: Das Imperfekt als Ausdruck durativer Handlungen

57/27 "... mužeskij pol i ženskij, ot mala i do velika, ... neprestanno $v$ serdcych svoich boga moljaše, i smirennomudrostiju umudrjašesja. Ne vysoko mysljaše, niže gordelive $v$ serdcych svoich voznošašesja, niže na čto nadejatisja chvaljašesja, no tokmo vsem vkupe serdca i usta glagolachu: ${ }^{87}$..."

'... (alle) baten Gott unaufhörlich von ganzem Herzen, und übten sich in weiser Bescheidenheit, keine hochmütigen Gedanken hegten sie, kein Stolz nistete sich in ihren Herzen ein, keinerlei Hoffnung, worauf auch immer, rühmten sie sich, sondern sprachen (=beteten) lediglich alle mit Herz und Lippen: ...'

Das Subjekt $z u$ all diesen Ipf.-Formen auf $-(j)$ aše steht im Plural. Nur die letzte Zeile zeigt den korrekten Numerus. Geradezu wie eine Reportage gibt der Autor hier seinen Bericht - viele einzelne Impressionen werden lose zusammengetragen und fügen sich zu einem großen Bild: wichtig ist, was geschieht, die Handlungen stehen in ihrer Zeitlichkeit, ihrer Ausdehnung vor uns.

Verwunderlich ist die korrekte Plural-Form "glagolachu" am SchluB des Komplexes. Auch an anderen Stellen verwendet der Pleskauer Autor am SchluB einer solchen reimenden Satzreihe - wie eine Antiklimax - eine nichtreimende Verbform.

In "voznošašesja" haben wir das Gegenstück zu "voznesesja", wie es uns oben, S. 356, begegnet war. Dort hatten wir sinngemäß übersetzt: 'für einen Augenblick wurde er etwas stolz', hier aber müBten wir wörtlich übersetzen 'und Uberheblichkeit breitete sich in ihren Herzen nicht aus'.

Typisch sind wieder die pleonastischen Wendungen "smirennomudrostiju umudrjašesjan und "gordelive ... voznošašesja" - 'stolz wurden sie überheblich'. Die anaphorischen Anfünge

87) Variante: S. 139 -dort ebenfalls: "glagolachu". 
der letzten vier Zeilen mit antithetischem Schluß bezeugen, daB der Pleskauer Autor seinen Text über weite Strekken hinweg ganz bewuBt stilistisch ausgestaltet hat.

51/24 "A jaže písal__eși ○ grade tom, jave toliko že 1 vo vsech našich stranach o grade tom velikom Pskove 1 bogatestve ego slava nośašesja. A jaže o četverokamennych ogradnych stenach grada togo kreposti pisaše, $i$ my vedaeve. ${ }^{88^{n}}$

(Aus dem Antwortbrief der polnischen und litauischen Würdenträger an den König:)

- Und was du über diese große Stadt geschrieben hast, ist in unseren Ländern längst bekannt, und auch der Ruhm ihres Reichtums zog (zieht) immer weitere Kreise. Und auch das ist uns bekannt, was du uber die vierfachen steinernen Mauern dieser Festung geschrieben hast.'

Die allmähliche Verbreitung von Pleskaus Ruhm findet in "nošašesja" den entsprechenden Ausdruck.

Für uns lst von Interesse die Form "pisal esi" einerseits und "pisaše" andererseits. Zweifelsfrei haben sie beide genau die gleiche Bedeutung 'was du geschrieben hast, ist bekannt/wissen wir'. Die Vermutung, daß die Variante mit periphrastischem Perfekt das Ipf. ersetzen soll, kann nicht zutreffen, da diese Ipf.-Form hier offensichtlich falsch ist. Denn die Tätigkeit des Schreibens (des Königs) kann nicht anders als abgeschlossen verstanden werden, da ja die Antwort, in der wir jene fragwürdige Form vorfinden, der beste Beweis für den AbschluB der Schreibhandlung des Königs ist. - "pisal esi" beschreibt die Situation besser, doch scheint mir, auch diese Form steht für eine andere: für die 2.sg.aor. "pisa". Diese wurde ja gern durch die 1-Periphrase ersetzt, weil 2. und 3.sg.aor. nicht zu unterscheiden

88) Der Pleskauer Autor liebt es, in Briefen usw. Dualformen zu verwenden. Diese sollen wohl dem Schreiben exklusiven Charakter verleihen, denn eine Veranlassung für diesen Dual (hier und anderswo) ist nicht zu erkennen - er hat also rein stilistische Funktion. Vgl.: 51/22 "soveta svoego ne otricaevesja" (gleicher Brief); vgl. ferner die hybriden Formen $83 / 12$ "este $k$ nam pisaste" (Brief), $50 / 12$ "da ašce choščete vkupe soveśćavsesja" (Brief). 
waren. 89 Offensichtlich empfand der Pleskauer Autor "pisati" so stark als imperf., daB er hiervon intuitiv keinen Aorist bilden konnte. Daß wir hier im engsten Kontext zwei so verschiedene verbale Kategorien zum Ausdruck des gleichen Tatbestandes, ja sogar beim gleichen Verb, vorfinden, zeugt abermals von der Nivellierung der verbalen Kategorien, der Austauschbarkeit (bis zum gewissen Grade) der einzelnen präteritalen Tempora - wichtig ist nur, daß Tempus und Aspekt ubereinstimmen (vor allem: Imperfekt - imperf. Verb). $\mathrm{Vgl}$. auch folgende Wendung:

$83 / 12$ "... o troim glupym pervosovetnikom, - nich že este $k$ nam pisaste. " 90

'... über deine törichten Ratgeber, von denen ihr uns geschrieben habt.'

"pisati" begegnet hier wieder in der gleichen Funktion, in der gleichen Bedeutung wie die beiden bereits zitierten Belege von "pisati". Wieder handelt es sich um einen Brief, wieder bezieht sich "este pisaste" auf einen Brief, den man beantwortet. Zwar verwendet der Autor nun den Aorist "pisaste", doch scheint er sich seiner Sache nicht sicher zu sein. Jedenfalls versieht er den Aorist noch mit der Kopula "este", wie er das bei der 1-Periphrase tun würde. Natürlich kommt eine solche hybride Form auch seinem Wunsch entgegen, in Briefen hochtrabende Formen $z u$ verwenden (s.o., Anm. 88).

$58 / 20$ "Gosudarevy že bojare i voevody svoja dela bezprestanno tvorjaše,

narjadu mesta tvorjaše

i narjad rostavljase, ..."

¿... sde waren in Erfüllung ihrer pflicht ständig im Einsatz, schufen Raum zur Aufstellung der Geschütze und verteilten sie ...'

89) Nikiforov, Glagol, S. 156 - Die 2.8g. der Perf.-Periphrase diente im 16. Jh. innerhalb aller Gattungen als Ersatz für die 2.8g.ipf. und die 2.8g.aor. (wörtliche Rede).

90) Variante: S. 155 - dort ebenfalls: "este k nam pisaste". 
Die Durativität der bezeichneten Handlungen wird durch "bezprestanno" unterstrichen. Trotz des Plural stehen alle Ipf.Formen in der 2./3.sg.ipf. Durch Endstellung des Verbs ergibt sich verbaler Reim; auffällig ist gerade an dieser Stelle die redundante Ausdruckweise des Pleskauer Autors - zumindest die beiden letzten syntaktischen Einheiten könnten zusammengefaßt werden.

48/20 n(knjazb Ivan Petrovič Sujskoj) ... s tovaryščy o ukreplenil grada vsjako dščanie pokazovaše $i$ neprestanno okolo grado obъežžaja, i povelevaše utveržati vsjakimi krepostbmi steny grada."

'Pürst Sujskij und die anderen Bojaren unternahmen alle nur erdenklichen Anstrengungen? 1 ritten ohne Unterbrechung um die Stadt herum? 2 und (immer wieder) befahlen sie, die Mauern der Stadt auf jede mögliche Weise zu befestigen.'

"neprestanno okolo grado obъežžaja" ist ein konkretes Beispiel für die vorherige allgemeine Pormulierung "vsjako dščanie pokazovašen; insofern bezieht sich "neprestanno" auch auf "pokazovaše". Signalisiert das Adverb bereits die zeitliche Ausdehnung der Handlung, so wird diese noch durch die suffigierte Verbform "pokazovase" nebst Ipf. unterstrichen. Suffiglerung in Verbindung mit Ipf. begegnet auch in "povelevaše", doch ist hier, wegen der Grundbedeutung 'einen Befehl erteilen' Iterativität anzusetzen ('befahlen immer wieder, andauernd').

ob hier korrekter Gebrauch der Verbform -aše bezüglich des Numerus vorliegt oder aber das Subjekt als Plural aufzufassen ist, kann nicht entschieden werden, da sich in unseren Texten bei einer Aufzählung vom Typus "knjazb Sujskoj $\underline{s}$ voevodami i $\underline{s}$ tovaryščy" noch keine klare Tendenz hinsicht$11 \mathrm{ch}$ des Numerus des Prädikats herausgebildet hat.

91) Ich verouchte, "vsjako dăčanie pokazovaše" adäquat zu übersetzen. Pür hohen St1l typische Umschreibung für "tscasesja" - vgl. Nikiforov, Glagol, s. $108 \mathrm{ff}$.

92 ) "okolo grado" (Verschreibung, sonst "okolo + Gen., vgl. Variante: S. 132. "okolon - 'um herum': Srezn. II 645). 
1.3.3 Das Imperfekt als Ausdruck sich wiederholender Handlungen

Nikiforov stellte fest, ${ }^{93}$ daß in den erzählenden Genres, insbesondere Stoffen mit historischem Hintergrund, Ipf.Formen in den meisten aller Fälle sich wiederholende Handlungen ausdrücken. In unseren Texten - Kriegserzählungen muß naturgemäß der Anteil Wiederholung bezeichnender Ipf.Formen besonders hoch sein, da die für den Kampf charakteristischen Tätigkeiten erst durch die Wiederholung ihre kriegsspezifische Effektivität gewinnen: hauen, schlagen, schießen, feuern, schreien ( = viele Schrele ausstoben) usw.

Hinzu kommt, daß all diese Tätigkeiten von einer großen Menschenzahl ausgeübt werden, so daB neben der Iterativität der einzelnen Handlung uberhaupt jede Handlung als von vielen Kriegern für sich vollzogen, also in viele Einzelvorgänge aufgegliedert gesehen werden kann, was durch Ipf. ausgedrückt wird (s.0., S. 354): distributive Funktion.

Wir verzichten hier darauf, die einzelnen Formen der wiederholten llandlungen getrennt $z u$ demonstrieren: Iterativität - z.B. schlagen, klopfen; gewohnheitsmäßig wiederholte Handlungen - er pflegte zu beten; gelegentliche Wiederholungen - im Kampfe Schreie ausstoßen usw. In der Praxis lassen sich solche feinen Untergliederungen wegen der nicht immer scharfen Grenzen, vor allem bei unseren Kriegserzählungen, nur mit geringew Erfolg anwenden.

\subsubsection{K-pel: Das Imperfekt als Ausdruck} sich wiederholender Handlungen

60/41 "Cesarb že Konstjantin posylaše po morju i po suchu, v Amoreju k bratii svoej, i v Veneciju i v Zinoviju - pomošči, i bratija ego ne uspeša, poneže rasprja velija be mežu imi i s arbanaši ratovachusja, ..."

93) Nikiforov, Glagol, S. 143. 
- Der Kaiser schickte zu Wasser und zu Lande um Hilfe nach Morea ( $=$ die Peloponnes), nach Venedig und nach Genua; aber seine Brüder kamen nicht, weil sie miteinander in Hader lagen und auch mit den Albanern (Skanderbeg!) Krieg führten, ...'

Die dehnstufige Verbform "posylaše" steht in bestem Einklang mit der Aufzählung der vielen Städte bzw. Länder, an die der Kaiser sein Hilfe-Ersuchen richtete - das 'immer wieder' kommt in der Verbform klar zum Ausdruck. Scharf abgesetzt erscheint darauf die Mitteilung "bratija ego ne uspeša" - 'sie kamen nicht', es genügt, diese traurige Tatsache neutral durch einen Aorist festzuhalten. Die Begründung - 'sie lagen in Streit miteinander und führten Krieg mit ...' ist weniger als Ausdruck der Wiederholung aufzufassen als vielmehr des Zustandes ("be") und einer durativen Handlung ("ratovachusja"). Es erubrigt sich beinahe, nochmals auf die sinnreiche Verwendung der Tempora hinzuweisen.

$61 / 10$ "Zustuneja že ne tokmo svoe mesto snabdjaše, no $i$ po stenam grada obchožaše i ukrepljaše ...ljudi, ..." Giustiniani sicherte/verteidigte nicht nur den ihm unterstellten Abschnitt, sondern inspizierte auch das uibrige Mauersystem der Stadt und bestärkte/festigte die Menschen, ...'

Während "snabdjaše" eine durative Handlung bezeichnet, sind die beiden Ipf-Belege klarer Ausdruck sich wiederholender Handlungen - 'er ging umher' = Ipf. eines nichtdeterminierten Kompositums; und uberall, wo er hinkam, interessierte er sich nicht nur für die strategischen Probleme, sondern auch für den psychischen Zustand der Verteidiger: er bestärkte sie in ihrer Verteidigungsbereitschaft.

Der Autor hätte diese Handlungen auch durch einen Aor. ausdrücken können (wie wir noch sehen werden, ist sogar ein "obchodiša") noch möglich. Aber dle faktische Ausdrucksweise durch Aor. hätte dieser Textstelle ihre ganze Lebendigkeit genommen. 


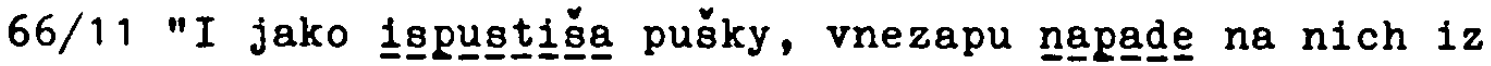
grada Paleolog stratig Singurla so mnogymi ljudsmi i bbjaše 1ch krepko; vostočnyj že flaburar Mustafa vskore nąjde na greky so mnogoju siloju, i sečaše ich surovo, i progną ich $v$ grad, 1 uže chotjachu stenu otъjati; ..."

'Und als sie die Geschütze abgefeuert hatten, warf sich der Paleiolog .... mit vielen Leuten auf sie und hieb mächtig auf sie ein. Der Flaburar des Ostens aber, Mustafa, stieß plötzlich mit starken Kräften auf die Griechen und setzte ihnen (mit Hieb- und Stichwaffen) furchtbar zu; und (so) drängte er sie in die Stadt - schon wollten sie die Mauer erstümen; ....'

"bsjaše" und "sečaše" sind typische Vertretungen für Iterativa, insbesondere im Rahmen einer Kriegserzählung. Sie beherrschen den $\mathrm{K}$-pler Text förmlich; ${ }^{94}$ sie benennen die für den Nahkampf charakteristischen Handlungen: hauen, schlagen (mit Hieb- und Stichwaffen), stechen usw. - Handlungen also, die erst durch ihre ständige Wiederholung ihren sinn im Nahkampf gewinnen. "chotjachu" bezeichnet den Zustand des Wollens. - Dagegen abgesetzt sind die Aoriste: "ispustiša pušky" - 'feuerten die Geschütze ab'. Wiewohl hier ein Imperfekt denkbar wäre (eine große Zahl von Kanonieren bediente die Geschütze - distributive Handlung), setzt der $\mathrm{K}$-pler Autor den Aorist - und zwar in der Bedeutung 'Geschütz abfeuern' stets den Aorist; offenbar hat der Autor dabei den alles entscheidenden, langandauernden Vorgang des Zielens vor Augen, den er als charakteristisch für das Abfeuern eines Geschutzes ansieht. 95 Die beiden Aorist-

94) Im Pleskauer Text hat "biti" die Bedeutung 'Geschütz abschieben' und kommt daher nur im Aor. vor. Vgl. Anm. 95.

95) Sonstiges 'Schießen' oder 'Ferfen', das offensichtlich nicht mit einem so sorgfältigen 21 elvorgang verbunden ist, erscheint meist im Jpf., vgl.: 94/13 "abie zazigachu bocku s smoloju i puscachu na nich" - 'und wieder entzundeten ole Fässer mit Teer und warfen sie auf die Tüken: $d . h$. ließ̧en sie auf sie herabfallen; $67 / 11$ "strely bezcisleny puscachu na nich" - 'unzählige Pfelle warfen ole thnen entgegen', vermutlich war auch beim Werfen von Pfeilen nicht das Zielen so wichtig, wichtiger war vielleicht die Menge der geworfenen Pfeile. 
Pormen "napade" und "najde" werden noch durch Adverbien ergänzt: "vnezapu", "vskore", die den Aorist der Verben unterstreichen. "progna" ist "sečaše" entgegengesetzt; dieser Aorist refertert das Ergebnis, das Resultat der imperfektisch ausgedrückten Handlung ('setzte innen mit Hieb- und Stichwaffen furchtbar zu - und so drängte er sie /hat er sie gedrängt ...').

64/18 "Greki že, vyšed 12 grada, pobivachu vo rvech turky, ko1 ešče živy bjachu, 1, sobravše ich v mnogie kuči, sožigachut ich vkupe so ostavšimi turami."

- Die Griechen verließen die Stadtumwallungen und töteten jene Turken in den Gräben, die noch am Leben waren. Dann trugen sie diese ... zusammen und verbrannten sie gemeinsamen mit den zurückgebliebenen fahrbaren Angriffstürmen.'

"pob1vachu" und "sožigachut" führen plastisch vor Augen, daß es sich um ein sich ständig wiederholendes Töten, nämlich eines jeden, der noch lebte, handelt. Ebenso signalisiert "sožigachut", daß wir uns kein einzelnes großes Feuer vorzustellen haben, sondern viele Haufen mit Leichen und zurückgebliebenem Krlegsgerät, die - einer nach dem anderen entzündet werden. "živy bjachu" drückt den zustand des 'noch am Leben Seins' aus.

Im Zusammenhang mit den zuletzt vorgestellten Belegstellen der K-pler Erzählung haben wir nfcht mehr darauf hingewiesen, wie meisterhaft der Autor das alte Temporalsystem handhabt, um uns nicht zu wiederholen. Deshalb wollen wir an dieser Stelle, da wir die Materfalsammlung zum Imperfekt in der K-pler Erzählung abschließen, gerade dies noch einmal hervorheben. 
1.3.3.2 Pleskau: Das Imperfekt als Ausdruck sich wiederholender Handlungen

69/18 "... i pskoviči tako že protiv ich krepko i mužestvenno stojachu:

ovii pod stenoju s kopbi stojachu, strelbcy že iz piščalej po nich streljachu, deti že bojarskie iz lukov streljachu; ovii na nich kameniem metachu; ..."

'... und die Pleskauer leisteten ihnen so wacker ... Widerstand:

es standen die einen mit Hellebarden/Lanzen unter der Mauer, es schossen die Schützen aus den Feldschlangen auf sie, es schossen die niederen Bojaren Pfeile von ihren

Bogen;
es warfen die anderen mit steinen auf sie; ..."96

Die Reihe der aufgezählten Handlungen wird fortgesetzt, nur die verbale Endung ändert sich - statt auf - (j)achu reimen die Sätze im folgenden auf -jušče, also auf Part.praes. 97 "stojachu" bezeichnet hier nicht nur den Zustand des Stehens, widerstehens, sondern reflektiert auch die vielzahl derer, die dies tut. "streljachu" und "metachu" gehören zu den Verben, die durch die Wiederholung der ausgedrückten Handlung erst ihre Bedeutung erlangen, vielleicht nicht im eigentlichen Sinn Iterativa, jedenfalls aber im Kontext einer Kriegserzählung. - Auch diese Textstelle verdeutlicht, daß es dem Pleskauer Autor stärker auf klangliche Effekte ankommt als auf Kürze des Ausdrucks.

96) In der tbersetzung wurde der Versuch unternommen, der Endstellung des Prädikats im Original durch Anfangsstellung des Prädikats zu entsprechen.

97) Auf unsere Textstelle folgen fün weitere ähnlich gebaute Sätze, z:T. mit den gleichen Verben. Die Reihe dieser auf -jusce reimenden Sätze wird durch auf "glagolachu" endenden Satz abgeschlossen, wodurch möglicherweise die Verbindung zu oben zitierter Textstelle wieder hergestellt werden soll. - s.u., S. 566 . 
82/1 "...: ovo že, smolbe zažigaja,

na nich metati gotovljachu,

ovo že vrjatok $s$ kalom $v$ kotlach vozgrevachu,

inoe že zelbe $v$ kukšinach na nich metati prigotovljachu,

ovo że suchuju sejanuju izvestb prigotovis se,

litovskomu voinstru bezstudnye ich oći zasypati...

ovo že $i$ dvaźdy $i$ triždy na denb,

i v noči, pristupachu

i christovym posobiem vsegda chrestbjane

litvu ot steny otbivachu

1 mnogich na vsjakich pristupech

litovskich ljudej pobivachu,

chrestbjanskoe že voinstvo vsegda bogom

sobl judaemo bystb.

'die einen entzündeten Pech und wollten es

ihnen entgegenwerfen,

andere brachten Hasser mit Kot/Fäkalien in

Kesseln zum Kochen,

andere wieder bereiteten SchieBpulver in Kannen vor, um es ihnen entgegenzuschleudern, andere wieder bereiteten gemahlenen/gestampften Kalk vor, um ihnen diesen in ihre schamlosen Augen zu schutten ...

(die Litauer) griffen manchmal zwei oder drei Mal täglich und in der Nacht an,

mit Christi Hilfe drängten die Pleskauer die Litauer immer wieder von den Stadtmauern herunter

und töteten bei solchen Angriffen ihrer viele.

Das christliche Heer stand eben immer unter der

Obhut Gottes.'

Wir haben hier eine Situationsschilderung vor uns, ähnlich der zuletzt vorgefühten. $D a B$ es sich um dauernd wiederholte Vorgänge handelt, wird verschiedentlich durch adverbiale Bestimmungen unterstrichen traždy i triždy na denb", "vsegda", "na vsjakich pristupech"). "prigotoviš" im vierten Satz ist sicher Verschreibung eines Kopisten (vgl. Variante) - es ist aber bezeichnend für das Sprachgefühl Ende des 16./Anfang des 17. Jh.s, daB solche Verschreibungen möglich wurden sie zeugen vom Verlust des Empfindens für die alten Tempora. Bemerkenswert ist wieder die zusammenfassende schlußsentenz, in der wir den Aorist vorfinden "sobl judaemo bystb".

98) Variante: S. 155 - "prigotovl jachu". 
77/4 "...: ovii že kamenbe voinom prinošachu

i temi litvu $z$ goroda i za gorodom pobivachu: ${ }^{99}$ ovii že, utružs̆iimsja voinom, ot žažy iznemogšim, vodu prinošachu

i retivyja ich serdca žažeju vodnoju utolevachu. " 100

'...: die einen brachten den Kämpfenden Steine, mit denen diese die Litauer von der Stadt herab und hinter der Stadt erschlugen:

die anderen trugen den erschöpften, von Durst verzehrten Kriegern Wasser herbei

und linderten (so die Qual) ihrer emsigen Herzen.'

Abgesehen vom Kontext, wo die Tatsache, daß diese Tätigkeiten der Frauen, von denen hier die Rede ist, erst durch die Wiederholung einen sinn bekommen, zeigen auch die dehnstufigen Ableitungen bzw. das nichtdeterminierte Kompositum (-iva-, -eva-; "prinošachu"), daB die ausgedrückten Handlungen immer wieder durchgefuhrt werden.

Es ließen sich noch entsprechende Beispiele hinzufügen, in anderem Zusummenhang haben wir auch schon auf entsprechende Ipf.-Belege, die wiederholte Handlung ausdrücken, hingewiesen. AbschlieBend wollen wir aber noch einige Textstellen vorführen, wo man - bei aller Vorsicht in der Beurteilung und bei aller Berücksichtigung der subjektiven Sicht des Autors - das Ipf. als unberechtigt bezeichnen muB.

59/28 "I se, jako $i$ divij vepro is pustyni, príde $i$ sam litovskij korolb so vsemi svoimi mnogimi silami, ... Sij že neutolimyj ljutyj zverb nesyt, svoeju gladnoju utroboju prišed, jako videv velikogo grada Pskova, ..., vsjačeski umom raspaljašesja, vojsku že svoemu okolo vsego togo grada obъechati $i$ osaditi veljaše."

99) Dieser und auch der das 2 itat einleitende Doppelpunkt sind wieder Beispiele für die eigenartige Zeichensetzung durch den Hrsg. unserer Textausgabe V. I. Malysev.

100) Die Variante bietet an dieser Stelle eine klarere Lesart: S. 151 - "i retyvija ich serdca vodoju utolevachu" - vgl. unsere Ubersetzung dieser Stelle. 
' Und siehe, wie ein wilder Eber aus der Wiistenei kam der litauische König heran, mit all seinen Truppen, ... Als dieses bösartige, unersättliche (= "neutolimyj", "nesyt") Tier mit seinem hungrigen Wanst angekommen war und ... Pleskau sah, da entflammte sein Geist gänzlich, und er befahl, dab sein Heer die Stadt umzingeln und belagern sollte.'

Der gesamte Kontext zeigt, daß es sich um ein plötzliches Aufflammen handelt, das Verb ist hier als Ingressivum aufzufasser. Von "veljaše" war bereits die Rede - es meint eindeit tig: 'Befehl geben, erteilen'. Statt dieser Ipf.-Formen würden wir Aor. "raspalisja" und "povele/vele" erwarten. Möglicherweise sollen aber die beiden Verbformen diese beiden Sätze reimend abschlieBen - dies wird nur durch das Ipf. möglich - vgl. die folgenden Textstellen, die beweisen, daB der Autor in anderem Kontext für ein bedeutungsähnliches Ingressivum den Aor. wählt:

$52 / 17$ "Togda vídev ... korolb mnogo ... velikuju silu, togda bolbmi razgordesja vo svoem ... pomysle,..."

'Als er sein Heer sah, da wurde er sehr stolz'

42/10 ".... vo vtoroe leto po Polockom vzjatse, razsverepisja 1 razgordisja l jutyj toj varvar, ..." '.... zwei Jahre nach der Einnahme Polocks brachen in diesem bösartigen Barbaren (wieder) Wildheit und Stolz aus/kamen zum Ausbruch, ...'

45/10 "Na vesnu že paki gotovitisja povelevaše: '..." 'Er befahl, sich im Prüjahr wieder bereitzuhalten.' Die Ipf.-Form ist unverständlich - es handelt sich um eine prägnante Feststellung am Anfang eines - durch tberschrift eingeleiteten Absatzes, in der wörtichen Rede folgt der Befehl im Wortlaut.

Die Reihe der Beispiele solchen fragwürdigen Gebrauchs des Ipf. ließe sich noch fortsetzen, vor allem könnten wir pluralBelege vorfuhren, doch sind die weniger uberzeugend, da sich dabei stets argumentieren lieBe, das Ipr. sei durch die Vielzahl der die Handlung Tragenden bedingt (distribative Funktion. Jedenfalls ist festzuhalten, daB es dem Pleskauer Autor 
nichts ausmacht, z.B. zur Erzielung klanglicher Effekte verbele Kategorien zu verwenden, die dem speziellen Charakter einer gegebenen Situation nicht entsprechen. Aber auch darüber hinaus sind Ipf.-Formen in Kontexten anzutreffen, wo sie nicht immer hinzugehören scheinen.

\subsection{Das_Imperfekt in unseren Texten = Zusgmmenfassung}

In unseren Untersuchungen sind wir von der allgemein anerkannten Feststellung ausgegangen, daB z.Z. der Entstehung unserer Texte (Ende 15. und Ende 16. Jh.) sich die aspektuelle Ausrichtung des Verbalsystems bereits ziemlich stabilisiert hatte. $\mathrm{Da}$ m.E. das Ausgehen von heutigen Aspektverhältnissen eine zu unsichere Ausgangsbasis für unsere Unterguchungen dargestellt hätte, sind wir von der den Verben innewohnenden Aktionsart ausgegangen. Ipf. bei Nichtdurativa (präfigiert und unpräfigiert) war für uns von vornherein von Interesse. Des weiteren betrachteten wir alle Komposita von durativen Simplicia, die ja heute meist perf. sind.

An Hand der Tabelle ergab es sich schon, daB in der K-pler Erzählung Ipf.-Belege der genannten Verbgruppen viel häufiger auftraten als im Pleskauer Text. Bei genauer Betrachtung jedes einzelnen Belegs stellten wir darüber hinaus fest, daB das Ipf.-Material der genannten Verbgruppen im K-pler Text viel bunter, viel lebendiger, viel breiter gefächert ist als die zumeist stereotypen Ipf.-Belege dieser Gruppen in der Pleskauer Erzählung.

Damit reflektiert die $K$-pler Erzählung noch stärker einen Zustand, der insbesondere für das fruhere altruss. Schrifttum charakteristisch ist - im fruhen altruss. Schrifttum sei ein deutliches Aufleben der Ipf.-Kategorie im Bereich der perf. Verben gegenuber dem Aksl. festzustellen. ${ }^{101}$ Die Tat-

101) Maslov, Imperfekt, S. 74. 
sache, dab in der Pleskauer Erzählung das Ipf. fast ausachlieblich von durativen Simplicia und von ouffigierten/ dehnstufigen Able1tungen gebildet wird, zeigt, daB in diesem Text dos Ipf. bereits auf den imperf. Aspekt fixiert ist.

Die Einzelbetrachtung aller Ipf.-Belege nichtdurativer und nichtouffiglerter/nichtdehnstufiger Komposita, aller Ipf.Belege von heute fast ausschlieblich perf. Verben, fuhrte uns zu folgender Feststellung:

1. Eine Ipf.-Form eines nichtdurativen Verbs bezeichnet Iterat1vität der ausgedruckten Handlung ("načachu").

2. Die Ipf.-Form eines präfigierten (nichouffigierten/nichtdehnstufigen) Durativums bezeichnet eine einmalige, durative Handlung, genau wie dles die anderen Tempora dieser Verben tun. Das Präflx bewirkt bel den meisten Durativa nur eine zeltliche Begrenzung der Handlung oder des Vorgangs.

Auf diese ursprunglich durativen präfigierten Verben, die heute fast ausschlieblich perf. sind, trifft die Bedeutung der Iterativität, die dem Ipf. perf. Verben immer wieder zugeschrieben wird, nicht zu. 102

Zu den Ipf.-Belegen nichtdurativer und präfigierter durativer Verben tritt häufig modale Schattlerung, die vielleicht entscheldend war fur die Wahl des nichtdurativen bzw. präfigiertdurativen Verbs (načachu", "pobbjaše") anstelle der suffiglerten/dehnstufigen Ableitung ("načinachu", "pobivaše"). Erkennbar waren voluntative, konative und konditionale Bedeutung; mir scheint, in solchen Ipf.-Formen auBert sich auch besondere Expressivität.

102) Die oft behauptete 1terative Bedeutung des Ipf. perf. Verben wird 1mmer an Satzen demonstriert, die inhaltilch Wiederholthe1t, Iterat1vität der ausgedrúckten Handlung ohnehin voraussetzen, vor sllem Satzgefuge vom Typus "(Jedes Mal,) wenn, dann ..." ("asce", "egda", "kto" u.a.) und Varlanten dieses Typus. 
Die Ipf.-Kategorie im Pleskauer Text hatte sich als fast vollkommen auf den imperf. Aspekt fixiert erwiesen. Darüber hinass läBt der Autor dieser Erzählung grobe Unsicherheit bezuglich der Ipf.-Formen erkennen: mehr als die Hälfte aller Belege auf $-(j)$ aše (3.gg.1pf.) stehen bel elnem Subjekt im Plur., ersetzen also die Endung $-(j)$ achu. Umgekehrt begegnet aber die Endung - $(j)$ achu niemals als Subst1tut für die 3.8g. $-(j)$ aše.

Der Gebrauch der Endung $-(j)$ aše beim Plur. In der Pleskauer Erzählung hat drei Grinde:

1. reine Verwechslung der Endungen;

2. stilistische Funktion (Endreim - $-(j)$ aše tritt an die Stelle von -achu, wenn es entweder mit anderen $-(j)$ ašeEndungen oder aber mit -šče (Part.präs.) oder mit $-(v)$ še reimen soll (Part.prät.).

3. Die Endung - (j)aše verwendet der Pleskauer Autor auch dann im Plur., wenn von Funktion und Kontext her die 3.pl.aor. zu erwarten 1st - es handelt sich hierbel vorwiegend um durative/imperfektive iti-Verben (4. Leskien' sche Klasse); so treffen wir statt z.B. "trorisan, "velesa" stets "tvorjaše", "veljašen - Aoristformen von imperf. Verben, die derartige Ersatzformen bilden, sind in der Pleskauer Erzählung nicht belegt (vgl. z.B. im K-pler Text "vele, velešn" usw.). Dies ist besonders auffällig, wenn in reimend ausklingenden Satzreihen sogar die Aor.Endungen -aša, -iša usw. mit imperf. - (j)aše alternieren können (vgl.36/13 "(on1) obvoevaša - zapustoš1ša - tvor1ašen ; 38/14 "(oni) ne polučiša - schožăse - poklon1ša$\left.8 j a^{n}\right)$.

In der K-pler Erzählung war diese Entwicklung - Verlust der Sing.-Bedeutung von - $(j)$ aše - nur ansatzweise im Nachhinein z:u erkennen. Dort handelte es sich in den meisten/Fällen nachweislich um Verschreibungen für -aša.

A.ls wir in einem gesonderten Abschnitt die wichtigsten Punktilonen des Ipf. In unseren Texten - Ausdruck eines Zustandes, der Durativität einer Handlung/eines Vorgangea, der Iterati- 
vitat, daneben die distributive Punktion - demonstrierten, nahmen wir auch Gelegenhe1t, auf andere fur den jewelligen Text charakteristische zuge hinzuweisen. Besonders deutlich trat die Absicht des Pleskauer Autors hervor, reimende Satzfolgen zu schaffen. Im $\mathrm{K}$-pler Text fiel immer wieder der feinsinnige Gebrauch der alten Tempora auf, für die der $\mathrm{K}$-pler Autor noch ein lebendiges Empfinden gehabt zu haben scheint. 


\section{Der Aorist}

Wie aus Tabelle 1 hervorgeht, 1st der Aorist das in beiden unserer Texte am besten belegte Tempus, das in manchen Bereichen fast $50 \mathrm{v} . \mathrm{Hd}$. aller Verbformen ausmacht (vgl. $\mathrm{K}$-pel: allgemeiner Bericht $=48,8 \mathrm{v} . \mathrm{Hd}$.). Diese Tatsache in Verbindung mit der vergleichsweise starken Vertretung der Imperfekt-Kategorie hatte uns $z u$ der grundsätzlichen Peststellung veranlabt, dab beide Texte als an der literarischen Tradition orientierte Werke $z u$ betrachten sind. Denn im 16. Jh. sind diese Tempora lüngst auBer Gebrauch gekommen; in Privat- und Geschäftsbriefen begegnen sie kaum nocin. ${ }^{1}$ In der "Stepennaja kniga", einem lusterbeispiel des moskovitischen Prunkstils, bildet der Aorist ebenfalls das Haupterzähltempus..$^{2}$ In Kurbskijs "Istorija knjazja velikago noskovskago", die ja nur wenige Jahre vor Entstehung der ErzählunE über die Belagerung Pleskaus durch Stephan Báthory geschrieben worden sein dürfte, macht das heutige Präteritum, gebildet durch das 1-Part., bereits mehr als die Hälfte aller finiten Präteritalformen aus: 1050 l-Part. (also ohne Kopula "estb" usw.) stehen 680 Aor.- und 170 Ipf.-Belegen gegenüber. ${ }^{3}$ Im 17. Jh. begegnet der Aor. zwar noch hüufiger, mehr und mehr aber in stilistischer Funktion (= hoher Stil); ${ }^{4}$ auch im 18. Jh. ist er noch nachweisbar, ${ }^{5}$ in der Kirchensprache lebendig sogar noch im 19. Jh. 6

1) Xernych, Istor. grammatika, S. 255; Efimov, Istorija russk. jazyka, S. 40; Sobolevskij, Lekcii, S. 235 - vom 15. Jh. ab verschwindet der Aor. aus der lebendigen Sprache.

2) Otten, Fin. Verbalformen, S. 232.

3) Boretzky, Tempusgebrauch, S. 38.

4) Cocron, La langue, S. $216 \mathrm{ff}$ - findet nur nogh Spuren (vestiges) des Aor. - Schneider, Sprache Posoškovs, S. $203-08$.

5) Nikiforov, Glagol, S. 151: "..., raspadaetsja on (= aorist) $1 v$ literaturnom jazyke (chotja étot process očen' dlitel'nyj, zatjanuvśijsja do XVIII v.) ...".

6) P. Scholz: Erstarrung und Entwicklung in der altslavischen Kirchensprache RuBlands. In: Orbis 6 (1957). S. 427-436: in einer 1898 entstandenen Vita fanden sich fast nur Ipf.und Aor.-Formen. Ders.: Studien zur Geschichte des umschriebenen Perfekts. Masch.-Diss. Hamburg 1952. S. 206 ff 9519790 
D1e morphologische Seite der Aorist-Kategorie bietet in unseren Texten keine wesentlichen Schwierigkeiten. Wie meistens in der altruss. Literatur begegnet uns fast ausschlieblich der sigmatische Aor. jüngerer Prägung. 7 Nur in der 2./3.sg. ist der Wurzelaorist noch erkennbar: Statt "rěchъ" lesen wir also "rěkoch", statt "rěša" finden wir "rěkoša" usw.; aber: "rěče".

Die 3.pl.ipf. kam im $K$-pler Text zureilon $m^{4} t$ oinem auslautstützenden - $t_{b} / t_{b}$ vor, z.B. 63/25 "dajachutb". Diese Endung $-t_{b} / t_{b}$ begegnet in der $K-p l e r$ Erzählung auch im Aor. - in der 3.sg.: beinahe regelmäbig lesen wir "načatb/-tb", "vzjatb/tz" (so auch die anderen Komposita von "jati"). Im Gegensatz zu der entsprechenden Ipf.-Endung ("dajachutb") giellen diese Aor.-Endungen Archaismen dar, die auf aksl. "načętъ" und "vъzъ-jętъ" usw. zurückgehen. ${ }^{8}$ In der Pleskauer Erzählung ist Derartiges nicht $z u$ beobachten.

In beiden Texten stoben wir gelegentlich auf Formen wie "pri-/predade" usw. neben üblichem "pri-/preda" ${ }^{9}$ vielleicht lehnt sich die erweiterte Porm an "pade" und dient expressivem Ausdruck. ${ }^{10}$ Die alte Form "dastz" finden wir nur einmal (K-pel 56/38) - sonst meiden beide Autoren den Aor. des. Simplex "dati".

Otten findet in der "Stepennaja kniga" zahlreiche Kongruenzfehler in Numerus und Person; ${ }^{11}$ Boretzky macht die gleiche Beobachtung. 12

7) Leskien, Handbuch, S. 132: Klasse II A.2 und Klasse II B.

8) Kiparsky, Russ.hist. Grammatik, S. 224 - findet diese "Verdeutilichung" der 3.sg.aor. durch -tb auch bei anderen Stämmen als "-čati" und"-jati", während otten, Finit. Verbalformen, S. 235 diese Verdeutlichung vorwiegend auf diese Stämme beschränkt sieht. Vgl. Borkovskij, Istor. grammatika, S. 256.

9) "pri-/predade" - KP 61/7; PS 45/4; "v-/vozda" - KP 57/8, 76/13; PS 95/28, 97/31.

10) Denkbar ist auch, daß "(-)dade" die 3.sg.aor. "(-)dastz", die der 3.sg.praes. homonym war: "(-)dastъ", deutlicher abheben sollte. Vgl. Otten, Finit. Verbalformen, S. $240 \mathrm{f}$.

11) Otten, Pinit.Verbalformen, S. 250 f. - Kongruenzfehler signalisieren "Schwächung der Aoristkategorie".

12) Boretzky, Tempusgebrauch, S. 54. 
Auch wir finden gelegentlich Kongruenzfehler - aber ole fallen kaum ins Gewicht. ${ }^{13}$ Der Vollständigkeit halber seien einige Beispiele vorgestellt:

3.pl. statt 3.8g.aor. - PS 79/6 "(on) lišiğasjan; seltener: 3.8g. statt 3.pl.aor. - KP 71/14 "strely 1ch pomrači svet"; in einer Rede der Pleskauer Voevoden an die Bürger von Pleskau kommt einige Male statt der zu erwartenden 1.pl.aor. die 3.pl.aor. vor - z.B. $79 / 5$ "my, nemoščn11, prepojasas̆asja siloju". Fehler wie die folgenden (aus der K-pler Erzählung) durfen wir sicher als Verschreibung (oder als Druckfehler) werten: $55 / 3$ "(Konstjantin) sobrach"; 60/24 "(oni) videšên; 66/8 "i vskore napadoše množestvo $1 \mathrm{ch}^{n} i^{14}$ die $1.8 \mathrm{~s}$.aor. hat meist die Endung der 1.pl.aor: KP 78/22 "vnidochom" koordiniert mit "ispytach 1 sobrach" (der Pleskauer Autor verwendet die 1.8g.aor. korrekt).

Da wir das Ipf. ja nur noch in kontrahierter Form antreffen, 1st bei stämmen mit Infinitiv-Stamm auf -a- ${ }^{15}$ in der 1.sg. und 1.pl. formal das Ipf. nicht vom Aor. zu unterscheiden: 2.B. 1.8g.1pf. "pisaachb" > "pisachb"

$$
\text { 1.8g.aor. "pisachb". }
$$

Diese unklaren Pälle haben wir in unseren Statistiken zum Aor. gestellt - die Einzeluntersuchungen werden zeigen, ob dies zu Recht geschieht. 16

Der Aorist war ursprünglich das Tempus der Nichtdurativa und bezeichnete daher einen Punkt in der Vergangenheit. ${ }^{17}$ Im Lauf der zeit entwickelte sich auch ein Aorist fur die durativen, iterativen und alle anderen nichtmomentanen Verben. Dieser Aorist konnte naturlich nicht aus der z.B. durativen

13) Die Constructio ad sensum - Plural nach Collectiva -, wie sie im Altruss. Ublich war, kann naturlich nicht als Kongruenzfehler angesehen werden.

14) Beispiel fur Constructio ad sensum - a. Anm. 13.

15) Leskien, Handbuch, S. $156 \mathrm{ff}$ : Verbalklasse III 1 B und III 2 .

16) Die wenigen Belege, auf die diese Prämisse nicht zutrifft, belasten unsere Statistik nicht.

17) Die Entscheidung des Aor. fur die Bezeichnung eines 
Handlung einen nichtdurativen Vorgang machen; vielmehr bezelchnete dieser Aorist ${ }^{18}$ den SchluBpunkt der durativen, iterativen oder wie auch immer gearteten nichtmomentanen Handlung. Es war dies "ein grammatikalisierter Aorist komplexiver Natur ..., der durch ein $\underline{s}$-Suffix und Dehnstufe der Wurzelsilbe charakterisiert war (aksl. Typus věsz, a1. avāksam, lat. vēxil).$^{19}$ So geben "vezéachz" - '1ch fuhr' und "věsz" - "ich fuhr eine Zeitlang, fuhr eine bestimmte Ze1t' exakt die gleiche Handlung an; der Aorist drückt lediglich die zeitliche Begrenzung dieser Handlung, dieses Prozesses, dieses Vorgangs usw. aus. Da diese Entwicklungen bereits in spätidg. Zeit fallen (s. Anm. 17), verwundert es nicht, daß uns der Aorist durativer ${ }^{20}$ Verben bereits in den ältesten aksl. Denkmälern als ganz natürliche Erscheinung entgegentritt (wohingegen das Ipf. nichtdurativer Verben in den aksl. Texten noch seltener aufscheint als in den altrussischen Denkmälern) 21 .

Die aksl. Denkmäler lassen die Grundlagen des slav. Aspektsystems bereits deutlich erkennen. "Das indeterminierte oder iterative Verb z.B. hatte Bedeutungsmerkmale, die sich leicht zum imperfektiven Aspekt wenden konnten; das durch Präfigierung determinierte Verb, Verben momentaner Aktionsart hatten potentiell Bedeutungskomponenten des perfektiven Aspek ts (...). ${ }^{22}$ Die Kriterien von Durativität und Nichtdurativität

Punktes in der Vergangenheit ist vermutlich für die spätidg. Zeit anzusetzen - 8. Trost, Perfekt, S. 4, § 7 mit Bezug auf Aitzetmuller. - Die subjektive Dehnung e1nes punktuellen Geschehens ist das Ergebnis von Abstrahierungsvorgängen, die in das Peld der Aspektbildung reichen - VGI. Budich, Aspekt, S. 15, \&23.

18) Trost, Perfekt, S. 9, $\S 18$; Budich, Aspekt, s. 16, $\$ 26$.

19) Trost, Perfekt, S. 4, § 7. Später trat zu dieser dehnstufigen Aor.-Bildung noch eine schmundstufige mit a-Suffix: "berg - bbrachz" - 'ich suchte eine bestimmte Zeit'.

20) "durativ" mag hier und im folgenden stellvertretend für alle nichtmomentanen Aktionsarten stehen.

21) Maslov, Imperfekt, S. 74; Leskien, Handbuch, S. 172 u.a.

22) Ruzicka, Verbalaspekt, s. 2. 
zeigen sich bereits im Aksl. und viel stärker noch im Altruss. von aspektuellen Kriterien uberlagert. Wenn wir uns nun mit dem Aor. beschäftigen, dann bleiben Belege nichtdurativer Verben von vornherein auBer Betracht, da der Aorlst ihr naturliches Vergangenheltstempus darstellt. Ebensowenig interessieren uns präfigierte Durativa, weil das Präfix eine semantische Elnengung, Spezifizierung, Begrenzung und/oder Zielrichtung der alten Bedeutung des Simplex mit sich brachte, die den Aorist mit seiner gleichfalls begrenzenden Punktion zum adäquaten Präteritum solcher Komposita werden lieben und diese gleichzeltig - s.0. die Worte Ruzickas - dem perf. Aspekt naherückten bzw. sie demselben eingliederten. Wir wollen vielmehr solche Aor.-Belege ins Auge fassen, die der Aspektualisierung der alten Tempora, von der wir im ausgehenden 15. und im 16. Jh. sprechen dürfen, nicht entsprechen: Aor.-Belege nichtpräfigierter durativer Verben, dehnstufige Ableitungen (= typische Imperfekt1v-Bildungen wie "strel jat1" und "pomogati") sowie Aor.Belege nichtdeterminierter Verben der Bewegung. An solchen Aor.-Formen interessiert uns,

1. ob der Gebrauch dieser Form an dieser Stelle dem individuellen Gestaltungswillen des Autors zuzuschreiben ist (was noch ein gewisses Empfinden für den rechten Bebrauch der alten Tempora bezeugen würde);

2. oder ob dieses unpräfigierte Durativum perfektiv geworden 1st;

3. oder ob der betr. Aor. dem Zufall seine Entstehung verdankt und somit als Anzelchen für den endgültigen Verfall der alten Tempora zu gelten habe, da offenkundig der Aspekt (hier: der perf.) nicht mehr das - im 15. und 16. Jh. - korrelierende Tempus (hler: der Aor.) stützt.

Ottens Untersuchung an der "Stepennaja kniga" und Boretzkys Arbe1t uber Kurbsk1js "Istor1ja" bieten uns kaum Vergle1chsmöglichkelten, da sle die Verben nur nach 1hrem Aspekt beurtellen. Abgesehen davon, dab Otten so gut wie gar kein statietisches Material zur Hand gibt, sind die Belspiele in 
diesem Terk nur schwer zu beurteilen, da es ja - bis auf die letzten Stufen - kein grundsätzlich neu geschaffenes Opus, sondern eine mehr oder weniger weitgehende Bearbeitung älterer Hss. darstellt.

In der "Istorija" Kurbskijs kommen 680 Aor.-Formen vor, davon seien - so Boretzky ${ }^{23}-32(=4,7$ v.Hd.) von imperf. Verben gebildet. Zwar nennt er viele (oder alle) imperf. Verben, die er mit Aor.-Formen vorfindet; umgekehrt ist aber nicht klar, welche Verben er als perf. ansieht - so betrachtet er offensichtlich das so uberaus häufige "reščl" als perf. Aus seiner liste imperf. Verben mit Aor.-Belegen wollen wir nur einmal jene typischen Imperfektiv-Bildungen mit dem Suffix -'a- ("Sekundërimperfektivan) ${ }^{24}$ vorstellen: "vozbronjati", "vozchvaljati", "preprovožatisja", "moljat1", "prošati", "choždati". Neben der Tatsache, daß mehr als die Hälfte aller präteritalen (finiten) Verbalformen in Kurbskijo "Istorija" mit Hilfe des 1-Part.s gebildet werden, zeigen gerade Aor.-Bildungen solcher Sekundärimperfektiva, daB Kurbskij trotz seiner literarischen Ambitionen ${ }^{25}$ das ksl. Tempussystem nicht richtig beherrschte. 26

Unsere Angaben in Tabelle 2 lassen sich mit denen Boretzkys nicht vergleichen, da wir nicht den Aspekt als Kriterium gewählt haben, sondern im Wesentlichen von Nichtdurativa und von Durativa ausgingen. Die uns interessierenden Angaben in den stark umrandeten Peldern - Aor.-Bildungen von durativen Simplicia, Sekundärimperfektiva sowie von nichtdeterminierten Verben der Bewegung - erscheinen verschiedentlich recht hoch. Von besonderem Interesse sind hier die Zahlen in den Klammern: die Zahlen ohne Klammer geben die absoluten Belege,

23) Boretzky, Tempusgebrauch, S. 52 f.

24 ) ebda., S. 53. 25) ebda., S. 4 - 9 .

26) Es sei noch einmal an die Untersuchungen H. Kolln's erinnert: Zum Aorist im Altrussischen. In: Scando-slavica 5 (1959). S. 64 - 77. Er stellte fest, dab die Festorchronik (PVI) keinen Aor.-Beleg solcher Sekundärimperfektiva enthält. 
die Zahlen in den Klammern aber nennen die Anzahl der Verbalstämme, von denen jene Aor.-Formen gebildet sind. So setzen sich im $\mathrm{X}$-pler Text z.B. die 18 Aor.-Belege durativer Simplic1a (ohne 3.pl. auf -sa) ausschlieblich aus "rekoch/rečen und "plsach/om" (= 2 Stämme) zusammen. Die 35 entsprechenden Belege der Pleskauer Erzählung haben zusätzlich zu Formen von "rešćl" und "plsati" noch einen Aor. "glagola" (neben 12 "glagolaše/glagolachu") - also Formen von auch nur drei Stämmen. Die 3.pl.aor. auf -ša durativer Simplicia zeigt im K-pler Text genau das gleiche Bild; dagegen ist mit neun Belegen von sieben Stämmen diese Gruppe im Pleskauer Text vielfältiger zusammengesetzt. - Im hohen Antell der Aor.-Formen von Simplic1a der 4. Leskien'schen Klasse äuBert sich der Prozeß der Perfektivierung, der hier besonders um sich greift.

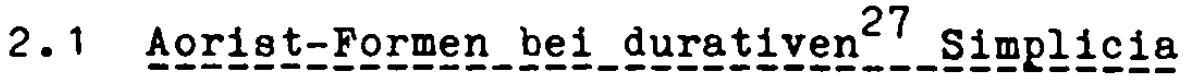

Anknüpfend an obige Bemerkungen uber die Zusammensetzung der Verbalstämme durativer Verben, die Aor.-Formen bilden, sei vorausgeschickt, daß wir uns die Erörterung solcher Belege wi e "rekoch/reče/rekoša" ersparen wollen; auch Formen wie "pisach/om" und "glagola" sollen lediglich gestrelft werden. 2war reflektieren diese noch einen voraspektuellen Zustand, doch sind sie in einem solchen Grade habitualisiert-formelhaft, dab sie für uns kaum noch Aussagekraft besitzen.

2. $1.1 \mathrm{~K}$-pel: Aor.-Formen be1 durativen Simplicia

62/12 "I jakože predi p1sachom: kyj jazyk možet izpovedati 111 izrešč toja bedy 1 strasti: ..."

'Tie ich berelts vorher geschrieben habe: Wer kann diese Nöte und Leiden beschreiben, wer sie aufzählen?...'

"pisachom" in diesem Satz entspricht sonst begegnendem "rekoch/omn. Die Pormelhaftigkeit dieser Wendung unter-

27) Es sei nochmals daran erinnert, daß "durativ" hier im allgemeinen stellvertretend für alle nichtmomentanen Aktionsarten steht. 
streicht die Tatsache, daB der betr. Satz bzw. Sinngembibs vorher noch gar nicht gesagt wurde. ${ }^{28}$ zum Vergleich eine Textgtelle mit "rekochom":

$61 / 17$ "Turky že bbjă̌esja po vsem mestom, jakože pred1 rekochom, bez opočivanija premenjajuščesja, ...n

Es erscheint mir legitim, "jakože predi plsachom" analog zu "rekochom", das ja als Aor. elndeutig ist, ebenfalls als Aor. zu interpretieren.

78/20 "Ulovljaja vremja dozreniem 1 ispytaniem velikym, pisach $v$ každyj denb tvorimaja dejanija vne grada ot turkov."

'Ich beobachtete alleg aufmerksam und befragte viele; und jeden Tag gchrieb ich nieder, was die Türken auBerhalb der Stadt begonnen hatten.'

Hier haben wir eines der wenigen Beispiele vor uns, wo eine zweideutige Form auf -ach klar Ipf.-Bedeutung hat: "pisach v každyj denb" bezeugt die Wiederholung der Handlung. 29

2.1.2 Pleskau: Aor.-Pormen bei durativen S1mplicia

In der Plegkauer Erzählung finden wir auBer den Aor.-Belegen von "reščl" je einen von "plsati" and "glagolati".

$83 / 10$ "... 1 pjat1 let vo Pskove chrestbjanskoe otroča posmeetca tvoemu bezumeju 1 troim glupym pervosovetnikom, - nich že este k nam pisagte."

'... und jedes fünfjährige Kind in Pleskau lacht uber deinen Unverstand und deine torichten Ratgeber, von denen/uber die du uns geschrieben hast.'

Es handelt aich hierbel um eine hybride Porm, die der Pleskauer Autor zuweilen gebraucht - wahrscheinlich, um Briefe

28) Daraus ließe sich schließen, daB ein Kompilator, auf den die uns vorliegende Redaktion der K-pler Erzkhlung zuruckgehen konnte, eine Vorlage exzerpiert hat, die don Satz enthkit, auf den sich "jakoze predi plachom" bozieht.

29) "pisach" - und so fast alle Aor.-Belege der 1.8g. (5 von 6) 1m Fachwort, - wahrend wir die 1.88.aor. songt nur 
st1list1sch aufzuwerten. ${ }^{30} \mathrm{Da}$ ja "pisaste" sowohl 2.pl.ipf. als auch 2.pl.aor. sein kann, wollte der Autor vielleicht auf diese Weise das Aoristische dieser Verbform hervorheben. Wenn man allerdings Parallelstellen vergleicht, kommt man an dem SchluB nicht vorbe1, daB wir hier besonders schlagende Beweise für den willkürlichen Gebrauch der alten Tempora in der Pleskauer Erzählung vor uns haben:

51/23 "A_jažze pisal esi o_grade tom, jave toliko že $i$ vo vsech nas̆ich stranach ..."

'Und was du (uns) über diese stadt geschrieben hast, ist in unseren Landen weithin bekannt ...'

$51 / 27$ "A_jaže_o ... stennach grada togo kreposti pisaše, $i$ my vedaeve."

' Und was du uns über die... Hauern dieser Festung geschrieben hast, ist auch uns bekannt.'

Der Aor. dürfte in allen drei Sätzen das angemessene Tempus sein, denn es wird Bezug genommen auf einen länger zurückliegenden Vorgang (des Schreibens), der nun - im Rahmen der Antwort auf den jeweiligen Brief - als Ganzes gesehen wird.

60/16 "On že glagola: '...'n

'Er aber sprach: ...'

Diese Wendung entspricht der Formel "(On že) reče: ..." vollkommen. Der Unterschied liegt vielleicht im Stilistischen - "glagolati" ist im 16. Jh. weit hinter "reščin zurickgetreten, vielleicht hat es daher eine etwas feierlichere luance.

Im solgenden wollen wir uns der 3.pl.aor. (-ša) zuwenden, die sich im K-pler Text in nichts von den anderen Personen und Numeri unterscheidet, aber im Pleskauer Text mit neun Belegen von sieben Stämmen etwas vielseitigeres Material zu bieten scheint.

in der Form "pisachom" antreffen. Diese Beobachtung werteten wir (s. Textgeschichte) als Hinweis darauf, daB der Verfasser des Nachworts - Nestor-Iskander - nicht mit dem Verfasser des Verteidigungsberichtes identischist. 30) vgl. 82/19 "esmi prildoch" - 'ich bin hergekommen'. 
88/4 "Tako že smolu gorjačjuju 1 ... na nich 1̧ jušče, tako že 1 , len ... na nich metaša, tako že 1 kukšiny z zelbem na nich metaja.

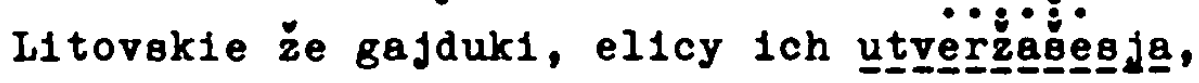

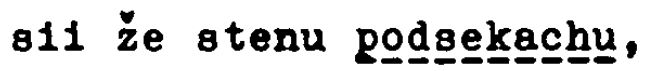

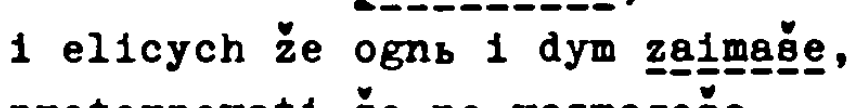
preterpevat1 že ne 므mㅡ으으르, skorozelbnym begstrom 1z-pod stenu bežgachu. 'So gossen sie auch brennendes Teer auf diese herab, so warfen aie auch hanf und ... auf ale herab, so warfen sie auch Gefäße (Krüge) mit Pulver auf sie herab.

Einige der 11 tauischen Helducken hatten sich aber verschanzt, die wollten sich unter der Mauer hindurcharbeiten; elnige aber waren Feuer und Qualm ausgesetzt und hielten es nicht mehr aus die flohen, so schnell sie konnten.

Ganz offensichtlich geht es dem Autor darum, dem Leser die Szene zu vergegenwätigen. In melot knappen Sätzen ochildert er die Vorgänge, die olch glelchzeltig abopielen. Eo sind Handlungen, die sich ständig wiederholen mulseen, wenn sie sinnvoll sein wollen (heiBes Wasser gieBen, brennenden Hanf werfen, PulvergefïBe schleudern usw.). Dies trifft auf die Handlungen der Litauer nicht zu, immerhin haben sie aber mit denen der pleskauer gemein, dab es viele sind, die sie ausfuhren. Furde man wegen der Iterativitit den Handlungen der Pleskauer als Tempus das Ipf. zuweisen, so böte sich dies Tempus auch für die Handlungen der litauer an, da diese von einer Vielzahl getragen werden. Dem Bericht lst vor allem aber gemeinsam die Erzahlhaltung des Autors: er versetzt olch in die szene hinein, berichtet unditelbar die Dimension der zelt einer Handlung tritt volikommen zurick, nur die ablaufenden Handlungen selbst stehen im Mittelpunkt. 31 Dag Ipf. wäre in dieser szene eweifelofrel das adkquate Tempus. Wir finden es auch in den meisten Sätzen vor, wenn auch ewe1 ual statt der 3.pl.1pf. d1e bekannte supplet1r-

31) Ausnahme " "vozmogoša" - das 'Hicht auehalten Kbnnen' ist 1nsofern zeltilch begrenzt, als es zum Anlab der Plucht vieler dient; mit der Flucht ist os beendet. 
vorm auf $-(j)$ aše $=3.8 g .1 \mathrm{pf}$. ("utveržašesja", "zaimašen) erscheint. Partizipien begegnen in der Pleskauer Erzählung auf Schritt und Tritt in der Funktion von Vollverben, so ist als einzige Form verwunderlich "metaš". Wir füren die ubrigen Belegstellen von "metati" vor: $69 / 21$ "ovil na nich kameniem metachu", $77 / 19$ "Ini1 že ogni zažigajušče, na nich mečjušče", $85 / 10$ "kameniem mnogim na to mesto vo grad metachu", $56 / 30$ "(korolb) strašilišča že svol, jako 1skry ogneny ... na Pskov metaše"

Da sich semantisch und vom Kontext her zwischen diesen Textstellen und der obigen mit dem Aor. "metaša" nicht der geringste Unterschied erkennen läBt, ist festzustellen, dab dieser Aorist falsch gebraucht wurde.

Ähnlich wie "metati" bezeichnet "strěljati" eine Handlung, die erst durch ihre Wiederholung ihren Sinn bekommt: erst das Abschießen vieler Pfeile, das häufige Schießen mit den Hand feuerwaffen kann strategisch von Nutzen sein. Wie bei "metati" fürt die Zielangabe nicht dazu, daß ein präfigiertes Kompositum mit Aor. verwandt wird. "streljati" begegnet uns $24 \mathrm{Mal}$ - im Infin., im Praes., als Part.praes, und im Ipf. Daher erweckt ein Aor.-Beleg unsere besondere Aufmerksamkeit:

87/7 "Iz-za Velikie reki, rozžigaja jadra, po choromom

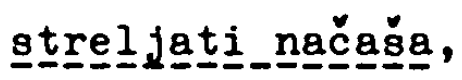

oktjabrja vo 24 denb,

1 toj dens malo ne črez vesb streljaša."

'Sis begannen, hinter dem Großen FluB hervor die Häuser m1t brennenden Kugeln zu beschießen; (das war) am 24.

Oktober; fast den ganzen Tag dauerte die BeschieBung an.' Anders als im obigen Beispiel handelt es sich bel dieser Belegstelle mit "streljaš" um eindeutig referierende Erzählweise. Der Autor erwahnt diese Beschießung nur kurz (anschließend heibt es nur noch: "... bog sobljude velikif grad Pskov ...n). Dem Autor schwebt die ganztätige BeschieBung als Ganzes, als längst glucklich Uberstandenes vor-sie ist vorbei wie das Datum, das er nennt. Ob nun der Aor. 
"streljaša" durch vorausgehendes "načaša" lautlich beeinflubt lst oder nicht - jedenfalls trifft er an dieser stelle den Sachverhalt sehr genau.

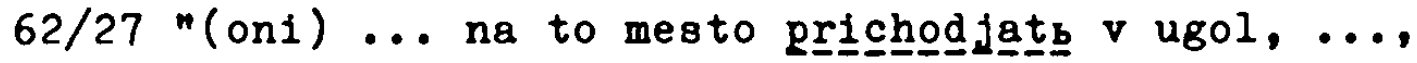
protiv togo mesta, ideže ti l jutí

litovakie gradoemcy gradoemnoe umyšlenie trorjağe. Molebnaja že mnogaja k bogu 1 bogorodicy tuto peša,

1 tako to mesto krestom ogradidi

1 svjatoju vodoju okropisia.

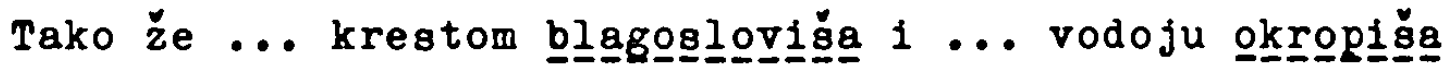
1 na podvig vooružziša, ..."

'(sie) ... kommen aber nun zu der Stelle,.... gegenüber welcher die Eroberungstürme aufgebaut worden waren. Hier sangen sie viele Gebete zu Gott und der Gottesmutter und wappneten so diese (gefährdete) Stelle mit Hilfe des Kreuzes und benetzten sie mit geweihtem Wasser. Und so segneten sie mit dem Kreuz und ...

Diese Beschreibung einer Prozession wird durch ein Praes. hist. - "prichodjatb" - eingeleitet. Diese Aktualisierung erscheint mir gerechtfertigt als Kontrapunkt zu dem zuvor Berichteten: Die Iitauer hatten Eroberungsturme ("gradoemnoe umys̆lenie" = "tury") vor der stadt aufgestellt. Die durch diese Tüme gefährdeten Stellen der Stadtbefestigungen sind Ziel der geschilderten Prozession. Dem einleitenden Satz ("prichodjatb") ist ein Relativaatz angegliedert, der auf das vorher Erzählte Bezug nimmt ("Ideže ... gradoemnoe umys̆lenie tvorjă̌en), also Vorzeitigkeit ausdrückt: "tvorjašen dürfte hier 3.pl. aor. "tvorišn" vertreten, welche Form von "tvoriti" im Pleskauer Text nicht erscheint - wegen der folgenden Aoriste auf - ba lst das Ausbleiben des zu erwartenden "tvoriša" (Reim!) besondere auffällig. - Hach dem einleitenden Satz, der den zielpunkt der Prozession angibt und näher beschreibt, erzählt der Autor, was an einer der besonders gefährdeten Stelien geschieht - gleichzeitig wechselt er vom Praes.hist. zum neutralen ${ }^{32}$ sorist. Ob die Handlungen der

32) van Schooneveld, A Semantic Analyses, S. 20: "The aorist is used to present a happening in the past in the simplest possible manner: ..." 
Geistlichen den Aorist notwendig machen, erscheint mir zweifelhaft. Es sind wohl viel eher die Verben, mit denen der Autor die Handlungen der Gelstlichen benennt, die an dieser Stelle den Anrist geraten erscheinen lassen: bis auf "pesan" sind alle genannten Tätigkeiten in irgendeiner Weise spezifiziert - "krestom ogradiša", "gvjatoju vodoju okropiša", "na podvig vooružiša", "krestom blagosloviša". Diese Detaillierung lot verbunden mit Präfiglerung; und es scheint dem Autor nicht möglich zu sein, diese Komposita in das Imperfekt zu setzen. Moglicherweise kam es thm an dieser stelle auf den Endreim-ěsa/-iša an. Aus welchen Gründen auch immer der Autor hier den Aorist vorzieht - "peša" ist den folgenden präfigierten/perfektiven Verben angegeglichen. Im Gegensatz zu "tvoriti", "velěti" u.a., von denen der Pleskauer Autor unter keinen Umständen den Aorist bildet, finden wir vom durativen Simplex "pěti" (sicher unter dem Druck des Reims) den Aorist "pesa" vor. Es mag hinzu kommen, daB "pětín in "pěvati" ein Pendant besab/besitzt, das die Iterativität, zumindest ein 'gewohnheitsmäBiges Singen', bezeichnet. 33 Da vielfach die Opposition 'Einmaligkeit - Wiederholtheit' zur Aspektopposition 'perfektiv - imperfektiv' gefuhrt hat, 34 waren Verben, die eine einmalige Handlung bzw. einen einmaligen Vorgang bezeichneten, eher aoristfähig als solche Verben, die keinen die Iterativität betonenden Partner hatten.

GroBe Unsicherheit im Gebrauch der Tempora innerhalb des Pleskauer Textes zelgt die folgende Textstelle - es handelt sich um "moščin - 'können'. Für das Aksl. spricht ihm Dostál vorwiegend imperf. Aspekt zu. ${ }^{35}$ In verstärktem Maße gilt dies m.E. fur die Verneinung "ne moščl, mit der wir es in

33) vgl. die Belege zu "pěvat1, pěvajun bel srezn. II, 1781; Iur heute: Daum-Schenk, Die russ. Verben, S. 359. Dostál befindet nach 176 aksI. Beglegstelien "petin als beiden Aspekten zugehörig - Dostál, Studie, S. $127 \mathrm{ff}$.

$34) V_{g l}$ Ruz1cka, Verbalaspekt, S. 13 - z.B. "kup1t1 - kupovati"; Beispiele dafür, daB "kupitin" auch imperf. gebraucht werden konnte - ebda. S. 36 .

35) Dostél, Studie, S. 160. 
unserem Textbeispiel zu tun haben:

80/14 "(korolb) getmanov že svolch 1 rochmistov ne možaśe videt1. Tako že 1 getmany ne mogoša svoemu kralju javit1sja, za nastojaščiju k nim sramotu ..."

- Der König konnte den Anblick seiner Hetmane und Rottmeister nicht ertragen; (und umgekehrt) waren die Hetmane nicht in der Lage, vor ihren König hinzutreten - so schämten sie sich ...'

Die Ubersetzung versucht, die Zuständlichkeit des 'Nicht erscheinen Könnens/Nicht vor ihn hintreten Könnens' hervorzuheben. Zwischen den Wendungen mit verneintem "mošc̆in 1st weder eine semantische schattierung noch ein stilistischer Unterschied erkennbar. Es kann auch nicht, wie so oft bel Ungereimtheiten im Tempusgebrauch, Reimabsicht des Autors als Grund für ein unangebrachtes Tempus angefunrt werden. Das Tempus von "mošc̆i" scheint sich nach dem Aspekt des Hauptverbs zu richten, dem es zugeordnet 1st: "viděti" 1st im Pleskauer Text nicht aoristfähig (s.u.) - es wird sicher schon als imperf. empfunden: also lesen wir "ne možase videti". "javitisja" dagegen ist schon längst auf den perf. Aspekt fixiert: ${ }^{36}$ also lesen wir "ne mogosa javit1sjan. 37

Die meisten Aor.-Belege im Rahmen der Gruppe durativer Simplicla (auBer der 4. Leskien'schen Klasse) finden sich von "biti", und zwar in der Bedeutung 'ganz gezielt schießen, einen SchuB tun, Geschuitz abfeuern'. In dieser Bedeutung w1rd "bit1" zum Determinativum, das auch im Praes. Gegenwartsbedeutung behält (PS 58/16 $n_{1}$ po 0strova gorodu 12 narjadu uže bbet"). Sonst hat "bit1" elnen anderen Sinn vgl.:

93/22 "Ego že bo, reče, lj jublitt bog, togo 1 nakgazuet, bset že syna, ego że príemlet."

'Denn welchen der Herr liebhat, den zuchtigt er; und er stäupt einen jeglichen Sohn, den er aufnimmt.' Hebr. 12,6 - tbersetzung: Iuther.

36) Dostál, Studie, s. $80 \mathrm{f}$.

37) Zum Vergleich seien die entsprechenden Stellen in der 
95/31 "..., knjazju Ivanu Petroviču Sujskomu Gansumeler ćelom bbet."

'Hans Möller grüßt untertänigst den Fürsten Sujskij.'

$70 / 27$

$70 / 32$

"v persi svoja bbjušče"

'(von Prauen:) sich (vor Gram) an die Brust schlagen'

$69 / 27$ ".... bezprestanno 1 premenjajasja litva bbjuščsja vojačeski, - ..."

'.... ohne Unterbrechung, sich ständig abwechselnd kämpften die Litauer mit allen Mitteln, - ...' "bitisja" - 'kämpfen, sich schlagen' erscheint im Pleskauer Text nur im Infin. und im Part.praes.; in der K-pler Erzählung begegnet "bitisja" in der genannten Bedeutung auBerdem im Ipf.

In der Bedeutung 'ganz gezlelt schieBen, einen SchuB tun, Geschütz ( = "narjad") abfeuern' erscheint "biti" neben Infin.Belegen häufig auch im Aor.:

64/13 "Takože 1 nautrija pjatb časov bezprestani po gorodu iz narjadu biša 1 vybíg da Svinoj bašni polovinu do zemli že zbi šă, da mestami

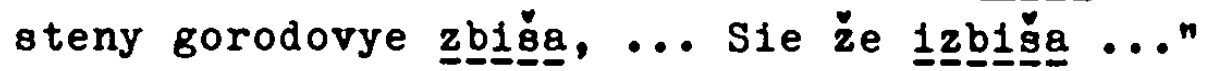

'Auch am Vormittag beschossen sie die Stadt ununterbrochen - fünf Stunden lang - mit dem Geschütz. Und sie schossen Stücke der Stadtmauer heraus, ...., und eine Hälfte des ...-Turms schossen sie in Grund und Boden; stellenweise zerschossen sie die Stadtmauer (völlig) ... Das alles hatten sie zerschossen ...'

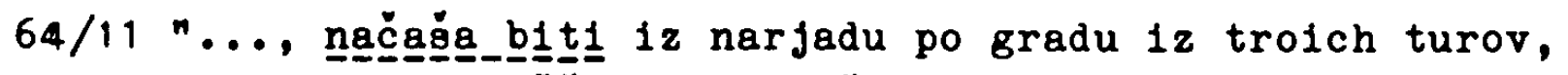
iz dvadcati piščlej, 1 blǒa po gradu bezprestanno vesb denb do noči."

'..., und sie begannen das Geschützfeuer auf die stadt aus dreien der Turme, aus 20 Feldschlangen; und sie beschossen die Stadt den ganzen Tag bis zum Anbruch der Nacht ununterbrochen.'

K-pler Erzählung angeführt:

59/31 :...; grazane ze ot bezčislennago streljanija ne mozachu otofat1 na stenach, .... a in11 strel jachu 12 pusek 112 piscalej, eliko možachu, ..."

$75 / 17$ "(cesarb) .... polde vo vrata, no ne možaše projt1 ot mnogago trupija, ..." 
89/14 "Sie že iz narjadu po gradu srjadu pjatb dnej biša,..." 'So beschossen sie die Stadt mit dem schweren Geschütz fünf Tage lang, ...'

In allen drei Textstellen ist von einer langanhaltenden Beschießung die Rede. Andererseits ist durch die Angabe der Dauer auch das Ende ins Auge gefaBt - die BeschieBung wird jeweils als einheitlicher Vorgang gesehen, der nun abgeschlossen ist. Daß wir aber nur diese Belege für den präteritalen Gebrauch von "biti" - 'gezielt schieBen' in der Pleskauer Erzählung finden, deutet doch auch darauf hin, dab der Aor. nicht allein Folge des abgeschlossenen, zusammenhängenden Zeitabschnitts, sondern ebenso Folge der spezifischen Bedeutung von "biti" in diesen Belegen ist, die man als determiniert ansprechen kann.

In der zuerst angefuhrten Textstelle (64/13) stehen dem Simplex "biti" verschiedene Komposita gegenüber, an denen die Differenzierung der Grundbedeutung deutlich wird 'ein Stück herausschieBen', 'zerschieBen'. DaB "biti" 'ganz gezielt schießen' trotz des Aor. imperf. bleibt, zeigt gerade der Gegensatz zu den Komposita: von "biti" erfahren wir lediglich die Zeitspanne, innerhalb welcher geschossen wurde; die Komposita haben so gut wie keine zeitliche Dimension: sie registrieren lediglich einen Effekt, ein Ergebnis.

Die Denominativa mit dem-ova-/-eva-Suffix haben sich anscheinend lange der aspektuellen Zuordnung entzogen. Das mag daran liegen, dab ihre Entstehung in einer zeit zu vermuten ist, da die aspektuelle Ausrichtung des slav. Verbalsystems zumindesten in den Grundzügen bereits festgelegt war. Bis in neuere $\mathrm{Ze1t}$ hinein hatten diese Verben keine Aspektpartner, sie blieben lange leit zur Bildung aller Tempora befähigt. 38

38) Eine umfassende Zusammenstellung dieser Denominativa nebst Belegstellen gibt Dostál, Studie, S. 194-207. Die wenigen Beispiele Bikiforoys Glagol, S. 69-71) sind für uns nicht sehr aufschlußreich, da sie die Verben vorwiegend im Infin., als Part.praes. Oder im Praes, vorfuhren. Von $8 \mathrm{fin}$. Präteritalformen aind 4 im Ipf., 2 im Aor. 
Perfektive Aspektbildungen vom Typ "pocelovati" sind sehr jung und auch nicht weit verbreitet. Wenn wir in der Pleskauer Erzählung einige Aor.-Belege solcher Verben entdekken, dann kann das als Hinwels darauf gewertet werden, daB auch im 16.Jh. diese Verben noch nicht so elndeutig imperfektiv empfunden wurden, wie dies heute der Fall ist.

79/17 "A ne pomys İİ $v$ serdcych našich koeju mysliju 111 bojaznestrom $v$ rozmyšlenie sja dat1 1 ll otčajat1, jako že emu, gosudarju, nepobedimoe oružie 1 životvorjaščlj krest celovaša." 39

' Und wir haben ganz und gar nicht vor (es kommt uns nicht in den Sinn), aus Furcht Zweifel in uns aufkommen zu lassen oder uns (sogar) der Verzweiflung anheimzugeben, we1l wir doch unserem Herrscher die unbesiegbare Waffe, nämlich das lebenspendende Kreuz, geküBt haben ( $=$ den Treueid geleistet haben).'

Statt des korrekten "celovachom" finden wir 3.pl.aor. "celovaša" - vielleicht, weil "celovachom" nicht eindeutig genug den Aor. bezeichnete (Ipf. lautet ebenso), dem Autor aber gerade das Abgeschlossene der Handlung 'wir haben den Treueld geleistet' als wesentlich erschien. M.E. wäre hier sogar Perfekt angebracht: "životvorjaščij krest celovali esmy" - 'wir haben den Treueid geleistet' = uns 1st das Merkmal eifen, daß wir das Kreuz gekußt haben; wir sind solche, die...: (vgl. F. Scholz, Studien zur Gesch.des umschriebenen Perf. S.29).

44/18 "Bojare že i voevody, jako 1stinnil rabi, obeščavšesja svoemu vladyce troriti po ego nakazanbju, na tom že 1 chrestbjanskoju veroju verovašasja emu." 40

'Die ... Voevoden versprachen ihrem Herren - wie wirkliche Knechte -, seinen Anweisungen entsprechend zu handeln, und sie beschworen ihm dies bei ihrem christlichen Glauben.'

Dile fragliche Wendung 1st derjenigen im vorherigen Beispielsatr synonym: 'Treueid leisten'; auch hier, so scheint es, wëre das periphrastische Perfekt angemessener als der Aorist.

39) "pomysl1m ... myslijun" - figura etymologica; "nepobedimoe oruzle 1 zivotvorjascij krest" - glossierende Synonymie.

$40)$ "chrestbjanskoju veroju verovašasja" - figura etymologica. 


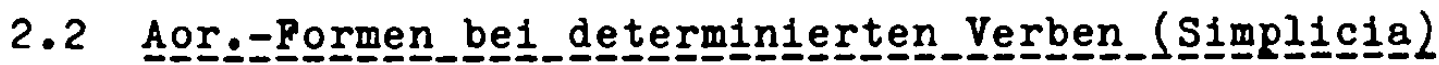 der. Bewegung}

Determinativa hatten auf Grund ihrer Zielgerichtetheit (und später auch Einmaligkeit) der ausgedrückten Bewegung eine gröBere Affinität zum Aorist als andere Durativa, da spricht man in der Vergangenheit - bei diesen Verben das Erreichen des 2 iels impliziert 1st. Diese Empfindung fürte maßgeblich dazu, daB Komposita der determinierten Verben der Bewegung den perf. Aspekt, die nichtdeterminierten Verben der Bewegung den imperf. Aspekt angenommen haben. Das Erscheinen determinierter Simplicia im Aorist hat also nichts Besonderes an sich. Daher ist es gerade verwunderlich, da $B$ wir in beiden Texten kaum entsprechende Belegstellen vorfinden. Wir müssen dies als Hinweis darauf werten, daß determinierte Simplicia Ende des 15 . Jh.s bereits stark dem imperf. Aspekt verpflichtet waren.

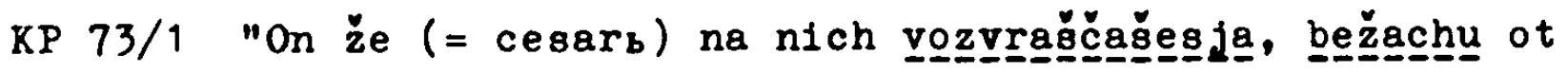

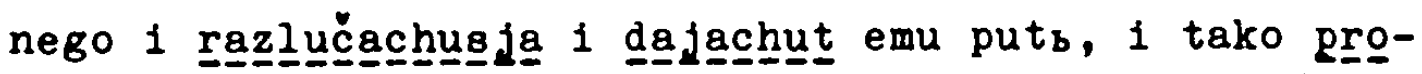

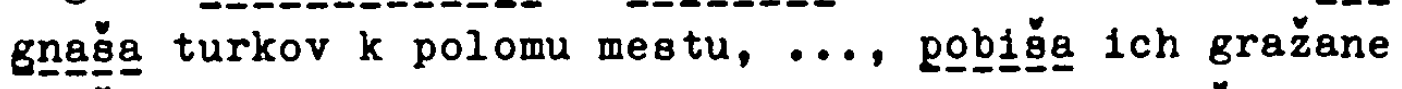
bezćisleno, zakaląachu bo ich aki svinej, dondeže projdogsa poloe mesto, a lže bežaša na storonu po ulicam

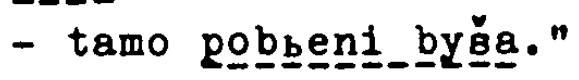

' Der Kaiser aber war ihnen zugewandt (= den Türken), sie aber flohen vor ihm und entfernten sich und gaben ihm den Weg frei; und so jagte man die Türken zur Mauerbresche - die Griechen töteten unzählige von ihnen (wie Schweine schlachteten sie jene ab), bevor sie durch die Bresche (ins Preie) geeilt waren; diejenigen aber, die zur seite in/durch die Straßen gelaufen waren, wurden dort getötet.'

In diesem Abschnitt stehen Ipf.- und Aor.-Formen in engstem Kontakt. Die Wahl der Tempora erweist sich als sehr sinnreich: Zunächst gibt der Autor die allgemeine Szene - der Kaiser, die Türken auf der Gegenseite - die Handlungen der beiden Gegenpole drückt der Autor der K-pler Erzählung durch das Ipf. aus. Dann werden die Griechen zum Handlungsträger - der Autor drückt - durch den Aor.- mit aus, daß die jeweiligen Tätig- 
ke1ten zu Ende (b1s zum Erfolg) durchgeführt worden sind. ${ }^{41}$ Dort also die aktuelle, nur tätigkeitsbezogene schilderung des Geschehens (Ipf.), hier Nennung der Handlungen mit Einbezlehung des Abschlusses bzw. Endeffekts - die Türken wurden zur Bresche gejagt, es wurden ihrer viele getötet. Einen bemerkenswerten Gegensatz bilden "zakalachu bo ich aki svinej" und "dondeže projdoša poloe mesto". Durch das Ipf. lenkt der Autor die Aufmerksamke1t des Lesers ganz auf das Geschehen - er unterstreicht seine Absicht noch durch einen drastischen Vergleich: 'schlachteten sie ab wie Schweine'. Der folgende Aor. benennt dagegen nicht nur die Tätigke1t der Türken, sondern zugleich den Endpunkt dieser Bewegung: 'bis sie durch die Bresche (Ins Frele) geeilt waren', gleichzeltig lst damit indirekt auch das Ende des 'Abschlachtens' bezeichnet. Anders als "zakalachu" ist "bežaša" richtungsbezogen, ersteres impliziert zudem noch die Wiederholung. Der Aor. "bežaša" 1st so zu interpretieren, daß die Türken, die gehofft hatten, durch Flucht ins Straßengewirr sich retten zu können, nicht auf der Stelle - während ihrer Plucht aufgegriffen und getötet wurden, sondern später erst, nachdem sich die Lage etwas beruhigt hatte, ihren Tod fanden. "bežachu" in der ersten Zelle des Zitats ist nur negativ erläutert - "ot nego" - 'von ihm weg'; "bežaša" dagegen folgt die klare Zielangabe "na storonu" - gemeint ist 'ins Stadtinnere'.

PS 77/27 "I tako litva ot goroda v stany pobeža. 2 goroda že vyskočivše chrestbjane daleče za nimi, sekušče ich, gnašasja: kotorych že vo pskovskom rvu zastavajušče 1 tech pribivajušče."

'So flohen also die It tauer in ihr Lager. Die Pleskauer aber verließen die Stadt, hieben auf sie ein und verfolgten sie: einige steliten sie bereits in lan den Stadtgräben - die töteten sie glelch.'

Der Erzählton dieser Eplsode 1st durch "pobeža" angeschlagen.

41) Vgl, van Schooneveld, A Semantic Analysis, S. 55: "..., the Imperfect may denote the general 'framing' situation, which has in such cases a longer duration than the events presented by the aorist." Hervorhebg. v. Schooneveld. 
Trotz der zielangabe ("litva $v$ stany pobeža") ist zu fragen, ob diese Aor.-Form berechtigt ist. Denn "v stany" stellt eine uberflüssige Information dar: In der Folge schildert der Autor nämlich Ereignisge, die sich auf dem Pluchtweg der Litauer zutragen. Die folgende fintte Verbalform "gnašasja" lehnt sich lautlich an "pobeža"; berechtigt ist sie im Grunde noch weniger als "pobeža", da diese Verbalform noch näher erläutert wird: "kotorych že ... zastavajušče i tech pribivajuščen - diessind ja Vorgänge, die im Verlauf der aoristisch ausgedruckten Handlungen geschehen. Resultativ-referierende Erzählweise, die hier zweifellos vorliegt, erklärt die Formen nur unvollkommen, denn dieser Erzählhaltung entsprechen nicht die Part.praes.-Pormen. - Die Tatsache, dab "gnati" eine zielgerichtete Bewegung ausdrickt, mag die Entscheldung des Autors (oder eines Kopisten ${ }^{42}$ ) für den Aor. erleichtert haben. - Offen blelbt, welchen Sinn hier die reflexive Form "gnasasja" ergeben soll.

Das stets als Belspiel für ein determiniertes Verb der Bewe-

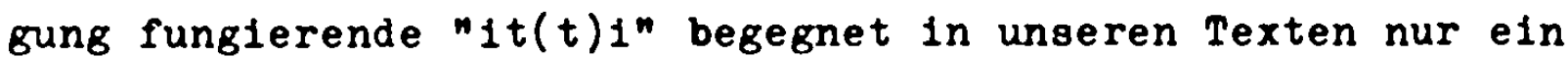
einziges Mal im Aorlst: im Pleskauer Text. Fährend der K-pler Autor stets in die Präfiglerung ausweicht, wenn er eine Aor.-Form von "1t $(t) 1^{n}$ bilden könnte, verwendet der Pleskauer Autor auber dem folgenden Aor.-Beleg zwel Mal die SuppletivPorm "idjaše" statt zu erwartendem "idošn".

PS 74/24 "Egda že, jako rekoch, 1doša k prolomnomu mestu 1 svjatyja 1kony, togo že času, .... vesnicy na konech pribežavše, ${ }^{43}$ ne volnskie, reku, l judi, no voint christovy ..."

'Als auch Ikonen zur Bresche zogen (= als gie mit Ikonen ... zogen), da kamen auch Boten zu Pferde herbe1 -

42) Variante, S. 152: "gnasesja" - dag wüde bedeuten: "gnachusja". - Vergleichsmaterial zu "gnati/sja" bieten unsere Texte nicht; "goniti" begegnet zwei Mal im Praes;: PS 50/8 "lev gonit verbijuda", PS $92 / 15$ "vetra gonisi".

43) Part.praet. "pribeźavǵe" ersetzt hier offenbar Aorist. 
aber keine Kriegsleute, sondern - 1ch sage euch Streiter Chrieti ...'

Ähnlich wie obiges "gnašasja" 1st "1doša" lediglich aus e1ner resultativen Erzählhaltung heraus verständlich. Die Prozession lst anscheinend noch auf dem Wege zur Bresche, als jene Streiter Christ1 herbelkommen. "Egda" wäre also in diesem Fall präzise mit 'während' zu ubersetzen, und statt "1doša" würde man "1djachu" erwarten. ${ }^{44}$ Pür die Interpretation 'Als sie zur Bresche gekommen waren, stieBen streiter Christi zu ihnen' muBten wir wohl lesen "... dostigoša" oder "... dojdoša", am besten noch einen Dat.abs.

Die ubrigen Textstellen mit "itti" im Präteritum geben uns keine sichere Interpretationshilfe an die Hand, da wir dort die Universalendung "1djaše" vorfinden $(65 / 23,-/ 26,66 / 4)$, als Glieder reimender Satzreihen. 45 Ähnlich wie be1 "gnaøaoja" Im Beispiel oben durfte also "1došn" weniger syntaktisch bedingt sein, sondern diesen Aorist seiner Determiniertheit verdanken.

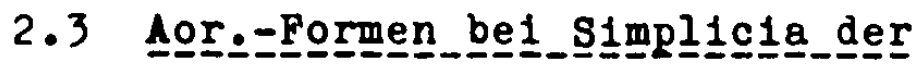 4._Leskín}

Ein Blick auf Tabelle 2 (vorletzte Spalte) zeigt, daB beide Texte viel mehr Aor.-Belege von durativen Simplicia der 4. Leskien'schen Verbalklasse aufzuweisen haben als von den anderen Verbalklassen zusammen. 46 wir unterscheiden hier die nicht produktive Gruppe der Verben auf -ěti/ati mit vorwiegend Zustandsbedeutung (Leskien: Klasse IV $B$ ) und die groBe Gruppe der sog. 1t1-Verben (Leskien: Klasse IV A): me1st Denominativa, aber auch viele alte Kausativa. Besonders auffal-

44) "egda" verlangt nicht zwingend den Aor. - etwa die Hälfte aller "egda"-Sätze führt den Aor., die andere Hälfte das Ipf. (PS 88/22, 85/7 u.a.), Prae8. (PS 71/25, 93/15-17), mit Part.praes. (PS 91/4) - 'wenn; während ; mit Part. praet. (PS 75/14,90/10 u.a.) - 'al B/nachdem'.

45) vgl. Ausfuhrungen uber - (j)ase beim Plural - S. 341 - 51.

46) AuBer Betracht bleiben bei dieser Peststellung die formelhaften Aor.-Formen wie "recen, "rekoch", "glagola" usw. 
lend ist die Homogenität der Gruppe der 1ti-Verben im morphologischen Bereich. Ebenso einheitlich werden ihre Ableitungen gebildet - durch das Suffix -'a-. Pruh schon muß diese Gruppe von Verben gleicher Struktur semantisch in zwei Abteilungen zerfallen sein - Verben, die eine Handlung, einen Vorgang einfach so benannten ("ljubiti", "myslitin, "měritin, "točiti" usw.) und Verben, die mehr und mehr speziell den einmaligen Vollzug der durch sie ausgedruckten Handlung bezelchneten und sich zur allgemeineren Benennung der Handlung, des Vorgangs, der Tätigkeit usw. der suffiglerten Ableitung bedienten, die unter den Komposita sicher bereits verbreitet war - einige bekannte Beispiele "javiti - javljati", "mbstiti - mbščtin", auch viele Kausativa wie "svjatiti - svjaščatin", "svoboditi - svoboždati" usw. Obgleich z.B. Ruzicka nachweisen kann, daß diese iti-Verben mit suffigierten Ableitungen z.2. der Entstehung der Nestorchronik keineswegs eindeutig auf den perf. Aspekt festgelegt werden können, 47 ist es 10gisch (und die heutigen aspektuellen Verhältnisse bezeugen es), dab sie zu Perfektiva wurden. Zwischen der Abfassung der PVL (Nestorchronik) und unserer Pleskauer Erzählung liegen uber vier Jh., innerhalb welcher die aspektuelle Entwicklung weitergegangen ist, innerhalb welcher Tendenzen sich gefestigt haben. Die hohe Anzahl von Aor.-Belegen durativer Simplicia im Rahmen der 4. Leskien'schen Klasse zeugt von weitgehender Perfektivierung. Umgekehrt hatten wir aber auch schon Gelegenheit, 1t1-Verben kennenzulernen, die sich konstant der Aor.-Bildung entzogen, und die sogar innerhalb reimender Satzreihen die Suppletiv-Form $-(j)$ aše zeigten (z.B. "tvorit1"). Andererseits ist aber auch festzustellen, dab manche imperf. Verben im Aor. erscheinen - einfach aus Grínden der Analogie. Allerdings wird man diesen Verben - s.u. vermutlich die eindeutige aspektuelle Zuordnung absprechen müssen - zumindesten im Sprachgefuhl der jeweiligen Autoren.

47) Ruzicka, Verbalaspekt, S. $24-40$. 
2.3.1 K-pel: Simplicia der

4. Leskien'schen Klasse

Beide Texte zeigen in bezug auf diese Klasse ein recht ähnliches Bild bei teilweise gleichem Wortmaterial. Eine Ausnahme bildet die Abteilung IV $B$ bei Leskien, jene Verben mit Präsens-Stamm auf -1 - und Infinitiv-Stamm auf - è-/-a-. Während uns in der Pleskauer Erzählung nur vier - mögliche Aor.-Belege von "slyšati" ("slyšach/om, -aste") begegnen, finden wir in der $\mathrm{K}$-pler Erzählung 14 Aor.-Formen, vorwiegend von "vidětı", "slyšati" und vereinzelt von "veléti" und "spati". 48 "viděti" und "slyšati" haben nach Dostál starke Affinität zum perf. Aspekt, wohingegen er "veléti" eindeutig dem imperf. Aspekt zuweist. 49 Im Falle von "velěti" mag diese Einschätzung auf Grund der wenigen Belegstellen im aksl. Textmaterial zustandegekommen sein (nur Praes.-, Part. Praes.- und Verbal-Substantiv-Belegel In der altruss. IIteratur hat "veléti" eine hohe Frequenz und gilt als aspektuell neutral oder sogar perfektiv. 50 Die im folgenden vorzustellenden Aor.-Belege der genannten Verben sind die einzigen finiten Präteritalformen in der K-pler Erzählung, also Ipf. und 1-Part. dieser Verben treten nicht auf. Die Praes.-Formen haben Gegenwartsbedeutung. 51

64/11 "...; 1 jako vzýdọsa pak1 gražane na stenu 1 vidě̌a vo rve množestvo turok, abie zažigachu bočky s smoloju

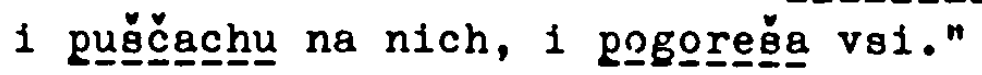

'...; und als die Griechen wieder die Mauer bestiegen hatten und die grobe Zahl der Türken im Graben sahen/ gesehen hatten, da entzundeten sie gleich die Teerfässer und lieben sie zu ihnen herabrollen; und es verbrannten alle.'

48) "spati" gehört an sich nicht hierher, da sein -a- im Infinitiv-Stamm nicht lautgesetzlich aus -è- hervorgegangen ist - vgl. Blelfeldt, Altslav. Grammatik, S. 202, § 258; Leskien, Handbuch, S. $164, \S 138$.

49) Dostál, Studie - "viděti" = S. 138; "slyšati" = S. 136; "veleti" = S. 238; "spati" = S. 237.

50) vgl. z.B. Nikiforov, Glagol, S. 76 .

51) z.B.: 63/18 "Vidim, cesarju, jako sej bezvernyj ne osla- 
"vzydoša" und "videša" sind gleichgeordnet und stehen im Verhältnis der Vorzeitigkeit zur Haupthandlung. Jenes Sehen, jener Anblick ist der AnlaB fur die folgenden Handlungen/Geschehnisse. Wir finden in der $\mathrm{K}$-pler Erzählung noch einige vergleichbare Sätze, die nach dem Schema aufgebaut sind:

'Als/nachdem er dies gesehen hatte, tat er dies (geschah jenes). .52

$56 / 1$ "..., 1 prišd $v$ Vizandiju, vide na tom meste semb gor 1 glušic morskich mnogo. I povele gory ryti ..."

'...., und als er nach Byzanz gekommen war, erblickte er sieben Hügel an dieser Stelle und viele Buchten. Und er befahl, die Hügel abzutragen ...'

$56 / 34$ "V sedbmoe leto vide cesarb malo živuščich $v$ grade, zane velik bo be zelo, i tako sotvorí, ..."

' Im slebten Jahr sah/erkannte der Kaiser, daB nur wenige ( $=z u$ wenige) Menschen in K-pel lebten - denn die Stadt war sehr groB, und daher tat er folgendes: ...'

66/6 "Na utrija že, jako videša turky stenu nezadelanu,

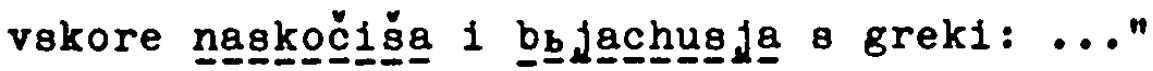

'Am Morgen aber, als die Turken sahen/erkannten, daB die Mauer noch nicht wieder instandgesetzt war, sturzten sie herbei und kämpften mit den Griechen: ...'

$72 / 7$ "..., no dnju sže uspevšu, egda videša turky baštu delajuščich, vskore pustî́s na nich izo mnogych pušek 1 ne desša im delati; ..."

-Als die Türken am Morgen entdeckten, daB die Griechen den Turm wieder aufbauten, beschossen sie diese aus vielen Geschutzen und hinderten sie daran; ...'

73/33 "Magumet že okajannyj, jako vide tbmu veliju nad gradom, gozve knižniki 1 moln 1 roprogsi ich: ' ...'n

-Als Mehmed, der Verruchte, die große Pinsternis uber der Stadt erblickte, rief er seine Weisen und Mullahs herbel und fragte sie: '...'"

beet delom, no ..."; $67 / 27$ "Vidim ubo, jako gaurove ochrabrisasja na nas ...".

52) Ähnliche Beobachtungen wie unsere machte auch Ruzicka, Verbalaspekt, S. 42 - 45: "vidéti". - vgl, auch u., S. uber plusquamperfekt und vorvergangenheit. 
Heute wurde man diese Aoriste mit "uvidet'" - 'erblicken' Ubersetzen. Die Vorstellung, die ursprünglich zur Verwendung des Aorist in dieser speziellen Konstruktion gefuhrt hat, dürfte wohl weniger ein punktuelles 'Erblicken' gewesen sein als vielmehr die Ablösung des Sehens, Schauens durch eine andere Handlung: 2.B. Mehmed sieht die Dunkelhelt uber der Stadt - dieser Anblick führt zu einer Reaktion: er ruft die Weisen herbe1. Das Geschaute initilert eine Reaktion das Sehen endet mit dem Einsetzen der Reaktion. Der Aorist "vide/ša" kann diesen Sachverhalt, zu dem heute perf. "uvidet'n nötig wäre, noch ausdrucken - in der Pleskauer Erzählung lst dies nicht mehr möglich: dort behilft sich der Autor mit dem Part.praet: "videv že sie" u.a. - aber auch diese Wendung verwelst darauf, dab "viděti" - vielleicht gerade wegen seiner hohen Frequenz - noch besonders lange in einem voraspektuellen Zustand verharren konnte. Ähnlich wie bei "reče", "glagola" u.a. durften wir es bei "vide/ša" mit stark formelhaft geprägten Wendungen zu tun haben.

Aber auch einfaches 'Sehen', ebenfalls mit dem Unterton 'Erblicken' wird mit dem Aor. von "vidèti" ausgedruckt. Es lst schon auffallend, daB der K-pler Autor - im Gegensatz zum Pleskauer Autor - "viděti" nie im Ipf. verwendet.

67/41 "...; sobravšimže sja ljudem mnozem videša u velikija cerkvi Premudrosti božija u vercha iz vokon plamenju ognennu veliju 1zšedšu, okruživšu vsju šeju cerkovnuju na dolg čas, ..."

'...; und es versammelte sich dort eine riesige Menschenmenge; es war zu sehen, wie eine große Flamme ausder Hagia Sophia durch ein Fenster in der Kuppel entwich und dann noch lange Ze1t die spitze der Kirche umspielte, ...'

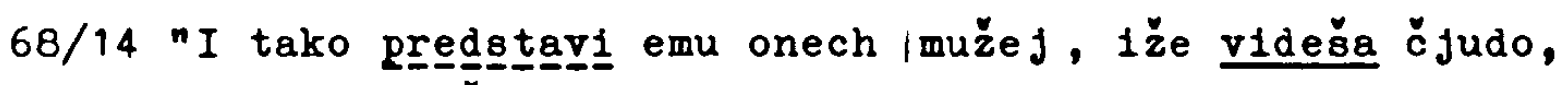

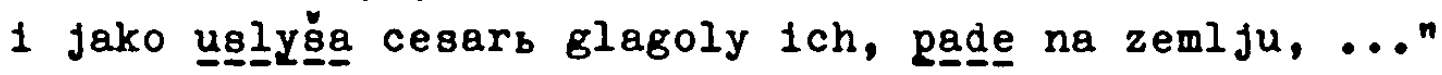
Und so atellte er (der Patriarch) inm (dem Kaiser) jene Männer vor, die das Wunderzelchen (= die aus der Hagia Sophia entweichende Flamme, d.h. den entweichenden Beiligen Geist) gesehen hatten; und als der Kaiser thren Bericht vernommen hatte, sank er zu Boden, ...' 


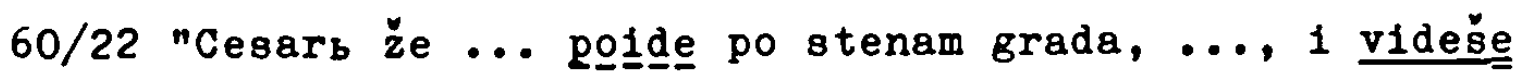
(sic) polny rvy trupija, a iny $v$ potocech 1 na brezech, i pometíg ša vaech ubbennych do 18 tys jać ..."

- Der Kaiser schritt die Mauern ab/inspizierte die Mauern, .... und sie sahen die Gräben voller Leichen, viele Gefallene in den Flüssen und an den Ufern; und sie schätzten ihre Zahl auf $18.000 \ldots$...'

Besonders die beiden ersten Belegstellen - 67/41 und 68/14 unterstreichen die eher zuständliche Bedeutung von 'Sehen'. Beide beziehen sich auf die lang anhaltende Erscheinung ("okruživšu vsju šeju cerkovnuju na dolg čas, ...") der entweichenden Plamme. In Beispiel 67/41 haben wir es mit einer knappen Schilderung zu tun, deren Komprimiertheit sich in den vielen partizipialen Konstruktionen äußert, "videša" trägt diesem referierenden Erzählton Rechnung, die Erscheinung wird als etwas Abgeschlossenes betrachtet. Das gleiche gilt fur 68/14, wo in einem Relativsatz auf die Flammenerscheinung Bezug genommen wird "iže videša čjudon - die Erscheinung als Gesamtes.

In der letzten Textstelle tritt die Nuance des Erblickens etwas deutlicher hervor, doch bleibt die Grundbedeutung des Sehens, Schauens wegen der dreigliedrigen Aufzählung - Leichen in den Gräben, in den Flüssen und an den Ufern - dominierend.

Wenn Ruzicka im Rahmen seiner Untersuchungen feststellt, daB sich "viděti" im Rahmen der PVI (Nestorchronik) als "dem Aspekt noch nicht unterworfen" 53 zeigt, dann können wir anknüpfend sagen, daß der Gebrauch von "viděti" in der K-pler Erzählung diesen Zustand ungebrochen reflektiert.

"slysati" ist semantisch und daher auch aktionsartlich sehr ähnlich zu bewerten wie "vidéti", und die Belegstellen auch dieses Verbs zeigen den gleichen voraspektuellen Zustand wie "vidéti". Allerdings sei daran erinnert, daB-während der Pleskauer Autor jede Aorist-Form von "vidëti" durch

53) Ruz1cka, Verbalaspekt, S. 44 . 
"vidjaše" ersetzt - er gelegentlich als Aorist interpretierbare Pormen von "slyšati" verwendet.

62/9 "I jako slyšaša ljudi zvon cerkvej božbich, abie

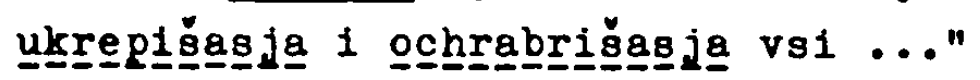

' Und als die Menschen den Klang der Glocken vernahmen, da wurden sie neu gestärkt und faßten frischen Mut ...'

Der Gebrauch von "slyšati" entspricht hier der hauptsächlichen Verwendung von "viděti" im Sinne von 'Vernehmen', das als AnlaB/Auslöser einer Reaktion fungiert. Vgl. Beleg $75 / 4 !^{54}$

$55 / 21$ "...; 1 sie umyšljajušče carju v dni 1 v nošči, slyša v sne glas: '...'"

'...; und wie der Kaiser dies alles (= der Platz der zu errichtenden Stadt) Tag und Nacht erwog, hörte er im Schlaf eine Stimme: ...'

Dieser Aorist ist ähnlich zu bewerten wie etwa "reče": in der Vorstellung des Autors ist das folgende 21 tat ein zusammenhängendes Ganzes.

$77 / 8$ "Ot inych že paki slyšashom, jako ostavšej ot suščich s cesarem u Zlatych vrat ukrradogosa ego toja nošči ..." 'Von anderen wieder habe ich gehört, dab die Uberlebenden der Kämpfe am Goldenen Tor, wo sie zusammen mit dem Kaiser gestanden hatten, den Körper (des gefallenen Kaisers) an sich gebracht ( = in Sicherheit gebracht) hätten ...'

"slyšachom" kann als Ipf. und als Aor. gedeutet werden; hier düften wir mit ersterem zu rechnen haben. Denn expressis verbis hat der Autor diese Version des Schicksal des kaiserlichen Leichnams von verschiedenen Leuten gehört - die Iterativität ist unausgesprochen der Grund für ein gewisses $M a B$ an Glaubwürdigkeit, das dies Gerücht für sich beanspruchen kann.

5.4) Hierher zu stellen ist auch 75/4 "Cesarb že, Jako slyša božle izvolenie, poide $v$ velikuju cerkovb $i$ pade na zemlju, ..." - Als dēr Kaiser ... vernommen hätte, ... sturzte er zu Boden, ...' 


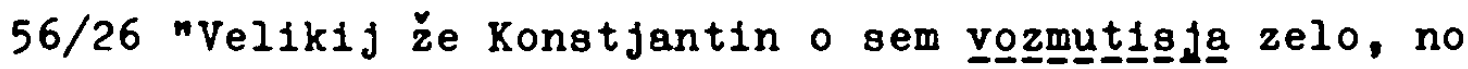
obače slovesa 1ch vele napisati, a magistry ... razdell na dvoe, ibo edinoj strane povele razmeriti gradskie steny 1 strelbnici 1 načati grad delati, a drugoj strane povele razmeriti ulicy 1 ploščadi na rimskij obyčaj; 1

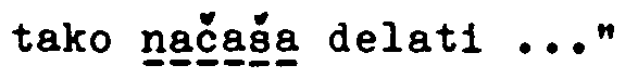

- Darüber (= Sieg der Schlange über den Adler) war der große Kalser Konstantin sehr beunruhigt; dennoch befahl er die Worte (= Deutung der Weisen) nlederzuschreiben. Und er ordnete an, daß de würdenträger der Stadt in zwe1 Gruppen aufgeteilt werden sollten - den einen befahl er, die Messungen zum Bau der Mauern und der Wehrtürme durchzuführen und den Bau der Wallanlagen zu beginnen, den anderen befahl er, Messungen für den Bau von Straßen und Plätzen nach römischer Art anzustellen; und so begannen sie, ... zu errichten.'

Der große Textabschnitt wurde vorgefuhrt, damit ein Vergleich von "vele" und "povele" möglich werde. Im Gebrauch der beiden Formen kann $1 \mathrm{ch}$ nicht den geringsten Unterschied feststellen. Leider lst dies die einzige Textstelle, die "vele" enthält, so daB wir uns mit der Feststellung begnügen müssen, daB "vele" und "povele" hier absolut bedeutungsgleich sind. Es handelt sich hier offenbar um einen Reflex der aspektuellen Neutralität von "velèti", die Nikiforov diesem Verb bescheinigt; im 16. Jh., für das die Aussage Nikiforovs gilt, ${ }^{55}$ finden wir - was die Pleskauer Erzählung anbelangt - keinen Reflex dieses voraspektuellen Zustandes mehr vor: weder rommt dort ein Aor. "vele" noch ein Part.praet. "velev" vor.

73/15 "Magumet że, videv tolikoe padenie svoich 1 slyšav cesarevu chrabrostb, toja noči ne spa, no sovet velif sotvori: ..."

'Mehmed konnte, da er an die vielen Gefallenen und an die Tapferkeit des Kaisers dachte, in dieser Nacht nicht schlafen, sondern er faßte einen wichtigen EntschluB: ...'

Die wichtigste Aussage dieses Satzes ist die, daß der Sultan elnen wichtigen EntschluB gefaßt hatte - nämlich die Belagerung $\mathrm{K}$-pels aufzugeben und abzuziehen. DaB er in jener Nacht

55) N1kiforov, Glagol, S. $176-78$. 
nicht schlafen konnte, dient der Illustration und der Dramatisierung - als Information ist die Schlaflosigkeit des Sultans zweitrangig. Der Autor erwähnt diese nur nebenbei der Aorist umfaBt den gesamten Zeitraum der Schlaflosigkeit "toja noči ne spa" in raffender witteilung.

Die im folgenden zu behandelnde Gruppe der iti-Verben mit Aor.-Belegen hat neben verschiedenem anderen vor allem dies gemein: Dostál bezeichnet die von uns aufgefundenen Verben bereits auf Grund des aksl. Textmaterials als perfektiv; ${ }^{56}$ das gleiche gilt auch für heute: 57 "udariti", "strěliti", "pustiti", "skočiti", "javiti".

Wenn wir davon sprachen, daß die aspektuelle Scheidung der iti-Verben davon abhing, ob der Gebrauch eines Verbs auf die Einmaligkeit der ausgedruckten Handlung eingeengt wurde (und zur Bezeichnung der Handlung allgemein oder ihrer Wiederholung die mit Hilfe des Suffix -'a-gebildete Ableitung Verbreitung fand) oder aber ob ein iti-Verb seinen umfassenden, auch Wiederholbarkeit einbeziehenden Sinn behielt, dann bietet das vorzulegende Material aus unseren Texten die besten Belege hierfür.

In der Pleskauer Erzählung, so hatten wir beobachtet, hat der Aorist von "biti" die Bedeutung 'ganz gezielt (mit einem Geschütz - "narjad") schießen'; sonst heibt es 'schlagen' bzw. "bitisja" - 'sich schlagen, kämpfen'. "biti" erscheint in der K-pler Erzählung nur einmal im Sinne von 'schieBen', jedoch im Imperfekt. ${ }^{58}$ In der Bedeutung 'abschießen einer Kanone oder Feldschlange' begegnet uns in der K-pler Erzählung in erster linie "pustiti".

56) Dostál, Studie - "udariti" = S. 408, "strěliti" = S. 498, "skociti" = S. 88 , "javiti" = S. 80 , "pustiti" = S. 86 .

57) Daum-Schenk, Die russischen Verben - "udarit'n = S. 647, "strelit"" =S. 624, "pustit'" = S. 525, "javit'" = S. 690; "skociti" ist als Simplex auBer Gebrauch gekommen - vgl. "skaknut" - skakat".

58) s.u. S. 409, zu "udariti" Beleg 65/13. 
$63 / 41$ "... pakı bezbožnyj povele prikatıt1 onu pušku

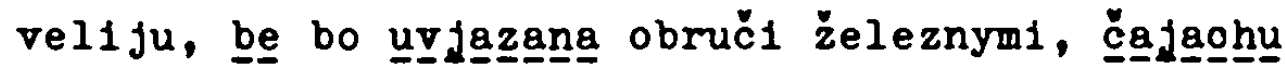
ukrep1t1 ju; 1 jako pustiǧa ju vpervie, abie razgaㅡdeoㅣㅡ na mnogyja časti.n

'.... und wieder befahl der Gottlose, jene grobe Kanone herbelzuziehen; diese war mit elsernen Reifen umfaBt, von denen man hoffte, sie würden (den Lauf) verstärken. Als sie aber zum ersten Mal abgeschosien wurde, zersprang/explodierte sie gleich in viele Stucke.'

$66 / 10^{\prime}$.... grek1 že razbegoša 1 pustiša na nich pušky 1 pob-íg

'...., die Griechen liefen (plötzlich) auseinander und schossen die Kanonen auf die Turken ab und töteten ihrer viele. 59

Auoh hier ist sicher die Vorstellung vom langwierigen Laden, dem sorgfältigen zlelen und dem AbschuB in den Gebrauch des Aorist eingegangen. 60 Umgekehrt wird - wie auch in der Pieskauer Erzählung - das AbschieBen der Pfelle imperfektisch gefaßt: das möglichst achnelle AbschleBen der Pfeile, also die Vielzahl beherrscht die Vorstellung, nicht das zielen vgl.: 67/11 "strely bezčisleny pušçachu na $n_{b} n$, vgl. auch jene uns bereits bekannte Textstelle: 64/11 "abje zažigachu bočky s smoloju i puščachu na nichn (s.0., s. 401 ).

EInmal gebraucht der Redaktor oder.Autor der K-pler Erzählung "pustiti" mit Aorist in Ubertragener Bedeutung - vielleicht soll es das AbschieBen von Kanonen assozileren: der Klang der muslimischen Instrumente wird dem christilchen Glockenklang entgegengeschleudert:

59/44 "Turk1 ż pak1, uslyšavóe zvon vel1f, pust1̇̌a surnyja 1 trubnyja glasy 1 tumban tbmočislennych, ..." 'Als die Tüken aber den Klang (der Glocken) vernahmen, schleuderten sie diesem den Schall ihrer Schalmelen, threr Hörner und tausender Pauken entgegen,....'

59) Elnen dritten Beleg "pustísa na nich 120 mnogych pušek" finden wir oben S. 402 , Beleg 72/7.

60) Vgl. hierzu: $71 / 29$ "Ot devjatoe godiny togo dni pakf bezvernyj povele bit1 grad.... 120 mnogych pusek 1 piscalej, 1, navadive pusku bolbs̆uju, udarisa v bastu, tako v drugie 1 v tretbi, 1 razbisa bastu, 1 tako projde toj denb; ..." - nach Runciman, Die Eroberung $\overline{X-p e 18, ~ S . ~ 101, ~ k o n n-~}$ te die groBe Kanone nur $7 \mathrm{Mal}$ am Tage abgefeuert merden. 
Wie "pustiti" hat auch "udariti" die Bedeutung 'ganz gezielt ein groBes Geschütz abfeuern'. Ein Beispiel hierfür bot bereits Anm. 60 auf der vorigen Seite: "navadivše pušǩk

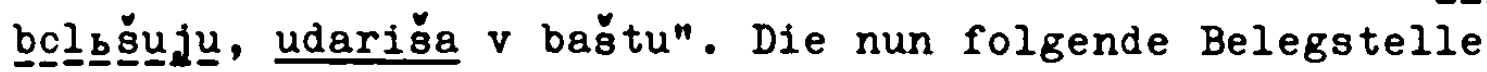
verdeutlicht, wie der K-pler Autor differenziert: "udaritin61 bleibt dem AbschuB der großen Kanone vorbehalten, während das Schießen mit kleineren Geschützen mit "bbjachut" und "streljati" bezeichnet wird.

65/13 "Ubo v 6-j denb maija mesjaca paki bezvernomu povelevšu biti grada $v$ to že mesto, ideže $i$ pervee,

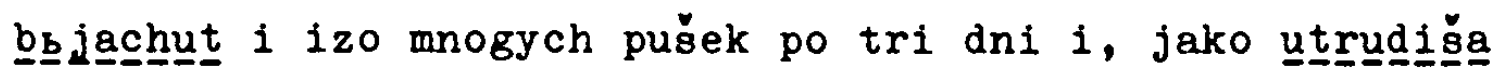
stenu, i udariša iz bolbšie pušky, i spąde kamenie mnogo. V drugie udariša, i raspades ja steny velikoe mesto, no uže večeru nastavšu, turky načăgaga streljati izo mnogych pušek $v$ to že mesto, ..."

'Am 6. hai befahl der Ungläubige, die gleiche Stelle der Stadtmauer zu beschießen wie zuvor. Und sie beschossen diese Stelle drei Tage lang mit vielen Geschuitzen. Als sie aber die Mauer beschädigt hatten, gaben sie aus der großen Kanone einen SchuB ab, und viel Gestein stürzte herab. Sie schossen noch einmal - diesmal stürzte ein großes Stuick der Stadtmauer ein. Gegen Abend begannen sie, diese Stelle aus vielen Geschiltzen zu beschießen,...'

SchlieBlich treffen wir auch einmal auf "strĕliti" in ebendieser Bedeutung 'ganz gezielt ein großes Geschütz abfeuern':

$61 / 31$ "Na utrija že paky nąčąge biti to že mesto iz mnogych

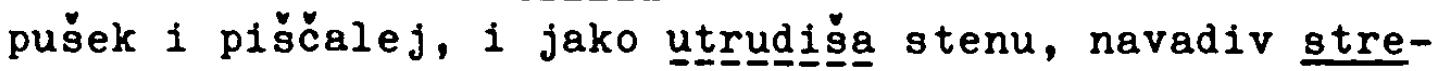
liša iz bolbšie pušky, ..."

'Morgens begannen sie abermals, diese Stelle aus vielen Geschuitzen und Feldschlangen zu beschießen. Und als die Mauer beschädigt war, zogen sie die groBe Kanone heran und schossen damit, ...'

61) An sich 1st "udariti" kein Simplex, doch dürften die Ablautverhältnisse die Abkunft von "udariti" verschleiert haben: "dira" - 'RiB', "dbrati, derg" - 'schinden, reiBen' - s. Sadnik-Aitzetmüller, HWB, S. 226.

62) $\mathrm{Vgl}$. weiter $65 / 20$ "Na utrija źe paky turki udariša iz

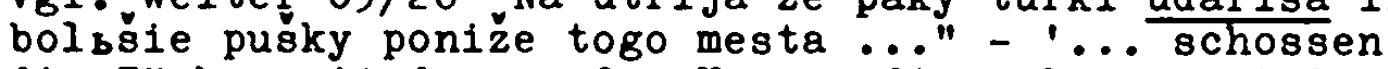
die Türken mit der groben Kanone diesmal etwas tiefer...'. 
AufschluBreich ist dagegen die Stelle 59/30, die "strèljati" bedeutungsmäßig klärt:

$59 / 30$ "..., načaša biti grad, takože streljati 1 iz ručnych 1 iz lukov tsmoćislennych; ..., a inil streljachu iz pušek $i$ iz piščalej, eliko možachu, ..." '..., und die BeschieBung der stadt begann, und sie schossen mit ihren Flinten und unzähligen Bogen, ... andere feuerten mit Geschützen und Feldschlangen, so viel sie nur konnten, ...'

"skočiti" im folgenden Textabschnitt wird beinahe $z u$ einem Synonym zu "napasti": 'einen Sprung tun' - 'auf etwas (herab-) fallen; sich stürzen auf'. Das charakterisiert mehr und deutlicher als lange Kommentare die Bedeutungsverengung, die altes iteratives 'springen' erfahren hat:

$72 / 17$ "(tri brateniki) ... skaçiša so steny, naaadośa na nich (= turkov) i seçachus ja $s$ nimi l jute, ..." 63 - (drei Blutsbrüder) ... sprangen von der Mauer herab, stürzten sich auf die Türken und hieben schrecklich auf sie ein, ...'

Vgl. hierzu

70/20 "...; cesarb že $i$ velbmoži s nimi skakachu po-_rgemu gra믐..."

'.... sprangen/eilten in der ganzen stadt umher, ...'

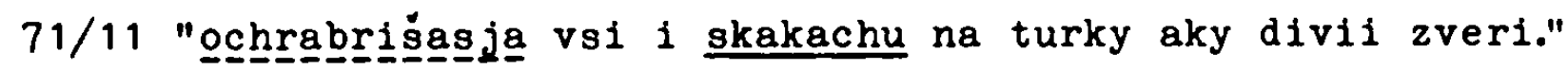
'faBten sie neuen Mut und sprangen den Türken wie wilde Tiere entgegen.'

Während in Beleg 70/20 das Ziellose des Umherspringens/Umhereilens Ursache für das Ipf. ist, dürfte in Beispiel 71/11 nicht nur das sich andauernd vollziehende Anspringen des Gegners für das Ipf. verantwortlich sein, sondern auch der Vergleich, der das Augenmerk des Lesers auf das Geschehen selbst, die Handlung an sich lenkt. ${ }^{64}$

63) "skäčiša" = A-kanje.

64) $V_{g l}$. S. 396, Beleg KP $73 / 1$ "pobiša ich gražane bezčisleno, zakalachu bo ich aki svinej". 
56/13 "...; orel że vozletev iz očbju na dolg čas, 1 paki javisja nizletajušč 1 pạde $s$ zmiem na tož mesto, ..." '...; der Adler aber erhob sich und verschwand für längere Zeit aus dem Blick; dann erschien er wieder - tief fliegend - und stürzte plötzlich zusammen mit der Schlange an derselben Stelle nieder, ...'

"javiti/sja" hat sich vielleicht am allerweitesten vom alten Durativum entfernt - bereits in den ältesten Texten begegnet es in dieser beinahe punktuellen Bedeutung.

Lassen wir einmal Lehnübersetzungen vom Typus "blagosloviti" beiseite, so können wir iber die Simplicia der 4. Leskien' schen Verbalklasse und ihre Aor.-Formen in der K-pler Erzählung folgendes festhalten:

1. Eine ganze Anzahl von Aor.-Belegen der Verben mit i-Stamm Im Präsens und $\check{e}-$ bzw. a-Stamm im Infinitiv belegt, dab diese Verben, die meist einen Zustand bezeichnen, noch einen voraspektuellen Zustand reflektieren - die Bildung perf. Aspektpartner bildet bei diesen Verben noch heute Schwierigkeiten.

2. Aor.-Formen von iti-Verben begegnen ausschlieblich bei solchen Verben, die auch heute perf. sind und die bereits Dostál an Hand des aksl. Textmaterials als perf. bezeichnet hat. An ihrer aspektuellen Ausrichtung in der $K-p l e r$ Erzählung dürfte kein $Z$ weifel bestehen.

2.3.2 Pleskau: Simplicia der 4. Leskien'schen Klasse

In der K-pler Erzählung fanden wir 14 Aor.-Belege von Verben der Klasse IV B nach Leskien, Formen von "vidéti" und "slysati" machten davon den Hauptanteil aus. In der Pleskauer Erzählung 1st diese Gruppe so gut wie gar nicht mit Aor.-Belegen vertreten. "viděti" und "velěti" kommen nur mit Ipf.Formen vor, wobei diese, wie wir feststellen konnten, häufig die 3.pl.aor. vertritt. Meist finden wir auBerdem zu erwartende Aor.-Formen durch einen prëfigierten Aor. ersetzt ("povelen) oder durch ein Part.praet. vertreten ("slyšav"). 
Lediglich von "slys̆ati" finden wir einige Aor.-Belege, die aber z.T. nicht eindeutig sind ("slysach/om" - Aor. oder Ipf.).

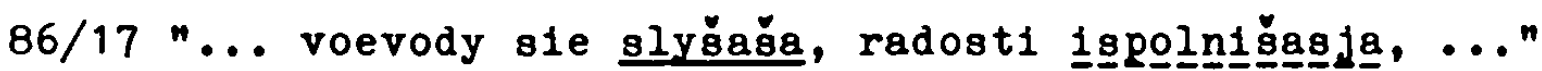
.... die Voevoden hörten dies und wurden von Preude erfüllt, ...'

Sinngemäß entgpricht dieser Satz einer Konstruktionsweise, wie wir sie in der Pleskauer Erzählung 32 Mal beobachten: z.B. "gosudarevy bojare 1 voevody sie že slys̆av, ..." oder noch deutlicher etwa 70/20 "jako že sie slys̆av, ..." Da oblger Beleg $86 / 17$ offensichtlich diese Haupttypen varifert, können wir also auch Ubersetzen:

'Als die .... Voevoden dies gehört/vernommen hatten, ten, wurden sie von Freude erfullt, ...'

43/18 "'Toj bo, reče, slys̆ach, Pskov grad prevelik zelo v zemli vašej, ..."

- Diese stadt Pleskau ist, wie ich gehört habe, eine große Stadt in eurem Lande, ....'

Diese Worte sagt der polnische König zu den Gesandten des Zaren. Hinter "slyšach" steht nicht etwas elnmal Gehörtes, "slysach" ist hier vielmehr zu interpretieren als 'es geht die Kunde', 'man hört' = 'es ist bekannt'. Glaubwürdigkeit erlangt diese Aussage fur den polnischen König dadurch, daB sie von vielen wiederholt, d.h. bestätigt wird. Daher sollten wir "slysach" in diesem Kontext als Ipf., nicht als Aor. ansehen.

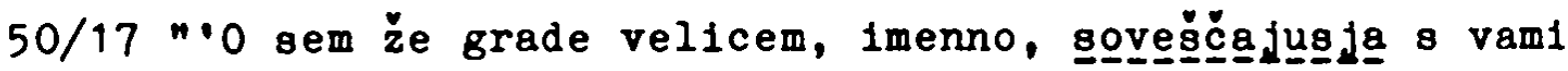
1 povedâjú vam, jakože o nem slyšachom. Pervie, zelo prevelika ego skazyvachu, ...m

- Namentlich wegen dieser großen stadt beratgchlage ich mit euch und will euch mitteilen, was ich alles uber sie gehört habe. Zuerst einmal, so hört man, ist sie ungeheuer groB, ...."

Wir haben es hier mit dem gleichen Sachverhalt zu tun wie in Beispiel 43/18 - hier kommt er nur noch deutlicher zum Ausdruck, denn in diesem Beleg lst zu "slysachom" gleichsam synonym "skazyvachu" gestellt. Nicht allein das Ipf. verweist auf die Hăufigkeit des Erzählens - und damit auch des Hörens - 
dieser Information, sondern auch das Verb selbst: Das-yvaSuffix breitet sich gerade im 16. Jh. zur Imperfektiv-Bildung aus. 65

49/24 "'Da vestẹ $i$ eže izvestno slyšaste, eliko v mimošedúee dva leta ruskomu carju pakosti sotvorich

"Ihr wiBt ja und habt sicher vieles (davon) gehört, wieviel Ungemach/Schaden ich dem russischen Zaren während der vergangenen zwei Jahre zugefügt habe ..."'

Formal gesehen haben wir in "slyšate" eindeutig einen Aorist vor uns. Vom Kontext her handelt es sich aber um die gleiche Art von Hören wie in den beiden vorherigen Textstellen: um ein vielfaches Hören. Während aber in den beiden vorigen Beispielen die 1.sg.ipf. und die 1.sg.aor. sich formal gleichen, bedeutet unsere Interpretation hier gleichzeitig, daB wir eine falsche Form vor uns haben, denn die Iterativität/Wiederholung des Hörens whirde ein Ipf. erfordern, und das lautet für die 2.pl. "slyšašete". Für die Wahl des Aor. an dieser Stelle sprechen $z$ wei Gründe: 1.) Während die 1.ps.sg. und die 1.ps.pl. sowie die 3.ps.sg. und die 3.ps.pl. von Ipf. und. Aor. auch im jüngeren altruss. Schrifttum noch einigermaßen sicher waren (sehen wir einmal ab von der Durchdringung der 1.sg. mit der 1.pl. "slyšach/-om"), herrschte gerade bezüglich der 2.ps. große Unsicherheit. Dies zeigt sich besonders im Hinblick auf die 2.ps.sg.ipf. als auch 2.ps.sg.aor., die ja bekanntlich, um sie von der 3.ps.sg.ipf./aor. abzugrenzen, gern durch die 2.sg.perf. ("slyšal esi") ersetzt wurden. 66 Das gleiche trifft verstärkt für die 2.ps.pl. zu. Nur fällt die Unsicherheit dort nicht so auf, weil die 2.ps.pl. noch seltener in Gebrauch kommt als die 2.ps.sg. Neben der genannten Unsicherheit, die Formen der 2.ps.pl.aor./ipf. betreffend ist bel obigem "slyšaste" in Rechnung zu stellen, daß 2.) der Autor den rhetorisch besonders stark ausgeformten Abschnitt

65) Nikiforov, Glagol, S. 122 - 23; Borkovskij, Istor. grammat1ka, S. 291 f., Otten, Fin. verbalformen, S. $452-59$.

66) S. Słoński: Tak zwane perfektum w językach slowiańskich. In: Prace filologiczne 10 (1932). S. 10. Hierzu auch van Schoonefeld, A Semantic Analysis, S. 14. 
dieses königlichen Briefes an selne Wüdenträger durch ein ăhnlichklingendes Verbpar - "veste 1 slyšaste" - elnleiten wollte. 66

In Bezug auf die 1 ti-Verben 1st das Wortmaterial in unseren beiden Texten tellwelse recht ähnlich. Für 'ganz gezieltes Abfeuern eines Geschutzes' fanden wir in der K-pler Erzählung "pustiti", "strĕliti", "udariti". In diesem Sinne verwendete der Pleskauer Autor, wie wir bereits beobachten konnten "bit1" mit dem Aorist; aber auch "udarit1" gebraucht er 80:

60/29 ".... nošči že prispevši, času jako na tretbem, poveleša po nich udariti iz bolbšovo narjadu; ..." '... als es Nacht geworden war, etwa zur dritten Stunde, ordneten sie an, sie (= die Litauer) aus dem groben Geschutz zu beschieben; ...'

$72 / 22$ "S Pochvalbskogo roskatu, 1z velikie piśçali iz Barsa 67 udariša po svinuskoj bas̆ni 1 ne pogrešisga; ..."

'Sle schossen von der Pochval'skij-Bastel mit der groBen Feldschlange, Irbis genannt, hinuber zum SchweineTurm, und sie fehlten nicht; ....'

$85 / 15$ "Udarǐga velikim kameniem v čjudotvornyj obraz, ..." 'Mit großen Steinkugeln schossen sie auf die wundertätige Ikone (impliziert ist: sie trafen auch), ...'

Im letzten Beispiel handelt es sich um den Bericht über ein bestimmtes Ereignis: Die Iltauer pflegten, auf Menschenansammlungen in Pleskau mit Steinkugeln zu schieBen, auch auf Prozessionen - so heibt es $85 / 10$ "kamentem mnogim na to mesto vo grad metachu ...' - das 1st eine Gewohnhe1t der Litauer. Dann aber fährt der Autor $85 / 11$ fort: "Edinoju žen - 'Elnmal aber/Eines Tages aber' - in diesem Zusammenhang und in Verbindung mit "velikim kameniem" (im Gegensatz $z u$ "kamentem mogim") verwendet er "udarisa". 68

66) Im Praes. hat "slyšati" nur Gegenwartsbedeutung, $z . B$. $47 / 4$ "Po semu że razsmotritelbne bojarina svoego bogongdeznoe o otstojanil ot korolja grada Pskova slovo slysit."

67) "Barg" - 'Irb1s, Panther'. 2.2. Ivan Gr.s und später hatten Geschütze in RuBland so kämpferische Namen.

68) "udarjachu" dagegen bezeichnet 'häufiges Schlagen/Schlagen 
Besonders häufig erscheint im Pleskauer Text "javitisja" bis auf einen Infin. nur im Aor. Es war bereits davon die Rede, dab gerade dies Verb die Entwicklung eines Teils der iti-Verben vom Durativum uber die Einengung der Bedeutung auf den einmaifgen Vorgang hin zur Perfektivität demonstriert. Es genügt sicher, wenn wir exemplarisch einen Beleg für "javitisja" und den einzigen für "javiti" vorstellen.

38/8 "Božieju milostiju i prečistye bogorodicy moleniem 1 svjatych velikich čjudotvorcov, carb 1 gosudarb naš blagoverny j, knjazb velikij Ivan Vasilbević vsea Rusil, 69 ne tokmo otomstitelb vragom božilm javisja, no $i$ gosudarb vsej zemli toja dostojaniju pros 'Durch Gottes Gnade und ... erwies sich der Zar und unser Herrscher ... nicht nur als Rächer an den Feinden Gottes, sondern wurde auch als Herrscher jener Länder ( = Livland) gepriesen.'

$\mathrm{Zu}$ "javitisja" vgl. weiter 59/18, $74 / 18$, dazu $80 / 16=$ Infin.

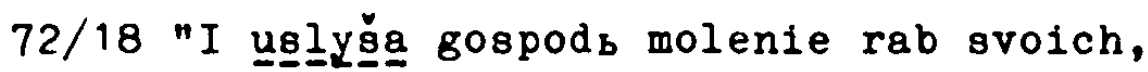
maniem neizrečennago svoego miloserdija načalo zbyt egda prízre na svoe dostojanie $i$ javi nad svoimi raby velikuju svoju milostb." 'Und es erhörte der Herr das Flehen seiner Knechte, und durch seine unermeBliche Güte bewegt begann er, seinen Herrscherwillen zu erfüllen. Als er sein Besitztum (= die Seinen) ansah, 70 erwies er den Knechten seine große Gnade.' 70

Neben "javiti/sja" können wir - bezüglich der Entwicklung zur Perfektivität - "roditi/sja" stellen; die Bedeutung wurde verengt auf den Moment der Geburt, während 'gebären/geboren werden' ganz allgemein durch "roždati/sja" ausgedrückt wird.

allgemein': 88/21 "I simi knuty, egda iz grada za gtenu protivu litovskich podsekatelej udarjachu, pugami ze temi 1 ... ( $1 \mathrm{ch}$ ) izvlaçachu" - "Und wenn sie über die Mauer hinweg auf die Litauer hinabschlugen, die .... dann zogen sie mit ihren Peitschen (diese) ... heraus'.

69) Hagiographisch-pleonastische Ausdrucksweise!

70) Zur Ubersetzung vgl. S. A. Zenkovsky (Hrsg.): Aus dem al ten RuBland. Epen, Chroniken und Geschichten. München 1968. S. 365. 
83/19 "Naipače,

onf bo ne znaja 111 po zavesti gospoda slave raspjąa nam že, znaja svoevo pravoslavnago gosudarja, carja, pod 1ch že carbskoju chrestbjanskoju vlastiju

1 praroditeli nas̆i rodišasja,

kako ostaviti?"

- Vor allem aber: jene haben entweder aus Unwissenheit oder MiBgunst den Herrn der Herrlichkeit gekreuzigt; wir aber, die wir unseren rechtgläubigen Herrscher, den Zaren kennen, unter dessen (eigentlich: unter deren $=$ der Herrscher) christlicher Zarenmacht auch unsere Vorfahren geboren wurden, wie können, wie sollen wir den verlassen?'

Ein weiterer Beleg findet sich $79 / 30$.

Neben den vorgestellten Aor.-Belegen, die sich mit solchen der K-pler Erzählung vergleichen lassen, kommen im Pleskauer Text auch Aor.-Formen vor, bei denen die Einmaligkeit der genannten Handlung - im Gegensatz zur Iterativität, zur allgemeinen Benennung - nicht so deutlich hervortritt wie in den vorigen Beispielen.

Aus dem Kontext erklärt sich der Unterschied zwischen "chvatat1" und chvatiti", der heute mehr oder weniegr deutlich aus der Aspektkorrelation "chvatati" - imperf.

$$
\text { "chvatiti" - perf. erhellt. }
$$

Sadnik-A1tzetmüller und Dostál führen nur das Simplex "chvatat1, -ajg" an und kennen nur Komposita mit "-chvatiti". 71 Sreznerskif belegt beide als Simplicia, doch mit Hss. des 14. und 15. Jh. $80^{72}$

$84 / 9$ "... mnogie jazyki litovskie vo grad chvatase

1 korolevskil 1 ego pervosovetnikov umyšlenie ... velikim iztjazaniem 1 pytkami dovedyvaréesja

1 tako protivu umyšlenej ich gotovjašcesja.

Paki že vo edin ot dni bjąge vylaska za ... vorota, 1 tamo chratisa 73 litorskie jazyki,

71) Sadnik-A1tzetmüller, HWB, S. 34 ; Dostál, Studie, S. 187.

72) Srezn. III, 1365.

73) Variante - S. 156: "1 tako uchvatiša litovskie jazyki". 


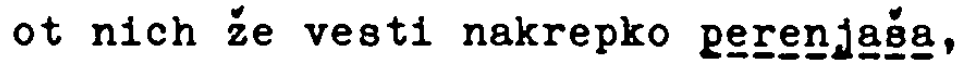

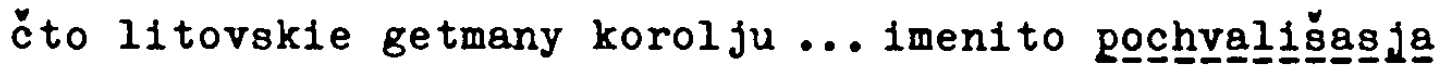
podkopami vzjati grad 1 kilždo ... svoj

podkop povedoğa: ..."

'... man brachte immer viele Gefangene in die Stadt und erfuhr (von innen) - mit Hilfe von Folter und Marter - die Pläne des Königs und der Ratgeber; so konnte man sich auf ihre Anschläge einstellen.

Eines Tages aber machte man wieder einen Ausfall aus dem ....-Tor und nahm dabei einige Iitauer gefangen, von denen sie die sichere Information erhielten, dab die litauischen Hetmane sich dem Konig gegenüber rühmten, Pleskau mit. Hilfe unterirdischer Gänge einzunehmen, (und sie erfuhren weiterhin), dab jeder Hetman seinen eigenen Gang baue: ...'

Die ersten drei Sätze bilden einen klanglichen Komplex "chvataše", "dovedyvašesja", "gotovjaščesja". -aše vertritt hier die 3.pl.ipf. "chvatachu" und "dovedyvachusja". Diese Ipf.-Formen (+ Part.praes.) schildern das Ubliche, Alltägliche; besonders augenfällig tritt das an der Verbform mit yva-Suffix zutage "dovedyvašesja". "Paki že vo edin ot dni" leitet den konkreten Fall ein, von dem der Autor sprechen will. Vom Ipf. wechselt der Autor zum Aor., "chvatiš" steht vollkommen gleichberechtigt neben "perenjaš", "pochvališa", "povedoša": "chvatiti" hat die Position des perf. Pendants zu "chvatati" bezogen.

83/25 "Jako ni vsego mira chošćem bogatestra protivu svoevo krestnago celovanbja, jaźe gosudarju svoemu verišasja." 'Tir aber wollen nicht allen Reichtum dieser Welt als Gegenleistung dafür, dab wir den Eid brechen, den wir unserem Herrscher geleistet haben.'

Um "věritisja" zu deuten, wollen wir einen bereits einmal angeführten Satz heranziehen:

$44 / 18$ "... voevody obeščavšesja svoemu vladyce tvoriti po ego nakazanbju, na tom že 1 chrestbjanskoju veroju verovašsja emu."

'...., darauf leisteten sie ihm den Treueid.'

"verit1/sja" und "verovat"" sind heute beide imperf. ${ }^{74}$ Auch

74) Daum-Schenk, Die russischen Verben, S. $28 \mathrm{f}$. 
der einzige für uns brauchbare Beleg bel Sreznevskif "věrja" deutet eher auf Imperfektivität. ${ }^{75}$ Dostál und Sadnik-A1tzetmuller verzelchnen kein simplex "věriti".

In unseren Belspielsätzen sind "věritisja" und "věrovatisja" synonym gebraucht 'schwören, E1d leisten'. Jedoch lst die S1tuation, in der uns die Verben jeweils entgegentreten, verschieden. "verišasja" wird innerhalb elner Rede gebraucht, in der kurz uber diesen Treue1d gesprochen wird: 'der Treueid, den wir ihm seinerzelt geschworen haben'. "verovašas ja" aber beschreibt den Vorgang selbst - der Autor beschreibt diese Szene. "věrit1sja" wäre demnach - sofern wir uberhaupt das Recht haben, auf Grund so schwacher Belege elne Annahme zu äuBern - zur Bezelchnung des abstrakten Sachverhalts verwendet, wohlngegen "věrovat1s ja" die konkrete Handlung, die äuBeren Vorgänge anläBlich des Schwurs beschrelbt. Hier, für "verišaja" gilt das, was wir uber "verovašaja" berelts sagten, in noch stärkerem Maße: eln Perfekt würde den Sachverhalt auch hier noch besser treffen: "verill esmy" - 'wir haben geschworen' = seitdem stehen wir unter Eid.

2we1 Mal begegnet uns "(ne) vred1" 1m engsten Zusammenhang. Dóstal bezeichnet es als perf., die suffiglerte Variante "vrěždat1" 1st in den älteoten aksḷ. Denkmälern nachgewlesen. 76

97/12 "I ot sego ... smertonosnago umyšlenija $v$ trolcy slavimy $j$ bog 1 ... gobl ... - tovaryăčl, no 1 togo ničlm ne vred1, jaže larec toj otpiravyj."

- Und der dreleinige Gott ... schutzte den Bojaren vor diesem mörderischen Anschlag und lies thn nicht zu Schaden kommen. Und auch derjenige blieb unversehrt, der den Kasten geöffnet hatte.

Durch die Koordinierung von "nevred1" mit "sobljude" wird deut$11 \mathrm{ch}$, daB der pleskauer Autor "vréd1t1" als perf. empfindet.

75) Srezn. I, 491.

76) Dostál, Studie, S. 500; Sadnik-Aitretmiiller, HuB, S. 154; Srezn. I 319 ; slovnik jazyka taroslovengkého I, S. 228 . 
In der Pleskauer Erzählung steht einem Aor.-Beleg von "Iišitisja" eine Praes.-Form von "lišatisja" entgegen. Den Angaben der einschlägigen Handbücher nach ist "lišiti/sja" die ursprüngliche Form, da es in den ältesten aksl. Texten reichlich bezeugt ist, wohingegen "lišati/sja" selten vorkommt. 77

$79 / 5$ "... a my nemoščnii, prepojasašas ja siloju

i ispolin chleba lišišasja,

a my, alčjuśćii, miloserdija božija ispolneny blag."

Nach Luther lautet diese Stelle (1. Sam. 2, 4 - 5):

'Die Schwachen sind umgürtet mit Stärke.

Die da satt waren, sind ums Brot Knechte geworden,

und die Hunger litten, hungert nicht mehr.'

Die Einengung, die Zuspitzung der Bedeutung wird hier besonders offenkundig, da wir auch einen Praes.-Beleg haben:

$80 / 31$ "... panbi panov plaç站, mužej svoich, materi že čad lišajutca, ..."

'... die (polnischen) Frauen beweinen ihre Männer, Mütter beklagen den (leiden unter dem) Verlust ihrer Kinder, ...'

"vrèditi/sja" ist bedeutungsmäBig eingeengt auf 'eine Verletzung, einen Schaden zufügen/erleiden',

"Iis̆iti/sja" ist bedeutungsmäBig eingeengt auf

'einen Verlust zufügen/erleiden;

"vrěždati/sja" ist nun bedeutungsmäßig festgelegt auf

'schaden/unter ständiger Schädigung leiden' (z.B.: das Klima schadet meiner Gesundheit/ich leide unter dem Klima),

"lišati/sja" ist bedeutungsmäßig festgelegt auf

'dauernd Verluste zufügen/ständig unter einem/vielen verlust /en leiden (=ständig einen/viele Verluste beklagen)'.

77) Dostél, Studie, S. 113 (Kommentar: "lišiti/sja" = vorwieGend perf.); Sadnik-Aitzetmüller, HWB, S. 51; Slovnlk jazyka staroslovenskeho II, S. $131 \mathrm{f}$.

78) Hier muß es wohl heißen: "ispolin chleba 1išisja" - also Sing. statt Plur. - 'der Mächtige ist des Brotes verlustig gegangen' (d.h. ist arm geworden). 
Es ist festzuhalten, dab in der Pleskauer Erzählung die aspektuelle Ausrichtung der Verben der 4. Leskien'schen Xlasse, zumindesten was das Verb.fin. anbetrifft, so gut wie abgeschlossen 1st. Traf das in der K-pler Erzählung auf die iti-Verben bereits zu, so bildeten dort aber diejenigen Verben mit Zustands- oder zustandsähnlicher Bedeutung eine Gruppe für sich (Leskien: Klasse IV B - Infin.-Stamm auf -èti-/ -ati-): sie bildete das (finite) Präteritum ausschlieblich mit Hilfe des Aorist. Das bedeutet, daB diese Verben noch zumindest innnerhalb der der literarischen Tradition verpflichteten Gattungen - ihren aspektuell neutralen Zustand wahren konnten. Gleichzeitig bedeutet dies aber auch, dab der Aorist noch nicht so stark auf den perf. Aspekt fixiert war wie dies im Pleskauer Text der Pall 1st. Verben der Klasse IV $B$ erscheinen hier nur im Ipf., selbst wenn der Aor. zu erwarten wäre - häufig mit der Suppletivform - (j)ăse für die 3.pl. aor. - ša.

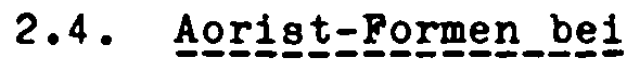

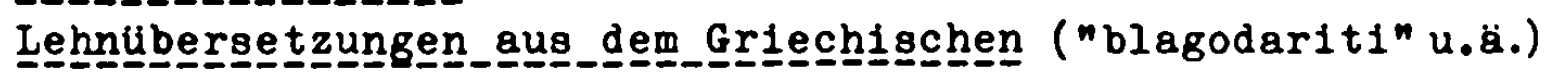

In unseren Texten finden wir ein par Belegstellen mit Verben vom Typ "blagosloviti" - gr. $\varepsilon \dot{v} \lambda$ ojeî $V$. Diese Lehnübersetzungen entstanden im Zusammenhang mit der Fixierung der slav., d.h. hier: der aksl. Sprache. Diese Verben blieben weitgehend auf den klerikalen Bereich beschränkt, waren als Wörter der Kirchensprache markiert. Da z.Z. der Entstehung der ersten aksl. Denkmäler die aspektuelle Ausrichtung des slav. Verbalsystems in ihren Grundzügen schon festlag, standen diese Verben - auch aus den anderen genannten Gründen - auBerhalb der Fntwicklung des verbalen Systems, sie gingen koinen einheitlichen Weg. Befand sie Dostál - den aksl. Denkmälern nach - beiden Aspekten zugehörig, 79 konstatiert Ruzicka an Hand der PVL "blagosloviti" ihre Neutralität in aspektueller Hinsicht, 80 so gilt

79) Dostál, studie, s. 473 f. und s. 627.

80) Ruzicka, Verbalaspekt, s. 37 - mit Berufung auf Dostál, seine zwe1 Belege reichen m.E. nicht zu einer solchen Feststellung. 
heute beispielsweise "blagodarit1" als imperf., "blagoslovitin aber als perf. 81

In der K-pler Erzählung gibt es außer einer Textstelle mit "blagovoliti" im Praes. (mit Zukunftsbedeutung) ${ }^{82}$ Aor.-Belege allein von "blagodarit1" - 'danksagen' :

57/24 "I vse ljudi rekkogsa: 'aminb', i blagodariśa cesarja 1 pochnvalíg go dobryj ego razum ..." 'Und alle Menschen sprachen: Amen!, dankten dem Kaiser und priesen seinen hohen Verstand ...'

$61 / 35$ "I videvše tu suščie ljudi blagodariša boga, ..." ' Und die Menschen, die dort waren und dies sahen, dankten Gott,...'

Die Koordination mit "pochvališa" im oberen Beispiel könnte die Vermutung nahelegen, daB "blagodariti" evt. als perf. zu bewerten sei, zumal sich auch im Zusammenhang mit dem zweiten Beispielsatz (allerdings nicht in so engem Kontext) ein perf. Aor. anfüren ließe. ${ }^{83}$ Die folgende Textstelle bezeugt aber, dab es auch zur Bildung des Ipf. befähigt ist:

64/21 "Cesarb že s patriarchom 1 ... b jagchu po vsem cerkvam

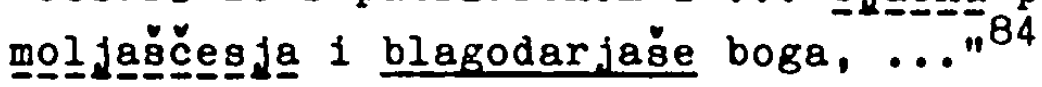

- Der Kalser und der Patriarch und ... beteten in allen Kirchen und dankten Gott, ...'

"vozblagodariti" scheint noch stark in seiner eigentlichen Bedeutung verstanden $z u$ werden und noch nicht so sehr als Perfektivum zu "blagodariti" - 'anheben zu singen':

$73 / 10$ "Cesarb že ... 1 vsi voiny poídoşa v velikuju cerkovb 1 vozblagodaris̆a boga 1 prečistuju ego materb."

- Der Kalser und ... alle Krieger zogen in die Hagia Sophia, begannen, Gott und der allerreinsten Gottesmutter Dank zu sagen.'

81) Daum-Schenk, Die russischen Verben, S. 19 und 20.

82) $69 / 13$ ne chosćesi bo ... sozdanie troich ruk pogubitit, nize blagovolisi o pogibeli celovečestej, no chosčsı voem spast18ja ..." 'willst...nicht zerstören', 'wirstnicht frohlocken:- "blagovolisin, 'willst alle retten': Voluntative Bedeutung stekt im Vordergrund.

83) "navadisa".

8.4) Möglicherweise liegt Verschreibung vor für "blagodarjašçe" 
Für "blagodariti" begegnet in der Pleskauer Erzählung folgender Beleg:

$84 / 26$ "Slyšav že sie gosudarevy bojare ...., jako litovskij korolb podo Pskor mnogie podkopy govelí, o sem že blagodariša boga, jako $i$ tot sovet ich uvedąăa, ..."

'Als die Bojaren ... hörten, daß der litauische König viele unterirdische Gänge graben ließ,85 dankten sie Gott dafür, daB sie von diesem Plan Kenntnis erhalten hatten, ...'

Der Aor. an dieser Stelle entspricht der raffenden Erzählweise, die diesen Abschnitt prägt. - "uvédati" ist nicht als Imperfektivum $z u$ "uvěděti" $z u$ deuten. "věděti" und seine Komposita kamen außer Gebrauch und wurden durch "vědati" und seine Komposita ersetzt. So ist "uvědati" als Perfektivum zu "vědati" aufzufassen. ${ }^{86} \mathrm{zu}$ "poveli" s.u. "Perfekt und l-Partizip", S. 498 .

48/2 "'Eže bog blagovoli 1 tebe, gosudarju, 1zzvolísją, vsjačeski $i$ po poveleniju troemu tebe, gosudarju, rab essmb az." "

-Was (auch immer) Gott wohlgefallen und auch deine Billigung, Herrscher, erfahren hat - immer und auf dein Geheib hin, Herr, bin ich dein Knecht."'

Die beiden formelhaften Aor.-Belege beziehen sich auf einen imaginären Vorgang, der, wie die Textstelle deutlich zeigt, als abgeschlossen gedacht wird.

$55 / 22$ "Vkupe že 1 toj (= archiepiskop) ... mužestrovati na podvig velit 1 blagoslovljaet 1 ukr ㅌepljaet. ..." 'Gleichzeitig befiehlt der Erzbischof .... diesem Ereignis mannhaft entgegenzusehen, und er segnet und er stärkt (die Pleskauer)...'

$62 / 32$ "Tako že 1 gosudarevy bojare 1 ... krestom blagoslaviša 1 svjatoju vodoju okropiša 1 ..."

"bjachu moljaščesja i blagodarjaǧče". Im anderen Falle h"̈tten wir hier einen der wenigen Pälle von Verwechselung der 3.pl.ipf. mit der 3.89.1pf. vor uns. - 63/27 "'Chvalju $i$ blagodarju sovet vas 1 vem, ...." - 'Ich 1085) Im Original: Synekdoche - der König für alle Litauer. 86) Borkovgkij, Istor. grammatika, S. 295; otten, Pin. 
'und so segneten sie (= die Geistlichen) die ... Bojaren und ... mit dem Kreuz und benetzten sie mit geweintem Wasser und ...'

Dostál weist "blagoslovljati" bereits im Cod. Supr. nach, 87 so ist die aspektuelle Ausrichtung der beiden Varianten nicht verwunderlich.

Auf Grund unseres sehr beschränkten Belegmaterials können wir nur festhalten, daB die Verben vom TXp "blagodariti" in belden Texten vorwiegend im Aor. auftreten, aber auch im Praes. erscheinen - im letzteren Fall haben sle Gegenwartsbedeutung. Das bedeutet, dab sie im Empfinden der beiden Autoren ihre aspektuelle Neutralität bewahrt haben. Ihre Zuordnung zum imperf. Aspekt (außer "blagosloviti"-s.o.) scheint also jüngeren Datums zu sein.

\subsection{Aor}

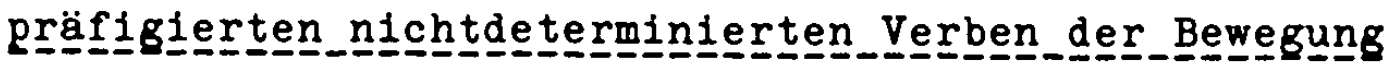

In beiden Texten kommen einige - wenige - Belege mit Aor.Formen von präfigierten nichtdeterminierten Verben der Bewegung vor. Als Simplex bezeichnet das eine - z.B. "itti" - die zlelgerichtete (einmalige) Bewegung, das andere - z.B. "choditi" - die Handlung allgemein, die Bewegung als solche - ohne Hinblick auf das 21el. Bekanntlich bilden die Komposita der entsprechenden Verbpaare (determiniert - nichtdeterminiert) Aspektpartner, wobei natürlich das präfiglerte determinierte Verb perfektiv 1st. Daher können Aor.-Formen nichtdeterminierter Komposita unser Interesse beanspruchen.

KP 63/2 "I bjągé videt1 po vsem grade ... (Ijudi) so slezam1 chvaljašče ... boga i prečistuju bogomaterb, 1 tako provodiša denb toj..."

- Und in der ganzen Stadt konnte man Leute sehen, die Gott und die allerreinste Gottesmutter weinend priesen und so den ganzen Tag verbrachten ...'

Verbalformen, S. 243.

87) Dostél, Studie, S. 588. 
"provoditi" hat in diesem Satz eine eigenständige Bedeutung, die sich von "voditi" - 'führen, lenken' gelöst hat, "provoditi" hat einen ubertragen-abstrakten Sinn erhalten. In dieser Bedeutung ist dies Verb sogar perf. geworden und hat durch -'a-Suffix einen Aspektpartner gebildet. So finden wir heute "provodit'" einerseits als imperf. Aspektpartner zu "provestin, andererseits als Perfektivum zu "provožat'" 'begleiten, geleiten'. 88

PS 61/24 "A V tech borozdach, jakože posledi chodivše 1 sčet obrretošą, dvorov bolbšich v zemli że vykopano, sirečb, jako izbušek ... sto tridcats dve izbe, da devjatbsot četyre menbšich: $v$ bolbšie že te dvory rochmisty s sotniki schodišasja, v mensšich že gaj-

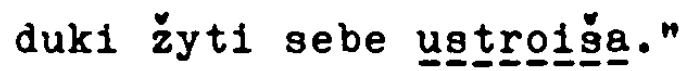

Wie man später, als man in den Gräben herumlaufen konnte, feststellte, waren Unterstände in die Erde gegraben .... in die größeren (132) zogen die Rottmeister und die Hundertschaftsfuhrer, in den kle1nen (904) richteten sich die Heiducken ein.'

In diesem Abschnitt trägt der Autor Dinge nach, die er viel später erfahren hat ("jakože posledi chodivše 1 sčet obretošn"), sle haben den Charakter ergänzender Anmerkungen. Nicht nur deshalb ist der Aor. das angemessene Tempus; vielmehr ist der beschriebene Zustand (das Leben der Litauer in Jenen Unterständen) mit deren Ruckzug beendet, der erst die genaue Kenntnisse der Unterstände und aller Einzelheiten ermöglichte. "schodišasja" soll wohl 'sich breitmachen, sich ausbreiten' ausdrucken, wobei in die Tendung vor allem die Bewegung eingeht, wie es etwa deutsches 'verkehren' ('er verkehrt in ... Kreisen') andeutet. In "schodisasja" ist aber auch das 'herab' enthalten, das diesem ziellosen Verkehren in den Unterständen vorausgeht. Komposita von "choditi" scheinen dem Pleskauer Autor noch nicht in dem MaBe dem Imperf. Aspekt verpelichtet zu sein, so daB es thm noch möglich ist, einen Aor. "schodisasja" zu bilden. 89

88) Daum-Schenk, Die russischen Verben, S. 493.

89) Anscheinend entziehen sich die Komposita von "choditi" lange der aspektuellen Zuordnung als imperf. Aspekt- 
PS 63/25 "... Bulgakov da Ofanasej vikulin, ..., s nimi že i pušečnovo prikazu gosudarev dijak Terentej L1chačev na sovet $k$ voevodam şezžašasja. " 90

'Bulgakov und Vikulin, ..., und auch der Dijak Lichacev trafen bel den Voevoden zur Beratung zusammen.'

"въež́atisja" ist Iterativbildung zu "şezditisja", das wiederum imperf. Aspektpartner zu "sъechatisja" wurde. In den aksl. Texten ist es (nach Sadnik-Aitzetmulller, HWB, und Dostál, Studie) nicht belegt. Sreznevskij verzeichnet "sъezžatisja" vorwiegend mit Praes.-Belegen (Gegenwartsbedeutung). 91 Iterativität bzw. eine bestimmte Gewohnheit scheint auch hier gemeint zu sein, wobei der Aor. ausdrücken könnte, dab diese bestimmte Handlung einer anderen - ubergeordneten vorgeschaltet 1st, eine Voraussetzung darstellt: Im folgenden wird nämlich berichtet, weswegen die verschiedenen Kommandeure zusammengekommen sind: "bogomudrenno o gradoukreplenbi smyšljachu" - 'mit Weisheit von Gott begabt, machten sie sich über die Verteidigung der Stadt ihre Gedanken'. Kontextangemessen wäre die Stelle etwa so zu übersetzen:

\footnotetext{
- Bulgakov und .... pflegten, bei den Voevoden zur Beratung zusammenzutreffen. (Wenn alle zusammengekommen waren), dann machten sie sich immer ... Gedanken.'
}

Dieser Aor.-Beleg eines präfigierten nicht determinierten Verbs bedeutet also hier eine sich gewohnheitsmäBig wiederholende Handlung, die aber eine wichtigere Handlung ( $=$ die Beratungen der Kommandeure) vorbere1tet - die erst abgeschlossen sein muв (es müssen alle da sein), wenn die übergeordnete Handlung einsetzen soll.

partner zu den Komposita von "itfi". Boretzky, Tempusgebrauch, S. 60 - stöBt auf "chodiBa" in Kurbskijs "Istorija", es hat die Bedeutung 'einen Feldzug durchfuhren'. - Ruzicka, Verbalaspekt, S. 23 - die meisten präfigierten Indeterminativa seien 2.2 . der PVL Aspektpartner der entsprechenden präfigierten Determinativa.

90) Variante, S. 142: "... na sovet k voevodam sъezźajasja." 91) Srezn. III $868 \mathrm{f}$. 


\subsection{Aor:-Formen_bei_dehnstufufigen und Loder

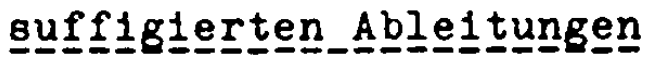

Bei den dehnstufigen und/oder suffigierten Ableitungen handelt es sich um Iterativbildungen, die automatisch imperfektiv wurden, als die aspektuelle Ausrichtung des Verbalsystems einsetzte (z.B. "strěljatín), oder es handelt sich um direkte Imperfektivbildungen (am typischsten sicher ist das-yva-Suffix). Von diesen Verbgruppen, die mit GewiBheit zur Entstehungszeit unserer Texte längst im imperf. Aspekt verankert waren, finden wir in der K-pler Erzählung folgenden Aor.Beleg:

56/23 "A poneže krestbjane zmija ubiša, a orla 1zymaša,

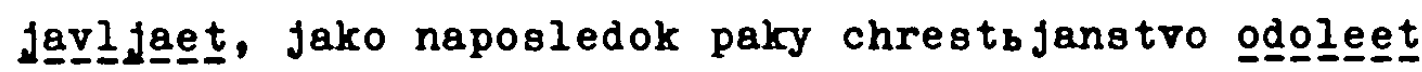
besermanstra ..."

- Und weil die Christen die Schlange getötet und den Adler befreit haben - so ist die Ausdeutung - wird die Christenheit wieder die Mohammedaner uberwinden ...'

Wenige Zeilen daruber wird Jenes Ereignis erzählt, das hier von den Weisen und Schriftgelehrten Kaiser Konstantins gedeutet wird ("javljaet"):

$56 / 15$ "Ijudie tekše zmija ubiša, a orla izymaše, 1 bystb cesarb vo užase velicem, ..."

'Die Menschen liefen herbel, töteten die Schlange und befreiten den Adler. Der Kaiser aber war sehr bestürt, ...'

Zwar wird im ersten Textbeispiel die jeweilige Handlung nur konstatiert, während das zweite Beispiel aus dem lebendigen Bericht stammt, dennoch scheint mir, daB es auch hier "izymašan heißen muß, da die Erzahlweise des Autors dort eine eher hektische ist, die die Ereignisse als sich uberstürzend darstellt.

"ubiša" und "izymaša" sind koordiniert. Negen der zweimaligen Setzung von "izymati" ist anzunehmen, daB der K-pler Autor dieses Verb ganz bewuBt verwendet hat. "ubiti" - 'töten; den Schlag fuhren, der totet' lot seit alters her punktuell. 
"1zymat1, -jemlju/-aju" - 'weg-, herausnehmen' ist eine alte Ableitung von punktuellem "1zjati". "izymati" diente bereits in den aksl. Texten dazu, punktuelles 'weg-, herausnehmen' subjektiv zu dehnen. Mit solcher Bedeutung wurde "1zymati" zur Entstehung der $K$-pler Erzahlung sicher schon als imperf. empfunden. - Wenn der K-pler Autor "ubiša" und "izymaša" koordiniert, dann ist das so zu interpretieren, daB er das Töten traditionsgemäB als punktuell, durch "ubiti" ausgedrickt, ansieht. Die Befreiung des Adlers aus den Windungen der Schlange empfand der Autor als langen Kampf uber den Tod der Schlange hinaus (Reihenfolge 1. ubiša, 2. izymaša). Den Endpunkt des Kampfes (Aor.) bildet die Befreiung des Adlers.

In der Pleskauer Erzählung erscheinen zwei - allerdings sehr fragwürdige - Aor.-Belege, die hierher gehören:

$71 / 15$ "'p̣ríidete že vsja svjatyja ruskija zemli i chrestbjanskogo pravoslavija, jaže $i$ vy s nami spobol-leznovagate i molitvami svoimi k bogu nami pomogaste 1 ...'n

'Kommt herbe1, ihr Helligen RuBlands und der gesamten Orthodoxie, die ihr euch immer unserer erbarmt und uns durch Gebete $z u$ Gott geholfen habt und ...'

"spobolèznovati" ist Perfektivbildung zu "bolěznovati". "pomogati" hingegen ist dehnstufige Ableitung $z u$ "pomošči". Von letzterem würde die 2.plaor., mit der wir es in obiger Textstelle zu tun haben, lauten "pomožete" oder "pomogoste". Es 1st also Verschreibung denkbar - "pomogaste" für "pomogoste". Denn die ausgedrückten Vorgänge entsprechen sich, was ihren Ablauf anbelangt: Vorgänge, die im Grunde fortdauern, aber mit dem Moment der Anrede "priidete!" im Denken des Sprechenden abgeschlossen sind, als - subjektiv - unterbrochener ProzeB empfunden werden. Insofern wäre nicht nur das gemeinsame Tempus, sondern auch die gemeinsame verbale Kategorie zu erwarten. Die Tatsache, dab die genannten Handlungen - '1hr habt euch (1mmer) unserer erbarmt', 'ihr habt (immer) für uns gebetet' - an sich schon ständig wiederholt, schlieblich aber auch von einer groBen Zahl verschiedenster Heillger ausgefuhrt wurden, läBt die Form "pomogaste", den Aor. des imperf. "pomogat1", als angemessener erscheinen als das aspektorientierte "spoboleznovaste". Die Koordination dieser beiden For- 
men spricht für Unsicherheiten des Autors (oder eines Kopisten $^{92}$ ) im temporalen wie auch im aspektuellen Bereich.

$49 / 24$ "Da veste 1 ě̉e izvestno slyšaste, eliko v mimošedšee dva leta ... pakosti sotýor $1 \underline{i c h} 1$ kolicy ego gradi $k$ moej zemli ... otnㅣㄹㅡh. $k$ svoemu deržavstru 93 prísovóokupich 1 elika v srazytelsnom boju ... odolenie pokazovach; $i$ eilcem ruskim bogatestrom obogatichsja

$$
\begin{aligned}
& 1 \text { voiny svoja obogatich } \\
& \text { i zemlju moju nakgatich ... ; } 1
\end{aligned}
$$

koliko uničiženbe 1 strach ruskija zemli nanesogch, 1 koliku slavu vysokomu svoemu polbskomu korolevstvu -.. prílobretoch.

' Ihr wiBt (sollt wissen) und habt sicher bereits davon gehört, welches Ungemacht ioh im Verlaufe der vergangenen zwei Jahre (dem Zaren) zugefügt habe, wieviele seiner Städte ich ihm entrissen - meinem Reich einverleibt habe; wie oft ich in blutiger Schlacht siegreich war, mit wievielen mosischen Schätzen ich mich selbst und auch meine Krieger bereichert und (alle möglichen Wertgegenstände aus RuBland) in mein Land geschleppt habe. (Sicher habt ihr auch gehört,) wieviel Schande und Schrecken ich über das russische land gebracht und zu welchem Ruhm ich mein polnisches Königreich geführt habe.'

Die Darbietung der Textstelle in obiger Form soll die dem Abschnitt zugrundeliegende struktur verdeutlichen (die Editionen gehen darüber hinweg); vor allem aber soll diese Darbie-

92) Variante, S. 148: "..., jaže i vy s nami spoboleznovaste 1 molitvami groimi $k$ bogu nam pomogoste ..." - Aor. von perf. "pomošcin".

93) "deržavstro" an dieser Stelle ist einer der ältesten Belege für dieses Wort, hier im Sinne von 'Herrschaft, Reich', so auch in der "Kazanskaja Istorija"; als "Land, Territorium" bereits in der "Stepennaja kniga" und im "Skazanie o knjazèch vladimirskich" - vgl. I. Auerbach: Nomina abstracta im Russischen des 16. Jh.s. Fünchen 1973. S. 253. - "derzavstvo" gehört zu einer Gruppe von Abstrakta auf -stvo, die "als Ableitung von einem anderen Abstraktum miBverstanden wurden. Eigentilch lag Bildung von einem Adjektiv vor, das seinerseits yon dem zweiten Abstraktum herkommt." (S. 13), also: "dbrzava" > "dbrzavnyin > "derzavstron. - Leider hat die Autorin im Quellenverzeichnis 
tungsweise den homogenen Charakter der reimenden Verben vor Augen fuhren: bis auf die uns interessierende Form "pokazovach" handelt es sich jeweils um präfigierte, nicht ouffigierte Verben. Der Aorist signalisiert, daB die ausgedruckte Handlung in der Vergangenheit zum AbschluB gekommen ist. Diese Aor.-Formen verwandeln die Sätze, die durch die anaphorischen Pragepronomen ("elikz" und "kolikz") Fragesätze wären, in rhetorische Fragen. Der Aorist in jedem Satz kehrt gedanklich "elikz" und "kolikz" - 'wieviel' in "tolikz" 'soviel' um.

Allen Aussagen ist gemein, daB für die ausgedrückten Vorgänge, Aktionen, Handlungen gerade die Wiederholung das Typische 1st; diese Bedeutung der Rede Stephan Báthorys trifft am besten die Form "pokazovach", die als (ziemlich altes ${ }^{94}$ ) Imperfektivum die Wiederholung stärker impliziert als das resultative "pokazach", "sotvorich", "otnjach" usw. In den drei zuletzt genannten Aor.-Pormen kommt natürlich die Korrelation 'Aorist - perf. Aspekt' zum Tragen, deshalb werden auch diese perf. Verben den Abschnitt beherrschen. Daß wir "pokazovach" lesen, ist wegen der Glelchartigkeit der ausgedrückten Handlungen sicher als Polge eines Zufalles zu werten.

vergessen, die Pleskauer Erzählung zu nennen: Zwar ist sie ausgewertet und jeweils mit dem Siglum "Stefan" gekennzeichnet, doch wird das Siglum im Abkurzungsverzeichnis, S. 222, nicht aufgelost.

$94)$ "-kazovati" 1st eine Ableitung von "-kazat1, -kažn". Dostál weist "po-, u-, szkazovati" im Cod.Supr. nach (Studie, S. 580, 583), Sadnik-A1tzetmuller, HWB, S. 91 und 127 - finden auBerdem "pokazovati" in den Blattern aus dem Zographos-Kloster. - Es handelt sich bei dieser Ableitung sicher um eine Parallelform zu "-kazati, -ajq". Mit der Aspektualisierung des slav. Verbalsystems wurde "-kazati, -ajQ" imperf. Die um sich greifende Kontraktion im Bereich der Präteritaltempora machte die Präteritalformen dieser beiden Aspektpartner zu Homonymen. Das frủe Auftreten von "po-, sb-, ukazovati" hat wohl seine Ursache darin, daB die Sprache danach trachtete, die imperf. Ableitung zu verdeutlichen, so dab die so wichtigen Prateritalformen a useinandergehalten werden konnten. - -ova-wird mit beginnendem 16. Jh. durch -yva- ersetzt, doch sich in die literarische Tradition steliende Autoren meiden -yva- noch lange. Vgl. etten, Pin. Verbalformen, S. 456,461 ; N1kiforov, Glagol, S. 122 f., Ruzicka, Verbalaspekt s. 71 . 


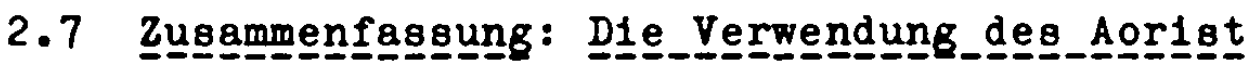 \\ in unseren Texten}

Wahrend im Aksl. der Aorist von allen verbalen Kategorien gebildet wurde, lot in unseren Texten dieses Tempus vorwiegend auf Verben beschränkt, die heute perfektiv sind. Eine naturliche Affinltat zwischen perf. Aspekt und Aor. liegt auf der Hand: Momentanverben sind von vornherein dem perf. Aspekt verpflichtet; die Masse der perfektiven Verben (präfiglerte Durativa, Iterat1va usw.) wird durch das Präfix im Vergleich zum Simplex bedeutungsmä日ig so eingegrenzt, so spezifiziert, daB normalerwelse die Vorstellung von der $A b-$ geschlossenheit, dem Beendetsein des betr. Vorgangs, der betr. Handlung, der betr. Tätigke1t assozliert wird, wenn man davon in der Vergangenheit spricht. Diese ursprügliche Aff1nitat zwischen Aor. und perf. Aspekt wurde umso mehr zu einer entsprechenden Korrelation schematisiert, je mehr das Aspektsystem das alte Tempussystem im Empfinden der Menschen zurllckdrängte. Diese Korrelation diente geradezu als Stutze beim Gebrauch der ksl. Tempora und erlaubte, fallo die Kenntnis der Pormen noch vorhanden war, einen wenn nicht gerade individuellen, so doch aber korrekten Gebrauch der Tempora.

Es bleibt aber doch erstaunlich, in welchem MaBe der Aor., der ja schlieblich das Haupterzähl tempus war (und in belden unserer Texte, wenn auch nicht mehr in prozentual so starkem Maße wie fruher, noch 1st), in unseren Texten perfektiviert 1st. Vergleiche mit anderen Texten an Hand anderer Untersuchungen waren nicht möglich, da diese sich in der Regel darauf beschränken, das Typlsche an ihren Texten herauszuarbe1ten.

Wie andere Untersuchungen (Otten, Boretzky) zeigen, erfolgt die Bahandlung des Aor. jewells mehr oder weniger der Vollständigke1t halber. Uber die Peststellung hinaus, dab der Aor. vorwiegend von Verben des perf. Aspekts gebildet wird, und Beobachtungen uber den Ersatz desselben (durch 1-Part. oder auch Part.praet.) wird dem Aor. wenig Aufmerksamke1t gewidmet. 
Entsprechend unserem Vorgehen im Zusammenhang mit der Besprechung des Imperfekts haben wir den typischen Erscheinungen keine Beachtung geschenkt - diese kommen in den Ausführungen über die Funktion des Aor. In unseren Texten zum Tragen bzw. fanden in Kommentaren zu bestimmten Belegstellen bereits Erwähnung. Wir haben alle die Aor.-Belege vorgefürt, die der Korrelation 'Aor. - perf. Aspekt' nicht entsprechen. Um nicht in den Pehler zu verfallen, aspektuelle Zuordnungen, die heute gulltig sind, auf das 15. und 16. Jh. zu übertragen, verfuhren wir wie im Abschnitt uber das Imperfekt: Wir untersuchten Aor.-Belege durativer (nicht präfigierter) Verben, dehnstufiger/suffigierter Ableitungen, nichtdeterminierter Verben der Bewegung und als gesonderte Gruppe: Simplicia der 4. Leskien'schen Verbalklasse. Das entsprechende Vorgehen (grob gesagt: Analyse perf. Ipf.-Belege) zeigte, daB Komposita alter durativer Simplicia, die ja inre Aktionsart meist beibehielten, auch durativ bleiben, wenn sie im Ipf. auftreten (entgegen der vorherrschenden Meinung, dab das Ipf. perf. Verben Iterativität anzeige). Im Zusammenhang mit den Untersuchungen am Aor. zeigte sich das umgekehrte Phänomen: die Masse der Aor.-Pormen von durativen Simplicia stellten Verben, die auch heute perf. sind, vor allem 1ti-Verben. Das Auftreten solcher Aor.-Belege, und vor allem in solcher Zahl, bestätigt, daB der ProzeB der Perfektivierung in den entsprechenden Pällen weit fortgeschritten oder abgeschlossen ist.

Statistisch gesehen machen habitualisierte Wendungen vom Typ "rekoch", "rečen, "rekoša"; "glagola" den größten Teil der uns interessierenden Formen aus. Wegen ihres geringen Aussagewertes ließen wir sie auBerhalb unserer Betrachtungen.

Diejenigen Aor.-Pormen, die fur uns von Interesse sind und von denen wir irgendwelche Hinwelse erhofften, kamen so selten vor, daß es uns fast unmöglich lot, elne uber die jewellige Beleganalyse hinausgehende Aussage uber den Gebrauch imperf. Aor.-Formen zu machen.

Während wir in der K-pler Erzählung Aor.-Formen durativer 
Simplicia (außer Leskien'scher 4. Klasse) nur von "rešči" und gelegentlich von "pisati" auffanden, konnten wir im Pleskauer Text von dieser Kategorie immerhin elf Aor.-Formen (ohne "rečen usw.) zusammentragen. Neben Belegen, die den Sinn des Aor. überhaupt nicht erkennen ("metašan) oder eindeutig äuBere Einflüsse vermuten ließen ("ne možaše videti" neben "ne mogoša javitisja"), gab es auch Textstellen, wo der Aor. des durativen Simplex den Sachverhalt sehr feinsinnig ausdrückte ("streljaša", auch "peša"). Drei Mal begegnet "bisa", und zwar im engeren Sinn: 'ein Geschütz/Geschütze ganz gezielt abfeuern'. Da es auch im Praes. mit Gegenwartsbedeutung vorkommt, ist "biti"- 'Geschütz abfeuern' - nicht perf., sondern wird als Determinativum empfunden. Andererseits finden wir in beiden Texten fast keine Aor.-Formen determinierter Simplicia (Ausnahmen: K-pel "bežaša", Pleskau "idoša" gegen drei "idjaše" für "idoša"). Im Pleskauer Text begegnen außerdem noch "celovaša" und "verovašasja", was als Reflex des ursprünglich und sehr lange aspektuell neutralen Zustandes der Verben mit -ova/-eva-Suffix gedeutet werden könnte.

Wie erwähnt, zeigte sich bei den iti-Verben, daB dort die Perfektivierung weit um sich gegriffen hatte. Dies war hier sicher besonders leicht, da es sich um eine formal sehr homogene Gruppe handelt. Die meisten Aor.-Belege von Simplicia der iti-Verben gehörten zu heute perf. Verben. Ausnahmen bildeten "skočiti" im K-pler Text (das heute nicht mehr existiert, aber in "skakati" einen nichtdeterminierten/iterativen Partner besaB), das sicher auch zur Perfektivität tendierte, sowie "věritisja" und "vrěditi" in der Pleskauer Erzählung. Bezüglich der letzteren ist zu vermuten, daß ihre abstrakte Bedeutung eine gewisse auBeraspektuelle stellung ermöglichte - es kann aber auch sein, daB sie im 16. Jh. oder vom Pleskauer Autor speziell als perfektiv empfunden wurden. Ein gravierender Unterschied zwischen beiden Texten besteht darin, daB der $\mathrm{X}$-pler Autor von Verben mit Infin.-Stamm auf finite Präteritum ausnahmslos mit dem Aor. bildet, wohingegen der Pleskauer Autor bei dieser Gruppe den Aor. vermeidet, ihn, 
wenn man einen Aor. erwarten würde, durch seine Suppletivform - z.B. "veljaše" für "veleša" - ersetzt. Vielleicht wegen ihrer hohen Frequenz konnten sich diese (zumeist zustands-) Verben, zumal "viděti" und "slysati", lange einen voraspektuellen (d.h. aspektuell neutralen) Zustand bewahren, der die Bildung aller Tempora ermöglichte. Hinzu kommt sicher auch ein bestimmter Gebrauch dieser Verben, der uber das zuständliche Sehen resp. Hören weit hinausgeht: nämlich Erblikken, (durch Hören) Erfahren. Typisch ist es ja, daB der Aor. von "viděti" am häufigsten in folgender Position auftrat: "(jako) cesarb sie vide (slyša), pade na zemlju ..." 'als der Kaiser dies gesehen/vernommen hatte, stürzte er ...' An den Vorgang des Sehens/Hörens knüpt sich eine Reaktion, die durch das Gesehene/Gehörte ausgelöst wird. Der Vorgang des Sehens/Hörens ist mit dem Eintritt der Reaktion beendet. 95 Während der $\mathrm{K}$-pler Autor also diesen Aor. noch regelmäBig gebraucht, verwendet der Pleskauer Autor in dieser Position fast ausschlieblich die Wendung "gosudarevy bojare $i$ voevody, (jako) slyšav/videv že sie, ..." (einmal nur lesen wir - s.o., s. 412 "slyšsa"). Das bedeutet, daB fur den Pleskauer Autor, der fast oin Jh. später schrieb alo der Verfasser der K-pler Erzählung, der Aor. von dieser Verbengruppe nicht mehr bildbar war, weil die Verben auf Infin.-Stamm -è-/-a- und Praes.-Stamm auf -inun bereits als imperfektiv empfunden wurden 96 GewiB spielt hier auch hinein, daB der K-pler Autor ein intimeres Verhätnis zur tradierten Literatursprache hatte als der Pleskauer.

Das Material zu den ubrigen uns interessierenden verbalen Kategorien - nicht determinierte Verben der Bewegung, dehnstufige/suffigierte Ableitungen, Verben vom Typus "blagodaritin - war zu sparlich und zu heterogen, als dab es möglich wäre, aus diesen Aor.-Pormen allgemeine Schlüsse zu ziehen. Insgesamt gesehen, läbt sich aus dem Vergleich der Verwendung

95) Ruzlcka, Verbalaspekt, S. 50 - spricht in diesem Palle von der "auslobend begrüdenden Punktion, die "vidéti" und "slyeat1" häufig als perfektiv auffassen läBt."

96) H1k1forov Glagol, S. 62: In der 2. Hälfte des 16. Jh.s sind "videti" und "slysati" auf den imperf. Aspekt festgelegt. 
des Aorlst im Rahmen des $\mathrm{K}$-pler und des Pleskauer Textes mit aller gebotenen Vorsicht folgender Unterschied herausarbeiten: Abgesehen von der Leskien'schen Klasse IV B ("viděti" usw.), die Im $\mathrm{K}$-pler Text voraspektuelle Neutralität bewahrt und infolgedessen als Präteritaltempus nur den Aor. kennt, ist diese Erzählung bezüglich des Aor. otärker auf den perf. Aspekt festgelegt. Der Autor vermeidet unpräfigierte Aor.-Formen (auBer von Momentan-Verben - "paden, "bystb", "načatb usw.). Der Aor. bei nichtmomentanen Simplicia begegnet nur häufiger von 1t1-Verben, die offensichtlich längst im perf. Aspekt befestigt waren: "otrělitin, "pust1tin, "udaritin, "javitin, sicher auch "skočlti". Dagegen welot die Pleskauer Erzählung einige Aor.-Belege nichtmomentaner Simplicia auf. Die Analyse der Textstellen fuhrte zu unterschiedlichen Ergebnissen: 2.T. Umschrieb dieser Aorist den geschilderten Tatbestand sehr genau, 2.T. war der sinn dieser Aor.-Porm nicht zu erkennen, vielmehr zeigte sich an diesen Stellen der Aor. durch äuBere Einflusse bedingt, z.B. "ne mogos̆a ... javitisja" durch den perf. Aspekt des Infin. Möglicherweloe haben wir in dem häufigeren Auftreten von Aor.-Formen nichtmomentaner Simplicia im Pleskauer Text Anzelchen fur eine Auflösung der starken Bindung des Aor. an den perf. Aspekt zu sehen. Die Aufgabe der Aspektkorrelation (Ipf. - imperf. Aspekt, Aor. perf. Aspekt) hatte - feststellbar besonders seit Ende des 16. Jh.s - mit zum Verlust des alten Tempus-Systems gefuhrt. Ein anderer unubersehbarer Faktor, der mit zum Verlust dieses Systems beitrug, wurde gebildet durch die Unsicherheit b2w. allmählich durch die Unkenntnis auf dem Gebiet der alten Formen. Dies mussen wir in Rechnung stellen, wenn wir otatt eines zu erwartenden loriot im Pleskauer Text gelegentlich die Suppletivform des Pleskauer Autors - "trorjabe", "velfä̌e" statt zu erwartendem "troriba", "veleša" - vorfinden.

Die Deutung, daB bestimmte Eracheinungen im Pleskauer rext auf den Hiedergang des Tempussystems hinweisen, beruht auf der Berücksichtigung aller mit dem Verb susamenhängenden Erscheinungen in diesem Text. 
Der Vergleich der Aor.-Bildung im Pleskauer und im $\mathrm{K}$-pler Text allein rechtfertigt diesen SchluB nicht. Dazu unterscheiden sich die beiden Texte auf diesem Gebiet zu wentg.

\subsection{Die}

Der Aorist als grammatische Kategorie besab in der zweiten Hälfte des 16. Jh.s keine elnheltliche (klar abgrenzbare) Semantik mehr. Er stellte zu dieser zeit nur noch ein rein literarisches Tempus dar, das nicht nur semantisch, sondern auch formal verfallen war - so charakterisiert Nikiforov den Aorist im 16. Jh. 97 wie die bisherigen Ausfürungen gezelgt haben, finden wir in beiden Texten die Kategorie des Aorist formal noch recht stabil. Wie es um die Bedeutung - und die daraus resultierende Funktion des Aor. bestellt ist, soll im Polgenden kurz angerissen werden.

Der Aor. war ursprünglich das Tempus nichtdurativer Stämme und bezeichnete einen Punkt in der Vergangenhe1t. Analog hierzu bildeten auch die durativen Verben einen Aorist, der naturlich keinen einzelnen Punkt in der Vergangenheit bezeichnen konnte, sondern die Handlung als Präteritaltempus selbstverständich in die Vergangenheit transponierte, dabel aber gleichzeitig den Endpunkt der ausgedrückten Handlung mit ins Auge faBte (= komplexiver Aorist ${ }^{98}$ ).

Mit der Aspektualisierung des slav. Verbalsystems schwand die objektiv-aktionartliche Betrachtungsweise einer Handlung; und mit dem Ersatz der Tempora (Ipf., Aor., Perf.) durch ein universales Präteritum, das l-Part. (in der ge-

97) N1k1forov, Glagol, S. 153: "Vo vtoruju polovinu XVI $\nabla$. aorist predstavljal soboju tradicionnuju prinadiezngst. rniznogo povestrovatel nogo jazyka, no uze razloziviujus ja formal'no (piscy smesivajut formy cisla 1 lica) 1 eemanticoski (aorist, kak grammaticeskaja kategorija, ne imeet edinoj semantiki)." Hervorhebg.: Hikiforov.

98) Irost, Perfekt, S. 4, $\S 7$; Budich, Aspekt, S. 13, $\S 16$ +17 sowie Anm. 23: "Als komplexiv wird hier jede durative Verbform verstanden, die eine Begrenzung der HandIung zum Ausdruck bringt, se1 es durch das gewählte 
sprochenen russ. Sprache bereits 2.2. der Entstehung der frühesten altruss. Denkmäler verbreitet), ging schon bald die Voraussetzung verloren, die Tempora ihrer urspringlichen Bedeutung gemäB zu gebrauchen. Dies trifft nicht in solchem MaBe auf das Ipf. zu, da dies als Ausdruck einer in der Vergangenhe1t fortlaufenden oder sich wiederholenden Handlung (Durativität und Iterativität) relativ scharf markiert war und - wie wir bereits feststellen konnten - auch in unseren Texten in der Regel diese Punktion ausubt.

Das Ipf. 1st für den Autor der jüngeren altruss. Perlode das merkmaihaltige Tempus 1m Vergle1ch zum Aor.: Der letztere, dies ergeben unsere Beobachtungen wird ganz allgemein gebraucht zur Wiedergabe des umgangssprachlichen Präteritums (1-Part.). Der Unterschied zu jener ze1t, da die alten Tempora noch lebendig waren, besteht anscheinend darin, das der Aor. als Vertretung für das 1-Part. grundsätzlich jede präteritale Funktion Ubernehmen konnte und der Gebrauch des Ipf., wenn er sich nicht automatisch durch die Aspektkorrelation (Ipf. - imperf. Aspekt) ergab, einer bestimmten Absicht des Autors entsprang (z.B. Aktualisierung der Darstellung durch die Wahl des eher Infintten Ipf. als Erzähltempus im Gegensatz zum konstatierenden Aor., stäkere Expressivität durch Gebrauch des Ipf. U.a.).

Der Aor. slgnalisiert Abgeschlossenhe1t einer Handlung - diese mus aber nicht objektiv beendet sein, sondern es genügt, wenn der Autor in seiner persönlichen sicht den entsprechenden Vorgang als zusammenhängende, abgeschlossene Einhe1t ansieht - die Lialson des Aor. mit dem perf. Aspekt befördert diese Vorstellung. Dabel splelt es kelne Rolle, ob die Handlung im einzelnen durativ oder expressis verbis iterativ 99

Tempus (Aorist) oder den gewahlten Aspekt ( $\left.p f_{.}\right)$. Im GegenBatz zu E. Hermann (...) sprechen wir deshalb bel einem Nichtdurativum niemais von Komplexitat. " Hervorhebg: Bdich.

99) Boretzky, Tempusgebrauch, \$. 57 - verwundert sich Uber Pälle wie "mnogazdy pokazaeasja", die er als Ausnahmen bezelchnet. Unserer Vorstellung nach ist diese Pormulierung durch Aor. elne Möglichkeit des Autors. Erst, wenn er "mnogazdy" hervorheben will, wird er Ipf. benutzen. 
1st. Wir stieBen schon auf Belspiele, wo "pustiti", "strělltin, "udariti" in der K-pler Erzählung nicht nur 'ganz gezielt einen KanonenschuB abfeuern' bedeuteten, sondern auch 'ganz gezielt Kanonenschüsse abfeuern' heiBen konnte:

KP $66 / 10$ "... greki že razbegoša 1 pustiğa na nich pušky 1 pobiša mnogo turok."

'.., die Griechen aber liefen (plötzlich) auseinander und feuerten aus (vielen) Geschützen und töteten so viele Tüken.'

PS $91 / 8$ "..., gosudarevy voevody mnogie litovak1ja grady obvoevăsa 1 poplenţa ..."

'.... die herrscherlichen Voevoden bekriegten viele litauische städte und unterwarfen sie...'

Wie sehr das Ipf. expressiv-unterstreichenden Charakter hat, sei noch einmal am Beispiel des Ipf. als Ausdruck distributiver Handlungen erläutert: Wenn wir lesen:

PS $82 / 3 n$...., inoe že zelbe $v$ kukšinach na nich metati prigotovljachu, ovo że suchuju sejanuju izvestb prigotoviša, ...n

'.... die einen bereiteten Schießpulver in Krügen/ GefäBen vor, um es auf sie (= die Litauer) zu werfen, die anderen bereiteten trockenen, geriebenen Kalk vor, ....'

dann handelt es sich zwar offensichtlich um Verschreibung, 100 doch könnte theoretisch in "prigotovljachu" der Autor besonderen Schwerpunkt auf die Zahl derer legen wollen, die das Schießpulver in den Krügen vorbereiten, wohingegen er in "prigotoviša" die Tätigkeit an sich betont. Ein Autor kann also jede Plural-Form eines Aor. auch, bei entsprechender Intention, durch eine Plural-Form des Ipf. ausdrícken, womit natürlich gleichzeitig ein Aspektwechsel verbunden ist - in der Regel zumindest.

Wir haben gesagt, daB in einer leit, da das slav. Tempussystem für die höheren literarischen Gattungen charakteristisch war und demzufolge allein stilisierende Funktion hatte, der Aor.

100) Der gesamte Kontext reimt auf $-(j)$ achu; die Variante, $S$. 155 zeigt auch "prigotorljachu". 
das 1-Part. ersetzte und daB dann erat von Pall zu Pall ein anderes Tempus - Ipf., Perf., auch 1-Part. - als Bedeutungsnuanclerung gewählt wurde. ${ }^{101}$ Das bedeutet aber nicht, daB der Aor. nur im neutralen Bericht erscheint: van Schooneveld hat bereits an den von ihm untersuchten ältesten russ. Denkmälern 102 zwel Hauptfunktionen des Aor. beobachtet -

1) der Aor. In konstatierender Punktion,

2) der Aor. In lebendig schildernder Punktion. 103

Die erste Punktion bedarf keiner Erläuterung. Der Aor. in engagierter, aktualialerender Schilderung bewirkt dadurch, daB er Jeweils die Abgeschlossenhelt einer Handlung evoziert, den Eindruck sich überstürzender Ereignisse, da ja die eine genannte Handlung auf den AbschluB der anderen, vorhergehenden folgt - oder wir haben den Eindruck eines chaotischen Handlungsdurcheinanders, wenn die Aor.-Folgen eine logische Handlungsfolge nicht vorstellbar erscheinen lassen. 104

Allerdings sind Beisplele fur den Aor. als lebendiges Glied im engagierten, lebendigen Bericht viel seltener als solche fur den Aor. im ruhig-neutralen Bericht. Fur beide Punktionen des Aor. wollen wir aus jedem Text einlge Belegstellen vorfuhren, wobel wir aber mit der zweiten Funktion beginnen, da wir uns mit dem Aor. Im ruhig-neutralen Bericht etwas ausfuhrlicher beschäftigen wollen. Zudem ist anzumerken, daB die Scheidung zwischen beiden Punktion nicht immer leicht ist und nicht immer eindeutig sein kann - mit anderen Worten: der persönliche Eindruck 1st, da keine objektiven Kriterien zur Hand sind, für die Elnordnung makgebend.

101) Das gilt für Werke, worin das 1-Part. so gut we gar nicht vertreten ist (unsere rexte, die "Stepennaja kniga", Maksim Grek u.a., vor allem ältere Werke); In Kurbskijo "Istorija" sind l-Part. und Aor. austauschbar - Boretzky, Tempusgebrauch, S. 79 f.; auch in den letzten Sturen der "Stepennaja kniga", etten, Pin. Verbalformen, s. $257 \mathrm{ff}$.

102) PVI, Igorlied, Vita Boris u. Gleb, 1.Novgor. Chronik, Chozenie Danilia russkija zemli igumena.

103) van Schoonefeld, A Semantic Analysis, S. 20 - "Diacrete Happenings in the Past", d.h. konstatierendes einzelnes Auftreten von Aor.-Pormen; S. 26 "Succeeding Actions in the Past", d.h. viele elnander folgende Aor.-Pormen mit einander folgenden Handlungen = lebendiger Bericht.

104) Pur das Handlungs-Chaos fehlen uns lelder Beisplele. 
2.8.1 Der Aorist in der

aktualisierenden Situationsbeschreibung

Textpassagen, die zusammenfassende oder reflektierende $\mathrm{Be}-$ richte uber ein bestimmtes Geschehen enthalten, zeugen davon, daB der Autor zu diesem Geschehen eine innere Distanz gewonnen hat, die thm eine Bewertung der Vorgänge erlaubt, die ihm erlaubt, entweder die wichtigsten Fakten zu konstatieren oder aber den einzelnen Vorgängen das thnen gemäße Tempus zuzureisen.

In der aktualisierenden Situationsbeschreibung dagegen schreibt der Autor aus der Warte des unmittelbar Betelligten; zumindest versucht er, diesen Eindruck zu erwecken. Gerade das Genre, dem unsere Texte angehören - Kriegsbericht, Kriegserzählung -, kennt vielerlei situationen mit sich uberstüzender Handlung, bei deren aktualisierender Beschreibung ein Differenzieren nicht möglich - oder zur Schaffung einer bestimmten Atmosphäre (Hektik, Chaos usw.) nicht ratsam erscheint. In solchen Berichten finden wir die sich überstürzenden oder nebeneinanderher laufenden Handlungen oft telegrammstilartig im glelchen Tempus dargeboten. Heute wird in solchen Szenen gern das Praes.hist. verwendet; in unseren Berichten finden wir häufig das Ipf. Im Rahmen solcher Beschreibungen: es charakterisiert am besten die schlachtspezifischen Handlungen, deren Hauptmerkmal die dauernde Wiederholung ist schlagen, fallen, sich erheben, schleudern, schieben ... Gelegentlich werden Szenen aber auch im Aor. als dominierendem Tempus festgehalten. Hierbei entsteht, wie gesagt, der Eindruck von Hektik - die Handlungen stellt man sich nicht nebeneinanderher-bzw. parallelverlaufend, sondern nacheinander ablaufend vor, da der Aor. ja den AbschluB der ausgedruckten Handlung in die Vorstellung einbezieht. 
2.8.1.1 K-pel: Der Aorist in der

aktualisierenden Situationsbeschreibung

$65 / 26$ "... I be strašno videt1 obolch derzost1 1 kreposti.

Zustuneja že paki sobra mnogye ljud1, voskryčav napade na turky tako mužestrene, jako $v$ mgnovenili oka sbi ich

(s) steny 1 napolni rov mertvych. Amurat že, nekyj janyčanin, krepok oyj telom, smeśavsja s greky, dojde Zustuneja 1 načat sešc̆l ego ljute. Grečin je nekyj, skočiv (s) steny, otseče emu nogu sekiroju 1 tako izbavi Zustuneja ot smerti. Plaburar že paki zapadnyj, Amarbej, s ovoimi polky napade na greky, 1 byotb seča velija."

'Und schrecklich war es, die Künhbeit und die Tapferkelt beider (Heere) zu sehen.

Giustiniani sammelte wiederum viele Leute, erhob ein Geschrei und stürzte sich mit solchem Mut auf die Türken, daB er sie buchstäblich in einem Augenblick von der Mauer herunterjagte und den Graben mit Getoteten anfullte. Ein Janitschare aber, Murad, ein Hüne von Gestalt, mischte sich unter die Griechen, kämpfte sich zu Giustiniani heran und begann, furchtbare Hiebe gegen ihn zu fuhren. Da aber sprang ein Grieche von der Mauer und schlug dem Janitscharen ein Bein ab - so rettete er G1ustintani das Leben. $D_{a}$ warf sich der Plaburar Omar-Bey, der Befehlshaber des Westens, mit seinen Abteilungen gegen die Griechen, und es kam zu einer gewaltigen Schlacht.'

Der das Zitat einfürende Satz ("I be strašno videti ...") schllebt elnen stärker referierenden Abschnitt $a b$ und leltet über zur folgenden dramatischen Szene. Die Sätze sind kurz, kurzatmig fast. Die Hektik des Geschehens uberträgt sich beinahe auf den Leser. Das Stakkato der kurzen Sätze, die Menge der Informationen auf engstem Raum, in knappster Polge, vermittelt jenen Eindruck sich ubersturzender Ereignisse, von dem wir bereits sprachen.

$56 / 10$ "I se $2 \mathrm{mij}$ vnezaapu vyšed iz nory, poteče po mestu, 1 able svyše orel spad, zmija pochvati 1 polete na vysotu, a $2 \mathrm{mlj}$ načat ukrepljatisb vokrug orla. Cesarb že 1 vol l judie bjachu_zrjağče na orla 1 na zmiju; orel že vozletev iz oćbju na dolg čas, 1 paki javisja nizletajušc 1 pade 8 zmlem na tož mesto, poneže odolen bystb ot zmija. 
Ijudie že tekše zm1ja ubišą, a orla 1zymaše, ${ }^{105} 1$ byatb cesarb vo užase velicem 1, sozvar knižnik1 1 mudreci, skaza 1ch znamenie, ..."

'Und siehe, da kam plotzlich eine Schlange aus ihrem Loch und kroch über die Stätte (wo die stadt entstehen sollte); aber ein Adler stieb von oben herab, packte die Schlange und $f l o g$ mit ihr davon. Doch die Schlange begann, sich um thn zu winden. Der Katser und alle selne Leute lieBen den Blick nicht von Adler und Schlange. Für längere Zeit verschwand der Adler aus dem Blick, tauchte dann wieder auf - nahe der Erde gleitend, schlieblich stürzte er an der glelchen Stelle zu Boden, von der Schlange uberwunden. Die Menschen aber liefen herbe1 und toteten die Schlange und befreiten den Adler. Der Kaiser aber war sehr erachrocken, rief die Schriftgelehrten und die Woisen herbel und befragte sie nach der Bedeutung dieses Zeichens, ...'

Während Im vorigen Textbelopiel eine Folge kürzerer Vorgänge in ihrem Ablauf dargestellt war, haben wir es in diesem Abschnitt mit einem einzelnen Geschehen zu tun - mit einem Erelgnis von höchster ldeologischer Brisanz. Telegrammotilartig werden die Fakten geboten; der lakonische stil erhäl noch weitere Konzentration durch die Verwendung von Partizipien in der Punktion von Adverbial-Partizipien. Einmal allerdings wendet der Autor den Blick von der Dramatik des Geschehens zu den regungslos den Vorgang Betrachtenden: "bjachu zrjašče" diese Verlaufsform betont die Dauer eines Vorganges, die fast an einen Zustand angrenzt. Durch diesen Kunstgriff - die Gegenuberstellung des atemberaubenden Geschehens und der wie gelähmt die Szene Beobachtenden - erhält die Beschrelbung zusätzliche innere Spannung.

Im Rahmen der Untersuchungen über das Ipf. war von " $12 y m a e^{\prime}$ die Rede, das wir wegen der Parallelstelle wenige Zeilen apäter als Verschreibung für "1zymas̆a" Interpretieren. "1zymaša" lot 3.pl.aor. der suffigiert-dehnstufigen Ableitung von "1zjati"; "izymati" murde sicher bereits als imperf. Aspektpartner zu "izjati" empfunden. Verwunderlich ist nun, warum der K-pler Autor an dieser Stelle "ubiěa" und "izymaše (=-ă̌a)"

105) Die Pargllelstelle, wenige Zellen tiefer, lautet: 56/23 "A poneze krestbjane zmija ubisa, a orla 1zymasa, javljaet, ..." 
koordiniert hat; denn nach "ubiša" wijde nan eher "12jaša" erwarten. DaB der $\mathrm{K}$-pler Autor nicht 80 schenatiach verfahrt, läbt die Vermutung su, dab der Autor habe differenzieren wollen: Das Töten der Schlange wird punktuell geeehen - als ein Schlag auf den Kopf oder Xhnliches, das Befreien des Adlers von der (toten) Schlange soll anscheinend als langwierige Handlung verstanden werden, an der viele Leute betelligt waren. Die ausdrückliche Wiederholung belder Verbformen "ubiša" und "izymaš" wenige zellen tiefer stutzt unsere Vermutung.

76/44 "..., 1 (Magumet) udivis ja toliku narodu ot odnoja chraminy 1ršedčim, 1 polde $k$ carskomu dvoru, 1 tu srete ego neky J serbin, prinese emu cesarevu glavu. On że vosradovasja zelo 1 vakore pozve boljar 1 stratig 1 spros 1ch, da ... On1 že, strachom oderž1m, rekoša enu: '...'n '...., und Mehmed verwunderte $81 \mathrm{ch}$ sehr uber die Menge Volkes, die da aus einer Kirche herausstromte. Er wandte sich zum Raiserpalast - hier erwartete 1hn ein Serbe und brachte thm das Haupt des Raisers. Daruber wurde er sehr froh und rief schnell die Bojaren und Strategen herbel, die er bat, das ... Sie aber, von Entsetsen ergriffen, sagten zu ihm: ...'

In diesem Bericht Ubersturzen sich die Erelgnisse nicht so wie im Rahmen der vorigen Textbelopiele. Dennoch durfen wir diese Textstelle zu den ubrigen atellen - das innere Engagement des Autors, das Entretzen uber das zu Beriohtende spurt man fast aus jedem Tort: Der Sultan 18t in K-pel, das Haupt des Xaloers wird ihm gebracht. Eo handelt oleh nicht un Vorgange, die in Sekundenschnelle nachelnander ablaufen. Vielmehr gibt der Autor in wenigen, ganz kurzen Sätsen in impressionistischer Manier die wesentlichen Tatsachen, alles Obrige aussparend.

An diesem Textbeisplel mit seinen vielen knappen satzen wird die Stellung des Prädikats vor dem Objekt, die fur die K-pler Ersählung typisch 1st, besonders deutlich. 
2.8.1.2 Pleskau: Der Aorlst in der

aktualisierenden situationsbeschreibung

Obrohl in der Pleskauer Erzählung der verbale Reim eine groBe Rolle spielt, lst es fast unmöglich, Beispiele emotionaler, aktualisierender Beschreibung mit dem Aor. als dominierendem Tempus aufzufinden. Wenn uns im Pleskauer Text auch gelegentlich 1-Part.ien begegnen, so ist doch der Aor. für den Autor das neutral-merkmallose Erzähltempus. Zur bewegten bzw. bewegenden Schilderung bedient er sich des Ipf., des Part.praes., des Part.praet, gelegentlich auch des l-Part. und schlieblich des Praes.hist.

Zwei Textstellen, die wir bereits in anderem Zusammenhang vorgestellt haben, könnte man hier anfuhren. Beim Lesen wird aber gleich auffallen, daB wir hier nicht jene Intensität der Darstellung, jene aktualisierende Wiedergabe des sich (faktisch oder im Denken des Autors) uberstúrzenden Geschehens wiederfinden, das in der K-pler Erzählung so häufig auch mit dem Aor. verbunden ist. Wiewohl man in der Pleskauer Erzählung (siehe Beispiele) die innere Beteiligung des Autors durchaus spüt, ist der Eindruck des statischen Berichts doch stärker:

62/30 "Molebnaja že mnogaja k bogu i bogorodicy tuto peša, 106 1 tako to mesto krestom ogradisa

i svjatoju vodoju okropiša.

Tako že i gosudarevy bojare i voevody krestom blagoslaviša i svjatoju vodoju okropiša

i na podvig vooružiš, ....n107

64/13 "Takože 1 nautrija pjatb časov bezprestani po gorodu iz narjadu biša 1 vybiša u goroda gorodovyja steny, dvadcatb četyre sažent do zemli, da Pokrovskuju bašnju do zemli, da u Svinoj bašni ochab vesb do zemli, da Svinoj bašni polovinu do zemli že zbisa, da mestami steny

106) Verbaler Reim - Objekt vor dem Prädikat.

107) Ubersetzung der Textstelle - s.0. S. 423 oben. 
gorodovye zb1 šă, šestbdesjat devjatb saženb. Sie že 1zb1s̆a 1 gorodovuju stenu vo mnogich mestech 1 12sprolomaša. I gie korolju svoemu vozvestiša. "108

Gerade die letztere Textstelle nimmt eine 2 witterstellung zwischen statistischer Aufzählung und verzweifelt-überstürzter Nennung der durch die Beschießung entstandenen Schäden ein. Andere Textstellen, die hlerher gestellt werden könnten, fehlen bzw. sind noch wentger liberzeugend als die beiden eben ange fuhrten.

2.8.2 Der Aorist in berichtenden Passagen

Wenn wir den Aor. in berlchtenden Passagen beleuchten wollen, dann geht es uns nicht darum, vereinzelte Belege hierfur vorzustellen, die wir überall zu Hunderten finden - etwa von folgender Art: ${ }^{109}$

KP 64/14 "I tako božilm promyslom $v$ toj denb 1zbav1sja grad ot bezbožnych turok."

- Und 80 wurde $K$-pel durch die gottliche Vorsehung vor den gottlosen Türken gerettet.'

PS 44/20 "I tako 1spust1 ich v bogochranimy grad Pskov: ..."

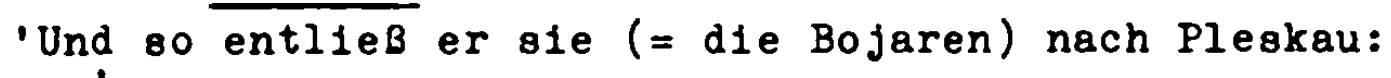
-..'

Vielmehr wollen wir den Aor. bzw. Aor.-Formen im gröBeren Kontext betrachten - einmal im raffenden, konstatierenden und einmal im stärker differenzierenden Bericht. Im letzteren Kontext werden die Vorgange stärker reflektlerend vorgetragen, die Handlungen je nach ihrer Qualität imperfektisch oder aoristisch bezelchnet - der Autor setzt die verschiedengearteten Geschehen, Tätigkeiten, Handlungen, Zustände, Prozesse usw. zueinander in Beziehung und er lot gezwungen, diese verschiedenen Informationen in der ihnen gemäBen Weise auszudricken -

108) Ubersetzung der Textstelle - s.0. s. 393.

109) Von dieser Qualität alnd die Belspielsätze Boretzkys, Tempusgebrauch, S. $56 \mathrm{f}$ : von 6 Sätzen sind 5 eine Zeile lang und haben elnen Aor. als Prädikat; kein Kontext. 
die subjektive wahl deo Tempus ist nicht mehr in dem HaBe gegebem (wie z.B. In der aktualisierenden Situationsbeschreibung, wo ein vorgegebenes bzw. einmal gewbiltes Tempus durchgehalten wird). An Textstellen mit differenzierend-reflektierender Textgestaltung kann man erkennen, ob ein Autor die Tempora so verwendet, das dem Leser eine sinnvolle, logische Vorstellung (und wenn es allein die des Autors 1st) vom Geschehen und das lachvollziehen der Gedanken des Autors möglich wird - oder aber, ob die Verwendung der Tempora eine zufallige ist, so das die Rekonstrulerung bestimmter Geschehensbzw. Denkstrukturen gestört 18t. 110

2.8.2.1 K-pel: Der Aorist in berichtenden Passagen

Bevor wir einige Textbeispiele mit reflektierender Darstellung vorfuhren, wollen wir an einigen Belegen die konstatierende Punktion des Aor. im Bericht demonstrieren. Auch dabei dominiert der Aor. als verbales Tempus den Abschnitt, doch im Unterschied zum Aor. In der aktualisierenden Situationsbeschreibung wird hier resumiert, zusammengefast, zurúckgegriffen, es wird der Ubergang zur nächsten lebendigen szene geochaffen, wobel im Aor. das zwischen zwol Szenen Geschehene berichtet wird.

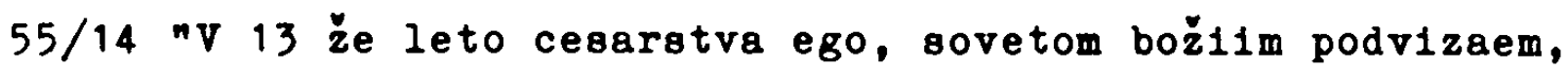
voschote grad sozdat1 $v$ Imja svoe 1 posla mužej dostojnych $v$ Asiju 1 v Liviju 1 v Evropiju na vayskanie 1 1zobranie preslavna 1 naročita mesta na sozdanie takovago

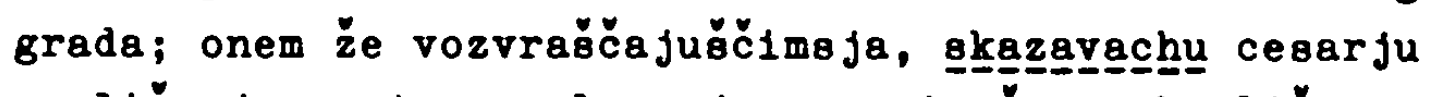
različnyja mesta preslavnaja, a naipače pochvališa emu Makedoni ju 1 Virandiju."

'Im 13. Jahr seiner Regierung wollte er (Kaiser Konstantin), durch Gottes Rat bewogen, eine Stadt gründen, die seinen Namen tragen ollte. Br schickte würdige Manner nach sifen und Lybien und nach Buropa, damit sie einen ruhmvollen Platz zur Grindung einer solchen stadt suchten. Als ole zurúckkehrten, nannten ole dem Kaiser ver-

110) Als Störung ist z.B. zu bezeichnen, wenn im Pleskauer Text die Endung der 3.8g.1pf. $-(j)$ ase auch die $3 . \mathrm{pl} .1 \mathrm{pf}$. oder die 3.pl. aor. ersetzen kann. 
schiedene beruhmte Gegenden, vor allem aber priesen ale Makedonien und Byzanz.'

Hach einigen allgemeinen Norten über die Regierungszeit Kaiser Konstantins teginnt mit dieser Textstelle der Bericht uber die Gründung K-pels: In raffender Erzählweise werden die wichtigaten Fakten zusammengetragen. Auffallend in diesem Abschnitt, $z$ wischen diesen konstatierenden Aor.-Formen lst das Ipf. "gkazavachu" (für "skazovachu") - es soll offenbar die Vielzahl der in alle Welt entsandten Kundschafter einerseits, aber auch die Vielzahl der von diesen genannten wirdigen Plätze unterstreichen. Wie aber bereits verschiedentIich betont, sind gerade Ausdrücke des Sagens so der Habitualisierung unterworfen, dab hier auch automatischer Gebrauch einer $x$-beliebigen Form vorliegen kann.

$56 / 39$ "Sozda že cesarb i polatu velikuju, 1podromu predivnuju 1 dve pole ustroi, rekše ulicy pokroveny na torgovanie. I nazva grad Novyj Rim. Potom že sozda cerkvl preslavnye: Sofeju velikuju, ...; postavi $z i$ prečjudnyj on stolp bagrjanyj, ego že iz Rima prinese morem treju lety do Carjagrada, ...."

- Der Kaiser ließ einen groBen Palast errichten, ein wundervolles Hippodrom und zwei uberdachte StraBen zum Handeltreiben. Er nannte diese Stadt 'Das neue Rom'. Sodann lieB er hochberühmte Kirchen bauen: die Hagia Sophia, ...; auch ließ er Jene vielbewunderte Porphyrsäule aufstellen, die aus Rom während einer drel Jahre dauernden Seereise nach $\mathrm{K}$-pel gebracht worden war,...'

Nach dem erregten Bericht über den Kampf des Adlers mit der Schlange folgt dieser wieder referierende Abschnitt, wo Fakten vermittelt werden, die einen Eindruck von der GröBe und Schönhe1t $K$-pels geben sollen (damit vor diesem Hintergrund der Nledergang der Stadt umso deutlicher werde).

Den konstatierenden Charakter der Textstelle unterstreicht auch der Relativsatz "ego že 1z Rima prinese ..." - Hypotaxe dieser Art 1st fur die aktualisierende situationsbeschreibung nicht typisch (1m Gegensatz zum Adverbial-Partizip, das der Darstellung noch mehr Gedrängtheit verleihen kann). "prinese" - 'hatte herbringen lassen' bezeichnet Vorzeitigkeit. 
58/13 "Takož 1 nyne, v poslednjaja vremena, grech radi nas̆ich, ovogda nachoždeniem nevernych,

ovogda gladom 1 povetrei častymi,

ovogda že mežusobnymi branbmi,

Imiže oskudeša silbnil 1

obniščaša I judie 1

preuničižisja grad 1

smirisja do zela,

1 bystb jako senb $v$ vinograde 1

jako ovoščnoe chranilišče $v$ vertograde."

'So 1st es auch jetzt und in jüngster ze1t, unserer Sünden willen:

tellwelse durch Einfälle der Ungläubigen,

tellweise durch Hunger und Seuchen,

teilweise durch Fehden innerhalb der Stadt

verarmten die vächtigen,

gerieten die einfachen Leute in Not

und murde die Stadt erniedrigt

und in unvorstellbarer Meise gedemutigt.

Ond sie glich einem Schatten im Neinberg und einer Prüchtescheuer im Obstgarten.'

Rhetorisch auggefellte Passagen wie diese pathetische Klage finden wir in der K-pler Erzählung selten - gelegentlich sind zwischengeschal te te Gebeto, Anrufungen oder auch die Prophezelungen am SchluB in dieser Form gestaltet. - Der Autor zählt betrubt die Orsachen auf, die den Niedergang des Imperiums herbelgefuhrt haben. Abgesehen von der dreifachen Anapher "ovogda" stehen auch die vier zu "imižen gehorigen Aor.-Formen in anaphorischer Position. Durch den parallelen Aufbau der einzelnen Kola gelangt ein leichter Rhythmus in die Sprache, der mithilft, diese Textstelle emotional stark aufzuladen. Das andert aber nichts an der Tatsache, dab wir es an dieser Stelle, was ihren Informationswert anbelangt, mit einem Resumee zu tun haben.

Wir kobnten auf diese Weise den Text weiter durchblättern und viele entsprechende Passagen hierherstellen. Doch wollen wir uns nun solchen Textabschnitten zuwenden, wo der Autor durch den Gebrauch verschiedener Tempora, vor allem Aor. und Ipf., eine stärker differenzierende Erzählweise anzeigt. 
66/6 Na utrija že, jako viděsa turky stenu nezadelanu, vskore naskočiša i bbjachnusja s greki: greky že bbjušcesja s nimi, pobegach hu ot nich, a turki vakryçach hu na nich, 1 vakore napadoše množestvo 1ch, ..."

'Am Morgen, als die Türken sahen, dab die Mauer noch nicht wieder hergestellt war, sturmten sie 108 und kämpften mit den Griechen. Während sich die Griechen so mit den Türken schlugen, zogen sie sich ein wenig zurück, die Türken aber schrien hinter ihnen her, und bald darauf warfen sich die meisten von ihnen zu Boden, ....'

Dem uns bereits bekannten "videša" folgt das Verbparr "naskočiša 1 bsjachusjan. Die Verschiedenartigkeit der Handlungen wird durch das Tempus besonders deutlich: die erste würden wir heute als ingressiv bezelchnen 'losspringen, auf-, losgtürmen'; die zweite Handlung ist durativ - 'fechten, kämpfen, sich schlagen', sie wird stets durch Ipf. oder Part. praes. ausgedrückt (Variante: "geščln). Ein Beweis für die differenzierende Betrachtungsweise des K-pler Autors ist "pobegachu": die Griechen waren im Begriff, eine Kriegslist anzuwenden - sie zogen sich ein wenig zurück, versetzten 80 die Tüken in einen Siegestaumel; diese folgten den Griechen; als die Turken im Schubbereich der griechischen Geschutze waren, wurde von der Stadt aus das Pouer auf sie eröffnet und Reserveabteilungen sturzten sich auf die Türken, unter denen ein schlimmes Blutbad angerichtet wurde. Selbstverständlich hätte der Autor auch "(po)bežăsa" anstelle von "pobegachu" verwenden können, doch wuirde diese Porm nie die feine Nuancierung von "pobegachu" ausdrucken - "sich ein wenig, gcheinbar zuruckziehen', der Aor. wirde der ausgedruckten Handlung den Charakter einer wirklichen Flucht verleihen. - Unter "vakryčachu" ist wohl das immer wieder einsetzende Kriegsgeschre 1 zu verstehen, mit dem die Türken ihren Kampf begleiteten, hier verstäkt durch die Hoffnung auf Sieg - keineswegs handelt es sich um einen Aufschre1, sondern um ein langanhaltendes $\mathrm{Ge}_{\mathrm{e}}$ schrei. "napadoše" (= "-ă̌ăn) - die Vorstellung des momentanen 'Sich zu Boden Ferfens' steht an dieser stelle im Vordergrund; möglich wäre auch ein Ipf., das die Vielzahl der sich zu Boden Werfenden plastischer hervortreten liebe - möglicherweise handelte es sich um eine Art Dankgebet für den (scheinbaren) 
Sieg, das die Turken auf Kommando, wie auf einen Schlag sozusagen, Boden liegend verrichteten.

67/14 "On że edin, 1meja meč $v$ ruce, gečğğe 1ch 1 na nich

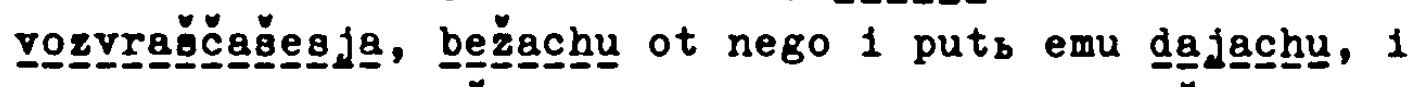
pogna $1 \mathrm{ch}$ k razrusennonu mestu 1 tu zatesnivíimsja pob18̆a 1ch mnogo, a inych zb1g̈a iz grada 1 za rvy. I tako božieju pomošc̆iju $v$ toj denb cesarb 12bavi grad, 1 uže večeru byvǐu turki otgtupiša."

'Er (= der Kaiser) allein schlug mit dem Schwert in Händen (dauernd) auf ole ein und wand te sich (immer wieder) gegen sie, sie (= die Turken) aber flohen (schlieblich) und gaben thm den Meg fre1. Er aber jagte gie zur Mauerbresche. Von denen, die sich hier zusammendrängten, töteten die Griechen viele, und die anderen jagten sie aus der Stadt und hinter die Gräben. So rettete der Kalser mit Gottes Hilfe die Stadt. Die Türken zogen sich aber erst zurick, als es bereits Abend war.'

"sečaše" bedarf keiner Erklärung. "vozvraščašesja" kann zwe1erle1 bedeuten - die Tüken sind in die Stadt gedrungen, alles flieht, nur der Kaiser lelstet weiter Niderstand. Diese Verbform meint nun entreder, daB der Kalser sich mit den Seinen zurlickzog, den Türken aber ständig zugewandt blieb, so mit ihnen kämpfend; oder sie bedeutet, daB er sich andauernd, also sehr häufig nach den Türken umwandte. Vom Ergebnis seiner Tapferke1t - die Türken zum Stehen gebracht und sie schlieblich zurúckgedrängt zu haben - her zu schließen, dürfte es sich um ein ständiges Zugewand $\operatorname{Se}$ in gehandelt haben. "bežachu" und "dajachu" zielen auf die Masse der Türken ab, die flieht und den Weg freigibt, in resultativer Erzählweige wären hier Aor.-Formen möglich. Die folgenden Aor.-Belege entsprechen gerade Jener Erzählwe1se - die Ergebnisge werden in den Vordergrund gerlickt. Der Wechsel vom durchgängigen Ipf. am Anfang zum Aor. kann dariberhinaus mit van Schooneveld so erklärt werden, daB der Autor zunächst die Szene gibt - mithilfe von Ipf.-Pormen; das im Vordergrund stehende Geschehen aber wird aoristisch ausgedrückt. 111

111) $\tan$ Schooneveld, A Semantic Analysis, S. 36 - das Ipf. gives the scene"; S. 41 - das Ipf. "1s mostly used for description, often of an effect produced by the main event, or for further elaboration." S. 55 - "the imper- 
70/27 "Patriarch že so vaem1 sobory bjagee vo svjatej velicej cerkvi 1 neotstupne mol 1 a boga 1 prečistuju ego bogomaterb o pomoženi1 1 ... Egda že uslyša zvonu, vzemše božestrennyja 1kony, 1zyde pred cerkvoju 1 sta na molitvu, osenjajušče krestom vesb grad, ..."

- Der Patriarch betete mit dem gesamten Klerus ununterbrochen in der Hagia Sophia zu Gott und der allerreinsten Gottesmutter um Rettung .... Als er den Glockenton vernahm, ergriff er die göttlichen Ikonen, trat aus der Kirche heraus und stell te sich auf zum Gebet, indem er die gesamte Stadt mit dem Kreuz beschattete, ...'

Die Verlaufaform "bjase moljan unterstreicht noch viel deutlicher als das Ipf. das Adverb "neotstupne" - 'ununterbrochen'. Besonders scharf kontrastiert es zu den folgenden Aoristen "1zyde" und "sta". Das diesen Formen folgende Part.praes. "osenjajušče krestom" lat wohl so zu deuten, daß der Patriarch die Stadt immer wieder mit dem Kreuzeszelchen segnete.

In "egda uslyğa zvonu" haben wir die einzige Textstelle vor uns, wo der sonst übliche unpräfigierte Aor. ("slyša/ša, vide/ sa" - s.S. 448, 66/6 "jako videša turky") von einem präfigierten Verb gebildet wird; vgl. Kap. 2.3.1: Aor.-Formen bei Simplicia der 4. Leskien'schen Klasse - K-pler Text. S. $401 \mathrm{ff}$.

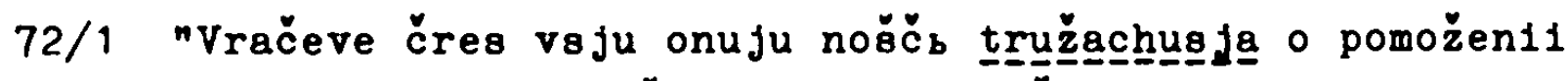
ego 1 edva 1apraviša emu grudb, vśiblenoe mesto ot udara. I abie otdochnnul ot bolezn1. I daša emu malo brašna 1 pitie, 1 tako poči (toj nošči) malo; ostavśej že dru-

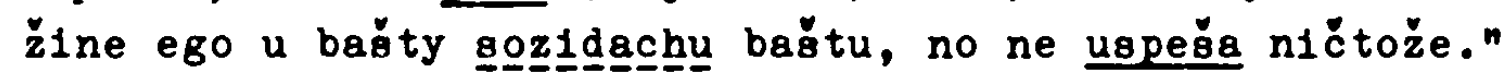
'Die Ärzte bemulhten sich die ganze Nacht darum, inm (= Giustiniani) zu helfen, und es gelang ihnen nur mit Mühe, seine Brustverletzung, die von einer Kanonenkugel herruhrte, $z u$ behandeln (und mit dem Notwendigsten zu versehen). Und bald erholte er sich. Man gab inm etwas zu essen und zu trinken. Auch ruhte er ein wenig. Selne Männer, die an jenem (zerstörten) Turm zurúckgeblieben waren und $81 \mathrm{ch}$ um dessen Tiederaufbau multen, brachten dies nicht zustande.'

"tružachusja" korrespondiert mit "čres vaju onuju noščc hervorragender Weise und unterstreicht es - isie mulhten sich

fect may denote the general 'framing' situation, which has in such cases a longer duration than the events presented by the arist." "Hervorhebg. - van Schooneveld). 
die ganze Nacht hindurch'. Den SchluBpunkt dieser Bemühungen bildet die Wiederherstellung Giustinianis - "edva ispravišn, die also durch den Aor. adäquat ausgedrückt 1st; die tbersetzung versucht, diesem Aor. gerecht zu werden - der Autor denkt offenbar an eine Art Operation mit entsprechender Nachbehandlung, die Giustiniani so weit wiederherstellt, daB er morgens an seinen Kampfabschnitt getragen werden kann. 112 Das folgende 1-Part. "otdochnul" hat die glelche Funktion wie die umliegenden Aor.-Formen. Es bezeichnet den Endpunkt von Giustinianis "bolezns", womit hier jener Zustand tiefer Ohnmacht, eines Komas vielleicht, gemeint sein dürte: 'er atmete auf = erwachte aus seiner Ohnmacht'. An ein verkürztes Perfekt 1st hier nicht zu denken, denn dies benennt eine Ursachehandlung, auf Grund welcher ein bestimmter Zustand eintritt. 113 "otdochnul ot bolezni" zeigt aber deutlich, daB wir es mit einem Endpunkt zu tun haben. "daša" deutet an, daB die Handlung selbst für den Autor ohne Interesse 1st - wichtig ist vielmehr, daB der Genueser etwas essen und trinken konnte - ein gutes Zeichen. Das gleiche gilt für die kurze Ruhe, die ihm gegönnt war "počl malo". ${ }^{114}$ Ein ähnliches Verbpar wie im ersten Satz finden wir auch im letzten: die Männer Giustinianis bauen (sicher auch die ganze Nacht) an der zerschossenen Bastel herum "sozidachu baštu", der lakon1sche Kommentar des Autors konstatiert dazu - 'es gelang ihnen nicht' - "ne uspeša ničtože".

Wir können uns weitere Belsplele, so interessant sie auch wären, ersparen. Sie wirden doch nur immer wieder den wohlbedachten Gebrauch der Tempora durch den K-pler Autor bestät1gen, den wir schon im Zusammenhang mit den Untersuchungen am Ipf. hervorgehoben hatten. Gelegentliche Unklarheiten ändern an diesem Bild gar nichts.

112) Die übrigen Quellen wissen von dieser ersten Verletzung Giustinianis nichts. Ihnen nach stirbt er unwurdig, als er nach einer Verwundung aus $\mathrm{K}$-pel geflohen war. 3.S. 58 .

113) Trost, Perfekt, S. $11, \S 22$ ff. 'er 1st gestorben = tot'.

114) "počlti" - 'ruhen', dazu in den ältesten akgl. Texten. reichlich belegt "poćivati". Das Simplex "-čijo, -čiješ" lst nirgends belegt. 
2.8.2.2 Pleskau: Der Aorist in berichtenden Passagen

Im resümierend-raffenden Bericht der Pleskauer Erzählung bildet der Aor. das Haupttempus. Ebenso wie bel der aktualislerenden Situationsbeschrelbung, wo der Aor. kaum durchgehend in Erscheinung trat und ir nicht in der Lage waren, überzeugende Beispiele für den Aor. als dominierendes Tempus vorführen, können wir auch hier nur wenige Textstelien mit alternierenden Aor.- und Ipf.-Pormen demonstrieren.

$77 / 20$ "Tako že 1 pod tuju bašnju zelsja podnesoša 1 zažgo:̌a, 1 božilm posobiem tako 1 dostals a Pokrovskie bašni vaech zbiša 1 christovoju blagodatiju paki očisti kamennaja pskovakaja stena ot skvernych l1tovskich nog. Noščl že prispevši, nam božilm miloserdiem svet blagodat1 vozsija, 1 ot steny $2 a$ gradom otbisa."

'Also brachten sie Pulver unter den Turm und entzundeten es. Und mit Gottes Hilfe gelang es, den Rest der Litauer aus dem Pokrovakij-Turm zu vertrelben; und durch die Gnade Christi war die Pleskauer Mauer wieder rein/frei von den verruchten Litauern. 115 Als die Nacht hereinbrach, brach durch Gottes Güte das Licht der Gnade luber uns herein - und man warf die Iitauer von der Mauer hinter die Befestigungsanlagen zurück.'

Nach einer sehr bewegten Schilderung der Vorgänge auf den Pleskauer Mauern (mit Anaphern und Endreim durch Part.praes., mit rhythmisierter Sprache) änderte der Autor mit unserer Textstelle Erzählperspektive und auch Diktion. "Tako že" signalisiert bereits den resumierenden Charakter des Abschnitts; durch Einwürfe wie "božilm posobiem", "christovoju blagodat1ju", "božilm miloserdiem" wird dieser Charakter unterstrichen wie auch durch die Gleichsetzung: das Vertreiben der Iitauer = das Hereinbrechen des Lichts der Gnade.

115) "očist1 ... stens ot skvernych litovakich nog" $=$ Pars pro toto (Lausberg HB I, $\$$ 573) für ide schändlichen Iltauer'. - Anschließend "svet blagodati" = sehr habitualisierte Metapher (Lausberg HB I, $\$ 558-64$ ). 
$81 / 26$ "I semu že gosudarevy ... voevody poveleša protivu prolomnogo togo mesta stenu drevjanuju sotvoriti, so mnogočlslenymi bo1, 1 mnogie bašn 1 postaviša 1 vo mnogich mestech 1 narjad 12gotoviša protivu pristupu litovskie sily. Promeži že obejuch kamennyja 1 drevjanyja steny vo grade poveleśa rov vykopati 1 postaviśa $v$ nem dubovy $J$ ostryj čosnok, tako že 1 po vsemu prolomu ... ostryj čosnok 1zstaviv, ukrepiša, jako nikolmi obrazy ... vozmožno promežb ego projti."
'AuBerdem ordneten die Voevoden an, daB eine groBe Zahl von Rriegern an der Bresche eine hölzerne Befestigung errichten sollte. Auch bauten sie mehrere Wehrturme an verschiedenen Stellen; - dort, wo sie den litauischen Angriff erwarteten, richteten sie Geschutze aus. 2wischen der (steinernen) Mauer und der hollzernen Pallisade (auf der Innenseite der Mauer) ließen sle einen Graben aushe- ben. Darin stellten sie einen Zaun mit scharfen Spitzen (aus Eichenholz) auf. Mit Hilfe dieses spitzen Zaunes, den sie längs der Mauerbresche errichteten, machten sie es jedermann unmöglich, (durch die Bresche) hindurchzu- gelangen.'

In diesem Abschnitt wird der Leser mit verschiedenen sachlichen Informationen versehen - es geht um bestimmte Verteidungsmaßnahmen zu einem bestimmten Zeitpunkt am neuralgischen Punkt der Verteidigung - nämlich der Breschenstelle, die bereits vor dem ersten Sturmangriff in die Mauer geschossen worden war und die den Litauern schon einmal als Einschlupf gedient hatte.

Trotz des rein referierenden Charakters des Abschnittes geht thm eine gewisse epische Breite nicht ab - "postavisa" und "povelešn" kommen je zwei Mal vor. Klangliche Wiederholungen oder Xhnlichkeiten sind im Pleskauer Text nichts Besonderes, doch erreichen sie hier besondere Dichte - abgesehen von den Aor.-Endungen ("-1̌̌an und "-ě̌an), die hier nicht die Sätze abschließen, fallen folgende lautliche Ähnlichkelten auf: "povelesa protivu prolomnogo togo mesta"; "protivu pristupu"; "promeži"; "po voemu prolomu"; "promežb ego projti".

Bereits an einem der Textbelsplele aus der R-pler Erzählung (8.0. S. 447, 58/13) war aufgefallen, dab belsplelswelse resinierende oder auch konstatierende Erzählwelse nicht unbedingt an nüchtern-sachlichen Erzählton gebunden 1st, sondern durchaus auch emotionalisierende Elemente enthalten kann. 
53/10 "Sija že mnogopochvalbnyja reči slyšav korolb ot sv(o) lch pervosovetnikov, tolbml že paće gordyneju na Pskov prevoznesesja, jako že drevnij 1 gordelivyj Senachirim, carb asir(ij)skij. Egda mnogija okrestnyja grady Erosalimskija za sja vzja, togda vysotoju pomysla 1 na Erosalim ustremisja, tako že na svoju silu na mnoguju nadejasja, jako reče, 'ne tokmo grada Erosalima ot mene carju Esekeju s narody otstojati, no 1 bogu nevozmožno posobiti protiv moeja bezčislenyja sily'. ZA GORDYNJU. ${ }^{116}$ Sego źe gordelivoe prevoznošenie ... uslyšav bog, sicevym obrazom. Egda prifti emu pod Erosalim 1 grad osadivšu, na utrie vostavšu Asenachirimu carju asirijsku 1 obrete ubitych svoich vo1 185 000; 1 sie uvidev, vmale družine v Ninevgiju ubeža 1 tamo ot svolch detej ubien bystb. Tako že 1 semu gordelivomu Stepanu slučisja podo Pskovom ..., jako že i Senachirimu carju."

- Diese schmeichelnden Lobreden hörte der Könlg von seinen Ratgebern; und er erhob sich in seinem Stolz uber Pleskau noch mehr als zuvor. - So verhielt es sich eingt mit dem stolzen König Sanherib von Assyrien: Als er viele Nachbarstädte Jerusalems erobert hatte, da $20 \mathrm{~g}$ es ihn im Uberschwang seines Planens nach Jerusalem selbst, wobei er sich auf die Größe seines Heeres verlieB, - denn wie geschrieben steht: 'Nicht nur wird es dem König Hiskia nebst seinen Völkern unmöglich sein, Jerusalem zu halten, sondern auch Gott yif dies gegen mein zahlreiches Heer nicht vermögen.' 17

Aber Gott sah diese stolze Uberheblichkeit und hörte die blasphemischen Worte (und er bestrafte Sanherib) auf folgende Weise: Sanherib zog nach Jerusalem und belagerte es. Als er gich am Morgen (des Sturms auf Jerusalem) erhob, fand er seine Krieger tot -185000 an der 2ahl. Als er dieg sah, floh er mit einer kleinen Schar Getreuer (= "druzina") nach Finive; dort aber wurde er von seinen kindern erschlagen. - So erging es auch dem stolzen König Stephan vor Pleskau ... - genau wie dem König Sanherib.'

Dieses Beispiel aus der biblischen Geschichte bildet eine besondere Art von Bericht - die beispielhafte Erzählung, ein

116) In der Textausgabe: fettgedruckte 2 wischenuberschrift.

117) Diese Worte fassen den Sinn aller Reden Sanheribs an Hiskia (Jesaja 36,4 - 20) zusammen, vielleicht ist besonders Vers 20 gemeint: "Welcher unter allen Göttern... hat sein Land errettet von meiner Hand, daB der Herr sollte Jerusalem erretten von meiner Hand?" 
Exempel. ${ }^{118}$ Es handelt sich um eine weitgehend summarische Tiedergabe des Geschehens. Von elnigen wertenden Epltheta abgesehen ("gordellvyj", "gordelivoe", mnogoboguchulbny ja"), verläBt sich der Autor auf die Autorität der Bibel als Quelle - er verzichtet auf jegliche Aktualisierung oder Dramatislerung, die sich u.a. In der Verwendung des Ipf. äuBern wurde. Die zwe1 Dat.abs. signalisieren die besonders hohe Stilebene, die der Autor in diesem Abschnitt anstrebt. Diesem 2weck dient offenbar auch die schwerfällige Wortstellung. In der Pleskauer Erzählung gibt es keinen anderen so langen zusammenhängenden Abschnitt, der so ausschlieblich mit Hilfe des Aor. gestaltet lot wie diesen (die verschiedenen Part1zipien schränken diese Aussage nicht ein, da wir mit diesen in der Pleskauer Erzählung ständig zu rechnen haben).

In diesem Text sind Passagen, wo der Autor Geschehnisse, Vorfälle usw. reflektlerend wiedergibt und dabei den Aor. im Wechsel mit anderen finiten Verbformen verwendet, ziemlich selten. In solchen Abschnitten bleibt der Autor meist beim Aor. (im Wechsel meist mit dem Part.praet., aber auch mit dem Part.praes. - 8.0.). Die Beisplele, die im folgenden vorgefüht werden, sind daher entweder bereits bekannt oder sind nicht immer sehr beweiskräftig.

59/9 "Gosudarevy že deti bojarskie na tom meste, na Cerechi rek1, na zastave bjase, dlja toe vest1 prichodu litovskich ljudej, uvidev zrichod 1ch na Cerechu reku ${ }^{119}$ vo Pskov pribežavše, vozvest1ša gosudarevym ... voevodam, čto uže l1tovakie pervye ljudi na Cerechu prị 'An der Cerecha waren niedere Bojaren aufgestellt (auf Wache), damit sie das Nahen der Iitauer meldeten. Als sie schileslich die Litauer gegen die Cerecha vorrücken sahen, ellten sie nach Plegkau und meldeten den Voevoden, daB die Iftauer an die Cerecha herangekommen seien.'

118) "exemplum" - Lausberg HB I, 412. Der Verbre1tung der Erzahlung nach (Jesaja, Kap. $36+37$ ) handelt es sich um oinen "typus" - Lausberg HB I, 901 - vgl. "Povestb 0 Temir-Aksake", Russkie povesti 15 - 16 vV., S. 53; NikonChrontk, PSRI 12, S. 193 u.a.

119) H1er wäre eln Komma zu erwarten - vgl. Variante S. 140: "... na Cerechu reku 1 vo Pakov pribeżase, ..." 
"na zastave bjase" muß natürlich "na zastave bjachu" sein 'befanden sich auf Wachdienst, standen Fache': die lange Dauer, für die jener Ausdruck geradezu ein Synonym ist, findet in diesem Ipf. treffenden Ausdruck. "vozvestiša" - 'meldeten, gaben Nachricht': dieser Aor. (wie auch die sonst üblichen Wendungen vor einer direkten oder indirekten Rede "reče", "rekoša") deutet an, daß der Erzähler die Nachricht als Ganzes begreift - 'sie machten folgende Meldung'. $2 u$ "prišli" sel nur vorwegnehmend gesagt (ausfühlicher s.u. Abschnitt E. V. 3: Das Perfekt und das 1-Partizip-S. 485 ff.): in der abhängigen Rede benutzt der Pleskauer Autor bevorzugt das Praes., wenn dies auch in der wörtlichen Rede gebraucht würde, und das 1-Part., wenn in wörtlicher Rede ebenfalls etwas im Präteritum ausgedrückt würde - es handelt sich also offensichtlich um den Versuch, wörtliche Rede zu stilisieren; dies ist auch hier der Fall: "... vozvestiša: 'Litovskle ljudi uže prišli!'n Und bel uns he1Bt es: "... vozvestiša, čto uže l1tovskie ljudi ... prišli." 120

"pribežavse" steht hier einwandfrei für einen Aor., es ist "vozvestiša" gleichzuordnen, also "pribežaša". 121

$64 / 28$ "..., 1 gradoemcy 1 gajduky na obed $k$ sebe paki vsech sozva. Po obede že vsem gorod Pskov vzjati ugotoviti_ sja povele. Oni že radostno 1 pochvalbno sśedšesja ch korolju, soveršenno i pochvalbno skkgzovęsé, jako ..." '.... und die Männer der Sturmabteilungen und die He1ducken lud er zu sich zum Mittagsmahl. Sie sollten alle, so befahl er, nach dem Mahle Pleskau stürmen. Als sie dann alle beim König versammelt waren - freudig und geschmeichelt, da rühmten sie ihn sehr und sprachen, daB ...'

Die Aor.-Formen bedürfen keiner Erläuterung 'er lud ein', 'er befahl'. Der folgende Tempuswechsel zum Ipf. ("skazovašen für "skazovachu") ist zwar nicht zwingend, kann aber in Hinblick darauf, daß die Rede etwas länger ist (vier Zeilen) als wenige

120) Vgl. 58/14 "slyšav vo Pskove, jako uže korolb ... prišel, 1 po ... gorodu iz narjadu uze bbet" - "dab er gekommen ist und schieBt'.

121) Variante, S. 139 - ebenfalls "pribežavšen. 
Worte, verstanden werden; $z . B$, begegnet vor meist sehr langen Reden oft "glagolachu" (52/23,67/35, 81/5, 85/25, 88/34). Uberdies mag die Entscheldung für das Ipf. auch durch die 2wei Adverbien "soveršenno i pochvalsno" beeinflußt sein, die die Aufmerksamkeit ja nicht nur auf das Gesagte, sondern auf die Art des Sprechens lenken.

$77 / 1$ "Ovil že ot nich, jako že rekoch, krepkija, v mužeskuju chrabrostb obolokšesja s l1tvoju bbjuščsja 1 nad l1tvoju odolente pokazaša:

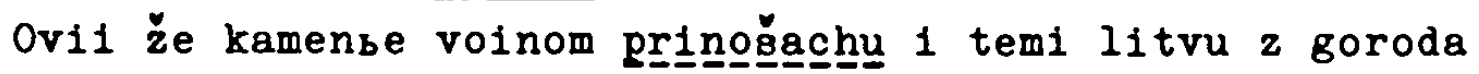
$12 a$ gorodom pobí

ovi1 že, utružšilmsja voinom, ot žažy 1znemogšim, vodu

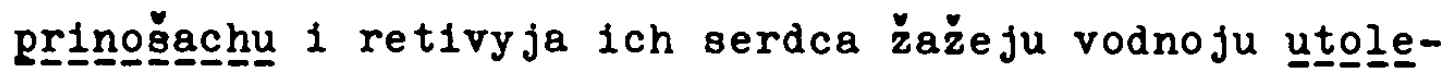
vaㅡㅁㅡ.

' Jene der Prauen, die sich - wie ich erwähnte - in männliche Kühnheit gehullt hatten 122 , kämpften mit den L1tauern und waren am Sieg beteiligt (besiegten sie): Die einen schleppten den Kriegern Steine herbei, mit denen sle die Litauer aus und hinter der Stadt vertrieben, die anderen brachten den erschöpften, von Durst ermatteten Kriegern Wasser und linderten so den großen Durst ihrer unermidilichen Herzen.'

Uns interessiert an dieser Stelle, warum es im ersten Satz heibt "odolenie pokazaš" und im nächsten Satz, der ebenfalls (anaphorisch) mit "ovil že" beginnt, "prinošachu" usw. zu lesen 1st. Die Interpunktion des Hrsg.s fuhrt uns m.E. In die Irre; die dreigliedrige Anapher tut ein Ubriges. In Wirklichkeit, so scheint es mir, liegt eine ubergeordnete Aussage vor - der erste Satz mit Aor.: Dieser Satz greift das Endergebnis vorweg, stellt fest: 'sle haben den Sieg errungen' - "odolenie pokazaš". Die belden folgenden Sätze lenken den Blick zurlick, wie nämlich die Frauen, namentlich die kräftigen unter ihnen, zum Sieg belgetragen haben - durch Herbeischleppen der Steine die einen, durch Wassertragen (und sonstige Hilfeleistungen) die anderen - das Ipf. in diesen Sätzen verleiht diesen Be-

122) 'hullten, kleideten sich in männliche Tapferke1t' "oboloksesja v muzeskuju chrabrostb; 76/25: kreposts" - 
schreibungen Lebendigkelt - "the descriptive qualities of the imperfect" ${ }^{123}$ zeigen sich hier ganz deutlich. Der Gegensatz zwischen Aor. und Ipf. druckt uberaus anschaulich zwei verschiedene Erzählhaltungen aus - die konstatierende, die das Bndergebnis mitteilt, und die aktualisierende, die den Leser in eine Szene mitten hinein versetzt.

88/13 "Elicy že 1ch litovakie gradoemcy gluboko pod stenu podsekoša, Jako 1 bez ščlta vozmožno podsekat1, 1 vodolitbem že 1 ognenym zapaleniem vyžigati ne_-_Emeǧčages voevody ... o gradoukreplenil umysliša: ...n - Einige der Litauer hatten sich bereits tief unter die Mauer gegraben, so daB ale ohne Schild hantieren konnten. Und es woilte nicht gelingen, sie durch (heiBes) Vasser (zu vertreiben) oder durch Pever auszuráuchern. ${ }^{124}$ Da fabten die Voevoden zur Sicherung der Stadt folgenden Plan: ...'

Syntaktisch stehen "ne vmeščašesja" - 'es wollte nicht gelingen' und "umyslisa" - 'sie faBten elnen Plan' auf einer Ebene. "podsekošaja" - 'hatten sich elngegraben, untergegraben' bezelchnet eine vorzeltige Handlung. - Pur das Ipf. haben wir die Ubersetzung gewählt 'wollte nicht gelingen', weil damit umschrieben 1st, daB man ständig versucht - durch heibes Wasser und Feuer -, sie zu vertreiben. Das Ipf. druckt diese ständigen Versuche durch selne mögliche Iterativ-Bedeutung mit aus.

87/22 "Podle toja že drevjanaja stena, ukreplenija radi, u kamenny ja poddelana, - s1 ju ognem zažešč ${ }^{124}$ chotłąchu. $\checkmark$ te pory 1z-za Velikija reki, 12 narjadu, vo grade u togo mesta stojaščich, streljati umysliša 1 oim grad

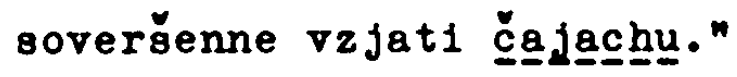

eine der ganz wenigen verbalen Metaphern in unserem Text; wir finden sie beinahe regelmäBig in der altruss. Iiteratur in derartigem Zusammenhang, vgl. z.B. Povestb - Carice Dinare, in: Rueskie povesti $15-16$ v., S. 90.

123) $\operatorname{van}$ Schooneveld, A Semantic Analysis, S. 55.

124 ) "ognenym zapalentem vy̌́igat1", "ognem zažeščln - pleonastische Wendungen, wie sie im Pleskauer Text so häufig sind. 
'Längs der (atelnernen) Mauer war zur zusátzlichen Sicherung noch eine hölzerne Befestigung (Pallisade) errichtet - die wollten ale verbrennen. Gleichzeltig - so war es 1m Plan beschlossen - wollten sie die dort Postierten hinter dem GroBen FluB hervor mit Geschutzfeuer belegen. So hofften sie, die Stadt endlich (doch noch) einzunehmen.'

Ze1tloses, zuständliches Wollen und Hoffen und - allerdings partizipial ausgedrücktes (Part.praes.) - Stehen finden wir 1m angemessenen Ipf. und im Gegensatz zu "umysliǧn". Wir haben Ubersetzt: 'so war es im Plan beschlosgen', möglich 18t auch 'so hatten sie geplant', es lot also an Vorzeitigkeit zu denken, wenn auch nicht recht einzusehen ist, warum diese so betont sein sollte; "umyšl jachu" ${ }^{125}$ wírde am Sinn der Aussage nichts andern. Diese Form bietet sich insofern besonders an, als sle "chotjachu" und "čajachu" ungefähr synonym wäre 'wollten, hofften, dachten/hatten vor'.

58/4 "Siml že slovesy ... v bogospasaemom grade Pakove

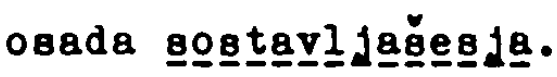

Blagodatb źs božija, upovanbe na ... ego pomoščb veem serdca na podvis podvíząše :...,

ognb že blagodat1 chriatovy

veem serdca na podvig vozvari,

vera na česnoe to delo, ....,

$$
\begin{gathered}
\text { veem telesa adamanta } \\
\text { tverźa ukrep1." }
\end{gathered}
$$

-Diese Worte leiteten die Belagerung Pleskaus ein. Die Gnade Gottes, die Hoffnung auf ... seine Hilfe bewirkten, daB sich die Herzen aller zum Kampf erhoben;

das Feuer der Gnade bewirkte, daB sich die Herzen aller zum Kampf entzundeten.

Der Glaube aber machte die Xörper aller härter als Diamant.'

Im letzten Beisplel waren bezlglich der Form "umysliğa" Pragen offengeblieben. Diese Textstelle nun reigt uns einen Tempuswechsel, der olch durch verschiedene Aktionsarten der Handlungen, durch verschiedene zeltlichkeit derselben, auch nicht durch eine geanderte Erzählhaltung des Autors er-

125) Der Pleskauer Autor verwendet auch "umyšl jat1": 95/21 "velikoe umyólenfe umys̈l jaet". 
klären läBt: Die Wiederholung ganzer Satzabschnitte in Kolon zwei und drel bewirkt, daB auch die allein sich untersche1denden Prädikate synonym werden:

... vaem serdca na podvig podvizaše: ....

... vaem serdca na podvig vozvari, ...

Dem Kontext und der Aussage selbst am angemessensten wäre an dieser Stelle sicher das Ipf., doch elne stärker resultative Erzählweise rechtfertigte durchaus auch den Aor. 'Dlese Worte hatten damal die Gnade Gottes hatte die Herzen erhoben, ... die Körper aller Gestählt'. Dies erlaubt aber nicht den Tempuswechsel im engsten Kontext. Ein solcher wäre noch denkbar nach "sostavljašesjan, da dieses Prädikat sich auf die vorauggehende Rede bezieht, diese praktisch abschliebt. Wenn wir jedoch 1m Rahmen der folgenden drei Sätze mit den Prädikaten "podvizasen, "vozvari" und "ukrepi" einen Tempuswechsel registrieren, dann können wir dies nur als willkurliche Handhabung der Tempora durch den Autor interpretieren. Der Grund lat klar: Der Autor möchte diese hochrhetorische Passage 126 nicht nur mit Endreim der Kola versehen, sondern den Reim noch variferen. So schlieBt er das erste Kolon an den vorausgehenden Satz an ("sostavljašesja - podvizaše") und schlieBt die folgenden Prädikate als gesondertes Reimpar zusammen

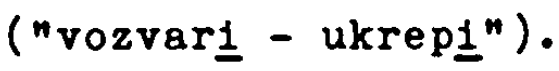

Daß diese willkürliche Verwendung der Tempora in Sätzen, die in jeder Hinsicht - formal, inhaltlich - identisch sind, möglich 1st, zeigt eine deutliche Schwächung des Tempussystems. Diese erlaubt es dem Autor, sich uber gewisse sprachimmantente zwänge hinwegzusetzen.

Textstellen, wo man einen Tempuswechsel gedanklich nicht nachvollziehen, nicht interpretieren kann, sind im Pleskauer Text wesentlich häufiger als in der $K$-pler Erzählung, doch

126) Neben den verbalen Endreimen und den refrainartigen Fiederholungen registrieren wir synonymie - "blagodatb ze bozija", "ognbze blagodati"; Antithesen - "led tajanija otçajaniem nadeźi" (in unserem 21 tat ausgelassen) "ognb ze bIagodat1"; "serdca - telegan"igesteigerter Verglelch: "voem têésa adamanta tverzae ukrepin. 
sind es letztlich jene Textstellen, wo der Autor statt des zu erwartenden Aor. (3.p8.pl.) die 3.8g.1pf. verwendet, we1l er von Verben, die seinem Bmpfinden nach imperf. aind (vor allem Verben der 4. Leskien'schen Klasse), den Aor. meidet. Sonst lassen sich Tempuswechsel immer, wenn auch im Pleskauer Text gelegentlich mit ziemlichen Schwierigkeiten (s. das letzte Beiopiel), irgendwie erklären.

36/12 "... svjatoe mesto ... Pečerskogo monastyrja okolo vae obroevaša 1 zapustö̌iša 1 mnogozelbnaja zlaja monastyrju tvor

'... die he1lige stätte des Höhlenklosters und alles ringsherum uberzogen ole mit Krieg und verheerten ele und fugten dem Kloster viel tbles zu.'

Die belden (Te1l-) Sätze beschreiben glelche Handlungen, sind also weitgehend synonym, der zweite (Te1l-) Satr opezifiziert seine Aussage vielleicht noch ein wentg. Jedenfalls muB dort einfach "so-/tvorisa" stehen - daB der Autor, wenn er von "tvoriti" intuitiv keinen Aor. bilden kann, nicht den präfigierten Aor. bildet, ist unverotändlich und kann wiederum nur mit einer gewissen Gleichgultigkeit den verbalen formen gegenuber erklärt werden.

73/19 "Tako že pak1 korolb userdisja, prílgylget k Pokrovokoj bă̌n 1 po voemu prolomu rochmistom 1 veem gradoemcem krepko bezotstupno Pskov vzjat1 veljąe. ."

'Daher geriet der König in Zorn - so schickt er zum Pokrovakij-Turm und befiehlt den sturmtruppen, Pleskau m1t aller Gewalt zu stümen/erobern.'

"userdisja" konstatiert den Zustand bzw. eine Reaktion des Könlgs, das folgende Praes.hist. aktualisiert die nächste Handlung des Königs, mit "veljašen fällt der Autor ins Präteritum suruck. "velëti" - 'Befehl ertellen' wurde ähnlich wie "reščl" im Präteritum beinahe ausschlieblich im Aor. verwendet, was die Bedeutung des Wortes nahelegt: ein fest umrisoener, klarer Befehl ist gemeint. Unser Autor weicht ins Ipf. aus, weil "velěti" in den imperf. Aspekt integriert 1ot. 
$60 / 5$ "... voevody iz narjadu po nich streljat1 veljašçe, 127 ... (puškarja) mnogie polk1 vozmuti 1 mnogich ijudeju nich narjadom pribiv. Onl že, ch korolju priechav, vozvestisa, jako ne mosno okolo grada obbechat1 ... Korols źe velja ${ }^{128}$ podale ot grada 1 lesami obbež́ati. Oni že, egdä poechaša $z$ goroda źe, tokmo černost $b$ v lese 1dušču videv. ... voevody 12 bolbs̆ovo narjadu $i$ tamo streljat1 velješe, 1 tamo že ot pskovskogo narjadu lesy prekloni 1 mogie polk1 prisloniv."

'Die Voevoden befahlen, auf sie mit Kanonen zu schieBen. Die Kanoniere brachten grobe Verwirrung in die 1itauischen Abtellungen und töteten auch viele mit ihren Geschüzen. Einige gingen darauf zum Könlg und teilten ihm mit, daß es unmöglich sel, die Stadt zu umschlieben. Daher befahl dieser, die Stadt im weiteren Abstand im Schutz der Wälder zu umgehen. Als sie sich von der Stadt zurückgezogen hatten, sah man sie nur noch als dunkle Schatten ( = schattenhaft) durch den Wald ziehen. Die Voevoden befahlen, dorthin die große Kanone zu richten. Auf diese Welse wurde viel Wald einfach umgemäht und manche Abteilung der Iitauer niedergestreckt.'

Der Abschnitt zelgt, auf welche Weise der Pleskauer Autor den Aor. von "velětı" vermeldet - neben "veljaše" statt "veleša" finden wir noch "voevody veljaščen und "korolb velja". Der Abschnitt soll aber auch etwas anderes zelgen: Man hat zwar beim Lesen der Pleskauer Erzählung 1mmer das Gefühl, dab der Autor mit den verbalen Pormen, mit den Tempora sehr frei und willkürlich verfährt. Geht man diesem Eindruck nach, hat man Schwierigkeiten, dies konkret nachzuweisen. Wir konnten zwar einfge solcher Pälle vorstellen, doch zeigen sie nicht den eigentlichen Grund der Unsicherheit, die man empfindet. Diesen Grund sehen wir an diesem Beisplel verdeutlicht: der extensive Gebrauch der Partizipien. Ich habe einmal die Partizipien unterstrichen, die ein Verb.fin., hier stets einen Aor., ersetzen. Lediglich "priechav" kann als erweltertes AdverbialPartizip gelten. Das Part.praet. tritt häufig fü den Aor. ein, gelegentlich auch das Part.praes. von imperf. Verben.

127) Variante, S. 140 - "veljasen
128) Varlante, S. 140 - "povelen. 
$84 / 14$ "..., 1 tamo chvatiöa 11tovakie jazyk1, ot nich że vest1 nakrepko perenjąa, čto l1tovakie getmany korolju ovoemu imentto pochvalisasja podkopam1 vzjat1 grad 1 ki1ždo načalbnikov roznych zemelb ovoj podkop povedoša:" '.... dort nahmen ole Iltauer gefangen, von denen ole erfuhren, daB die litaulachen Hetmane vor 1hrem König geprahlt hatten, Pleskau mit Hilfe unterirdischer Gänge zu erobern, und das der Heerfuhrer jeder Fation e1nen solchen Gang graben lieB.'

Nach den belden eraten Aorlsten, die verachiedene Pakten konatatieren (Gefangennahme von I1tauern, deren Nachrichten) werden die Mitteilungen der Gefangengenommenen referiert. "pochvalisasja" bezelchnet elne vorzeltige Handlung, die ze1tlich vor "povedoš" anzusiedeln 1at. Unklar erscheint dagegen "povedošn" selbst. Wie es hier oteht, würde man uberoetzen: 'jeder Heerfuhrer hat einen Graben gebaut'. Diese Interpretation 1at aber falach, da wir im nachsten Satz u.a. lesen: "a naperede $1(\mathrm{ch})$ vaech ugorskoj podkop pospeet" 'am weitesten olnd die Ungarn mit 1hrem Graben vorgedrungen', d.h. d1e Gräben sind noch 1m Bau.

Wentg tiefer finden wir fur den gleichen Sachverhalt eine andere Porm:

$84 / 30$ "... (on1) ne uvedåa, pod kotorye mesta podkopopy ved jaㅡ를

'... sie wuBten nicht, wo der Endpunkt der Gänge sein werde'

"vedjab̌e" könnte für "vedjachu" oder fúr "vedoša" stehen, letztere Porm wurde bedeutungsmkilg obigem "povedoša" oehr nabekomen. Da aber die unterirdischen Gange noch im Bau befindlich sind, wäre "vedjab̌e" fur "vedjachu" angemessen Ipf. als das Tempus, das eine fortlaufende durative Handlung 1ne Priteritum projiziert. Eben dieses "vedjachu" wirden wir 1n oberen Belopiel statt "povedoba" erwarten.

"vedjachu" begegnet uns in folgendem Satz:

60/16 "'Kto 11 voditelie mo1, 1 b̆e mja na Pskor vedjachnu, 1že glagolachu, jako vo Pakove bolsbovo narjadu net,... in - Mer oind diese Heerfuhrer, die nich nach Pleskau gefuhrt haben, die geaggt haben, dab...' 
Hier aber würde man "povedoša" erwarten: der polnische König spricht diese Forte vor Pleskau in dem Augenblick, als ihn die heftige Kanonade aus Pleskau zwingt, sein Lager weiter zuruckzuverlegen - er ist also vor Pleskau angelangt. Das Gleiche gilt für das folgende "glagolachu", das offenbar aus klanglichen Gründen angefugt wurde, wenn hierbel allerdings auch iterative Bedeutung denkbar ist.

Im Sinne eines temporär nicht begrenzten 'vesti', bezogen wieder auf den Bau der unterirdischen Gänge, finden wir: $84 / 24$ "A ni edin ot tech ... ne vedajut, k koemu to mestu te podkopy poveli....n

' Doch keiner von denen wuBte, wo diese Gräben ihren Zielpunkt haben würden/hinführten, ...'

Das 1-Part. 1st präfigiert, entspricht also obigem "povedošn", obgleich auch hier, wie die tbersetzung zu zeigen versucht, von einer Vollendung uberhaupt keine Rede sein kann - in unserem Text S. 86/8 - 31, zwei Seiten später erst also, wird von der Entdeckung und Sprengung dieser Gänge erzählt.

Schlieblich ist noch anzumerken, daB "povesti podkopy" auch Im Sinne von 'beginnen, Gräben zu bauen' gebraucht wird:

$84 / 22$ "... skazaša, čto uže te podkopy vae govelíi sentjabrja v 17 denb, ..."

'... ele sagten, daß diese Gräben seit dem 17. Sept. im Bau sind, ...'

In diesem und jenem Sinn schlieblich ist folgender satz zu deuten:

$84 / 26$ "Slyšav že sie ... voevody, jako litovskij korolb podo Pakov mnogie podkopy povelí, ...n

'Als die Voevoden gehört hatten, daB die Iltauer Gräben unter die Mauern Pleskaus begonnen hatten/bautẹn, da...'

Dieser kleine Abschnitt sollte abschließend an einem einzelnen Verb "po-/vesti" den oft sehr inkonsequenten Gebrauch der Tempora Ipf. und Aor. (und damit auch der Aspekte) demonstrieren. An anderen hochfrequentierten Verben lassen sich die gleichen Beobachtungen machen. 
2.9 Der Ersatz des Aor. durch das Part.praet.

Im Zusammenhang mit der Behandlung der Partizipien wird dieser Gegenstand verschiedentilch zur Sprache kommen, doch als Ergebnis anderer Pragestel.lungen.

Innerhalb der letzten Abschnitte wurde gelegentlich auf Partizipien hingewiesen, die die Punktion des Aor. erfullen. Da wir auf das Problem der Partizipien allgemein opäter zu oprechen kommen, möchten wir diesen speziellen Komplex hier ganz kurz im Zusammenhang darstellen.

Im 16. Jh. besteht eine "buchsprachliche Korrelation ... zwischen dem Aorist und der Nominalform des Partizipo Prëteritum aktiv", 129 diese Beobachtung macht Otten an der "Stepennaja knigan, Nikiforov stellt diese Erscheinung als für die zweite Hälfte des 16. Jh.s allgemeingultig hin (nennt allerdings ausschlleblich Belspiele aus dem "Kazanskif letopisec"). 130

Boretzky fuhrt einige zahlen an, aus denen wir uns eine ungefähre Vorsteilung von den Verhältnissen machen können: ca. 2000 finiten Verbalformen stehen ca. 800 nominale Partizipien (in welcher Punktion auch immer) gegenuber, wie es scheint, als "Partizipial-Adverb", wie er es nennt - d.h. die nominalen Partizipien machen dort knapp $29 \mathrm{v} . H d$. aller verbalen Pormen aus; ${ }^{131}$ exakt den gleichen Prozentsatz ermitteln wir im Pleskauer Text - auf 1070 finite Verbalformen kommen 430 Partizipien (Kurzform); im K-pler Text ist der Anteil der nominalen Partizipien etwas niedriger - knapp 26 v.Hd. ( 1150 fin. Verbformen - 400 Partizipien).

Wie wir später sehen werden, besagen diese zahlen recht wenig. Wenn wir aber lesen, dab die melsten Kurzformen der Partizipien bel Xurbakij als adverb. Bestimmung (sekundäres Prädikat) fungieren, dann sehen wir darin einen wesentlichen Unterschied zum Pleskauer Text, wo das Part. oft ein Verb.fin. ersetzt.

129) Otten, Pin. Verbalformen, S. $269-73$.

130) Ilkiforov, Glagol, S. 154.

131) Boretzky, Tempusgebrauch, S. 55 und 127 - 140. Merkwurdig nur, dab bei Kurbskij $2 / 3$ aller nomin. Part.ien Part.praes. sind, in den von uns untersuchten Texten machen sie stets weniger als die Helfte, etwa $2 / 5$, aus. 
In der K-pler Erzählung muB man Partizipien, die ein Verb. fin. ersetzen, mühsam suchen. Das Grundschema einer Konstruktion in diesem Text ist das folgende:

(erweiterteg)
Adv.-Part.

(gebildet ron

Part.praet.)
- Hauptsatz mit -
Verb.fin. (erweitertes)

Adv.-Part.

(gebildet von

Part.praes.)

Oft fehlt eine der beiden partizipialen Konstruktionen. Aber wenn sie auftreten, stehen sie in den allermelsten Fällen an der hier bezeichneten Position.

Halten wir uns dieses Satzschema vor Augen, dann müssen uns die folgenden Konstruktionen, die ein Partizip in prädikativer Funktion enthalten, als Vergchreibungen oder sonstige Zufälle erscheinen.

65/23 "I jako učiniša mesto veliko, able vskryçav množestvo

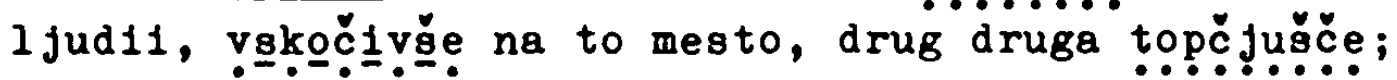
...n

' Und als sie ein groBes Loch in die Mauer geschossen hatten, da erhob die Menge (der Türken) ein Geschre1, sturmte auf diese Stelle 108, wobel elner den anderen (in der Eile) stieB; ...'

Meinem Empfinden nach wäre der Satz zu rekonstruleren:

"I jako učiniša mesto veliko,

abie vakryčav .... vokočiša na to mesto, ... topčuščen

$70 / 3$ "I tako urjadiv skvernyj v 26 denb malja, propovednikom ich otklikavse skvernuju svoju molltvu, abie vakrycavge, vge voinstvo skakachu k gradu 1 prikat1vö püky

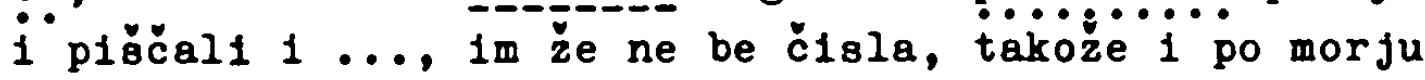
pridvinuvge korabli 1 katargy mnogyja 1 načach hu bit1 grad otvsjudu ..."

'So hatte denn der Unreine zum 26. Mai alles vorbereitet. Als ihre Prediger ihr widerliches Gebet hatten ertönen lassen, da sprangen sie alle (= das gesamte Heer) - nachdem sie in ihr Geschrei ausgebrochen waren - gegen die Stadt vor. Als dann Kanonen und Feldschlangen ... herbeigeschleppt worden waren und viele Schiffe und Galeeren in günstige Position manövriert waren - da

131) Adv.-Part. = Adverbial-Partizip. 
begannen sie, die Stadt von allen Seiten zu beschieBen -..'

Diese Stelle erinnert noch am ehesten an verschiedene Satzungetümer in der Pleskauer Erzählung. Doch bel genauerer Betrachtung zeigt sich, dab es sich hier kelneswegs um eine chaotische Ansammlung partizipialer Formen handelts "urjadiv" ersetzt allerdings einen Aor. "otklikavsé" ist entweder falsch gebildet oder verschrieben für "propovednikom ich otklikavšlm" - also Dat.abs., gebildet vom Part.praet. - also Vorzeitigkeit anzeigend zu "skakachu"; dazwischengeschaltet 1st noch das fast formelhafte "abie vakryčavsen", das sich unmittelbarer noch als das Gebet der Priester auf "skakachu" bezieht. Die Reihenfolge der Handlungen entspricht auch der Reihenfolge ihrer Nennung "otklikavše - abie vakryčavše - skakachu".

Hierauf beginnt ein neuer Komplex, der in "načachu biti" die Haupthandlung hat. Die beiden anderen - durch Part.praet.ausgedruckten Vorgänge bilden glelchberechtigte - daher auch glelchgeordnete - Voraussetzungen für das SchieBen: erst als die Geschütze in Stellung gebracht waren und die Schiffe Stellung bezogen hatten, begann die Beschiebung der Stadt.

Zwar werden wir im Zusammenhang mit den Untersuchungen am Partizip auch noch die eine oder andere stelle kennenlernen, wo ein Aorist durch ein Partizip ersetzt zu sein scheint, doch die hier vorgeführten Abschnitte enthalten die größte Konzentration von Partizipien in der K-pler Erzählung. 132

Im Pleskauer Text brauchen wir nur wahllos irgendeine Se1te aufzuschlagen und finden dort Belsplele für Ersatz des Aorlst durch ein Partizip (Part.praet. zumeist):

$42 / 1$ nMnogie že 1 besčislenye ... vol 1 v Polocki 1 vo okrestnych gradech chrabro mužestrovağğe, 1 krovi svoja za christovu veru 121 ijasa, ..."

'Viele ... Krieger in Polock und Umgebung hatten gröBte Tapferkeit bewiesen und inr Blut ... vergossen,...'

132) Abgesehen von rhetorischer Verwendung des Part.praes. in Gebeten und Prophezeiungen, z.B. $75 / 29$ ff., $69 / 7$ f. 
"mužestrovavše" und "izlijaša" sind als gleichgeordnet aufzufassen, denn es handelt sich bel diesem Satz um einen kurzen Kommentar zu der knappen Information uber die Einnahme Polocks: Es kam die Nachricht, daß der litaulsche Könlg Polock eingenommen hat - die (russische) Besatzung hat sich aber tapfer geschlagen und ihr Blut fur den christlichen Glauben vergossen.

$42 / 25$ "On že, vsegordelivyj, n1 k ušesam svolm slyšati ○ miru chotja, gosudarevych že poslov bezčesnym1 1 bezdelbnymi slovesy svolmi otḱazav."

- Dieser ubermäBig Stolze aber wollte von einem Frieden (s-SchluB) nlchts hören, sondern er jagte die Gesandten des Zaren mit Beschimpfungen davon.'

Der Diktion der Pleskauer Erzählung nach kann man "chotja" noch als erweitertes Adv.-Part. dem Hauptsatz zuordnen, obwohl die Tendenz, sich hiervon zu lösen, auch bei der von "chotja" abhängigen Konstruktion, sehr deutlich ist. Der ubergeordnete Satz hat als Prädikat "otkazav", das hier an Stelle elnes Aor. 133 "otkaza" steht. - Obige Textstelle bildet einen Abschnitt fur sich, d.h. sie 1st von zwel Uberschriften umgeben, so dab am prädikativen Charakter von "otkazav" nicht der geringste 2 weifel bestehen kann.

64/9 "... (korolb) povele panu Jurbju ugroveckomu ... iz narjadu bit1 1 velikie prolomy ... sotvorit1 dlja vijatbja Pskova grada. On že povelenbe ot korolja pr. ... (der König) befahl Herrn Georg aus Ungarn, mit dem groBen Geschutz für den Sturm auf Pleskau groBe Breschen in die Mauer zu schieBen. Dieser nahm den Befehl seines Könlgs entgegen.'

"priem" steht hier in der Punktion elnes elgenständigen Prädikats, hier also "prija", denn der Satz mit "priem" als Prädikat ist mit dem vorausgehenden Satz eyntaktisch nicht verbunden, ebensowenig wie mit dem folgenden, der mit einer Datumsangabe einen ganz neuen Abschnitt einleitet.

Im Kapitel uber die Partizipien werden wir noch viele solcher Belspiele aus dem Pleskauer Text kennenlernen.

133) Aorist $=$ Haupterzähl tempus in unseren Texten. 


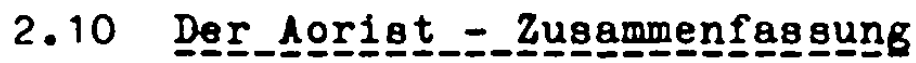

In unseren beiden Texten bildet der Aorist das Haupterzahltempus. Bezúglich seiner Bildung waren kaum Erscheinungen zu beobachten, die auf den Verfall der Kategorie als solche schließen lassen (bezüglich des Ipf. hatten wir dagegen in der Pleskauer Erzählung bere1ts deutliche störungen registriert). In belden Texten wird der Aor. belnahe ausschlieBlich von Verben geblldet, die heute perf. sind, die sicher zur Entstehungsze1t unserer Texte auch schon als perf. empfunden wurden. Die Korrelation 'präfigiert - perfektiv' deutet sich darin an, daB wir kaum Aor.-Formen, von Simplicia gebildet, auffinden (sehen wir einmal von ausgesprochenen Momentanverben vom Typ "past1, padu" ab); es handelt sich meist um Formen von 1ti-Verben, die aber heute ebenfalls vorwlegend als perf. gelten ("strélitin, "udaritin, "pustitin u.a.).

Die Texte unterschelden sich wesentlich darin, daB der K-pler Autor das Präteritum von Verben der Leskien'schen Klasse IV B (Infin.-Stamm auf -ě-/-a-, Praes.-Stamm auf-1-), vom Typ "vidětin, "slyšti" ausschlieBlich mit Hilfe des Aor. b1ldet - also lesen wir regelmäBig "vide/šan, "slys̆a/šan (zwölf Mal), "vele" und "spa" (je ein Mal). Hierin reflektlert noch ein älterer voraspektueller Zustand, den sich diese Verben, vor allem "viděti", "slyšati" und "velěti" wegen threr hohen Prequenz sicherlich erhalten konnten. Im Praes. haben sie Gegenwartsbedeutung, das Präteritum bilden sie mit dem Aor., wenn, was meistens der $\mathrm{Pall}$ ist, von einer ganz bestimmten, klar ungrenzten Angelegenhe1t die Rede 1st: der Aor. umschliebt hier die Gesamtaussage (das gesamte gesehene Bild, die gesamte gehörte Nachricht, den gesamten gegebenen Befehl Jewe1ls als Ganzes). Die Pleskauer Erzählung dagegen splegelt in dieser Hinsicht die in dem Jahrhundert, das zwischen der Entstehung unserer beiden Texte liegt, stattgefundene Entwicklung: Diese Vurben sind im Empfinden des Pleskauer Autors bere1ts 60 weit im imperf. Aspekt verankert, daB er den Aor. vermeldet und thn durch das Ipf. ungeht, verschiedentlich 
durch Part.praes., besonders oft auch durch Part.praet., was die lange Bewahrung des voraspektuellen Zustandes dieser Verben erinnert. Schlieblich sei noch einmal an den Ersatz der 3.pl.aor. durch die 3.8g.1pf. auf $-(j)$ aše erinnert ("veljašen), die so häufig im Pleskauer Text zu beobachten war (s.0. S. 341 ff.)

In der $\mathrm{K}$-pler Erzählung finden wir den Aor. In allen Bereichen gut vertreten. In der aktualisierenden Situationsbeschreibung kommt er zwar nicht so häufig vor wie das Ipf., doch konnten wir genügend Abschnitte zitieren, worin auch der Aor. dominierte. In der Pleskauer Erzählung waren gröBere Abschnitte mit dem Aor. als Haupttempus im Rahmen der lebendigen Situationsbeschreibung so gut wie nicht zu finden - diese gestaltete der Autor uberwiegend - oft reimend - durch Ipf. und Partizip.

Wie nicht anders zu erwarten, dominiert der Aor. In den sachlich berichtenden Passagen - ob diese nun elnen Sachverhalt raffend-resumferend, einfach konstatierend oder aber stärker reflektierend darstellen. In Textabachnitten, die man der zuletzt genannten Kategorie zurechnen kann, wechselt der Aor. - im K-pler Text häufig, im Pleakauer Text seltener - mit dem Ipf. Während die Wahl der Tempora in der $\mathrm{X}$-pler Erzählung durchweg elne sehr treffende oder zumindest nachvollziehbare Deutung der geschilderten Vorgänge ermöglicht, war in der Pleskauer Erzählung auch willkürlicher Gebrauch, willkülicher Wechsel der Tempora zu konstatieren. SchlieBlich brachten wir Beisplele aus der Pleskauer Erzählung herbel dafür, das manchmal das verwendete Tempus der ausgedruckten Handlung - bei Bericksichtigung des Kontextes und der jewelligen Perspektive des Autors - nicht entspricht.

Schlieblich war darauf hinzuweisen, dab in der Pleskauer Erzählung der Aor. als Haupterzlahl tempus durch das Part.praet. ersetzt wird. Diese Erscheinung - im Pleskauer Text überaus häufig - spielt in der $\mathrm{K}$-pler Erzählung fast keine Rolle. die genannten Nivellierungserscheinungen (Aor. - Ipf., Verb.fin. Part.) sind als Anzeichen beginnenden Verfalls des Temporalsystems z.z. der Entstehung des Pleskauer Textes zu werten. 


\section{Die Perfekt-Per1phrase und das 1-Partizip}

"In der zwelten Hälfte des 16. Jh.s bildete das Perfekt in der Umgangssprache die alleinige Präteritalform. ${ }^{1}$ Diese Peststellung Nikiforovs gilt bereits fur einen viel fruheren Ze1traum: so wird angenommen, dab das 1-Par.t. (mit oder ohne Kopula $)^{2}$ die ubrigen Präteritaltempora 1m 13. oder 14. Jh. 3 aus der lebendigen Sprache verdrängt habe.

Das Perfekt - so die allgemeine Auffassung - drickt einen Zustand aus, der aus einer abgeschlossenen Handlung resultiert, jedoch in der Gegenwart noch wirksam 1st. ${ }^{4}$ Diese Auffassung wurde von Trost in folgender Welse differenziert:

"Ist der Aorist eines Verbums nichtdurativ, dann ist das 1-Part. dieses Verbums perfektisch. Ist der Aorist eines

Verbums komplexiv, dann lat auch das 1-Part. dieses Verbums komplexiv. ${ }^{5}$

Anslog hierzu kommt er zu dem Ergebnis:

$$
\begin{aligned}
\text { "1-Part. eines nichtdur. Verbums }+ \text { "jestb" } & =\text { Perfekt } \\
1 \text {-Part. eines dur. Verbums }+ \text { "jestb" } & =\text { komplexi- }{ }^{n} 6 \\
& \text { ver Aorist. }
\end{aligned}
$$

1) N1kfforoy, Glagol, S. 155: "Ko vtoroj polovine XVI v v zivoj reci (perfekt - G. Str.:) ustanovilasb (...) edinaja forma prosedsego vremeñI, ..." - Hervorhebg. - Nikiforov.

2) Ich halte es nicht für sinnvoll, das durch 1-Part. ausgedruickte Präterıtum als 'Perfekt' zu bezelchnen (Nikiforov, Glagol, S. $155 \mathrm{ff}$, Boretzky, Tempusgebrauch, S. $68-91$ u.a.). Da die alte Perfektfunktion z.Z. der Entstehung unserer Texte nur noch gelegentlich durchschimmert, halte ich es fur richtiger, von 7-Part. ohne' bzw. 'l-Part. mit Kopu1a (oder Perfekt-Periphrase)' zu sprechen.

3) Efimov, Istorija russk.l1t.jazyka, S. 72 - meint, daB die Kopula ("gvjazka") bere1ts zwischen dem 11. und 13. Jh. verlorenging; Borkovgk1j. Istor. grammat1ka, S. 284 und Cernych, Istor grammatika, S. 260 - im 14. Jh.

4) Borkovskij, Istor.grammatika, S. 282 ; Cernych, Istor.grammatika, S. 259; Samsonov, Drevnerussk1 j jazyk, S. 130 u.a. Standardwerke. - otten, Pin. Verbalformen, S. 275.

5) Trost, Perfekt, S. 82, \& 153. Dort alles hervorgehoben.

6) ebda., S. 83, § 155. Also otellt die Periphrase m1t 1-Part. durat. Verben "elgentlich eine periphrastische Ausdrucksweise des komplexiven Aoristes" dar - ebda. S. 89, $\S 182$. 
Mit dieser Ansicht tritt Trost der bisherigen Forschung entgegen, welche die dem Verb innewohnende Aktionsart nur ungenligend oder gar nicht berucksichtigt habe. Seine Wiedergabe anderer Meinungen ist leider - sicher aus Raumgründen - sehr summarisch.

So kommen m.E. die Studien von P. Scholz zur Perfekt-Periphrase im Slavischen ${ }^{7}$ viel zu kurz, wenn Trost das Ergebnis dieser Analysen auf die Pormel reduziert, 8 daB nach Scholz die Perfekt-Periphrase - von perf. und imperf. Verben gebildet - die Handlung in Beziehung zur Gegenwart setze. 9 Mit solcher Charakterisierung übergeht Trost aber die Tatsache, daB für Scholz die Grundbedeutung der 1-Periphrase eine ganz andere ist: Scholz geht davon aus, dab ursprïnglich nominale 1-Bildungen die Bedeutung eines Nomen agentis hatten, ${ }^{10}$ auch im Slav. seien l-Part.ien noch lange als Nomen empfunden worden - dies bezeuge die Tatsache, dab jene fast nie ohne Kopula auftreten, jedenfalls in den ältesten Schriftdenkmälern. 11 Durch das Präsens der Kopula wird die vergangene Handlung in Beziehung zur Gegenwart gesetzt, das subjekt erscheint als der "Vollzieher einer vergangenen Handlung". "Das Perfekt versetzt nicht in den Moment der Ausfuhrung der Handlung in der Vergangenheit zurück wie Aorist und Imperfekt, sondern schreibt dem gegenwartsbezogenen Subjekt die vergangene Handlung gewissermaßen als besonderes Merkmal, Kennzeichen $z u$, das es in der Gegenwart von anderen unterscheidet." "Er (...) ist bekannt als einer, ist jetzt einer, der das und das getan hat." 12 Aus dieser Grundbedeutung erst leiten sich die verschiedenen Anwendungsmöglichkeiten $a b$, die sich daruber hinaus aus der spezifischen Semantik des jeweiligen Verbs und des Kontextes ergeben:

\footnotetext{
7) F. Scholz: Studien zur Geschichte des umschriebenen Perfekts in den slavischen Sprachen. Masch.D1s8. Hamburg 1952. weiterhin zitiert als: Scholz, Studien.

8) Trost, Perfekt, S. 87, 168.

9) Scholz, a.a.0., S. 99, 241 u.a. Nach Scholz können sogar Perf.-Periphrasen mit l-Part.ien imperf. Verben resultative Bedeutung erlangen.

10) Scholz, a.a.0., S. 7. 11) Scholz a.a.0., S. 10. 12) Scholz, a.a.0., S. 28 - unter Berufung auf Potebnja.
} 
1. Die Bedeutung des Verbs bedingt einen resultativen Sinn.

2. Subjekt, Objekt, adverbiale Bestimmung (auBer punktueller Zeitangabe!) sind besonders betont, 80 daB die $1 \mathrm{~m}$ Prädikat ausgedruckte vergangene Handlung lediglich als Tatbestand registriert wird.

3. Das Perfekt bezeichnet einen Zustand, wohingegen Aor und Ipf. (vor allem im Kontext) den spezifischen Verlauf einer Handlung charakterialeren.

AuBer diesen Bedeutungen des Perfekts, die das Subjekt in Beziehung zur Gegenwart zeigen, gibt es noch seltene Fälle, wo das Perfekt das Subjekt nicht in direkte Beziehung zur Gegenwart setzt.'13

Das Wichtigste aber bleibt, daß die durch Perfekt ausgedrükte Handlung zu einem Merkmal dessen wird, der sie vollzieht - von daher ist es letztlich unwesentlich, ob diese Handlung perfektiv oder imperfektiv, ${ }^{14}$ durativ oder nichtdurativ ist.

Diese Grundbedeutung, die Scholz dem Perf. zuweist, können wir sogar noch gelegentlich an unseren Texten nachweisen, bezeichnenderweise im sakralen Kontext, in welchem beatimmte archaische Formen und Formeln bis auf den heutigen Tag tradiert werden; auBerdem ist im Zusammenhang mit sakralen Texten oder Abschnitten religiöger Orientierung darauf hinzuweisen, "dass in den Fällen, wo Gott das Subjekt eines Satzes ist, ebenfalls Gegenwartsbezogenheit des Subjekts vorliegen kann. Denn fur den gläubigen griechischen oder slavischen Ubersetzer ist Gott eben gegenwärtig, wenn er sich in Predigt oder Gebet an Ihn wendet." 15 Wir nennen nur einige Beispiele, auf die wir später (s.u., S. 490) eingehen werden: KP 59/13 "rekl ests" - '(Christus) ist Einer, der gesprochen hat ein gesprochen Habender'; KP 59/7 "Vsja sija ... sotvoril esi" - 'Du (= Gott) hast dies alles getan - Du bist der Schöpfer'; PS 71/28 "Bog ostavil estb egon - "Gott ist der, der ihn verlassen hat'; PS $72 / 17$ "bog izbavil ny estb" - 'Gott ist es, der uns erretet hat - Er ist unsere Rettung'.

13) Scholz, a.a.0, S. $33 \mathrm{f}$.

14) Scholz, a.a.0., S. $29 \mathrm{f}$.

15) Die Ubereinstimmung meiner Pormulierung, S.490, mit dieser ist das Ergebnis volikommen unabhägiger Untersuchungen; die Scholz'schen Studien wurden mir erat nach AbschluB meiner Untersuchungen zugänglich. 
In einer Ze1t, da das 1-Part., vermutlich längst ohne Kopula gebraucht, umgangseprachlich das universale Präteritum darstellte, kann man nicht erwarten, daß so feine Differenzierungen, wie sie Scholz, Trost u.a. an den aksl. EvangelienTexten erarbeltet haben, noch relevant aind. Sogar der perfektische Zustand, resultierend aus einer Ursachehandlung, ist Im 15. und 16. Jh. am 1-Part. nur noch selten nachwelsbar, obwohl dies doch eine der wichtigsten Bedeutungen des alten Perfekts war.

In der Schriftsprache hatte sich bereits im 14. und 15. Jh. das 1-Part. (oft ohne Kopula) sehr ausgebreitet. ${ }^{16}$ Die Entwicklung hin zum Stand der lebendigen Sprache wurde 1m 15. Jh. durch den 2weiten Sudglavischen Einflub unterbrochen, die ksl. Tempora erlebten eine nachhaltige Renalssance. Diese wurde 1m 16. Jh. erneuert durch Metropolit Makarif und die Sprache seiner Kompilationen.

Unsere belden Texte gehören fewe1ls einer der genannten Epochen an - die K-pler Erzählung gehört in die Hoch- oder Spätze1t des 2weiten Sudslavischen Elnflusses, die Pleskauer Erzählung 1st zwelfelsfrel ein Spätprodukt der Makarif-Ära. Wie ein Blick auf Tabelle 1 zelgt, bemulhen sich die Autoren beider Texte darum, das umgangsoprachliche 1-Part. aus ihren werken herauszuhalten, mit unterschiedlichem Erfolg allerdings: in der K-pler Erzählung sind von ca. 850 Präteritalformen (finite!) nur sechs durch 1-Part. (mit und ohne Kopula) gebildet, das sind 0,7 v.Hd.! In der Pleskauer Erzählung finden wir von etwa 610 fintten Präteritalformen 1mmerhin schon 41 1Part.ien (mit und ohne Kopula), das sind 7 v.Hd.

Diese Verzehnfachung des Antells von 1-Part.ien am Präteritum zeigt den stelgenden EinfluB der gesprochenen auf die geschriebene Sprache, zumal alch fa belde Autoren um Vermeldung

16) Ef1mov, Istor1 ja russk.11t. jazyka, S. 72 ; Rparsky, Russ. hist. Grammat1k, S. 228: 3.8g./pl. bere1ts 1m 13. Jh. ohne Kopula die Regel; die 1.8g./pi. und $2.88 . / \mathrm{pl}$. dagegen $\frac{0 \text { r- }}{\mathrm{r}-}$ scheinen 2.B. In Birkenrindenurkunden fast ausnahmolos mit Kopula, woraus er schllebt, das diese in den genannten Fillen zur Umgangssprache gehörte. 
umgangsoprachlicher Pormen bemuhen. Um die Pleskauer Erzählung und ihren Verbalbestand richtig zu beurtellen, sel ihr die zeltgenöв818che "Istorlja velikago knjazja Moskovakago" von Kurbskif entgegengestellt: Von 1900 finiten Präteritalformen bestehen 1050 aus l-Part.1en, das oind 55,5 v.Hd.17 Bekanntl1ch hatte Kurbak1j beträchtliche l1terariache Amb1tionen..$^{18}$ - Wie achon gelegentlich erwähnt, imacht otten kaum atatiotiache Angabon uber das Vorkommen von Verbformen in der "Stepennaja kniga". Doch zelgt er, dab der Antell von 1-Part.ien in den ersten Stufen, die ja Bearbeitungen bereito vorhandener Schriftdenkmäler darstellen, hin zu den zeltgenössischen letzten Stufen sich verdoppelt. ${ }^{19}$ - Besonders aber der Vergleich mit Kurbakif durfte helfen, die Pleskauer Erzählung als - bezogen auf den Verbalgebrauch - besonders konservativ einzustufen.

Unsere Texte entoprechen bezuglich der Kopula den Normen der alteren und jungeren altruss. Ilteratur: 20 die 1.8g./pl. erocheint melst mit Kopula, die 2.8g./pl. fuhrt das Hilfsierb fast regelmäB1g, die $3.8 \mathrm{~g} / \mathrm{pl}$. kommt selten mit Kopula vor. Das belnahe regelmäß1ge Auftreten der 2.8g. m1t Kopula 18t sicher nur nebenher darauf zuruckzufuhren, daB man wegen der Homonymität der $2 . / 3.8 g$ von Aor. und Ipf. gern auf die Perfekt-Perlphrase ausgewichen sel, um die Person eindeutig zu charakter181eren: vgl. 2.3.8g. "p188ве" - Ipf., "p18a" - Aor. Durch "p1sal esin war kein Zweifel mehr möglich. 21

17) Boretzky, Tempusgebrauch, S. 38 .

18) ebda., S. 10-15. Neben der "Iotor1fa" schrieb er eine Geschlchte des Plorentinlochen Konzils 1439-42, evt. elne Erzählung uber die Erscheinungen des $\mathrm{HI}$. Augustin, evt. eine Vita Maksim Greks, dem er geistig nahestand, tbersetzungen ("Iovys Margarit" insbesondere von Joh. Chryoostomos; Joh. von Damaskus - "Nebesa" u.a.).

19) Otten, Fin. Verbalformen - Tabellen S. 287 und S. 290.

20) Vgl. die Zkhlungen D. N. Kudrjavok1jo bel K1 pargky, Ruso. hist. Grammatik, S. 228.

21) S, Słońok1; Tak zwane perfektum jezykach oXowiańskich. In: Prace f1lologicane 10 (1926). S. $1-33-$ hier S. 19 ff. : Ae Destál, Staroglovénakg praeterita,jejlch cas a vid. In: Cesky casopio filologicky 3 (1944). S. 67; Cernych. 
Die distinktive Punktion, die die Perfekt-Periphrase "vzjal es1", "plsal esin innehat, erklirt aber nicht, warum auch die 1.8g. und die 1./2.pl. so häufig in Form des 1-Part.s mit Kopula auftreten. Die 1./2.ps. Sing. und Plur. erscheinen fast ausschlieblich in der Rede bzw. im Dialog. Schon in den aksl. Evangelientexten erscheinen die melsten Belege für das Perfekt in der wortlichen Rede. ${ }^{22}$ "Die lebendige Anteilnahme des Sprechenden, die ... durch die Verwendung der Perlphrase zum Ausdruck gebracht wird, hat zwelfellos deren häufiges Aufscheinen in der lebendigen Rede bedingt; wird doch durch sie eine vergangene Handlung dem Sprecher unmittelbarer, gegenwartiger. In der lebendigen Rede durfte die 1-Periphrase zur Ze1t der Abfassung der bltesten Chroniken den Aorist durativer Verba schon weitgehend zuruckgedrängt haben." 23

D1e Perfekt-Perlphrase hatte also schon in den ältesten aksl. und altruss. Denkmälern einen Raum, in welchem sie regelmáBig, elgentlich ohne Rücksicht auf ihre spezielle Semantik, verwendet wurde. Die Annäherung der geschriebenen an die gesprochene Sprache zunächot in verschiedenen Genres, dann bie zum 15. Jh. sich ausbreitend, fuhrte zum weitgehend undifferenzierten Gebrauch des 1-Part.8 (mit und ohne Kopula), so wie er in der lebendigen Rede der altesten schriftlichen Denkmaler schon Uberliefert war. .

Während die $3.8 \mathrm{~g} . / \mathrm{pl}$. schon in den ältesten altruss. Denkmälern manchmal ohne Kopula erscheint, ${ }^{24}$ häl diese sich andererselts (besonders in der 2.8g.) bis weit in das 17. Jh. hinein - vorwlegend zu stilisierungszwecken. 25

Istor.grammatika, S. 259; N1k1forov, Glagol, S. 156; gegen Slonisi spricht sich aus: Scholz, Studien, S. $26 \mathrm{f}$.

22) Troot, Perfert, s. 92, \$§ $196-98$.

23) I, Sadnik: Der Ersatz von lorlst und Imperfekt durch die 1-Poriphrase, namentlich in Russischen. In: inzeiger fur olavische Philologie 1 (1966). S.16 - 30. Hier: S. 21. Sie erkennt in der Chronik von Susdal' (14. Jh.) erstals gróBere Ausbreitung dor Perlphrase - ebda., S. 16.

24 ) Borkovak1 1, I8tor.grammatika S. 283 , Dernych, Istor.grammat1ka, S.'260, K1 parsky, Ruse.h1st.Grammatik, S. 227 u.a.

25) Vgl. Anm. 15; dazu: Sobolevak1j, Lekc11, S. 242, Potebnja, 
3.1 K-pel_:_Belege_fur

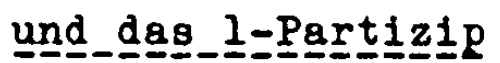

Die wenigen Belege - sechs - für Perfekt-Periphrase und l-Part. im $\mathrm{K}$-pler Text wollen wir ungegliedert vorstellen, da sich eine Auftellung des Materials nicht lohnt. 26

Drel der sechs Belegstellen bestehen aus 1-Part. mit Kopula zwe1 Mal 2.8g. und ein Mal 3.8g. Den beiden Perfekt-Periphrasen der 2.8g. otehen drei (bzw. vier) Textstelien gegenüber, die das Präteritum mit Ipf. oder Aor. bilden.

59/6 "V8ja 81ja, 1že nazede na ny 1 na grad ovjatyj, pravednym 1 lotinnym sudom sotvoril esi grech radi nas̆ich, 1 neatb nam otverst1 usty čto glagolat1; ...n 27

'Dies alles, was Du uns und Deiner helligen Stadt auferlegt hast, hast Du um unserer sünden willen in Deiner unerschöpflichen Gerechtigkeit getan; und es ziemt sich für uns nicht, den Mund zu öffnen und zu sprechen. ...'

Diese Belegstelle ist aus einer klagenden Anrufung Gottes herausgenommen: die Büger K-pels flehen Gott um Rettung an, wobe1 sie sich aber zu ihren sünden bekennen. Der präsentierte Satz und auch die vorherigen Phrasen erinnern mehr oder wentger stark an Jesaja 64, 1 - 12. Es 18t anzunehmen, das der Autor/Kompilator eine Vorlage ausschreibt oder das entsprechende Kapitel bel Jesaja gedächtnismäBig wiedergibt.

In diesem zitierten Satz finden wir den Aor. neben der PerfektPeriphrase. Beide Verbformen sagen das glelche aus - beide sprechen von den Strafen Gottes, allerdings in verschiedener We1se: während "navede" diese Strafe konkreter umschreibt, glbt "sotvoril esi" die abstrakt-theologische Pormulierung; sofort kommen Assoziationen wie "tvorec" - 'Schopfer', "tvorb", "tvarb" - 'Werk, Tat; Schöpfung, Kreatur, Geschopf' usw.

Iz zapisok, S. 243 ; Cocron, La langue, S. 230 f.; Eflmov, Istorija ruse.I1t.jazyka, S. 72; Hikfforov, Glagol, S.162.

26) Wenn in Tabelle 1 sieben Belege fur 1-Part. verzeichnet -ind, so lot darin ein Pluaguamperfekt enthalten: $60 / 10$ "dymnoe kurenie pokrylo bjase grad" - o.u.,s. 517.

27) Vgl. 58/43 - 59/10 mit Jesaja 64, besonders $1-6$, aber sinngemäB auch der Rest. 
Die Anlehnung an eine Bibelstelle, der hochsprachliche Stil der Anrufung Gottes, die Assozlationen weckende Verwendung von "sotvoriti" im Präteritum, bezogen auf Gott, den Schöpfer dies alles zusammen dürfte für den Gebrauch der Periphrase entscheidend gewesen sein. ${ }^{28}$ Generell murde von Verben, die abstrakte Vorgänge bezelchneten, bevorzugt das Perfekt gebildet. 29

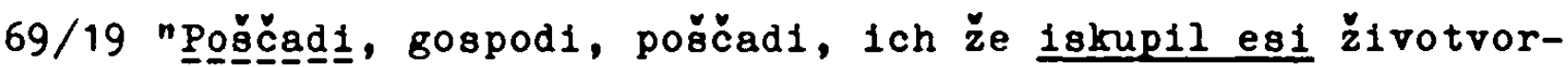
noju kroviju svoeju, 1 ne_predaj že nas vragom ..."

'Verschone uns, o Herr, die Du mit Deinem elgenen lebenspendenden Blut losgekauft hast, und gib uns nicht in die Hände der Feinde ...'

Auch diese Perlphrase durfte unbewuBt (oder bemuBt) an biblische oder andere geistliche Wendungen angelehnt sein. Sie zeigt jedenfalls ein richtig gebrauchtes Perfekt: Christus hat das Hauptkennzeichen, uns erlöst zu haben - er lst der Erlöser; s.0., S. 472 f., wir im Zustand des Erlöstseins (s.u., S. 490). Betrachten wir diese Wendung und die vorige ("sotvoril esin), die fa auch an geistliches Vokabular angelehnt ist ("gospodb sotvoril estb...n) und wie "1skupll esin einen echten 2ustand beschreibt (Gott hat alles geschaffen - seitdem ist Schöpfung), dann fragen wir nach der Berechtigung von Trosts These, daB ein echter 2ustand nur aus einer vollbrachten punktuellen, d.h. nichtdurativen Handlung erwachsen könne. Abgesehen davon, daB Trost den Stand der aksl. Sprache 2.Z. ihrer frühesten schriftlichen Plxlerung zu fassen suchte und seitdem die Entwicklung und Umformung des Verbalsystems der slav. Sprachen weit fortgeschritten waren, ist $z u$ bedenken, daB im Denken und Fühlen der Menschen alle Handlungen Gottes und Christi Ewigkeltswert hatten und ihnen daher, welcher Art die betr. Handlung auch gewesen sel, a priori Zuständlichke1t anhaftete. Solche Wendungen, die semantisch so eng an Gott und Christus gebunden sind, können

28) Otten, Pin. Verbalformen, S. 291 - 96 - ähnliche Belege aus der "Step.kniga" sleht auch Otten als Wiedergaben Elterer Vorlagen. - Vgl. van Schooneveld, A Semantic Analasys, S. 102.

29) Boretzky, Tempusgebrauch, S. 81.

30) "1skupiti" und "sotvoriti" sind durat1v.-Vgl. hierzu Scholz, Studien - 8.0., S. 472 f. 
nicht gegen Trost ins Peld gefuhrt werden.

Zum Vergleich wollen wir kurz jene Belegstellen vorfuhren, die die 2.8g. des Präteritums im Ipf. bzw. Aor. zelgen:

$68 / 43$ "Gospod1 bože nă̌, .... 1že nas rad1, neblagodarnych 1 zlonravnych, š̈ed 8 nebese, voplotivaja 1 krovb za ny prol1je: ...."

'Herr, unser Gott, der Du unseretwegen, der Undankbaren und Ungehorsamen, vom Himmel herabgestiegen und Mensch geworden bist und Dein Blut für uns vergossen hast: ...'

$73 / 26$ "Svetlejŏlj cesarju, vaja prežerečennaja o grade sem dobre vegi , tako 1 otšestrie svjatago ducha vide 1 ..." Erhabenster Herrocher, du kennst alle Prophezelungen, die diese Stadt betreffen, sehr wohl; und du hast gesehen, wie der Heilige Gelst die stadt verlassen hat ...'

$75 / 31$ " (0, gore tobe, sedmocholmi1)

.... ovogda že na vragy pobedaml proslavljaja, ne preotå̌e bo poučaja 1 k apaseniju prizyvaja ... Ty že, .... eže na tebe m1lostb božlju 1 ščdrot otvraščšesb 1 na zlodejanie 1 bezakonte obraščăesja, ...n

(Weh uber dich, siebenhugelige!)

...., wie oft hast du (siegreich) uber deine Feinde triumphiert, hast nie aufgehört zu belehren und zur Rettung aufzurufen ... (Nun aber) hast du dich von Gottes Gute und Barmherzigkeit ab- und der Misetat und der Ungerechtigkeit zugewand,$\ldots$. '

Die Zitate zelgen ganz deutlich, daB sie alle aus dem gle1chen Kontext herruhren, wie die Absätze mit den Perfekt-Periphrasen. Ein glucklicher Umotand 1st es, dab wir in der ersten Textstelle dieser Se1te - 68/43 - ein Synonym zu Beleg 69/19 der vorigen Se1te besitzen: ".... 1ch že 1skupll es1 životvor-

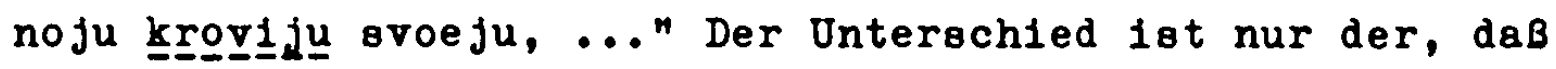
die Periphrase den Tatbestand wieder abstrakt-theologisch formuliert, wohlngegen der Aor. "prolija" den konkreten Vorgang in Worte kleidet. Die Periphrase "iskupil esin otellt klar auf den Zustand der Menschen - des Losgekauft, Erlbst-Seins ab, wahrend der Aorlot das Vergieben des Blutes Jesu vergegenwartigt, aktual181ert.

Die beiden Ubrigen Belege haben den Kaiser und $\mathrm{X}$-pel zum unmittelbaren Gegenstand der Anrede - nicht Gott oder Christus. 
Zumindest im dritten Beleg - 75/31 - haben wir eine abstrakte Aussage vor uns, die aber in dissem Pall kelne Verwendung der Perlphrase verursacht.

$59 / 11$ n..., 1 ne (ot) getavi milostb troju ot nas, 1 oglagb1 nam vo vremja se, ...; sam bo vladyka rekl estb: '....n 31

'..., und wende nicht ab von uns Deine Gute, und erbarme Dich unser in dieser zeit, ...; denn Christus selbst hat doch gesagt: ...'

Wir brauchen hier nur an Obengesagtes anzuknupfen: Handlungen Gottes oder Christ1 wurden, als das Temporalsystem noch nicht abgedrängt war, als in die zukunft weisend, neue Zustände herbelfuhrend empfunden. Daher murden auch Gott oder Chrlatus zugeschriebene Handlungen gern perfekt1sch susgedrlickt.

Im 15. Jh., da der K-pler Text entstand, war dies feine Empfinden nicht mehr lebendig. Es wird die archaische, daher ehrwirdige und im entsprechenden Kontext tradierte Porm verwendet.

Doch lot für den K-pler Autor andererselts der Gebrauch der Periphrase nicht obligat, was die st1l181erende Verwendung derselben gerade unterstreicht - vgl.:

69/9 "No ubo sam, carju 1 vladyko, čelovekoljubec 1 nezlob1v syj, ...., prorokom svo1m rek: '....n32

'Du aber selbst, Herrscher, der Du die Menschen liebst und ound los bist, hast doch durch Deinen Propheten gesagt: ...'

Die Pëfekt-Perlphrase wird in der $\mathrm{X}$-pler Brzählung ausschlieBlich verwendet, wenn Gott oder Christus Subjekt oind. Doch auch in diesem Fall gebraucht der Autor/Zompilator diese Form nicht durchgängig, vor allem Beschrelbungen konkreter Vorgänge erhalten Aor. oder Ipf. als Priteritaltempus.

31) "rekl estb" folgt Luc. 5, 32. Otten, Pin. Verbalformen, S. $287 \mathrm{f}$. - findet in der "Step.kniga" vier Textstellen vom Typ "rekls es1, Gospodi", worauf regelmbilg - wie auch bel uns, ein Blbelvers folgt.

32) Es schliebt ofch hier an Hesek1el $33 / 11$. 
Weltiche Gestalten bzw. personifizierte Gegenstände (z.B. $\mathrm{K}$-pel) werden, so scheint es, nicht der Perfekt-Periphrase gewürdigt. Während in der altruss. Literatur dieser ze1t (und später) die 2.8g. des Präteritums generell durch die 1-Perlphrase ausgedruckt wird (8.0., s. 475$), 33$ weist der $\mathrm{K}$-pler Autor weltlichen Gestalten usw. Offenbar ausschlleBlich Ipf. und Aor. zu.

Dre1 Belege finden wir im K-pler Text für 1-Part. ohne Kopula, ein Mal 1.8g., ein Mal 3.8g., ein Mal 3.pl.:

78/15 "Spisatelb že sim az mnogogrešny 1 bezakonny j Nestor Iskander, iz mlada vijat by 1 obrezan. Mnogo vremja prostradal v ratnych choženijach, ukryvajasja semo 1 ovamo, da ne ümru $\nabla$ okajanoj sej vere."

- Verfasser dessen bin 1ch - Nestor Iskander, von klein auf gefangen und beschnitten. Auf den langen Krlegszugen habe ich viel erduldet, habe mich hier und dort verborgen gehalten, um nicht in diesem verfluchten Glauben sterben zu mussen.'

So beginnt das Nachwort des Nestor Iskander, das wir nur in der von Archimandrit Leonid entdeckten Ho. lesen. Verschiedentlich hatte 1ch die Vermutung geäuBert, daB dies Nachwort einen anderen Verfasser hat als der ubrige Text, weil im Nachwort die 1.8g.aor. fast regelmäbig korrekt auf -ach, -1ch auslautet, während im gesamten Text die 1.8g.aor. fast durchgängig der 1.pl.aor. glelcht - -achom, -1chom, -ochom usw. Die 1.8g. ohne Kopula und zudem noch ohne verdeutlichendes Personalpronomen wirkt richtig modern. Auch der fast exzessive Partiziplalgebrauch entspricht nicht dem ubrigen Text.

Im obigen 21 tat ersetzt "prostradal" zweifelsfrel einen Aor. - "prostradal mnogo vremja". Der Verfasser dieser Zellen hat ewar eine riesige Zeitspanne im Sinn, doch hat er sie als Ganzes, als abgeschlossenen Abschnitt vor dem gelstigen Auge.

33) Qtten, Pin. Verbalformen, S. 307 - zwar findet er auch ein1ge Belege fur die 2.8g. Prateritum, gebildet durch Aor. - aber (seinen Belspielen nach) offenbar nur dann, wenn im gleichen Satz oder in unmittelbarer Hihe Person und Fumerus durch eine 1-Periphrase geklärt sind. 
$72 / 2$ "... 1 edva 1̇pravisge emu grudb, vŏiblenoe mesto ot udara. I able otdochnul ot bolezn1. I dąša emu malo brašna 1 pitie, ...n34

'... und mit whe gelang es ihnen, seine Brustverletzung, die von einem KanonenschuB herruhrte, zu behandeln (und mit dem Notwendigsten zu versehen). Und bald erholte er alch von der Krankhe1t (= erwachte aus seiner Ohnmacht?). Man gab thm etwas zu essen und zu trinken,...'

Die Ärzte hatten Giustiniani, den eine Steinkugel getroffen hatte, die halbe Nacht lang behandelt, vermutlich operiert "edva 1opraviša" deutet das Muhsame des Onterfangens an - doch der Aor. läBt vermuten, daB die Operation gelang. Dieser Eindruck wird wenig später bestätigt, wenn es he1Bt, daB sich der Genueser zu selnem Kampfabschnitt tragen lieB. "otdochnul" unterscheldet sich vom Kontext nur dadurch, das es Giustiniani zum Subjekt hat, während olch die umliegenden Prädikate (Aor.Formen) auf andere Personen-/Krelse bezlehen. Elne PerfektPorm kann in diesem 1-Part. auf keinen Fall gesehen werden 1m Gegente11: das Perfekt bezeichnet einen aus einer Uraachehandlung herruhrenden zustand. "otdochnul" aber signalisiert das Ende elnes Zustandes "otdochnul ot boleeni" - d.h. die krit1sche Phase war uberwunden. Naturlich lot Giustiniani damit auch im Zustand der Genesung - aber das ist nicht ausgedruckt, der Autor will zeigen, daB das Schlimmste nun uberstanden war. Das 1-Part. tritt hier in die Funktion eines komplexiven 1 or.

$66 / 29$ "... 1 tako rekogęa: 'Se uže pjatb mesjac prob̆l1, otvel1 35

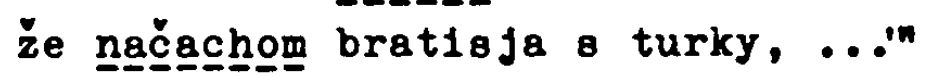

'... und so antworteten sie (wurdenträger): Sieh, aun sind schon funf Yonate vergangen, se1tdem der Kampl mit den Turken begonnen hat, ....'

Die Sprecher haben einen ganz bestimaten zeitraum vor Augen, der durch Kampfbeginn einerselts und die Gegenwart anderer-

34) $\mathrm{Zu}$ dieser Textstelle s. auch S. 450.

35) "otveli" - unklar. Ich konnte kelnen Hinwe1s auf eine solche Ronjunktion finden - weder bel Sreznevglif noch bel Sadnik-ijtzetmuller, Handworterbuch. Slovnlk, jasyka otaroslovénského II, S. 594 - fuhrt "otsve, otsvesan gesondert an als elne Art intwort-Partikel. Diese Funktion 1st hier auch gegeben, da es sich um die Antwort auf eine Rede des Kalsers handelt. Trotzdem scheint hier etwas vorderbt. 
seits begrenzt wird, zudem wird die zeitdauer - funf Monate genannt. Wie im Zusammenhang mit dem vorherigen Beleg haben wir auch hier mit einem 1-Part. mit typischer (komplexiver) Aorlst-Bedeutung zu rechnen - vgl.

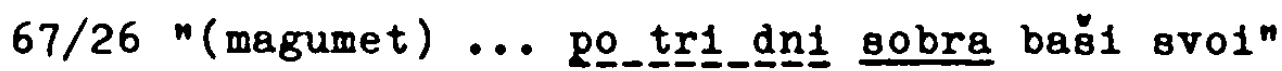
$=$ ' ... sammelte nach drei Tagen seine Paschas um a1ch'.

63/26 "Cesarb nga_dolg_čą umolča"

= 'Der Kalser verstummte für einige zeit'.

Marum der $\mathrm{K}$-pler Autor an dieser Stelle das Präteritum durch 1-Part. ausdrückt, ble1bt dunkel. Die Untersuchungen über das durch 1-Part. ausgedruckte Präteritum in der Pleskauer Erzählung zeigen (s.u., S. $507 \mathrm{f}$ ), daB besonders hoch frequentierte Verben häufig in Porm des 1-Part.s erscheinen - so, als ob es dem Pleskauer Autor besonders schwer gefallen se1, von Verben, die er andauernd - und in der Vergangenhe1t als 1-Part. im Munde führt, die alten Tempora zu verwenden; insbesondere die Komposita von "1t1", vor allem "pojti", haben den höchsten Anteil an 1-Part.ien im Pleskauer Text. Es 1st anzunehmen, daB auch an dieser Stelle "Rjat_b_mesjac prošl1" eine hab1tualialerte, geradezu 1diomatische mendung darstellt, die selbst der konservative Autor der K-pler Erzählung nicht anders als in der umgangsoprachlichen Form niederschreiben konnte.

Zusammenfassend läBt sich sagen, daB der K-pler Autor das 1-Part. sorgsam meidet. Mit Kopula wird es nur in besonders hochsprachlichen Passagen verwand, wenn Gott oder Christus angeredet werden oder aber als Subjekt eines Satzes fungieren. Doch auch dabel scheint die Perfekt-Periphrase nur dann gebraucht zu werden, wenn die Aussage abstrakt ist und zudem die betr. verbale form, die betr. Periphrase in der aksl. Literatur bereits formelhaften Charakter hat. Konkrete Aussagen erhalten im Priteritum die Porm des Aor. ("krovb za ny prolijan - 'Du hast Dein Blut für uns vergossen'). - Darüberhinaus verwendet der K-pler Autor auch für die 2.gg. Ipf. oder Aor. Das 1-Part. ohne Hilfoverb, das heutige Prateritum also, begegnet überaus selten, offenbar rein zufällig und erscheint in der Punktion des Aorist (drei Mal). 


\subsection{Plegkauㅡ: Belege fuir

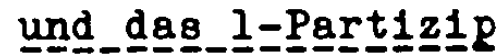

Wir haben betont und gezeigt, daB die Pleskauer Erzahlung, wenngleich aich darin der Antell an I-Part.ien verzehnfacht hat, im Vergleich zur zeitgenössischen Ilteratur als besonders konservativ im Gebrauch der verbalen Xategorien einzugtufen 1st. Wenn er auch nicht die sprachlichen Qualitäten des Autors der "Kazanskaja 18torlja" oder der Verfasaer der "Stepennaja knigan mitbringt, so lot doch das Bemühen des Pleskauer Autors unverkennbar, die Umgangssprache aus seinem Werk weitestgehend herauszuhalten.

Von daher ist es von einigem Interesse aufzuspuren, wie der Pleskauer Autor die 41 1-Part.ien in der Erzählung anwendet. Vielleicht lassen sich in Verfolgung dessen Trends aufzeigen, auf welchen Wegen das l-Part. als allgemeines Präteritum in die Literatursprache eindringen konnte.

Eine nur fluchtige Durchsicht der Belege zeigt uns, dab eine Aufteilung in 1-Part.ion mit und 1-Part.ien ohne Kopula nicht olnnvoll 1st. Die Kopula findet Verwendung regelmäig bel dem durch 1-Part. gebildeten Präteritum der 1.8g./pl. sowie der 2.eg./pl.; 36 umgekehrt erscheinen Belege mit 1-Part. der $3.88 . / \mathrm{pl}$. fast durchgehend ohne Xopula. 37 Der Inhalt der jewe1ligen Passage, worin ein 1-Part. auftritt, hat auf dessen Eracheinungsform (Perlphrase oder 1-Part. ohne Kopula) keinen EinfluB. Die Kriterien fü die Verwendung der einen oder anderen Erscheinungsform sind also keine stilistischen, oondern formal-schematische - allein auf die Person bezogen: 1./2.p8. mit Kopula, 3.po. ohne Kopula.

Im Zusammenhang mit der I-Perlphrase orscheinen folgende Formen von "byt1":

1.8g. "esmb"/negn1", 2.eg. "es1", 3.eg. "eetb";

1.pl. "esmja"/nesmen, 2.pl. "eeten, 3.pl. - fehlt.

36) Ausnahme: 82/22 "ě̌e ne vejal" - 'die ich nicht erobert habe.'

37) Ausnahme: zwe1 Bibelveree - 71/28 "Bog ostavil egts ego", 
In den folgenden Untersuchungen lassen wir den Brief eines Ausländers ("Gansumeler" - Hans Möller), 95/30 - 96/8, der vler l-Part.len enthält, auBer Betracht. Auf diesen Brief werden wir gesondert eingehen.

Von den verbleibenden 37 1-Part.ien werden 22 von folgenden Stämmen gebildet (alles Komposita):

$-1 t 1(8 j a)-8$ Belege -vesti - 3 Belege

-jati - 6 Belege -voločiti - 2 Belege

-stavit1 - 3 Belege

Einmalig kommen vor: pobili, pochvalisja, učinili, nasypali, prines, počall, posobil, zatejal, izbavil, ostavil.

2weifelsfre1 imperfektiv sind: pisal, velel, smel;

skazyvalı, vyprošalisja.

\subsubsection{Das 1-Partiz1p in der Rede}

und nach Verben des Sagens und Erfahrens

Mehr als 22 v.Hd. der Pleskauer Erzählung (13 $1 / 2$ Seiten) sind in 1rgendeiner Form persönlicher Diktion abgefabt - Monologe des Autors, Reden handelnder Personen (insbesondere der Pleskauer Voevoden), Briefe (des polnischen Kön1gs, seiner würdenträger, aber auch der Voevoden von Pleskau). Der Tempusgebrauch innerhalb solcher Abschnitte unterscheidet sich generell nicht von dem erzählender Passagen. Der Unterschied ist nur der, daB in weltlichen Reden und Briefen der Anteil der Part.ien an verbalen Formen fast ganz zurükgeht (= St1lisierung direkter Rede).

Wenn wir eingangs sagten, dab die 1./2.8g. und die 1./2.pl. des durch 1-Part. ausgedrilckten Präteritum belnahe durchgehend mit Kopula gebraucht werden, so bedeutet dies nicht, daB die betr. Personen des Präteritums ausschlieblich durch l-Part. bezeichnet werden. Dies gilt nur fur die 2.8g., die fün Mal als "l-Part. + esin" erscheint, 38 gegen eine einzige synthetische Form: 51/28 "p1saše" - 'du hast geschrieben'. Die 1.8g., die

$72 / 17$ "(gospodb) 12bavil ny estb".

38) Ygl: Nikiforov, Glagol, S. 156: "2 liço edinstv. čisla prosedsego vremeni $v$ pamjatnikach veech żanrov vyraźaetsja 118 berfektom." 
1.pl. und die 2.pl. dagegen werden vorwiegend durch Ipf. bzw. Aor. ausgedrickt. Die 3.8g. und die 3.pl. erscheinen innerhalb der Abschnitte persönlicher Diktion niemals in Form des 1-Part.8, sondern ausschlleblich in Ipf. oder Aor.

Einige Beispiele fur den Gebrauch der 1-Periphrase innerhalb peraönlicher Diktion mögen als Illustration dienen.

82/18 " $D_{a}$ veseté, reče, bojare 1 voevody, jako ne na to esm1. pri1doch pod grad vas Pskov, aby ne vzem mne ego ottyt1. Na1paçe sam1 vestê, kolocy grad1 gosudarja vašego $v$

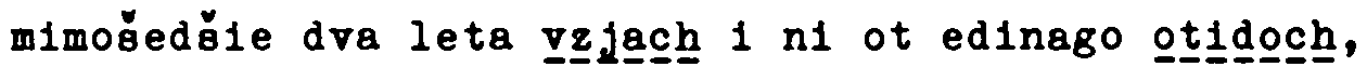
eže ne vzjal, ..."

' Ihr sollt wiseen, Bojaren und Voevoden, daB 1ch nicht nach Pleskau gekommen bin, um dann - ohne es erobert zu haben - wieder abzuziehen. Besonders gut wiBt ihr, wieviele Städte 1ch während der vergangenen zwel Jahre erobert habe und nicht abgezogen bin, bevor eine Stadt nicht erobert war, ...'

So beginnt der Brief Stephan Báthorys an die Pleskauer Voevoden, mit dem diese aufgefordert werden sollen, die Stadt dem polnischen König zu übergeben.

Eine Mischform stellt "esm1 prildoch" dar (ahnlich wie 83/12: "este k nam pisaste"), der Aor. Wird durch die in Person und Numerus entsprechende Form von "bytin, wie sle in der 1-Periphrase stehen wirde, eingeleitet. Offensichtlich handelt es olch um den Versuch, elne groBartig klingende Verbform zu konotruleren. "esmi prišel" war dem Autor wegen "prišel" (bzw. in "este pisaste" wegen "pisal") zu schlicht, da belde in der Umgangseprache wohl uberaus hiufig waren.

Danach finden wir "vzjach", "ot1doch" und "vzjal" nebeneinander. "vzjal" lat den Aor.-Formen untergeordnet, doch stehen auch diese in einem von "veste" abhbigigen (1ndirekten) Pragesatz. Die Verneinung hat auf den Gebrauch des l-Part.8 olcher keinen Binflus - sie erschelnt in diesem Zusamenhang nur noch ein Mal (92/22 "ne vajal es1"). Das 1-Part. In Verbindung mit einem Relativaatz hingegen werden wir noch ofter ronstatieren. - Semantisch besteht zwischen "vzjach" und "vzjal" kein Unterschled, es lot jewells konkret de Broberung einer Stadt gemeint. Der Autor scheint nur den Ausdruck varileren zu wollen. 
Während obige Textstelle die einzige der Pleskauer Erzählung ist, die ein 1-Part. sowie Ansatz zur 1-Periphrase im Zusammenhang mit der 1.sg. aufwelst, wir sonst aber ausschlieblich Ipf. oder corist antreffen, steht die 2.sg. im Präteritum meist mit der 1-Periphrase.

$93 / 4$ "Ty že pochvalilsja esi do konca razoriti carstvo chrestbjanskoe. Kako smel esi svoim derzostnym jazykom takoe pochvalente izrešci, - ...n

'Du hast dich geruhmt, das christliche Reich vollkommen zu zerstören. Wie konntest du es wagen, mit deiner dreisten Zunge solch prahlerischen Ausspruch zu tun?'

Beide 1-Part.ien sind von Durativa gebildet. Dennoch haben belde Äußerungen eine andere Qualität als die der bloBen Festotellung: gemeint ist nicht - 'irgendwann hast du mal das und das gesagt, die und die kuhne Behauptung aufgestellt'. Vielmehr unterstreicht die 1-Periphrase in diesen Sätzen, daB diese ÄuBerungen, diese Frechheiten nicht vergessen sind, sondern merkmalhaft dem polnischen König aufgeprägt sind. Wie einer, der gestohlen hat, gewissermaBen gebrandmarkt als 'Dieb' herumläuft, als Dieb gilt, so ist (in der Pleskauer Erzählung) der polnische König derjenige, der die (orthodoxe) Christenhe1t bedroht. Seit er die Dreistheit besessen hat, mit der Zerstörung des Reiches Christi zu drohen, ist sein wichtigstes Merkmal, die Personifizierung des Antichrist zu sein. Die rhetorische Frage "Kako smel esi ..." unterstreicht die enge Beziehung des durch die 1-Periphrase Ausgedrückten zur Gegenwart: diese Handlungen/ Worte haben nichts von ihrer Aktualität verloren, sind unvergessen. Bezeichnenderweise sind diese ĂuBerungen wieder dem religiösen Bereich zuzuordnen, zwar geht es um den Erzfeind, um Drohungen des Antichrist, aber dadurch, daB sich die Worte gegen das Relch Christi richten, gewinnen sie eine ganz andere Dimension, andere Qualität als sonst kuhne oder dreiste Worte: sie stellen die christliche Weltordnung in Frage. 39

39) Ganz deutlich zeigt sich hier die Scholz'sche Grundbedeutung der Perfekt-Periphrase: die so ausgedrúckte Handlung kennzelchnet den, der sie ausgefuhrt hat. Scholz, Studien, S. 28 . 
Im Vergleich zu den anderen Belegen von "sméti" wird die unterschiedliche Dimension der Aussagen ganz deutlich:

59/27 "k gorodu że ni pristupiti smejašen 'wagte er es nicht anzugreifen'.

95/6 "gradoemnym že delom ni s kolm ko gradu ne smejaše 1 približitisjan

'mit allem Gerät, das inm zur Einnahme einer Stadt zur Verfugung stand (evt. auch Geschütz), wagte er es nicht, sich derselben zu nähern'.

47/34 "protivo slovesi sija nikako že veščat1 smeja" 'gegen dieses Wort wagte er nicht, noch etwas zu erwidern'.

Zwar 1st diesen Aussagen auch Zuständlichkeit eigen, die in der Grundbedeutung des Verbs "smèti" liegt und in diesen Beispielsätzen noch unterstrichen 1st durch die Verneinung: 'wagte nicht anzugreifen/ sich zu nähern/ etwas zu erwidern'. Aber im Grunde sind es doch alltägliche, profane Vorgänge, die vergessen sind, wenn die jewelligen Umstände, in deren Gefolge jene Zustände eintraten, sich ändern. Man hat den Eindruck, dab der Pleskauer Autor den Unterschied in der Qualität der Aussagen noch spürt.

$96 / 33$ "No ćto rekku troeja bezumnyja derzosti, glupyj roevoda, kanclere 1 ...? Zatejal esi vyše dumy delo, vyše že boga sovet, no az tebe reku vakore: ...n

'Wle soll $1 \mathrm{ch}$ denn deine wahnsinnigen Dreistigkeiten bezeichnen, du törichter Voevode, Kanzler und ...? Da hast du ja eine Geschichte begonnen, die alle Vernunft ubersteigt, den Willen Gottes ignoriert. Ich aber sage dir schon jetzt: ...'

In diesem Satz wäre elne gewisse Zustandsbedeutung als Folge der Aussage leicht nachruweisen; jedoch: bei "zatejati" haben wir es quasi mit einem Ingressivum zu tun: 'ersinnen, im Schilde fuhren; einfädeln, beginnen'. Die desolate Lage, in der sich der Kanzler befindet, 1st daruber hinaus nicht Polge des Beginnens an sich, sondern eine Folge dessen, was er (bzw. der König) begonnen hat. Die Zustandsbedeutung, die sich aus der Aussage ergibt, 1st also nicht Folge der Periphrase, sondern des Kontextes. 
92/20 "... pri evoem stojani1 vojakimi svoiml raznymi zamyslenil velikago grada Pokova ne vzjalesi, ..."

'... Im Verlauf deiner Belagerung hast du doch trotz aller erdenklichen Pläne Pleskau nicht eingenommen,...'

Nach den beiden eher abstrakten Aussagen der beiden vorigen Belege mögen diese und die folgende Textstelle zeigen, daB ganz konkrete Aussagen genauso durch die 1-Periphrase ausgedruckt werden. 40

$51 / 24$ "A jaže p1sal es1 O grade tom, jave toliko že 1 vo vaech näich stranach ..."

' Und was du uber diese stadt geschrieben hast, ist auch in all unseren Lëndern allgemein bekannt ...'

Wenige Zellen später lesen wir:

$51 / 27$ "A jaže o ... otenach grada ... Rígegée, 1 my vedaeve ${ }^{4}$." 'Und was du uber die Mauern Pleskaus geschrieben hast, wiseen wir auch.'

Schlieblich ist auch hierher zu stellen

$83 / 11$ "... chrestbjanskoe otroča possmeetça troemu bezumeju 1 troim glupym pervosovetnikom, o nich že este $k$ nam pigeste."

'... jedes Kind in Pleskau lacht über deine Dummheit und uber deine törichten Ratgeber, von denen ihr uns geschrieben habt.'

Drei yal finden wir in diesen Sätzen im gleichen Kontext 'woruber du uns geschrieben hast' - es wird jeweils Bezug genommen auf ein Schreiben des Adressaten. SinngemäB und auch syntaktisch 18t der Kontext gleich. Die fragliche Form befindet sich jeweils in einem Relativatz, der in allen drei Sätzen fast identisch 18t. DaB wir trotzdem jedes Mal eine andere Verbalform vor uns haben, zeigt, dab die Tempora im Pleskauer Text letztlich vorwiegend stilisierende Funktion haben.

40) Vgl. van Schooneveld, A Semantic Analys18, S. 94: "the perfect does not narrate, but objectivizes." Er meint (so auch an anderen stellen), dab die Perfekt-Periphrase abstrahiert. Wir können ihm nicht folgen, wenn v.S. Iunkt1onal zwischen 1-Part. mit und l-Part. ohne Kopula scheidet. "vajal esi" und "pisalesi" sind sehr konkrete Aussagen. Zur Kritik an van Schooneveld: Budich, Aspekt, S. $44-50$.

41) "vedaeve" = eine der st1lisierenden Dualformen, wie sie der Pleskauer Autor gelegentlich in Briefen verwendet. 
Die hybride Porm "este plsaste" entspricht der bereits vorgestellten Wendung "esmi prildoch", die Funktion dürfte auch hier eine stilisierende sein: den Brief sprachlich aufuwerten und vom Kontext abzuheben, was dem Autor vielleicht durch "plsal1 este" oder "prisel esmin" nicht gesichert schien. ${ }^{42}$

Eine Ausnahme bilden zwe1 Bibelverse, die in einen Monolog des Autors eingefügt sind. Mit gröbter Sicherheit reflektiert in diesen zitaten ein sehr alter Sprachotand:

$71 / 28$ "..., vkupe glagoljušče:

- Bog ostavil estb ego, poženenete 1 vozmem ego, jako

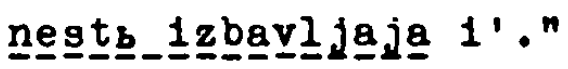

'.... (die Herrscher der Erde) rufen gemeinsam aus: - Gott hat thn verlassen, jaget nach und ergreifet ihn, denn da 1st kein Erretter'.'

Psalm 71/11 - Ubersetzung: Luther.

$72 / 16$ "..., jako vo smiren11 našem pomjannu ny gospodb 1 12bavil ny estb ot vrag naśich."

- Denn er dachte an uns, da wir unterdrúckt waren denn seine Güte whihret ewiglich -, und erlöste uns von unsern Peinden ...' Parlm 136/23-24. denn seine Güte währet ewiglich -;

D1e belden 1-Periphrasen haben zweifelofrel Zustandsbedeutung, obgleich keine von ihnen mit dem 1-Part. elnes Momentanverbs gebildet 1st. Der Zustand tritt ubrigens an dem ein, der objekt der Handlung Gottes 1st: der von Gott Verlassene befindet sich Im schlimmsten nur denkbaren Zustand, der von Gott Gerettete 1m Zustand der Erlösung. Gleichseltig gerät der betr. Akt nicht in Vergessenhelt, sondern blolbt als Charakteristikum haften an dem, der die Handlung vollzieht: Gott lst der Strafende (Altes Test.); Chrlstus 1st der Retter, der Erlöser (Neves Test.). Die Prage 1st, ob diese Bezelchnung elnes Merkmals (Subj.) und elnes Zustandes (Obj.) durch die l-Perlphrase alleln an die Allmacht Gottes oder an Chrlstus gebunden 1st - oder aber, ob

42) Sonst kommt die 2.po.pl. Prateritum in Form des 1or. vor, z.B. $71 / 16$ "spoboleznovaste; pomogaste, $49 / 24$ "slysaste". Vgl. 0., S. 472 f.: Scholz, studien, S. 29 f. 
sie der Perfekt-Periphrase dieser Verben "ostaviti" und "1zbaviti" innewohnt. Letzteres scheint der Pall zu sein, denn auch im profanen Bereich, im normalen Leben gewissermaßen, fuhren sowohl Verlassen als auch Erretten bestimmte Zustände im Betroffenen herbe1. ${ }^{43}$ Diese Annahme wird durch die Belegstelle selbst gestutzt, die ja nicht von einer Rettung im eschatologischen Sinne opricht, sondern von einer Rettung vor feindlichen Heerscharen.

In diesem Beisplelsatz - 72/17 - finden wir die Perfekt-Periphrase "izbavil ny estb" koordiniert mit einem Aor. "pomjanu ny gospodb". Diese Stelle demonstriert geradezu beiopielhaft den Unterachied 2wischen Aor. und echtem Perf. 'Gott hat unserer gedacht, hat sich unserer erinnert' - es wird etwas konstatiert, ein Faktum. Diese Handlung 'gedenken, sich erinnern' wäre im Gesamtgeschehen bedeutungslos, hätte sie nicht eine andere Handlung ausgelobt - die Rettung der Juden vor den Feinden durch Gott. "pomjanu" bezeichnet einen abgeschlossenen Vorgang, allein auf Gott bezogen; "izbavil ny eatb" aber bezeichnet eine Handlung Gottes unter Einschlub der Wirkung dieser Handlung auf die Juden - Gott rettet, die Juden befinden sich im Zustand des Gerettet-Seins - sind Gerettete.

Nun wollen wir uns solchen Sätzen zuwenden, die kurze Redeteile in den Text einbringen, die durch Verben des Sagens, des Mitteilens und auch des Erfahrens (Hörens) eingeleitet werden. Gern spricht man in solchen Pällen von indirekter Rede, zumal die betr. Nebensätze, um die es uns hier geht, fast 1mmer mit "jako" (im Pleskauer Text auch mit "cto") beginnen. ${ }^{44}$ Der Terminus 'indirekte Rede' erscheint mir hier unangebracht. Vielmehr habe ich den Elndruck, daß russ. Autoren b1s uber das 16. Jh. hinaus kurze wörtliche Äußerungen auch als solche in den Text hineinnehmen wollten. "Jako"

43) Vielleicht waren "izbaviti" und "ostaviti" schon in aksl. punktuel1, wie ja Trost, Perfekt, S. $64, \S 128.2$ "roditi oę" diese Aktionsart zuweiat.

44 ) Otten, Pin. Verbalformen, S. $308 \mathrm{f}$. - von den funf dort aufgefuhrten Belegen fur indirekte Rede würde ich (mit $\mathrm{B}_{e-}$ denken) dem ersten und dem letzten diese Bezelchnung geben. 
ist hier wohl in der Punktion eines Achtung-Zeichens, eines Doppelpunktes zu sehen; dagegen scheint mir die Konjunktion "čto" bereits die Entwicklung vorzudeuten - vom Aussagesatz zum Objektsatz, als welchen man die indirekte Rede ja bezeichnen kann.

In unseren beiden Texten werden Handlungen, die in direkter Rede präsentisch ausgedrulckt werden, auch nach Verben des Sagens, Mittellens, Brfahrens durch das Präsens bezeichnet, auch wenn der die Aussage enthaltende Satz durch "jako" ("čton) eingeleitet wird. Das Präteritum wurde in Sätzen, die wörtliche Rede wiedergaben, vorwiegend durch das Perfekt bezeichnet. 45 Der 2weite Suldslavische EinfluB hat in den hochsprachlichen Genres das 1-Part. we1t zuruckgedrängt, die 1-Periphrase erhielt stilisierende Funktion - wir konnten dies am K-pler Text beobachten. Dies bestätigt sich auch bezuglich der in den Text eingebrachten, durch "jako" eingeleiteten Redeteile: Nicht in einem einzigen Palle begegnen wir dort einem l-Part. (weder mit noch ohne Kopula) - auch in diesen Sätzen verwendet der K-pler Autor ausschlieBlich Ipf. bzw. Aor., z.B. $:^{46}$

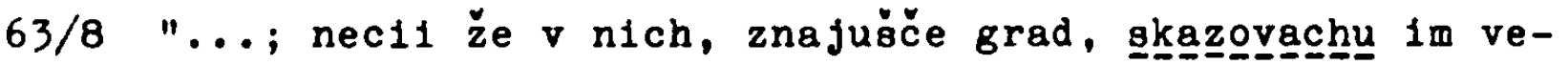
ličestvo grada 1 prostranstva 1 jako ne kosnetsja im smrad."

'..., etliche aber, die die Stadt kannten, erzählten thnen von der Größe der Stadt und ihrer ausgedehnten Lage und auch, dab der Gestank ihr nichts anhaben wer-

$73 / 12$ "... 1 tako necil skazzağa, jako 1 sam cesarb $v$ serdc1 svoem voznesesja, ..."

'... und einige sagten auch, daß selbst der Kaiser in seinem Herzen von Stolz erfulltt murde, ...'

In der Pleskauer Erzählung dagegen uberwiegen in entsprechenden Sätzen im Präteritum deutlich 1-Part.ien; das Präs. wird fast durchgängig durch eben dieses Tempus ausgedrilckt.

45) Ich verwelse nochmals auf die Zählungen Kudrjavskifs bei K1paraky, Russ.hist.Grammatik, S. 228; Tabellen bei otten, Pln. Verbalformen, S. $287+290$; Trost, Perfekt, S. 92, $\S$ 198: Uberwiegen der Periphrase in der direkten Rede.

46) Solche Sätze sind im K-pler Text selten: der Autor bevorzugt Einleitung der direkten Rede durch "se". 
Im Folgenden wollen wir die Textbeispiele ganz in den Vordergrund stellen und die Kommentare knapp halten. Auf diese Welse wollen wir das gesamte Belegmaterial vorfuhren.

$59 / 12$ n..., (det1 bojarsk1e) vozvest1 ǧa ... voevodam, śto uže l1tovskie pervye ljudi na Øerechu prï̈l1." '.... die Leute vom Aufgebot der Bojaren teilten den Voevoden mit, daB die ersten I1tauer an der Cerecha angelangt selen.'

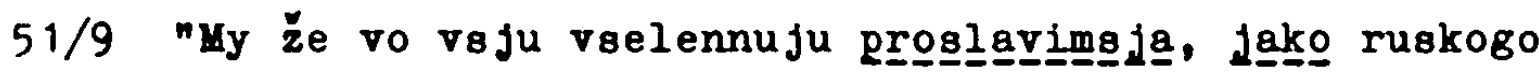
velikogo knjazja 1 slavnyj ego grad Pskov vosprifal1 esmian

'Wir aber werden uns uberall rühmen, den russischen Großfürsten und selne beruhmte Stadt Pleskau in unsere Gewalt gebracht zu haben'.

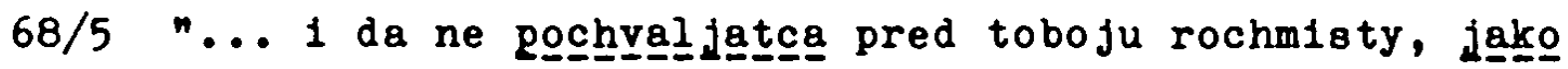
ediny 2 gajduki Pskov vosprifali esmjan". '... und damit sich die Rottmeister nicht vor dir brüsten, sie allein hätten mit den Helducken Pleskau erobert'.

In diesen dre1 Textstellen finden wir das 1-Part. nach Verben des Sagens: mittellen, sich rühmen, prahlen. Der erste Satz zelgt den Prototyp: "vosvest1ša, čto ... prišlin. Die beiden anderen Belege sind selbst Telle umfangreicherer Reden. Gerade der letzte Satz - 68/5 - zeigt ganz deutlich, daB solche Aussagesätze nach Verben des Sagens, eingele1tet durch "jako" bzw. "čto", z.z. der Abfassung der Pleskauer Erzählung d1e wörtliche Rede direkt wiedergeben sollten: die Höflinge, die Gunstlinge 47 bitten ihren König, an der Erstürmung Pleskaue tellnehmen zu dürfen - 'damit sich die Rottmeister nicht vor dir brüsten: "Wir allein haben ... Pleskau erobert!n" "vosprijal1 esmja". In indirekter Rede wäre an dieser Stelle die 3.pl. zu erwarten: "1 da ne pochvljatca ... rochmisty, jako ediny ... Pskov vosprijalin - 'damit diese sich nicht brüsten, sie hätten allein ... Pleskau erobert/ daß sie ... erobert hätten'. 48

47) "približnye ... 1 ego l jub1mye 1zbrannye dvorjane".

48) "vzjati" bezelchnet den technischen Vorgang, "vosprijati" drickt den Vorgang erhabener aus - etwa 'in Besitz nehmen'. 
$D a B$ es sich bei diesen Konstruktionen um den Versuch handelt, den betr. Satz wortlich wiederzugeben, zelgen die zahlreichen Textstellen, wo auf ein Verb des Sagens der durch "jakon bzw. "čto" angeschlossene Satz ein Prädikat im Präs. hat, z.B.

$64 / 2$ "(Zinovbev) ... priechav k korolju vozveg jakno 'uže, gosudarju, kralju Stepane, voja gradoemnyja vešci gotovy sutb ..."n

'(Zinov́ev) ... kam zum König und meldete ihm, daB das zum Sturm auf die stadt notwendige Gerät bereit sei ...'

In Pällen wie diesen hat der Hrsg. durch das Setzen von Anfuhrungszeichen den Charakter der wörtlichen Rede hervorgehoben. 49

Die beiden Textstellen mit "vosprijali esmja" sind die einzigen Belege für 1-Part. In Verbindung mit der 1.pl.; in ungefähr 30 Pällen erscheint die 1.pl. mit Ipf. oder (meist) Aor.

$41 / 34$ n... vestb $z$ e gosudarju vo Pskov pride, jakgo I1tovskij kralb Polocko vzjal 1 so okrestnyml ego grady."

.... In Pleskau errelchte den Herrscher die Nachricht, dab der polnische König Polock mitsamt den umliegenden Ortacharten erobert habe.

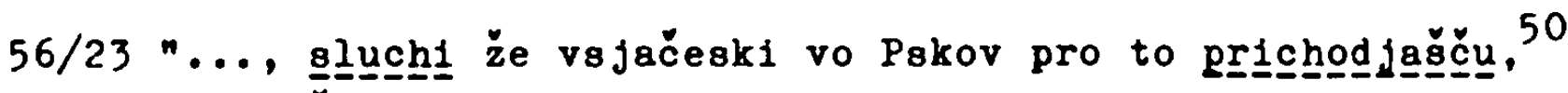
jako uže litovakij korolb na Pskovakuju zemlju, na

Voronoč gorod prišol, ..."

'.... Geruchte/Meldungen gelangten allenthalben nach Pleskau daruber, daB der poln1sche Könlg auf Pleskauer Gebiet - gegen Voronoč - vorgestoBen sei, ...'

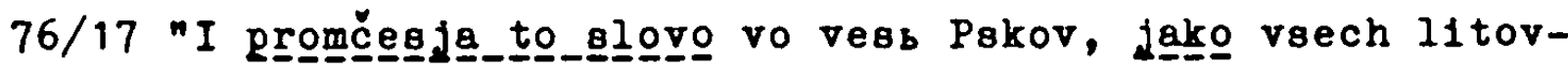
skich ljudej bog posobil z goroda zbit1 ..."

'Und es breitete sich in Pleskau die Nachricht aus, dab Gott geholfen habe, die Litauer aus der stadt zu verjagen ...'

49) Bezelchnend fur den Charakter der direkten, der wörtlichen Rede scheint mir zu sein, dab nach Vorben des Sagens (auBer den genannten finden wir im Text noch "otvescati", "voprosit1", "skazovat1 + Praes.") das Pradikat des Aussagesatzes nach "jako/cto" nie im Aor. bzw. Ipf., sondern nur im Praes. (Gegenwarts - oder Puturbedeutung) oder beim 1-Part. steht.

50) Palscher Dat.abs. statt "sluchom prichodjaščmn. 


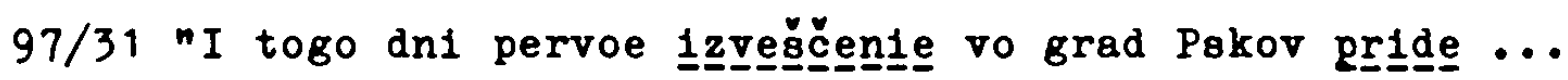
voevodam, ́t.o gosudarevy posly po gosudarevu prikazu $s$ korolevakimi posly mir učinili."

- An diesem Tage erhielten die Voevoden erstmals Nachricht, daB die Gesandten des Zaren auf GeheiB desselben mit den Gesandten des Königs einen Prieden ausgehandelt hätten.'

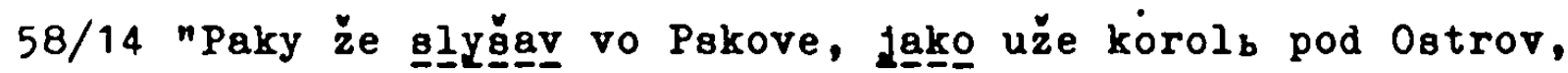
pskovakoj prigorod, prišel, ..., 1 po Ostrovu gorodu

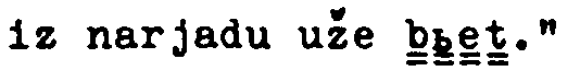

'Schlieblich erfuhr man in Pleskau, daB der König schon nach Ostrov, eine Pleskauer Belstadt, gezogen sei und diese bereits beschiebe.'

Die vorgestellten Belopiele sprechen für sich: Das, was man erfahren, gehört hat, wird in quasi-direkter Rede nach "jako/ čton festgehalten. Das 1-Part. st1lisiert die lebendige Sprache. Im letzten Beleg finden wir 1-Part. und Praes. koordiniert: ersteres bezelchnet eine zuruckliegende, abgeschlossene Handlung - 'der König lat nach 0strov gezogen, ist dort angekommen'; das Praes, aber bezeichnet eine Handlung, die zum Zeitpunkt, da die Nachricht ubermittelt wurde, noch im Gange war - 'der König beschiebt 0strov/ die BeschieBung ist (noch) in vollem Gange.'

Im Unterschied zu Aussagesätzen nach Verben des Sagens, Mittellens usw., wo wir das Prädikat entweder im Praes. oder in Form des 1-Part.8, nie aber im Ipf. oder Aor. antrafen, finden wir in Aussagesätzen nach Verben des Erfahrens, Hörens usw. das Prädikat beinahe genauso oft im Aor. (vier Mal) wie in Form des 1-Part.s (fünf Mal). Das folgende Belspiel soll für alle ubrigen stehen:

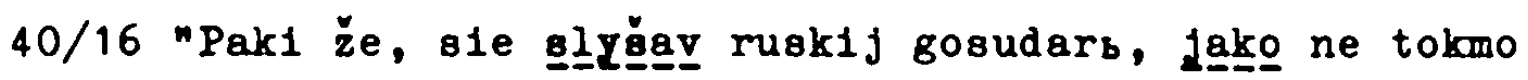
obetor svolch po svoeja im vere zabysa, no 1 na branb voopolčıv̌esja 1 gradi paki vospriemljut, razgnevavǎe że sja na nich ..."

' Wederum - als der russiache Herrscher erfuhr, daB ole (die Deutschen) nicht nur die ihm unter Eld gegebenen Versprechen vergessen hätten, sondern - nach entsprechenden Rustungen - Ihre Städte wleder eroberten/ in Besitz nähmen, geriet er in heftigen zorn gegen sie -..' 
Die abgsechlossene Handlung "obetor svolch zabyšn" steht im Aor., die im Verlauf befindliche im Praes. - Die ubrigen Gegenbelapiele zu den Aussagesätzen mit 1-Part. sind - kurz gefast folgende :

$55 / 7$ "(gosudarb) tože gly̌ğâv, jakko ... korolb na ... Pskov ustremisja. $"$

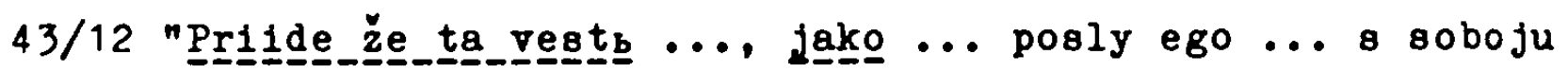
pod Luk1 poveze, ... 1zrygnu $1 \ldots$ prevozneses,a ..."

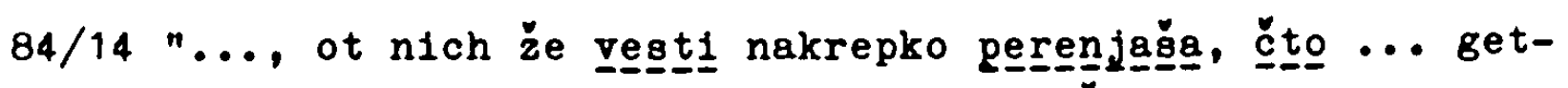
many korolju svoemu iment to pochvališasja, ..."

In diesem Bereich - Aussagesätze nach Verben des Erfahrens, Hörens usw. - können wir genau beobachten, wie das l-Part. Im Begriff 1st, den Aor. zu verdrängen. Beide haben in diesen Sätzen exakt die gleiche Funktion: die zum Zeitpunkt des Berichtens/Erfahrens bereits abgeschlossene Handlung auszudrukken. Die noch im Verlauf befindliche Handlung steht jeweils Im Praes. Gibt der Autor die Aussage nach Verben des Sagens berelts generell durch das umgangssprachliche 1-Part. wieder, 1st dies nach Verben des Erfahrens noch nicht lmer der Pall. Die zahl der Belege 1st zu gering, um evt. GesetzmäBigkeiten aufzuspuren, nach denen der Autor Aor. oder 1-Part. verwendet, doch hat es den Anschein, als seien Zufall bzw. extraverbale Kriterien fur die Wahl des Tempus bzw. der Verbform maBgebend gewesen.

Im folgenden soll noch eine Textpassage vorgestellt werden, die (zum wiederholten Male) die Inkonsequenz demonstriert, mit der der Pleskauer Autor oft die Verbalformen verwendet. Zugleich finden wir hier Textbelsplele fur die verschiedenen Erscheinungen aneinandergereiht, die wir in diesem Abschnitt untersucht haben. 
$84 / 14$ "..., ot nich že (= l1tovskich jazyk) vesti nakrepko pereñ jăge日, čto litovskie getmany ... 1 ki1ždo načalbnikov roznych zemelb svoj podkop povedoss: ...51

b) Sie že litovskie jazyki ... voevodam skkaząge日a, čto uže te podkopy vse poveli sentjabrja $\vee 17$ denb, a naperede $1(\mathrm{ch})$ veech ugorskoj podkop posgeet.

c) A ni edin ot tech litovskich jazyk ne vedajut, $k$ koemu to mestu te podkopy poveli, 1 u našej-de 1 litovskoj si-

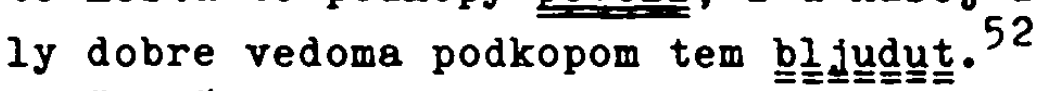

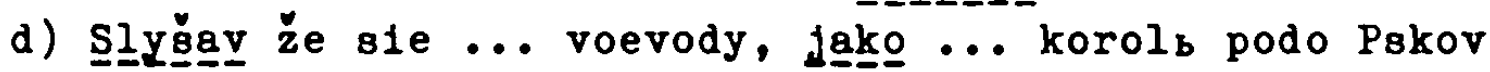
mnogie podkopy poveli, ...,

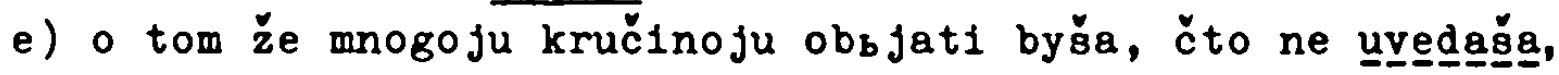
pod kotorye mesta podkopy vedjaše."

a) 'Von den litauischen Gefangenen erhielten die Voevoden die glaubwirdige Information, daß die Hetmane und die Befehlshaber der einzelnen Nationen jeder für sich unterirdische Gänge gruben: $\ldots$

b) Die Gefangenen sagten den Voevoden (auch), daß diese Gänge am 17. Sept. begonnen worden wären und dab der ungarische Gang wohl als erster fertig würde.

c) Keiner der Gefangenen wuBte (=weiB - Praes.hist.) aber, wohin die Gänge führten - (und sie wuBten auch, ) daB die Gräben auch im/vor dem litauischen Heer streng bewacht würden (evt.: streng geheim gehalten würden).

d) Als dies die Voevoden erfuhren - nämlich daB der König unter Pleskaus Mauern Gänge treiben lie $B$,

e) da wurden sie von groBem Kummer erfaßt, weil sie nicht wußten, wohin diese Gänge führen sollten.'

Alle vorgeführten Sätze sind gleich strukturiert: einem Verb des Sagens ("skazaša"), Erfahrens ("vesti perenjaša", "uvedaša", "slyšav") und auch Wissens ("vedajut") folgt die Aussage in einem durch "jako/čto" an das betr. Verb angebundenen Satz.

In Satz a) stoßen wir auf die Schwierigkeit, "povedoša" adäquat zu ubersetzen. Aus dem Kontext geht hervor, daß die

51) Durch das gleiche-im Pleskauer Text "teuflische" - Unterfangen wurde 1553 durch Ivan Grozny $j$ Kazań erobert: es wurden unterirdische Gänge unter die Mauern getrieben und diese dann gesprengt.

52) "u našej-de" : Vasmer, REW I, S. 332 : "den : 'näml1ch, es heiBt, soII', urspr. zur Anfuhrung der Rede eines andern, dann Flickwort, ... - Gerade um letztere Bedeutung handelt es sich hier: 'vor unserem (sagten sie) lit. Heer'. 
Gänge vor kurzem erst begonnen worden waren und nie ihr ziel errelchten - "povedoša" kann also nicht helBen 'sle hatten Gänge getrieben'. Aus Satz b) gchlieBen wir, daB in beiden Pällen "poverti" - 'zu bauen beginnen' he1Bt. In Satz a) oteht nach einer Wendung, die 'erfahren' bedeutet, der Aor., In Satz b) nach "skazasa" ein 1-Part. Eine die Zukunft betr. Ausgage finden wir, koordiniert mit dem 1-Part., in Porm eines perf. Praes. In Satz c) haben wir es mit einem verneinten Verb des Wisens zu tun, dem ein Pragesatz angeschloseen 1st - hier begegnet uns "povel1" wieder, doch kann es an dieger stelle unmöglich die für oben angesetzte Bedeutung ' $2 u$ bauen beginnen' haben, sondern es 18t doch gemeint: 'keiner wuBte: Wohin führen diese Gänge/Unter welche Stellen der Stadtmauer zlelen diese Gänge?' Inhaltlich die glelche Stelle bietet Satz e): 'sie wuBten nicht, unter welche stellen die Gänge führten' "ne uvedasa, pod kotorye mesta podkopy vedjaǧen. Setzen wir für "vedjaše" korrektes "vedjachu", dann haben wir elne Möglichke1t, den Sachverhalt (der Bau der Gänge 1at noch 1m vollen Gang) als indirekte Rede zu formulieren: die olch in der Gegenwart (vorerst) unbegrenzt vollzlehende Handlung konnte vom Autor aus der Nachträglichkeitaperspekt1ve heraus durch das zettlich in kelner Weige begrenzende Ipf. ausgedruckt werden. "povel1" in Satz c) jedoch $18 t$ grammatisch einfach falsch. Dies umso mehr, als dem Pragesatz noch ein durch "jako" angeschlosienen Satz folgt, der ellipt1sch auf ein unverneintea "vedajut" abstellt. Der Charakter der wörtlichen Rede, die vielleicht das 1-Part. "poveli" auch signalisieren soll, wird hier unteratrichen durch "u nabej-de 1 litovakoj olly" 'be1/In unserem 11taulachen Heer'; "-den verdeutlicht, daB dies die Worte der litaulachen Gefangenen sind, nicht die des Autors (8.0., Anm. 43). Die Aussage selbst 'werden bewacht/ gehoimgehalten' steht korrekt im Praes. - In Satz d) lesen wir abermala "poveli" im Sinne von prkeentiechem 'Puhren' 'sle horten, das der König dabel ist, viele unterirdische Gräben unter die Mauern Pleskaus zu bauen'.

Der unverständliche Gebrauch der verbalen Pormen in diesem Textabschnitt lot nur so zu erklbiren, dab der Autor hier einen bestimmten klanglichen Effekt erzielen wollte und um dieses 
Effekts willen semantisch nicht getrennt hat. Verschiedene Bedeutungen fließen in die glelchen Formen; gleiche Pormen meinen Verschiedenes; die Erzählperspektive des Autors wechselt - hier Gleichzeitigkeitsperspektive (Gegenwärtiges setzt er Ins Praes.), da Nachträglichkeitsperspekt1ve (Gegenwärtigea setzt er ins Präteritum - und da oft ins falsche Tempus). Diese Technik qualifiziert den Pleskauer Autor nicht nur ab, sondern zeigt vor allem, daß das Gespür in ihm für die Semantik der Tempora so geschwächt 1st, daB es $1 \mathrm{hm}$ möglich 1st, mit den Formen zu spielen, wie hier, wo dem klanglichen Effekt (drei Mal "povelin") Wortbedeutungen und Tempora untergeordnet werden.

3.2.2 Das 1-Partizip bei punktuellen Zeitangaben

Die Halfte aller durch 1-Part. (mit und ohne Kopula) gebildeten finiten Präteritalformen steht in Zusammenhang mit punktuellen Zeitangaben - von den 37 Textatellen mit 1-Part. (ohne den "Ganoumeler"-Brief) folgen 18 irgendeiner Datierung. Meist folgt in den aksl. Denkmälern und den altruss. Texten, die der ksl. Tradition folgend die alten Tempora verwenden, einer punktuelien Zeitangabe der Aor. ${ }^{53}$ Das lot ganz natürlich, da ja auch der Aor. einen Punkt angibt - entweder eine punktuelle Handlung uberhaupt oder aber den Endpunkt einer durativen, iterativen, kursiven usw. Handlung (= komplexiver Aorist).

Den 18 Datierungen mit 1-Part. stehen 23 gegenüber, wo das zur Zeitangabe gehörige Prädikat in einem anderen Tempus bzw. als Part. erscheint: $17 \mathrm{Mal}$ im Aor., zwe1 Mal 1m Ipf. ${ }^{54}$, ein Praes. hist. (92/3), zwei Mal als Part.praet. und eln Mal als Dat.abs. (Part.praet.).

53) Im K-pler Text steht bel allen Datierungen (bis auf ein Part.praet.) der Aor. In der Chronikerzählung Pleskau 1510 (8. Tabelle 1: Veraleichstext), wo das 1-Part. 40 v.Hd. aller Verbformen ausmacht, sind von 10 Datierungen noch dre 1 mit Aor. - Vgl. insbesondere: Scholz, Studien, S. 33, 99 und 241: nach punktuellen Zeitangaben ateht Aor. - kein Perf.

54) $85 / 13$ "..., sentjabrja v 20 denb, ... gajdukt pak1 po voz-

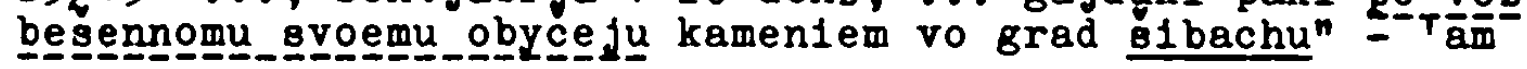


Wir wollen uns damit begnugen, einen Teil der Belege vorzustellen und diese mit Beispielen zu konfrontieren, wo in entsprechenden Sätzen das Prädikat im Aor. steht.

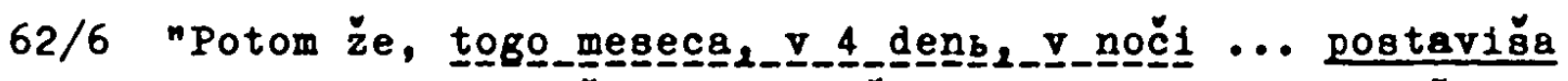
tury. Pervie, u čeloveka božija Alekseja, ...; taže drugoj dvor $v$ turach pogtavili, protiv tovo źe, ... Vse že te tury, pjatery, toe_že_noć 1 zemleju nasypali.

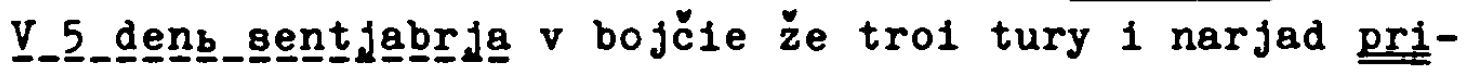
volokli 1 postavili. I tak vajakimi gradoemnymi obrazy ... 11tovskie ... na ... Pskov grad vooružišsia."

'Dann, am 4. Sept., nachts, stellten sie die Eroberungstürme auf. Den ersten in der Nähe der Kapelle des seligen Alexej ( = dort sollte ein Unterstand sein); einen anderen Unterstand richteten sie in den Turmen ein - dem ersten gegenüber ... Alle diese fünf Türme fullten sie in dieser Nacht mit Sand an. Am 5. Sept. schlieblich schleppten sie in die zum Angriff bestimmten Tüme Geschüze und richteten sie aus. Auf diese Welse wappneten sich die Litauer mit allen erdenklichen strategischen Mitteln fur den Kampf gegen Pleskau.'

Das Zitat wird eingeleitet durch eine Datierung, bei der ein Aor. steht. Schon im folgenden Satz begegnet das gleiche Verb in genau der gleichen Punktion - In Porm des 1-Part.s "postavili". Hatten wir kúrzlich beobachten können, dab der Pleskauer Autor in der Lage ist, die Punktionen der einzelnen verbalen Kategorien zu beugen, zu ignorieren, nur um einen bestimmten klanglichen Effekt zu erzielen, so können wir hier nur konstatleren, dab er an dieser Stelle die Verbform varileren wollte. Wir beobachten ja auch, daB der Autor diesen Absatz 55 wider Erwarten durch einen Aor. abschliest, wodurch die 1-Part.ien von den Aor.-Formen gewisgermaBen elngerahmt werden.

Die übrigen 1-Part.ien - masypali", "privolokli" und "postavilin. stehen in Verbindung mit Ze1tangaben. Es ist nicht zu ubersehen, daB der Autor mit Hilfe der 1-Part.ien nicht gerade reimende wirkung, aber doch einen klanglichen effekt erzielen wollte.

20.9. schleuderten sie ihrer Gewohnhe1t gemäB ...' - dss Ipf. wird durch die iterative landiung an sich und durch die Gewohnheit motiviert. $89 / 18$ n..., nojabrja $v 2$ denb, velikim pristupom ... pristupachu" - aktualisierende Beschreibung.

55) Die zitierte Textstelle wird durch eine Uberschrift eingeleitet; "vooruzisasja" folgt wieder eine Uberschrift. 


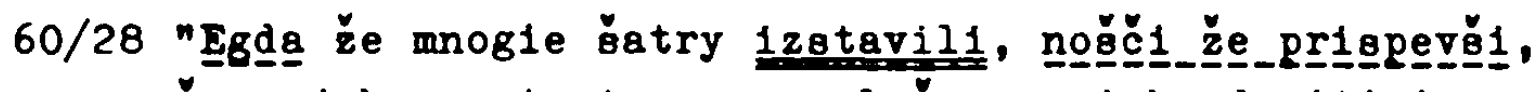
čas bolbs̆ovo narjadu; na 1 mogich, ekazyvali jazyk1, 1 v_te_pory mogich panov 56 dobrych tuto pobili."

'Als sie gegen Anbruch der Nacht, so um die dritte Stunde herum, viele zelte aufgestellt hatten, wurde befohlen, diese mit dem schweren Geschütz zu beschießen. Am nächoten Morgen war kein Zelt mehr zu sehen. Gefangene wuBten $z u$ berichten, daB während der BeschieBung $\}=" v$ te pory") viele angesehene Herren getbtet worden waren.'

Die Verbform "1zstavili" signalisiert, daB zum angegebenen Zeitpunkt der Bau der Zelte abgeschloseen war. Vorzeitigkeit unter Elnbeziehung des Abschlusses der bezelchneten Handlung wird, auch im Pleskauer Text, im allgemeinen durch Aor. ausgedruckt - auch nach "egda" - vgl.

$53 / 13$ "Egda mnogija okrestnyja grady Erosalimskifa $2 a$ oja

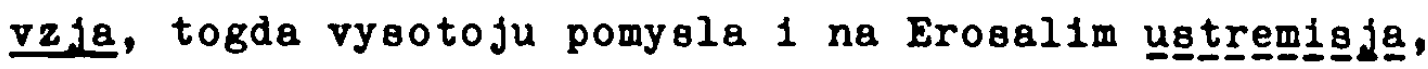
-..."

'Alo/nachdem er (Sanherib) viele Jerusalem benachbarte Städte erobert hatte, da zog es ihn in seiner Verblendung nach Jerusalem selbst, ...'

"pobili" am 21tatende lot elgentlich "povelešn" koordiniert, denn eine Abhkingigkeit von "gkazyvalin" ist nur bedingt gegeben, da letzteres lediglich als Binwurf aufufassen 18t. AuBerdem vertraten wir den Standpunkt, daB Redeteile nach Verben des Sagens als wörtliche Rede, als elgenständige Sätze aufzufassen oelen; hier fehlt auch einleitendes "jako/čto". "pobili" steht nicht nur wegen der ayntaktioch koordinierten Position zu "poveleša" fur einen Aor., sondern vor allem wegen der Ausaage: die Gefangenen berichten aus der Nachträglichke1toperopektive - "v te pory" - 'damals bel der BeschieBung' waren viele bekannte Persönlichkelten umgekommen: elne Pestatellung.

"okazyvali" - Ableitung von "gkazati" mit Hilfe deg jungen Suffixes -yva-deutet hier auf Iterativitat 'wie die verschiedensten Gefangenen zu berichten wubten'. Wenige Zeilen

56) An dieser stelle 18t unser Text offenbar verderbt, vgl. Variante, S. 141: "mnoglch, okazyrall jazyk1, tu panov dobrych pobili." 
oberhalb unseres Z1tates heibt es:

60/24 "Pro se ̌̌e glagolachu, Jako korolevskomu stanu byt1 ... ne moskovskoj doroge."

' In bezug hierauf/In Verbindung damit wurde berichtet/ war zu hören, daB das Lager des Könlgs an der Moskauer Land atraße liegen sollte.'

So ähnlich 57/8 u.a., in dieser Bedeutung finden wir "skazovašen (statt 3.plapf.) 50/24,64/32, aber auch "skazyvachun $50 / 19$.

Die l-Part.ien haben also in jedem Palle eine Punktion, die in anderem Kontext Ipf. oder Aor. Ubernehmen. DaB wir diese Tempora an dieser Textstelle so masiert durch l-Part.ien ersetzt finden, können wir wiederum nur damit zu erklären versuchen, daB der Autor einen bestimmten Gleichklang erstrebt, der den Abschnitt beherrschen soll. Bemerkenswert bleibt hier, dab das 1-Part. Verbformen verschledenster Funktion eint: "1zstavili" - Aor./Vorze1tigkeit/perf.; "skazyvali" Ipf./Iterativität/1mperf.; "pobil1" - Aor./Peststellung/perf.

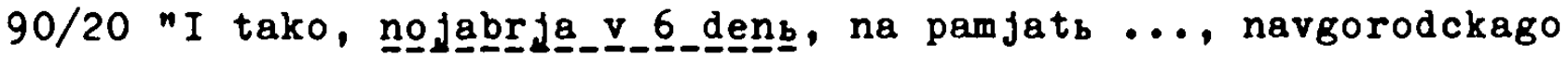

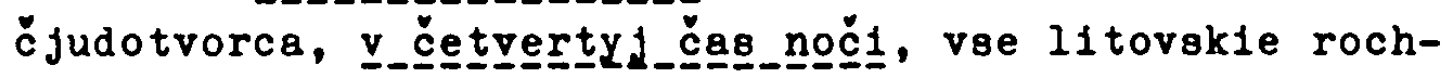
misty 2 gajduki iz jam vys̆li 1 narjad 120 vaech turov otvolokli."

'Und so verließen alle Iitauischen Rottmeister und die Helducken am 6. November, am Tag des Gedëchtnisses an den Novgoroder Wundertäter .... Ihre Laufgräben und zogen die Geschutze aus den Angriffsturmen zurlick.'

Komposita von "it1" haben im Pleskauer Text den höchsten Antell an den 1-Part.ien - wir fanden 8 Belege. 57 Bei so hoch frequentierten Verben ist der Antell dieser universalen Präteritalform relativ höher als bel weniger hiufig gebrauchtenvielleicht deshalb, weil bel hochfrequentierten Verben die Diskrepanz 2 wischen gesprochener und geschriebener sprache besonders stark empfunden wurde, so dab sich häufiger die umgangssprachliche Form einschlich. AuBerdem ist zu vermuten,

57) Den 8 1-Part.ien der Komposita von "1t1" stehen 10 entsprechende Aor.-Formen gegenuber, das 1-Part. macht hier also 44 v.Hd. der finiten Prateritalformen aus. Das Simplex 
daB "it1" und seine Komposita im Rahmen einer Kriegserzählung viele militarische Termini technici abdecken, die der Autor mit den zeitgenössischen Präteritalformen versah.

Dies gilt auch für "otvolokl1" (ebenso wie für "privolokli" in Beleg 62/6 - 8.0., S. 501). In diesem Kontext handelt es sich jeweils um einen Terminus technicus. Nicht zuletzt aus diesem Grunde finden wir das Verb in seiner russ. bzw. ostslav. Lautung "-volokl1" vor, nicht aber ksl. (-suidslav.) "vlačiša". Auch hier fügt es also der Autor, daB auf engstem Raum zwe1 l-Part.ien zusammenkommen.

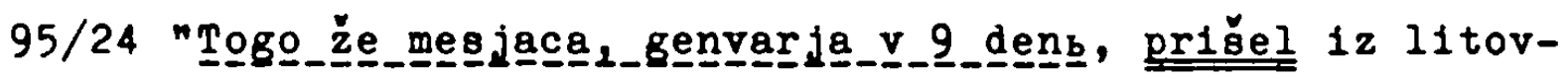
skogo voinstva ruskoj polonjanik vo Pskov, a prines 8 soboju velik larec."

- Am 9. Januar kam ein russischer Gefangener aus dem polnischen Lager, und dieser brachte eine große Riste von dort mit.'

Dieser Satz leitet uber zu jenem bereits erwännten Brief eines Ausländers (= "Gansumeler") an die Pleskauer Voevoden, in welchem 1-Part.ien dominieren. Während diese Textatelle im Vergleich zu den melsten anderen stark umgangssprachlich anmutet (vgl. auch "polonjanik" = russ./ostslav. gegen sonstiges "plennik", "plenenie", "plen" = ksl./südslav.), bringt der folgende Satz zwei (allerdings falsch gebildete) Dat.abs. ${ }^{58}$ Gleichklang der Verbalformen liegt hier nicht vor, da sich der Autor auch der endungslosen Form des l-Part.s bedient, wie es schon (nach konsonantisch auslautenden Stämmen) umgangssprachlicher Konvention entaprachs 59 "prines" statt "prinesl". Belde Verben, "priti" und "prinesti", gehörten sicher auch im 16. Jh. zu den am allerhäufigsten gebrauchten, so dab der Autor in einem Abschnitt, der auf einen atilisierend-umgangssprachlichen Abschnitt (den "Gansumeler"-Brief) hinfürt, dem Druck der gesprochenen (bzw. gedachten) Sprache nachgebend die entsprechende Präteritalform verwendete - das 1-Part.

"1t1" hingegen erscheint im Präteritum nur in Porm des Ipf. und des Aor.

58) "Sego ... priemğu, sego .. privedğun für "Im sego - ğ1m". 59) $V_{g l}$. K-pel 59/13 (allerdings habitualisiertes) "rekl estb". 
86/22 "Protivu že tech podkopov skoro 1 spešne sluch1 kopati

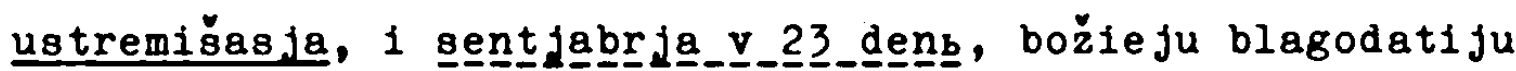
s podkopy litovskimi nasi ruskie sluchi sošlisja, 1 zlozamyšlenoe $1 \mathrm{ch}$ umyšlenie christovym posobiem razrušiša, ..."

'Sie beeilten sich, den litauischen unterirdischen Gängen Horchgänge entgegenzutreiben. Und durch Gottes Güte trafen am 23. September unsere Horchgänge auf die litauischen Stollen, und mit Christi Hilfe wurde dieser üble Plan vereitelt ( = zerstörten sie diesen üblen Anschlag), ...'

Alle drei Verbformen sind koordiniert bzw. stehen in Parataxe. "sošlisja" und "razrušisa" beziehen sich auf das gegebene Datum; die Gleichrangigkeit dieser beiden Formen wird durch den Autor unterstrichen, indem er jedem eine synonyme adverbiale Wendung zuordnet - 'durch Gottes Güte'; 'durch Christi Beistand'. Das 1-Part. steht in diesem Abschnitt vollkommen 1soliert da; abgesehen von dem ElnfluB, den die punktuelle Zeitangabe auf die Verbform gehabt haben mochte, ist auch in Rechnung zu stellen, daB es sich bel "sošlisja" um einen Terminus technicus handeln könnte.

Abschließend hierzu eeien einige Textstellen vorgefuhrt, die nach einer Datierung den Aor. zeigen:

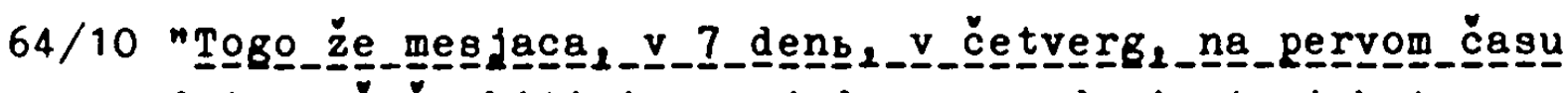
dñ ..."

'Am 7. Jenes Monats, einem Donnerstag, begannen sie zur ersten Tagesstunde, die Stadt aus den drei Angriffotürmen heraus mit Geschützfeuer zu belegen, ...'

86/8 "Togo_že_dñí, egda bezzakonnych derzostb 1 do svjatogo

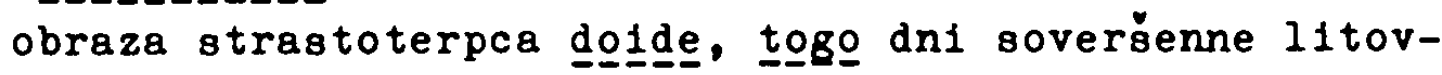
skogo korolja umys̆lente ... otkryšasja, ..."

- An jenem Tage, da durch die Dreisthe1t dieser Gesetzlosen die hellige Ikone des Märtyrers zerstört worden war, 60 da wurde der Anschlag des Königs endgulltig entdeckt.'

Auch in der"Step.kniga" zeigen konsonantisch auslautende Stämme Abfall des -18 in der 3.8g. Ausnahmen gehen meist auf ältere Textvorlagen zuruck - Qtten, Fin.Verbalformen, S. 287 ff. N1k1forov, Glagol, S. 163: "nesls"-archaisch. 60) "egda + Aor." - Vorzeltigke1t, vgl. S. $523 \mathrm{f}$. 


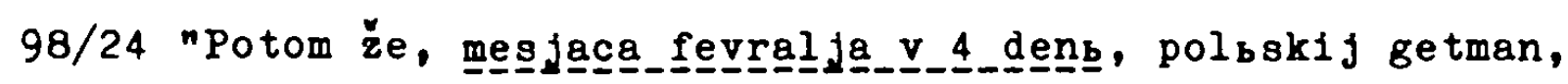
pan kancler, oto Pskova so vseju siloju v litovskuju zeml ju otyde."

'SchlieBlich hat dann der polnische Kanzler Pleskau am 4. Februar verlassen und ist nach litauen gezogen.'

Wie anfangs erwähnt, halten sich die Belege, die nach Datierungen Aor. und die nach Datierungen 1-Part. zeigen, ungefähr die Waage. Allerdings schlägt bei diesem Vergleich zu Buche, daB nach verschiedenen Zeitangaben mehrere l-Part.ien stehen, so daB - an Datierungen gemessen - der Aor. nach Zeitangaben doch noch etwas häufiger ist. Im letzten Beispiel finden wir sogar eine Aor.-Form eines Kompositums von "iti" - "otyde".61 Es läbt sich aber nicht leugnen, daB das l-Part. - im Rahmen der Pleskauer Erzählung - im Begriff ist, nach Datierungen an die Stelle des Aor. ${ }^{62} \mathrm{zu}$ treten. Wir können die Frage, warum dies in dieser Position geschieht, nicht beantworten. Wir können nur konstatieren, daß dies ein weiterer Weg gewesen zu sein scheint, auf dem das 1-Part. als universales Präteritaltempus Eingang in die tradierte Literatursprache gefunden hat. 63

\subsubsection{Sonstiges Auftreten des 1-Partizips}

In den bisherigen Ausfuhrungen hatten wir verschiedentlich Gelegenhe1t, auf das Erscheinen des 1-Part.s in Relativä̈tzen hinzuweisen. ${ }^{64}$ zwei weitere Textstellen, im Zusammenhang dargeboten, mögen diesen Komplex abrunden:

61) $\mathrm{Vgl}$. auch auf der vorigen Seite Beleg $86 / 8$ "egda ... doiden", Vorzeitigkeit.

62) Fur 1-Part.ien von imperf. Verben in dieser Position fanden wir keinen Beleg; das Ipf., das ein imperf. 1-Part. ersetzen würde, ist nach Datierungen naturgemäB sehr selten.

63) Diese Beobachtung muBte an breiterem Material verifiziert werden.

64 ) $51 / 24$ "a jaže pisal es1 o grade sem"; 83/12 "o nich že este $k$ nam pisasten (= Ansatz einer l-Periphrase); $82 / 20$ "eze ne vzjal"; evt: 84/24 "ne vedajut, k koemu to mestu te podkopy povelin. 
$41 / 17^{n}$ (korolb) ... na Ruskuju zeml ju ustremisja, k staromu Litovskifa zemli ich gradu Polocku, v 17-e leto, ot_neže vzjal ego ot litvy gosudarb našb."

- Der König eilte nach RuBland, (zunächst) zur alten litauischen Stadt Polock, im 17. Jahr, nachdem unser Herrscher diese Stadt erobert hatte. (wörtlich: im 17. Jahr, nach welchem unser Herrscher ...)'

Die worrtliche Ubersetzung verdeutlicht, daB sich die Datierung nicht auf das 1-Part. bezieht, sondern auf den Hauptsatz mit Aor.

$72 / 27$ "Togda że vse te vysokogordelivyja korolevskija približnye dvorjane, jąze u korolja vyprošalisja napred vo Pskov vniti 1 korolja sresti ..."

- Damals (kamen unter dem Schweineturm ums Leben) alle jene stolzen Gunstlinge des Königs, die durch andauerndes Bitten vom König die Erlaubnis erhalten hatten, zuerst in Pleskau einzudringen und (dort) den Könlg zu begrüien und ...'

Die suffigierte Ableitung "vyprošatisja" trifft den Sachverhalt sehr genau: es hat die Günstlinge, Höflinge aus dem Gefolge des Könlgs beträchtliche Uberredungskraft gekostet, die Erlaubnis vom König zu erhalten, am Sturm auf Pleskau teilzunehmen: auf $11 / 2$ Selten berlchtet der Autor daruber (67/33 69/6). Die imperfektive Ableitung signalisiert Dauer und Iterativität gleichzeltig. Der resultativen Erzählweise an dieser Stelle, zumal der Position im Relativsatz mit Vorzeitigkeitsbedeutung, würde ein Aor. am ehesten entsprechen: "vyprošasasja", doch scheint der Autor die Bildung eines Aor. von diesem eindeutigen Imperfektivum zu scheuen - so verwendet er das 1-Part., das möglicherweise eine gewisse Affinität zum Relativatz gewonnen hat und gleichzeitig temporale Differenzierungen verwischt und vermeidet.

Häufig hatten wir die Vermutung geäuBert, daB der Gebrauch des l-Part.s in manchen Fällen dadurch begründet zu sein schien, daB es sich in diesen Fällen um hochfrequentierte stämme und - In unserer Kriegserzählung besonders - um Termini technici handeln durfte: "-itin, "-jatin, "-stavit1", "-vesti", "-nesti", noločiti", "pobiti", "nasypati". Indem wir dies noch einmel hervorheben, wollen wir noch ein sehr typisches Belsplel vorstellen: 


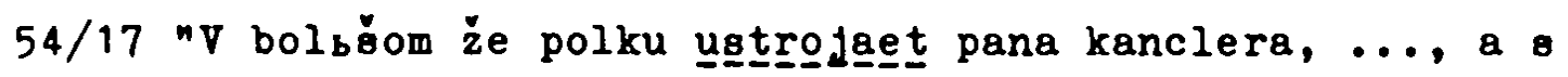
nim mogie rochmiety: ... A sam pošl za kanclerovym polkom. A u korolja približnye Ijud1 a nim pošli: pan Tiška, ... A u narjadu velel byt1 voevody ugroveckomu, panu Jurbju Zinovbevu, ..."

'An die Spitze des Großen Aufgebot stellte er (= der König) den Herrn Kanzler, .... thm gab er noch viele Rottmeister be1: ... Er seibst marschierte (m1t seinen Abtellungen) hinter dem Kanzler. Mit dem König zogen diejenigen, die thm besonders nahe standen: Herr Tiska, ... An die spitze der Artillerie stellte er den ungarischen Voevoden, Herrn Georg Zinov́ev (?), ....'

"pojti" dürfen wir hier gewiB als den militärischen Terminus 65 'marschieren, ziehen' deuten. Insofern verwundern uns die 1-Part.ien nicht. Erstaunlich lot aber "velel" - sonst begegnet dieser Stamm entweder in Form des Ipf. von "velèti" (ausschließlich "veljaše", sowohl für sing. als auch für Plur.) oder des Aor. von "povelét1" ("povele", "poveleša") - abgesehen von Part.ien. Vor allem konnten wir - im Zusammenhang mit den Untersuchungen an den Ipf.-Pormen - beobachten, wie der Pleskauer Autor die 3.8g.1pf. auf $-(j)$ aše benutzt, wenn man einen Aor. erwartet. Hier nun umgeht der Autor den Aor. ausnahmsweise einmal mit Hilfe des l-Part.8. Dazu wird er zwe1felsohne durch die beiden anderen in der Nähe befindlichen 1-Part.ien animiert. Er nutzt die Gelegenhe1t, mehrere gleichklingende Formen auf engstem Raum zu konzentrieren.

Eo steht m.E. auBer Prage, daB der Pleskauer Autor nicht umhin konnte, sich bel bestimmten schilderungen, bel bestimmten Inhalten des 1-Part.s zu bedienen. Bestimmte ldiomatische Nendungen und spezielle Termini mubte er wahrscheinlich im Präteritum durch das 1-Part. ausdrücken, wenn er nicht Gefahr laufen wollte, miBverstanden zu werden. AuBerdem werden viele solcher Wendungen so automatisiert gewesen sein, dab der Pleskauer Autor deren Vergangenhelt nur mit Hilfe des l-Part.s ausdrucken konnte.

65) Sorokoletov, Istorija voennof leksik1, S. 145 - verweist darauf, dab die Wendung "itti/poit1 polkom" der die obige sehr nahekommt, bereits seit dem 12.-13. Jh. bekannt 18t. Den weiteren Belegen - ebda., S. $145 \mathrm{ff}$. - nach, wird "polk" fast ausschlieblich mit "-iti" gebraucht. Vgl. die weiteren Termini: "bolssoj -, storozevoj polk"; "pravaja -, levaja ruka" (= Plügel) $54 / 7,-/ 10,-1 / 4,-/ 19$ ). 
3.2.4 Exkurs: Das Schrelben des Hans Möller 66

Nachdem alle Versuche, Pleskau einzunehmen, gescheitert waren, machte der polnische Kanzler, der ja die melate Ze1t die Belagerung geleitet hatte, einen letzten, verzweifelten Versuch, Herr der Stadt zu werden - so berichtet es zumindest der Pleskauer Autor. 67 Der polnische Kanzler - Jan Zamoysk1 - hatte vor, die militärische Pührung des belagerten Pleskau zu vernichten. $Z u$ diesem Zwecke 11 eB er elne Art Höllenmaschine bauen. Diese wurde, mit einem Brief versehen, durch einen russischen Gefangenen an den Füraten I. V. Sujsk1f geschickt. In diesem - uns hier interessierenden - Brief wird dem Pürsten Sujakif mitgetellt, daB der Absender, Hans Möller, vorhabe, auf die russische seite überzuwechseln. In der K1ste befinde sich sein Geld. Diese solle Sujskif an sich nehmen, niemanden an sie heranlassen und nur ganz allein hineinsehen. Beim Offnen der Truhe wurde eln Mechanlsmus ausgelöst, der den Inhalt derselben - SchieBpulver - zur Explosion bringen und mindestens Fürst Ivan Sujgkıj töten sollte.

Der Absender - "Gansumeler" - 'Hans Möller' -, der namentlich In den ubrigen Quellen nicht erscheint, 68 wird als Gefolgsmann Georg Pahrensbeks, eines derzelt in den Diensten Stephan Báthorys stehenden deutschen Heerfuhrers hingestellt, mit dem er auch schon in moskovitischen Diensten gestanden habe:

$95 / 32$ "Byval egm1 u vašego gosudarja s nemčlnom, s Jurbem Prjanbrekom. I nyne yegpamjateral egmi gosudarja vašego chleb-solb, 1 ne choč̣u na ego gosudarevo imja gtojat a chočju na ego gosudarevo imja vyechati. A napered eomi sebja poglal vašlm polonjanikom svoju kaznu v tom larcy, kotorom on $k$ tebe prineset."

66) $95 / 32$ "knjazju ... Sujokomu Ganguneler čelom bbet".

$67)$ tber die Vorgeschichte und den Ablauf dieses Attentatsversuchs - s.0.,8.121; dort sind auch die Quellen genannt.

68) Die mir vorliegenden Quellen - Chronika l1tovgkaja 1 Émojtskaja, PSRI 32 (1975), S. 125; R. He1denste1n, De rerun Polonicarum, S. 249 - 52 - nennen nur einen (prusak) 0stromecklf, der die technische seite und die Organisation des Attentatoversucho in der Hand hatte. 
In den folgenden Zellen hat Malyšev, der Hrsg. unserer Textausgabe, kräftig interpoliert, wobel er sich allerdings auf die Varianten stutzt. ${ }^{69}$ Die Interpolationen macht Malyšev, wie immer, durch Klammern kenntlich:

96/4 (Der Brief wird an der abgebrochenen Stelle, also hinter "prineset" fortgesetzt).

"I ty(by), gosudarb, knjazb Ivan Petrovič, tot moj larec $u$ tovo polonjanika vzjal 1 kazny moej $v$ tom larcy edin dosmotrils ja, a inym by__eg(m) budu vo Pskove po vremeni totčas."

' Ich habe eurem Herrscher unter Georg Pahrensbek gedient. Und jetzt habe $1 \mathrm{ch}$ mich an die Grobzügigkeit eures Herrschers erinnert und will nicht mehr gegen ihn kämpfen, sondern mich unter seine Pahne stelien. Mit diesem russischen Gefangenen habe $1 \mathrm{ch}$ nun mein Vermögen/mein Geld in jener Truhe abgeschickt, in welcher er es dir bringen wird. Nimm du, Herr, Fürst Ivan Petrovic, diese meine Truhe von dem Gefangenen und schau dir meine Tertsachen nur ganz allein an, niemand sonst darf sie sehen. Ich selbst werde bald in Pleskau sein.'

Die zweite Interpolation "a inym by es(m) i ne daval smotreti" 'andere wurde ich nicht (hinein-) sehen lassen' erscheint mir unnötig - 'lab keinen anderen (hinein-) sehen' halte ich für sinnvoller. - Die erste Interpolation " 1 ty(by) ... vajal 1 ... dosmotrilsja" lot zwar grammatisch korrekt, doch ist zu fragen, ob die Varianten, die diese Lesart haben, nicht vielleicht den ursprünglichen Text korrigiert haben - immerhin beruht die uns vorliegende Textausgabe auf der ältesten Hs. Ist nicht anzunehmen, daB der Autor durch die stereotypen 1-Partien, durch das Fortlassen der Konjunktiv-Partikel (96/4 ni ty(by)... vzjal") den sehr einfachen und fehlerhaften Schreibstil des Ausländers karikieren mbchte? Der Ausländer ist Soldat, kennt nur die gesprochene Sprache - und die wohl auch nur gebrochen. Diese Sprache wird in diesem in den Pleskauer Text eingefugten (sicher fingierten) Brief stilisiert. Das 1-Part. als einziges Präteritaltempus beweist dies, aber auch die fehlerhaften KonJunktiv-Konstruktionen; hinzu kommt zweimaliges umgangssprachlicheo "polonjanik" (sieben Mal begegnet der Stamm "plen-"); das zweimalige "chočju" hat zwar stark voluntative Bedeutung,

69) 2.B. unsere Variante, S. 164. 
dürfte aber als reines Futur gemeint sein - dagegen stehen sechs Futur-Belege mit "iměti, imamı" und "imat1 + Infinltiv". Schlieblich ist "kotoryj" hier als Relativ-Pronomen gebraucht, in welcher Funktion uns melst "iže" begegnet. "kotoryj" (hier auch noch "kotorom" statt "kotoroj") heibt im Pleskauer Text normalerweise 'jemand'. Es wird an dieser Briefstelle bereits im heutigen Sinn gebraucht.

Selbst, wenn wir in Rechnung setzen, daß es sich bel diesem Brief um eine Persifllerung der (Schrift-) Sprache eines feindlichen Ausländers handelt, ist ein Vergleich mit dem ubrigen Text von elnem gewissen Interesse - er verdeutlicht die Kunstlichkeit der Sprache uber weite Teile hinweg, derer sich der Pleskauer Autor bedient. 70

\subsubsection{Zusammenfassung: das 1-Partizip 1m Pleskauer Text}

1. Wie 1m 16. Jh. ublich, erscheint die 2.8g. Präteritum be1nahe ausschlieblich in Form der 1-Periphrase "l-Part. + esin. Die ubrigen Personen (außer 3.8g./pl.) bilden das Präteritum fast ausschlieBlich mit Hilfe von Ipf. und Aor. Erscheinen sie ausnahmswelse in Form des 1-Part.8, dann steht bel thnen in fast allen Fällen die Kopula ("vajal esmi", "vosprijali esmja", die 2.pl. hat nur einmal den Ansatz der Periphrase "este $k$ nam pisaste"). Die 3.sg./pl. erscheint häufiger in Form des 1-Part.s, bis auf zwe1 Psalm-Verse regelmäBig ohne Kopula.

2. Zwischen 1-Periphrase und einfachem 1-Part. besteht keine funktionale, sondern lediglich elne formalpersonelle 71 Opposition: $1.8 \mathrm{~g} . / \mathrm{pl}$. und $2.8 \mathrm{sg} / \mathrm{pl}$. = 1-Part. mit Kopula $3.8 \mathrm{~g} \cdot / \mathrm{pl}$.

$$
=" \text { ohne }
$$

3. Nachklänge der alten perfekt1schen Bedeutung der 1-Per1phrase lassen sich nur selten (z.B. die genannten PsalmVerse) nachwelsen; perfektische Bedeutung, wenn uber-

70) Die regelmäBige Verwendung der Periphrase "esmi byval" usw. läßt den SchluB zu, daß diese zumindest in der privaten Korrespondenz noch weit verbreitet war.

71) Boretzky, Tempusgebrauch, S. 66 verwendet "formalpersonelle 
haupt vorhanden, ist zumeist eine Folge der Semantik des Verbe und des Kontextes (Gott, Christus/Antichriat alo Subj.).

4. Die umfangreichen Reden, Briefe und die Monologe des Autors unterscheiden sich in ihrer Diktion nicht von den ubrigen Tellen der Erzählung (Ausnahme: der Brief des "Gansumeler"), wenigstens, was das Verb.fin. anbelangt: Ipf. und Aor. dominieren, das 1-Part. (mit und ohne Kopula) spielt eine ganz untergeordnete Rolle.

5. Das 1-Part. erscheint am hiufigsten in kurzen Aussagesätzen, die Verben des Sagens (dort regelmäB1g) und Verben des Hórens und Erfahrens (dort meistens) folgen und die mit "jako" oder "čto" angeschlossen sind, also:

"skazaša/vozvestiša ..., jako + 1-Part."

"Blysav/pride vestb..., jako + l-Part. (manchmal Aon)"

In solchen Sätzen mit angefügten Redeteilen scheint der Autor gesprochene Rede zu stilisieren.

6. Häuf1g beobachteten wir das 1-Part. In Sätzen, die eine Datierung bzw. eine punktuelle Zeltangabe enthielten. In der relchlichen Hälfte solcher sätze mit detallilerter Zeitangabe fanden wir den Aor. vor.

7. Immerhin fünf (sechs) Mal begegneten 1-Part.ien in Relativsätzen.

8. Idlomatische Tendungen, Termint technicl und besonders hoch frequentierte Verben erscheinen im Präteritum besonders häufig in Form des 1-Part.s - an solchen stellen schelnt die Diskrepanz zwischen russischer Umgangs- und kirchenslavischer Literatursprache (um die sich der Pleskauer Autor Jedenfalls bemunt) zu grob, der Druck der gesprochenen Sprache zu stark gewesen zu sein, als daB der Autor bel solchen Verben und Wendungen hätte immer die literarischen Tempora durchsetzen kbnnen.

Opposition in Bezug auf die Verteilung von Ipf.- und Aor.Pormen in Kurbskijo "Istorlja": dort wird die 3.8g. vorwiegend durch Ipf., die 3.pl. n " Aor auggedrickt - wenn nicht, wie in 55 v.Hd. aller finiten Präteritalformen das 1-Part. erscheint. 
9. 1-Part.1en treten in der Hegel massiert auf: Das Bestreben des Pleskauer Autors, beinahe uberall bestimmten Textabschnitten aus euphonischen Grïnden ein dominierendes Tempus zuzuweisen, konnten wir bereits im Rahmen der Untersuchungen an Praes., Ipf., Aor. und sogar am Konditional beobachten; auch das 1-Part. macht hiervon keine Ausnahme. Es tritt weniger in reimender Stellung auf, aber die Absicht des Autors, mit Hilfe des 1-Part.s ähnlichen oder Gleichklang zu erzielen, lst unübersehbar. Man kann sogar sagen, das das elnzeln auftretende 1-Part. eine Ausnahme darstellt.

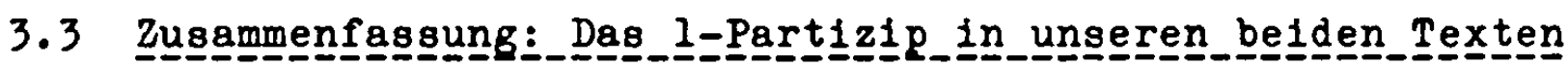

Beide Autoren meiden das 1-Part. Der $\mathbb{K}$-pler Autor benutzt die 1-Periphrase in besonders hochsprachlichen Passagen, um von Gott oder Christus ausgehende Handlungen auszudricken; dabei verwendet er tradierte Wendungen ("rekl estb", "1skupil esin, "sotvoril esi"). Während also die 1-Periphrase die höchste Stilebene anzeigt, tragen die l-Part.ien ohne Kopula zufälligen Charakter, oine bestimmende Gemeinsamkeit ist nicht zu erkennen, dazu ist das Belegmaterial (drei Beispiele) nicht ausreichend. Es handelt sich um perf. Verben ("prošlin, "otdochnul", "postradal ${ }^{n}$ ), das l-Part. ersetzt jewe1ls einen Aor., wie die Analysen zeigten.

Verdanken 1-Part.1en im R-pler Text - sofern ohne Ropula - ihr Erscheinen offensichtlich irgendwelchen Zufällen (z.B. Abschreibfehler eines Kopisten), so hat das 1-Part. in der Pleskauer Erzählung doch schon einen - zwar bescheidenen, aber doch - festen Platz gefunden. Die Barriere, das 1-Part. (ohne Kopula) um jeden Preis zu meiden - noch existent in der "Kazanskaja Istorijan, abgefabt um 1565 -, hat der Pleskauer Autor bere1to'uberwunden. Oft verwendet er das 1-Part. In st1lisierender Absicht, um kurze gesprochene oder als gehört aufzufassende Sätze wiederzugeben ("vozvestiša/skazaša ..., jako/čto + 1-Part." und "slyšav/pride vestb..., jako/čto + 1-Part. (oder

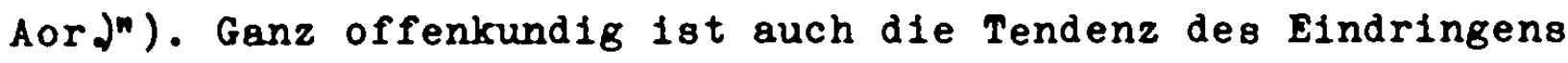
von 1-Part.1en in Sätzen mit punktuellen Zeitangaben/Datierungen; 
erkennbar 1st diese Tendenz auch beim Relativartz. Bei bestimmten, idlomatisch oder technisch gefärbten und bel sehr häufig gebrauchten Tendungen gibt der Pleskauer Autor dem Druck der Umgangssprache oft nach. Auch verwendet er das 1-Part. ganz bewuBt zur Erzielung klanglicher Effekte (Gleichklang), deshalb treten 1-Part.ien me1st in Gruppen auf, was wir ja auch in bezug auf andere Tempora konstatiert haben.

Lehnten sich 1-Periphrasen im $\mathrm{K}$-pler Text an biblische und liturgische Vorlagen an, so herracht im Pleskauer Text eine formalpersonelle Opposition - die $3.8 \mathrm{~g} / \mathrm{pl}$. erscheint ohne, die $1.8 \mathrm{~g} \cdot / \mathrm{pl}$. und die $2.8 \mathrm{~g} / \mathrm{pl}$. erscheinen mit Kopula.

In der $\mathrm{K}$-pler Erzählung begegnen - auBer habitualialertem, aspektuell neutralen "rekl estb" - nur l-Part.ien von solchen Verben, die heute perf. sind. Dagegen finden sich in der Pleskauer Erzählung auch einige Belege mit klaren Imperfekt1vBildungen - "vyprošalisja", "skazyvalin," "pisal esi" (letztere Porm sogar in aoristischer Funktion).

Alle Beobachtungen am Pleskauer Text durfen wir als deutliche Zeichen werten, daB das l-Part. Im Begriff stand, sich als universales Präteritaltempus in der literarischen Sprache zu installieren. 
00050711 
4. Das Plusquamperfekt - Vorvergangenhe1t

Das Plusqpf. kam schon Im Aksl. selten vor; häufig wurde stattdessen der Aor. gebraucht. ${ }^{1}$ Gebildet murde das Plusqpf. Im Aksl. durch die Ipf.-Formen von "byti" + 1-Part.:

a) "bĕchz prišblon - '1ch war gekommen',

b) "běachz prišblon - $n n n$ n

In den frühen altruss. Denkmälern (z.B. Ostrom1r-Evg.) finden wir diesen Zustand unverändert. Offenbar vom 12. Jh. ab ${ }^{3}$ tritt zu diesen beiden Varianten eine dritte, die ubrigens auch im Serbokroat1schen, Slovenischen und West-Slavischen bekannt $18 t:^{4}$

c) "prišlz bylz esmb" - '1ch war gekommen'.

Vor allem in der 3.8g./pl. tritt dieser Typus immer häufiger ohne "estb/sutb" auf, gelgentlich erscheinen auch die 1.8g./pl. und die $2.8 \mathrm{~g} \cdot / \mathrm{pl}$. ohne Kopula. 5

Typus c) breitet sich zunächst in der altruss. Geschäftsoprache (Urkunden, Briefe usw. ${ }^{6}$ ) aue, kann sich dann aber auch in den literarischen Genres etablieren, bis er im 16. Jh. zur vorherrschenden Vertretung fur die Plusqpf.-Periphrase wird. 7

Schlieblich entwickelte sich aus Typus c) noch eine bereits erstarrte Porm der Plusqpf.-Perlphrase:

1) Vondrák, Aksl. Grammatik, S. 518 f. - mit Hinweis auf die gleiche Erocheinung im Griech.

2) Van Schooneveld, A Semant1c Analy818, S. 122 - 40 - veroucht, diesen Varianten bestimmte Bedeutungen zuzuweieen; wegen des wenigen Belegmaterials, das er zur Hand hat, sind seine Polgerungen 'nlcht absolut zwingend' ( $=$ Kiparsky, Russ.h1st.Grammat1k, S. 229). Ausfuhrliche Krit1k: Budich, Aspekt, S.44-50.

3) V.I. Cernov: $K$ voprosu o strukture novogo russkogo pl juskvamperfekta (TIpa 1-byl). In: Slav1a 30 (1961), S. $432-442$

4) Sobolevsk11, Lekc11, S. 164. h1er: S. 434 .

5) Belgpiele bel van Schooneveld, a.a.0., S. 136 - 39 aus PVI, Chozenie Danitia und 1. Novgoroder Chronik.

6) Beispiele: Sobolevsk1 , Lekc11, S. $242 \mathrm{f}$.

7) Cernov, a.a.0; H1k1forov, Glagol, s. $163-65$ - fast alle seine Beispiele; auch In Kurbokijo "Istorifa" kommt fast nur Typus c) vor - Boretzky. Tempusgebrauch, S. 98; in der "step. knigan jedoch $18 \mathrm{t}$ deser junge Typus unbekannt - etten, in. Verbalformen, S. $333 \mathrm{f}$. 
d) "prišels bylo" - 'ich (mask.) war, du (mask.) warst, er war gekommen',

"prišla bylon - 'ich (fem.) war, du (fem.) warat, sie war gekommen'.

"prï̌lı bylon - 'sie (mask., aber zunehmend auch andere Genera) waren gekommen'.

Dieser Typus $18 t^{8}$ - mit anderer Bedeutungsnuance allerdings ${ }^{9}$ heute noch anzutreffen.

Das Plusqpf. tritt vorwiegend in der Hypotaxe auf, wo es im Nebensatz Vorzeitigkeit in Bezug auf die präterital ausgedruckte Handlung des Hauptsatzes bezelchnet. Weniger klar ist die Relation zwischen der Handlung eines Hauptsatzes, die mit Hilfe des Plusqpf. ausgedruckt ist, und Handlungen von Sätzen, deren Prädikate im Ipf. oder Aor. stehen. In solchen Fällen ist anzunehmen, daB der durch Plusqpf. bezelchnete Vorgang in bezug auf das vordergründige Geschehen allgemein sehr weit zurückliegt, gelegentlich wird auch durch Plusqpf. etwas nachgetragen, was bel streng chronologischer Erzählweise schon früher hätte berichtet werden müssen (s. das folgende Beispiel aus dem K-pler Text, aber auch in der "Stepennaja knigan 10): Solche Ruckgriffe werden im Deutschen gern durch ein eingeschobenes 'nämlich' verdeutlicht - s.u. 11

8) In Kurbskijs "Istorifa" sind von 30 plusqpf.-Belegen 5 so gebildet, sie haben - im Gegensatz zur heutigen Bedeutung dieger Periphrase - Plusgpf.-Bedeutung: Boretzky, Tempusgebrauch, S. 100 .

9) "prisel bylo" - heute: 'ich war beinahe angekommen' ('unterbrochenes Präteritum') - diese Bedeutung der erstarrten Plusqpf.-Variante greift von der 2. Hälfte des 17 . Jh.s an um sich, belegt aber auch schon bel Avvakum; vgl. Cocron, La langue, S. $236 \mathrm{ff}$; Kiparsky, Russ.hist.Grammatik II, S. 230; Schnelder, Sprache Posorkovs, S. $208 \mathrm{f}$. Boretzky, Tempuegebrauch, S. 98 - "Wenn der Typ -1 bylo immer mehr die Bedeutung annimmt, die er im modernen Russ. hat, so liegt dies einerseits am formalen (Beseltigung der Kongruenz) und andererse1ts am funktionelien Verfall (Schwinden des Gefuhls fur den Ausdruck der Vorvergangenhe1t) des Plqpf., wodurch die nun allein herrschende Form ausschliesslich für die modale Bedeutung beansprucht werden konnte."

10) otten, Pin.Verbalformen, S. 336 f. - Beispiele.

11) Gans selten erscheint folgende Periphrase: 'l-Part. "bychz", "by" usw.' - etten, a.a.0., S. $334+350$; A. I. Hensersiky: Značennja form mynulogo casu $v$ Halicko-volinkromu litopysu. Ky1v 1957. S. 72 f. "pocali bychomb, "byetb ne byralo". 
In unseren beiden Texten kommt das Plusqpf. so gut wie gar nicht vor - einen einzigen Beleg finden wir in der K-pler Erzahlung:

60/8 "I pak1 ot množestva ognej 1 streljanija ... dymnoe kurenie zgustivsja, pokrylo bjaše grad 1 vojsko vse, jako ne videti drug druga, s kem s ja bset, 1 ot zelejnago duchu mnogim umreti."

'Es hatte nämlich (wieder) ${ }^{12}$ der Qualm - durch die vielen Brände und das SchieBen ... hervorgerufen - die gesamte Stadt und das ganze Feer überzogen, so dab nicht zu erkennen war, mit wem man kämpfite; viele starben sogar durch den Pulverrauch.'

Der hier beschriebene Zustand ist zeitlich nur vage einzuordnen, da der direkte Bezug, wie er in der Hypotaxe vorliegt, in diesem Satz ja fehlt. Breit schildert der Autor hier Eindrücke vom Kampfgeschehen, welche die Sinne am stärksten treffen: Trompetenschall, das Dröhnen der türkischen Pauken, der Krach der Flinten und Geschütze, die Glocken, das Geschrei der Menschen ...., die Peuerstöße der Waffen, die wie Blitze hin und herzucken - und zuletzt Qualm und Rauch. Palls der Autor diese Form bewuBt und bedeutungsgemäB gebraucht hat, will er damit vielleicht ausdrucken, daB der Rauch, obwohl zuletzt genannt, ebenso zum allgemeinen Bild gehört wie etwa die erstgenannten akustischen Eind rücke; möglich 1st auch - und die Detaillierungen stützen diese Vermutung (es war nicht erkennen, mit wem man kämpfte; viele starben durch den Rauch allein) -, daB der Autor mit der Plusqpf.-Periphrase das Entotehen des Rauches auf die gesamte Kampfschilderung ausdehnen will, die mit dem Datum (14. Tag nach Beginn der Belagerung - 59/28) beginnend, verschledene Kampfplätze und -szenen, aber auch das Gebet des Klerus umfabt: dies alles muB gleichsam durch eine wolke von Qualm und Rauch gesehen werden. So hätten wir es auch hier mit einem Rückgriff zu tun.

Es ist aber auch nicht auszuschlieBen, daB der K-pler Autor diese Form wegen ihres archaischen Charakters gebraucht, ohne ihre elgentliche Funktion noch zu kennen. Die übrigen Sinnes-

12) "pak1" - 'wiederum, auch' wird oft, wie auch hier, eher als stark bedeutungsentleerte Satzeingangsformel gebraucht. 
eindrücke, die mit Hilfe von Ipf. und Aor. Wiedergegeben werden, empfing der Autor ja auch vom Beginn der Kampfeshandiungen.

In der Pleskauer Erzählung kommt gar kein Beleg fur Plusqpf.Periphrase vor. Diese Tatsache bestätigt Nikiforovs Peststellung, da $\beta$ das Plusqpf. Ende des 16. Jh.s nicht mehr lebendig war. ${ }^{13}$ Die uberaus spärliche Vertretung auch in der K-pler Erzählung zeigt darüber hinaus, das das Plusqpf. bereits Ende des 15. Jh.s selbst in der Literatursprache auBer Gebrauch kam.

Dies erinnert uns an die bekannte Tatsache, daB die slavischen Sprachen die Consecutio temporum - und hier besonders die durch Plusqpf. ausgedrückte Vorvergangenhe1t - nicht so zwingend gebrauchen, wie dies belspielswelse in den romanischen oder germanischen Sprachen geschieht: Wenn nicht die Notwendigke1t bestand, Vorgänge, die anderen präterital ausgedruckten Handlungen zeitlich bereits vorausgegangen und abgeschlossen sind, gesondert auszudrücken, dann wird man davon ausgehen dürfen, daB das Gefühl für Vorvergangenheit nicht stark entwickelt ist. Unseren Texten nach mus es bereits Ende des 15. Jh.s bereits weitgehend erloschen gewesen sein. ${ }^{14}$

Im folgenden wollen wir skizzieren, wie Vorzeitigkeit in unseren beiden Texten ausgederückt wird.

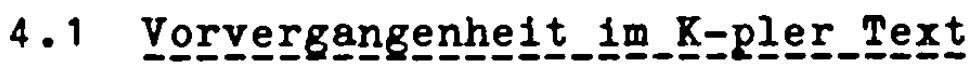

Da, wie bereits erwähnt, Vorvergangenheit in der Parataxe nur schwer und nur mit Hilfe weitreichender Inhalts- und KontextAnalysen einigermaßen zu fassen ist, wollen wir uns darauf beschränken, auf Vorvergangenheit im Rahmen der Hypotaxe hinzuweisen. Vorzeltigke1t im Nebensatz in Relation zu einer präterital ausgedrückten Handlung im Hauptsatz 1st leichter zu fassen.

13) N1kiforov, Glagol, S. 165: Plusqpf. "byl otmiravejej grammaticeskoj kategoriej".

14) Ein GroBteil der Plusqpf.-Belege der "Step.kniga" wird "auf Grund älterer Vorlagen weitgehend tradiert" - Qtten, Pin. Verbalformen, S. $341-48$. 


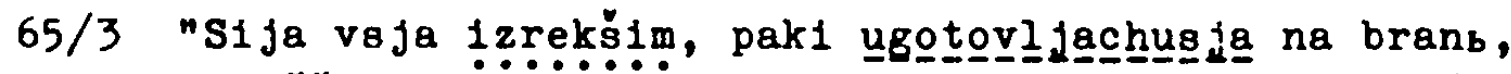
kajuščejsja o posiani1 k Moametju, zane tem uderžachu ego."

' Nachdem sie (= die Bürger K-pels) dies alles (= StoBgebete) ausgerufen hatten, rüsteten sie sich abermals zum Kampf und grämten sich wegen ihrer Gesand tschaft (= Bitte um Frieden) zu Mehmed, weil sie 1hn dadurch zum Bleiben bewogen hatten.'

Der Dat.abs. ("izrekšlm") bezeichnet eine der Haupthandlung unmittelbar vorausgehende Tätigke1t. Auf diese ganz normale Möglichke1t - Vorzeltigke1t durch Part.praet. und mit dessen Hilfe gebildeter Konstruktionen - brauchen wir hier nicht näher einzugehen. Der Haupthandlung "ugotovl jachusja" folgt ein Part.praes., das einen die Haupthandlung begleitenden $\mathrm{zu}-$ stand beschreibt. Der abschlieBende Kausalsatz bezieht sich auf das Part.praes., das er erläutert, begründet - sie bereuten Ihre Gesand tsahaft an den Sultan. Der Leser weib aus dem bisher Gelesenen, daB Mehmed hatte $K$-pel verlassen wollen, well er die Belagerung für aussichtslos hielt (so jedenfalls unsere Erzlihlung). Die Bitte der Griechen um Frieden zeigte inm erst die verzwelfelte stimmung in $\mathrm{K}$-pel und veranlabte $1 \mathrm{hn}$, die Belagerung und die Bestürmung der Stadt fortzusetzen.

Die Vorvergangenhelt ist hier durch Ipf. bezelchnet. Durch das Präfix "úderźati" - 'zurúckhalten' wird deutlich auf den Ausgangspunkt der Handlung verwiesen - 'sle hatten ihn veranlabt zu bleiben'. Das Ipf. zeigt aber, daB der Autor den Vorgang nicht punktuell sieht, wie unser 'veranlassen' vermuten lassen könnte; vielmehr betrachtet er "uderžati" als in die erzählte Gegenwart hineinreichend im Sinne von 'zurück-bleiben' als Polge von 'zuruickhalten. Das Präfix von "udderźati" differenzlert die zuständliche Grundbedeutung von "deržati" nur. (vgl, auch oben, S. 328). 


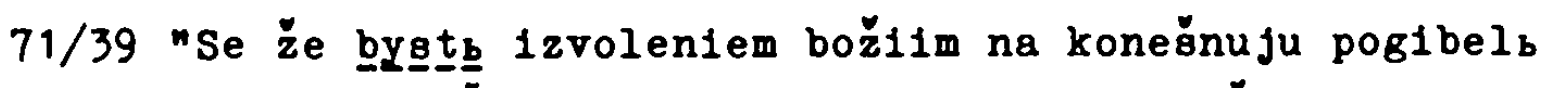
gradu, poneźe poloe ono mesto on chranjase velikoju siloju 1 mužestrom, ..."

(Giustiniani war von einer Steinkugel getroffen worden) - Dies war einer der Grunde für den Untergang der Stadt, denn er (Giustiniani) hatte die Bresche mit groBer Kraft und Umsicht verteidigt, ...'

Der altruss. Satz gibt die kausalen Verhältnisse nicht ganz korrekt wleder, doch lot der Sinn klar: Well der Genueser so vorbildich und erfolgreich an der Verteldigung $K$-pels mitgewirkt hatte, war seine Verletzung (Nichteinsatzfähigkeit) für die Verteldigung ein solcher Verlust, der mit zum Ontergang der stadt gefüht hat. ${ }^{15}$

Die "bystb" zeltlich vorauggehende Handlung ist eine durative, entsprechend dieser Aktionsart finden wir die Vorvergangenheit durch Ipf. ausgedrückt.

$61 / 24$ "..., a protivu Zustuneja navadiša pušku bolbšuju, ...

a) i jako udariša po tomu mestu, načat stena kolebatioja, a v drugle udariša, 1 sbǐa steny sverchu jako sažene pjatb;

b) v tretif že ne uspegęa, zane nočb uspe." Gegen Giustiniani richteten sie die große Kanone, ...

a) und als sie dorthin geschossen hatten, begann die Mauer zu schwanken. Und sie schossen zum zweiten Mal - dabe1 wurden etwa funf Klafter vom Mauerrand weggerissen.

b) Zum dritten SchuB aber kamen sie nicht mehr, weil (bereits) die Nacht hereingebrochen war.'

In a) 1st das Abfeuern des Schusses (und impliziert: das Treffen) Voraussetzung dafür, daB die Mauer zu wanken beginnt. Im Falle b) 1st die Dunkelhe1t, d.h. die Tatsache, dab die Nacht hereingebrochen 1st, der Grund fur die Vereltelung des dritten Schusses. Beide in den Hauptsätzen beschriebenen Handlungen werden erst möglich, wenn die Handlung der Nebensätze abgeschlossen ist.

Die vorzeltige Handlung erscheint, entsprechend dem Charakter der Handlungen, im Aor.

15) Hier 1st von der ersten Verletzung G.s die Rede, sicher hat aber der Autor den Tod G.s und den endgultigen Untergang $\mathrm{K}-\mathrm{pels}$ an dieser Stelle vor Augen. 
64/11 "...; 1 jako verdoša pak1 gražane na atenu 1 v1deša vo rve množestvo turok, abie zążigachnu bočky s smoloju 1 puéčachu na nich 1 ..."

' Und nachdem die Griechen die Mauern erklommen und die Menge der Türken in den Gräben erblickt hatten, zündeten sle gleich GefäBe mit Teer an und schleuderten sie auf die Türken herab und ...'

Die sich wiederholenden Handlungen des Hauptsatzes setzt der Autor ins aktualisierende Ipf. Diese werden ausgelöst und sind damit Polge des durch "jako" elngele1teten Temporalsatzes. 2war lot auch elne Handlungsfolge 'erklimmen - sehen/erblicken' erkennbar, doch sind belde Tätigkeiten syntaktisch gleichgeordnet - ebenso wie die Prädikate des Hauptsatzes nacheinander ablaufende Handlungen bezelchnen.

Auch in diegem Satz finden wir also die Vorvergangenhelt durch Aor. ausged rilckt.

Der K-pler Autor unterscheidet also nicht zwischen der präteritalen Erzählhandlung und Fandlungen, die dazu 1m Verhältnis der Vorzeltigkelt stehen. Ipf. und Aor. sind die Erzăhltempora Im K-pler Text - sie dienen auch zum Ausdruck der Vorvergangenhe1t.

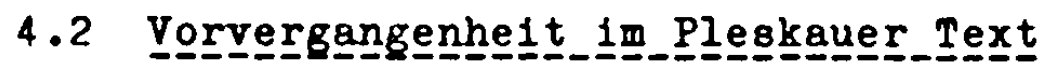

$73 / 3$ "I pervye korolevskie dvorjane ot ruskich ... voevod, pro nich že glagolachu, jako svjazanny k korolju privest1, pod Svinoju baśneju ... rov napolñ 1 ge.

' Und die Höchsten aus dem Gefolge des Königs, die in bezug auf die russischen ... Voevoden erklärt hatten, sie wurden sie gebunden dem König zufuhren, fullten nun den Graben unter dem Schweineturm.'

Die aoristiach-resultative Erzahlwe1se beherrscht diesen $A b-$ ochnitt - "napoln18̈a". Im Relativaatz "pro nich že glagolachu" wird Bezug genommen auf die prahlerischen worte der polnisch11 taujachen würdenträger $(68 / 22--/ 34) .{ }^{16}$ Das der Autor hier entgegen dem dominferenden Tempus des Abschnitts - Aor. -

16) \&.B. 68/30: "slavnych Sujokich svjazannych pred toboju postarim" - d.h. die Fursten V. F. und I. P. Sujakij. 
eine Ipf.-Form einbringt ("rekoš" hätte er auch verwenden können), gibt zu der Deutung AnlaB, daB der Autor dies als ständige Redensart der Litauer brandmarken möchte - "glagolachu" als Ausdruck der Iterativität sowie distributiver Handlung. Jedenfalls bezelchnet diese Ipf.-Porm eine dem Haupttempus Aor. vorhergegangene Handlung.

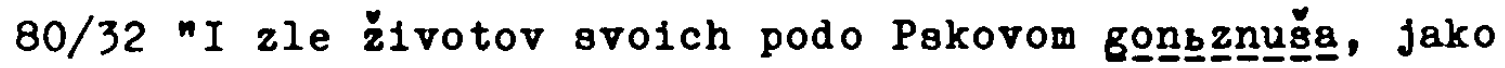
1 panbjam avoim povelevachu $1 z 0$ Pakova atretat1, ..." - Auf ganz schlimme Meise haben sie (die litauischen und polnischen Oberen)ihr Leben unter Pleskaus Mauern verloren, weil sie nämlich ihren Damen befohlen hatten, sie zu begrüBen, wenn sie (als sieger und beutebeladen) aus Pleskau zurückkehrten. 17

Die Ipf.-Form "povelevachu" hat exakt die gleiche Punktion wie "glagolachu" im vorigen Beleg: sie spielt einerse1ts an auf prahlerische Reden der koniglichen Heerfuhrer, andererselts betont sie gegenüber sonstigem Aor. - "povelešan -, daB der Autor in derartigen Wendungen keine vereinzelten AuBerungen, sondern allgemein verbreitete, dauernd wiederholte uberhebliche Worte der Litauer sieht.

Um den Aor. als Substitut für das Plusqpf. zu belegen, genügte es, die zahlreichen Einwürfe vom Typus "jako že (preže) rekoch" - 'wie ich bereits (fruher schon) gesagt hatte' heranzuziehen. ${ }^{18}$ Doch sollen zwei etwas aufschluBreichere Beispiele den Gebrauch demonstrieren:

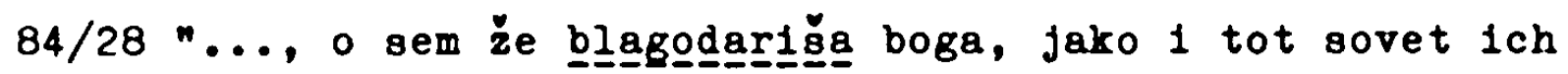
uvedå̌a, ..."

'..., und sie dankten Gott dafür, daB gle diesen litauischen Plan erfahren hatten, ...'

Die Voevoden musten erst von den unterirdischen Gängen Kenntnis erhalten, bevor sie Gott für diese Jachricht, für diesen Hinwe1s danken konnten. Be1 "blagodariti" handelt es eich - im weitesten Sinne - um ein Verb des Sagens. Der kal. Chararter

17) Vgl. 65/15 "Tako že 1 gvo1m panb jam 1 iz zanka Pskova radostno 1 a korystbju sebja stretati veljase."

18) $74 / 27,75 / 9,77 / 2,-/ 9$. 
von "blagodarit1" mochte aber verhindert haben, dab das Präd1kat dee Aussagesatzee in Porm des 1-Part.s erscheint. Zudem lot der Charakter des Objektsatzes hier stärker ausgeprägt, da d1eser durch "o sem že" vorbereltet wird, wodurch der Charakter des Redete1ls nach "jako" doch stark verlorengeht. - Jedenfalls wird das der aorlotisch wiedergegebenen Handlung des Hauptsatzes vorausgehende Ere1gnis auch durch Aor. ausgedrickt.

89/16 "Stenu že egda 1 ot toj storony, ot Velik1ja rek1, gb1в̈a, togda posled1, nojabrja $\vee 2$ denb, vel1kim pristupom ot Velikie rekı po ledu uže prisotupachnu: ..." 19

'Nachdem sie die Stadtmauer vom GroBen FluB aus beschosoen hatten, trugen sie später - am 2. November - einen mächtigen Angriff uber das Els des berelts gefrorenen Pluses vor: ...'

D1e Vorze1tigke1t von "zb1sa" wird dadurch unterstrichen, daB der Im Hauptsatz geschilderte Vorgang expressis verbis "pooled1 ... pristupachu" als spater geschehend bezelchnet lot. Auch hier finden wir also die Vorvergangenhe1t durch Aor. Wiedergegeben.

Das 1-Part. In der Bedeutung von Vorvergangenhe1t war uns in anderem Zusammenhang bereits aufgefallen: Im Relativatz bezelchnet es Vorzeltigkelt in bezug auf die Handlung des Hauptsatzeo, das glelche gilt fur das 1-Part. In Aussagesätzen nach Verben des Sagens/Mittellene und Hörens/Erfahrens.

Diese unsere Beobachtung kann $1 \mathrm{ch}$ aber nicht als Anze1chen fur eine Ablosung des Plusqpf.s durch 'Perfektformen' bewerten, we dies otten tut. ${ }^{20}$ wr haben es nämlich in den genannten Satztypen nicht generell mit 1-Part. In Punktion der VorverBangenhe1t eu tun, sondern lediglich mit 1-Part. In der runktion von Vorke1tigke1t. Wir wollen dies an je einex Belopiel

19) $\nabla_{G l}$ oben 8, 500, Anm. 45: D1ea lat der zweite 8ate alt Ipf. nach e1ner Dat1erung in extenso. D1e Ipf.-Forw "pristupaohu" entspricht der folgenden aktualisierenden Benohreibung.

20) Otten, P1n.Verbalforen, S. 349 - 52. Fr ber1eht sch dabel aul Ilkiforor, Glggol, 3. 165: "Pl Juskramperfert ko rtoroj

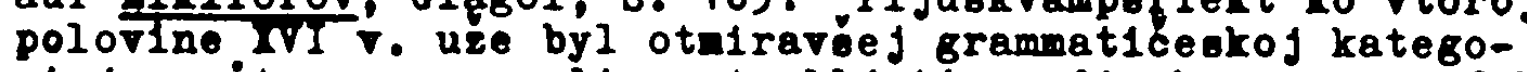
riof, podtom ego mogli upotrebljat $v$ odinakore perfekton enaón11." (hervorhebg. - Mik1forov)-allordings lobt 


\section{In Erinnerung rufen:}

$72 / 27$ nTogda že vse te vysokogordelivyja korolevskija približnye dvorjane, jaže u korolja vyprošalisja napred vo Pskov vniti 1 ..., jako druguju bašnju, podo Pskova so-

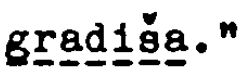

Damals bildeten all jene ... Höflinge, die sich vom König ausgebeten hatten, zuerst in Pleskau eindringen zu diurfen und ..., gleichsam einen neuen Turm vor der Stadt. 21

Dieses 1-Part. eines durch Suffigierung entstandenen Imperfektivums hat hier genau die gleiche Funktion wie die oben vorgestellten Ipf.-Formen mit Vorvergangenheits-Bedeutung (s.0. S. 521 f., Belege $73 / 3+80 / 32$ ); die Ipf.-Form "glagolachu" (73/3) und das 1-Part. "vyprošalisja", gebildet von einem durch suffigierte Ableitung entstandenen Imperfektivum (vgl. "povelevachu" - 80/32), signalisieren Iterativität: eine von den vielen Günstlingen des Königs oftmals vorgetragene Bitte (= Betteln), von welcher der Autor vorher (S. 68/3 - 6) berichtet hatte und auf die sich der Autor nun bezieht. Wie die genannten Ipf.-Formen vertritt das l-Part. hier das Plusqpf. Im Relativatz - Vorvergangenheit. 22

Einfache Vorzeltigke1t in Hinblick auf eine präsentisch ausgedrückte Haupthandlung finden wir im folgenden Beleg: ${ }^{23}$

$51 / 24$ "A jaže plsal esi O grade tom, jage toliko že 1 vo vaech našich stranach ...." 24

' Und was du uber diese Stadt geschrleben hast, 1st in unseren Landen weithin bekannt ...'

Die normale Vertretung des Relativsatzes im Pleskauer Text zelgt aber bel Vorvergangenheit Ipf. oder Aor.

Nikiforov das 1-Part. keineswegs als Ablösung des Plusqpf.s schlechthin - Nikiforov, a.a.0., S. 147: "Kak imperfekt, tak 1 aorist 1 perfekt mogli polucat pl juskvamperfektnoe značenle (...) potomu, cto ko vtoroj polovine XVI v. pl juskvamperfekt ifteraturnym ( 1 tem bolee razgovornym) jazykom byl uze utracen." Vgl. weiter ebda., S. 149 und 155.

21) D.h. die Leichname bildeten mit den Trummern einen Turm.

22) $\mathrm{Vgl} .41 / 17,82 / 20 . \quad 23) \mathrm{Vgl}, 84 / 24,83 / 12$.

24) "javě" - 'kund, offenbar, klar': Sadnik-A1tzetmuiller, HWB, S. 6 ; Slovnlk jazyka staroslovenskeho, S. 11; Srezn. III 1637 . 
$86 / 20$ "(voevody) ... ovjatago velikomučenika Dimitrija, jaǧe ego radi ovjatago obraza 1 sie bog nevedinie otkry, blagodarenie oㅛda jachu."

'(die Voevoden) ... dankten dem helligen Martyrer D1m1trif, weil die Zerstörung soiner Ikone (durch die Litauer) der AnlaB war dafur, daB Gott den Pleskauern das bloher Onbekannte (= die geplanten Zielpunkte der unter1rdischen Gräben) offenbart hatte.' wortlich:

- ... dankten Dimitrif, um der Zerstörung dessen Ikone wilien Gott das bislang Unbekannte offenbart hatte.'

Fur die Aussage nach Verben des Sagens/Mittellens und Hörens/ Erfahrens mag der folgende Satz als Belopiel dienen, der eine In bezug auf das Hauptverb (hier: "slyša") vorzelt1ge Handlung durch 1-Part., elne gle1chelt1ge Handlung durch Praes. ausdruckt:

58/14 "Paky že sly̌ğav vo Pskove, jako uže korolb pod 0strov ... prišol, ...., 1 po Ostrovu gorodu 1z narjadu uže bbet."

- Ond dann war wleder in Pleskau zu hören, daB der Kön1g bere1te gegen 0strov gezogen wäre, .... und die stadt ... besch1eBe.'

Das 1-Part. druckt aber auch Innerhalb dieses Satztypo Vorze1t1gke1t nach elnem Hauptverb im Praes. aus:

92/19 "Ot sego že jave troego bezumija obličenie, jako pri sebe 1 prl ovoem stojanlil vojakiml svolmi rasnymi zamyšlenil velikago grada Pakova ne vejal es1, nyne že po ovoem uničižennom 1 velikosramotnom otsestril oto Pskova grada cholopu ovoenu vzjat1 vellö velik1j grad Pakov." - Dies offenbart deine ganze Torhe1t/Dummhe1t: Selbst durch delne personlich Le1tung der Belagerung und all deine Machenschaften hast du Pleskau nicht elngenonmen - und jetrt, nach delnem schubhlichen Abrug, befiehlot du deinem Knecht, Pleskau zu erobern.'

Unsere Boobachtungen am 1-Part. haben uns zu dem Ergebnis geelurt, dab es zwar in bestimnten Hebenslitzen (Relativ-, Aussage-) Vorvergangenhe1t ausdricken kann - dies jedoch nur, we1l das 1-Part. (wle auch, und zwar noch ofter, andere PräteritalTenpora) dann in elner Vorzolt1gke1tsbeziehung zu einer praterital wledergegebenen Handlung des Hauptsatres steht. lot 
letztere aber präsentisch ausgedrückt, dann hat das 1-Part. lediglich die Bedeutung eines einfachen Präteritum.

Elne Tendenz, daß das l-Part. das Plusqpf. generell ablösen wurde, konnten wir weder im Pleskauer noch im K-pler Text beobachten. 25

In den späteren Ausfuhrungen uber die Kurzform des Part.praet. (us-Part.) werden wir darlegen, daß dieses Partizip im Pleskauer Text praktisch alle Funktionen eines Verbs im Präteritum Ubernehmen kann. Daher ist es nicht verwunderlich, das Part. praet. In der Bedeutung eines Verb.fin. vorzufinden, das in bezug auf die präterital ausgedruckte Handlung des Hauptsatzes im Verhältnis der Vorzeitigkeit steht - also Vorvergangenheit bezeichnet.

$67 / 25$ "... korols Stepan, vídev svoich rochmistov ... i gajdukov, jako vzlesša na stene $1 \mathrm{v}$ bašnjach $1 \mathrm{ch} 1$ znameny uže

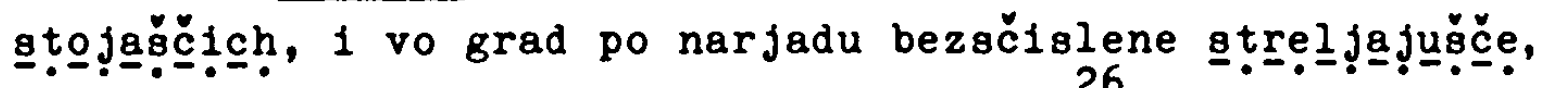
..., neskazannye radost1 1spolnisja ...n26

'Als der König Stephan sah, dab seine Rottmeister ... und Heiducken die Mauer erklommen hatten und dab in/auf den Basteien bereits deren Banner standen und dab jene die Geschulze in der Stadt heftig beschossen, ..., da wurde er von großer Preude erfüllt ...'

Nach Verben des Sagens/Mitteilens und Hörens/Erfahrens fanden wir Handlungen, die z.Z. der Rede oder der Nachricht bereits vollzogen waren, sehr oft durch l-Part. wiedergegeben - nach Verben des Sehens/Erkennens geschieht dies nie, auch wenn die jeweilige Mittellung uber das Gesehene/Erkannte durch "jako" angeschlossen 1st. Meist wird das Gesehene, wie hier, durch Part.praes, ausgedrückt, wenn es sich gewissermaßen vor den Augen abspielt (Gleichzeitigkeit), und durch Part.praet. wiedergegeben, wenn das Erkannte bereits geschehen ist bzw. zuvor Gesehenes nachgetragen wird (Vorzeitigkeit). Hat der Objekt-

25) Dies wäre auch aus dem Grunde vermunderlich, well ja das Plusqpf. als Tempus und wohl auch das Gefuhl für Vorvergangenheit längs $t$ verloren waren.

26) Variante, S; 145, hat folgende Lesart: "... 1 v bašnech 12 znamenami uze stojascich, 1 vo grad po narodu ... strelıajuacen 
satz ein Verb.fin. zum Prädikat, dann signalisiert das Ipf. Im allgemeinen Gleichzeitigkeit, beim Aor. ist wegen nicht ausreichenden Materials keine eindeutige Aussage zu treffen. 27

Im obigen Beispielsatz oteht "vzlesša" in Verhältnlo der Vorzeitigke1t zu "videv" - 'als er sah, dab sie erklommen hatten'. "vider" steht in quasi adverbialer Funktion zu "18polnisja" 'Als er gesehen hatte, daB..., da wurde er erfullt'.

$97 / 13$ "... slavimyj bog 1 bogorodica sobljude 1 nevred1 ...28 knjarja Ivana Petroviča Sujakago a tovaryščl, no 1 togo ničim ne vredil, jaže larec toj otpiravyj."

'... der gepriesen Gott und die Gottesmutter beschutzten den ... Fürsten I. P. Sujskij und die anderen Voevoden, aber auch denjenigen, der den Kasten geoffnet hatte.'

Es handelt sich hlerbel um den resultierenden SchluBsatz zum Bericht uber den Attentateversuch auf den verantwortlichen Voevoden, Furst Sujak1j - daB das Offnen der Truhe ohne Unfall vor elch gegangen war, war berelts der aktualisierenden Beochrelbung der entsprechenden szene zu entnehmen - insofern ist die Interpretation von "otpiraryj" als Vorvergangenheit gerechtfertigt.

Abschliebend wollen wir noch einen kurzen Abschnitt zitieren, der - auBer l-Part. - die verschledenen Möglichkelten, Vorvergangenhelt auszudrucken, bietet:

- '... und daB sie (= die Rottmeleter etc.) sich bereits mit ihren Bannern in den Basteien befanden und in die stadt, In die Volksmenge, schossen' - dlese Lesart scheint mir beeoer, da der "jako"-Satz hier ein durchgehendes subjekt ('sien enthklt; auch "po narodu" $18 t$ besser als "po narjadu", denn die Geschutze befanden sich gewis auf der Mauer und in den Turmen, nicht aber in der stadt.

27) z.B. 97/26 "vidjachu, jako l1tovskomu vojsku ostavajuǒčesja, ot nich ze edin konny $k$ gorodu uetremieja, ..." - ale eahen, wie das lit. Heer zurluckblieb (unvolistäniger Dat.abs) und ein Reiter auf die Stadt zukam, ...' - belde Handlungen im "jako"-Satz splelen sich vor aller Augen ab, and also gleichze1tig mit "vidjachu". - 90/17 "Videv... korolb, jako nikoiml obrazy ... ne vozmogoba gradà vajat1,..." - 'Der Konig sah, daB er Pleskau nicht nehmen konnte/nicht hatte nehmen kơnnen/nicht wirde nehmen können'?

28) Gott und Gottesmutter sind hier wohl als Einpeit gesehen daher Singular statt "sobljudoea" und "vredisa". 
74/35 "...; tret1j že a niml Mart1rej 1gumen, - znaem že be vo Pskove vaem1 1 toj. S11 že predpomjanutye černorizcy,

a) plotckim roženiem det1 bojarskie, 1 egda bejachu $\nabla$ mire, tako že 1skusni1 vo1n1.

b) Sego rad1 ..., egda pribežavše k prolomnomu mestu, 1deže krovoprolitnoe toržestvo obolch stran soveršaseges velikiml glasy ... voevodam 1 voemu chrestbjanskomu

c) voinstvu, jako že preže rekoch, ${ }^{29} \ldots$ rekkoğa: '..."n '...; der dritte 1m Bunde war der Abt Martirej - auch er war allen Pleskauern wohlbekannt. Diese erwähnten Mönche, ihrer Geburt nach niedere Bojaren, 30 waren erfahrene

a) Krieger gewesen, als sie noch nicht iñöroter lebten.

b) Deshalb riēieñ sie, nachdem sie die Bresche erreicht hatten, wo das Blutvergien solche Triumphe feléré, dén- vóevoden und dem ganzen christlichen Heer, wie $1 \mathrm{ch}$

c) schon früher_gegagt_hatte, mit lauter Stimme (folgendes)
zu: ...

Das Erzähltempus in Belsplel a) 18t durch "be" (znaem že ben") angeschlagen. Der folgende Satz belnhaltet einen Ruckrerwe1s 'damals, als sie noch nicht die Kutte trugen, waren ole nämlích er erfahrene Krieger gewesen.' Der zeitliche Ruckgriff, hier in Parataxe, erfolgt mit Hilfe des Ipf.

Im Belsplel b) wird durch "soveršasesja" die Szene zeltlich markiert, vor deren Hintergrund sich das Hauptverb - "rekosia" abhebt. "egda pribežavǐe" bezeichnet eine Handlung, die Voraussetzung fur die ooristisch ausgedruckte Haupthandlung 1st: Vorvergangenhe1t also wiedergegeben durch Part.praet.

Be1spiel c) stellt einen syntaktioch unabhängigen Einschub dar, der - wie wir schon oft sehen konnten - auf eine fruhere AuBerung, hier elne solche des Autors selbst, Bezug nimmt. Vorvergangenhe1t bezelchnet hier der Aor.

29) " jako žel preže rekoch, jako ot 11ca ovjatych 1kon nilost1 rekosa:'..." - 'wie 1ch bereits fruher gesagt habe, gleichoam rom Angegicht der Gnade der hlg. Ikonen oprachen e1e: ...'. "Jako ze preźe rekoch" erinnert daran, daB die folgende Wendung schon kurz zuvor gebraucht wurde: 74/28 "jako ot lica milost1 orjatych 1kon". In der auszugewelsen

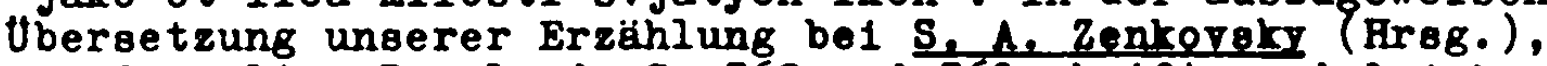
Aus dem alten Russland, S. 368 und 369 , he18t es gleichsam durch die Gnade vom Angesicht der helligen Ikonen'.

30) "děti bojarakie" gehörten zur "mladíaja družinan, d1s 


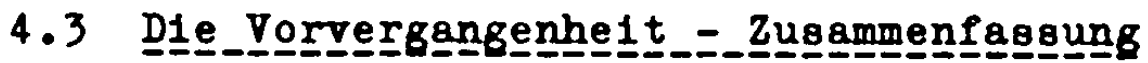

Belde Texte bieten keinen Anhaltspunkt, daB die Vorvergangenheit durch ein bestimmtes Tempus bzw. eine bestimmte Verbalform bevorzugt ausgedrückt worden wäre; auch Tendenzen in dieser Richtung lassen sich nicht erkennen. Handlungen, die in bezug auf präteritale Erzähltempora 1m Verhältnis der Vorzelt1gke1t stehen, werden nicht besonders markiert, sondern erhalten die im jewelligen Text zum Ausdruck des Präteritums ublichen Verbalformen: K-pel - Ipf. und Aor.; Pleskau Ipf., Aor., 1-Part, und Part.praet.

Das Empfinden für Vorvergangenhe1t scheint erloschen zu sein. Dies lot slcher der Grund dafür, daB wir in unseren Texten, die sich belde nicht auf (slavisch geschrlebene) Vorlagen stutzen, so gut wie keine Plusqpf.-Belege vorfinden.

\footnotetext{
"bojare" aber zur "staráaja družina", der sozlal ubergeordneten Sch1chtung. Naren b1s hin zum 14. Jh. soziale stellung und militärische Punktion noch weitestgehend 1dentisch, so bezelchnen diese Titel bzw. Etikettierungen 1m 16. Jh. nur noch die soziale stellung; im Militärischen aber sind so viele funktionale Differenzierungen eingetreten, daB wir den personlichen Titeln die militärische Punktion belgegeben finden - z.B. "gosudarer voeroda, mjazb I. P. Sujakij", "gosudarevy bojare 1 voevody". Vgl. Serokoletor, Istor1ja voennof leksiki, s. 701 . und s. 141 l.
} 


\section{Zusammenfassung:}

Die finften Präteritalformen in unseren Texten

Sowohl in der Erzählung uiber die Erstürmung K-pels durch die Türken als auch in der Erzählung uber die Belagerung Pleskaus durch Stephan Báthory bilden Aor. und Ipf. die dominierenden Tempora. Diese sind weitestgehend aspektualisiert entsprechend der Korrelation: Aor. = perf. Aspekt; Ipf. = imperf. Aspekt. Wir haben uns gehutet, den Aspektbegriff uber Gebuhr zu strapazieren. Wenn wir aber beobachten, daß durative, iterative, kursive usw. Simplicia sowie dehnstufige und/oder suffigierte Ableitungen beinahe ausschlieblich das Ipf., momentane Simplicla aber und präfigierte stämme fast ausschlieblich den Aor. bilden, dann dürfen wir ohne Vorbehalt von der Aspektualisierung der Tempora sprechen. Besonders die Beschränkung des Aor. auf Verben, die wir heute als perf. kennen, unterstreicht das, denn den Aor. bildeten Verben aller Aktionsarten - Momentanverben den punktuellen (ursprünglichen) Aor., Nicht-Momentanverben den komplexiven (jüngeren) Aor.

Das Ipf. erschien im $\underline{K}=\mathrm{pl}$ er Text formal nicht gestört; falsche Bildungen fielen nicht ins Gewicht und ließen allenfalls ansatzwelse eine Tendenz erkennen, die die Pleskauer Erzählung charakterisiert. Ipf.-Belege von heute perf. Verben waren zwar selten, aber doch vergleichsweise häufiger als im Pleskauer Text. Vor allem erwies sich das Belegmaterial für (heute) perf. Ipf.-Formen in der K-pler Erzählung als insgesamt vielseitiger und bunter als das des Pleskauer Textes.

Im Pleskkauer Text erschien das Ipf. formal erheblich gestört. Es zeigte sich, dab in dieser Erzählung die 3.8g.1pf. auf -(j)aše im Begriff steht, sich zur Universalendung des Ipf. zu entwickeln; vor allem ersetzt sie die 3.pl. auf $-(j)$ achu: die Endung - (j)aše in Funktion der 3.pl.1pf. kommt viel häufiger vor als korrektes - $(j)$ achu. - Daruber hinaus ersetzt - $(j)$ aše gelegentlich auch die 3.pl.gor. von Verben der 4. Leskien'schen

1) Das Ipf. von Verben, die heute als perf. gelten, ist auch im Aksl. recht selten. 
Klasse. Es handelt sich dabel um bestimmte Durativa, von denen der Pleskauer Autor nie den Aor. blldet; z.B. lesen wir in Passagen resultativ-referlerender Erzbihlwe1se, in denen der Aor. das angemessene Tempus 1st, in Abschnitten sogar, in denen Aor.-Pormen die Sätze reimend abschlieben, statt zu erwartendem "tvorišan 3.8g.1pf. "tvorjašen, statt "velešan 3.8g.1pf. "veljašn" usw. - Belege für Ipf. von perf. Verben sind im Pleskauer Text selten und haben keinen groBen Aussagewert.

2war bietet die K-pler Erzählung in dieser Hinsicht quantitativ auch nicht sehr viel, doch sind die Belspiele dort vielseltiger und lebendiger. Die Polgerung daraus, der K-pler Text splegele bezüglich des Ipf.-Gebrauchs viel stärker als die Pleskauer Erzählung einen Zustand, da aktionsartorientiertes Empfinden gelegentlich noch das aspektgebundene Gefuhl uberlagerte, können wr wegen des quantitativ so schwachen Materials nur als Prage bzw. Andeutung formulieren.

In beiden Texten konnten wir beobachten, daB das Ipf. perf. Verben nicht - wie so oft behauptet - Iterativität schlechthin bedeutet. Ipf.-Pormen von Momentanverben haben diesen Sinn zweifellos. Auch ist natürlich Iterativität in jedem Pall gegeben, wenn das Ipf. eines heute perf. Verbs z.B. In Konditionalsätzen erscheint, die eine Gewohnheit ausdrúcken ('Jedes Mal,wenn ..., dann ..." - "ašče ..., (to) ...", "egda ...., (to) ...n u.a.). Wlederholte Handlung kann auch ohne syntakt18che Signale aus dem Kontext hervorgehen - in den genannten Satztypen und in bestimmten Kontexten drückt jede Verbform Wiederholung aus, auch das Ipf. perf. Verben. ${ }^{2}$ - Ipf.-Pormen von präfigierten Stämmen aber, die keine momentane Bedeutung haben, zeigten im Kontext, der die Verbform nicht von vornherein auf Iterativitat festlegt, ihre sonstige Bedeutung. Das perf. Ipf. unterschied sich vom gewohnten imperf. Ipf. gelegentlich durch modale schattierungen (konative, voluntative), vor allem, so scheint es mir, durch seinen expressiven charakter.

2) Vielleicht begegnen präfigierte Ipf.-Formen in solchem Kontext besonders häufig, das ware einmal zu untersuchen. 
Der Aor. wird in beiden Texten meist richtig gebildet - er 1st ja auch das Haupterzähl tempus. Manchmal treten Verwechslungen zwischen der 1.pl. und der 3.pl. - zugunsten der letzteren auf, und im $\mathrm{K}$-pler Text erscheinen die wenigen Belege für 1.sg. melst in Form der 1.pl.; also statt -ach, -ich usw. lesen wir -achom, - 1chom usw.

Aor.-Formen von durativen simplicia und von suffigierten und/ oder dehnstufigen Ableitungen kommen in belden Texten selten vor, wenn man von formelhaftem Gebrauch bestimmter Wendungen absieht: "rekoch", "reče", "rekochom", "rekoša"; "glagola" oder auch "plsach". Das seltene Auftreten (heute) imperf. Aor.Pormen erlaubt kaum eine allgemeine Beurteilung - dazu sind sie zu uneinheltlich. Selbst von simplicia determinierter Verben der Bewegung gibt es kaum Aor.-Belege.

Eine Form "izymaša" im K-pler Text führt anschaulich den langwierigen ProzeB vor Augen, wie die Menschen den Adler aus den Windungen der Sohlange befreiten (koordiniert mit punktuellem "ubiša"). Entsprechend typische Imperfektiva aus der Pleskauer Erzählung ("pomogaste" und "pokazovach" ${ }^{3}$ ) sind falsch gebraucht bzw. unverständlich: Signale für den Verfall des temporalen Verbalsystems.

Aor.-Belege von präfigierten nichtdeterminierten Verben der Bewegung (K-pel: "provodišan, Pleskau: "schodišasjan, "sъezžasasja") lassen etwas anderes erkennen: Bis ins 16. Jh. hinein wird diese Gruppe von Verben offenbar noch nicht von vornherein oder noch nicht in jedem Fall als imperf. Entsprechung des jeweiligen Determinativums empfunden; einen gewissen semantischen Freiraum hatte sich diese Gruppe offenkundig noch bewahrt. ${ }^{4}$

Simplicia von iti-Verben stehen oft im Aor. Deren perf. Bedeutung steht außer Prage - "streliti", "udariti", "pustitin u.a., zumal die imperf. Entsprechung auch erscheint, "strel jatin usw.

3) "pokazovach" murde auf Grund des Kontextes als Aor. klassifiziert: in einer Reihe reimender Kola, die alle eindeutig mit der 1.sg.aor. enden, steht diese Form.

4) Mit bestimmter Spezialbedeutung aind Nichtdeterminierte heute manchmel auch perf. - vgl. "provodit'n - 'begleiten', dazu: "provozat"n; "schodit'n (perf.) - 'Notdurft verrichten'. 
Diese 1t1-Verben beschreiben eine einmalige, ganz gezielte Handlung. 5

2wischen der Abfassung der K-pler und der Pleskauer Erzählung liegt ungefähr ein Jahrhundert. Diese Zeitdifferenz verdeutlicht eine Erschelnung, die als der wichtigote Unterschied im Aor.-Gebrauch beider Texte anzusehen 18t: in der K-pler Erzählung stoBen wir auf knapp 15 Aor.-Belege von "vidět1", "slyša$t 1 "$ und "velètı" 6 . Diese Verben wurden bis ins 15. Jh. hinein meist in Form des Aor. (als Präteritum) verwendet. Die Vorstellung war offenbar die, dab das Gesehene, Gehbrte, der Befehl als Ganzhe1t empfunden wurde. Be1m Befehl liegt diese Vorstellung nahe, fur die anderen Verben demonatriert folgender Satztypus diesen Gebrauch: 'als ole dies gehören/gesehen hatten, taten sie jenes'. Eine bestimmte Nachricht, eln ganz bestimmter Anblick löat eine Reaktion aus. In der $\mathbb{K}$-pler Erzählung erscheint nur der Aor. als Vergangenheltstempus der genannten Verben - im Pleskauer Text kommen sle Im Präteritum nur in Porm des Ipf. vor ${ }^{7}$ - der Pleskauer Autor empfindet ole bereits so atark alo imperf., dab er nicht in der Lage 1ot, von Ihnen den Aor. zu bilden. 8 In diesen Zusammenhang gehort auch die gelegentliche Substitution der 3.pl.8or. durch die 3.8g.1pf., von der wir oprachen - "veljaše" für "veleša" usw.

Das alte Perfekt exlstiert in unseren Texten fast nur noch der Form nach. In der $\underline{K}=$ pler Erzählung wird es fur Handlungen verwendet, die von Gott oder Christus auggehen ("1skupil esin, "sotvor1l esi", "rekl estb"). Wie die Belege zeigen, handelt es elch ausschlieslich um tradierte Wendungen, die vermutlich beinahe automatisch gebraucht wurden und ihrer emotionalialerenden wirkung wegen im entsprechenden sakralen Kontext ${ }^{9}$ etablert

5) In der Bedeutung 'gezlelt Geschutz(e) abfeuern' verwendet der Pleskauer Autor melat "b1t1" mit $\Lambda$ or. als Präteritum.

6) "vele" - nur einmal, sonst: "povele/sa".

7) Ausnahme: eln Mal heibt es "olyáasan.

8) Me1st umgeht der Pleskauer Autor entsprechende Aor.-Pormen aber nicht durch Verwendung des Ipf., sondern durch Part. preet. - "slyeav", "vider".

9) Ich erinnere in diesem Zusammenhang an den 8tre1t um neuere B1belubersetzungen, etwa Versuche im protestantischen Berelch, die Luther-Bibel zu ersetzen. 
waren. Diese Periphrasen besitzen durchaus perfekt1sche Qualität, ${ }^{10}$ nicht so sehr im Sinne eines aus einer Ursachehandlung erwachsenen Zustandes als vielmehr im Sinne einer Kennzeichnung desjenigen, der eine durch Perf. ausgedrückte Handlung begangen hat: Dieses getan zu haben, ist merkmalhaft fur ihn, z.B. Gott hat die Erde geschaffen = er 1st der Schöpfer; Christus hat uns errettet $=$ er 1st der Retter; Stephan Báthory hat geprahlt, er werde das christliche Reich (Pleskau, RuBland) zerstören $(93 / 4$ "Ty že pochvalilsja es1 ...") = er lst ein Gotteslästerer, Antichrist... ${ }^{11}$ - Ubrigens finden wir neben "rekl estb" auch das Part.praet. "rek", neben den genannten 1-Periphrasen auch "(ty) krovb svoju za ny prolija": Gott und Christus als Subjekte von Handlungen haben nicht zwangsläufig die Perfekt-Periphrase zur Polge. - Dre1 1-Part.ien ohne Kopula ("prošli", "otdochnul", "postradaln) stehen für Aor.-Formen, die als zufällige Erscheinungen zu bewerten sind - sicher sind sie dem Autor versehentlich in die Peder geflossen oder verdanken einem Kopisten Ihre Existenz. - Diese sechs Belege machen 0,7 v.Hd. aller finiten Präteritalformen im K-pler Text aus.

Wenn wir die Plegskguer Erzählung im literarischen Kontext des ausklingenden 16. Jh.s sehen, dann 1st sie durchaus als sprachlich sehr konservativ zu kennzelchnen. Viele Werke auch der Makarij-Tradition (z.B. Nikon- und L'vov-Kodex) spiegeln die gesprochene Sprache - hier: verwenden das 1-Part. als universale Präteritalform - in viel stärkerem Mabe als die Pleskauer Erzählung, wo das 1-Part. (mit und ohne Kopula) 7 v.Hd. aller finiten Präteritalformen ausmacht. Damit hat sich der Antell des 1-Part.s im Vergleich zum K-pler Text zwar verzehnfacht, in Wirklichkeit aber täuscht diese Relation etwas, we1l der Pleskauer Autor 1-Part.1en (wle er dies ja auch mit anderen Verbformen tut) zur Erreichung von Gleichklang in einzelnen Abschnitten massiert; fast immer erscheinen also 1-Part.ien in Gruppen. Uber we1te Abschnitte hinweg ist, was

10) Zustand aus (punktueller) Ursachehandlung - Trost; die perfektisch ausgedrlickte handlung wird zum Merkmal - Scholz.

11) Be1 Gott, Christus - oder dem Antichrist Báthory 1st perfektische Wirkung spurbar, nicht mehr aber bei einfachen Menschen. 
den Gebrauch verbaler Pormen anbelangt, die Pleskauer Erzählung mit dem $\mathrm{K}$-pler Text oder mit so hochkonservativen Verken wie der "Kazanskaja 1storija" oder der "Stepennaja kniga" vergleichbar.

2wischen 1-Part.1en mit und 1-Part.ien ohne Kopula 1at kein funktionaler Unterschied zu erkennen, vielmehr herrscht eine formal-personale Opposition: $1.8 \mathrm{~g} . / \mathrm{pl}$. und 2.8g./pl. ersche1nen fast ausnahmslos mit Kopula, die $3.8 g . / \mathrm{pl}$. fast ausnahms108 ohne Kopula. Das 1-Part. wird meist von heute perf. Verben gebildet und ersetzt den Aor,; 1-Part.ien imperf. Verben ersetzen das Ipf., was durch Kontextvergle1che nachgewiesen werden konnte ("vyprošalisja" - 'sie bettelten'; "povelevachu" 'viele, verschiedene gaben immer wieder den Befehl', "glagolachu" - 'viele, verschiedene sagten wiederholt, andauernd'). Das 1-Part. erscheint in der Pleskauer Erzählung im Wesentlichen in sechs Funktionen:

1. In Aussagesätzen nach Verben des Sagens/Mitte1lene und Hörens/Erfahrens, wobei der Aussagesatz durch "jako" an das Verb des Sagens oder Hörens angeschlossen 1st; ${ }^{12}$

2. nach punktuellen Ze1tangaben und Datierungen;

3. In Relativä̈tzen;

4. bei Verben, die entweder selbst einen Terminus technicus darstellen oder Teil eines solchen sind, oder bei hochfrequentierten Stämmen ("jati", "-it1") oder auch bei russischen oder ostalavischen Lautungen ("ot-, privolokl1").

5. zu Stilisierungszwecken: möglicherweise stilisiert der Pleskauer Autor die lebende Sprache ein wenig, wenn er in bestimmten Aussagesätzen (s. Punktion 1) als Präteritum das umgangsaprachliche 1-Part. verwendet. - In einem Brief, den der Autor einem Ausländer ("Gansumeler" - 'Hans Möller-) zuachre1bt, wird Vergangenhe1t nur durch 1-Part. ausgedruckt.

6. Durch Verwendung von mehreren 1-Part.1en auf engstem Raum sucht der Autor, Gleichklänge/verbalen Reim zu erzielen.

12) Das 1-Part. erscheint aber nis nach Verben des Sehens/Erblickens. 
Im Rahmen der Funktionen 1. und 3. bezelchnet das 1-Part. e1ne Handlung, die zu derjentgen im Hauptsatz im Verhältnis der Vorzeltigkeit steht - da präteritale Formen dominieren, handelt es sich also meist um Vorvergangenheit. 13

Bezüglich des 1-Part. (bzw. der 1-Periphrase) liegt der Unterschied zwischen unseren Texten darin, daB der $\underline{X}=\mathrm{p} \underline{\text { eq }}$ Autor diese Verbform (jedenfalls das 1-Part. ohne Kopula) bewuBt zurúckdrängt, wohingegen der Plegskauer Autor das 1-Part. zu ganz bestimmten $Z$ wecken und in ganz bestimmten Funktionen bewuBt einsetzt - obwohl auch er im Prinzip diese Verbform meidet. Be1 bestimmten Wendungen kommt der Pleskauer Autor an umgangsoprachlichen Wendungen - mit 1-Part. - gar nicht mehr vorbei.

Vorvergangenhe1t wird im Rahmen unserer beiden Texte nur ein Mal durch Plusqpf. ausgedrückt (in der K-pler Erzählung). Sonst 1st Vorvergangenhe1t nicht besonders gekennzelchnet. Handlungen, die $z u$ anderen präterital ausgedrückten Vorgängen Im Verhältnis der Vorzeltigkelt stehen, geben beide Autoren so wieder, wie sie gewöhnliches Präteritum bezelchnen: durch Ipf. und Aor. der K-pler Autor, durch Ipf., Aor., 1-Part. und auch Part.praet. der Pleskauer Autor. - Es gibt keine Anzeichen dafur, daB das Empfinden fur Vorvergangenhe1t noch lebendig $18 t$.

In bezug auf den Gebrauch der Tempora im laufenden Text verdient feotgehalten zu werden, daß wir immer wieder Gelegenheit hatten, deren feinoinnige, differenzierende Anwendung im K=plę rext hervorzuheben. Es lot fast immer möglich, aus dem Jewe1lo gewählten Tempus elnen guten sinn herauszulesen und aus dem gewählten Tempus zusätzliche Information über die Art der geachilderten Handlung zu beziehen. Zwar haben wir es in der Regel mit einer rein mechanischen Trangformierung des imperf. 1-Part.s in Ipf. und des perf. 1-Part.8 in Aor. zu tun, doch gelingt es dem K-pler Autor, durch geschicktes Gegeneinandersetzen der Tempora, die Breignisge lebendig und effektroll zu schildern.

13) Diese Aussage bezieht sich nur auf die genannten Ausageund Relativietze, in letzteren wird Vorzeltigkeit aber 
Im Plegkauer Text liegen die Dinge etwas anders. GewiB stoBen wir h:n und wieder auf geschickte, lebendige und auch formal korrerte Darstellungen, aber allzu oft bricht der beständige Hang des Autors durch, bestimmte klangliche Effekte erzielen zu woilen: $\mathrm{Zu}$ den häufigsten rhetorischen Figuren der Pleskauer Erzähiung gehört der (gelockerte) Parallelismus, im Rahmen dessen meistens verbaler Reim das Kolon bzw. den Satz beschliebt. Oft begnügt sich der Autor auch mit dem klanglichen Effekt, den das Dominieren einer bestimmten verbalen Endung innerhalb eines überschaubaren (überhörbaren) Abschnittes bewirkt; ${ }^{14}$ im letzteren Pslle ist Endreim nicht die Regel ('homoeoptoton' ${ }^{15}$ ). Wenn der Axtor eine bestimmte verbale Endung uber einen Absatz hinweg dirchhält, kann es natürlich zu Störungen im Bereich des Numeris, der Person oder - und dies meistens - im Bereich des Tempus kommen - die beinahe universale Ipf.-Endung - $(j)$ aše ist der biste Beweis fü das MiBachten grammatischer Kategorien: oft essetzt $-(j)$ aše die 3.pl.jpf. auf $-(j)$ achu, wenn die im Abschilt dominierende Endung - (j)aše oder auch $-(j)$ ašče ist. Kompl:kationen treten in reimenden Absätzen (Wort-oder Endreim) dann auf, wenn Subjekt oder Erzählhaltung des Autors wechsiln.

Innerialb von Passagen mit nichtreimenden Verbformen lot zu erkennes, daB der Pleskauer Autor recht gut mit den temporalen Formel umgehen kann. Wenn er sich dann in reimenden Abschnitten uber lie dem Temporalsystem immanenten Notwendigkeiten hinwegsetzt. 1st anzunehmen, $d a B$ er sich der Verletzung der Normen bewuB; 1st. Das zeigt, daB inm das Temporalsystem innerlich fremd ist. Es dient inm lediglich als stilistisches Mittel, als archa:sierender Anstrich, der so verfremdend wirkt, dab formale Fehle: in Kauf genommen werden, wenn es darum geht, andere

milst durch Aor. bezelchnet; in den Aussagesätzen ist dies nich recht häufig der Fall. Insgesamt gesehen wird Vorvergingenhe1t im Pleskauer Text in ca $25 \mathrm{v}$. Hd. durch 1-Part. assgedrückt, sonst durch Ipf., Aor. oder Part.praet.

14) Si erklärt sich die relativ hohe Zahl der l-Part.ien.

15) Llusberg, Elemente, 361: "Das homoeoptoton besteht in der Eitsprechung der (nominalen und nichtnominalen) Flexionsformin melst am SchluB (aber grundsätzlich auch an anderen Stellin) der Teile des Isokolon,...n 
Stilmittel einzusetzen.

Liest man zum Vergleich in der K-pler Erzählung, dann gewinnt man den Eindruck, daß für deren Autor die alten Tempora kein äußerlicher Anstrich sind. Vielmehr scheinen sie Bestandteil derjenigen sprachlichen Schicht bzw. sprachlichen Möglichkeit zu sein, die allein fur inn in Betracht kommt, das tragische Geschehen um den Untergang des Mittelpunktes der orthodoxen Welt in adäquater Weise $z u$ beschreiben - für den Autor/Kompilator/Redaktor der K-pler Erzählung ist jenes stark kirchenslavisch gefärbte Idiom, das wir dort vorfinden, die Literatursprache schlechthin; mit ihr ist er innerlich vertraut. 
VI. Das nominale Partizip (aktiv) ${ }^{1}$

In den bisherigen Ontersuchungen haben wir bereits einige Unterschiede $2 w i s c h e n$ unseren beiden Texten herausgearbeitet, die als charakteristisch für die Entricklung der mss. Ilteratursprache innerhalb jener 100 Jahre gelten können, die zwischen der Abfassung belder Erzählungen liegen: der Pleskauer Text zeigt z.T. erhebliche Störungen im Gebrauch des TemporalSystems - einerse1ts im Formalen (Imperfekt!), andererseits aber auch im Funktionalen (oft willkürlicher Gebrauch der Tempora, z.B. zur Erzielung von verbalem Reim); trotz der offenkundigen Absicht des Pleskauer Autors im allgemeinen, umgangssprachliche Erscheinungen zurickzudrängen, ist doch ein - im Vergleich zur K-pler Erzählung - recht häufiger Gebrauch des l-Part.8 als universales Präteritum, wie es umgangssprachlich verwendet wurde, in ganz bestimmten Bereichen ebenso wie zu Reimzwecken zu beobachten.

Ein Vergleich belder Texte wäre jedoch gänzlich unzureichend, wollten wir den Komplex 'nominales (aktives) Partizip' aus unseren Untersuchungen ausklammern. Schon beim flüchtigen Lesen beider Texte wird deutlich, daB sie sich auch im partizipialen Bereich sehr unterscheiden. Dabel haben wir es nicht mit einem quantitativen Unterschied $z u$ tun: jeweils ungefähr 400 nominale Partizipialformen sind in den ca. 1500 verbalen Formen jedes Textes elngeschlossen (vgl. Tabelle 1), das sind in jedem Text 23 v. Hd.

1) Wir haben das nominale (aktive) Partizip den verbalen Formen zugeordnet wegen aeiner verbalen Herkunft, vor allem aber wegen seiner (daraus regultierenden) Pähigkeit, in einem durch Ergänzungen (Objekte, Adverbien $u_{.} a_{0}$ ) entstehenden Syntagma eine gewloge (Neben-)Prädikation zu erlangen. Das kónte man sogar für das heutige pronominale Part. in attributiver Punktion, sofern es in entsprechnder Weise erweitert 1st, geltend machen. Umso mehr gilt dies fur das nominale Part. In attributiver Punktion im Altruss., das ja vom nominalen Part. In prädikativer Funktion oft nicht zu unterschefden 1st - s.u. Ober das heutige Adv.-Part. lesen wir bei Tauscher-Z1rachbaum, Grammatik der russ. Sprache, S. 341: "Das Adverblalpartizip bezelchnet gewöhnlich eine der Haupthandlung eines Satzes zugeordnete Nebenhandlung, die sich auf das gleiche Subjekt wie die Haupthandlung bezieht." 
Der Unterschied liegt darin, wie beide Autoren die nominalen Partizipien gebrauchen, welche Funktion sie diesen zuweisen. Die Schwlerigkeit besteht darin, diese unterschiedliche Punktion der Partizipien, die man beim Lesen intuitiv empfindet, aufzuzeigen.

Im Prinzip wollen wir uns auf das nominale Partizip in prädikativer Punktion beschränken und das nominale Partizip in attributiver Punktion ausklammern, aber:

"Ein absolutes Kriterium, prädikative und attributive Funktion auseinanderzuhaiten, gibt es nicht. Eine sichere Entscheidung ist also nicht in jedem Palle mbiglich. Nur mit dieser Einschränkung sind die Kategorien prädikativ und attributiv dem Partizip angemessen. Pur eine grundsätzliche Gliederung der merkmallosen Kurzpart1z1pien sind sie nicht geeignet." 2

"Die attributive Funktion tritt weit hinter die prädikat1ve zuruick. ... Die Prädikativität ist ... die úberlegene Hauptfunktion der Kurzpartizipien, zu der vor allem die Nominativformen drängen." 3

Wir betonen diese Tatsache so, weil wir in den folgenden Untersuchungen gelegentlich auch Partizipion einbeziehen, die als attributiv gedeutet werden können. ${ }^{4}$ Dies fällt nicht ins Gewicht, da es uns um eine ganz andere Differenzierung geht, die für die Unterscheldung unserer belden Texte von Relevanz 1st: Nicht die Prage, ob ein nominales Partizip attributiv oder prädikativ/adverbial gebraucht ist, erweckt unser Interesse, sondern die Prage, ob das nominale Partizip von Pall zu Pall Mittelpunkt eines abhänglgen Syntagmas (also attributiv und adverbial) 1st oder aber ob es von Pall zu Pall den Mittelpunkt eines autonomen syntagmas darstellt (also ein Verb.fin. vertritt).

Hervorhebg. - G.Str.; $\nabla g l$. auch Grammatika sovremennogo russkogo ilteraturnogo jazyka. AN SSSR. M. 1970 (= AkademieGrammat1k 1970). \$\$782 und 880 .

2) Re Rư̌ička: Das syntakt1sche system der der altslavischen Partizipien und sein Verhältnis zum Griechischen. Berlin 1963. (weiter zitiert als: Ruzicka, Das sjntakt1sche Systea).S.232.

3) $a .8 .0 ., \mathrm{s} .13$.

4) Z.B.: KP 67/14 "On že, 1meja meč v ruce, sečă̌ 1ch ..." 'Er (der Kaiser), der das schwert in Händen hielt, focht gegen $81 e^{\prime}$ (attrib.) oder 'Mit dem Schwert in Hënden, locht er gegen sie' (adverb.) - mir scheint letzteres richtiger. 
Tir werden es also in den folgenden Untersuchungen mit dem nominalen Partizip zu tun haben, das, in einer Nominativform befindlich, sich direkt oder indirekt auf das subjekt des Satzes bezieht. Allerdings werden wir am Rande auch andere als Nominativformen behandeln, da sie - wenn auch nicht in dem MaBe - für die Charakterisierung jedes der Texte von gewisser Bedeutung sind (nominales Part. als Prädikativum; nominales Part. beim direkten Objekt; Dat.abs.).

Wir beziehen nicht in unsere Untersuchungen ein pronominale Partizipien (aktiv) und pro-/nominale Partizipien (passiv),

da wir im Gebrauch dieser Kategorien zwischen beiden Texten keinen Unterschied feststellen konnten, da außerdem entsprechende Formen nicht sehr zahlreich sind und auch keine drängenden Fragen aufwerfen.

\section{Das nominale Partizip (aktiv) der Nominativform in der sprachlichen Entwicklung}

Die älteste, noch immer gultige ausführliche Behandlung des nominalen Part.s findet sich in Potebnjas 'Notizen zur russischen Grammatik' (1874).5 In den (historischen) Grammatiken wird dieser Komplex meist nur sehr kurz, stets mit ausdruicklicher Berufung auf Potebnja, behandelt. ${ }^{6}$ An älteren Arbeiten sind zu nennen die Untersuchungen Istrinas an der 1 . Novgoroder Chronik (Synod.-Hs.), worin der Darstellung des Gebrauchs der Part.ien breiter Raum gewidmet ist, sowie die Monographie uber Partiziplalkonstruktionen in den aksl. Denkmälern von G. Angelowa. 7 Seit etwa 25 Jahren ist das nominale Part. Immer

5) A. Potebnja: Iz zapisok po russkoj grammatike. Chaŕkov 1874 , Charkov 1888, 3Moskau 1958. S. 185 - 231. (weiterhin 21tiert als: Potebnja, Iz zapisok).

6) Z.B. Cernych, Istor. grammatika, S. 278-68; Borkovsk1, Istor. gramatika, S. 350 - 57; Stecenko, Istor.sintaksis, S. 30 - 32 ; Samsonov, Drevner. jazyk, S. 231 - 33. Kiparsky, Russ. hist. Grammatik II, S. $339-49$ - befaBte sich mit der morphologischen Seite.

7) E.S. Istrina: Sintaksičeskie javlenija Sinodal'nogo opiska 
stärker in den Mittelpunkt des Interesses gerúckt, 8 besonders ist in diesem Zusammenhang die Arbeit Ruzickas ${ }^{9}$ zu nennen, aus der wir bereits zitiert haben und in welcher er die nominalen Part.ien der aksl. Evangelientexte mit dem griech. Original vergleicht. All diese Arbeiten haben viele Einzelerkenntnisse gebraoht, Potebnjas Ansichten gelegentlich modifiziert, im Wesentlichen aber diese immer wieder bestätigt.

In vorhistorischer Zeit haben die Sprachen zwischen Hypo- und Parataxe nicht differenziert, die Organisation von Syntagmen war lose, sie waren nicht scharf voneinander abgegrenzt. 10 Eine Organisationsform der Rede war das Syntagma 'Subjekt nominales Partizip', ${ }^{11}$ das anderen Organisationsformen, mit Hilfe von Verb.fin. gebildet, parataktisch verbunden war.

I Novgorodskoj letopisi. In: Izv. ORJas 24 (1919). S. 1 172 und ORJaS 26 (1921). S. 207 - 39 - für uns ist nur von Interesse Bd. 24 (1919). - G. Angelowa: Die Partizipialkonstruktionen in den altbulgarischen Sprachdenkmälern. Sof1a 1929. (lag uns nicht vor).

8) Vor allem sind Arbelten čechischer slavisten zu nennen R. Večerka, J. Zubaty, F. Trávnfček, B. Havránek nähere Angaben hierzu s. be1 Ruzicka, Das syntaktische Sygtem, S. VII - XVI (IIteraturverzelchnis). Auch: J. Sedlaćek: K otáce slovanských part.praes.act. a praet.act.I. In: Slavia 23 (1954). S. 509 - 26. A.G. Rudnev: 0 proischoźdenil deepricastija - po materialam pamjatnikov staroslgvjanskogo 1 drevne-russkogo jazykov. In: Ceskoslovenska rusistike $1(1956)$. S. 19-63. R, Stola: Zum Gebrauch der unbestimmten Formen von aktiven Partizipien in der Punktion von zweitrangigen Prädikaten im Lavrent'evskij splsok. In: wSIJb $5(1956)$, S. 14 - 27. Ders.: Zur Frage der Entwicklung des deepricastie im Altrussischen. In: Slavjanskaja filologija. Sbornik Statej I. M. 1958. S. $189,-93$. Wichtig, sind auch zwel Arbeiten Vl. Barnets: $K$ vývoji slovanských konstrukcl s participil aktivnimi. In: Acta Univ. Carolinae - Slavica Pragensig. 2 (1961). S. $151-63$. Ders.: Vyvoj systému participil aktivnlch $v$ rustinè. Praha 965 (Acta Univ. Carolinae. Monographia 9). (weiterhin zitiert als: Barnet, výoj). Nikiforov, Glagol, S. 224 - 87 demonstriert das Vorkommen der Partiziplen - er analysiert nicht.

9) Wir schreiben weiter Ruzicka statt Rǚička - so wie R. sich in seiner Diss.: Verbalaspekt in der Nestorchronik, die wir bereits zitierten, geschrieben hat.

10) Potebnja, Iz zapisok, S. 191; Ruzicka, Das syntaktische System, S. 22 f.

11) Die Meinungen differieren geringfügig darin, ob dies 
M1t wachsender Differenzierung der sprachlichen Organisation, derzufolge sich Hypo- und Parataxe herausbildeten bzw. verdeutlichten und sich klar gegeneinander absetzten, wurde das mehr oder weniger autonome Partizipial-Syntagma (= der part1zlpiale Nominalsatz) allmählich in eine größere syntaktische Einhe1t inkorporiert, wobel sich dieses dem Syntagma mit finitem Prädikat unterordnete. ${ }^{12}$ Die Sprache wurde "kompaktnee $n^{13}$ 'komprimierter'. Die Unterordnung des partiziplalen unter das verbale ${ }^{14}$ Syntagma stellt einen'Sonderfall der Entwicklung der Hypotaxe' dar. ${ }^{15}$ Hierbel sind zwel Entwicklungsotufen symptomat1sch: ursprínglich lat das nominale Partizip nebst Ergänzung(en) dem Subjekt unmlttelbar verbunden, das auch dem Syntagma mit Verb.fin. als Prädikat vorateht. Haben verbales und partiziplales Syntagma ein gemeinsamea Subjekt, spricht Potebnja vom 'appositiven Gebrauch des Part.8.16 Ruzicka zieht die Bezelchnung '18oliertes (Partizipial-) Syntagma' vor, ${ }^{17}$ welcher Terminus der "relativen Selbotändigke1t des Partizipialsyntagmas /Partizip-Subjekt/ und der prädikativen Kraft des Part1z1pe Rechnung" trägt.

"Diese relative Selbotändigkelt einersefts und die Unselbotändgke1t der offenen Prädikation 18 andererseits halten die syntaktioche Struktur der Konotruktion am Anfang des slavischen Schrifttums in der Schwebe und drängen bald zu der geschloseenen parallelen Entwicklung der Gerundien in den Einzelaprachen. "19

Syntagma selbotändg gewesen sei (Ruzlcka, Das synt. Syatem, S. 23; N1kiforov, Glagol, S. 247 1.) oder einem Syntagma mit Verb.fin. fast glelchgewichtig ("pocti ravnoa1l'nye centra" - Potebnja, a.a.0., s. 190) war. Vgl. Borkovik1 j. Ist.grammatika, s. 350 ff.; lotrina, sint. javienija, s. 84 u.a.

12) Potebnja, a.a.0., S. 191; Ruzicka, Das synt.System, S. 23.

13) Potebnja, a.8.0., S. 190.

14) "verbal" hier und auch später als Gegensatz zu "partiz1pial": 'verbales Syntagma' = Syntagma mit Verb.fin. als Präd.

15) Ruzicka, a.8.0., S. 23.

16) Potebnja, a.a.0., S. 185: "appozitivnoe upotreblenie prič."

17) Ruz1cka, a.8.0., S. 21.

18) Ruzlcka, ebd.: 'periphere Prädikation' als Gegensatz zu 'zentraler Prädikation' = Verb.fin.

19) Ruzicka, ebd. 
Allmählich löste sich aber das nominale Part. aus der unmittelbaren Verbindung mit dem Subjekt, was sicher dadurch gefördert murde, daB dieses ja oft gar nicht ausgedruckt 1st. Das Part. gerät immer stärker in den Einflubbereich, in die Abhängigkeit des Verb.fin., das die 'zentrale Prädikation' (8.0. Anm. 18) besitzt. DaB die enge Verbindung zum Subjekt sich lockerte, zeigt sich daran, dab die Kongruenz in Numerus und Genus zwischen Subjekt und Part. schwindet. Die partizipialen Formen, die vorher klare, mit dem Subjekt kongruierende Funktion besaBen, waren nicht mehr distinktiv, wurden austauschbar. Aus dem 'appositionellen Partizip' in der Funktion eines 'untergeordneten' bzw. 'zweitrangigen Prädikats ${ }^{20}$ entwickelte sich allmählich das Adv.-Part., welches das Verb.fin. (= Prädikat) erläutert, ergänzt; der Pormenreichtum schwand, wenige unflektierbare Formen blieben zurück.

Potebnja bezeichnet erst das Partizip mit undeklinierbaren Formen als "deepričastien. Das Part. mit einer Vielzahl - allerdings nicht distinktiver - Formen bezeichne eine Ubergangserscheinung. 21

Folgende Spuren lassen sich in den slavischen Schriftdenkmälern für diese Entwicklung erkennen:

1. Part.-Syntagma mit autonomer Prädikation, besonders be 1 elgenem Subjekt, das sich von dem jenes verbalen Syntagmas unterscheidet, mit dem es gedanklich mehr oder weniger stark verbunden ist ('Nominativus absolutus'22).

2. Das 1solierte Part.-Syntagma (Subjekt-Part.) bewahrt sich durch seine unmittelbare Verbindung zum subjekt (gleichze1tig auch des verbalen Syntagmas) relative Eigenständigkeit, die oft dadurch unterstrichen ist, dab eine koordinierende

20) "vtorostepennoe skazuemoe" - meines Wissens stammt dieser Ausdruck, der sich im slavischen Sprachbereich und daruberhinaus durchgesetzt hat, von Potebnja, a.a.0.,.s. 185.

21) "pričagtie" - volle Kongruenz des Part.s mit dem Subjekt; "otpricastnoe slovon - es bezeichnet eine "arednjaja stupens", '2wischenstufe', die durch nichtdigtinktive Part.Endungen chrakterisiert ist; und "deepricastie" mit nicht flektierbaren Formen - Potebnja, a.8.0., s. 200.

22) "Imenitel'noe samostojatel'noe" - Potebnja, a.a.0., s. 197. 
Konjunktion zwischen partizipiales und verbales Syntagma tritt und diese trennt.

3. Lockerung der unmittelbaren Verbindung des nominalen Part.s zum Subjekt, immer stärkere Unterordnung unter das durch Verb.fin. ausgedrickte Prädikat - Hineinwachsen in die heutige Rolle: es drückt eine Nebenhandlung aus, die die Haupthandlung erläutert, modifiziert; es verliert seine absolute Zeitlichkeit - es kann nur noch Vor- und Glelchzeitigkeit in Bezug auf das Verb.fin. bezeichnen. Fehlende Kongruenz (Numerus und Genus) zwischen Subjekt und Part. sind charakteristisch für dieses stadium. 23

4. Der quasi-adverbialen Funktion entspricht eine unflektierbare Endung der beiden Varianten der Kategorle 'AdverbialPartizip' - heutiger stand.

Schon beim ersten Anlesen unserer Texte wird klar, daB $2 w 1-$ schen Subjekt und Partizip bezüglich Genus und Numerus oft kelne Kongruenz mehr besteht. $D_{a}$ wir also partizipiale Formen in verschiedener Funktion anzutreffen erwarten, wollen wir im Folgenden nur von 'Partizip' und nur in elndeutigen Fällen z.B. von 'Adverbial-Partizip' sprechen.

\section{Erscheinungsformen des nominalen Partizips}

Bevor wir uns mit den partizipialen Konstruktionen selbst befassen, wollen wir einen Blick auf den Formenbestand des nominalen Part.s werfen. Nach einer allgemeinen, knappen Ubersicht über die wichtigsten Erscheinungen wollen wir uns der Prage der Kongruenz zwischen Subjekt und Part. zuwenden - In der Hoffnung, bereits in diesem Bereich ein Kriterium zu finden, das es uns ermöglicht, belde Texte voneinander abzugrenzen und einen Hinweis zu finden darauf, wo wir den jeweiligen Text bezuglich der Punktion der nominalen Part.ien einzuordnen haben.

23) Störungen der Kongruenz findet Borkovsk1j, Sintaksis drevnerussk.gramot I, S. $212 \mathrm{f}$. bereits im 11. Jh.; 1m 14. Jh. lst in den Urkunden kaum noch Kongruenz anzutreffen (ebd.). Potebnja, a.a.0., S. 186: Zeitliche Hinweise sind schwlerig; das 'appositive Part.prges.' gab es wohl nur noch "v kniznom jazyke"; das "deepriçasten habe zu dem Zeitpunkt bereits existiert. 


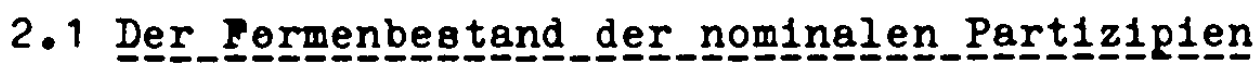

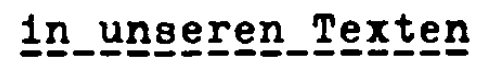

Wir können uns diesbezuglich auf allgemeine, beide Texte charakterisierende Bemerkungen beschränken, da sie im formalen Bereich absolut das gleiche Bild bieten.

Sowe1t die vereinfachte Wledergabe der Hss. In unseren Textausgaben zu beurtellen erlaubt, 1st in belden Texten der aksl. For menbestand des nominalen Part.s noch gut erhalten. Auffallend 1st das Pehlen des Formans -y fur Nom.sg.maek./ntr. be1 konsonantisch auslautenden Verbalstämmen ("nesy", "teky" usw.). Allerdings 1st diese Erschelnung typisch fur die altruss. L1teratur, besonders der jüngeren Perlode; nicht einmal der 2we1te Sudslavische Einfluß bewirkte die Renaissance dieser Endung. ${ }^{24}$ In keinem einzigen Fall wird das aksl. Pormans -y durch die altruss. Variante -a ("nesan, "tekan usw.) ersetzt, wie sie beispielsweise in den Urkunden vorherrschte. ${ }^{25}$ vielmehr tritt an die stelle der eindeutigen sing.-Endung bei konsonantisch auslautenden Verbalstämmen ausschließlich die Plur.-Porm -ušče. 2war zeigt gerade dieses Formans die Intention der Autoren der literarischen Tradition zu folgen ${ }^{26}$-, gleichzeitig demonstriert aber gerade der Ersatz der eindeutigen Sing.-Endung durch die Nom.pl-Form, daB der Numerus-Korrelation offenkundig keine große Relevanz mehr zukam.

Hingegen ist die Nom.eg.mask./ntr.-Endung -a/-ja/-aja/-jaja bel Stämmen der 4. Leskien'schen Klasse sowie vokalisch auslautenden Verbalstämmen gut erhalten, z.B. "kryčan < "kryčat1, kryčlı̆1n; "moljan < nolitin; "vidjan < "vidětin; "rydajan < "rydat1", "imejan < nimětin; "ukazujan < nukazovatin; nukrepljajan < "ukrepljat1". Allerdings steht diese Endung auch, wenn das Subjekt des Satzes Plural hat.

24) Borkoygk1 1, Ist.grammat1ka, S. 353 ; N1k1foroy, Glagol, S. 244 ff., 261 - 64: kein Beleg fur Formans -y.

25) Borkovsk1j, a.a.0., S. 354 ; ders,., Sintaksis drevnerussk. gramot I, s. 212 f:

26) N1k1forov, Glagol, S. 263: Endung -šče 1st typisch fur ksi:-archaisierenden St1l, "siroko rasprostranennym $v$ kniznom stilen. 
Feminina kommen in unseren Krlegserzählungen naturgemäB selten vor, einen Sing.-Beleg finden wir im $\mathrm{K}$-pler Text:

$57 / 32$ "... bogorodica čelovekol jubivaja estestrom suščl, ne ostavi grad sej,...n27

Hinsichtlich des Nom.8g.mask/ntr. beim Part.praet. ist nichts weiter zu vermerken, als daB die korrekte Form -vb (bzw. konsonantische Stamme: Stammkonsonant + b, z.B. "tek-z") mit der Plural-Endung alterniert: - vše (bzw. "tek-še"), wie auch umgekehrt das Singular-Formans anzutreffen ist, wenn das subjekt im Plural steht.

Die Endung -šc̆i bzw. -v ši lst in jeweils 1 - 2 v.Hd. aller entsprechenden Belege auch bei nominalen Part.ien anzutreffen, die in mittelbarer Verbindung $z u$ substantiven masc.generis stehen; vorwiegend handelt es sich um Plur.-Belege:

KP 69/7 "... razgnevachom tvoe božestvo, prestupajuščce 1 popirajušci ..."

Dies Pormans erscheint aber auch gelegentlich beim sing.: PS $36 / 22$ "... gosudarb ... na vragi voopolčaetca .... priemšl že blagoslovenie ot ... mitropolita ..."28

Die Endung -če, die typisch für Schriftdenkmäler ist, die der gesprochenen sprache nahestehen, ${ }^{29}$ kommt in unseren Texten fast gar nicht vor (Ausnahme: PS 44/4 "otpušcajučin"), abgesehen von seltenen adjektivierten Part.ien (PS $77 / 18$ "gorjašçeju vodoju" - 'kochendes Wasser'? - dagegen: 88/5 "smolu gorjač̣ju" - '(kochend-)heiBes Pech'?).

27) "sušči" hier sicher in ăttribut. Funktion. Vgl. auch KP $69 / 9$ "carju i vladyko, celovekol jubec ... syj" - der Autor ist sich des Part.s "sy" nicht sicher und versieht es mit der Endung deg pronominalen Part.s "syj" - dieses aber lautet ja "suscil/suscij" (so auch PS 91/3).

28) - (v) ši hat sich beim Adv.Part.praet (perf.) durchgesetzt. Borkovskij, Ist.grammatika, s. 355, u.a. füren sie auf das Nom.8g.fem.-Formans -8ci/-(v) si zurúck; Kiparsky, Russ.hist.Grammatik II, S. 243 nennt noch Dat.8g.fem.,Lok. gg.mask./ntr./fem., Instr.pl.mask./ntr. + Nom.-Akk.-Vok. dual.fem./ntr. Mir sçeint eher, Analogie zu o-bzw. joStämmen (Nom.pl. "mozi", "rabi") vorzuliegen. 29) $\frac{\text { Nikiforov }}{\text { stilen }}$ Glagol, 262 "v bytovoj reći ... i v kanceljarskom 
Zu den Cas.obl. 1st zu bemerken, daB der Akk.mask./ntr.gewhinlich dem Nom. gleicht, wobel ebenfalls sing.- und Plur.Pormen alternieren. In seltenen Pällen - bei Lebewesen - erscheinen auch Gen.-Pormen.

Der Gen.sg.mask./ntr. endet korrekt auf $-a$, wohingegen die Gen. pl.-Form auf $-b$ durch die pronominale Form -ichb ersetzt ist - vgl. das folgende kurlose Beispiel, das alle Möglichke1ten des Akk. resp. Gen.mask./ntr. realisiert:

PS $67 / 25$ "... Stepan, videv svolch rochmistov ..., jako vzlesša na stene $1 \mathrm{v}$ bašnjach ... uže stojă̌c̆ich, 1 vo grad ... streljajušce, ....n

'... Stephan sah seine Rottmeister..., wie sie erstürmt hatten und standen/besetzt hielten und... schossen, ...'

"vzlesšan" steht sogar beim subjekt im Plural.

Der Dat.sg.mask./ntr. lautet korrekt auf $-u$, doch die entsprechende Plur.-Form -ščem/-(v) šem erscheint nie, nur die

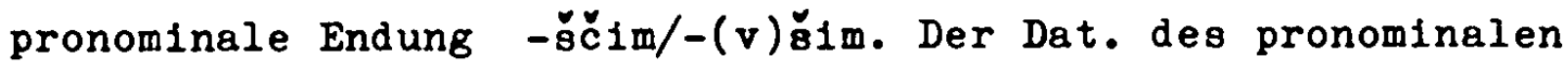
Part.s erscheint nur im Zusammenhang des Dat.abs.

Im Rahmen des Dat.abs. erscheinen auch feminine Part.-Formen,

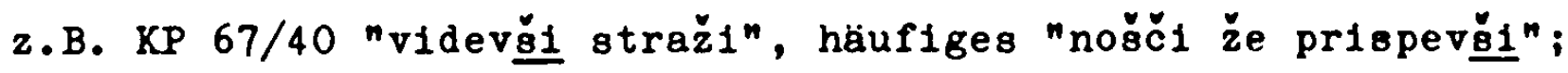
im Pleskauer Text finden wir auch - neben korrekten Bildungen - 50/22 "rece teküčej", mit pronominaler Endung also.

Der Akk.fem. 1st überaus selten - den elnzigen Beleg finden wir im K-pler Text:

$67 / 42$ "... vides̆a ... plamenju ognenu veliju 1zšedğu, okru-
żivă ..."

Der Nom.pl.fem. lautet gewöhnlich - šče/-(v) še (< altruss. -čè) $-(v) \ddot{8} \ddot{e}$ - aber vgl.:

PS $70 / 25$ n... ženy blagorodnyja ... sob̌edb̌esja, kričjuščl 1 glasy rekusče, ...n

Istr.- und Lok.-Pormen kommen von nominalen Part.ien nicht vor. An dieser Aufstellung ist für uns von grb̈berem Interesse allein die Tatsache, daB die Endungen $-v_{b}$ und -vŏe (gelegentlich -vŏ1) in Nom./Akk.sg./pl.mask. (ntr.) fre1 vertauschbar sind, das glelchegilt für -ǒče; -a/-ja steht nur bel Nom./Akk.8g. ag. 


\subsection{Díe_Numerus-Kongngruenz_zw18chen}

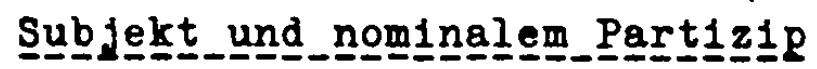

Für die (weitestgehende) Elgenständgke1t des partizipialen Syntagmas, beruhend auf der engen Bindung zum Subjekt, ist die Numerus- und Genus Kongruenz zwischen Subjekt und Part. ein wichtiger Indikator. In den aksl. Evangelientexten $18 t^{30}$ diese Kongruenz im Wesentlichen gewahrt. Zwar nicht ganz in diesem Maße, aber doch fast regelmäbig korrelieren subjekt und Part. auch in den altesten russ. Chroniken; so stellte Stola 1m Zusammenhang mit Untersuchungen an der LaurentiusHs. der PVI in knapp $5 \mathrm{v} . \mathrm{Hd}$. aller Belege fur 'zweitrangiges Prädikat' Störung der Kongruenz fest. ${ }^{31}$ Istrina hebt hervor, daß sle in der Synodal-Hs. der 1. Novgoroder Chronik nur e1nen Fall von Inkongruenz zwischen Subjekt und Part. (als 'zwe1trangigem Prädikat') gefunden habe. ${ }^{32}$ Der konservative Charakter der Sprache der Chroniken tritt hervor, wenn man neben diese Beobachtungen diejenigen Borkovskij's stellt, dem bere1ts in Urkunden des 11. Jh.s Störungen der Kongruenz aufgefallen sind. ${ }^{33}$ Potebnja meinte, dab das appositive' Partizip Ende des $14 \mathrm{Jh} .8$ nur noch in der L1teratursprache gebraucht wurde. Pur das 16 . Jh. haben wir schlieblich die Angaben Boretzkys, der in Kurbskij's "Istorija" beim Part.praes. die Endung - šče so stark verallgemeinert vorfindet, daß fast die Hälfte des Vorkommens Sing.-Belege sind. Die Endung $-a /-j a$ hingegen erscheint nur in $20 \mathrm{v}$.Hd. aller Pälle beim Plur. Zum Part.praet. bemerkt er: "Bei der Porm auf -vъ uberwiegt die

30) Davon zeugen die fast 1400 Belegstellen bel Ruz1cka, Das syntaktische System. Allerdings ist hinsichtlich seines Materiale auch in Rechnung $2 u$ stellen, dab es $81 \mathrm{ch}$ be 1 den Evangelientexten um Ubersetzungen aus dem Griech. handelt.

31) Stola, Zum Gebrauch der unbest.Formen von akt. Part.1en, S. $19 \mathrm{f}$. In den jungeren Teilen dieser Hs. erhöht sich der Antell inkongruenter Bildungen bis gegen 6,7 v. Hd.

32) Istrina, Sint.javlenija, s. 92.

33) Borkovsk1, Sintaksis drevner. gramot I, S. 212; ders, Ist. grammatika, S. 354 . 
singularlache, bel der auf -vŏe die pluralische Bedeutung jewe1la zu 75 v.Hd." 34 In der Sprache Posoškov8 (18. Jh.) haben entsprechende Partiziplal-Belege bereits eindeutig adverb1alen Charakter; Schnelder ${ }^{35}$ opricht bereito ohne die geringote Einschränkung von 'Adverbialpartizipien', betont, daB es sich um Gerundien, nicht um Part.1en handele. 36 zwar ist der Formenrelchtum dieser Kategorle bel Pososkov noch immer groB, aber fur den Gebrauch der jewelligen Endung and morphologische und funktionale Kriterien ausechlaggebend. 37 'Wlederholt' korrelieren die 'Adverbialpartiziplen' nicht mit dem Subjekt des Satzes. 38 sie stehen manchmal für ein Verb.fin. und sind in solchen Fällen mit dem ein Verb.fin. enthaltenden Satz durch koordinierende Konjunktion verbunden. 39

In unseren beiden Erzählungen stoBen wir häuflg auf Fälle von fehlender Kongruenz 2 wischen Part. und Subjekt. Da wir intu1t1v einen grundsätzlich unterschiedlichen Gebrauch der part1z1pialen Formen in unseren Texten opuren, haben wir zunächst das Verhältnis zwischen Subjekt und Part. nachgepruft.

Dabel fiel auf, daB die Constructio ad sensum, wie sie das Altrus8. ${ }^{40}$ kannte, allmählich aufgegeben zu werden scheint zugunsten des grammatischen Numerus, vgl. $2 . B$.

KP 64/4 "I jako pristup18̈a množestro l judej ..." "množestro" mit Plurals "pristupišn".

34) Boretzky, Der Tempusgebrauch, S. 130; den Komplex der KonBruenz behandelt er auf S. 127 - 30 .

35) Schne1der, die Sprache Posoǧkovo, S. 230 - 38.

36) ebd., s. 233.

37) ebd.., S. 233 f. und 235 f: Die Endung -a/-ja ergcheint be 1 Verben der 3. und 4. Leskien'schen Klasson. Hervorzuheben 1st, daB Vorze1t1gke1t bol Vorben der 4. Leakien' schen Klasse regelmäig durch deren Part.praes., also auf $-8 /-j a$ ausgedruckt wird, nicht durch des Pormane $-1 v$; Die ubrigen stämme bjlden das Part.prass. (=Adv.-Part.) auf -uci; - usce/-asce wird nur in Passagen hohen Stils gebraucht.'Part.praet. (Adv.-Part.) b1lden vokalioche Stamme auf $-v b, 80$ auch häuflg, konsonant1sch auslautende, sonst ergcheint be1 letzteren - vä. Reflexive Verben haben me1st -visb.

38) ebd., S. 237. 39) ebd., S. 2361.

40) Sehr ausfuhrlich hlerzu: Borkovakif, Iot.grammatika, S. $324 \mathrm{ff}$. 
Aber: KP $37 / 31$ n..., takože 1 kl1rik vesb 1 sunklit mnogo glagolaše emu, da..."

'Gelstlichke1t' und 'Sinklitos' (griech.6 $\tilde{v}_{\gamma} \times \lambda \eta T 05$ ) mit Sing.: "glagolašen.

Haufiger als im einfachen Satz erscheint der Sing. nach Kollekt1va im Rahmen des Dat.abs.:

KP 76/41 "Narodu že 1dušču ..."

Wenige Zellen später aber lesen wir:

KP 76/44 "... toliku narodu ot odnoja chraminy 1zšedčim, ..."

Im Pleskauer Text stehen beide Konstruktionsweisen - logische und grammatische - beinahe gleichberechtigt nebeneinander:

$87 / 3$ "Paki že l1tva na stary f svof gradoemnyj obyčej ... sami $\nabla$ sebe istjazujutca, ..."

Aber: 77/27 "I tako litva ot goroda v stany pobežą."

Belm Dat.abs., bestehend aus Kollektivum und Part., begegnet nur ein Mal Constructio ad sensum:

$67 / 1$ "Bezzakonnomu vojsku krepko 1 derzostno na steny luzuščñm."

Sonst entzieht sich der Pleskauer Autor einer Entscheldung, indem er dae Part. statt mit der Dat.pl.-Endung mit der Nom.pl.-Endung versieht, z.B.

69/25 "Litovakomu že volnstru krepce 1 naporne so steny, ... po ruskomu volnstru streljajušče...n41

Eine gewisse Unsicherheit hinsichtlich des Numerus zeigt sich auch be1 Aufzählungen, be1 denen eine Einzelperson zuerst genannt wird oder im Mittelpunkt oteht:

XP 74/8 "Cesarb že, priglasiv grộ드 so vosklicaniem mnogym, vnidoğa vo vae polki $1 \mathrm{ch} \ldots$..."

- Der Kalser rief die Selnen herbel ... und zog mit__diegen gegen die (türkischen) Haufen ...'

324 - 27; Istrina, Sint.javlen1ja, s. 92 f. - hebt hervor, daB bel einem Kollekt. als Subj. ein Part. im Plur. ateht.

41) Zum Dat.abs. - 8. ausführlicher S. $631 \mathrm{ff}$. 


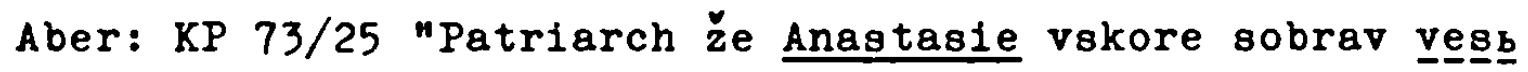
klírik__i_sinklit, poide $k$ cesarjui reče mu: ..." 'Patriarch Anastasios begab sich - zusammen mit der schnell herbeigerufenen Geistlichkeit_und dem_Rat - zum Kaiser und sagte

PS $48 / 17$ "Gosudarev ... voevoda knjazb ... Sujskoj, vo Pskov

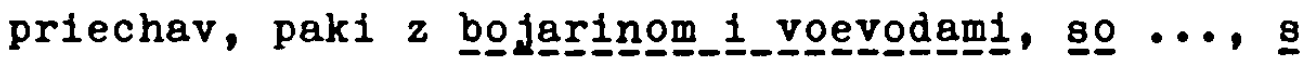
tovaryyščy, o ukreplenil grada vajako dščanie pokazovaše ... 1 povelevä̌e ....n $n^{42}$

' Fürst Sujskif fuhrte, nach Pleskau zurückgekehrt, mit den anderen Voevoden und ... zusammen alle zur

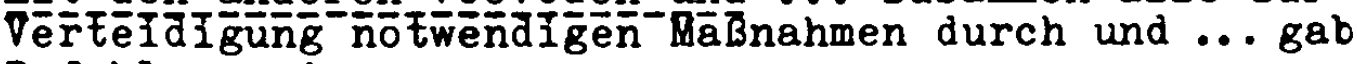
Befehle ....

Aber: PS 62/24 "Pervie, pečerskij igumen Tichon, 으ㅁㅗㅛㅡㅡ ogvjağčennyㅛ. soborom, $s \ldots$ na to mesto prichod jat

' Zuerst zog der Abt des Höhlenklosters Tichon mit

Beobachten wir also in den genannten Fällen Unsicherheiten hinsichtlich des Numerus beim Verb.fin., so ist zu erwarten, daß gerade diese Schwankungen mit zum Verlust der Kongruenz zwischen Subjekt und Part. beitrugen. 43

Wenn wir nun nur wenige Beispiele vorstellen werden, dann deshalb, weil in den bisher vorgeführten und künftig vorzustellenden Belegen dieser Verlust der Kongruenz zu beobachten $18 t$.

$\underline{\text { K}}=\underline{\mathrm{p}} \underline{\underline{1}}$ :

$63 / 17$ "Sija že uvedav, velbmoži 1 Zustuneja, sobravsja vkupe s patriarchom, načasa uveščvat1 cesarja, glagol jušče: '....n

'Als die Würdenträger und Giustiniani hiervon erfahren hatten, kamen sie mit dem Patriarchen zusammen und begannen, auf den Kaiser einzureden, indem sie sprachen: -...'

42) An dieser Stelle fst nicht auszuschlieBen, das der Autor die Endung -ase fur -achu gebraucht, wie er es sonst ja auch häufig tut.

43) Stola beobachtet Störungen der Kongruenz zwischen Subj. und Part. gerade in diesen Bereichen - Stola, Unbestimmte Formen von akt. Part.ien, S. 22 f. 
Während die präpositiven Part.ien im Sing. stehen, hat das nachgestellte Part.praes. den korrekten Plural.

70/30 "Egda že uslyša zvonu, vzemše božestvennyja ikony, izyde pred cerkvoju 1 sta na molitvu, osenjajušce krestom vesb grad, 1 rydajusče 1 glagol jusče: '...." 'Als der Patriarch das Geläut vernahm, ergriff er die Ikonen, trat vor die Kirche und stellte sich zum Gebet auf, wobei er die Stadt mit dem Kreuz segnete und weinte und sprach: ...'

In diesem Satz besteht in keinem Fall Kongruenz zwischen dem Subjekt (Patriarch) und den Partizipien.

$66 / 42$ ".... stratigi poskoriša na pomoščb, 1 sretoša narod mnog begajušce 1 bb ja, ..."

'.... die strategen eilten zu Hilfe, und ihnen begegnete viel Volk, das sich kämpfend zuruckzog, ...'

"begajušče 1 bsja" gehören zu einem direkten objekt "narod", 44 Die Ubersetzung gibt die Konstruktion nicht ganz richtig wieder, denn die Part.ien sind gleichgeordnet. Allerdings verwundert, $d a B$ sie unterschiedliche Formen haben - "begajušč" kann auch bel Akk.pl.mask. stehen (der Orthographie unserer Textausgaben für -šce eintretend). "bbja" allerdings ist keine Akk.-Form und wird auch in keinem unserer Texte im $\mathrm{Zu}-$ oammenhang mit dem Akk. gebraucht. Diese Tatsache deutet auf rein adverbialen Gebrauch der Form. Gegen solchen Gebrauch steht freilich die Konjunktion " 1 ", die beide Part.ien voneinander trennt.

\section{Ple으트므:}

$54 / 32$ n... sija slyšav bojare i voevody, jako uže idet korolb na Pskov grad, vsjačeski i neoslabno ... vo grade osadu ukrepl jaja. Vo volosti že ... neprestanno posylaja, vajakie zapasy 'v gorod voziti veljăe; dvory že 18 dostalbnymi kormovymi zapasy žešči povelevaja, ..." 'Als die Voevoden erfahren hatten, daB .... trieben sie in Pleskau die SchutzmaBnahmen für den Fall der Belagerung voran. In die (umliegenden) Ortschaften schickten sie pausenlog (Boten) und befahlen, alle Vorräte inlaie stadt zu bringen. Die Höfe befahlen sie zu verbrennen.

44) Uber das direkte Objekt mit Part. - 8.0., S. $643-51$. 
Von "idet korolb" im Nebensatz abgesehen, ist in der gesamten Satzfolge weder eine verbale noch eine partizipiale Form korrekt gebildet. Als finite Verbform finden wir "veljaše" für 3.pl.ipf. Dieser Verbform entsprechen formal auch die Part.ien: sie haben alle Sing. auf -(j)aja. An anderer Stelle sagten wir, dab die Störung der Kongruenz zwischen Subjekt und Part. die einsetzende Adverbialisierung des nominalen Part.s anze1ge - zwar existiert hier überhaupt keine Kongruenz mehr, doch handelt es sich bei diesen Part.-Syntagmen keineswegs um adverbiale Bestimmungen, sondern um selbständige Sätze. Die Endung des nominalen part.s scheint so wenig distinktiv zu sein, dab Kongruenz zwischen Subjekt und Part. nicht einmal dort bewahrt bleibt, wo sie notwendig scheint: im elgenständigen Part.-Syntagma.

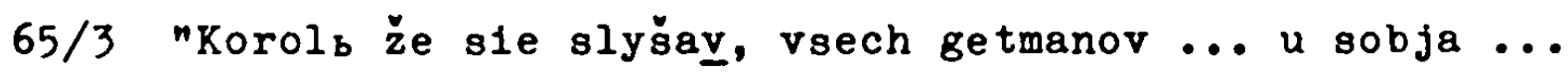
učredi, 1 ... bezotstupne sladko uslovesovaše, 1 velikimi obety ... lasku pokazat1 obeščavosesja, ..." 'Als der König dies vernommen hatte, bewirtete er alle Hetmane bel sich, sagte ihnen viel Schmeichelhaftes und schwor, ihnen seine Gnade zu bezeigen.'

Das nahe beim Subjekt stehende Part. hat den korrekten Numerus, wohingegen das weit entfernte Part. nicht kongruiert. Möglicherweise besteht bei "obeščavšesja" klangliche Anlehnung an "uslovesovaše", well der Pleskauer Autor von diesem keine Ipf.Form bilden konnte - sicher empfand er "obeščati" als perfekttiv. Es erhebt sich allerdings die Frage, warum der Autor dann kein Ipf. vom drei Mal auftretenden "obesčevatisja" gebildet hat.

63/3 "Gosudarevy ... voevody povelę̆a ... steny podtveř́ati. Protiv że kamennyja steny, podalee, drevjanye steny delati načasse 1 vsjakija kreposti ugotovl jaja, ..." 'Die Voevoden ordneten an, daB die Mauern befestigt werden. Hinter der Stelnmauer begannen sie, eine hölzerne (Pailisade) zu errichten, und sie trafen alle sicherheitsmaßnahmen.'

Der Ersatzendung für die 3.pl.1pf. auf -achu, der 2./3.8g.1pf. auf -aše, entopricht auch hier die Porm des Part.s, das als Prädikat in einem unabhängigen partizipialen Syntagma funglert. 
Der Vergleich beider Texte auf ihre Kongruenz zwischen Subjekt und Partizip hin führte zu folgendem Ergebnis:

\begin{tabular}{|c|c|c|c|c|c|}
\hline $\begin{array}{l}\text { Subj. } \\
\text { im } \\
\text { sing. }\end{array}$ & $\begin{array}{l}\frac{p t \cdot p s .}{-a / j a} \\
-\ddot{s c e}\end{array}$ & $\begin{array}{l}\text { X-pel IP sk } \\
30=60 \% \\
20=40 \%\end{array}$ & $\begin{array}{l}\text { pt.pt.K-pel iPsk. } \\
\text {-vъ } 73=94 \%_{1}^{\prime} 51=86 \% \\
\text {-vse } \quad 5=6 \%, 8=14 \%\end{array}$ & $\mid \begin{array}{l}\text { K-pel } \\
17=100 \% \\
---\end{array}$ & $\begin{array}{l}\text { Psk } \\
27=87 \% \\
4=13 \%\end{array}$ \\
\hline $\begin{array}{l}\text { Subj. } \\
\text { Im } \\
\text { Plur. }\end{array}$ & $\begin{array}{l}-\dot{8} \dot{c} e \\
-a /-j\end{array}$ & $\begin{array}{l}64=82 \% \\
14=18 \%\end{array}$ & $\begin{array}{ll}-v \text { še } & 46=68 \% ; 68=81 \% \\
-v ъ & 22=32 \%, 16=19 \%\end{array}$ & $\begin{array}{l}3 \\
3\end{array}$ & $\begin{array}{l}19=58 \% \\
14=42 \%\end{array}$ \\
\hline
\end{tabular}

Die dre1 Abtellungen der Graphik geben Auskunft über das Vorkommen von Part.praes. (pt.ps.), von Part.praet. (pt.pt.) sowe in der dritten Abteilungen (ohne gesonderte spezifizierung) Part.praet. durativer Verben, d.h. im Wesentlichen von "videv/ $-s ̌ e n$ und "slyšav/šen". 45

Die mit dem Subjekt korrelierenden partizipialen Formen befinden sich jeweils auf der oberen, die inkongruenten Formen auf der unteren Ze1le; so haben z.B. In der K-pler Erzählung von 50 Part.praes. bei einem Subjekt im Sing. 30 Belege die Endung $-a /-j a$, das sind 60 v.Hd. Die restlichen 20 (= 40 v.Hd.) stimmen mit dem Subjekt im Sing. nicht überein - sie haben die Plur.-Endung - šce. 46

Die Erwartung, dab sich die Texte in der Numerus-Kongruenz deutlich unterscheiden könnten, hat sich nicht bestätigt. Es verwundert ein wenig, daß der Pleskauer Text, genau genommen, etwas seltener gestörte Kongruenz zeigt.

Hinsichtlich des Part.praee. hat die K-pler Erzählung stärkere Vertretung der Plur.-Endung -ǧče: 40 v.Hd. aller Sing.-Belege haben diese sowie mehr als $80 \mathrm{v} . \mathrm{Hd}$. aller Plur.-Belege. ${ }^{47}$

45) Abgetrennt von den librigen Part.praet.-Formen haben wir diese Gruppe deshalb, well sie so formelhaften Charakter hat und daher evt. ein anderes Bild zelgt als die Masse der ubrigen Belege.

46) Part.-Formen nach Kollekt1va wurden, da wir es offenbar mit einer Zeit dee Umbrucho zu tun haben, in jedem $\mathrm{Fall}$ als richtig gewertet - z.B. "Iltva voskrycav" murde reg1otrifert unter 'Part.praet.ging. - korrekt'; "I1tva voskrycavbe" unter 'Part.praet.plur. - korrekt' eingestuft.

47) Paarig auftretende Part.ien ("plačjušč 1 rydajuščen, "kryca 1 vopija") galten wegen der gegenseitigen Beeinflusoung als ein Beleg. 
In Plural der Belege für Part.praes. dominiert in beiden Texten die adäquate Endung -šče mit jeweils uber 80 v.Hd.

Bezüglich des Part.praet. fällt auf, daB der K-pler Autor die Endung - $\mathrm{vb}$ bevorzugt - im Sing. mit 94 v.Hd.; und wenn das Subjekt im Plural steht, haben 32 v.Hd. aller entsprechenden Part.ien diese Form. Dagegen finden wir im Pleskauer Text im Sing. und im Plur. ungefähr die gleiche Abweichung vor: -vše beim Sing. = 14 v.Hd., $-\mathrm{vb}$ beim Plur. $=19 \mathrm{v} . \mathrm{Hd}$. In der dritten Abtellung ("videv/še" und "slysav/še" sowie wenige andere Part.praet.-Formen von Durativa) bestätigt die K-pler Erzählung den Trend, der sich bei den anderen (perfektiven) Part.praet.-Belegen abzeichnet: Bei einem Subjekt im Sing. kommt nur die Form -vb vor, die wenigen Belege mit einem Subjekt im Plur. enden in der Hälfte aller Pälle auf -vb . Die Bevorzugung dieser heute in der Literatursprache dominierenden Endung des Adv.-Part.s finden wir bei den formelhaften Wendungen ("slyšav" usw.) auch im Pleskauer Text: Annähernd die Hälfte dor Part.ien mit Subjekt im Plur. endet auf $-\mathrm{vb}$.

Irgendeine Entwicklungslinie läBt sich aus den gewonnenen Daten nicht ableiten. Die Endung $-a /-j a$ fand eine Stuitze in festen Wendungen, die die Volkssprache kannte; ${ }^{48}$ andererseits war sie auch in der Literatur verbreitet. ${ }^{49}$ Insgesamt gesehen, geht der Gebrauch der Endung -a/-ja im Pleskauer Text zurück - in der K-pler Erzählung kommen auf sie ca. 35 v. Hd. aller Part.praes.-Formen, Im Pleskauer Text sind es nur noch ca. $27 \mathrm{v} . \mathrm{Hd}$. - bei Kurbokij machen diese aber noch viel weniger - 18 v.Hd. - aus. ${ }^{50}$ Bel Kurbskij 1st die Form $-a /-j a$ stark auf den Sing. fixiert - in nur $20 \mathrm{v.Hd}$. aller Fälle bedeutet sie Plur. ${ }^{51}$ Damit ist diese Form im Pleskauer Text

48) Boretzky, Tempusgebrauch, S. 126.

49) Nikiforov, Glagol, S. 262; -a/-ja war auch Im Kanzleistil verbreitet: Nikiforov, Glagol, S. 261.

50) Zählen wir zu den Formen auf -šče noch die auf - ğčl und $-c 1$ hinzu, verringert sich der Anteil von $-a /-$ ja auf $15 \mathrm{v}$. Hd.

51) Boretzky, Tempusgebrauch, S. 129. 
zwar soltener ale bel Kurbskij, aber stärker verallgemeinert als bel diesem. 52 Die Dominanz der Endung - šce beim Part. praes. In Kurbskif's "Istorija" (75 v.Hd., mit - šćl und -či sind es uber $80 \mathrm{v} . \mathrm{Hd}.)^{53}$ finden wir in unseren Texten nicht, vor allem lot bemerkenswert, daB diese Form in der "Istorija" beinahe genauso oft beim Sing. wie beim Plur. steht. Das ist slcher darauf zurückzuführen, daB die Endung -šče im 16. Jh. fur die höchste stilebene charakteristisch ist. 54

Tenn Boretzky hinsichtlich des Part.praet. bemerkt, dab die Belege in jeweils etwa 75 v.Hd。 den richtigen Numerus haben (s.0.), dann können wir festhalten, daB unsere Texte da einen höheren Grad der Kongruenz zeigen: weit uber $80 \mathrm{v} . \mathrm{Hd}$. - mit Ausnahme der Gruppe "slyšv" uow. sowle der Tendenz in der $\mathrm{K}$-pler Erzählung, die Form -vo zu verallgemeinern, was sich bel Part.1en mit Subjekt 1m Plur. niederschlägt ( 32 v.Hd. derselben enden auf $-v_{b}$ ). Da diese Endung umgangseprachlich geprägt war, 55 mutet diese Tatsache insofern eigenartig an, als wir beim Part.praes. eine Ausbreitung der hochliterariochen Form -b̌če auf die Sing.-Bedeutung hin ( 40 v.Hd. aller Beloge mit Part.praes. auf -šce hatten ein subjekt im Plur.) konstatiert hatten.

Die Uberprufung der Kumerus-Kongruenz ${ }^{56}$ im Rahmen unserer be1den Texte hat uns keine klaren Ergebnisse gebracht, keine eindeutigen Tendenzen aufgeze1gt. Freilich waren wir erstaunt, ein 80 hohes $M a B$ an tbereinotimmung der Texte bezuglich der Humerus-Kongruenz vorzufinden: ca. $80 \mathrm{v} . \mathrm{Hd}$. aller nominalen Part.ien, die mittelbar (über ein Verb.fin. = Prädikat) oder unmittelbar mit dem Subjekt des Satzes verbunden sind, kongru1eren mit diesem.

52) Im X-pler Text hat die Part.praes.-Form-a/-ja in 32 v.Hd. aller Belege Plural-Bedeutung.

53) Boretzky, Tempusgebrauch, S. 127.

54) Iikiforov, Glagol, S. $263 \mathrm{f}$.

55) ebd., 8. 272 .

56) Die wenigen nominalen Part.1en be1 femininen Subjekten (Kriegserzählungenl) erlauben es nicht, Irgendeine Aussage besuglich der Genus-Kongruenz zu treffen. 


\section{Die Punktion der nominalen Partizipien (Nominativ) \\ im Rahmen unserer Texte}

Der Vergleich der Numerus-Kongruenz in nominalen Part.-Syntagmen (Subjekt im Nominativ) förderte nicht jenen grundsätzlichen Unterschied $\mathrm{zw}$ ischen unseren Texten zutage, den wir auf Grund der Lektüre erwartet hatten und der uns eine Klassiflzierung ermöglich hätte. Zwar konnten wir relativ häufige Störung der Kongruenz feststellen, aber - besonders hinsichtlich des Pleskauer Textes - nicht im vermuteten AusmaB. Auf Grund unserer Vorinformationen 57 hatten wir erwartet, im Pleskauer Text deutliche Tendenzen erkennen zu können, die auf eine Entwicklung des Part.-Syntagmas in die Richtung des heutigen (erweiterten) Adv.-Part.s zielen.

Die weitgehende Ubereinstimmung unserer Texte in bezug auf die Numerus-Kongruenz: Subjekt - nominales Part. zwingt uns, mit Hilfe anderer Operationen jenen syntaktischen Unterschied im Gebrauch der partizipialen Konstruktionen herauszuarbeiten, den wir beim Lesen so deutlich spüren, zunächst aber noch nicht klar fassen können.

Am Anfang dieses Kapitels hatten wir kurz die Entwicklungslinie des nominalen Part.s (Nominativ) aufgezeigt: vom eigenständigen Partizipial-Syntagma der (vorhistorischen) zeit, da die Hypotaxe kaum ausgebildet war, uber das 'zweitrangige Prädikat' bis hin zum Adv.-Part. heutiger Prägung.

Die Endungen der Part.ien haben uns nicht die Möglichkeit an die Hand gegeben, den Standpunkt der einzelnen Belege bzw. der Texte auf der beschriebenen Entwicklungslinie zu bestimmen: Offensichtlich verbergen sich hinter den gleichen partizipialen Pormen verschiedene syntaktische Funktionen der

57) Vgl: Nikiforov, Glagol, S. 246: "V XVI v. proischodit (točnee - prodolźatsja) process utraty kratkimi pricastijami, yypolnjavsimi rol' skazuemogo, soglasovanija 8 podleżascim (kak $\mathrm{y}$ rode, tak $1 \mathrm{v}$ cisle), t.e. proischodit process 1ch preroźdenija $v$ napravlenii $k$ deepricastiju." (Hervorhebg.: G.Str.). - AuBerdem: In Kurbskij's "Istorija" hatte die Plur.-Endung -sce in fast der Hälfte aller Pälle sing.-Bedeutung. 
Part.ien. Diese im einzelnen zu bestimmen, erfordert die sorgfálige Analyoe einer Jeden Belegstello.

Das Problem be1 solchen Untersuchungen besteht nëml1ch darin, festzustellen, ob das Part.-Syntagma otárker zum subjekt 'gravitiert.58 (= 'zweitrangiges Prädikat') oder aber ob es zum Verb.fin. hin tendiert, also die Haupthandlung modifiziert, näher bestimmt (= Adv.-Part.). Istrina hat derartiges am Part.Material aus der 1. Novgoroder Chronik versucht - mit Hilfe ihrer Intention; ihre Schlüsse sind m.E. nicht immer uberzeugend. 59 Immer wieder betont sie, das die Ubergänge fließend sind. - Ruzicka versuchte, mit Hilfe von Transformationen eine gewisse Klärung der Bezlehungen herbeizufuhren 60 - ein Weg, der mir vielversprechender erscheint als das Kriterium des e1genen Empfindens. Frellich bleibt auch Ruzicka in seinen Schlubfolgerungen sehr vorsichtig. - Wie komplex das Problem allgemein 1st, die Punktion der partizipialen Konstruktion, den Grad Ihrer Abhängigkelt und das Bezlehungsglied im Satz festzulegen, mag elne Äußerung aus einer modernen deutschen Grammatik belegen:

"Auch das Partizip hat ... die Fáhigkeit, sich aus dem Gesamtbogen elnes Satzes herauszulbsen, wenn andere Glieder zu thm treten. Der Ubergang lot auch hier fliebend: ... Auch hier 1ot der Tellbogen, unter dem die Partizipialgruppe steht, erst dann ausgebildet, wenn sich der Wirkungsbereich des Partizips genugend von dem verbalen Wirkungsbereich des elgentlichen Satzes abhebt, Wir oprechen dann von einem satzwertigen Partizip. 1

58) Stola, Unbest. Formen von akt. Part.ien, s. 17 ubersetzt so Petebnjas Ausdruck "tjagoteet" (Iz zapisok, z.B. 190 "tjagoteet $k$ nemu" = $k$ skazuemomu).

59) Vgl. Istrinas Charakterisierung des Part.-Syntagmas im folgenden Textbelopiel als '18ollertes Syntagma! - "obosoblennyj clen" - Sint. javlentja, S. 75 "1 prislasa k nims vtoroje posly tatari, rekuace tako" - die ubrigen Part. Syntagma dort, die auch 18011ert sein sollen, gcheinen mir bhnlich eng dem Subj. verbunden wie oben "rekusce". S. 81: Part. mit großer Selbotändigeit gravitiert zum Subj., mit geringerer Selbständigkeit tendiert es zum Verb.fin.

60) Ruz1cka, Das oyntakt18che System, z.B. S. 94 f., S. 101 u. 8 .

61) Gramnatik der deutschen Gegenwartsoprache. Hrage Paul Grebe, Mannheim-Zurich 21966 (Der grobe Duden. Bd. 4). S. 584, 6085. Hervorhebg. - G.Str. 
Pür derartig diffizile Untersuchungen, wie sie zur exakten Bestimmung des Standpunktes der Part.1en auf der EntwicklungsIInie zwischen sekundärem Prädikat und Adv.-Part. nötig sind, ist in dieser Arbeit kein Raum. Uns geht es um den Gebrauch der verbalen Kategorien insgesamt und den Platz des Part.s im verbalen System; elne Spezialuntersuchung uber das Part. in unseren beiden Texten, so interessant und nutzlich ${ }^{62}$ sie wäre, sprengt den Rahmen unserer Arbeit entschleden. Zum Glück beeinträcht1gt diese Tatsache unsere kontrastivvergleichenden Untersuchungen nicht im geringsten, da der Gegensatz im Gebrauch der Part.1en gar nicht in dem eben als so komplex skizzierten Rahmen zu suchen 1st. Der Unterschied ist viel grundsätzlicherer Natur.

Diese Tatsache erlaubt es uns, das vorliegende Material nach bestimmten formalen Kriterien zu untersuchen. Dadurch werden subjektive Wertungen weitestgehend ausgeschaltet:

W1r fragten nach Part.-Konstruktionen mit eigenem Subjekt, das sich vom Satz mit Verb.fin. als Prädikat unterscheidet, welchem die Part.-Konstruktion logisch verbunden (untergeordnet?) 1st;

wir fragten nach partiziplalen Syntagmen, die vom Satz mit Verb.fin. als Prädikat durch eine (koordinierende) Konjunktion getrennt sind;

wir fragten schlieblich nach partizipialen Konstruktionen, die uberhaupt keine logische Verbindung zu einem Satz mit Verb.fin. als Prädikat haben. Um bei der Suche nach derartigen Syntagmen möglichst wenig subjektiver Vertung zu uberlassen, haben wir hierher vorwlegend Part.ien in Passagen gestellt, in denen gar kein Verb.fin. erscheint. Dariber hinaus haben wir in Zweifelsfällen die Zeitlichkeit des Part.s uberprift - hat es absoluten zeitwert, gilt es als autonom; hat es relativen Zeitwert, bezogen auf das Verb.fin., gilt es als abhängig;

62) Die Entwicklung des nominalen Part.s (Nominativ) vom sekundären Prädikat zum "Deepricastien ist noch immer dunkel. Pür das 15. - 17. Jh. gilt die Vermutung Stolas, 
wir fragen nach Part.1en mit Ergänzung (Objekt, Adverb usw.), die eine durch Verb.fin. ausgedruckte Handlung modifizieren, sle erläutern und dieser gegenuber im Verhältnis einer Nebenhandlung stehen;

schlieblich erfassen wir Part.ien ohne Ergänzung, die direkt be1 einem Verb.fin. stehen - bel diesen 1st der adverbiale Charakter besonders ausgeprägt.

Die ersten drei Kriterien signalisieren relative bzw. vollkommene Autonomie des Part.-Syntagmas. Die beiden letzten Kriterien aber zeigen das nominale Part. schon sehr weit auf dem Entwicklungsweg zum Adv.-Part. fortgeschritten; das alleinstehende nominale Part. hat das Stadium des Adv.Part.s praktisch erreicht.

Mit Hilfe dieser Kriterien soll es uns gelingen, den so deutlich empfundenen Unterschied unserer Texte im Gebrauch partiziplaler Formen aufuzeigen.

daB die Entwicklung des nominalen Part.s zum "deepricastie" geradlinig verlaufen se1, sondern elnen recht komplizierten Teg genommen habe - s. Stola, Unbestimmte Formen von akt. Part.ien, S. 24. 
3.1 Partizipiale Syntagmen mit eigenem_Subjekt

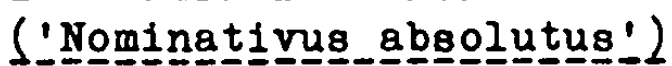

DaB partizipiale Syntagmen irgendwann einmal völlige oder doch sehr groBe Eigenständigkeit besessen haben, dafür spricht m.E. die Existenz des sog. Nominativus absolutus (Nom.abs.).63

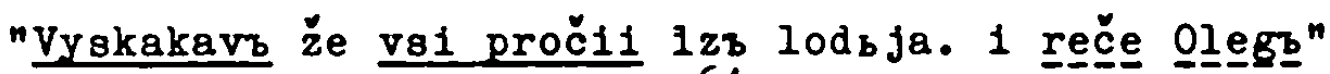

$$
\text { Laur.-Chr. } 64
$$

'Alle ubrigen sprangen aus dem Boot, und Oleg sagte'

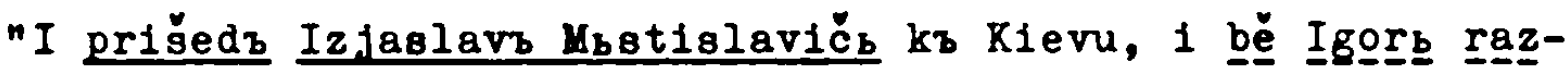
bollělg ja vъ porubé 1 bé bolenъ velmin

Hyp. $-\mathrm{Chr} .65$

'Und I. M. kam nach Kiev, Igor aber war im Gefängnis schwer erkrankt .

In solchen Konstruktionen hat das Part.-Syntagma anscheinend die größte Eigenständigkeit, gelegentlich volle Autonomie. ${ }^{66}$ Die Konstruktion ist allerdings selten, viel seltener z.B. als der Dat.abs. Die Fähigkeit des Part.s im Altruss. ${ }^{67}$, ein eigenes Subjekt zu erhalten, begrundet Potebnja ausdrücklich damit, dab das (nominale) Part. dem Verb.fin. funktional viel ähnlicher war als heute. 68

63) Potebnja, Iz zapisok, S. 197 ff.: "imenitel'noe samostoJatel'noen.

64 ) ebd., s. 200

65) ebd., S. 199

66) Die Zweitrangigkeit der im Nom.abs. ausgedruckten Handlung gegenuber der im Satz mit Verb.fin. bezeichneten Handlung ird immer betont, doch sieht sich Istrina, Sint, javlenija, S. 89, zu folgendem Xommentar veranlaBt: "Znacenie vtorostepennosti predloženija s pričastiem skazuemym ne vosprinimaets ja nami lis' $v$ primere: '..."

67) In den aksl. Evangelientexten findet Ruzicka nur einen unbefriedigenden Beleg - Ruzicka, Das syntaktische System, 8. $100 \mathrm{f}$.

68) Potebnja, a.a.0., S. 199: "... pričastie $v$ dremem jazyke bolee Bchodno g glagolom, cem $\nabla$ novom; ..." 
61/42 "...; gradckye že ljudi věed na stenach ot mala 1 do

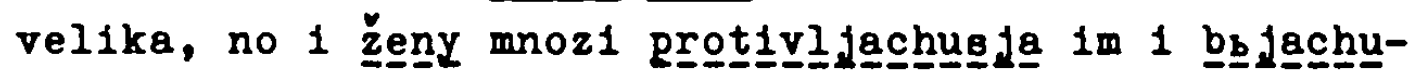
e da krepce, ..."

'...; alle Griechen - alt und jung - waren auf die Umwallungen geeilt, aber auch viele Prauen warfen $81 \mathrm{ch}$ thnen $(=$ den Türken) entgegen und kämpften gegen sie ...'

Zwar finden wir in diesem Satzpar verechledene grammatische Subjekte vor, aber es handelt alch eigentlich um eine spezifizierung: im partizipialen Satz ist indirekt auch das Subjekt des verbalen ${ }^{69^{\circ}}$ Satzos enthalten - 'Prauen' als eine bestimmte Gruppe des allgemeineren Begriffs 'Griechen/Menschen' - "ljudin. Belde Syntagmen sind durch koordinferende Konjunktion ("no") verbunden, die hier sicher nicht so sehr adversativ als eher distinkt1v gebraucht lot - um das Polgende noch mehr zu betonen. Der partiziplale satz beschrelbt die szene allgemein, der verbale Satz gibt die Nachricht, auf die es dem Autor ankommt. Wir fühlen uns an Borkovskij's Pormulierung erinnert, daB die partiziplal ausgedruckte Handlung 'weniger wesentlich' se1. 70 mir erinnern nur daran, wie bre1t die aktive Bete1l1gung der Prauen in der "Kazanskaja Istorija" und in der Pleskauer Erzählung ausge日tal tet 1st. 71

$64 / 37$ "... patriarch 1 va1 lfudie, 1že voschotjat, bez vreda, ostavivèe mne grad pust, 1 az mir sotgror '...f falls/wenn der Patriarch und alle Burger, die dies wollen, ohne Gefährdung72 die Stadt verlassen haben, werde ich Frieden ochlioBen, damit nicht ...'

Es handelt olch hier um die Antwort des Sultans auf eine Priedensbitte der Griechen - dis Griechen und der Sultan ("az" '1ch') otehen einander als Subjekte der zwe1 Syntagmen gegen-

69) 'Verbaler Satz', 'verbales Syntagma' usn. wie schon vorheraleGegensatz benutzt zu 'partizipiales Syntagma' uEm., um langatmige Pormulierungen zu verwelden.

70) Borkovik1 1, lst. grammatika, S. 353.

71) Razanakaja Istorija, S. 135; Textausgabe Pleskauer Text, S. $76 \mathrm{f}$.

72) D.h.: 'ohne Geflahrdung von meiner = turkiocher Se1te'. 
Uber. Autonom ist das Partiziplal-Syntagma dennoch nicht, da es, wie ein Part.praet. häufig vor elner Praes.-Porm mit PuturBedeutung, konditionale Bedeutung hat. ${ }^{73}$ Istrina hat an ihrem Material die Beobachtung gemacht, daB der Nom.abs. nicht selten einen Nebensatz vertritt, der durch subordinferende Konjunktion dem (Haupt-) Satz mit Verb.fin. als Prädikat verbunden werden muBte. ${ }^{74}$ Die enge Beziehung aubert sich auch darin, das das Subjekt des verbalen Satzes in Form eines Dativus ethicus in der partizipialen Konstruktion erscheint: "mne".

$71 / 3$ "I, udariv faris, chotfaǧče bo proskočit1 razrušenoe mesto, dostup1t1 Magumeta, na otmščenie krovi christb-

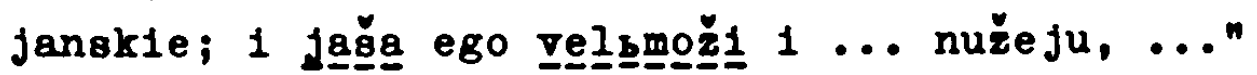
- Und er schlug auf sein ROB ein in der Absicht, durch die Bresche zu sprengen und Mehmed zu stellen, un das vergossene Christenblut zu rächen - es ergriffen ihn aber verschledene wurdenträger und ... und hlelten ihn mit Gewalt zurick, ...'

Die beiden Ausagen - die partizipiale und die verbale - sind elgenstandig. Elne gröBere Bedeutung der verbalen oder 1rgendeine Abhängigke1t der partiziplal ausgedrickten Handlung ist nicht zu erkennen. - Mir scheint allerdings, das wir es bei "chotjağče" mit Verschreibung für "chotjağe" zu tun haben. Darauf deutet das vorausgehende Part.praet., das elne vorbereltende Handlung bezelchnet, die durch die Form des Part. praet. (perf.) schematisch als abgeschlossen hingestellt wird. "udariv faris, chotjağe bo proskočit1 ..." entspräche genau dem allgemelnen Satzschema in der K-pler Erzählung. Auch räumlich sind "chotjašče" und "jaša" deutlich getrennt durch das Supinum (in Form eines Infin.), was auch dafur spricht, das "chotjašće" entweder Verschreibung darstellt oder aber in Verbindung mit "proskočlti" Zentrum elnes autonomen Partiz1pial-Syntagmas 1st, dem elne andere Partizipial-Konstruktion noch untergeordnet iot ("udarir").

73) 8.0., S. 291 , PS $81 / 14$ " "... koždo svoj podkop zamysliv, pod stenu podvedem ..." - irenn jeder seinen Gang ...'

74) Istrina, Sint. javlenija, s. 88. 
3.1.2 Pleskauer Text

Während wir alle Textstellen aus der K-pler Erzählung, die nur den Anschein erweckten, eine Part.-Konstruktion mit eigenem, vom Verb.fin. also unterschiedlichen, subjekt zu haben, vorfuhren konnten, aind wir nicht in der Lage, die 15 entoprechenden Belege aus dem Pleskauer Text insgesamt vorzustellen.

$38 / 1$ "...; 1n11 že vo gradech svo1ch zatvor st1 že grada nadejuščisja;

ov11 že smuščajuščesja vo gradech: 111 sedet1 vo grade krepko, 111 pokoritisja ..."

'...; die einen hatten sich in ihren städten verschanzt und hofften auf deren Sicherhe1t/stärke;

die anderen aber wuBten nicht, olch zu entscheiden: sollten sie in ihren Städten ausharren oder sich (dem Zaren) ergeben ...'

Schon das anaphorische "inil" - "ovil", das ja eine Antithese anzeigt, beweist die Gleichgewichtigke1t der Aussagen - gedanklich und syntaktisch sind sie gleichgeordnet. An anderen Textstellen sind derartige detallilerende Aufzählungen oder antithetische Gegenuberstellungen ("In11 - ovi1"; "1ni1 inil"; nlicy - elicy" u.a.) $)^{75}$ mit den gleichen Verbformen, in der Regel Verb.fin., versehen. Um einen Nom.abs. In dem Sinne, $d a b$ er eine weniger wichtige Handlung bezelchnet, kann es sich hier also nicht handeln. Man muB annehmen, daB "smuščajuščesja" an die Stelle eines Verb.fin. getreten 1st, viellelcht beeinflubt durch "nadejuščisja" (das dem Satz "infl ... zatrorisasja" untergeordnet ist); wir kennen bereits hinlänglich den Hang des Pleskauer Autors, Glelchklange und verbalen Endreim zu schaffen - es scheint, dab dieses Bestreben des Pleskauer Autors nicht auf das Verb.fin. beschränkt bleibt, sondern auch auf Part.ien ausgedehnt wird; es scheint sogar - wie hier -, dab Verb.fin. und Part. austauschbar sind.

75) vgl. $38 / 13,77 / 1,81 / 8,82 / 1,88 / 9$; dagegen weitere Ausnahmen 69/19 - 8 . nächste Se1te, das folgende Textbe1spiel; 77/12 - s.u., S. 594 , als Beleg fur elgenständige Part.-Syntagmen ohne Kontakt zu einem Verb.fin. 
69/17 "Gosudarevy ... voevody ... mužestvenno stojachu: oví ... stojachu, strelbcy ... streljachu, deti źe bojarsk1e ... strel jachu;

ovi1 na nich kameniem metachu;

ovi1 že vsjačeski o izbavienil grada obrazy pokazujušče. Tako że iz narjadu po nich neprestanno strelfajušče

I nikoimi obrazy snit1 vo grad ne dajušce.

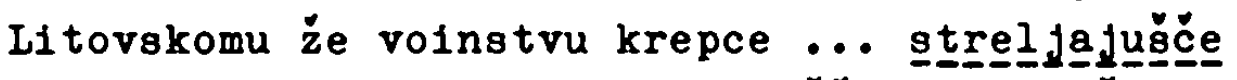

... 1 premenenjajag ja litva bbjuščesja vsjačeski, - ..."

'Die Voevoden des Herrschers hielten sich wacker, diese standen .... die Schützen schossen ..., die niederen Bojaren schossen ...; die einen warfen Steine auf sie herab; andere wieder trugen auf jegliche Weise zur Rettung der Stadt bei. So feuerte man ohne Unterlab die Geschiitze auf sie ab und lieb keinen elnzigen in die stadt. Das litaulsche Heer schoB (aber) auch mächtig; sich dauernd abwechselnd, kämpften die Litauer auf jegliche Weise, - ...'

Wir können hier an das zum vorigen Beleg Gesagte anknüpfen. Anaphorisches "ovil" bezeichnet verschledene Personengruppen, die verschiedene Dinge tun, welche aber zusammengenommen die Verteidigung Pleskaus ausmachen - die einzelnen Handlungen stellen also einzelne, gleichberechtigte Tellhandlungen des Gesamtvorgangs 'Verteidigung' dar. Daher sind auch "metachu" (nach dem zweiten "ovii") und "pokazujušče" (nach dem dritten "ovil") vollkommen gleichberechtigte Verbformen - das Part. praes. steht fur ein Verb.fin. und ersetzt Ipf.

Das gleiche gilt für die folgenden Part.-Formen. 2war fehlt hier "ovil" oder ein anderes ausgedrucktes Subjekt, dennoch sind von den Aussagen wohl verschiedene Personengruppen betroffen bzw. es werden verschiedene gleichwertige Aspekte der Haupthandlung genannt.

Die letzten zwei Zeilen sind der litauischen Seite gewidmet. Der begonnene Dat.abs. bleibt unvollkommen - das Part. "strel jajuščen steht nicht im Dativ, sondern im Nominativ wie die ubrigen Part.ien. Das folgende "bbjusčesja" hingegen bildet das Prädikat eines elgenständigen Satzes mit Subjekt im Nominativ: "litva"; das partiziplale Prädikat wird genauer bestimmt durch ein anderes Part.praes., offenkundig in adverbi- 
aler Punktion - charakteriet1scherwe1se hat es bere1ts die Form des heutigen Adv.-Part.s (1m Gegensatz zu den partiripialen Prádikaten, die auf - šce enden).

Der Pleekauer Autor gibt hier elne Szenenbeschreibung, ein $8 \mathrm{chlach}$ tengemalde sozusagen. Charakteristisch fur Kampihandlungen 1st, w1e wir 1m Zusammenhang mit den Untersuchungen am Imperfekt 1mer betonten, deren otandige Wiederholung, deren Ausfuhrung durch eine Vieleahl von soldaten/Kriegern. Dieser Charakterlolerung entoprechen auch die eroten Verbformen -10 tehen 1m Imperfekt. Dann erfolgt ein Bruch - die gleichen Handlungen werden plotelich partiziplal ausgedruckt - so stehen sch belopielsweise ewe1 Mal "streljachu" und zwei Mal "streljajuščen 76 gegenuber. Die Part.praes.-Formen ersetzen an dieser stelle Ipf.-Formen.

Um den Reim zu varileren, hat der Pleskauer Autor die finten Verbalformen (Ipf.) elnfach durch partiziplale Formen (Part. praes.) vertreten.

81/1 "Pak1 ze korolk sed na svoem vyeokogordom meste, emu be predetédeachu velikija ego getmany ...." 'Und wieder hatte der uberaus otolee Kon1 ${ }^{77}$ auf selnem Thron Plate genommeni vor lhm standen selne vichtigen He tmane ...'

D1e belden beschrlebenen Vorgknge sind bedeutungsmaBig vollkomnen gle1chwert16, oine lbhangigke1t besteht nirgends, wenn man einmal davon absieht, das d1e Hetmane auf Befehl des Konigs vor diesem erschlenen olnd. Die belden satze gehbren zur allgemeinen szenenbeschrelbung, de eine sitrung des polnischlitaulachen Kriegerates elnleitet. - Belde Formen - Part. und Vorb.fin. - bezelchnen einen zustand: "predotojachu" = Ipf. -1nes präfigierten Zustandeverbe, "sed" = Part.praet. eines Momentanverbs bezelohnet o1nen Zustand. ${ }^{78}$ Keineswegs kann

76) Ein Mat allerdings als Part.-Form eines Dat.abs.: "11torskonu ze volnstru ... otrel ja juscén" - s.o.

77) Enallage: der KOn1g sab auf seinem stoleen Thron $=$ der -tolze KOn18 sab … Laueberg, HB I, 8685 ; elne bellebte Hgur in der Pleskaue $\bar{r}$ Erablung; in $\mathrm{K}$-pler Text unbekannt.

78) "Dae 1 - und das ue-Partiz1p elnes Nichtdurativums sagten 
die partizipial ausgedrickte Handlung als die durch Verb.fin. bezelchnete Handlung vorbereitend, daher vorzeitig interpretiert werden; in diesem Palle wurde man nicht "predstojachu" - das Zustandsverb - als 'Haupt-'Handlung erwarten, sondern 2.B. "predstašasja" oder "stašasja pred ego". Gegen vorzeitigvorbereitende Bedeutung der partiziplal wiedergegebenen Handlung spricht auch die Vorstellung, daB sich der König niedersetzt, um so das Erscheinen seiner Hetmane zu erwarten; der König, der Zar oder wer auch immer pflegte zu den ihn erwartenden Untergebenen zu treten.

Part.praet. "ged", von einem Momentanverb gebildet, ersetzt an dieser Stelle elnen (punktuellen) Aorlst: "gěden".

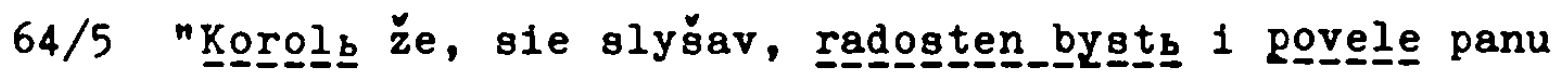
Jurb ju ugroveckomu po gorodu 12 narjadu biti 1 velikie prolomy, 1 ne $v$ odnom meste,sotvoriti dlja vajatbja Pskova grada. On že povelenie ot korolja priem." - Der König war, als er dies erfahren hatte, hocherfreut und befahl Herrn Georg aus Ungarn die Stadt mit Geschützfeuer zu belegen und für die Erstürmung der Stadt an verschiedenen Stellen große Breschen in die Mauern zu schieBen. Jener (Herr Georg) nahm den Befehl vom König selbst entgegen.'

Wiederum haben wir zwel voneinander unabhängige Aussagen vor uns. Zwar ist nicht zu bestreiten, daB die partiziplale Handlung nicht so viel Gewicht besitzt wie die durch Verb.fin. bezelchnete Handlung, doch bedeutet dies nicht, dab sie der letzteren untergeordnet 1st. Das Part.praet. 1st den finiten Verbformen, auf die es sich bezlehen könnte, nachgestellt aber es besitzt absolute zeltlichkeit: wir können nicht interpretieren 'nachdem er den königlichen Befehl angenommen hatte, war der König froh und befahl Herrn Georg ...'

Es besteht zwschen beiden Aussagen keine zeitliche Beziehung, möglicherwelse wäre die durch nachgestelltes Part.praet. bezelchnete Handlung als der durch Verb.fin. gemachten Aussage folgend zu betrachten. Gerade diese Tatsache list wichtig

einen perfektischen Zustand aus, ..." - Budich, Aspekt, S. 21; speziell zu 'sich setzen' und 'sitzen' s. Trost, Perfekt, S. $16, \S \S 34+35$. 
fur die Charakteriolerung einer partizipialen Konstruktion: hat sie relative, auf das Verb.fin. - als ubergeordnete oder allgemein wichtigere Handlung - bezogene Zeitlichkeit, dann handelt es sich um sekundäres/zweltrangiges Prädikat (= gravitiert zum Subjekt) oder um Adv.-Part. (= gravitiert zum Verb. (1n.); hat das Part.-Syntagma aber eigene, absolute Zeltichke1t, dann haben wir es mit einem elgenständigen Part.-Syntagma zu tun, worin das Part. autonome Prädikation besitzt. 79

Part.praet. "priem", Prädikat eines eigenständigen Part.-Syntagmas also, steht hier für einen (punktuellen) Aorist "prija(tz)n.

"sie slysar" düfen wir sicher schon, insbesondere wegen seiner Formelhaftigkeit als Adv.-Part. betrachten.

$63 / 22$ "Tako že 1 voe ... voevody na to mesto na sovet şezžajasja. Sovetovachu 8 nimi že gosudarevy d1 jak Pskova: ..."

'Auch alle anderen ${ }^{80}$ Voevoden kamen dort zur Beratung zusammen. Mit ihnen gemeinsam berieten die in Pleskau (eingestzten) Beamten des Zaren: ...'

Zwe1 Personengruppen, die an den Beratungen uber die Verte1digung Pleskaus teilnehmen, werden gesondert benannt; der Autor nennt die belden Gruppen jewells in einem elgenen Satz, in denen die Prädikate synonym sind: "na sovet şezžašasja" und "sovetovachu". Keine der beiden Aussagen ist der anderen gedanklich untergeordnet.

Eine auf das Verb.fin. bezogene zeitliche Aussage des Part. praes. - Im Sinne von Gleichzeitigkeit - ist nicht erkennbar. Wenn man nach einer zeitlichen Abfolge fragte, wurde man die partiziplale als der verbalen Handlung vorausgehend ansehen: 'Auch die Voevoden kamen dort zusammen, dann berieten mit thnen ....'

79) Vgl. z.B. Potebnfa, Iz zap1sok, S. 195: bezüglich der groBen Eigenständigkeit des durch Konjunkt. vom Verb.fin. getrennten Part.B: "1, a vo 'vostavb 1 recen usilifvajut otnosenie posledovateI'nosti vo vremeni, vytekajuscee uze iz vremen1 prićastija: 'vstavsi, potom skazal'." Auch Ruzicka, Das synt.System, S. 112; Istrina, Sint.javlenija,S.76.

80) 'alle anderen': zuvor waren elnige voevoden namentlich genannt. 
Be1 der Bestimmung des Tempus, das das präpositive Part.praes. hier ersetzt, mussen wir davon ausgehen, daß das Verb.fin. (Ipf.) die aktuelle Handlung bezeichret; das Part. gibt eine Handlung an, von der wir annehmen, daB sie vorzeitig ist, Vorvergangenheit bezeichnet. Diese Annahme beruht auf der Vermutung, daB der Autor den ProzeB des Sich Versammelns, des Zusammenkommens als abgeschlossen verstanden wissen will. Das würde bedeuten, daß dieses Part.praes. als Ersatz für einen Aorist zu interpretieren wäre. Dies widerspricht nicht der sich abzeichnenden Korrelation

$$
\begin{aligned}
& \text { Part.praet. - Aor. - perf. Aspekt } \\
& \text { Part.praes. - Ipf. - Imperf. ". }
\end{aligned}
$$

Auch von der Aspektkorrelation der Tempora gab es Ausnahmen; eine solche Ausnahme bildete der Aorist "şež̌ašasa" wenige Zeilen tiefer $(63 / 27) .^{81}$ Wir hatten bereits Gegelenheit, darauf hinzuweisen, daB nichtdeterminierte Verben der Bewegung auch im 16.Jh. noch nicht in dem MaBe dem imperf. Aspekt verpflichtet gewesen zu sein scheinen, wie dies heute der Pall ist. 82

$86 / 34$ "(11tovskie) ... paki pristupami povsednevnymi na gra-

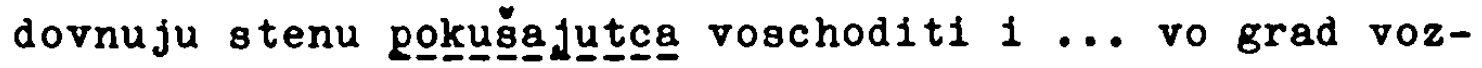
skočiti. Ruskoe že chrestbjanskoe voinstvo ni k počinaniju ich voschod na steny popuščjušč."

'.... da verauchten die Litauer wieder, die stadtmauer in täglichen Großangriffen zu ersturmen. Die Pleskauer lieben sie aber gar nicht erst bis an die Mauer herankommen.'

Die Aktionen der Iitauer sind den Gegenaktionen der Pleskauer gegenubergestellt - die zwei Teilaspekte des Begriffes 'Kampf' also. Dennoch kann von Gleichgewichtigkeit der Handlungen an sich keine Rede sein, denn für den Pleskauer Autor muB doch die Tatsache, daB die Litauer erst gar nicht an die stadt herankommen, von größerer Bedeutung sein - jene Handlung, die partizipial ausgedrückt ist.

Es handelt sich um zwei gegeneinandergerichtete Handlungen, deren Benennung keine zeitliche Beziehung impliziert.

81) S.0., S. 425.

82) S.0., S. 532 . 
Das Verb.fin. zeigt Praes. hist. Dieser aktualisierenden Darotellungsweise, die zeltliche Bezüge vollkommen auBer acht läßt, entspricht im Präteritum das Imperfekt. Diesen beiden Tempora entspricht in Bezug auf die zeitliche Aussage das Part.praes.: es bezeichnet einen Vorgang an sich, aus einer Situation heraus ohne Riucksicht auf zeitliche Dimensionen Im Gegensatz zum Part.praet., das eine Handlung unter Einbezlehung des - gedachten oder realen - Abschlusses derselben benennt. So durfen wir also abschliebend konstatieren, dab "popušçajǚce" im obigen Textbelspiel eln Praes.h1st. vertritt, das, ins Präteritum transponiert, durch Imperfekt wiedergegeben wirde.

Aus der Vorstellung weiterer Belege fur Part.-ASyntagmen mit e1nem anderen Subjekt als dem des Syntagmas mit Verb.fin. als Prädikat, lassen sich weitere Erkenntnisse nicht ableiten. Es bestätigt sich immer wieder, dab das partizipiale und das (vermeintlich) dazugehörige verbale Syntagma im Grunde keine engere innere Beziehung zueinander haben als andere, meist unverbundene Sätze Im engeren Kontext. Die Part.-Syntagmen sind als selbständige Sätze zu betrachten - das Part. hat autonome Prädikation. Der Hrsg. der Pleskauer Erzählung unterstreicht diesen Tatbestand gelegentlich dadurch, daB er die fraglichen Syntagmen durch Punkte voneinander trennt.

Im Rahmen solcher Sätze mit partiziplalem Prädikat ateht das Part.praes. gewöhnlich für Imperfekt, das Part.praet. für Aorist, wobel bestimmte Sondererschelnungen sich auch bei den Part.ien niederschlagen (vgl. "sbež̈ajasja" offensichtlich für Aor., den wir auch später antreffen "obež̌ăasja").

Im K-pler Text war solche Eigenständigke1t nur in einem $\mathrm{Fall}$ (Beleg 71/3) zu erkennen, gerade hier lag aber der Verdacht der Verschreibung sehr nahe; in einem Pall waren die Subjekte der beiden Syntagmen grammatisch zwar verschieden, logisch aber 2.T. Ident18ch (61/42: Part.-Syntagma-"ljudin, Syntagma alt Verb.fin. - "ženy" als Subjekt); in einem Beleg (64/37) berelchnete das Part.-Syntagma die Bedingung in einem Kondit1onalsatz-Gefuge. 


\subsection{Koordininierende Konjunktion zwischen

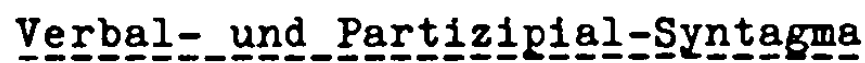

Eine koordinierende Konjunktion, die zwischen das Syntagma mit Verb.fin. und das Syntagma mit Part. als Zentrum tritt, wird als wichtiges Anzeichen dafür gesehen, daB die Partizipialkonstruktion eine gewisse Ebenbürtigkeit im Vergleich zur verbalen Konstruktion erlangt. ${ }^{83}$ Ruzicka hält die Konjunktion "1", die meist in der genannten Position erscheint, fur ein Relikt aus gemeinglavischer zeit, da para- und hypotaktische Fügungen noch nicht klar ausgeprägt waren, also auch 2 wischen Partizipial- und Verbal-Syntagma kein erkennbarer syntaktischer Gegensatz oder Unterschied bestand. ${ }^{84}$ Die Kombination 'Partizip/koord.Konjunktion/Verb.fin.' scheint genuin slavisch zu sein, dafür spricht einerseits die ratsache, dab die Ubersetzer der aksl. Evangelientexte auf diese Weise griech. 'Aorist - kai - Aorist (gelegentlich Imperfekt) 85 wiedergeben, anderergeits spricht dafür auch das reichliche Belegmaterial, das Potebnja, Istrina, Borkovskij, Nikiforov u.a. (s. Anm. 83) zusammengetragen haben.

Dem Part.-Syntagma wird 1m Rahmen dieser Pügung noch gröBere Elgenständigkeit als der Part.-Konstruktion mit eigenem Subjekt bescheinigt. Dennoch bleibe die partizipiale Handlung eine zweitrangige, untergeordnete. In allen Sammlungen finden sich aber auch immer Belege, denen die Kommentatoren mehr oder weniger volle Prädikation, volle Eigenständigkeit zugestehen muissen. 86

83) Potebnja, Iz zapisok, S. 191 ff.; Istrina, Sint.javlenija, S. 81 f., Nikiforov, Glagol, S. 247 , Ruzicka, a.a.0.,S.102ff.

84 ) Ruzicka, a.8.0., S. $107 \mathrm{ff}$.

85) ebd., S. 106: "Die Ubersetzer, die der griechischen Konstruktion leicht hätten folgen können, wie sie ihr oft gefolgt sind, erproben inre Selbstindigkeit, getzen aber auch die Entsprechung fur raic und erzielen damit eine slavische Konstruktion, die im Griechischen strukturell-kaum zulässig war. Die slavische Kongtruktion 1st in jedem Palle eine Abweichung von der griechischen."

86) Potebnja, Iz zapisok, S. 195 f.; Istrina, Sint.javlenija, S. $90 \mathrm{ff}$; Ruz1cka, a.8.0., S. 112 . 
Den dre1 Belegen mit elgenem Subjekt im Part.-Syntagma stehen in der $\mathrm{K}$-pler Erzbihlung 1mmerhin 16 Pügungen gegenuber, in denen partizipiales und verbales Syntagma, welche eine gewisae logische Bindung zueinander haben, durch eine koordinferende Konjunktion getrennt ${ }^{87}$ sind, in denen also das Part.-Syntagma syntaktisch aufgewertet 1st. Aus Raumgründen mulseen wir uns auch hier auf eine Auswahl beschränken.

70/13 "Magumet že okajannyj so voemi činy vrat svoich zaigrav vo vae 1gry 1 v tumbany, 1 vopli velikiml vozǧumę̌a, ak1 burja s1lbnaja, 1 pri11de na poloe mesto, ...n $88^{\circ}$ 'Mehmed, der Verruchte, lieB - zusammen mit allen wurdenträgern der Pforte - die Instrumente und Pauken ertonen, und sie erhoben ein Geschrei, einem wilden Sturm gleich, und sie (er) zogen gegen die Mauerbresche, ...'

Objektiv betrachtet, dürften "zaigrav" und "vozsumeša" auch in inrem Kontext gleichgewichtige Aussagen sein. Durch den dem Verb.fin. angefugten Vergleich "aki burja silbnaja" wird aber deutlich, daB der Autor das Krlegsgeschre1 als bedrohlicher empfindet. Abgesehen von der Tatsache, daB das Part. noch durch zwei Objekte ergänzt wird, wird im Part.-Syntagma auch noch das gewichtige subjekt genannt. ${ }^{89}$ Dies alles zusammen bewirkt, daB die Part.-Konstruktion ganz erheblich an Bedeutung gewinnt, als 'zweitrangig', 'untergeordnet', 'sekundär' oder 'peripher' (Ruzicka) im Vergleich zum 'Haupt-' Satz e1gentlich nicht mehr betrachtet werden kann.

87) 'getrennt': die Konjunktion verhindert das Ubergrelfen des Binflusses des Verb.fin. auf das Part., durch welchen letzteres mit der Zeit dem Verb.fin. untergeordnet - zum Adv.-Part. umge formt wurde.

88) Man beachte den Inkonsequegnten Numerus: "magumet so činy vrat svoich zaigrav - vozsumesa - pri1den".

89) Dem präpositiven Part. In Verbindung mit dem Subjekt wird besonders groBes Elgengewicht eingeráum, vor allem in Verbindung mit einer Konjunktion: Istrina, Sint.javlenija, S. 84, Ruz1cka, S. 20 ff. - differenziert: Part.-Sub1. -1-Verb.In. zeige grbBeres Gewicht des Part.-Syntagmas als: Subj.-Part.-1-Verb.fin. Nik1forov, Glagol, s. 247 meint, daB das prêposit.Part. dann aber wegen seines vorbere1tenden Charakters fruh zum $1 d v$.-Part. murde. 
Die Beurteilung der zeitlichen Komponente ist schwierig, doch scheint mir, daß die Vorzeitigkeit, die das Part.praet. suggeriert, vom Autor nicht gemeint ist - ganz sicher, und das kommt auch im Präfix "zalgrav" zum Ausdruck, ist gemeint, daß sie zu spielen begannen und danach das Geschrei einsetzte, wobel aber das Getöse der Instrumente auch weiterging. M.E. kann man diesem Part. auch die absolute Zeitlichkeit nicht gänzlich absprechen.

Als Part.praet. eines Inchoativums vertritt "zaigrav" hier einen Aorist.

$71 / 34{ }^{~ " C h r i s t b j a n s k o e ~ s o g r e s ̌ e n i e ~ n e ~ v o s c h o t e ~ s e, ~ n o ~ p r i l e t e v ~}$ is pušky jadro kamennoe na izlete, $\stackrel{1}{=}$ udariv Zustuneja po persem, 1 razrazi emu pers1, 1 pagde na zemlju: ..." - Die Sünden der Christenheit ließen es aber nicht dazu (d.h.: zu einem guten Ende der Belagerung) kommen: (es ereignete sich nämlich folgendes:) Eine Steinkugel kam geflogen und schlug Giustiniani gegen die Brust, zerrib thm diese und stürzte dann zu Boden: ...'

Vor uns haben wir eine Handlungskette: die Kugel kam geflogen - schlug gegen G.s Brust - zerriB diese - stürzte zu Boden. Die einzelnen Aussagen sind durch "1" miteinander verbunden. In diesem Satz sind die partizipial ausgedrückten Vorgänge klar vorbereitender Natur - sie führen zum Hauptereignis hin: die Kugel zerschlug/zerriB ihm die Brust. Allerdings fördert der 1sokolonartige Aufbau der letzten drei Syntagmen - zusammen mit der anaphorischen Wirkung der Konjunktion "i" - das Gefühl, daß alle drei Glieder parataktisch gefügt sind; das erste Glied der Reihe (priletev ...") hat durch das dort genannte Subjekt ohnehin stärkeres Gewicht.

Lassen wir einmal die nivellierende Wirkung des Isokolon beiseite, läßt sich gerade an diesem Satz die trennende Funktion der Konjunktion aufzeigen:

$$
\begin{aligned}
& \text { "jaciro - udariv Zustuneja po persem, I razrazi emu persin } \\
& \text { " }
\end{aligned}
$$

Der kommentierende Charakter, die untergeordnete Punktion des Part.-Syntagmas kommt in der Pügung ohne Konjunktion viel klarer zum Ausdruck als in derjenigen Mit Konjunktion, wo die das Hauptereignis einleitenden Vorgänge elgenständiger wirken. 


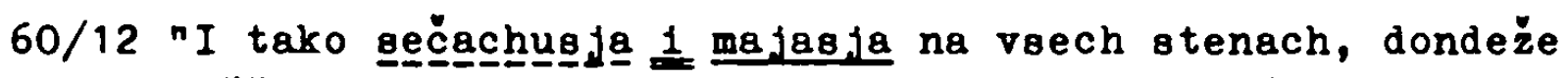
noščnaja tbma 1ch razdel1: turk1 ubo otydo atany 1 mertvyja pozabyvóe, a gradckie ljudie padoša jako mertvy, ..."

'So fochten ole und qualten sich auf allen Mauern, bis die Dunkelheit sie trennte: die Turken aber zogen sich in ihre Lager zurück und lieBen ihre Toten liegen; und die Griechen stürzten vor Erschöpfung (zu Boden) - wie tot, ...'

Die angebotene Ubersetzung 'fochten und quälten sich' versucht, der Konstruktion des Textes gerecht zu werden, die durch "1" zwischen Verb.fin. und Part.praes. markiert 18t. Ohne die Konjunktion wäre - sicher eleganter - zu interpretieren 'fochten wankend'. Das Verb.fin. gibt die im Vordergrund stehende Handlung, während das Part. elnen Begleltumstand bezelchnet. Ob gewollt gesetzt oder nur zufällig dorthin geraten, 90 jedenfalls lobt die Konjunktion sofort das Part. aus der semantischen Einengung des Verb.fin.: "sečachuo ja majasjan - 'kämpften wankend': Das Part. in der Funktion eines Adv.-Part.s, die Konjunktion 1soliert es vom Verb.fin., schiebt es stärker hin zum Subjekt - gibt ihm etwas von der "energičnosti", von der Istrina gelegentlich im Zusammenhang mit 1solierten (eigenständigen) Part.-Syntagmen opricht. 91 Der Charakter der Nebenhandlung blelbt dennoch erhalten, ja stärker noch: der Charakter elner Begleiterschelnung, die durch die Konjunktion aber stärker ins Blickfeld gerückt lot. Daher ist auch die zeitliche Komponente engstens an die zeitlichkeit des Verb.fin. gebunden - dieser entsprechend.

Im zweiten Satz finden wir nachgestelltes Part.praet. Die wichtigste Information ist zweifellos die des Rúckzugs der Turken. Ahnlich wie "majasja" beschreibt das Syntagma um "pozabyvie" die Art und We1se, wie sich die Haupthandlung vollzog - dort fochten sie wankend, hier zogen $81 \mathrm{ch}$ die Turken surlick - entweder so schnell oder 1hrerse1ts so erschöpt, dab sie ihre Toten liegenlieben.

90) Postpositives Part. erscheint uberaus selten durch Konjunkt. vom Verb.fin. getrennt - Potebnfa, a.a.0., S. 194; Istr1-

91) I8trina, Sint. Javienija, S. 82 . 
Tenn die Prädikation des Part.-Syntagmas untergeordnet, zweitrangig lst ("vtorostepennoe skazuemoe" oder "deepricastie"), dann bezeichnet die durch Part.praet. ausgedrickte Handlung einen Vorgang, der zur Haupthandlung (Verb.fin.) im Verhältnis der Vorzeitigkeit steht:

'Sie zogen sich zurück, nachdem sie ihre Toten vergessen hatten'.

Man kann zwar argumentieren, daB sie erst die Toten vergessen haben muissen, wenn sie ohne diese fliehen, aber diese Interpretation trifft, so scheint es mir, nicht den Kern der Textstelle. - Wir haben es bel "zabyt1/po-" - 'vergessen' mit einem Momentanverb zu tun. Das 1 - und das us-Part. von Verben punktueller Aktionsart drücken jenen Zustand aus, der aus der punktuellen Handlung resultiert (s.0., S. 567, Anm. 78). Insofern haben wir es bel "pozabyvse" nicht in erster linie mit einer vorzeltigen Handlung zu tun, sondern mit einem die Haupthandlung begleitenden Zustand. Wir würden also übersetzen:

'Sie zogen sich zurück, ihrer Toten nicht mehr gedenkend.' Diese Interpretation käme wiederum folgender (alt-)russ. Konstruktion sehr nahe:

"turkı ubo otydoša $v$ svol stany

i mertvyja pozabyvaja, ..."

Die Konjunktion löst in diesem Textbeispiel das Part. keineswegs aus dem Einflußbereich des Verb.fin, der begleitend-kommentierende (= adverbiale) Charakter bleibt erhalten, immerhin erfolgt durch die Konjunktion doch eine gewisse Verstärkung der partiziplalen Aussage - die Trennung des Part.s durch die Konjunktion vom Verb.fin. bewirkt, daß das Part. einen Teil seiner alten "ênergičnost'n behält. 92

Im Part.-Syntagma einen autonomen Part.-Satz zu sehen, verbietet der begleitend-kommentierende (= adverbiale) Charakter der partizipialen Aussage (s.o.).

92) Potebnja bemerkt zu der Konstruktion mit koordinierender Konjunktion, daB letztere die Beziehung zwischen Verb.fin. und Part. nicht grundsätzlich verändere: "Prisutstvie soju$z a$ delaet 11s' bolee javstrennym syojstra oborota, suscestvovavsee $i$ bez sojuza, imenno to, ćto $v$ predlozenil dva pocti ravnosilbnye centra; ..." - Iz zapisok, s. 190. 
59/36 "Egda že turki načajachu - uže vaich ljudi1 a sten điša, abie vakryčavŏ vse voinstvo 1 napadoša na grad vkupe so vsech stran, kličjušče 1 voptjušče, ..."

'Als die Tüken glaubten, sie hätten bereits alle Griechen von den Mauern vertrieben, da erhob inr ganzes Heer ein großes Geschrel und griff $\mathrm{K}$-pel von allen Seiten an (brullend und schreiend) ...'

2weifellos hat das Part. in diesem Satz stärkere Aussagekraft als das sonstige, beinahe formelhafte "v(o)skryčav(šen, das wir im Zusammenhang mit türkischen Aktionen so oft antreffen. Das wird besonders deutlich dadurch, daB dem Verb.fin. exakt die gleiche Aussage nachgestellt wird ("kličjušče 1 vopijušče" haben hier die Funktion von Adv.-Part.1en). Während im Belspiel 70/13 (s.0., S. 573) "zaigrav" als Part.praet. eines Inchoat 1 vums mit dem Anfangspunkt, dem Einsetzen des Spiels der Instrumente auch das Weiterspielen in die Aussage einbezleht (ähnlich dem Momentanverb, dessen Part.praet. den aus der Ursachehandlung resultierenden Zustand bezeichnet), ist hier offenbar allein der Anfang des Geschreis gemelnt: 'brachen in Geschrel aus; schrien 208', denn die Fortsetzung des Geheuls wird ja durch die nachgestellten Part.praes.-Formen gesondert ausgedruckt. Zudem befindet sich das subjekt des Satzes im Part.-Syntagma, durch die Konjunktion vom Verb.fin. getrennt - jener Position, der Ruzicka (auch ohne trennende Konjunktion) die stärkste partizipiale Prädikation einräumt.93 Den Kommentar Ruzickas zu seinem Beleg $491^{94}$ können wir daher auch auf obiges Beispiel übertragen:

"Das Partizip erreicht hier einen Grad von Selbatändigke1t, der fast zur Verwischung der Grenze zwischen diesem und der finiten Form führt."

93) Ruzicka, Das syntakt1sche System, S. $26-30$.

$94)$ ebd., S. 112. 


\subsubsection{Pleskauer Text}

In der K-pler Erzählung gibt es 16 Textstellen, wo eine partizipiale und eine finite Form, die in einer gewissen logischen Beziehung zueinander stehen, durch die Konjunktion "i" voneinander getrennt sind. 66 solcher Konstruktionen finden sich im Pleskauer Text, wobel die Vielfalt der Konjunktionen (bzw. als solche zu wertender Wendungen) auffällt: $33 \mathrm{Mal} \mathrm{"1n} ; 10 \mathrm{Mal}$

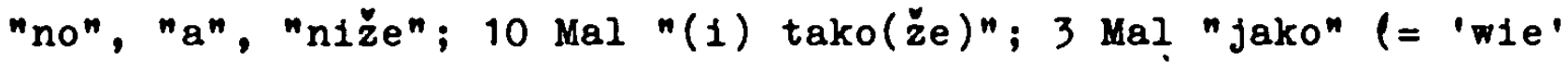
bel ausgedehnten Vergleichen).

48/17 "Gosudarev že ... voevoda knjazb Ivan Petrovič Šjujkoj, vo Pskov priechav, paki z bojarinom 1 s voevodami ... o ukreplenil grada vsjako dščnie pokkazovağe 1 neprestanno okolo grado obßežžaja, 1 povelevaše utveržati vsjakimi krepostbmi steny grada."

' Nach Pleskau zurückgekehrt, machte sich Fürst Sujskij - zusammen mit den ubrigen Bojaren und Voevoden ... mit größtem Eifer an die Vorbereitungen zur Verteidigung Pleskaus. Unablässig ritt er um die stadt herum und gab unermüdich Anweisungen, die Stadtmauern auf jede Weise zu befestigen.'

"vo Pskov priechav" ist eine fast ebenso formelhafte Wendung wie solche mit "slyšav/se" oder "videv/se" in adverbialer Funktion. Pür uns von Interesse 1st die Reihe "pokazovase 1 obъežžaja 1 povelevašen. Das Part. muß wohl auf "povelevašen bezogen werden, während die allgemeine, ubergeordnete Aussage sicher "vsjako dščanie pokazovaše" darstellt, denn "obъežžaja 1 povelevaše" können als Detalllierung, als Interpretation von "pokazovaše" aufgefaBt werden. Von den detaillierenden Aussagen 1st "povelevaše" die bedeutendere, während das Part. praes. erläutert, auf welche Weise Plirst Sujskif unablässig seine Anweisungen gibt: 'ständig um die Stadt herum reitend'. Wie das Part. die durch Verb.fin. ausgedruckte Handlung näher beschreibt, kommentiert, so ist die partizipiale Handlung auch zeitlich eng an diejenige, die durch Verb.fin bezeichnet wird, gebunden - sie läuft derselben parallel, ist ihr gleichzeitig.

Die Konjunktion setzt also auch hier das Part. vom Verb.fin. $a b$, kann ihr aber keine volle Eigenständigkeit verleihen. 
90/25 "Gosudarery že bojare 1 roevody, tako že 1 vee christoIjubivoe ruskoe vo1nstro 1 so veemi prebyvajuéčinl vo Pokove narody o sem slychavé, 1 blagodarno 1 radostno chvalu o sem bogu rogdağa, nadejače že sja, jako vakore 1 korolju so veem rojekom otyt1."

- Die Bojaren und Voevoden des Herrachers, auch das ganzo christliche Heer, mit linnen alle Jene, die alch nach Pleakau gefluchtet hatten, horten hiervon ( = das die Iltauer ihre Angriffepositionen aufgegeben, d.h. die ramplose, passive Belagerung begonnen hatten), und m1t dankbarem und freudigen Herzen priesen sle Gott dafur, hofften ole doch, daB der Konig in Kurze mit seinem ganzen Heer abziehen werde.'

Wir haben dies Textbelopiel, insbesondere das Part.-Syntagma, in seiner ganzen Llange vorgestellt, um zu zelgen, das die Konjunktion ewlochen dem sonet formelhaften "olysev/son" und dem Verb.fin. ("vozdasa") an dieser stelle sicher nicht zufal118 steht. Sonst lesen wir etwa:

$43 / 23$ "Gosudarb že se slyěav, velbml vozdochnuv 12 glub1ny Berdca: '..., re $\underline{e} \underline{g}, \ldots$, .."

'Ala der Herrocher dies vernommen hatte, seufzte er ... und eprach: ...'

"elyžav" 1at formelhaft an die nuchotfolgende (verbale) Porm, hier oin Part. "vozdochnur", angebunden und hat adverbiale Funtion. Im obigen Textbsiopiel gewinnt "slyšavén jodoch durch das vielgliedrige subjekt besonders atarkes Elgengew1cht. Ee kommt hinzu, das jene Handlung, die das Part. aus188t - "rozdaža chvalu" -, auggedruckt durch Verb.fin., nicht wie melot dem formelhaften "vidav/öen, "slyšav/b̌en mehr oder woniger direkt folgt, sondern an das Ende des Polgesatzes ruckt. W1r wollen nicht behaupten, daB das Part.-Syntagma hier nun zu einem autonomen Syntagma mit partieipialem Pradikat geworden se1. Be ging uns hier nur darum aufuzeigen, wie die Konjunktion zmischen Part. und Verb.fin. in Verbindung mit breiterer Ausgestaltung des Part.-Syntagmas letzteron einen groBen Zugewinn an E1genstandigke1t, an elgener pridikaler Iraft bringen kann. Dazu schien mir das oonst blab-formelhafte "slyšav/B̈en" besonders geelgnet. 
75/16 n..., vkupe že s simi sluchi bogorodicy milostbju osenenie $i$ pomošç na vse pravoslavnoe chrestbjanstro pri1de, 1 nemoščnych serdce adamanta kreplee uttrer $\underline{1}$ vo1 vkupe na podvig vooruživšesja.."

'..., zugleich mit dieser Kunde wurde der rechtgläubigen Christenhe1t (= Pleskauer) Schutz und Hilfe der Gottesmutter zuteil: die Herzen der Ermatteten wurden fester als Diamant, und alle rlisteten sich zur Tat.' oder auch:

... wurde Schutz und Hilfe zuteil, so daB die Herzen ... fester ... wurden und sich alle ... rüsteten.'

Beide Interpretationsvarianten verdeutlichen, daB wir hier zwel absolut gleichgeordnete, gedanklich gleichbedeutende Aussagen vor uns haben. Wenn formal auch nicht ausgedrückt, so sind beide Vorgänge Folgen jenes geistigen Belstandes, der den Pleskauern durch die Güte der Gottesmutter zuteil wurde. Das unterstreicht die Tatsache, daß die Vorgänge als gleichgeordnet zu denken sind.

Genauso, wie die belden in Frage stehenden Handlungen gedanklich für sich stehen, genauso haben sie auch ihre eigene zeitliche Dimension; eine Abhängigkeit, insbesondere des Part.s vom Verb.fin., in dieser (und anderer) Hinsicht ist nicht zu erkennen. Wir dürfen also in diesem Beleg völlige Elgenständigkeit des Part.-Syntagmas konstatieren. Das part.praet. steht an dieser Stelle für einen Aorist, entsprechend "utverdišsja", dem das Part. logisch und syntaktisch gleichgeordnet lst und dem es in aspektueller und aktionsartlicher Hinsicht entspricht.

67/14 "Togo rad1, litovskie mnogie ljudi na steny grada Psko-

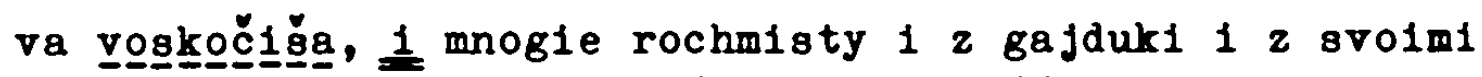
znameny $v \ldots$ bašnju vlezše, 1 1z-za ščltov svolch 1 iz okon $v$ gorod ... streljajusče."

- Daher stúrmten viele Iitauer auf die Mauern Pleskaus, viele Rottmeister und Heiducken drangen mit inren Peldzeichen in die... Bastei(en) und schossen hinter inren Schilden hervor und aus den Schiebscharten in die Stadt.'

Die drei genannten Handlungen zerfallen in zwei Bereiche: "voskočiša na steny" und "vlezše na bas̆nju" sind Teilaspekte des Komplexes 'Sturmangriff auf Pleskau'; "streljajušce $\checkmark$ gOrod" ist eine Handlung, die von beiden Personengruppen, die 
also Mauern einerseits und Basteien andererseits gestürmt haben, getragen wird - 'nach der Eroberung von Mauer und Turmen eröffnen sie das Feuer'.

"voskočiba" und "vlezb̆e" sind also in jeder Hinsicht gleichgeordnete Handlungen. Eine zeitliche Abhängigkeit des Part.s vom Verb.fin besteht nicht. Zwar verlaufen beide Geschehen zu gleicher Zeit, doch separat - wie im vorigen Beleg ist die Part.Konstruktion vollkommen unabhängig; auch hier vertritt das Part.praet. - entsprechend "voskočiš" - einen 1orist.

Genauso eigenständig lot die folgende partizipial ausgedruckte und durch Konjunktion von den zuvor genannten Handlungen getrennte Aussage "v gorod streljajuščn. Sle hat mit jenen nur soviel zu tun, das jene zwei Personengruppen sie durchfuhren, nachdem Mauer und Basteien erobert sind. Das Part.praes. "streljajušcen sagt also nichts uber zeitliche Verhältnisse aus; daß die Beschießung nach der Eroberung erfolgt, ergibt sich lediglich aus der (chronologischen) Wiedergabe der Handlungen - erst die Eroberung (Aor. und Part.praet nennen zwei unabhängige, aber gleichzeitig verlaufende Handlungen), dann die Beschiebung (Part.praes. nennt eine unabhängige, nach den vorigen Vorgängen erfolgende Handlung). Die Form des Part.8 (Part.praes.) sagt nur etwas daruber, wie der Autor das Geschehen sieht oder gesehen haben will - aus der situation heraus, aktuell, eine Begrenzung des Geschehens wird nicht ins Auge gefabt - damit entspricht dieses autonome Part.praes. einem Imperfekt (oder Praes.hist.).

Wir konnten an den vorgefuhrten Textstellen beobachten, daB in der Pleskauer Erzählung die Konjunktion "in zwischen einem partizipialen und einem verbalen Syntagma - genau wie im K-pler Text - die Punktion haben kann, zwei fast gleichwertige (8.0., S. 576, Anm. 92 - die Bemerkung Potebnjas) prädikative Zentren zu verbinden, oder besser gesagt: wie die Konjunktion das Part. vom Verb.fin. absetzen und ihm einen Teil seiner prädikativen Kraft erhalten kann. Wir haben aber auch gesehen, wie "in zwei vollkommen gleichgewichtige, logisch und syntaktisch koordinierte Aussagen verbinden kann, deren eine durch Verb.fin., deren andere durch Part. bezeichnet ist. 
Einige Textbeispiele für andere Konjunktionen als "i" zwischen Verb.fin. und Part. wollen wir noch, knapp kommentiert, vorstellen. Bei diesen dominiert jene Variante, die wir im Zusammenhang mit der Konjunktion " 1 " vorgestellt haben - jene, wo die Konjunktion absolut gleichwertige Aussagen - eine verbal, die andere partizipial - miteinander verbindet.

$38 / 24$ "Slyšav že sle .... jako ot rosijskago gosudarja ni kaja že tverdostb ustólaț možet, a prichodjaščil k nemu, gosudarju, 2 darmi 1 s čestiju velikoju oslabu priemljusče, sobravše že aja načalbnicy strany toja, kurlanskich nemec, sovet sotvorse."

'Als sie (die Deutschen in Kurland) erfahren hatten, daB dem russischen Herrscher keine Festung trotzen kann und dab diejenigen, die sich dem Zaren mit Geschenken und grober Ehrerbietung unterwerfen, Vergebung erfahren - da versammelten sich die fürenden Persönlichkeiten Kurlands und hielten Rat.'

Diese Fügung wird von partizipialen Formen bestimmt. Für uns ist wichtig, was die kurländischen Ritter erfahren haben (sollen): dem Zaren widersteht keine Pestung; und: alle, die sich unterwerfen, werden begnadigt. Es handelt sich um zwei vollkommen unabhängige Informationen, die nichts miteinander zu tun haben. Das Syntagma um "priemljuščen ist dem um "ustojat1 možet" in jeder Hinsicht gleichgeordnet. Das Part.praes. entspricht in seiner Allgemeingultigkeit dem Praes. der anderen Information, ersetzt hier also auch eine Praes.-Form.

$47 / 33$ "Rabski že protiva svoego gosudarja, protivo slovesi sija nikako že vešçat smeja, niže za mogonaloženoe ot nego toliko bremja ni edinogo slovo otrícatis no tokmo gosudarju otvešca: '..."n

' In seiner Demut dem Herracher gegenüber wagte er nicht, sich gegen dessen Worte auszusprechen, und er wehrte sich auch mit keinem Wort gegen die hohe Verantwortung, die thm auferlegt wurde, sondern er antwortete dem Herrscher nur: ...'

Die Aussagen des partizipialen ("nikako veăčati smeja") und des verbalen ("ni otricatisja naça") syntagmas sind fast synonym, durch "niže" koordiniert; sie stehen in Antithese zu "no tokmo otveščan: Fürst Sujakij - um ihn handelt es sich hier - 
lehnt den heiklen Auftrag (= Verantwortung zu tragen für die Verteldigung Pleskaus) nicht $a b$, sondern nimmt thn demulis an. - Belde Aussagen sagen das glelche aus; die gesamte Satzfolge hat resultativ-referierenden Charakter, was an den zwe1 Aor.-Formen deutlich wird. Entsprechend ersetzt hier dies Part.praes. einen Aorist. Da diese Beobachtung gar nicht zu unseren bisherigen Festatellungen paßt, sel darauf hingewlesen, daß "smèt1" ein Durativum 1at, von dem der Pleskauer Autor keinen Aor. ("gmě") zu bilden pflegt. Das glelche gilt - s.u., S.622f- In sogar noch starkerem MaBe für das Part. praet., das bis auf die Formeln "slysav/šen und "videv/sen" fast ausnahmslos von heute perf. Verben gebildet wird. Es sleht also so aus, als könne das Part.praes. In besonders gelagerten Fällen auch elnen Aor. ersetzen: die heute bekannte Perfektiv-Bildung "posmet'", von der man hätte ein Part.praet. bilden können, eracheint bel Srezn. (II, 1249) noch nicht.

Schlieblich müssen wir noch einen Konstruktions-Typ, der in der Pleskauer Erzählung vorkommt, im $B$-pler Text aber fehlt, vorotellen: Uns begegnon elf hypotaktiach gefugte Satzpare, innorhalb welcher das Verhältnis Hauptsatz - Nebensatz durch eine subordinferende Konjunktion verdeutlicht 1st. Daruber hinaus hat der Hebensatz ein partizipiales Prödikat. 95 Die partizipiale Ausgage lat so naturlich besonders deutlich als untergeordnet gekennzeichnet, die direkte Bindung an das Verb. fin. Wird auf diese Welse aber noch stärker gestört, ja unterbrochen, ale dies durch die koordinierende Konjunktion geschah. Mir scheint, daB es sich bel solchen Pügungen um Ubergangserschelnungen handelt: Turde Hypotaxe se1t den Anfängen des slavischen Schrifttumg vorwlegend durch Part.Syntagma auggedrückt, so löste die Kennzelchnung der Hypotaxe durch subordinierende Konjunktion allmählich die ältere Konotruktionoweise ab.

\footnotetext{
95) Vgl. Istrina, Sint.javlenija, S. 87 - zwe1 Belege mit partizipialem Nebensatz, eingeleitet durch "kden, sorie ein partizipialer Relativatz.
} 
$75 / 5$ "..., egda pribežavǧe k prolomnomu mestu, ideže krovopolitnoe toržestro obolch stran soveršašesja, velikimi glasy ... reksoša: ' ...'n

'Als sie an die Breschenstelle geellt waren, wo sich zwischen beiden Seiten Triumphe des BlutvergieBens vollzogen, da riefen sie mit mächtiger Stimme: ...'

Der Temporalsatz nennt elnen Vorgang, der der Haupthandlung "rekoša" vorauggegangen 1st. Das Part.praet. ersetzt hier einen Aorist. 96 Dies Beispiel demonstriert den Ubergangs-Charakter dieser elgenartigen Konstruktionsweise besonders deutlich, weil wir uber den ganzen Text verstreut und auch innerhalb dieser Untersuchung 97 immer wieder auf gleichbedeutende partizipiale Wendungen ohne subordinferende Konjunktion stoBen, z.B. 44/24 "voevody v ... Pskov priechav", 59/11 "(det1 bojarskie) vo Pskov pribežavšen, 60/8 "oni že, ch korolju priechav" usw.

62/2 "Vysypnyja že tyja zemli mnogle 1 bezčisleny okna provertêğa, $1 z$ nich že streljat1 ugotovivšesja, dl ja gradoemstra i dl ja vylazok na nich 1 z grada." 'In die aufgeworfene Erde bohrten gie unzählige SchleBscharten, aus denen sie schieBen wollten (während eigener Angriffe und bei Ausfällen der Pleskauer).'

Relativaätze mit partizipialem Prädikat kommen noch häufiger ${ }^{98}$ vor als Temporalsätze mit "egda + Part.". Wegen der raffenden Darstellungsweise in diesem Abschnitt ist damit zu rechnen, dab dies Part.praet. einen Aorist ersetzt.

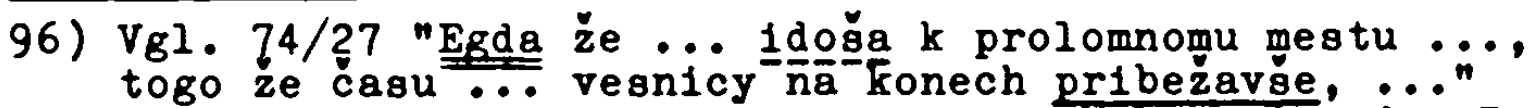
Hier befindet gich das Verb.fin. im Rebensatz, das Part. im Hauptsatz: 'Als sie zur Bresche gezogen waren - zu der Stunde kamen Boten $z u$ Pferde angesprengt'. Weiteres zu dieser Erscheinung - s.u., s. 600 .

97) Z.B. s.0., S. 578, Beleg 48/17.

98) Relativsatz mit partiziplalem Prädikat ist keineswegs selten - die von uns herangezogenen Arbeiten behandeln diese Erscheinung bzw. erwähnen sie: Potebnja, Iz zapisok, S. 212, Istrina. Sint.javlenija, s. 87 (ein Beleg), Ruzicke, Das synt.System, S. $197-200$; viele Beispiele für Part. als Prádikat konjunktionaler Nebensätze bel likiforov, Glagol, S. 244 ff. 
Die Pleskauer Erzählung enthält also nicht nur ein quantitativ viel breiteres Material (den 16 Belegen im K-pler Text mit "i" zwischen Part. und Verb.fin. stehen 66 Belege mit koordinierenden und 11 Belege mit subordinierenden Konjunktionen in der Pleskauer Erzählung gegenuber), sondern die entsprechenden Textstellen in der Pleskauer Erzählung sind von einer ganz anderen Qualität als die des Vergleichstextes: Trifft auf die Belege des letzteren in jedem Pall die Charakterisierung Potebnjas zu, dab die zwischen Part. und Verb.fin. gestellte (koordinierende) Konjunktion dem Part. mehr E1genständigkeit gebe, daß aber dennoch die volle Autonomie nie erreicht werde, 99 so stimmt gerade das letztere im Hinblick auf die Pleskauer Erzählung nicht mehr: Viele, wenn nicht gar die melsten Fügungen 'Part. - koord. Konjunktion - Verb. fin.' (bzw. umgekehrt mit nachgestelltem Part.) verbinden zwei in jeder Hingicht gleichgeordnete, gleichgewichtige Aussagen.

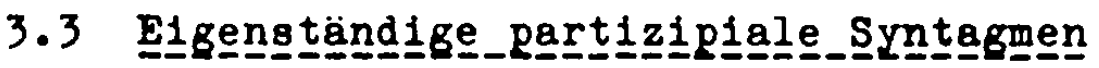

Beisplele, die wir in diesem Abschnitt vorstellen wollen, unterscheiden sich von denjenigen, die bisher behandelt worden waren, dadurch, dab sie mit keinem Verb.fin. mehr Kontakt haben. Uns waren ja bereits Textstellen begegnet, wo scheinbar 2wischen einem Verb.fin. und einem Part. eine innere Bezlehung bestand, weil die entsprechenden Syntagmen in direktem Kontakt zueinander standen, wo aber tatsächlich die beiden Syntagmen keine logischen Beziehungen - über die des gemeinsamen Kontextes hinaus - zueinander hatten, die man hätte als Einordnung im Sinne einer unter- bzw. ubergeordneten Handlung werten können. Im folgenden wollen wir Textstellen vorfuhren, wo Part.ien kein Verb.fin. neben sich haben, also schon von daher keinem Verb.fin. untergeordnet sein können. In ganz wenigen Fällen haben wir auch Part.ien hierher ge-

99) Nochmals: Potebnja, Iz zapisok, S. 190: "počti ravnosil'nye centra ${ }^{\hbar}$ - Hervorhebg. - Potebnja. 8. Anm. 92. 
stellt, die trotz ihres unmittelbaren Kontaktes mit einem Syntagma, das ein Verb.fin. als Prädikat enthält, vollkommen selbständig sind - in der Regel haben wir aber auf subjektive Interpretation verzichtet und uns auf die Gegebenheiten des Textes allein gestützt. Besser als weitere Erklärungen werden hoffentlich die Beispiele selbst unseren Auswahlmodus demonstrieren.

Die Existenz wirklich selbständiger partizipialer Konstruktionen in der älteren altruss. Literatur ${ }^{100}$ wird im allgemeinen geleugnet; Istrina, die einige Beispiele anführt, die an der absoluten Selbständigkeit des Part.-Syntagmas überhaupt keinen $\mathrm{Zweifel} \mathrm{lassen,} \mathrm{stuft} \mathrm{diese} \mathrm{als} \mathrm{Ausnahmen} \mathrm{ein.}{ }^{101}$ Und Ruzicka bemerkt zum'Partizip als selbständiges Prädikat (absolut prädikativ)': "Aus unserem Material der Evangelientexte sind Beispiele kaum herbeizubringen. Auch sonst sind sie selten: ...n102 Für das 16. Jh. sind aber selbständige Part.Konstruktionen reichlich belegt, wenngleich uns nirgends eine Vorstellung vermittelt wird, in welchem MaBe sich diese Erscheinung ausgebreitet hatte. Boretzky spricht von sechs "Präteritumspartizipien als Prädikaten 103 und erwähnt "unter den 343 Formen auf -šče etwa 30 mit prädikativischem Gebrauch." 104 Otten erwähnt - wie melst ohne präzise statistische Angaben diese Erscheinung ebenfalls, die er allerdings teilweise als graphische Verwechslungen wertet. ${ }^{105}$.

Bevor wir uns den Texten zuwenden, wollen wir festhalten, daB Häufungen partizipialer Syntagmen, die rhetorisch (meist in Form eines Isokolon) an ein Verb.fin. angeschlossen werden, in die statistik und die Erörterungen nicht einbezogen sind, vgl.

100) "drevnerusskij jaz." - 'gemeinostslavisch' "staror. jaz." - 'altruss.' (ab 2. Hälfte 14. Jh.) als Abgrenzung gegen "staroukrainskif jaz." und "starobeloruss. jaz.".

101) Istrina, Sint.javlenija, s. $90 \mathrm{ff}$.

102) Ruzicka, Das synt. System, S. 226.

103) Boretzky, Tempusgebrauch, S. 138.

104) ebd., S. 132.

105) Otten, Die fin.Verbalformen, s. $227 \mathrm{f}$ : Korrelation von Ipf. 3.8g. -se und Part.praes. -sce, "die einander graphisch und zum Teil auch semantisch sehr nahe kamen." $\mathrm{Zu} \mathrm{Aor.} \mathrm{-} \mathrm{Part.praet.} \mathrm{8.} \mathrm{S.} 269$ f. - N1kiforov, Glagol, 
Vgl. 2.B. KP $75 / 27$ nO gore tobe, sedmocholmi1, jako poganil toboju obladajut,

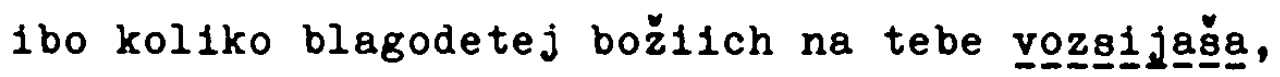

ovogda proslavljaja 1 veličaja ....

ovogda ... nakaza ja 1 nastavljaja ....

ovogda ... proslavl jaja, ..."

' Wehe dir, Siebenhügelige,

da dich die Heiden beherrschen -

denn wieviel der. göttlichen Gnade hatte über dir geleuchtet, wodurch du manchmal gerühmt und erhöht wurdest, wodurch du manchmal bestraft und belehrt wurdest, wodurch du manchmal (abermals) gerühmt wurdest...'

Die Part.-Syntagmen hängen alle in glelcher Welse von "vozsijaša" ab und erläutern, was mit diesem abstrakten Ausdruck gemeint ist. - $V_{g}$. auch KP 68/42 und KP 69/5 - solche zwar umfangreichen, vielgliedrigen Häufungen partizipialer Syntagmen haben wir nicht in die folgenden Betrachtungen einbezogen, weil sie auf Grund ihrer klaren Gliederung stets jenes Verb. fin. erkennen lassen, dem sie zu- und untergeordnet sind.

\subsubsection{K-pler Text}

In der K-pler Erzählung sind eigenständge partizipiale Syntagmen mit absoluter Prädikation selten. Wir zählten nur acht (nicht einmal immer überzeugende Belegstellen.

Bevor wir uns diesen zuwenden, wollen wir kurz auf das Grundschema des Satzes bzw. des Satzgefüges im K-pler Text eingehen. Man kann folgende Pormel aufstellen:

$$
\text { (Part.praet.) - Verb.fin. - (Part.praes.). }
$$

Diese Reihenfolge ist in einem solchen Maße schematisiert, dab nicht immer die Handlung, die durch eine finite Verbform bezeichnet ist, die Haupthandlung darstellt. Gelegentlich 1st ein partizipial ausgedruckter Vorgang wichtiger als das durch Verb.fin. wiedergegebene Geschehen. Es kennzeichnet den St1l des K-pler Autors, daB jegliche Handlungskette, alles Gesche-

S. 149 ff. und S. 264 ff.: Ipf:-Part.praes.; S. 154: Aor.Part.praet.; 8. auch Barnet, Vývoj, S. $98 \mathrm{f}$. 
hen, auch Reflexionen und Reden hypotaktisch gefabt werden in der Weise, daB das zu Beschreibende anscheinend oft schematisch in obige Porm gebracht wird - die zuerst zu nennde Handlung erhält die Porm des Part.praetm die nächste erscheint als Verb.fin., die nächste schließlich als Part.praes. Doppelungen eines der genannten Glieder sind möglich, häufig natürlich auch Auslassungen einer Stufe. Oft hat es auch den Anschein, daB der K-pler Autor - gewissermaBen, um dem Satz das rechte Gewicht zu geben, oder einem bestimmten rhythmischen Empfinden folgend - dem Verb.fin ein Part.praet. (mit kurzer oder längerer Ergänzung) voranstellt, das von der Ausgage her überflussig 1st. Vgl.:

60/22 "Cesarb že, vzemb bol jar, poide po stenam grada, chotjašče videti ratnych, ..."

- Der Kaiser ging, nachdem er die Bojaren um gich geschart hatte, zur Stadtumallung, weil er die Streiter aufsuchen wollte, ...'

Das Part.praet. hat im Grunde keinen Informationswert - "Cesarb s boljary polde/poidoša ..." sagt genau das Gleiche aus. Aber diese Pormel "vzemb boljar/cesarja / stratig ..." begegnet immer wieder vor Verben der Bewegung anstelle einer Aufzählung mit "s + Instr." oder einfach mit "in - vgl.

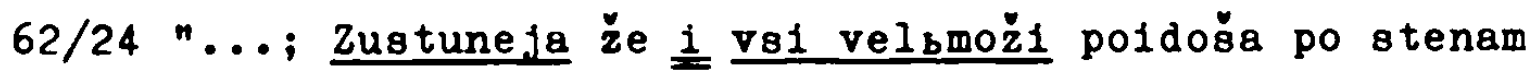
grada, smotrjašče sten ..."

'...; Giustiniani und die würdenträger gingen .... um zu inspizieren ...'

Andererseits erscheinen Aussagen in Porm eines Part.s, die von ihrer Bedeutung her absolute Prädikation verdienten, z.B.: 64/23 "Takože 1 toj zlovernyj Magumet mnogo dnij sovetovavše,

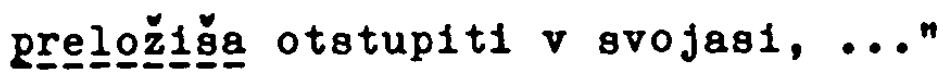

'So beriet auch der 1rrgläubige Mehmed mehrere Tage (mit seinen Würdenträgern), und sie beschlossen, (die Belagerung aufzugeben und) heimwärts zu ziehen, ...'

In den meisten Pällen läBt sich aber doch beobachten, wie der K-pler Autor komplexe Vorgänge durch seine Wahl der Porm Verb.fin. oder Part. - gliedert, ordnet bzw. den Eindruck eines bestimmten Wertungssystems vermittelt, das dem Leser durch eben jene Formen angeboten wird, z.B.: 


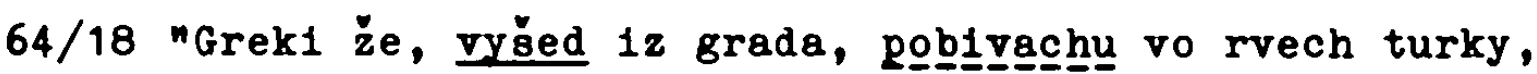
ko1 ešče živi bjachu, 1 ,

sobravše $1 \mathrm{ch} v$ mnogye kuč1, eožígachut $1 \mathrm{ch}$ vkupe so ostavíiml turami."

- Die Griechen verlieBen die Stadt/traten heraus und töteten die Turken in den Gräben, die nogh am Leben waren. Sie trugen sie zu vielen Haufen 106 zusammen und verbrannten diese mit den zurückgebliebenen Rammböcken.'

Sehr feinsinnig sind Haupt- und Nebenhandlungen voneinander abgesetzt. - Im folgenden Belopiel muB man dem Autor einfach folgen, seine Wertung akzeptieren:

63/32 "I, pad, pokklonîg ja 1m, plačušče gorbko."

- Und er fiel nieder, verneigte sich vor ihnen und weinte bitterlich.'

Entweder war fur den Autor die Tatsache, daß sich der Kaiser, von dem hier die Rede ist, vor seinen würdenträgern verneigt, die allerwichtigste Mittellung - oder wir haben es hier mit schematischer Aufgliederung einer Reihe von Informationen zu tun.

Das soeben vorgestellte Satzschema müssen wir uns vor Augen halten, wenn wir uns nun Konstruktionen, Satzgefugen zuwenden, die m.E. eigenständige Part.-Syntagma enthalten.

$70 / 3$ "I tako urjadiv skvernyj $\nabla 26$ denb maija, propovednikom ich otklikavse skvernuju svoju molitvu, able, voskryčav-

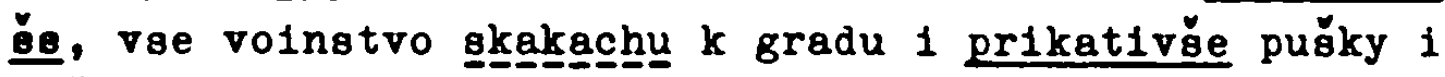
piščal1 1 ... 1..., im že ne be čisla, takože 1 po morju pridvinuvše korabli 1 katargy mogyja 1 načach b1t1 grad otvojudu ..."

' Und so hatte der Unreine zum 26. Ma1 alles vorbere1tet. Als die Muezzin $1 \mathrm{hr}$ widerwätiges Gebet ausgerufen hatten, sturmte das gesamte Heer mit dem gewohnten Geschrel gegen die Stadt. Auch schleppten sịe Geschütze und Peldschlangen und ... In unvorstellbarer Anzahl her- . be1 und zogen viele Schiffe und Galeeren zusammen, dann begannen sie, von allen Seiten die Stadt zu beschieBen.'

An der Selbotändigke1t des ersten Part.-Syntagmas "urjadiv"

106) "kuča" - 'Hütte, Zelt' (Srezn, I, 1384); vielleicht ist hier an zelt- (pyramiden-) förmige Haufen gedacht. 
kann es keinen 2weifel geben. Das folgende Part.praet. "otkl1kavšen 1st Tell eines falsch gebildeten Dat.abs. für korrektes: "propovednikom 1ch otklikavšim ..." ${ }^{107}$. Möglicherwelse lst die Datumsangabe noch in den Dat.abs. einzubeziehen, dies lat in der K-pler Erzählung sehr häufig zu beobachten. ${ }^{108}$ Der Dat.abs. lst eigentlich auf "vakryčavše" zu bezlehen - 'nachdem sie ihr Gebet beendet hatten, brachen sie in Geschrei aus', doch wird "v(o)akryčav/še" so formelhaft verwendet, daB man es - wie die Ubersetzung vorschlägt - am besten adverbial direkt dem Hauptverb "skakachu" zuordnet.

Mit "prikativše" beginnt ein neuer Komplex. Das Syntagma um "prikativše" 1st wegen der vielgliedrigen Aufzählung (1m ganzen sechs Glieder) sehr umfangreich, ihm ist belzuordnen das Syntagma um "pridvinuvse". Beide beziehen sich auf "načachun, sind diesem untergeordnet und stehen (wie auch die Part.praet.Formen des vorigen Komplexes) Im Verhältnis der Vorzeitigkeit zu diesem: hachdem Geschütze und ... herangeschleppt und Schiffe und ... zusammengezogen worden waren, begann die BeschleBung von allen Seiten (d.h. vom Land und von der Seeselte her).'

Immerhin 1st hervorzuheben, daB im zweiten Komplex die Part.ien durch "1" vom Verb.fin. "načachu bit1" abgesetzt sind und daher ein gewisses Elgengewicht haben - dennoch lst nicht zu verkennen, daB im Vergleich zur BeschleBung das In-Stellung-Bringen der Schiffe und Geschütze rein vorbereitenden Charakter hat und insofern die Form des Part.s für diese Handlungen durchaus berechtigt 1st. Ahnliches kann man vom ersten Komplex sagen: Der Dat.abs. ("otklikavén") gibt die zeltliche Einordnung - vermutlich: nach dem Morgengebet, "vskryčavše" eine begleftende Handlung, die durch ihren Anfangspunkt ausgedrickt 1st. Wirklich autonom 1st nur "urjadiv"; das Part.praet. vertritt hier einen Aorist, weil das Syntagma eine resultative Feststellung beinhaltet: 'Und so hatte ...' (Uberschriftfunktion).

107) An sich 1st richtig: -věem, -ščex, doch treffen wir in unseren Texten nur die pronominale Endung an: -vóm usw.

108) Von den 23 Datierungen im $K$-pler Text sind 9 mit Dat.abs. verbunden. 


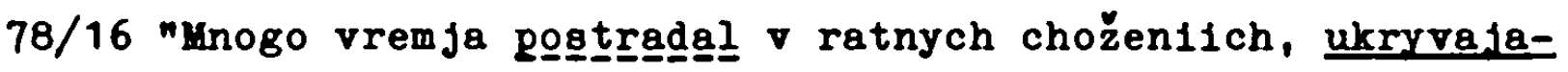
s ja semo 1 ovamo, da ne umru $v$ okajanoj sej vere. Tako 1 nyne $v$ sem velikom 1 strašnom dele uchitrjajasja ovogda bolezniju, ovogda skryvaniem, ovogda že soveščaniem prijatelej svoich. Ulovl faja vremja dozreniem 1 18pytaniem velikym, pisąach $v$ každyj denb tvorimaja dejanija tne grada ot turkov."

'Auf den langandauernden Kriegazugen habe ich viel erduldet und verbarg mich (während derselben) hier und da, um nicht in diesem verfluchten Glauben sterben zu müssen. So driuckte $1 \mathrm{ch}$ mich auch in diesem furchtbaren Treffen/Rampf listenreich um den Einsatz: 'mal durch Krankhe1t; 'mal, Indem $1 \mathrm{ch}$ mich versteckte; 'mal auch mit Hilfe der Ratschläge meiner Freunde. Well 1ch (so) immer zeit fand, zu beobachten und häufig die Menschen zu fragen, konnte ich alles, was auBerhalb der Mauern auf türkischer Seite geschah, niederschreiben.'

Auch bef dieser Textstelle lst die Satzstruktur nicht ohne weiteres erkennbar. "ukryvajasja" erläutert, detallliert "postradal". "ulovljaja" eteht in kausalem Verhaltnus zu "pisach": 'weil lch zeit fand, Leute zu fragen, konnte ich niederschre1ben'. ${ }^{109}$ Schwierigkeiten bereitet die Zuordnung von "uchitrjajasja". Zwar bezieht sich in gewisser Meise "ulovljajan auf das in Jenem Syntagma Gesagte (s. Ubersetzung: 'Te1l $1 \mathrm{ch}(\mathrm{so})$ immer leit fand ...'), aber es handelt sich nur um einen sehr vagen Bezug. "uchitrjajasja" m1t dem dazugehörigen Syntagma schliebt im Grunde genommen an "ukryvajasja" - 'verbarg mich" an: 'So dricke $1 \mathrm{ch} \mathrm{mich} /$ verberge mich listenreich auch jetzt'. "uchitrjajasja" ist dem vorherigen Part.praes. faktisch aynonym. Die Bezlehung $2 \pi 18 c h e n$ beiden lat aber rein semantischer Natur, bildet die Bricke 2 wischen $2 w e 1$ verschiedenen syntakt1schen Einheiten: "Tako 1 nyne ... uchitrjajaeja" stellt ein elgenständiges Syntagma dar - während "ukryvajasja" sich auf "postradal", auf ein Damals bezieht, bezeichnet "uchitrjaJasja" einen jetzigen zustand (bzw. meint die in der Erzablung geschilderten Ereignisee). Das Part.praes, steht hier fur eine Inperfokt-Form ("uch1trjach" - entsprechend "pisach"), die zu bilden dem Autor vielleicht schwer fiel, weil sie so starken Aor.-Charakter hat.

109) Vgl. N1kiforov, Glagol, S. 268. 
76/41 "Narodu že 1dušču do devjatyja godiny 1 ešče mnogym guščem $v$ cerkve ne dožda - $\underline{\text { izšed }}$ iz cerkve."

- Weil das Volk schon bis zur neunten Stunde aus der Xirche herausströmte und noch immer viele darin versammelt waren, da wartete er (der Sultan) nicht länger und verließ die Kirche.'

Die Dat.abs. stehen in kausalem Verhältnis zu "dožda". Das folgende Part.-Syntagma steht gleichsam in Antithese zu "ne doždan: 'er wartete nicht (länger), sondern verlieB die Kirche'. Diese Gegenuberstellung unterstreicht in besonderem Maße, daß "ne dožda" und "izšed" koordinierte Vorgänge sind und dab "izšed" keineswegs der durch eine fintte Verbform ausgedruckten Handlung untergeordnet anzusehen ist. Das Part.praet. vertritt an dieser Stelle - entsprechend "dožda" - einen Aorist.

65/23 "I jako uže uć̣̂ni ǧa mesto veliko, abie vakryčav množestro ljudil, vskočivše na to mesto, drug druga topčušče; ..."

'Und als sie eine große Bresche in die Mauer geschossen hatten, erhoben die Türken ein riesiges Geschrei; sie stürten (so wild) zu jener Stelle hin, daB sie sich gegenseitig stieBen/traten; ...'

Der Autor schildert hier hektisch ab- und durcheinanderlaufende Vorgänge. Die Part.ien könnten als Mittel zur erregenden, knappen Darstellung aufgefabt werden. M.E. handelt es sich hier aber um einen unbeabsichtigten Fehler des Autors (als Polge der beschriebenen aufregenden Handlung) oder um irgendeinen Abschreibfehler, denn sobald wir die mittlere Part.-Porm in einen Aorist umwandeln, haben wir die fur den $\mathrm{X}$-pler Autor typische Satzstruktur vor uns:

"I fako učiniša mesto veliko, abie voskryčav ..., vskočiša ..., ... topčušče."

Einen ähnlichen Pall stellt die folgende Textstelle dar, wo der Verdacht, daß dort Verschreibung vorliegen durfte, durch eine merkwürdige Porm - -vŏgaja - erhärtet wird, die im $\mathrm{X}$-pler Text beim Nominativ nie begegnet: 


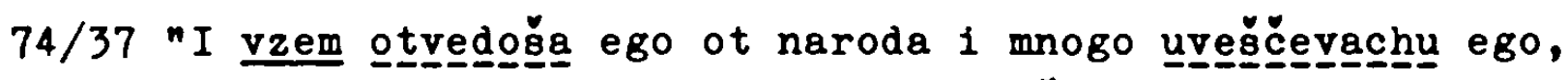
da izydet iz grada, 1 dav emu konečnoe celovanie, stonja i rydaja vozvrativesasja voi na urečennoe mesto." 'Sie (ergriffen ihn und) fuhrten ihn aus der Menge und versuchten, inn zu uberreden, daB er doch die Stadt verlassen möge. Als sie $1 \mathrm{hm}$ den Abschieds-/Todeskuß gegeben hatten, kehrten sie wieder alle - stöhnend und klagend an ihre Plätze zurück.'

"vzem" 1st auch an dieser Stelle überflüssig, denn der Kalser war ohnehin im Gespräch mit seinen mürdenträgern; von einer besonderen Handlung, die "vzem" beschreiben würde, kann also nicht die Rede sein (etwa 'liefen inm nach', 'ergriffen ihn = fangen' oder ähnliches). "dav" funglert als Adv.-Part. zu "vozvrativšsja"; das gleiche gilt in verstärktem bzw. noch eindeutigerem MaBe für "stonja 1 rydaja", deren adverbiale Elgenschaft an dieser Stelle noch dadurch unterstrichen wird, daB sie vor der Porm, die die Haupthandlung ausdruckt, stehen - Im K-pler Text stehen Part.praes.-Formen gewöhnlich hinter, Part.praet.-Formen meistens vor dem Verb.fin., das gewöhnlich den Vorgang, der im Mittelpunkt des Interesses steht, bezelchnet. Der gesamte Satzaufbau in Verbindung mit der Part.-Endung -ivisesja macht es sehr wahrscheinlich, daß die Form ursprunglich "vozvratisasja" gelautet hat oder lauten sollte.

Im Ubrigen scheint mir an dieser Stelle die Frage berechtigt, $o b$ in diesem Satzgefüge nicht elgentlich "dav emu konečnoe celovanie" die bedeutendste Information darstellt. Doch kann "dav" in keinem Pall als syntaktisches Zentrum des Satzgefüges gelten - diese Punktion hat eindeutig "vozvrativšasja".

Folgende Textstellen könnten wir noch hierher stellen:

$64 / 23$ (8.0., S. 588), $71 / 3$ (s1cher auch Verschreibung). ${ }^{110}$ Wie die vorgefuhrten Beisplele zelgen, ist nicht in jedem Fall die Elgenständigke1t der in Frage kommenden partizipialen Form gesichert, da verschiedentlich Verschreibung zu vermuten 1st. Dennoch wollen wir für unsere Statistik bel diesen acht Belegen bleiben.

110) "I, udariv faris, chotjašče proskočiti ..." 


\subsubsection{Pleskauer Text}

Während ir in der $\mathrm{K}$-pler Erzählung nur mit Mühe selbständige partizipiale Syntagmen finden können und alle wichtigen Belegstellen, die nur irgend den Anschein machten, hierher zu gehören, vorgefuhrt haben, können wir aus der Pleskauer Erzählung nur einen geringen Bruchteil der Part.-Konstruktionen mit absoluter Prädikation präsentieren.

$77 / 12$ "Gosudarevy $\check{z} e$... voeovdy paki boga na pomoščb prizvavše $i$ chrestbjanskiml glasy kriknuvğe $i$ vkupe snemšesja.

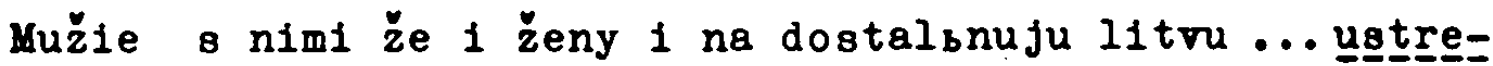
míğasją, koegoždo s čim 1 kak bog vrazumit:

ovil že iz ručnic streljajušče,

Inil že kameniem litvu pobivajušče,

ovil že ich gorjaščju vodoju polivajušč,

inii že ogni zažigajušce, na nich mečjušč i

vajačeski 1 promy šljajušče."

- Die Voevoden riefen Gott wiederum um Hilfe an, riefen mit christlichen Stimmen und brachen alle miteinander auf. Männer und Frauen stürzten sich auf die übrigen Iitauer - jeder mit dem, was (und wie) Gott (es) inm gerade eingegeben hatte:

die einen schossen mit ihren Plinten,

die anderen bewarfen die Iitauer mit steinen,

die einen begossen sie mit kochendem Tasser,

die anderen entziundeten Feuer (Fackeln) und warfen sie ihnen entgegen.

So dachten sie sich immer etwas aus.'

Eine Parallelstelle hierzu mit ähnlichem Inhalt und fast dem gleichen Aufbau haben wir bereits an anderer Stelle zitiert (8.0., S. 566, Beleg 69/18). Die Aufzählung der einzelnen Tätigkeiten war dort aber noch länger und in zwei reimende Blökke aufgeteilt - der erste Teil war durch 3.pl.ipf. -(j)achu, der zweite Tell durch Part.praes. auf-jusče reimend gestaltet. Dort hatte sich ganz deutlich gezeigt, dab die partizipialen Formen die Ipf.-Pormen varilerten, also vertraten. Das können wir auf diese Textstelle ausweiten.

Ebenso selbständig wie die Part.praes.-Formen sind die Part. praet.-Belege der ersten Zeilen. Es werden knapp einige Pakten mitgeteilt, die für die folgende reimende Szenenschilderung unerläßlich sind. Diese Informationen entsprechen in 
1hrer Vertigkeit vollkommen der anschlleBend gegebenen, die durch Aorist ausgedruckt 1st. Entsprechend durfen wir die Part.praet.-Formen an dieser Stelle als Ersatz für Aor.-Formen betrachten.

$37 / 22$ "Znamenavše že sja siloju voobraženija kresta christova ot pečersko(go) 1gumena Selivestra. Taže po čjudotvornym ikonam znamenavšisja 1 mnogie obety svjatym mestom 1 ... svjatym ikonam vozdati obeščavšesja, naipače ..."

- Der Abt des Hohlenklosters Sylvester segnete ihn (den Zar) durch die Kraft des Kreuzeszeichens. Auch wurde er mit vielen Ikonen gesegnet und gab den helligen stätten und den Ikonen manches Versprechen, vor allem ...'

In diesem ganzen Abschnitt (der durch Uberschriften am Anfang und am Ende klar markiert ist) gibt es keine finite Verbform. Es handelt sich wieder um eine kurze Notiz - die Pakten werden knapp referiert; solch resultativer Erzählweise entspricht der Aorist, den hier die part.praet.-Formen ersetzen.

45/26 "Simi že slovesy lukavymi nakazav izvyšnich svoich getmanov 1 rochmistov 1 ..., 1 tako raspustiv $1 \mathrm{ch}$, koegoždo na svoe panstvo. Sie že prirek im, jako 'po vrement sestbvija puti liety vozveščatelbnyja $k$ vam imaju prislati'. Sił že načalbnyja volki ko krovoprolitiju, izvyšnil ego getmany s ... voi obeščavšesja k svoemu korolju, ..., po evo velenbju sovers̆iti,

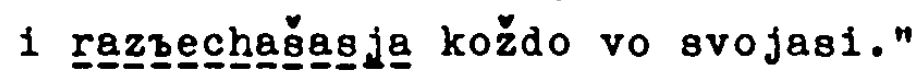

'Mit diesen falschen Worten (die zuvor zitiert wurden) hatte er seine grobartigen Hetmane und Rottmeister und ... angewiesen; und so entlie $B$ er sie in ihre Heimat. Folgendes sagte er ihnen (noch): Ich werde euch mitteilen/schreiben, wann der Feldzug beginnt. - Diese (die Herde) zum Blutvergießen leitenden Wölfe, jene großart1gen Hetmane und ... Krieger versprachen 1hrem König, alles gemäß seinem Befehl zu verrichten. Und (dann) zog jeder in seine Heimat.'

Durch den abschlieBenden Aor. $18 t$ das Tempus der vorausgehenden vollkommen autonomen Part.-Konstruktionen angegeben. Wir können die Erzahlweise hier distanzlert-resultativ nennen. Dem widerspricht nicht die pejorativ-metaphorische Ausdruckeweise gegen SchluB - im ersten Tell der Erzählung begegnet diese uberall. 
61/4 "Nesytosti že svoeja alčbu vsjačeski i načala nakormiti ískasše, vsjačeski ko gradu gradoemnago umyšlenija mesta is skasse, i so vsemi svoimi ... pervosovetniki usovetovav že i usmotrev mesta, ugol grada, ...; sie mesto iz narjadu rozbiv 1 tako vzjati gorod. Semu že ego sovetu tverdo uloživšusja." "

'Seinen unersättlichen Hunger wollte er gänzlich und von Anfang an stillen - (mit anderen Worten:) mit ganzer Energie suchte er eine Stelle (in der Stadtmauer), wo sich die Erstürmung der Stadt am besten durchführen lieBe. Er beriet sich mit seinen Ratgebern und nahm die (in Frage kommenden) Stellen in Augenschein,...; eine (bestimmte) Stelle sollte mit dem Geschütz beschossen werden und hier dann auch die Erstürmung der Stadt erfolgen. Diesem seinem Plan wurde vehement zugestimmt.'

Die Ipf.-Formen stehen im Rahmen allgemeiner Feststellungen, deren eine die Interpretation der vorangehenden metaphorischen Aussage ist. Daraufhin werden konkrete Vorgänge genannt: eine Beratung und eine Besichtigung der Mauern Pleskaus fanden statt, eine bestimmte Stelle ausgewählt (die genaue Beschreibung beginnt mit "ugol grada", ohne Verb- oder Part.-Form). Dann wird die Konstruktion sehr undurchsichtig. Die folgenden Worte ("... rozbiv ...") können nicht bedeuten, dab sie diese bestimmte Stelle beschossen - dies erfolgt viel später (S. 64) Der letzte Satz (Dat.abs. "... uloźivšusja") stützt unsere Interpretation, daß "rozbiv" und "tako vzjati gorod" die Kernpunkte des Plans darstellten: wenn die Mauer an dieser Stelle zerschossen ist, soll mit dem Sturm auf die stadt begonnen werden. An solchen Stellen wie dieser zeigt sich deutlich, dab dem Pleskauer Autor die partizipiale Ausdrucksweise nicht nur dazu dient, die finiten Verbalformen zu varileren, sondern es wird auch offenbar, dab sich hinter dem Gebrauch der Part.ien erhebliche formale bzw. syntaktische Unsicherheiten des Autors verbergen.

Die Tatsache, daß die Part.ien allesamt von präfigierten Verben gebildet werden, die sonst der Bildung von Aor.-Formen dienen, stützt die Annahme (auf dem referierenden Charakter, fast Telegrammstil der Darbietung der Fakten beruhend), daB auch diese Part.praet.-Formen an die Stelle von Aor.-Formen getreten sind. 
70/17 "... pečerskij igumen Tichon 1 protopop Luka 1 ..., jako že sie slyšav, vo1 že vogkričavǧe glasy nemolčnymi 1 ruce prostirajušče k prečistomu obrazu; na kolenu pripadajušče, slezam1 že mramor pomosta cerkovnago ... vozmočcišg; $k$ bogorodicy o spasenbl gradu Pskovu ... moljašcesja. Tako že 1 ženy blagorodnyja k molebnomu stojaniju v sobornuju cerkovb sošedšesja, kričjušč 1 glasy rekušce, 1 v persi svoja bbjušce, $1 \mathrm{k}$ bogu 1 prečistoj bogorodicy moljaščesja, o zabrala že 1 o most ubivajuščesja, molebneno vopijušče. ... plačjušče 1 glasy vop1 jušče, ... bьjušče, ... prizyvajušče, ...mol mašče."

'... der Abt des Höhlenklosters Tichon und der Oberpriester Luka und .... - als sie dies erfahren hatten, da entfuhr thnen ein unuberhörbarer Aufschrei (oder: sie schrien 108 mit unüberhörbaren/nicht verstummenden Stimmen) und streckten die Hände aus zum Bildnis der Allerreinsten; auf die Knie fielen sie, und mit ihren Tränen netzten sie den Marmorboden der Kirche; sie flehten die Gottesmutter um die Errettung Pleskaus an. Auch edle Prauen waren in die Kathedralkirche gekommen, um dort stehend $z u$ beten, sie schrien und heulten ${ }^{11}$ '(mit lauter Stimme), schlugen sich die Brüste, flehten zu Gott und zur allerreinsten Gottesmutter, schlugen (mit dem Kopf?) an Wand und Boden, schrien im Gebet. ...'

Wie uns bereits im Zusammenhang mit den finiten Verbalformen aufgefallen war, liebt es der Pleskauer Autor, die gleiche verbale Form über längere Abschnitte durchzuhalten - so erzielt er leicht verbalen Reim, gleichzeltig bedingen gleiche verbale Formen auch parataktische Pügungen, die hinsichtlich der Konstruktion kaum Probleme aufgeben. Die gleiche Beobachtung machen wir nun beim Part. Immer wieder begegnet uns das gleiche Part. - entweder Part.praes. oder Part.praet. Die beiden in de Masse der Part.praes.-Formen gestreuten präteritalen Part.ien bilden eine Ausnahme. "voskričavăe" könnte so gemeint sein, wie die Ubersetzung versucht, die Form zu deuten: 'ole erhoben groBes Geschrei/Wehklagen' - als erste Reaktion auf dae soeben Vernommene: die Litauer haben Telle der Mauer

111) Verschiedene Varianten haben hier: "glasy revuéče" houlten mit (lauten) Stimmen - Vgl. Textausgabe, S. 102 (ZITIET III, 4). 
und einzelne Basteien gestürmt. Das Inchoative, Plötzliche des Aufschrels ist mit dem Verb "voskričati" sehr gut ausgedruckt - und das mit diesem Perfektivum korrelierende Tempus lst der Aorist bzw. für den Pleskauer Autor auch ersatzwelse das Part.prast.

Annlıch 1st der Pall von "sošedšesja" gelagert. Man könnte diese Form zwar einem folgenden Part.praes. unterordnen im Sinne einer temporalen Ergänzung (Vorzeitigkeit) - etwa: 'nachdem sie in die Kirche gekommen waren, schrien und heulten sie...', worauf das Pehlen von "1" zwischen "sošedšesja" und kričjuščl" deuten könnte. Doch scheint mir, daß die durchgängig parataktische struktur auch dieses Abschnitts eine solche Interpretation nicht erlaubt. Für 'zusammenkommen' stand dem Autor nur "sojtisja" zur Verfügung - wie schon verschiedentlich erwähnt, scheinen nichtdeterminierte Entsprechungen präfigierter Verben der Bewegung noch nicht vollkommen als imperf. Aspektpartner der letzteren empfunden worden zu sein - so ist z.B. "schoditisja" im Sinne von "sobiratisja" bei Sreznevskij (III, 861) kaum belegt. 112 Da inm sprachlich anscheinend nur "sojtisja" zur Verfügung stand, kam auch hier nur Aorist oder Part.praet. in Prage.

Die Ubrigen Handlungen sind (fast) alle durch Part.praes. bezeichnet. In dieser aktualisierenden Schilderung, die jede Einzelheit registriert, die auch vor wiederholungen nicht haltmacht, diese anschelnend sogar forciert, dürfen wir die Part. praes.-Formen als Ersatz von Ipf.-Formen einschätzen, da sie Vorgänge, entsprechend dem Praes.h1st. - ohne jegliche ze1tl1che Perspektive benennen.

Erotaunen muB in diesem Kontext "vozmočiša". An sich hat es in dieser Aufzählung von Vorgängen keine andere Wertigkeit als die ubrigen Handlungen. Ein realer oder gedachter Abschlus deo 'Benetzens' 1st an dieser Stelle gar nicht möglich. Allerdings murde im Zitat oben ein Vergleich ausgelassen, den wir der Deutlichkeit halber erst hier einfuhren:

112) Dort sind zwei Belspiele angeführt, für "ssitiseg" in diesem und ëhnlichen Sinne (Srezn. III 712 ) aber fǘnf Belege. 
70/22 "..., slezami že mramor pomosta cerkornago, jako strujam1 mnogimi reki vozmočiša."

'.... sie netzten den Marmorboden der Kirche mit ihren Tränen wie mit mächtigen Strömen eines Plusses.'

Es kann sein, daB der Autor dieses Bild als in sich abgerundet vor Augen hat, was diese Aorlstform bewirken würde.

$75 / 21$ "Tako že vo edino serdce vse bogorodicy milostb priemše, i seja pomoščiju vooruživšesja, jako edinemy usty bogorodicju na pomoščb prizyvajušče 1 vo edin glas kriknuvse, gosudarevy ... voevody, s nimi že 1 ... vse volnstro

Gleichsam in ein Herz nahmen so alle die Gnade der rekusče : " Gottesmutter auf und wappneten sich mit deren Hilfe, gleichsam mit einem Mund riefen sie die Gottesmutter zur Hilfe herbe1, gleichsam mit einer Stimme schrien die Voevoden und ... und sprachen: ...'

Trotz der rhetorischen Ausgestaltung handelt es sich um einen Abschnitt, der auf die folgenden programmatischen Worte hinfuhrt, darin haben wohl die Part.praet.-Formen, welche ja im Pleskauer Text wie der Aorist Abgeschlossenhe1t der ausgedrückten Handlung bezelchnen, ihren Grund. "rekušč" verwundert uns nicht - es handelt sich um eine Formel, die wörtliche Rede einleitet.

Verwundern muB uns aber "prizyvajušče". Dieses Syntagma ist praktisch demjenigen um "kriknuvse" synonym. Wir können uns die unterschiedlichen Pormen nur so erklären, daB der Autor dem Pluraletantum "ediny usty" automatisch das mit der imperf. Verb-Variante ("prizvati - prizyvati") korrelierende Part. praes. verband und dem Sing. "edin glas" das einmalig/momentane, sicher bereits klar perfektive "kriknutin/"kriknuvšen zuordnete. An anderer Stelle lesen wir:

$84 / 31$ nO sem že mogo boga na pomošč prizvavsen .

Im Beleg 77/12 (s.0., S. 594) sind "prizvavše" und "kriknuvše" einander belgeordnet:

$77 / 12$ "Gosudarevy ... voevody ... prizvavše 1 chrestbjanskimi 
Hier nun steht "kriknuvše" nach einem Instr.pl. Aus dem Gebrauch dieser Pormen lassen sich also keine Kriterien ableiten, die uber die Verwendung der Verb- bzw. Part.-Form verbindlich Auskunft geben. Vielmehr müssen wir einen zuweilen recht willkürlichen Gebrauch der Formen konstatieren, der sogar in Abschnitten mit verbalem Reim beobachtet werden kann. ${ }^{113}$

Bevor wir den Abschnitt über eigenständige Part.-Syntagmen im Pleskauer Text abschließen, seien noch einige Textbeispiele vorgestellt, wo entgegen dem allgemeinen Gebrauch das Part. die übergeordnete, ein Verb.fin. die untergeordnete Handlung wiedergibt. Ein Beispiel hatten wir schon vorgestellt (s.0., S. 584 , Anm. 96):

$74 / 27$ "Egda $\check{z} e$... ídogsa $k$ prolomnomu mestu .... togo že času, ..., vesnicy na konech pribežavše..." -Als sie an die Breschenstelle gezogen waren/zogen, kamen Boten zu Pferde herbeigesprengt ...'

DaB dies kein Einzelfall ist (oben, S. 584, Beleg $75 / 5$, hatten wir den umgekehrten Fall vorgestell ${ }^{114}$ ), mag die folgende Textstelle demonstrieren:

60/11 "Oni že, egda poechăğa 2 goroda že, tokmo černosts $v$ lese idušču videv."

- Die Litauer waren, als sie sich von der Stadt zurückgezogen hatten, nur noch als dunkle, sich im Wald dahinbewegende Stelle zu erkennen.'

40/16 "Paki že, sie slyšav ruskij gosudarb,

jako ne tokmo obetov svoich po svoeja im vere zably șa. no i na branb voopolčivšesja i gradi paki vospriemljut, razgnevavše že sja na nich gosudarb, ..."

'Als der Herrscher erfahren hatte, daB sie nicht nur ihre geleisteten Eide vergessen, sondern sich wieder frisch geruistet hatten und die Städte wieder zurückeroberten, da entbrannte er in Zorn gegen sie.'

113) Die Frage, ob hier evt. Abschreibfehler vorliegen, können wir nicht beantworten, da unsere Textausgabe keine morphologischen Varianten gibt.

114) "egda pribežavše ..., ... rekoša". 
Wir konnten nur einen ganz geringen Tell der insgesamt 92 Part.-Syntagma mit absoluter Prädikation vorstellen. Die Be1splele haben gezelgt, daB in der Pleskauer Erzbhlung verbale Formen mit Part.1en frel austauschbar sind - daß also das Part. als vollwertige Varlante für das Verb.fin. fungieren kann.

Wir haben versucht $z u$ bestimmen, welches Tempus die beiden Part.-Varianten vertreten. Das Ergebnis war nicht überraschend:

Das Part.praes. Wird von imperf. Verben gebildet und ersetzt das Imperfekt;

Das Part.praet. Wird von perf. Verben gebildet und ersetzt den Aorist.

Partizipiale Formen in der Punktion des Verb.fin. treten wie dieses meist in Gruppen auf und dominieren einzelne Abschnitte. Gelegentliche Alternationen konnten nicht immer zureichend erklärt werden und fügten $81 \mathrm{ch}$ zu keinem zusammenhängenden Bild. Es scheint so, dab auch die Part.len (praes. - praet.) ziemlich willkülich gebraucht werden; entscheidend 1st auch hier, dab die Aspekt-Korrelation gewahrt bleibt.

Wahrend uns be1 der Untersuchung vermuteter selbstandiger partizipialer Konstruktionen im $\mathrm{K}$-pler Text meistens klar wurde, dab die Unabhängigke1t derselben oft recht fragwürdig oder aber Verschreibung zu vermuten war, erwiesen sich die Belegstellen aus dem Pleskauer Text als so eindeutig, dab wir die Frage nach der Eigenständigke1t erst gar nicht zu stellen brauchten und uns mit der Frage nach dem Grund fur den Gebrauch der Part.praes.- oder Part.praet.-Formen befassen konnten. 


\subsection{Dags_untergergeordnet_e_Partt121_p1al_-Syntaggma}

Das Part. in der Funktion eines 'untergeordneten', peripheren', 'zweitrangigen' usw. Prädikats war in seiner Aussage immer dem Verb.fin. untergeordnet, doch nicht in dem unmittelbaren MaBe wie das heutige Adv.-Part. ("deepričastien), sondern mittelbar, über das Subjekt. Einhellig wird festgestellt, daB das präpositive Part. besonders starke prädikative Kraft besitze - vor allem, wenn das Subjekt bei inm steht. ${ }^{115}$ Umgekehrt habe das nachgestellte Part. immer stärker unter dem EinfluB des Verb.fin. gestanden. Von untergeordnetem Prädikat spricht man, wenn ein Part. mit dem Subjekt des Satzes, das natürlich auch das Subjekt des Verb.fin. darstellt, bedeutungsmäBig sehr eng verbunden ist und mit jenem ein ziemlich eigenständiges Syntagma bildet, wobei aber die Bindung an das Verb.fin. auch stets erhalten bleibt, ebenso die übergeordnete Bedeutung desselben. Charakteristisch für diesen Zustand ist die Numerusund Genus- Kongruenz zwischen Subjekt und Part. Die Störung derselben zeigt an, dab sich die Bindung zwischen Subjekt und Part. gelockert hat und jene Entwicklung, die mit der adverbialen Punktion des "deepričastie" abgeschlossen ist, ihren Anfang nimmt, d.h. in der gesprochenen sprache schon längst ihren Anfang genommen haben muB. ${ }^{116}$ wie sich die Entwicklung abgespielt hat, ist noch weitgehend im dunkel.

So wäre es sicher von einigem Interesse zu erfahren, welchen Entwicklungsstand unsere Texte zeigen. Da aber, wie wir zu zeigen versucht haben, der Unterschied zwischen unseren Texten hinsichtlich der Funktion des Part.s auf einer ganz anderen Ebene liegt, wollen wir die Prage, ob das Part.Syntagma von Fall zu Fall stärker zum Subjekt oder stärker zum Verb.fin.

115) Istrina, Sint. javlenija, S. 87; Nikiforov, S. 247; Ruzicka, Das synt.System, S. $15-43$; uv.a.

116) Allerdings ist die Prage zu stellen, in welchem MaBe hier überhaupt eine umgangssprachliche Entwicklung vorliegt. Sicher kamen die Unsicherheiten in der Schriftsprache daher, weil die lebende Sprache nominale Part.ien gar nicht mehr verwandte, von einigen voll adverbialisierten Pormen ("molca" u. ̈. vielleicht) abgesehen. 
gravitierte, auf olch beruhen lassen - sie würde eine spezielle Ontersuchung erforderlich machen.

Methodisch schlieBen wir uns dabel an Nikiforov an, der folgende klare Scheidung trifft:

Absolute Prädikation hat das Part. dann, wenn im betr. Satz kein Verb.fin. zu finden 1st; das trifft auch auf den konjunktionalen Nebensatz zu. 117

Die Punktion eines "pričastie-predikat" (= zweitrangiges/peripheres Prädlkat - "vtorostepennoe skazuemoen) erfullt es dann, wenn es durch eine Konjunktion vom Verb.fin. getrennt 1st. Das subjekt, wenn es ausgedruckt wird, tritt in das Part.-Syntagma. 118 In allen anderen Fällen spricht Nikiforov vom "deepričastie" die Form des Part.o opielt dabei keine Rolle. 119

Wir übernehmen zwar diesen Standpunkt bezüglich des "deepričastien, betonen aber, daß wir dies nicht so sehr im heutigen Sinne verstanden wiosen wollen, sondern im allgemeineren Sinne - wie es die Uberschrift dieses Abschnittes ausdruckt: als untergeordnetes Part.-Syntagma. Denn mir scheint es noch verfrüt, generell vom Adv.-Part. ("deepričastien) zu sprechen, da in manchen Fällen die Bindung an das Subjekt b1s zum gewissen Grade gegeben zu sein scheint, wohol aber gleichze1tig am Charakter elner Erläuterung des Prädikats (Verb.fin.) durch das fragliche Part. nicht zu zweifeln ist. Wenn wir also allgemeiner vom 'untergeordneten Part.-Syntagma' (und nicht vom "deepričastien) oprechen, dann stellen wir dies in Gegensatz zum Part. mit absoluter oder aber mit relativ eigenständiger (eigenes Subjekt; Konjunktion zwischen Part. und Verb.fin.) Prädikation. Glelchzeitig wollen wir mit dieser allgemeineren Pormulierung bestehende syntakt1sche Onterschiede, besser:

117) D.h. Funktion und Art des Nebensatzes ergeben sich aus der subordinierenden Konjunktion, nicht aus der Form des Prädikat8: nkmlich deo Partizips. Das Part.-Syntagma kann e1genes Subjekt haben. - Ilkiforov. Glagol, S. $243 \mathrm{ff}$.

118) Allerdings bleibt das postpositive Part. mit oeiner geringeren prädikativen Kraft im Vergleich zum priposit. Part. melst ohne Subjekt, das oich dann meist beim Verb.fin. befindet. Ilkiforov, a.a.0.. s. $247 \mathrm{ff}$.

118) ebd.. S. $260 \mathrm{ff}$. 
feine Nuancen, die hinsichtlich des heutigen Adv.-Part.s ("deepričastie") noch bestehen, auBer acht lassen, um so alle die Konstruktionen zu erfassen, innerhalb welcher sich das Part.Syntagma uberhaupt in gröBerer Abhängigkeit befindet - auch wenn dessen Funktion also von der des "deepričastien geringfügig abweicht.

\subsubsection{K-pler Text}

55/23 "I abie cesarb vozbudivs,a ot sna, vskore posylaet v Vizandiju magystrov 1 gradckych delatelej gotoviti mesto; sam že cesarb, ostaviv v Rimu kesari ..., poịde s materiju svoeju Elenoju $v$ Vizandiju, ...

'Kaum vom Schlaf erwacht, schickte der Kaiser sogleich Magister und Stadtbaumeister, damit diese die Stätte (zum Bau einer Stadt) vorbereiteten; unter Zurücklassung der Mitkaiser (= seiner Söhne) in Rom begab er sich mit seiner Mutter, Helena, nach Byzanz, ...'

In beiden Sätzen steht das Subjekt direkt beim präpositiven Part. Dennoch ist, besonders im ersten Satz, dle geradezu adverbiale Punktion des Part.-Syntagmas außer Prage. Im Prinzip gilt dies auch fur den zweiten Satz, wie ihn der vorgefuhrte Ausschnitt zeigt. Im Original wirkt das Part.-Syntagma etwas selbständiger, weil der Ausdruck "kesari" - 'Mitkaiser' dort erläutert ist, dem russischen Leser war der Begriff offenbar fremd. 119

57/8 "I, preukrasiv grad, oㅡ믈 emu čestb veliju obnovleniem 1 prazdniky 1 toržestvy velikimi na mnogye dni, ..." - Nach der liberaus gelungenen Verschönerung der Stadt verlieh er dieser durch die Einwethungsfeierlichkeiten und sich uber viele Tage erstreckende Peste hohes Ansehen,...'

Das Part. faBt das zuvor Gesagte zusammen - es waren verschiedene Maßnahmen zur Verschönerung der Stadt genannt - "preukrasiv grad" leitet uber zu den erwähnten Peierlichkeiten und vor allem zur Namensgebung: "Carbgrad".

119) "kesari: dva syna, Konstu 1 Konstjantina, a synovca svoego Adamanta v Bretaniju (poslav), poide ..." mgr. Katcke = Mitkaieer, auch Designatus. Das im K-pler Text allgemeine "cesarb" gibt Bubldérs wieder. 


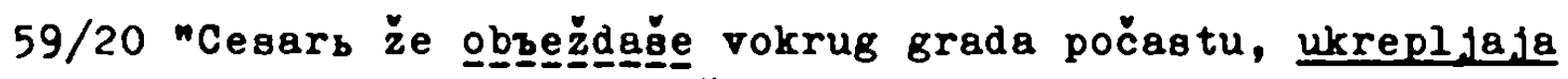
stratig 1 voin, takože 1 ..."

'Der Kalser ritt oft die Befestigungsanlagen entlang (= ritt um die Stadt herum), wobei er die Strategen und die streiter, und auch die ..., (geistig) stïrkte.'

An dieser Stelle wäre zu fragen, welche Tät1gke1t als wesentlicher einzuschätzen wäre, das Umherrelten oder die moralische Stärkung der Verteidiger. Das Umherreiten 1st doch nur Mittel zum 2weck. Allerdings scheint es, als werde "obъě̌(d)ati" im K-pler Text semantisch eingeengt auf die Bedeutung 'inspizieren' - vgl. auch den folgenden Beleg. Mit solcher Semantik des Verb.fin. würde der Gebrauch der Part.-Form verständlich:

- Der Kaiser inspizierte die Befestigungsanlagen, wobe1 er den Verteidigern auch Mut machte, sie stärkte.'

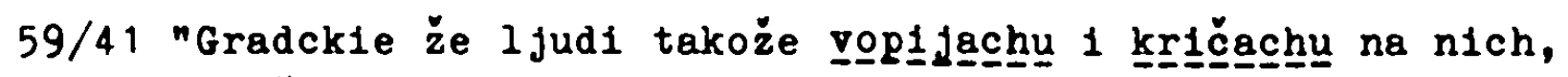
bbjuščesja s nimi krepko.

Ceвarb že ob̧̧ězağe po vsemu gradu, ponužaja l judi svo1, dajušče im nadežu božiju, ..."

'Die Griechen riefen und schrien ihnen ebenfalls entgegen und kämpften mit ihnen erbittert.

Der Kaiser ritt an den Wehranlagen entlang (= inspizier-

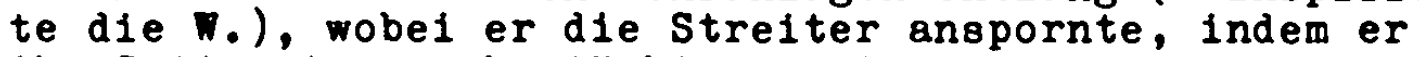
inr Gottvertrauen bestïkte, ...'

Die erste Pugung bringt wieder die Prage der Wertigkeit der Handlung ins Spiel - kämpften sie schreiend oder schrien sie kämpfend? Es sei an unseren eingangs dieses Kapitels geäuBerten Eindruck erinnert, daB der $K$-pler Autor seinem Satzschema oft automatisch zu folgen scheint, weil gelegentlich die offenbar wichtigere Handlung in Form des Partizips, und umgekehrt manchmal die begleitende Handlung in Porm des Verb.fin. erscheint.

Im eweiten Satzgefuge finden wir als Hauptverb wieder "obbežab̌en - 'umherreiten/inspizieren'. Im ersten Augenblick mag die Tatsache verwundern, daB zwe1 Part.1en mit unterschiedl1cher Endung folgen: "ponučaja" und "dajuscce". Das mag daran liegen, daB "dajušče" Im K-pler Text auf Grund des häufigen Gebrauchs formalisiert 18t - "daja" erscheint nie. So aber ob vom Autor gewollt oder nicht, erscheinen verschiedene partizipiale Pormen in verschiedener Punktion: "ponužaja" lat zum 
Verb.fin. "obъežăen zu stellen, wohingegen "dajuščen das vorhergehende Part. "ponužaja" detailliert.

$64 / 32$ "On že, lukavyj, se slyšav, porágovag jâ v serdc1 svoem, čajušč, nuža nekaja priide gradu,

1 otložše svoe otstuplenie, năça_soveščevatí o miru."

'Als dieser Hinterhaltige davon erfahren hatte, freute

er sich von ganzem Herzen, nahm er doch an, K-pel sel

in großer Bedrängnis.

Er verschob seinen Rückzug und begann (stattdessen)

Priedensverhandlungen.'

"slyšav" steht hier in der bekannten auslösend-begründenden Funktion ('als er dies gehört hatte, tat er jenes = reagierte er auf jene Weise-), wir düfen diese Formel als vollkommen adverbialisiert (d.h. Adv.-Part.) betrachten. Das Syntagma um "cajuščen (wozu der folgende objektsatz "nuža ..." gehört) ersetzt einen Kausalsatz: 'freute er sich, weil er annahm, K-pel sei .... 120

Genauso wie besonders umfangreiche Part.-Konstruktionen (in adverbialpartizipialer Punktion) trotz engster Anbindung an das Verb.fin. ein gewisses Eigengewicht erlangen, genauso sind Part.ien (in adverbialpartizipialer Funktion) ohne Erweiterung dem Verb.fin. in besonders enger Weise verbunden - der untergeordnete Charakter des Part.s, das wir in diesem Falle ohne Einschränkung als Adv.-Part. ansprechen düren, tritt dann ganz besonders hervor.

Pür Part.praes. ohne Erweiterung ${ }^{121}$ haben wir 16 Belege mit insgesamt 24 Pormen. 122

Funf einzeln auftretende Part.ien (Adv.-Part.ien) enden auf -a/ja, drei auf-šče. Vier Adv.-Paare haben die Porm -a/ja, ebenfalls vier die Form -šče.

120) Nikiforov, Glagol, S. $265 \mathrm{ff.:}$ "deepričastie" in der Funktion adverbialer Bestimmungen (Grund, Bedingung etc.).

121) Ganz kurze Ergänzungen wie "vsjačeski" bleiben unberúcksichtigt.

122) 8 einzelne Adv.-Part.ien und 8 parig auftretende Adv.Part.ien, z.B. "kriča 1 vopijan, "placusce 1 rydajuscén. Da in solchen Fällen gegenseitige Beeinflussung vorliegt, haben wir solche Stelien als nur einen Beleg gewertet. 
Von den neun Belegatellen mit (Adv.-) Part. auf -a/-ja stehen drei bel einem Verb.fin. 1m Sing., drei bel einem Verb.fin. im Plur., ewe1 Pormen stehen bel einem Prädikat, dessen Subjekt ein Kollektivum 1st; und ein Part. bezieht alch mittelbar (also uber das Verb.fin.) auf ein Femininum. ${ }^{123}$

Von den fünf Belegstellen mit (Adv.-) Part, auf -šče stehen dre1 bei einem Prädikat im Sing., zwe1 bel einem solchen 1m Plur.

Beim Part.praes. können wir also - auch in Hinblick auf jene bereits eindeutig als Adv.-Part. funglerenden Pormen - keinerle1 Affinität eines Numerus $z u$ einer bestimmten Endung erkennen. Nir konstatieren lediglich, daB die heutige Endung des Adv.part.8 (praes.) -a/-ja in mehr als der Hälfte der Belege erscheint: in neun von sechzehn Fällen.

72/29 "... pạdogsa nad nim bol jare 1 I judie, kryča 1 rydaja ..."

'... Bojaren und einfache Leute warfen sich über ihn (den niedergestrecktei Giustiniani) - schreiend und schluchzend.'

59/38 "... nnapadoǧą na grad vkupe so vsech stran, kl1čjušče i vopijusiće, ..."

'... von allen Seiten warfen sie sich schreiend und rufend auf die Stadt, ...'

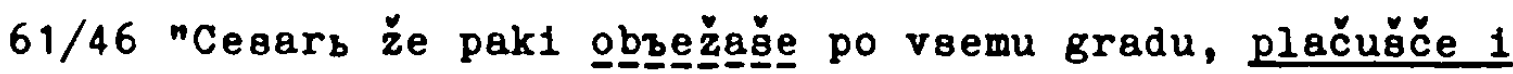
rydajusče, molja stratig 1 vaech ljudej, glagol juğče:..." - Der Kaiser inspizierte wieder die Pestungsaniagen, wobel er weinend und schluchzend die Bojaren und alle Krieger anflehte (und sprach): ...'

"glagoljuăče" leitet formelhaft die wörtliche Rede ein. Das paarig auftretende Adv.-Part. erläutert "moljan, das sich

"obsežaše" unterordnet.

$70 / 20$ "(on1) ... skkakrachan po vsemu gradu, plačušče 1 rydajuščo mol 18:̌cesta boljarom 1 stratigom 1 ..."

'... - oprengten die Festungsanlagen entlang, wobei sie schluchzend und weinend Bojaren und Strategen und ... anflehten ...'

123) $57 / 20$ "Ho jako mat 1 krests janekomu rodu ... pomiluj ego, nastarl ja ja 1 nauca ja ..." ; folgendes "vo vB Ja"vrémena" berleht Blch aur "pomilus ego". 
Diese Stelle ist mit der vorigen beinahe identisch; das parig auftretende Adv.-Part. ohne Erweiterung hat jeweils die Plur.Porm, wohingegen das Part.-Syntagma mit Erweiterung NumerusKongruenz zum Subjekt zeigt ("cesarb - moljan, "oni - moljašcesjan ).

$71 / 18$ "..., no ogni bezčislennye bezbožnyj sotvorše, sam skka= kaše po vsem mestom, kryča $i$ vopija ponužajuşče svoich, ..."

'.... der Gottlose aber lieb Lichter entzünden und ellte von Kampfplatz zu Kampfplatz, wobei er schreiend und rufend seine Leute antrieb, ...'

In Gegensatz zu den beiden vorigen Textstellen zeigt das Part., das (in deutlich adverbialer Funktion) dem Hauptverb (Verb.fin) zugeordnet ist, keine Numerus-Kongruenz ("bezbožnyj - ponužajušcen), diese finden wir aber belm parigen Adv.-Part.

Ubrigens hat das präpositive Part.-Syntagma trotz der vorbereitenden, "skakaše" begründenden Aussage (es war Nacht geworden, daher wurden Lichter angezüdet) eine erstaunliche Eigenständigkeit ("bezbožnyj - sotvoršen), vielleicht besonders deshalb, weil das Subjekt im partizipialen Syntagma genannt, dann aber im verbalen Syntagma wieder aufgegriffen wird ("sam skakašen).

Das Part.praet. ohne Erweiterung tritt nicht parig auf. Wir zählen 22 Belegstellen. Zehn dieser Adv.-Part.ien (praet.) stehen bel einem Prädikat mit subjekt im Plur., nur drei davon haben die korrekte Endung $-(v)$ se, sieben haben die Sing.Porm - $(v)_{b}$. Von den zwolf Adv.-Part.ien, die sich indirekt auf ein Subjekt im Sing. beziehen, erscheinen elf mit kongrulerendem $-(v)_{b}$. Die heute bei vokalisch auslautenden Stämmen dominierende Endung des Adv.-Part.s (-av, -iv, -ev usw.) ist also auch im $K$-pler Text schon die vorherrschende. $56 / 17$ "..., oni že, porazsudiv, gkazağa cesarju: ..." '..., nach einiger tberlegung sagten sie dem Kaiser:...'

$65 / 27$ "Zustune ja .... voskryčav napade na turky ..." -Giustiniani sturzte sich mit einem Aufschrei auf die Türken ...'

$72 / 20$ "..., tako voskričav, ngapadoǧą na nich ...." 
59/32 "(gražane) ... ne možachu stojati na stenach, no, zapadse, ždachu pristupu, ...n

'Die Griechen konnten auf den Mauern nicht stehenbleiben, sondern erwarteten gebuckt/zusammengekauert/versteckt den Angriff, ...'

$63 / 22$ ".... 1 uslys̆avse l judie tvol i brat1ja troja k tebe prifidut na pomoćb, no 1 arbanasa, ubojavaja, gri11dut $k$ sim že, eda kako $i$ on bezbožnyj, ustrašysja, otgitupit ot grada'."

'..., und wenn das in aller Felt - und besonders deinen Brüdern - bekannt wird, dann werden sie dir zu Hilfe ellen, und auch die Albaner werden sich diesen aus Angst anschließen - wird dann nicht auch dieser Gottlose sich aus Purcht von $\mathrm{K}$-pel wieder zurückziehen?'

Alle drei Part.praet.-Formen stehen in konditionalem Verhälnis zu den finiten Formen, denen sie zugeordnet sind: sie haben Futur-Bedeutung. 124 "ubojavgja - priidut" und "ustrašivaja - otstupit" zeigen das in gewisgem Grade gefestigte Adv.-Part. (praet.) beim Prädikat im Plur. und beim Prädikat im Sing.

74/5 "Cesarb že, podav emu ščlt, otvede emu kople, 1 udariv ego mečem $v$ gläu, i razseče ego do sedla, 1 able vö

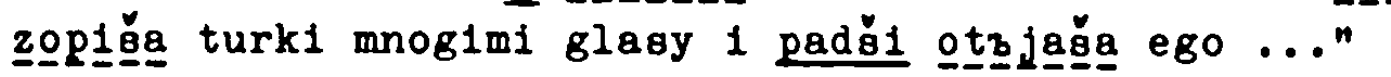
'Der Kalser wehrte mit dem Schild ab und entwand inm (dem Begler-bey) den Speer, hieb thm mit seinem Schwert auf das Haupt und spaltete seinen Leib bis zum Sattel. Sogleich erhoben die Türken ein gewaltiges Geschre1, gtürzten nieder und hoben inn auf ....'

"padšl" hat jene Form des Adv.-Part.s, die bis vor einiger Zeit allein gültig war. ${ }^{125}$ Belde anderen Part.-Syntagma bezelchnen Handlungen, die den durch Verb.fin. ausgedrückten Vorgang einleiten, zu ihm hinführen. Der adverbiale charakter der Part.-Konstruktionen 1st deutlich. DaB der Autor Im Eifer des Gefechts' die elnzelnen Handlungen beinahe als gleichwert1g empfindet, zeigt "udariv ...v glavu, 1 razseče ..."

Die letzten Textbeispiele zeigen die oft schematische Aufgliederung von Handlungsketten in Part. und Verb.fin.

124) Vgl. Ruz1cka, Das synt. System, S. 69.

125) Heute 1st "pav" gebräuchlicher - vgl. Daum-Schenk. Die russischen Verben, S. 359. 


\subsubsection{Pleskauer Text}

Während in der $\mathrm{K}$-pler Erzählung beinahe jedes einzelne Part.Syntagma in ganz klarer Weise einem Verb.fin. untergeordnet ist, muß man im Pleskauer Text immer erst prüfen, ob es sich um ein elgenständiges oder untergeordnetes Part.-Syntagma handelt.

$37 / 32$ "Ṣlyğavğe že sie žiteli vifljanskija zemli, nemcy, carskoe na nich našestvie 1 razumejušče ego $v$ voinstve krepko silbna, nemošč že svoju znajušče, vozmjatogogasja

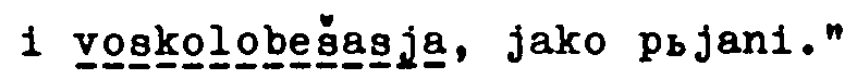

'Als die Deutschen in Livland vom Feldzug des Zaren gegen sie erfahren hatten, da gerieten sie in große Unruhe und zitterten, weil sie wuBten, wie ungemein mächtig er im Krieg ist, und weil sie ihre eigene Machtlosigkeit kannten, wie Trunkene.'

Die präpositiven Part.praes.-Formen stehen in Numerus-Kongruenz zum Prädikat bzw. zum Subjekt, sie haben kausale Bedeutung.

$38 / 1$ "...; inil že vo gradech svoich ż日țor sti že grada nadejuščisją; ..."

'...; einige aber hatten sich in ihren städten verschanzt, weil sie auf deren Uneinnehmbarkeit/Stärke vertrauten, hofften; ...'

42/43 "..., k nemu že posly svoja predposylaet, prosja miru, daby ... miren byl."

'.... (der Zar) schickte seine Gesandten zu ihm (St. Báthory) und bat um Prieden, damit dieser Frieden hal te.'

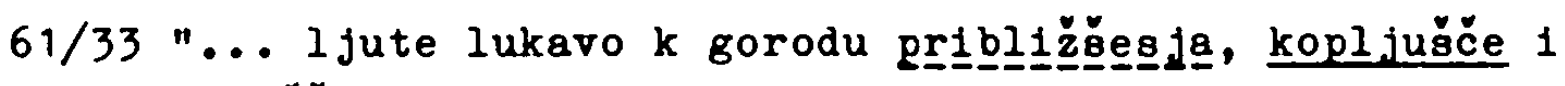
rojušce zemlju, jako kroty; ...n

'... hinterlistig näherten sie sich der stadt, wobel

sie gruben und die Erde aufwihlten wie die Maulwirfe;...'

Im letzten Satz wird das Hauptrerb durch ein Part.praet. ersetzt ("približšesja").

$54 / 27$ "Sich že svolch velikich panov $i$ getmanov rozrjadiv 1 nakazav, litovakij korolb Stepan gordelivomu svoemu

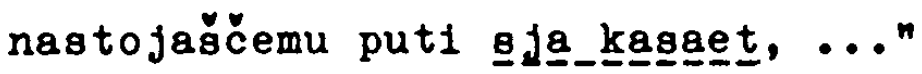

'Nach der Auftellung der groBen Herren und der Hetmane sowle der Befehlsausgabe machte sich der stolze König auf den Weg, ...' 
Dadurch, daB die Ubergeordnete Handlung durch Praes.hist. ausgedrickt 18t, wird ganz deutlich, dab die.durch Part.praet. wiedergegebenen Handlungen beim Elnsetzen des Hauptgeschehens abgeschloseen sind.

44/23 "Bojare že 1 voevody, v bogospasaemy grad Pakov priechav, po gooudarevu prikazu vaja naçağa trogrtt1: ..." 'Hach Pleskau zurückgekehrt, begannen die Bojaren und die Voevoden, die Befehle des Herrochers auszufuhren:...'

62/16 "I tak vojakiml gradoemnyml obrazy ljutil litovakie gradoemcy utverd1vöesja, na bogospasaemy Pskov grad

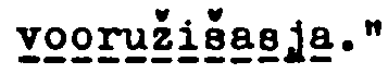

'Und als oich die litauischen Sturmtruppen so thre Stellungen in jeder Hinsicht gesichert hatten, wappneten ole sich gegen Pleskau.'

$O b$ in diesem Belopielsatz die im Part.-Syntagma bezelchnete Handlung als der durch Verb.fin. ausgedruckten Handlung untergeordnet zu betrachten 18t, erscheint nicht ganz oicher. streng genommen ist naturlich die Sicherung der eigenen Position Voraussetzung fur die Angriffo-Vorbere1tungen - doch kommt diese Bezlehung durch die partizipiale Form allein nur vage zum Ausdruck; die untergeordnete Bedeutung der einen Handlung im Verhältnis zur anderen wirde sicher viel deutlicher werden, wüde das Verb.fin. näher zum Part.praet. treten; die (parallele) Endatellung der beiden Formen otärkt den Bindruck von paraktaktisch gefügten Sätzen.

$87 / 6$ "... 1 tako vo grade omjatenbe učiniv, možęm na prolomnye mesta vo grad 므는.."

'... wenn wir erst einmal in der Stadt Verwirrung angerichtet haben, dann werden wir durch die Breschen in die Stadt gelangen können.

In diesem Satz tritt die enge Bezlehung 2 wischen untergeordnetem Part. und ubergeordneten Verb.fin. besonders deutlich hervor, weil belde nebenelnanderstehen. Durch das oinngemäbe Futur des Verb.fin. erhklt das Part. Konditionale Bedeutung.

ulr scheint, daB die wenlgen vorgefuhrten Belopiele fur erweitertes, untergeordnetes Part.-Syntagma geze1gt haben, wie otraff der Satz im $\mathrm{K}$-pler Text aufgebaut 1st, wie otringent die Bezlehung: Part. = untergeordnete Handlung - Verb.fin. 
= ubergeordnete Handlung im allgemeinen herausgearbeitet erscheint. Obwohl die Beispielsätze, die wir aus der Pleskauer Erzählung vorgestellt haben, ausgesucht sind, wirken sie doch bezüglich der Beziehungen zwischen partizipialen und verbalen Formen merkwuirdig vage.

Beispiele für die klarste Erscheinungsform des Part.s in adverblaler Funktion - das eng zum Verb.fin. gestellte Part. ohne Erweiterung - treten im Pleskauer Text viel seltener auf als in der K-pler Erzählung, was die eben geäuBerte Beobachtung bestätigt, daB nämlich das Part. im Pleskauer Text nicht in dem hohen MaBe der Hypotaxe verpflichtet ist wie im Vergleichstext.

Das Part.praes. finden wir zehn Mal ohne Ergänzung (vgl. K-pel: 16 Belegstellen mit 24 Formen); das Part.praet. erscheint nur drei Mal ganz allein (vgl. K-pel: 22 Belege). Von den zehn Part.-praes.-Formen enden acht auf -a/-ja, von denen in fünf Fällen Prädikat und Subjekt im Plur. stehen; die ubrigen zwei Belege auf -šce gehören zu einem Prädikat im Plur. Die heutige Form des Adv.Part.s (praes.) dominiert also auch im Pleskauer Text, denn von sieben Plur.-Belegen haben funf die Endung $-a /-j a$.

36/18 "... ćjudotvornoe Pečerskoe mesto krepce vooružajuěčesja utessna jut.."

.... das Höhlenkloster bedrängten sie mit unvorstellbarer Waffengewalt.'

Mir scheint, daB das Part.praes. - bedingt durch das Praes. hist. in unmittelbarer Nähe - hier für ein Part.praet. gebraucht ist; ${ }^{126}$ etwa im Sinne '(kräftig) gerüstet bedrängten sie (kräftig) das Höhlenkloster'.

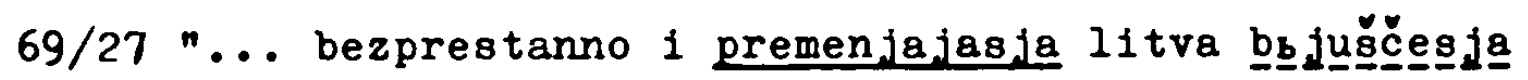
vsjačeskl, - ..."

'... pausenlos und sich ständig abwechselnd kämpften die Litauer auf jede Weise, - ...'

Den adverbialen Charakter von "peremenjajasja" unterstreicht die Koordinierung mit "bezprestanno". Das Adv.-Part. ist einem

126) Vgl entsprechende Beobachtungen Nik1 forovs, Glagol, S.267,
S. 279. 
Part. mit absoluter Prädikation ("bbjuščesja") untergeordnet.

$82 / 15$ "... sie korolju svoemu i nechotja skazachu."

'... widergtrebend oagten sie dies threm König.'

$83 / 19$ "Nalpače, onl bo ne znaja 111 po zavest1 goopoda slave

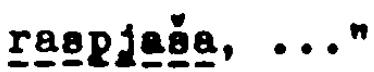

'Vor allem: Jene habes aus Unkenntnis oder MiBgunst den Herrn der Herrlichkeit gekreuzigt, ...'.

Im Beleg 82/15 haben wir es mit einem sicherlich schon voll ausgeprägten Adverb zu tun, worauf die Zusammenschreibung "nechotja" hindeutet. 127 Im Beispiel $83 / 19$ ist die adverbiale Punktion betont, weil das Part. der adverbialen Bestimmung "po zavesti" beigeordnet ist.

Die drei (Adv.-) Part.1en ohne Erwelterung kónnen wir vollständig vorführen - Irgendwelche Schlüsse lassen sich daraus nicht ableiten. Alle drei Belege enden auf $-(v)_{b}$, einer davon hat Plur.-Bedeutung:

62/6 "Potom že, togo meseca, v 4 denb, $v$ noćl, prikativ,

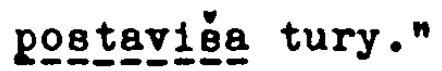

'Dann, am 4. Sept., nachts, schleppten sie die Rammbocke herbel und stellten sie auf.'

Das Adv.-Part. ist an dieser Stelle ähnlich pleonastisch gebraucht, wie wir dies häufig im $\mathrm{K}$-pler Text beobachten konnten - "prikativ" kann auch wegbleiben, ohne daB die Aussage unvollständig oder gar verändert wïrde.

56/31 "...; ne doletev, vo utrobe u sobja togo Pakova slysat1 gkazovase."

'...; noch gar nicht herbeigeflogen, prahlte (= sagte) er ( $=$ der Drache) auch schon, er hore Pleskau bereits in seinem Tanst."

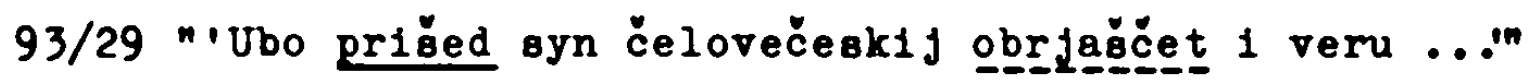
'Tenn der Menschensohn wird kommen, meinst du, er werde Glauben finden auf Erden?' Hebr. 12, 6 (nach Luther).

Wie wir sehen, hat das Adv.-Part. im Pleskauer Text oft nicht so engen Kontakt zun Verb.fin. wie in der K-pler Erzahlung.

127) Allerdings wissen wir nicht, inwieweit hierfur der Hrsg. verantwortlich $18 \mathrm{t}$. 


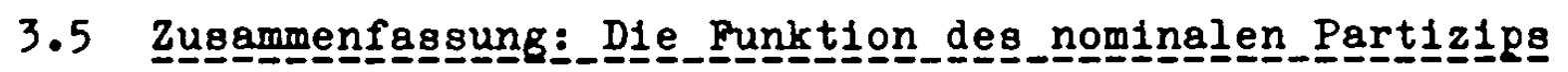
in unseren Texten

Bevor wir die Untersuchungen über die Funktion des nominalen Part.s in unseren Texten abschlieBen, sollen die in den vorhergegangenen Abschnitten an Textbeispielen demonstrierten Möglichkeiten an Hand einer Graphik, die die statistischen Daten veranschaulicht, zusammengefabt werden.

Wir haben versucht, jedes partizipiale Syntagma auf seine Funktion hin zu prüfen. Im ersten Feld (von links) finden wir die Angabe 'Adv.-Part.' - damit sind die soeben vorgeführten Fälle von Adv.-Part. ohne Erweiterung, die die engste Bindung an das ubergeordnete Verb.fin. haben, gemeint.

Im zweiten Feld lesen wir 'Untergeordnetes Part. mit Erweiterung'. Hierbei handelt es sich um jene Gruppe, die Nikiforov als "deepričastie" (mit Erwelterung) bezeichnet - zwar hat sich noch keine allgemeingulltige, unveränderliche Form herausgebildet, aber funktional entspreche dieser Typus der partizipialen Konstruktion weitgehend dem heutigen Adv.-Part. Wir hatten wegen einiger syntaktischer Nuancen zum heutigen Gebrauch den Begriff 'Adv.-Part.' nicht generell auf diese Konstruktionen beziehen wollen und uns entschieden, den etwas neutraleren Begriff 'Untergeordnetes Part.-Syntagma' zu verwenden.

In der dritten Spalte ist die Zahl jener Part.-Syntagma genannt, die vom Verb.fin., auf das sie sich beziehen bzw. zu dem sie eine mehr oder weniger enge logische Beziehung haben, durch eine Konjunktion getrennt sind. Im R-pler Text handelt es sich nur um koordinierende, im Pleskauer Text von den 77 Belegen in 11 Fällen um subordinierende Konjunktion (Relativpronomen, "jako", "egda" u.a.). Nach Nikiforov bilden die durch Konjunktion vom Verb.fin. getrennten Part.-Syntagmen das 'zweitrangige Prädikat', das er "pričastie-predikat" nennt.

In der letzten Spalte schlieblich sind Part.-Syntagmen mit absoluter Prädikation (= vollkommen selbständig) und Part.- 
Syntagmen mit eigenem, vom Syntagma des Verb.fin. unterschiedenen Subjekt zusammengefabt, well diese beiden Gruppen einerseits das Part.-Syntagma in seiner gröbten Elgenständigkeit repräвentieren und well sie andererseits im $\mathrm{K}$-pler Text prozentual kaum ins Gewlcht fallen. Part.-Syntagmen mit absoluter Prädikation registrierten wir im $\mathrm{K}$-pler Text acht Mal, im Pleskauer Text $92 \mathrm{Mal}$; Part.-Syntagmen mit eigenem Subjekt trafen wir in der K-pler Erzählung drel Mal, in der Pleskauer Erzählung fünzehn Mal an.

\begin{tabular}{l|r|r|r|r} 
& Adv.-Part. & $\begin{array}{l}\text { Untergeordn. } \\
\text { Part.-Synt. }\end{array}$ & $\begin{array}{l}\text { Part.-Synt. } \\
\text { +Konjunkt. }\end{array}$ & $\begin{array}{l}\text { Part.-Synt.mit } \\
\text { absol.Präikat. } \\
\text { od.eigen.Subj. }\end{array}$ \\
\hline K-pel & $46=17 \%$ & $197=73 \%$ & $15=6 \%$ & $11=4 \%$ \\
Pleskau & $13=4 \%$ & $97=33 \%$ & $77=26 \%$ & $107=37 \%$ \\
\hline
\end{tabular}

Die Tendenz zur Verselbständigung partiziplaler Syntagmen 1st im Pleskauer Text sehr stark, während sie im $\mathrm{K}$-pler Text kaum ausgeprägt erscheint. Stellen wir die belden letzten Spalten einander gegenuber, so kommen wir zu folgenden Relationen: Part.ien mit relativer (= durch Konjunktion vom Verb. fin. getrennt) und mit absoluter Prädikation machen im $\mathrm{K}-\mathrm{pler}$ Text 10 v.Hd., in der Pleskauer Erzählung jedoch 63 v.Hd. aus! Dieser funktionale Gegensatz im Gebrauch des nominalen Part.s erwelst sich als der entscheidende stilunterschied 2 wischen belden Texten, der sich insgesamt stärker auswirkt als Unterschiede in der Verwendung rhetorischer und metaphorischer Elemente.

Neben obige Graphik wollen wir ergänzend noch eine andere stellen, die den Umfang partiziplaler Syntagmen aufschlusielt. Pur sich genommen lot mit elner solchen statistik nichts anzufangen, denn auch ein sehr umfangreiches Part.-Syntagma kann enge Bindung zum Ubergeordneten Verb.fin. haben - dennoch hat ein umfangreiches $\Lambda d v$.-Part.-Syntagma gröBeres Igengewicht, grbBere (relative) Selbstandigkeit als ein einzelnes Adv.-Part. ohne oder mit nur kurzer Erweiterung. Von groberer Relevanz $18 t$ der Umfang des Part.-Syntagmas, wenn die Bezlehung zu einem Verb.fin. vage, die Bindung an dieses 
locker oder aber eine solche gar nicht mehr vorhanden ist. Wir betonen nochmals, daß wir mit der folgenden Tabelle nichts beweisen, nur die vorlge Graphik durch diese zusätzliche Information ergänzen und illustrieren wollen.

Als 'Ergänzungen', 'Erwelterungen' betrachten wir Objekte, Adverbien, adverbiale Bestimmungen und Genitiv-Attribute. Auch konnten wir, besonders im Pleskauer Text, nicht die Häufungen von Attributen ubersehen. In diesem Falle verfubren wir so, dab wir ein Epitheton mit Objekt (oder adverbiale Bestimmung usw.) als elne Ergänzung gewertet haben, sobald aber zu der substantivischen Ergänzung ein zweites oder drittes Epitheton trat, dann zählten wir auch 2 we1 bzw. dre1 Ergänzungen. Trotz aller grundlegenden Bedenken wollen wir die Graphik vorlegen, weil sie nämlich demonstriert, daB die partizipialen Konstruktionen oft wegen ihres Wucherns, 1hres Umfanges Kontakt und Bindung an finite Verbformen verloren zu haben scheinen.

In der Tabelle unterscheiden wir zwischen Part.praes. und Part.praet. Sie zerfält in zwei Teile: im ersten Teil wird der Anteil der Part.-Syntagmen kürzeren Umfangs (ohne, mit einem und mit zwei Ergänzungagliedern), im zweiten Tell der Antell der Part.-Syntagmen längeren Umfangs (mit dre1, vier füf und mehr Ergänzungagliedern) angegeben. Paarig auftretende (Adv.-) Part.1en ("kryča 1 vopija" usw.) sind wieder zusammengefaBt.

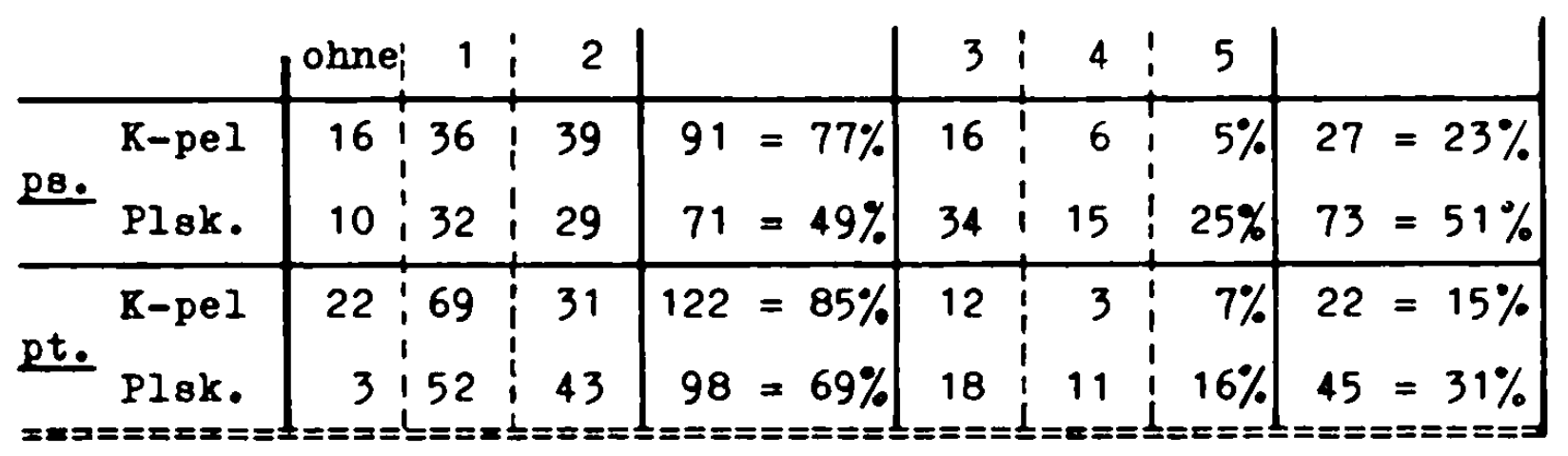

Part.-Konstruktionen mit mehr als drei Gliedern erscheinen im Pleskauer Text viel häufiger als im K-pler. Das flilt vor allem beim Part.praes. auf, wo diese umfangreicheren Part.-Syntagmen in der Pleskauer Erzählung über $50 \mathrm{v} . \mathrm{Hd}$. ausmachen. 
Syntagmen mit Part.praet. alnd generell weniger umfangreich; es 1st intereseant $z u$ beobachten, dab das Verhältnis umfangreicher Part.(praet.)-Konstruktionen vom Pleskauer zum K-pler Text ungefahr das gleiche bleibt wie beim Part.praes.: In der Pleskauer Erzăhlung 18t der Antell unfangreicher Part.-Konstruktionen jewe1ls doppelt so hoch wie im K-pler Text.

Der vergleichsweise geringe Umfang der mit Part.praet. geb1ldeten Syntagmen - In Verbindung mit der Beobachtung, daB kürzere Part.-Konstruktionen in der Regel enger an das Verb.fin. angebunden sind als lingere - erinnert an Nikiforov, der zwar generell zugestand, daß das präpositive Part.(praet.) größere Selbatändigkeit gehabt habe als das postpositive Part.(praes.), doch könne dies für das 16. Jh. nicht mehr so verbindlich gelten: Das präpositive nominale Part. hatte im Verhältnis zum Verb.fin. Vorzeitigkeitobedeutung, es fuhrte zur durch Verb. fin. ausgedrückten Haupthandlung, bereitete diese vor - dies habe zur Schwächung der ursprünglich großen Eigenständigkeit des präpositiven Part.praet. b1s hin zur Punktion des Adv.Part.8 ("deepričastien) geführt. Im Gegensatz dazu hat sich das ursprünglich enger mit dem Verb.fin. verbundene Part.praes. (melot nachgestellt) offenbar stkirker verselbständigt. ${ }^{128}$

Abschließend hierzu sei eine Textatelle mit umfangreicheren Part.-Syntagma - keineswego den umfangreichoten - aus dem Pleskauer Text vorgefürt. Sie belegen glelchzeitig die Korrelation: umfangreiche Part.-Konstruktion $=($ oft $)$ eigenständg.

$94 / 14{ }^{n} \mathrm{~K}$ gosudarju že carju I velikomu knjazju Ivanu Vasilbeviču voea Rusil gosudarevy bojare 1 voevody mnogo $1 z 0$ Pekova z gramoty goncov posylajüče / 1 o veech nastojaв̌člch. Jaže vo Pakove, 1 nadežeju na boga neoslabno gosudarju p1šüče. / S1e že pr1 korolevakim otojanil. rako ze 1 korolevakof ot goroda otchod 1 roevod ego,

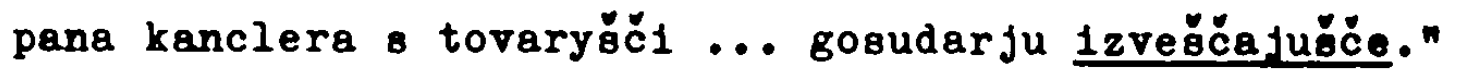

128) Ilkiforov, Glagol, S.247, . besonders "Primećäín", bd., wo er - olch gegen Istrina wendend bew. deren' AuBerung von der groberen Autonomie des präpositiven Part.s differensierend - obigo Ausfuhrungen macht. Vgl. Iatrina, Sint.javlenija, S. 84 inzicka, Das gynt.System, S. $20 \mathrm{ff}$. 


\section{Partizip und Aspekt}

Der Gebrauch von Part.praes. und Part.praet. ist in noch viel stärkerem Maße aspektorientiert als die Verwendung von Imperfekt und Aorist: Part.praes. wird beinahe ausschlieBlich von Verben gebildet, die heute als imperf. gelten, Part.praet. von Verben, die heute perf. sind. Eine Aufgliederung des Belegmaterials in der Art, wie wir sie im Zusammenhang mit den Untersuchungen an Imperfekt und Aorist durchgefuhrt hatten, um voraspektuelle Spuren zu sichern, erübrigt sich daher.

\subsection{Part.praes.-Formen perfektiver Verben}

\subsubsection{K-pler Text: Part.praes.-Formen perfektiver Verben}

Eine scheinbare Ausnahme vom aspektkonformen Gebrauch der Part.ien bildet im K-pler Text die Form "zapovedaja".

62/44 "I povele patriarch pozvoniti po vsemu gradu, zapovedaja vsem ljudem, iže ne bjachutb na brani, 1 ženam $i$ detjam koiždo ich, da poidut $k$ svoemu prichodu, ..." - Und der Patriarch ordnete an, dab überall in der Stadt die Glocken geläutet würden, womit den Menschen. 189 angezeigt werden sollte, daß sie sich in ihren Kirchen sammeln sollten, ...'

Das Part. erläutert "pozvoniti", die erkennbare finale Bedeutung beruht wohl auf "povele". Doch ist auch finale Beziehung 'Glocken läuten, damit die Menschen sich sammeln' - "pozvoniti - zapovedaja" denkbar. 130

"zapovedati" ist heute perf. Das Part. in obiger Textstelle hat aber die gleiche Zeitlichkeit wie "pozvoniti", die Form des Infinitiv läßt das vielleicht fraglich erscheinen, wir brauchen aber nur "povele" einmal wegzulassen, um die zeitliche Komponente zu verdeutlichen: "pozvonisa po vsemu gradu, zapovedaja vsem ljudem ..." - 'sie läuteten in der ganzen Stadt, damit den Menschen anzeigend, ...' Das Part.praes.

129) "prichod" - 'Parochialkirche, Pfarr-', s: Srezn, II 1489: "prichods = prichod, cerkovnaja obscina" (Bedeutung 5 ).

130) Nikiforov, Glagol, S. 268 nennt kausale und konditionale Bedeutung des Part.praes. - finale wäre also zuzufügen. 
perf. Verben bezelchnet aber bekanntlich (heute) eine zur Haupthandlung im Verhältnis der Vorzeitigkeit stehende Jebenhandlung.

Die Gleichzeitigkeit der partizipial ausgedruckten Handlung "zapovedaja" reflektiert einen lilteren Zustand - "zapovédati" wird fur das Aksl. und das frühere Altruss. im allgemeinen der imperf. Aspekt zugeschrieben. ${ }^{131}$ Komposita vom Typus "-vědati" bildeten die iterative Variante $z u$ den Komposita von "vèdět1".

4.1.2 Pleskauer Text: Part.praes.-Formen perfektiver Verben $61 / 35$ "...; ot grada že 12 rovov tech vykopaja, velik1ja

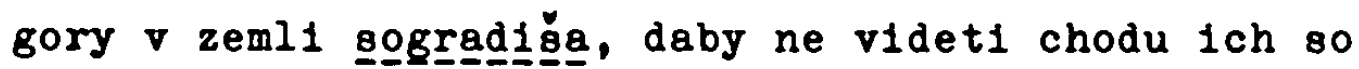
gradny ja steny."

'...; Indem sie die Erde aus den Gräben zur Stadt hin hinausschaufelten, bildeten sie große Haufen, damit sie von der Stadtmauer aus nicht gesehen werden konnten.' oder:

'...; nachdem sie die Erde aus den Gräben zur Stadt hin aufgeworfen hatten, machten sle große Erdhaufen...'

Die Textstelle erlaubt keine Entscheidung, ob die partiziplal ausgedruckte Nebenhandlung als glelchzeitig oder als vorzeltig aufzufassen ist. Mir scheint, dab die iterative Grundbedeutung von "kopati" im obigen Satz doch noch stark durchschlägt. Jedenfalls spricht die sehr vage, sehr unklare Beziehung zwischen "vykopaja" und "sogradiša" dafür, daß "vykopat1" noch keinen sicheren Platz im aspektuellen Empfinden des Pleskauer Autors gefunden hatte. ${ }^{132}$

131) Ruzicka, Aspekt, S. 50 f. findet auch für "şvědět1" imperf. Belege in der PVL, so auch Dostal, Studie, S. 367. E. Hermelin: Uber den Gebrauch der Präsenspartiz1pien von perlektiven Verben im Altkirchenslavischen. Uppoala 1935. S. $29 . \mathrm{ff}$. findet neben Imperf. Belogen für Komposita von "védét1" auçh gelegentlich perf. Bedeutung bel Komposita Fon "-védgti". Dostál, Studie, S. 583 findet die Komposita von "-vedatin in durativer, iterativer, manchmal auch in perf. Bedeutung.

132) X. Trost: Uber den Gebrauch der Präsenepartizipien von perfektIven Verben im Altkirchenslavischen. In: AzfSIPh. 1 (1966). S. 31 - 51: Im Aksl. stand das Part.praes. 
76/19 "..., a vam, ostavšimsja ženam, veleno po litovskij narjad itti 1 ostatok litvy pobivati, ot proloma skopjas,a."

'Euch Prauen, die ihr zurückgeblieben seid, ist geboten, die litauischen Geschützstellungen zu besetzen und den Rest der Litauer niederzuschlagen -

a) indem inr euch an der Bresche versammelt/ euch an der Bresche versammelt habend.

b) die sich an der Bresche sammeln/ gesammelt haben.'

Abgesehen davon, daß gar nicht so recht klar ist, wie "skopjasja" zu beziehen 1st - ob auf "veleno" oder aber auf "ostatok litvyn"133 -, bleibt in jedem Pall die zeitliche Dimension der partizipialen Aussage im dunklen - aus dem Kontext geht nicht hervor, ob wir mit Vor- oder Glelchzeitigkelt zu rechnen haben. Dostál bezeichnet "sokupitisja" als klar perf., und auch die Belege bel Sreznevakif sprechen dafür. ${ }^{134}$ Dennoch scheint mir obige Textstelle eine gewisse Unsicherheit bezüglich des Aspekts dieses Verbs zu signalisieren.

82/24 "Nyne že pišu k vam, žaluja vas i snabdją blagorodie vaše, ..."

- Jetzt schreibe ich euch und erweise euch damit meine Gnade, gleichzeitig achte 1ch damit eure hohe Stellung, -..'

Da "snabdja", das ja vom heute perf. "snabdet"n abgeleitet 1st, mit "žaluja" (dem Part. eines heute noch imperf. Verbs) koordiniert ist, scheint mir die Bedeutung der Gleichzeitigkeit gesichert. Das spricht für imperf. Aspekt-d.h., daB die alte durative Bedeutung noch vorherrscht. ${ }^{135}$

perf.-durat. (= komplexiver) Verben zur präterital ausgedrückten Haupthandlung im Verhältnis der Gleichzeitigke1t. Nur, wenn es sich auf eine gegenwärtige Haupthandlung bezleht, steht das Part.praes. Im Verhältnis der Nachzeitigkeit zu dieser.

133) Es wäre der elnzige Pall in unseren Texten, das ein Part.praes. auf -a/-ja be1 einem Akk.-Objekt steht.

134) Srezn. III 721; Dostál, Studie, S. 417.

135) Dostál, Studie, S. 456: "şnabsdèt1" - oft imperf.Aspekt. 
92/29 "...; ašće l1 sam gosudarb nelspravja, cholopu 1̇gpra= vitt1__velitt, - bezčestno estb se ..."

'...; wenn der Herr, oelbst unfähig, eine Angelegenhe1t auszufuhren, einem knecht befiehlt, diese zu besorgen, so ist das unehrenhaft (eigentlich: unfair) ...'

Die Ubersetzung entzieht sich bewubt einer Entscheidung, ob "neispravja" als vor- oder gleichzeitig zu interpretieren se1. Gonau genommen, 1st Vorze1tigke1t anzusetzen. Denn der Herr wird die Angelegenheit dann delegieren, wenn sich herausgestellt hat, daB er sie nicht ausführen kann. Dostál bezeichnet die Komposita von "praviti" ohne Einschränkung als perf. ${ }^{136}$ Wenn es so ist, wie Trost feststellte, das die Part.Paes.-Form eines komplexiven Verbs - bezogen auf eine präsentische Handlung ("velit")- Nachzeitigkeit ausdrucke, 8.0. Anm. 132, dann reflektiert obiger Beleg bereits den modernen Sprachgebrauch - das Part.praes. eines perf. Verbs bezeichnet Vorzeitigkeit.

Aus den vorgeführten Textstellen können wir kelne Schlüsse ziehen, da die unklaren Konstruktionen - bis auf die letzten Beleg-keine eindeutige Interpretation erlaubten. Das könnte darauf deuten, dab "vykopati" und "skopitisja" noch nicht vollkommen auf den perf. Aspekt festgelegt waren.

136) Dootál, Studie, S. 351. 


\subsection{Part.praet.-Pormen imperf._(durat.) Verben}

Wir haben eine beträchtliche Anzahl entsprechender Belege registriert, doch handelt es sich fast ausschlieblich um den bereits erwähnten formelhaften Gebrauch von "slyšav/še" und "videv/šen. ${ }^{137}$ Im K-pler Text begegnen diese Formeln $20 \mathrm{Mal}$, in der Pleskauer Erzählung gar $57 \mathrm{Mal}$.

Der Grund für die Diskrepanz zwischen beiden Texten in dieser Hinsicht ist nicht nur darin zu sehen, daB der K-pler Autor seine Wendungen häufiger varilert, sondern auch darin, daB er für "slyšav/še", "videv/še" in 14 Fällen den Aorist verwendet: "slyša/ša", "vide/ša". Wir hoben anläßlich der Untersuchung durativer Aorist-Formen hervor, daß der K-pler Autor von Verben der 4. Leskien'schen Klasse mit Infin.-Stamm auf -ëti- noch den Aorist bildet, während der Pleskauer Autor ein Jahrhundert später dazu nicht mehr in der Lage zu sein scheint: selbst von den beiden hochfrequentierten Verben "slyšati" und "viděti" umgeht er die Bildung des Aorist, indem er die Part.praet.-Formen verwendet.

Wir beobachten dreierlei Verwendung dieser Formel, wobei die dritte Variante nur im Pleskauer Text vorkommt. Wir präsentieren zu jeder Variante nur jeweils ein Beispiel: ${ }^{138}$

1. "slyšav/šn", "videv/še" haben begründend-auslösende Funktion - mit Hilfe der Formel wird an eine zuvor mitgeteilte Nachricht angeknüft ("videv že sie", "sija vsja slyšavsen u.a.) und die Reaktion darauf geschildert, z.B.:

KP 58/33 "Sie že videv, cesarb povele velbmožam 1 megistanom razdeliti voinom gradckija steny ..."

'Als der Kaiser dies gehört hatte, (= Daraufhin) befahl er den Würdenträgern und Megistanen, die Mauern abschnittweise ... aufzuteilen ...'

137) Manchmal lesen wir auch "vedev" oder "vediv", z.B. PS $86 / 32$ - hierbei dürfte es sich um dije für die Pleskauer Mundart typische Verwechslung von -é- und $-i-$ handeln, die auch im gesamten Nordwesten ublich war.

138) Belege mit "videv/še" und "slyšav/še" machen auch einen beachtlichen Tell der Beispiele Nikiforovs für Part. praet. durativer Verben - Glagol, S. $276 \mathrm{ff}$. 
2a) In Pleskauer Text wird die Nachricht oder das Gesehene mit Akk. direkt angeschlossen; oft, wie im folgenden Be1op1el, mit doppeltem Akkusativ (hierzu ausuhrlicher B.u.):

PS 52/17 "Togda videv vaegordelivyj toj korolb mnogo sobravĕujusja u Bobja velikuju silu, togda bolbmi razgor= deㅛㅛㅛ vo Bvoem vysokom bezbožnom pomysle, ..." 'Als der ... Kontg sah, dab sich dieses riesige Heer bel inm sammelte - da wurde er in selnem uberheblichen, gottlosen Sinn von großem Stolz erfullt, -...'

2b) In beiden Texten wird hin und wieder das Gesehene/Gehörte durch "Jako" angeschlosien, bevor die Reaktion beschrieben wird:

KP 60/36 "V1dev že bezbožny turok, fako ne uspe ničtože, no pače ovolch pogub1, 1 povele magistrom vikore pribav1t1 pušk1 1 ..."

'Als der Gottlose erkannte, daB alles nichts einbrachte, das er vielmehr seine Krieger (Binnlos) opferte - da befahl or seinen Magistern, schnell weitere Geschutze und ... herbelzuschafffen.'

3) Eine Varlante der Verwendung von "olysav/še, jako" finden wir nur in der Pleskauer Erzahlung: Fach der Pormel folgt das (melst) Gehorte quasi in Form von wörtlicher Rede. 139 Bine Reaktion darauf erfolgt nicht.

PS 58/14 "Paky že elyğav vo Pekove, jako uže korolb pod Oetrov ... pribel, ..., 1 po Ostrovu gorodu 12 narjadu uže bbet."

'Und dann hörte man in Pleskau auch, daB der Kön1s gegen Oetrov geruckt (d.h. dort schon angekommen) se 1 und die stadt ... beschlebe.'

PS 55/7 "(gosudarb) ... tože Blyŏav, Jako soverb̌enoe 11tovok1 j bezbožnyj korolb na ... Pakov ... uetrem 1 sja." 'Auch erfuhr der Zar, daB der I1tauische Xonig ganz -1cher ("eoversenoe") nach Pleskau abmarechiert se1." oder: 'Der Zar erfuhr ala alcher, daB ...'

139) S.0., \$.485 ff., Uber das 1-Part. nach Verben des Brfahrens, Horens, Mttellens usw. 


\subsubsection{Part.praet.-Formen 1mperf. (durat.) Verben - K-pler Text}

Uber die genannten Wendungen vom Typ "slyšav/šen, "videv/še" hinaus sind Part.praet.-Belege heute imperf. Verben in beiden Texten überaus selten. Prinzipiell hätten solche Part.ien bezuglich der Haupthandlung Gleichzeltigkeitsbedeutung, doch drücke das präpositive Part.praet. durativer Verben meist Vorzeitigkeit aus ${ }^{40}$ und Präposition ist ja beim Part.praet. die Regel. 141

Gleichzeitigkeitsbedeutung ist im folgenden Textbeispiel am nachgesteliten "videv" erkennbar:

$60 / 29$ "... čajachu bo uže otgtúpItti bezbožnomu, toliko padenie videv svoim."

'.... hofften sie doch, daß der Gottlose die Belagerung aufgeben werde - angesichts so groBer Verluste.'

Eg spielt hierbel keine Rolle, daB "videv" sich nicht auf "čajachu" (= Griechen), sondern auf "otstupiti bezbožnomu" bezieht. Wichtig ist die zeitliche Bedeutung von "videv" die Ubersetzung versucht, die Gleichzeitigkeit durch 'angesichts' herauszustellen; denn die ungeheuren Verluste der Türken stellen einen geradezu toposhaften Grundzug der Erzählung dar, dem die Tapferkeit der Griechen gegenübersteht. Auch igt ein konkreter Bezug gegeben - obige Bemerkung betrifft die Mittellung, daB man 18000 gefallene Türken gezählt habe. Dieser unmittelbare Bezug legt also auch eher Gleichzeitigkeit nahe - "videv" könnte ohne weiteres durch "vidja" ersetzt werden.

Zwei der drei übrigen Belege für Part.praet. durativer Verben können wir zusammenstellen:

140) Nikiforov, Glagol, S. 276 f. "značenie deepričastij prosedsego vremeni ot osnov s leksiceskim znaceniem neopredelennoj diftel'nosti dejotvija".

141) Im KP-Text 1st abhängiges Part.praet. in 9 v.Hd., im PSText in 22 v.Hd. aller Fälle nachgestellt. Ruzicka, Das syntakt.System, S. 84 und 136 errechnete 23 v.Hd.

142) Uber Austauschbarke1t von Part.praes. und Part.praet. durativer Verben - 8. Nikiforov, Glagol, S. 279. 


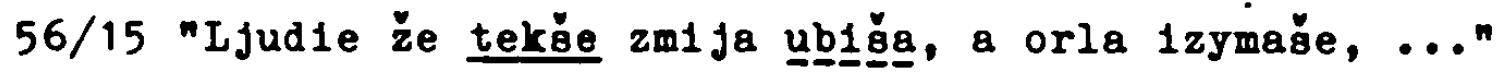
' (e1ligst) herbelgelaufen, erschlugen Leute die Schlange und entwanden ihr den Adler, ...'

68/3 "Na utrija že šedše skazagęa patriarchu."

'Morgens (schon) herbeigeeilt, berichteten sie dem Patriarchen (davon).'

In beiden Sätzen haben wir es mit determinierten Verben der Bewegung zu tun. Ganz o1cher auBert s1ch darin, dab der Autor Part.praet.-Formen von Simplicia verwendet, eine archalalerende Tendenz - denn wir muBten in der tbersetzung jewells verdeutlichen 'herbellaufen', 'herbelellen', was "pritekse" und "prišedše" entspräche. Im 16. Jh. z.B. (und sicher auch schon 1m 15. Jh.) besteht die Ne1gung, neben Aor.-Formen auch Part.praet.-Formen von Simplicia (z.B. be1m Abschreiben) durch präligierte Komposita zu ersetzen. ${ }^{143}$ Das geschleht bel determinierten Verben der Bewegung anscheinend erst opäter - die Determinlerthe1t otellt auch die entoprechenden Simplicia in d1e Tähe perf. Verben. ${ }^{144}$

64/23 "Takože 1 tof zlovernyf Magumet mnogo dnif sovetovavše,

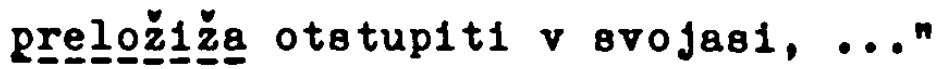

'So hielt dieser 1rrglaubige Mehmed tagelang Beratungen $a b$, Im Rahmen welcher die Aufhebung der Belagerung vorgeschlagen wurde, ...'

Wahrend in den vorigen Textstellen die Vorzeltigke1tsbedeutung der Part.ien keinem zweifel unterliegen konnte, scheint hier die durch Part.praet. ausgedrückte Nebenhandlung zur mit Verb. fin. bezeichneten Haupthandlung im Verhältnis der Gleichze1t1gke1t zu stehen. - Verben mit dem Suffix -ova-/-eva waren ja lange Ze1t zur Bildung aller Tempora befinigt, aspektuell noutral. Erot in jungerer Ze1t gingen ole in den Bestand des 1mperf. Aspekts ein.

143) Mlkiforov, Glagol, S. 277: z.B. ersetzen jungere Hs8. des "Domostroj" und der "Kaz. Istor1ja" unprafiglerte Part.pretr Formen durch praflglerte Pormen.

144) Jungere Abschriften haben ob1ge Pormen: T1kon. Letop. (PgRL 12), S. 90 "gedsen, "Step.kn1ga" (PSRL 21/1), S. 499 "bedbe" ausgelassen; "Chronograf 1512" (PSRL 22/1), S. 444 "tekzén", S. 453 "Bedsen; "Voskresengk1f letop." (PSRI 8), 
4.2.2 Part.-praet.-Pormen 1mperf. (durativer) Verben -
Pleskauer Text

Zum zuletzt genannten Typus gehört auch der folgende Beleg aus der Pleskauer Erzählung, was dle lange währende aspektuelle Neutralität der Verben mit -ova-/-eva-Suffix bezeugt: ${ }^{145}$

42/1 "Mnogye že ... vo1 1 v Polocki 1 vo okrestnych gradech chrabro mužestrovavge, 1 krovi svoja $2 a$ christovu veru

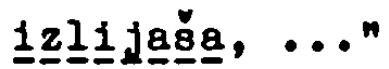

- Viele haben in Polock wacker ihren Mann gestanden und ihr Blut für den christlichen Glauben vergossen, ...'

Partizipiale und verbale Aussage sind koordiniert, was die 2wischen Part. und Verb.fin. gestellte Konjunktion "1" unterstrelcht. Bis zum gewissen Grade sind die Aussagen 1dentisch: im zweiten Syntagma wird die Ausgage des ersten abstrahiert, in eine geistliche Sphäre transponiert - 'sie standen wacker Ihren Mann, mit anderen Worten: sie vergossen ihr Blut ...' So durfen wir annehmen, daB "muźestvovavše" einen Aor. ersetzt.

$37 / 22$ "Znamenavše že sja s1loju voobražentja kresta christova ot ... Selivestra. Taže po ... 1konam znamenavŏisja 1 mnogie obety svjatym mestom ... vozdat1 obeščavsesja, ..."

- Sylvester segnete ihn durch die Kraft des Kreuzeszeichens. Auch mit den Ikonen wurde er gesegnet; und er versprach den heiligen Stätten viele Schenkungen...'

Auch hierbei handelt es sich um freie Part.-Syntagma mit absoluter Prädikation. Ein Bezug zu finiten Verbalformen - wie 1m Be1spiel oben - 1st nicht möglich.

Be1de Verben - "znamenat1/sja" und "obeščat1/sja" - gehörten im Aksl. und Altruss, beiden Aspekten an. ${ }^{146}$ Im Altruss. hatten sie wegen suffiglerter Ableitungen "obeǧčevati" und "zna-

S. 126 "tekšen, S. 136 "šedšen.

145) Nikiforov, Glagol, S. 69.

146) Dostál, Studie, S. 111 - "znamenatisjan, S. 325 f. "obegeatiojan; Barnet, Vývoj, S. 153 - das letztere gehört zu den "slovesa, která $\nabla$ stare rustine kollsala ve vidu." 
menovatin 147 ganz sicher starken Hang zum perf. Aspekt. "obešcat'sja" wird auch heute noch beiden Aspekten zugezlihlt. ${ }^{148}$ "obeščav/šesja" begegnet in dieser Form im Pleskauer Text noch sechs Mal, jedes Mal als Zentrum eines unabhängigen Part.-Syntagma mit absoluter Prädkation und ersetzt dort Aor.-Pormen; eine solche treffen wir nur ein Mal (47/17) im Rahmen eines Briefes. - Vor diesem Hintergrund 1st das Vorkommen dieser belden Belege für Part.praet. durativer Verben nicht verwunderlich.

Das einzige Part.praet. eines heute imperf. Verbs zeigt der folgende Beleg:

61/24 "A $v$ tech borozdach, jako že posled1 chodivǎe 1 sčet obretogea, dvorov bolbšich v zemli vykopano, .... sto tridcatb dre ..."

'Und in diesen Gräben fand man, als man später darin umherging, 132 in die Erde gegrabene groBe Höfe (gemeint sind 'Unterstände')...'

Das Part.praet. hat hier Gle1chzeitigke1tsbedeutung: 'später, während man umherging ..., fand man ...'. Das Part. bildet den Mittelpunkt elnes als Temporalsatz funglerenden Syntagmas, das durch "jako" in der Funktion einer subordinierenden Konjunktion eingele1tet wird. Die relative Elgenständigke1t des Part.-6yntagmas wird durch die zwischengeschaltete Konjunktion "1" hervorgehoben. - Hatten wir bereits bezliglich eines Aor.-Belegs "schod1šasja" (61/28) die Vermutung geäußert, daB auch im 16. Jh. Indeterminierte Verben der Bewegung möglicherweise noch nicht vollkommen in die Funktion des 1mperf. Aspektpartners der entsprechenden Determinativa gedrängt waren, sondern noch eine gewlsse Bigenbedeutung und Selbständgke1t besaßen, so wird diese Vermutung durch das Part.praet. "chodivěe" bestärkt.

147) "obèštavat1 aẹ" - Slovnfk jazyka staroslověnského II 503; Sadnik-Altzetmuller, HWB, S. 72; Hermelin, tber den Gebrauch von Präв.-Part.1en, S. 37; Dostal, Studie, S. 539. - "znamenovat1" : Slovn1k ... I 679; Sadn1k-11tzetmuller, HTB, S. 167 ; srezn. I 990.

148) Daum-Schenk, Die russ. Verben, S. 277. 
4.2.3 Anzeichen für die Aussonderung von Part.praet.-Formen, die von imperf. (durativen) simplicia gebildet sind:

DaB derartige Pormen in beiden Texten Ausnahmecharakter haben und in den melsten Fällen, wie gezeigt wurde, z.z. der Abfassung unserer Texte gar nicht als eindeutig imperfektiv einzuschätzen sind - das beweisen die wenigen Belege. Nur "slyšav/še" und "videv/še" hatten sich auf Grund ihres weitgehend formelhaften Charakters in beiden Texten gegenuiber der Beschränkung der Part.praet.-Kategorie auf perf. Verben als widerstandsfähig erwiesen.

In beiden Texten finden wir aber auch Beweise dafü, dab selbst in diese homogene Gruppe präfigierte Pormen einzudringen beginnen: 149

KP 59/44 "Turk1 že pak1, uslyğav zvon velif, pustt1ga… tumban tbmočislennych, ..."

'Als die Türken das Glockengeläut vernahmen/vernommen hatten, ließen sie tausend und abertausend Pauken erschallen, ...'

PS $53 / 25$ n...; 1 sie uvidev, vmale družine $v$ Ninevgiju ubeža $1 \ldots n^{150}$

'...; als er (Sanherib) dies sah/gesehen hatte, da fioh er mit wenigen Getreuen und ...'

Aus jedem Text ließen sich noch verschiedene entsprechende Be1spiele benennen (KP 63/22, 66/38; PS 53/21, 56/27, 60/31, $65 / 25)$.

149) Es wird nochmals an die Beobachtungen Nikiforovs, Glagol, S. 277 f. uber die Präfigierung von Part.praet.Formen (gebildet von Simplicia) in jüngeren Hss. erinnert - 8.0. Anm. 143.

150) Sicherlich ist hier zu lesen:

"uvidev, $v$ male družine ubeža", nicht aber:

nuvidev, 可西le 
5. Der Dat1vus absolutus 151

Der Dativus absolutus (Dat.abs.) stellt eine hochliterarische Fendung dar, die in Bildung und Funktion dem lateinischen Ablativus absolutus und dem griechischen Genttivus absolutus verglelchbar 1st. Meistens tritt der Dat.abs. an die Stelle eines Temporalsatzes, seltener eines Kausalsatzes; manchmal ubernimmt er auch die Funktion eines konditionalen oder auch konzessiven Nebensatzes. Die Bezlehung zwischen dem Dat.abs. und dem Hauptsatz sind verschleden eng, oft steht $2 w 1$ schen beiden eine koordinierende Konjunktion.

Die Bildung eines Dat.abs. erfolgt in der Weise, daB das Subjekt der so formulierten Aussage (Nomen oder Pronomen) im Dativ erscheint; das Prädikat dieses Syntagmas wird durch ein (meist) nominales Part. ausgedruckt, das mit dem Subjekt in Kasus (Dativ), Numerus und Genus korreliert. Das Subjekt des Dat.abs. (also das im Dativ stehende Nomen oder Pronomen) 1st in der Regel von dem des ubergeordneten Satzes (mit Verb. fin.) verschieden. Das im Dativ stehende Part. besitzt keine absolute, sondern auf das Verb.fin. bezogene zeltlichke1t das Part.praes. bezelchnet Gleichzeltigke1t, das Part.praet. Vorzeitigkeit.

Hauptaachlich erschelnt der Dat.abs., wie betont, in literarischen Genres - Viten, Lobpreisungen, Belehrungen, theologischer Literatur - und in Gattungen, die traditionsgemäB einer archalolerenden Diktion verpflichtet waren - Chroniken, historische Erzählungen usw. In der profanen literatur begegnet diese Fendung nicht. 152

151) Die folgenden allgemeinen Ausführungen orlentieren sich an: Potebnja, Iz zapisok, S. 329 - 35 ; Borkovak1 1. Ist. grammat1ka, S. 445 - 52 ; Cernych, 325 - 327; I1kiforov, Glagol, S. 256 - 60; Istrina, Sint. Javlent ja, S. 211-20; Sticenko, Ist.sintaksis, S. 122 f.; Barnet, Vývoj,S.4345; Samsonov, Drevneruss.jazyk, s. $240 \mathrm{f} \cdot \mathrm{u}_{.} \mathrm{.}$.

152) Borkovak11, Ist.grammatika, S. 446: "My ne votret1l1 ego (Dat.abs.) ni $v$ gramotach na pergamene, ni $v$ gramotach na bereste." 
Der Dat.abs. wurde noch lange als Wendung besonders hohen Stils empfunden - noch Lomonosov empfahl ihn für Oden und andere Dichtungen dieser Stilschicht; ${ }^{153}$ sogar bei Radiščev und auch Zukovskif finden sich - letzte - Beispiele. ${ }^{154}$

Mit der Zeit erscheinen folgende Bildungsvarianten:

1. Die jeweilige Beziehung zwischen Hauptsatz und Dat.abs. wird durch eine entsprechende Konjunktion unterstrichen (z.B. "egda + Dat.abs., Verb.fin.").

2. Selt dem 14. Jh. häufen sich die Pälle, da die Kasus-Kongruenz unterbleibt - melst hat nur noch das Part. die Porm des Dat.

3. Oft hat das Part. die pronominale Dat.-Endung, insbesondere beim Plural (-1mb statt nominalem -emb), aber auch beim Dat.8g.

In beiden Texten kommen - kurioserweise - je 76 Dat.abs. vor. ${ }^{155}$ Be1 jeweils um 1500 Verbalformen (incl. nominaler Part.ien) entfallen auf den Dat.abs. Jeweils ungefähr $5 \mathrm{v} . \mathrm{Hd}$. Leider fehlt mir jegliches Vergleichsmaterial, so dab eine uberzeugende Aussage, ob dies sehr viel oder sehr wenig ist, sich als unmöglich erweist. ${ }^{156}$ Meinem Empfinden nach erscheint der Dat.abs. In unseren Texten noch häufiger als in so hochkonservativen Texten wie der "Stepennaja kniga" oder der "Kazanskaja Istorija".

In unseren Texten erscheint der Dat.abs. (Plur.) fast ausschlieblich in der dritten Bildungsvariante: auf -ščlm bzw. ilm endend. 157

153) Lomonosov hofft, daB "sija poterjannaja kratkost' 1 krasota v russkoe slovo vozvratits ja", 8. Borkovskif, Ist. grammatika, S. 448, Anm. 368 .

$154)$ Cernych, Ist.grammatika, S. 326.

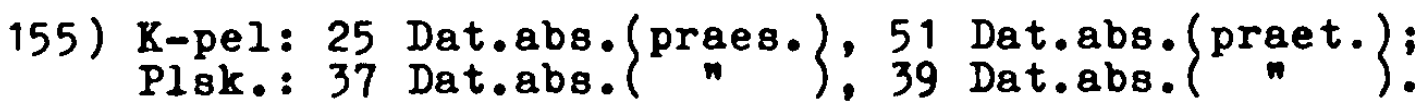

156) Hicht einmal Boretzky, Tempusgebrauch - geht auf den Dat.abs. ein; sonst stellt er die einzelnen Erscheinungen wenigstens vor.

157) Nikiforov, Glagol, S. 259: fast alle Beispiele auf -1m. 


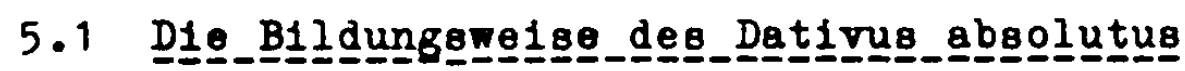

(Kongruenz zwischen (Pro-) Nomen und Partizip)

Sieht man einmal von der eben erwähnten Abweichung ab (-ǒčim/ -sim beim Dat.abs.-Plur.), sind Dat.abs. In beiden Texten in erstaunlich hohem MaBe korrekt gebildet: ${ }^{158} 61$ Mal herrocht Kasus-/Bumerus-/Genus-Kongruenz im K-pler, 57 Mal im Pleskauer Text - das sind 75 - 80 v.Hd. ${ }^{159}$ Z.B.:

56/21 "Vrement že sego overepstvu prispevajušču,

litovskomu korol ju stepanú 80 mnogoju siloju ... prišeds̆u, slucht že vsjačeski vo Pskov pro to prichodjašču, ... 'Die Zeit dieser Grausamke1t (= diese schlimme Zeit) 'Dahte; der litaulsche Könlg war mit seinem riesigen Heer viele Nachrichten darüber gelangten nach Pleskau, .... Wie wir es im Zusammenhang mit den Untersuchungen an den Tempora und den nominalen Part.ien im Nominativ sehen konnten, so zeigt sich auch belm Dat.abs. die Reimabsicht des Pleskauer Autors: Noch drel ähnliche Blöcke finden wir, stets mit Dat.abs. Sing. - offensichtlich erscheint dem Pleskauer Autor die Endung -u markanter als die des Plur.s. ${ }^{160}$

Alle dre1 Dat.abs. sind vollkommen unabhängig; von "sluch1 ... prichodjašču, jako ... korolb ... prišoln 1st sogar noch ein Objektsatz (oder wörtliche Rede) abhängig. Der letztgenannte Dat.abs. zeigt falsche Bildung in zweierlei Hinsicht: es müBte heiBen "sluchom prichodjaščim" - "sluchín steht im Hom.pl., und "prichodjašču" reimt mit den vorausgegangenen Sing.-Formen. - Onklar 1st bedeutungsmäBig "prišedšun - hier

158) Als korrekt haben wir in jedem Pall Dat.-Formen von Part.1en be1 Kollektiva betrachtet - ob Sing; ("narodu ze 1zsedéu") oder Plur. ("narodu že 1zéedgim).

159) Nikiforov, Glagol, S. 258 stellt fest, daB ca. 50 v.Hd. aller Dat.abs. Keine Kasus-Kongruenz aufweisen, Indem das Part. auf die Universalform -scet-ree endet. Solche Pälle - s.u. - kommen Im K-pler Text $8 \mathrm{Mal}$, im Pleskauer Text 9 Mal vor.

160) 46/1: vier Dat.abs., 63/29: dre1 Dat.abs., 94/7: dre1 Dat.abs. und verschiedene zweiergruppen. 
wäre auch "prichodjašcun" zu erwarten, well der König noch unterwegs ist, z.B. wird erst auf $S$. 58, also zwei Selten später, von der Beschießung der Pleskauer Belstadt Ostrov durch Stephan Báthory berichtet.

KP $71 / 16 " \ldots, 1$ uže solncu zašed šu 1 noč $\underline{1}$ nastavŏ1 seča ne_preseta, no ..."

'..., und als/nachdem die Sonne untergegangen und die Nacht hereingebrochen war, endete die Schlacht nicht, sondern ...'

Die Doppelung des Dat.abs. 1st eine Folge der pleonastischen Ausdruckswelse (Hendiadyoin ${ }^{161}$ ), sonst begegnen Häufungen von Dat.abs. Im K-pler Text nicht. Das Beispiel wurde nur deshalb ausgewählt, well es zwel schulmäBig gebildete Belegstellen enthält: ein Dat.abs. (mask.) und ein Dat.abs. (fem.). Die Dat.abs. fungieren als temporale Nebensätze.

Selten erscheint der Dat.abs. von femininen Nomina gebildet, acht Mal im K-pler Text (vier Mal allein obiges "nošči/noči nastavsı"), in der Pleskauer Erzählung dre1 Mal.

In der Punktion eines kausalen Nebensatzes tritt der Dat.abs. im folgenden Satz auf:

KP 58/31 ".... no ubo sile velice 1 tjažce suğčl, ne vozmogosa im nikoeja pakosti sotvoriti, ..." ...., aber we1l er von groBer... Kraft war, konnten ole ihm nichts anhaben, ...'

Pronominale Endung des Part.s finden wir im folgenden Textbelspiel, wo der Dat.abs. - vollkommen autonom - Mittelpunkt einer indirekten Rede ist:

PS 50/21 nØrez sego vel1kogo grada, povedachu, rece tekuščefl, skroze kammenye steny, ...

- Durch diese Stadt - so hort nan - flieBt ein PluB, durch die Mauern hindurch, ...'

Während UnregelmäBigkeiten in der B1ldung des Dat.abs. Sing. nicht ins Gewicht fallen und auch im Plur. falsche Bildungen

161) Lausberg, Elemente, \& 305. 
Im allgemeinen nichts ins Auge fallen, konzentrieren sich Kongruenzfehler auf solche Dat.abs., deren Nomen ein Kollektirum 1st. Im K-pler Text stehen sich Bildungen, die DativKongruenz aufweisen, und Blldungen, die diese Kongruenz nicht aufweisen, etwa gleichstark gegenúber:

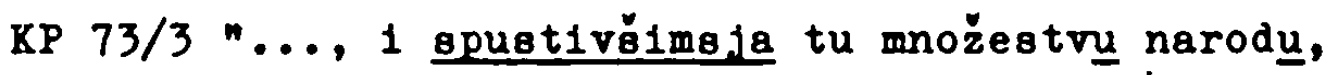
pobiša $1 \mathrm{ch}$ gražane bež́lsleno, ..." '.... und we1l sich hier viele Türken drängten, machten die Griechen Ihrer viele nieder, ...'

Das Part. hat logischen Numerus.

KP 76/41 "Narodū že 1dušču do devjaty godiny 1 ešče mnogym suščem $v$ cerkve ne dožda - ...n

- (Ne1l) das Volk bis zur neuten Stunde aus der Kirche herausetrömte und lmmer noch viele darin waren, wollte er nicht (länger) warten - ...'

Der einzige Beleg im K-pler Text für grammatischen Numerus bel einem Kollekt1rum als Nomen eines Dat.ab.: KP $70 / 25$ "..., 1 sobravšes ja vsem 1 judem po stenam bb jachusja s turky, ..."

'.... und als die Krieger auf die Mauer geellt waren, kämpften sie mit den Turken, ...'

Im Gegensatz zum Dat. des Nomens steht das Part. Im Nom.pl.

Während also im K-pler Text bel elnem Kollektivum als Nomen die Dat1v-Kongruenz (melst Constructio ad sensum) in der Hälfte aller Pälle gewahrt blelbt, oteht im Pleskauer Text in solchem Zusammenhang sechs Mal das Part. Im Nom.pl., nur einmal begegnet Dativ-Kongruenz:

PS 67/1 "Bezzakonnomu vojaku krepko 1 derzostno na steny lezušc̆

'Das gesetzlose Heer strebte unaufhaltsam der Mauer zu.'

Die folgende Vertretung iot Ublich:

PS 66/33 "Pskovakomu že voinstru vachodu na gradovnuju stenu l1 tovakomu volnstru ne dajǚce."

- Das Aufgebot der Pleskauer I1eB die Iitauer nicht die Hauern erstürmen.'

Belde zuletzt angefuhrten Dat.abs. besitzen volle Eigenständigke1t. 
Sonst begegnen noch folgende Abwelchungen von der Norm, die wir jeweilo nur an einem Beispiel demonotrieren wollen:

1. Das Nomen ateht im Dat.8g., das Part. im Nom.pl.:

KP $62 / 7$ "Sija 1 inaja mnoga vop1fušč cesarju $k$ ljudem;

1 povele zvoniti ...n

'Dies und manches andere rief der Kaiser den

Kriegern zu, und er befahl zu läuten ...'

Im K-pler Text zwei Mal, im Pleskauer Text drei Mal.

2. Das Nomen steht im Nom.8g./pl., das Part. Im Dat.8g./pl.: PS $91 / 13^{n V}$ ta že vremena k nemu priechavǒu ljuterakija že ego very rimskago latynakago papy protopop Antonej."

' $\mathrm{Zu}$ dieser Ze1t traf bel $1 \mathrm{hm}$ - vom römisch-late1nischen Papst lutherischen Glaubens (gesandt) der Erzpriester Antonius ein.'162

Im K-pler und im Pleskauer Text je dre1 Mal.

3. E1genständiger Dat.abs, ohne ausgedrucktes Subjekt:

KP $59 / 17$ "Sija vaja 1 ina mnoga 1zreks̆im,

takože 1 preneporočnej bogorodice ... moljachusja."

'Dies und vieles andere sprachen sie,

auch zur makellosen Gottesmutter ... beteten sie.'

PS $73 / 14$ "Ênu że otveščrǒu, jako '..."n

he1Bt nicht: 'Er aber antwortete, daB ...', gondern:

'Man antwortete ihm, dab...'

Im K-pler Text nur oblger Beleg, im Pleskauer Text funf Mal.

4. Das Nomen steht im Dat.pl. oder Nom.pl., das Part. Im

Dat.8g. auf -u:

PS $85 / 11$ n..., svjaščennikom 80 kresty ... prišedšu ..."

'.... die Gelstlichen kamen mit den Kreuzen ...'

PS $56 / 23$ n..., slucht že vajačesk1 vo Pskov ... prichodjašcu, ...."

'.... vielerle1 Nachrichten gelangten nach Pl....'

Diese Varianten gibt es nur im Pleskauer Text.

162) Vermutlich rürt "ljutersk1j" in diesem Zusammenhang nicht nur von der Unkenntnis des Autors her, sondern ist wegen selner lautlichen Vähe zu "ljutyj" usw. verwendet. 
Schlieblich sei noch erwähnt, daB - im Pleskauer Text - gelegentlich der Nebensatz-Charakter des Dat.abs. durch die entsprechenden subordinierenden Konjunktionen unterstrichen wird:

91/4 "Egda bo l1tovskomu korol ju Stepanu podo Pskovom stojascu, v to že vremja (carb) ... na litovskuju zemlju voevod svoich s rojskom posylaet ..."

'Während Stephan Báthory vor Pleskau stand, schickte der Zar seine Voevoden mit inrer Streitmacht nach Litauen ....'

$97 / 26$ "...; pomale že vidjachu, jako litovskomu vojsku ostavajuščesja, ..."

'...; bald darauf sahen sie aber, dab das litaulsche Heer zurückblieb, ...'

Wie angedeutet, gibt es im K-pler Text solche Erscheinungen nicht, doch auch Nikiforov erwännt keinen solchen $\mathrm{Pall}$, noch erscheint ein entsprechendes Beispiel in seinem reichhaltigen Belegmaterial. ${ }^{163}$ Sind auch solche Fälle im Pleskauer Text selten, so scheinen sie anzudeuten, daB die Nebensatzfunktion des Dat.abs. nicht mehr als so selbstverständlich empfunden wird, so das es nötig erscheint, die spezielle Punktion des Dat.abs. durch eine kIärende Konjunktion zu unterstreichen.

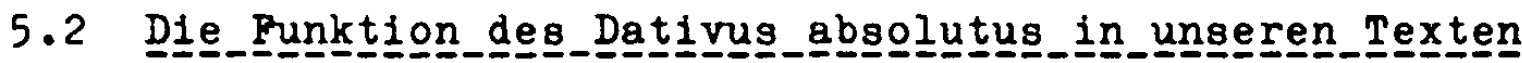

Istrina charakterisiert den Dat.abs. als in seiner Punktion sehr ännlich dem Nominativus absolutus ${ }^{164}-d_{0} h$. Jener partiziplalen Konstruktion, die uber ein subjekt verfugt, das sich von dem des (Haupt-) Satzes mit Verb.fin, als Prädikat unterscheidet. Wir hatten derartige Syntagmen als zur absoluten Eigenständigke1t hin tendierend gekennzeichnet und entsprechend in unseren Tabellen vermerkt. In der 1. Novgoroder Chronik registriert Istrina sogar Fälle von absoluter Autonomie des Dat.abs., dem gelegentlich auch ein Satz mit finiten

163) Dikiforov, Glagol, S. 256 - 60. Borkovsk1j allerdings erwähnt derartige Pälle - Ist.grammatika, S. 4471.

164) Istrina, Sint. javlenija, S. 212. 
Verbalformen untergeordnet sein kann. ${ }^{165}$ Ausdrücklich betont sie, daB der Dat.abs. - entsprechend dem griech. Genitivus absolutus - ein elgenes Subjekt besitzen muß, das sich vom Subjekt des Satzes mit finiter Verbalform, dem der Dat.abs. vage untergeordnet 1st, unterscheidet. ${ }^{166}$ Die vage Abhängigkett des Dat.abs. In der Form, die Istrina als verbreitet in der 1. Novgoroder Chronik anfuhrt - Trennung des Dat.abs. vom (ubergeordneten) Satz mit finiter Verbalform durch koordinierende Konjunktionen -, splelt in unseren Texten eine ganz unbedeutende Rolle. ${ }^{167}$ Den Dat.abs. In der Funktion vor allem temporaler und kausaler Nebensatze ${ }^{168}$ haben wir in den bisher angefuhrten Textstellen kennenlernen können.

DaB sich unsere Vergleichstexte im Gebrauch der Dat.abs. unterscheiden, deutete sich bereits an den vorgestellten Textbeispielen an. Der allgemeine Elndruck ist der, dab im K-pler Text die Subordinierung des Dat.abs. unter einen Satz mit Verb.fin., ja sogar seine Einbindung in einen solchen in einem viel stärkeren Maße stattfindet, als dies im Pleskauer Text geschieht. Damit elne klare Vorstellung von den Verhältnissen in den Texten möglich wird, haben w1r die Dat. abs.-Belege zunächst elnmal daraufhin untersucht, ob sle ein eigenes subjekt (ausgedrückt oder unausgedruckt) besitzen, das sich von einem evt. ubergeordneten Satz mit Verb.fin. unterscheldet, oder aber ob das Nomen des Dat.abs. gleichzeitig auch das Subjekt des ubergeordneten Satzes mit Verb.fin. ist. Die Gruppe der Dat.abs. mit elgenem Subjekt teilten wir dann auf in abhängige und elgenständige Dat.abs. Das letzte Unterscheidungskriterium erscheint vielleicht subjektiv, tatsäch-

165) Istrina, Sint. javlenija, S. 213 f.

166) ebd., S. 216: "V oborote 'datel'nom samostojatel'nom', sootvetstvenno dr.-grečeskomu Genetivus absolutus, kotorym i stavjat' ego y svjaz', dat.pad. imeni ne dolzen sovpadat' s podlezašćlm predioženija." ('Genetivus' - sic).

167) $\mathrm{Vgl}_{\text {gl }}$ 2.B. Beleg KP 62/7, S. ."... mnoga vopljǚč ceBarju ...; 1 povele ..." Der Hrsg. trennte durch Semlkaton.

168) lotrina, a.a.0., S. 216. Borkovakif, Ist.grammatika, S. 446 betont, daB der Dat.abs. Kaum in konditionaler Funktion vorkommt. Vgl. KP.68/22 "Tebe, cesarju, 1zğedo 12 grada a elicymi voschoscesi, paki, bogu pomogajuscu, 
lich aber wirft das Textmaterial so gut wie keine diesbezliglichen Pragen auf.

An einigen Beispielen wollen wir die obengenannten Unterscheidungskriterien demonstrieren:

1. Den besten Beweis für eigenständigen Dat.abs. Ilefern Jene bere1ta erwähnten Blöcke aus dem Pleskauer Text, von denen wir noch einen vorstellen wollen:

46/1 "Gosudar 1u že našemu, carju 1 vel1komu knjaz ju ... sie slyšavŏu,

soverśennoe emu ustremlenie na ego gosudarevu votčinu, na Pakov grad ugotovljajuščusja;

vrement že sego overepotvu prispevajušču, našim chrestbjanskim zakonom svjatomu

velikomu postu prichodfašču."

'Unser Herrscher ... erfuhr folgendes:

Er (der König) hatte fest beschlossen, den Peldzug nach Pleakau vorzubereiten.

Diese furchtbare zelt rückte näher, als es auf die großen Fasten zuging.'

Zwar ließen sich gewisse Abhängigkeiten zwischen den einzelnen Konstruktionen herausarbeiten - durch den reimenden SchluB der Satze will der Autor dies aber gerade verhindern, er will den suggestiven Eindruck erzielen, den rhy thmisierende Sprache, Anklänge an Parallelismus und Endreim bewirken. - In der Form des Dat.abs. leitet der Pleskauer Autor oft neue Abschnitte ein oder schlieBt Abschnitte ab. Melst ist der Dat.abs. dann elgenständig und gibt die Ausgangssituation:

$41 / 21$ "Ruskomu že gosudar ju šestbvie puti na nemcy trorjašcu, dostigšu že emu paky slavnago grada Pakova, ..." - Auf seinem Wege nach Itvland erreichte der russ. Herrscher auch wleder Pleskau, ...'

oder er gibt ein Reglimee:

44/33 "Kral ju że litovokomu stepanu pod luk1 Velikie pribedău, posly že gosudarevy s soboju privedšl."

- Der litauische König war gegen Velikie Luki gezogen, mobei er die russ. Gesandten mit sich fuhrte.'

močno estb 1 gradu pomošči" - "Wenn du gehst und wenn Gott hilft, dann wird auch der stadt geholfen werden können'. 
Eine für den K-pler Text ganz untypische Stelle gehört auch hierher; sie erinnert ein wenig an Konstruktionen im Pleskauer Text:

63/9 "I abie prišed so mnogoju siloju, vzjaša ich 1 požgoša; krovị że ostavšel $v$ rvech 1 v potocech sgnivšesja - smrad prinošaše velij, no obače gradu ne povred1, vetru otnosjašcu. "

'Wleder kamen die Turken mit groBer Macht, holten ihre Gefallenen ein und verbrannten sie. Das Blut blieb in den Gräben zurück und faulte in den Wasserläufen - mächtiger Gestank wehte heruber, doch richtete er in der Stadt keinen Schaden an, weil der Wind inn wegtrug.'

Der erste Dat.abs. Ist autonom, der zweite hat die Funktion elnes Kausalsatzes.

2. Während der erste Typus vorwiegend im Pleskauer Text zu finden 1st, kommt der zweite Typus in beiden Erzählungen recht häufig vor: Der Dat.abs. mit einem Nomen (1m Dativ), das sich von dem Subjekt des übergeordneten Satzes mit Verb.fin. unterscheldet. Soeben fanden wir schon so einen Dat.abs. Beleg KP 63/9 "vetru otnosjašču" - Subjekt des übergeordneten Satzes 1st "smrad", 1hm steht gegenuiber "vetru".

Hierher gehören die Ze1tangaben wie die folgende: KP 62/27 "Nošć1 že nastavs̆1́, turky otstupíg ..."

-Als die Nacht hereinbrach, zogen sich die Türken zuruick ...'

Diese machen allerdings fast alle zu Typus 2. gehörigen Belege aus; vgl. auch Anm. 168 das Belsplel dort, S. 636, Beleg $76 / 41$ und ganz wentge andere.

PS 46/9 "Semu že k nemu, gosudarju, priechavšu, rasprasivaet že sego gosudarb o gradoukrepleni1 ..." 'Als jener (= Pürst Sujgkij) zum Zaren gekommen war, fragte inn dieser nach dem Fortgang der Befestigungsarbeiten ...'

PS $41 / 32$ "Bogų že popustivšu krepkago sego varvara na chrestbjany grech radi nas̆lch, vestb že gosudarju vo Pskov pride, jako litovskoj kralb Polocko vajal ..." 'Als Gott um unserer Sünden willen den Feldzug dieses Barbaren gegen die Christen zulieB, da 
erfuhr der Herracher in Pleskau, daB der l1taulsche Köntg Polock elngenommen habe ...'

3. Das Nomen des Dat.abs. ist gleichzeitig Subjekt des ubergeordneten Satzes (mit Verb.fin.). Solche Konstruktionen zeugen von engster Verschmelzung des Dat.abs. mit dem Hauptsatz, auch von groBer Stringenz der Aussage, z.B.: 169 KP 68/17 "Vostavǒu že emu reče patriarchu 1, vsem boljarom, da ..."

' Er erhob sich und sagte zu dem Patriarchen und den Bojaren, daB ...'

KP 73/43 "...; - otratıgom že 1 meg1stanom 1 ... priopevǒım, pokreptéa narod 1 borjachusja s turki. Cesar ju že prignavău so vaemi volbmož1 1 ... 1 napade na turki, uže mnogu sušču vojokŭ vnutri grada, ..." '...; Strategen und Megistanen eilten herbei, beatärkten die Kämienden und Tochten mit den Türken. Der Kalser war mit allen wurdenträgern herbelgeeilt und otürte sich auf die Türken, deren schon viele in der Stadt waren, ...'

Die beiden ersten Dat.abs. entsprechen den fur Typus 3 gultigen Kriterien vollkommen; im letzten Pall ("susču vojsku") lot der AnschluB indirekt, als der Dat.abs. Blch auf das Objekt des Vorsatzes "turk1" bzeiht, "turk1" aber im Dat.abs. durch den synonymen Ausdruck "vojsko" ersetzt 1st.

Von sehr großer Stringenz kann man im Pleskauer Text auch nicht angesichts entsprechender Konstruktionen sprechen:

PS 70/5 "Ovim že, mnogočlslenym ranenym ot l1tovekogo oruìja, 1znemogrs $1(\mathrm{~m}) 1$ ot mnogago truda 18tajavóim, - denb že togda zelo ot solnečnych lučb žarostnu bjaše, - no tokmo božilm pokrovom 1 na nego nadežnym rooruženbem krepjašesja."

'Diejenigen aber, die durch die litaulschen Waffen verletzt, ermattet und wegen der großen Hitze ganz auggelaugt waren - es war damale ein uberaus he1Ber Tag -, die wurden nur durch Gottes Schutz und die Hoffnung auf ihn bestarkt.'

169) Istrina, a.a.0., S. 216 - findet solche Belege kaum und bezelchnet ole als "eomnitel'nyen. 
Selbotverständlich gibt es im Pleskauer Text auch Stellen, wo sich der Dat.abs. als untergeordnetes Syntagma auf e1nen Satz bezleht, der als Prädikat kein Verb.fin., sondern ein Part. besitzt:

PS 77/9 "Pjatkü že tomu dnju, ..., k večeru prispevajuв̌ču, l1tovakım že ljudem éšce v Pokrovakoj že bašn1

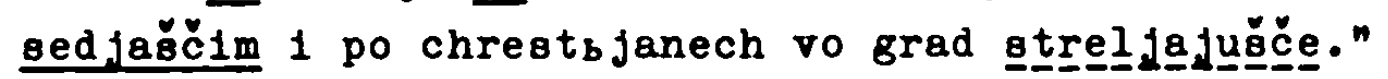
Preltag, als es abend murde, schossen die Lltauer, die noch 1mmer im Pokrovskif-Turm saben, auf' die pleskauer.'

Der Dat.abs. mit der Ze1tangabe am Anfang lot falsch gebildet, es handelt sich an sich um zwei Dat.abs. ("pjatku byvšu" und "večeru prispevajušcun). Der folgende, uns interessierende Dat.abs. könnte dem folgenden Partiziplal-Satz aber auch glelchgeordnet sein, wobel nicht auszuschlieBen lat, daB statt "streljajuščen "streljajušč $\underline{\text { ma }}^{n}$ gedacht war.

Stellen wir also schon bel im Prinzip gleicher Konstruktionsweise große Unterschlede $2 \pi 18 c h e n$ den Texten fest, so deckt die folgende Aufatellung auch die prinziplellen Unterschiede auf:

$$
\text { K-pel Pleskau }
$$

1. Dat.abs. mit eigenen Nomen - elgenständ1g $: 6$ 41

2. Dat.abs. mit eigenem Homen - abhing1B : 28 16

3. Nomen des Dat.abs. = Subjekt d.verbal.Satzee: 42 19

Während also dle Dat.abs. der Gruppe 3, die so eng in den Sateverband integriert sind, im $K$-pler Text weit uber die Hälte aller Dat.abs, ausmachen, machen diese in Pleskauer Text nur die Hälfte davon, nämlich eln Viertel aller Belege aus. Auf der anderen Selte hat der K-pler Text nur sechs autonome Databs., während diese in der Pleskauer Erzahlung sieben Mal so oft vorkomen und damit weit uber die Hilfte aller Dat.abs. stellen. 


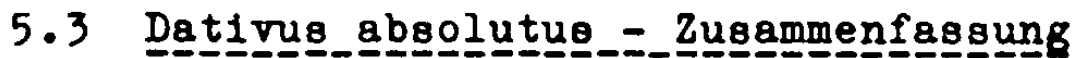

Der Dat.abs. kommt in unseren Texten, so scheint es mir, ungewöhnlich häufig vor. Nikiforov hatte beobachtet, dab in der zweiten Hälfte des 16. Jh.s der Dat.abs. ungefähr in jedem zweiten Pall in von der Norm abweichender We1se gebildet wurde: In der Hälfte aller Belege für Dat.abs. fand er das Part. nicht im Dat., sondern mit der Universalendung -šče/-še ausgestattet. So war es für uns überraschend, nicht nur im K-pler, sondern auch im Pleskauer Text über 75 v.Hd. korrekter Bildungen anzutreffen. Da wir es belm Dat.abs. mit einer hochliterarischen Wendung zu tun haben, düfen wir hieraus schließen, daB sich belde Autoren als literaten verstanden und ihr Terk auf hohes otilistisches Niveau stelien wollten. Damit enden aber auch die Gemeinsamke1ten. Hatten wir bere1ts hinsichtlich der Verwendung partiziplaler Konstruktionen immer wieder auf die Klarheit des Satzaufbaus (z.T. auch Schemat1smus), die zentrale Ausrichtung der gesamten Konstruktion auf ein Verb.fin. als Zentrum des Satzgefüges in der $\mathrm{K}$-pler Erzählung hingewiesen, so können wir hier diese Festetellung noch erweitern: Der grobte Tell aller Dat.abs.-Belege ist in der Neise in einen verbalen Satz integriert, dab das Nomen des Dat.abs. glelchzeltig das Subjekt des verbalen Hauptsatzes darstellt - damit wird die Aussage zentralisiert. Istrina bescheinifte - an Hand des Materials der 1. Novgoroder Chronik dem Dat.abs. gerade gegenteilige, also zentrifugale Tendenzen. Der X-pler Autor neigte zur komprimierten Aussage, die er durch konsequente (manchmal schematische) Anwendung der Hypotaxe errelchte - diese Beobachtung machten wir beim einfachen Part.Syntagma, diese Beobachtung bestätigt olch gerade durch die Bevorzugung dieser das Gewicht des Verb.fin. In keiner Weise in Prage stellenden Konstruktionswe1se.

170) In belden Texten beträgt der Dat.abs. ca. 5 v.Hd. aller verbalen und nominal-partialpialen Formen. Die Vermutung, daB dies sehr viel 1st, kann 1ch nur abstützen durch Zkihlungen in grbBeren Abschnitten der "Stepennaja kniga", wo der Dat.abs. 1,3 v.Hd. der fraglichen Formen ausmachte. 
Wie üblich, vertritt der Dat.abs. 1m K-pler Text vorwiegend Temporalsätze, doch funglert er nicht selten auch als Kausal-, gelegentlich auch als Pinalsatz; als Relativsatz lat er natürlich, wenn "Subjekt" des Dat.abs. und des Hauptsatzes gleich sind, immer auflösbar. Wirklich freie Dat.abs., ohne engere logische Bindung an ein Verb.fin. sind in der K-pler Erzählung überaus selten.

Im Pleskauer Text hat der Dat.abs. otarke zentrifugale Tendenzen. Meistens besitzt er absolute Prädikation - genau wie das nominale Partizip beim Subjekt. 2wischen diesem und dem Dat.abs. besteht überhaupt kein syntaktischer, sondern nur ein ot1listischer Unterschied. Vor allem bel Kapitelanfängen, doch auch am Ende 1 rgendwelcher Ausführungen tritt der Dat. abs. Oft auf, dort dann auch in Blöcken zu drei, ja auch zu vier aufeinander folgenden - und naturlich reimenden - Dat.abs. Bel dieser Wendung lst ja die klangliche Wirkung, besonders im Sing. wegen der Lautung -omu und $-u$, besonders atark, und sie kann durch Anfügung von Attributen noch intensiviert werden. - Wohl steht auch in der Pleskauer Erzählung der Dat.abs. in hypotaktischer Beziehung zu einer übergeordneten, durch Verb.fin. auggedrückten Handlung, doch ist diese Beziehung in der Regel verschlelert, dem Autor vermutlich gar nicht bewuBt. In vielen Fällen muB man hypotaktioche Bezlehungen sozusagen mühsam aus dem Kontext herauspräparieren.

Ein Unterschied im Gebrauch des Dat.abs. In unseren Texten lst noch zu erwähnen: Im $\mathrm{X}$-pler Text erscheint er überall, nicht gerade gleich häufig, aber doch in allen Bereichen Im Gebet, Im Kriegsbericht, in der wörtlichen Rede; er dient hier generell der Kennzelchnung des hohen St1ls. Im Pleskauer Text 1st das zwar auch so - aber wie wir an anderer stelle (S. 267 ) hervorgehoben hatten, verwendet der Pleskauer Autor nominale Part.-Konstruktionen, und ait diesen den Dat.abs., selten in Abschnitten wörticher Rede, in Gebeten, Monologen und Briefen; vgl. auch Tabelle 1. Durch Berorzugung finiter Verbalformen (wenn auch der ksl. Tempora) versucht er offenbar, eine gewisge Annaherung an die lobendige Sprache su signalloleren und so diese Abschnitte vom Kontext etwas abzuheben. 


\section{Arkusetiv mit Partizip}

"Das nominativische Partizip liegt durch den gemeinsamen Subjektbezug auf der gleichen syntaktischen 'Iinie' wie das Prädikat und kann auch deshalb vorzugsweise peripheres Prädikat sein; ...n171 Periphere (= sekundäre), ja sogar absolute Prädikativität kann, wie wir gesehen haben, auch der Dat.abs. erlangen; aber es handelt sich bel dieser absoluten Konstruktion gewissermaBen um die Umformung eines einfachen (wenn auch in 1rgendeiner Beziehung oft untergeordneten) Satzes: dessen Subjekt hat im Dat.abs. die Form des Dativ, dessen Prädikat die Porm eines nominalen Part.s im Dativ.

Anders liegen die Dinge, bezieht sich ein Part. nicht auf das Subjekt, sondern auf ein anderes Satzglied - vorzugsweise auf ein Objekt. Das Part. bezelchnet dann eine Handlung, die von elnem von vornherein abhängigen Satzglied begangen wird.

Das am häufigsten vorkommende objekt 18t das direkte - entsprechend begegnen Part.ien in Verbindung mit objekten fast ausschlieBlich beim Akkusativ, und zwar nach den Verben "viděti", "slyšat1", "uzbreti", "obrěsti". Wir denken sofort an den AcI im Lateinischen.

Kann man generell behaupten, dab das nominale Part. Im Nom1nat1v vorwlegend zum Adv.-Part. geworden 1st, well es me1st die Punktion elnes untergeordneten Prädikats besessen hatte, seltener in attributivischer Punktion erschien, so 1 st es im Gegensatz dazu schwierig, die Punktion des Part.o beim (Akk.-) objekt zu bestimmen. "Die Skala der stilistischen Variabil1tät lst so breit, daB die Grenzen $2 \pi 18 c h e n$ Attributivität und Prädikativität sehr undeutlich werden können. Eine sichere grammatische Signalisierung des Unterschieds gibt es kaum: ...."172 wir wollen uns hier nicht mit diesem problem aus-

171) Rug1cka, Das synt.System, S. 238. Allgemein Uber diese Konstruktion - S. 240 - 262; Potebnja, Iz zapisok, S. 308 - 11; Borkovak1 1. Ist.grammatika, s. $370-73$; Iotrina, sint.javienija, s. 170 - 73; Nikiforov, Glagol, S. $253 \mathrm{f}$.

172) Ruzicka, a.a.0., s. 240. Vgl. Potebnja, a.a.0., s. 308. 
elnandersetzen, zumal das von uns aufgefundene Belegmaterial dazu nicht ausreicht. Es se1 nur schon jetzt auf dieses Problem hingewiesen, we1l es möglich 1st, dab die hier vorgelegten Ubersetzungsvorschläge für entsprechende Konstruktionen nicht immer volle Billigung erhalten.

Heute werden entoprechende Konstruktionen durch Nebensätze wiedergegeben (= Objektsätze), die durch "čton an das Hauptverb angefügt werden, z.B.: 173

KP 65/36 "On že, videv Rachkaveja ljute sekǚca turok, ..." 'er aber oah, dab/wie Rangave mächtig auf die Tüken einschlug, ...'

Heute wilde man die Konstruktion folgendermaßen wiedergeben:

"On videl, čto/kak Rachkavej krepko/užasno sečet turok" bzw. "..., kak on užasno sek turok."

Borkovakif hält auch folgende Wiedergabe nicht für falsch, wenn auch für ungebräuchlich: ${ }^{174}$

"On videl Rachkaveja krepko/užasno geküúčm turok"

Das Part. erscheint im Instr., so wie auch andere 'doppelte Akkusat1ve' heute wiedergegeben werden: "Kocelb knjazb postavi Mefedbja eppa vb Pani1"175= "Knj. Kocel naznačll Mefodija episkopom v Panonii".

Puir uns ist von Wichtigke1t, daß Nikiforov in seinem Belegmaterial 176 kelne Bildung mit Instr. anführt; auch nennt er keine Ersatzkonstruktionen - aber das besagt wohl wenig; dieses Pehlen von Eraatzkonstruktionen im Material Hikiforovs düfte eher auf einen Mangel seiner Arbeit als auf das absolute Pehlen derselben im Material zurickzuführen sein. - Er hebt hervor, daß Kongruenzfehler auftreten - also dem Nomen im Akk. oft die Part.-Porm-ǧče/-vǒe, die wir als Universalform bezeichneten, entspricht. ${ }^{177}$ Auch wird, wenn der Akk.pl. bel Beseelten

173) Borkovakij, Ist.grammatika, S. 373.

174) ebd., S. 373. 175) ebd., S. 365 (das Beiopiel).

176) Nikiforov, Glagol, S. 254.

177) ebd., S. 254 . 
in der Form des Gen.pl. erscheint, meist nicht die Nominalform, sondern die Pronominalform des Part.s gebraucht (also 2.B. "videv kazancev mjatuščlchojan" anstatt "videv kazancev

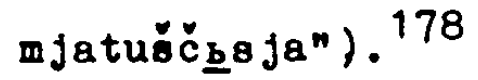

Neun Belege finden wir im $K$-pler Text fur Akk. mit Part. Dabei lot die Konstruktion im Sing. vollkommen intakt:

$67 / 42$ "(1jud1) ... víge日ga ... iz vokon plamenju ognennu vel1ju 1zšedšu, okruživǒu voju šeju cerkovnuju na dolg ças, ..."

'Man sah, daB eine große Flamme aus den Fenstern der Hagia Sophia entwichen war und lange Zeit die Kuppel derselben umsplelte.'

Sehen wir einmal davon $a b$, daB der Autor hier "plamenb" wie ein Femininum gebraucht, was sonst nicht vorkommt, 179

lot die Konstruktion korrekt.

Man muB sich fragen, welchen Sinn ein Part.praet. In solcher Konstruktion hat - die Verben der sinnlichen Wahrnehmung, nach denen der Akk. mit Part. melst ateht, ${ }^{180}$ sowie "obréstín, "srèsti" usw. bedingen ja, daB sich das Gesehene, Gehörte, Angetroffene vor den Augen resp. Ohren abspleit - es wird also etwas sich gegenwärtig Abspielendes geschildert. Etwas Vorgangenes, Abgeschlossenes hingegen kann auf diese Weise nicht berlchtet werden, da ja Vergangenes nicht artuell orlebbar 18t. Bloher pelegten wir eine durch Part.praet. auegedruckte (abhingige) Handlung als im Vorhaltnis der Vorzeitigko1t zur Haupthandlung tehend zu deuten. Auf Grund deo eben Gesagten 1ot diese Deutung im Rahmen des Akk. m1t Part. nicht möglich. Jach Ruzicka "bleibt den partiziplalen Partizipien al. Hauptfunktion die prädikat1ve Darstellung elnes Zustandes, der stch aus der Handlung ergeben hat. Sie stehen dann für griochisches Perfektpartizip."181 luf "1zb̆edun trifft dies

178) Iikiforov, Glagol, S. 254 - 2w1schenbemerkung 2.

179) Vgl. z.B. d1e Belege bel Srezn. II 952.

180) Barnot, Výrof, S. 40 nonnt 12 Verben, nolst gandelt os -1ch um synonyme zu Obengenannten, dazu "vedet1", "cajatin.

181) Rusicka, Das synt.System, 3. 254. 
sicherlich zu - sie sahen die Flamme, die herausgetreten war: Das durch das Part. Beschriebene wird zur Eigenschaft des Objekts - ich würde "izšeds̆un attributive Funktion zusprechen. Anders liegen die Dinge m.E. bel "okruživšu" - das ist ja ein Vorgang, den die Augenzeugen beobachten. Während wir "izšedšun als Terminativum punktuelle Bedeutung zuerkennen, aus der ein Zustand resultiert, ${ }^{182}$ ändert sich durch die Präfigierung an der Aktionsart von "kružitin" gar nichts - sie wird nur erweitert. "okružitin 1st komplexiv (perfektiv-durativ), und das us-Part. komplexiver Verben ist in Bezug auf eine präteritale Haupthandlung gleichzeitig, ${ }^{183}$ jedenfalls im Aksl. Möglich wäre also die Deutung, daß "okruživǒun aus den genannten Gründen als gleichzeitige Handlung zu "videšan zu sehen sei. Da wir aber eine so weitgehende Aspektualisierung des Verbalsystem am Material unserer Texte, insbesondere bei den Part.ien festgestellt haben, wird uns diese rein aktionsartlich begründete Deutung etwas skeptisch lassen. Mir scheinen solche Part.praet.Formen ganz einfach erklärlich zu sein: sie spiegeln die Perspektive des Autors selbst, der ja eine große zeitliche Distanz zum Geschehen, das er beschreibt, hat. Ich würde solche Pormen ähnlich deuten wie Aorist oder Perfekt - sie spiegeln den distanzierten Blickwinkel des Autors (sofern es sich nicht tatsächlich um Zustände, die aus punktuelien Handlungen resultieren, handelt); Part.praes.-Formen hingegen in der Konstruktion Akk. mit Part. wirde ich gleichsetzen mit Imperfekt oder auch Praes.hist., wo sich der Autor in das Geschehen selbst hineinversetzt, unreflektiert das aktuelle Geschehen schildert. "okruživǒun beschreibt demnach einen Vorgang, der parallel verläuft zu "videša", aber aus der Sicht des Autors eben längst abgeschlossen ist.

Fur die aktualisierende Erzahlweise des Autors sollen die folgenden Belege als Beispiel dienen - sie enthalten Part. praes. beim Akk.

182) Trost, Perfekt, s. 2, \$§ 2 und 3.

183) Budich, Aspekt, S. $21, \S 42$. 


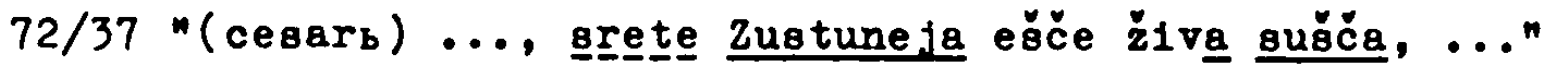
'der Kalser traf Giustiniani noch lebend an, ...'

$77 / 37$ "... 1 obrjagẹ̌etete čeloveka u droju stolpov stojašča, ... nosjašca nišcaja, ..."

'... und ihr werdet einen Menschen finden, der auf zwe1 pfosten steht und nackt ist ...'

Besonder der letzte Satz verdeutlicht die Gleichzeltigkeit der Handlungen - wir können die Konstruktion auch folgendermaßen auflösen:

'... und ihr werdet einen Menschen finden und er wird auf zwei Pfosten stehen und wird nichts anhaben ...'

Die Konstruktionen mit Akk.-Objekt im Plural lassen bezliglich der Bildung keine weitgehenden Schllisse zu: es handelt sich jewe1ls um Menschen:

$66 / 42$ "..., 1 gretetoğa narod mnog begajušče 1 bb ja, ...."

te...... und thnen begegnete viel Volks, das floh und kämpf-

Ungeworhnlich 18t an diesem Satz die Koordination von "begajušć 1 bbja" - eine ungewöhnliche Erscheinung fur den K-pler Text, wo zwar häufig Part.praes.-Formen parig, aber stets in der gleichen Porm (entweder auf -a/-ja oder - šče endend) auftreten. Vermutlich lot "1" versehentlich oder nachträglich an diese stelle getreten - mir scheint, dab "bbjan in adverbialer Funktion "begajuščen, das hier m.E. attributir zu deuten 1st, erlüutert. -

$56 / 34$ "... vide cesarb malo živuéčich v grade, ..."

$\therefore$ der Kaiser bemerkte, daB (zu) wenige in der stadt lebten, ...'

Wie der vorige und dieser sind auch die ubrigen Belege des Akk. m1t Part. konstruiert - entweder mit einem Kollektivum (auch 75/16) oder mit "mnogo" + Gen.pl. auf -1ch endend (76/43). Elnmal sind auch "pjatb mužej" als Akk. anzutrefien:

72/16 "V1dêevéa ... tri bratenik1 pjatb mužej onech sračin bb fuéce tako o1lbne gražan, ..."

'Dre1 Blutebrider oahen aber, wie funf von diesen Sarazenen furchterlich auf die Griechen einschlugen, ...' 
Während die Konstruktion Akk. mit Part. im K-pler Text funktional und weitgehend auch formal intakt ist, können wir in der Pleskauer Erzählung nur noch Reste bzw. Ubergangsersche1nungen aufspüren.

Pür Akk.8g.mask. können wir nur ein Bruchstück vorstellen:

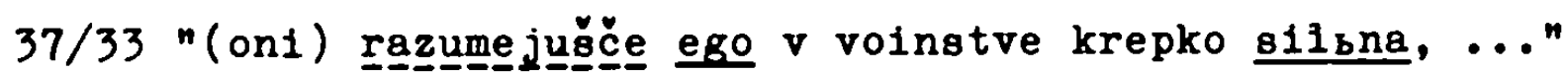
'sie wubten sehr wohl, daB er im Krieg meist siegreich ist, ...'

Die Kongtruktion muB wohl richtig lauten

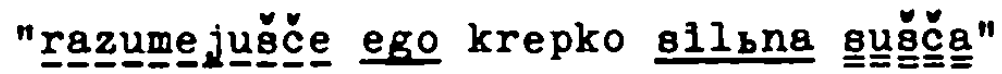

Als Beispiel für unsere Konstruktion ist wegen der Wortstellung der folgende Beleg kaum noch zu erkennen:

$60 / 11$ "On1 že, ...., tokmo černosts v lese 1dušču videv."

' Sie sahen aus wie ein dunkler Fleck, der sich im Wald bewegt.'

Dieser Sinn ist wahrscheinlich obigem Satz zu unterlegen, die adäquate Konstruktion würde etwa lauten:

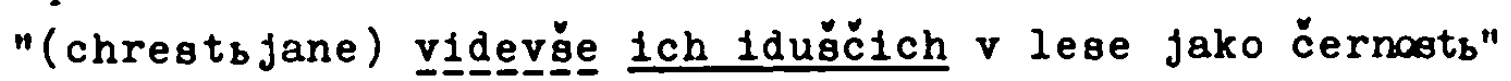

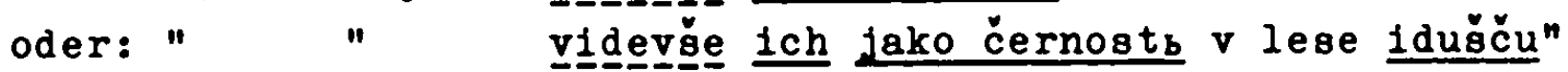

Sonst sind nur Plur.-Belege hierherzustellen, die zudem noch fraguturdig erscheinen.

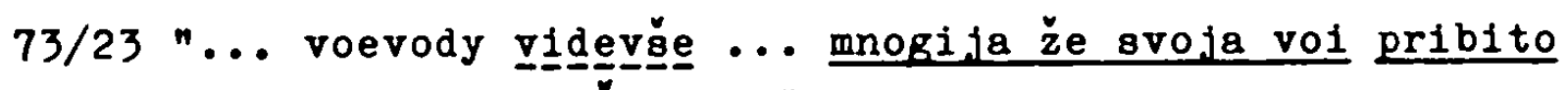
1 raneny 1znemogsi, ...n

'... die Voevoden sahen, daB viele Kämpfende niedergeschossen und die verletzten (oder: verletzt) völlig ermattet waren, ...'

"Iznemogs̆in" und "pribito" lassen den Eindruck entstehen, als liege hier eine Hinwendung zu elner adverbialen Konstruktion vor. Vermutilch handelt es sich hier aber doch um eine Anoammlung beinahe zufälliger, jedenfallo inkongruenter Pormen, wie wir sie im Pleskauer Text häufiger antreffon und die oft nur elne ungefähre Deutung zulassen. An dieser Stelle kommt

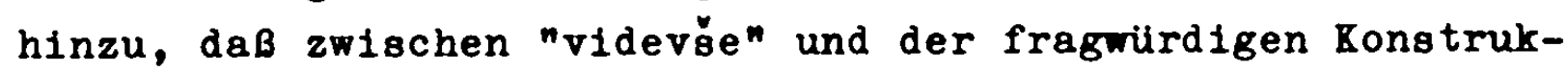
tion noch von "videvse" regierte objekte (Substantive) stehen, was dem Autor bei der Konstruierung seines Satzes noch zugätzliche Schwierigkeiten bereitet haben mag. 
$85 / 27$ "..., vidi vragov našlch derzostb, ne tokmo nad nam1, no 1 nad srjatym troim ... porugajuščsja."

'..., sieh an die Drelsthelt unserer Feinde, die nicht nur uns, sondern auch delne Helligen lästern.'

Im Ansatz scheint hier ein Akk. mit Part, vorzuliegen, doch bezieht sich das Part. offensichtlich auf das Gen.-Attribut "vragor našich". Die Endung des Part.s "porugajuščasja" bleibt unklar - sollte sie zu "derzostb" gestellt sein? Dann mübte man -šchoja erwarten; sollte sie auf einen Gen.gg. von "vragov naślch" bezogen sein?

$67 / 25$ "... korolb stepan, vídev svolch rochmistov .... jako vzlesša na stene ... 1 znameny uźe stojaščich, ${ }^{184}$ 1 vo grad ... strelfajuǧče, ..."

'... König Stephan sah, daB seine Rottmelater bereits die Mauern erstürmt hatten und mit den Bannern (dort) standen und in die stadt hineinschosen ...'

In diesem Satz finden wir verschledene Realloationsformen des Akk. mit Part. vor:

1. Part. Im Akk.8g. = Gen.8g. (hier unzutreffend);

2. " "Akk.pl. = Gen.pl., pronominal. (zutreffend);

3. " hat die Universalendung -ǧče.

Den Part.ien 1st "jako" vorangestellt, das die weltere Entwicklung andeutet - mit "jakon bzw. "ćto" werden bald die dem Akk. mit Part. entsprechenden Ergänzungssätze angeschlossen werden.

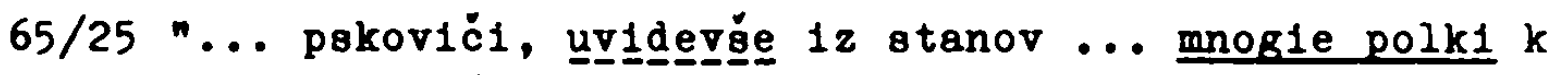
gorodu 1djase 1 voe $v$ borozdy utesnene napolnjağes a l1tovakich gajdukov, urazumevgée že, jako ... na prolomnye mesta 1dušče , ..."

'Die Pleskauer sahen, daB viele Heerhaufen aich auf die Stadt $z u$ bewegten und $\mathrm{da} B$ sich die Heiducken in den Laufgräben drängelten;

und Ihnen war klar, daB ole die Breschen zum Ziel hatten, ...'

Der Akk. mit Part. 1ot hler bereits aufgelöst: der Akk. erscheint als Nom. = Subjekt ("mnogie polkin), das Part. als

184) Varlante, S. 145: "1 żmamenami uže stojaščichn". 
Verb.fin. ("idjasen) - wir haben einen formal vollkommenen Satz vor uns, dessen logische Abhängigkelt von "uvidevšen nur durch den Kontext erkennbar 1st. Das folgende Syntagma kann inhaltlich nicht eindeutig erklärt werden; die Ubersetzung stellt einen Vorschlag dar, mehr nicht. Einerseits finden wir "vse" bei "napolnjašesja", andererselts könnte "litovskich gajdukov" die vage Erinnerung an die richtige Konstruktion bezeugen. Am SchluB finden wir noch eine neue Konstruktion, die wohl folgendermaBen $z u$ verstehen ist:

"úrazúmevose lich na prolomnye mesta 1duščich".

Trotz der Andeutung der partizipialen Konstruktion sind die syntaktischen Bezlehungen durch subordinferendes "jako" unterstrichen.

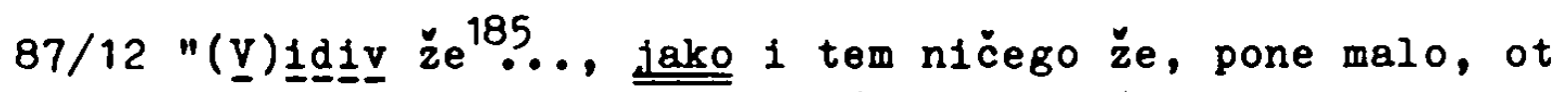
chotentja svoego ne ulučiša, na in že 1 zelo naporen soveščajutca sovet."

'Als sie sahen, dab ihnen nichts, aber auch nicht das Geringste von ibren Plänen gelungen war, da sannen sie auf einen anderen sehr bedrohlichen Plan.'

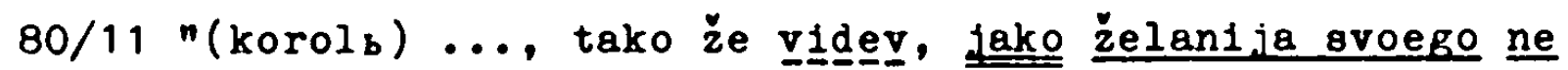
ulučivsa, so studom ... litovskoe svoe voingtvo ot grada bežavỏich, sam že velika sramu ispolnen bystb."

'Als der König sah, daß sich seln Wunsch nicht erfüllte, dab sein Heer... floh, wurde er von groBem Zorn/Enttäuschung ( $f u_{r}$ 'Scham') erfüllt.'

Die belden rom Aufbau her identischen Satzgefüge sind in den uns interessierenden Punkten verschieden konstruiert. Im zweiten Satz ist anfangs noch richtig aufgebaut, wobei der Gen. durch die Verneinung bedingt ist ("videv želanija svoego ne ulučivša"); der zweite Tell läBt Kongruenz zwischen Objekt und Part. vermissen - letzteres zeigt den Akk. = Gen.pl. (pronominal), der Akk. des Objekts hat aber die Porm des Nom.sg., die Unsicherheit hängt sicher mit dem Kollektivum "voinstvo" zusammen. - Trotz der einigermaben richtigen Bildung werden die partizipialen Konstruktionen durch "jako" als untergeordnet markiert.

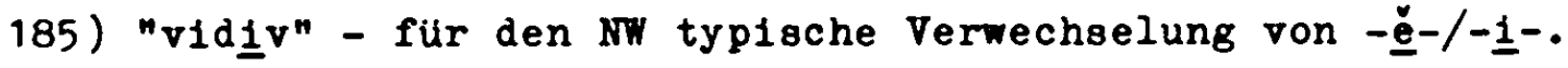


Vor diesem Hintergrund wird deutlich, daB die Konstruktionsweise im oberen Beleg 87/12 eine Notlösung darstellt - durch doppelte Verneinung war der Autor vielleicht verunsichert; auch wäre der lachdruck, der auf der finten Aussage liegt, durch die partizipiale Konstruktion allein vielleicht nicht errelchbar gewesen; vgl.:

"Yidę že ( Jako) 1 tem ničego že, pone malo, (ot) chotenija sroego ne ulučivéa"

Der Genitiv ("chotenija svoego") ist hier auch nicht als Form eines verneinten Akkusativ zu werten, sondern ihm wurde die (unnöt1ge) Prk̈position "ot" vorangestellt.

Jedenfalls zeigt die Gegenüberstellung der beiden Textbeisplele deutlich die Entwicklung der Konstruktion Akk. mit Part. hin zum Ergänzungseatz mit finitem Verb als Prädikat und Anschlus des Satzes, dem der ehemalige Akk. nun als Subjekt dient, an den ubergeordneten Satz durch subordinferende Konjunktion. Diese Entricklung 1st, wie wir zeigen wollten, im Pleskauer Text weit fortgeschritten; korrekte Bildung der partizipialen Akk.-Konstruktion begegnet kaum noch.

Demgegenüber hat der $\mathrm{K}$-pler Text die alte Konstruktionswelse sehr gut bewahrt, wenn sie auch - mit neun Belegen - nicht allzu häufig angewendet wird. Nicht nur werden die Konstruktionen weitgehend korrekt gebildet - es kommt auch daruberhinaus nicht ein Pall vor, wo die fragliche Konstruktion durch eine subordinferende Konfunktion an des Verb der sinnlichen Vahrnehmung oder "srésti" angeschlossen wäre. "Und: es rommt im $\mathrm{K}$-pler Text auch nicht ein einziges Mal vor, daB nach entsprechenden Verben eine Konstruktion mit finiten Verbalformen verwendet wird, es heibt niemals: sondern:

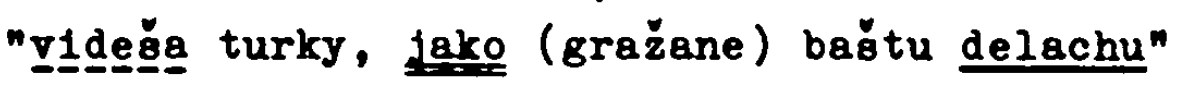

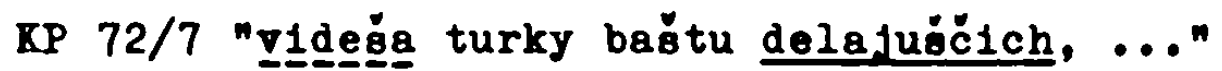

'die Turken sahen, dab sie den Turm (wieder) errichteten, ...' 


\section{Das nominale Partizip als Prädikativum}

Eine unübersehbare Rolle spielt in der $\mathrm{K}$-pler Erzählung eine Variante des Prädikats, die gelegentlich durch die Formel "bè učę" 186 oder auch "esmb čitajan"187 bezeichnet wird. Es kann uns hier nicht darum gehen, klärend in die Diskussion einzugreifen, ob es sich bel dieser pugung nun um eine analytische Verbalform oder aber um die syntaktische Verbindung zweier Formen handelt, die jede für sich eine gewisse Selbstständigkeit bewahrt haben. ${ }^{188}$ wir haben in der K-pler Erzählung einen Text des späten 15. Jh.s vor uns, dessen im Altruss. sehr bewanderter Autor geschickt die aksl. Formen benutzt, stilisierend nachahmt. Aus einem Text, der einen alten Zustand nur reflektiert, können wir natülich nicht die urspringliche Funktion der benutzten Kategorien rekonstruieren.

Die Funktion dieses Typus 'flektierte Form von byt1 + nominales Part.act.' beschreibt m.E. sehr treffend und anschaulich Ruzicka mit dem Terminus: Tempus intensivum . Gleichreitig weist er den Deutungsversuch van Schoonevelds zuruck, der meint, die Dauer der Handlung, des Vorgangs stehe im Vordergrund. ${ }^{189}$ M.E. trifft auch diese Interpretation 24 , doch die Formulierung Ruzickas scheint mir die Funktion dieser Fendung umfassender zu umschreiben. Potebnja äußert sich ähnlich wie Ruzicka, er rúckt die betonte Zuständlichke1t des auf diese Weise beschriebenen Vorgangs besonders ins Auge. ${ }^{190}$

186) Ruzlcka, Das synt.System, S. 202 - 22; Zlatanova, Rs: Die Struktur des zusammengesetzten Nominalprädikats im Altbulgarischen. München 1976 (Slavistische Beiträge. 103). (21tiert als: Zlatanova, Die Struktur), S. 126-39.

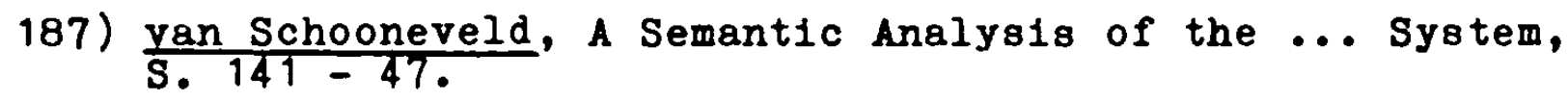

188) Analytische Verbalform: Ruzicka, a.a.0., S. $202-22$. Zusammengesetztes Prädikat: Potebnja, Iz zapisok, S. 132 1f.; Borkovgkij, Ist.grammatika, S. $344-48$; Nikiforov, Glagol, S. 244; van Schooneveld, a.a.0., S. $147-47$.

189) $\operatorname{van}$ Schooneveld, a.a.0., S. 141. Ruzicka, a.a.0., S. 213.

190) Potebnja, a.a.0., S. 143 f.: "sutb danb dajuščen rückt Zustand und Dauer stärker ins BewuBtsein als "oni danniki". 
In diesem Zusammenhang sei an die Verlaufsform des Englischen - 'progressive form' - erinnert, die aus den analogen Strukturtypen zusammengesetzt ist:

"esmb čitajan - II am reading' - 'ich bin am Lesen 191

"bé učę" - 'he was teaching' vgl.: 'er war am Lesen'.

Ganz selten kommt eine Variante mit Part.praet. vor, etwa "esmb sudivi"; sie 1st eine solche Ausnahme, dab eine Funktionsbeschreibung notwendig hypothetisch bleiben muB. Potebnja ${ }^{192}$ meint, daB diese Variante der slavischen Perfekt-Periphrase sehr nahegekommen sein muB und von ihr verdrängt murde, da aich solche funktionalen Dubletten in einer Sprache nicht halten können.

In der K-pler Erzählung kommen mit 25 Formen 14 Belegstellen vor. Durch die häufige Doppelung von Part.ien im Rahmen solcher Wendungen wird deren Intensität noch erhöht. Uns begegnen nur Zusammensetzungen mit Imperfekt von "byti" - "be", "bjašen, "bjachu". Wendungen wie "estb čitaja" sind deshalb nicht zu erwarten, well der K-pler Autor das Praes.hist. so gut wie nie benutzt, wie wir im Rahmen der Betrachtung des Prabens herausgestellt hatten. ${ }^{193}$

57/43 "K aim że 1 preneporoćnaja vladyčice matí Christa boga našego vo_vsją_vremena bjaše carstrujuščij grad sochranjajušce 1 pokryvajusče 1 ot bed spasajusče 1 ot neiscelbnych napastej premenfajušče."

'AuBerdem behutete und beschutzte die Gottesmutter K-pel die ganze Ze1t, errettete die Stadt von allem Ubel und wendete das achlimmste Unhell von ihr.'

191) Das 80g. 'Westfälische Gerundium'; allerdings würde man 'er war am Lehren' sicher nicht sagen.

192) Potebnja, Iz zapisok, S. 138: "Ọts juda možno zakl jučłłt’, cto jazyki slavjanskie stremilis izbavit'sja ot izlisestva dvuch schodnych pričastij prosed. dejatv. $(-z,-v z 1$ $\left.-I_{3}\right)$...n. So auch Borkovgki, Ist.grammatika, S. 346 Zlatanova, Die Struktur, S. $137 \mathrm{f}$.

193) "Eln Intensivum des 'aktuellen Präsens' ist kaum anzutreffen." Buzicke, Das oynt.System, s. 216 uber die Variante "estb citaja". 
Die zeitliche Dimension ist durch "vo vaja vremena" noch unterstrichen. Die sich wiederholenden Formen haben stark suggerierende Wirkung. Die hohe Intensität der uns interessierenden Wendung tritt besonders hervor, wenn man die Aussage durch das Tempus ausdrückt, welches die Wendung "bě učę" Intensiviert: das Imperfekt: "mati Christa boga našego vo vaja vremena sochranjaše carstvujuščij grad ..." Man kann dieser Wendung auch nicht eine gewisse Feierlichkeit absprechen.

64/21 "Cesarb že s patriarchom 1 vesb svjaščennyj klirik bjachu po vsem cerkvam moljašcesja 1 blaggodar jağe boga, ..."

- Der Kaiser, der Patriarch und die gesamte Geistlichkeit zogen betend und Gott dankend durch alle Kirchen, -...'

"blagodarjaše" ist mit sicherheit Verschreibung für "blagodarjaščen; zwar kommen (ganz selten) im K-pler Text auch Pälle von 3.pl.1pf. auf $-(j)$ aše vor, doch würde in diesem Beispiel das vorhergehende "bjachu" die richtige Form schon nahelegen.

68/8 "...: svet ubo on neizrečennyj, Lže be sodejstvuja v velicej cerkvi božija Premudrosti s prežnimi svetilbniki 1 ..., v siju bo nošč otbidoša na nebo: ..." 1...: dieses unbeschreibliche licht, das seit ältesten Zeiten den Erleuchtern und ... schien, ist diese Nacht in den Himmel entwichen: ...'

Es ist davon die Rede, daB dieses Licht seit der Grindung K-pels in der Hagia Sophia schien, "s prežnimi svetilbniki" deutet 2 war die groBe Zeitspanne, die diese Aussage umgreift; aktualisiert, untermalt wird diese aber durch die Form des Prädikats "be sodejstruja".

64/16 "Zlonravnyj že Magumet ... izdaleča bjắs smotrja byvšee 1 pomyšljajušče čto sotvoriti, ..."

- Der sittenlose Mehmed betrachtete, was da geschah, und überlegte, was nun zu tun se1, ...'

Das Nebeneinander von - ja und-šce verwundert, aber ein Abschreibfehler oder ähnliches liegt wohl nicht vor, es sei denn, daB man "in vor "pomyšljajuščn" für eine zufällige Erscheinung hält und dieses Part. als adverbiale Ergänzung 
zu "bjaše smotrja" ansieht. Onter "bjaše smotrja byvǐeen stellt man sich buchstäblich eln gedankenvolles, sinnendes Betrachten vor.

62/26 "... gražane va1 uže bjachu iznemogše."

'... die Griechen waren alle zu Tode erschöpft.'

Das lot die einzige Textstelle, wo unsere wendung mit einem Part.praet. gebildet wird. Die Interpretation, es handele sich um eine dem Perfekt ähnliche Wendung, könnte durch diese Textstelle bestëtigt werden - "1znemoščl" 1st wohl als punktuell anzusehen 'kraftlos niederstirzen': 'sie waren entkräftet niedergestürt/zusammengesunken $=$ waren im Zustande der Erschöpfung' .

In der Pleskauer Erzählung gibt es eine Textstelle, die man mit einigen Bedenken hierherstellen kann:

$53 / 7$ "Tako že 1 do nas milostiv bud1, jako serdečne a toboju bechom ko vzjatbju tolika grada potrudivesja."

'So erwelse auch uns deine Gnade, weil wir uns mit dir von ganzem Herzen um die Eroberung einer solchen Stadt bemilht haben.'

Es handelt sich hier um eine Schmeichelrede litauischer Würdenträger. Merkwürdig ist es, diese Worte am Anfang des Peldzugs zu vernehmen, aber am Inhalt der Worte ändert keine Interpretation etwas. - Möglich wäre belsplelowelse eine Te1lung des Satzes:

"gerdečne $s$ toboju bechom,

ko vzjatbju tolika grada potrudiv(e) aja"

-wir waren mit ganzem Herzen dabel,

als wir uns um die Einnahme ... bemühten/zur Eroberung rusteten.'

Vermutilch haben wir es hier aber mit einem Dual zu tun, den wir manchmal in Briefen angetroffen hatten und den wir, da er nicht anders zu erklären war, als wegen selnes seltenen Vorkommens exklusive und daher zur Stilisierung besonders geeignete Form deuteten ( $v$ gl.: 51/28 "jaže pisaše, 1 my vedaeven", $51 / 21$ "k tebe ze soveta sroego ne otricaeviesja, no 1 paće ... predposylaem" - 'wir lehnen delnen Plan nicht $a b$, sondern nehmen $1 \mathrm{hn} . .$. an'). In diesem Sinne wäre zu ubersetzen: 
'So erweise uns denn deine Gnade, weil wir von ganzem Herzen bei dir (= doinem Unternehmen) gewesen sind und uns um die Eroberung ... bemühen.' (1.dual.praes.)

Nikiforov, Borkovskij, Ruzicka ${ }^{194}$ u.a. bescheinigen dem Prädikat, das sich aus einer flektierten (melst Ipf.-) Porm von "byti" und einem nominalen aktiven Part.(praes.) zusammensetzt, besonders archaischen Charakter. Bringen wir diesen Sachverhalt mit jener Tatsache in Verbindung, die wir an vielen Erschelnungen erhärten konnten, daB sich nämlich der Pleskauer Autor um archaisierend-hochliterarischen Stil bemüht, dann kann man erkennen, in welchem MaBe dieses plastische Mittel zur Intensivierung einer Aussage, zur sprachlichen Untermalung von Durativität Ende des 16. Jh.s in Vergessenheit geraten war. Das bestätigt auch Nikiforov, der diese Wendung als aussterbend und nur noch recht selten vorkommend bezeichnet. 195

Der reichliche Gebrauch dieser Variante des Prädikats im $\mathrm{K}$-pler Text bestätigt auch unsere bezuglich des Autors bzw. Redaktors wiederholt gemachte Feststellung, dab dieser die altruss.-ksl. Schriftsprache bis in die letzten Feinhelten beherrschte.

Die hier in Frage stehende Konstruktion wurde oft als Gräzismus bewertet (angefangen von Miklosich bis zu H. Birnbaum), da die griech. und die slavische Konstruktion absolut identisch sind. Verbinden wir nun diese Tateache mit der Beobachtung des geradezu extensiven Gebrauchs dieser Periphrase im K-pler Text und der noch immer offenen Frage, ob diese Erzählung vielleicht auf einer griechischen Vorlage beruhe, dann haben wir hier einen Anhal tspunkt, die Prage im Sinne einer griechischen Vorlage $z u$ beantworten.

194) Nikiforov, Glagol, S. 243; Borkovsk1j, Ist.grammatika, S. 346; Ruzicka, Das synt.system, S. 224 .

195) "vo vtoroj polovine XVI v. javljaetsja otžívajuščim, predstavlennym otnositel'no nebol'sim kolićestrom siucaev." N1kiforov, Glagol, S. 243.

196) Ruzicka, a.a.0., S. 223 f. - Die griech. Periphrase gehörte offenbar der volkstumlichen Erzählkunst an; ebd., S. 224 . 


\section{Zusammenfassung: Das nominale Partiz1p in unseren Texten}

Bel der Behandlung des nominalen Part.s haben wir uns auf das Part. Im Nominativ konzentriert - auf das Part. also, das mit dem Subjekt des Satzes unmittelbar oder mittelbar (uber das Prädikat = adverbiale Punktion) verbunden ist. Hierfür finden wir in jedem unserer Texte etwa 300 Belege. Auch der Dat.abs. war für uns von Interesse, da er in jeder Erzählung ungefähr 75 Mal erscheint. Akkusativ mit nominalem Part. sowie nominales Part. als Prädikativum (Typus "bě učę") behandelten wir nur am Rande, da der Pleskauer Text für diese Erscheinungen kaum Belege aufwe1st.

Es ist davon auszugehen, daB auch das Gemeinslavische sehr einfach - parataktisch - strukturiert gewesen 1st. Der Bau des Satzes war relativ fre1, das partiziplale Syntagma bildete eine Möglichkeit der Aussage. ${ }^{197}$ ob das Part. vollkommene oder - im Hinblick auf das Verb.fin. - eingeschränkte Prädikation besab, bleibe dahingestellt. Wir wollen nur festhalten, daß das Parto-Syntagma einst weitestgehende Eigenständigkeit besessen zu haben scheint. Heute dagegen ist das nominale Part. (bzw. der Uberrest dieser Kategorie) dem durch Verb. fin. ausgedruckten Prädikat in adverbialer Punktion untergeordnet: die Aussage des Part.-Syntagmas bezieht sich stets auf die Aussage des Verb.fin., erläutert und modifiziert diese. Das äußert sich sinnfällig in der relativen Zeitlichke1t des nominalen Part.s, dieses kann Vor-, Gleich- oder auch Nachzeitigkeit im Verhältnis zur Haupthandlung ausdrücken. Die veränderte Bezlehung des nominalen Part.s vom Subjekt hin 'ad verbum' - äuBert sich auch in der Form: das nominale Part. 1st heute nicht mehr flektierbar; es ist zum Adv.-Part. erstarrt.

Welchen Punkt auf dieser Entwicklungslinie unsere Texte reflektieren, wollten wir an Hand unserer Untersuchungen mar-

197) Potebnja, Iz zap1sok, S. 190 f.; Ruz1cka, Das synt.System, s. 22 f.; Zlatanova, Die Struktur, s. 127 u.a. 
kieren. Der Pormenreichtum des alten nominalen Part.s ist in beiden Texten erhalten. Die Numerus-Kongruenz erweist sich zwar als gestört, aber in ca. 80 v.Hd. aller Belege stimmen Numerus (und auch Genus) von Subjekt und Part. überein. Das ist zwar in bezug auf den Pleskauer Text erstaunlich, da Ende des 16. Jh.s die partizipialen Formen meist nur noch promiscue verwendet werden, doch ist auch zu relativieren: PluralFormen dominieren; dabei fällt die auf einzelne Personen bezogene Aussagen nicht sehr ins Gewicht, weil unsere Kriegserzählungen überwiegend kollektive Leistungen schildern. Entwicklungstendenzen, die auf den heutigen Formenbestand wiesen, sind nicht $2 u$ erkennen; $2 u$ vermerken wäre höchstens, dab in der K-pler Erzählung ein Vordringen der Endung -av/-iv/-ev usw. für Part.praet. von vokalisch auslautenden Verbalstämmen erkennbar ist, eine Form, die ja zur Bildung des heutigen Adv.-Part.s (praet.) der entsprechenden Stämme gebraucht wird.

Die Funktion der nominalen Part.ien in unseren Texten versuchten wir, mit Hilfe einiger formaler Kriterien zu bestimmen, die es ermöglichen sollten, subjektive Wertungen auszuschalten.

Wir registrierten Part.-Syntagmen, die ein anderes Subjekt haben als der Satz mit Verb.fin, auf den sich die Part.-Konstruktion mehr oder weniger deutlich bezieht. Sodann überpruften wir die Texte auf solche Part.-Syntagmen, die vom Verb.fin. durch koordinierende, gelegentlich auch subordinierende 198 Konjunktionen getrennt sind. Es hatte sich nämlich gezeigt, dab besonders Part.-Syntagmen, die durch koordinierende Konjunktion vom Syntagma mit finiten Formen getrennt sind, mehr oder weniger klare Eigenständigkeit besitzen, die sich beispielsweise in absoluter Zeitlichkeit äuBert (z.B. drückt postpositives Part.praet. dann eine Handlung aus, die der des Verb.fin. folgt); meist haben die durch Verb.fin. und die durch Part. bezeichneten in diesem Falle nur allgemeine, kontextuelle Bezüge zueinander. - Die beiden hier genannten

198) Wird der partizipiale Satz durch eine subordinierende Konjunktion eingeleitet, ist dieser zwar naturlich dem Hauptsatz untergeordnet, aber nicht wegen der partizipialen Form, sondern wegen der Konjunktion. Das Part. vertritt hier Verb.fin. 
Gruppen machten im Pleskauer Text $25 \mathrm{v} . H d .$, in der $\mathrm{K}$-pler Erzählung nur 7 v.Hd. aller Belege aus.

Schlieblich registrierten wir solche partizipialen Konstruktionen, die uberhaupt keinen Bezug zu einem Verb.fin. haben. Auch hierbel konnten wir subjektive Wertungen weitestgehend ausschließen, weil im Pleskauer Text oft ganze Abschnitte nur partiziplale, keine finiten Formen aufweisen und daher die Bestimmung keine Schwierigkeiten bereitete. Letzteres gilt für den $\mathrm{K}$-pler Text auch: dort herrscht ein ganz bestimmtes Satzschema vor, und Abwelchungen fallen daher gleich ins Auge. Diese Abwelchungen galt es dann zu bestimmen, doch spielten sie statistisch kaum eine Rolle ( 3 v.Hd.). Im Pleskauer Text aber bestätigten die Zahlen den Eindruck beim Lesen: $37 \mathrm{v}$.Hd. aller nominalen Part.ien haben absolute Prädikation, die Part.-Sätze sind vollkommen eigenständig.

Diese drei Varianten der Verwendung nominaler Part.ien Part. mit eigenem Subjekt; durch Konjunktion vom Satz, der das Verb.fin. enthält, getrennt; ohne echten Bezug zu einem Verb.fin. - zeigen das Part.-Syntagma in seiner größtmöglichen, meist absoluten Eigenständigkeit. Sie machen im K-pler Text 10 v.Hd., im Pleskauer Text 62 v.Hd. aus.

Andererseits stellten wir fest, welche Part.-Syntagmen (meist dem Verb.fin.) untergeordnet sind - es handelt sich um jenen Typus, den wir, wenn erweitert, als 'adverbial-partizipiale Konstruktion' bezeichnen können, weil er der Funktion des heutigen Adv.-Part.s entspricht. ${ }^{199}$ Gesondert führten wir noch Part.ien ohne Erweiterung auf, weil diese die adverbiale Funktion ganz besonders klar erkennen lassen. Die gesamte Gruppe kommt im K-pler Text auf 73 v.Hd., im Pleskauer Text nur auf 35 v.Hd. Eine deutliche Relation ergibt sich hinsichtlich der Part.ien ohne Erweiterung: $17 \mathrm{v} . \mathrm{Hd}$. im K-pler, $4 \mathrm{v} . \mathrm{Hd}$. im Pleskauer Text.

Diese Zahlen splegeln nur unvollkommen, was an Hand vieler

199) Vgl. Tauscher-Kirschbaum, Grammatik der russ. Sprache, S. $300, \$ 400:$ "Indem das Adverbialpartizip so einer finiten Verbalform zur näheren Bestimmung oder Erläute- 
Textbeispiele deutlich werden sollte: Einerseits die klare, oft modern anmutende hypotakt1sche Strukturierung des Satzes im $\mathrm{K}$-pler Text, in dem Haupt- und Nebenhandlung in erster Linie durch finite und partizipiale Formen bezeichnet und voneinander geschieden werden. Andererselts die Dominanz der Parataxe im Pleskauer Text, in dem auch Part.-Konstruktionen mit adverbialer Punktion viel lockerer gefugt sind als diejenigen des K-pler Textes.

Mie finite Verbformen, so bestimmen im Pleskauer Text auch partizipiale Formen oft ganze Abschnitte, in welchen sie dann auch reimen bzw. einen bestimmten Gleichklang bewirken. Im Pleskauer Text 1st das Part. als gleichberechtigte Porm neben das Verb.fin. getreten.

In beiden Texten sind die beiden Part.ien - praes. und praet. streng nach aspektuellen Gesichtspunkten geblldet. Ausnahme bildet nur die formelhafte Wendung "glyšav/šen, "videv/šen. Es kommen fast keine durativen Simplicia in Form des Part. praet., so gut wie keine Part.praes.-Pormen von heute perf. Verben vor. Die Textstellen mit elgenständigem Part.-Syntagma haben wir darauf hin untersucht, welches Tempus das jeweilige Part. vertritt. Dabel gelangten wir zu folgender Korrelation, welche die uns bereits bekannte Aspektkorrelation der präteritalen Tempora erweltert:

$$
\begin{aligned}
& \text { Part.praes. }=\text { Imperfekt }=\text { imperf. Aspekt } \\
& \text { Part.praet. }=\text { Aorist }=\text { perf. Aspekt }
\end{aligned}
$$

Die Verselbständigung des Part.s im Pleskauer Text kann man auch am Dat.abs. erkennen: Mehr als die Hälfte aller Dat.abs. sind dort völlig autonom, in der K-pler Erzählung hingegen nur knapp $8 \mathrm{v} . \mathrm{Hd}$. Andererseits erscheint im $\mathrm{K}$-pler Text der Dat. abs. In mehr als der Hälfte aller Belege besonders eng mit dem ubergeordneten Satz, der das Verb.fin. enthält, verbunden: das Homen des Dat.abs. ist gleichzeltig Subjekt des Satzes mit der fintien Form. Solche Kombinationen machen im Pleskauer Text nur 25 v.Hd. aller Dat.abs. aus.

terung zugeordnet ist, vertritt es syntaktisch die Punktion einer Adverblalbegtimmung." (Hervorhbg. - dort). 
Wie eingangs bemerkt wurde, bewirkte die durch Metropolit Makarif um die Mitte des 16 . Jh.s initilerte kompilatorische Tätigkeit eine Erneuerung des Zweiten Südslavischen Einflusses. Da es sich hierbei im Tesentlichen um eine Aufarbeitung der Historlographie mit hagiographischer Grundtendenz ( = Herrscherlob) und der panegyrischen Neufassung der Heiligenviten handelte, bedienten sich die Kompilatoren und sonstigen Mitarbelter des Metropoliten jenes literarischen Stils, der die höchste Tertschätzung besaB: des ksl. Idioms. Darüber hinaus kamen verschiedene Stilmittel zur Anwendung, die einerseits für hagiographische, andererselts für religiös motivierte ${ }^{1}$ Werke charakteristisch sind: breit ausladende Anreden und Apostrophierungen der Herrschergestalten, bestimmte Preisformeln, entsprechende Negativ-Schablonen für irgendwelche Feinde; in beiden kommt die ideologische Ausrichtung der Werke deutlich zum Ausdruck: Verteidiger des Glaubens - Zerstörer des Reiches Christ1; hinzu kommen breit angelegte Schilderungen christlicher Bräuche (Prozessionen) und Gebete, die sich elgentlich nur durch den Umfang der aufgehäuften religiösen Formeln unterschelden, sowie viele zitate aus dem groBen Schatz der offiziellen geistlichen Literatur.

Nicht jeder, der sich dieses pompösen Stils bedienen wollte, war des Ksl. so mächtig wie die Kompllatoren in Makarijs Schreibstuben. Es kam $z u$ Ubertreibungen und $z u$ Verballhornungen. So finden wir in der 'kurzen Antwort' Pürst Andrej Kurbskif's ${ }^{2}$ auf eine 'sehr umfangreiche Epistel' Ivan Gr.s die schärfste Kritik an den Auswïchsen des Moskovitischen Prunkstils: Kurbskij nennt das Schreiben grobsprecherisch und groB-/hohltönend - "mnogoveščatelsnoe 1 mnogošumjaščee poslanie"; er bezelchnet diese Art, sich auszudrucken, barbarisch

1) "Moskau - das Dritte Rom"; der Zar als alleiniger 'Defensor fidei'; das Heilige RuBland.

2) Gudzij, Chrestomatija, S. 296 ff. 
und lächerlich-"...; 1 tak varvarsko, jako ne tokmo učenym $i$ iskusnym mužem, no $i$ prostym $i$ detem so udivleniem $i$ smechom, ..." Schließlich verhöhnt er die Unsitte, ganze Passagen aus den geheiligten Schriften abzuschreiben - "...; no zelo pače mery preizlišno 1 zvjaglivo, celymi knigami, 1 parembjami celymi, i poslanbmi!n

In ähnlicher Weise hätte Kurbskif vermutlich auch unsere Pleskauer Erzählung charakterisiert - großsprecherisch und hohltönend sind die zahllosen vielgliedrigen Anreden und Benennungen des Zaren sowie seiner Voevoden, die endlosen Aufzählungen, Synonymhäufungen. Nicht so umfangreich sind die Apostrophierungen der Gegenseite - des polnischen Königs und seiner Hetmane, doch verwendet der Pleskauer Autor auch dabei oft Reihen wertender Epitheta. Wenn wir feststellten, daB die Pleskauer Erzählung bel fast doppeltem Umfang uber die gleiche Anzahl finiter und (nominaler) partizipialer Pormen verfügt wie die $\mathrm{K}$-pler Erzählung, beide Texte also ungefähr die gleiche Anzahl von (Haupt- und Neben-) Sätzen haben, dann geht dies in erster Linie auf die 'hohltönenden' Häufungsfiguren, von denen Verben und Partizipien nicht betroffen sind, zurück. In der K-pler Erzählung dagegen wird z.B. der Kaiser beinahe ohne Ausnahme, selbst in der Anrede, ohne Epitheton, einfach "cesarb/cesarju" bezeichnet, der sultan wird "saltan", "Magumet", "bezbožnyj", "beznravnyj" - höchstens einmal "bezbožnyj Magumet" apostrophiert.

Innerhalb von Gebeten, Anrufungen, Danksagungen und Monologen spielen im Pleskauer Text Bibelzitate eine bedeutende Rolle. Das trifft zwar, vor allem im Schlubteil, auch auf die $\mathrm{K}$-pler Erzählung zu - Visio Danielis, Methodios von Patara u.a. -, doch sind diese durch die Erzählstruktur derselben motiviert, die ja ganz besonders auf die dort angefuhrten Prophezeihungen ausgerichtet ist.

Ein bewuBtes Aufbauschema ist in der Pleskauer Erzählung nicht zu erkennen. Die vielen Einschübe (Gebete usw.) und die dem Hauptansturm nachgetragenen Ereignisse lassen sie unproportioniert erscheinen. 
Insbesondere im ersten Drittel der Pleskauer Erzählung worden der polnische König und sein Heer mit immer neuen Variationen der Schlangen-/Drachen-Symbolik bedacht, die oft sogar allegorischen Charakter (und Umfang) annehmen. Später bezieht sich der Autor durch bestimte (wertende) Epitheta auf diese Symbolik. Dagegen verblassen die zahlreichen Beispiele der christlichen Metaphorik und Symbolik sogar, weil sie gar zu formelhaften Charakter haben. - Der K-pler Autor macht sparsamen Gebrauch von bildsprachlichen Elementen. Nur in der Exposition finden wir die Schlange als Symbol des Heidentums - in der allegorischen Erzählung über den Kampf des Adlers (= Christenheit) mit der Schlange, die das Grundmotiv der gesamten Erzählung darstellt.

Auch in der Verwendung rhetorischer Mittel zeigt der K-pler Autor große Zurückhaltung - wirkungsvoll werden Anapher, Antithese, auch klangliche Mittel innerhalb von Anrufungen und im Schlubteil (Prophezeiungen) eingesetzt, sonst kaum. Im Pleskauer Text jedoch spielen sie eine so dominierende Rolle, daß wir von emotionalisierendem Stil sprechen müssen; auch die genannten Häufungsfiguren, die 21 tate und die Bildersprache dienen der Emotionalisierung des Lesers. Uber weite Teile der Erzählung hinweg können wir rhythmisierte Prosa beobachten: ähnlich strukturierte Sätze folgen einander, reimend durch jeweils die gleichen Verbformen abgeschlossen; oft sind die Kola, Syntagmen oder Sätze auch anaphorisch eingeleitet, z.B. durch "ovii - ovil". Reimeffekt erzielt der Pleskauer Autor mit Hilfe aller verbaler/partizipialer Formen: Präsens, Imperfekt, Aorist, 1-Partizip, Konditional, nominale Partizipien (praes, und praet.), sogar durch Blöcke mehrer aufeinander folgender Dat.abs. (vorwiegend im Sing.). Eine ganz bestimmte verbale/partizipiale Porm dominiert also oft ganze Abschnitte. Das aber hat zur Voraussetzung, daB die Sätze in solchen Abschnitten vorwiegend parataktisch gefugt sind, sonst wäre die gleiche oder ähnliche Satzstruktur, die uns oft von (gelockertem) Parallelismus sprechen lieB, uber längere Passagen hinweg nicht durchzùhalten. Im Zusammenhang mit den reimenden Satzabszhlussen (verbaler Reim) mulssen wir kurz auf einen grundsätzlichen Unterschied 
zischen unseren Texten eingehen, den wir aus Raugründen in dieser Abhandlung nicht herausarbelten konnten: die Nortstellung. Das häufige Auftreten verbalen Reims im Pleskauer Text schlägt sich deutlich in der Statistik nieder: $74 \mathrm{v}$. Hd. aller Satze, die sich mindestens aus finter bzw. partizipialer Verbform und Ergänzung ( = Objekt, adverbiale Best1mmung usw.) zusamensetzen, zelgen Endstellung des Prädikats. Diese Endstellung der Verbform ist charakteristisch fur die 1m 16. Jh. weitverbreitete Bittochrift - das "Celobitien. ${ }^{3}$ und in der Tat erinnert die Grundhaltung des Pleskauer Autors den Zaron gegenuber an die demülige Haltung eines Bettelnden gegenúber dem, In dessen Hand sein Leben liegt - die für den Autor der Makar1j-Ära charakteristische Grundhaltung. Sehr unfangreiche Untersuchungen, die $1 \mathrm{ch}$, wie erwähnt, hier nicht darlegen kann, bestätigten die Vermutung, daB Endstellung des Prädikats typisch ist fur emotionalisierenden St1l: Monologe, Predigten 2.B. Sehen wir elnmal von (an sich unerläsalichen) Differenzle rungen $a b, 80$ kommt im 15. Jh. in nur $25-35$ v. Hd. aller Syntagmen (8.0.) Endotellung des Prädikats, also die Position hinter der Ergänzung vor, z.B. Epifanif Premudry j: nur 32 v.Hd.). Der Antell von Sätzen mit Endstellung des Prädikats in der Makarij-Ära ste1gt auf uber $50 \mathrm{v} . \mathrm{Hd}$. (uberpruft an "Stepennaja kniga", "Kazanskaja Istorija", Briefen Ivan Gr.s, auch an Bittochriften I. Pereovetovs u.a.). In der K-pler Erzählung steht das Prädikat nur in durchachnittlich 20 v.Hd. aller sätze am Satzende, im Kampfbericht sogar nur in $11 \mathrm{v} . \mathrm{Hd}$. Dagegen erfolgt Endstellung des Prädikats im K-pler Text Im Rahmen von Gebeten, Prophezelungen usw. In fast $30 \mathrm{v} . \mathrm{Hd}$. aller Fälle. Der $\mathrm{K}$-pler Autor errelcht Emotionalisierung durch verstärkte Endstellung des Prädikats. Dies lot dem Pleskauer Autor nicht möglich, verzeichnen wir doch 1m Kampfbericht den höchsten Antell von Sätzen mit Prädikat am Ende: 83 v.Hd.! In Passagen wit emotionalisierender Diktion bedient er sich eines anderen Mittels: er wechselt dauernd die Position des Prädikats verzeichneten wir im K-pler Text im Rahmen von Gebeten, Anru-

3) Ef1mov, Istorija russk.l1t.jazyka, S. 66. 
fungen, Monologen und ähnlichen Passagen wörtlicher Rede gelstlichen Inhalts knapp 30 v.Hd., damit den Höchststand von Sätzen m1t Endotellung des Prädikats - so notierten wir in den entsprechenden Bereichen des Pleskauer Textes den Tiefststand: nur 40 v. Hd., also sogar tberwiegen der Stellung des Prädikats vor dem Objekt - der Pleskauer Autor 1st also in Passagen, wo der höchste Grad von Emotionalisierung zu erwarten ist, gezwungen, mit dem Mittel des Kontrasts $z$ arbeiten, da eine weitere Steigerung der Endstellung des Prädikats keine emotionalisierende Wirkung mehr haben dürfte.

Zwar konnten wir im Rahmen der Stiluntersuchungen schon viele Unterschiede zwischen den Verglelchstexten erarbe1ten, wobel immer wieder der geradezu effekthascherische Einsatz best1mmter rhetorischer Mittel (Reim, Rhythmisierung, (Synonym-) Häufungen u.a.) zu betonen war, so hofften wir daruber hinaus, durch die Untersuchung des Gebrauchs der verbalen Kategorien bestimmte Entwicklungstendenzen aufzelgen zu können, die für die russische Ilteratursprache in jener Zeit, viellelcht für den Moskovitischen Prunkstil bestimmend sind.

Zu Bildung und Gebrauch des Präseng war nur so viel anzumerken, daB der Pleskauer Autor zur Aktualisierung und Emotionalisierung ausglebig das Praes.h1st. verwendet, das im K-pler Text eine seltene, vereinzelte Erscheinung darstellt.

Das Futur wird in der Regel durch Praes.-Pormen heute perf. Verben gebildet, selten durch "iměti/imati", gelegentlich, besonders im K-pler Text, durch "chotèti", wobel aber stets die voluntative Nuance sehr stark durchschlägt.

Häufiger begegnete im Pleskauer Text der Konjunktiv, sogar reimend, vor allem in Final-sowie in Helsche-Sätzen. Der K-pler Autor konstruiert in solchen Fällen anders: nämlich mit Hilfe der besonders archalschen Konstruktionswelse "..., da + (perf.) Präsens". Dennoch lot das Bemühen des Pleskauer Autors um Vermeldung umgangssprachlicher Blldungen erkennbar: er verwendet meist das atärker literarische "..., daby + 1-Part." anstatt des umgangsoprachlichen "..., čtoby + 1-Part."

Von größtem Interesse für uns war das Präteritum. Die archa1- 
sierende Tendenz beider Vergleichstexte hatte sich bereits von vornherein darin geäuBert, daß das Präteritum der lebendigen Sprache, das 1-Part., zurückgedrängt ist und der Aor. das Haupterzähl tempus bildet.

Generell muB der immer wieder erstaunende feinsinnige Wechsel zwischen Ipf. und Aor. im K-pler Text hervorgehoben werden, wohingegen in der Pleskauer Erzählung solche Beobachtungen selten sind, was allein schon durch die häufigen verbalen Reime bedingt ist, die ja einen Tempuswechsel nicht zulassen.

Eine gewisse semantische Annäherung von Imperfekt und Aorist ist allerdings in beiden Texten zu vermerken. Im exakt gleichen Kontext, bei z.T. gleicher Wortwahl, steht das Verb gelegentlich einmal im Aor., einmal im Ipf., wobei natürlich die Aspektkorrelation gewahrt bleibt. Allerdings ist - zumal im K-pler Text - nie ganz auszuschließen, daB mit dem Tempuswechsel auch eine Nuancierung im Ausdruck gemeint sein kann.

In der K-pler Erzählung sind Anzeichen für falschen Gebrauch eines Tempus oder für Verschleifung der ksl. Kategorien meist nur nach umfangreichen Kontextanalysen erkennbar. Dagegen findet im Pleskauer Text in einem bestimmten Bereich eine regelrechte Durchdringung von Aor. und Ipf. statt. Eine gewisse Voraussetzung dafür bildet eine klar erkennbare Auflösung der Ipf.-Kategorie: die Endungen haben weitgehend ihren distinktiven Charakter verloren, die Form $-(j)$ aše (3.sg.ipf.) steht im Begriff, zur Universal-Endung des Ipf. zu werden. So erscheint in mehr als der Hälfte aller Fälle, wo ein Subjekt im Plural die 3.pl.ipf. - (j)achu erwarten läBt, die SingularEndung $-(j)$ aše. Die Verallgemeinerung dieser Form geht noch weiter: der Pleskauer Autor bildet von durativen Simplicia, wenn sie imperf. sind, keinen Aorist - statt einer aus dem Kontext und von den umliegenden Verbformen her zu erwartenden Aor.-Form erscheint das durative Simplex mit der Endung $-(j)$ aše; so lesen wir beispielsweise anstatt korrektem ntvorišan die Ersatzform "tvorjašen". Auch Otten weist im Rahmen seiner Untersuchungen an der "Stepennaja kniga" auf diese Erscheinung hin, doch ist nicht erkennbar, ob die Verwendung 
der Form - ( $f)$ ase in der Funktion der 3.8g.1pf., der 3.pl.1pf. und der 3.pl.aor. dort so regelhaften Charakter hat wie in der Pleskauer Erzahlung. 4

Der Aorlst bildet in beiden Texten das Haupterzähl tempus und lat formal noch intakt.

Wie eingehende Untersuchungen bestätigten, verwenden belde Autoren Ipf. und Aor. schematisch nach folgender Aspektkorrelation:

$$
\begin{aligned}
\text { Imperfekt } & =\text { imperf. Aspekt, } \\
\text { Aorlst } & =\text { perf. Aspekt. }
\end{aligned}
$$

Bei diesen Untersuchungen sind wir nicht vom heutigen Aspektgebrauch, sondern von den Aktionsarten der Verben ausgegangen, um vielleicht noch Spuren des alteren Verbalsystems zu entdecken. So fanden wir eine - allerdings nicht sehr groBe Anzahl von Ipf.-Belegen heute perf. Verben. Es handelte sich um präfigierte Durativa, die durch die Präfiglerung ihre Durativität nicht verloren, sondern lediglich eine spezialisierung ihrer Semantik erfahren hatten. Auch im Ipf. behielten diese heute perf. Verben inre durative Grundbedeutung, 1terative Bedeutung hatten sie seltener. ${ }^{5}$ Wir vermuteten, daB die Autoren durch diese Ipf.-Formen dem Ausdruck gröBere Expressivität verleihen wollten; manchmal waren auch modale Nuanclerungen erkennbar.

Der Aorist wird fast ausschlieBlich von Momentanverben und von präfigierten Durativa, Kursiva usw. gebildet, die heute als perf. gelten. Selbst Aor.-Belege von determinierten Verben der Bewegung, die nicht präfigiert sind ("idoša", "gnaša" z.B.), kommen uberaus selten vor. Die vollzogene Perfektivierung solcher 1t1-Verben wie "strěliti", "udariti" usw. zelgt sich darin, dab diese (1m Präteritum) nur in Porm des Aor. erscheinen und

4) Otten, Die fin.Verbalformen, S. 474 - spricht von "wechselse1t1ger Austauschbarke1t" der 3.8g.1pf. und der 3.pl.aor. Boretzky, Tempusgebrauch, S. 66 f. - konstatiert eine Fformalpersonelle Opposition" zwischen Ipf. und Aor.: Mit der 3.8g.1pf. bildet Kurbskij meist den Sing., die 3.plooor. verwendet er uberwiegend für den Plur.

5) Maslov, Imperfekt glagolov soveršennogo vida ... vertrat, wiewir sahen, vehement diesen weithin verbreiteten standpunkt: Iterativität auszudrücken sel die Hauptrunktion 
die suffigierten Varianten vom Typus "strěljati" und "udarjati" zur Seite haben, mit denen Praes. und Ipf. gebildet werden.

Ein Reflex des voraspektuellen zustandes zeigt sich in der K-pler Erzählung: "viděti" und "alyšati" (dazu ein Mal "velěti" und ein Mal "gpat1") bilden nur ( 14 Mal)Aor.-Pormen, nie das Ipf. ${ }^{6}$ Diese Verben erscheinen Im Pleskauer Text ausschlieblich (b1s auf eine Ausnahme) in Form des Ipf.; den Aor. bilden sie von präfigierten Komposita ("uslyšašan, "uviden, povelen usw.). Im Empfinden des Pleskauer Autors sind "viděti" und "slyšati" fest im imperf. Aspekt verankert, obwohl sie in unseren Texten meist einen Sinn haben, der allein durch Aor. treffend wiedergegeben wird - die "auslösend begründende Punktion":7.Als/ nachdem er dies gesehen/gehört hatte, tat er (als Reaktion) jenes'. Der K-pler Autor konstruiert in diesem Falle oft: "jako (einmal: egda) slyša sie, (abie) ... ${ }^{8}$ Dem Pleskauer Autor 1st diese Konstruktionsweise mit Aor. eines imperf. Verbs nicht mehr möglich, er kann die aspektuelle Barriere nur noch mit Hilfe des Part.praet. uberwinden - er konstruiert so: "(jako/egda) videv že gle, ..."ng

Reste der alten Perfekt-Periphrase sind noch in beiden Texten erhalten. Der K-pler Autor verwendet die Periphrase (auch bel der 3.ps. - z.B. "rekl estb") in Abschnitten mit besonders feierlicher Diktion (Gebete, Anrufungen), wo sie der Stilisierung dient. Lediglich drei Mal stoBen wir auf das l-Part. ohne Hilfsverb (3.ps.gg. und 3.ps.pl.), diese Belege sind offenbar zufälliger Natur. - Mit 42 l-Part.ien (mit und ohne Hilfgrerb)

des Ipf.s perf. Verben. Vgl. auch den Kommentar zu einem seiner Belege aus der PVL - van Schooneveld, A Semantic Analys18, S. 39: "Here we have one of the few places where the connotation of repeated action 18 absent in the perfective imperfect."

6) Neben den 14 Aor.-Belegen von "viděti" und "slys̆ati" kommen im K-pler Text noch über 20 Part.praet.-Formen von diesen vor.

7) Vgl. Ruzicka, Aspekt, S. 50.

8) KP $66 / 6$ "jako videša turky stenu nezadelanu, vakore naskočsa 1 .... aber: $58 / 33$ "Sie ze videv, cesarb povele ..." 9) PS $58 / 17$ "Sie ze slyŏav, gosudarevy bojare 1 voevody, 
ist diese Verbalform im Pleskauer Text zwar sechs Mal so stark vertreten wie in der K-pler Erzählung, macht aber dort immer noch nur knapp 4 v.Hd. aller finiten und (nominal-) partizipialen Formen aus. Zwischen 1-Part. mit und 1-Part. ohne Hilfsverb besteht kein funktionaler, sondern lediglich ein personaler Unterschied; dieser wirkt sich auch auf den Kontext aus, in welchem die Varianten auftreten: die 1. und $2.8 \mathrm{~g} . / \mathrm{pl}$. wird fast 1mmer mit Hilfsverb gebildet, die 3.sg./pl. dagegen erscheint ohne Hilfsverb. Das hat zur Folge, daB sich die Periphrase "Praes.-Form von 'byt1' + 1-Part." In wörtlicher Rede, in Anrufungen, in Monologen und Briefen Verwendung findet, während das einfache 1-Part. In berichtenden Abschnitten vorkommt. ${ }^{10}$ So signalisiert die Periphrase auch im Pleskauer Text eine höhere stilebene.

Wie die anderen Verbformen, tritt das 1-Part. (ohne Hilfoverb) ebenfalls meist gehäuft auf und bewirkt so verbalen Reim oder Gleichklang. Außerdem entstand der Eindruck, daß nach Ausdrücken des Hörens, Erfahrens usw. das Prädikat der kurzen Nachricht in Form des 1-Part.s erscheint, wenn das berichtete Ereignis berelts zurückliegt - gleichzeltig werden Vorgänge, die z.Z. des Berichtens noch weiterlaufen, durch Praes. wiedergegeben. Es scheint, daB der Pleskauer Autor nach Ausdrükken wie z.B. "pride vestb, jako ...", auch "slyšav, jako ..." oft (nicht immer) die Nachricht quasi in wörtlicher Rede gibt, wobei er auch die lebendige Sprache stilisiert. Zweifelsfrei ist dies der Fall, wenn wir auf S. 95 f. den Brief elnes Ausländers (Hans Möller) in den Pleskauer Text eingefügt finden, der als Präteritalform nur das 1-Part. enthält. ${ }^{11}$ offenkundig will der Autor die elnfache Sprache des Ausländers, der der Schriftsprache nicht kundig 1st, andeuten.

Ist das 1-Part. 1m Pleskauer Text auch noch relativ selten, so lst doch der quantitative, vor allem der qualitative Unterschied im Gebrauch dieser Verbform innerhalb der Verglelchs-

10) Das gilt für das 16. Jh. allgemein - N1kiforov, Glagol, S. 162 ff.

11) Da wir nur Belege für die 1. und 2.ps.8g. vorfinden, handelt es sich stets um die Periphrase, z.B. "byval esmin. 
texte nicht zu ubersehen. Die Periphrase ist auf Abschnitte der höchsten Stilebene beschränkt und hat oft noch nachweisbare perfektische Bedeutung. Im Pleskauer Text dient die Periphrase fast regelmäBig zum Ausdruck des Präteritums für die 1. und 2.ps.sg./pl. Das 1-Part. ohne Hilfsverb, das in der K-pler Erzählung fast nicht erscheint, wird im Pleskauer Text schon bewubt eingesetzt: wie andere verbale Kategorien dient es Reimzwecken und zur Stilisierung lebendiger Rede. Von einem zufälligen Auftreten des 1-Part.s (ohne Hilfsverb) kann im Pleskauer Text also nicht mehr die Rede sein.

Das Plusquamperfekt ("Präteritalform von 'byti' + l-Part.") ist in beiden Texten fast gänzlich geschwunden. Vorvergangenheit wird nicht gesondert bezeichnet, sondern durch jene verbalen Kategorien, die den Autoren auch sonst zur Wiedergabe des Präteritums dienen - Ipf. und Aor.; der Pleskauer Autor verwendet darüber hinaus auch l-Part.ien sowie nominale Part.ien zu diesem 2 weck.

Ein ganz entscheidender - wenn nicht: der entscheidende Unterschied 2 wischen $\mathrm{K}$-pler und Pleskauer Text offenbart sich im Gebrauch der nominalen Partizipien. Wir hatten bereits den differenzierenden Gebrauch von Ipf. und Aor. In der K-pler Erzählung hervorgehoben und demgegenüber die Verwendung gleicher verbaler Formen uber ganze Abschnitte des Pleskauer Textes betont, was auf parataktische Pügung der syntaktischen Einheiten schlieben läBt. An diese Beobachtung können wir anknüpfen, wenn wir die Verwendung der nominalen Part.ien in unseren Texten vergleichen. Im $K$-pler Text hat das nominale Part. fast immer die Funktion einer adverbialen Bestimmung es ist der finiten Verbalform zur näheren Bestimmung bzw. Erläuterung zugeordnet und bezeichnet eine der Haupthandlung des Satzgefüges, ausgedrückt durch Verb.fin., untergeordnete Nebenhandlung. Das nominale Part. Im Nominativ vertritt damit syntaktisch die Punktion einer adverbialen Bestimmung, die im heutigen Russisch dem Adv.-Part. zukommt. ${ }^{12}$ wie dieses,

12) Vgl. Tauscher-Kirschbaum, Grammatik der russ.Sprache, S. $341, \S 400$; Grammatika 8ovr.russk.11t.jazyka, $\S 767$ und $\S 782$ ( = Akademie-Grammatik 1970). 
besitzt das nominale Part. Im $K$-pler Text keine absolute, sondern eine auf das Verb.fin. bezogene Zeitlichkeit, kann also lediglich im Verhältnis zu jenem vor-, glelch-oder auch nachzeitig sein.

In der K-pler Erzählung dominiert ein klares Satzschema:

$$
\text { Part.praet. - Verb.fin. - Part.praes. }
$$

Natürlich fehlt vielen Satzgefügen/Sätzen eines der partizipialen Glieder oder auch beide. Andererseits, und das ist viel signifikanter, stießen wir immer wieder auf Fügungen, wo der Autor, um jenes (1deale) Satzschema zu erreichen, partizipiale Wendungen um das Syntagma mit finiter Verbalform gruppiert,

die entweder ganz überflüssig waren (XP 74/27 "I prišed, bezbožnyj sta protiv polago mesta ...n - die ganze zeit ist aber schon von Mehmed die Rede; oder die verschiedenen Sätze vom Typus KP 74/37 "I vzem otvedoša ego ..." - der Kaiser war im Gespräch mit den Würdenträgern - 'sie führten ihn fort' würde vollauf genügen. Die Part.ien dienen hier der Vollständigkeit);

oder die gar keine Nebenhandlung bezeichnen, mitunter sogar eine wichtigere als die durch Verb.fin. ausgedruckte

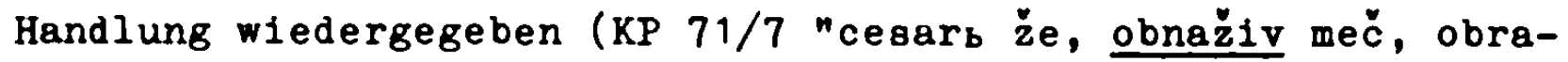
t1sja na turky 1 jakože kogo dostigaše ... - presekaše 1ch" ' zog das Schwert und wandte sich gegen die Türken, und wen auch immer er traf - den hieb er mitten durch'.

Im Hinblick auf die Beschreibung der Kunstfertigkeit, mit welcher der Kalser das Schwert handhabt, düfte das 'Ziehen des Schwerts' von gröBerer Wichtigkeit sein als die überflüssige Mittellung, daB er sich gegen die Turken wandte).

Das Satzschema 'vorzeitige Nebenhandlung - Haupthandlung glelchze1tige Nebenhandlung' ist jedoch dem Leser so in Pleisch und Blut ubergegangen, daB ihm solche Ungereimthe 1ten, die auf dem automatischen Bestreben, das Schema auszufullen, beruhen, gar nicht auffallen. Jedenfalls stellt die hypotakt1sche Fügung, die oft ganz modern anmutet, einen Grundzug der K-pler Erzählung dar. 
Die Punktion einer adverbialen Bestimmung übernimmt das nominale Part. (Nominativ) in der Pleskauer Erzählung nur in einem Drittel aller Belege. Sonst aber hat das Part. absolute Prädikation - vertritt ein Verb.fin. Wie die verschiedenen Kategorien des letzteren dominiert das Part. (praes. und praet.) ganze Abschnitte, schliebt lange Satzreihen reimend ab: es bildet eine vollwertige Variante zu den finiten Verbalformen. Damit dient es - in zwei Drittel aller Fälle - nicht der Hypo-, sondern der Parataxe.

Diesen Beobachtungen entspricht auch die Verwendung des Dat.abs. innerhalb der Vergleichstexte: In der K-pler Erzählung ist (bei je 76 Dat.abs. In jedem Text) die reichliche Hälfte aller auftretenden Dat.abs. In der Weise mit dem Hauptsatz (mit finiter Verbalform) engstens verbunden, daB das Nomen des Dat.abs. (sein Subjekt gewissermaßen) gleichzeitig das Subjekt des Hauptsatzes bildet, z.B.

KP 67/40 "i videvši straži , tečachu videti byvšee" 'als dies die Leute von der Wache sahen, liefen sie (dorthin), um zu sehen, was sich ereignet hatte'.

In der Pleskauer Erzählung sind solche Pügungen selten; melst hat dort jeder Dat.abs. sein eigenes Subjekt (= Nomen im Dativ). Darüber hinaus ist die Hälfte aller Dat.abs. in diesem Text vollkommen selbständig. Im $\mathrm{K}$-pler Text fungiert der Dat.abs. meist als adverbiale Bestimmung der Zeit, auch des Grundes - in der Pleskauer Erzählung meist als eigenständiger, von keinem Verb.fin. nur irgendwie abhängiger Satz. Er erscheint oft in parataktisch gefügten Blöcken zu drei bis vier $D_{a} t . a b s .$, besonders im Singular, wo die dominierende Lautung auf $-u$ einen besonderen klanglichen Effekt verursacht.

In den eigenständigen Partiziplal-Konstruktionen vertreten Part.praes, und Part.praet. folgende Tempora, wodurch wir die vorgestellte Aspektkorrelation ${ }^{13}$ noch erweitern können:

13) Die aspektuelle Ausrichtung der Part.ien (Part.praes.-imperf. Aspekt, Part.praet. - perf. Aspekt) ist noch deutlicher als bei Ipf. und Aor. Lediglich "videv/slysav" bilden in beiden Texten eine Ausnahme. 
Imperfekt - Part.praes. = 1mperf. Aspekt, Aorist - Part.praet. = perf. Aspekt.

Schlieblich 1st noch hervorzuheben, daB in der K-pler Erzählung noch einige sehr archaische Wendungen lebendig sind, von denen wir 1m Pleskauer Text kaum noch Reflexe vorfinden: 1. Der Akk. mit nominalem Part. nach "vidět1", "nuzrèt1", "sbrést1" u.a. (vgl. lat. AcI) - "On že, vldev Rachkaveja ljute sekušča turok, ..." 2. Das nominale Part. (Nominativ) als Prädikat1vum vom Typus "bě učę" - eine Zusammensetzung, die der intensiven oder gar expressiven Bezeichnung einer sich länger hinziehenden Handlung diente; wir können also von einem intens1vierten Imperfekt sprechen (vgl. Ruzickas Formulierung: Tempus intensivum ${ }^{14}$ ).

Mehrfach haben wir die archaisierende Tendenz als Grundzug beider untersuchter Erzählungen herausgestellt. Entsprechend der Differenz von einem Jahrhundert, die zwischen der Abfassung der Texte liegt, sind trotz allen Bemühens von Seiten des Pleskauer Autors, an der literarischen Tradition festzuhalten, Elemente der lebendigen Sprache in recht starkem Maße eingedrungen - beachtliche Unsicherheiten im Gebrauch der ksl. Tempora flelen durch den Vergleich mit dem $\mathrm{K}$-pler Text besonders ins Auge. Das ist nicht verwunderlich. Der Grad der Störung des alten Systems, das AusmaB der Annäherung von Ipf. und Aor., besonders der desolate Zustand der Ipf.-Kategorie (man kann fast von 'Verwahrlosung' sprechen) versetzen aber doch in Erstaunen.

Gravierend und eher grundsätzlicher Natur ist der Unterschied zwischen beiden Texten im Gebrauch der nominalen Part.ien. Ziehen wir zum Vergleich einmal die "Stepennaja kniga" und die "Kazanskaja Istorija" heran, so fällt auf, dab auch sie einen so extensiven Gebrauch von nominalen Part.ien machen wie unsere verglichenen Texte. Was die Funktion der Part.ien in jenen Texten anbelangt, so ist es schwierig, ohne eingehende Untersuchungen Güliges zu sagen. Bs zelgt sich aber fast

14) Ruzicka, Das synt.System, S. 213. 
Uberall recht deutlich, daB die klare logische, oft allerdings auch schematische Gliederung des Satzgefuges, wie sie für die K-pler Erzählung charakteristisch ist, in den genannten Werken nur selten erreicht wird - vielleicht gar nicht angestrebt 1st. Mir scheint, daB eine eher lockere Bindung des Part.s an das Verb.fin. fur Werke der Makarij-Ara bezeichnend ist. Das äuBert sich belopielswelse in einem offenbar noch stärkeren Gebrauch der trennenden koordinierenden Konjunktion zwischen Verb.fin. und Part., als wir ihn in der Pleskauer Erzählung registriert hatten; das äußert sich besonders auch darin, daB das Part. mit absoluter Prädikation, also die eigenständige Part.-Konstruktion, keine Ausnahme darstellt - sie lst keineswegs häufig, bildet aber doch eine auffallende Erscheinung. Dem pompösen, 'erhabenen', auf Breite der Darstellung ausgerichteten Stil der Makarij-Ära entsprach nicht die komprimierte, stringente Aussage mit klarer hypotaktischer Aufgliederung der Handlungen, mit logischer Durchdringung des geschilderten Sachverhalts (die sich in dem Versuch äuBert, die Handlungen als wichtiger = Verb.fin. - oder unwichtiger = Part. - einzuordnen). Der erhabenen Ideologie muBte wohl auch ein erhabener St1l entsprechen, die Breite der Darstellung (umfangreiche Apostrophen, Synonymhäufungen, inhaltliche Wiederholungen usw.) mußte mit einer entsprechenden Gestaltung der Sprache korrespondieren. Das Werk sollte den Leser offenbar nicht allein durch seinen Inhalt (d.h. die Darstellung des Herrschers, seiner Getreuen und der Kirche), sondern auch durch seine Sprache beeindrucken. Die Lockerung der Bindung des Part.s an das Verb.fin., die Trennung beider durch koordinierende Xonjunktion - das sind deutliche Tendenzen zur parataktischen Gliederung elnes Textes, wodurch die Sprache deselben ohne 2weifel eine gewisse Pelerlichkeit erlangt. Diese Tendenz lat aber nicht zu vergleichen mit der vollzogenen Verselbständigung des Part.-Syntagmas in Pleskauer Text, wie wir sie im Pleskauer Text uber weite strecken hin konstatieren. Ideologisch und sprachlich gesehen stellt die Pleskauer Erzahlung ein Werk dar, das in die Tradition der Makarij-Ära eu stellen 1st. Aus vielerlei Erscheinungen können wir schließen, 
daß der Autor zwar recht belesen war, jedoch längst nicht jene sprachliche Befählgung (= Int1me Kenntnis des K1rchenslavischen) und jenes otilistische Empfinden besaß, das zur Erreichung seines vermutlichen $Z$ ieles nötig gewesen wäre nämlich ein ähnliches Werk wie die "Kazangkaja Istorija" zu schaffen.

AbschlleBend wollen wir noch zusammenfassend darlegen, warum die Pleskauer Erzahlung dem Moskov1t1schen Prunkst1l zuzurechnen lot bzw. In welcher Bezlehung ole zu Werken dieser St11richtung steht. Wenn wir elnen Text dem Makarij-St1l zuordnen, dann naturlich auf Grund bestimmter aprachlicher und stilistischer Kriterien, die in fenem Text eine mehr oder weniger wichtige Rolle oplelen.

Dieser Stilrichtung ist eine stark archaisierende Tendenz e1gen. Dennoch bestät1gen alle Untersuchungen an Texten der zweiten Hälfte des 16. Jh.s, daB die ksl. Verbalkategorien nicht mehr sicher beherrscht werden - Unsicherhe1ten im Pormalen we auch im Punktionalen werden reglotriert, Angkitze zum nivellierenden Gebrauch der Tempora konstatiert. Was uns allerdings hinsichtlich des Gebraucho der verbalen Kategorien im Pleskauer Text begegnet, wurde meines W1seens bisher an Texten mit literarischem Anspruch, den jener ganz o1cher hat, noch nicht festgestellt, jedenfallo nicht an Werken des 16. Jh.s: weitgehender Verfall des Ipf. im formalen Bereich (3.8g.1pf. $-(j)$ ase = Einhe1tsendung - sie erscheint häufiger in Funktion der 3.pl.1pf. als die korrekte Endung $-(f) a c h u) ;$ freie Vertauschbarkeit nicht nur von Ipf. und Aor., wobel melst - aber nicht 1mmer! (vgl. Ersatz fur Aor. "tvor1в̈a", "veleša" durch "tvorjab̌e", "veljaв̌en) - die Aspektkorrelation gewahrt wird (Aor. = perf. Aspekt, Ipf. = 1mperf. Aspekt); ausgetauscht werden konnen auch finfte und partiziplale Formen nach dem bekannten 8chema (8. z.B. S. 673). Von Kurbsk1f wiseen w1r, daB er, wenn er s1ch der kol. Form nicht alcher war, das universale Prateritaltempue der lebendigen Sprache, das l-Part., verwendete. Solche Skrupel kannte der Pleskauer Autor offenslchtlich nicht. Zwar konnten wir in der Plegkauer Erzahlung im Vergleich 
m1t der Erzählung über die Eroberung $\mathrm{K}$-pels einen deutlichen Anstieg des durch 1-Part. gebildeten Präteritums verzeichnen, doch hatte diese umgangssprachliche Form insgesamt nur einen winzigen (wenn auch schon ziemlich fest umrissenen) Platz im Pleskauer Text. Das Präteritum der lebendigen Sprache wurde gewaltsam zurückgedrängt und vielfach geradezu wahllos durch ksl. Formen ersetzt.

Wie auf dem Geblet des Tempusgebrauchs gewisse Ansätze (die Tendenz zum nivellierenden Gebrauch der verbalen Kategorien), die in zeitgenössischen Werken erkennbar sind, in der Pleskauer Erzählung bestimmenden Charakter gewinnen, ja sogar zum Stilmerkmal werden - so beobachten wir auch im Bereich der bewuBt eingesetzten Stilmittel, daB der Pleskauer Autor bestimmte Kunstgriffe, die (weil öfter als andere angewendet) für den Moskovitischen Prunkstil charakteristisch sind, ausschlieblich und dementsprechend maBlos gebraucht.

Konzentriert treten jene Stilmittel innerhalb der "Stepennaja kniga" oder der "Kazanskaja Istorija" nur in hagiographischen und geistlich ausgerichteten Passagen auf, in den rein berichtenden Abschnitten hingegen kann man von einem häufigen Auftreten von Belopielen jenes "pomphaften und preziösen, mit Bildern stark überladenen Stils" keineswegs sprechen. ${ }^{15}$ Dagegen 1st die Pleskauer Erzählung von Anfang bis Ende, bis auf ganz wenige Textstellen, auf affektische Schilderung angelegt - auf Emotionalisierung des Lesers. Den gesamten Katalog der den Makarij-Stil charakterisierenden Kunstgriffe finden wir hier in einer beinahe unglaublichen Konzentration belegt, ob es sich um eine Anrufung Gottes oder eine Beschreibung des polnischen Lagerlebens, ob es alch um einen Monolog des Autors oder um eine Kampfachilderung handelt:

15) Stender-Petergen, Geschichte dor ruse. Itteratur, S. 191 bei uns zitiert S. 47: Diese Charakterisierung durch Stender-P. (vgl. auch Tsch1zewgk11, Vergl.Gesch.d.slav. Literaturen, S. 91 "Bchwer-/reich geschmlickter Stil"). 
- klangliche Effekte: (verbaler) Re1m, paronomastische F1guren, insbesondere figura etymologica, Assonanzen und andere Versuche, vollen oder ungefähren Glelchklang zu erzielen;

- Synonymie sowle bestimmte immer wiederkehrende Worthäufungen, die durch 1hre Wiederholung allmählich semantisch zusammenwachsen, also synonyme Bedeutung erlangen;

- Häufungofiguren (Epltheta und Nomina), die der Aussage sicher Erhabenhelt verleihen sollen;

- unwahrscheinlich weitschweifige Apostrophlerungen der Gottesmutter, der Helligen (nie aber Gottes oder Christ1), insbesondere des Zaren sowie selner höchsten Beamten ("... gosududarevy bojare 1 voevody"), Pleskaus und auch der Verteldiger Pleskaus;

- relchlicher Gebrauch b1ldsprachlicher Elemente, wobe1 aber charakterlotischerwelse 1m wesentlichen nur zwe1 gängige Motive varilert werden (der polnische kunig - ein giftspelender, alles verschlingender Drache; die Russen Märtyrer Christ1).

Das Auftreten dieser St1lmittel verbindet die Pleskauer Erzählung mit dem Moskovitischen Prunkst1l; daB wir diese Mittel im Pleskauer Text so konzentriert, in solcher AusschlleBlichke1t angewand finden, das unterscheidet diese Erzählung von anderen umfangre1cheren Werken des Makar1j-St1ls.

Als Ubertrelbung gewisoer Tendenzen besonders in der "Kazanskaja Istorlja" 1st auch die Verselbständigung der nominalen Partiziplen in der Pleskauer Erzahlung zu bezelchnen - in uber 60 v.Hd. aller Mominativ-Belege haben diese Partizipien absolute pridikative Funktion und treten an die Stelle des Verb.fin. Hierin kuBert sich nicht nur eine recht primitive Art der Nachahmung - vielmehr ze1gt olch in der syntaktischen Gleichsetzung finiter und partiziplaler Formen auch die paratakt1sche Grundetruktur des Satzes im Pleskauer Text. Der Pleskauer Autor nutzt nicht - wie dies belsplelhaft am $\mathrm{X}$-pler Text $z u$ beobachten war - die Möglichke1t, durch die Verwendung partie1pialer Konstruktionen (zume1st in Punktion ad- 
verblaler Bestimmungen) die Darstellung in Wichtiges und weniger Wichtiges, in Haupt- und Nebenhandlung zu gliederm. Die Partizipien ordnen sich in die Aspektkorrelation ein (s.0., s. 673): Ipf. und Part.praes. stehen für das 1-Part. des imperf. Aspekts, Aor. und Part.praet. ersetzen stilisierend das 1-Part. des perf. Aspekts: die Formen selbst sind nicht mehr merkmalhaft, dienen nur der stilisierung - signifikant ist nur noch der Stamm des Verbs - nicht suffigiert: perfektiv; suffiglert oder dehnstufig: imperfektiv. Diesem Zustand entspricht die Verwendung eines allen Stämmen gemeinsamen Präterital-Zeichens: des l-Part.s in der lebendigen Sprache.

So stellt sich uns die Erzählung über die Belagerung Pleskaus durch Stephan Báthory nicht als Spiegel, als Musterbeispiel für den Moskovitischen Prunkstil dar - wie zunächst angenommen, vielmehr erweist sie sich als ein Zerrbild, als (sicher unbeabsichtigte) Karikatur desselben - als epigonenhafte Nachahmung: Verwendung finden allein die Hauptzüge, die schreienden Farben der Vorlage, die feineren Abtönungen, die Schattierungen dagegen fehlen. 
A) B $\equiv R I C$ II T E II D E PAS S A G $I N$

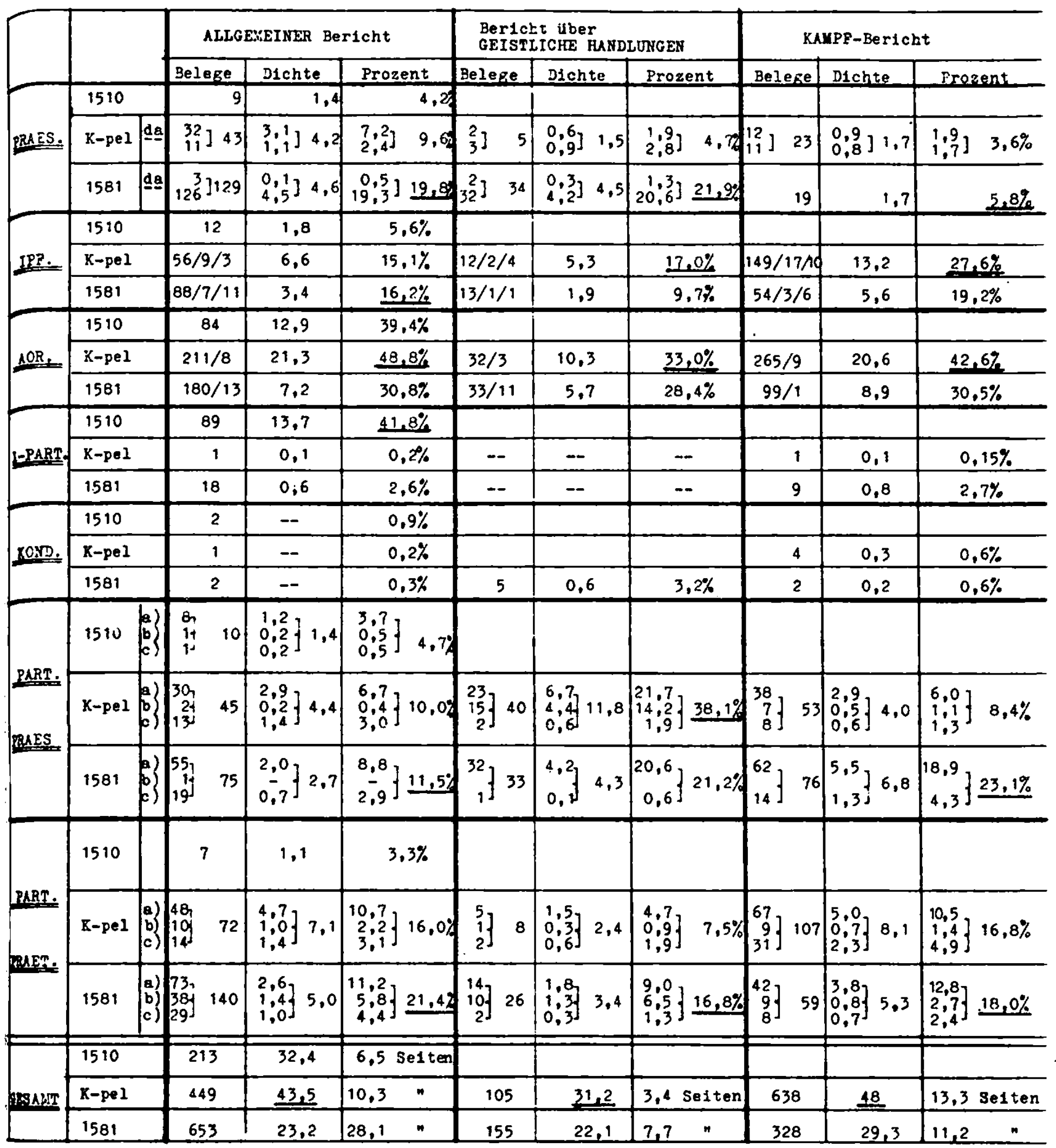

\section{Huterungen:}

$\$ 1510$ Frichlung Uber die Annexion Pleskaus 1510 durch Yasilif III., aue der pleskauer Chronik;

I-pel = Erzbhlung liber die Eroberung K-pels durch die Zurken 1453 ;

1581 Erzahlung uber die Belagerung pleskaus durch stephan Bathory $1581 / 82$.

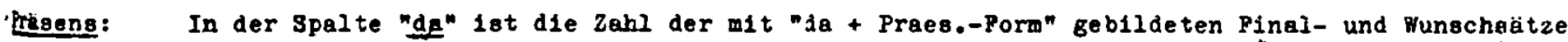
tperfekt: $56 / 9 / 3=56$ Ipf.-Belege von Vollverben, 9 Xal "be", 3 Mal "bjasen. genannt. leriet: $\quad 211 / 18$ - Von 1nagesamt 219 Aor.-Formen sind 8 ron "resčl" gebildet (melst "rečen).

'art.praes.: a) nominales Part. 1m Nominativ; b) = nominaleg Part. als Prädikativum: Typ nbe/bjabe molja"; c) = Dativus abaolutus.

:urt,praet.: a) = nominales Part. Im Kominativi b) = "slysav" und "videv"; c) = Dativus absolutus.

'is den Angaben fur Präsens der 'Passagen personlicher Diktion' (Tabelle B) aind auch Belege fúr periphraitsaches Putur enthalten: Pleskau $1510=11 ; \mathrm{K}-\mathrm{pel}=2 ;$ Pleakau 1581 a 11 .

He jewe1ls dritte Angabe unter "GESAMr" nennt den Umfang des betr. Berelchs $1 m$ Geagmttext - ao zelgt

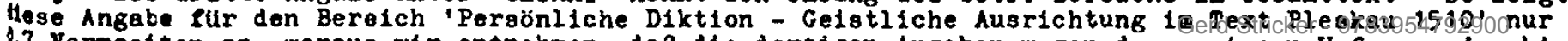
1,7 Kormseiten an, woraus wir entnehmen, dab die dortizen Angaben wegen *r gehorigen Abschnitte rein statistischen, nicht abes wrilich insormativen iert haben. free access 
B) PASSAGEN PERSONLICHERTIETION Wörtliche Redes Dialoge, Sendschrelben, Monologe, Gebete, Reden

\begin{tabular}{|c|c|c|c|c|c|c|c|c|}
\hline & & & \multicolumn{2}{|c|}{ ALLGEXEINER } & \multirow{2}{*}{$\begin{array}{l}\text { Inhalt } \\
\text { Prosent }\end{array}$} & \multicolumn{3}{|c|}{ GEISTLICHE Ausrichtung } \\
\hline & & & Belege & Dichte & & Belese & Dichte & Prozent \\
\hline \multirow{3}{*}{ PRAES: } & 1510 & & 48 & 29,1 & $77,4 \%$ & 5 & 5,8 & $16,1 \%$ \\
\hline & $\mathrm{K}-\mathrm{pel}$ & da & 87 & 32,2 & $67,5 \%$ & $\left.\begin{array}{l}44 \\
96\end{array}\right] 110$ & $\left.\begin{array}{r}8,6 \\
18,8\end{array}\right] 27,4$ & $\left.\begin{array}{l}19,3 \\
42,1\end{array}\right] 61,4 \%$ \\
\hline & 1581 & da & ${ }_{54}^{7} d 61$ & $\left.\begin{array}{r}1,0 \\
22,4\end{array}\right] 23,4$ & $79,3 \%$ & $\left.\begin{array}{r}1 \\
113\end{array}\right] 114$ & 17,5 & $75,5 \%$ \\
\hline \multirow{3}{*}{ IPF. } & 1510 & & -- & -- & -- & - & -- & -- \\
\hline & $K-p e I$ & & -- & -- & - & 5 & 1,0 & $2,2 \%$ \\
\hline & 1581 & & 6 & 0,9 & $3,0 \%$ & -- & -- & - \\
\hline \multirow{3}{*}{ AOR. } & 1510 & & - & - & -- & 15 & 21,4 & $(55,6 \%$ \\
\hline & K-pel & & 20 & 7,4 & $15.5 \%$ & 35 & 6,9 & $15,4 \%$ \\
\hline & 1581 & & 15 & 2,2 & $7,4 \%$ & 24 & 3.7 & $16,0 \%$ \\
\hline \multirow{3}{*}{ 1-PART. } & 1510 & & 5 & 3,1 & $8,1 \%$ & 2 & 2,9 & $4,0 \%$ \\
\hline & K-pel & & 2 & 0,7 & $1,6 \%$ & 3 & 0,6 & $1,3 \%$ \\
\hline & 1581 & & 7 & 1,0 & $3,4 \%$ & 6 & 0,9 & $4,0 \%$ \\
\hline \multirow{3}{*}{ KOND. } & 1510 & & 7 & 4,4 & $11,3 \%$ & -- & -- & -- \\
\hline & $\mathrm{K}-\mathrm{pel}$ & & - & - & - & - & - & - \\
\hline & 1581 & & -- & - & -- & 2 & 0,3 & $1,3 \%$ \\
\hline \multirow{3}{*}{$\begin{array}{l}\text { PART. } \\
\text { PRAES. }\end{array}$} & 1510 & & - & - & -- & 4 & 5,7 & $(14,8 \%)$ \\
\hline & $\mathrm{K}-\mathrm{pel}$ & a) & $\left.\begin{array}{l}7 \\
2\end{array}\right] 9$ & $\left.\begin{array}{l}2,6 \\
0,7\end{array}\right] 3,3$ & $\begin{array}{l}5,4 \\
1,6] 7,0 \%\end{array}$ & 28 & 5,5 & $12,3 \%$ \\
\hline & 1581 & $\begin{array}{l}\text { a) } \\
\text { c) }\end{array}$ & $\left.\begin{array}{l}2 \\
2\end{array}\right] 4$ & $\left.\begin{array}{l}0,3 \\
0,3\end{array}\right] 0,6$ & $\left.\begin{array}{l}1,0 \\
1,0\end{array}\right] 2,0 \%$ & 1 & 0,15 & $0,7 \%$ \\
\hline \multirow{3}{*}{$\begin{array}{l}\text { PART. } \\
\text { PRAET. }\end{array}$} & 1510 & a) & $\begin{array}{l}1 \\
1\end{array}$ & 1,2 & $3,2 \%$ & 1 & 1,4 & $3,7 \%$ \\
\hline & $\mathrm{K}-\mathrm{pel}$ & a) & $\left.\begin{array}{l}9 \\
2\end{array}\right] 11$ & 4,0 & $8,6 \%$ & 15] 17 & 3,3 & $7,5 \%$ \\
\hline & 1581 & a) & $10 \quad 10$ & 1,4 & $4.9 \%$ & 44 & 0,6 & $2,6 /$ \\
\hline \multirow{3}{*}{ GESAMT } & 1510 & & 62 & 38,8 & 1,6 seiten & 27 & 38,5 & 0,7 secten \\
\hline & X-pel & & 129 & 43,3 & 2.7 & 228 & 44.7 & 5,1 \\
\hline & 1581 & & 203 & 30,8 & 6 & 15 gerd Str & Ker - 989079290 & 6,5 \\
\hline
\end{tabular}


$\begin{array}{rl}1 & 1 \\ 4 & \forall\end{array}$

$=N$

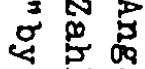

古宓

$\approx 50$

罗

品㖞

- 迥。

$\sigma 5$

岗怘

要

- 号貝

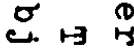

\$

今 :

E。

$\therefore$ 象

ए心

首

$\rightarrow$ D

点聂

$\circ$ क

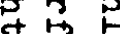

兵

क त

ह: :

$\underset{x \rightarrow}{0}$

0

궁

it 0

सम

$+5$

5

ㄷ.

?

50

2.

(8)

十

品

足

๑

$\rightarrow$

$\rightarrow$ o

a

ष

草.

अ

붕

P

茼

옹

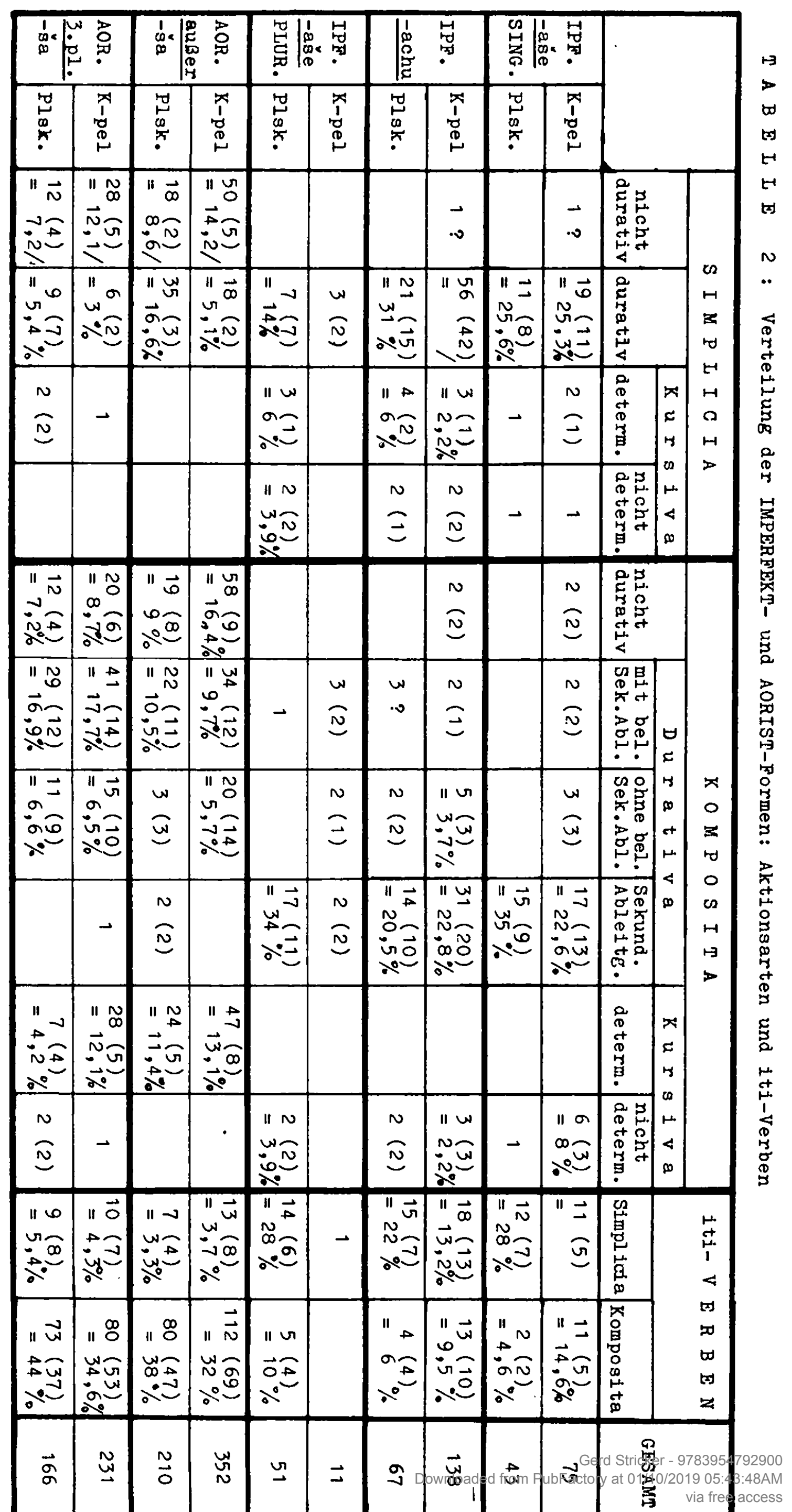





\section{SLAVISTISCHE BEITR ̈}

83. Baumann, w.: Die Sage von Heinrich dem Löwen bel den Slaven. 1975. $185 \mathrm{~S}$.

84. Everts-Grigat, S.: V. V. Majakovskij: Pro éto. Ubersetzung und Interpretation. 1975. $262 \mathrm{~S}$.

85. Mirsky, S.: Der Orient im Werk Velimir Chlebnikovs. 1975. VIII, $112 \mathrm{~s}$.

86. Ditterich, M.: Untersuchungen zum altrussischen Akzent anhand von Kirchengesangshandschriften. 1975. $147 \mathrm{~S}$.

87. Cummins, G. M.: The Language of the Old Crech Legenda o svaté Katetine. 1975. VIII, $371 \mathrm{~s}$.

88. Foldeak, H.: Neuere Tendenzen der sowjetischen Science Fiction. 1975. VI, $208 \mathrm{~s}$.

89. Drews, P.: Devétsil und Poetismus. Künstlerische Theorie und Praxis der tschechischen literarischen Avantgarde am Beispiel vitéslav Nezvals, Jaroslav Seiferts und Jifi Wolkers. 1975. $330 \mathrm{~S}$.

90. Schónle, P. W.: Zur Wortbildung im modernen Russisch. 1975. VIII, $195 \mathrm{~S}$.

91. Okuka, M.: Sava Mrkalj als Reformator der serbischen Kyrilliza. Mit einem Nachdruck des Salo debeloga jera libo Azbukoprotres. 1975. $123 \mathrm{~S}$.

92. Neuhauser, R.: The Romantic Age in Russian Literature: Poetic and Esthetic Norms. An Anthology of Original Texts $(1800-$ 1850). 1975. VIII, $300 \mathrm{~s}$.

93. Doring, J. R. (Hrg.): Literaturwissenschaftliches Seminar: Zur Analyse dreier Erzählungen von VI. I. Dal'. Mit einem methodologischen Geleitwort von Johannes Holthusen.1975. $203 \mathrm{~S}$.

94. Alexander, R.: Torlak Accentuation. 1975. XVI, $806 \mathrm{~S}$.

95. Schenkowitz, G.: Der Inhalt sowjetrussischer Vorlesestoffe für Vorschulkinder. Eine quantifizlerende Corpusanalyse unter Benutzung eines Computers. 1976. $767 \mathrm{~S}$.

96. Kitch, F. C. M.: The Literary Style of Epifanij Premudryj. Pletenife sloves. 1976. $298 \mathrm{~S}$.

97. Eschenburg, B.: Linguistische Analyse der ortsnamen der ehemaligen Komitate Bács und Bodrog von der ungarischen Landnahme (896) bis zur Schlacht von Mohács (1526). 1976. $156 \mathrm{~s} .3 \mathrm{Kt}$.

98. Lohse, H.: Die Ikone des hl. Theodor Stratilat zu Kalbensteinberg. Eine philologisch-historische Untersuchung. 1976.XX,242 S.

99. Erbsloh, G.: "Pobeda nad solncem". EIn futuristisches Drama von A. Krutenych. Ubersetzung und Kommentar. (Mit einem Nachdruck der Originalausgabe.) 1976. $121 \mathrm{~s}$.

100. Koszinowski, K.: Die von prafigierten Verben abgeleiteten Substantive in der modernen serbokroatischen Standardsprache. Eine Untersuchung zu den Prafixen do, 1z, na, za. 1976. $271 \mathrm{~s}$.

101. Leitner, A.: Die Erzählungen Fedor Sologubs. 1976. $249 \mathrm{~S}$.

102. Lenga, G.: zur Kontextdeterminierung des Verbalaspekts im modernen Polnisch. 1976. VIII, $233 \mathrm{~S}$.

103. Zlatanova, R.: Die Struktur des zusammengesetzten Nominalprädikats Im Altbulgarischen. 1976. VIII, $220 \mathrm{~S}$.

104. Krupka, P.: Der poinische Aphorismus. Die "Unfrisierten Gedanken" von Stanisław Jerzy Lec und ihr Platz in der polnischen Aphoristik. 1976. $197 \mathrm{~s}$.

105. Pogà̃nik, J.: Von der Dekoration zur Narration. Zur Entstehungsgechichte der slovenischen Literatur. 1977. $165 \mathrm{~s}$.

106. Boj1ć, V.: Jacob Grimm und Vuk Karadxić. Ein Vergleich ihrer Sprachauffassungen und ihre zusammenarbeit auf dem Gebiet der serbischen Grammatik. 1977. 257 S. 
107. Vintr, J.: Die ältesten Cechischen Evangeliare. Edition, Textund Sprachanalyse der ersten Redaktion. 1977. $367 \mathrm{~S}$.

108. Lohff, U. M.: Die Bildlichkeit in den Romanen Ivan AleksandroviC Goncarovs (1812-1891). 1977. XVI, 244 S.

109. Regier, Ph. R.: A Learner's Guide to the Old Church Slavic Language. Part 1: Grammar with Exercises. 1977. XLIV, 368 S.

110. Worth, D. S.: On the Structure and History of Russian. Selected Essays. With a Preface by Henrik Birnbaum. 1977. X, 276 S.

111. Schulte, B.: Untersuchungen zur poetischen Struktur der Lyrik von Sima Pandurovíc. Posmrtne potasti. 1977. $345 \mathrm{~S}$.

112. Albert, H.: Zur Metaphorik in den Epen Żivana, Medvjed Brundo, Ut. va und Ahasver des kroatischen Dichters vladimir Nazor. 1977. $171 \mathrm{~s}$.

113. Girke, W. und $H$. Jachnow (Hrgb.): Slavistische Linguistik 1976. Referate des II. Konstanzer Slavistischen Arbeitstreffens (5. 7. 10. 1976). 1977. 261 S.

114. Matuschek, H.: Elnwortlexeme und Wortgruppenlexeme in der technischen Terminologie des Polnischen. 1977. VIII, $417 \mathrm{~s}$.

115. Schreier, H.: Gogol's religiöses Weltbild und sein literarisches Werk. Zur Antagonie zwischen Kunst und Tendenz. 1977. $123 \mathrm{~S}$.

116. Beitrăge und Skizzen zum Werk Ivan Turgenevs. 1977. $142 \mathrm{~S}$.

117. Neureiter, F.: Geschichte der kaschubischen Literatur. Versuch einer zusammenfassenden Darstellung. 1978. $281 \mathrm{~s}$.

118. Russel, M.: Untersuchungen zur Theorie und Praxis der Typisierung bei I. A. Goncarov. 1978. $401 \mathrm{~S}$.

119. Referate und Beitrăge zum VIII. Internationalen slavistenkongreB Zagreb 1978. 1978. $451 \mathrm{~S}$.

120. Slavistische Linguistik 1977. Referate des III. Konstanzer Slavistischen Arbeitstreffens Bochum 27.9.77-29.9.77. 1978. $260 \mathrm{~S}$.

121. Müller, V.: Der Poetismus. Das Programm und die Hauptverfahren der tschechischen literarischen Avantgarde der zwanziger Jahre. 1978. VI, $215 \mathrm{~S}$.

122. Pailer, $W .:$ Die fruhen Dramen $M$. Gor'kijs in ihrem Verhăltnis zum dramatischen Schaffen A. P. Cechovs. 1978. VIII, $210 \mathrm{~S}$.

123. Thomas, G.: Middle Low German Loanwords in Russian. 1978. 269 S.

124. Lehfeldt, $W_{.:}$Formenbildung des russischen Verbs. Versuch einer analytisch-synthetisch-funktionellen Beschreibung der Prăsensund der Präteritumflexion. 1978. $114 \mathrm{~S}$.

125. Schön, L.: Die dichterische Symbolik V. M. Garక̌ins. 1978. VI, 203 S.

126. Berg, R.: Die Abstrakta auf -nie/-tie, -ka/-ok, -ost', -stvo/ -stvie, -ie/-be in den "Pis'ma 1 Bumagi" Peters des GroBen. 1978." IV, $352 \mathrm{~s}$. 